


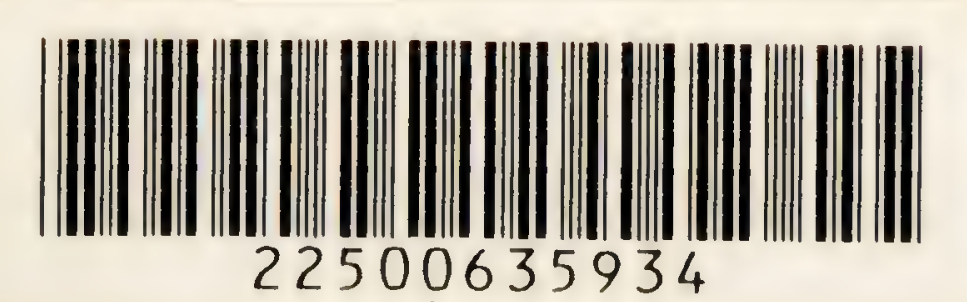




$$
I_{2.17} \underset{42}{81 / 2}
$$




Digitized by the Internet Archive in 2017 with funding from Wellcome Library

https://archive.org/details/b2993154x_0002 


\section{WANDERINGS IN \\ WILD AUSTRALIA}




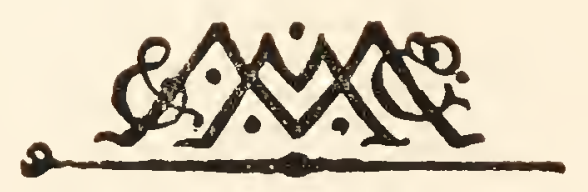

MACMILLAN AND CO., Limited

I.ONDON - BOMBAY . CALCUTTA . MADRAS

MELBOURNE

THE MACMILLAN COMPANY

NEW YORK - BOSTON . CHICAGO

DALLAS . SAN FRANCISCO

THE MACMILLAN CO. OF CANADA, LTD.

TORONTO 


\section{WANDERINGS IN WILD AUSTRALIA}

BY

SIR BALDWIN SPENCER, K.C.M.G., F.R.S.

M.A., LITT.D., D.SC. (HON. MAN.), HON. FELLOW EXETER AND LINCOLN COLLEGES, OXFORD; PROFESSOR EMERITUS OF BIOLOGY IN THE UNIVERSITY OF MELBOURNE; SOMETIME SPECIAL COMMISSIONER FOR THE COMMONWEALTH GOVERNMENT OF AUSTRALIA AND CHIEF PROTECTOR OF ABORIGINES IN THE NORTHERN TERRITORY

\section{IN TWO VOLUMES \\ VOL. II}

MACMILLAN AND CO., LIMITED ST. MARTIN'S STREET, LONDON 1928 


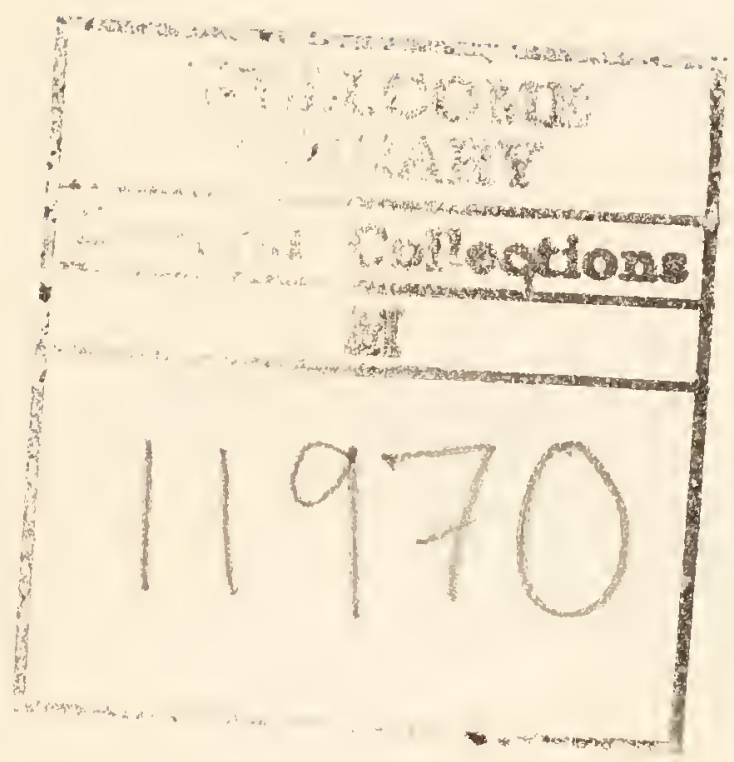

COPYRIGHT

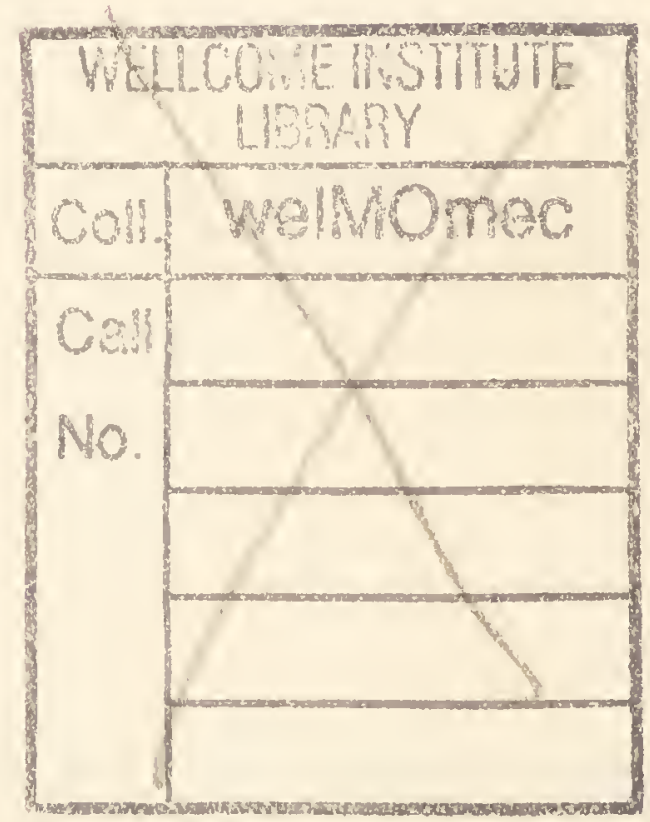

PRINTED IN GREAT BRITAIN 


\title{
CONTENTS
}

\author{
Book II (continued) \\ ACROSS AUSTRALIA (continued)
}

CHAPTER

XIX. The Great Wollungua . 457

XX. Death, Burial and Mourning Ceremonies of the Warramunga . • . . 476

XXI. Stone Tools of Australian Savages . . 495

XXII. Tennant Creek to Powell Creek • . 5I 2

XXIII. Powell Creek to the Gulf of Carpentaria 529

XXIV. Borraloola and the Coastal Tribes • 561

Book III

AUSTRALIA'S GREAT LONE LAND

XXV. Work in Darwin.-I • • • . 597

XXVI. Melville and Bathurst Islands and the ISLANDERS . . . . . . 64I

XXVII. Decorative Art of the Melville Islanders 695 XXVIII. WORK IN DARWIN.-II. . . . . 7I4

XXIX. The East Alligator River and the Kakadu People.-I. . . . . . . 736

XXX. The East Alligator River and the KaKadu

PeOple.-II . . . . . . 792

XXXI. By Motor to the Gulf of Carpentaria . 859

XXXII. The Flora River and Bathurst Island • 89I INDEX . . . . . . . . 9 I 5 



\section{LIST OF ILLUSTRATIONS}

FIG.

282. Ant Totem Ceremony. Warramunga Tribe

FACING PAGE

283. Lizard Totem Ceremony. Warramunga Tribe

$45^{8}$

284. Thaballa, Laughing Boy, Totem Ceremony. Warramunga Tribe

285. Lizard Totem Ceremony. Warramunga Tribe

286. Wild Cat Totem Ceremony. Warramunga Tribe • . 459

287. Tjinqurokura . . . • • • . • 459

288. Decoration for Black-Snake Totem Ceremony. Warramunga Tribe . . . . . 460

289. Decoration for Black-Snake Totem Ceremony. Warramunga Tribe . . . . . . . . 460

290. Close of Black-Snake Totem Ceremony. Warramunga Tribe

29I. Preparing a Ground Drawing. Black-Snake Totem Ceremony. Warramunga Tribe . . . . . $46 \mathrm{I}$

292. Close of Black Snake Totem Ceremony. Warramunga Tribe 462

293. Ceremony of Irrimunta. Warramunga Tribe . . . 463

294. Worgaia Medicine Man . • . . . . . . 463

295. Performer carrying the Wollunqua Bundle. Warramunga Tribe

296. Close of Wollunqua Ceremony. Warramunga Tribe . 465

297. Making the Wollunqua Mound. Warramunga Tribe . 466

298. Showing the Wollunqua Mound. Warramunga Tribe . 467

299. Stroking the Wollunqua Mound. Warramunga Tribe • 468

30o. Surging round the Wollunqua Mound. Warramunga Tribe

30I. Preparation for Ground Drawing. Wollunqua Totem Ceremony. Warramunga Tribe . . . . . 470

302. Ground Drawing, Wollunqua Totem Ceremony. Warramunga Tribe . . . . . . . . 470

303. Ground Drawing, Wollunqua Totem Ceremony. Warramunga Tribe . . . . . . . . 47I

304. Ground Drawing, Wollunqua Totem Ceremony. Warramunga Tribe . . . . . . 47I

305. Ground Drawing, Wollunqua Totem Ceremony. Warramunga Tribe . • . . . • . • 47I

306. Men standing round Ground Drawing, Wollunqua Totem Ceremony. Warramunga Tribe . . . . . 472

307. Ground Drawing of Wollunqua Totem Ceremony of Ununtumurra. Warramunga Tribe . . . . 473 
308. Close of the Final Ceremony of the Wollunqua Totem. Warramunga Tribe $\cdot \cdot \cdot \cdot \cdot \cdot \cdot \dot{*} \cdot \cdot$

309. Stone Churinga of Munga-Munga Women. Warramunga Tribe

3ıо. Plan of Thapauerlu

3 I $a$. Section of Thapauerlu along the line $a-b$ in Fig. 3 Io

3II. Thapauerlu

312. Young Men being rubbed with Kangaroo Stones at Thapauerlu

313. Worgaia Medicine Man .

3I4. Young Medicine Man wearing the Kupitcha. Warramunga Tribe

3I5. Medicine Men at Work. Warramunga Tribe.

3I6. Death Scene. Warramunga Tribe .

3I7. Mourning Ceremonies. Man with Gashed Thigh. Warramunga Tribe

318. Mourning Ceremonies. Two Widows. Warramunga Tribe

319. Mourning Ceremonies. Women challenging one another. Warramunga Tribe

320. Mourning Ceremonies. Women wailing. Warramunga Tribe

32I. Mourning Ceremonies. Women cutting their Heads. Warramunga Tribe

322. Mourning Ceremonies. Visiting the Tree Grave. Warramunga Tribe

323. Mourning Ceremonies. Visiting the Death Mound. Warramunga Tribe

324. Mourning Ceremonies. Climbing the Grave Tree. Warramunga Tribe

325. Mourning Ceremonies. Raking the Bones into a Bark Dish. Warramunga Tribe .

326. Mourning Ceremonies. Burying the Bones in an Ant-hill.

327. Mourning Ceremonies. Wrapping up the Arm-bone. Warramunga Tribe . . . . .

328. Mourning Ceremonies. Waiting for the Arm-bone. Warramunga Tribe

329. Mourning Ceremonies. Bringing in the Arm-bone. Warramunga Tribe

330. Mourning Ceremonies. Weeping over the Arm-bone. Warramunga Tribe

33I. Mourning Ceremonies. Women cutting their Thighs. Warramunga Tribe . . . . . . .

332. Mourning Ceremonies. Old Women with Arm-bone. Warramunga Tribe . . . . . .

333. Mourning Ceremonies. Men standing over the Trench. Warramunga Tribe. . . . . .

334. Mourning Ceremonies. Women crawling along the Trench. Warramunga Tribe . . . . . . 493 
FIG.

335. Mourning Ceremonies. Bone-breaking. Warramunga Tribe

336. Mourning Ceremonies. Bone Burial. Warramunga Tribe

337. Rough chipped Block of Diorite . • • . . 499

338. Pecking the Axe-head . . . . . . . . 498

339. Grinding the Axe-head . . . . . . . 498

340. Hafting the Axe-head . . . . . . . 499

34I. Hafting the Axe-head . . . . . . . 499

342. Melting the Resin for hafting the Head . . . . 500

343. Flints from a Kitchen Midden . . . . 500

344. Curved and Straight Adzes . . . . . . 50I

345-348. Various Forms of Adzes . . . . . 501, 502

349. Warramunga Man using Adze . . . . 502

350. Pitchi in course of making, showing the Adze Marks $\quad 5^{02}$

35I. Diagram illustrating the making of a Stone Knife . page 504

352-370. Various Forms of Stone Knives . • . 503-507

37I. Pick showing both Faces and Hafting in a Bent Withy . 508

372. Pick hafted in a Split Handle . . . . . 507

373. Knife and its Sheath . . . . . . . 508

374. Stone Spear-head . . . . . . . . 508

375. Slate Spear-head . . . . . . . . 508

376. Opalescent Quartzite Spear-head . . . . . . 508

377. Chipped Spear-heads . . . . . . . 509

378. Wallet and Chipped Spear-heads in course of making . 5 I2

379. Tappin Ceremony. Warramunga Tribe . . . . 5I3

380. Whirlwind approaching Tennant Creek . . . . . $5^{\mathrm{I} 3}$

38r. Water-hole on Tennant Creek . . . . . $5^{\mathrm{r} 6}$

382. Water-hole, Powell Creek . . . . . . 5 5 5

383. Full-grown and Sapling Gum Leaves • • . page 895

384. Bungalow with Bauhenia Trees, Powell Creek . . . 5 I7

385. Ceremony of Fire Totem. Tjingilli Tribe . . . 526

386. Close of Tjingilli Ceremony . . . . . . . 526

387. Yam Ceremony. Slabs . . . . . . 527

388. Bates Lagoon . . . . . . . . 534

389. Indiarubber Tree . . . . . . . . . 535

390. Betaloo Downs Station. Front view . . . . 534

391. Betaloo Downs Station. Back View . . . . 536

392. "Bay of Biscay" Country . . . . . . . 536

393. Totemic Ceremonies. Umbaia Tribe . . . . 537

394. Projecting the Anjulukuli Stone. Umbaia Tribe . $\quad 537$

395. Man of Gnanji Tribe with Hair in Plaits . . . . 540

396. Lignum Swamp . . . . . . . 540

397. Water-lily Pool on the Roper River . . . . 54 I

398. Storm on the Leila Creek . . . . . . . 54 I

399. Parcel of Bones and three Bone-Coffins. Binbinga Tribe . 554

400. Leichhardt Pine . . . . . . . 555 


\section{xii LIST OF ILLUSTRATIONS}

484. Spears. Kakadu Tribe and Melville Island

485. Spears. Melville Island

486. Spears. Melville Island

487. Clubs. Melville Island .

488. Clubs. Melville Island .

489. Clubs. Melville Island

490. Darwin Harbour and Fort Hill

491. Wayside Station on Darwin-Pine Creek Railway

492. Unloading Stores for the Bachelor Experimental Farm

493. Parliamentarians getting themselves out of a Hole .

494. Early Morning on the Daly River .

494A. Mouth of the Daly River

495. Oenpelli. East Alligator River

495A. Oenpelli, looking North across the Billabong

499. Korno Ceremony. Kakadu Tribe . . . . . . 760

50o. Plan of Korno Ceremony Ground . . . . . page 759

50r. Korno Ceremony. Kakadu Tribe . . . . . 761

502. Medicine Man at work. Kakadu Tribe . . . . . 762

503. Medicine Man at work. Kakadu Tribe . . . . $\quad 762$

504. Carrying Dead Body to Grave. Kakadu Tribe . 763

505. Placing Stones on Grave. Kakadu Tribe . . . 763

506. Burial Rock. Oenpelli. E. Alligator River . . . . 764

507. Boys carrying Wands during Initiation Ceremony. Kakadu Tribe

508. Diagram of Ground during Ober Ceremony. Kakadu Tribe . . . . . . . . page 769

509. Scene in Kangaroo Performance. Ober Ceremony . . 770

510. Scene in Kangaroo Performance. Ober Ceremony . $\quad 770$

5II. Scene in Kangaroo Performance. Ober Ceremony. Kakadu Tribe.

\begin{tabular}{lll} 
5I2. Purification Ceremony after Burial. Kakadu Tribe & $\cdot 77$ I \\
\hline & 772
\end{tabular}

513. Purification Ceremony after Burial. Kakadu Tribe . . 772

514. Painting with Black after Burial Ceremony. Kakadu Tribe

515. Women wearing Mourning Armlets. Kakadu Tribe $\quad 773$

516. Two Kakadu Men . . . . . . . 780

517. Kakadu Man with Seven Wives . . . . . 780

5 18 . Kakadu Man killing Snake . . . . . . 78 I

519-535. Bark Drawings. Kakadu Tribe . . . 802-8I4

519. Old and Young Numereji Snakes . . . . . 802

520. Tradition of Bubba Peibi . . . . . . 802

52x. Ingwalin, a Mormo . . . . . . . . $\quad .803$

522. Nangitain . . . . . . . . . 804

523. Auenu . . . . . . . . . 804 
524. A Geimbio Mormo

525. Jerobeini

526. Warraguk

527. Three Snakes

528. Crocodile

529. Hunting the Black Kangaroo

530. A Kangaroo Hunt

531. Pigmy Goose; Fish; Red Hand

532. Barramunda Fish (Osteoglossum) . . . . . 8 8 2

533. Man spearing "Native Companion" . . . . 8 8r3

534. Palmated Goose • • • • • • . . 8 8 I3

535. Echidna . . . . . . . . . 8I4

536. Spear-throwers (Figs. I, 2, 3, 4). Kunjolio (Figs. 5 and 6) 8I 5 537-539.-Rock Drawings of Animals. Kakadu Tribe • 824, 825 540. Rock Drawing of Gnome. Geimbio Tribe . . 826 54r. Kakadu Woman's Dilly-bag with Child's Bones . $\quad$. 827 542. Sacred Muraian Sticks. Kakadu Tribe . . . . 836

543. Sacred Muraian Turtles. Kakadu Tribe . . . . 837

544. Sacred Muraian Sticks. Kakadu Tribe . . . . $\quad 838$

545. Sacred Muraian Stones. Kakadu Tribe . . . $\quad$. 839

546. Muraian Ceremony. Kakadu Tribe . . . 842

547. Muraian Ceremony. Kakadu Tribe . . . . 843

548. Muraian Ceremony. Kakadu Tribe . • . . 843

549. Clubs. Kakadu, Larakia, etc., Tribes • • • • . 844

550. Roughly Ground Stone Axes. Melville Island and Kakadu Tribes . . . . . . . . 845

55r. Palm Leaf and Paper-bark Baskets . . . . 846

552. Bags. Kakadu Tribe . . . . . . . 847

553. Bags. Kakadu Tribe . . . . . . . 848

554. Bags. Kakadu Tribe . . . . . . . . 849

555. Conchs. Kakadu Tribe . . . . . . 850

556. Various Articles. Kakadu Tribe . . . . . $85 \mathrm{I}$

557. Yai-illa. Kakadu Tribe . . . . . 852

558. Waist-belts. Kakadu Tribe . . . . . . 852

559. Kakadu Ornaments . . . . . . . . $\quad$. 853

559A. Bush Fires. South Alligator River . . . $\quad$. 858

560. Ant-hills, Mary River District . . . . . 858

56r. Motor-car stuck in King Creek . . . . . 859

562. A Lonely Grave . . . . . . . 868

563. Passing Teams on the Overland Telegraph Line . $\quad$. 869

563A. Newcastle Waters . . . . . . . 869

564. Leaving Camp at Pundara . . . . . . 876

565. Night Camp amongst the White Gums . . . $\quad 877$

566. Bauhenia Downs Station Water-hole . . . . 890

567. Water-hole on the Roper River . . . . . 890

567A. Water-hole on the Roper River . . . . . . 89I 
568. Grass Growth. Flora River.

570. Watering Pool . . . • • . . . . 896

57I. Section across Rock Bars. Flora Falls . • . page 898

572. Framework of Mosquisto Mia-Mia. Roper River • • 897

573. Mosquisto Mia-Mia closed in with Paper bark. Roper • • 897

574. Women Cooking. Waduman Tribe . . . ' 900

\section{NOTE ON ILLUSTRATIONS.}

The author is indebted to Dr. L. Keith Ward, Dr. Mervyn Holmes, Dr. Woolnough, Dr. Breinl and A. McFeat for permission to use the photographs under the reproductions of which their names appear.

Illustrations with the signature F.J.G. are reproductions of photographs taken by F. J. Gillen, those with the signature B.S. are reproductions of photographs and drawings by the author.

\section{LIST OF COLOURED PLATES}

IX. Initiation Ornaments. Melville Island • • • 676

X. Grave-posts. Melville Island . • . . . . 684

XI. Mourning Armlets. Melville Island . • . . 700

XII. Mourning Ring. Melville Island . . . . . 700

XIII. Bark Baskets. Melville Island . • . . . . 702

XIV. Bark Baskets. Melville Island . • . . . 702

XV. Spears. Melville Island . • • • • . 7 I2

XVI. Muraian Objects. Kakadu Tribe . • . . 840

\section{MAPS}

3. Route traversed from Oodnadatta to the Gulf of Carpentaria and the Distribution of the Tribes . . . . 594

4. Northern and Central Australia . . . . . 9I4

\section{BLOCK DIAGRAMS}

I, 2, 3, representing the Original Form of the Sheets of Bark out of which Three Armlets have been made. . page 697 


\section{CHAPTER XIX}

\section{THE GREAT WOLLUNQUA}

THE Warramunga believe in the existence of mythical ancestors just as firmly as the Arunta do. They call the far-past time Wingara, which is the equivalent of the Arunta word Alchera, and say that, in those far-away days, their ancestors walked about the country, making all the natural features that can be seen to-day. Each totem group has one great ancestor, who was full of spirits, or spirit children, which he carried about with him and deposited at different places, which thus became the local centres of different totem groups. Some striking natural feature, easily seen by the natives, such as a water-hole, a prominent rock or a large gum tree, always arose to mark the places at which he rested and left his spirit children behind. The Warramunga now perform ceremonies that commemorate these ancestors and their doings. The time occupied by their performance may run into months. While we were living amongst the Warramunga, Gillen and myself saw no fewer than eighty-eight of them performed. They began on July 27 th, and when we were obliged to leave them in the middle of September and travel north they were by no means completed. Sometimes there was only one ceremony held during the twenty-four hours, but the number varied up to as many as nine on one occasion, representing eight different totems. There are one or two curious features about them as compared with those of the Arunta. In the latter, each totemic group has its sacred ceremonies, but they may be performed singly and in any order. In the VOL. II. 
Warramunga the old totemic ancestor is supposed to have wandered across the country; his line of travel is well known and, when his descendants perform the ceremonies at the present day, they must begin at the beginning and go steadily through them, in serial order, just as he performed them. Thus, for example, in the case of the black snake and a huge mythical one, called Wollunqua, the series that we saw began right at the beginning of the recorded history of the snake and went completely through to the end of his wanderings.

Whilst, on the whole, the ceremonies were reminiscent of those of the Arunta, they differed from the latter in one very important point. No Churinga were used. The Warramunga possess a certain, but only a small, number of these, and they have not the same significance in regard to totemic ancestors and the relationship between them and the spirits as have those of the Arunta.

A further very curious feature in regard to all the ceremonies is that, whilst the actual performers must belong to the moiety of the tribe with which the ceremony is associated, all decorations and everything needed for it are carried out, and provided, by the men of, the other moiety. If, for example, the ceremony belongs to the Uluuru moiety, then the actual performers must also, but no other men of that moiety are present during the preparations, which are carried out by the Kingilli men, whose duty it is to provide all the materials such as down, red and yellow ochre, gypsum, charcoal, and even draw from their own bodies the blood that does duty for gum. No Uluuru men come near the ceremonial ground until all is ready for the performance, when they are summoned by the Kingilli men.

A Kingilli ceremony can always be distinguished from one of the Uluuru, first by the fact that the performers carry on each thigh a bunch of leafy twigs attached to a stick, 


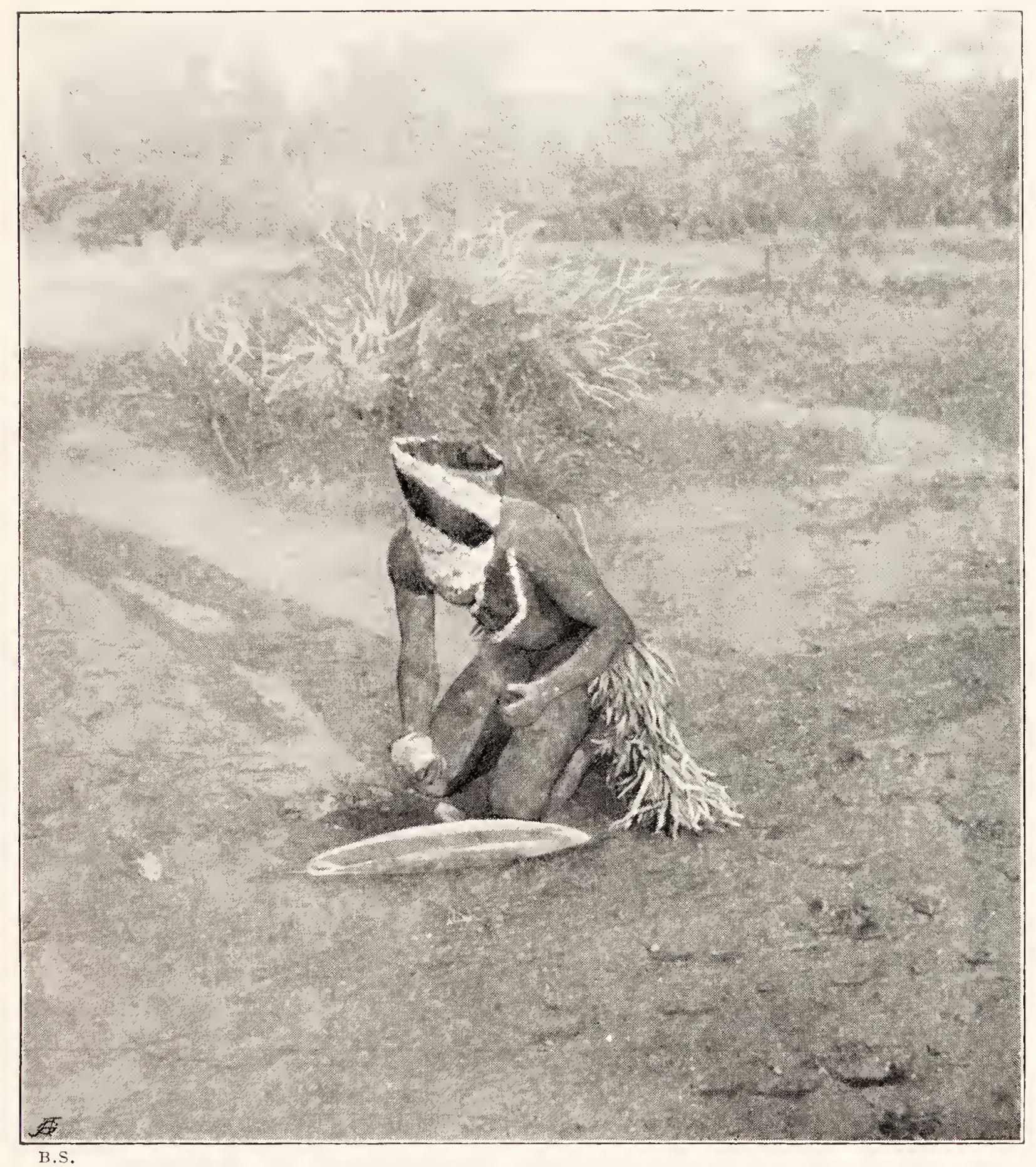

FIG. 282.-CEREMONY OF AN ANT TOTEM BELONGING TO THE KINGILLI MOIETY OF THE WARRAMUNGA TRIBE.

The performer is supposed to represent one of two women ancestors of the totem, searching for and gathering ants, on which she fed. He wears a helmet and carries a wand of leafy twigs attached to each thigh. 


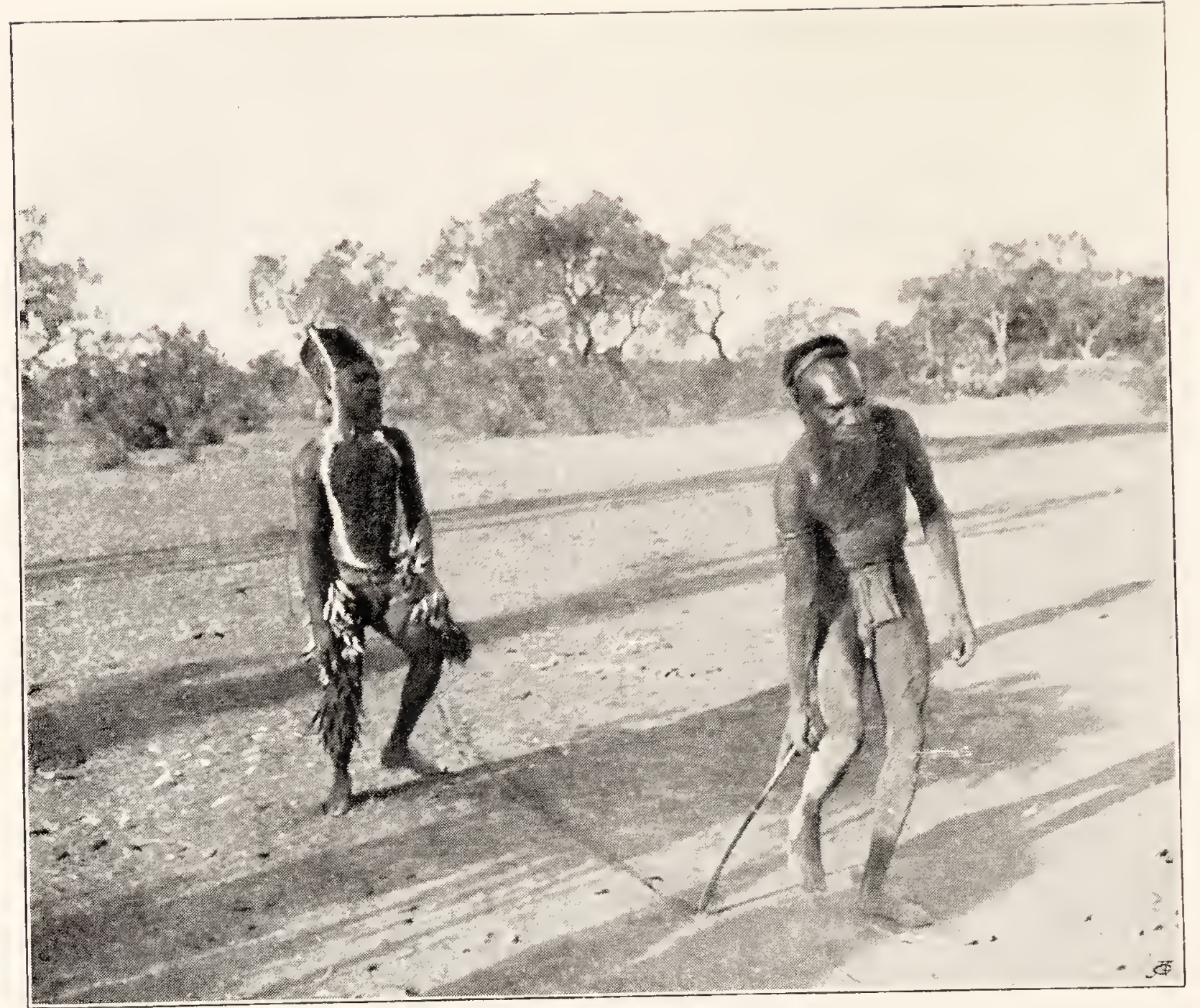

B.S.

FIG. 283.-CEREMONY OF A LIZARD TOTEM, WARRAMUNGA TRIBE.

The man in front is making a track in the sand with a boomerang. The performer is following the track.

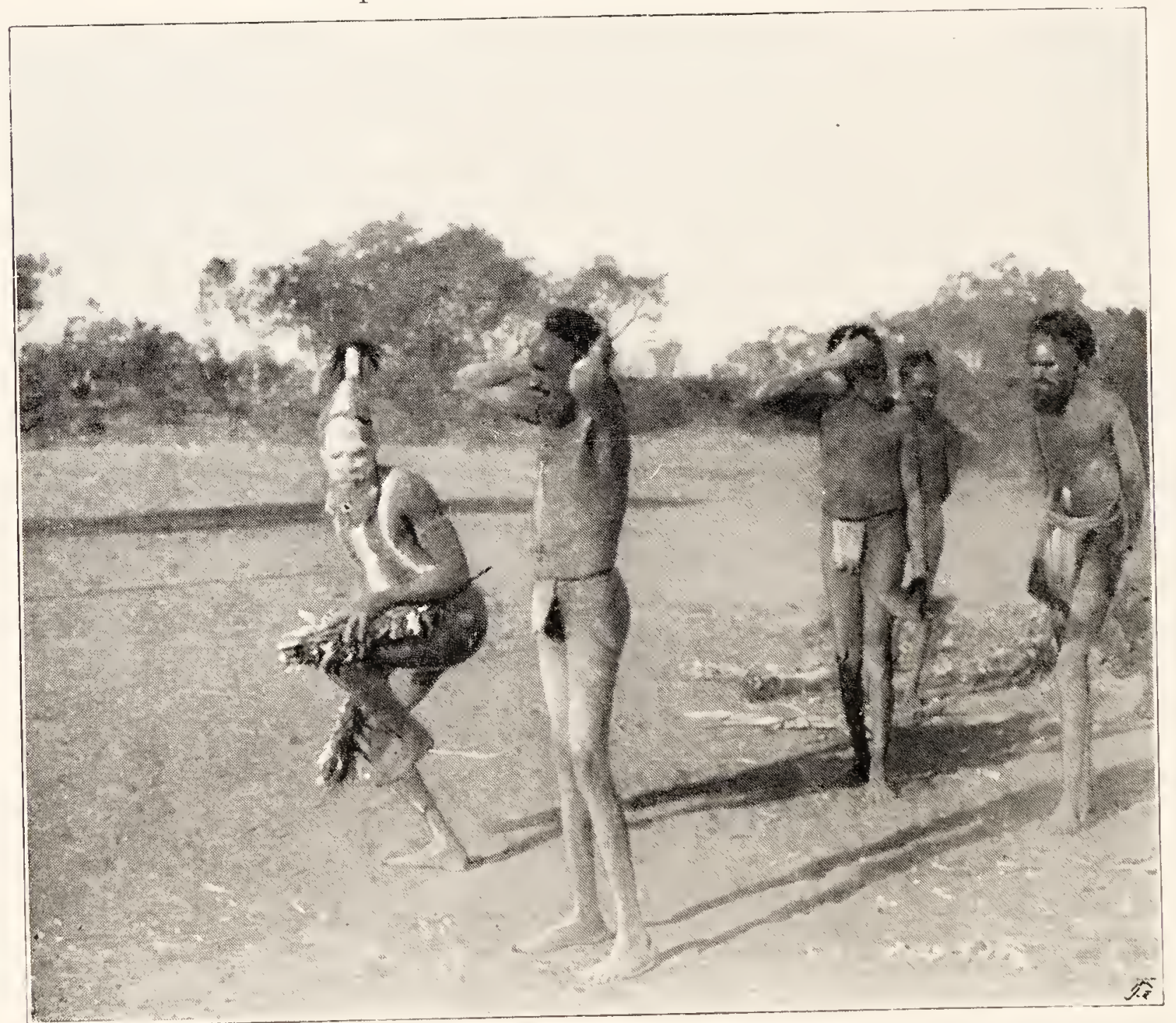

B.S.

FIG. 284.-MAN PERFORMING A CEREMONY OF TIE THABALLA OR LAUGHINGBOY TOTEM, WARRAMUNGA TRIBE.

The man standing in the centre is waiting to knock the performer's helmet off. 


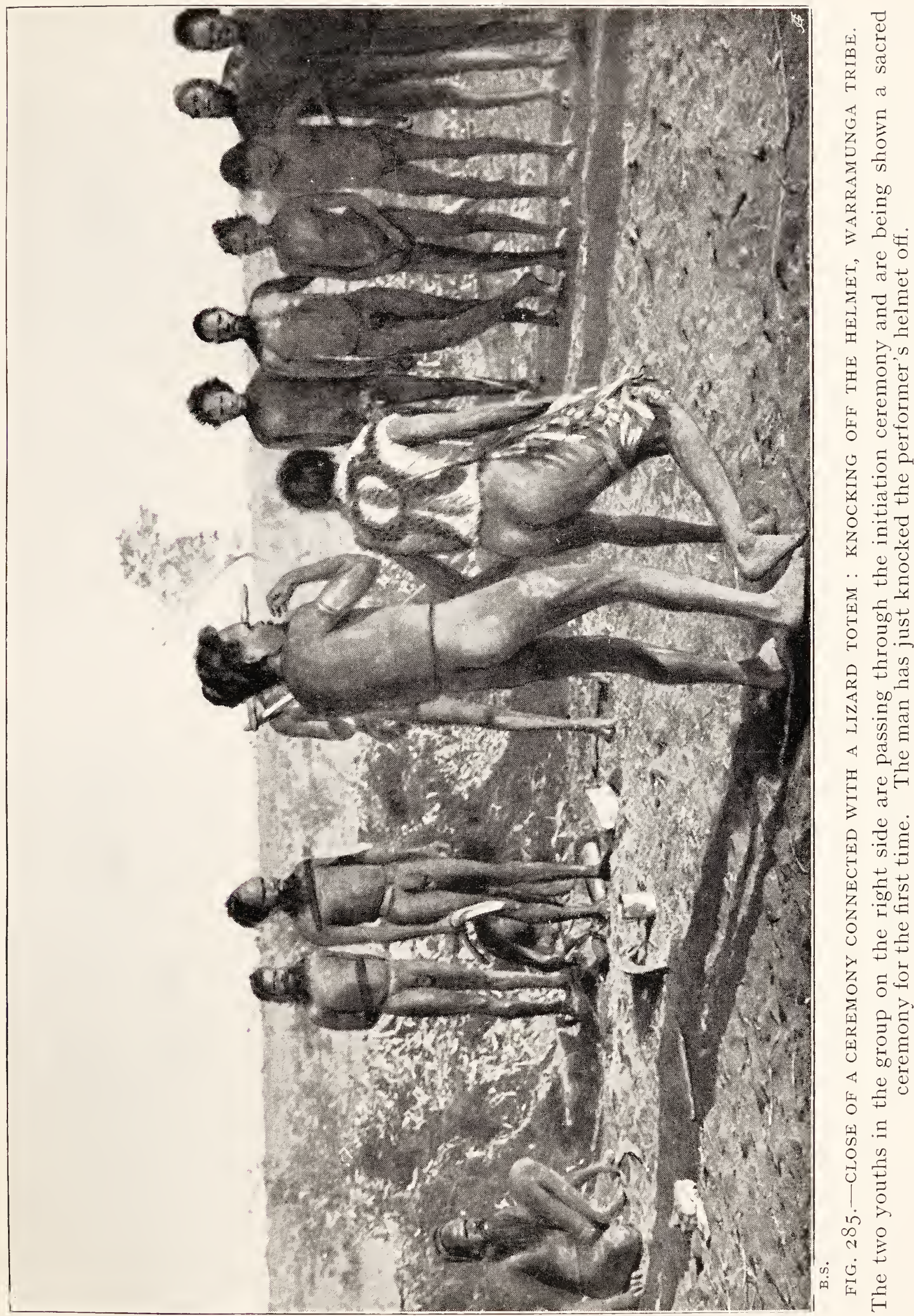




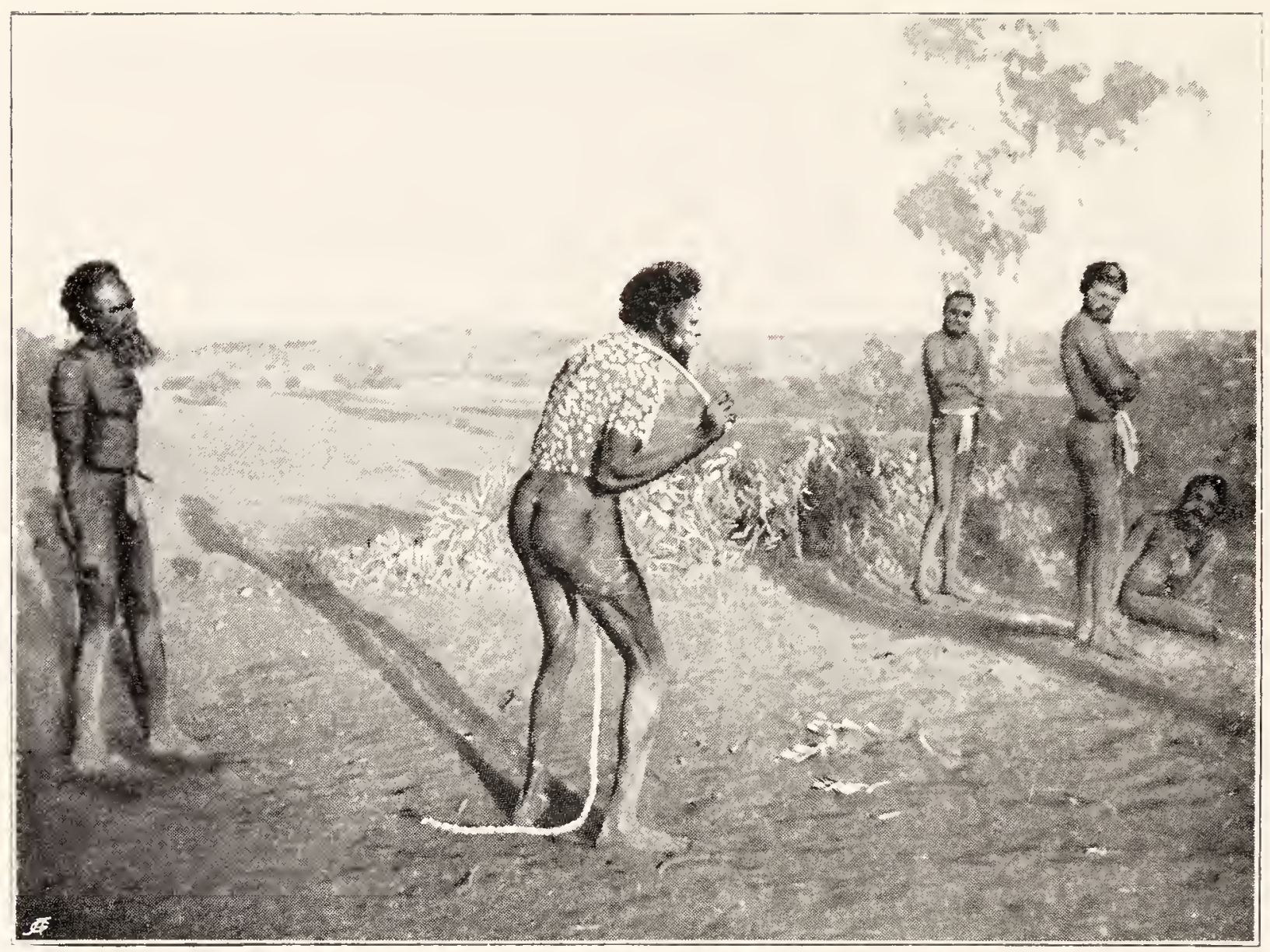

B.S.

FIG. 286.-CEREMONY OF WILD-CAT (Dasyurus sp.) TOTEM, WALPARI TRIBE. The long, trailing pendant is supposed to represent the animal's tail.

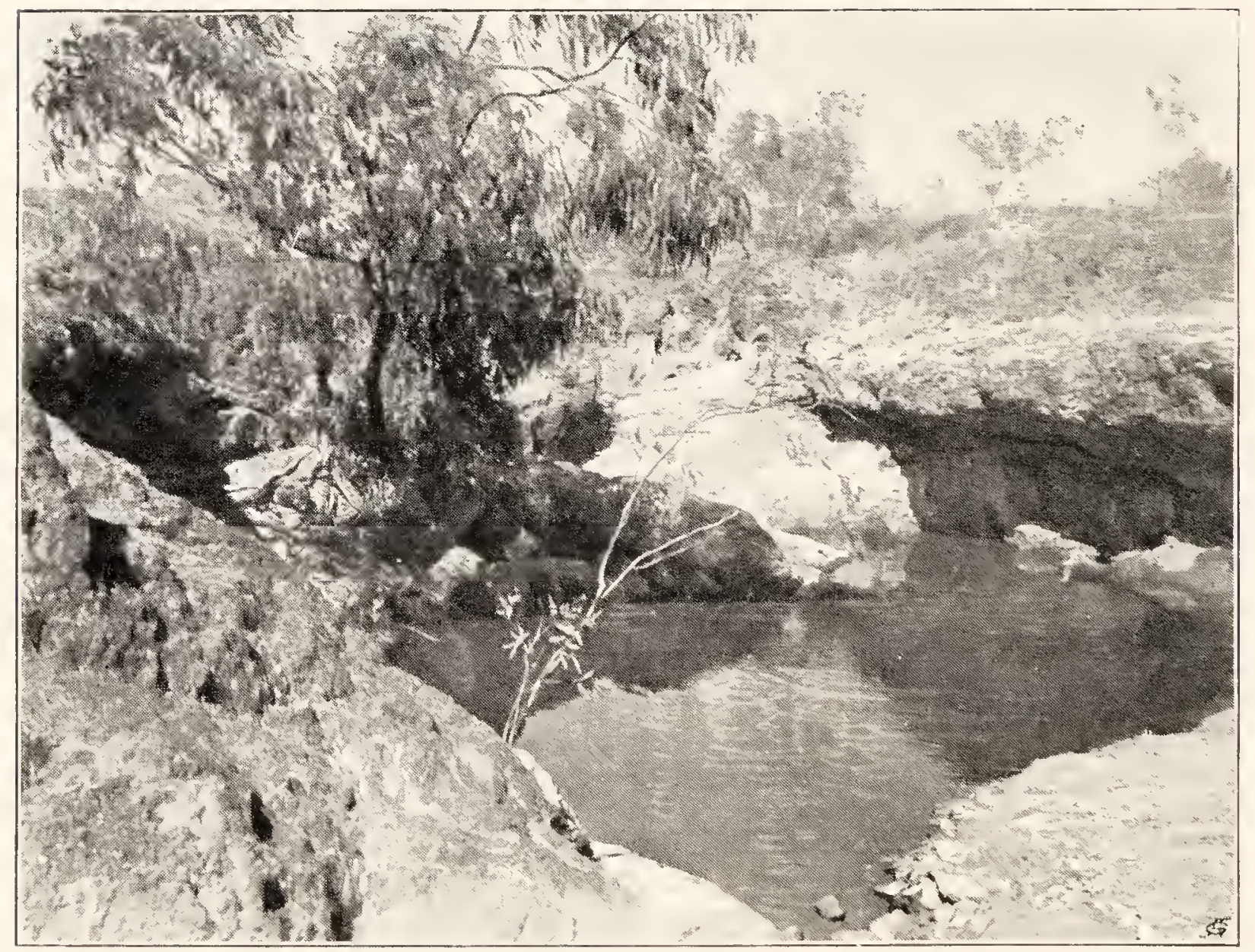

B.S.

FIG. 287.- TJINQUROKORA, A WATER-HOLE IN THE TENNANT CREEK WHERE THE ANCESTOR OF THE BLACK-SNAKE TOTEMIC GROUP AROSE, WARRAMUNGA TRIBE.

No member of the totem may drink wates here. 
the free end of which points upwards, and, secondly, by the wearing of some form of helmet (Fig. 282). The performer when decorated is always led away for some distance and hidden behind bushes. The men in camp are then summoned and the performer comes out into the open and runs on to the ceremonial ground (Fig. 283), with the usual highknee action, often pausing every now and then to shake his body, with the result that some of the down flies off, which is supposed to represent the emanation of spirits from the body of the old Wingara ancestor. He circles round and round a man who stands waiting for him (Fig. 284) and who, as he tumbles down, knocks the helmet off (Fig. 285). The other men cluster round, but there is no running round or shouting of "Wha! Wha!" which is so characteristic a feature of Arunta ceremonies.

It is very usual when a visitor from another tribe is present to ask him to perform one of his own tribal ceremonies. On this occasion two or three men of the Walpari tribe were in the Warramunga camp and, by request, one of them performed a "wild-cat" ceremony. It was interesting in that there was a very evident attempt in the decoration to suggest the animal with its spotted fur and long tail (Fig. 286). In this respect it differed radically from all the Arunta and Kaitisha and from all the Warramunga, except to a certain extent the Wollunqua.

The illustrations referring to the black snake, called Thalaualla, may be taken as fairly representative of a series of ceremonies connected with the Uluuru (Figs. 288-92). The old snake arose at a water-hole called Tjinqurokora, which lies in a curious conglomerate formation about a mile away from the station along the course of the Tennant Creek (Fig. 287). Starting from there he wandered over the country. The decorations consisted, partly of designs on the body-a prominent curved red or black band very often representing the snake itself-and partly of ground 


\section{WANDERINGS IN WILD AUSTRALIA сн.}

drawings (Fig. 29I). We very rarely met with these in the Arunta, but in the Warramunga they form a very striking and picturesque feature of some ceremonies. Instead of bird's down the Warramunga use the involucral hairs of a grass seed (Epaltes sp.), which allows of the drawing of a more sharply outlined and definite design than does the down. The beautiful curves and symmetry of some of the designs are very striking, all the more so because the ochre used is of a deep, indian-red tint.

Amongst the Arunta, all their original totemic ancestors are supposed to have died in the Alchera, and the same is true of all except two in the Warramunga. One of these is a curious creature called Thaballa, or the laughing boy (Fig. 284), who can even now be heard laughing by anyone who goes to a place called Jappa-kulinia, where he dwells amongst the rocks. The other is a gigantic snake called Wollunqua, which gives its name to one of the most important totemic groups.

The Wollunqua occupies a very prominent place in the mythology of the Warramunga. The ceremonies that are performed in connection with it are the most elaborate of any that I have seen amongst all the Central and Northern tribes. It is reported to have arisen in the far-past Wingara times-the equivalent of the Alchera of the Arunta-at a place called Thapauerlu, a rocky water-hole amongst the Murchison Ranges. Stretching itself as far as it could, whilst its tail end remained in the water-hole, its body extended over a distance of about one hundred and fifty miles. Then it gradually withdrew back again, but it halted, that is, its head end did, at various places, where it performed ceremonies, leaving spirit individuals behind who are now born in the form of men and women. Finally, it reared itself up into the sky and, with one gigantic plunge into the ground, returned to Thapauerlu.

The first Wollunqua ceremony was performed on July 


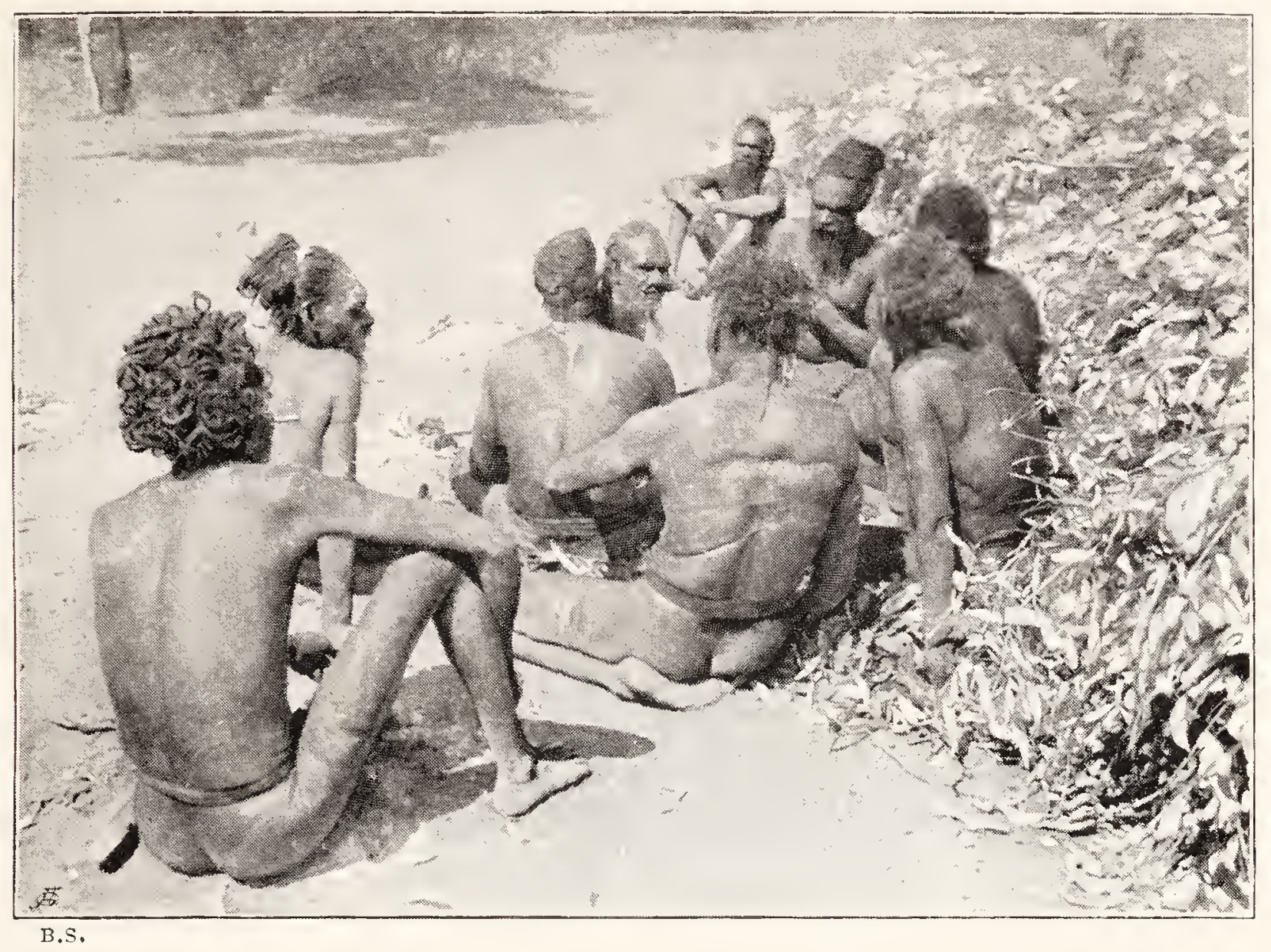

FIG. 288.-BEGINNING TO DECORATE THE BODIES OF PERFORMERS, WARRAMUNGA TRIBE.

The outline of a band is being indicated in grease.

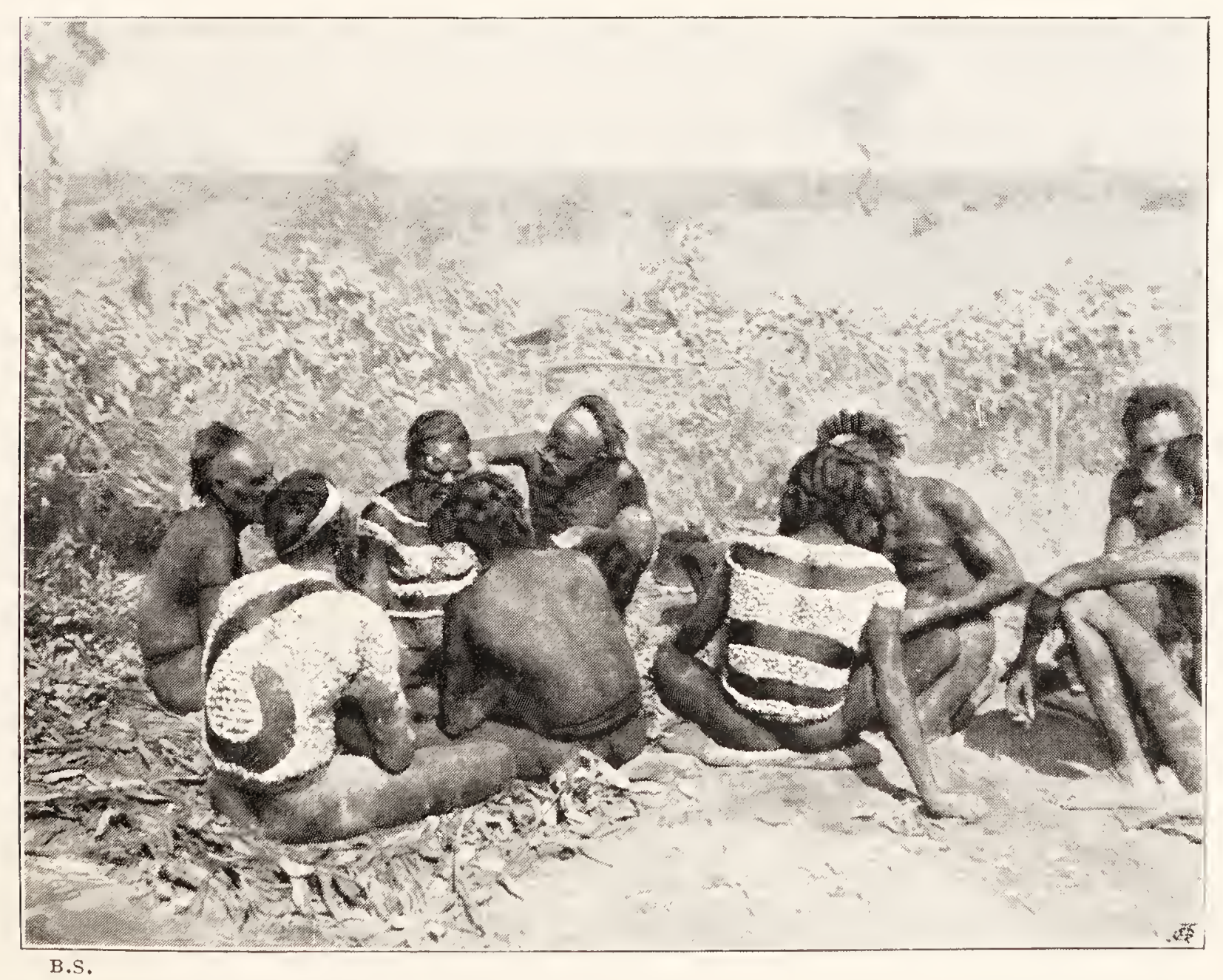

FIG. 2S9.-PREPARATION FOR A CEREMONY IN CONNECTION WITII THE BLACK-SNAKE TOTEM, WARRAMUNGA TRIBE. 


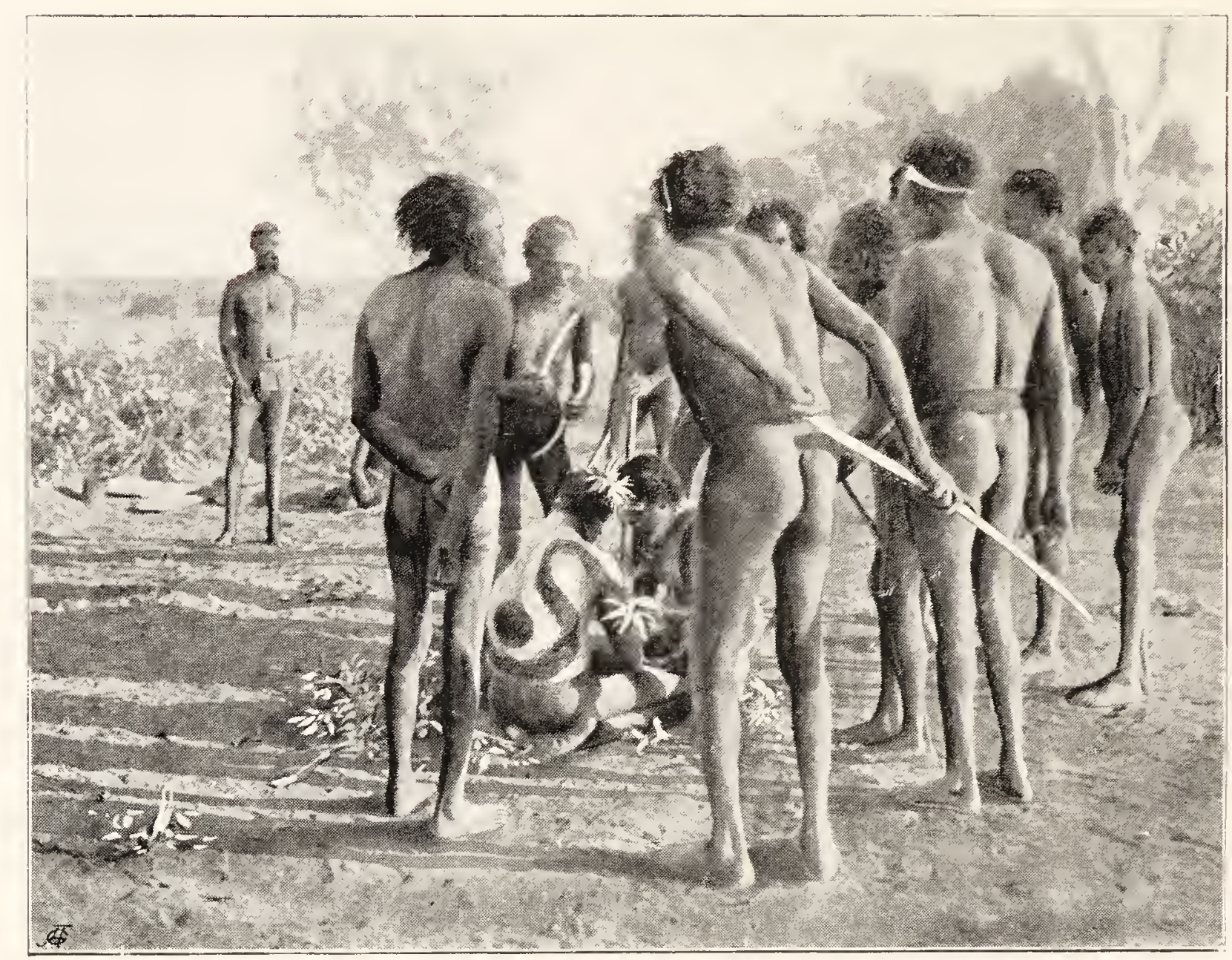

B.S.

FIG. 290.- THE AUDIENCE GATHERING ROUND THE PERFORMERS AT THE CLOSE OF A CEREMONY CONNECTED WITH THE BLACK-SNAKE TOTEM, WARRAMUNGA TRIBE.

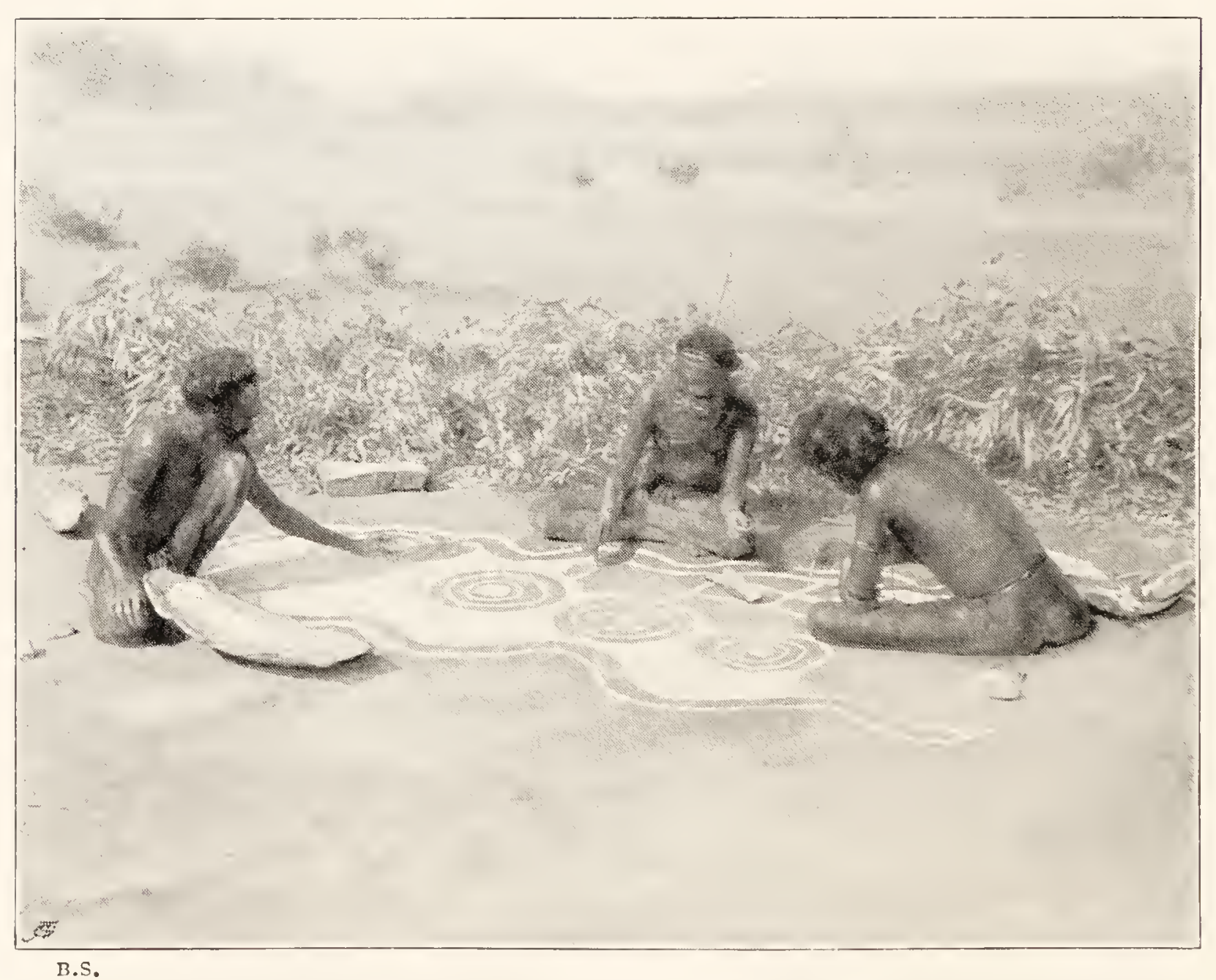

FIG. 29I.-PREPARING A GROUND-DRAWING IN CONNECTION WITH A CEREMONY OF THE BLACK-SNAKE TOTEM, WARRAMUNGA TRIBE. 
$27^{\text {th }}$ and the last on September I Ith. The great beast is supposed to be still alive at its home in the water-hole at Thapauerlu, and there is always a fear that it may take it into its head to come out and do some damage. On one special occasion it is known, apparently for no special reason, to have killed a number of natives, though on another, when it came out and attacked them, the men were able to drive it off. That the fear of the natives is something very real to them is shown by the fact that, instead of using the name Wollunqua, when they speak of it they call it Urkulu napparinia, because, so they told us, if they were to call it too often by its real name they would lose control over it and it would come out and eat them all up. Urkulu is the general term for snake, and napparinia means "belonging to the water," evidently in allusion to the fact that its home is in the water-hole at Thapauerlu.

There are eleven places especially associated with the wanderings of the Wollunqua. When it left Thapauerlu it travelled at first underground towards the east and came out, or rather its head end did, at a water-hole called Pitingari, its tail end remaining at Thapauerlu. In the ceremony connected with Pitingari, two men were decorated with a broad curved band of red down running across both the back and front, the whole of the upper part of the body, except the band, being covered with a mass of white down. Each man wore also a tall, conical helmet, decorated with a red band. All the bands represent the Wollunqua. When the decorations were complete, each of the two men went and hid himself behind a bush, away from the ceremonial ground, on to which the Uluuru men came and mixed with the Kingilli. To an accompaniment of singing and beating of boomerangs, the performers came out on to the open ground and ran in, stopping every now and then to shake themselves, in imitation of the snake, and finally sat down close together on a few green gum-tree boughs 


\section{WANDERINGS IN WILD AUSTRALIA сн.}

with their heads bent down. Their head-dresses were immediately knocked off by a Kingilli man and the performance was over, except that some of the men came up and stroked the curved bands of red down, a little ceremony that is called Irrimunta and is supposed to have a soothing effect on the snake itself (Fig. 293).

At the time of our visit there was a celebrated old man of the Worgaia, a neighbouring tribe living in the Warramunga camp. He was not only a medicine man of such repute that he was known in this capacity even to the Warramunga, but he was also a great maker of medicine men (Fig. 294). It is quite likely that he owed his reputation in part to the fact that his magic belonged to a distant country and, being more or less unknown, was correspondingly potent. Be this as it may, he was evidently a man of considerable influence, so much so that he actually took the leading part in preparing the Wollunqua ceremonies. On the second day he made a curious curved bundle, somewhat like an enormous rounded boomerang. It was made of grass stalks, bound round and round with human hair string and then ornamented with white down. One of the performers carried it on his head, as shown in the illustration (Figs. 295, 296), and, as he ran on to the ceremonial ground from his hiding-place in the scrub, he kept stopping to peer about from side to side, quivering his body as he did so, with the result that he threw off small showers of white down. The natives have a peculiar power of making their bodies shake and quiver whilst they are performing their ceremonies.

Three or four days later a much more interesting ceremony was performed. Under the guidance of the old Worgaia man, the Kingilli men spent the whole day, from ten in the morning till between five and six in the afternoon, building a most remarkable mound of sandy earth. First of all they made two breaks of boughs enclosing a space about thirty feet long and fifteen in greatest breadth. The breaks were 


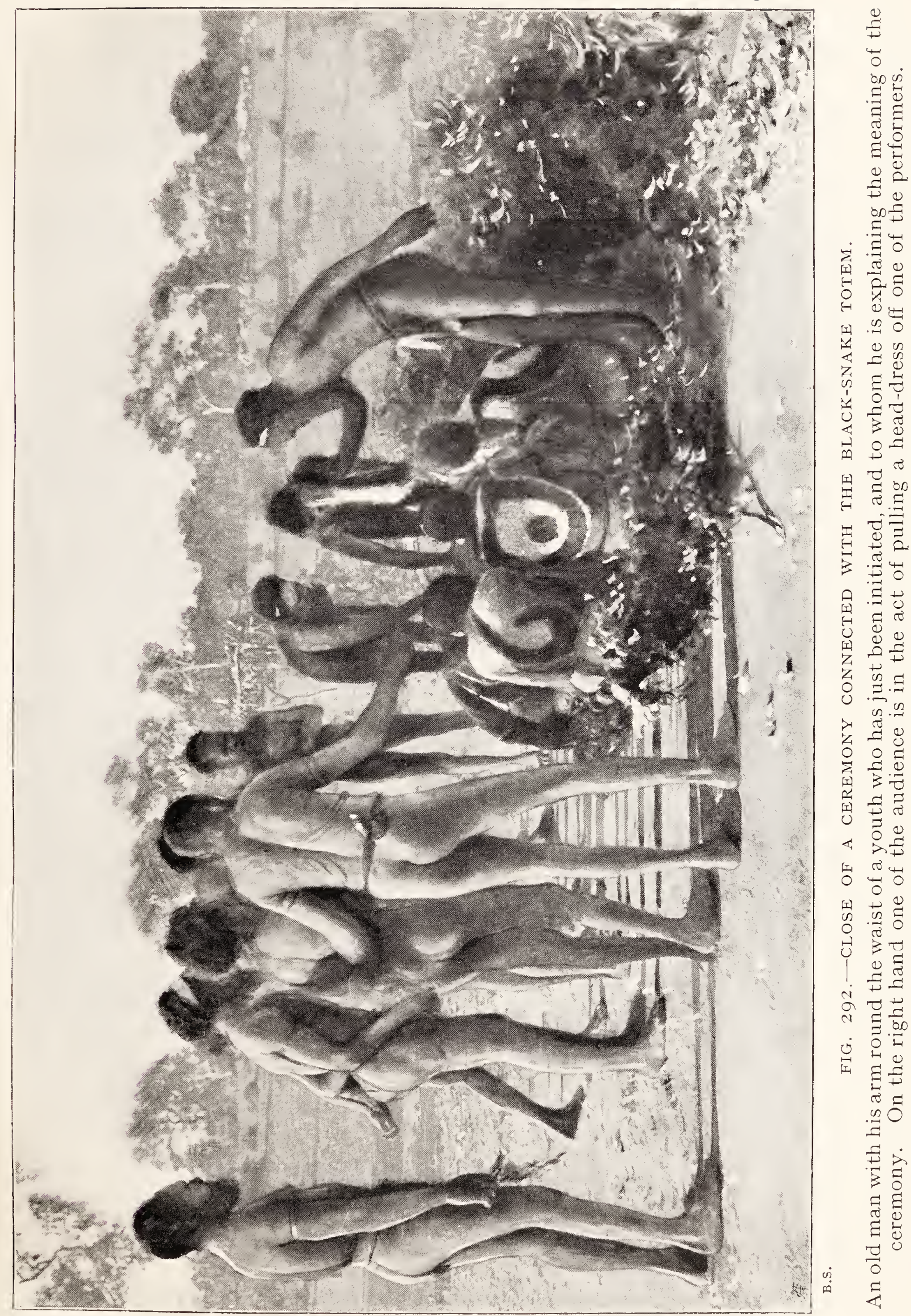




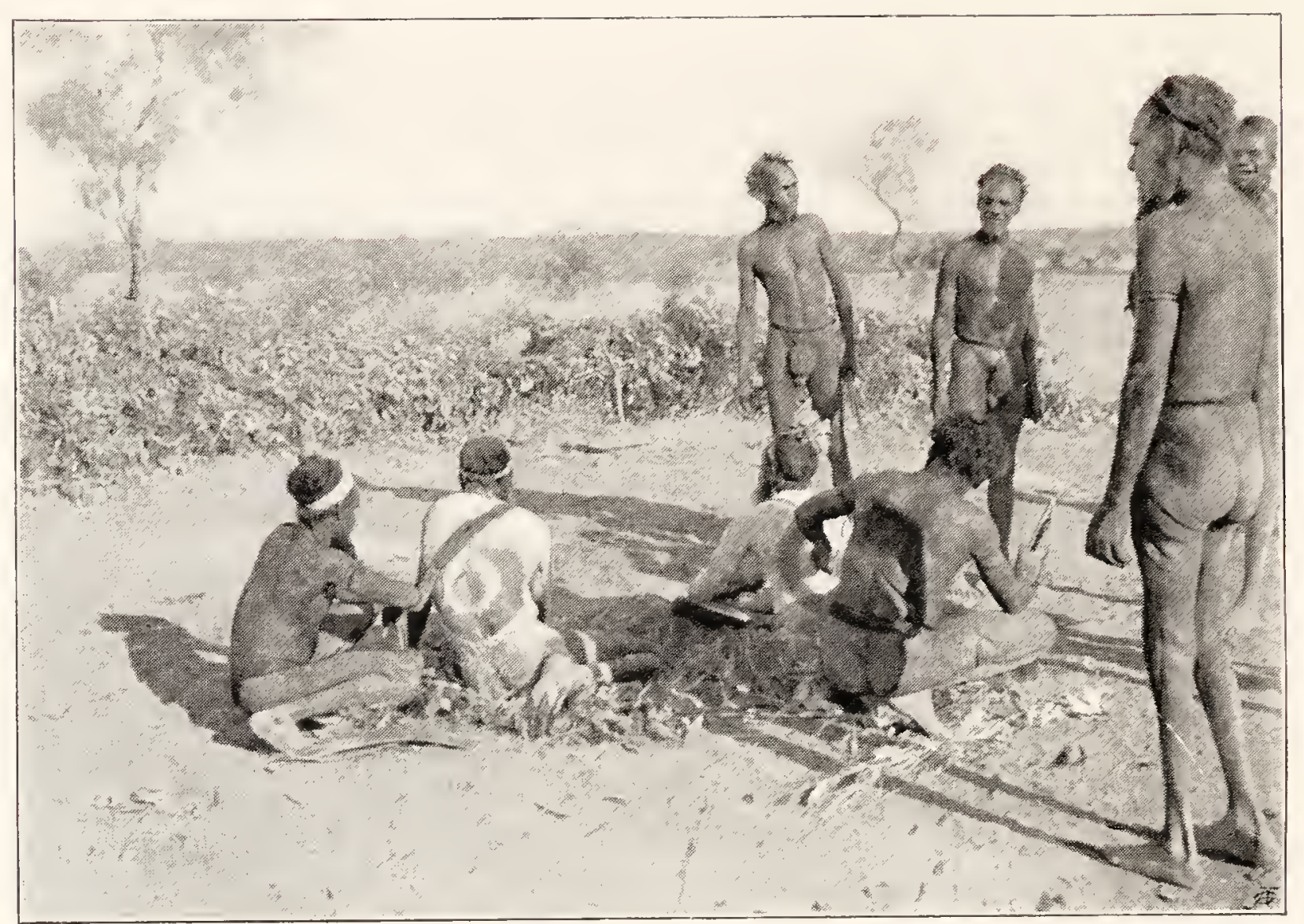

B.S.

FIG. 293.-CEREMIONY OF IRRIMUNTA, WARRAMUNGA TRIBE.

Stroking the drawing of the snake on the back of the performers.

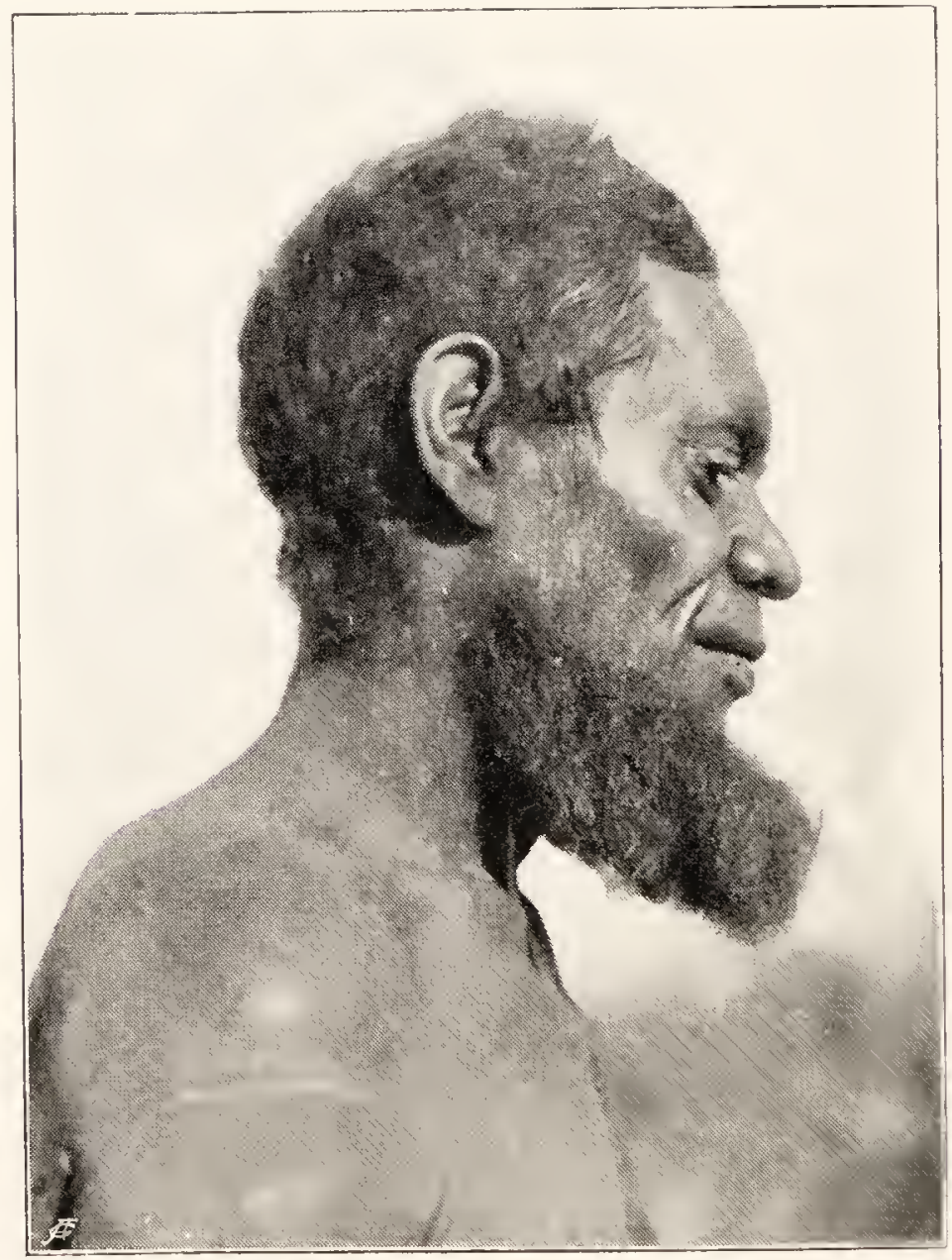

B.S.

FIG. 294.- MAN OF THE WORGAIA TRIBE, SHOWING THE HAIRS PULLED OUT ON THE LIPS AND SIDE FACE. 
curved, so that there was a comparatively narrow entrance at each end. The object of this was to hide the mound from the sight of all except those who were actually engaged in building it. When this was ready, a trench, fifteen feet in length and two in width, was dug and then filled again with sand mixed with water. Handful after handful was carefully patted down, until, finally, a keel-shaped mound was built, about two feet in greatest height and tapering off at either end, its length corresponding to that of the original trench. The surface was as smooth as it could possibly be made by dint of constant patting. The old Worgaia man then outlined, on each side, a long wavy band, about four inches wide, the two bands meeting at each end. These were supposed to represent the snake. At the northern one a small round swelling was afterwards added to the design indicating the head, and at the southern a median prolongation representing the tail. Then the Kingilli men sat down beside it, and hour after hour they patiently stuck endless dots of red and white down on to it, until the whole surface was completely covered - the wavy band with red, and the rest with white down (Fig. 297). Every now and then they burst out into chants referring to the great Wollunqua, its wanderings and its goings down into the ground. At others they broke out into refrains, such as "Yanga le deba; le deba; yanga le deba"; or "Waiu irri; we gar dudu; waiu wanga wanga; waiu irri; irri wanga du du du; wanga du du du du." These have been handed down with the ceremony and their meaning is unknown. This went on hour after hour with wearisome repetition, the singing as usual always beginning on a high note and gradually dying away, falling lower and lower as it did so.

The whole mound was supposed to represent a special large sand-hill on the side of which the snake stood up and looked around, and with which he was in some way closely associated. 


\section{WANDERINGS IN WILD AUSTRALIA $\mathrm{cr}$.}

It was between five and six in the afternoon when word was sent to the older men amongst the Uluuru that all was ready. Led by an old man, the head of the Wollunqua totem, they came on to the ceremonial ground, escorted by an old Kingilli man. The Kingilli stood in a group at one end while the Uluuru walked twice round the mound, gazing at it with intense interest and apparent astonishment (Fig. 298). Only one or two of the older men had seen anything like it before and the younger men only knew of it by hearsay. This over, one of the Uluuru men took a gum-tree bough and stroked the ground all round the base of the mound (Fig. 299); the old Worgaia man, who knew most about it, was hard at work gesticulating wildly and explaining its meaning, telling them, finally, that the Wollunqua and the mound that they, the Kingilli, had made belonged to them.

Everybody then sat down quietly, examining the mound and talking in low voices about the snake, after which the Uluuru rose and silently went back to their camp, leaving the Kingilli once more in charge of the ground. Nothing more was done until dark, and then three old Kingilli men lighted fires and began to sing loudly, so that the Uluuru men in their camp could hear them. First of all they sang as follows :

$$
\begin{aligned}
& \text { "Da dun burri wurri a, } \\
& \text { Da dun burri wurri a, } \\
& \text { Da iwun ma, } \\
& \text { Da dun burri wurri a, } \\
& \text { Da iwun ma," }
\end{aligned}
$$

alternately with this-

$$
\text { "Jam anna yanti andi," }
$$

repeated time after time. They did not know the meaning of these words. When not singing they shouted at the top of their voices, telling the Uluuru they were "singing their Wingara." It was evident that something special 


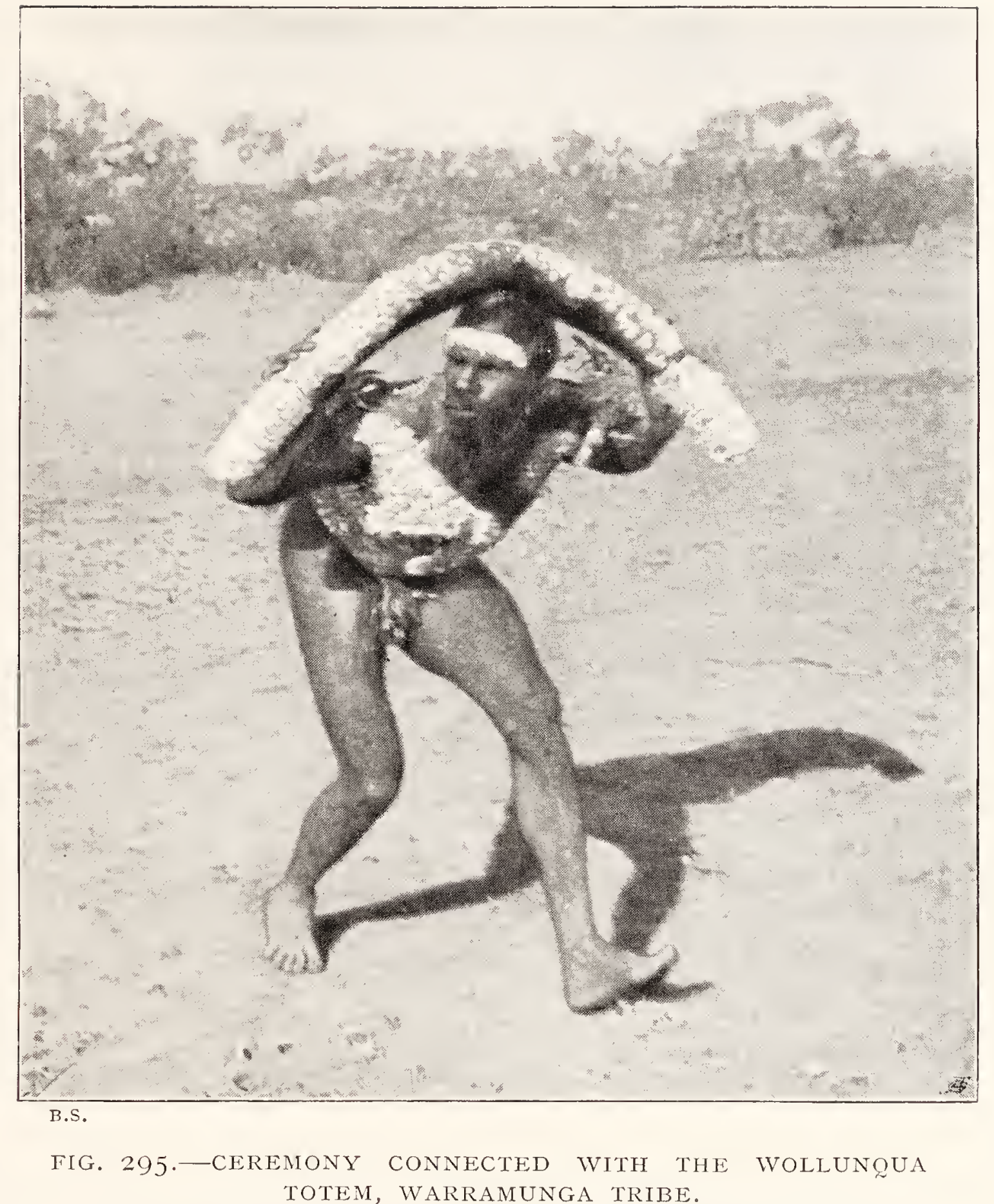

The curved bundle represents the Wollunqua snake. 


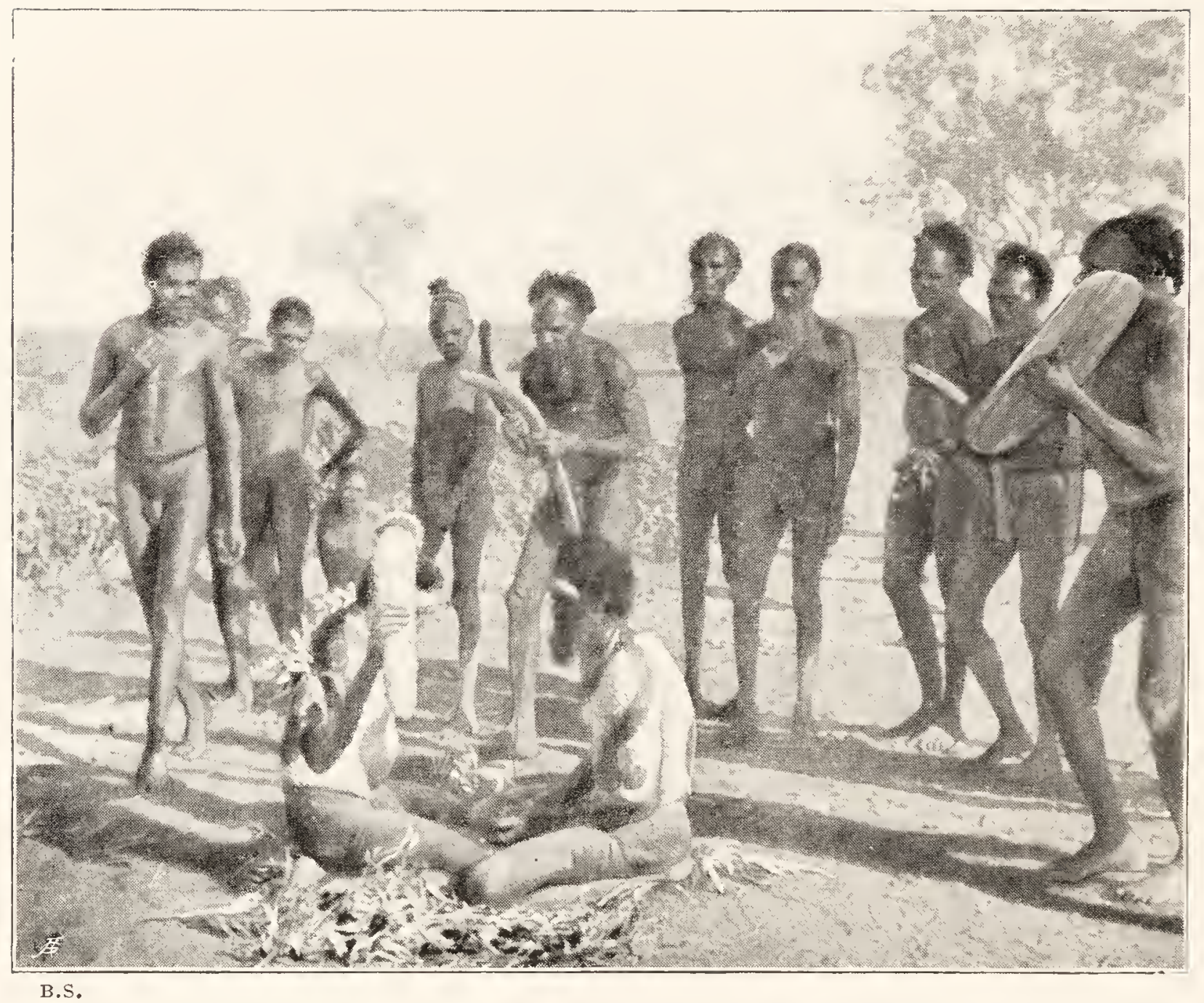

FIG. 296.-CLOSE OF A CEREMONY CONNECTED WITH THE WOLLUNOUA TOTEM, IVARRAMUNGA TRIBE.

The youth in the background with his hair tied up has been recently initiated, and is witnessing the series of sacred ceremonies for the first time. 
and out of the ordinary was going to happen, so we took our rugs down to the ceremonial ground and prepared for an all-night sitting. About ten o'clock the Uluuru came up, more fires were lighted and the singing was interminable. Towards midnight, three recently initiated youths were brought up, their heads covered in rugs, which were removed as they stood by the side of the mound and had its meaning explained to them. After this, until three in the morning, singing went on without a pause and we waited patiently, wondering what was going to happen. Suddenly the excitement increased. Fires were lighted all round the ground, making the white trunks of the gum trees and the near scrub shine out brilliantly against the darkness beyond. The Uluuru men, kneeling down, ranged themselves in single file beside the mound and, with their hands on their thighs, surged round and round it, every man, in unison, bending down, first to one side and then to the other. The Kingilli men stood round in a state of great excitement, the oldest man amongst them swaying his body about while, with exaggerated high-knee action, he walked backwards at the head of the kneeling procession. As the Kingilli men clanged their boomerangs together, the Uluuru, with rhythmic movement, swayed about wildly from side to side, yelling "Yrrsh! Yrrsh!" at each movement, until they had passed twice completely round the mound. As the fires died down they rose from their knees and everyone once more sat down round the mound. Every now and then the singing flagged and we thought there would be peace and quiet for a little time, but suddenly some old veteran would rise to the occasion and, with a squeaky voice, set them off again. The scene with the men yelling and surging on their knees round and round the mound in the firelight was very wild and picturesque, and as it was impossible to photograph it I have attempted to give a little idea of what it was like in a rough sketch (Fig. 300). 


\section{WANDERINGS IN WILD AUSTRALIA сн.}

This went on till four o'clock, and as soon as the first streak of dawn appeared, a signal was given and every man stood up. Then the old Kingilli man gave the word and, amid frantic yells, they hacked the mound to pieces, until all that remained was a rough heap of sand. The fires died down and for a short time there was silence. This did not last long. Everyone was very excited and, just at sunrise, we all went over to another ceremonial ground, about half a mile away, and an extraordinary night's performance was brought to a close with the final and gruesome initiation ceremony of three youths.

The mound and the ceremony connected with it are called Miniimburu, which means "laying the snake to rest," and is associated in the native mind, partly with the idea of propitiating him and partly with that of forcing him to do what they want. They say that when he sees the mound with its representation of himself drawn in down upon it, he is gratified and wriggles about underneath with pleasure. The savage attack on the mound is associated with the idea of driving him down. It is necessary to do things to please him, or else he might grow sulky and come out and hurt them; but at the same time they now and then use force to make him do what they want. On the evening of the day on which the Miniimburu was held the old Kingilli men who had made the mound said that they heard the Wollunqua talking, and that he was pleased with what had been done and was sending rain, the explanation of which doubtless was that they, like ourselves, had heard thunder in the distance. Unfortunately no rain fell, but a few days later the distant rumble of thunder was again heard in the distance, and the old men now said that this was the Wollunqua growling because the remains of the mound had been left uncovered. They also told the young men that a heavy bank of clouds that lay along the western horizon had been put there as a warning to them by the snake, and 


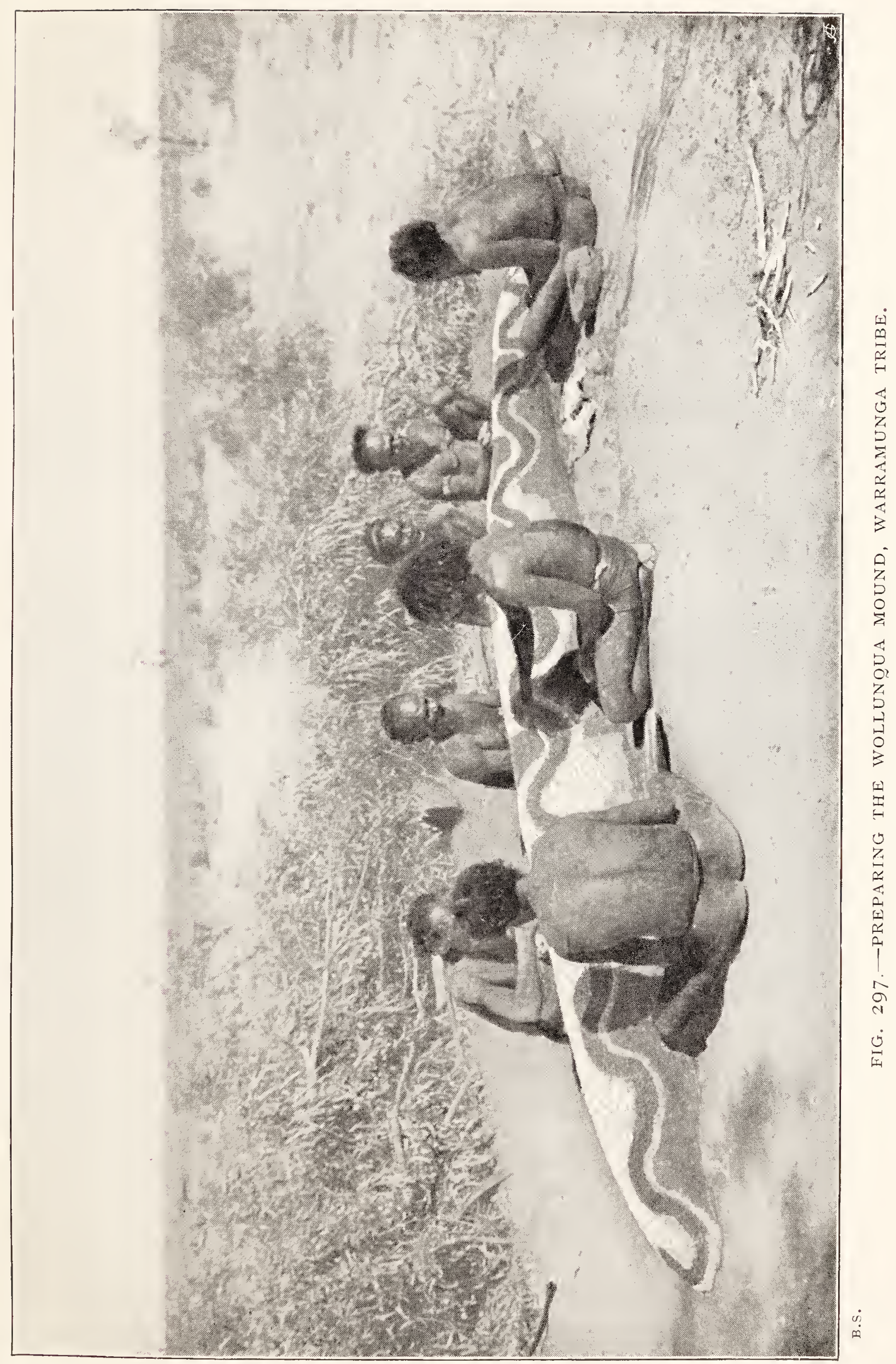




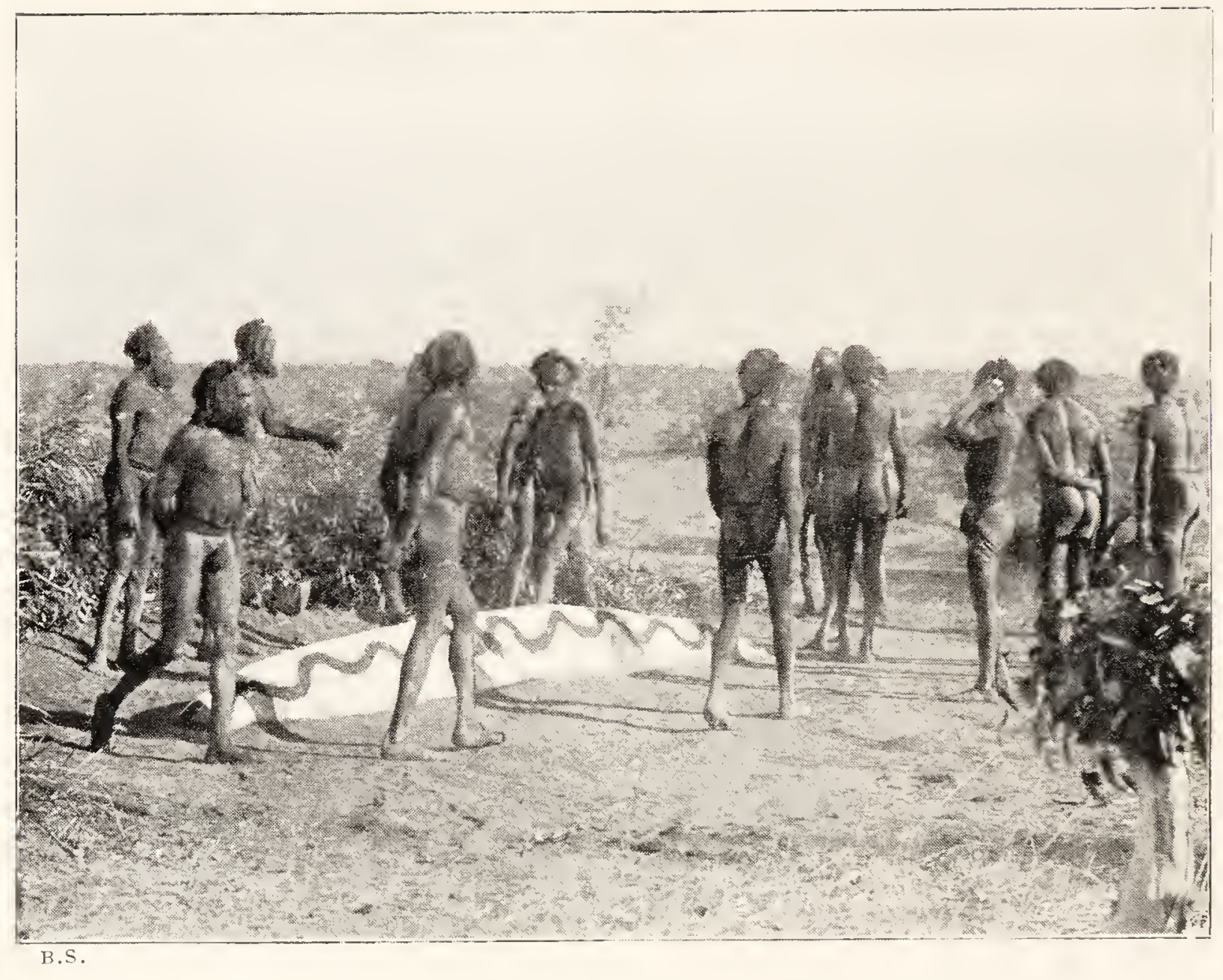

FIG. 298.-THE KINGILLI MEN SHOWING THE WOLLUNQUA MOUND TO THE ULUURU, WHO ARE WALKING ROUND IT, WARRAMUNGA TRIBE. 
at once cut down boughs and hid the ruins of the mound from view, after which the Wollunqua ceased from growling and gave no more trouble.

For four days after this there were no more Wollunqua ceremonies, though we had plenty of others, connected with ant, lizard, fire and wild-cat totems. When they did begin again they were quite different, in one respect, from the earlier ones. On eight successive days a special drawing was made on the ground, each of which was supposed, in some way, to be associated with a special spot at which the snake stood up and left spirits behind it (Figs. 30I-307). The drawings were all made on the same spot on the ceremonial ground, and each was either rubbed out on the morning after the ceremony had been performed-never on the same day-or was restored and added to. The sandy soil was first smoothed down with the palm of the hand, then sprinkled with water and smoothed again so as to give a compact surface. It was then covered with a coat of red and yellow ochre and, when this was dry, the design, which always consisted of concentric circles and curved lines, was drawn upon it in red ochre, or a mixture of grease and charcoal, and the whole of the remainder of the space was covered with white dots. The drawing of the main design, that is, of the circles and lines, was always done by an old man, usually by the Worgaia medicine man, who, after issuing instructions, sometimes remained and assisted in the further work, but more often left this to the younger men. The material used for the white dots was always a kind of kaolin, of which there is a deposit near to Tennant Creek. After smashing up the larger lumps on a stone, the small ones were taken into the mouth and ground up finely with the teeth, a somewhat gritty proceeding. The semi-fluid material was then spat out into a small pitchi, or a piece of bark, and mixed with water. The dots on the ground were made with a primitive kind of paint-brush that 


\section{WANDERINGS IN WILD AUSTRALIA cH.}

was merely a little twig, with the fibres frayed out, at one end, by the teeth, so as to form a flat disc like a very minute chimney-sweeper's brush. The brush was just daubed into the emulsion and then on to the smooth ground surface, on which it made a round white dot. The work of drawing these designs, every part of them being made by Kingilli men, usually occupied the best part of the day. Their nature can be seen from the illustrations, and they certainly were very effective. Seeing that the circles were drawn simply with the old man's fingers, without any mechanical help of any kind, their comparative accuracy was astonishing.

The last ceremony was on a somewhat large scale, so far as the size of the drawing was concerned and the number of performers, of whom there were no fewer than nine, all of them elaborately decorated. It was associated with a place called Ununtumurra, where the Wollunqua ceased from his wanderings. All the time, it must be remembered, he had been travelling further and further away from Thapauerlu -or, to speak more correctly, his head had, because he was so huge in size that the latter was many miles away from his tail end which remained in the water-pool. The ground drawing was very elaborate. In the centre of it were three concentric circles (Fig. 307) that were supposed to represent the place, Ununtumurra. Attached to one side of the outermost was a semicircle, forming the end of a broad, sinuous band of black, fully eighteen feet in length. Close by, and attached also to the outer circle, were two large bands curving over towards one another like great beaks. All along by the side of the main band there was outlined, also in black, a single series of tracks that very cleverly imitated those made by a man walking with naked feet. Two other impressions of feet were also drawn, side by side, close to the head. The footmarks were interesting, because they were distinctly realistic, whilst all the rest of the drawing was conventional. Four other series of concentric 


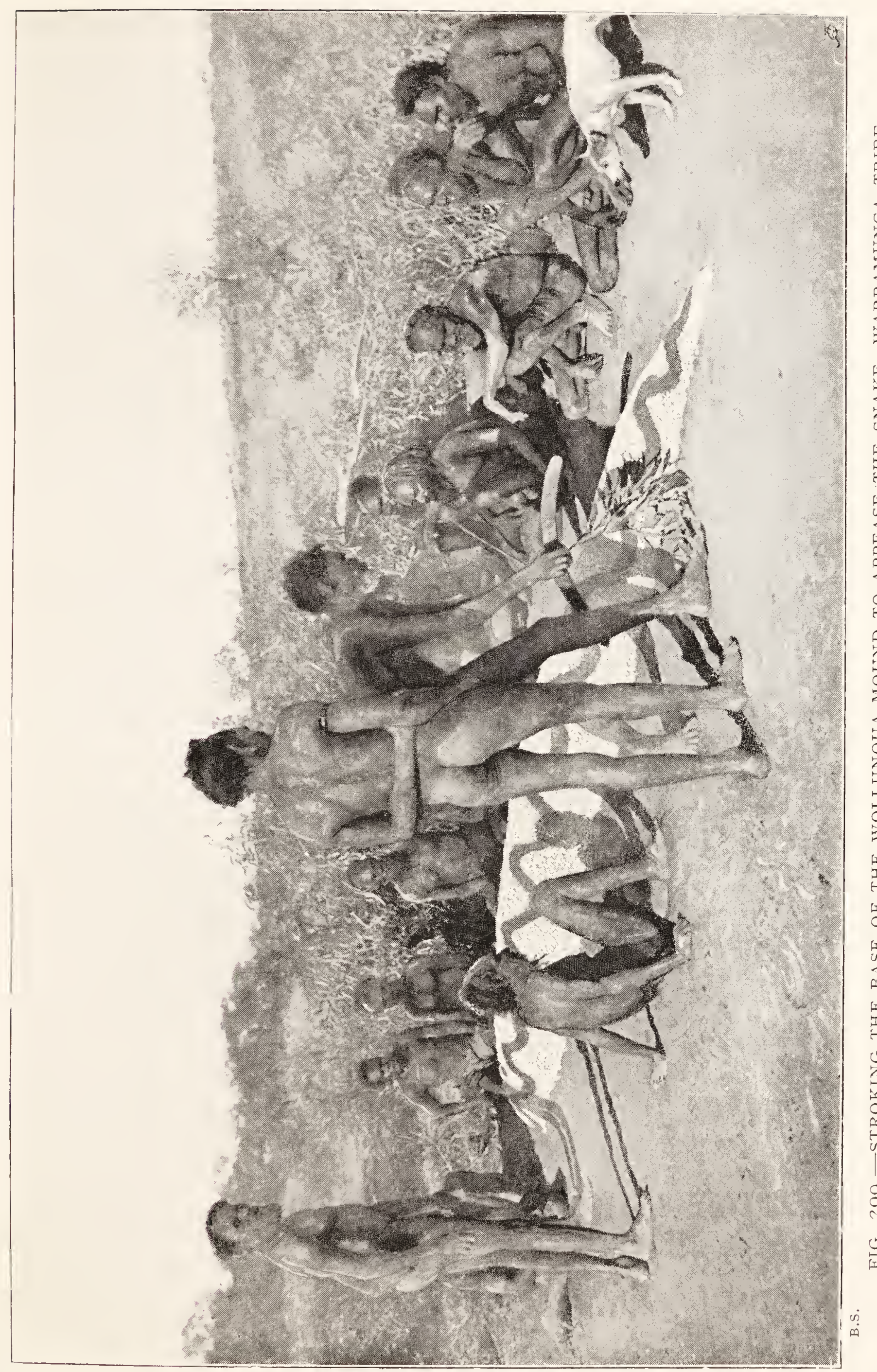




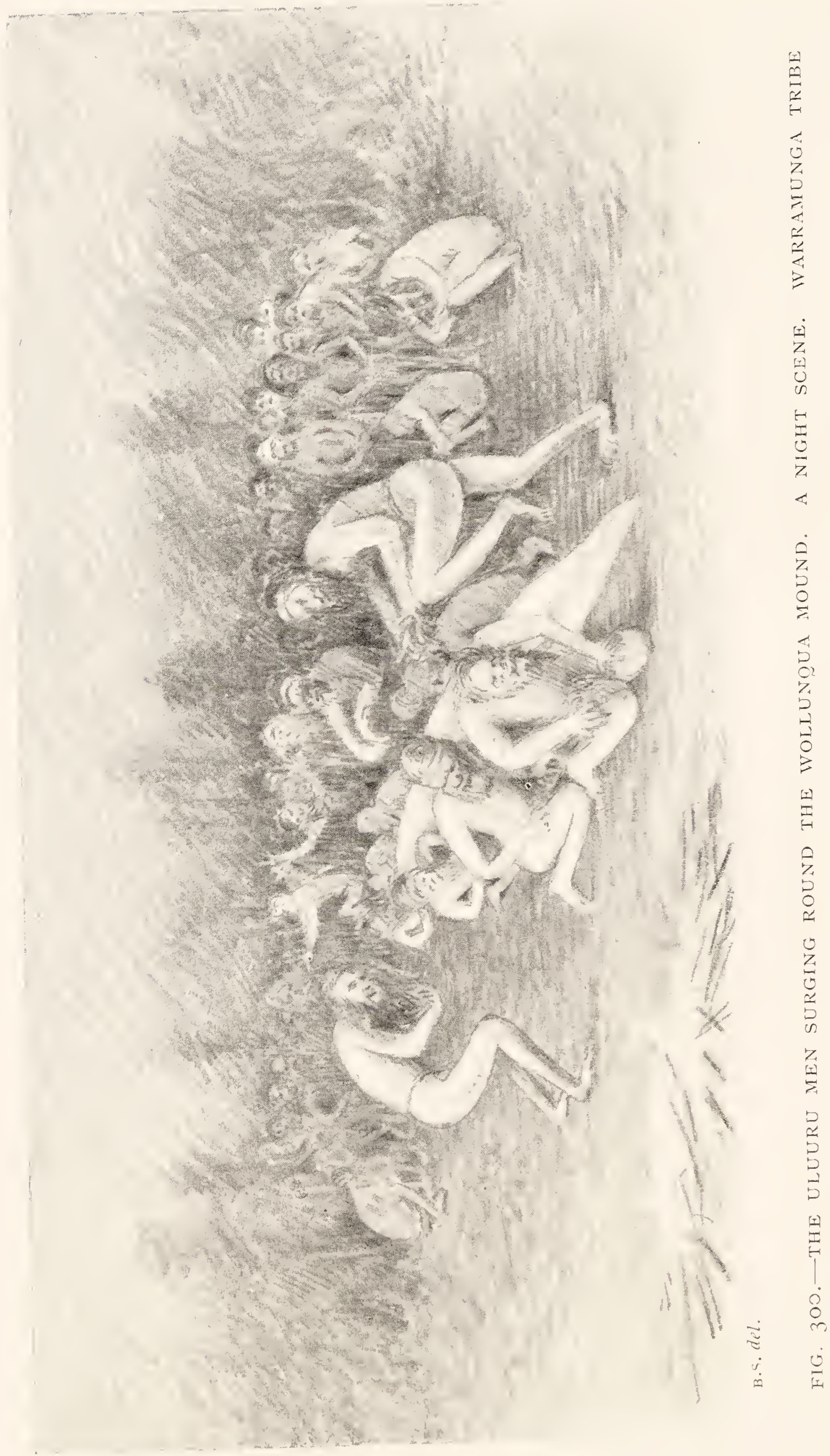


circles were drawn and the bands and circles were enclosed in the usual groundwork of white dots.

The interpretation of the whole drawing was as follows:Tradition says that, in the Wingara, a man named Mumumanungara came out of the snake's body and remained with the Wollunqua as his mate. When the old snake set out on his travels the man was very much distressed for fear lest he should leave Thapauerlu for ever. After the snake had been gone away for some time, he set out to track him, and came across him, or rather his head end, close to Ununtumurra, and at first walked along quietly by the side of his track. Finally, standing close by the snake and lifting up his arms, as indicated by the two curved bands and also by the double footmarks, he struck the snake as hard as he could, hoping to drive him back to Thapauerlu. In this he was successful. The old Wollunqua coiled his body round that of his mate Mumumanungara, lifted himself on high and, with a great dive, plunged into the earth, and thus the two went back to Thapauerlu.

We had been very much interested in the Wollunqua ceremonies and were anxious to see for ourselves the snake's home at Thapauerlu and the sacred spots around it, of which we had heard much from the old men of the totem group, so we proposed that they should take us there. They readily fell in with our suggestion, and, a few days after the ceremony was over, we started off from Tennant Creek, in company with a small party of about a dozen of the older men, including the two chief men of the totem group.

For the first two days our way led across very uninteresting plain country, covered with poor scrub, with here and there a low range of hills. Every prominent feature of any kind was associated with some tradition of their past. A range, five miles away from Tennant Creek, had arisen to mark the path traversed by the great ancestor of the Pittongu (bat) totem. Several miles further on, a solitary, 
upstanding column of rock represented an opossum man, who rested there during his travels, looked about the country and left spirit children behind him when he travelled on. A low range of remarkable white quartzite hills indicated a large number of white ant eggs, thrown away by some women, called Munga-munga, who belonged to the yam totem. These women were sent away to the east from a place close to Tennant Creek by the ancestor of the black snake totem, carrying their yam-sticks with them. These were Churinga, and they deposited them (Fig. 309), along with the spirits associated with them, at various places as they travelled on towards, and across, the country of the Worgaia tribe; indeed one of the old Worgaia men with us was the reincarnation of one of these yam spirits.

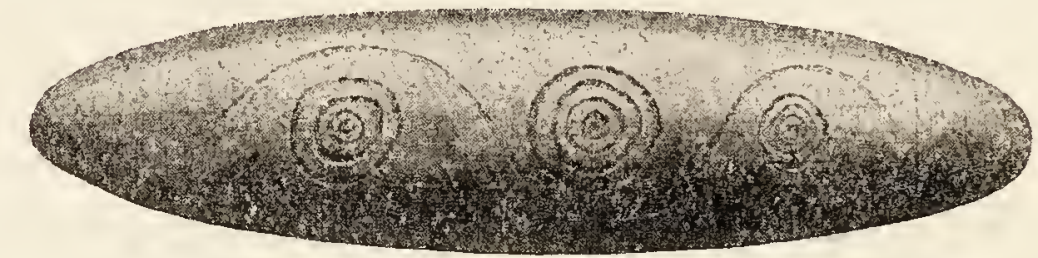

FIG. 309. - STONE CHURINGA REPRESENTING ONE OF THE YAMS CARRIED BY THE MUNGA-MUNGA WOMEN IN THE WINGARA TIMES, WARRAMUNGA TRIBE.

As we rode slowly along, the natives keeping pace with us on foot, the old men were continually talking about the natural features associated in their traditions with various totemic ancestors, pointing out to us every feature that interested them.

On the second night we camped by a water-hole where an old crow ancestor once lived and where there are now plenty of crow spirits. On the third day we travelled along by the side of a dry creek and passed the spot where two hawk ancestors first made fire by rubbing sticks together, fine gum trees on the banks now representing the place where they did this. There is rather a quaint myth connected with the origin of fire and fire ancestors. In the Wingara there lived two handsome hawks named Kirkalanji and Warra-pulla-pulla who, though they were birds, 


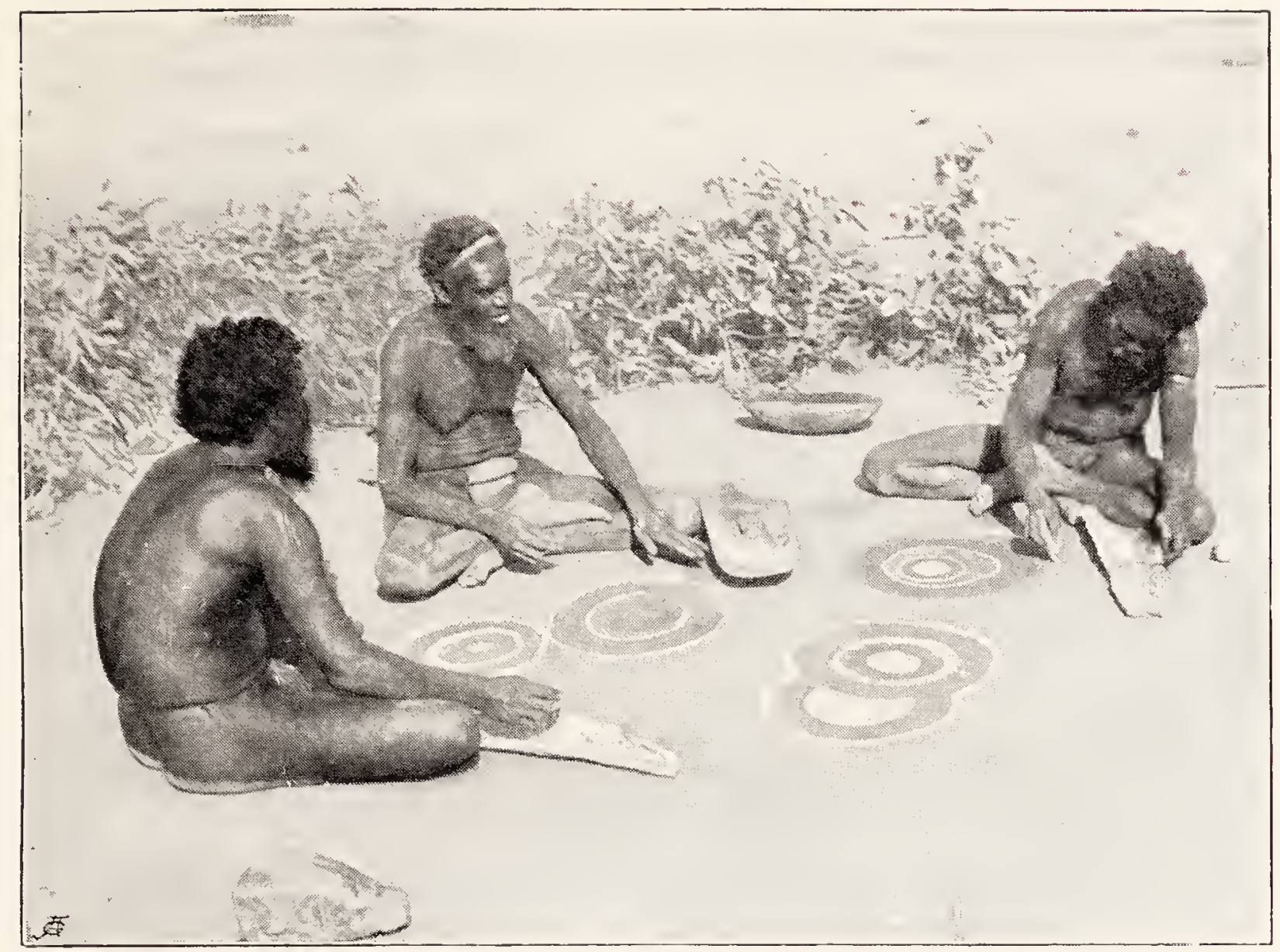

B.S.

FIG. 3OI.-PREPARATION FOR A GROUND-DRAWING IN CONNECTION WITH A CEREMONY OF THE WOLLUNgUA TOTEM, WARRAMUNGA TRIBE.

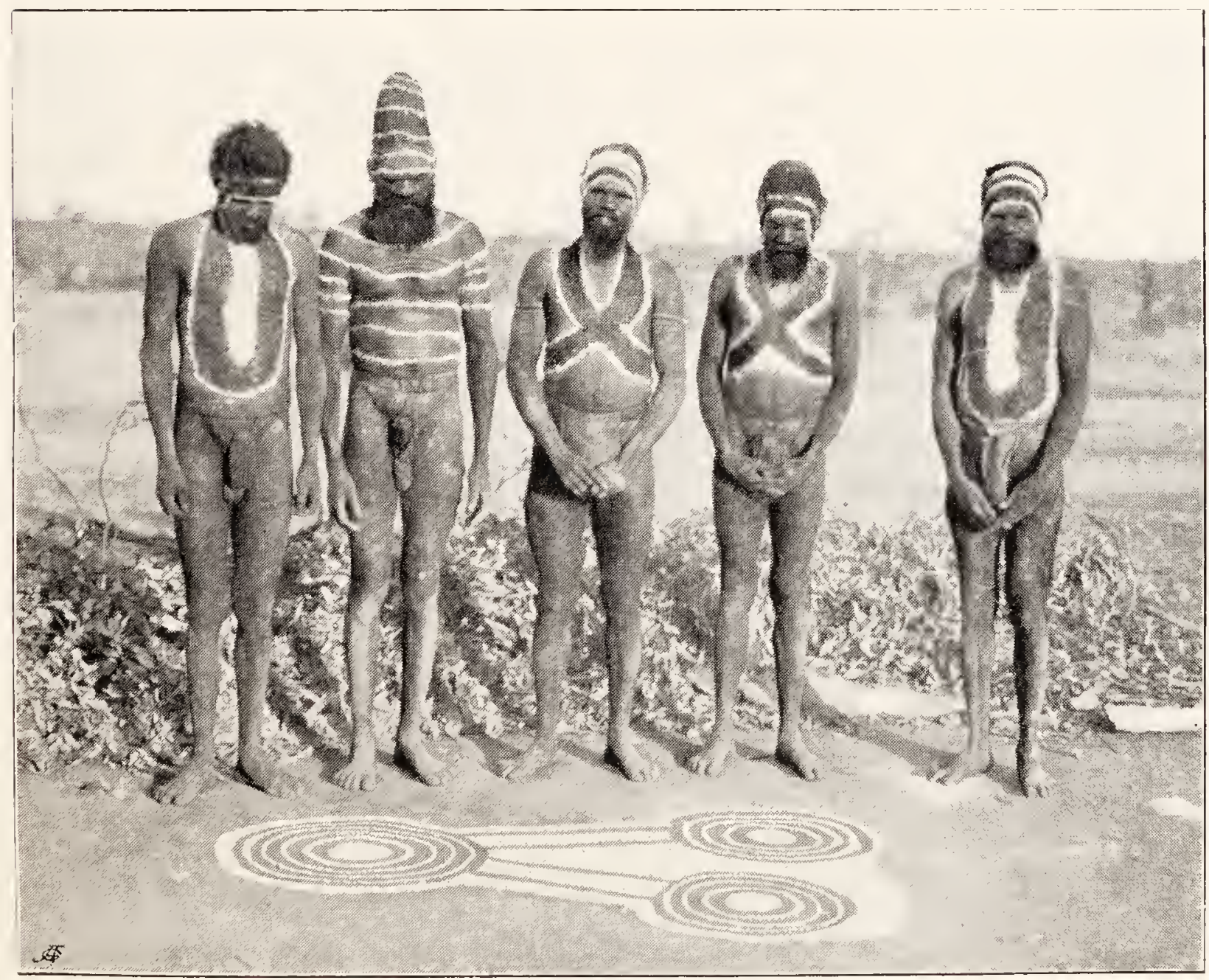

B.S.

FIG. 3O2.-GROUND-DRAWING IN CONNECTION WITH A CEREMONY OF THE WOLLUNQUA TOTEM, AND FIVE PERFORMERS TAKING PART IN THE CEREMONY, WARRAMUNGA TRIBE. 


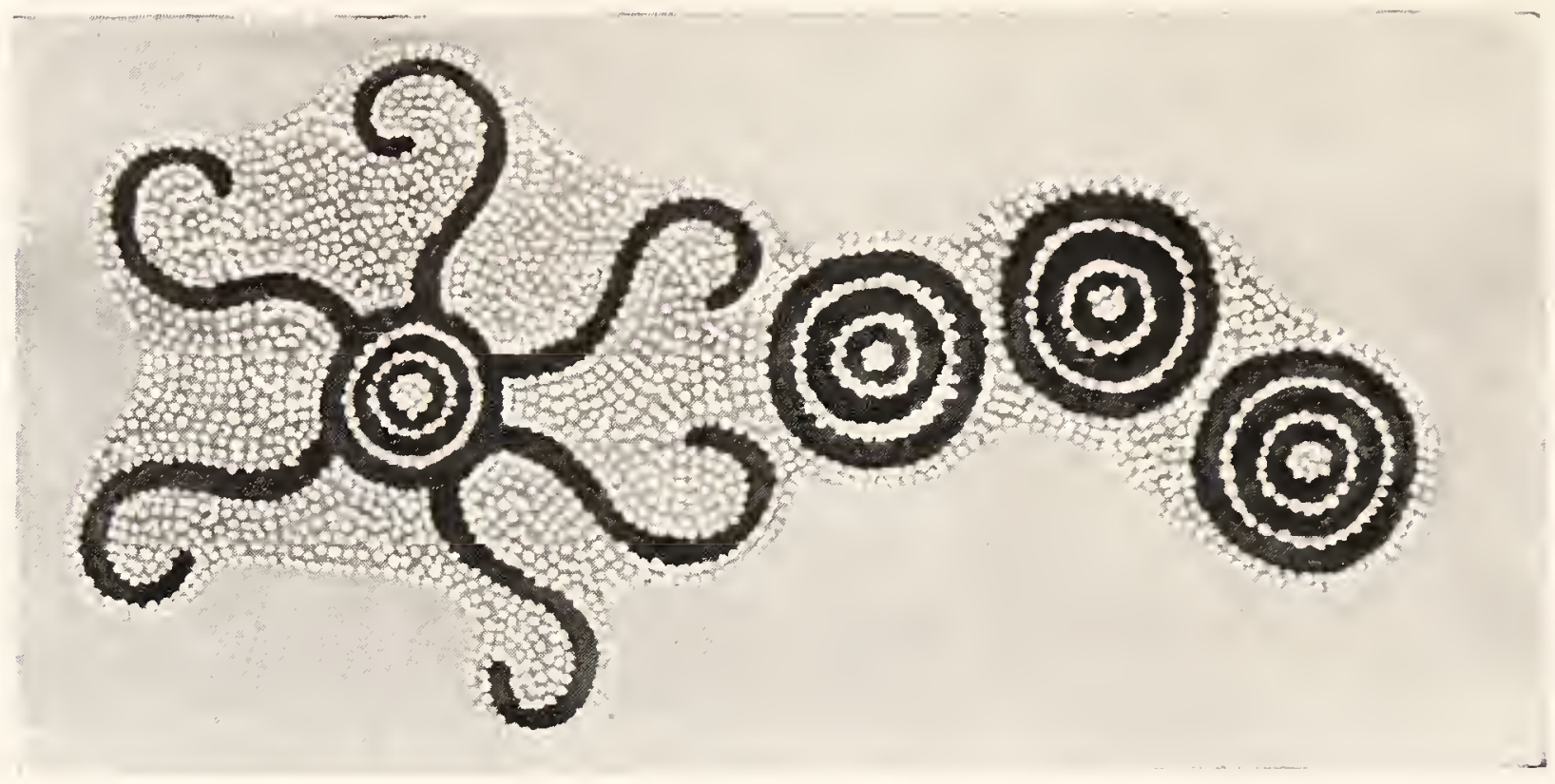

B.S.

FIG. 3O3.-GROUND-DRAWING ASSOCIATED WITH THE WOLIUNQUA

TOTEMIC CEREMONY OF A PLACE CALLED PARAPAKINI.

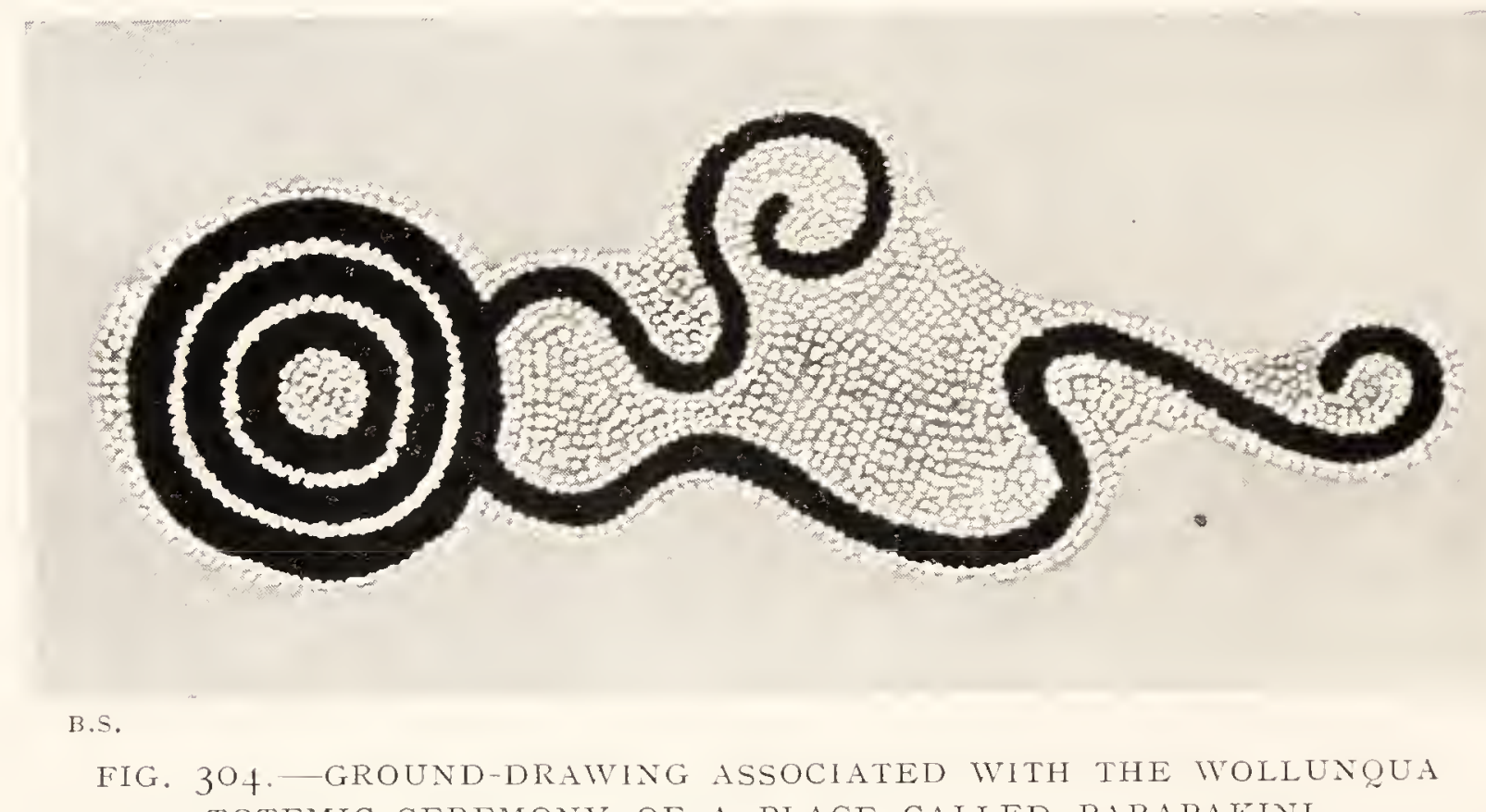
TOTEMIC CEREMONY OF A PLACE CALLED PARAPAKINI.

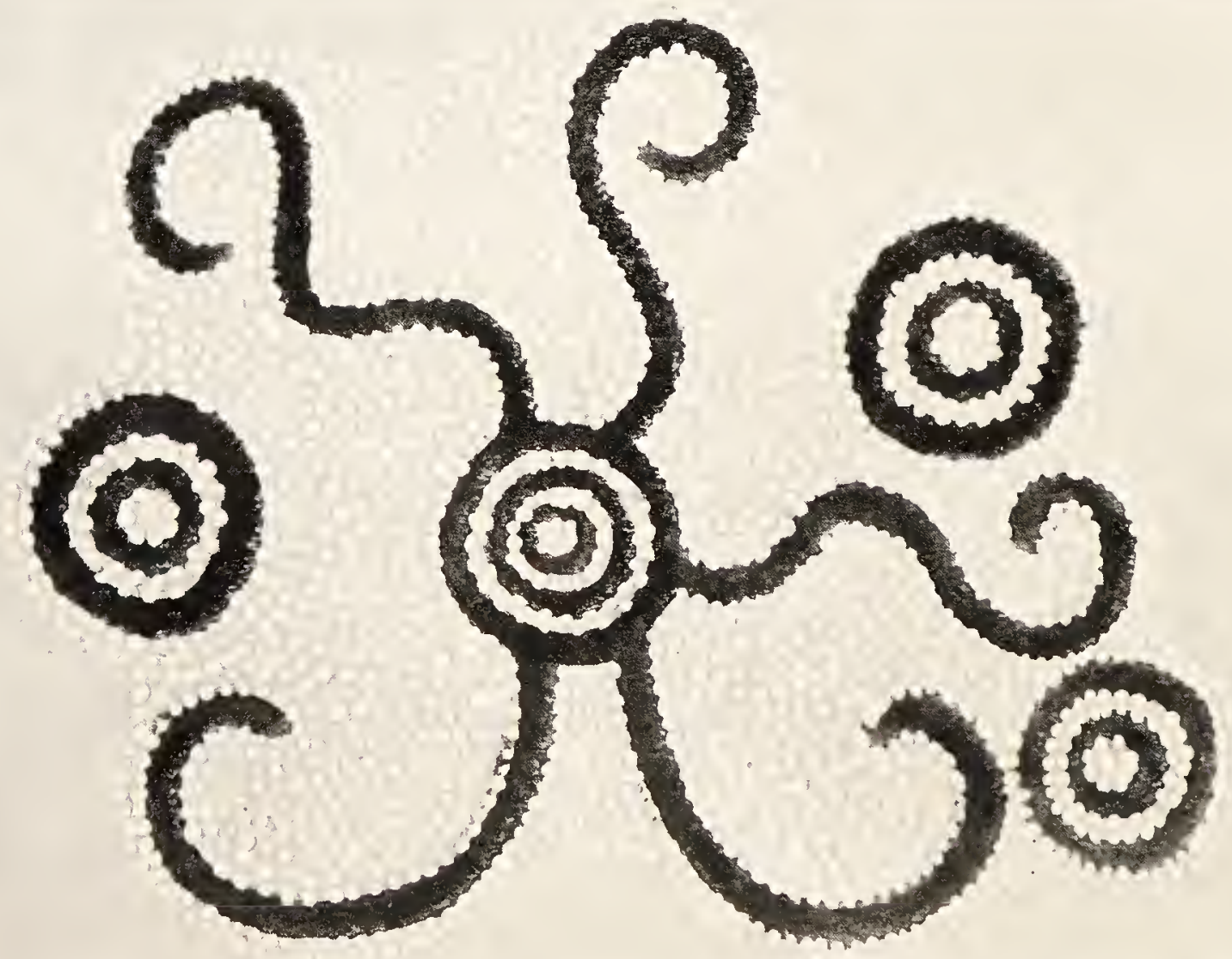

B.S. del.

FIG. 3O5.-GROUND-DRAWING ASSOCIATED WITH THE WOLLUNQUA TOTEMIC CEREMONY OF A PLACE CALLED TIKOMERI. 
were the first to make fire in this part of the country. They always carried their fire sticks about with them and one day Kirkalanji lighted a fire that was bigger than he meant to make, with the result that he himself was caught in it and burnt to death. Warra-pulla-pulla being very grieved went away somewhere in the direction of what is now Queensland, and was never heard of again. The moon then came up-in those days he was a man who walked about on earth. He met a bandicoot lady near the spot where Kirkalanji had made the fire and had a stroll with her. Then they sat down on a bank, with their backs to the fire and were so long talking to one another that they did not notice it until it was quite close upon them. The result was that the bandicoot lady was badly singed and swooned away. However the moon man, not being an ordinary mortal, soon got over the difficulty and cured her and together they went up into the sky. It is a curious feature amongst all the tribes that the moon is always represented as a man and the sun as a woman.

We were gradually approaching the Murchison Range and, late in the afternoon of the third day, skirted its base and, following up a valley leading into the hills, camped, just after dark, by the side of a picturesque water-hole, called Wiarminni. We were now, so to speak, in the very midst of Mungai-that is, spots once inhabited by the old ancestors and full of spirit children whom they left behind them. These old ancestors displayed a commendable fondness for walking about in the few picturesque spots that their country contained, and seem to have chosen these rocky ranges as their ancestral home. All around us the water-holes, gorges and rocky crags were peopled with spirit individuals left behind by one or other of the totemic ancestors-Wollunqua, Pittongu (bat), Wongana (crow), wild dog, emu, bandicoot, fish, kangaroo and wallaby - whose lines of travel in the Wingara 
formed a regular network over the whole country-side. At night, as we lay on the ground by the side of our camp fire with the natives - all of them elders of the tribe-talking about what had happened in the far past times, we realised, perhaps more vividly than we had ever done before, what these old traditions meant to them, and could almost believe with them that the ancestral spirits were actually wandering around us as we fell asleep, surrounded by the very rocks,
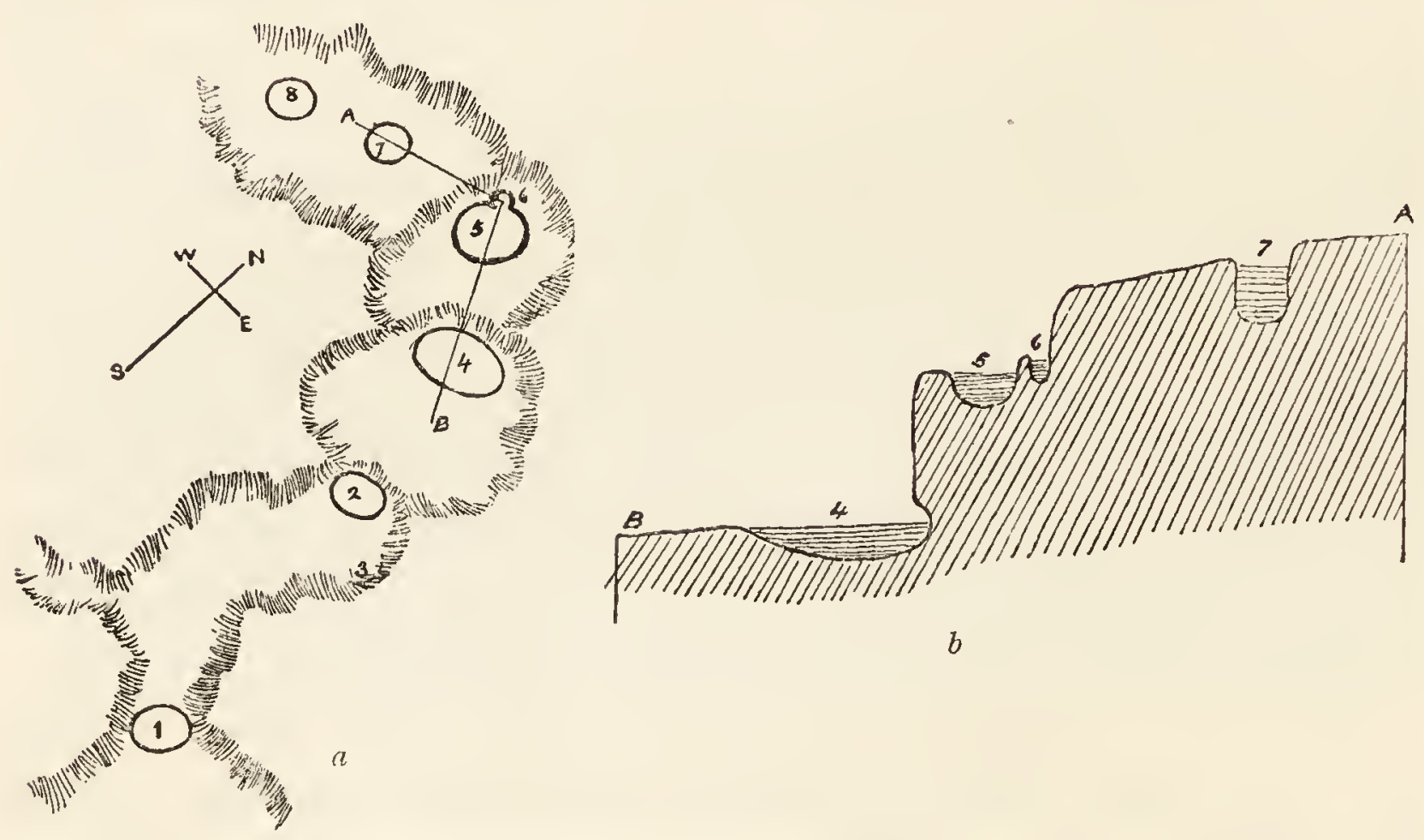

FIG. 3IO.- (a) GROUND-PLAN OF THE VALLEY IN WHICH THAPAUERLU IS SITUATED.

Fig. 3ioa.- (b) Section along the line A B in Fig. 3 io.

$\mathrm{I}, 2,3,4,5,6,7,8$ indicate water-holes in the rocky bed of the stream which flows down the valley.

trees and water-holes in which they lived. In the morning we set out, under the guidance of the natives, and for some miles followed on foot the broad valley, which after a time narrowed down to a rocky gorge, running right into the heart of the Ranges.

The plan (Fig. 3IO) will serve to indicate the chief features in the gorge, the entrance to which is blocked, save for a very narrow passage that runs round the rocks on one side of the water-hole, called Tjintjinga (I), where 


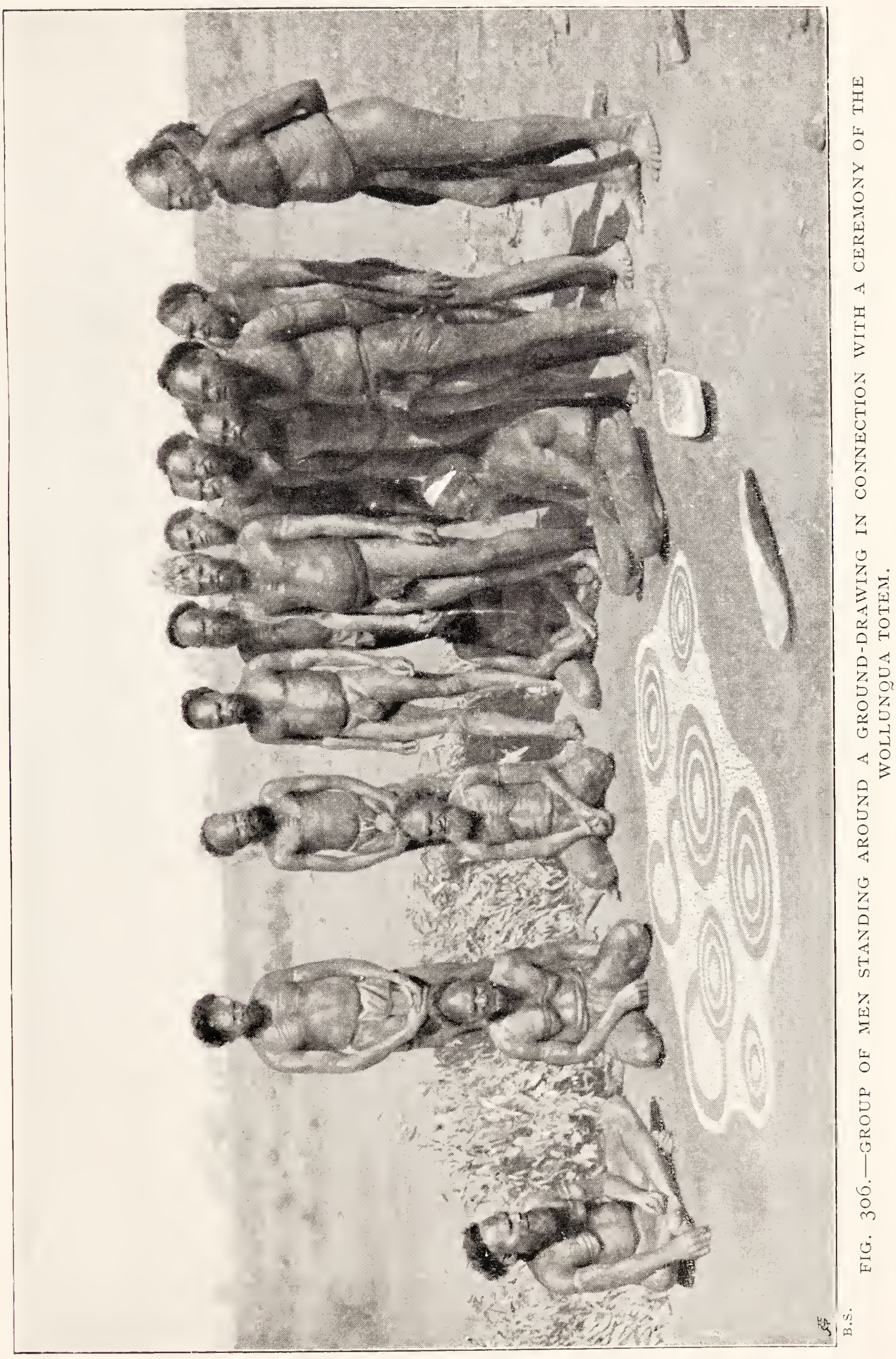




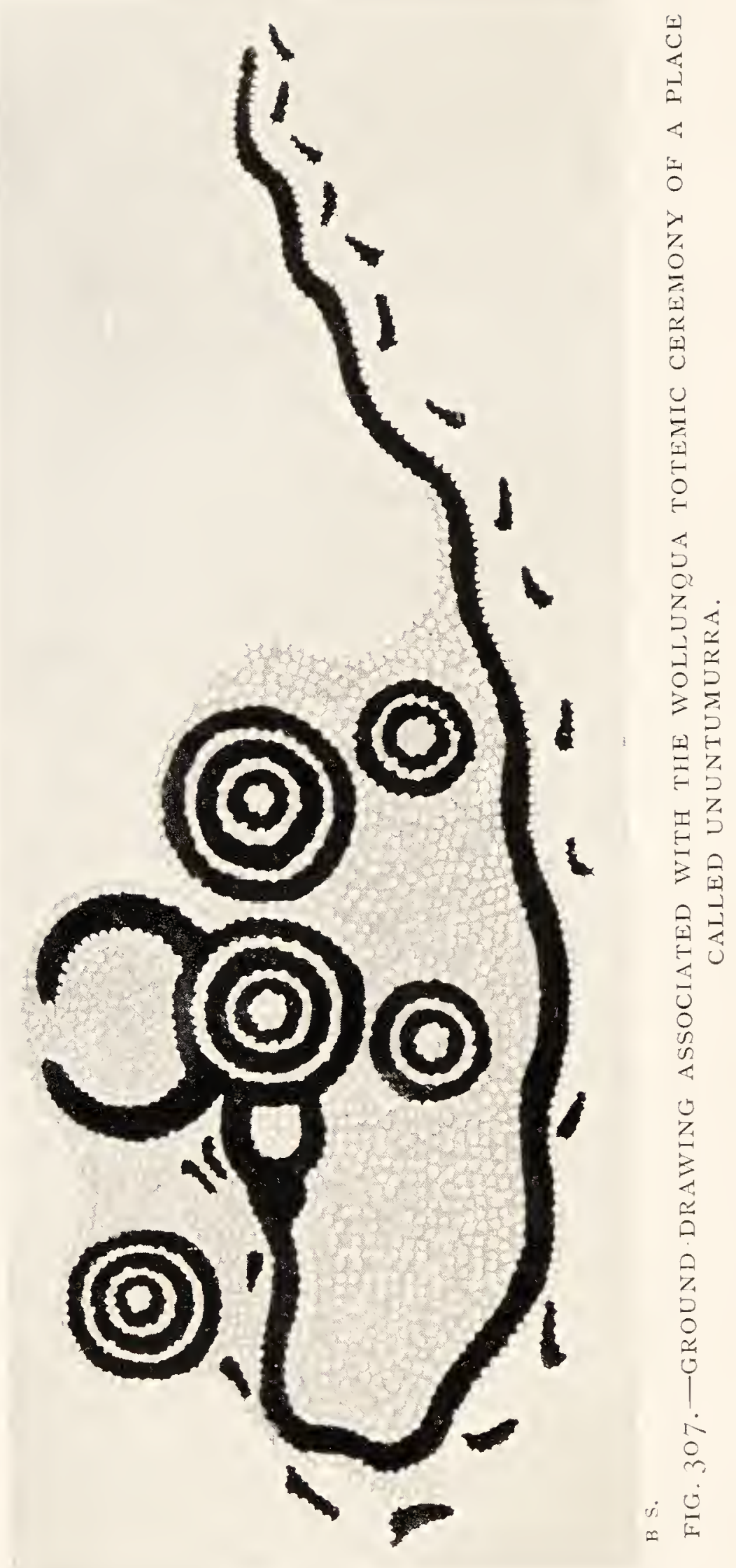


there is a Wollunqua Mungai. All the trees bordering the creek contain spirit children. A little distance further up the passage is blocked by a rock hole (2), close to which is a lofty shallow cave called Maralintha-taparinia (3). This was made by two old men in the Wingara times, and now two weather-beaten shrubs on the opposite rocks show where they stood up and looked at the water-hole and cave.

Making a detour to the west, we scrambled up the steep side of the gorge and then came down to Thapauerlu, and found ourselves by the side of a picturesque pool with a sandy margin on the south and a little precipice of red quartzite rocks curving round its northern edge, over which, in rain seasons, the water falls for a height of from twenty to thirty feet into the pool below (Fig. 3IO, no. 4, and Fig. 3I I).

The rocks are hollowed out so that they overhang the water and form a long, shallow cave, from the roof of which clusters of what are evidently roots of trees that have forced their way down hang pendent. They are supposed to represent the whiskers of the Wollunqua.

While we were walking up the gorge, the natives had been laughing and talking freely, but, as we approached Thapauerlu itself, they became very quiet and solemn; and, as we stood silently on the edge of the pool, the two old chief men of the group went to the edge of the water and, with bowed heads, addressed the Wollunqua in whispers asking him to remain quiet and do them no harm, for they were mates of his and had brought two great white men to see where he lived and tell them all about him. We could see plainly that it was all very real to them and that they implicitly believed that the Wollunqua was indeed alive beneath the water, watching them, though they could not see him.

Thapauerlu is evidently a permanent water-hole, though in seasons of drought it is doubtless much smaller in size than when we saw it. Under such conditions the margins VOL. II. 
of the water will retreat towards the rocks, immediately under which it is not only very deep but completely sheltered from the sun. After the natives had pointed out the chief features to us we made another detour, climbing up over the hillsides, and then descended again into the bed of the gorge, higher up the valley. Immediately above Thapauerlu itself is a deep rock basin called Miradji (5), the overflow of which runs down into the former. This upper basin was made, in the old Wingara time, during a fight between a kangaroo and a wild dog. As they fought fiercely, the former lashed its tail round and round, thus hollowing out the rock and making the present water-hole, but in the end the dog was victorious and killed and ate the kangaroo. Attached as it were to one side of Miradji is a kind of very large pothole, about five feet in diameter (6), that is especially associated with the same kangaroo. It contains a large number of rounded boulders, varying in sizes from an inch to a foot in diameter. They are supposed to represent different parts of the organs of the animal-kidney, heart, tail, intestines, etc. The two younger of the men who came with us at once went out into the hole, which contained about three feet of water, and, after splashing this all over their bodies and rubbing each other with a few of the stones, they were rubbed again by an older man (Fig. 3I2). This little ceremony has the object of enabling the men, who are thus rubbed with stones that represent parts of the kangaroo, to go out into the bush and catch kangaroos more easily than they would otherwise be able to do.

Above Miradji there lie two more rock-holes, both intimately associated with the Wollunqua, who left spirit children here; indeed the oldest of the natives who accompanied us was the reincarnation of one of these, and his personal and secret name, Marunquagnuna, is derived from Marunqua, the upper and the smaller of the two holes. The large one is like a great pot-hole, about ten feet in 


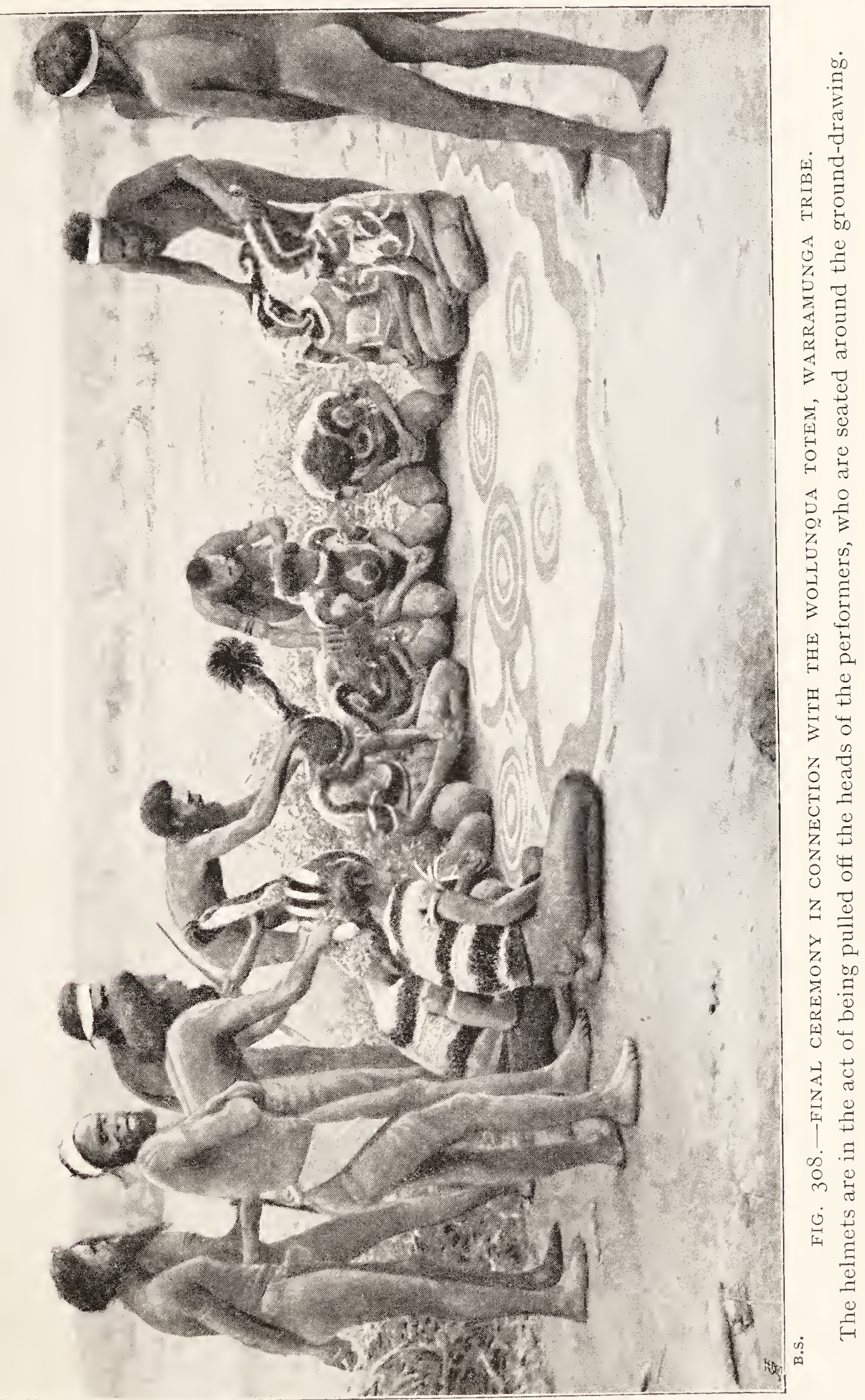




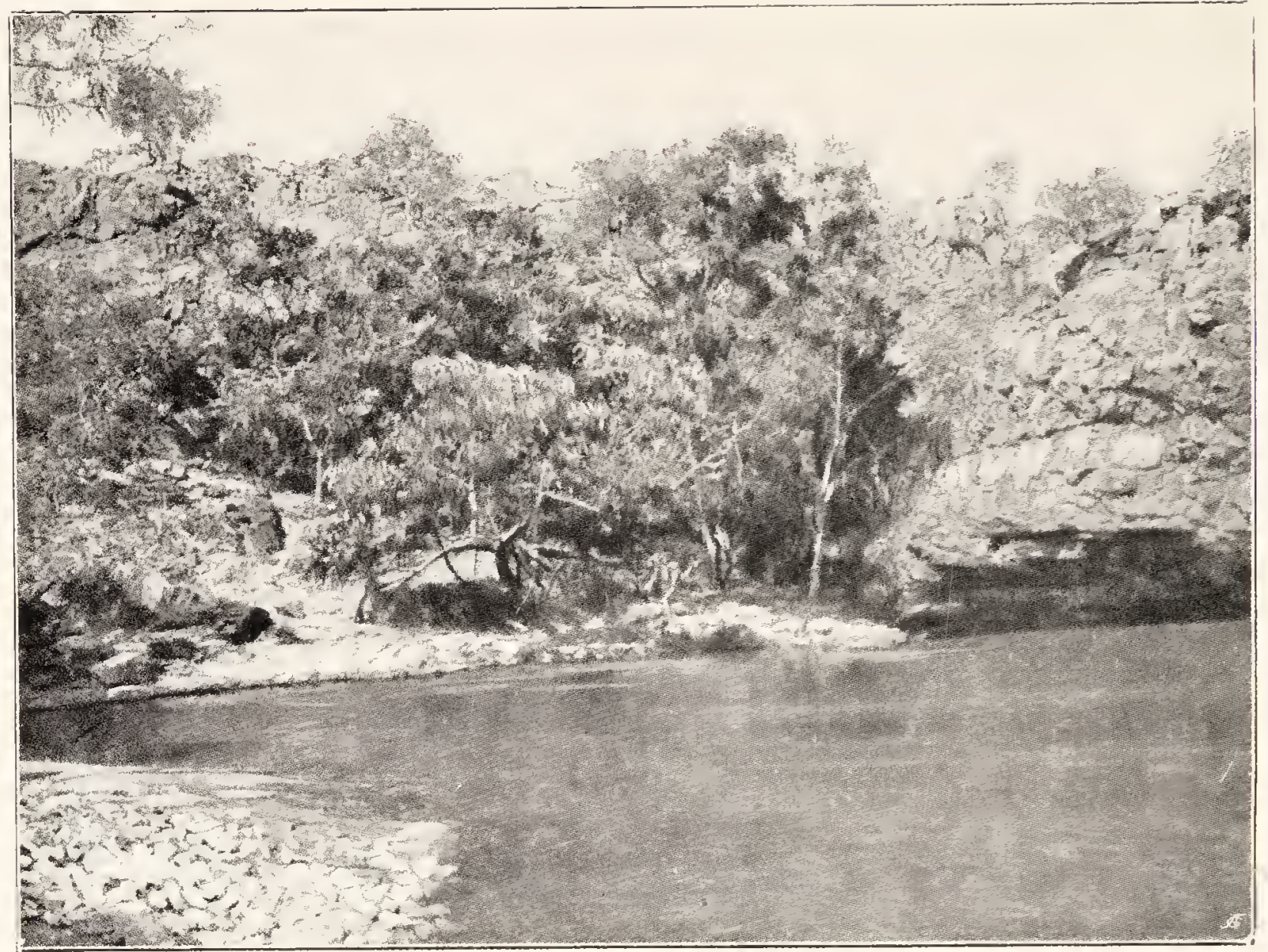

B.S,

FIG. 3II.-THAPAUERLU, A WATER-HOLE IN THE MURCHISON RANGE WHERE THE WOLLUNQUA SNAKE IS SUPPOSED BY THE WARRAMUNGA TRIBE TO LIVE.

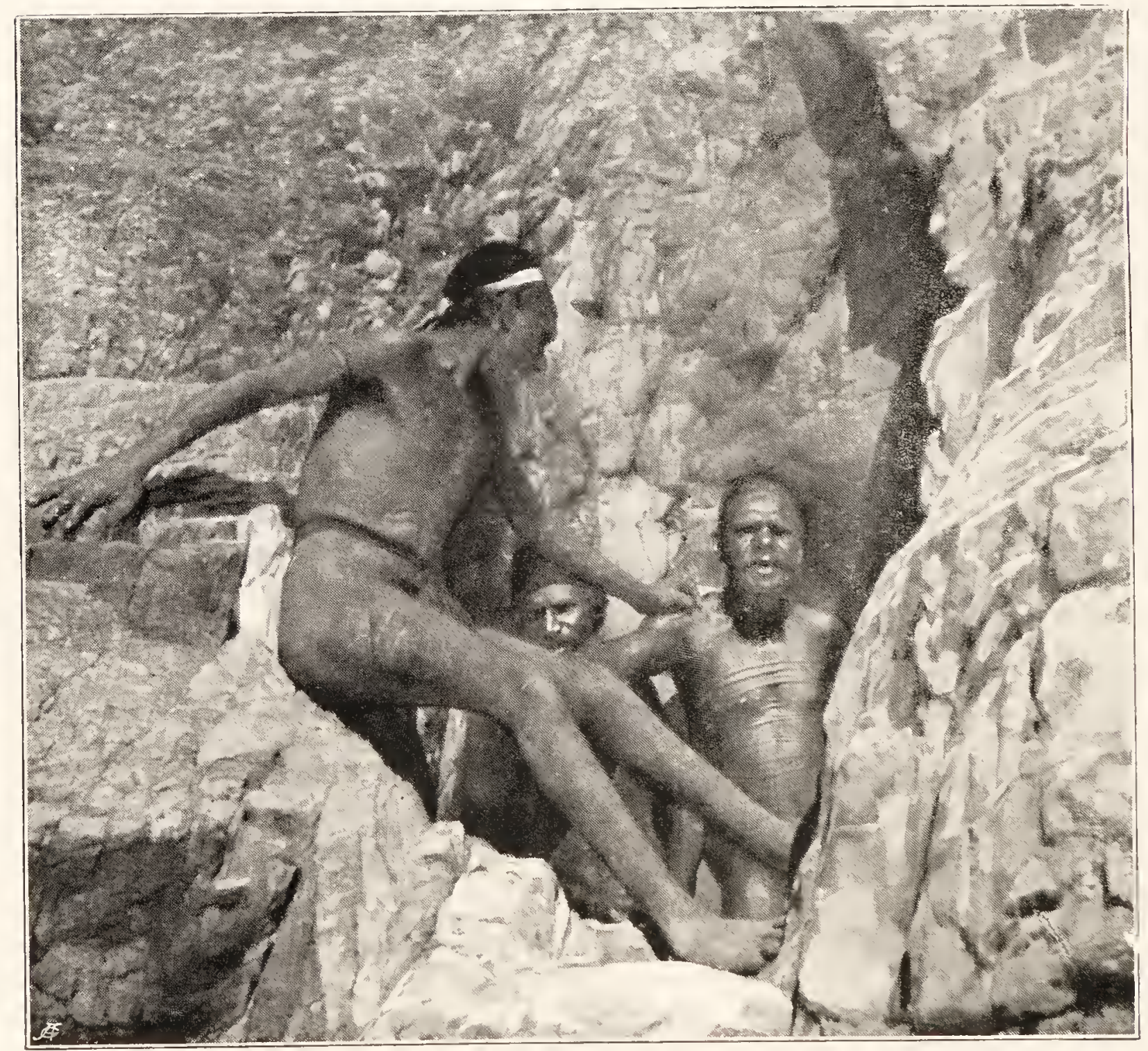

B.S.

FIG. 3I2.- TWO YOUNGER MEN BEING RUBBED BY AN OLDER ONE WITH STONES WHICII ARE SUPPOSED TO REPRESENT PARTS OF THE BODY OF A EURO (KANGAROO), WARRAMUNGA TRIBE.

The rubbing is supposed to enable them to catch liuros easily. 
diameter. Its name is Tidjinara, and is of special interest, as it was here that the great Wollunqua originally arose. When he started out on his travels he still kept the end of his tail here and only withdrew it when, at Ununtumurra, he made his great dive into the earth and returned underground to take up his final abode in Thapauerlu. 


\section{CHAPTER XX}

\section{DEATH, BURIAL AND MOURNING CEREMONIES OF THE WARRAMUNGA}

While staying amongst the Warramunga we were able to see what, so far as we could tell, was the complete series of ceremonies from the moment of death until the final burial of the bones of a dead native in the earth. The various ceremonies were, of course, concerned with more than one individual, because the entire series, in the case of one person, is spread over a period of two years or longer.

In the Warramunga tribe the doctors possess a little red thing shaped like a rod about three inches in length and a third of an inch in diameter (Fig. 3I4). It is called Kupitcha, and is worn through the hole in the nasal septum and is full of magic, placed in it by some distinguished medicine man like the old Worgaia man. The latter was a tall, powerfully-built man with all the hairs pulled out of his upper and lower lips, and when in full medical costume carried a great fighting club and had a strong design consisting of two horseshoe-shaped and a lozengeshaped black patches, outlined with white down, painted on his chest and abdomen (Fig. 3 I 3). This was the equivalent of his diploma.

It was a long time before we could persuade them to let us have one of the Kupitchas, because they are regarded as being very precious, but finally the old men decided to give us one each. However, we had to pay a shirt, a tomahawk and six sticks of tobacco for each of them. This is the highest price 


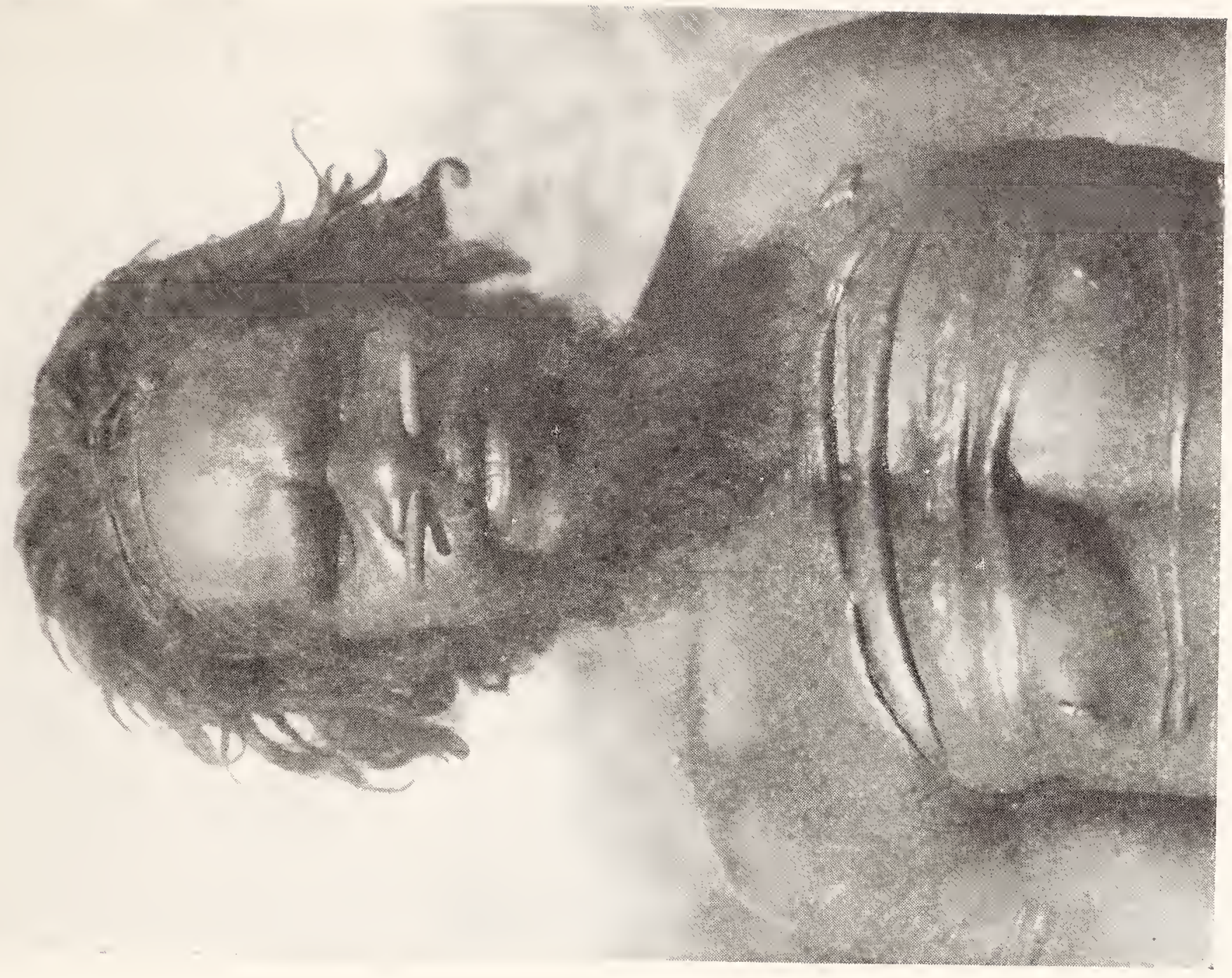

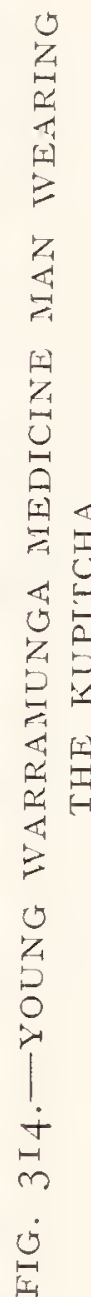

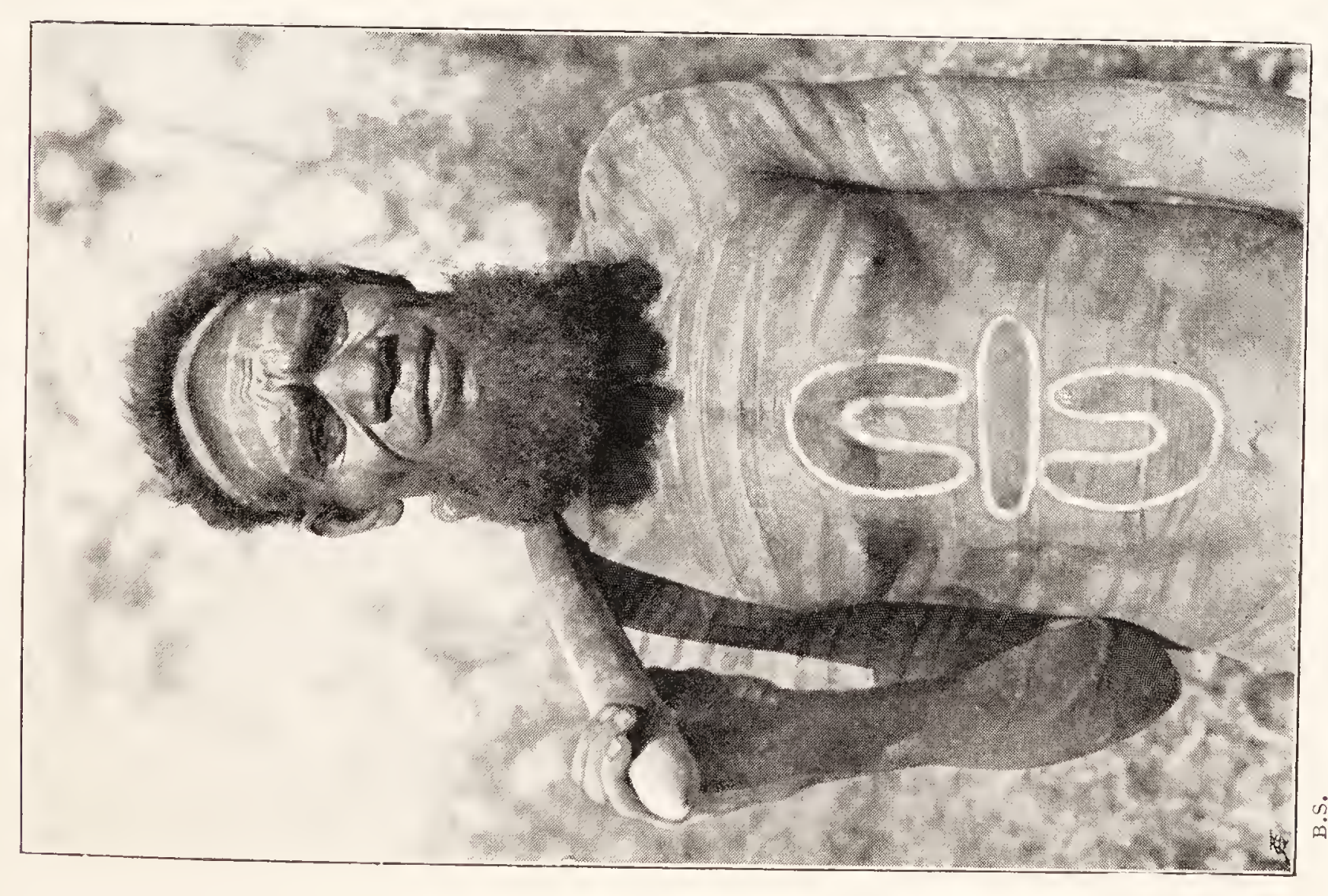

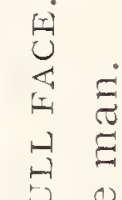

텅

要

덩

品

H

岸.

\&

넝

常

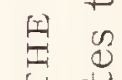

$H+$

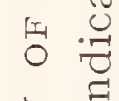

兄. 击

द

1. की

$\dot{m}$

ำ

i 


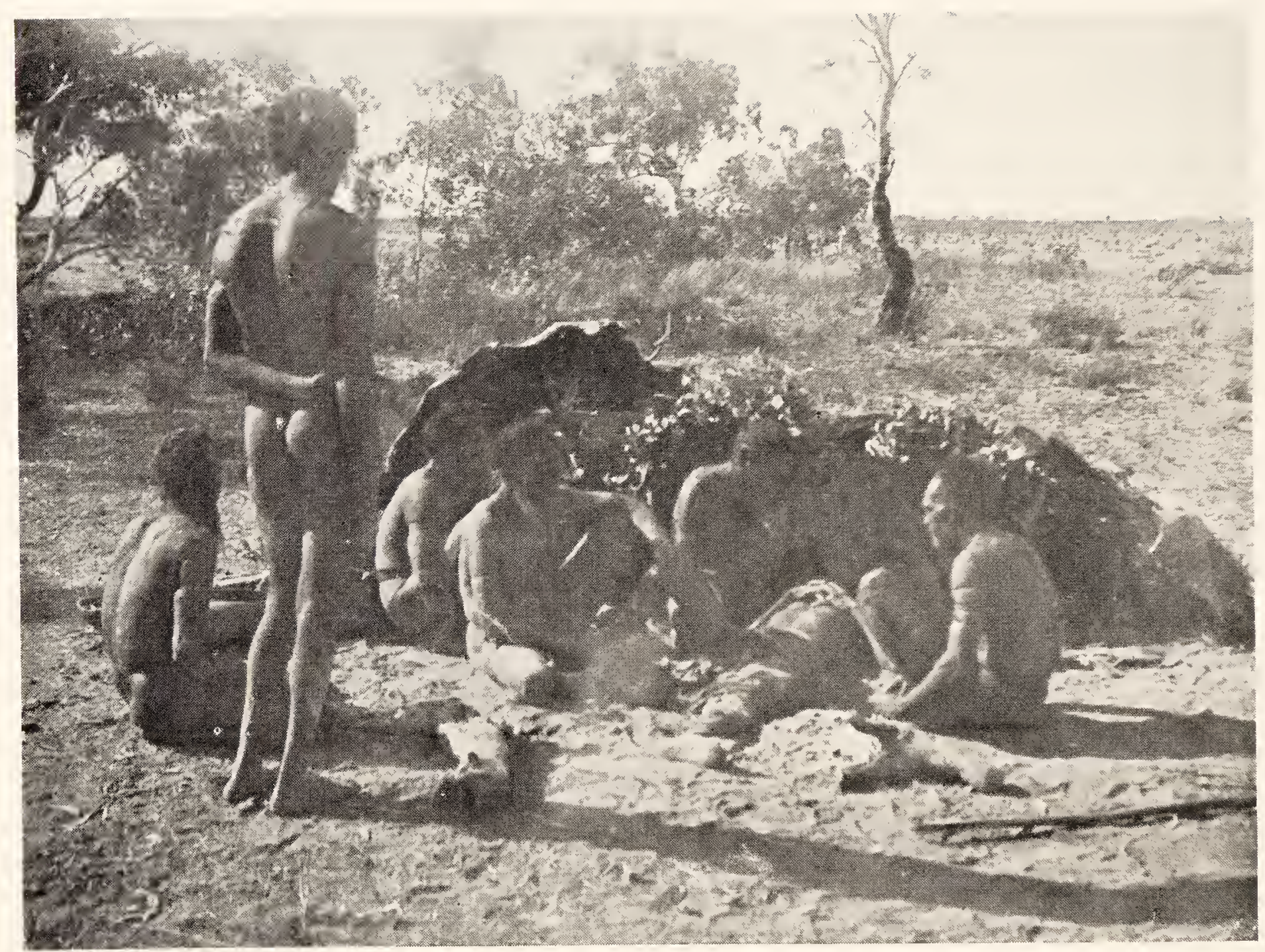

B.S.

FIG. 3I5.-MEDICINE MEN AT WORK.

The patient is lying on the ground with hands clasped. The Worgaia man on his right side is examining him. The oldest Warramunga medicine man is seated on the patient's left. Reproduced from a snapshot taken just at sunset. 
I have ever paid for any native object of such small size and insignificant appearance. There is something of special magic power inside it that is supposed, in some way, to derive its efficacy from a great snake that lives in foreign parts and hence is much more potent than anything local. I wanted mine for the Museum at Melbourne, and as Gillen did not fall in with the suggestion that his should be sacrificed in the interests of research, I have never found out what the innocent-looking thing contains, but suspect that it is made of nothing except human hair string red ochred and well greased and perhaps wound tightly round a little wisp of some dead medicine man's hair. It is supposed to be able to smell so that by its means, as he wears it in his nose, the doctor can detect at once the exact spot at which a magic bone or stick has been placed in a native's body, and not only this, but they can smell out the enemy who put it there. They will not even speak of it except in a whisper; as a matter of fact it is a source of revenue to one or two of the oldest and most learned medicine men who alone can make them, and have to be given heavy fees, in the way of food and hair string and implements, by the younger practitioners to whom they are given. They especially asked us not to show it to any women or children.

One of the older men became ill whilst we were in camp, so we fortunately had the chance of seeing the medicine men at work. No fewer than six practitioners were called in to a consultation. The leader of them was the old Worgaia man, and, after a great deal of discussion, mysterious mutterings and "singing" over the patient's body, he gave it as his opinion that the case was a very serious one. The patient was questioned very carefully, and it was found out that, the night before he was taken ill, he had been cooking a damper, when suddenly it gave out a kind of explosive noise. He did not think anything 


\section{WANDERINGS IN WILD AUSTRALIA ch.}

of it at the time, but, as he said, he "felt bad" in the morning and then remembered what had happened. This gave the old doctor a clue as to what was the matter, and serious discussions were held during the day. Late in the afternoon the six men went to the patient's camp, where they set to work to find out what was really the matter, and we were able to watch their modus operandi. They were so occupied in their work that they took no notice of us and I was able, just at sunset when they were completing their examination, to take, unknown to them, the little snapshot reproduced in Fig. 3 I 5. After two or three of them had blown hard into his ear and sung over him for about a quarter of an hour the old Worgaia man, after a good deal of mysterious passing of his hands over the patient's body, gave it out as his opinion that a dead man's bone, attracted by the firelight, had come up and gone into his body. The senior local doctor, whilst agreeing with the diagnosis of his "learned brother," but evidently not wishing to show himself inferior in ability to him, expressed the further opinion that one of the warts, that sometimes grows on a gum-tree trunk, had also gone into the man's body and was aggravating the trouble. The four younger practitioners offered no opinion of their own but agreed with the diagnoses of their elders. They decided, however, that nothing could be done until night-time, which was perhaps not altogether unconnected with the fact that their operations could be more successfully carried out under the cover of darkness.

We sent down some food and medicine for the patient, and in the evening went down again to his camp and arrived just in time to see one of the medicine men at work. $\mathrm{He}$ was kneeling beside the patient, alternately stroking his head and blowing hard into his ear. At intervals after doing this he retired into the darkness of the scrub close by, but away from the light of the camp fire, and apparently 
spat something out of his mouth. It turned out that he was withdrawing the wart in small pieces. It had made the man, so they said, rotten inside, but they assured us that after all the evil magic was removed he would be quite well again. After more than two hours' hard massaging and sucking, the whole of the wart was supposed to be removed, but the dead man's bone still remained. The doctor's mouth had now got very "hot" and he decided that he could not do any more extraction that evening.

Next morning we took some castor oil to the patient, but he declined to touch it, so the two leading physicians in attendance drank it up with evident relish; the same fate, I fear, overtook the bovril and everything else we sent down. The medicine men were very polite, but said that any native in their camp who had taken white man's medicine had died, and the man was evidently so ill that nothing we could do whilst he remained in his camp surroundings would be likely to help him. Meanwhile the six physicians continued their attentions. They discovered amongst other things that an additional and very serious cause of the patient's illness was the fact that, being himself only a middle-aged practitioner, he had eaten emu flesh, with the result that the evil magic from it had entered him, because this is strictly forbidden to all except very old medicine men. However, the bone was the most important thing and it was urgent that this should be removed. As a preliminary, the senior man inserted in the patient's head the little stick that he wore through his nose and was supposed to be endowed with wonderful magic powers. This was done one evening, and before leaving the man for the night he gravely felt behind his left ear and satisfied himself, the patient and several friends and relations who were anxiously watching the performance that it really was there. Then they left it to work its magic against the bone. Next morning they held another long consultation and found 
480 WANDERINGS IN WILD AUSTRALIA ch.

that it had been successful, its magic having driven the bone down below the level of the ribs. To prevent it from returning to the patient's head, they tied a long human hair-string belt tightly round his body and left him to the care of the women, intending to return later in the day to complete the cure, because they had to take part in important ceremonies. That day also the wind shifted round suddenly from N.W. to S.E. and the temperature fell accordingly, so much so that the natives, who were wearing nothing, left off the preparations for the ceremonies, crouched round their little fires and the patient was left alone.

During the night we were awakened by the sound of loud wailing across the creek close to the man's camp. We thought at first that he was dead, but it turned out to be only the lubras who had gathered round him and were expressing their grief, just as he knew they would do if he were really dead. It must have been rather trying to his feelings. In the morning we went to his camp and persuaded the men to order the lubras away, and left him in charge of one man who was to give him a little bovril at intervals, which at least could do him no harm and might preserve him from worse treatment.

We had just got well through the performance on the ceremonial ground in the late afternoon, and everyone was laughing and talking, when suddenly we heard a loud wail coming from the camp of the ill man. Everyone knew what this meant and there was a sudden stampede over the flat and across the creek. The performers still wore their decorations, but this made no difference. On the way the men began to howl at first in a low tone, but gradually they worked themselves up and it got louder and louder. On the creek bank some of the men sat down mourning loudly, with their hands clasping their knees and their heads bowed down. I found out later that this was all a 
ceremonial matter and that they were men standing in a certain relationship to the dying man, who had to howl but must not go close up. The women had pulled the man's little bough shelter to pieces and some of them, according to custom, had thrown themselves prostrate on his body, while others were standing about digging the sharp ends of their fighting clubs and yam-sticks into the crown of their heads, from which the blood streamed down their faces. All of them were howling and wailing at the top of their voices, and many of them stretched out their arms, beckoning the men to come up. Many of the men rushing up threw themselves in a heap on the body, from which the women arose, until we could see nothing but a struggling mass of bodies.

One man had been to his camp for a stone knife and now rushed up yelling and brandishing his knife in the air. Suddenly he jumped into the group of men, gashed both his thighs deeply, cutting right across the muscles and, unable to stand, fell down into the middle of the group, from which, after a time, he was dragged by a few female relatives-his mother, wife and sisters-who immediately applied their mouths to the gaping wounds while he lay exhausted on the ground. It was a wild scene in the evening light, for the sun was just setting, but, by good fortune, I had my little Anschutz hand-camera with me and managed to secure a snapshot of the group, with the men sitting on and around the body and the women standing by, wailing and beckoning towards the men away in the distance, who, cutting themselves with stone knives as they ran along, were hastening to the spot (Fig. 3I6).

Gradually the struggling mass of dark bodies began to loosen and then we could see that the unfortunate man underneath was not actually dead, though, as can easily be imagined, there was not much life left in him. The weeping and wailing still continued and the sun went down, 


\section{WANDERINGS IN WILD AUSTRALIA сн.}

leaving the camp in darkness. Later in the evening, when the man actually died, the wailing was still louder and the excitement more intense. Men and women, apparently frantic with grief, were all rushing about cutting themselves with knives and sharp-pointed sticks, the women battering one another's heads with fighting clubs, no one attempting to ward off either cuts or blows. There was no light, save that from a few scattered fires, and it was difficult to believe that the naked, howling, prancing figures, smeared with dirt and streaming with blood, were actually those of human beings. It was a fiendish scene. Without more than an hour's delay, a small torchlight procession started off across the plain to a belt of timber, a mile away, and there the body was laid on a platform of boughs built in a small gum tree.

During the night all the camps were demolished and shifted across the creek, the only trace left in the morning being a small, low mound of earth, called Kakita, piled on the actual spot on which the man had died: around this the ground was carefully smoothed down for a few feet in all directions. Every camp was moved to a considerable distance, because no one was anxious to meet the spiritthe Ungrulan-of the dead man, which would be hovering about the spot, or that of the man who brought about the death by evil magic, because it would probably come to visit the place in the form of an animal. As a matter of fact, the man was said by the medicine men to have died because he had deliberately defied tribal custom, and this had laid him open to an attack of evil magic on the part of some enemy, though exactly whom it was was not yet known - that would be found out later on.

All sacred ceremonies were suspended for the time being, and the whole camp entered with zest into the very serious business of performing properly the mourning ceremonies. The etiquette of mourning is elaborate, and the omission 


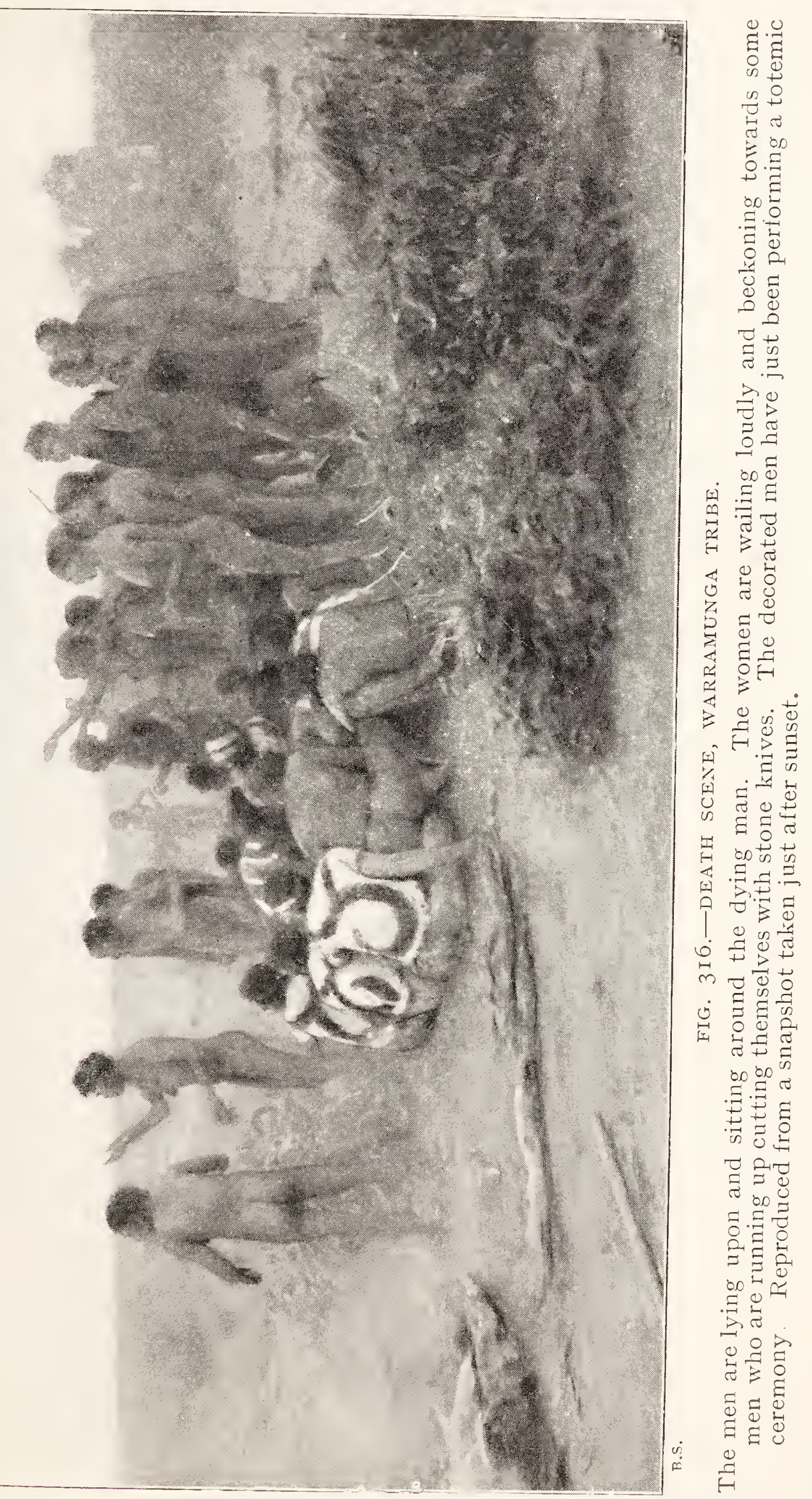




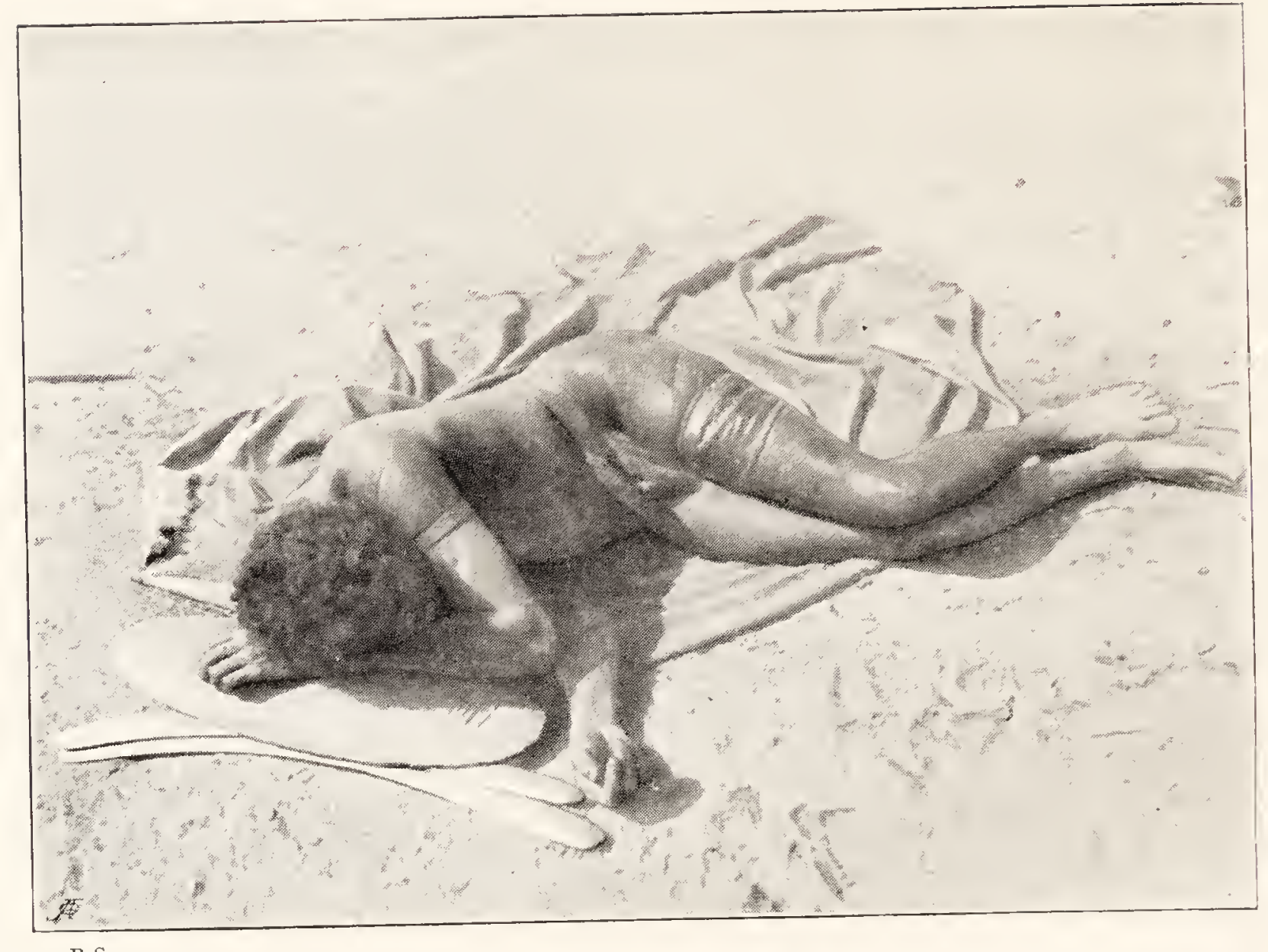

B.S.

FIG. 3I7.- MAN WITH GASHED THIGH, DURING MOURNING CEREMIONIES, WARRAMUNGA TRIBE.

The wound is made to gape as widely as possible by being tightly tied round on either side.

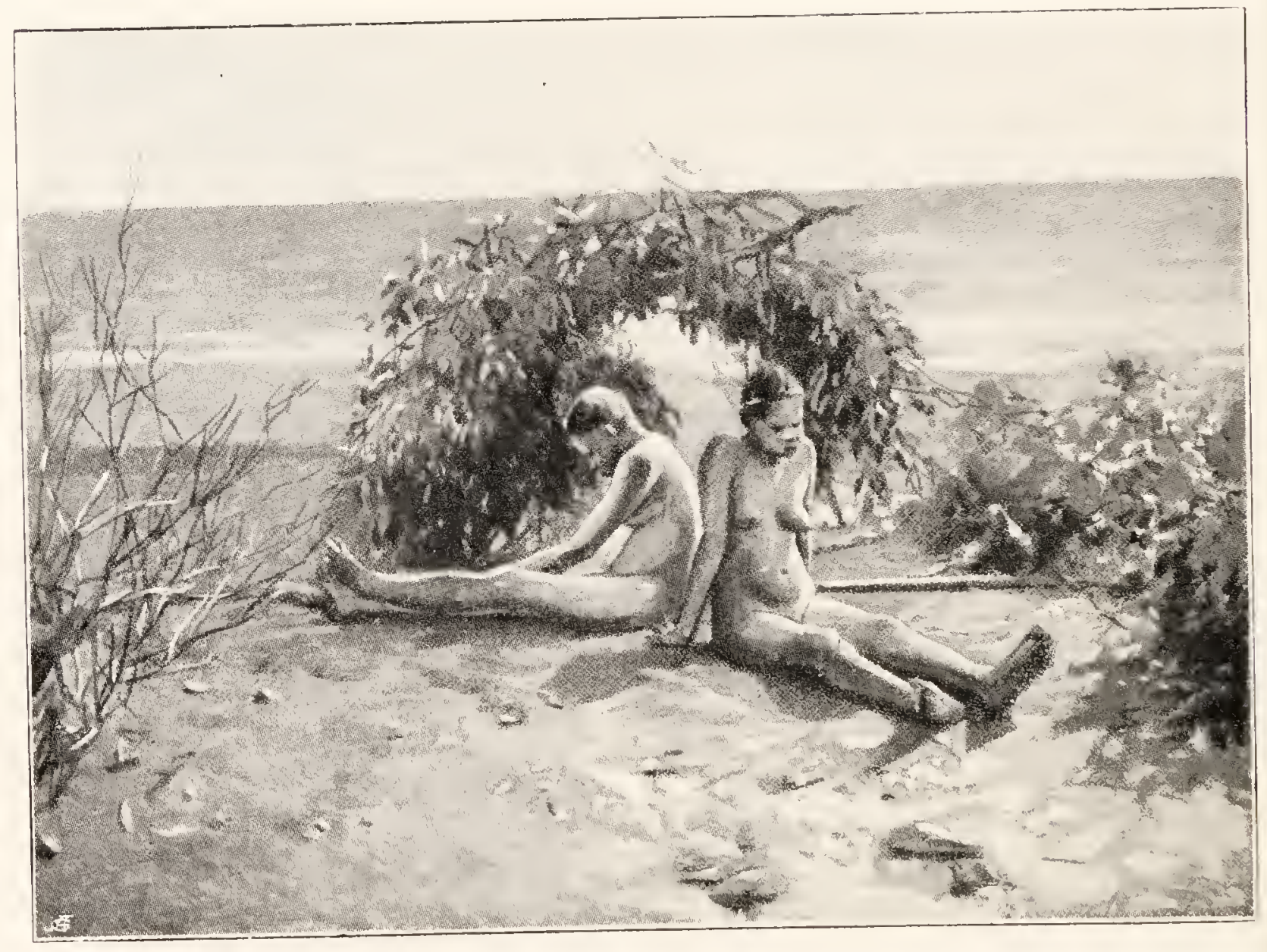

B.S.

FIG. 3IS. TWO WIDOWS ON THE MORNING AFTER A MAN"S DEATH.

They have daubed themselves over with pipe-clay and built a small lean-to of boughs a little distance away from the main camp. 
to do what was proper would indicate a want of respect that would be much resented by the dead man's spirit. On the camping ground, several men were lying hors de combat with gashed thighs (Fig. 3I7). They had done their duty and henceforth, in token of this, would be marked with deep scars. On one of these men I counted no fewer than twenty-three that had been self-inflicted at different times. Everything is hedged round with definite rules and, when a man of any particular section of the tribe dies, it is men who stand in a particular relationship to him who must cut themselves. On this occasion it was men who stood to him in the tribal relationship of grandfather on the mother's side, mother's brothers, brothers of the mother of his wife and wife's brothers. Some tribal fathers had cut their whiskers off, others cut their hair off closely and smeared their scalps with pipe clay. The leg of the man who had most deeply gashed himself was held by his actual father, who, in turn, was embraced from behind by an aged man - the father-in-law of the patient - as if to support him in his grief. Sundry other men came up, one after the other, and there was a succession of embracings, accompanied by alternate howlings and moaning. Most of this was merely a matter of etiquette and had no reference to any genuine feeling of regret. If a man who stands in a particular relationship to you happens to die, you must do the proper thing, which may be either gashing your thigh or cutting your hair, quite regardless of whether you were personally acquainted with the dead man or whether he was your dearest friend or greatest enemy.

The women meanwhile were taking a very active share in the proceedings. The dead man had left behind him two widows, who, according to custom, had gone far away from the old camp, cut off their hair, smeared themselves over with pipe clay from head to foot, and were now under the shelter of a few boughs that they had fixed in the ground 


\section{WANDERINGS IN WILD AUSTRALIA сн.}

so as to make a small wurley for themselves, to one side of the main camp (Fig. 3 I 8). The only personal belongings that they had been allowed to retain were their yam-sticks. Early in the morning the two widows, in company with two tribal sisters, came towards a place where a group of men were seated. An old man, who was a tribal brother of the widows, arose, went towards them and, after striking their yam-sticks with a club, they all sat down on the ground embracing one another. After a few minutes the man left them and the women began to wail and cut their scalps. This went on for some time, and then they rose and approached the lubras' camp, where forty or fifty women were assembled (Fig. 3 I9). The latter came out in small bands of perhaps six or eight at a time, everyone carrying a yam-stick. After a series of sham fights they all sat down in groups (Fig. 320), with their arms round one another, weeping and wailing frantically, while the actual and tribal wives of the dead man, together with his mother, wives' mothers, daughters, sisters, mother's mother, sister's husband's mother and granddaughters, once more cut their scalps with their yam-sticks (Fig. $32 \mathrm{I}$ ). Mourning is a very serious matter amongst the women.

Altogether it was a most extraordinary scene, and the women, seated on the ground with their arms round one another, looked like nothing so much as a number of ancient apes, crouching close together. After the women had finished this part of the performance, one of the older ones, who was a tribal mother of the dead man, brought up all his effects and placed them, weeping as she did so, on the knees of an old man who was her tribal brother-that is, he stood to the dead man in the relationship of mother's brother, a very important one amongst the natives. With him there was a younger man belonging to the same section as himself, but to a younger generation.

The old man opened the bundles, which consisted of 


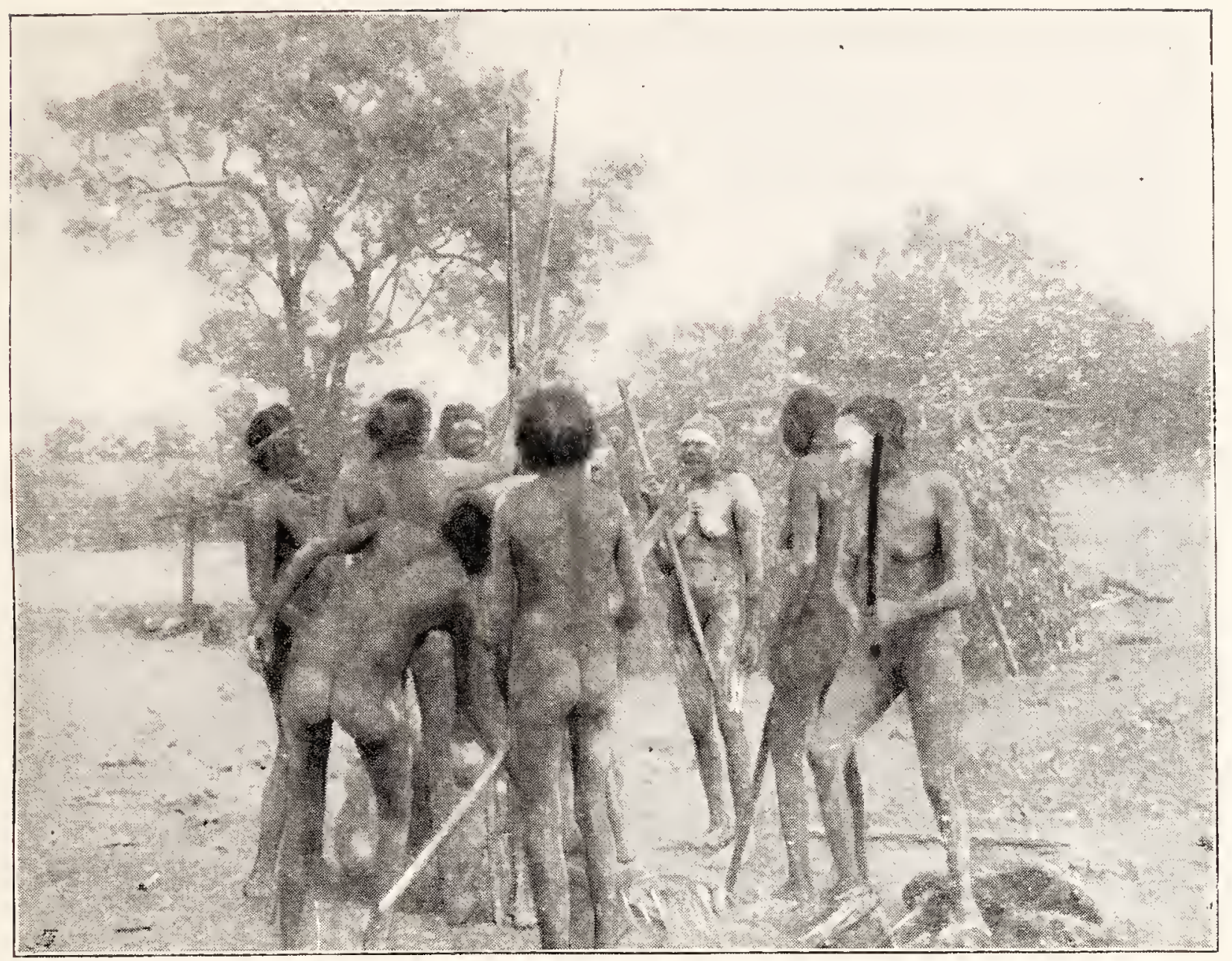

B.S.

FIG, 3I9.-WOMEN CHALLENGING ONE ANOTHER TO FIGHT AND CUT THEIR HEADS DURING MOURNING CEREMONIES, WARRAMUNGA TRIBE.

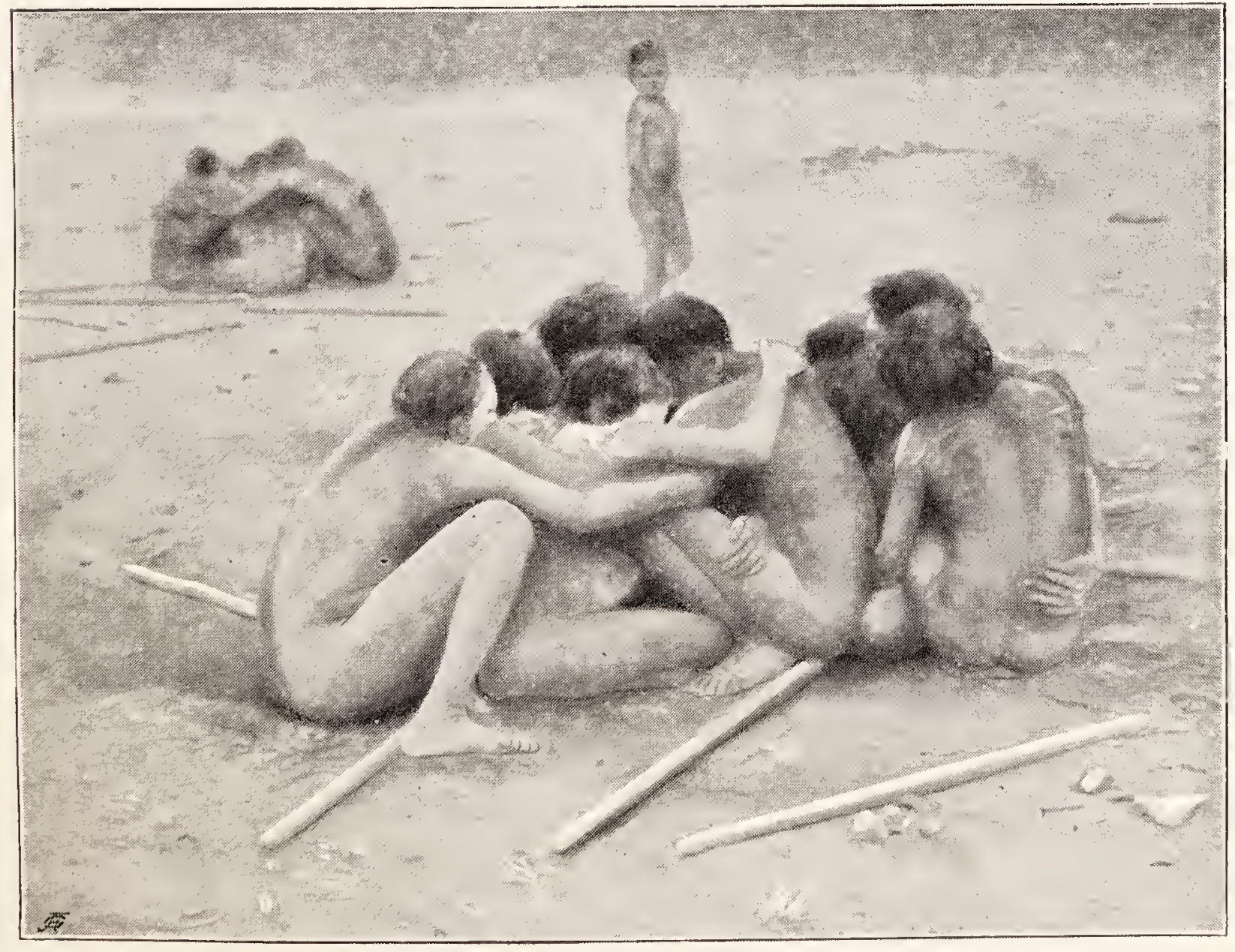

B.S.

FIG. 320.-WOMEN EMBRACING AND WAILING ATTER CUTTING THEIR IIEADS DURING THE MOURNING CEREMONIES, WARRAMUNGA TRIBE. 


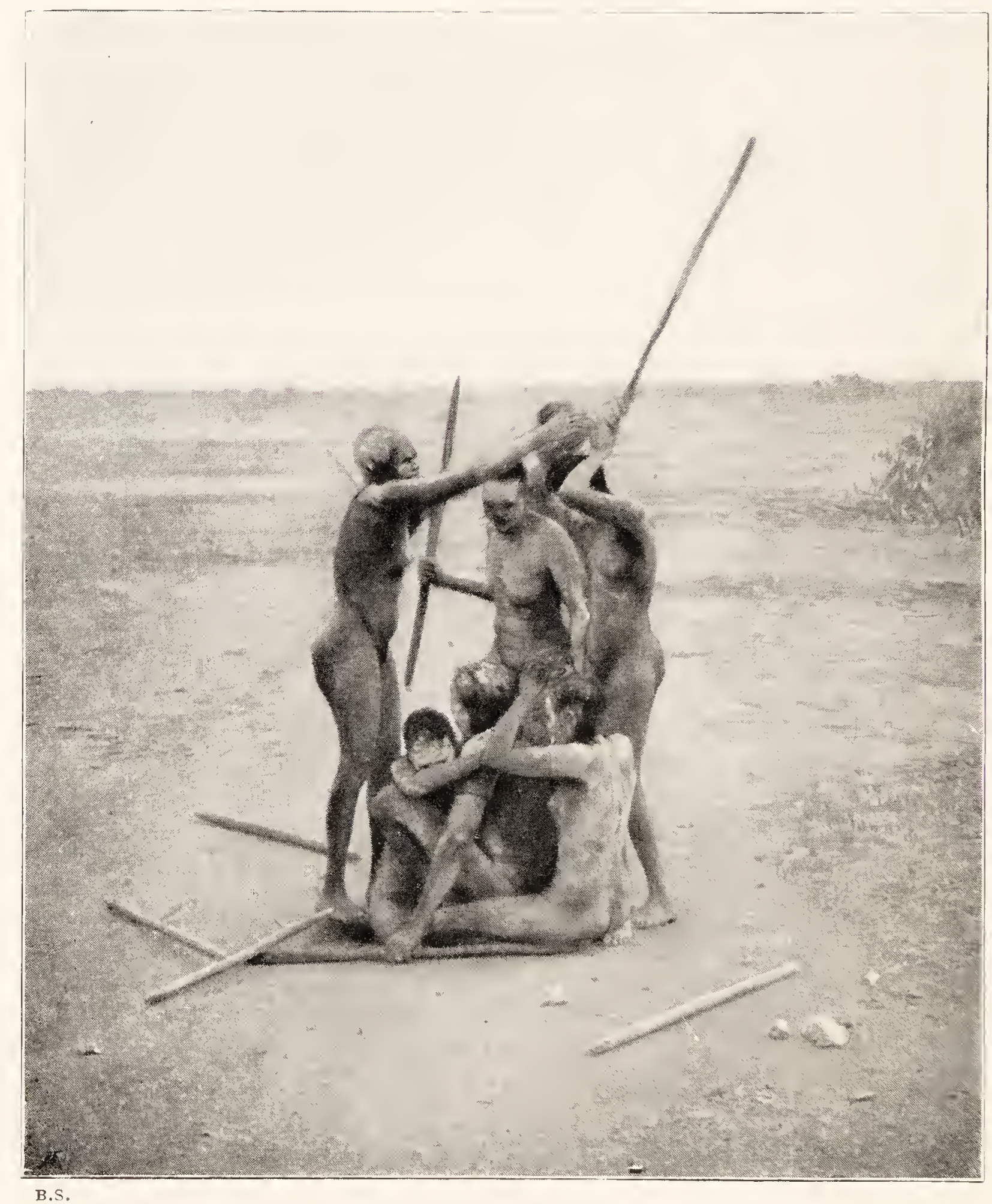

FIG. 32I,-GROUP OF WOMEN CUTTING THEIR HEADS WITH YAM-STICKS DURING MOURNING CEREMONIES, WARRAMUNGA TRIBE. 
boomerangs, clubs, pitchis, tomahawks, hair girdles, etc., and asked the younger one which he would take, pressing him first to take them all. This, of course, was only a matter of etiquette and he replied, "No, I will take the clubs and boomerangs; you take the other things." The result was that everything passed into the possession of men who belonged to the side of the tribe to which the dead man's mother and wife belonged.

These ceremonies occupied the whole of the day, and next morning, to our dismay, we found that there was again great trouble in the camp. One of the older men had found out, during the night, that the knife with which he had gashed his thigh was supposed to have been " sung," that is, endowed with evil magic. At a time such as this, when there has been a death and when the spirit of the dead man, and probably also that of the man who killed him, is hovering around, there is a suppressed feeling of general uneasiness and fear in the camp and, if the idea be suggested to him at the right moment, anyone is ready to believe that he is the victim of magic. A man from the northern part of the tribe was sent for, in order that he might "sing " the wound and so remove the evil influence, but, when he came, he found himself unable to do anything. The knife had been "sung " by a native belonging not to his own group in the north, but to a distant tribe, and he did not know the special song that was necessary to remove the evil magic, or to work successfully against it.

If the old man once became convinced that the evil influence could not be removed, he would certainly make up his mind that he had to die, and die he would have done. There was nothing for it but to act promptly, so we held a hurried consultation and told him that we could get rid of it by means of a powerful incantation that had been taught to one of us for use in such a case as this by the wise old Arunta men. We made him light a small fire, which, to 


\section{WANDERINGS IN WILD AUSTRALIA сн.}

be efficacious, had to be done by himself. The very act of doing it made him pull himself together a little and turned away his thoughts for the moment. Then, while he knelt over the smoke, holding in both hands the blade of the magic knife, we chanted solemnly the words "Lima perta arungquilta etira ura ulquinai," repeating them time after time. The incantation was a very simple one and was only an exhortation to the Arungquilta, or evil magic in the stone, to go back to the fire and be eaten up quickly. Being in a foreign language, he had no idea of what it meant, which added to its mysterious power, and very soon it had the desired effect. The old man and his friends were much relieved; in half an hour all danger was past and the patient was resting quietly, at ease in both mind and body. We were as much relieved as he was, because this old man was a person of great consequence in the tribe and, if he had insisted on dying, the ceremonies would have come to an abrupt end.

In our medicine chest we had one bottle labelled " Livingstone Rouser." If he does take medicine the native likes to have some definite, tangible proof of the efficacy of the white man's magic. The "Rouser" admirably fulfilled all conditions in regard to this, and was held in great respect as a potent antitoxin which could deal successfully with almost any form of Arungquilta and remove it from his body.

Three days later we were awakened early in the morning, long before sunrise, by an old native who said that they were going to visit the tree grave in order to try to find out who was guilty of killing the dead man. We had, of course, no idea of what they were going to do, but it was not safe to miss anything, so I dressed hastily-it is rather chilly in the very early hours of the morning in Central Australia-and left camp at 3 a.m. There were just six of us, myself and five natives, two of whom were brothers, 
one a mother's brother, one a father and the other a wife's father of the dead man. Once in the scrub away from the camp, the two latter sneaked across the plain, travelling in a more or less direct line towards the grave, a mile off. The other three, with whom I went, followed a roundabout course. For two miles, in the dim light, we walked quietly along the bed of a winding creek, the high bands of which prevented us from being seen by anyone on the plain, on which the other two men dodged about from bush to bush. The object of all this secrecy was to catch sight of the grave without, if possible, alarming, or being seen by, the spirit of the murderer, if it should chance to be hovering about. A long distance away from the grave we came out from the creek and stole quietly along over the plain, bending down and taking advantage of every bit of scrub available, gliding across the open ground from one patch of shelter to the next, until we were all well in sight of the tree. Whilst still in shelter, the two parties communicated with one another by means of gesture language, but neither had seen anything in the nature of a spirit hovering about, so we all came out into the open and approached the grave. First of all a careful search was made round the base of the tree in the hope of finding the track of some animal, but without success, and, just before sunrise, two of the men, one of whom was still decorated with a design painted on him during a sacred ceremony the day before, climbed up, lifted the boughs above the body of the dead man and carefully examined it (Fig. 322) to see if it had been interfered with in any way by the spirit of the murderer, but could find no trace of anything that would serve as a clue to his identity. It was a very picturesque little scene, in the early morning light and, with my little Anschutz camera ready, I stood to one side watching them. Some fresh boughs were added to the grave, and then we set off back to the camp, making no further effort at secrecy. On 
the way we visited the remains of the dead man's camp and the little Kakiti, that is, the mound of earth that had been raised on the exact spot on which the man died. It was examined very carefully in search of traces of any animal such as a dingo, kangaroo or bird, because the spirit of the murderer might have come to visit it in the form of his totemic animal (Fig. 323). If there had been a track left by any animal, then it would be clear proof that some person belonging to the totemic group, named after and associated with it, was responsible for the man's death. However, the mound was perfectly smooth and untouched, just as they had left it three days before, and there was no indication of animal, bird or beast having been there, so we had to return to our camps before the natives were astir, without having been able to gain any clue as to the culprit. Sooner or later, however, the guilt would be fixed upon someone and an avenging party sent out to punish him.

After this little ceremony, which may be repeated two or three times, has been performed, the grave remains undisturbed for at least a year and usually longer. The dead man's spirit, called Ungwulan, hovers about the tree and sometimes visits the camp, watching, if it be that of a man, to see that the widows are mourning properly. There are even times when it can be heard making a low whistling sound. When a brother thinks that it is getting near to the time to perform the final ceremonies he goes to the tree and, addressing the spirit, says, "Shall I go away?" If it says "No," he returns to camp at once and waits. It is often not until after several such inquiries have been made that the spirit tells the man that it wishes the period of mourning to come to an end. When its consent has been obtained, the brother tells the dead man's father-in-law, who immediately makes arrangements for the final ceremony. 


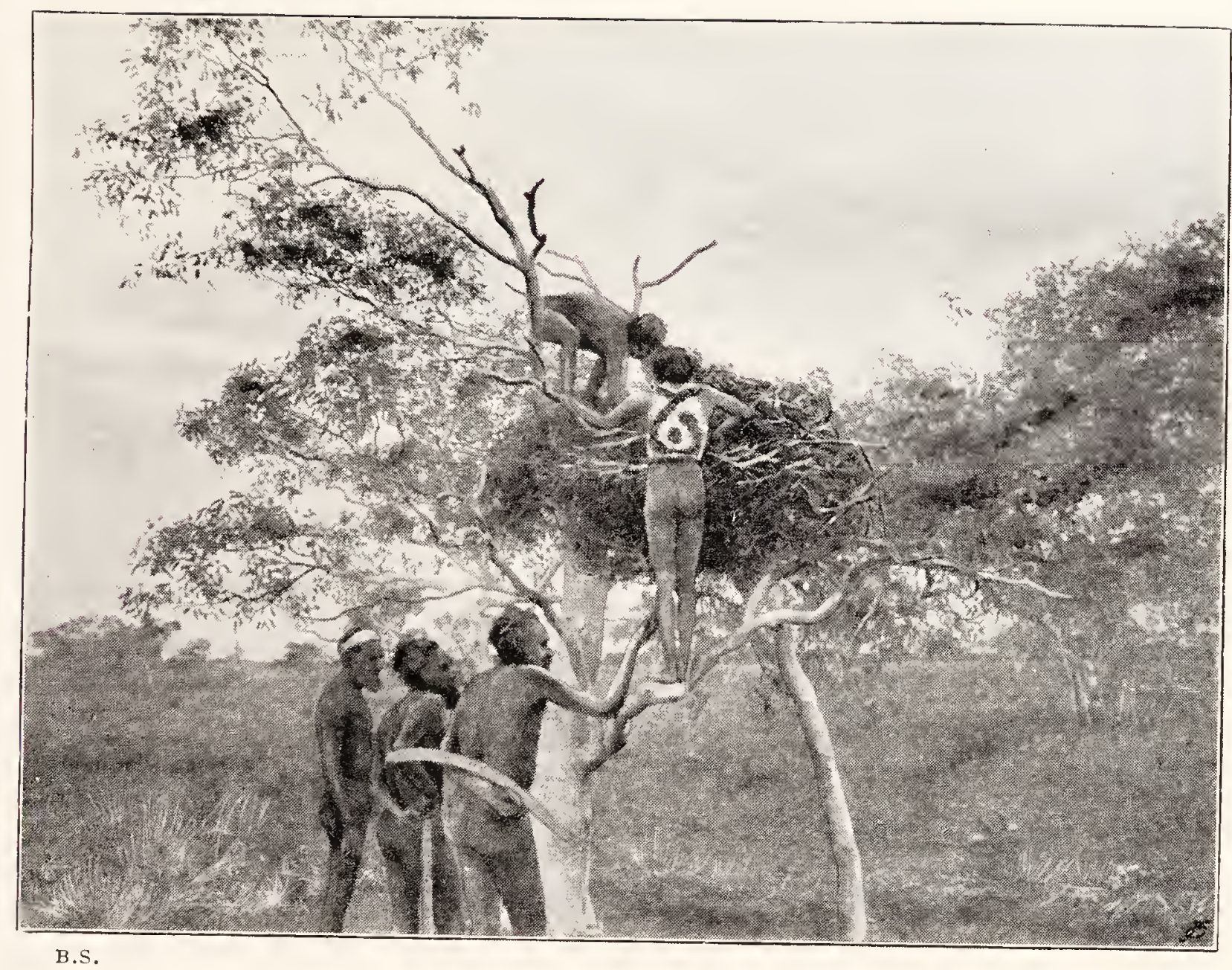

FIG. 322.-VISIT TO TREE GRAVE AT SUNRISE, A FEW DAYS AFTER THE DEATH OF A MAN, TO TRY TO DISCOVER SOME CLUE TO THE SUPPOSED MURDERER, WARRAMUNGA TRIBE.

The men in the tree are examining the body. 


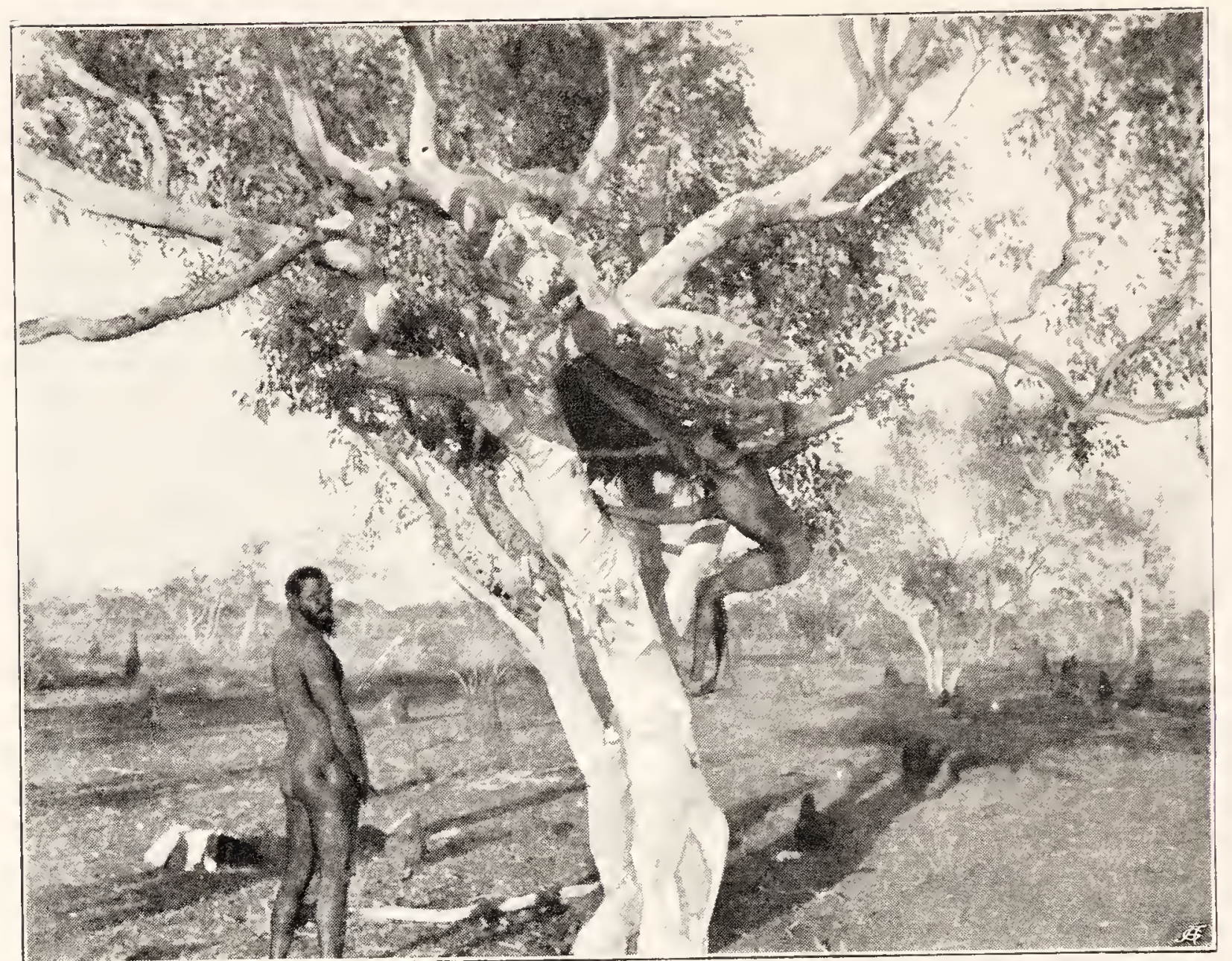

B.S

FIG. 324.-CLIMBING UP TO THE TREE GRAVE IN ORDER TO RAKE THE BONES OUT ON TO THE GROUND, WARRAMUNGA TRIBE.

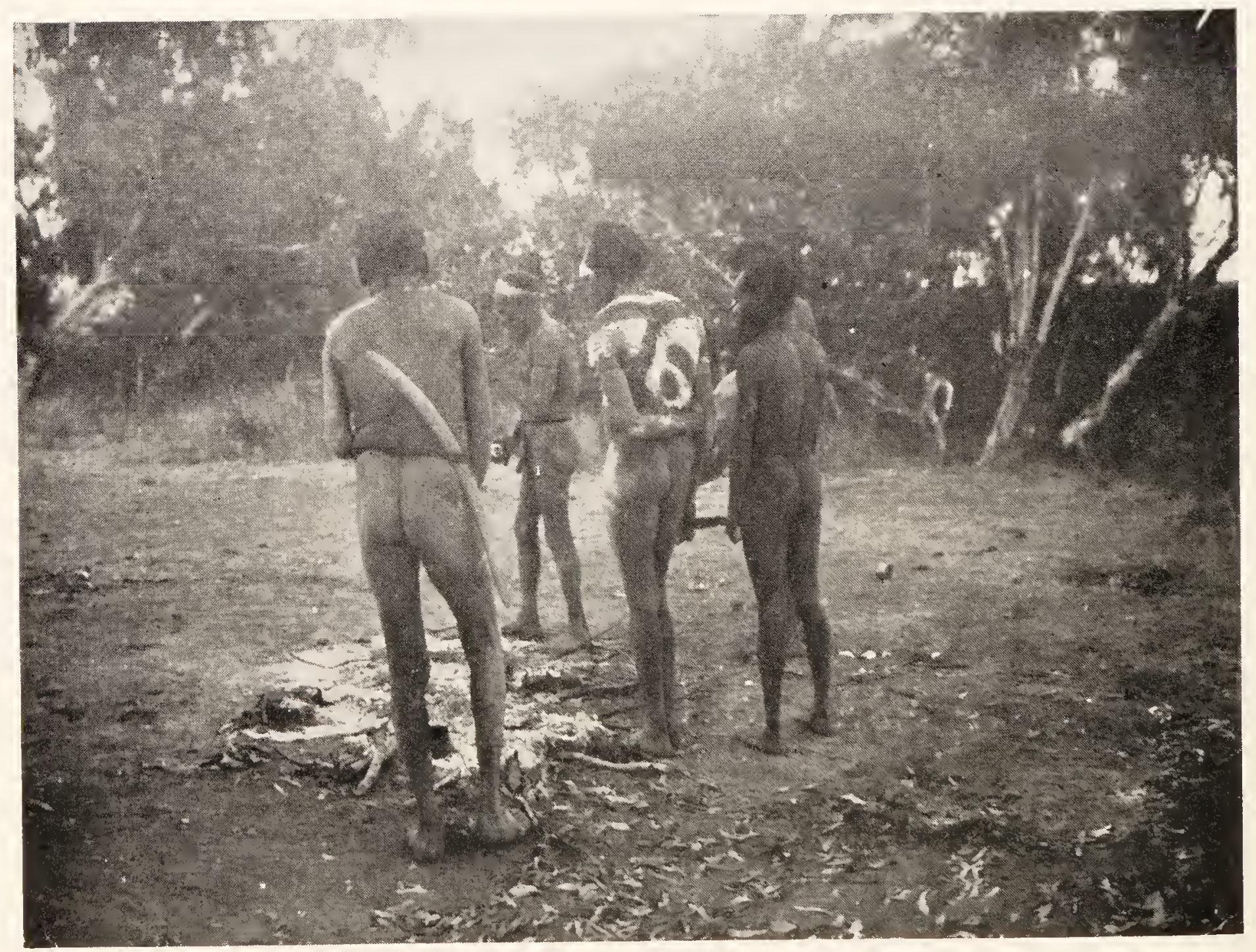

$13, S$

FIG. 323.- VISITING TIE DEATIT MOUND, WARRAMUNGA TRIRE. 
We saw two of these-one connected with the remains of a man and another with those of a woman. They were precisely similar to one another in all important features, no more respect being shown to the remains of the man than to those of the woman, which is partly, no doubt, to be associated with the fact that the Warramunga believe that the sex of the individual alternates at each reincarnation - a dead man being subsequently reborn as a woman and vice versa.

Early one morning, in the middle of August, as usual before sunrise, Gillen and myself started off to visit the grave of a woman whose body had been buried on a tree platform a year ago. The party consisted of five, ourselves and three natives, two brothers of the mother of the dead woman's husband and another man who was her tribal son, though old enough to be her brother. A little way from the camp, where all was perfectly quiet, the father of the dead woman came up and gave a ball of fur string to the oldest of the three men, and then we set off in the dim light, wondering what we were going to see. The tree was in a lonely spot, about a mile and a half away from the camp. Its trunk was perfectly white, and amongst the branches we could see the platform on which the bones, now bleached, were lying. The youngest man cut a bark dish from a gum tree close by and then, just as the sun rose, throwing long shadows across the level ground, he cut steps in the trunk and climbed up on to the platform (Fig. 324). With the end of a stick, so as not to touch the bones, he raked them all out on to the ground below and then clambered down. First of all, one of the armbones (a radius) was placed by itself on a sheet of paperbark and put on one side. When this had been done, the youngest man smashed the skull into fragments with a tomahawk and then all the bones, except the radius, were raked into the bark dish (Fig. 325). We wondered what

VOI. II. 
was going to be done with them, and had not long to wait. As soon as they had been gathered together the youngest man carried the dish with its contents to a whiteant hill, two or three hundred yards away. Here one of the elder men took the dish from him, knocked off the top of the mound, slid the bones into a cavity in the centre and then replaced it (Fig. 326). No one, save perhaps a native, would for a moment suspect that the ant hill was the grave monument of a blackfellow.

The whole ceremony occupied only a very short time, and when it was over we returned to the spot where the arm-bone had been left. The oldest man took this and wrapped it up carefully in paper bark, round which he twined the fur string that had been given to him when we left camp (Fig. 327). The whole made a torpedo-shaped parcel, about eighteen inches long and three or four in diameter, one end being decorated with a bundle of emu feathers-in the case of a man, owl feathers are used. It was secreted in the hollow of a gum tree and left there, while the three men went off for a day in the scrub in search of game which, according to custom, they had to present to the father of the dead woman. As there was nothing more to be seen, we returned to camp, and next day a messenger came in from the three men, saying that they were returning late in the afternoon, bringing the bone with them.

The lubras were at once instructed to prepare themselves for the ceremony and, under the guidance of a few old women, who had been through the performance before, they spent several hours painting the upper part of their bodies with red ochre and longitudinal lines of yellow, reaching down to their waists. When the time drew near, a number of old men assembled at a little distance from the main camp and sat down in solemn silence, with the father of the dead woman in the middle of the front line. 


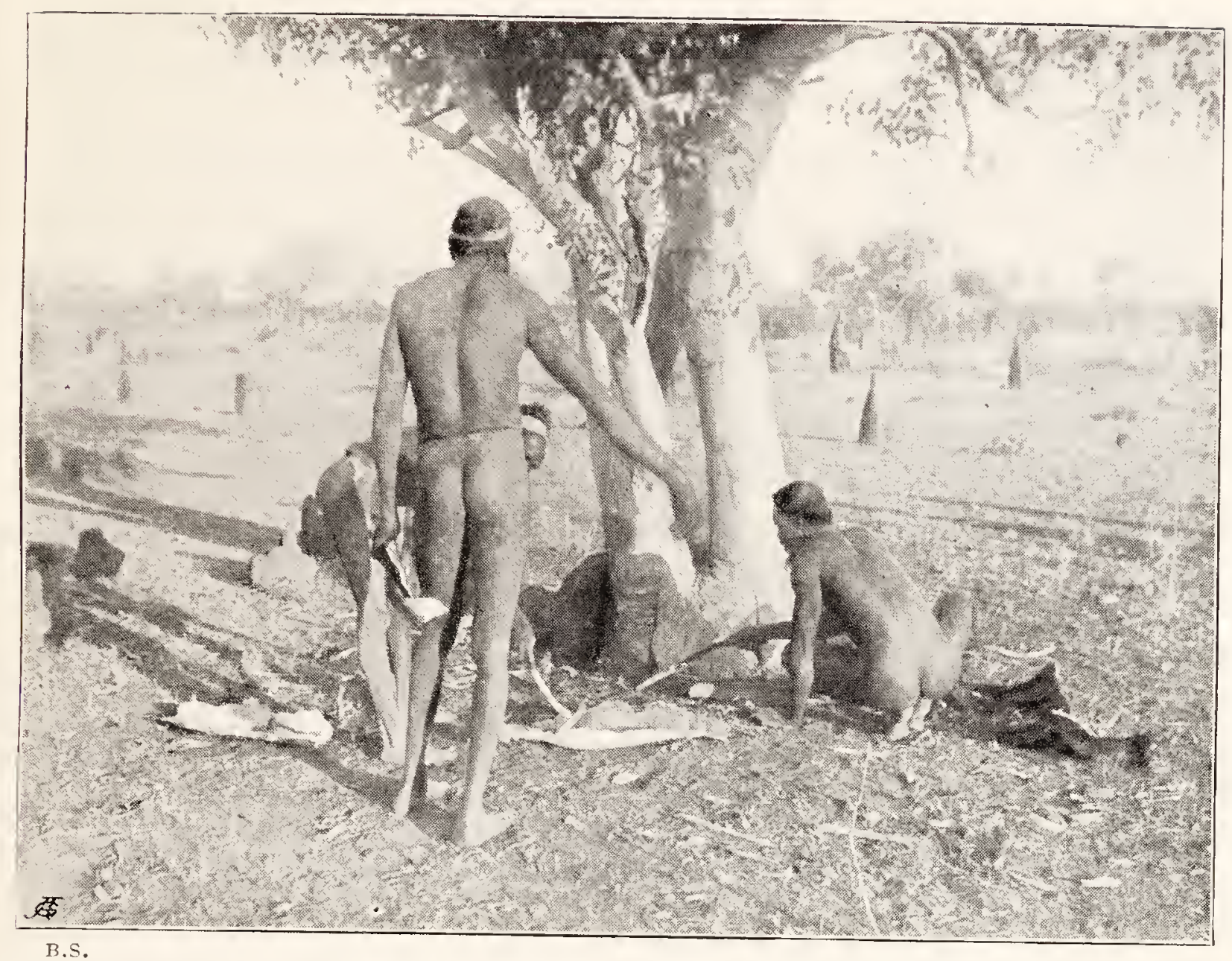

FIG. 325.-RAKING THE BONES INTO A BARK DISH.

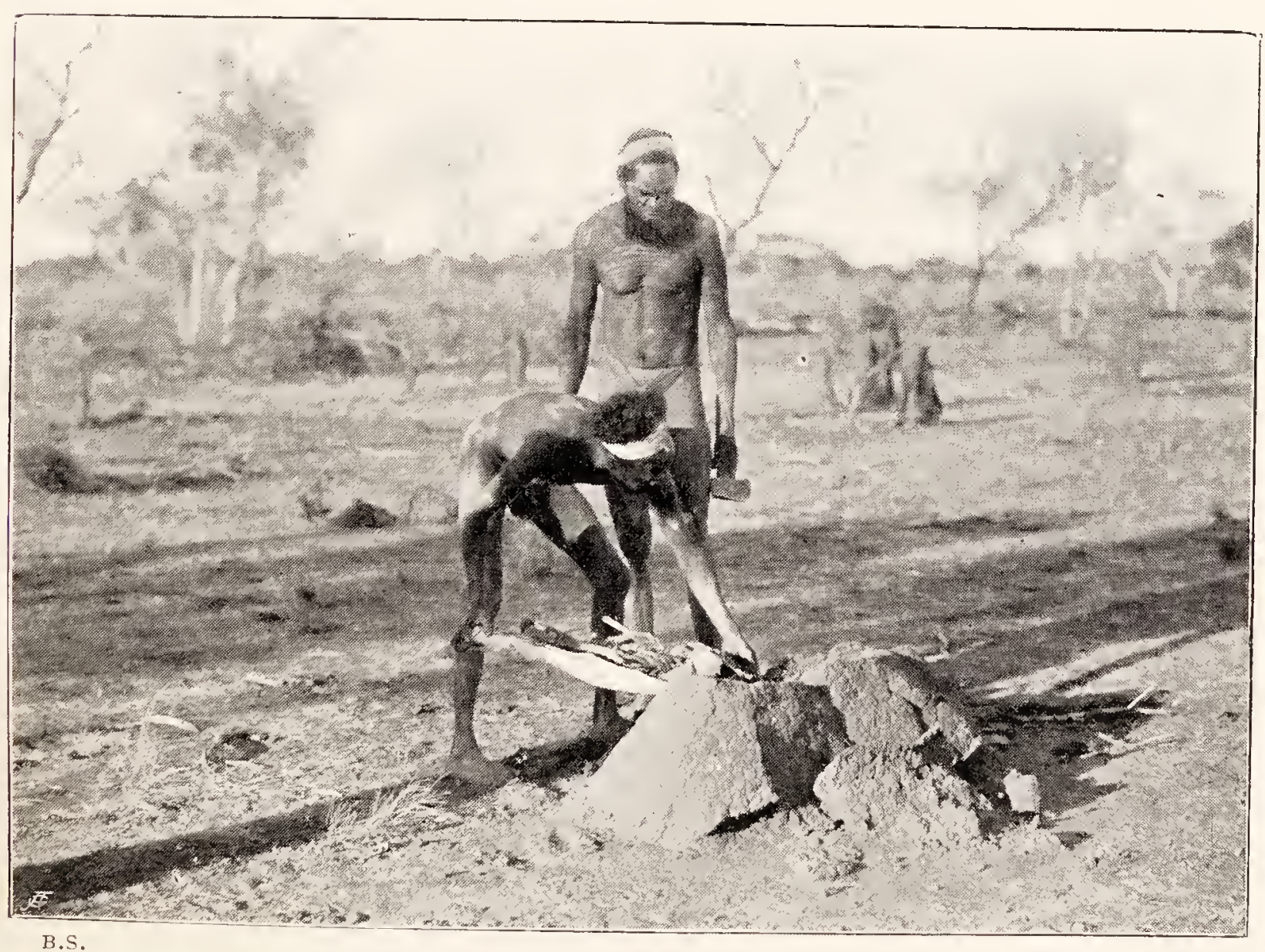

FIG. 326.-BURYING THE BONES IN AN ANT-HILL, WARRAMUNGA TRIBE. 


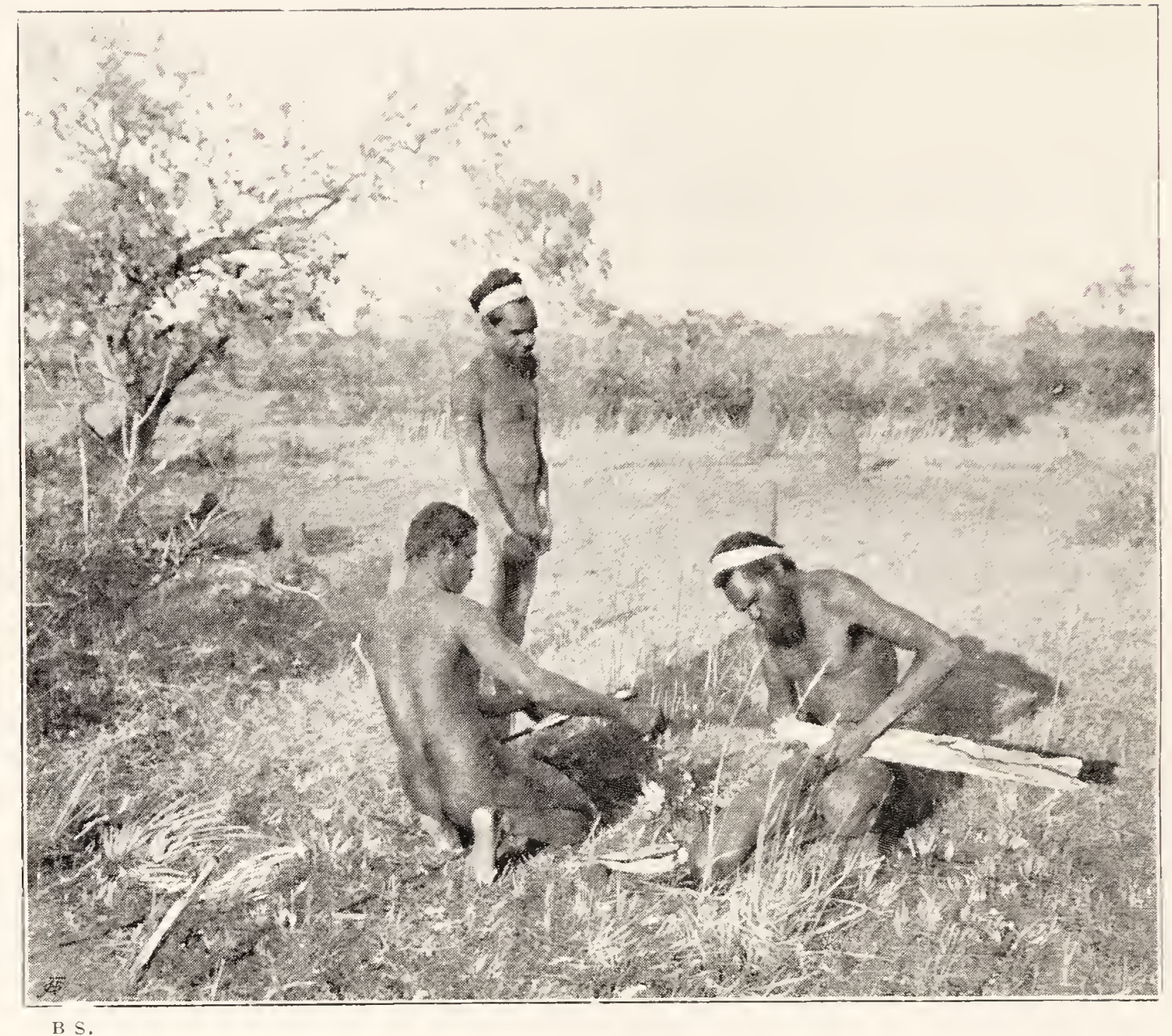

B S.

FIG. 327.-WRAPPING THE ARM-BONE UP IN PAPER-BARF, WARRAMUNGA TRIBE,

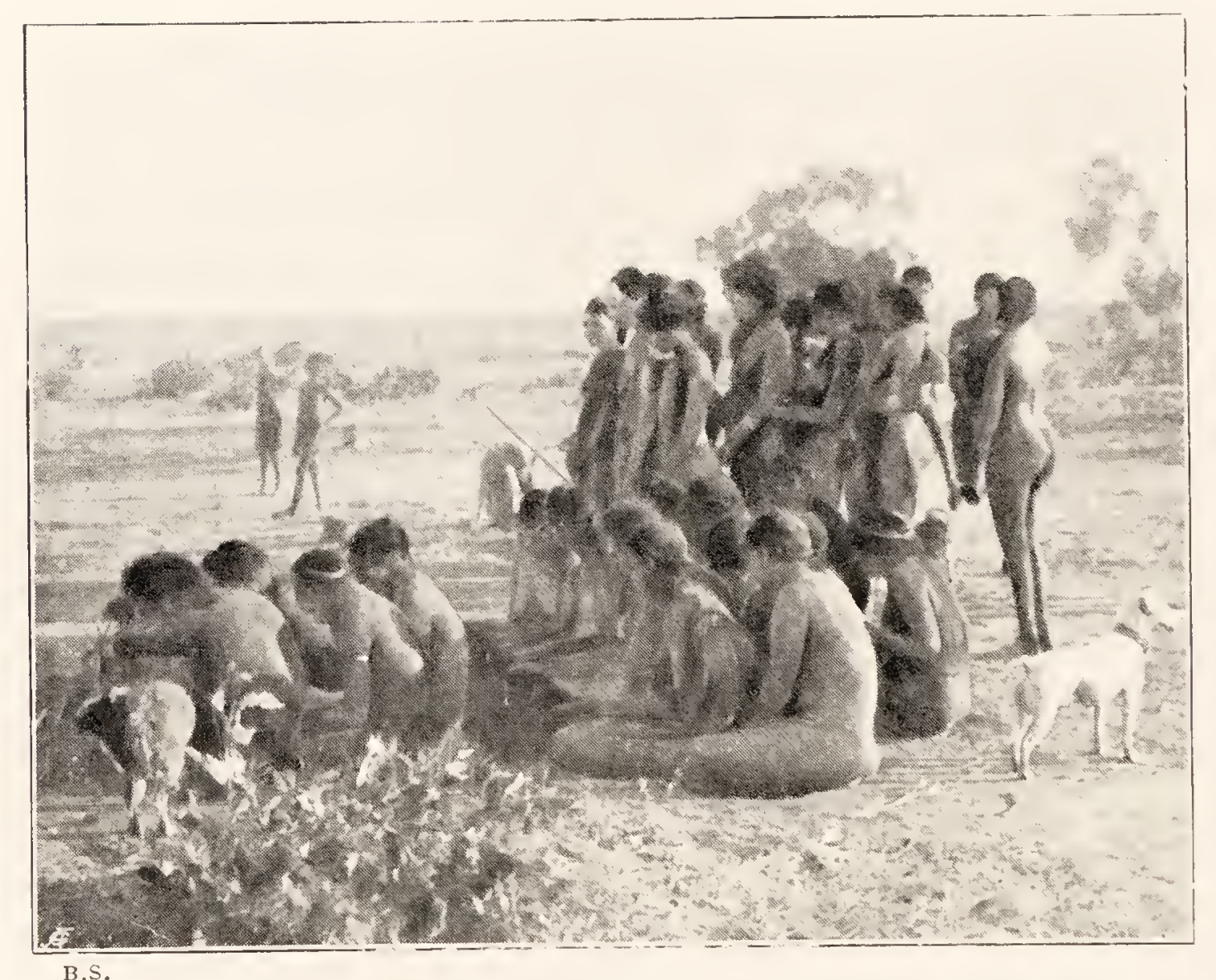

FIG. 328.-GROUP OF MEN AND WOAEN AWAITING THE BRINGING IN OF TIEE ARM-BONE OF A DEAID PERSON. 


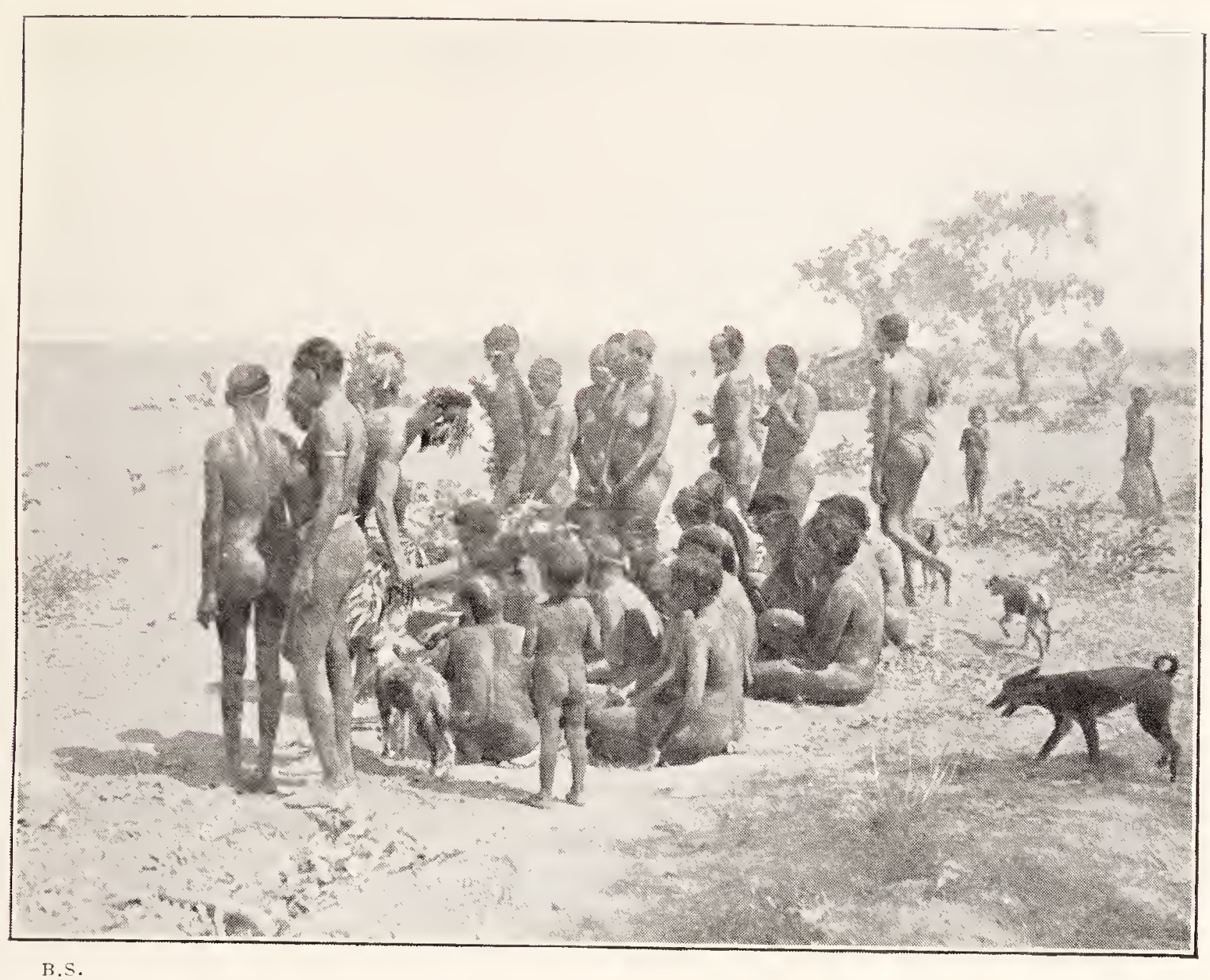

FIG. 329.-BRINGING IN THE ARII-BONE.

The man on the left side is just handing the bone in its covering of paperbark to a man who is seatcd on the ground.

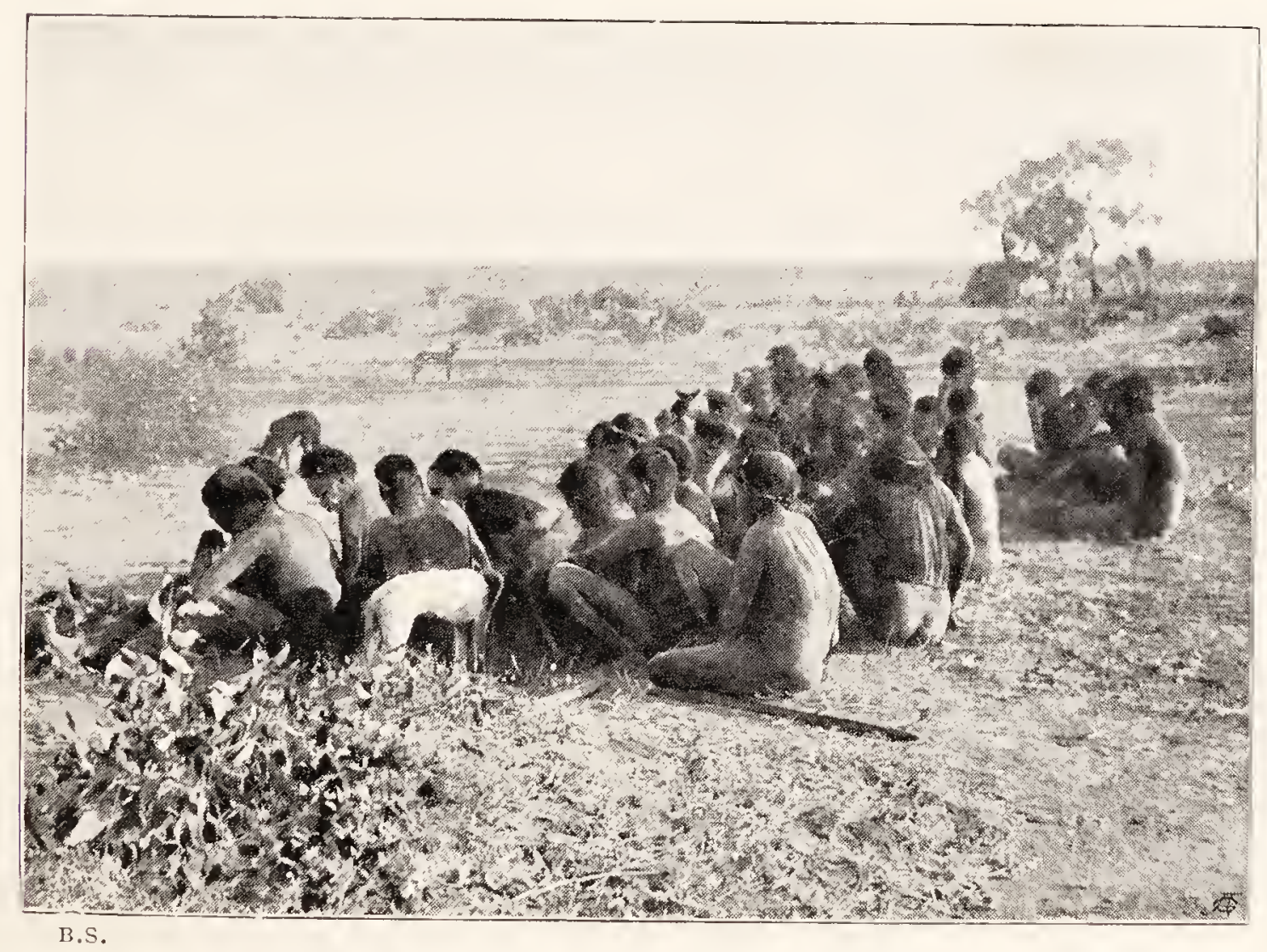

FIG. 330. -GROUP OF MEN AND WOMEN SITTING ON THE GROUND WAILING AND WEEPING OVER THE IBONE. 


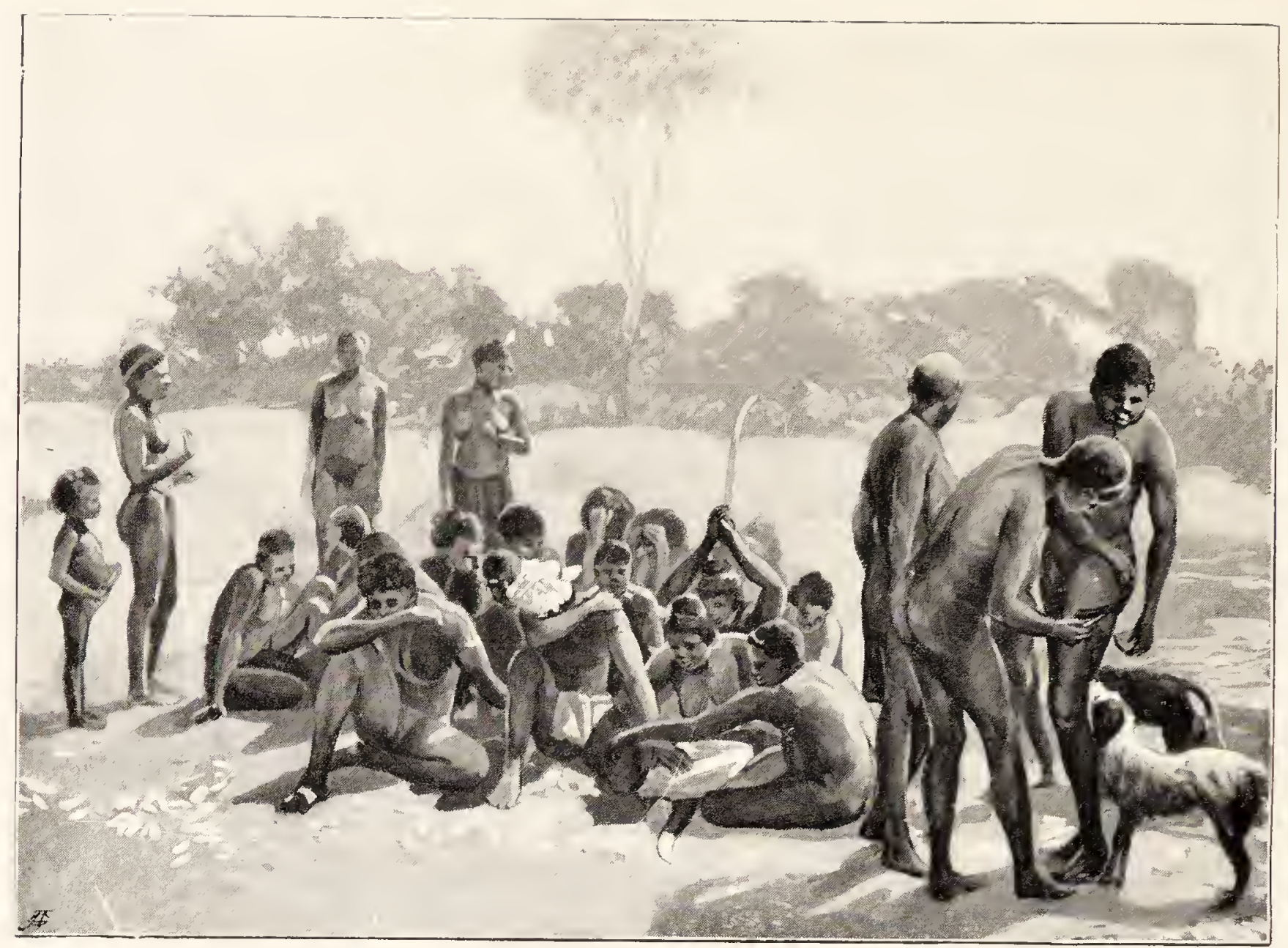

B.S.

FIG. 33I.-GROUP OF MEN AND WOMEN AFTER THE ARM-BONE HAS BEEN BROUGHT IN.

On the right side the women are seen cutting one another's thighs, and in the middle one woman is cutting her scalp with a boomerang. The central man has placed his left hand on a large "damper " or loaf which is being given to the men by the women.

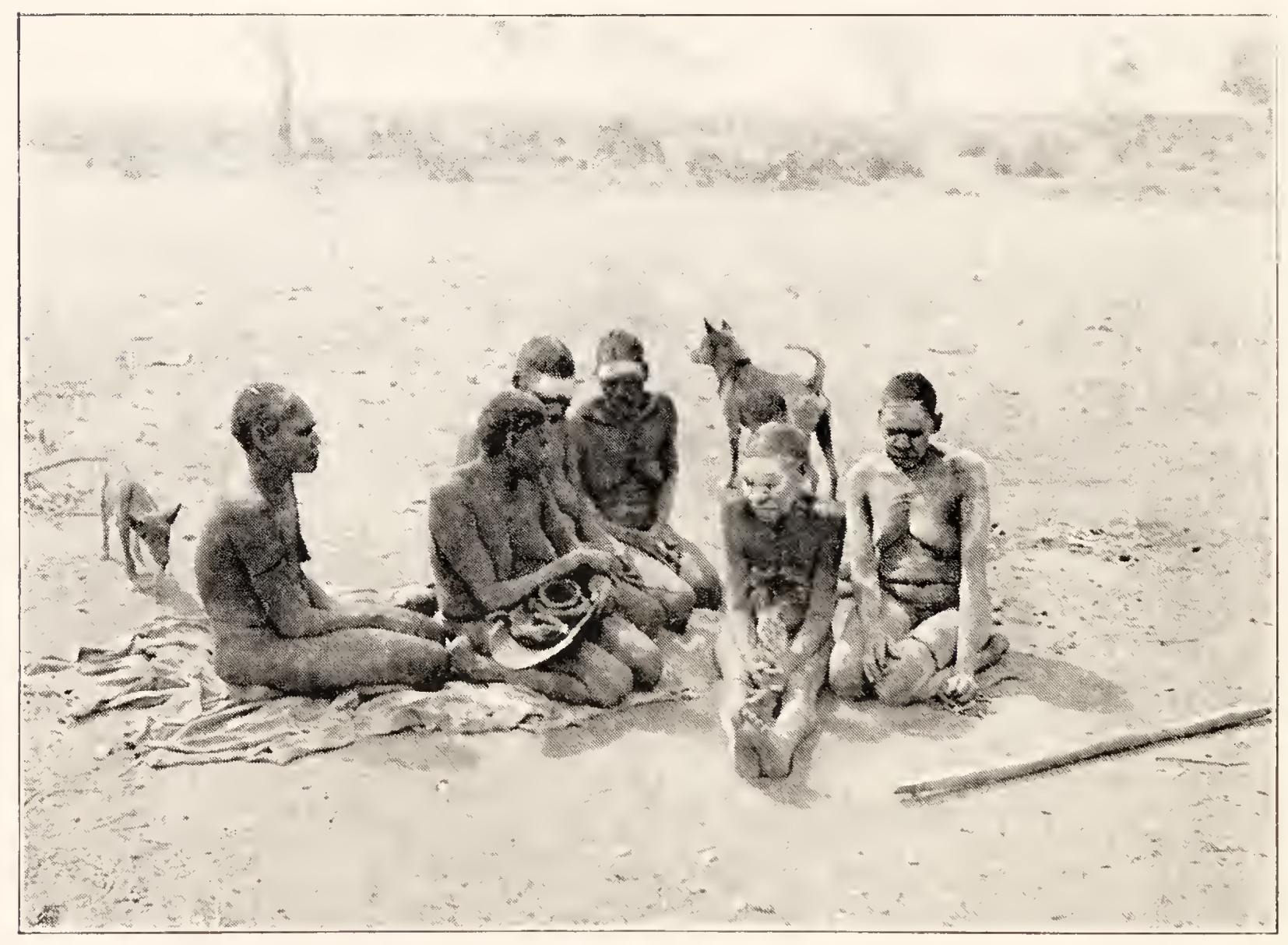

B.S.

FIG. 332.-GROUP OF OLD WOMEN WAITING IN CAMP UNTIL SUMMONED TO THE CEREMONIAL GROUND.

One with her face daubed over with pipe-clay has the arm-bone in its case betwecn her legs, another has a pitchi containing coolicd snalies which will be given to the old men. 
Just before sunset, word came into the camp, from the watchers on the look-out, that the three men, with the bone, had been seen in the distance. The women and children were at once summoned and came up, grouping themselves, standing, behind the men, who were all seated on the ground, everyone perfectly silent and all with their heads bowed down (Fig. 328). A long way off we could see the men, wending their way towards us through the scrub in single file. Each of them had green twigs hanging down over his forehead and tied under his arm-bands The front man carried the bone, hidden under boughs; the second carried the meat offering, also hidden under boughs; the third carried boughs only. Twice they walked quickly round the whole group of men and women and, at the close of the second round, the leader (Fig. 329) bent down and placed the bone in its bark covering on the knees of the father of the dead woman, the second at once laid the meat offering at his feet and then, without a moment's pause, the three retired quickly out of sight, into the scrub, and took no further part in the proceedings. The handing over of the bone was a sign for the women to sit down and, while the men bent prostrate over it, in silence, the former broke out into a loud piercing wail, that became louder still when the old father passed the bone behind him to one of his tribal sisters-a very old, decrepit woman -in whose charge it was to remain until the final ceremony took place (Fig. 330). After a time, some of the women arose and cut their thighs, while others cut their scalps with sharpened yam-sticks (Fig. 33I). When this was over they retired to their camps. The old woman, who was nearly blind, was led away by another, carrying with her the bone, which she hid in the boughs of her bush wurley.

Nothing further was done for seventeen days, during which time the men were busy every day performing sacred 


\section{WANDERINGS IN WILD AUSTRALIA сн.}

ceremonies. The most important of these were connected with the Wollunqua snake totem, and it was decided that the final burial ceremony should take place at the close of one special performance, in which a considerable number of men were to take part. The dead woman was the daughter of the head-man of the snake totem, to which also she belonged. On this final day of the ceremonies, a special drawing was made on the ground, representing the old snake, together with a water-hole where he went into the ground, and certain sacred trees near by where he left spirit children behind him. Ten men were elaborately decorated with designs of red, white and yellow, the exact nature of which can be seen in the illustrations. Word was sent to the women to have everything ready and, on going to their camp, we found a group of six of the older ones seated, apart from the rest, looking a picture of abject despair and misery. The oldest, who was a veritable hag, had her hair close cropped and her face all daubed over with pipe clay. She held the bone in both hands between her outstretched legs. Another held on her knees a pitchi containing a few cooked snakes, not pleasant to look at, that were intended as a food offering to the old men (Fig. 332).

The women, of course, were not allowed to see the sacred ceremony and, as soon as it was over, a trench about a foot deep and fifteen feet in length was dug on the ceremonial ground a few yards to one side of the drawing. A little pit was dug close to the latter by an old man who had charge of the ceremony. The ten performers arranged themselves in a line, with their legs straddled across the trench, each man with his hands clasped behind his head. They were still wearing the totemic design, in white and red down, which looked like a close-fitting thick, woolly vest. All the other men who had been watching the ceremony sat beside the painting, so that this was prac- 


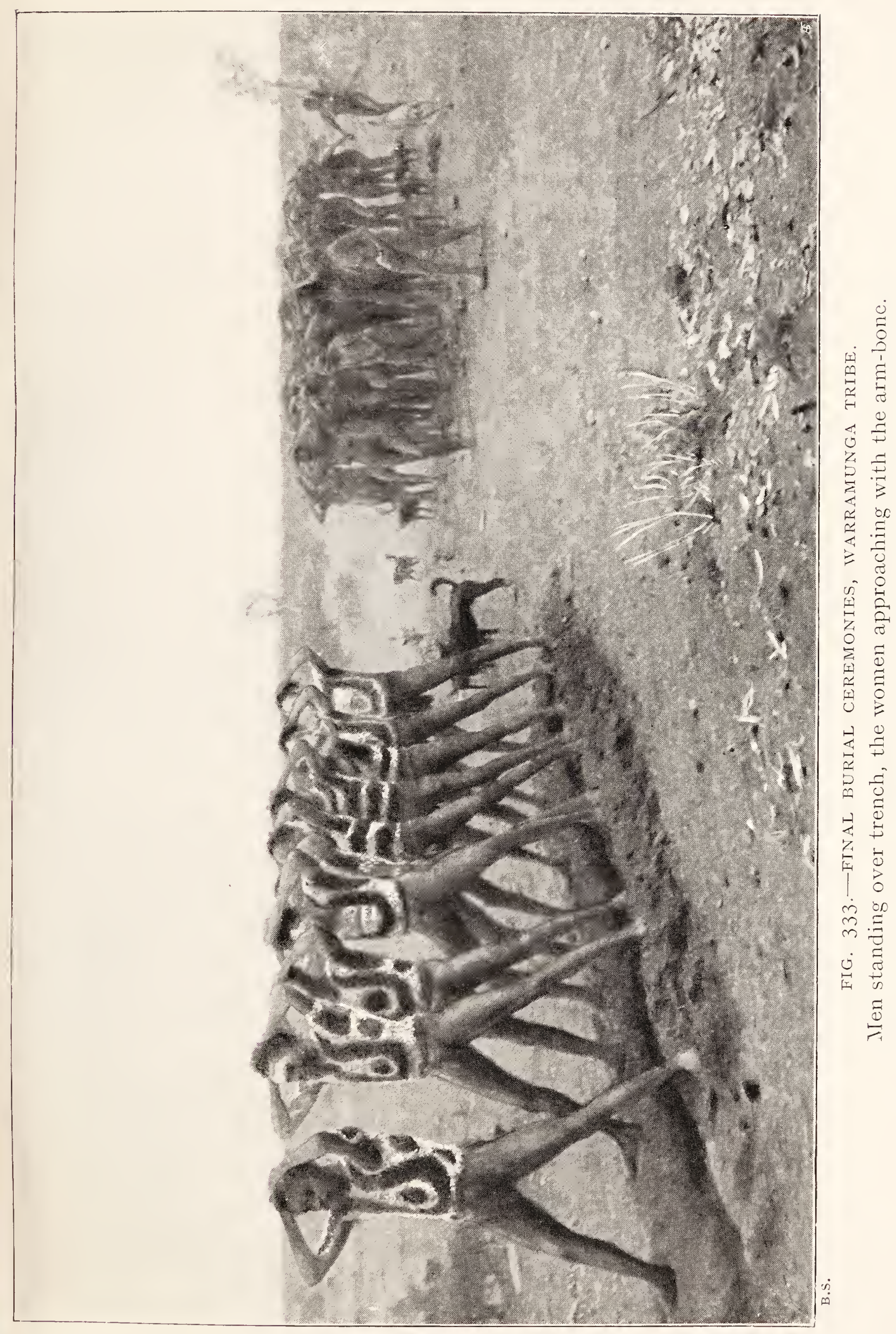




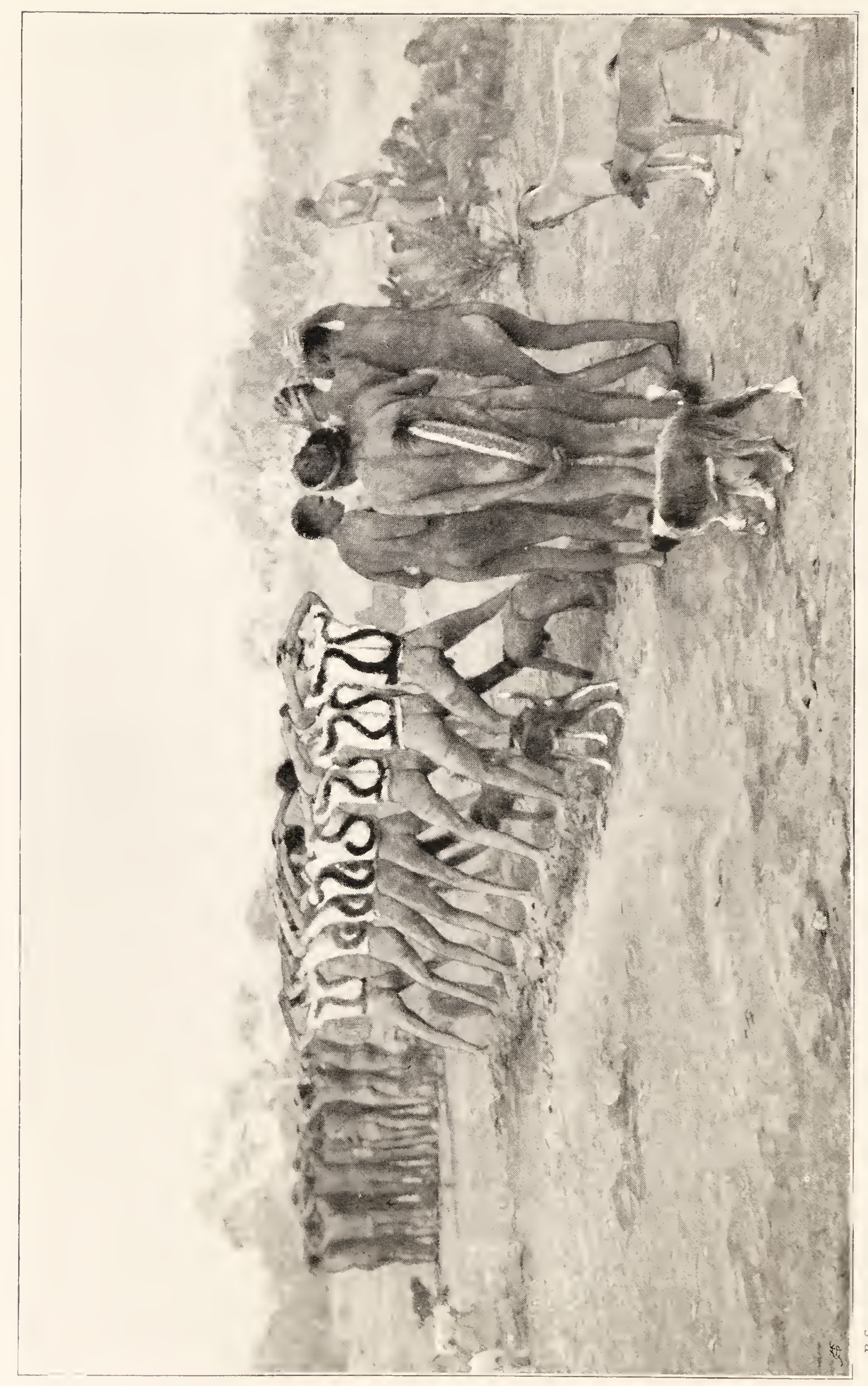

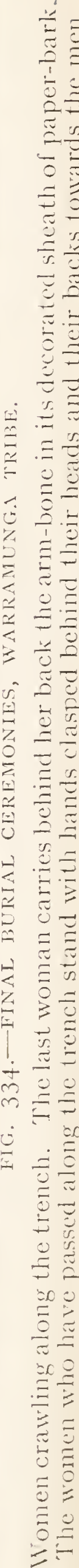


tically hidden from the sight of the women, who were now called up from their camp and came across the creek to the ceremonial ground in perfect silence, one aged woman directing them, by signs, what to do. We were watching their movements with much interest, quite ignorant of what was going to take place. As they approached the trench they could see only the decorated backs of the men, and came on at first in a dense group, with the woman carrying the bone in the rear, slightly to one side (Fig. 333). Coming nearer, they fell into single file and then, without a pause, each woman came forward, fell down on hands and knees and, in this way, crawled along the length of the trench, under the straddled legs of the men. Passing out, they stood up and arranged themselves in a group, some little distance away, with their backs turned towards the men, so that they could see neither them nor the sacred painting on the ground (Fig. 334). Each woman held her arms high up and her hands clasped behind her head, just like the decorated men. The file of women passed rapidly through, the last one to do so being the old woman carrying the bone. As she rose to her feet, it was snatched from her by a brother of the dead woman, who, without a moment's pause, carried it over to where an old man, armed with a stone tomahawk, stood beside the little pit (Fig. 335). By good luck I caught sight of him standing with the hammer ready to strike, and guessing what was going to happen, managed to dodge round the end of the trench with my little Anschutz camera, just in time to catch the bone-snatcher as he held it, in its covering of paper-bark, in front of the old man, who smashed it with a single blow and at once thrust it into the little pit dug beside the emblem of the dead woman's totem (Fig. 336). Not more than fifteen seconds intervened between the snatching of the bone from the woman and its burial in the hole. As soon as ever the last woman had joined the 
others and the blow had fallen, they all fled away, shrieking loudly, across the creek to their camps, and there, in the distance, we could hear them wailing. After a few minutes, most of the men rose and went silently to their camps, but for some time the father of the dead woman and a few other men of his own side of the tribe remained bowed down on the ground, while one of the decorated men filled in the little pit with earth and closed the opening with a large flat stone. The whole ceremony was very picturesque and impressive; more especially the final act when the bone was buried beside the sacred drawing, indicating, as it were, that the dead woman had been gathered unto her totem.

The illustrations will serve to give some idea of the ceremony, but the reader will understand that it is often difficult to watch carefully what is taking place and, at the same time, be in a position, at the critical moment, when events follow one another in rapid succession, to take a snapshot of any specially interesting part of the performance, when one has not the slightest idea, from moment to moment, of what is going to take place. The natives also seem to have a predilection for holding their most interesting ceremonies either just before or just after sunrise or sunset, without any regard to the possibility of securing photographic records.

By special permission of the old men we were allowed, at a later date, to unearth the bone in its decorated wrapping. This is now in the Melbourne National Museum and forms a very interesting memento of one of the most picturesque ceremonies that we witnessed. We were very fortunate in being able to see the whole series concerned with death and burial. It was indeed by the merest chance that the time of death of a native and that of holding the bone-breaking ceremony of another coincided and so gave us the chance of doing so. 


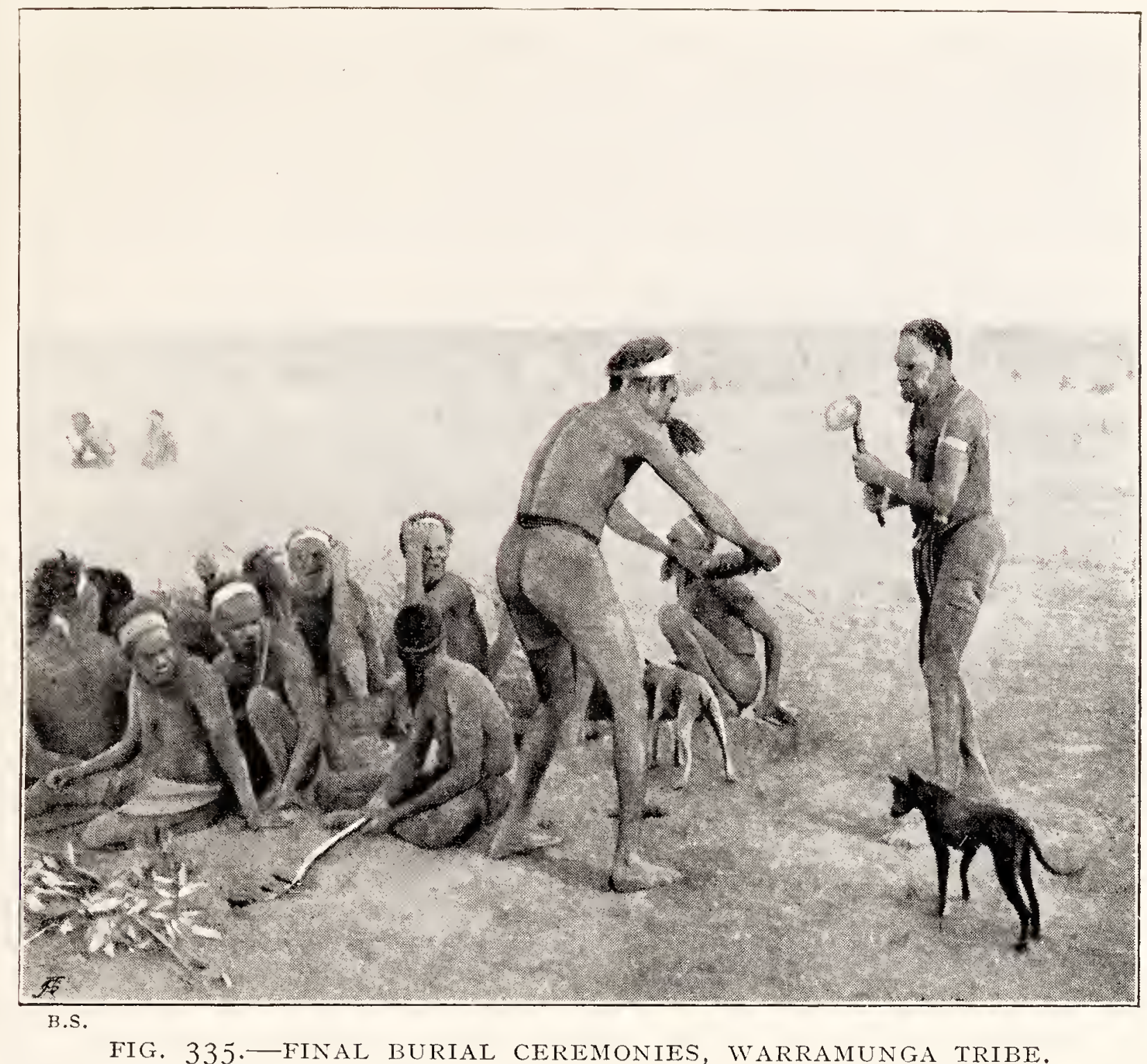

Breaking the arm-bone, which is then buried in the small hole seen behind the right leg of the man holding the bone.

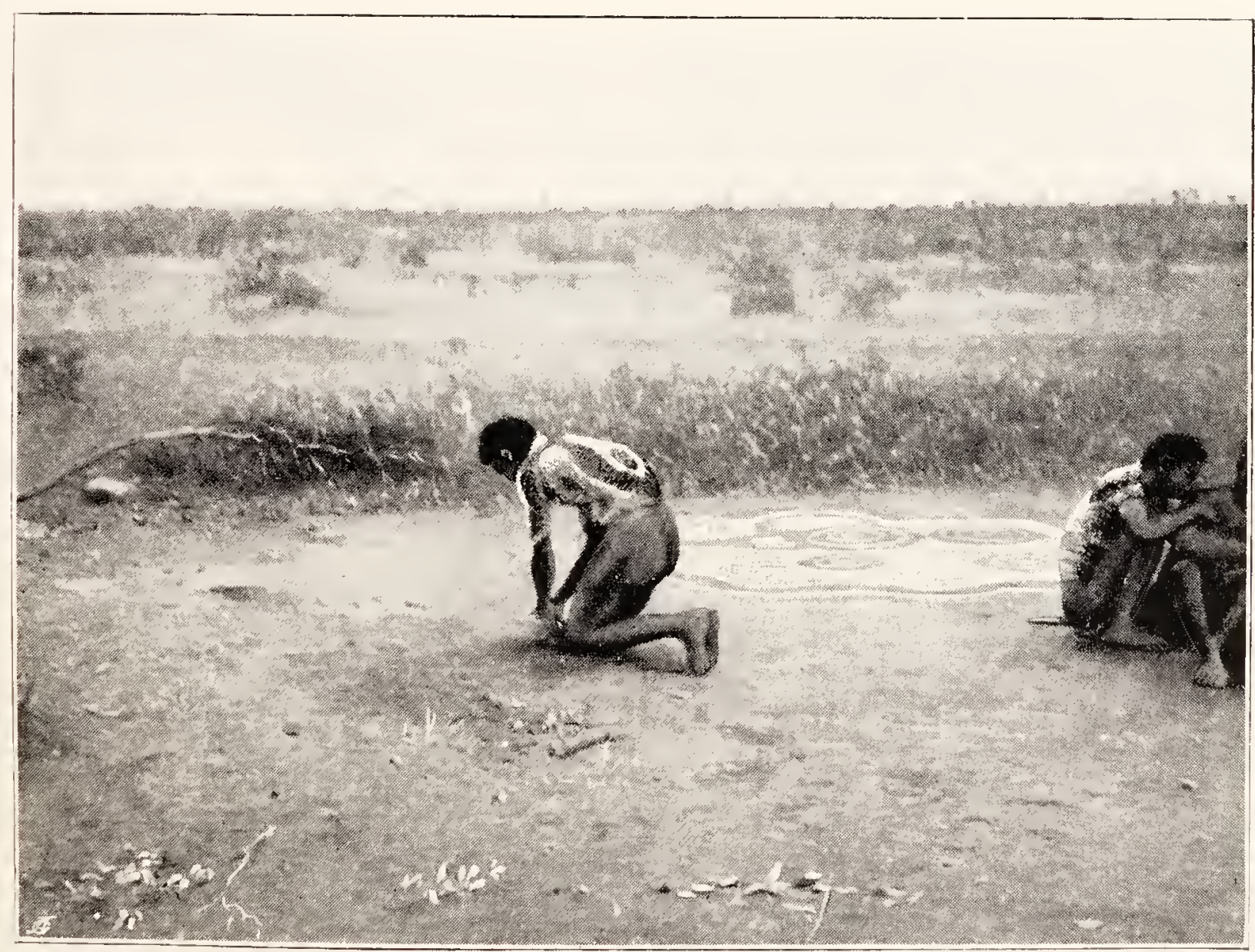

B.S.

FIG. 336.-FINAL BURIAL CEREMONIES.

Placing the bone in the ground and filling the little pit with earth. The ground design is the one that has just been used in the last Wollunqua ceremony to which totem the dead person belonged. 



\section{CHAPTER XXI}

STONE TOOLS OF AUSTRALIAN SAVAGES

So far as his implements are concerned, the Australian aboriginal has never emerged from the cultural level of men of the Stone Age. For making the tools with which he cuts and flakes, pounds, grinds and sews, he uses only stone, bone and wood.

His stone implements may be divided into two main series-(a) cutting and flaking, (b) grinding and pounding. So far as my experience goes, and this includes the tribes from Oodnadatta in the south to Darwin and Melville Island in the north, and from the Daly River on the west to the Gulf of Carpentaria on the east, women, with the rarest exception, neither make nor possess any cutting or flaking implement. The only exception that I know of is in the Warramunga tribe, amongst whom I found a few, but only very few, women in possession of a crudely-flaked stone knife, used mainly for skinning animals, and resembling curiously in form the stone implement usually described as "rostro-carinate." They possess neither knives, picks, adzes nor tomahawks. Of course, in the performance of their duties in camp, they use pounding or grinding stones, but these belong to the Mia-mia and its occupants generally, and not exclusively to any woman in the way in which knives and boomerangs belong to a man. The only implements that may be regarded as their private property are wooden yam or digging sticks, wooden fighting clubs, and, every now and then, little skewer-shaped bits of wood and bone that are used as awls and needles. That this is so is shown 
by the fact that you can secure a yam-stick or fighting club direct from a woman, but for everything else you must barter with the men.

A description of the stone tools amongst the Warramunga will give a good idea of those used by Australian aboriginals generally. It must always, however, be remembered that, owing to the system of barter that prevails amongst all tribes, natives in any one district will be found in possession of tools and other things that have been made by other people, living, it may even be, hundreds of miles away. It is interesting also to find that, apparently, no attempt is made by any tribe to copy for themselves any special form of tool or implement received from outside sources, even when the material necessary to make it lies to hand. If they do not secure it by barter, they simply do without it.

Cutting and flaking tools include two series-(a) ground axes and (b) flaked and chipped tools. In the camp at Tennant Creek there was one middle-aged man who was especially skilful in making ground stone axes and, while we were there, he spent a good deal of time in this occupation. At the present day, ground stone implements are much less common than flaked ones, because material suitable for making them is only found in relatively few spots in Central Australia, while quartzite-that can easily be flaked and chipped but not ground-is very widely distributed. In the Macdonnell Ranges there is a quarry where supplies of diorite, suitable for grinding, used to be obtained, but now the making of stone axes has ceased in this part. Amongst the more northern tribes, such as the Warramunga, they are still made, but it will not be many years before they disappear.

I watched the whole operation on several occasions. In each case a large rounded diorite pebble was used. First of all, while held in the hand, it was roughly chipped, by means of a lump of hard quartzite, to approximately the 
desired size and shape, as shown in Fig. 337, which represents, at this particular stage of its manufacture, one of the actual axes in process of making by the Warramunga native. This process occupied only a short time, but, though it looked simple enough, it really required much care, because a mistake in the cutting off of a flake might easily result in the removal of a part of the surface that was intended to form the cutting edge, whilst too hard a hit with the quartzite might break the stone in two. Unless the operator is an adept at his work, he is likely to spoil many pebbles before he is successful in making a single satisfactory axe. Every quarry where suitable stone is found is strewn around with such discarded attempts, which among Australian collections are known as "blanks."

When the preliminary flaking was over, then there followed the tedious process of levelling the surface. In some parts of Australia the general surface of the axe is left in a rough state and only the cutting edge is further treated, a smaller or larger, sometimes only a very small part, being ground and polished, but amongst the Central tribes it is usual to work more or less over the whole surface. For this purpose the operator took a small rounded pebble of quartzite and, hour after hour, for a day or two in succession, he patiently hammered, or rather pecked, unceasingly on the rough surface, each peck removing a minute fragment of the stone, until it was covered all over. with little dents and all the irregularities were smoothed down (Fig. 338). Of course the extent to which this is done varies considerably, but, in a well-made axe, the work is so thorough that all tracings of the first-made rough flaking are removed. The exact shape of the axe varies according to that of the original pebble: sometimes it is broad and flat, at others longer and narrower. When the pecking operation was complete, then followed the grinding and polishing (Fig. 339). For this purpose the man took one of the large flat 


\section{WANDERINGS IN WILD AUSTRALIA сн.}

blocks of sandstone, commonly known as a nardoo-stone, used for grinding grass-seed, nardoo or ochre. Squatting on the ground in the position easily and normally assumed by a native, but very difficult, and more or less painful to a white man, he took a small quantity of fine sand, strewed it over the surface of the grindstone and then, sprinkling a little water over it, began to rub the axe backwards and forwards, first on one side and then on the other. Every now and then he added more sand and water, holding the axe very carefully, so as to fashion two surfaces, meeting at and forming the cutting edge. This process occupied two days, during the whole of which time the man worked hard, evidently taking the keenest interest in what he was doing. Time, of course, is no object to the native, and hour after hour he patiently ground away until, at last, the axe was completed to his satisfaction. There is one feature of the uncontaminated native that struck me as revealing an interesting side-light on his outlook, in regard to anything that he makes- that is, anything that is supposed to conform to a general standard of workmanship, such as an axe or boomerang or pitchi. Whilst he is quite willing to part with the finished article, it is not by any means easy to induce him to part with it in a half-finished state. He does not like you to have it unless it has been finished to his satisfaction, so that it really represents his best work.

After the grinding was over there remained the hafting of the stone. To provide for this, the man cut from a gum tree a small, straight young stem, about three feet long and two inches in diameter, and split it in half along its length. Then he stripped the bark off one of the pieces and chipped away at the curved side with a sharp stone flake until it was of the desired thickness. In order to make it pliant, the middle part was placed over a slow fire consisting of a little heap of charcoal. It was continually removed from the fire and carefully tested to find out whether or no it could 


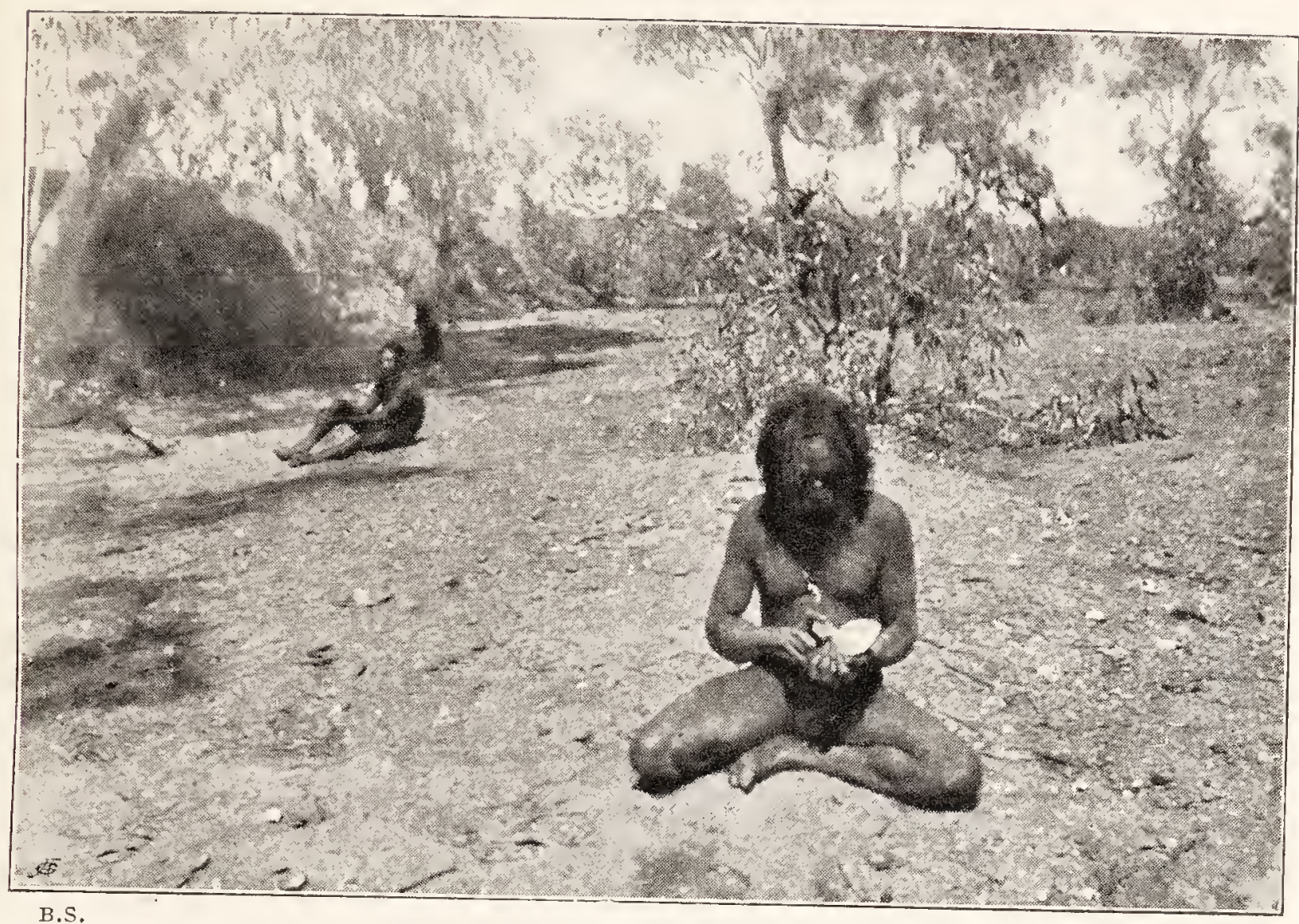

FIG. 338.-PECKING A BLOCK OF DIORITE PRIOR TO GRINDING IT DOWN TO FORM AN AXE-HEAD, WARRAMUNGA TRIBE.

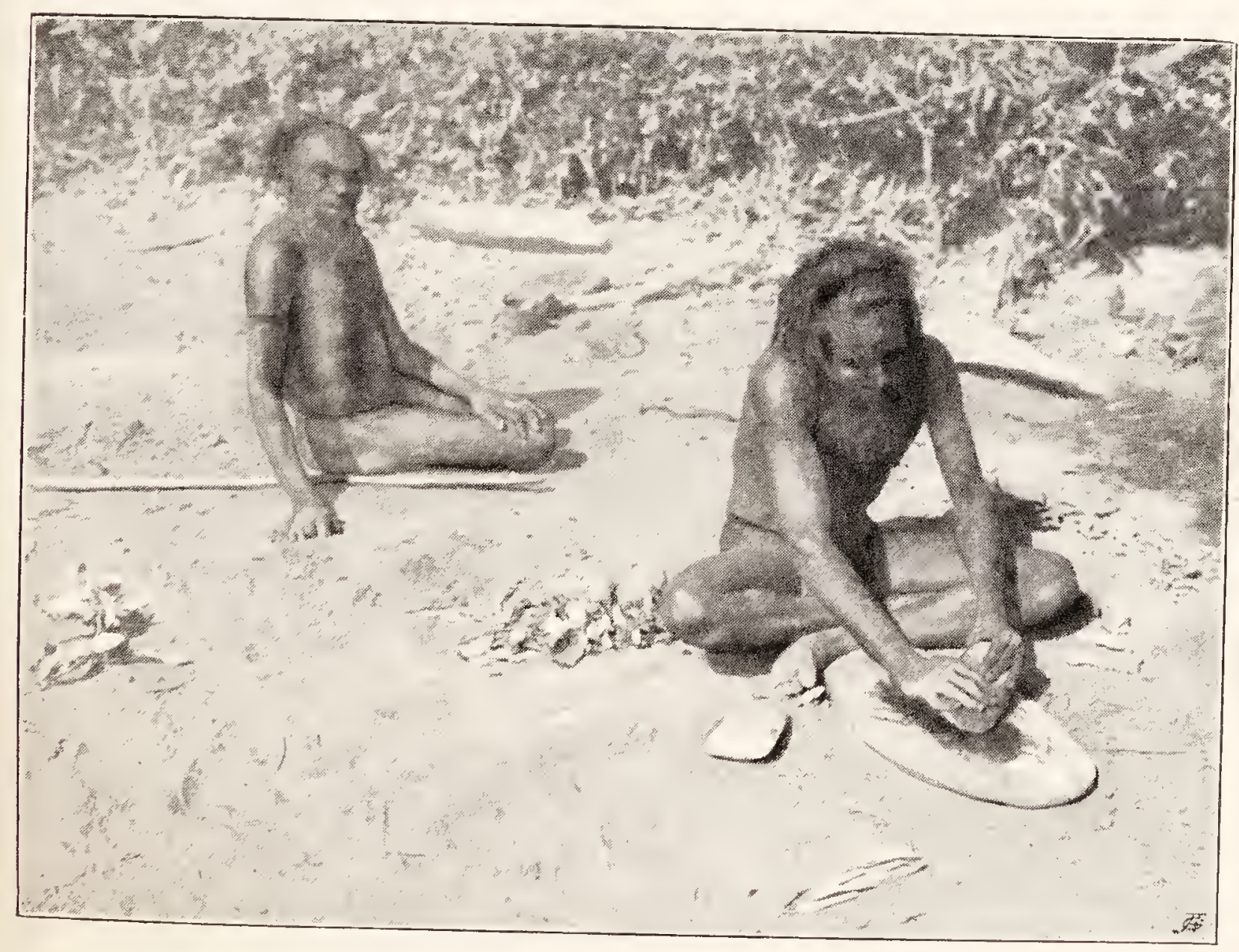

FIG. 339.-MAN GRINDING AN AXE-HEAD, WARRAMUNGA TRIBE.

A partially ground axe-head is lying besicle the grindstone. 


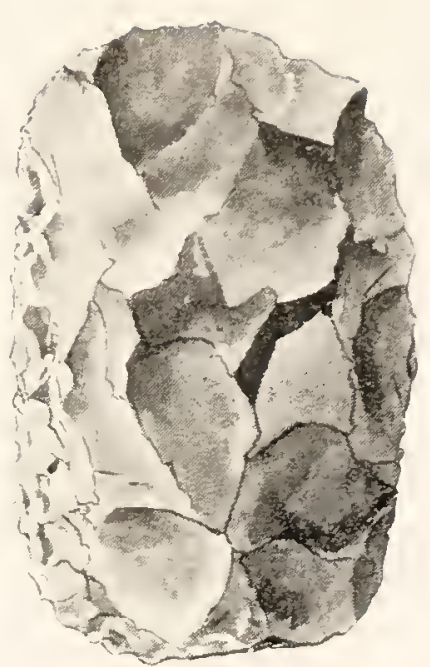

FIG. 337- BLOCK OF DIORITE, ROUGHLY CHIPPED INTO SHAPE, REA D Y TO B E FUR THER CHIPPED AND THEN GROUND TOFORM AN AXE-HEAD, IVARRAMUNGA TRIBE.

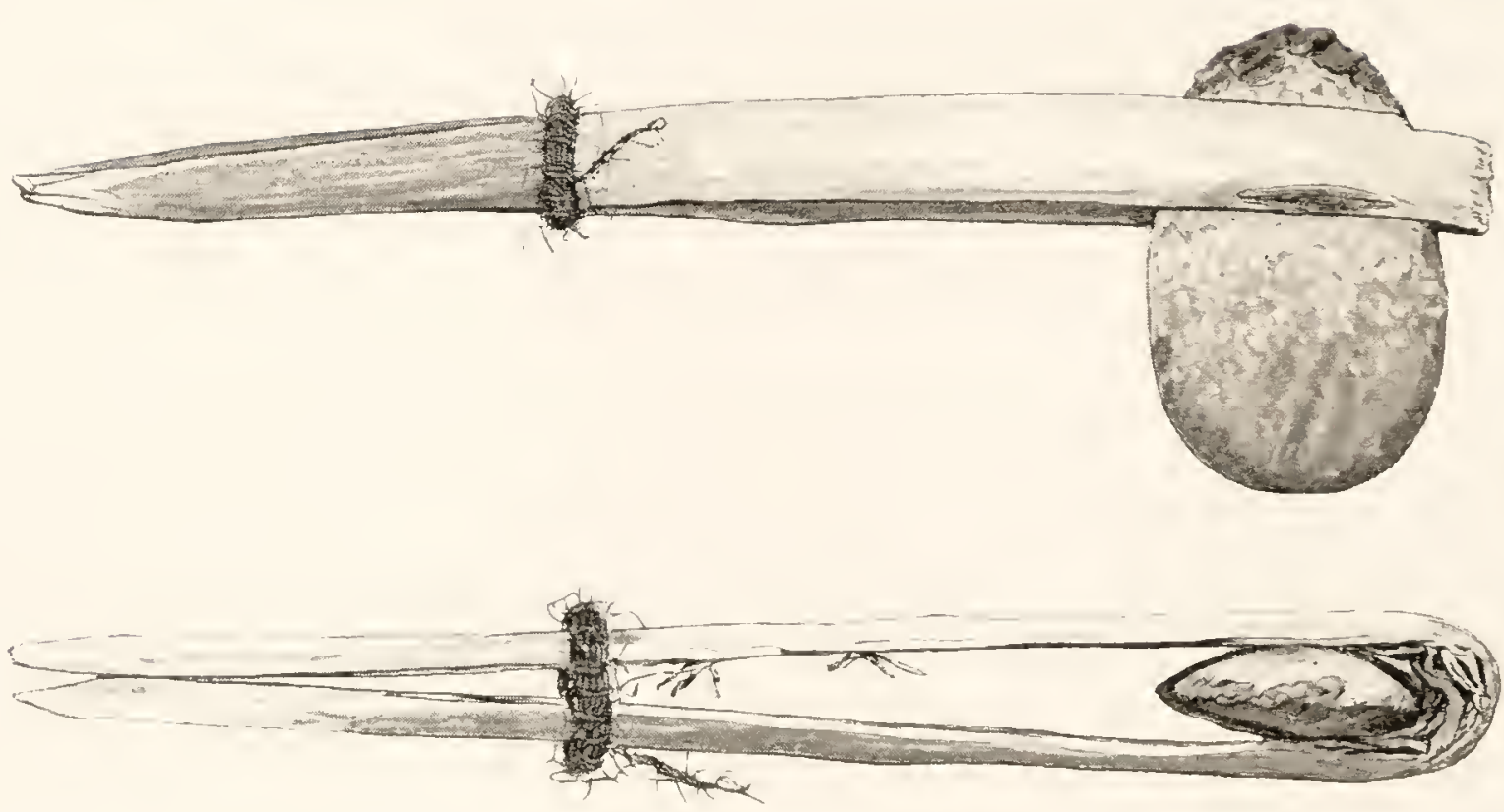

FIG. 340. METHOD OF HAFTING A GROLND AXE, WARRAMLNGA TRIBE.

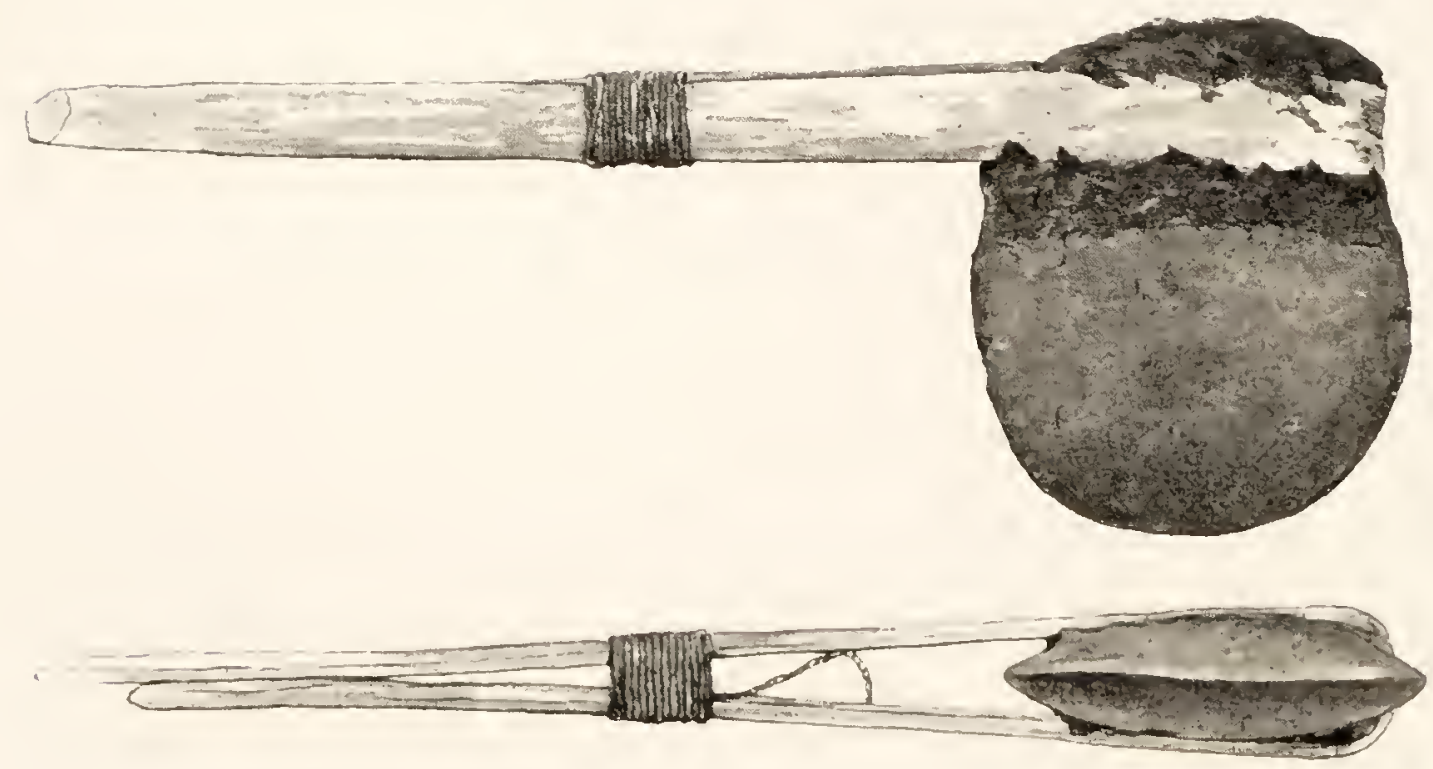

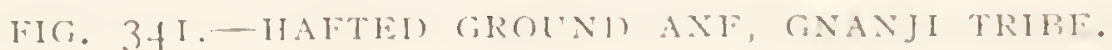


be bent in half without breaking. When this could be done with safety, it was very slowly bent double, round the blunt edge of the axe, and the two halves were tied together with a band of human hair or vegetable-fibre string (Figs. 340, 34. I). To help in fixing the stone in the withy, the enclosed end was encased in a resinous material obtained from porcupine grass. A lump of this was heated and, when soft enough, was pressed in between the withy and the stone. The resin rapidly hardened as it cooled, and its outer surface was smoothed down by means of a fire-stick which the operator passed slowly backwards and forwards over it (Fig. 342). The axe was now ready for use, but, to make it look better, some red ochre was ground, mixed with a little grease, and rubbed over the handle.

Ground axes of this kind are generally used for such purposes as cutting slabs of bark from gum trees, such as the bean tree, the wood of which is very soft and can easily be hollowed out and fashioned into more elaborate pitchis or shields. They are also used for cutting steps in the bark of trees, to enable a native to climb up the trunk and catch an opossum or other animal hiding in the hollow branch, or to secure what the natives call a "honey-bag." This is the honeycomb of the native bee that makes its rough hive in a hollow tree or bough.

The most unsatisfactory feature of the Central Australian axe is the method of hafting, and it is rather surprising that, in connection with this, the natives have not discovered the value of string or kangaroo sinew. For the purpose of splicing spears, or mending a broken spear-head or pitchi, they use a damp tendon which, when dry, shrinks and holds the broken parts together; but it never seems to have occurred to them that string or sinew would hold the axe-head securely in its place between the halves of the bent withy. As it is, the stone axe is at best a clumsy tool, because the resin is very brittle and cracks 
easily, so that a hard blow at once results in loosening the stone.

Of flaked and chipped implements there are six main types in use. The simplest ones are just ordinary and roughly-flaked stones, for use on the spur of the moment, when they are wanted for such a purpose as to smash a shell open or crack a bone to get at the marrow. These are left lying about on their camping places, most often by the side of water-holes, but they can also be picked up by the score near to any bed of quartzite from which the natives have been knocking pieces off for the making of knives. They are met with in such numbers that one often feels very doubtful as to whether any particular stone has been artificially shaped or owes its form to natural agencies. This is the case when, as in Central Australia, the flakes are met with in profusion, scattered over the ground, in country where the quartzite rock of which they are formed is met with everywhere. In other parts of Australia where similar roughly-shaped stones are found in places far away from any formation in which that special kind of stone exists, there can be no doubt as to their human origin. On Wilson's Promontory, for example, on the southern coast of Victoria, in the kitchen middens amongst the sand dunes, scores of such roughly-fashioned flakes can be picked up. The nearest formation in which such stones are found lies more than forty miles away, and from here they must have been brought years ago by the natives to break open the oysters, mussels and Turbos on which they fed (Fig. 343). The natives have long been extinct in these parts, leaving behind them their flints, ground axe heads and broken shells, piled up together in countless thousands.

There is every variation in size and form between their roughly-flaked, heavy stones, some of which measure three or four inches in width, and little delicate, sharp-pointed chips that can be used for cutting and scraping or for simple 


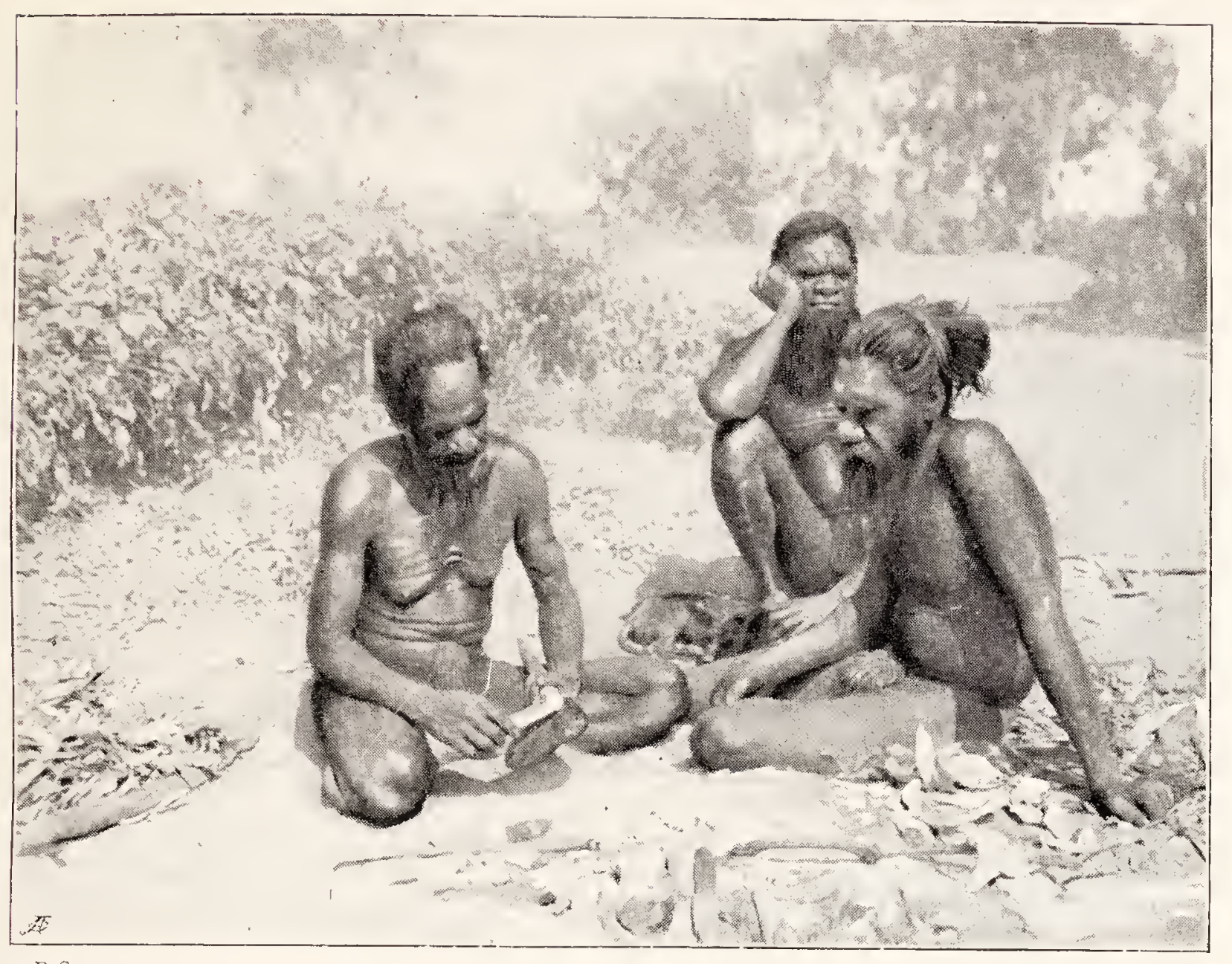

B.S.

FIG. 342.- FIXING THE AXE-HEAD ON TO THE HANDLE WITH RESIN, WARRAMUNGA TRIBE.

The man is applying a fire-stick to the resin to soften and mould it into shape.
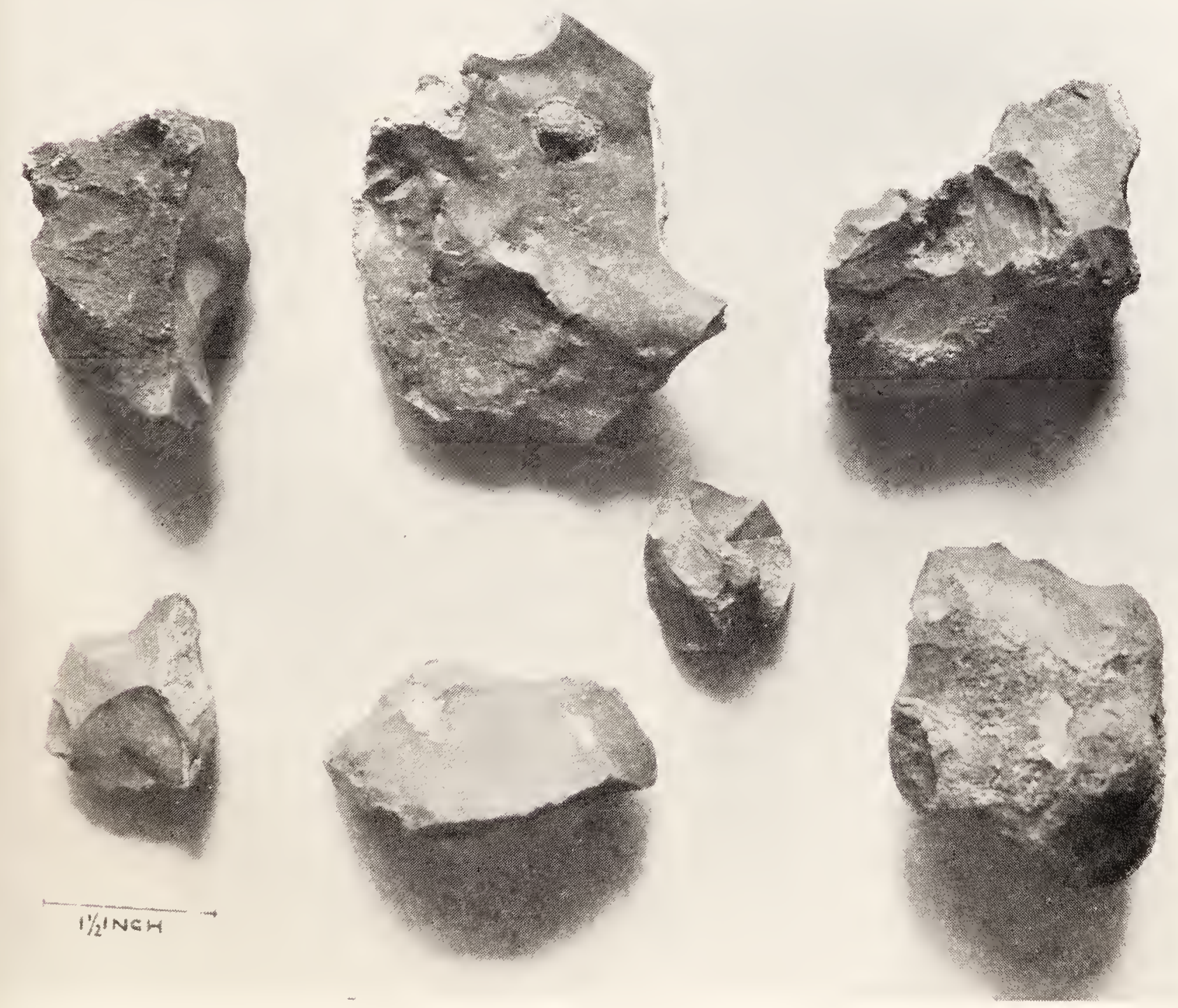

Fig. 343-- FLINTS FROM A KITCHEN MIDDEN. WILSON'S PROMONTORY, VICTORIA. 


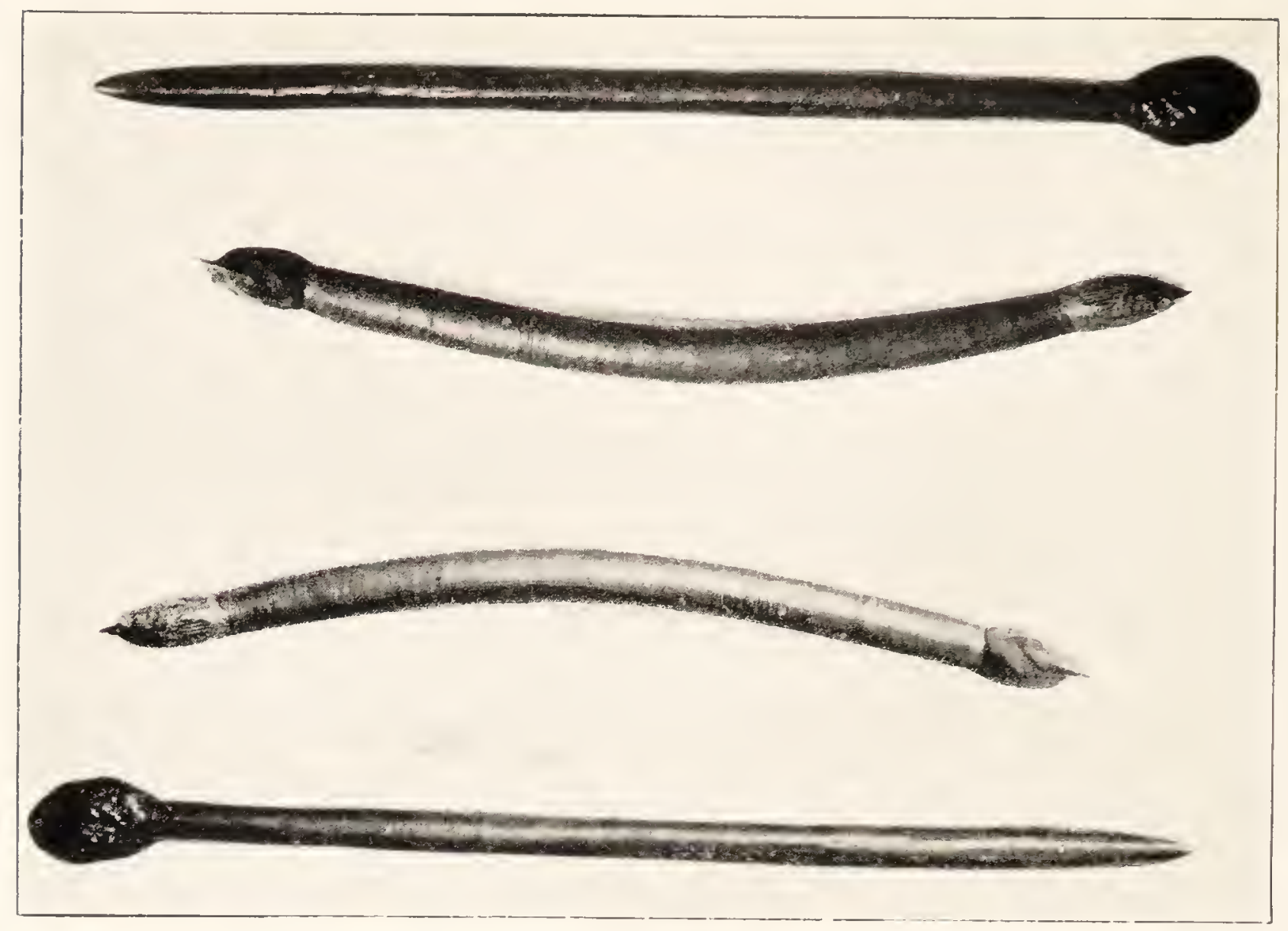

FIG. 344-CURVED AND STRAIGHT ADZES,

WARRAMUNGA TRIBE.
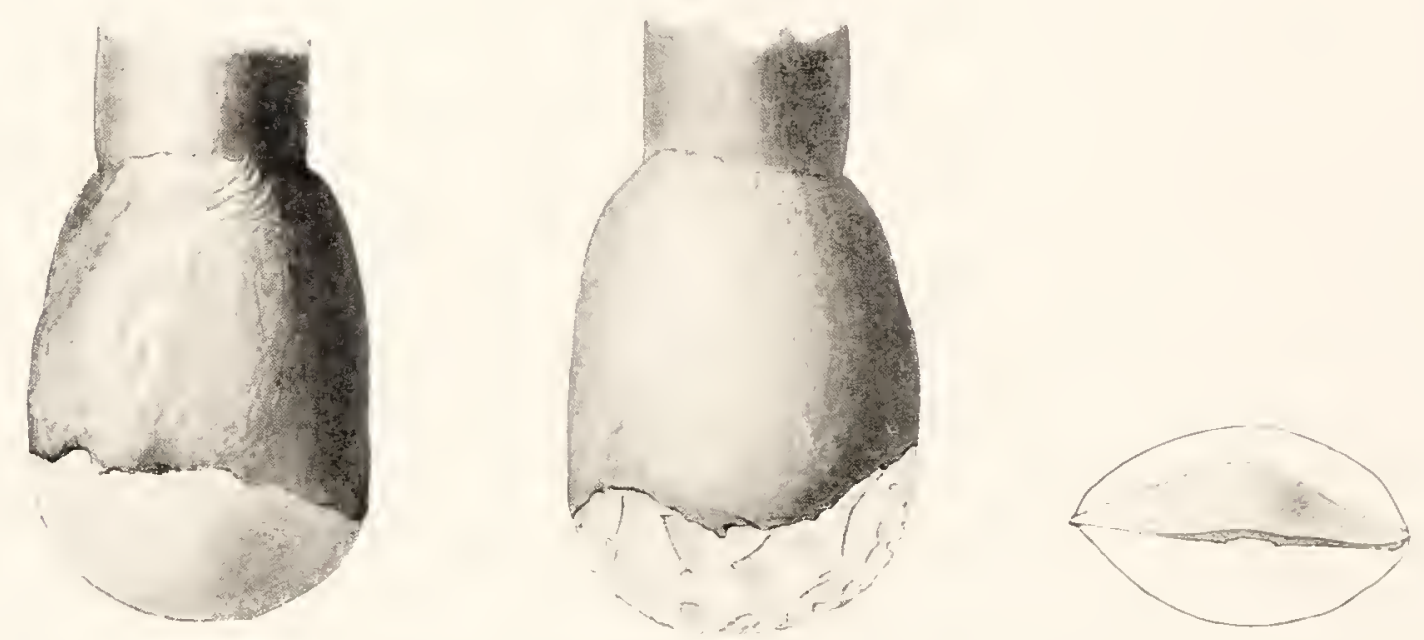

FIG. 345.- ADZE WITI LARGE FLINT ('SED FOR COARSER WORK, WARRAMUNGA TRIBE,
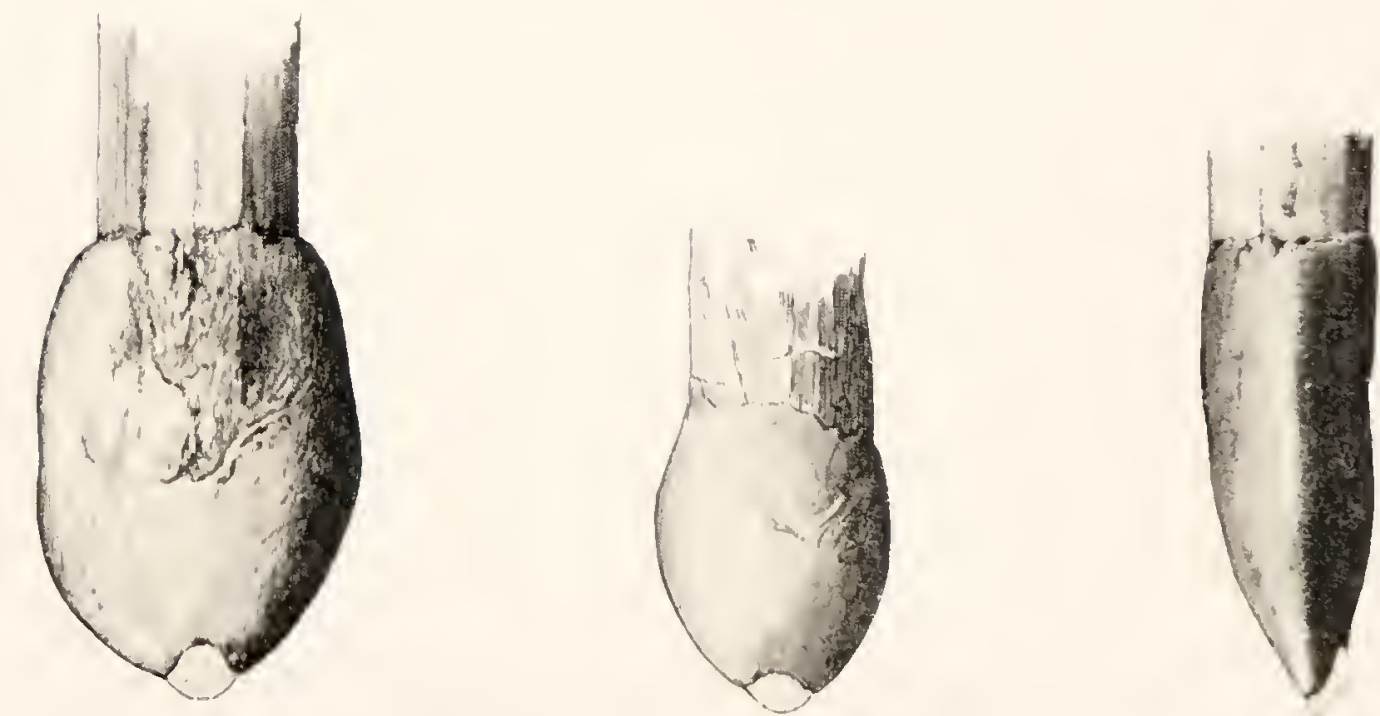

FIG. 3.40.-AH\%E, WHII SAALL, VERY REGULARLY SHALEL FLIAT,

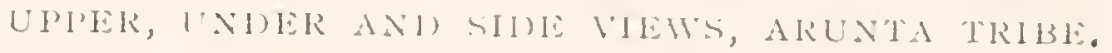


surgical work, such as pricking boils or cutting thorns out of flesh. These are very rarely hafted.

The second form may, from its shape and use, be best described as an adze (Fig. 344). It consists of a curved or a straight piece of heavy wood such as Mulga, to one or both ends of which a sharp-edged, close-grained opaline quartzite is fixed by means of porcupine grass and resin. The straight form never has the flake at both ends and is the typical form amongst the Arunta and Luritcha; the Warramunga and more northern form seems to be usually curved and has two flakes. This is a peculiarly Central Australian implement, its distribution extending across into the interior of West Australia and about as far northwards as Powell Creek. The flint varies very much in shape and size, but is typically plano-convex in section and has a convex cutting edge. One surface is always distinctly convex and is left perfectly smooth. When being made a block of suitable stone is held in one hand and struck with a short pebble of quartzite until a flake of the desired size is separated off. This flake is then held in the left hand, with the side on which is the conchoidal fracture turned away from the operator, who with another and smaller block of quartzite chips the surface nearest to him, so as to lessen the thickness of the flakes. Finally, he carefully chips the cutting edge into the desired shape, so that it is convex in outline, with a series of fine chippings that give it a more or less serrated appearance when examined closely. These secondary chippings on the edge vary, however, to a large extent in number and size. The ends of four adzes are drawn to show the more important variations in shape and size of the flints. Fig. 345 represents one with an especially large flint showing the very characteristic single facet forming one side. It shows also the secondary chipping on the opposite face and the convex outline of the cutting edge. Fig. 346 shows almost the opposite extreme 
in regard to size, the flint being remarkably small. An implement such as this is used for making the finer grooves on pitchis, while the former is used for rough work, such as the preliminary hollowing of a block of wood, or the making of wide, shallow grooves like those on the handles of picks and axes. Fig. 347 shows one of the intermediate size, not so carefully chipped as either of the first two. It is chipped almost to a point that is very useful in making fine grooves. Fig. 348 represents a distinct type. The flint is large, but the cutting edge, instead of being distinctly convex, is very slightly concave, and on one surface there are a good many secondary chippings, especially towards one side. A flint such as this is very serviceable in smoothing down the excrescences on the handle of a spear or adze.

Fig. 349 shows the way in which the adze is used. It is a snapshot of a man whom I came across one day in camp while he was busy making a pitchi. It was a curved adze and he held it in both hands, close to the end that he was using, with the concave side facing towards him. He held the pitchi firmly between his knees, two sticks stretched across within it preventing the pressure from bursting the sides in (Fig. 350). He spent hour after hour laboriously cutting a series of parallel grooves, each of them not more than an eighth of an inch in width and all of them cut with great regularity. It was only after a lot of persuasion that I could get him to part with the pitchi in its unfinished state.

The third, and perhaps most characteristic form of flaked stone implement, is the knife. In days gone by, every Central Australian aboriginal carried one of these with him, now they are only rarely met with and have become almost entirely superseded by the pocket-knife of the white man. However, when we were first among the Warramunga they were fairly abundant and, with the help of $\mathrm{Mr}$. Field at Tennant Creek, I was able to collect 250 of them, forming a really good representative series. 

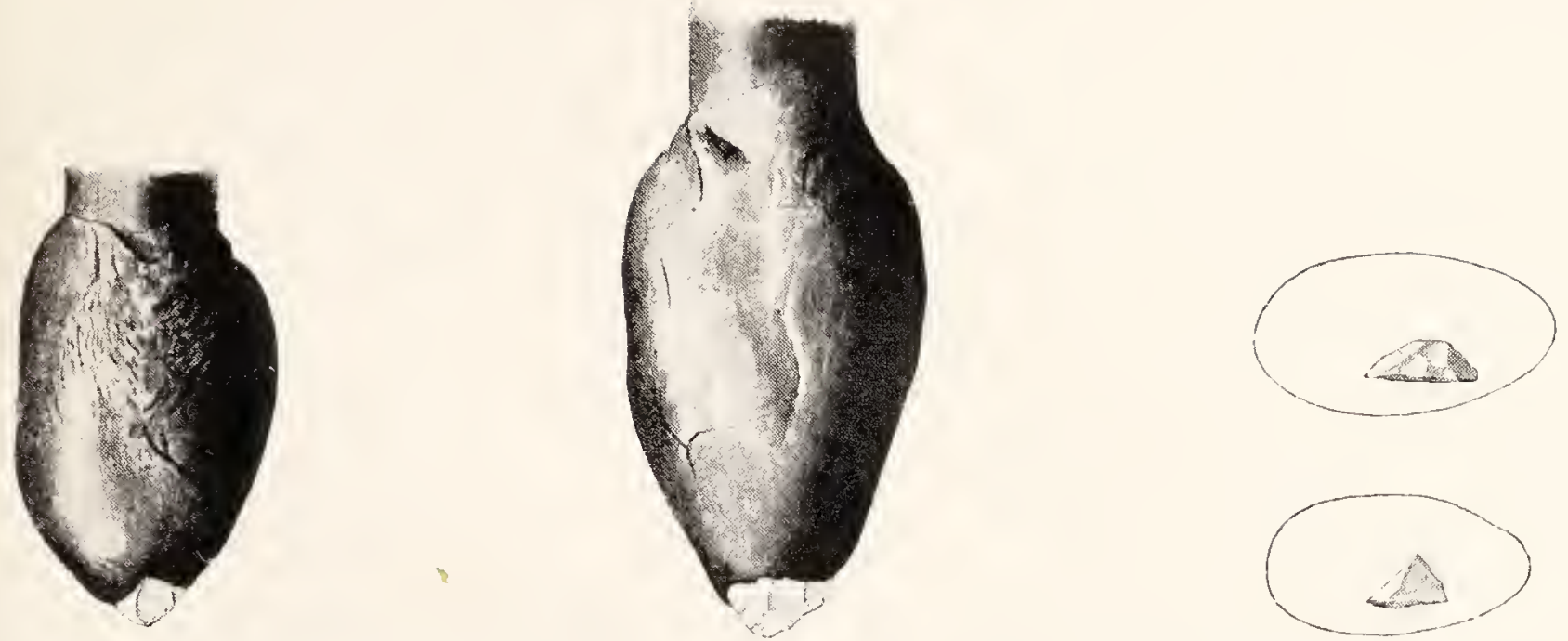

FIG. 347.--TWO ENDS OF AN ADZE, UPPER AND END VIEIVS, ARUNTA TRIBE.
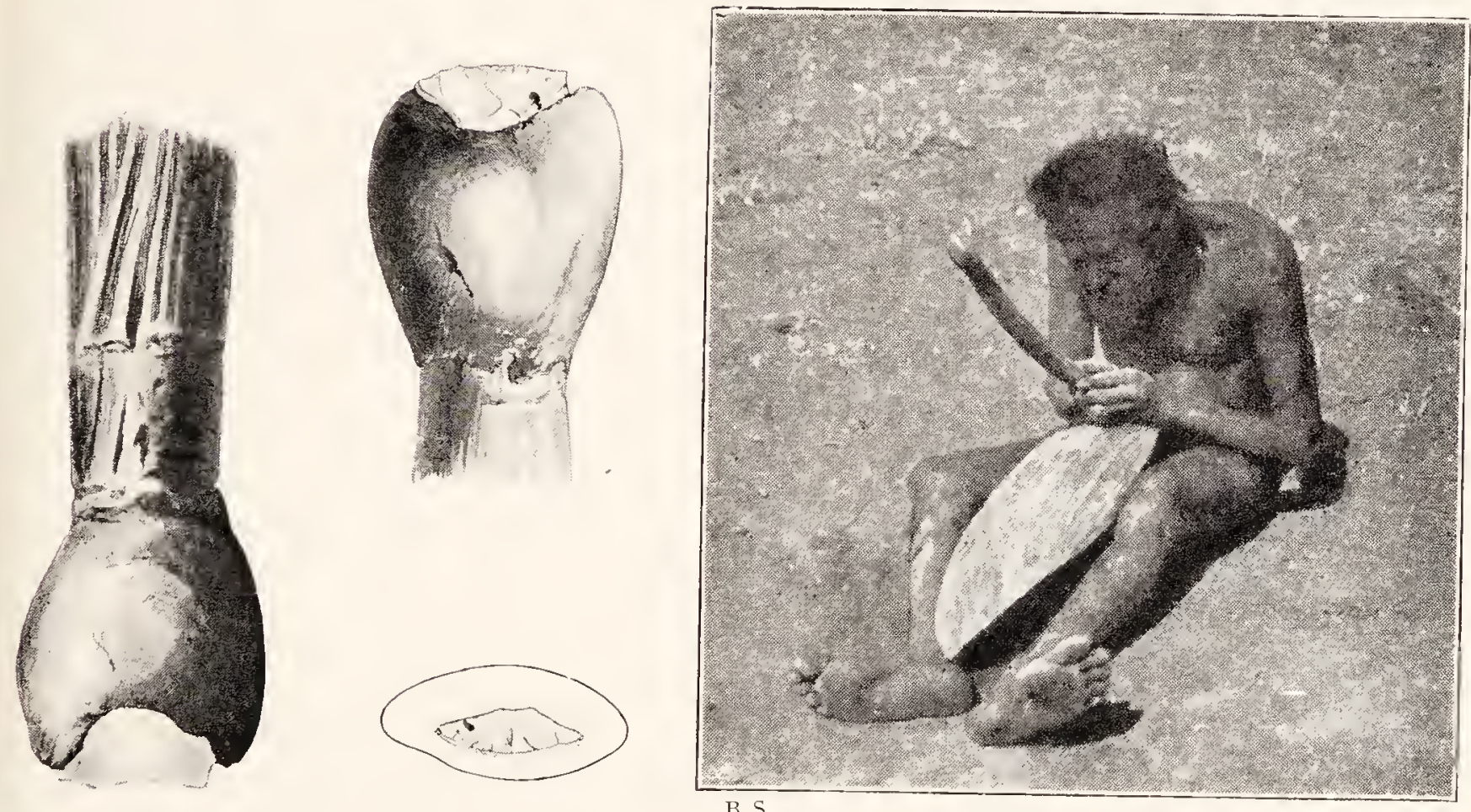

FIG. 348.-ADZE WITH LARGE, IRREGULAR-SHA PED FLINT, UPPER, UNDER AND END VIEWS, ARUNTA TRIBE.

FIG. 349.--MAN USING ADZE FOR MAKING THE GROVES ON THE OUTSIDE OF A PITCHI, WARRAMUNGA TRIBE.

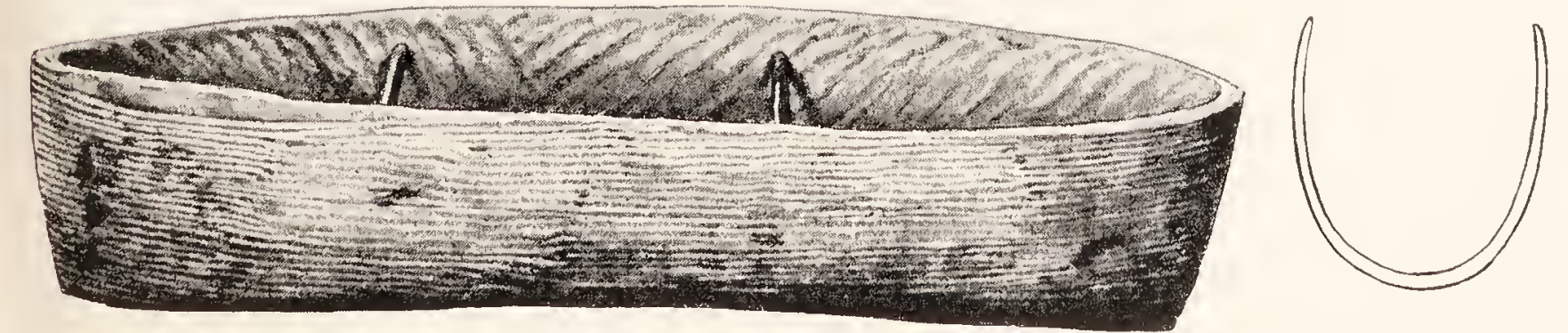

FIG. 350.-BOAT-SHAPED PITCHI. IN COURSE OF MAKING, SHOWING THE ADZE MARKS AND STICKS SUPPORTING THE SIDES, WARRAMUNGA TRIBE. 


$$
\frac{11}{19}
$$


They vary to a large extent in size, but are all fundamentally alike in form, any difference between them, except so far as secondary chipping is concerned, being due, not to deliberate design on the part of the maker, but to peculiarities in the nature of the material used, which varies in structure from a close-grained to a smooth, chalcedonised, opalescent quartzite. Each blade has three principal facets, a fourth, smaller one, being often present, though it may be hidden from view in the resin that forms the haft. In rare cases it may extend along the whole length of the blade. The shape of the blade varies much. Sometimes it is broad in proportion to its length, at others long and narrow; but apparently this is not a matter of design and depends entirely on the way in which the stone happens to flake. From the same block of quartzite a native will chip off broad, lanceolate, and narrow or elongated blades, and will use them indiscriminately so long as the points and edges are satisfactory.

The Warramunga and its northern neighbour the Tjingilli tribe are famed for their knives, which are traded far and wide among the Central tribes. Just within the southern boundary of the Warramunga country, at a spot called Renner's Springs, we came across a quarry that has been worked by the natives for many generations. The ground was strewn with endless discarded flakes, because, for every one considered good enough to use, there are at least a score thrown away as useless.

At this quarry we watched with much interest the process of manufacture as carried out by a Warramunga man. First of all he chose a lump of quartzite which measured roughly eight inches in length and six in diameter, the surface at one end being approximately flat, while the sides tapered away slightly towards the other. The latter was placed on the ground and then, holding the block upright with his left hand, he gave a series of sharp blows with a 


\section{WANDERINGS IN WILD AUSTRALIA ch.}

quartzite stone held in his right hand. The first two blows were on spots close together, just within the margin, each resulting in the detachment of a flake in such a way as to form two surfaces that ran down the face of the block and met towards the lower part. As a general rule, these two surfaces are not in contact along their whole length.

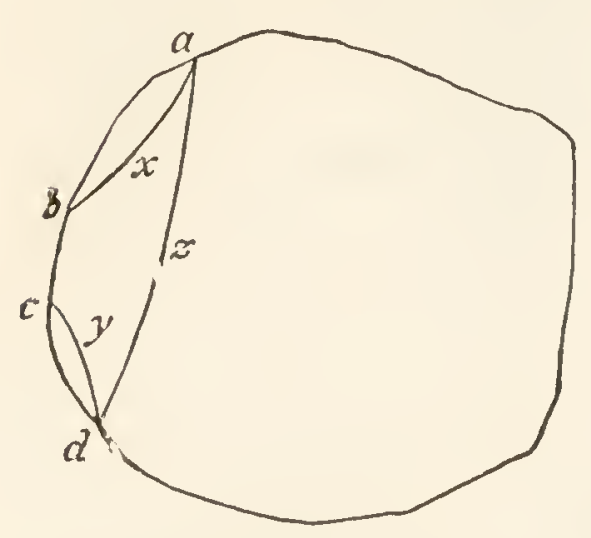

How far this is or is not the case depends simply on whether the first two flakes lie closely side by side or are separated from one another at their upper ends by a longer or shorter face, with the result that, when this is present, the blade where it occurs is

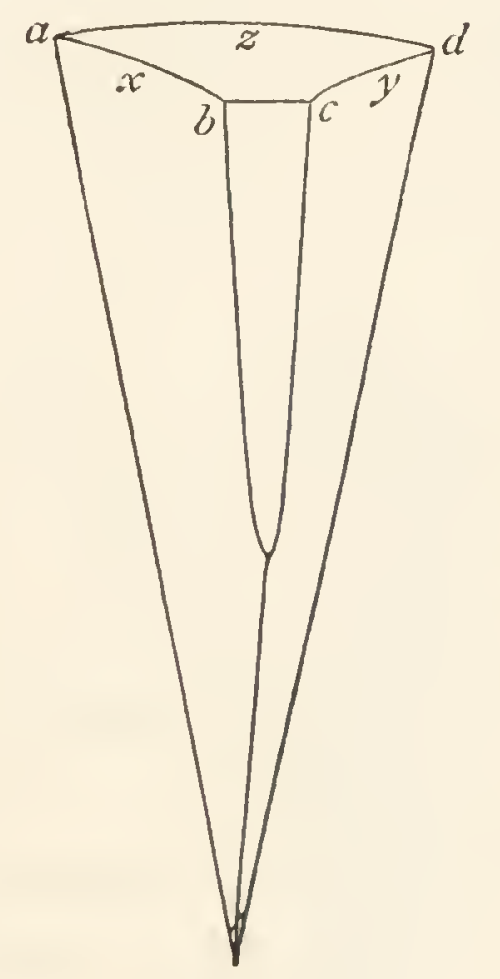

FIG. 35 I. tetragonal in section. The diagram (Fig. 35 I) shows what takes place when a successful flake is secured. The upper one represents the block seen from above, the lower one the knife-blade that has been flaked off from its side. The first two blows are made at spots marked $x$ and $y$, resulting, respectively, in flaking off chips lying between the points $a$ and $b$, and $c$ and $d$. The two surfaces thus formed meet below, but, at the upper end, are separated by the face lying between the points $b$ and $c$. It is simply a matter of chance whether the points $b$ and $c$ are confluent or more or less wide apart. By means of a third blow, on the point $z$, a flake like the one figured is separated from the block. The face of the main block from which the flake is struck may chance to have smaller surfaces more or less irregularly arranged, and one or more of these may be included, giving the flake an irregular shape, but so long as it has a good cutting edge it is used. Some idea of the 


$$
\frac{9}{9} \frac{9}{8}
$$




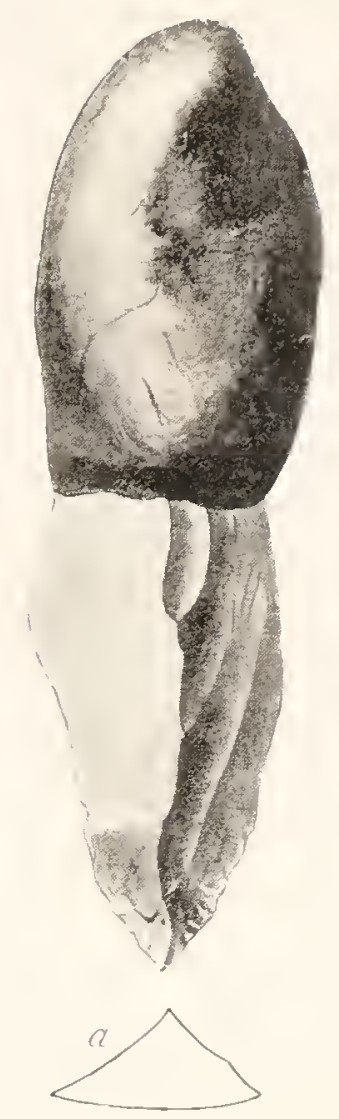

FIG. 360.-STONE KNIFE WITH IRREGULAR FLAKINGS AND SECONDARY CHIPPING ALI ROUND THE POINT, WARRAMIUNGA TRIBE.

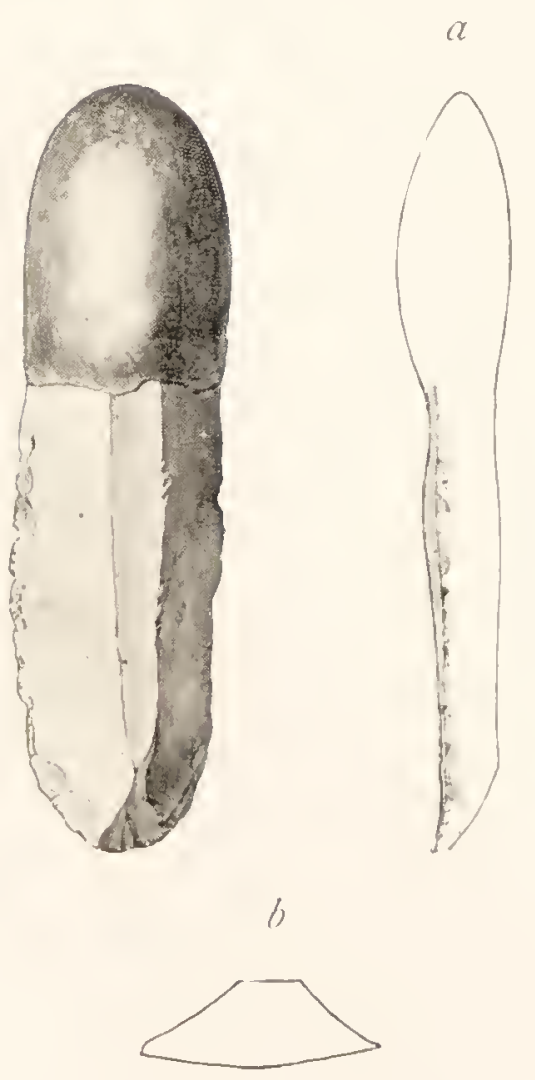

FIG. 362.-WOMAN'S STONE KNIFE, WARRAMUNGA TRIBE.
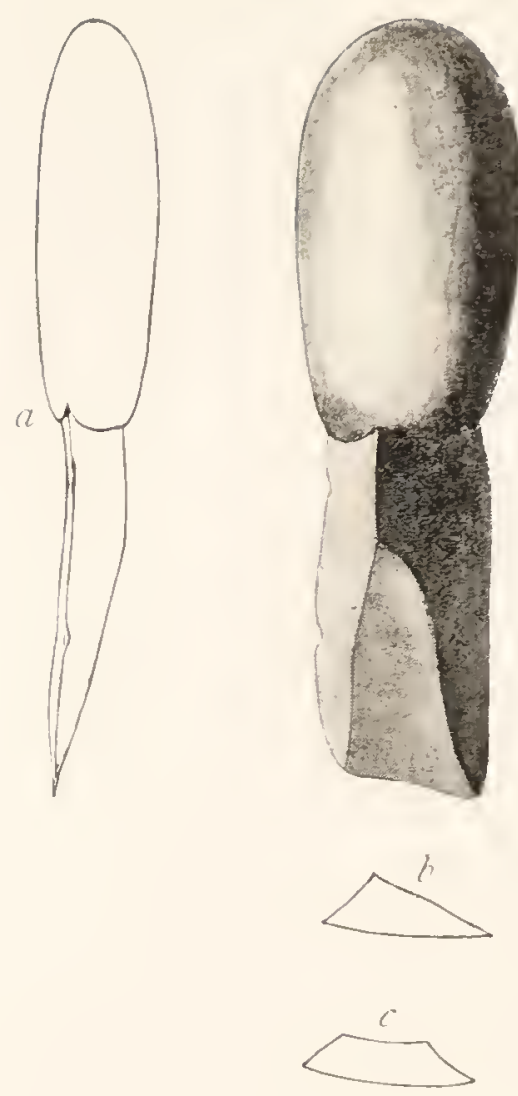

FIG. 36I. STONE TNIFE WITH FLINT BLADE, WITH FOLR FACETS, THE FOLRTH FORMING A BROAD TERMINAL CUTTING EDGE, ARUNTA TRIBE.
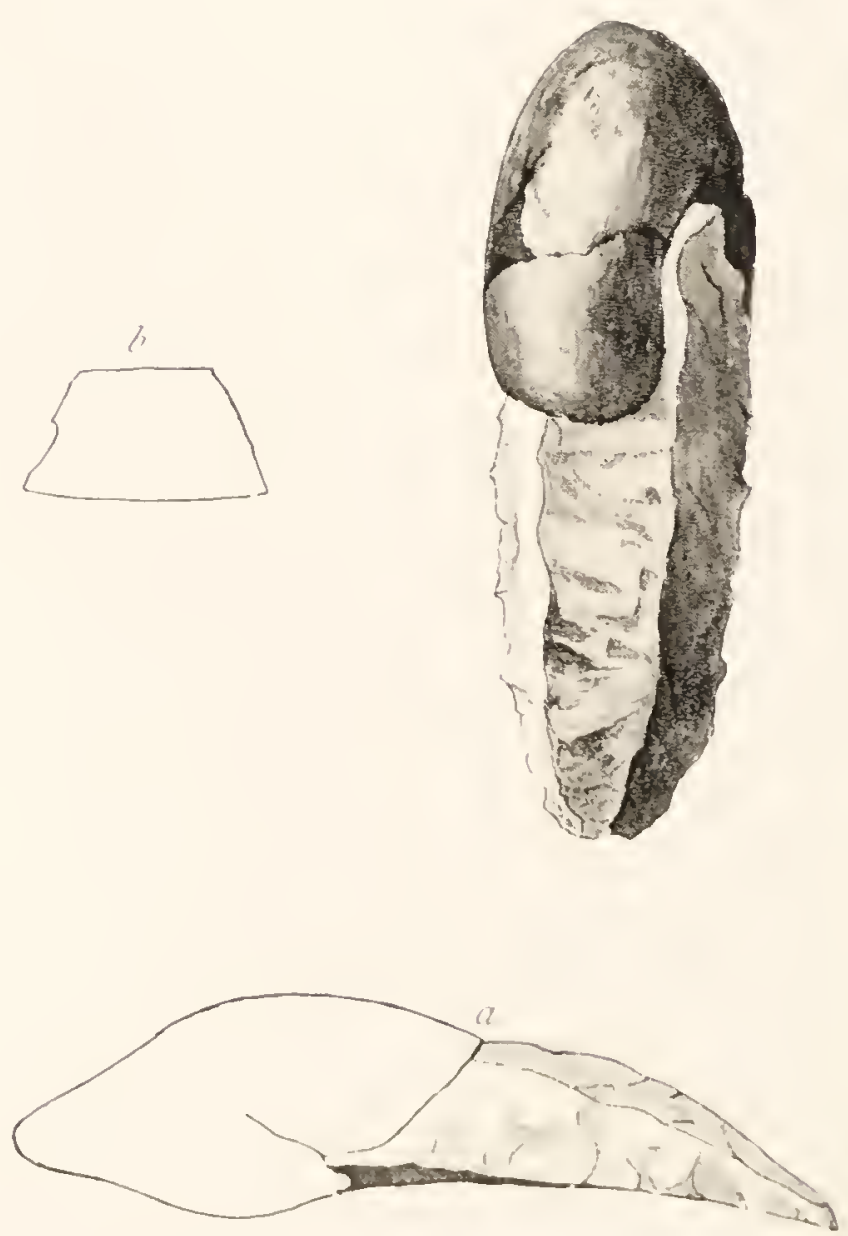

Fili. 303.- WOMAN"S STONE KNIF，WARAMUGA TRIBL. 
principal variations in form may be gathered from the drawing of the series represented in Figs. $352-70$, but it must be remembered that the shape of the blade, as finally produced, is largely a matter of chance. Sometimes, as in Fig. 360, the point and, to a certain extent, the sides may show a series of secondary chippings, foreshadowing the beautifully chipped spear-heads of the north-west natives.

So far as the hafting is concerned, there are two very distinct kinds. The simpler knives have only a rounded knob of porcupine-grass resin; the more ornate ones have a flattened mass of resin into which, at one end, the blade is fixed and, at the other, a small, flat slab of wood that is always ornamented with a pattern of lines and dots in yellow, white and black, the resin being always red-ochred (Figs. $366-70)$.

There is one special kind of knife that we only saw in use amongst the women of the Warramunga and Kaitisha tribes, though, of course, it is quite possible that it may be more widely distributed. It has a short, stout and usually very rudely-flaked blade of quartzite, calling to mind in its general appearance the better class of stone implements used by the lost Tasmanian race, except that it is hafted with a small mass of porcupine-grass resin. It is, really, only a very rude flake with a large number of irregular conchoidal facets, chipped in such a way that a fairly good cutting edge is produced, though, as a general rule, it is more useful as a scraper than as a true cutting implement (Figs. 362, 363, 364). Possibly this may represent the original principal form of stone knife used amongst the early ancestors and now lingering on amongst the women, who are never allowed to possess the better flaked forms.

Perhaps the most striking feature in regard to the various stone implements now in everyday use amongst the Central tribes, viewing them as a whole, is that, if they had lived in Prehistoric days, as did the old Stone Age people in Europe, VOL. II. 


\section{WANDERINGS IN WILD AUSTRALIA сн.}

giving place, later on, to others who had reached a higher state of culture, we should find, amongst their remains, flakes as crude as those of the Tasmanians, chipped and flaked knives and spear-heads of Palæolithic form and, side by side with these, ground axes of Neolithic form.

The only remnants that they could leave behind them would have been their stone and bone implements and crude drawings, pencilled in charcoal, pipe clay and ochre, on the walls of shallow caves and rock shelters, in the shade of which they passed their idle hours, cooked and ate their food and slept.

All that we know of the culture of Prehistoric Stone Age people in other parts of the world is of necessity confined to stone and bone implements, rock paintings and carvings that they left behind them. Save a few of their skeletons, everything else has vanished, but we shall probably not be far from right in picturing them as leading very much the same life as the Australian savage does at the present day. Like the latter they were probably segregated in local groups, each with its main camp, in which centred the life of the group, placed in some favourable position for food, water supply, shelter and protection from attack. We may picture them going out daily, as the Central Australians now do, the men to hunt the larger animals, the women and children in search of smaller ones and vegetable foodall returning to spend the evenings round their camp fires or on the dancing ground, common to all the members of the camp, men, women and children. Away from the main camp, hidden from the view of women and children, there would be, if one may judge from what is never wanting amongst the present-day Stone Age people in Australia, a sacred ceremonial ground, where only the old men of the tribe gathered, at certain times, to perform sacred ceremonies connected with myths and beliefs that are very real to them and play so large a part in the actual life of the community. 

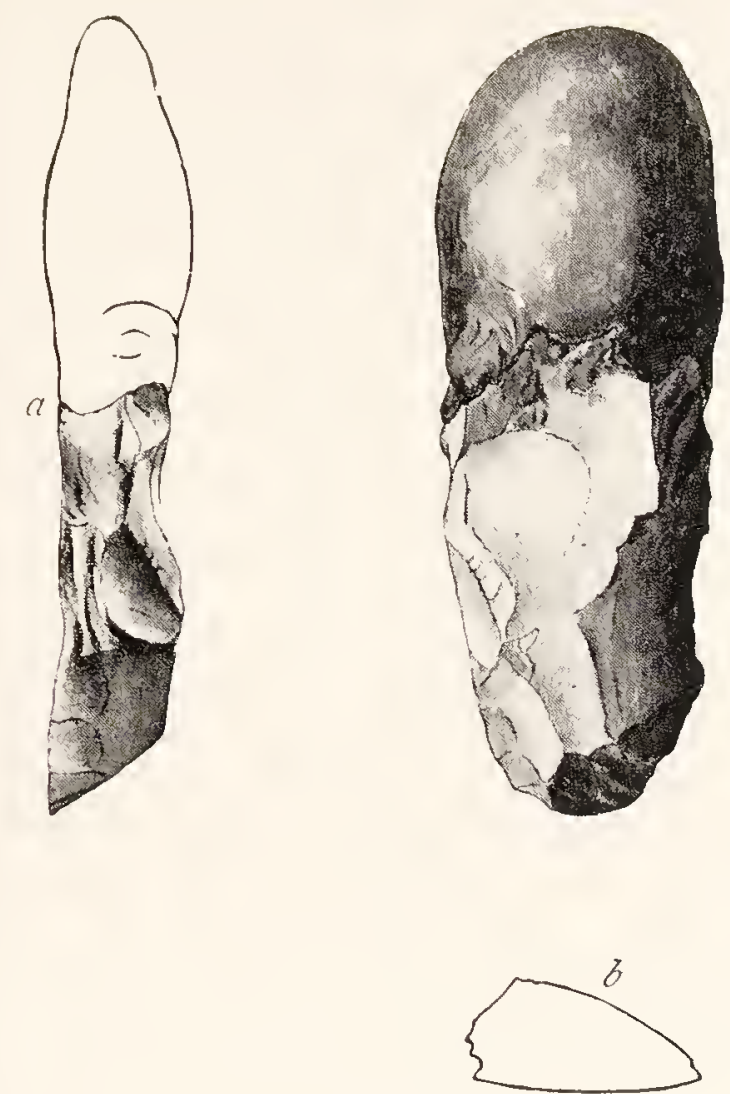

FIG. 364.-WOMAN'S STONE KNIFE, WARRAMUNGA TRIBE.
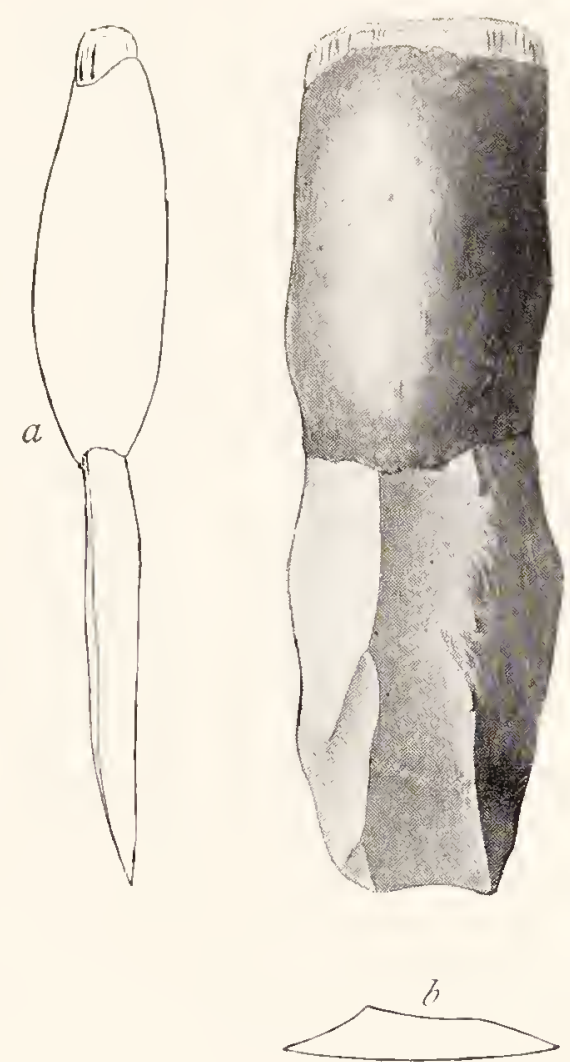

FIG. 365.- STONE KNIFE WITH VERY SHORT WOODEN HAFT, WARRAMUNGA TRIBE.

The blade is very irregularly flaked, a broad facet extending to the end and forming a cutting edge.
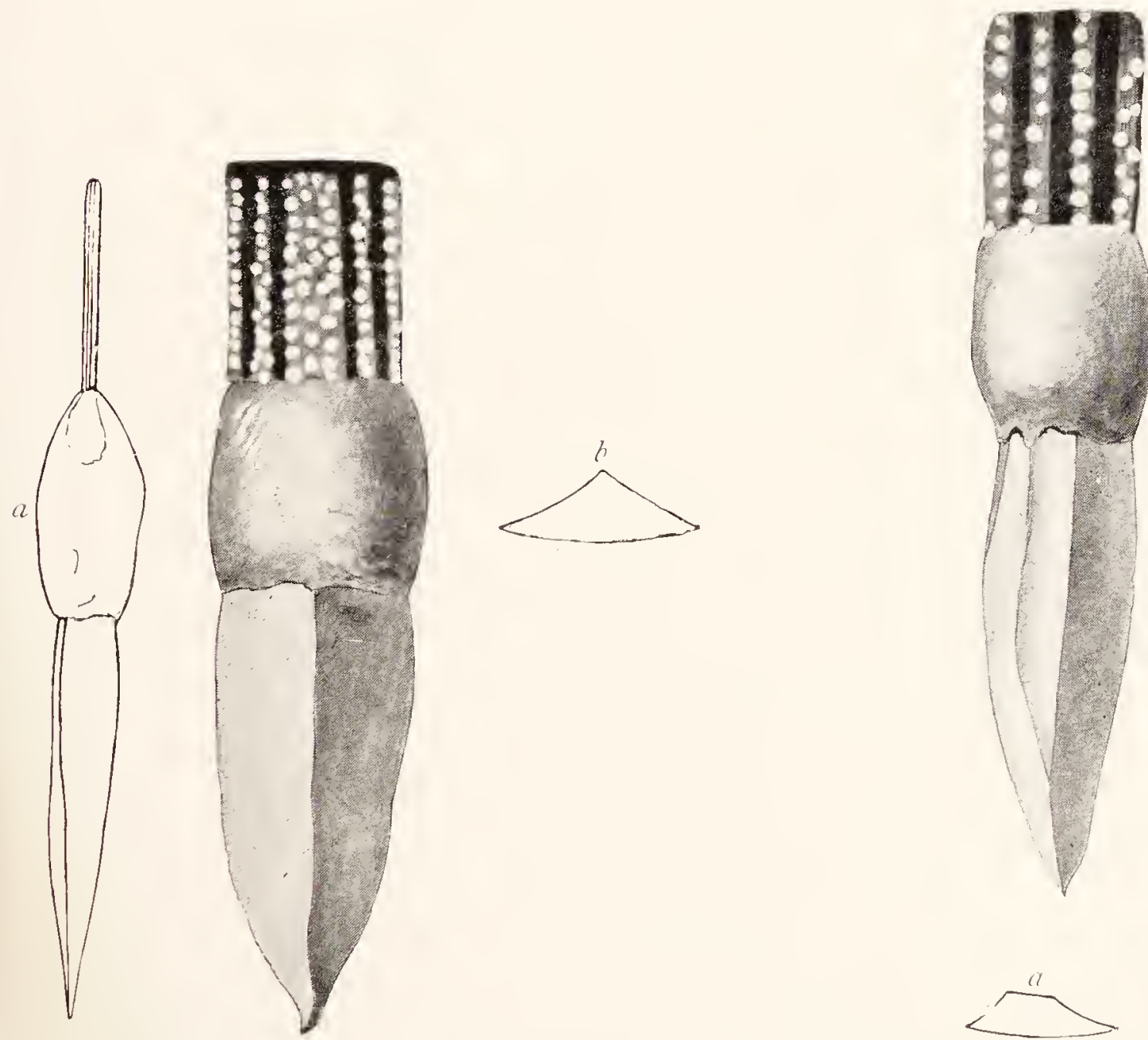

FIG. 366.-WOODEN-HAFTED STONE KNIEE WITH VERY REGULARLY FLAKED QUARTZITE BLADE, WARRAMUNGA TRIBE.

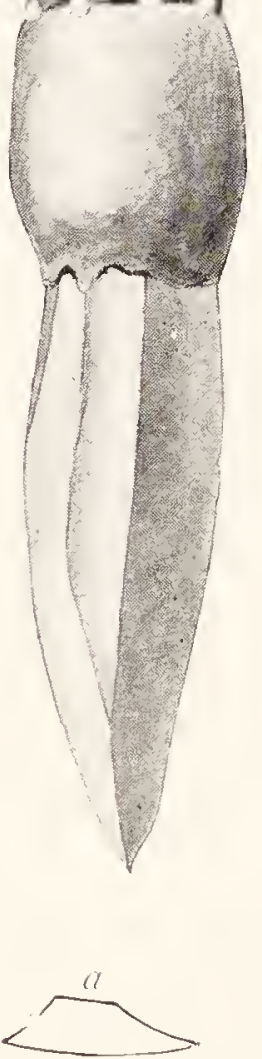

FIG. 367.-WOODEN-HAFTED STONE KNIFE, WITH FOUR FACETS, IVARRAMUNGA TRIBE. 

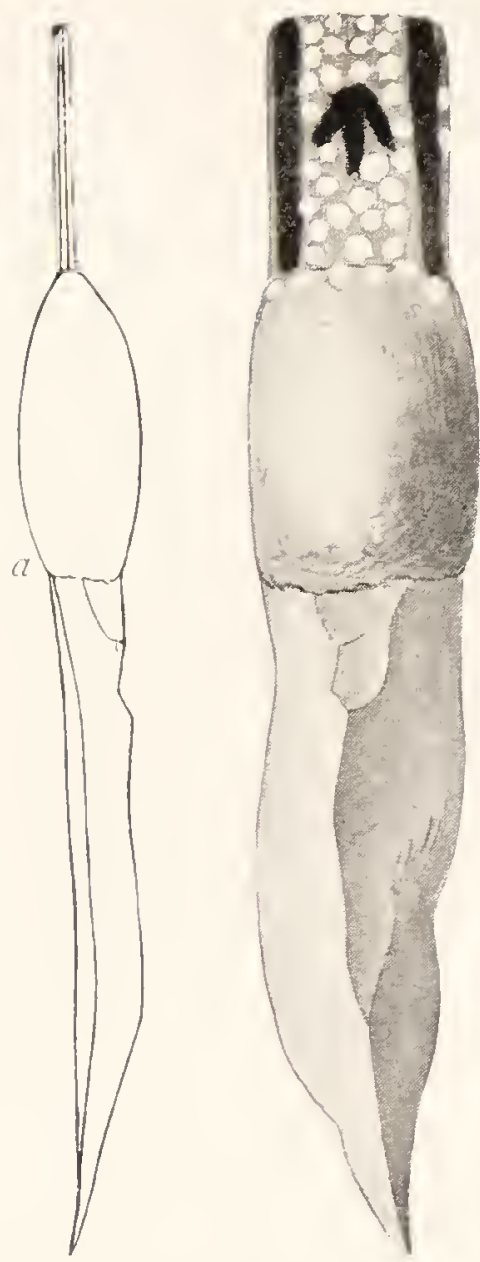

FIG. 36S.-WOODEN-IIAFTED STONE KNIFE, WARRAMUNGA TRIBE.

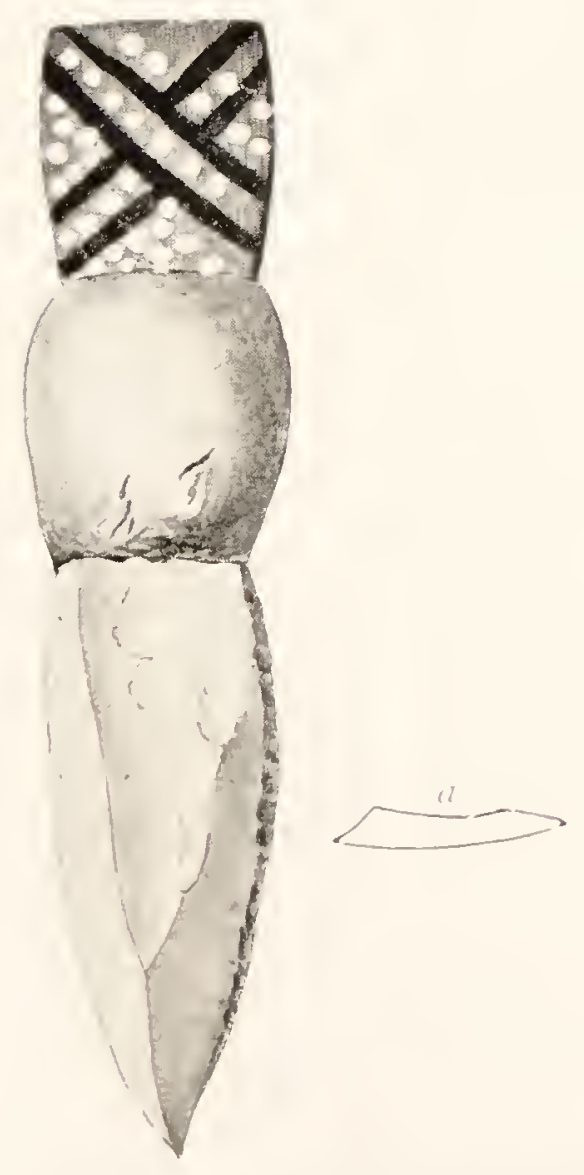

FIC. 370. WOOHI:N-11.17T1:1 STONE KNIFIE SIIOUING SECONIART CHII'INGS, WARRAMUXCi.) TRIIE.

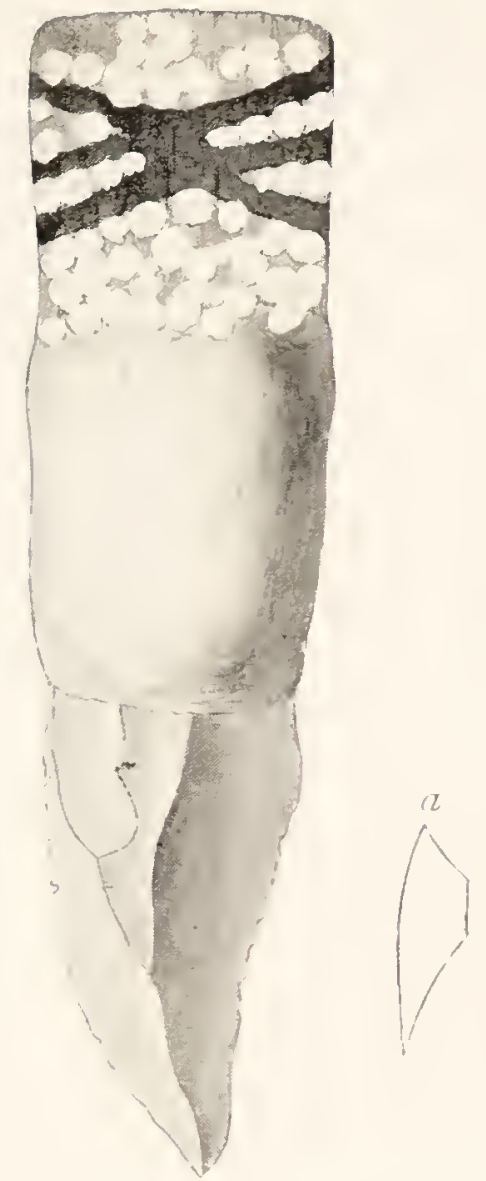

FIG. 369. -WOODEN-HAFTED STONE KNIFE WITH IRREGLLAR FLAKING AND THE BLADE SMALL IN COMPARISON TO THE IIANDLE.

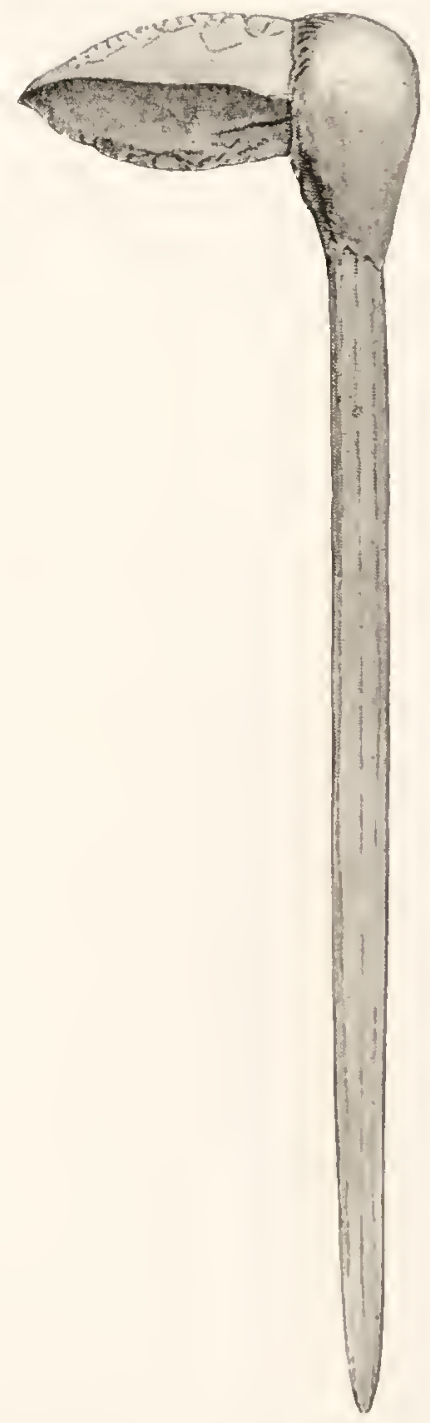

FIC, 372.—PICK WITH THI: STUN1: HEA1) IXSLRTEL IN

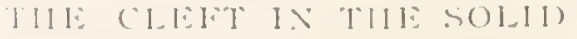
IIANIIE, W.IRRAMIXNG '1 li1:1:. 
For long ages Australia has been isolated from the outside world. Wherever they came from, its original inhabitants were early Stone Age people. Whatever contact they may have had at later periods with the outside world there were certainly two main original waves of immigration. The first was that of the curly-haired people, with only the most primitive of stone implements. They may have come in either from the north or the south, at all events they came when the configuration of the continent was different from that of the present day, and when what is now the island of Tasmania was a southern prolongation of the mainland, extending also further towards Antarctic lands than it does now. If these people came across from an American continent by way of Antarctica, as certainly many of the earlier primitive marsupials and probably, before them, the ancestors of Platypus and Echidna did, then they gradually spread northwards. On the other hand, they may have come in from northern lands, entering the continent on its north-western or north-eastern borders, and gradually spread southwards. According to some authorities they came by way of a land bridge extending across the Indian Ocean, according to others by one coming down through what is now Malaysia, whilst others call in the aid of a bridge across the Pacific. By whatever way they came, this second immigration, or perhaps more than one immigration, spread over the continent in waves. One main one probably spread down the eastern side and another, dividing into two, down the centre and western side. Each wave drove before it and, in all likelihood, exterminated as it did so the old and lowly cultured, curly-haired people. Meanwhile Bass Strait had encroached upon the sinking south-east corner of the continent, cutting off Tasmania with its remnant of the earlier people. The later comers had evidently no boats fit for battling against the winds and currents of Bass Strait and of carrying them over to the 


\section{WANDERINGS IN WILD AUSTRALIA ch.}

Island, so there the early Palæolithic men remained and lived in safety, until, unfortunately for them, the white man found the island and wiped them out of existence. So effectually was this done that, apart from their crude stone implements, a few wooden ones, a small number of skulls and skeletons, and a few more or less fanciful drawings in the books of explorers, we know nothing about them. Of their customs, organisation and beliefs our ignorance is total.

If it had not been for the isolation of Australia, we should know nothing of the lowest forms of mammals except their skeletons, and so, just in the same way, we should know nothing, or next to nothing, of the manner of life of primitive communities of human beings now represented by the Australian aboriginal.

Amongst the Warramunga we sometimes came across a fourth kind of flaked stone implement, in the form of a curious pick-like axe, which, however, though not common anywhere, is not confined to this tribe. Its native name is Kulungu, and it consists of a flaked stone precisely similar to the one used as a knife (Figs. 37 I, 372). It is hafted in one of two ways. The first method consists in fixing it in the cleft end of a stick about sixteen inches or two feet long, which is then enclosed in a lump of resin. A second method is to enclose it in exactly the same way as in the case of a ground stone axe.

Now as to the use of these flaked knives and picks. In the first place, the nature of the stone out of which they are made renders them entirely unfitted for cutting hard material, such as wood. They can only be of much service for cutting flesh and it is, in reality, for this purpose that they are made. They are well adapted, that is, the knives are, for cutting through the skin and flesh of animals, such as wallabies, kangaroos and emus, on which the native feeds. In addition to this, they are constantly used during fights and in ceremonies, such as those in connection with 

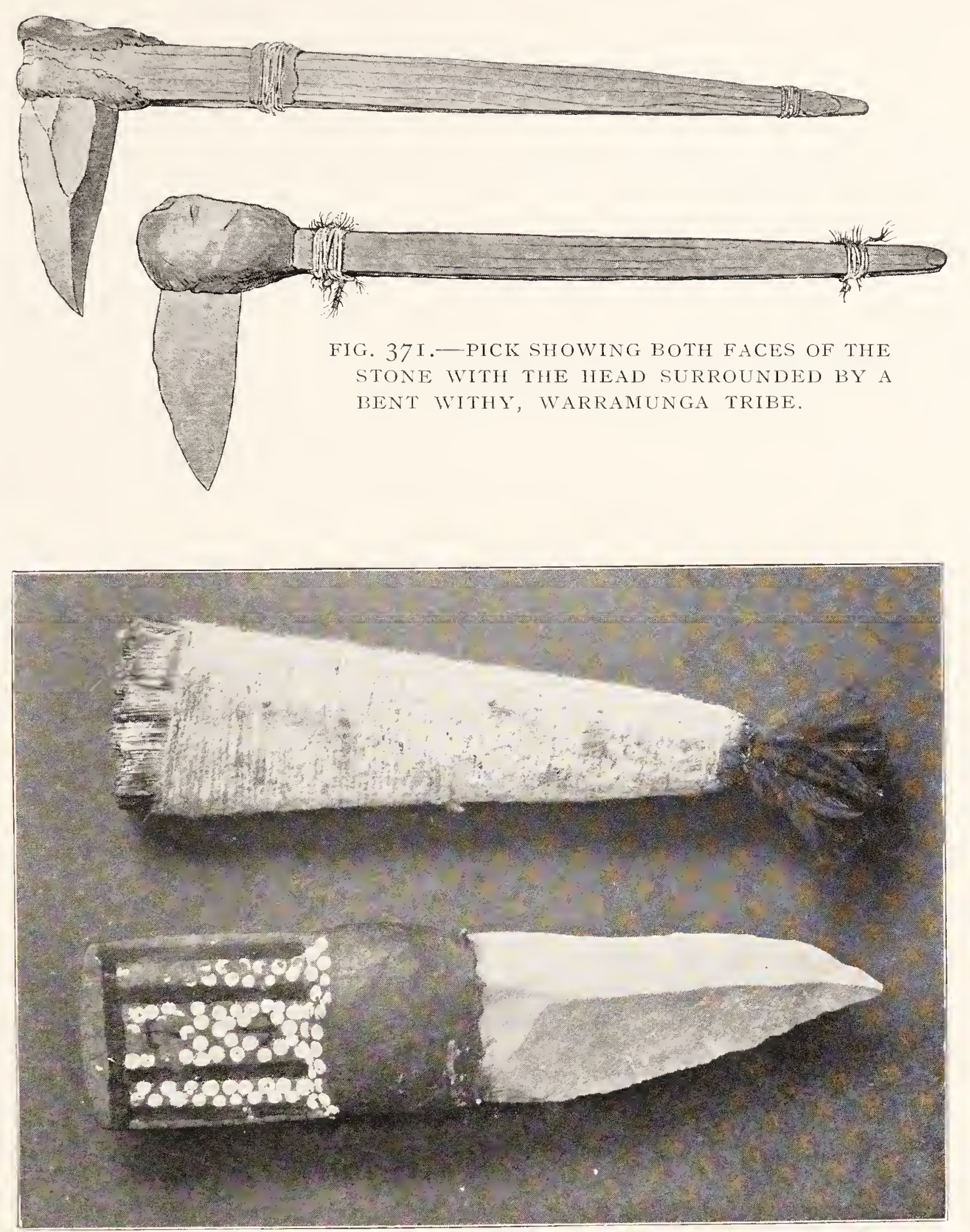

FIG. 373.-STONE KNIFE WITH ITS SHEATH.

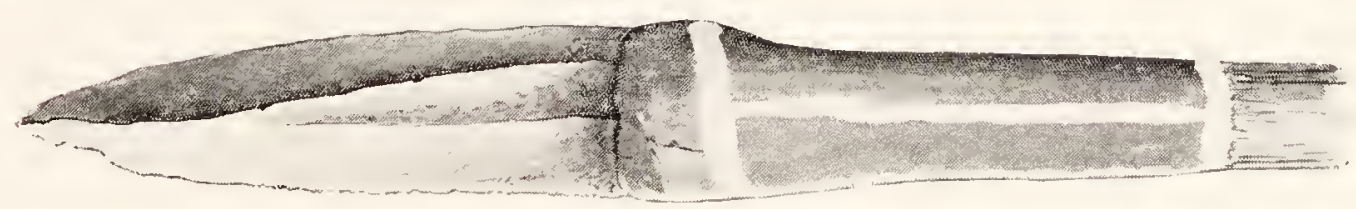

FIG. 374.- STONE-IIEADEI) SPEAR, WARRAMUNGA TRIBE.

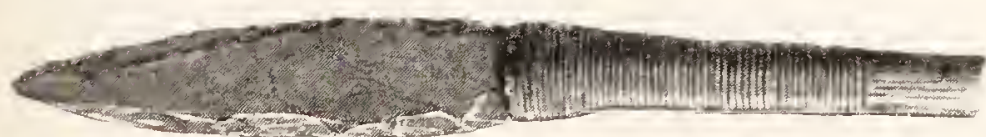

FIG. 375.-SLATE-HEADED SPEAR.

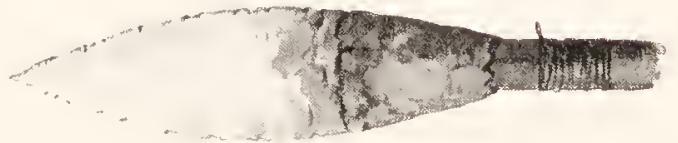

FIG. 376.-SPEAR WITH IIEAD OF JINELY CHIPPED OPALINE QUARTZITE, KAITISII TRIBE. 


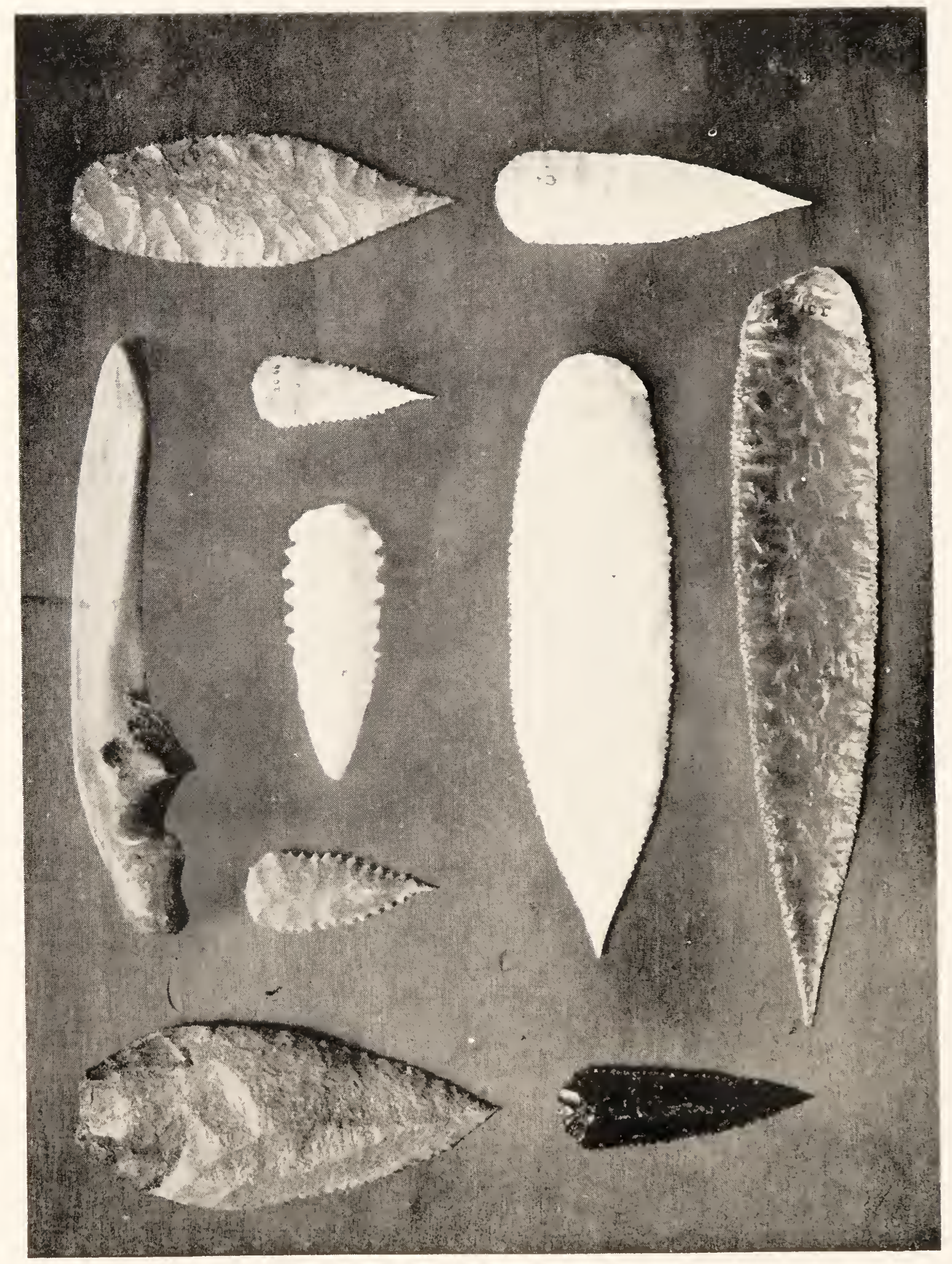

FIG. 377.- TLAKED AND CIIPPED QLARTZITE, PORCIEAIX AND GIASS SPEARHEADS, ANI THE BONE IMILEMENT LSED IN MAKLA THEM : NORTH-WEST AUSTRALIA. 
initiation and mourning. The very numerous scars that mark the bodies of most natives are all produced by cuts with these stone knives, and there are many occasions on which the men cut their shoulders. During a fight two men will stand with their arms round one another, and, with their knives, cut deeply into the fleshy part of each other's back and thighs. These fights and markings of the body, and what may be called ceremonial cuttings, are constantly taking place.

A curious feature about the knives is that, though numbers of them are seen in the hands of the men, it is a very rare thing to come across one that shows any trace of having been used. Those in my possession that I have actually seen used, during mourning and initiation ceremonies and fights, are perfectly clean and look as if they were quite new and had never been soiled in any way by use. The reason of this is that, in the first place, blood does not easily attach itself to quartzite, and, in the second place, each knife, after being used, is carefully cleaned; sometimes indeed the blood has to be removed by the mouth of some special individual, but in other cases it is always wiped off so that no trace is left.

The points of all the flaked instruments are very liable to be broken and the blade is usually protected by a sheath, made of very thin strips of bark, cut from an Acacia tree or, in the Warramunga and far north, from a special " paperbark" tree (Melaleuca leucodendron). The strips are placed lengthwise along the blade and are then wound round closely with fur or vegetable fibre string. The whole surface is covered with pipe clay, and a small bunch of red-ochred emu or cockatoo feathers is inserted at the end (Fig.373). When the former are used, about twenty or thirty of them are attached, always by their tips, to a short stick an inch or two long, so that when it is inserted into the sheath the quills form a radiating bunch projecting from the end. Neither 


\section{IO WANDERINGS IN WILD AUSTRALIA $\mathrm{cH}$.}

the design on the haft nor the bunch of feathers is of any use, but they are interesting as showing that even primitive mankind likes to have something that, according to his ideas, is pleasant to look at as well as useful.

The fifth and last kind of flaked implement is the stoneheaded spear. There were three types of these in the Warramunga camps. In the most common form the head is made of quartzite, the blade being precisely similar to that of a flaked knife, measuring in the case of the one figured (Fig. 374) I $4 \mathrm{~cm}$. in length and $4 \mathrm{~cm}$. in width. It is attached to the spear by resin, round which, while it is soft, string made of fur or vegetable fibre is wound. Sometimes the blade is made of a flattened piece of chipped, slate-like rock (Fig. 375). A third kind is by far the most beautiful of all stone implements made by the aboriginals, and, though they are traded down to the Warramunga and even as far south as the Arunta, the best ones are made by the tribes inhabiting the very north-west angle of West Australia; from here they pass along the Victoria and Daly River country, eastwards along the upper reaches of the Roper and southwards down the Centre to the Macdonnell Ranges. They are in the form of leaf- and lanceolate-shaped flakes that are used almost exclusively as spearheads, only rarely as knives. The material originally employed was a very fine-grained white or pinkish opaline quartzite. Nowadays they use porcelain telegraph insulators and are especially fond of glass, the colour and nature of which often indicate the favourite beverage of the white man in the district, be it gin, beer, whisky or Eno's fruit salts, or some special form of patent medicine then in favour. In the early days of the telegraph line, the officials, not seldom, had to go out in search of breaks in the line, due to the natives climbing the poles and smashing the insulators, until one day the bright idea occurred to one of the former of scattering supplies of discarded ones at 
intervals along the line. What these fine and delicately chipped spear-heads are like can be seen from the photographs of those reproduced in Fig. 377. They are made by the pressure of a bone implement, such as the ulna of a kangaroo, one end of which is ground down to a blunt point. It is so clumsy a tool that it seems scarcely possible to use it for such delicate work, and yet the extraordinarily fine points and the serrated margins of all of them have been fashioned with this. An expert in the work-and it is only comparatively few natives who are really expertsmay every now and then be met with in possession of a small bark wallet in which he will have a number of the spearheads in process of manufacture (Fig. 378). Though the most beautifully formed ones, with tips wonderfully drawn out to almost a needle-like point, and always finer or coarser serration along their sides, are very distinctive in their beauty, shape and delicate workmanship, yet, in reality, a large series of spear-heads will show a complete graduation through such a form as that represented in the lower left one in Fig. 377 to the spear-head with its roughly chipped surface in Fig. 375, and the knife blade in Fig. 370, with very distinct secondary chippings along each side of the point. 


\section{CHAPTER XXII \\ TENNANT CREEK TO POWELL CREEK}

Time went by and, in the middle of September, after three months amongst the Warramunga, we began to realise that, though we would willingly have spent a year with them, yet we must press on, if we were to reach the Gulf of Carpentaria before the wet season set in, when travelling might at any time be made impossible.

Our last few days were busy ones and we lived mostly on the ceremonial ground. On September I $3^{\text {th }}$ we were sleeping peacefully, when, before sunrise, a native woke us up, saying that they were going to perform an important ceremony. Late on the evening before we had left them singing in their camp but had decided to rest quietly. The series of the great Wollunqua snake, the black snake, wind and Thaballa or " laughing boy " ceremonies were complete, and in all essential features the great majority of them were closely similar to one another. However, it was not safe to miss anything, but, as we got up and dressed hastily, we hoped that we were going to see and hear something not quite so monotonous and discordant as the performance of the two screeching white cockatoos. First of all, just at daybreak, when it was decidedly cool, we had a quaint little ceremony called Tappin. Six men were painted, their upper halves with red ochre and their lower halves with charcoal and grease. Each of them carried, on both thighs, one of the small gum-leaf wands, indicating a ceremony of the Kingilli moiety of the tribe, and all six of them huddled together on the ground (Fig. 379). They were supposed 


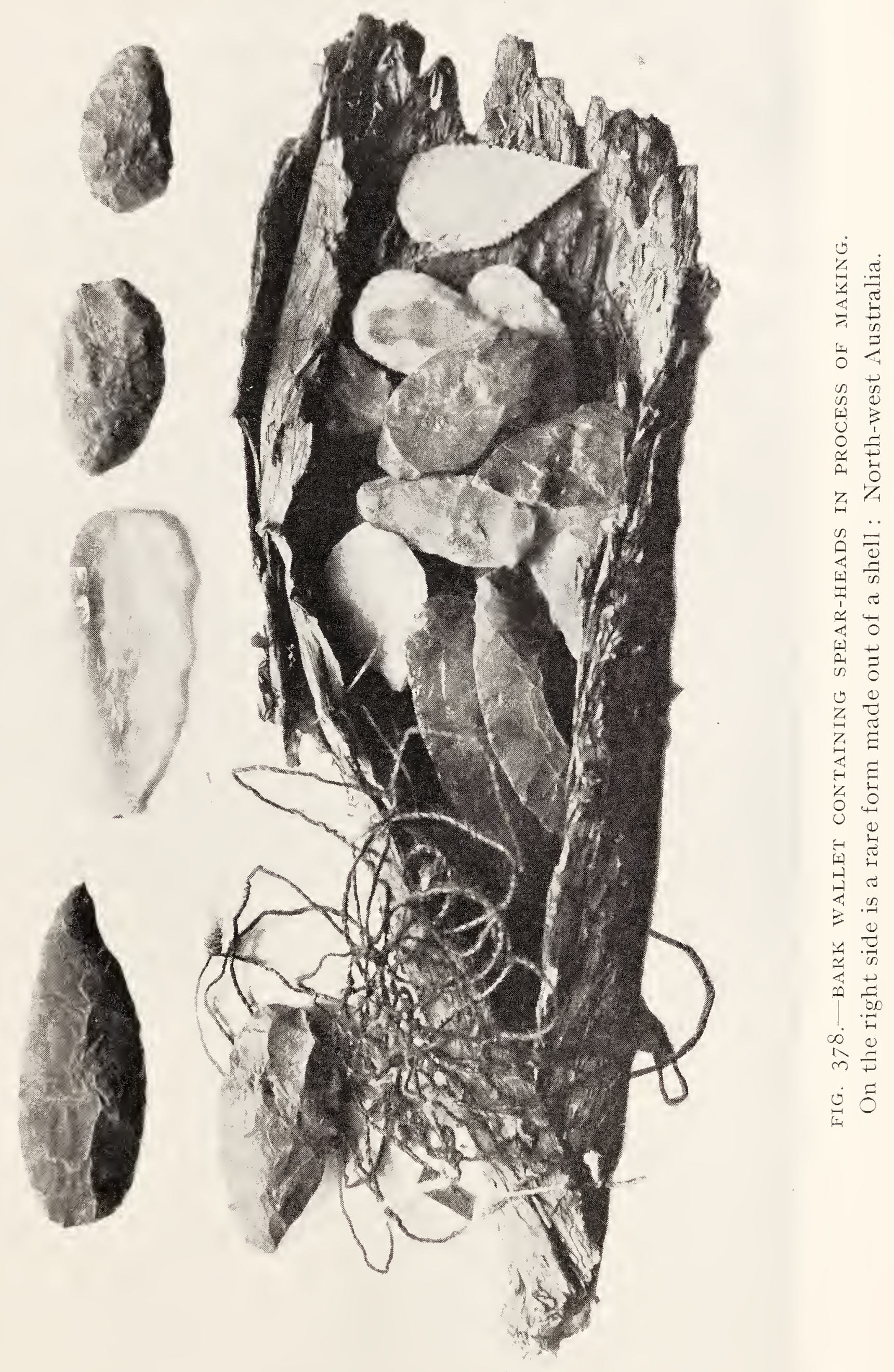




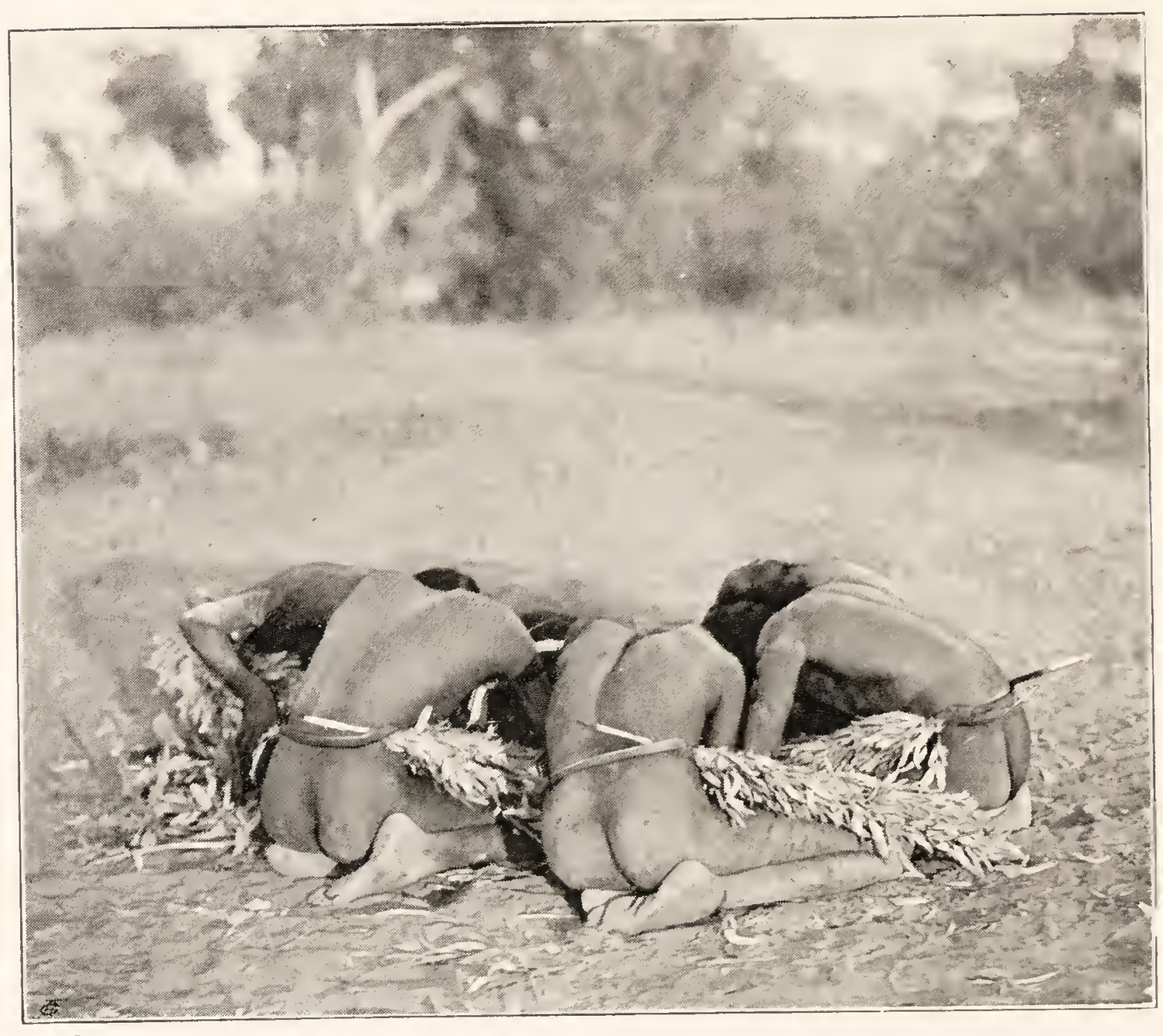

FIG. 379. TAPPIN CEREMONY, WARRAMLNGA TRIBE.

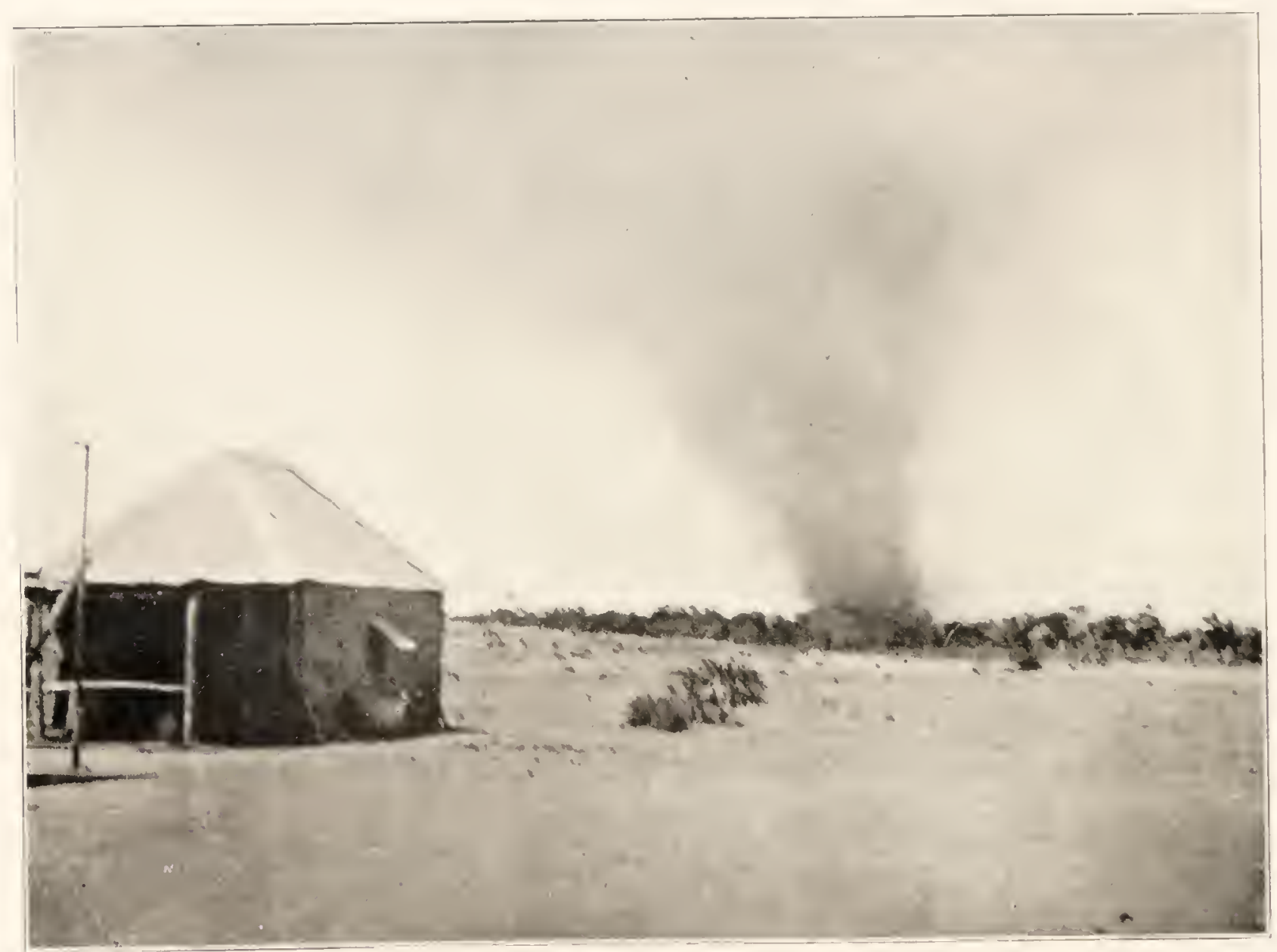

I3. S.

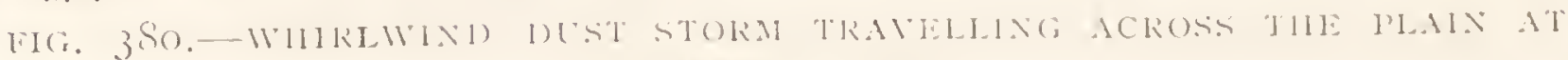
"LNANA ('RELR. 
to be emblematic of " the cold," which is the meaning of Tappin, before the natives had discovered how to make fire, or, rather, before fire had been given to them.

When that was over, we had a ceremony representing two ancient lubras who spent their time collecting and eating ants. The two men representing them were decorated, as usual, with down and wandered up to the centre of the ground, from bushes some distance from one another, behind which they had hidden themselves, stopping every now and then to imitate women digging out ants. After a time they discovered and embraced one another, which was supposed to represent the two women coming together for the first time in the Alchera.

We were now busy packing up the wagon with all our remaining stores. These had to carry us through to the Gulf, until we reached Borraloola, near to the mouth of the Macarthur River, where there was a store to which supplies were supposed to come from Darwin three times a year. We had, at first, intended to go straight through to Darwin, but it was getting late in the season and, after taking all things into consideration, we decided to go as far north as Newcastle Waters and then strike eastwards, overland to the Gulf.

On September I th we sent Chance and the wagon on ahead of us, keeping our light buckboard and such things as we needed for a few days, until we overtook him. It was one of those disagreeable days that one meets with at times in the Centre. The wind was hot, and frequently huge dust storms swept across the plain, hiding everything and covering it with fine dirt. Sometimes a whirlwind came twirling the sand round and round, carrying it up for two or three hundred feet into the air. Once one of them came right across the native camp, scattering the Mia-mias that lay in its course in all directions (Fig. 380). The women yelled, running away, as usual, as hard as their legs could 


\section{I4 WANDERINGS IN WILD AUSTRALIA ch.}

carry them, fearful lest any of the spirit children that the whirlwind carried with it should enter them. What with dust and wind and measuring natives, which is always a tedious and by no means a fragrant work, the day was an unpleasant one and I was glad when it was over. By bad luck we had sent up two or three dozen tins of preserved butter amongst our stores, hoping to enjoy it as a luxury on special occasions to make the dry damper more pleasant, but to our disgust it had not stood the rough carriage and heat and was hopelessly rancid. Much to their satisfaction, but to our subsequent regret, we gave it to the natives, who, of course, used their fingers as spoons and rubbed what remained of it into their hair.

Late in the afternoon, on September I 7 th, we came to the end of the ant, lizard and wind ceremonies. Some of the natives also had been busy all day long, making a huge torpedo-shaped bundle called Miniurka, about twelve feet long and three in diameter. It contained some forty wands, each made of a central stick, on to which gum-tree twigs were tied. The outside covering was made of sheets of paper-bark, wound round and round with, literally, hundreds of yards of human hair string. It took the whole day to make, only a very few of the older men being allowed to take part in it, and, at sunset, when it was finished it was hidden away under a bank in the creek bed. What it all meant we could not find out exactly, except that, in some way, it was connected with an old tradition referring to the fact that in ancient times the Kingilli men had given light and fire to the Uluuru men, who had previously lived in cold and darkness. The wands were associated both with the Kingilli men, who always used them during ceremonies and with fire, and were strikingly suggestive of those used during the fire ceremony, except that they were on a smaller scale. Late in the evening, at 9.30 p.m., when it was quite dark, we went with some of the natives to the spot where the 
Miniurka was concealed, and then, to the accompaniment of loud cries of "Wu! Wu! Wu!" they carried it on their shoulders to the ceremonial ground, in the middle of which it was deposited. A few fires were immediately lighted, and then the men began to sing over it, as loudly as they could, amidst the incessant clanging of boomerangs and clubs. As, according to custom, it was necessary for this to continue all night long, and as nothing else was to take place, we decided to return to our camp for a few hours' sleep. We were up and down in the camp before sunrise, and, just as we reached the ground, the main body of the men, who had spent the night in the bed of the creek, were brought up by a few of the old men who had been "singing" the bundle. Behind the latter stood the men who had made it, some singing, others beating their boomerangs and clubs and all of them in a state of great excitement, waving their arms, pointing to the bundle and beckoning the other men to come near. The latter affected the keenest astonishment, opening their eyes wide, throwing their arms forward and their bodies backward, when they saw the great torpedo-like thing. One by one they came up to it, the oldest man amongst them first, with a curious prancing kind of movement. He tried, unsuccessfully, to lift up one end of the Miniurka, but it was evident that he was only pretending to do so. Then one of the men who had made it handed him a bunch of eagle-hawk feathers with which he brushed it over from end to end. This little performance was enacted by every man in turn and, whilst it was going on, the men who had made it pranced about backwards and forwards, singing and yelling. One old man, in his excitement, tumbled head over heels backwards over the bundle, which quietened him down for a time and much amused the others. When everyone had brushed it, they sat down for a few minutes, and then three of them got up and ran away over the creek. I followed 


\section{I6 WANDERINGS IN WILD AUSTRALIA сн.}

them, to see what was going to happen, and found that they were making a wide circle, so as to come up behind the lubras, who had all gathered together a quarter of a mile away, in the bed of the creek. I took a short cut across towards where the lubras were stationed, and close to them came across two boys who had recently been initiated. They were crouching down hidden by bushes, so I guessed what was happening. The three men, shouting loudly, came up behind the lubras, and, as soon as the men were within fifty yards of them, up jumped the boys and ran for their lives towards the ceremonial ground, followed by the boomerangs of the men. I kept carefully to one side of the line of fire and managed to arrive on the scene, more or less breathless, just in time to see the boys received by the men, who showed them the bundle and explained to them what it meant. So far as the boys and lubras were concerned, this little ceremony evidently meant that the boys were now being taken away from the women and adopted into the ranks of the men, by whom they were received on the ceremonial ground, to which no lubra might come near.

This was the last ceremony that we saw amongst the Warramunga. It was still early in the morning when it was all over; by half-past nine we had packed up and were once more on the northward track, and in the evening were camped twenty-four miles away, by the side of a small soakage on the Phillips Creek.

The next day's traverse was over the most desolate country possible, just mile after mile of wide, open plain with nothing but thin scrub until, just before sunset, we came into a range of low hills, through a broad valley, amongst which a belt of gum trees indicated the course of Attack Creek, and camped beside the first water-hole of any size that we had seen since leaving Charlotte Waters (Fig. 38 I). My little terrier enjoyed it as much as we did. It was the first time that he had seen real water except in a 


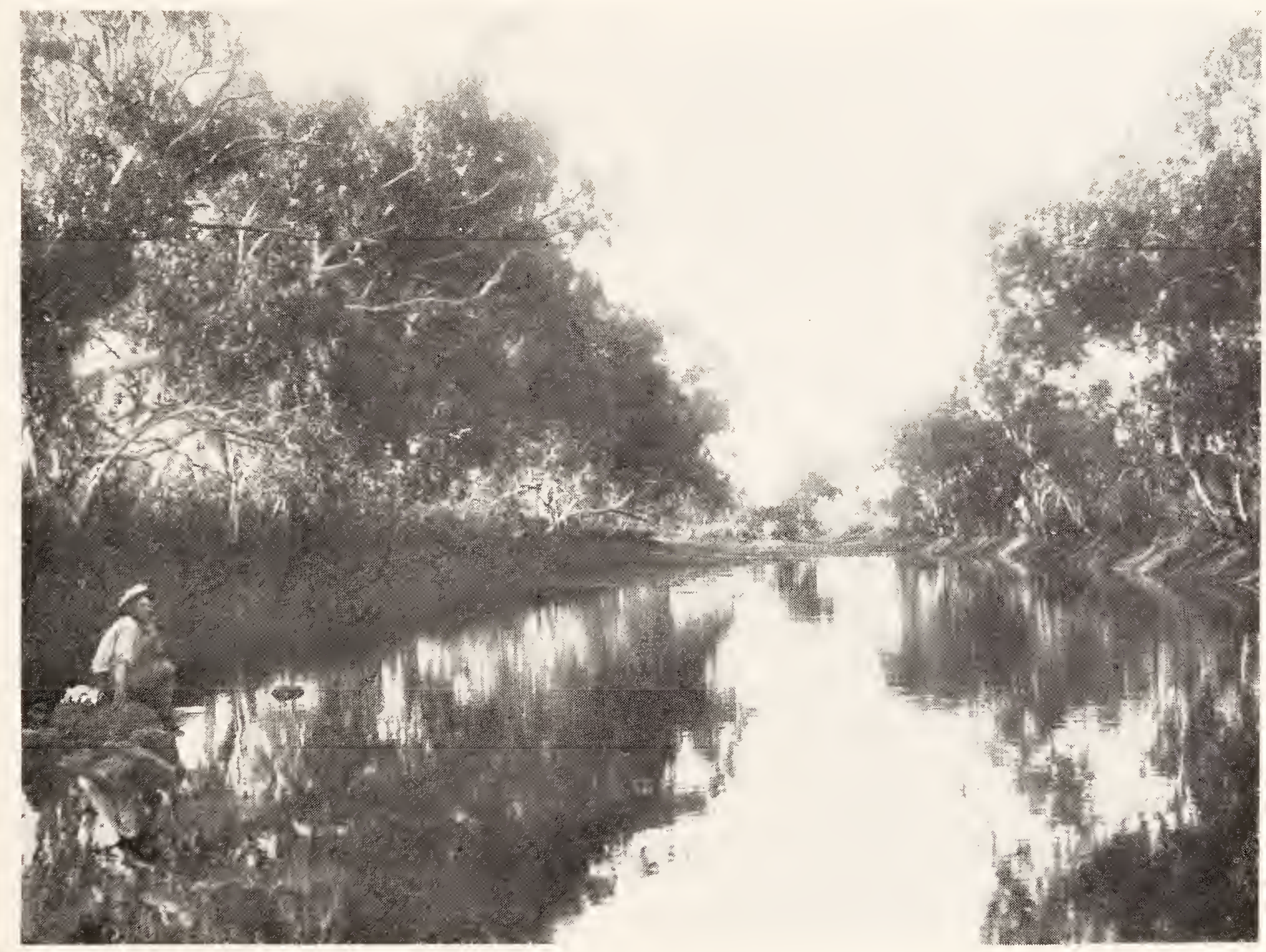

F.J.G.

FIG, 3SI.-WWATER-HIOLE ON TENNANT CREEK. 


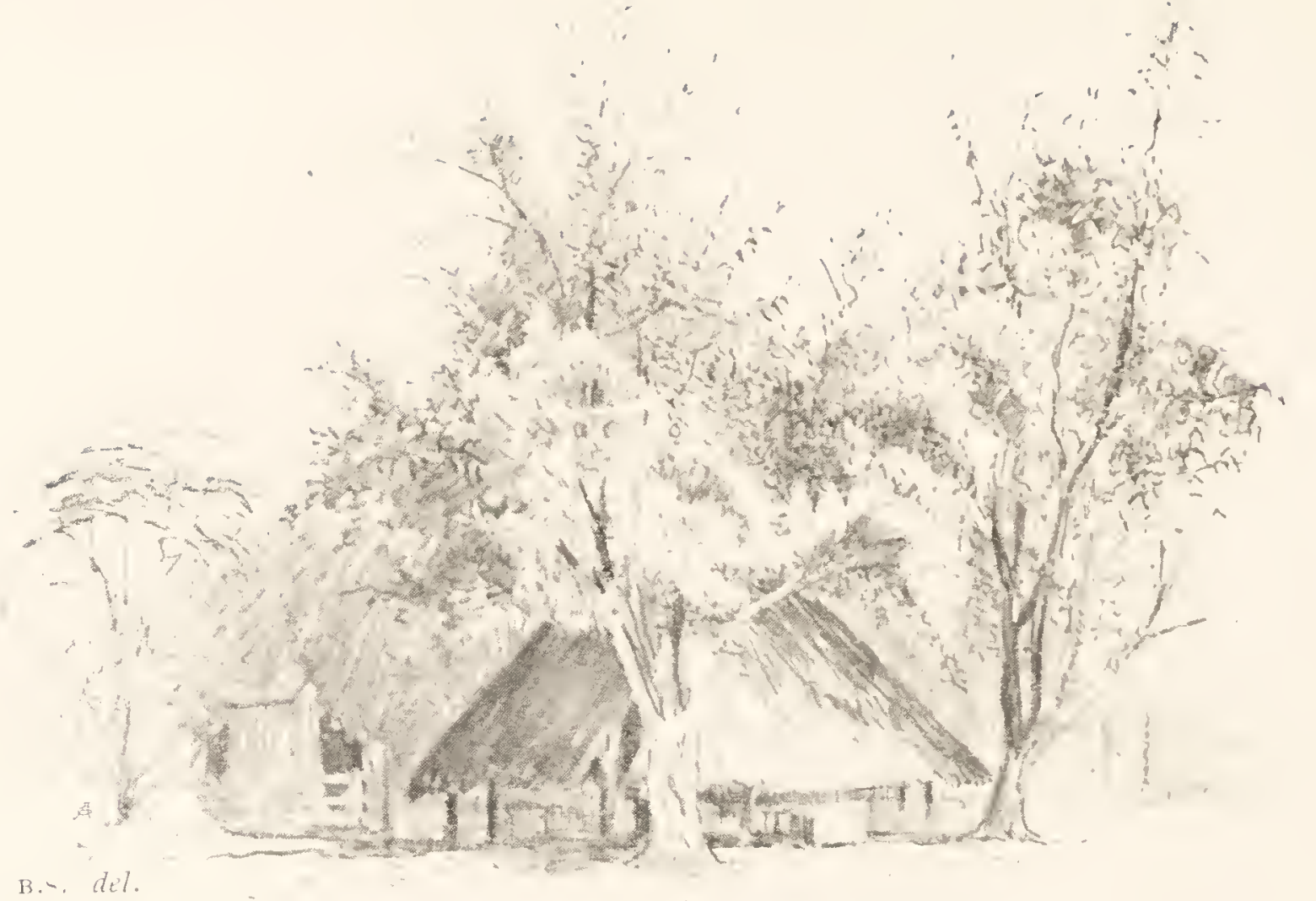

FIG. $3 S_{4}$ - BUNGALOW SHELTER AT POWELL CREEK, WITH BALHENIA TREES.

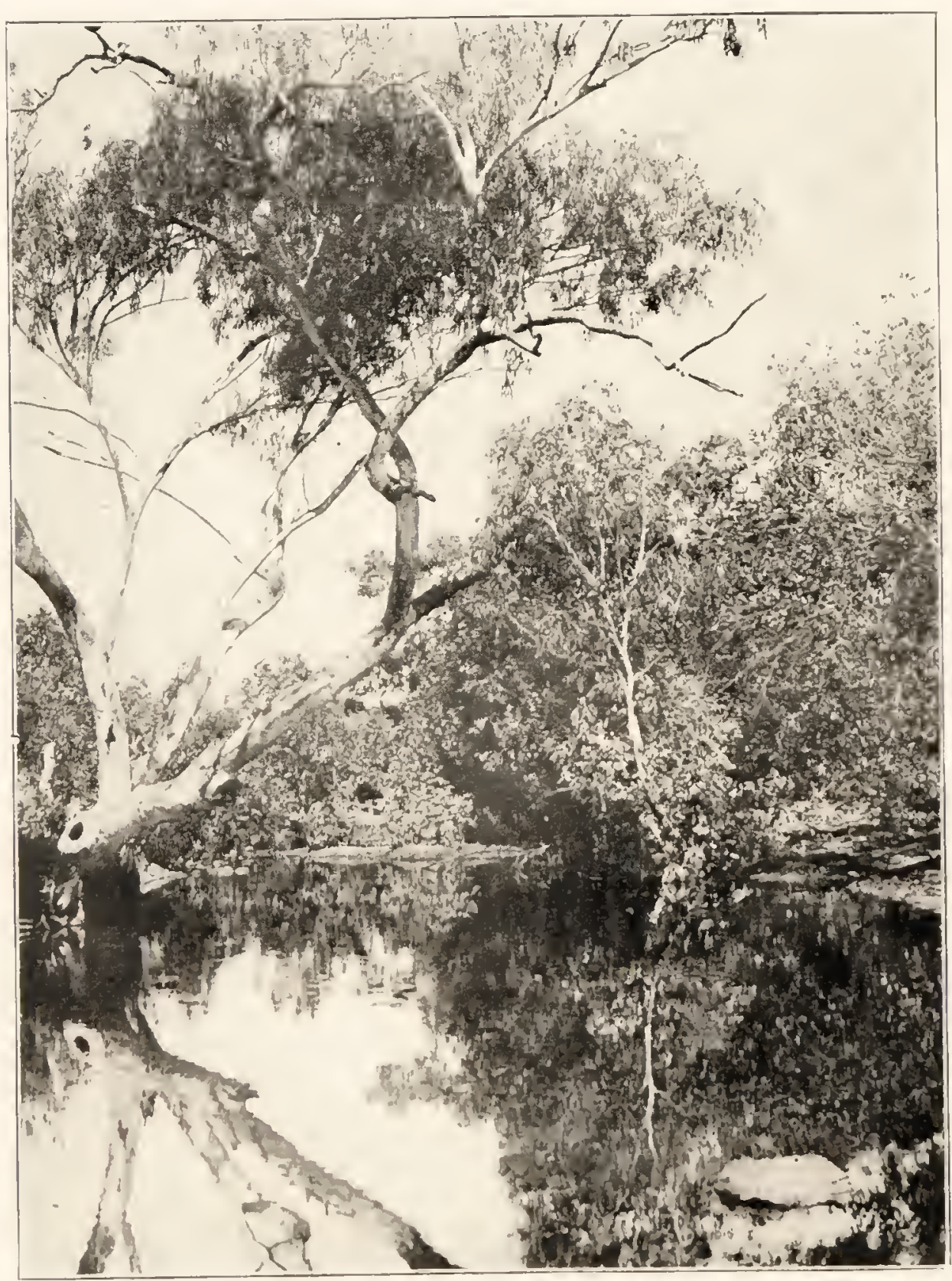

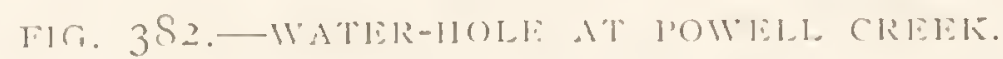


bucket, or a little soakage, or, at most, a shallow pool in which he could walk, but, when once I had persuaded him to come with me out of his depth and he discovered that he could swim, his keen enjoyment was only equalled by his unmistakable look of astonishment, and he spent the whole evening exploiting his new discovery-mightily pleased with himself.

Attack Creek is one of the most interesting spots in Central Australia, because it was here that, in 1860 , Mcdouall Stuart, one of the greatest of Australian explorers, was attacked by the natives-hence the name that he gave the Creek-and forced to relinquish, for the time being, his attempt to cross the continent.

A day or two before reaching it, Stuart came across a few natives, one of whom was an old man whom he describes as being very talkative and friendly. ${ }^{1}$ The country was very dry and he tried, by means of signs, but without success, to get information as to the whereabouts of the water-holes. To Stuart's surprise the old man, after talking to the younger men, turned round and, in the words of Stuart's narrative, "surprised me by giving one of the masonic signs. I looked at him steadily; he repeated it and so did his two sons. I then returned it, which seemed to please them much, the old man patting me on the shoulder and stroking down my beard. They then took their departure, making friendly signs until they were out of sight." Two days later he discovered Attack Creek and followed it down for some distance. The natives now seemed to be distinctly unfriendly. They gathered round in considerable numbers " and commenced jumping, dancing, yelling and throwing their arms into all sorts of postures like so many fiends." According to Stuart the attack was of such a serious kind that he felt compelled to fire upon the natives, and, as his party was only a small one, he fell back,

1 "Explorations in Australia," p. 213. 


\section{WANDERINGS IN WILD AUSTRALIA ch.}

and in his Journal of June 27th he writes: "After considering the matter the whole night, I have most reluctantly come to the determination to abandon the attempt to make the Gulf of Carpentaria."

Amongst the natives whom we met at Tennant Creek was a very old man of the Warramunga tribe who had actually taken part in the attack on Stuart's party, and, from what he told us, we came to the conclusion that Stuart rather exaggerated the capacity of the natives to hinder his progress northwards. As a matter of fact, the old man told us that, though they certainly did not want the white men to travel through their country, they were actually very frightened of them and were very glad when they went away. In fact, so far as I could gather from the old man, all that the natives wished to do was to frighten the uncanny-looking white strangers away, but whether they went north or south did not matter, so long as they went out of their country and left it to themselves.

We spent a very pleasant evening by the side of the waterhole, luxuriating in a real bathe and watching great flocks of white cockatoos and grey and rose-coloured parakeets, coming in to drink at sunset. The natives had told us that, after the performance of the white cockatoo ceremony that we had seen at Tennant Creek, the bird was quite sure to increase in numbers, and here they were in hundreds. We were up next morning at sunrise and started off at 7 a.m. The country was very miserable, with here and there small, dry creeks, crossing which we jolted over rough boulders. Fortunately, the buckboard on which we carried our light impedimenta was strongly built, with the result that only one bolt was broken.

This was one of our hottest days. The thin, meagre Mulga and Hakea trees forming the scanty scrub gave practically no shade. Miy little terrier spent the whole day, when it was not riding with us, in running on ahead 
from the shelter of one thin tree trunk to the next. Every bit of metal on the buckboard became too hot to touch and, when walking, the heat struck through the soles of our boots. It was one of those days when the natives with their bare feet, tough-skinned and hardened as they are, remain in camp, unable to endure the ground temperature. Everything was, of course, absolutely dry. After leaving Attack Creek there was no water, and all day long the sun shone down fiercely. It was a great relief, late in the afternoon, to turn off from the track along the telegraph line into somewhat better country and to reach a little outlying cattle station, built by the side of a small spring of water, called Banka Banka by the natives. A small patch of light green herbage indicated the position of the spring that bubbled up at the foot of a low hill. The evaporation at this time of the year was so great that the stream only flowed away from it for a few yards. The "station" itself consisted of a small, roughly-built log hut. There was no floor, except the bare earth, and the sum-total of furniture consisted of one box, a short form that served as seats, and a rough deal table. Fowls, that we were very glad to see, wandered in and out, with a stray pig or two and half a dozen dogs. It is under conditions such as these that many of the Australian pioneers have lived whilst opening up the "never never" country. The owner, Tom Holmes or Tom Nugent-you called him which you liked-was a most interesting and picturesque type of bushman, known far and wide over the Northern Territory, of which there were very few parts that he had not traversed. His real name-he died many years ago nowwas Thomas O'Brien Harrington Nugent, and he used to describe himself as the worst of the Harringtons, the last of the Nugents and the King of Benaraban, the name of a station that he once managed. The surname Holmes was, I think, assumed when in early days he was, or was supposed 


\section{WANDERINGS IN WILD AUSTRALIA сн,}

to be, a member of a party known as " the ragged thirteen," who were credited with being bushrangers, but their exploits seem to have been very mild and harmless and, long years before this, he had settled down to the more prosaic and respectable, if hard and unpicturesque, life of a genuine bushman. We had previously met him at Tennant Creek and he made us heartily welcome to Banka Banka, where, amongst other things, he gave us a feast of fresh eggs, one of the most enjoyable meals that I, at all events, had had since leaving Adelaide. They were boiled in an old kerosene tin that still retained a distinct suggestion of its first contents. Gillen came to a stop at the end of his sixth, but I struggled on to, and through, my fourteenth, after which none were left. After this sumptuous meal we had time to take in our surroundings. There were plenty of chinks between the logs of the hut walls to allow the fresh air, dust and flies to come in, but a large part of the wall space was covered with a gallery of portraits of prizefighters-eighteen of them altogether-the only other individuals who were allowed to figure amongst them being Gladstone, Banjo Paterson and Kruger, who were kept in their place by overlapping prints of Kid McKoy, Peter Jackson, Fitzsimmons and other celebrities of the same kind. The Bishop of Carpentaria spent a night here on his way through, and I have no doubt enjoyed it as much as we did. Holmes was astounded to learn that I had never heard of a certain Richard K. Fox, I think his name was, anyhow he is, or was then, the editor of the "Police Gazette" of New York, of which remarkable paper Holmes presented me with a copy. This and the Sydney "Bulletin" were the main, in fact almost the sole, features of the station library. We spent a most interesting evening with him, listening to tales of his experiences during early days in the far north, over which he had wandered during the past thirty years and more, and to his accounts of the country 
that we still had to traverse, where blue-bush swamps with chasms big enough to swallow horse and man, and snakes of great size and ferocious nature abounded. Long before this, however, we had learned to take tales of the far north cum grano. There is a sense of bigness in the country that seems to find its way into the tales of the bushmen. It was close upon midnight when Holmes and Gillen started on Home Rule and the wrongs of their native country. Being only an Englishman, with no special wrongs to cherish and perhaps even a little bit enjoy the recounting of, I went to my bunk beside the spring and left them at it.

One of our horses had strayed, so it was 8.30 before we left Banka Banka in the morning. The fowls must have been brooding over their wrongs, because there were no fresh-laid eggs forthcoming, and it was months before I was destined to have another one. We had been wondering whatever we should do with our buckboard, wagon and horses, when we got to Borraloola, because there would be no sale for them there. We intended to go thence to Darwin by a little steamer that, once every three months, was supposed to ply down the Gulf, carrying stores, so we accepted Holmes' offer of fIOO for the whole turn-out. He was to send someone after us to take delivery of them at Borraloola. It did not sound very much, but then he had to take all risks of horses dying on the road and the chances of the buckboard and wagon getting smashed, because from the station to the Gulf and back again meant a journey of some 900 miles over very rough country. However, it was better than getting nothing for them, and we were glad to learn, long afterwards, that everything reached him safely.

Leaving Banka Banka, we passed over a little bit of what is called "Downs" country. Our track along the telegraph line since leaving the Macdonnell Ranges had led us over some of the poorest parts of the Centre. There was for the VOL. II. 


\section{WANDERINGS IN WILD AUSTRALIA cr.}

most part nothing but thin scrub and porcupine grass, with, every now and then, low quartzite ranges. Away to the east, stretching across to Queensland, lies what is known as the table-land or Downs country-splendidly grassed, plain country which, granted the normal rainfall, is of immense value for stock purposes. The table-land has an average elevation of 2000 feet, and at various places bores have been sunk, yielding a good water supply. At the Alexandra Station, for example, there is one that goes down for I 664 feet, the water rising to within 200 feet of the surface, so that, by pumping, a daily supply of 2400 gallons can be secured. The few stations on the table-land are, at the present time, mostly dependent for their supply on the water that, after the heavy summer rains, lies in the shallow lagoons. When rain does fall the whole countryside is transformed for a time into a huge swamp, over which it is impossible to travel until the surface waters sink into the ground. When once the plains are dry there are vast areas covered with rich feed, though with only a scanty and precarious supply of surface water. Artificial storage and the tapping of the subterranean supply will in course of time probably solve the water difficulty. There is undoubtedly plenty of it, if only it can be made available all the year round, and there is only one opinion, granted the solution of the water difficulty, in regard to the enormous capacity of the Downs and table-land country for stock-raising purposes.

We only made eighteen miles the first day after leaving Banka Banka, and camped by the side of an almost dried-up muddy flat with just a shallow pool of thick, white-looking water, known as Prentice Lagoon. Fortunately we had brought some fresh water with us from the spring at the station, and the horses did not seem to mind mud, nor did the terrier, who waded in and returned to camp very pleased with himself and caked with mud.

We left camp in the morning before 7 a.m., and for hour 
after hour, plodded on monotonously over sand-hills and across rough and, of course, quite dry, stony creek beds until we reached a small plain with low quartzite ranges round it. Close to its northern end there was a small clump of green trees with fresh herbage. Here we found another spring, or rather a small group of tiny springs, bubbling up out of black, clayey soil. It was just like a little oasis in the otherwise dry country, but here again, as at Banka Banka, the evaporation was so great that the water only trickled away for a few yards. Its temperature was $90^{\circ} \mathrm{F}$. These springs were found by the construction party on the overland telegraph line and were named after Renner, one of the medical officers. At a later period the land was taken up and small station buildings were put up close to the springs. Years ago they were deserted, and now they were in ruins and only inhabited by white ants, scorpions, spiders, lizards, snakes and bats-samples of all of which were collected.

It was blowing a hard south-east wind and we were just about as uncomfortable as wind, warmth and dust, combined with a plentiful supply of flies, could contrive to make us, but, when the wind quieted down after sunset, things were a little better, and we lay down in our rugs and went to sleep, because there was nothing else to be done.

Next morning two natives came in to make stone knives, because, close by, there is an outcrop of finely-grained quartzite, especially suitable for the purpose. It was very interesting to watch them chipping the little blocks of quartzite until they secured flakes that would serve as knives and spear-heads. The quarry from which they obtained the stone had evidently been used for long years and is littered with numberless flakes that have been chipped off and discarded as not good enough to use. There are now only very few natives who are adepts in the art of stone chipping and flaking, because iron has almost entirely 


\section{WANDERINGS IN WILD AUSTRALIA $\mathrm{cr}$.}

superseded the stone knife, even in this remote part of Australia, and the quarry at Renner's Springs remains as one of the few traces of the old Stone Age that is now fast disappearing.

Another day's journey brought us to Powell Creek. On the way we had to cross a succession of stony creeks, coming down from low ranges to the east of the track. We broke four bolts in the fore-carriage of the buckboard and began to wonder if it would hold together until we reached the station, but, by good luck, it did.

While enjoying the comfort of the station and the warm welcome of our friends, Mr. and Mrs. F. J. Kell, we were almost tempted to forget that there was anything uncomfortable connected with travel in Central Australia. You think you enjoy a rough camp meal, but it is a wonderful relief, after camping out for six months, to have one properly served. The station itself is a picturesque bungalow, placed on a slight rise amongst the low hills and surrounded by shady Bauhenia trees, with a picturesque water-hole close by, overhung by gum trees and paperbarks (Fig. 382). Bean trees, Bauhenias, bananas and palms gave a semi-tropical touch to the scene and, as we sat smoking comfortably in lounge chairs on the broad verandah, watching on one side the rich afterglow in the western sky and on the other the moon rising red in the east, it was difficult to believe that, only a few hours earlier, we had been jolting over rough creek beds and ploughing through deep sand, under a blazing sun, amidst the dreariest of dreary scrub. A few miles to the south of the station, after passing through a low range of hills, there had been a very marked change in the nature of the vegetation. The gum trees seemed to be thicker and the Bauhenias, which we met with here for the first time, gave us a distinct impression of shade. They have a dense foliage of small, thick leaves and were covered with crimson pods, from four to six inches in length, which, at sunset, made the trees look as if they 
were on fire. One special gum tree was especially interesting (Eucalyptus platypoda). There is often a very considerable difference between the leaf of many sapling gums and that of the full-grown tree, in shape, method of attachment to the stalk and size, but in this case the contrast, especially in size, is most striking (Fig. $3^{8} 3$ ). The sapling leaves were nearly eight inches in length and six in greatest width. Gradually, as the tree grows, the leaves diminish in size, until, on the mature tree, which reaches a height of at least sixty feet, with its branches widely spreading and throwing a welcome shade, they only measure two to three inches in length and a little more than one in width. The tree is popularly called "Karbeen." Further north there are at least two other gum trees, the "Khaki," so called on account of the delicate light-brown colour of its trunk, and the "Cabbage" gum, in which there is almost the same difference in size between the sapling and the full-grown leaf as in the case of the "Karbeen."

There are some quite pretty spots close to the station, especially one water-hole with overhanging, white-stemmed gums and paper-bark trees, on whose boughs, at sunset, flocks of galahs and other birds, and amongst them lovely white ibises, that came in to water, perched in countless numbers. In the station grounds there are two bungalows (Fig. 384), built under the shade of Bauhenia trees, with thatched roofs and open sides, so as to afford shade during the heat of the day and cool, fresh air at night, when it is too hot and stuffy to sleep indoors.

Six days after our arrival, Chance, whom we had left behind us on the track a little to the north of Tennant Creek, came in with the wagon; also a mailman arrived with letters for us that had first of all been up to Oodnadatta, then south again to Adelaide and Melbourne, and then north by way of Sydney, Brisbane, Thursday Island and Darwin and, finally, south to Pine Creek and along the telegraph line, so that the news they contained was somewhat belated. 


\section{WANDERINGS IN WILD AUSTRALIA ch.}

In those days there were no such things as motor-cars in Central Australia and the aeroplane was not dreamt of.

Close to the station there were camps belonging to the natives of the Tjingilli tribe. We found that, in all essential features, so far as beliefs and customs were concerned, they were closely akin to the Warramunga tribe that adjoins them on the south, and yet they spoke a completely different dialect. It is a great puzzle how the different tribes became so sharply marked off from one another in the matter of dialect. These dialects are not by any means the same thing as those, for example, of English counties. In most cases the words are quite different. A Warramunga man can no more understand a Kaitisha or Arunta man than an Englishman can understand a Frenchman without learning his language. It must, of course, be remembered there is no such thing as a written language anywhere in Australia, so that every word is transmitted from one generation to another by word of mouth. In strong contrast to the difference in the dialects, there is an equally marked agreement in the most essential points concerning the customs and beliefs of various tribes inhabiting the whole of the Central area. It may be taken for granted that these developed when, under more favourable climatic conditions that we know once existed in the far past, communication between the groups of natives inhabiting the various parts of the Interior was much more easy than it is at the present day. With the gradual desiccation of the interior of the continent, larger groups and, within these, smaller ones became segregated. With this gradual segregation, which really consisted of a drawingin towards certain centres, where, in times of drought, physical conditions were more favourable than elsewhere, intercommunication between the various groups and their constituent tribes became less and less frequent, and thus, in course of time, the dialects arose. While words, more or less with ease, can be modified and changed in savage 


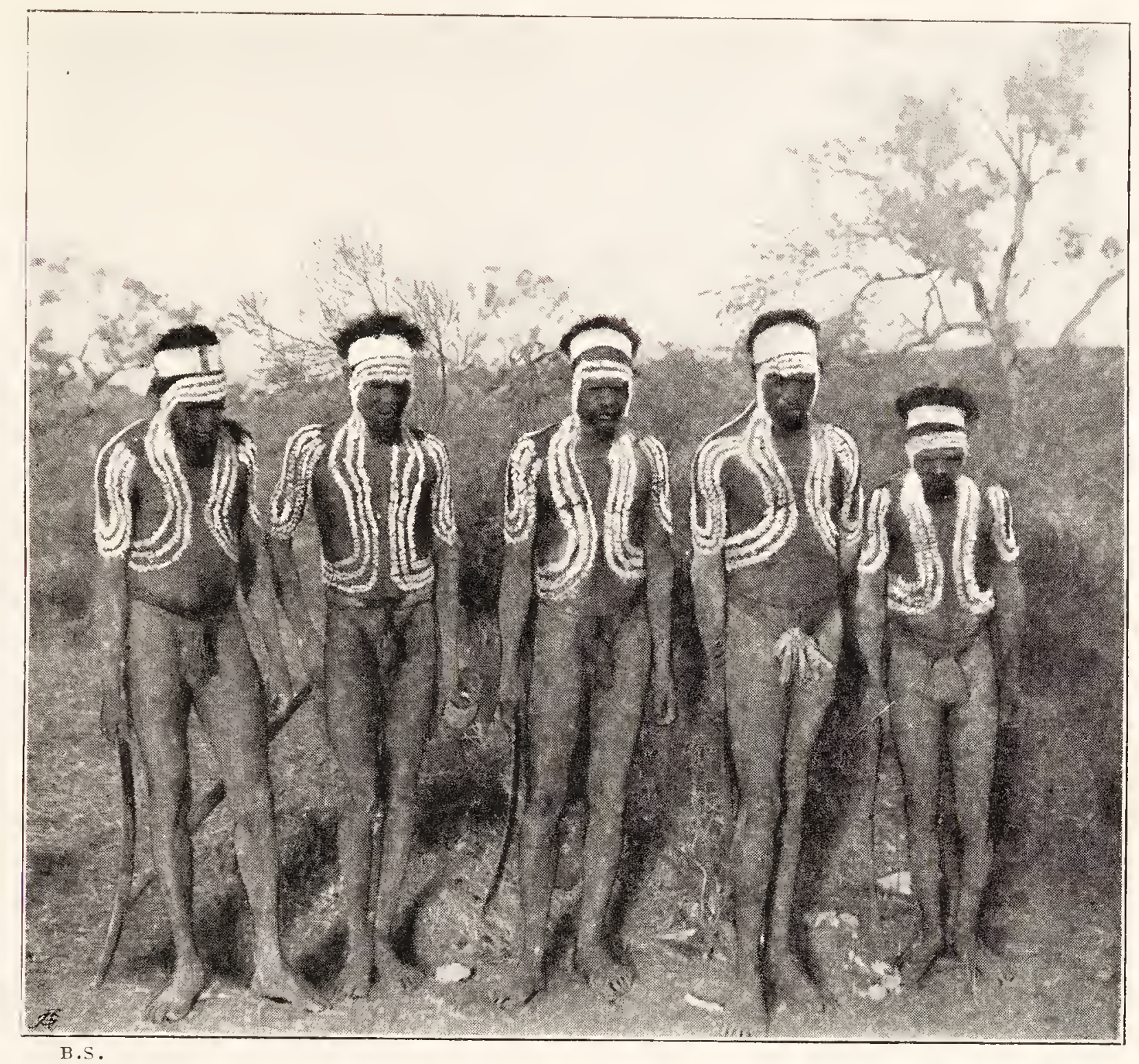

FIG. 385.-DECORATION OF PERFORMERS IN A CEREMONY CONNECTED WITH THE FIRE TOTEM, TJINGILLI TRIBE.

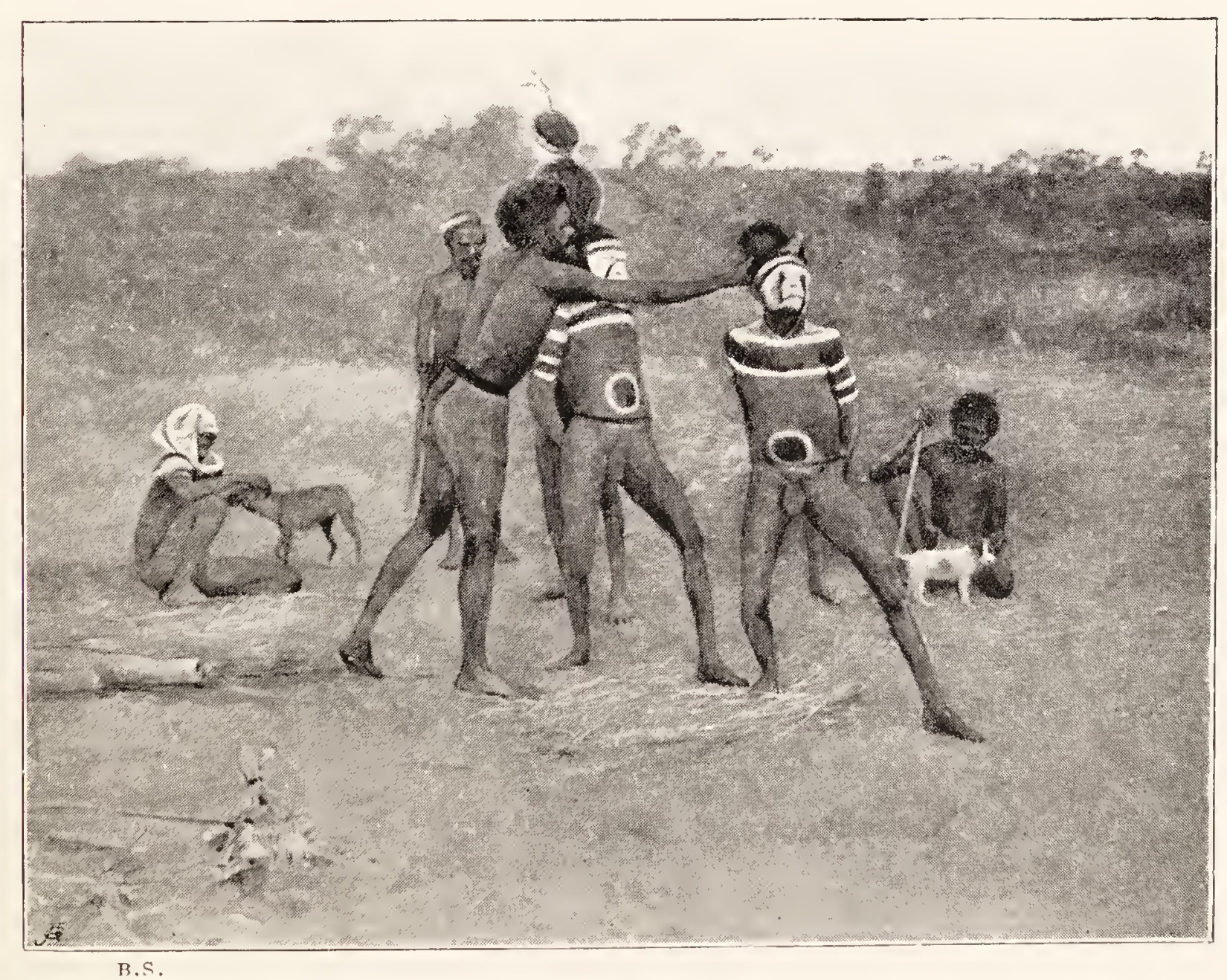

FIG. 3 S6.-CLOSE OF A CEREMIONY OF TIE YAM TOTEM, TJINGILII TRIBE. 

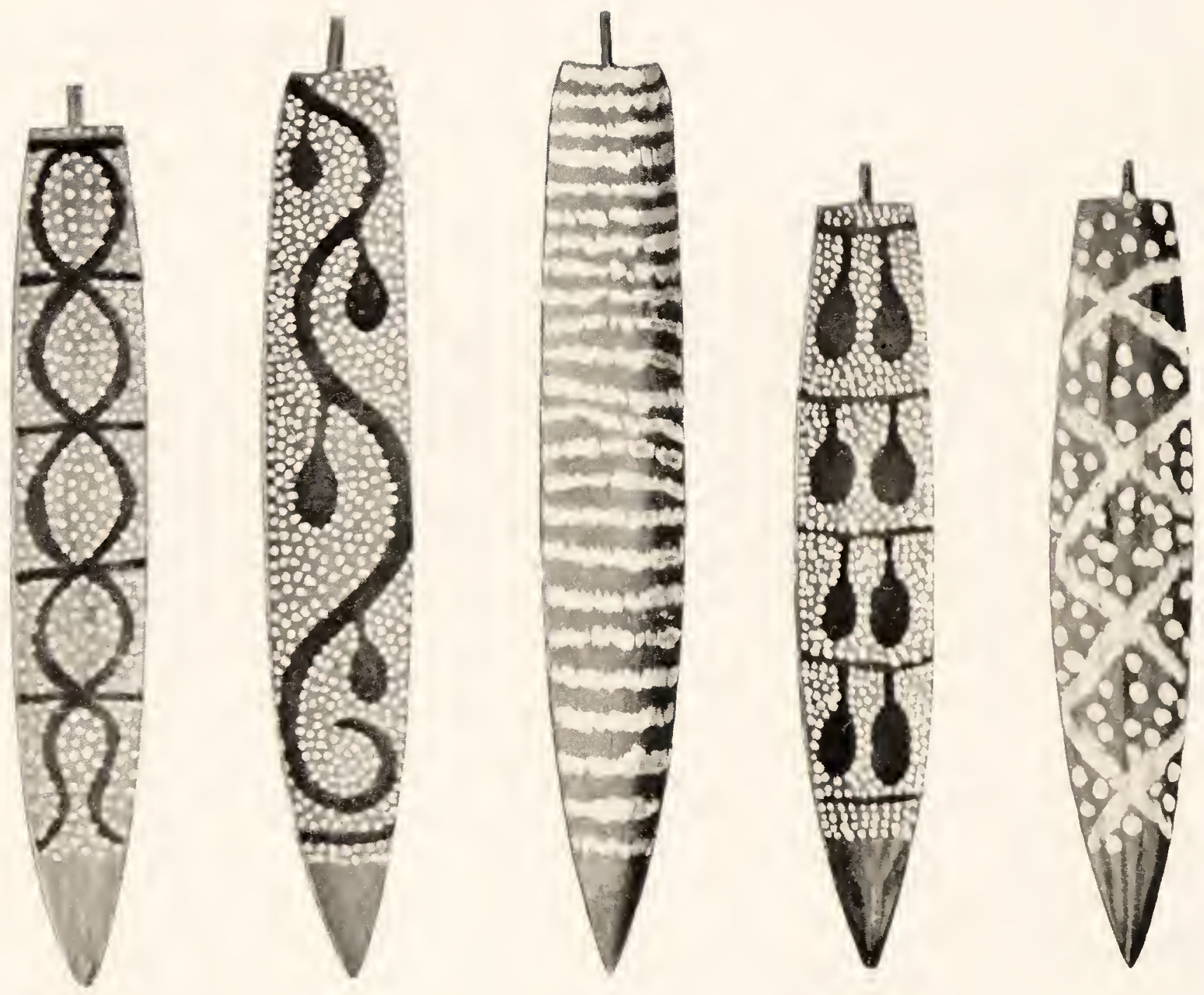

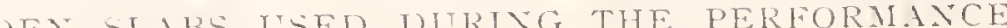

OF CEREMONIES CONNECTED WITH TIE YAII TOTEM, TJINALA TRIBE. 
tribes who have no stabilising written language, it is quite otherwise in the case of customs and beliefs, more especially with those that are associated with sacred matters and are thus fortified and made permanent by the existence of what is the equivalent of the "religious sanction " amongst more highly developed peoples. At all events, when once such things have become settled, they are, of all things, the least likely to change amongst savage people. It has probably thus come about that, whilst there is agreement in fundamental points amongst the Central tribes in regard to organisation and customs, there is a marked difference in regard to dialect.

The Tjingilli men were engaged in the performance of a series of totemic ceremonies that, in general features, were very closely similar to the very many that we had seen amongst the Warramunga at Tennant Creek. The whole series was called $W$ antju, and the object of their performance was to ensure the growth of the boys and girls, to make the former grow up strong and able to fight and endure, and to make the girls plump and well formed from a native point of view. We saw ceremonies concerned with the "laughing boy," fire, yam, eagle-hawk and white cockatoo totems (Figs. 385,386$)$. In some of those of the yam totem, decorated slabs were used, on a few of which the designs clearly represented yams attached to their roots, but, as a general rule, no relationship could be traced between the decorations and the totemic animals and plants (Fig. 387). The performance always took place just at sunset, when the decorated men, representing the different totems, came and stood in single file, with their backs towards the audience, amongst whom one or two men stood up and struck their clubs with short staves. To the accompaniment of this clanging noise, the performers walked out, one by one, each of them usually holding a boomerang upright behind his back, and then crouched down behind a bush so as to hide themselves. After the men had gone away there was a 


\section{WANDERINGS IN WILD AUSTRALIA сн. XXII}

short pause, and then the clanging was resumed and, one by one, each came out from his hiding-place and, with exaggerated high-knee action, walked on to the ceremonial ground and stood with his back to the audience, moving his body from side to side with a jerk as he kept time to the clanging of the clubs. His head was suddenly pulled backwards and the ceremony was over. In the case of the white cockatoo and eagle-hawk ceremonies, the performers marched out, imitating the cry of the birds, and continued to do so all the time they were hidden behind the bushes and while they walked in again.

Etiquette counts for much amongst the natives. While we were watching a yam ceremony, one of the men suddenly retired to one side and, sitting down on the ground, began to howl loudly. No one took the slightest notice of him, and it was quite evident that his grief was not proportionate to the noise he was making. We found that, some years ago, his brother, now dead, used to perform one of the ceremonies, and he was supposed to be so overcome by the recollection of his dead brother that he had to retire and give vent to his feelings. There was also another little bit of etiquette that we noticed. Two or three Warramunga men were visiting the Tjingilli camp, and, being fully initiated, they were, of course, allowed to witness the ceremonies. After having seen the latter, however, they were under a ban of silence until such time as they had made a present of food to the men in charge of the performance. This, of course, did not mean any great trouble to themselves. They simply sent their women-folk, whom they had with them, out into the scrub to gather grass-seed and make a damper, which, on the second night, they brought to the ceremonial ground and handed over to their hosts. The Tjingilli men, one after the other, struck their heads lightly with a green gum twig and thus released them from the ban of silence. 


\section{CHAPTER XXIII}

POWELL CREEK TO THE GULF OF CARPENTARIA

IT was now early in October and we were within the north-west monsoonal area, where, so far as climate is concerned, the year has two divisions, a rain season extending from October to April and a dry one from May to September. Very pleasant though it was at Powell Creek, we felt compelled to move on without delaying longer than was necessary for us to do work that was essential. The country that we had to travel between Powell Creek and the Gulf of Carpentaria was liable, during the rain season, to torrential downpours that flood the lowlands far and wide and, even when the waters dry up, leave them for weeks like quagmires, over which travelling is absolutely impossible. As we traversed the country we saw flood wrack piled up in the tree branches ten to twelve feet above the ground, and this in parts miles away from the nearest watercourse. The only chance that any belated travellers, caught in one of these sudden floods, have of saving themselves, horses and impedimenta, is to camp on any rising ground, if such by good fortune be near at hand. Here they must remain, sharing their island refuge with countless numbers of scorpions, centipedes, rats, lizards, snakes and creeping things innumerable, that, like themselves, have succeeded in escaping from the flooded lowlands. This is by no means an uncommon experience during the rain season, and tales are told of more unlucky travellers who have been forced, in the absence of rising ground, to take to the trees and stay there for days. Others, still more 


\section{WANDERINGS IN WILD AUSTRALIA $\mathrm{cH}$.}

unfortunate, have been swept away, bag and baggage, leaving not a trace behind them, their bodies and everything they possessed buried in some unknown spot, deep beneath the flood wrack. It is quite likely that Leichhardt and all his party were swept away, and all trace of them obliterated, in one of these sudden floods.

Once more Chance and the wagon went on ahead and, after a careful inspection of our buckboard, we decided that it was too shaky and dilapidated to make it safe for us to trust to it further and take it across the rough country between the telegraph line and the Gulf, so Gillen and myself packed our little impedimenta on two strong packhorses and, taking these with us, rode away north.

We were now almost in the centre of the Lake Woods Basin, over which we had been travelling ever since leaving the line of watershed in the Macdonnell Ranges that forms its southern boundary. The elevation of the Burt Plain, where we had come down on to it from the Ranges, is 2600 feet, and we had been gradually descending, until now, close to Newcastle Waters, our height above sea level was only 700 feet, with the land rising slightly in every direction. We were, in fact, in the middle of a great saucer-like depression centering in Lake Woods. From Powell Creek we had been travelling north, on the west side of the Ashburton Range, crossing a few creeks, such as the Fergusson, that come down from the hills and flow into the Newcastle. The latter itself rises away to the east of the Ashburton-its course has not yet been definitely marked out-flows round the northern end of the Range, and then turns abruptly south, running parallel to the latter, never more than two or three miles away from the hills, for a distance of between thirty and forty miles, when it empties itself into Lake Woods. The term "Lake" is not altogether an appropriate one to apply to this sheet of water. It is very variable indeed in extent and 
outline, dependent entirely on the nature of the seasons, and is formed, for the most part, by the overflow of the flood waters of the Newcastle and other smaller streams. Like Lake Eyre, it has no outlet to the sea but, fortunately, the northern part of the inland basin that centres in it is well within the area affected by the north-west monsoons, and consequently an annual rainfall can be depended upon. The average at Powell Creek is more than eighteen inches and the fall increases to the north, so that this inland basin has, so far, escaped the fate of the region round Lake Eyre.

As we travelled on we crossed mile after mile of country covered with herbage and sloping down to the banks of large, permanent water-holes-the home of flocks of pelican, geese and ducks. It was now the end of the dry season, the water-holes had shrunk to their lowest level and the herbage was at its driest. In the wet season a large part of the country round these Newcastle waters-including the whole of the Sturt Plains, stretching away for nearly twenty miles to the north-is under water to the depth of a foot. When the water drains off, the herbage and grass that grow on the black soil are, as can be imagined, luxuriant. In all these pools, some of which may be miles in length, the water has a very characteristic, almost milk-white colour, due to the presence of innumerable white particles of clay material, derived from a shale formation underlying the sandstone rocks of the Ashburton Range. We could almost imagine, as we drank our tea, that we were indulging in the luxury of milk.

The water-holes contained plenty of mussels, water snails and small fish, on which flocks of cormorants and pelicans were feeding. Some of the mussels showed very clearly the nature of the recent seasons in those parts. Each of them had a small complete kind of shell, the last two or three lines of growth in which were very close together, 


\section{WANDERINGS IN WILD AUSTRALIA $\mathrm{cH}$.}

then followed a wide margin lighter in colour and thinner than the older part. The explanation of this remarkable variation in the width of the zones of growth is that the animal grew the first shell during the relatively severe droughts of the two years previous to our visit, during which the water receded and it could do nothing but lie in its hole in the damp mud, with only a minimum of food to allow of growth, so that its body and, in consequence, its shell remained small. Then, when the rains fell and food became abundant, it set to work and grew rapidly, adding the broad margin.

About seventy miles north of Powell Creek we tapped the telegraph line for the last time, "spoke" to Powell Creek in the south and Darwin in the north, and then turned off eastwards into the scrub. We travelled far enough north to avoid having to traverse the Ashburton Range, the extreme northern end of which we rounded. The country was decidedly rough-in fact we had our first experience of what is known as "Bay of Biscay" country, a characteristic feature of this part of the Territory. During the rain season the floods extend far and wide over the low-lying flats, which for miles are covered with long grass or are at most only thinly wooded. When the waters dry up, the intense heat cracks and furrows the black soil, forming, as it were, waves of hard earth over which horses stumble wearily along and wagons jolt and bump incessantly. For the first time we met with the gutta-percha or india-rubber tree (Excecaria sp.), a rather small tree with a very sharp, angular growth of branches to which the small, leathery leaves adhere closely (Fig. 389). When the bark is cut it exudes a thick whitish fluid that soon sets like gutta-percha. Both natives and white men are careful how they handle the juice, because, if it comes in contact with the soft membrane of the eye, it sets up severe inflammation that often results in temporary blindness, 
indeed one of the bushman's names for it is "blind-youreye." We soon got to dislike it, because it grew on "Bay of Biscay" country and was a sure sign of uncomfortable travelling. On the other hand, we were always glad to see the "Lance," or "Hedge Wood " tree (Macropteranthes Kekwickii), so called because its branches, usually ten to fifteen in number, radiate out straight from an underground bole. Its leaves are small and prickly, rather like those of the Mulga, and though, when growing close together, they form a dense scrub, yet they are always a sign of better country, where travelling is comparatively light and easy, and where also we might expect to find some food for horses.

The scrub soon hid the telegraph line from view and we rode along in the heat until, towards sunset, we came to a broad creek bed, really part of the Newcastle, which was only distinguishable from the rest of the country because there were fewer trees growing on it than elsewhere, and also because the ground had a coating of fine silt and was scarred with deeper cracks than usual, where the water had lain longest. Following this up over a flat, we came upon a water-hole-its contents milky-white as usual-and camped beside it. The grass tussocks were very dry, so we carefully cleared a patch around our camp, to make us secure in case of fire, and, using the long grass stalks as a mattress, lay down to sleep, lulled by the buzzing of countless mosquitoes. It was a warm, close night. At 9 p.m. the thermometer registered $85^{\circ} \mathrm{F}$. and at sunrise next morning $76^{\circ} \mathrm{F}$. Travelling on, we found we had been camping within a mile or two of a station, dignified with the name of Betaloo Downs and situated by the side of an extensive sheet of milk-white water called Bates Lagoon-one of a series of three fine water-holes in the bed of the Newcastle. The country out to the east was low-lying, but on the west there were slight rises, only a few yards high, but still elevated enough to serve as a 


\section{WANDERINGS IN WILD AUSTRALIA $\mathrm{cH}$.}

retreat in time of flood. At first we looked in vain for the station, misled by the dignified title given to it, but, on coming nearer to the water's edge, we discovered it and were cordially welcomed to Betaloo Downs by Mr. Bostock, one of its proprietors, who, fortunately for us, was at home. The station was certainly unpretentious and well adapted to the open-air life, and we spent three very pleasant days camped close by (Figs. 390, 39 I).

It was just about the most primitive thing in the way of a "station" that could be imagined. There was an ancient tent-fly that covered a sleeping-room, all openfront, back and sides-close to this was a bough wurley that did duty as a dining and sitting room, with an old box that served as a table, but no such thing as a chair. There was just room on it for the main dishes-bread and beefyour plate you held on your knees or placed on the ground, whichever chanced to be the more convenient. The only other building was a platform with a bush roof. Here the supply of beef was kept safely out of reach of the camp dogs. Close by was a small railing round an open fireplace, where two lubras, not over-dressed, did the cooking. At one end of the station buildings was an old gum tree and at the other an india-rubber tree (Fig. 389). It was close by the water edge, so that, when water was wanted for drinking or domestic purposes, it was quite handy, and a lubra simply waded in with a bucket (Fig. 388). When the heavy rains come, the water-hole spreads over the station and the proprietors and staff retire to a bark hut, conveniently built on a low rise close by, and here they sit down quietly for a month or two, until the station and country once more dry up.

We had ridden on from the telegraph line and, as it was the first time that we had come across any genuine "Bay of Biscay" country (Fig. 392), we were anxious to know what Chance, who was behind us, thought of it and how 


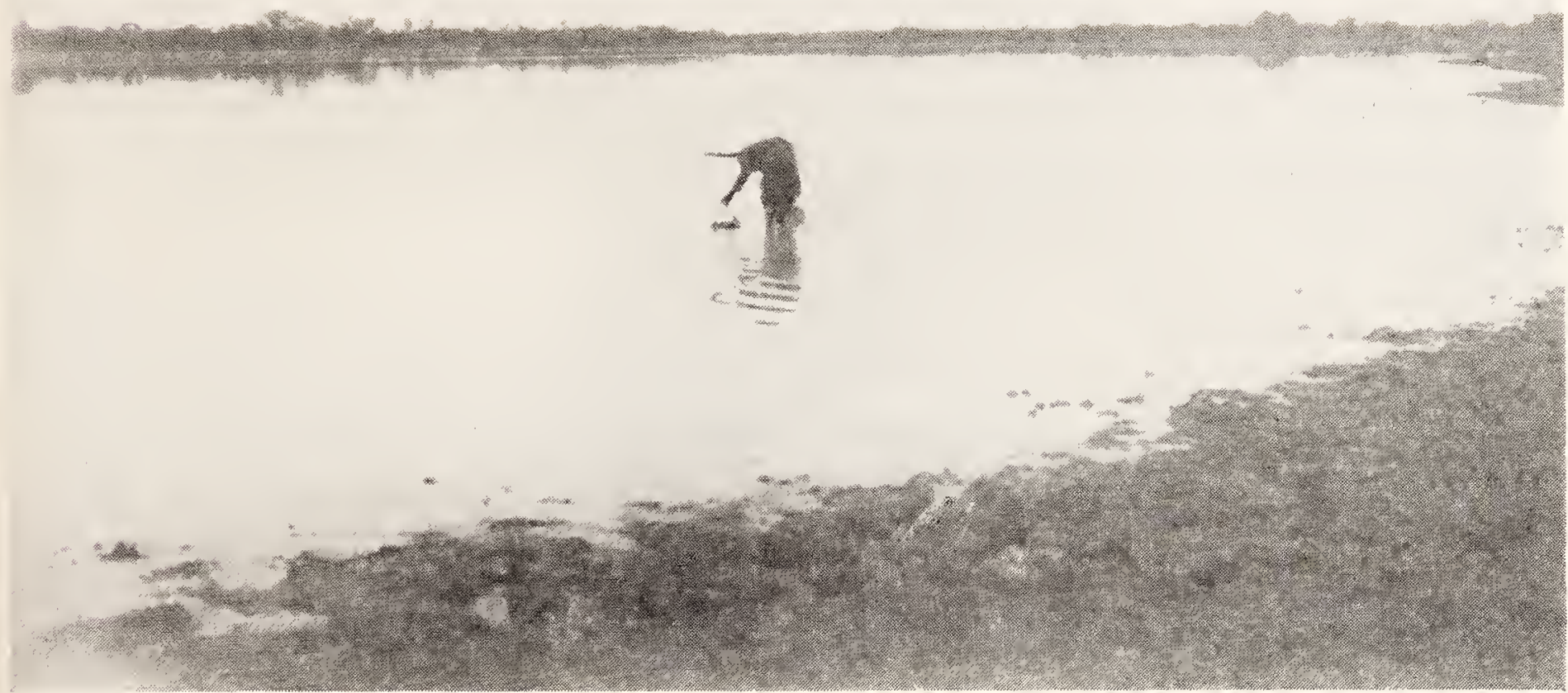
B.S.

FIG. 388.-BATES LAGOON.

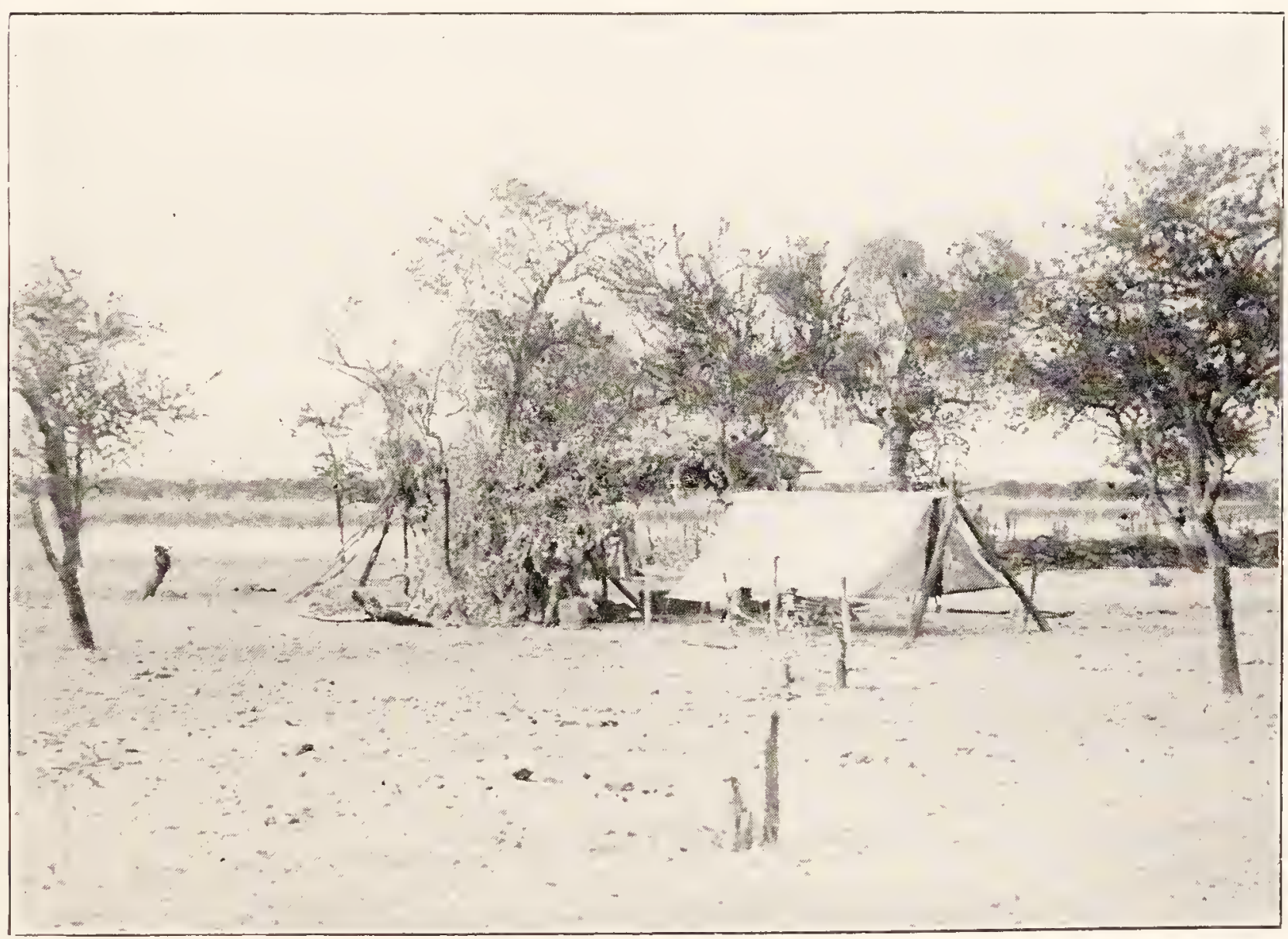

B.S.

FIG. 390.-BETALOO DOWNS STATION, FRONT VIEW.

Bates Lagoon is seen in the background. 


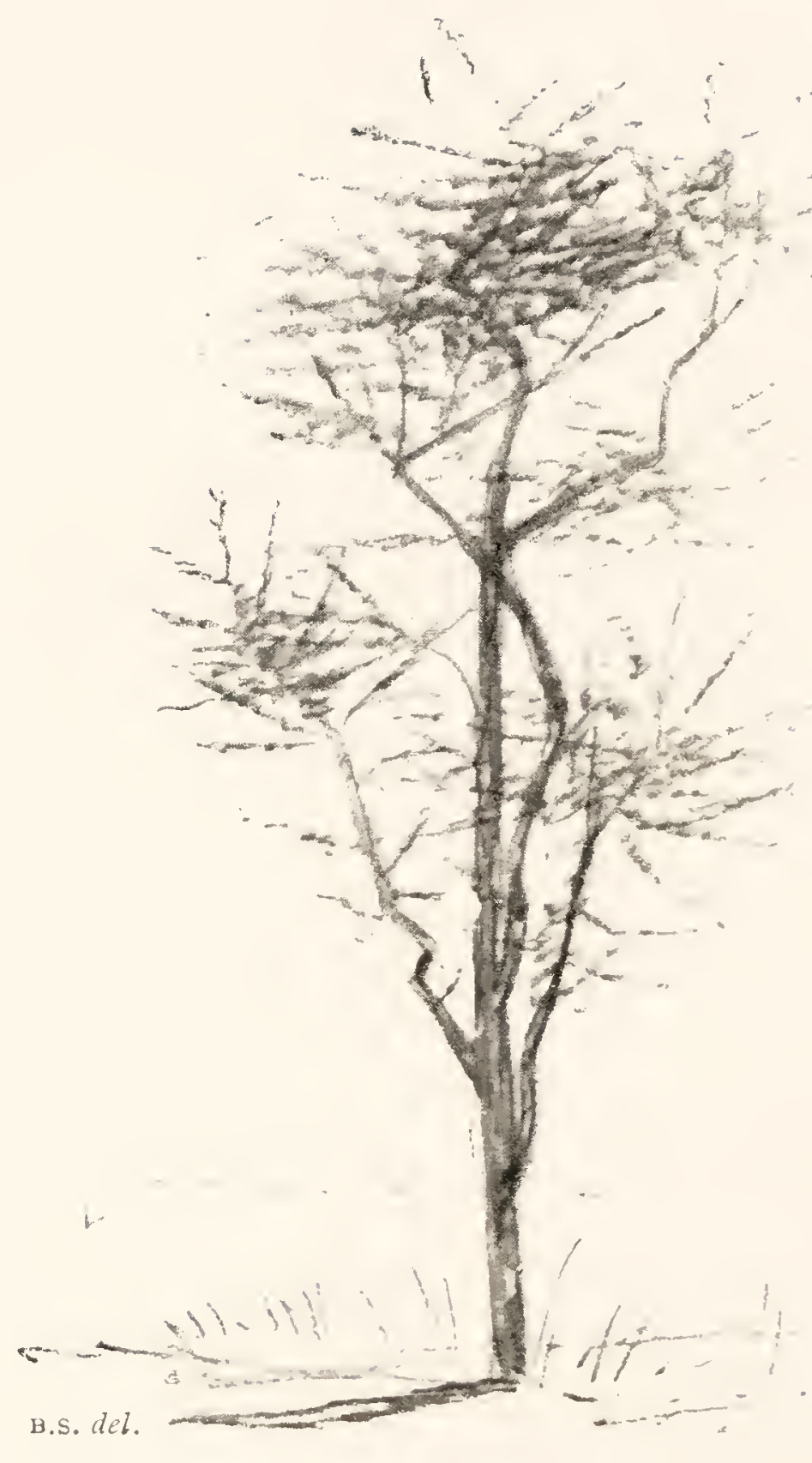

FIG. 3S9.-INDIARUBBER TREE. 
the wagon and its contents had stood the jolting. When at last the team came in, Chance, whom usually nothing whatever disturbs, declined to say anything-he had absolutely nothing left to say. We set to work to lighten the load as much as we could, with the help of Mr. Bostock, who came to our assistance by taking over such of our stores as we thought it safe to discard, trusting to our being able to replenish them at Borraloola. Chance meanwhile was replacing four broken bolts, evidently, judging by his silence, deep in thought as to what would happen before we reached the Gulf.

Close by the station there was a native camp, and we were not a little surprised to find that the natives knew all about us and were actually expecting us. We found out afterwards that the Tjingilli men, without saying anything to us, had sent messengers on ahead to tell the natives that we were coming and that we were friends. Bartering with them, I got thirty stone-headed spears, a dozen stone knives and two hafted ground stone axes that are now very difficult to secure. Large wooden pitchis and shields, though very tempting because they were of excellent workmanship, I had reluctantly to pass by, owing to difficulty of transport. Here also we came across a special and rather rare form of spear-thrower that seems to be made only in this part of the Centre. The shaft is a straight, round stick about three feet long, slightly tapering to one end, at which a bluntly-pointed wooden knob is attached by means of a lump of porcupine-grass resin. At the handle end there is a tassel of human hair string that helps in gripping (Fig. 4I2). We were much amused with one of the natives who brought a half-crown to show us, evidently regarding it as something that must be quite new to us. The natives of course never see money and have no idea of what it means. For the matter of that, the white men in the Centre rarely, in those days, possessed any coins, 


\section{$53^{6}$ WANDERINGS IN WILD AUSTRALIA сн.}

all business being transacted by cheques that passed from hand to hand, until they were often so dilapidated as to be scarcely recognisable or negotiable. This half-crown had evidently been originally given to a native by a white man in Darwin or Borraloola and had at last found its way to this remote place, and its owner was astonished and delighted to find that it was worth twenty sticks of tobacco.

We built a little bough shelter for ourselves, or rather our boys did, to give us some shade, as the sun was shining hotly and a warm wind was stirring up the sand, blowing our papers about and making things generally uncomfortable, save that it kept the flies off to a certain extent. However, they returned to the attack as soon as ever the wind died down for a time. Early in the morning it was cool and perfectly quiet and, from my bunk, I could see the water-hole with the trees reflected in it, and its surface only ruffled with ripples where a flock of ten large pelicans were leisurely swimming about, one or other of them dipping down to reappear with a fish in its pouch. It is interesting to watch them when they come to feed at a water-hole. You can see them far away, high up in the sky, flying along in single file. From above the pool they aeroplane gracefully down in a spiral line and alight on the water in a wide circle, then, splashing about, the circle narrows into a small one, evidently with the aim of frightening the fish and driving them into a small space where they can easily be caught. When the birds dip down into the water they always spread their wings out, apparently to act as balancers. The natives catch fish by means of a very simple contrivance. They take a hollow log from four to six feet long and perhaps a foot or more in diameter, which they have no difficulty in finding, because the white ants provide them with plenty, and lay it down lengthwise in the shallow water. As a general rule they leave it alone for a day or two and then, wading in, quickly close up each 


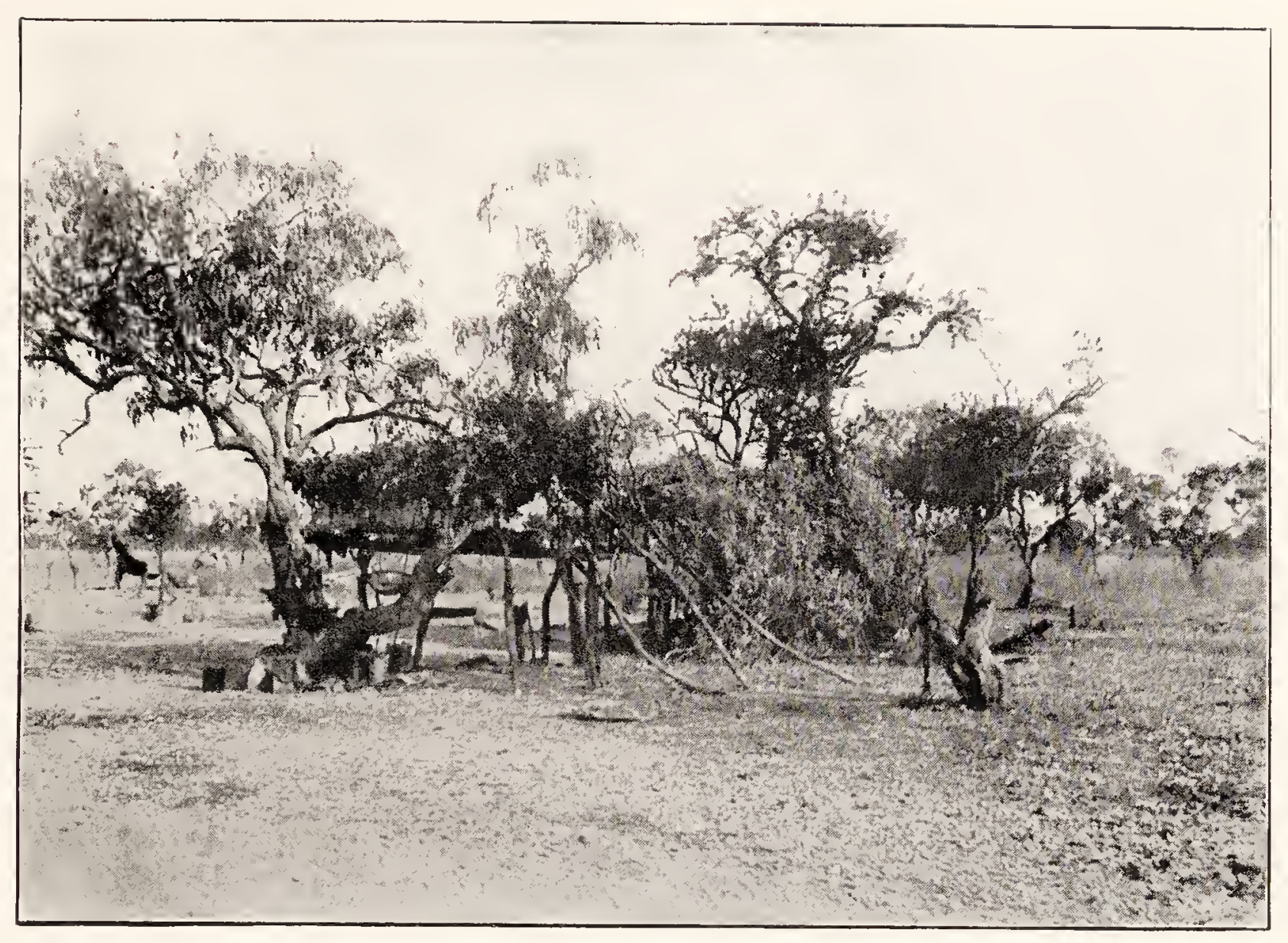

R.S.

FIG. 39I-BETALOO DOWNS STATION, BACK VIEW.

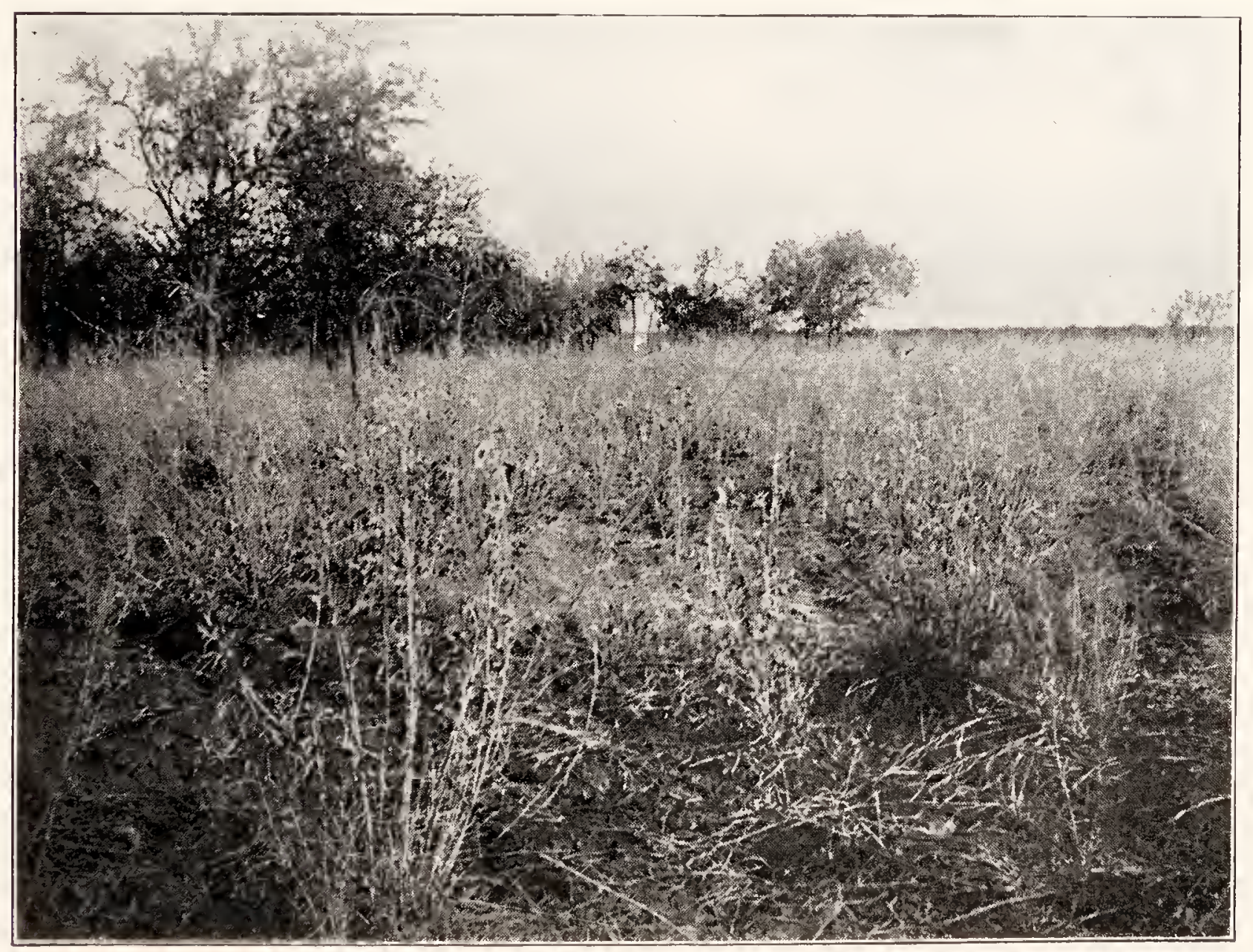

R.S.

FIC. 392.- "BAY OF BISCAY" COUNTRY. 


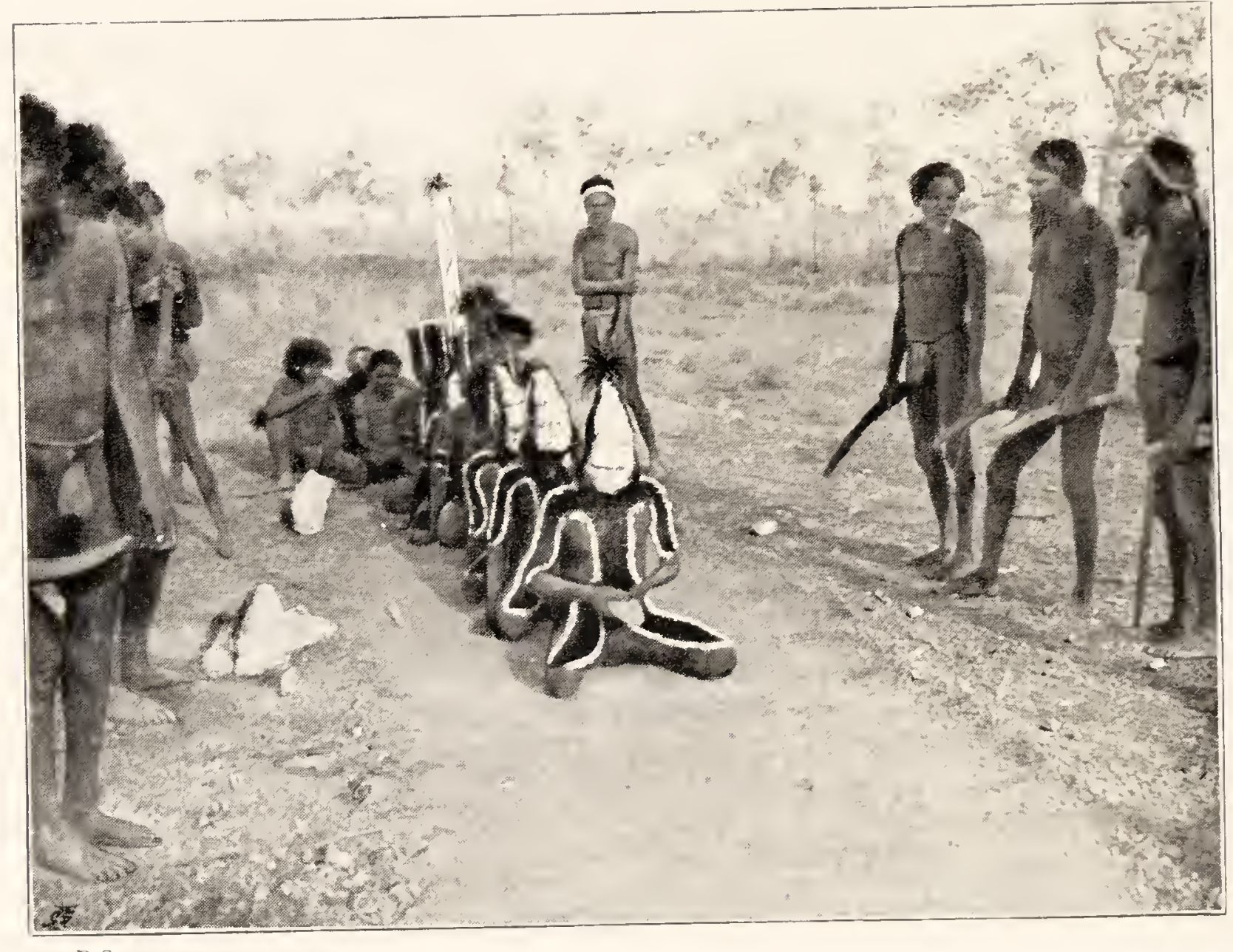

FIG 393.-PERFORMERS ON THE CEREMONIAL GROLND. CEREMONIES CONNECTED WITH THE FLY, LIZARD, AND WALLABY TOTEMS, UMIBAIA TRIBE.

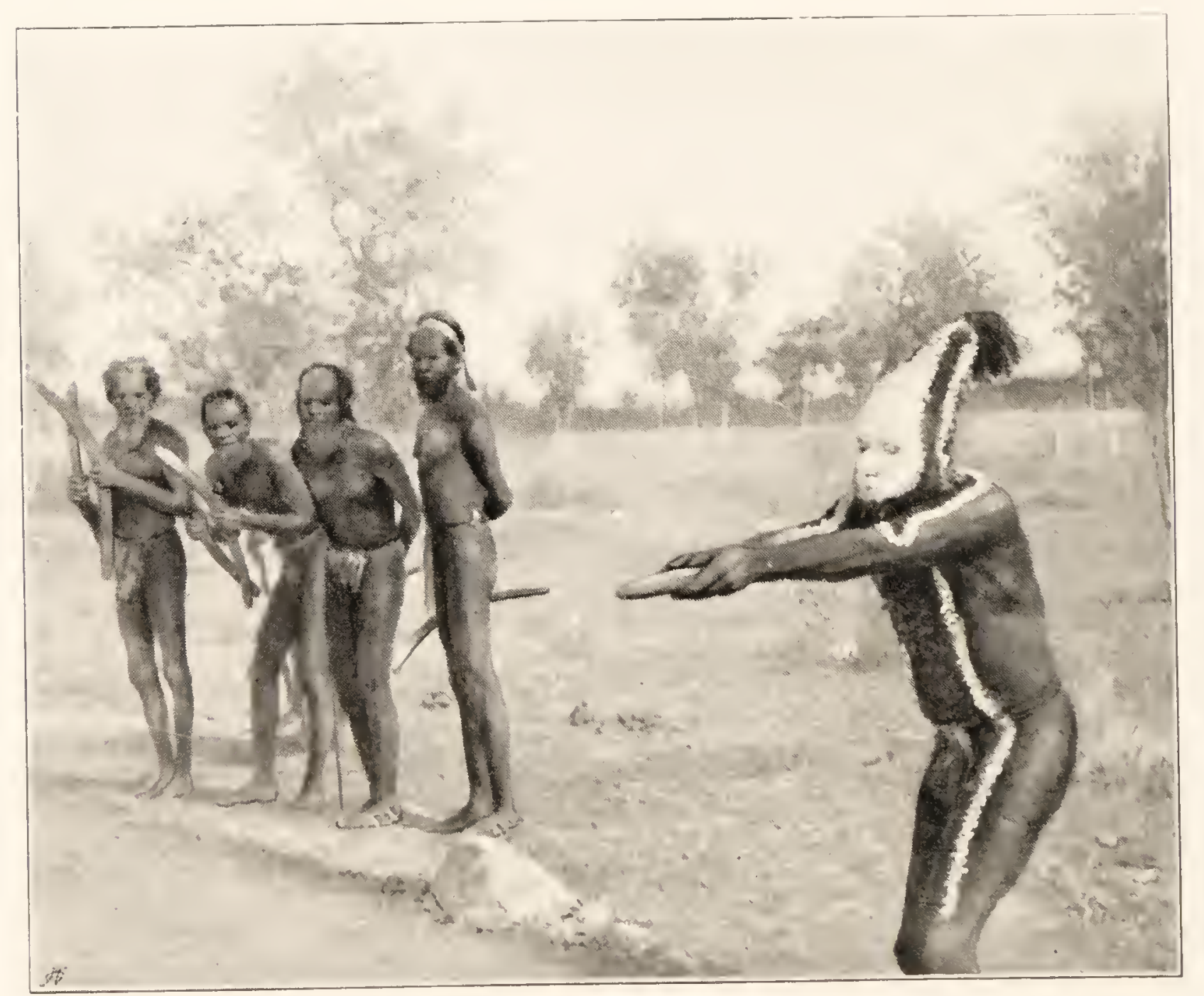

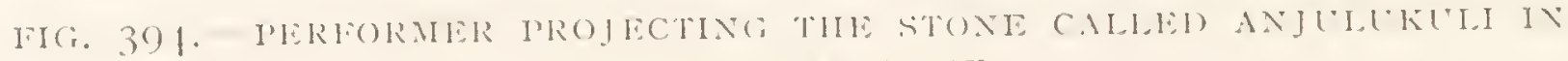
THE LMHAI TKIBE. 
end with grass, carry it on to land and turn out the fish, which seem to go into these logs in numbers. In this pool the fish, usually a kind of bream, were only six or eight inches in length, but the natives could always depend on getting plenty. As soon as caught they are baked in hot ashes and form quite a palatable dish, though the number of bones is rather trying to a white man.

We were now on the fringe of the country occupied by the Umbaia tribe, and were glad of the chance of learning something about them. They are usually called Wombaia, or Wumbaia, by the whites, but this is not the correct name. A blackfellow is often so willing to fall in with what he fancies to be the wish of the white man that if, for example, the latter calls him Wombaia instead of Umbaia, he will cheerfully agree to the change, in order, as he thinks, to please the white man. Thus mistakes arise and are perpetuated.

The Umbaia have just the same belief in regard to totemic ancestors as the Warramunga and very much the same kind of traditions associated with them. 'The three large water-holes at Betaloo had been made, respectively, by a green snake, a water snake and a fresh-water mussel man. Each of the ancestors had left spirit children behind them, and it is these who now come to life in the form of men and women.

They call their sacred ceremonies Arambatja, and though, so far as their significance and the decorations of the performers are concerned, they are practically identical with those of the Tjingilli and Warramunga, they differed in detail in regard to the actual performance. This is true of the different tribes, and, without knowing previously whether any particular ceremony that you were watching the performance of belonged to the Arunta, Kaitisha, Warramunga, Tjingilli or Umbaia tribe, the method of procedure would reveal the fact at once. We went on VOL. II. 


\section{WANDERINGS IN WILD AUSTRALIA ch.}

to the ceremonial ground, which was some distance away from the main camp, just over the brow of a slight rise, so that its performers, though the scrub was thin, could not be seen by the women and children in the main camp. The ceremonies were concerned with two lizard totems, a fly, a wallaby, a little bird and a snake totem. A space measuring about thirty feet in length by five or six in width was cleared of grass and débris and smoothed down to form a definite ceremonial stage such as we had not seen in other tribes. At one end of this the performers squatted on their haunches, one behind the other. The audience arranged itself in two lines one on each side of the stage, with a few men, including two from the Gnanji tribe, seated on the ground immediately behind the performers (Fig. 393). The front man carried a curious, oval, red-ochred stone that he held in both hands. It is called Anjulukuli, but the natives had no idea as to its significance. All they know is that a stone like this has been, and always must be, used and that it forms an essential part of the paraphernalia of the ceremonies. When all was ready the audience began to clang their boomerangs, and the front man, rising to his feet, ran along to the end of the stage with the usual high-knee action, turning his body from side to side as he pushed the stone out at arm's length (Fig. 394). The action was continued for a short time and then he ran back to the other performers, squatted down in front of the leading man, placed the stone in his hands and, having done this, joined the audience in the background. Exactly the same thing was repeated in the case of every man, and, during the performance of one of the lizard ceremonies, two of the audience retired to one side and wailed aloud-just as the man had done in the Tjingilli ceremony at Powell Creek and for the same reason. There was one curious little ceremony quite unlike anything that we had seen 
before. In a performance connected with a snake totem, a wooden slab, decorated with spots of down enclosing a central sinuous line of black, was worn on the head of one of the performers, as can be seen in the illustration (Fig. 393). When the performance was over it was taken from the man's head and broken by bending it over the back of another man. This was done to prevent it from being used again, and I secured the two fragments as a memento of the performance.

From Betaloo Downs our track lay, generally, towards the north-east. We took on with us an extra black boy in the person of a Gnanji native to show us the waterholes. He was marked with very strong cicatrices across his chest and, when he started out with us, had his hair done up in numbers of plaits (Fig. 395). When he undid these it stood out in the form of a frizzy mop like that of a New Guinea native on a small scale. The first waterhole lay to the south of our main route, so we arranged that Chance should take the wagon on as far as he could while Gillen and myself with the pack-horses went to the water, to which the boys would bring the wagon horses. The summer was coming on, the weather getting much warmer and the holes drying up rapidly. It was just getting dark when the horses came in, Chance having gone as far as he could so as to shorten the next day's journey. The temperature in our last bush shelter at six o'clock in the evening was $103.5^{\circ} \mathrm{F}$. The country all around us had been fired and looked as desolate as possible, so we were not sorry to be up early, before 4 a.m., and rode straight across very rough "Bay of Biscay" country until we came to where Chance was camped with the wagon and our two other boys. After seeing that Chance and the wagon were all right, we rode on ahead with the pack-horses. The country was awfully rough, with holes and cracks in the ground over which our horses stumbled 


\section{WANDERINGS IN WILD AUSTRALIA ch.}

along, every now and then nearly tumbling over on their noses. Early in the afternoon we reached a water-hole called Munda, and decided to camp here for a day to give the horses a rest in a place where we were sure of water and feed. The water-hole was fed by streams that came down from the Ashburton Range, so it had the usual milky-white colour and was surrounded by swamps, covered with a wiry shrub called Lignum (Fig. 396) that grows in great bushes and has a bluish colour. I wandered round the lagoon and sat down quietly watching the birds. A dozen kites were flying round, swooping down every now and then upon little flocks of chestnut-eared finches. Mobs of galahs with grey bodies and rose-coloured crests, perched on trees or, searching the ground for seeds, screamed as, every now and then, they rose in flocks and flew around, and amongst them a few black cockatoos, with yellowbarred tails, added to the din. Little green parakeets were flying about in dense flocks, flashing glittering green from their wings as, in perfect unison, they wheeled round and round in the sunlight. Around the water's edge white cranes and ibises and spoonbills were solemnly stalking about, digging down every now and then into the mud in search of food. One solitary old pelican came and settled down in a dignified way in the middle of the pool. He seemed to regard himself as superior to the noisy crowd around him and kept aloof from all the others, quietly fishing on his own account. All along the line we had seen and heard little flocks of babblers (Pomatostomus rubeculus), or, as the natives call them, in imitation of their cry, Tjuokitcha. A little to the north of Powell Creek we saw the last of them and, from Newcastle Waters onwards, their place was taken by troops of cat-birds (Struthidea cinerea) that were quite as noisy and restless. They are nearly allied to the bower bird, only, instead of making a bower and playing on the ground, they dance up and down 


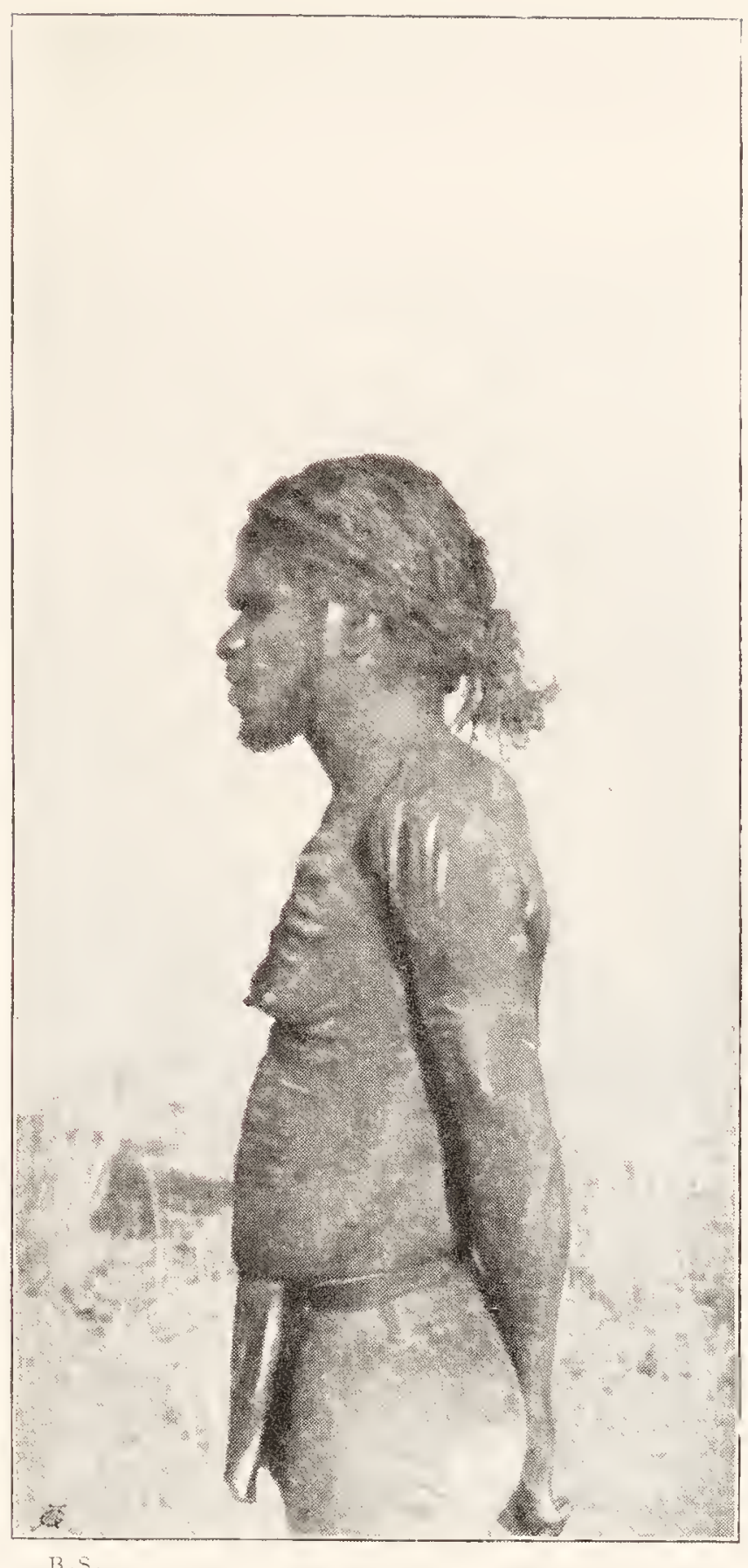

13.5

FIG. 395.-SIDE VIEW OF A MAN OF

THE GNANII TRIBE, SHOWING THE

METHOD OF PL.IITING THE HAIR.

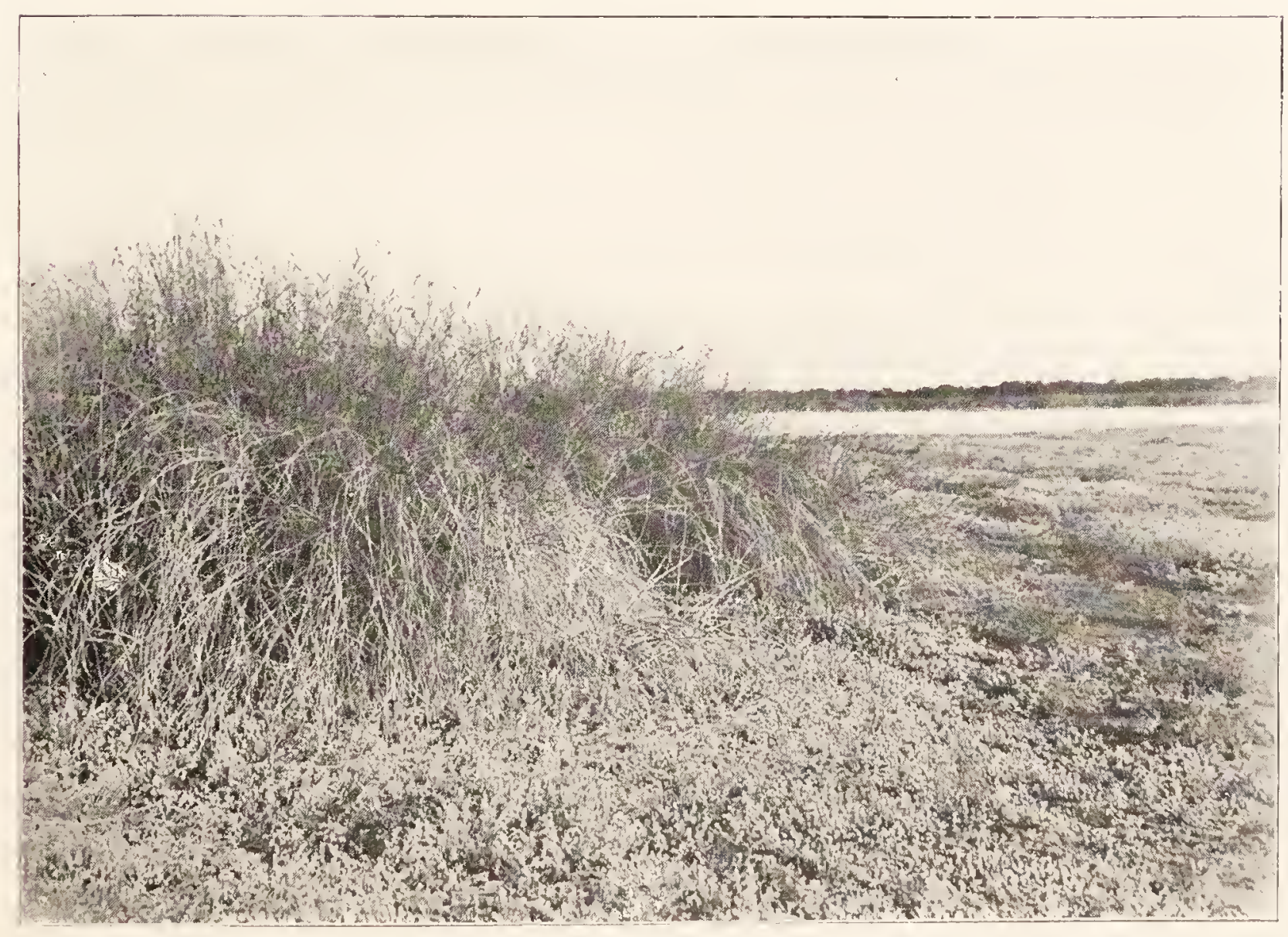

B.S.

FiG. 396.-LIGNUM SIVAMP. 


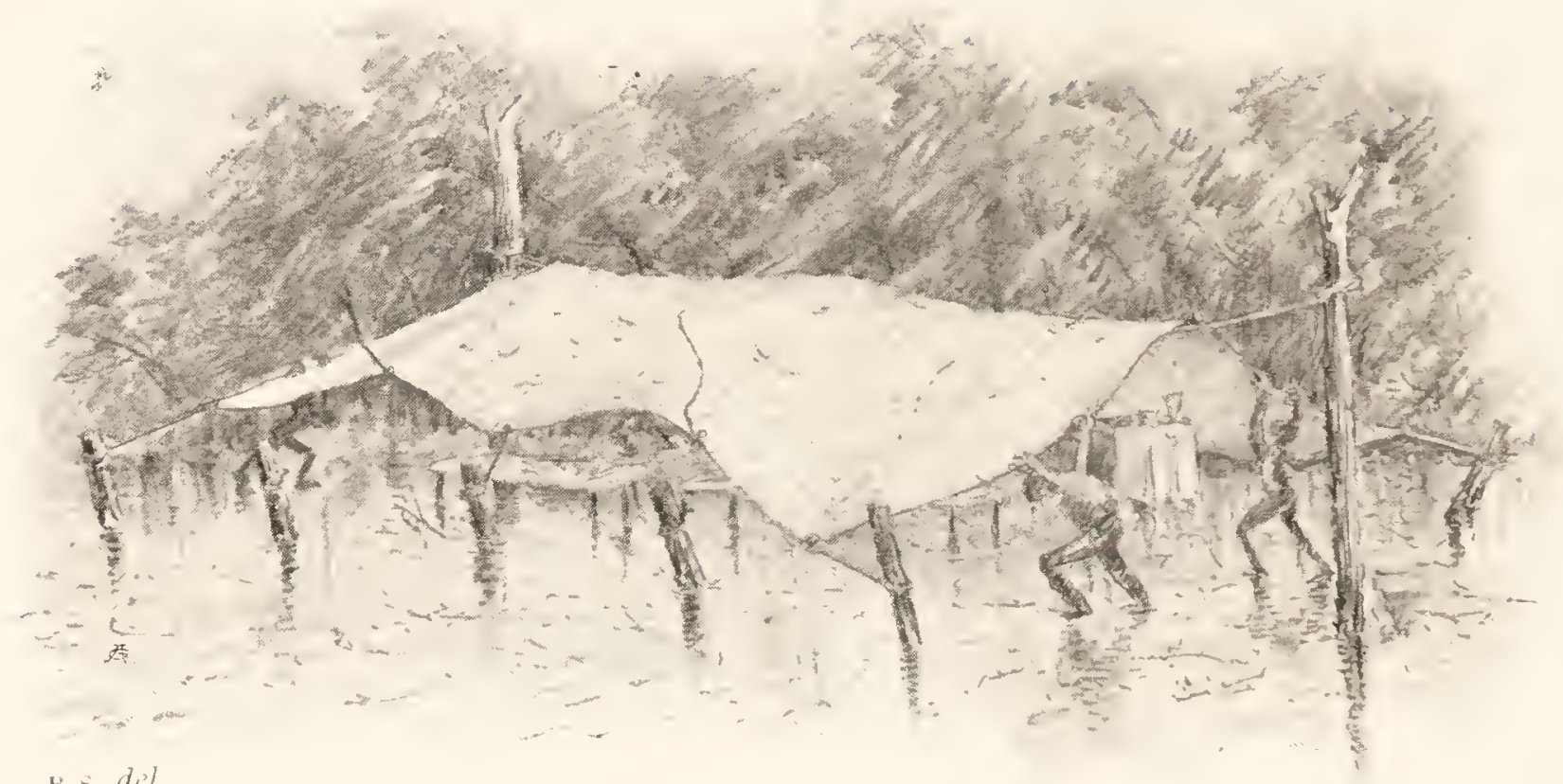

FIG. 398.--STORM ON THE LEILA CREEK. HIOLDING ON TO OUR TENT.

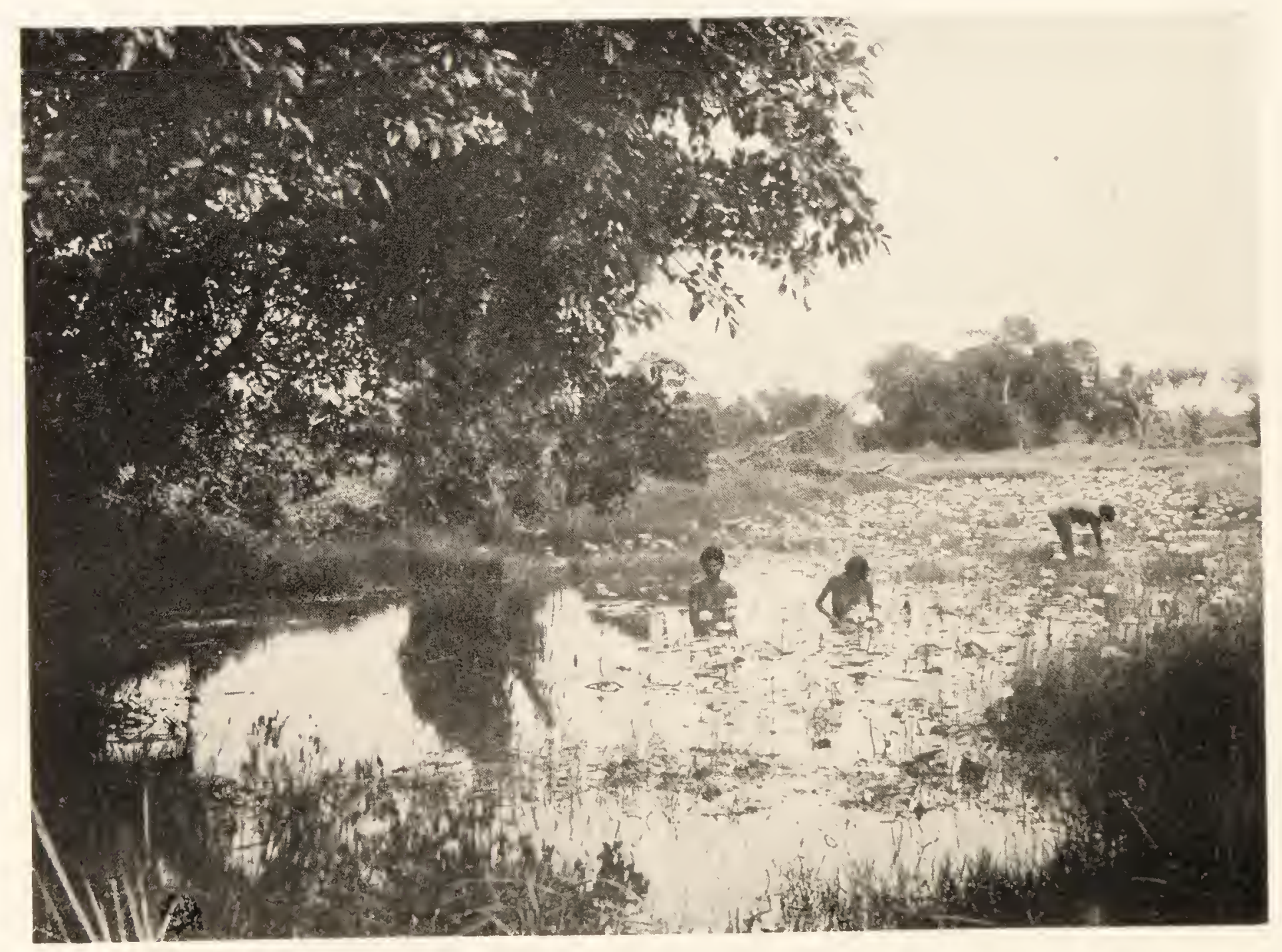

DR. HFRYYV HOLAHA.

FIG. 397.- WATER LILY POOL ON THE ROPER RIVIK. 
on the trees, uttering without ceasing their harsh call of "qua-a-ak, qua-a-ak." We even heard them calling out in the middle of the night. The most interesting time around all these water-holes is just at sunset, when flocks of bronze-winged and crested pigeons come in and glide down to the water and the trees are alive with all kinds of cockatoos that repeatedly, as if by common consent, rise and circle round in great flocks, forming clouds of lovely colour.

We spelled a day at Munda and then, travelling on to the north-east, came to a small lagoon called Uranwinni, where the birds were even more numerous than at Munda, and where also the water was clear, because we had passed on to somewhat higher ground and were away from the influence of the shale formation underlying the Ashburton Range. Our track led through what is commonly known up here as Forest land, which consists mainly of rather small gum trees with every now and then patches of Acacias, India-rubber trees and Lancewoods. On the way we heard our boy, who was riding ahead of us, firing his revolver, and on coming up found that he had got a dingo in a hole. A little further on four big emus were feeding, but made off as soon as they saw us. We had just settled down in camp, shortly after midday, and were enjoying our quart pots of tea, when two natives, clothed only in smiles, came out of the bush. One of them could speak a little broken English and told us that there was a better water-hole a little further on, so we saddled up and were soon in camp under a shady gum tree on a well-grassed flat by the side of a clear water-hole, flecked with little yellow lilies. The name of the place was Karrabobba, which, when pronounced as the natives do, is so closely similar to the rather mournful but very distinctive note of the "peaceful dove"-one of the sounds most frequently heard here in the bush-as to suggest that this is its origin. 


\section{WANDERINGS IN WILD AUSTRALIA $\mathrm{cH}$.}

The scrub round the water-hole was thick, and we found that a considerable number of the Gnanji tribe were camped close by, though we should have had no idea of their presence if they had not made themselves known to us. Like the Umbaia people, they knew about us and were quite friendly, and during the afternoon they invited us to see one of their ceremonies that they had gathered together to perform. The Gnanji people occupy the country between that of the Umbaia on the west and the coastal tribes on the east. They have a very bad repute, and certainly the mob that we saw contained about the most villainous, evil-looking natives that could be imagined. A few years ago they had speared a white man, ate his flesh and then carefully collected his bones together and left them in a heap by the side of a track where it was likely they would be seen by those who went out in search of the murderers. This was really in retaliation for the shooting of some of their tribe by white men a little while before. We did not know this at the time, but noticed that there were two or three in the mob who carefully retired out of sight whenever we came near. However, the others were perfectly friendly and helped us to find out as much as we could in the limited time at our disposal.

One of the most striking features in this part of the country-and indeed right away north throughout wide stretches of the Northern Territory-is the enormous number and size of the white-ant hills. There are different kinds of these, varying in height from a foot or two to as much as twenty feet. They vary not only in size but shape. Some are simply flat slabs-those made by the "meridian ant"; others are constructed of a number of spherical masses, looking like big bubbles of earth; others are bluntly rounded, but the great majority are conical. Amongst the latter you can distinguish those in which the nest consists of a single conical mass, and others in which 
a large number of cones are combined to form a gigantic pyramidal ant-hill that may reach a height of twenty feet and more, and consist of even as many as fifty or sixty separate cones. Most of the hills in this district were of this form. They seem to be usually built round a small gum tree, the trunk of which they finally enclose completely. After a time they eat through the wood and kill the tree, the branches falling off, until at last the ant-hill stands by itself. Another very striking feature is their variation in colour, which of course depends on the nature of the soil, and that again on the rock formation out of which the surface of the country is formed. In some parts they are brown, almost black, in others they are red and in others yellow.

You never by any chance see a white ant in the open, because it is a most helpless, soft-bodied insect and everywhere, and always, works in the dark. Strictly speaking, it is not an ant at all but a Termite. The true ant belongs to the same order of insects, Hymenoptera, as does the bee, whilst the Termite is allied to the cockroach and belongs to the order Orthoptera. It has one curious habit, that, when once the pest is seriously tackled, will be of great service in dealing with it, and that is, its eating and re-eating everything, including the bodies of its dead comrades. It not only eats wood or almost anything else with which it comes in contact, but, when once anything has passed through its body, the refuse material thrown out is eaten again and again until there is not a particle of nutriment left. This voracious instinct may be taken advantage of, because any poisoned ant is immediately eaten by its fellows who, when they die, are in their turn eaten by others, and so on with far-reaching results. Not only this, but the opening up of the ground seems to be injurious to the insect, which has a decided objection to being disturbed. It is certainly a great pest and scarcely 


\section{WANDERINGS IN WILD AUSTRALIA $\mathrm{cH}$.}

anything is proof against its attacks. At Darwin I have seen lead pipes bored through and through, and there is one case on record there of its having successfully tackled a billiard ball.

The natives in these parts have no lack of food supply, both animal and plant. The water-holes are full of fish, which are caught in two ways. The first is by means of a hollow log that we saw in use at Bates Lagoon. In the second a small hand net, about three feet in length and two in width, with meshes from half an inch to perhaps an inch in size, is employed. A bent stick is run through each side along the margin, and then the native goes into the shallow water and uses it as a scoop. Mussels they get in plenty by feeling for them with their toes. There were said to be tortoises in the water-holes here, though we had not seen any hitherto, so I offered the boys a stick of tobacco for one. Five of them waded in, and after feeling about with their toes they soon found one. It turned out to be the same as the long-necked turtle of the River Murray Basin (Chelodina longicollis), so I let it go, but am afraid that it made a meal for one of the boys. These water-holes dry up when the great heat comes, but, even before they are completely empty, the turtles bury themselves in the mud around their margins. It becomes as hard as a brick and they lie imprisoned, like the waterholding frogs do, until the next heavy rain releases them.

From Karrabobba we travelled on to a lagoon half a mile long called Whanaluru. Its surface was flecked with the broad green leaves and lovely blue flowers of a water-lily. On their leaves little long-legged, black-and-white mudlarks were hopping about, searching for food; in the lanes of water ducks were swimming, and in the centre of the lagoon a few stately pelicans were floating, holding themselves, as usual, quite aloof from other birds.

These lily-pools are a striking feature in the northern 
parts of sub-tropical Australia and are, naturally, favourite camping-places of the natives (Fig. 397). Wandering round them I often came across heaps of mussel shells, charred and broken bones and rudely chipped flakes used in smashing them. The lilies themselves are a staple article of food. The men, but more especially the women, wade in, often breast high, pulling up stalks and roots. The former they eat, the latter they bake in hot ashes. They collect the hard seeds in great numbers, pound them up and knead them into loaves that are baked, and when cold are almost as hard as a rock. The pools also are associated with one or two interesting customs. When a man or woman has a front tooth knocked out, it is buried by the side of a lagoon to make the lilies grow, and when a native dies, his body is first of all laid on a bough platform in a gum tree, but, when the flesh has gone and the bones are bleached, then, in the Gnanji tribe, they are put in a wooden pitchi and buried in a hole on the lagoon bank in order, so the natives say, partly to keep them cool and partly to make the lilies grow. If necessity arises, a native finds, at least so far as a white man is concerned, a safe hiding-place amongst the lilies. They usually grow close together, the flower stalks projecting in endless numbers above the water. The native conceals himself amongst them with the whole of his body immersed in the water, above the surface of which he projects his nose and mouth from time to time to breathe-but so carefully that he does not even cause a ripple and it requires a very trained eye to detect him.

Our boys brought in two pelicans and some ducks and pigeons. We kept the latter for our own consumption and handed the pelicans over to our Gnanji friends, several of whom followed us up from Karrabobba, telling them to go and camp on the opposite side of the lagoon. We did not know them well enough to trust them too close to us 


\section{WANDERINGS IN WILD AUSTRALIA сн.}

at night-time, and of course our own Arunta boys were very nervous about any such strangers. At any rate they and their camps looked more picturesque in the distance. Just as we were sitting down to our evening meal we saw two blackfellows coming up, one of them carrying what is called in these parts a "paper yabber." It turned out that our friend Mr. Kell had very kindly sent out after us some messages that had come along the line after we had left Powell Creek. The two men had followed us up for just one hundred and ninety miles, carrying the "paper yabber" in a cleft stick. Though they had come through strange tribes, first the Umbaia and then the Gnanji, yet, so long as they carried this emblem, showing that they were messengers, they were perfectly safe. The natives are quite accustomed to messengers travelling from tribe to tribe to summon distant groups to take part in sacred ceremonies. Such messengers always carry a token of some kind-very often a sacred stick or bull-roarer. Their persons are always safe, and so this safety has been transferred to natives carrying "paper yabbers" for the white man. They were perfectly happy when they reached us, the sense of having been successful in their errand being apparently quite sufficient to satisfy them, with, of course, plenty of food and tobacco when they reached us. They spent the night in camp and left us next morning with a good supply of flour, meat and tobacco and a pipe and knife for each of them, quite cheerful at the prospect of a return journey on foot of nearly two hundred miles to their home camp at Powell Creek. Their only luggage, apart from food, was a spear and spear-thrower.

These "paper yabbers" are a mystery to the unsophisticated native. On one occasion, a friend of ours sent a native with a small parcel of tobacco to a camp some distance away. At the same time he sent a message saying how many sticks the parcel contained. As a general rule 
a parcel such as this would be delivered intact, but the native knew what it contained and the temptation to open it and abstract a few sticks was too strong. When, on his arrival, he was taxed with the theft he was highly indignant with the "paper yabber," because he had hidden it away in the hollow of a log while he opened the parcel, so that it could not see what he was doing, and he thought that it had, in some unfair way, been watching him and had found out what he was doing and told the white man.

One of the choicest foods of the blackfellow here as everywhere is the "honey-bag" : that is, of the native bee. It nests in hollow limbs of different trees-gums, lancewoods, etc.- - the white ants providing it with plenty of opportunity for building its hives. Whenever we had a spell at any place, such as Karrabobba, I had the chance of wandering in the bush with one or two of the natives and they were always on the look-out for opossums and " honeybags." There were but few of the gum trees without hollow boughs-the possible resting-place of an opossumand the trained eye of the native at once detected any scratching on the trunk, showing that an opossum had climbed up or down. The look of the scratch told him at once whether it was an old or a new mark. If the signs were satisfactory, the method adopted to dislodge the animal, which is nocturnal in its habits, was both simple and ingenious. A small hole was made low down in the hollow trunk, dry grass was put in and lighted and fuel added until there was a continuous stream of thick smoke coming out of every hole in the boughs. The treatment was continued until the animal was driven out, when it had no resource but to jump to the ground, where it was quickly captured. If no animal appeared after a thorough smoking, then the native concluded, and probably quite correctly, that it was "not at home." The whereabouts of the "honey-bag" is determined in one of three ways. The simplest is that 


\section{WANDERINGS IN WILD AUSTRALIA сн.}

of coming by chance across a tree where the bees can be seen flying in and out of the nest. The second is more ingenious. A native will catch a bee and fasten on to its body a little speck of light, white fluff and follow it up as it flies away to its hive. The third, that I often saw them using, was to place the ear on the trunk or bough of a likely-looking gum tree, when, if it contained a nest, the low hum of the bees at work could be heard. During the rain season and in very cold weather the natives say that the bees close the entrance with mud. If, as sometimes happens, it is attacked by predatory ants, a number of bees close the opening with their own bodies. When once the "honey-bag" has been located it is chopped out. The comb is quite irregular in shape, varying, of course, in different hives. The cells are like little round balls much like, only smaller than, those of the English bumble-bee, the largest about a quarter of an inch in diameter, some of them containing honey and some pollen and nectar, not yet made into honey. A third kind is much smaller and contains the eggs, larvæ and pupæ. The whole mass is scooped into a piece of bark. Hundreds of bees get mixed up with the pollen and honey, but the natives do not mind this and eat the whole of it with relish. So far as the honey itself is concerned it is excellent.

We had ridden on for an hour or two through the scrub when the country began to fall away slightly and little creeks appeared trending eastwards, so that we knew, though the indications of it were very slight, that we had crossed the watershed from which, on one side, the stream flowed away to the centre of the continent and, on the other, down to the Gulf of Carpentaria. Through the trees we could just catch glimpses of ranges and forestcovered country, stretching away to the east for mile after mile, but the scrub, that is called "forest" in this part, and consists of three or four kinds of Eucalypts, none of 
them tall ones, lancewood, and "quinine" trees, was too thick for us to see much and we rode on for five hours, following down a dry creek by the side of which we camped. It is so warm in the middle of the day that if you stand up, or walk, or sit down, or lie down or, in fact, do anything, you perspire, and flies innumerable and little black ants, crawling over anything laid down on the ground, made peaceful rest impossible, except to our boys, to whom nothing save shortage of food seemed to cause any discomfort.

Heavy clouds came up and made things very muggy and sticky, and we actually had a slight shower during the night, showing us that the wet season was near at hand and that we must press on. We had been looking forward to reaching a water-hole called Pinda, because we had heard that there were plenty of small crocodiles in it, and camped beside it full of expectation. We were, however, doomed to disappointment. Once or twice we saw, or thought we did, little eyes appearing just above the surface, but the animals were too wary to be caught. Even the Gnanji boys, one of whom was supposed to be an expert at the work, could not catch one. These small crocodiles rarely reach a length of more than five or six feet; nine feet is a maximum. The natives do not seem to have any fear of them, in fact some of them will actually go into the water and catch them with their hands. It was reported that there was one of the larger crocodiles in the pool, but we saw nothing of it, not even a track along the banks, so that probably it was more or less mythical, like not a few other things in this remote part. The smaller species is called Crocodilus johnstoni and is confined to the fresh waters of Queensland and the Gulf country, never going down to the sea. The larger species, Crocodilus porosus, is identical with the common form of the Malay Peninsula and India. It is found all along the coastal districts of Northern Queensland, the Gulf of Carpentaria, the shores of the Northern 
Territory and North-west Australia, but rarely penetrates further inland than the tidal parts of the rivers. The bushmen in the Territory call them respectively "Crocs" and "Alligators," which is usually shortened into " Gaitor," but there is really no such thing as an alligator in Australia. In a crocodile the fourth large, lower tooth on each side slides into a groove on the outer side of the upper jaw, so that it can be seen when the mouth is closed. You can tell a crocodile skull at once by the very distinct nick on each side of the upper jaw. However, nothing will persuade the bushman that the crocodile is not an alligator, and one soon gives up arguing any such point with him. His knowledge of natural history is generally as superficial as that of the aboriginal is deep and accurate, so far as it is concerned with anything that interests the latter and is concerned with his daily life and needs.

While camped at Pinda we had a little bit of experience very characteristic of the "Never Never Country." Our stock of dried beef was running short and we were still more than a hundred miles away from Borraloola. We knew that there was a solitary white man living on an outlying cattle run some thirty miles from Pinda, so we sent him a "paper yabber" by a boy, asking him if he could let us have some beef to carry on with us. He not only did so but, without thinking anything about it, at once rode over to our camp with a pack-horse to bring it. As we were perfect strangers to him, we much appreciated his help, but it was only what one always meets with amongst the bushmen of the "Never Never." After a meal with us he rode back to his camp, just as if it were an ordinary part of the day's work. His next-door neighbour on one side lived a hundred and, on the other, a hundred and thirty miles away, and the homestead consisted only of a solitary hut, far away from anywhere in the lonely bush. 
The Pinda lagoon is hemmed in by a low hill on one side and surrounded by screw pines (Pandanus) that gave it a semi-tropical appearance. The Pandanus has great palm-like fronds, arranged in a spiral band around the trunk. The stalks have broad, sheathing bases, and as the fronds drop off they leave a definite screw-like mark on the trunk. Spoonbills, cranes and Nankeen night-herons were enjoying themselves in and around the pool, and for the first time we came across the Coucal, which is really a cuckoo, but quite unlike most of these in appearance. It is commonly called a "pheasant" because the male bird has a long, black, arching tail. Close to our camp was the playground of a pair of bower-birds. The male had a beautiful metallic lilac-coloured crest, and the bower itself formed a complete arch of twigs, about two feet long and eighteen inches high. All around were scattered snail shells and brightly coloured feathers with which the birds played unceasingly, picking them up and running through and round the bower. They did not seem to be much disturbed by our presence. Galahs and black cockatoos were shrieking round and small flocks of beautiful parrots with moss-green bodies, crimson wings and a patch of cobalt blue above the tail. There were numbers of little greyish doves and bronze-winged pigeons, "redbeaks" and different kinds of honey-eaters, for the most part dingy-coloured. There was one lovely little wren (Malurus sp.) with a long blue tail, like the Malurus superbus of the south, only the rest of his body was grey, except for a bright metallic-blue patch on the crown of the head with a dark, purple splotch in the middle of it, and black-andwhite bands on the side of his face.

We were now near to the head waters of the Leila Creek, just where it descends from the edge of the table-land to the coastal district. None of this country has been mapped, except in the vaguest way. The table-land is bordered 


\section{$55^{2}$ WANDERINGS IN WILD AUSTRALIA сн.}

by a slight escarpment that has been cut into by various streams to form valleys through which they run down.

Gillen and myself went on ahead with one boy and the pack-horses, and got into a regular jumble of hills following down the track of a small creek and wondering however the wagon would follow us. At times it was actually picturesque with shady trees and screw pines. There was one small tree that was sometimes covered with bright yellow blossoms, and at others a dark fruit shaped like a small elongated orange with five "quarters." When it opens the fruit is very pretty. The five outer sections turn dark brown, and alternating with them there are five other cream-coloured, petaloid parts that enclose a mass of dark seeds, each of them coated with a soft fluffy white down. When they are ripe the wind catches the down and blows them away in all directions. From the cottony coating of the seeds they are called Kapok trees, and seem to prefer the rocky hill-sides, in fact we never found them growing anywhere else. We camped by a small water-hole in the Leila Creek, called Ballanbrini, where we waited for Chance, and were relieved when, later on, in the comparative cool of the evening, he came in safely with the wagon. On these hot days. we always started very early in the morning, so as to be in camp by noon and thus avoid the greatest, or at least the most trying, heat of the day, which falls between noon and three o'clock, when Chance, who travelled more slowly with the wagon, camped for a time to spell the horses. As soon as ever we got into camp, our boys' first business, after watering the horses, was to build a bough shelter. On this occasion I was skinning birds, though it was decidedly hot-I I $5^{\circ} \mathrm{F}$. in the coolest shade of the wurley. Ominous banks of clouds had been rolling up, but we had got so accustomed to them and to their passing harmlessly away that we paid no attention to them. Fortunately, however, we had taken the precaution 
to rig a tent-fly over the wagon and another tied to strong pegs in the ground over our bunks and personal belongings. Without any warning, a few heavy drops fell suddenly and then, before we knew what was happening, a roaring wind swept up the valley. Gillen was peacefully resting in his bunk, I was skinning birds in the wurley and had only just time to seize a few things and escape from it before the wind scattered the whole thing-table, camp stools, knives, plates, forks, collecting materials, bird-skins and branches were sent whirling away. We all rushed for the tent-fly. The trees bent and groaned as the wind swept by, and down came the rain in a perfect deluge. There were six of us, three white men and three black boys, and we were all busy holding on to the tent-fly while the water streamed all over us (Fig. 398). The canvas flapped and flapped and the fly-ropes snapped. The thunder was deafening and the lightning flashed incessantly. If there had been anyone to watch us, we must have presented a very comical appearance, absolutely drenched to the skin and every now and then lifted off our feet by a terrific gust of wind. However, our combined efforts kept the tent from flying away into space, and in less than half an hour the worst was over, though we could hear the thunder rolling away in the distance. When the storm had passed by we set to work to collect our scattered belongings, some of which took a good deal of tracking up by the boys. As soon as the rain ceased, the flies came in myriads, and we were glad of the comparative cool of the night, when they disappeared and when fortunately very few mosquitoes came about, so that we had a few hours' quiet rest.

The night was quiet; we had breakfast at 4.30 a.m. next morning and left camp early. Our day's stage to the next water-hole, on the same creek, was only twelve miles, so that we had a leisurely camp on a small flat, where there was really green grass, and amongst fine gum trees, with VOL. II. 


\section{WANDERINGS IN WILD AUSTRALIA сн.}

cream-white trunks and branches and strips of lavendercoloured bark, peeling off for a few feet up from the ground. The foliage hung in dense, pale green masses from the white branches. Stuart Bean trees were bright with scarlet blossoms and the paper barks (Melaleuca), some at least eighty feet high, with trunks more than a yard in diameter, were laden with great pendent masses of white, fluffy flowers that scented the air with their honey, upon which oirds and bees were busily feeding. Large fig trees with dense foliage bordered the creek, their trunks and branches covered with little, close-set masses of fruit, looking like bunches of red and green grapes. The little figs were quite sweet-tasting and palatable. Every here and there clusters, three or four feet in length, of yellow and brown orchid flowers hung down from the gum trees, on the branches of which they were growing, and, to add to the beauty, flocks of gaily-coloured Blue-mountain parakeets were flying from one tree to another, gorging themselves with honey. It was much the most beautiful spot that we had seen in the whole of our traverse of the continent, and at night, when the full moon rose and our camp fires lighted up the white stems of the gum trees, it was like fairyland and we looked forward to spending the last part of our journey amidst surroundings as pleasant and beautiful as these. Alas, it was not to be, and no sooner had we moved out of our camp next morning than we found ourselves in the usual dull, monotonous forest country that continued with us right down to the Gulf.

We left Chance spelling the wagon horses for a day, and rode on ahead over most uninteresting country until, at last, we struck the Macarthur River. The bed was very broad without a drop of water and filled with great rough boulders that made us wonder how the wagon would fare, but though there was no water the banks were bordered with fine gum trees. We followed its southern bank for 


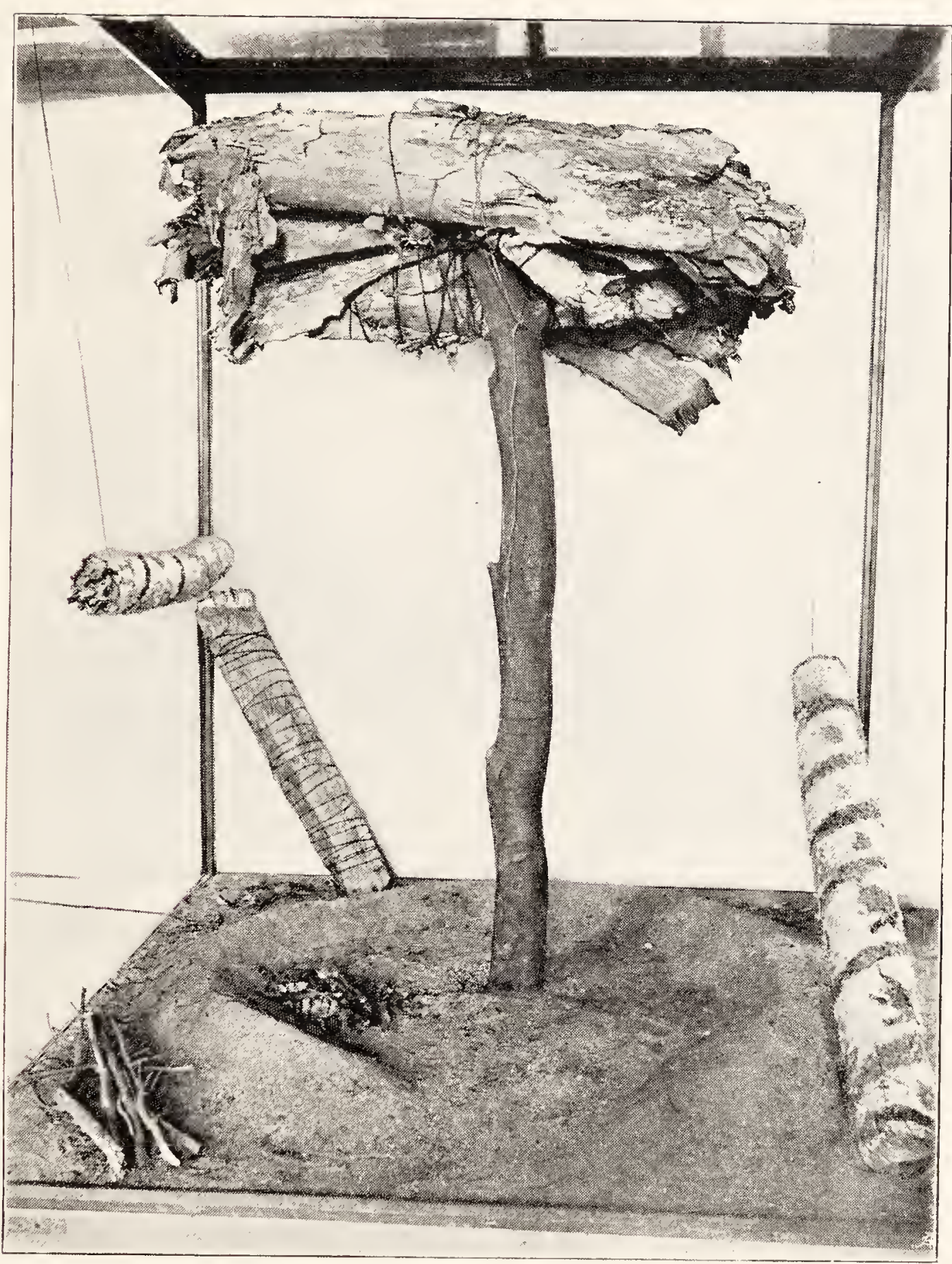

FIG. 399.- PARCEL OF DEAD MAN'S BONES WRAPPED IN PAPERBARK AND PLACED IN THE FORK OF A BRANCH STANDING UPRIGHT IN THE GROUND.

Around the base is a horseshoe-shaped ridge of sand within which a small fire is kept burning. The photograph is taken from a case in the National Museum, Melbourne. The scene is an exact reproduction of the original one. The parcel of bones was obtained from the Binbinga tribe, where it was found in the middle of a camp on the banks of the Macarthur River. In the same case are seen three log coffins decorated with totemic designs, the one on the right belonging to the dugong totem. 


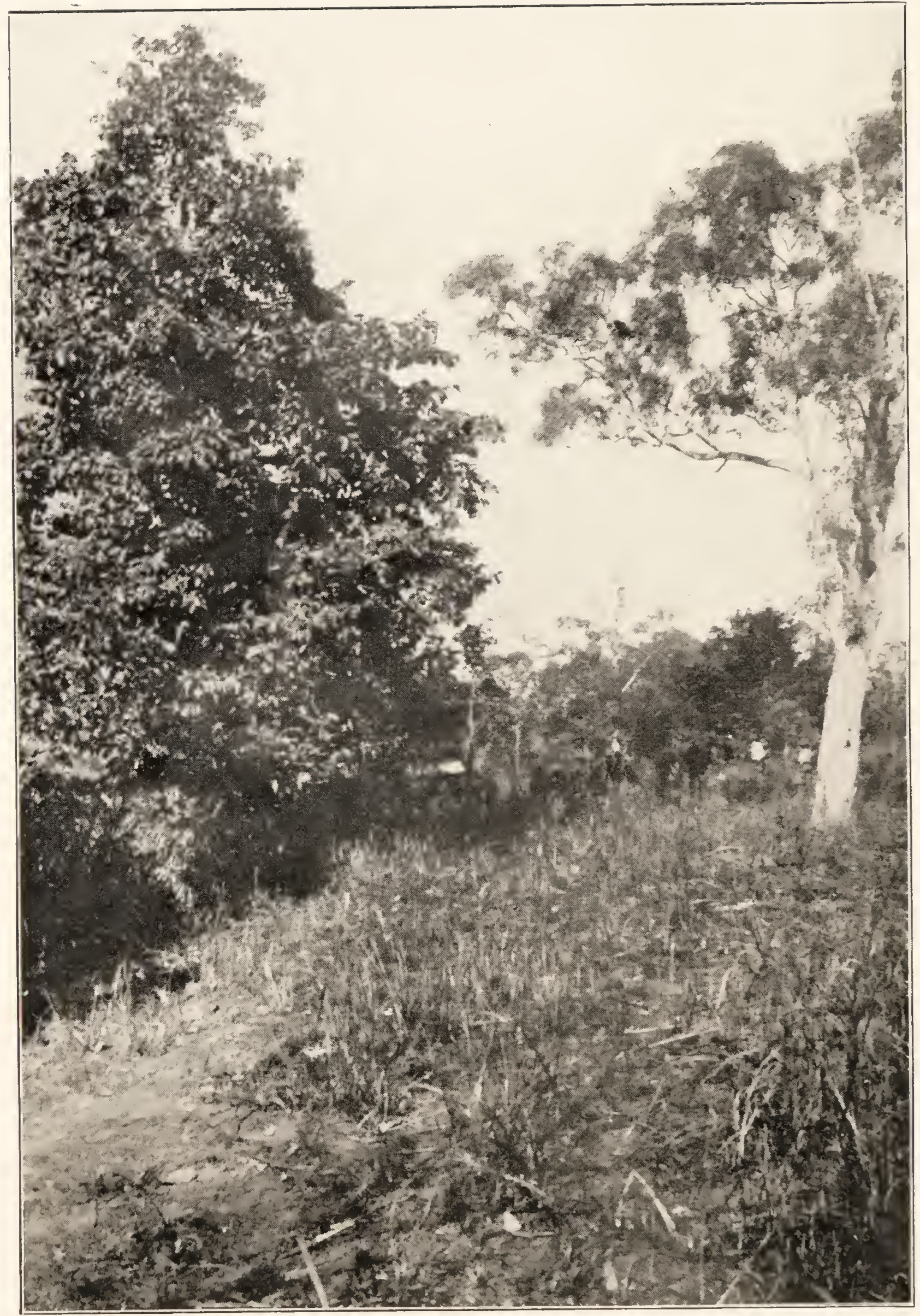

B.S. 
two or three miles until we reached the Macarthur Station, where we were welcomed by Mr. Amos, one of the owners, who was then managing the station. It was only about forty miles up the river from Borraloola, so we felt as if our long journey was nearly over. We enjoyed a most welcome rest on the verandah, which was completely closed in with wire netting, a remnant of the early days when the natives were troublesome and it was not safe to sit out in the open after dusk unless protected from spears and boomerangs that might be thrown under cover of darkness. Later on we went down to the native camp occupied by members of the Binbinga, a large and powerful tribe, inhabiting the country from the watershed right down the Macarthur to Borraloola. It was placed in a picturesque spot, close by the river-side amongst shady fig trees, paperbarks, Leichhardt pines and screw pines (Figs. 400, 4OI). The water looked deep and clear and very inviting, but there were too many crocodiles about to make bathing safe.

Our attention was at once attracted by a curious-looking structure that consisted of a forked branch, about five feet high, in which was fixed a parcel evidently containing something very special, wrapped up in sheets of paper-bark and tied round with human hair string, with a few sheets of bark over it to protect it from the weather. The ground all around the base of the branch had been cleared of weeds and smoothed down, and a horseshoe-shaped ridge of sand, two or three inches in height, enclosed a space six feet in greatest diameter, from the centre of which the fork rose. A small fire smouldered on the sand inside the horseshoe (Fig. 399). It was right in the middle of all the Mia-mias, so that everyone could see it, and was under the charge of an ancient, evil-looking native, whose duty it was, together with a still more ancient-looking lubra, to see that the fire never went out, day or night. We found that the parcel contained the bones of a dead man, and set 


\section{$55^{6}$ WANDERINGS IN WILD AUSTRALIA сн.}

to work to devise some scheme of enticing the old man to part with them, or at least some part of them. As a preliminary, we made friends with him by means of a generous donation of tobacco, knives and a shirt, of which he was much in need, and secured three of the arm-bones that, as usual, had been kept apart from the rest and painted with pipe clay. Each of them was wrapped up separately in paper-bark and they were ready to be used as pointing bones to kill other natives. We wandered round the camp, judiciously distributing tobacco, and, before leaving, told the old man that if he wished to sell the whole, or part, of his relative's remains, we would buy them with flour, tobacco and a tomahawk, but received no visible sign of encouragement.

At a later date we learned a good deal more about the death and burial customs of the Binbinga and other tribes round the western shores of the Gulf. The following is what takes place in the Mungarai and Binbinga tribes. When anyone dies, provided he or she be not very old, certain of the male relations take the body out into the bush and cook it in a native oven. The latter consists as usual of a hole dug in the ground, in which a fire is lighted and stones heated, on which, in this part of the country, sheets of paper-bark are laid. Then comes the body, then another layer of paper-bark and the earth piled in. The lubras are not allowed to see the actual cooking, but some of them, who stand in a definite relationship to the dead person, are in the scrub close by and, when all is ready, are summoned to take part in the gruesome meal, though, so far as we could judge, neither the men nor women regarded it as such. When all the flesh is removed-and everything apparently is eaten - the bones are collected and, with the exception of the long ones from the arm, are wrapped up in paper-bark and handed over to the custody of a relative who also watches over them, as we saw this one doing in 
the Binbinga camp. The spirit, called Padinia, is supposed to hover about the bones. This is why, in the first place, a fire is always kept burning so that the spirit may warm itself, and, secondly, why an opening is left in the sand ridge to allow it to get to the fire with ease. After about a year the Ngagung, or mother's brother, decides to hold the final ceremony. He tells the Naminjerri men, that is, his sons, to prepare a log coffin. This is made from the bough of a gum tree that has been hollowed out by white ants. All the bones, except those of the arm, are put into it, the two ends are stuffed with paper-bark and the surface decorated with designs emblematic of the totem of the dead person. If, for example, he be a lizard man, then a lizard drawing will be made; if he be a dugong man, a dugong, and so on. The men, meanwhile, have gone to a special, ring-shaped ground, called Kalal, a short distance away from the main camp in the scrub, and here the coffin, called Lurkun, is fixed upright at one end of the groundnear to which no woman is allowed to come.

Stores of food, damper made from lily seeds, lily roots and "honey-bag," have been brought up by women to their camp. Two men are sent to bring these supplies to the Kalal, on which a fire is lighted. This must be done by a man of the same totem as the dead person. First of all, he takes two sticks from the fire and strokes the coffin with them. This is a sign for all the men to rise to their feet and sing out "Yo! Yo! Yo! Yo!" The coffin is then taken out of the ground and carried round the Kalal by several men who cry "Ma Yai; Ma Yai"; ending up with a prolonged "Srr!" This takes place late in the evening, when the coffin is again set upright in the ground and the night spent in singing and performing ceremonies belonging to the person's own totem and others associated with his own group in the tribe. All night long their boomerangs clang incessantly. In the early 


\section{$55^{8}$ WANDERINGS IN WILD AUSTRALIA cr.}

morning the coffin is lifted up and placed on the head of a Naminjerri man, who carries it thus at the head of a long procession of men, walking in single file, to the lubras' camp. Everyone cries out "Oh! Oh! Ss! Yai! Ss! Yai! Oh! Oh! Sr! Yai!" and each man holds a boomerang between his arms and behind his back. The coffin is placed upright in a hole that has been made by the dead person's mother in the middle of the lubras' camp, the men retiring to one side, about fifty yards away, where they sit down quietly watching the women, who weep and wail. After a time the lubras walk away, leaving the coffin, which is taken out by the Naminjerri, and the ceremony is over. All that remains is the final disposal of the Lurkun. In some cases it is buried in the bank or placed in the boughs of a tree overhanging a lily-pool, where it remains until it is swept away and overwhelmed in flood wrack; in others it is placed in a hole in the rocks, in some secluded spot, the whereabouts of which is known only to the older men.

We said nothing further to the old man and had given up all hope of getting any more of the bones, when, just in the early morning, before the native camp was astir, he came quietly into our camp, carrying a parcel of bones wrapped up in paper-bark. Evidently the thought of losing the tobacco and tomahawk had preyed upon his mind and overcome his scruples. He must have extracted them under cover of darkness, and asked us earnestly to be sure and hide them safely away, so that no one could see them, and was very anxious lest we should let anyone know that he had given them to us. We promised him faithfully to keep the matter quite secret and paid him well, after which he stole back, evidently without any qualms of conscience, to continue his vigil over the depleted parcel of bones, possibly to share his confidence and tobacco with two or three of the older men who were more directly associated 
with him in the conduct of the ceremonies attendant upon the final disposal of the bones, and might perhaps ask awkward questions if they noticed any serious discrepancy between the number of those actually present and of those that ought to have been available for final placing in the coffin. A judicious distribution of his tobacco, as well as our previous gifts to the older men, would probably stave off any inconvenient questions that might otherwise have been asked.

Below the water-hole we crossed to the northern bank of the river course and travelled over rough table-land country until, after about twenty miles' traverse, we came to the edge of a steep escarpment and followed a creek down to a water-hole. We were in a kind of deep gully, with great trees growing up to the light. Still following down the creek, and after crossing and recrossing its rough bed, where it was hemmed in by low rocky hills, we came out at last on to the broad Macarthur flats and camped by the side of a nearly dried-up lagoon. We had pictured the Gulf country as being more or less tropical, but, the nearer we came to the coast, the less tropical it was, and now, within a few miles of Borraloola, we found ourselves in a wide open plain with little else to see save cracked earth, coarse grass, gum trees and grasshoppers innumerable. The latter were flying about in clouds and, where we were camped, had eaten all the leaves off the trees, making everything look as desolate as possible. After a time, as we went on, there were only scattered gums, and then, across the plain, covered with dry tussocks of yellow grass stalks, we could see a dark belt of gum trees bordering the Macarthur River. As we came still nearer we saw, about a mile to the north of the river, the roofs of four corrugatediron buildings that comprised the little township of Borraloola (Fig. 402). They belonged to the hotel, police quarters, court house and store. It was not exactly exciting, 
and we were a little depressed at the thought of possibly having to spend three hot summer months in such hopelessly unpicturesque surroundings, where, so far as I could see, the only thing of beauty was a solitary flame tree in full flower, forming a blaze of brilliant scarlet colour. The police quarters were under the charge of our old friend Sergeant Stott, who at once offered us the use of the deserted court-house as a camping-ground, an offer that we gratefully accepted, because the wet season was rapidly nearing and it afforded us a permanent shelter from heavy thunderstorms and deluges of rain that might fall at any moment. This was our seventieth and last camp in our traverse of the continent from Oodnadatta in the south to the Gulf of Carpentaria in the north. 


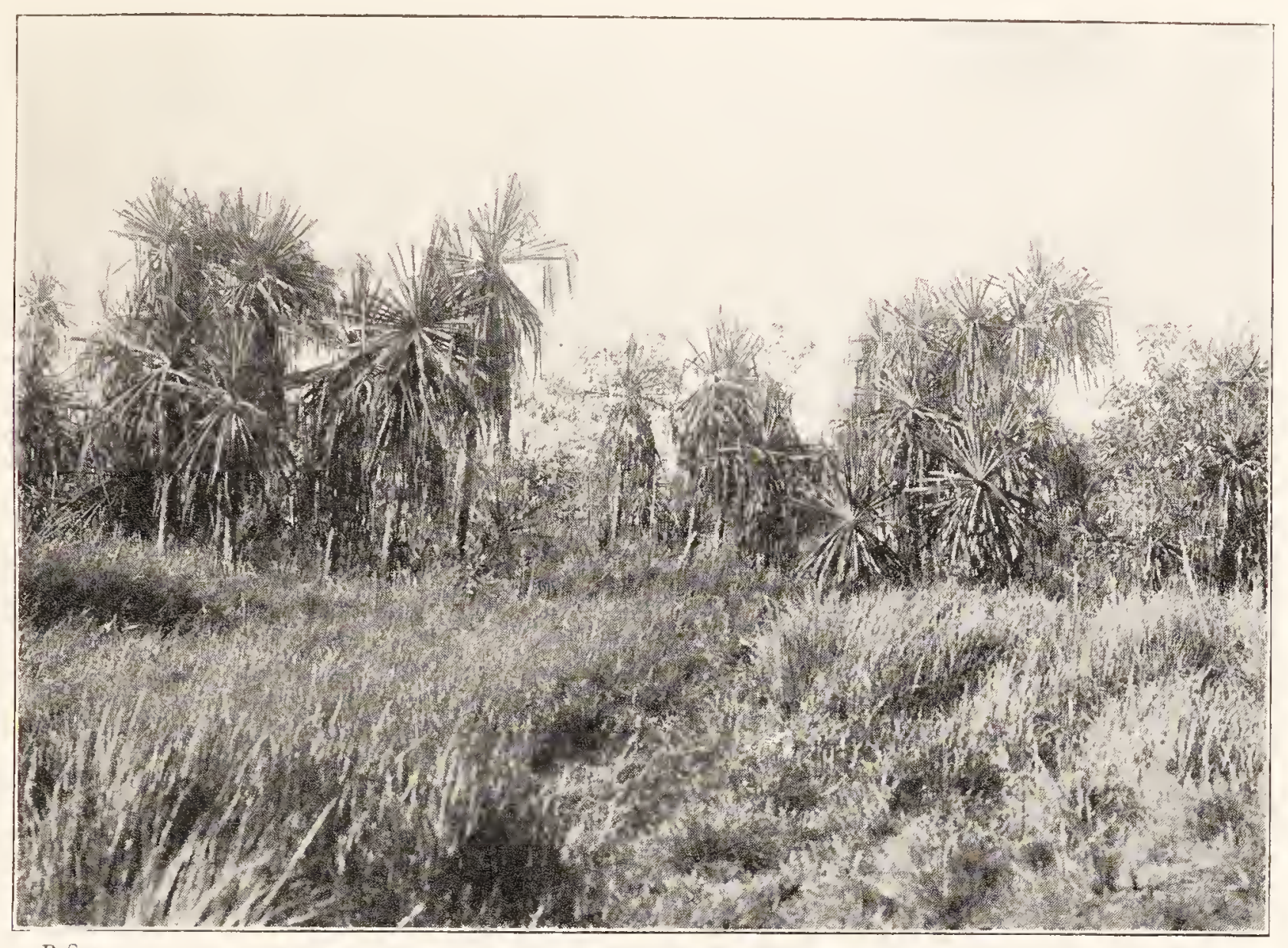

B.S.

FIG. 4OI. SCRETV PINES (PANDANUS).

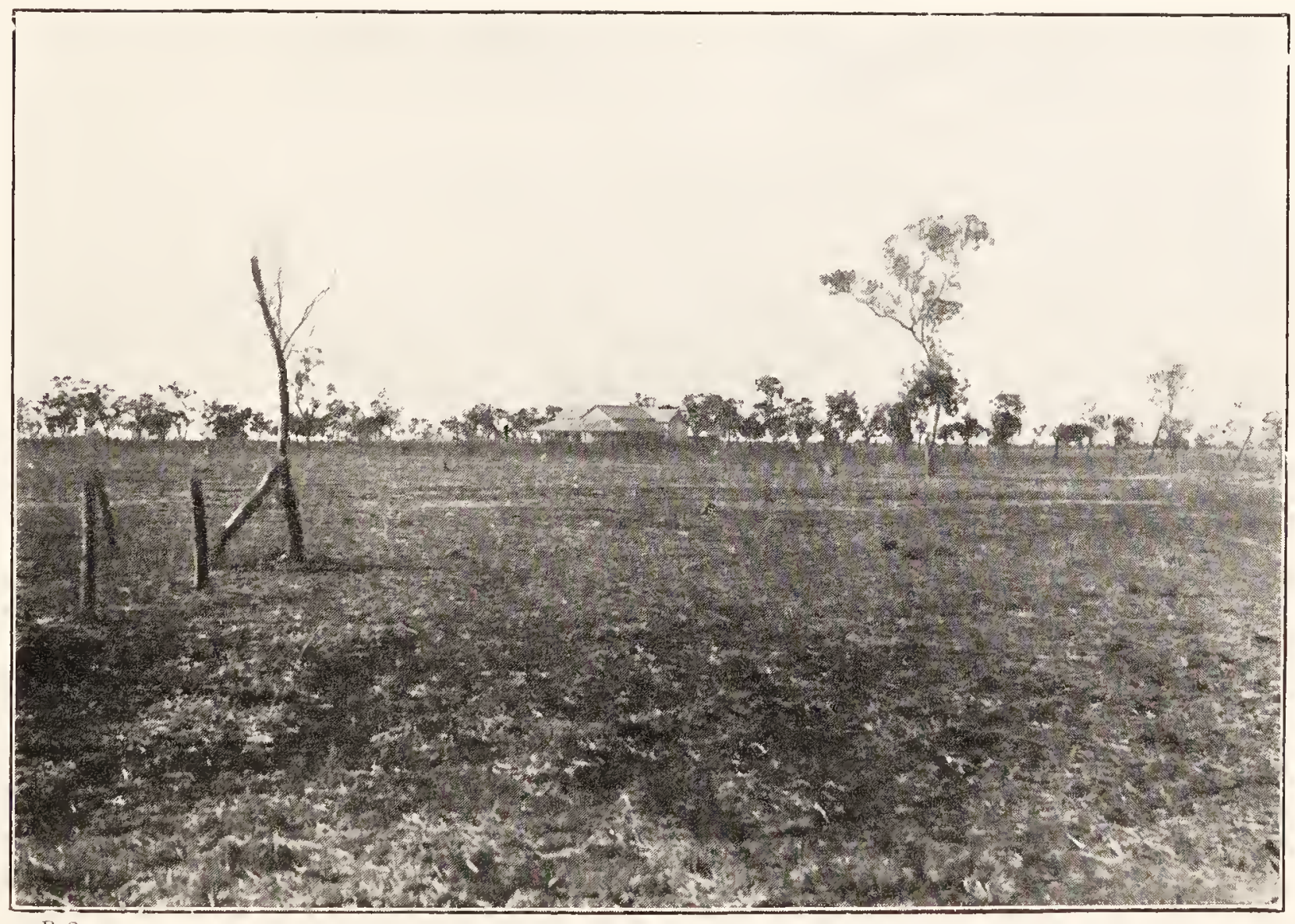
B.S.

FIG. 4O2.-POLICE QUARTERS, BORRALOOLA. 


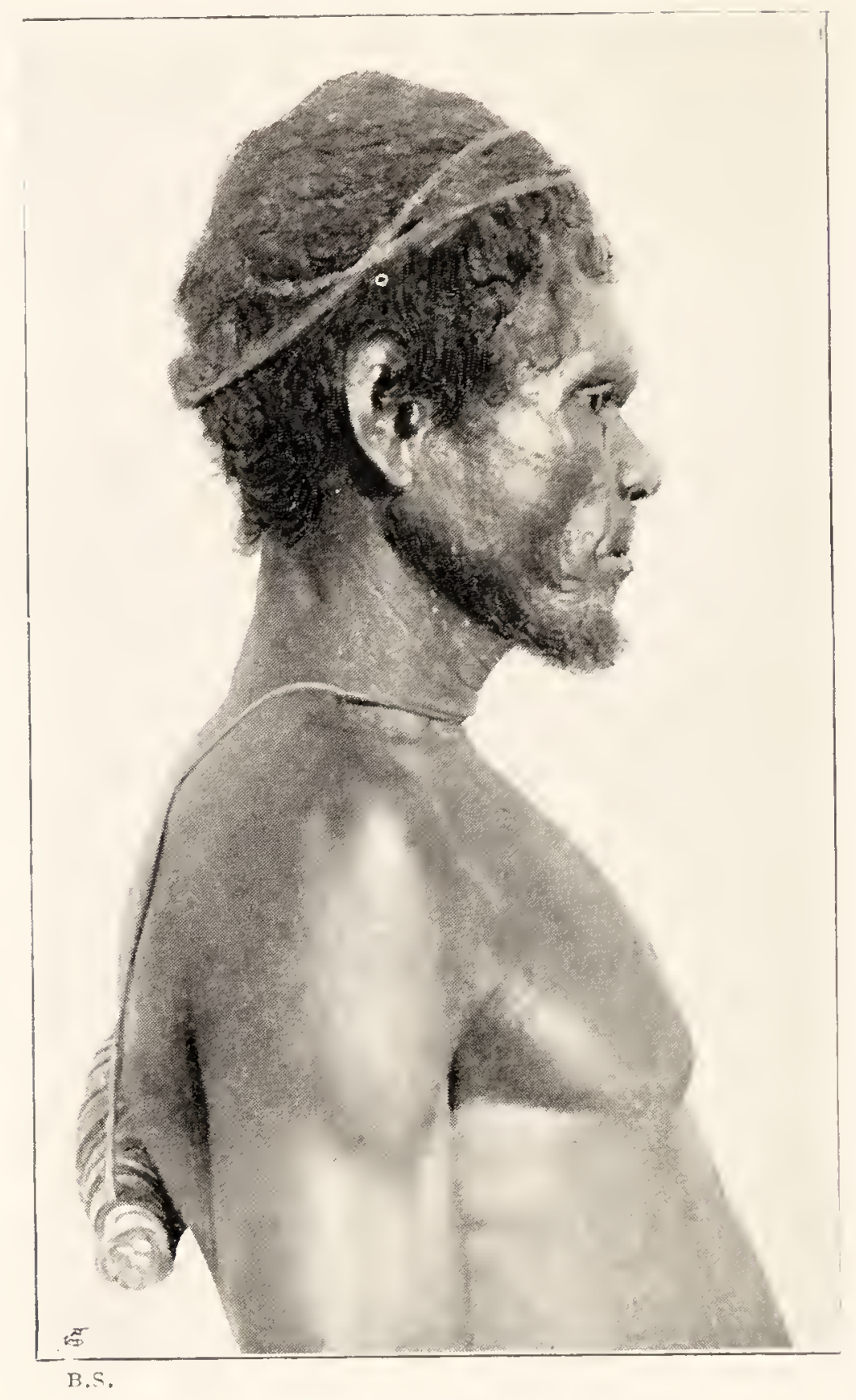

FIG. 4O3.-MEDICINE MAN, BINHINGA TRIBE, CARRYINGA WALLET ON HIS BACK. SHOWING MIETHOD OF PLAITING HAIR. SIDE FACE.

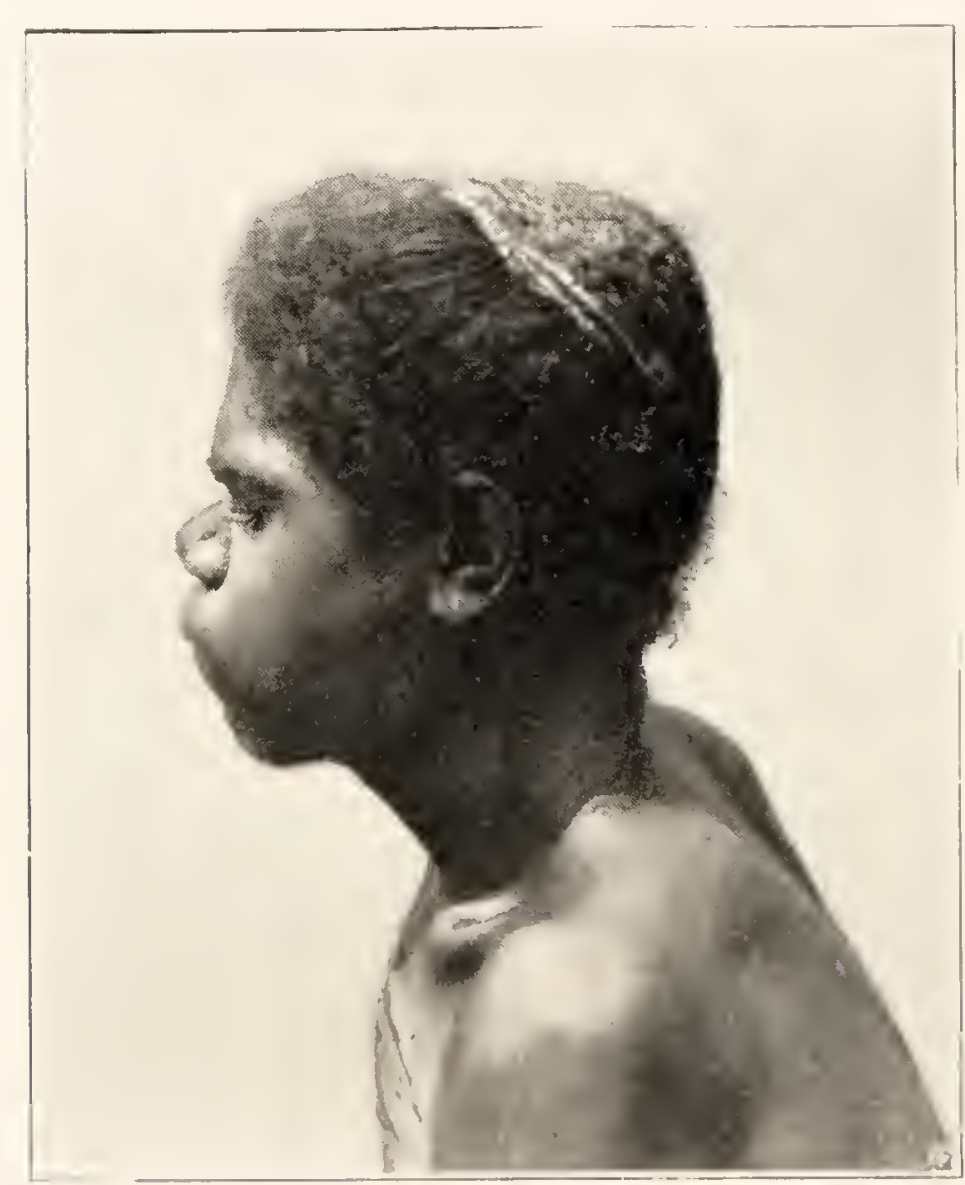

B...

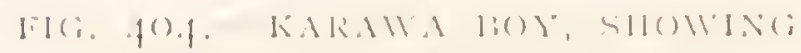

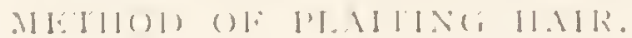




\section{CHAPTER XXIV}

\section{BORRALOOLA AND THE COASTAL TRIBES}

YEARs ago Borraloola was a more populous place than it now is, and the Macarthur District, until a mounted trooper was permanently stationed there, had a somewhat unenviable notoriety as the home, or rather hiding-place, of at least a few men who found it convenient to be, at least for a time, away from more populous centres. Those old days had long since passed away and, when we saw it, Borraloola was simply a little township, the white inhabitants of which consisted of Mr. McLeod, a well-known Territorian and manager of the store, the mounted trooper, the hotel-keeper, the owner of what had once been a fine Chinese fruit and vegetable garden, and a few odd hangerson, while, at rare intervals, stray men from outlying stations came in for a spell. Three times a year a little coastal steamer from Darwin was supposed to call, bringing stores. We had been relying upon this to carry us up to Darwin, but, to our consternation, the first news that we heard in Borraloola was that it had foundered in the Gulf on its last trip. Even if travelling overland had been possible, which it was not, except at great risk during the wet season, we could not do so because we had sold all our horses and impedimenta and were stranded. However, there was plenty of work for us to do amongst the coastal tribe, so we settled down as comfortably as we could and rigged our bunks under the shelter of the verandah of the court-house, that was completely empty save for a few bats.

As soon as we were settled down we set out to investigate $56 \mathrm{I}$ 


\section{WANDERINGS IN WILD AUSTRALIA ch.}

our surroundings, especially the Chinaman's garden, of which we had heard glowing accounts and from which we hoped much. There were springs of fresh water and everything, in contrast to its surroundings, was fresh and green. There were mango and passion-fruit trees and bananas and pineapples, but it was much too early for fruit. However, there was a small supply of onions and sweet potatoes for which we were thankful, as no other vegetables were to be had. The ordinary bushman does not trouble about such things and, now that the Chinaman had left, the garden was more or less a wreck. During the course of the evening a boy came in with a paper-yabber from Chance saying that he was detained on the road, some bolts in the wagon having been broken while descending the steep bank of the gully leading down to the Macarthur flats. Two days later he came in safely and, for the last time, we unloaded and stored everything safely in the courthouse. We had had the best of good fortune right through, and it was a great relief to us to have got the wagon and everything safely across the continent without even the loss of a horse. That we had been able to do so was due to the good management of Chance and the willing service of our two black boys, Purunda and Erlikiliakirra, who had come with us right through from Charlotte Waters.

Wandering about, we found two native camps in the neighbourhood of the township. One was occupied chiefly by the Binbinga, the other, and larger one, by men of the Anula and Mara tribes-principally the former. The Binbinga occupied the Macarthur country from the coastal ranges down to Borraloola. From here to the coast was the country of the Anula, and away to the north, in the coastal districts from the Limnen to the Roper River, lived the Mara people.

We started with the Binbinga tribe. The first day or two's work amongst a strange tribe is always difficult, in 
fact, often for days you seem to get nowhere, but then gradually and, often very slowly, the natives begin to understand what you are driving at, and usually, but by no means always, become interested and help you as much as they can.

In regard to its organisation and classificatory system, which is the first thing that you must get some knowledge of, if you want to understand the customs of the natives, the Binbinga people belong to the same large group as the Arunta, Warramunga and other inland tribes, and we had comparatively little difficulty with them, but in the case of the Mara and Anula it was different. They belong to quite another group and it was a long time before we could puzzle out their organisation.

Taking Australian tribes as a whole, that is, those of them in which there is a definite classificatory system, we find that there are two main groups. In both of them the tribe is divided, first of all into two moieties. A man of one moiety always marries a woman of the other moiety. In one set of tribes the child passes into its mother's and in a second set into its father's moiety. In most, each moiety is divided further into either two sections or four subsections.

The following tables show the main features in regard to the classificatory systems of the Urabunna, Arunta and Mara tribes, which may be taken as representative of the very many tribes occupying Central and North Central Australia. In each case column (I) gives, in the Urabunna, the moiety and in the other two the section or subsection name of the father, column (2) that of the mother and column (3) that of the children. A indicates one moiety of the tribe, $\mathrm{B}$ the other.

(I) URABUnNa.

Moiety A.

Moiety B.
Kirarawa

Matturi
(2)

Matturi

Kirarawa

\section{(3)}

Kirarawa Matturi 


\section{WANDERINGS IN WILD AUSTRALIA $\mathrm{cH}$.}

(2) Arunta (Southern).

(I)

$\begin{array}{ll}\text { Moiety A. } & \left\{\begin{array}{l}\text { Panunga } \\ \text { Bultara }\end{array}\right. \\ \text { Moiety B. } & \left\{\begin{array}{l}\text { Purula } \\ \text { Kumara }\end{array}\right.\end{array}$

Purula

Kumara

Panunga

Bultara
(3)

Bultara

Panunga

Kumara

Purula

Appungerta

Bultara

Uknaria

Panunga

Kumara

Umbitchana

Purula

Ungalla

Murungun

Mumbali

Purdal or Kuial

Kuial or Purdal

Purdal

Kuial

Murungun $\beta$

Murungun $\alpha$

Mumbali $\beta$

Mumbali $\alpha$

Purdal $\beta$

Purdal $\alpha$

Kuial $\beta$

Kuial $\alpha$

It will be seen that, in the Urabunna tribe, descent is counted in the direct female line, in the Arunta in what is called the indirect male line-that is, the child goes into the father's side of the tribe, but into the half of it to which he does not belong. In the Mara, descent is in the direct male line, so far as the section name is concerned. The most difficult tribe to understand was the Mara, in which it was puzzling to come across one family in which a Murungun man was married to a Purdal and might not marry a Kuial, and another in which a man 
of the same section was married to a Kuial and might not marry a Purdal woman, or vice versa. It was only after very careful investigation that we found out that each of the four sections, Murungun, Purdal, etc., was really divided into two subsections that had no names, and then, by carefully tracing them back across the continent, we were able to find out the equivalence of these unnamed subsections with the named ones of adjacent tribes such as the Binbinga, then the equivalence of these with the Warramunga further away, and finally their equivalence with those of the Arunta.

In the Mara tribe the child apparently goes, so to speak, directly into its father's section, but, as a matter of fact, this is really divided into two and the child goes into the one to which its father does not belong. For example, the child of a Murungun a father is Murungun $\beta$, the child of a Purdal a man is a Purdal $\beta$, and so on, and each of these unnamed groups is the equivalent of a named subsection in other tribes. Not only is this so, but where a tribe with maternal descent comes into contact with one with paternal descent, or where one with indirect paternal descent, like the Binbinga, meets one with direct paternal descent, like the Mara, the sections and subsections are deliberately rearranged to make them fit in with one another.

The whole system is so intricate and detailed that one wonders how savage people, with no written record of any kind, elaborated such a scheme and yet at the same time, only in rare cases, discovered how to count beyond five.

It is by no means an easy thing to unravel and, if anyone wishes a lesson in patience, I can strongly recommend an investigation into the social organisation of a more or less highly specialised tribe such as the Mara.

Of the two main camps near Borraloola, one was situated close to the river where the "salt-water" natives as they are called-that is, the Anula and Mara, together with a few 


\section{WANDERINGS IN WILD AUSTRALIA cн.}

visitors from the Karawa tribe-built their Mia-mias. The other was further inland where the Binbinga camped. The members of the two camps did not appear to have very much to do with one another though they seemed to be on quite friendly terms when they met.

We worked at first amongst the Binbinga, because we had come in contact with them on our way down the Macarthur. Our chief informant was an old medicine man named Kurkutji, from whom we learned a good deal and found that, in essential features, the Binbinga were closely allied in organisation and beliefs to the Central tribes. They had just the same traditions in regard to their old ancestors walking about the country and leaving spirit children behind them, who are continually being born again.

The old man Kurkutji was a good example of the Binbinga tribe. The men of the latter have very little hair on the face, and that on the head is allowed to grow to a considerable length and is then made into plaits that are wound round the crown so as to produce the appearance of a close-fitting cap or helmet (Fig. 403). He told us how he had graduated in his profession. One day he walked into a cave in a hill not far away from Borraloola, quite unaware that the two spirits, called Mundagadji and Munkaninji, who make medicine men, were walking about. Before he knew what was happening, old Mundagadji caught hold of him by the back and killed him. Then he cut him open, right down the middle, removed all his insides and exchanged them for his own, which he placed in Kurkutji. After this had been done, the younger spirit, Munkaninji, came up and restored him to life, told him that he was now a medicine man and showed him how to make "poison bones " out of dead men's bones. Then he took him up into the sky and, finally, brought him down near his own camp, where his people were mourning for him, thinking that he was dead. For a long time he remained in a more or less dazed con- 
dition, but gradually he recovered and the natives knew that he had been made into a medicine man. He is in great demand, not only in his own tribe but in the Anula also, who, curiously, have only medicine men who can implant but cannot extract " poison bones."

The Binbinga have a belief in three special spirits, two of whom live in the sky. They have great knives instead of arms, their bodies are covered with feathers and they are always on the look-out to kill natives. The third is a friendly one who lives on earth amongst the forests, and is constantly watching to prevent the evil spirits from doing harm. He also has feathers all over his body. Snakes figure largely in the traditions of all the tribes. The Binbinga have one referring to a very powerful one named Ulanji, who made the Macarthur River. There were also two youths who walked across the country. One day they started off from their home away out near the shores of the Gulf and made creeks and hills as they travelled. At one place they killed and ate a kangaroo and at another a bird that sang "Pui, pui, pui, pu," all day long. Then they struck the earth with their stone axes and the old snake Ulanji, who travelled underground, heard them and sent some bats (flying-foxes) after them to see what they were doing. However, as soon as the foxes flew up the boys took their waddies and killed so many that they had to make several trips to bring them all into camp. The boys had no right to kill flying-foxes, because they are a great delicacy and only old men may do so and eat them; the old snake-man Ulanji was angry, but as yet he said nothing. The boys made a native oven, that is, a hole in the ground, with a fire and hot stones in it. They put the bats on the stones, covered them with grass and earth and, leaving them to cook, went away to bring some more. Returning they opened the oven and, to their surprise, the bats came out and flew away. The boys said, "Hullo, what is this? 
what is the matter? the bats are flying away." They tried to cook some more, and then the old snake, who was watching them from below, took out one of his ribs and threw it up on to a plain where one of the boys found it and said, "Hullo, this is a very good boomerang." Then in turn each of them threw it at the foxes, who tumbled down. At last one of them threw it up into the sky, in which it made a hole and disappeared. After a time, down it came with a great whizz and stuck straight up in the ground. One of the boys tried to pull it up, but the harder he pulled the deeper down it went. Then he called out to the brother to come and help him, but it was no use, and at last the old snake, who was underneath and had hold of it, caught the two boys by the legs and dragged them down. Where they went down, a big water-hole called Nimbi-Nimbi was made. The snake took the boys away underground to an island in the Gulf, and has kept them there ever since and they will never be set free again. The moral of this tale, as told to boys nowadays by the old men, is evident.

The terms of relationship used by these natives are very difficult for a stranger to remember and, all told, there are between thirty and forty of them. A few are as follows:elder brother is naluru-napinini; wife's mother is nunartjurlunga; husband's mother is nerungwinia-arunga; sister's husband's mother is gnunga-tatchulunga; son's wife is nirilumpakarunga. The strange thing is that the aboriginals can remember them.

We were much interested in the Anula, Mara and Karawa tribes. They belong to a group of coastal tribes inhabiting the western shores of the Gulf of Carpentaria. For generations past they have been in contact, to a certain extent, with the Malays, who annually came down in their prahus to trade for tortoiseshell, pearls and trepang or bêche-de-mer. So far as we could see, judging by the natives of the coastal tribes that we met, and there were a 


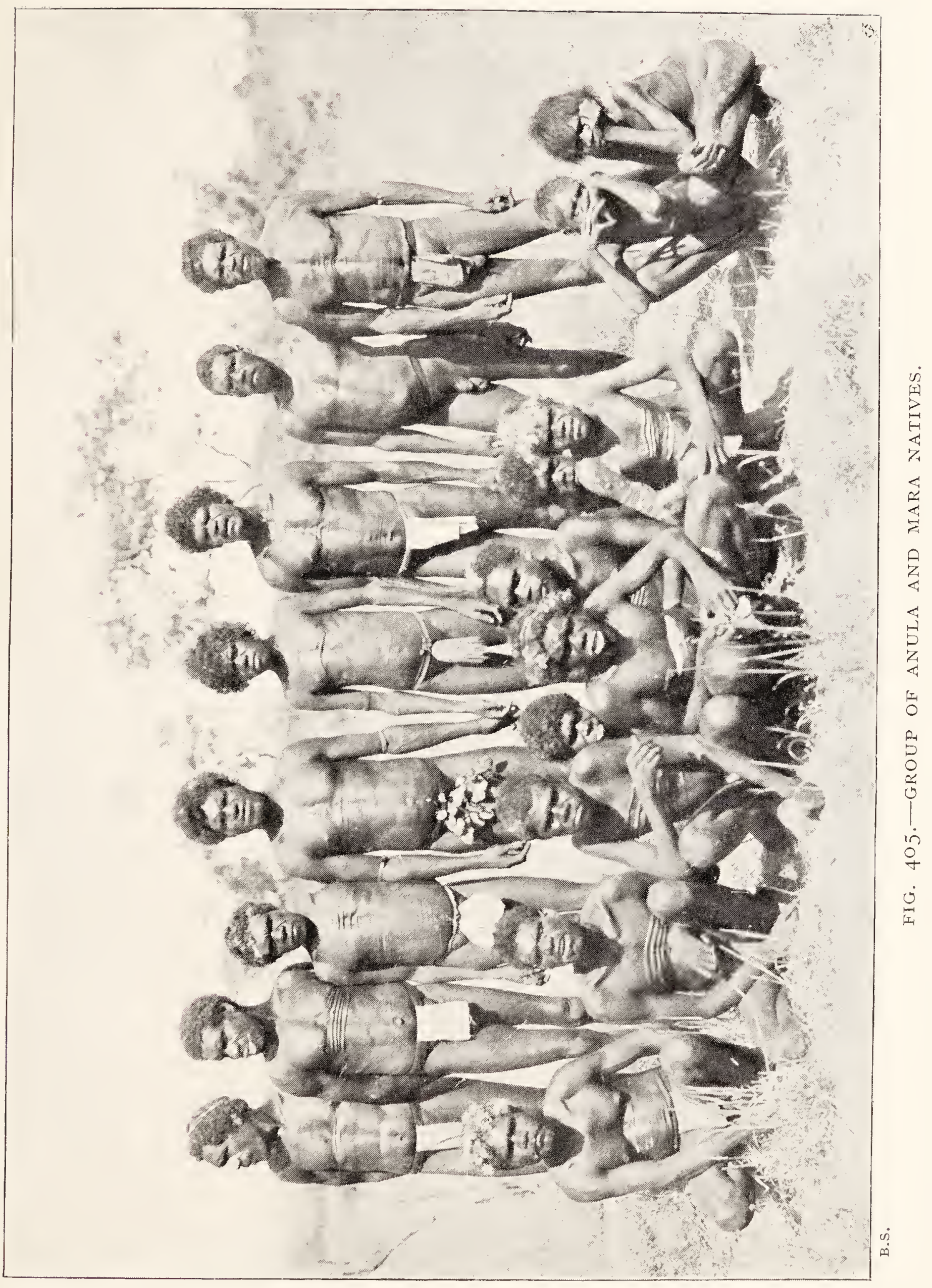



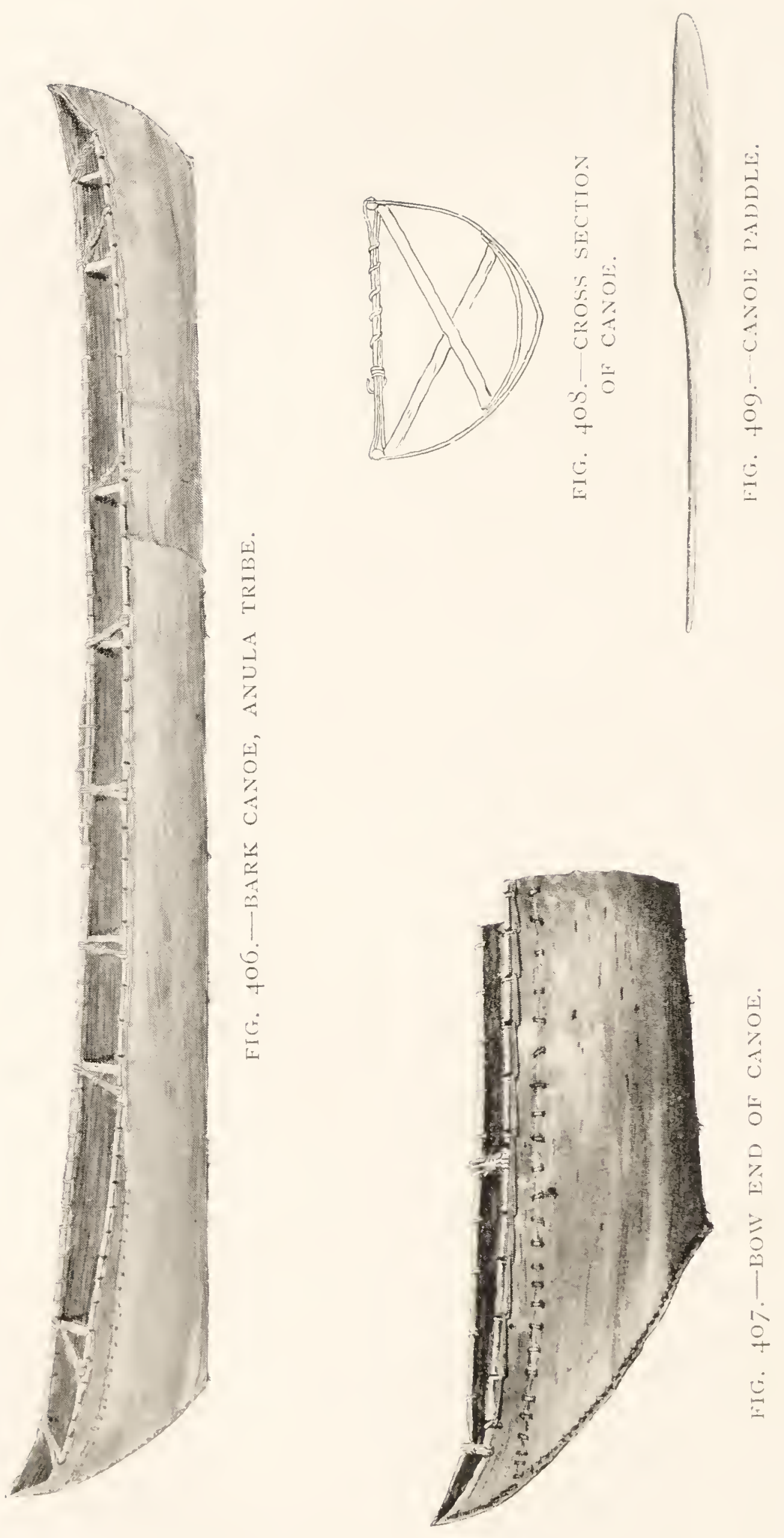
good number at Borraloola at various times, there had been but little mingling of the two races. One of the most characteristic features of the Malay is their lank, straight hair. On the other hand, all the coastal natives that we saw were strongly characterised by the possession of very distinctly curly, in fact sometimes decidedly frizzy, hair. This is well shown in the group photograph of some of the Anula and Mara men living in the camp at Borraloola (Fig. 405).

These natives have two kinds of boats, one a "dug-out" and the other made of sheets of bark, carefully sewn together. Though the natives now make the former, they have probably derived it originally from the Malays: at all events it is only found where the two races have come in contact, in the same way in which the outrigger canoe is only found where the Australian aboriginal has been in contact with Torres Strait Islanders. It is rather strange that the outrigger is never met with on the west side of the Gulf of Carpentaria, but extends down the eastern coast of Cape York, probably as far as Cooktown, but the advent of the white man, and his constant navigation of the eastern coast of the continent, influenced the life and movements of the native and makes it difficult to be quite sure as to the original distribution of a sea-going boat such as the outrigger.

The " dug-out" may be twenty feet or more in length and three in beam and is hollowed out of a single log. Each end is slightly raised so as to form a bow and a stern, but there is no attempt at a keel.

The boat almost always met with along this part of the coast is the bark canoe, which is certainly indigenous and is met with everywhere around the coast of Arnhem Land and across to Melville Island. The one represented in Fig. 406 is seventeen feet long, slightly more than two feet in beam and has both ends raised, the bow rather more than VOL. II. 
the stern. There is no keel. We secured this one from six Anula men who had just come across in it from the Pellew Islands in the Gulf to the mouth of the Macarthur, and then up the river for fifty miles to Borraloola. It looked a very frail craft for such a voyage that can only be undertaken safely during fine weather, when the sea is smooth, and even then two of the boys were kept busy bailing with the aid of big shells. The bark for making these canoes is stripped during the wet season from a species of gum tree from which it easily peels off in long sheets. In this canoe there were seven pieces. One of them stretched from bow to stern forming the whole of one side, the other was made of two pieces. These three pieces formed the main body of the boat and were sewn together along the bow, stern and keel lines. There was thus an indication of a keel but no projecting ridge. At each end, and on one side, a small strip was added so as to form the pointed, upward-turned bow and stern (Fig. 407). To strengthen each bulwark a thin branch of mango-wood was lashed securely to the bark. To prevent the sides from collapsing outwards, nine ties of rope passed across from side to side, two of them serving to pinch in the extreme ends of bow and stern. To prevent the sides from collapsing inwards, three sticks were arranged at the level of each of the cross ties, one passing across from side to side immediately under the rope, the other two slanting down and crossing one another, their lower ends serving to keep in place sheets of bark that form a kind of false, dry bottom (Fig. 408), and also add additional strength to the sides where the sticks press against them. There is never any attempt at caulking, but the sewing is so efficient that very little water soaks through. The paddles are five or six feet long, and very crudely made, with the blade about as long as the handle (Fig. 409).

The twine used in the making of articles such as this boat is very simply made and often looks just as good, and is 


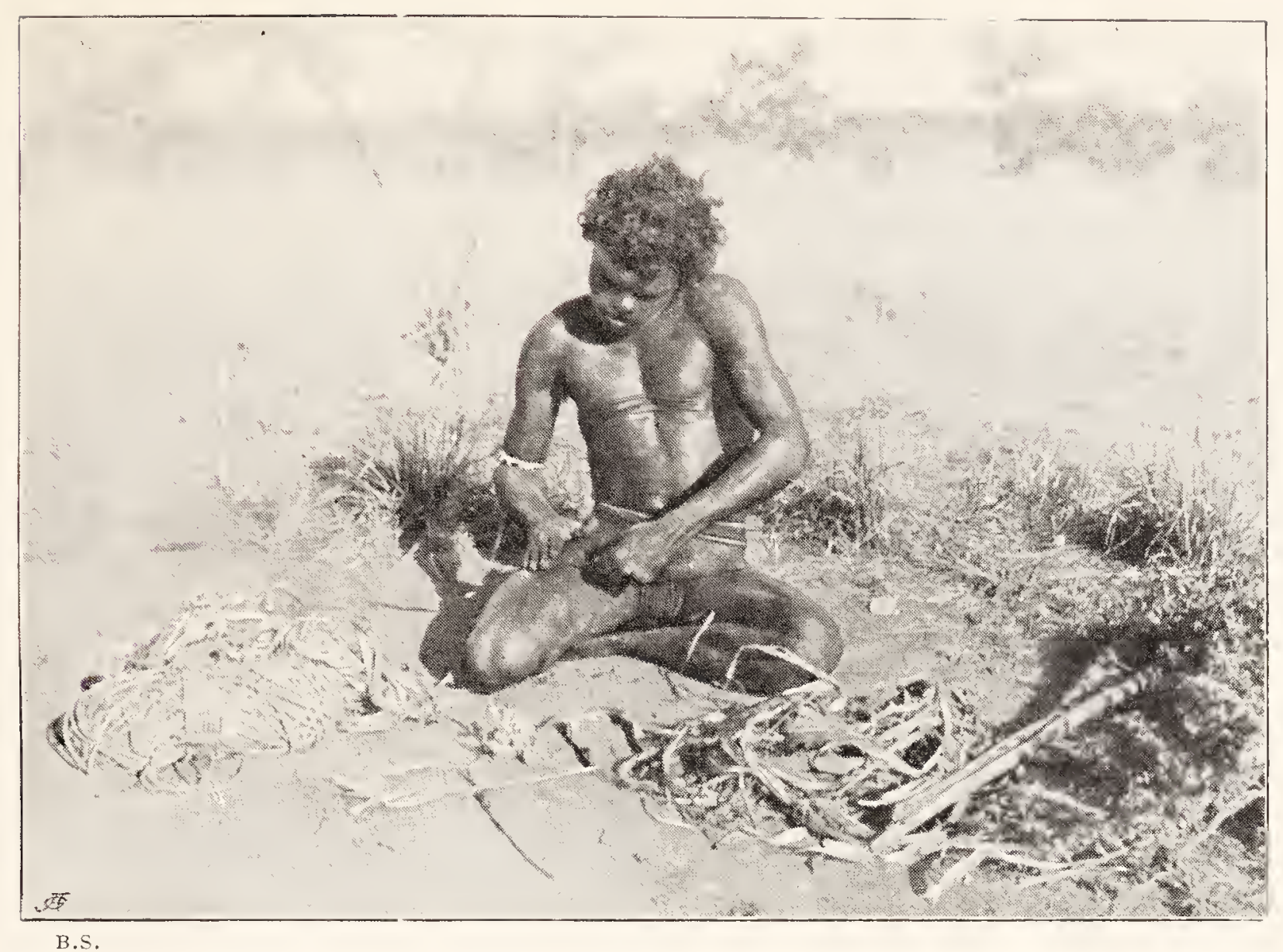

FIG. 4IO.- ANULA MAN MAKING TWINE OUT OF LONG SHREDS OF BARK.

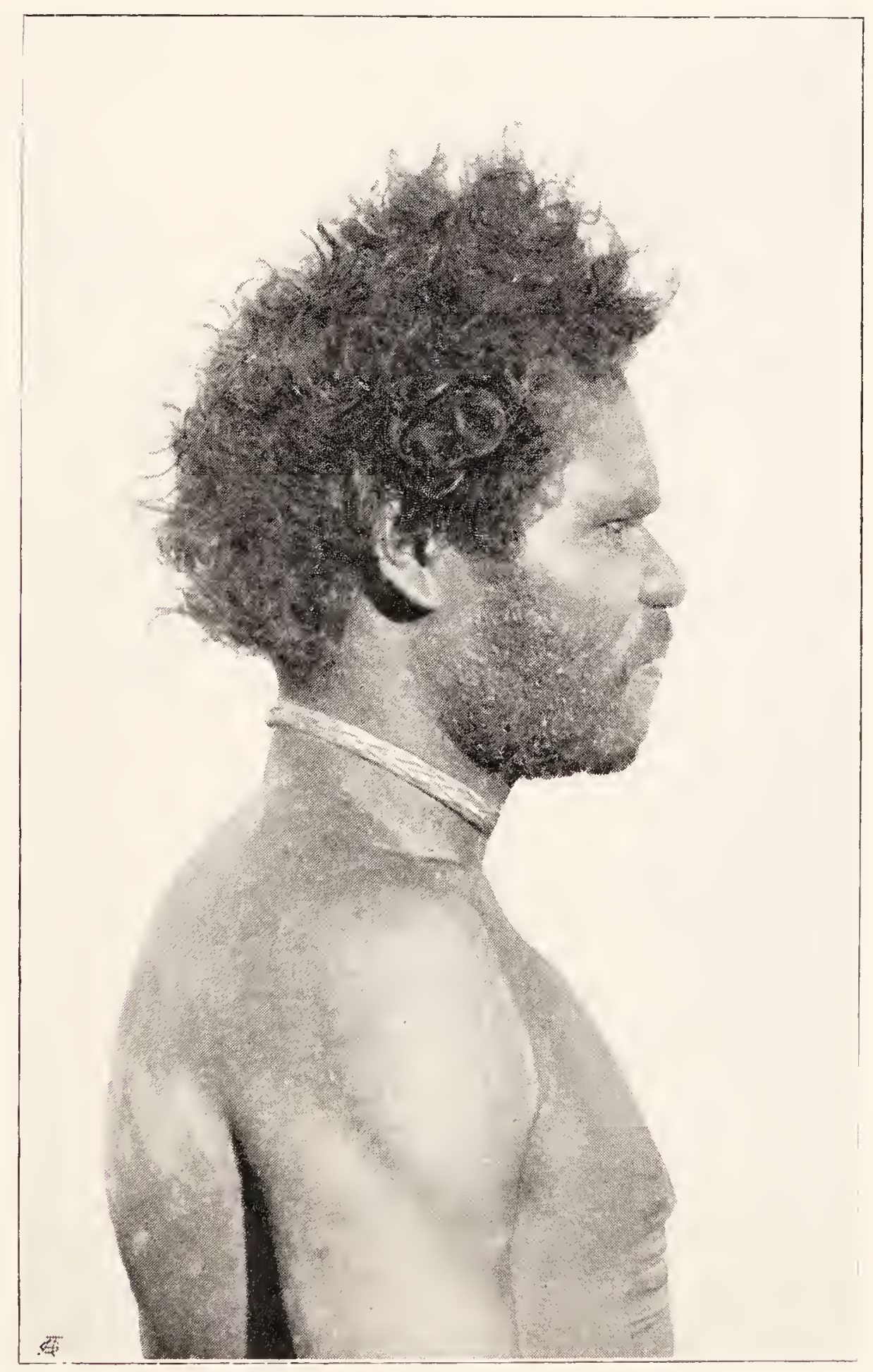

FIG. 4I I, ANULA MAN WEARING CANE NECKLET. 


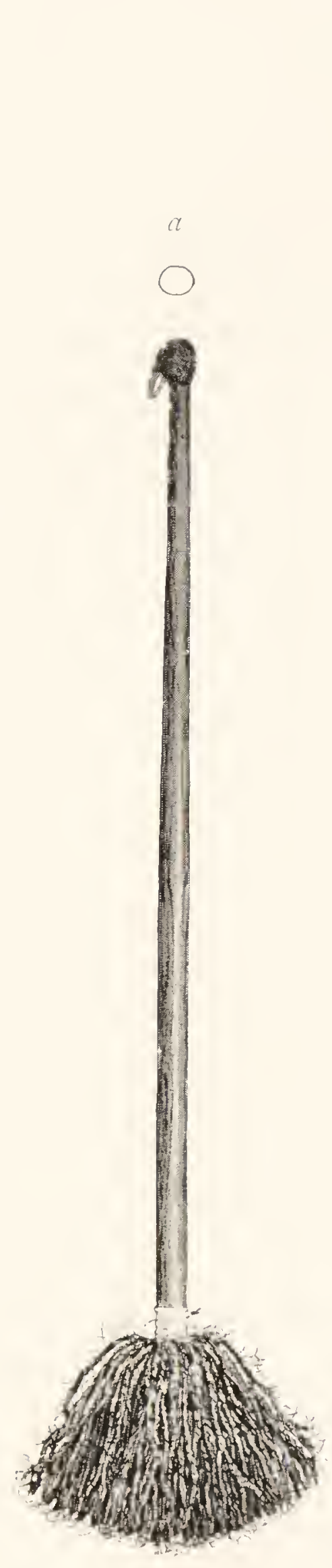

FIG. 1 2.- TASSIE, SPEAR-I11ROWER, ANULA TRIBE.
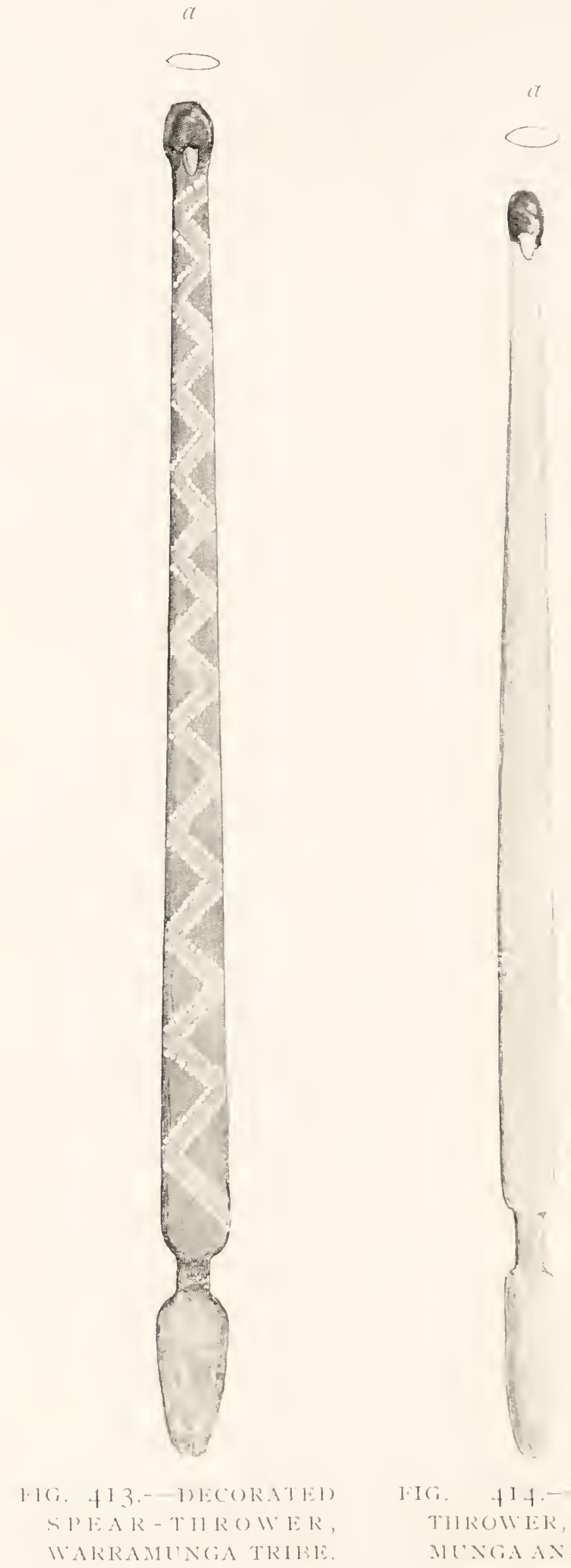

IIC. +1 4- SIEARTHROWER, WARRAM(NGA ANI) NORTH-

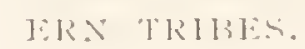


certainly just as serviceable, as the white man's string and rope. Native twine can generally be detected because it is never more than two-ply, or perhaps, to put it more correctly, twine with more than two-plies is not likely to be Australian. In the Arunta only human hair and fur of animals, such as the opossum or bandicoot, are used for spinning string. The Warramunga and other more northern tribes use also vegetable fibre that makes a much stronger twine. In the Gulf country and the far north it is made out of the inner bark of trees, principally gum and Banyan trees, or, more often, where they are found, out of the leaves of Screwpines torn into shreds. The spindle is merely a short stick, perhaps a foot long, which is thrust through a slit in two other short pieces that are placed at right angles to it and to each other. A little twine is first of all made by the hand and fastened on to the spindle, which the spinner rotates with his right hand on his thigh, while he continually serves fresh material with his left hand. This gives him a single ply, and two of these are then twisted together in the same way to make the two-ply string. The strong rope made from shreds of Pandanus leaves is twisted without the aid of a spindle. The shreds are rotated on the thigh by the right hand, the resultant cord being drawn out by the left hand. It is astonishing how rapidly and easily an expert, such as the one represented in the illustration, will make great lengths of string, of varying thickness, according to the purpose for which it is going to be used (Fig. 4IO).

On the whole, the weapons and implements of these coastal tribes were disappointing. They use two types of spear-throwers. The commonest of them, which we had first seen in use amongst the Warramunga, though it is sometimes traded further south, has the form of a long, thin, flattened slab of wood with a very distinctly marked handle (Figs. 4I3, 4I 4). The second, which is much rarer and is made especially by the Umbaia and Gnanji tribes, has the 
form of a stick, circular in section and almost three feet in length. The handle end is ornamented with a tassel of human hair string (Fig. 4 2). In both types the knob that fits into the slight hole in the end of the spear is made of wood and attached to the thrower by means of porcupinegrass resin in the Warramunga and Interior tribes, and by beeswax in the coastal tribes. The latter method is really the better of the two, because, though the wax is rather soft, it never becomes brittle and liable to be cracked and broken as easily as the grass resin. There was only one kind of spear that we had not seen before. On one side of the terminal part (Fig. 4 I 5) a row of barbs was clearly indicated, but their points were not cut out, so that, though there were a number of holes corresponding to the spaces between successive barbs, the edge was a continuous instead of a barbed one. This terminal part of the spear had a long, sharp point and was spliced on to the main haft by resin wound round with string. It is, of course, quite possible that, sooner or later, the barbs may be separated, but spears of this kind are often seen and are certainly used in this state.

Sometimes, but rarely, we saw stone-headed spears (Fig. 4 I6), but blades of sheath iron and iron prongs are rapidly replacing stone and wood, as the natives have found out that they are much more effectual, both for fighting and spearing cattle, than any other form.

A very characteristic feature of men and women alike is armlets and necklets made of split cane (Fig. 4I I). As many as twenty or thirty of the former may be worn on one arm. So far as ornaments are concerned, the coastal natives seem to have much more eye for colour than the tribes of the Interior. They will take a single piece of split cane, bind it tightly round with fur string and cover it thickly with bright red, yellow and blue-green feathers of the Blue-mountain parakeet, or the pink ones of the Galah 


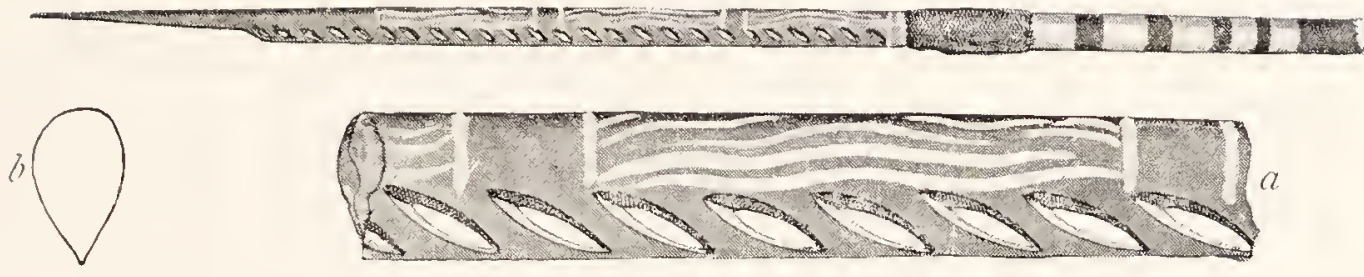

FIG. 4I5.-SPEAR WITH UNCUT BARBS, ANULA TRIBE.

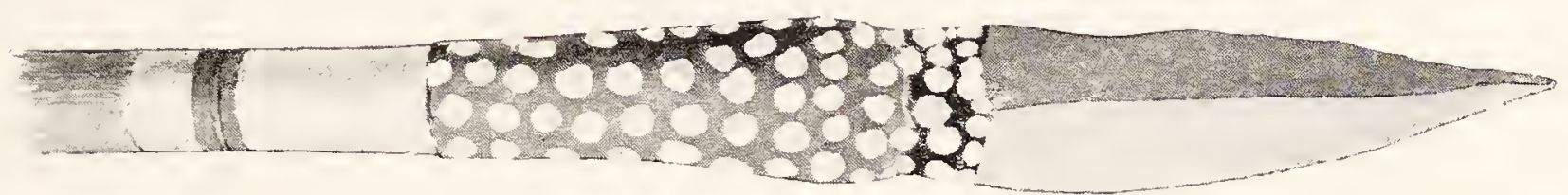

FIG. 4I6.-DECORATED SPEAR-HEAD, TJINGILLI TRIBE.

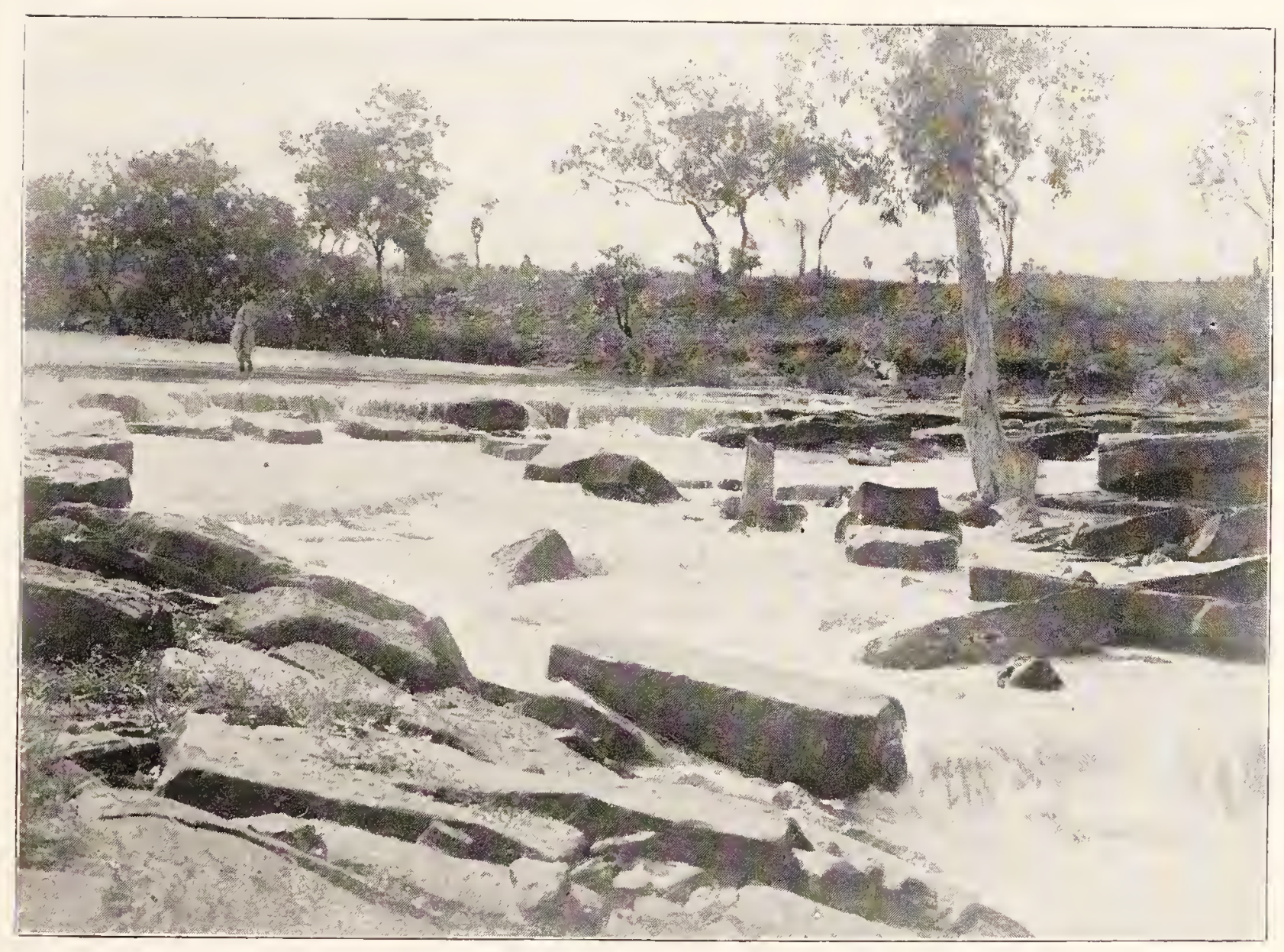

B.S.

FIG. 4I7.-TIIE CREEK AT BORR.ILOOLA AFTER A STORM. 

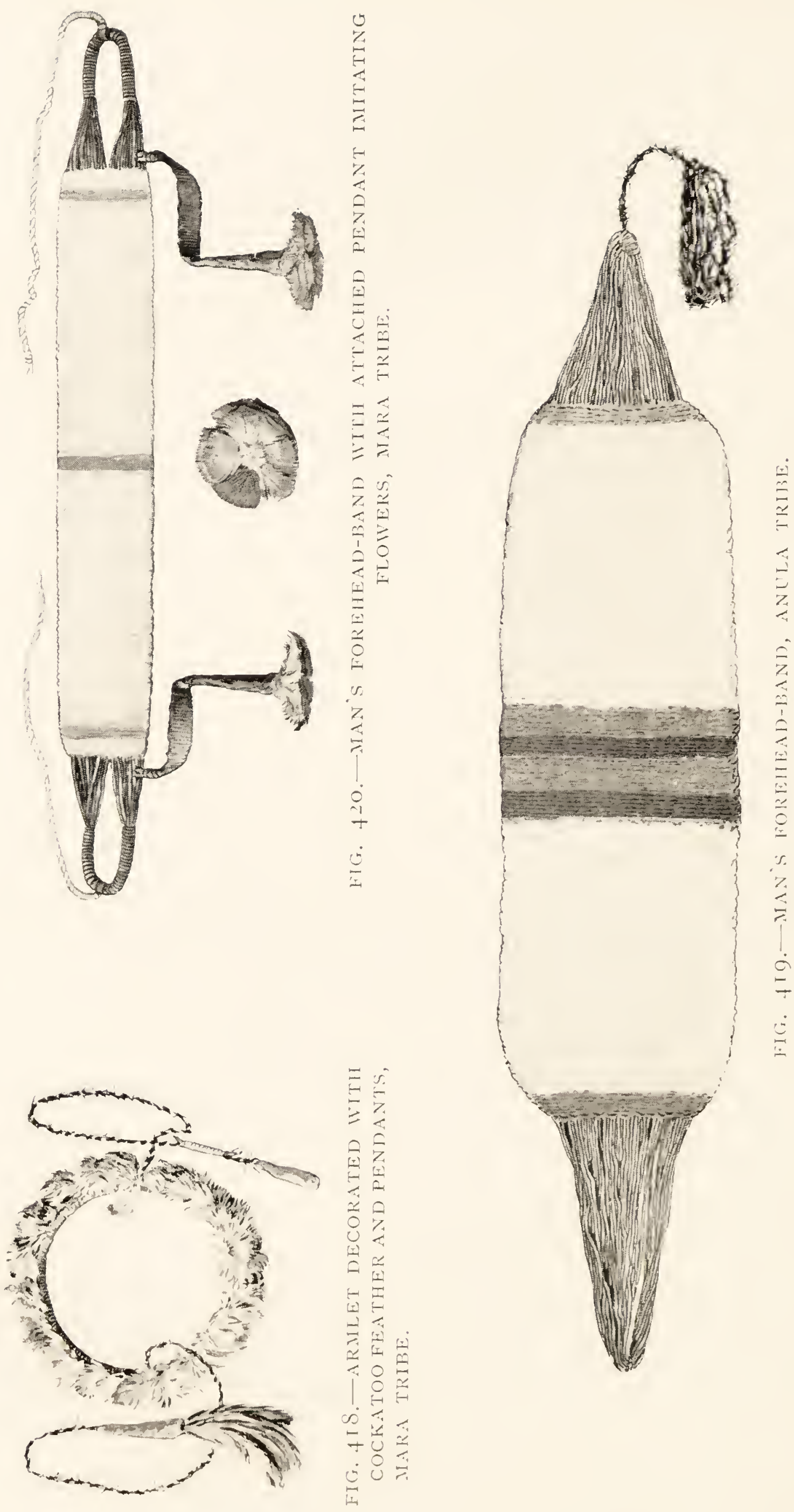
cockatoo. In the one illustrated (Fig. 4I 8) there are two pendants of human hair string ending in beeswax into which feather tufts are fixed. They also made beautiful waist girdles, in which the string is hidden from view by gaily-coloured feathers. Head-bands are very commonly worn. Each consists of a number of strands of opossumfur string, tied together at either end. By means of moistened pipe clay, the string can be made to form a flat band on which designs can be painted in red and yellow ochre (Fig. 4I9). The two figured are typical examples. The most interesting feature present in one of them (Fig. 420) consists of two little pendants, each terminating in what is evidently an imitation of a flower, cleverly made out of birds' feathers with a centre of down representing the stamens. It is only very rarely, and only in these far northern parts, that any attempt is thus made to imitate any natural object such as a flower.

We were very anxious to secure one of the larger crocodiles. You can see them along the banks of the river, or lying, at first glance, like a log in the water, with only a little of their head and back showing, and gruesome tales are told of men who have mistaken them for floating logs. As soon as disturbed on land, they glide rapidly down the bank into the water and, if shot, sink to the bottom at once. They are ugly brutes and very dangerous, and in the Anula camp there were two or three natives who were terribly scarred as the result, so they said, of encounters with crocodiles. One of them had lost the greater part of his thigh and hip on one side. It is very difficult to understand how they can survive such fearful wounds. The crocodile lies in wait at some place where horses and cattle come to drink, and where the water is often so thick that it cannot be seen lying motionless beneath the surface. The unfortunate beast is suddenly seized by the legs or thrown down by a swish of the brute's great tail and then dragged under- 
neath. The crocodile, like the white man, likes his game to be a little " high," so, instead of eating the body at once, it always carries it away to some quiet "billabong" and leaves it on a sand-bank for a few days to mature. Both white men and natives fall victims now and then to the crocodiles. The natives say that if you can manage to poke your fingers into its eyes, you so disconcert the brute that it lets you go and you can escape. I know that they will actually dive in and try to catch small crocodiles in this way, but it must require a good deal of coolness and self-possession to poke your fingers deliberately into the eyes of a twelve- or fifteen-feet-long crocodile that has seized you by the leg or arm. The natives have one very quaint way of protecting themselves that they told us about quite naively, as if it were the most natural thing to do. If a party of them has to cross a stream in which crocodiles are known to lurk, they go in single file and always put an old woman in the rear, because, so they believe, the crocodile always seizes upon the last person, and the loss of an old woman does not matter much. Crocodiles are often caught with a bait of poisoned meat, and one day the natives came to us in a state of great excitement, saying that they had secured one and were bringing him into our camp, and, shortly after, we saw a procession of about twenty blackfellows carrying the beast slung on to a pole, all of them anxious to share in the reward that we had offered. He was decidedly dead, but it was the first that we had been able to get, so Chance and myself set to work to skin it, and his odour remained with us for weeks. It was a tedious, malodorous business, and several days later, when we were taking it out for an airing in the sunlight, its peculiar scent was so strong that it woke Gillen, who was enjoying an afternoon siesta some distance away. Unfortunately, though there was a building between us, the wind was blowing in his direction. The 
smell became so intolerable and penetrating that we had, finally, to abandon all thoughts of curing the skin and had to content ourselves with the head-the rest we had to burn, as also the clothes we had used during the skinning operations. Chance and myself, not being adepts in the art, learnt from experience that the hot season was not a good time in which to skin crocodiles.

The time of the north-west monsoons was drawing near and the weather was rapidly getting warmer and moister, making any physical exertion a trouble. Day after day the clouds gathered in great masses, but it was a very late season and the middle of December came before the wet season really set in, and even then, to our great disappointment, we had only passing storms. One day was very much like another. Of course we had to sleep under mosquito-proof nets and there was no need for any save the lightest covering, because the lowest temperature at night, even in the open, was rarely under $75^{\circ} \mathrm{F}$. Just about five o'clock every morning a faint light appeared in the east. Gradually it deepened into a warm orange, the fore-glow, which again faded away, giving place to a cold grey light. Once more it warmed into saffron, the trees on the low hill-tops were tinged with pink and, a few minutes later, everything was bathed in brilliant sunshine. Just when the first glow appeared the birds woke up and the magpies, pigeons and kingfishers welcomed the returning light, while flocks of Galahs and Blue-mountain parakeets came screeching to the water. After a short time all was quiet again. Not a breath of air stirred and it felt as if everything were watching and waiting for the sun. All day we perspired and waited patiently, while the shadows of the houses and trees gradually drew in from the west, until at noon a straight-up post threw no shadow at all and we walked upon our own. Then, only too slowly, the shadows lengthened out towards the east and we waited for 


\section{WANDERINGS IN WILD AUSTRALIA сн.}

the sunset and the lovely orange-coloured afterglow that always followed it, melting above into the turquoise-green of the sky. Every morning there was a dead calm till between nine and ten o'clock, when a sea breeze came up which cooled things down to anything between $95^{\circ}$ and $105^{\circ}$ in the shade. In the afternoon it died away and was followed by a sultry calm, until usually, but by no means always, a sea breeze again sprang up and lasted for an hour or two. The lowest temperature on one comparatively cool night in the middle weeks of December was $7 \mathrm{I}^{\circ} \mathrm{F}$. At sunrise on most days it was between $80^{\circ}$ and $85^{\circ} \mathrm{F}$.; then it started to rise, and at ten o'clock registered from $90^{\circ}$ to $95^{\circ} \mathrm{F}$. By noon it was $100^{\circ} \mathrm{F}$, and up till three $\mathrm{o}^{\prime}$ clock anything between this and $\mathrm{I} 09^{\circ} \mathrm{F}$.; at 6 p.m. it was $90^{\circ}$ to $95^{\circ} \mathrm{F}$, and at $9 \mathrm{p} . \mathrm{m}$. from $82^{\circ}$ to $88^{\circ} \mathrm{F}$. These readings were in the shelter of the court-house: those taken out in the open were of course much higher. The day of our first thunderstorm was very typical of the weather during this season of the year in the Gulf country. At sunrise the thermometer registered $85^{\circ} \mathrm{F}$; at 9 a.m. it was $94^{\circ} \mathrm{F}$.; then it went up steadily, and from I p.m. to 3 p.m. it stood at $109^{\circ} 5^{\circ} \mathrm{F}$. It must be remembered that the heat was a damp, not a dry one, and that there was but a slight difference between the registrations of the dry and wet bulbs. We were soaked through with perspiration all day long, sitting quietly, reading and writing under the verandah of the court-house. All day a heavy bank of dark cloud lay along the horizon out to the south and east. The thermometer fell to I00 F. Suddenly we heard a wind rising and then, from the sandy plains out to the south-west, a dense dust-storm swept down on us, hiding everything from view. About three o'clock the clouds quickly came up and jagged forks of lightning seemed to streak right down to the ground. The rain came down in torrents: it only lasted for a few minutes, 
during which a quarter of an inch fell. The thermometer ran down to $94^{\circ} \mathrm{F}$. at $3 \mathrm{p} . \mathrm{m}$. and for a short time after the rain had fallen we had a refreshing earth smell, but soon everything was again moist and sticky and at 4.30 p.m. the temperature was $100^{\circ} \mathrm{F}$. Close to our camp there was a creek running down to the Macarthur River from some low hills two or three miles away. Its bed was soon filled with rushing water tumbling over a succession of rocky ledges in miniature waterfalls (Fig. 4I 7). For a short time it was really picturesque, but within two hours of the passing away of the storm the creek stopped running, leaving only a few shallow pools that very soon dried up.

The next excitement we had was the spearing of a calf quite close to the township by three natives. Of course the culprits, after enjoying their meal, cleared out, but some of their friends went after them and captured two out of the three. They were safely locked up in a strongly-built log hut that does duty for a gaol. The way in which offending natives are often brought into justice by their bosom friends is very amusing and saves the representatives of the law a good deal of trouble. If a native spears a bullock, one or two of his relations, usually brothers-in-law, are sent out to find him. When they have done so, which is an easy affair, they just talk the matter over and, as likely as not, persuade him to come back with them. Of course they are not always amenable to reason and then the trooper must go out, but, as they have no rooted objection to gaol, where they have free tucker and not too much hard work, they are quite often willing to be brought in. The reason given to me why the third man did not come on this occasion was simply that he had only been released a few weeks earlier, after " doing" three months, and wished to have a spell in the bush before going in again.

Next day, as a magistrate in the person of Gillen was available, a trial was held. The prosecutor, Sergeant 


\section{WANDERINGS IN WILD AUSTRALIA сн.}

Stott, in deference to the feelings of the magistrate and to uphold the dignity of the law in the eyes of the natives, appeared in semi-uniform, full uniform being dispensed with on account of the temperature. The magistrate also was not in full dress. Chance, who was a mounted trooper, donned a pair of official-looking trousers to support his superior and brother officer and impress the natives who gathered round the door, much interested in the proceedings. Witnesses, black and white, appeared in any available costume that was convenient and cool. I was the solitary spectator. The proceedings were commendably brief, the prisoner, called Jack, being quite anxious to give all the assistance in his power and get through the business before the court without any unnecessary delay. The constable laid a formal charge and then addressed the prisoner as follows:- "Your name Jack." Prisoner: "Yes, my name Jack all right." Constable, speaking slowly: "Now, Jack, you listen longa me." Prisoner: "Yes, Mr. Stott, me listen longa you all right." Constable: "You been go longa that calf with intent, mind you, with intent," he was evidently going to add, "to spear him." Jack, however, was too much interested and anxious to help to allow him to finish the sentence and broke in with, "Yes, me been go longa im tent all right." The magistrate, however - the court was very hot and he had a good deal of experience of natives and their ways-decided it was not necessary to enter upon any lengthy course of cross-examination and, taking the matter into his own hands, put one simple, leading question to the prisoner. "Jack, you talk straight-fellow longa me; you been spear him that one calf?" Prisoner: "Yes, me been spear'em all right," and to clinch matters, added, with evident pleasure in the recollection, "then me been eat 'em all right." That was both final and satisfactory to all concerned and the prisoner was led forth, quite cheerfully, to 
do " two months' hard," which meant mainly that he would do a fair, but not excessive, amount of work by way of chopping wood for use in the household of the constable during the next cool season, and keep the vegetables well watered in his garden, in return for which, and the temporary loss of his liberty, he would be provided, on loan, with a shirt and pair of trousers, be well fed and enjoy what the native appreciates above most things, two or three good smokes daily. In the opinion of his compatriots, who had watched the proceedings with great interest, rather envious of his being, for the time, the centre of interest, he left the court "without a stain upon his character."

It was now getting well on into December and, with monotonous regularity, the thermometer daily registered $109^{\circ} \mathrm{F}$. at 3 p.m. We were wringing wet all day long and for a good part of the night also, and the natives were not at all inclined for such hard work as answering questions meant, so, in the lightest possible attire and a towel for a mop, I started to write up our notes. Despite the heat we were all perfectly healthy, but the only living things with energy were the flies and mason wasps and now and again my little terrier, who made valiant attempts to capture a big hornet-like wasp that was building its nest on the legs of my camera that was leaning against the wall close to where I was writing. It was deeply intent on its work and took no notice whatever of me. It was just two inches in length and bright golden in colour, save for one broad dark band on its thorax and another on the swollen abdomen, which was hung on to the front part of its body by a long, gracefully curved waist. It was a most persevering little animal. First of all it perched on the side of the open water-bag, hanging under the verandah close by, and took a good drink. Then it flew away, and in a few minutes returned to its nest with a pellet of sand, about an eighth of an inch in diameter. It placed this very carefully on the open rim of the chamber 


\section{WANDERINGS IN WILD AUSTRALIA сн.}

in course of construction, moistening it with water out of its mouth as it did so. The chamber was roughly spherical in shape and, when once the full diameter of about three inches had been reached, the margin of the wall was curved over until finally only a small opening was left. Then, for a time, it stopped building operations and flew off in search of little grey spiders, of which there was an abundant supply handy under the eaves of the verandah, put about ten or twelve of them, stupefied, in the nest, laid a few eggs, resumed building operations, closed up the opening and at once began to build a new chamber. It is a most remarkable instinct, especially when it is remembered that the adult insect neither watches over nor sees its offspring.

Time was passing by, there was still no news of any boat arriving from Darwin and supplies were beginning to get low in Borraloola. However, there was plenty of work to be done when one felt energetic enough to do it. Chance and myself used to go out in search of birds, hoping that the rain season might bring with it some migrants. The most interesting, and at the same time most attractive one, was the Torres Strait pigeon. It is a beautiful bird about twice the size of the common blue-rock. The body is pure ivory-white, the head a shade of very light pearl-grey and the large wing feathers a soft, dull, very dark grey almost approaching black. There is no trace of a metallic sheen on any part of its plumage. It makes its appearance here every year at the beginning of the wet season and nests in the tall gum trees, returning north when the breeding season is over.

It is a curious feature of pigeons and doves, which are always delicate birds to skin, that the breast muscles of the light-plumaged ones, such as the Torres Strait pigeons, are always dark-coloured and those of dark-coloured ones are pale.

Late one evening, Chance, who had been over at the police 
quarters, came back and told us that something had bitten him on the leg in the dark. At first we were afraid it was a snake, but there were two main large punctures and two other smaller ones on one side and one on the other side behind them. The natives recognised them as made by one of the big centipedes, six or eight inches long, that are often met with here. The two larger had been made by the strong fangs and the others by the sharp-pointed legs of the beast while it was hanging on. The pain was intense and remained so, as the natives said it would, for twenty-four hours, after which it began to wear off and the swelling of the ankle, foot and lower leg subsided. It was a nasty experience, and henceforth Chance walked about warily at night-time with a hurricane lamp.

Christmas Day, thanks to the kindness of Mr. McLeod, the manager of the store, and Sergeant Stott, the representative of the law, formed a pleasant break in our somewhat monotonous life. We dined with them and had genuine Christmas cheer, including a pudding that contained the few remaining plums left in the Gulf country, and a solitary bottle of whisky, the only one within a radius of at least three hundred miles. This had been carefully and thoughtfully treasured up for the occasion, as all supplies in the hotel had run out long before our arrival at Borraloola. Owing to the temperature, it was agreed that all superfluous clothing should be discarded, so, in decidedly light attire, we sat down to the most sumptuous and certainly the most pleasant meal that we had in Borraloola, followed by a quiet smoke and chat in the brilliant moonlight.

I spent many hours watching the women playing string games-just like our " cat's-cradle," only on a much more elaborate scale--and sketching a few of the stages during the making of some of them, representing eagle-hawks, opossums, lizards, yams and dugongs. The lubras became so interested in their games that, once they started, they 
582 WANDERINGS IN WILD AUSTRALIA сн.
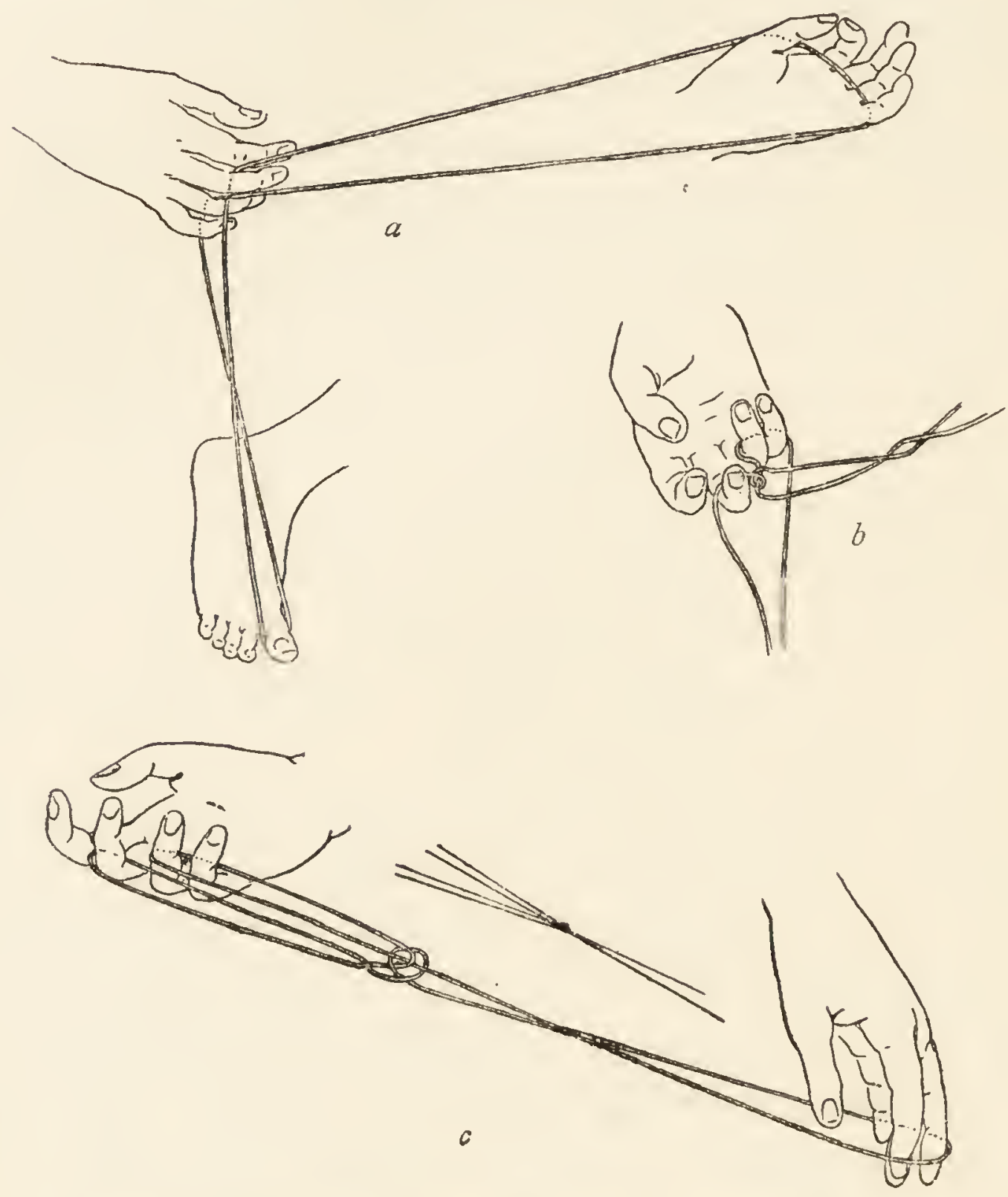

FIG. 42I.-MARA STRING GAME. YAM DESIGN.

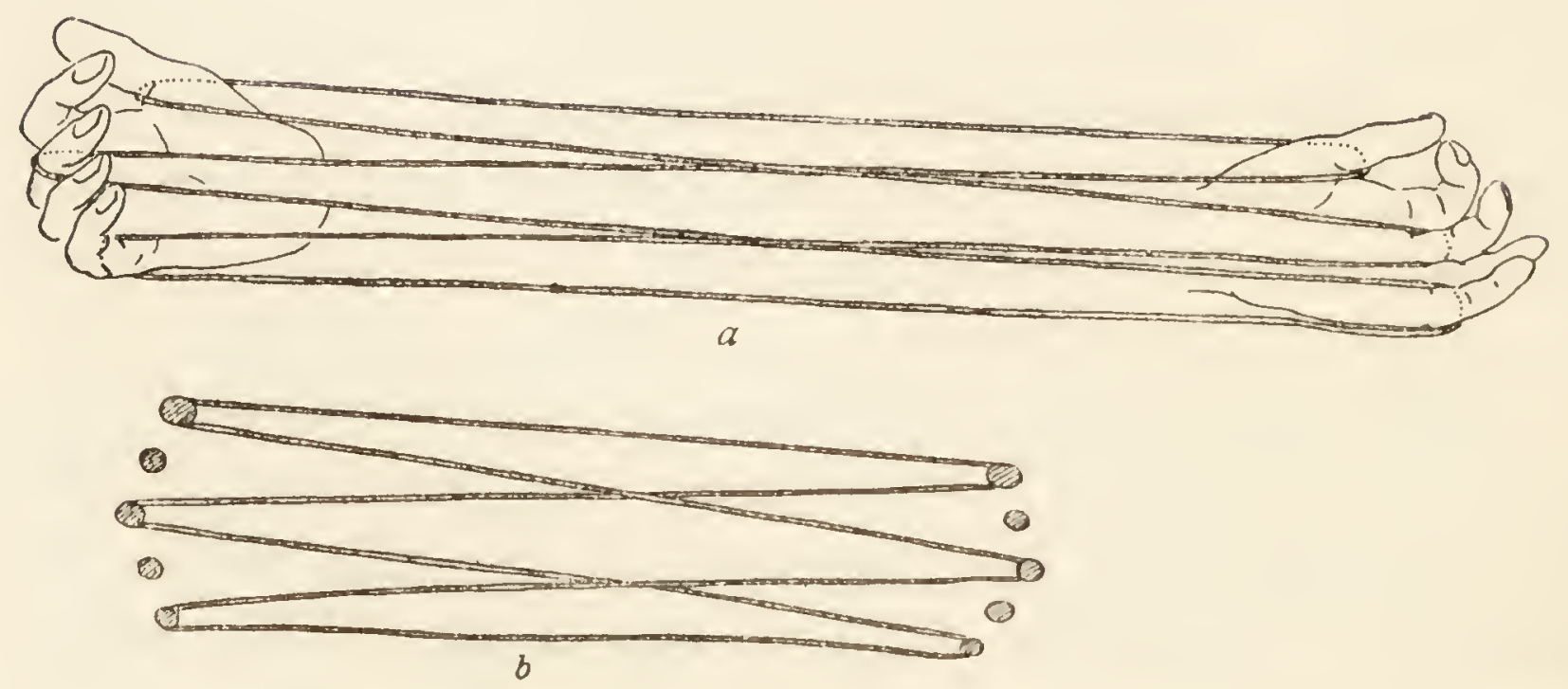

FIG. 422.-MARA STRING GAME. DUGONG DESIGN. 
xxIv BORRALOOLA AND COASTAL TRIBES 583
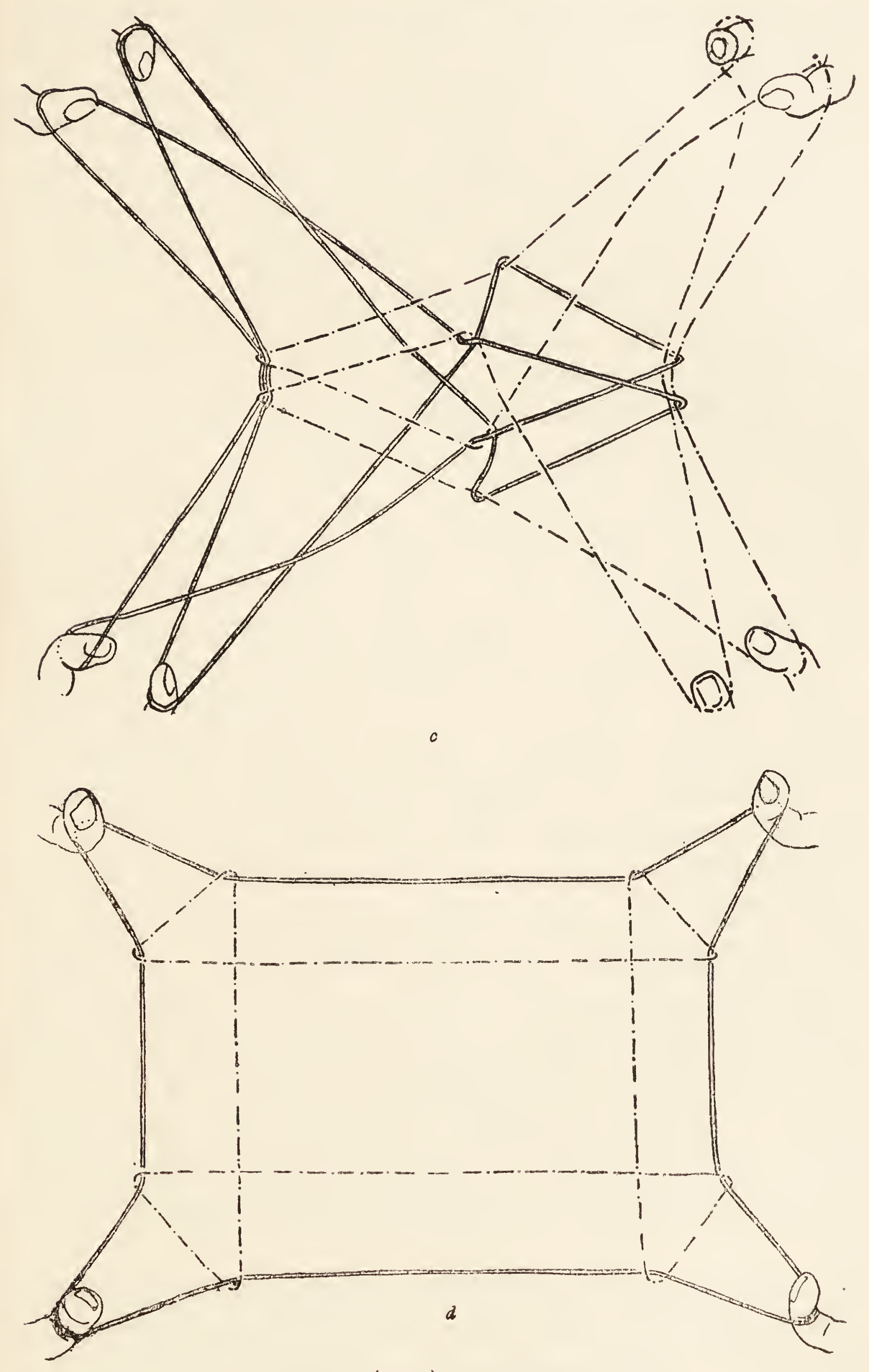

FIG. 422 (cont.).-DUGONG DESIGN. 


\section{WANDERINGS IN WILD AUSTRALIA сн.}

played away all day long of their own accord, in fact, for a time string games became " all the rage," just as amongst street children tops or marbles, or any other game, may become the "rage" for a time. Some of the designs were so complicated that they required two lubras to make them, each of the latter using the fingers and toes of both hands and feet and also her mouth. The accompanying diagrams (Figs. 42 I, 422) represent stages in the making of a yam and dugong design. In the former a single string was used, and at one stage a toe and fingers of both hands were used. The dugong was more complicated, requiring two strings and four hands. When it was finished, the two strings were intertwined in such a way that the outer framework was made of one piece and the inner of the other, the whole structure being held taut by the women's fore-fingers. Some of the intermediate stages were decidedly complicated.

It was now January, and occasionally we had heavy rain showers--once as much as an inch-and the ground began to show a tinge of green. Also it brought the frogs out. Soon after sunset, one old fellow would start with his deep "qua-ak, qua-ak," until, excited by him, there would be a few hundred others at work. It sounded like an endless repetition of " hot water, water, water, hot hot wat, hot water, water wat, wat," with a few deep solemn " qua-aks" interspersed every now and then. At the same time the cicadas started, so that by about eight o'clock and until far on in the night, in fact usually until dawn, the noise was incessant. Before sunrise all was quiet, and then for an hour or two there was a dead, hot calm, without a leaf moving and nothing to be heard but the low buzzing of the flies.

We had attached three natives to our staff representing the Binbinga, Anula and Mara tribes, and were sometimes interested in slight disturbances in their domestic affairs. One morning our Binbinga boy came to us in a state of great 
excitement. When he quieted down a little we found out what the trouble was. Another boy had run off with his wife. He evidently expected that we should start off at once and capture the fugitives, and was much disappointed when we told him that we had no authority over them and suggested that he should consult the owner of the store, who happened to be the employer of the boy who had run away with his wife. Two days later he had secured another wife and appeared to be perfectly happy. Probably he had stolen her from some other blackfellow. Apart from perhaps a feeling of wounded vanity and the infringement of individual rights, there was nothing seriously wrong in these transactions, because, in each case, the men and women belonged to intermarrying groups. One morning, a little later on, we heard a great deal of shrill talking in our boys' camp, where, of course, there were not only our own boys and their lubras but sundry hangers-on, who profited much by their association with the boys. One of the latter, an Anula native, was the possessor of two wives, but, as their tempers were incompatible, and their constant quarrels annoyed him, and interfered with his domestic comfort, he decided to part with one of them. She naturally felt somewhat annoyed and challenged the more favoured one to a fight, which was in progress when we went down to see what was the matter. The man was seated on the ground, quite unconcerned, while his two wives were belabouring each other's heads with their fighting-sticks, at the same time hurling the most opprobrious epithets at one another. The man showed not the least sign of taking any interest in the quarrel and was seated on the ground, quite unconcernedly going through his little store of personal belongings, ornaments, etc., throwing out such few items as belonged to, or had been given to, him by the discarded wife. After the fight was over, the rejected lubra went to the women's camp, where she and her children were speedily VOL. II. 


\section{WANDERINGS IN WILD AUSTRALIA сн.}

adopted by another lawful husband who was in want of a wife.

There was really nothing for our two Arunta boys, Purunda and Erlikiliakirra, to do at Borraloola, so after a good rest there it was decided that they should return to their native country. The final decision, however, was based on a rather amusing incident that occurred one day when Purunda had gone to look after our horses. We had sent them across the river to a place at which there was good feed. The river, though here forty miles from its mouth, is affected by the tide. When first Purunda took the horses across, the tide was low and a slight current was flowing seawards over the rocky bar. When next he went across, the tide was rising and driving the water in the opposite direction. This was too much for Purunda, who had never heard of a tidal river. He came back to camp in a state of great excitement and anger, and told us that the river had started to run the wrong way. "No good like that," he said. "Him gammon; one day him go one way and to-day him go another way." He was really angry with it and clearly believed that the river was deliberately trying to annoy him. We tried to explain to him the mystery of a tidal river, but it was no use and, after discussing the situation with his mate, he and Erlikiliakirra decided to return to Charlotte Waters, where at all events, when there was any water, it did not go uphill one day and downhill the next.

A few days later the boys started to retrace our tracks across the continent. Each of them had a riding horse and they took with them two pack-horses, on which their belongings and a supply of tucker were packed. In fact they left us with possessions enough to make a black boy happy for the rest of his life. We had also secreted, as we came up, supplies of food at different spots in the bush between Borraloola and the telegraph line, and had arranged 
for a further supply at the stations along the line when once they reached this. Each of them had a revolver in case of need, as their track lay, at first, through the country of strange tribes; when once they reached the line they would be safe. They started away in the best of spirits, proud of the fact that they had been with us right through to the Gulf and brimful of experiences that they were treasuring up for the edification and admiration of their stay-at-home friends, far away to the south. The weather was very hot, so they were obliged to travel slowly, but some four months later they reached Charlotte Waters safely and delivered their horses and impedimenta, all in perfectly good order, to our friend Mr. P. M. Byrne, officer in charge of the station.

Once more we had a slight disturbance amongst our native friends. The boy who had already discarded one wife was evidently somewhat fickle and transferred his affections from his remaining wife to another lubra with whom, to avoid any scene in the home circle, he quietly eloped, leaving his first wife evidently very annoyed, all the more so because the one who had been originally discarded was there to see what had happened to her erstwhile successful but now forsaken rival. When the discovery was made, two of the eloping man's mother's sisters, that is, two of what would be aunts to us, came into the camp of the deserted lubra, sat down beside her and began to howl aloud, which we learned was, under the circumstances, strictly the correct thing for these relatives to do. When this had gone on for an hour or two, all three of them recovered their cheerfulness, and next day the widow married again and everyone seemed to be quite happy and contented, but it will result in a fight sooner or later.

Late in January the natives brought in word that a boat was coming up the river and that there had been an accident of some kind. It turned out to be a little ketch, the Venture (Fig. 423), that had been sent from Darwin with a 


\section{WANDERINGS IN WILD AUSTRALIA}

$\mathrm{CH}$.

welcome supply of stores, because we were just down on to our last bag of flour. When the boat came in, we found that the captain had his right arm badly injured and completely disabled, and that one of the small crew-a Malagasy boy-had a fractured skull. They told us that, on the way down, they had put in at one of the English Company's Islands, which lie just at the western entrance to the Gulf, in order to obtain a supply of fresh water and wood for cooking purposes. They were helped by natives, who came out to them and were apparently quite friendly, and to whom they had given, amongst other things, some flour in a bag, with injunctions to bring the latter back filled with some more wood. The captain and crew were all resting, not suspecting any danger - the former lying down in the small cabin aft. When the boat came alongside, one of the crew, the Malagasy boy, leaned over the gunwale, to get the bag, when suddenly he was hit on the head with a Malay kris, and three or four natives immediately jumped on board. One of them threw a spear down into the cabin which, luckily, did not strike his head or body, but went straight through the captain's arm between the shoulder and the elbow, breaking, or at all events severely bruising, the bone and, for the time being, rendering him helpless. There were only two members of the crew left-one a black boy and the other a very powerful Macassar boy, who immediately seized an iron bar that was fortunately lying handy and laid about him to such good purpose that he knocked two of the assailants overboard and frightened the others so much that they dived into the water and swam for the shore, leaving their boat behind them. But for him the whole crew would have been massacred and never a word heard of them again. It took them two weeks to reach the mouth of the Macarthur, and during all that time the captain steered with his left arm, the right being bound to his side. The Macassar boy and the native managed the sails and did 


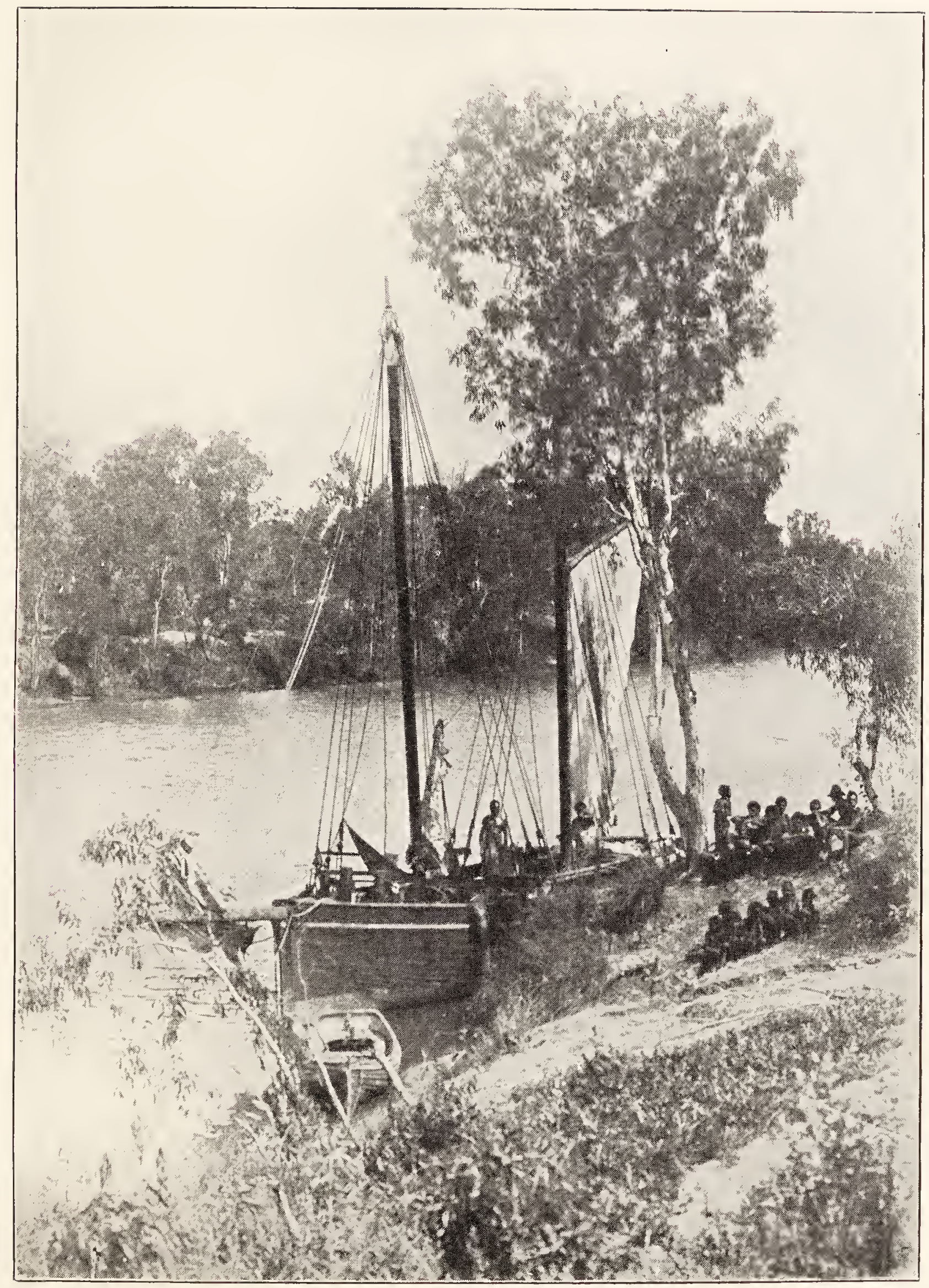

B.S.

FIG. 423.-THE KETCH "VENTURE" ON THE MACARTHUR RIVER. 


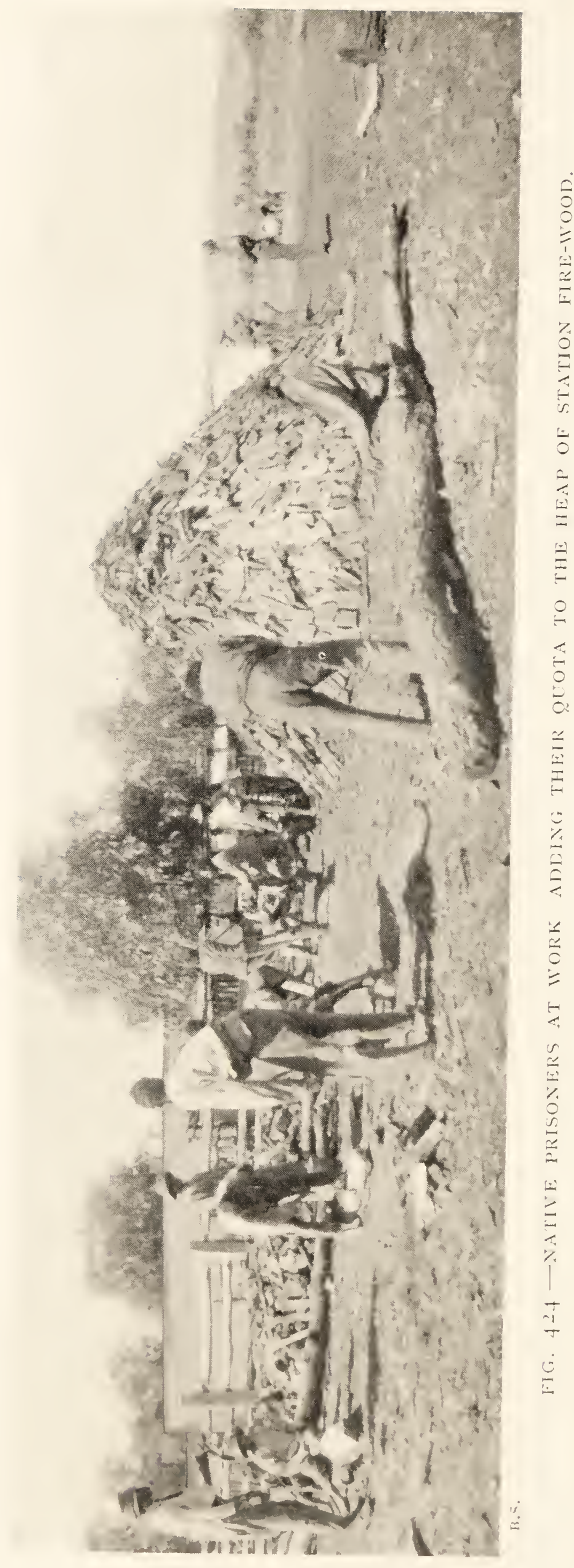


all the work of the boat; the Malagasy boy remained unconscious, moaning and groaning all the time. When they reached Borraloola, the captain's arm was so swollen and discoloured that we could do nothing but bind it up carefully, bathe it continuously, and wait. The spear had gone right through and, after the shaft had been sawn off, the head end was drawn out, point first. In some mysterious way it seemed to have missed the main blood vessels and nerves, because the arm gradually recovered, and ten years later I met him, looking hale and hearty, at Katherine Creek, showing no sign of his narrow escape except for two ugly scars on his arm, of which he had quite recovered the use. The Malagasy boy was brought into our camp and there he lingered on till the last day of January. We could do nothing for him because the kris had driven in a little bit of the bone of his skull, and he never regained consciousness. Wrapped in canvas, he was carried out into the bush and buried in a little lonely cemetery where there are other nameless graves. No one knew anything about himnot even his full name nor where he came from. A formal inquest was held by Gillen in his capacity as magistrate, and that was the end.

Despite the climate I managed to get through a good deal of writing. Mr. Amos, the manager of the Macarthur River station, came, as the few scattered inhabitants of the Gulf country describe it, "up to town," that is, to Borraloola, for a few days and, as he was also a magistrate and there was a prisoner available, it was decided to hold another court. The proceedings, as usual, were not altogether dull or precisely formal. The prisoner, a blackfellow, was charged with stealing yams, or sweet potatoes, out of a garden kept by one Price-he had recently taken it over from the Chinaman-in company with another native, still at large, and likely to remain so until the weather cooled down. The method of procedure was briefly as follows: 
Scene: the Court House, Borraloola.

Present: two magistrates, two constables, one native prisoner, three native witnesses, Charlie, Peter, George, an audience consisting of one white man.

The constable laid the charge briefly as follows:

"You been steal 'em potatoes along garden, all same fifteen shillings. Then you been carry 'em away."

Calls up first witness.

"Your name Charlie?"

"Yes, me Charlie all right."

"You tell 'em straight-fellow longa these gentlemen, no tell 'em lies. You work longa Mr. Price. You work 'em yesterday longa garden?"

"Yes, me been go longa potato yesterday, longa $\mathrm{Mr}$. Price."

"You been see 'em anyone track?"

"Yes, me been see 'em that one fellow track" (pointing to prisoner).

"You savee him track?"

"Yes, me plenty savee."

"You been see 'em which way him dig up potato?"

"Yes, me been see 'em, then me been follow 'em up that one track longa garden. Then him go outside longa little fellow road, then him go longa camp."

"You quite sure you plenty savee track?"

"Oh, yes, me plenty savee, all right."

Calls up second witness.

"Now, Peter, you talk straight-fellow longa these gentlemen. You countryman, longa this boy?" (pointing to prisoner).

"Yes, me countryman all right."

"You remember another one night, this boy and "doctor" " (name of escaped culprit) "been sleep along camp?"

"Yes, me plenty savee." 
"Well, what name him been do first time?"

"First time him sleep, then him wake up. Moon longa top of sky. Him say you and me go longa Price potato. Doctor been first time yabber this. Me no been go. Then two fellow walk. By and by him come back. Him been bring 'em three fellow bag longa potato. Doctor been carry 'em two fellow bag, him " (pointing to prisoner) " been carry one fellow. Two fellow been sit down and tuck out." (Witness avoided any suggestion that he had partaken of the feast, and the constable discreetly asked no question, the truthful answering of which might involve the admission that the witness was an accessory after the fact.) "Him been first time leave 'em one fellow bag longa old man alligator camp. By and by him take 'em two fellow bag longa crossing" (i.e. the creek). "Two fellow been go self longa crossing, me no been go."

Calls up third witness.

"Now, George, you yabber straight-fellow, no tell 'em lies."

"All right, Mr. Stott, me yabber straight-fellow."

"You been go along crossing yesterday?"

"Yes, me been go along crossing all right."

"Well, you tell 'em these two gentlemen what you been see."

"Me been see 'em two fellow track."

"What name him been do?"

"Him been sit down make 'em fire."

"You been see anything along creek?"

"Yes, me been see 'em two fellow bag potato. One fellow been bring 'em up, then him been chuck 'em down first time. By and by him been make 'em fire, cook 'em."

The witness retired.

Presiding magistrate to prisoner: "You been hear 'em what blackfellow been say?"

"Yes, me been hear 'em all right." 


\section{WANDERINGS IN WILD AUSTRALIA сн.}

"What name? You been steal 'em that potato?"

"Yes, me been steal 'em all right."

"What name? Me send you longa Port Darwin or you sit down here?"

"Me sit down here."

Magistrate solemnly pronounces sentence: "No good blackfellow steal 'em potato. Suppose 'em blackfellow steal 'em, white fellow sulky. You sit down two fellow moon longa gaol, work 'em. Suppose you steal 'em more you sit down big fellow time longa Port Darwin."

The prisoner was then marched off to assist his fellowculprit, sentenced a few weeks before, in the work of adding his quota to the station heap of firewood and watering the cabbages (Fig. 424).

We had just turned into our mosquito nets on the evening of February 8 th when we heard the barking of camp dogs and the tramp of heavy feet, very evidently not those of blackfellows. Very soon, accompanied by four men armed with rifles, Captain Myles came into our camp and told us that he had been sent by the Queensland Government to bring us away from Borraloola. He had come across the Gulf from Normanton in a little pilot boat, the Vigilont, and with great difficulty had found his way up the Macarthur River to within five miles of our camp. Fortunately the steamer only drew five feet, but no boat except small ketches had been up the river so far before. Captain Myles had heard marvellous tales of the ferocity of the natives, hence his armed escort, and he fully expected to find us in an invalid condition, instead of which he found three individuals in a particularly good state of health. We were not long in packing up our personal belongings, leaving our collections packed up to go round by the ketch to Darwin later on, and at ten o'clock next morning left Borraloola. Our friends Messrs. Amos and McLeod came with us to the steamer, Sergeant Stott had to remain behind in charge of his prisoner and the township. All day long 
the little Vigilant steamed slowly down the river, between low banks of mangrove swamps. At sunset we came into a broad reach where there were the remains of a rough jetty, dignified with the name of Port Macarthur-a remnant of the time, years ago, when steamers unloaded here and when it was thought that Borraloola was to be a flourishing port of the Gulf country. Perhaps some day it may be, at present it is merely a decayed little township. Here we anchored for the night. By sunrise next morning we steamed on, carefully feeling our way across the shallow bar. Every now and then the keel grated on the sand. Twice we stuck and had to go astern, but at last we got safely out. For several hours we were in smooth water, under the shelter of the Pellew Islands, enjoying the fresh cool air and the calm of the green-blue waters with the mangrovelined shores of the mainland and the low hills of the islands gradually dying away in the distance. The little Vigilant was really only a river boat, with no passenger accommodation, but we were perfectly content to be aboard her with nothing to do. Everything, of course, was on deck, except a cabin for the crew in the fore-part and one for the captain in the stern, but this was minute and very hot and stuffy. The engine-room staff and an assistant, who, when not lubricating the machinery, acted as cook, were unprovided for, and took shelter under the little bridge, where the cooking galley was placed, also in the open, as was the dining saloon, the position of which was indicated by a table on deck, just forward of the bridge, so as to be quite convenient to the galley.

Out from the shelter of the islands the little boat began to move about a good deal. The only charts then existing of the part of the Gulf that we were crossing were those of Flinders drawn in 1803 , and these, though incomplete, were, Captain Myles said, wonderfully accurate so far as they went. All night long we steamed slowly on so as not to run the nose of the boat too firmly into it if we chanced 


\section{WANDERINGS IN WILD AUSTRALIA сн. xxIV}

to graze a sand-bank not charted by Flinders. About noon next day we sighted the Wellesley Islands Group and a couple of hours were spent trying to find a passage amongst the sand-banks between Mornington Island and the mainland. At length, after several groundings of no serious nature that only meant that we had to back out and start again, we got safely through into smooth water under the shelter of Bentinck Island. Steaming carefully on to the east, we made Sweer's Island at sunset, and stopped just long enough to land one of the crew who lived there in a lonely hut. He and his family were the only inhabitants of the remains of a township known as Carnarvon that had once been a kind of port for the trade of the southern part of the Gulf. Now it is entirely neglected; some of the trade passes up the Albert River to Burketown, but most of it up the Norman River to Normanton. We were soon out in the open, tossing about all night long, until, a little before daybreak, we caught the distant flash of the lightship lying a few miles outside the Heads of the Norman River. Once inside these it was perfectly calm. Fortunately for us, the tide was too low for even the Vigilant to go up stream, so we were able to spend a few very pleasant hours with Captain and Mrs. Myles in their little home at Karumba, where they and the chief officer and the small crew live, keeping watch over the lights, beacons and buoys and piloting ships in and out of the Heads. All afternoon we steamed on up the river. There was nothing to be seen except a broad, winding stream of muddy water, hemmed in by mangrove swamps, and it was dark before we saw the lights of Normanton. From here, a pleasant voyage up the eastern side of the Gulf to Thursday Island brought us in touch with steamers running for I 300 miles down the coast of Queensland, within the Great Barrier Reef, touching at Cooktown and Cairns, then threading our way through the lovely Palm Islands in Whitsunday passage, on to Townsville and Rockhampton and so to Brisbane and the south. 


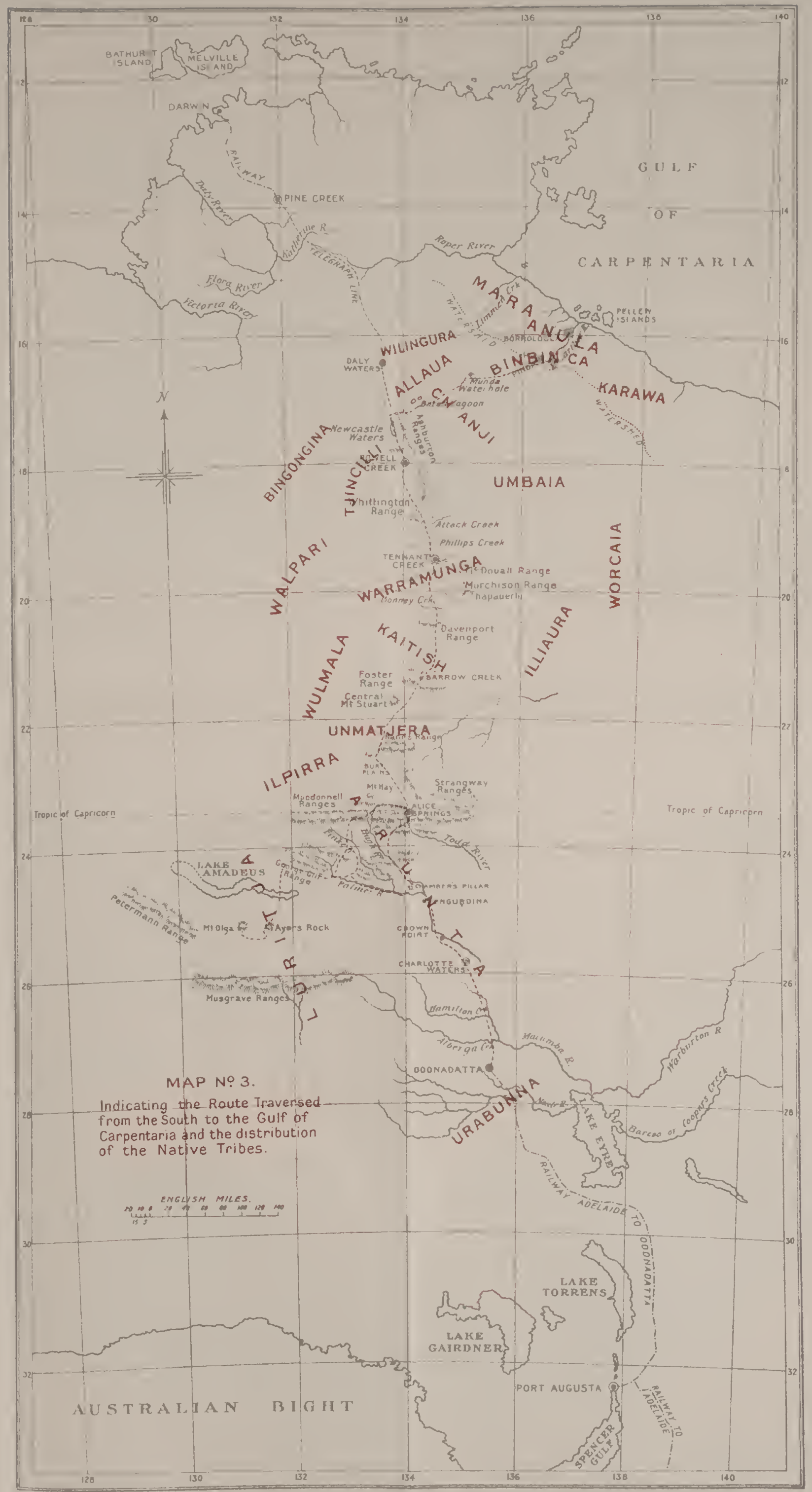





\section{BOOK III}

AUSTRALIA'S GREAT LONE LAND 



\section{CHAPTER XXV}

WORK IN DARWIN-(I)

Away beyond the Macdonnell Ranges, stretching to Darwin in the far north, to the Gulf of Carpentaria and Queensland on the east, to the borders of West Australia and the Indian Ocean on the west, lies Australia's Great Lone Land.

Its development for long years baffled the efforts of South Australia, to which State it was entrusted in I 863 by the British Government, when it became known officially as the Northern Territory of South Australia. In 1907 the Commonwealth took it over and, with it, all financial responsibilities. From that day to the present, money has been lavishly spent in the attempt to develop agriculture and mining industries, in the creation of various departmental staffs, in the continuation southwards from Pine Creek of the overland railway, and, more recently, in the continuation northwards of the line from Oodnadatta. Private enterprise when attempted, as in the case of the Vestey freezing works at Darwin, has been crippled and rendered well-nigh helpless to assist in the development of the country by the extraordinary attitude and demands of labour.

Soon after the Commonwealth Government had taken it over, Dr. Gilruth, then Professor in the Melbourne University, suggested the sending out of a small expedition, representative of the Australian Universities, to make a preliminary scientific investigation into certain matters, information in regard to which would be of value in dealing 


\section{WANDERINGS IN WILD AUSTRALIA cH.}

with future work concerned with the development of the Territory. The Commonwealth agreed to the proposal and appointed Dr. Gilruth to investigate conditions in reference to Agriculture and Stock; Dr. Breinl, Health matters; Dr. Woolnough, Geology, and myself the Aboriginals. We reached Darwin by steamer in May I 9 I I and spent three months over our work, visiting Melville Island, investigating conditions around Darwin and on the Adelaide River, travelled south to the Katherine and Daly Rivers and then eastwards along the Roper River, under the guidance of Mr. Alfred Giles, an old pioneer of the Territory whose knowledge and experience stood us in good stead, and so to the shores of the Gulf of Carpentaria, where we were picked up by H.M.S. Gayundah under the command of Captain Curtis and carried over to Thursday Island. It was only a flying trip, but, thanks to the cordial assistance that we received everywhere, and not least from Judge Mitchell, who was then Acting Government Resident, we were able to see a good deal of country, both coastal and. inland, and secured much information. ${ }^{1}$

Towards the end of the same year I was asked by the late Mr. Bachelor, then Minister for External Affairs, to return to the Territory for a period of twelve months to act as Special Commissioner for Aboriginals and Chief Protector in charge of the Department instituted to safeguard the interests of the aboriginal population. The Council of the University granted me the necessary leave of absence and, on December 25 th, I left Melbourne and once more travelled up the east coast to Brisbane and thence on to Cairns. On this voyage we passed out into the open sea through a break in the Great Barrier Reef, steaming about due north to Port Moresby in Papua, then south

I The Reports submitted to the Government by Drs. Gilruth, Breinl, Woolnough and myself were published in "Bulletins of the Northern Territory," issued by the Commonwealth Government in I9I 2 and I9I 3. 


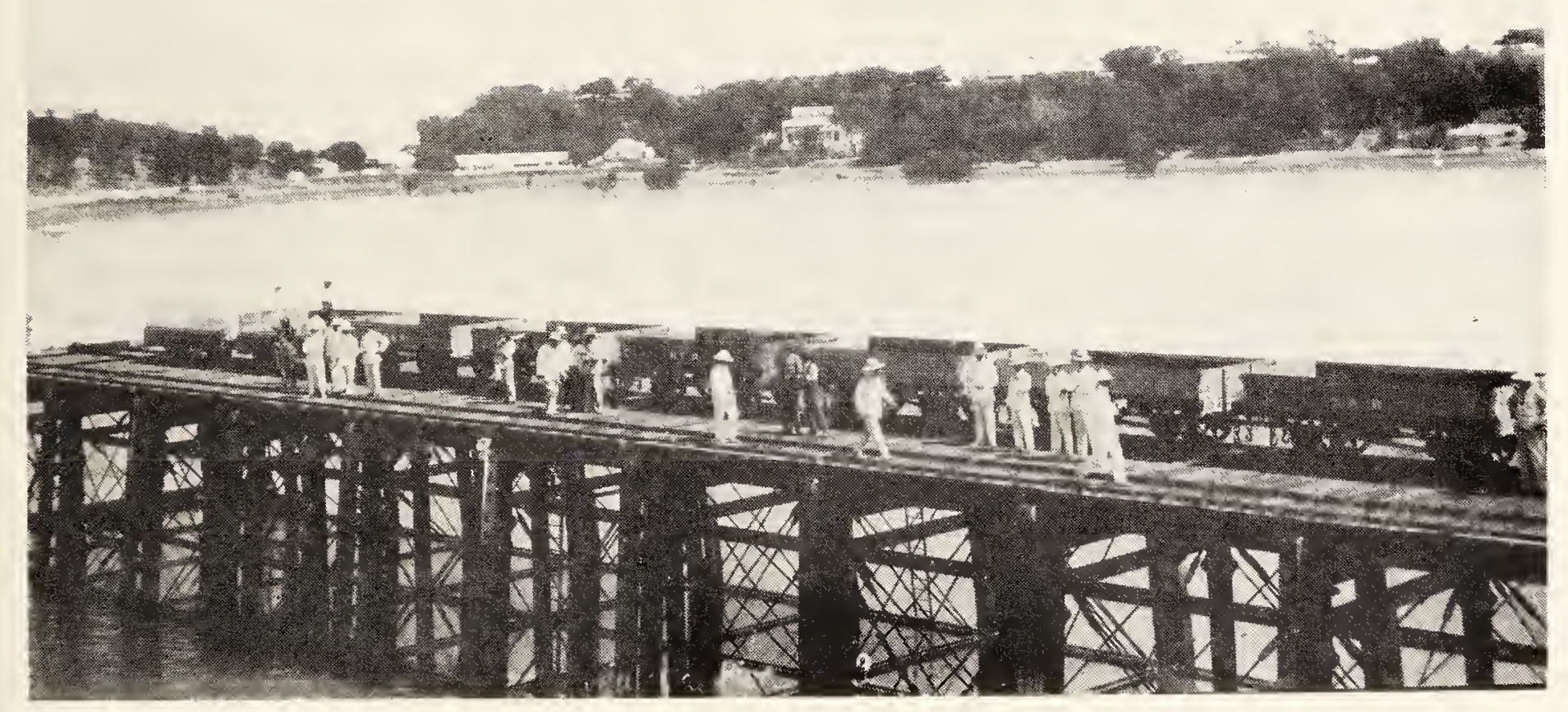

FIG. $425 .-D A R W I N$ IN WIITE. 


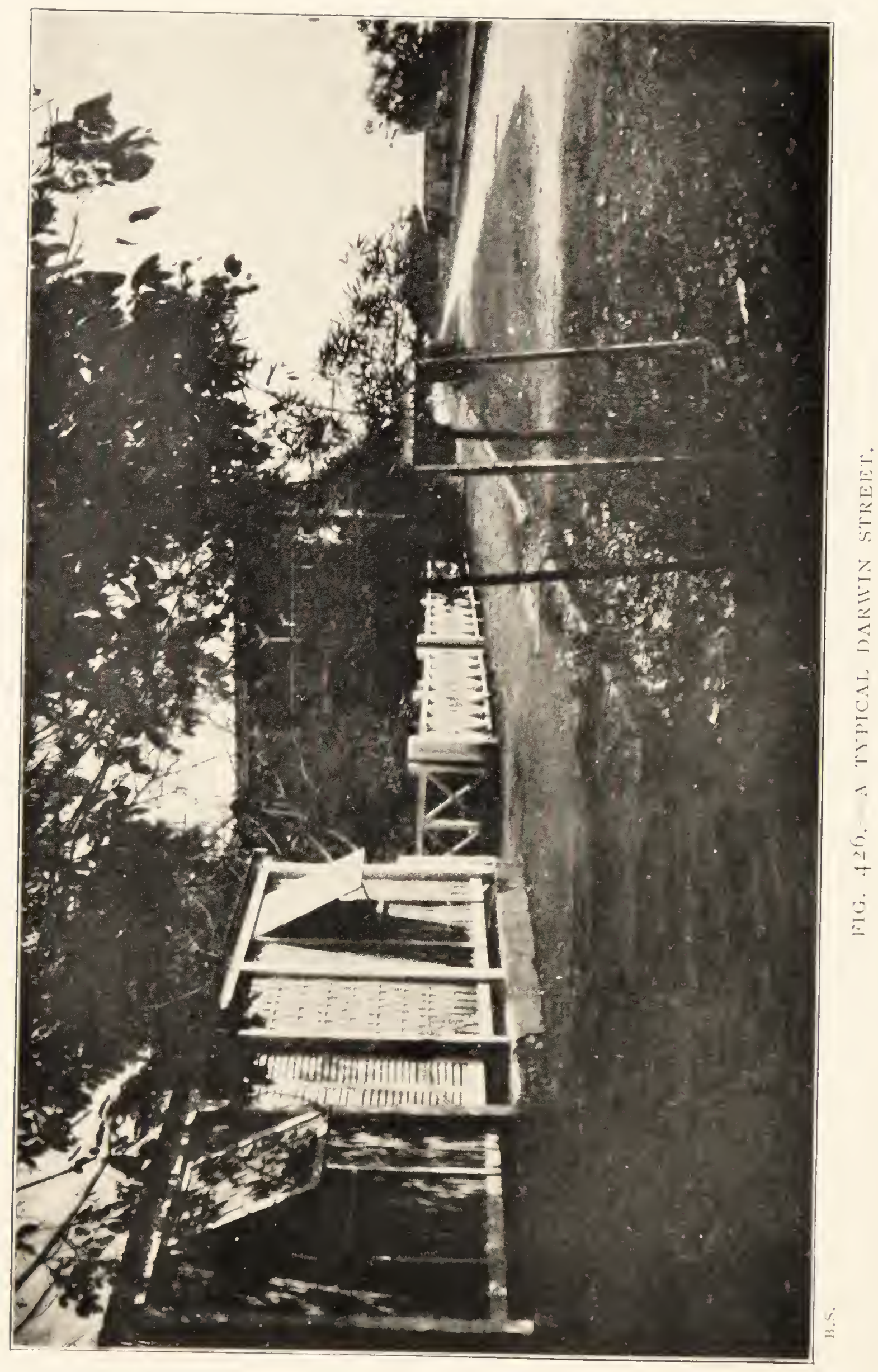


across Torres Strait to Cape York and Thursday Island, and then due west to Darwin, which we reached on January I $5^{\text {th, I }}$ I 2. It is only after actually travelling round the coast, calling in at port after port, that one is able to realise the length of the sea voyage that separates Melbourne from Darwin. The route we traversed was roughly 4400 miles as compared with 3068 from Liverpool to New York. So again it is difficult to form any idea of the area of the Northern Territory from the map, unless it be compared with that of a well-known country like England, which would go four and a half times into the Territory (Map I).

It was nearing sunset when we rounded East Point and turned south into the almost landlocked harbour of Darwin. I had often seen the harbour before, but had never seen it as it was that evening. The colours were intense-blues, purples, and rich deep green on the eastern cliffs and wonderful reds and orange-pinks and pea-greens on the water and hills far away to the west. It was, as everyone on board felt, absolutely entrancing in its colour beauty. When we came to the wharf, the whole European population must have been there, all dressed in spotless white (Fig. 425). In those days there was no such thing in Darwin, nor indeed throughout the whole of the Territory, as ice, the only chance of getting a really cool beverage of any kind was when a steamer came in to port, and this was rarely more than once a month. Darwin is not a favourite port with steamers. The tides run strongly and there is a rise and fall of some twenty-four feet. You may have to clamber down a steep gangway from the deck to the jetty when you land, and a few hours later, when you re-embark, as likely as not you see only the tops of the funnel and masts above the level of the jetty and have to clamber down a steep gangway, this time from the jetty on to the deck. The tide was running hard and we were carried alongside with a bump that sent our boat lurching 
$\mathrm{CH}$.

over and gave the old pier and the people on it a great shaking. However, they and the pier were quite accustomed to this and thought nothing of it.

As soon as faces were distinguishable, I saw one with a broad grin on it and recognised an old friend, Shepherd, the half-caste boy who had been with us on our previous expedition down the Roper and was attached to the Residency. Hearing that I was on board he had come down to see if he could do anything, so I gave him my bag with all my valuables in it to carry up to the town, where, together with my friend Mr. Wilding, who was coming up from the south on mining business and whom I was fortunate enough to meet on board, I was soon comfortably housed in the Victoria Hotel (Fig. 426), which, during the long and kindly, but firm, regime of its proprietress, Mrs. Ryan, was well known throughout the length and breadth of the Territory. Two or three years later the hotels in Darwin, Pine Creek and Katherine Creek were taken over and run by the Government, with results that, at all events in Darwin, were little short of farcical, in fact, from the point of view of the traveller and resident, they were disastrous. Mrs. Ryan went south to Adelaide, carrying with her the grateful recollections of all old Territorians.

In the evening I went down to the Residency to call upon Judge Mitchell, then acting Government Resident. At that time he was living there alone, while the building was being overhauled, and we sat smoking and talking till late in the broad verandah, facing out towards the harbour, with the moonlight shining through the trees and glinting on the water that was quietly lapping the beach at the foot of the cliffs below us.

Judge Mitchell had a wide experience and knowledge of the Territory and until when, later on, owing to the reorganisation of the Territory Administration, he relinquished his post in Darwin and was appointed to a judicial 
position in South Australia, I was much indebted to him for valuable help in the early days of my work amongst the aboriginals in Darwin. I remember well that he had as his body-guard and factotum in the Residency a Chinese boy, Chee Quee by name, who was well known to all visitors. His manners were perfect, more especially if the Resident chanced to be out, when the visitor was politely ushered in, placed in a comfortable chair on the verandah, provided with papers, periodicals and cigarettes and asked "what he would like to take" to while away the time until his Honour should return. Chee Quee himself probably " took" a good many things and must have had a certain sense of humour. In those days smuggling opium was rife and very profitable, because the Chinese residents insisted on having it at any price. Even Chee Quee himself, though aide-de-camp in chief to the highest legal official in the Territory, in fact almost his under-study in the Residency, was suspected of adding to his already generous salary and perquisites by acting as receiver and secreting agent of the valuable drug, one great charm of which was that even a very small tinful represented much ready money, if only it could be smuggled safely into Chinatown. It was no unusual thing for passengers on a steamer coming south from China along the coast to Darwin to watch with interest, when the light was dim in the evening, one or two picturesque and innocent-looking craft, manned by Chinese, absorbed in their fishing, so absorbed indeed that they sometimes came perilously near to being run down. When the danger was passed, the shouting and gesticulating over and the simple-minded fishermen had recovered their equanimity, they resumed their innocent occupation, but in their boats were small tins of opium, attached to little floating buoys that had been thrown out by their friends on the steamer during the confusion. The quarters of the crew were of course rigorously searched by the Customs VOL. II. 
CH.

officials in Darwin, but the Chinese stewards went about their work smiling blandly.

Once the Residency itself was searched. Chee Quee, with the utmost urbanity, showed the Customs officers round, asked them, with a smile, as was his invariable custom, "what they would take," even helped them in prying minutely into the rooms occupied by himself and his two Chinese assistants, but the officers left without discovering that his Honour, the Government Resident and Chief Justice of the Supreme Court, slept soundly every night on a mattress in which Chee Quee kept his hidden store. In the end, however, Chee Quee's desire to amass wealth for the betterment of his family in China and the adding of honour to the memory of his ancestors led to his downfall. The Government decided to deport, free of charge to themselves, many of the older inhabitants of Chinatown who spent their time living on their relatives and smoking opium. Before this policy had been fully developed, Chee Quee was at work. He represented to his compatriots, by whom he was then held in great repute, that, owing to his influence with the authorities, and especially the Governor Resident, he could secure a free trip to China for those who were willing to pay for his services as intermediary. Unfortunately this leaked out and Chee Quee left the Territory suddenly under a cloud. What he took with him and what he had sent on ahead was never known, but he left behind him debts that caused much anxiety in Chinatown. $\mathrm{He}$ was a most engaging personage and the Residency was never quite the same after his departure.

The morning after my arrival I started to work. The Aboriginal Department consisted at that time, so far as its staff was concerned, of myself as Chief Protector, Dr. Holmes, Medical Officer, a Chief Inspector and two Protectors. We were working under an Aboriginal Ordinance that had been drawn up tentatively and, on the 
whole, worked fairly well. Up to the time of its coming into force there had been no official control exercised over, on the one hand, the movements of the natives or, on the other, their employment by settlers and residents, either European or Chinese. The Ordinance provided for the issue of permits to employ male or female aboriginals, or both, at the direction of a Protector, and the withdrawal of the same if deemed desirable. To employ any aboriginal without such a licence was a penal offence, punishable by fine or imprisonment. It also empowered the Chief Protector, or any person authorised by him, to take charge of any aboriginal, including half-castes, who for the purpose of the Ordinance were regarded as aboriginals, if, in the interests of the aboriginal, he deemed it advisable to do so. This gave him power to deal with a custom, only too prevalent in the early days, when there was no control over the relations between aboriginals and whites, of one of the latter taking a lubra away from an aboriginal man. The most flagrant example of this was that of many cattle drovers who habitually either employed a man and his lubra, taking possession of the latter during his travels, or even went into a native camp and, either by persuasion or threats, secured a lubra to accompany him. A man who thus lived with a lubra was known as a "Combo," and already the number of half-castes and the question of dealing with them was becoming a serious problem. It must be said that the lubra who lived with a white man was frequently a willing accomplice and was usually well treated, so long as she was with him, but the blackfellow to whom she belonged had no redress, and if he objected it was simply so much the worse for him. In some cases, when the living together was more or less a permanent one, or at least extended over a period of time sufficiently long for his half-caste children to grow up in his camp, the white man, so far as was possible, recognised his obligations to 


\section{WANDERINGS IN WILD AUSTRALIA сн.}

them, but in by far the great majority of cases the union was only a temporary one and the lubras and their children were abandoned and left to drift back into some native camp. It was also by no means uncommon for aboriginals to be taken away by sea or land to some place far distant from their own tribal country and left adrift there when they ceased to be useful. Under the Ordinance a guarantee had to be given for the return of any such aboriginal to his native country at the employer's expense.

$\mathrm{Up}$ to the present time there had indeed been no control whatever in regard to the employment of aboriginal labour. In Darwin aboriginals employed more or less permanently in stores or domestic service and, on many of the upcountry stations, those employed as, or assisting, stockmen were paid wages, but there was no definite system in regard to, nor any control over, the rate or method of remuneration, or the expenditure of this in such a way as to be of permanent advantage to the aboriginals, very few of whom had any idea whatever of the meaning of money. Under the Ordinance, regulations were now made dealing with the conditions of employment and amount of wages which, if the Chief Protector so directed, must be paid into an Aboriginal Trust Fund for the use of the native under the supervision of a Protector.

The Administrator had power to declare any Crown lands a reserve for aboriginals, and to recognise any Mission Station, school, etc., as an Aboriginal Institution to which land could be leased, and on all stations, mines and other holdings an approved area must be set apart as a native camp. Entrance to any such Institution, Reserve and camp, except by Protectors and officials, was declared a penal offence.

It was, on the other hand, equally urgent that the aboriginals should be prevented from having access to certain places where, in return for the prostitution of the 
lubras, they could secure, especially from the Asiatics, who were the chief offenders, supplies of drink and opium, of which they were as fond as the Chinese themselves. To deal with this, the Administrator could declare certain areas to be prohibited, and any aboriginal found on these could be removed and taken into the custody of the Chief Protector.

At this time there was no Government Aboriginal Institution, and the only serious attempt to deal with the natives was being made in the Church of England Mission Station on the Roper River and in the Roman Catholic station that was then in course of formation on Bathurst Island.

The Commonwealth Government was keenly anxious, in view of the development of the Territory and the expected influx on a large scale of settlers, to make provisions for dealing, not only equitably but generously, with the aboriginals on a more extended scale than was possible otherwise, and it was with this end in view that, as soon as the Northern Territory was taken over from South Australia, the Aboriginal Department was instituted.

Beyond the enforcement of the issuing of licences to employ aboriginals and a general supervision, carried out with the aid of the Mounted Troopers in charge of the stations, then fourteen in number, scattered over the vast area of the Territory, it was not possible to do anything more than patrol work, except in the neighbourhood of Darwin and along the railway line to Pine Creek. It was essential for the work of the Department to have the assistance of the Mounted Troopers, a small but fine body of men, and therefore, in order to give them the authority necessary to ensure the enforcement of the conditions in regard to the employment of aboriginals, they were now, on my recommendation, appointed ex-officio Protectors. As Chief Protector I was much indebted to the cordial assistance received from the late Inspector Waters, then 


\section{WANDERINGS IN WILD AUSTRALIA сн.}

head of the Police Department at Darwin, and to the officers under his control. Some idea of the difficulties, and it may be added also the expense, involved in carrying out the Act can be gathered from the fact that, very soon after my arrival, a Protector and a Mounted Trooper had, each of them, to traverse, along different routes, upwards of 1000 miles over wild country in order to arrest one man who was setting it at defiance. It was some consolation to know that, though his arrest and subsequent appearance before a magistrate, some hundreds of miles away from where he wished to be, cost us some trouble, it was the cause of considerable surprise and still greater inconvenience to himself. He and certain other men like him, who had been accustomed to treat the aboriginals just as they thought fit and imagined that they were too far away to be interfered with, realised, to their annoyance, that the law had a long arm, stretching out if necessary for even a thousand miles. The cattle drovers could be more or less efficiently supervised because their routes of travel, determined by the location of wells and water-holes, were well known. If, by chance, they escaped from the north, they were not likely to avoid the vigilance of Sergeant Stott, an old friend of mine in early days on the Gulf of Carpentaria, who was now fortunately in charge of the Police Station at Alice Springs and a zealous Protector in the Macdonnell Ranges in the south of the Territory. ${ }^{1}$ The main difficulties of carrying out

1 Since the above was written, to my deep regret, news has come of the death by accident, in Adelaide, of Sergeant Stott, within a very short time of his retirement from the Government Service. His work in the Territory extended over more than forty years, and with him has passed away one of the few remaining of the old Territorians who were officers under the South Australian Government in Pre-Commonwealth days. For years past Sergeant Stott, as head of the Police, Warden of Mining Fields, Protector of Aborigines and holder of other official positions had done, and done efficiently, the work of at least two ordinary men and was practically the Chief Executive Officer of the Government in what is now called Central Australia, where there was no one who was better known or more respected for his sterling work and character. 
the provisions of the Ordinance were concerned with Darwin, the mining fields and the long-drawn-out line of sea-coast, where the trepang or bêche-de-mer fishers, the collectors of tortoise-shell and pearl fishers carried on their work, practically free from interference because we had no means of patrolling the coast.

There was no need to do more than ask for the assistance, always cordially given, of the station holders. On the large pastoral areas the holders of the stations permanently employed numbers of aboriginals, varying from three or four on smaller stations, to forty or fifty on large runs, and these were fed and provided with clothes and tobacco. In all cases, except very exceptional ones, these natives lived far away from a settlement and had no knowledge of, or use for, money. The managers of the various stations that I was able to visit, and on all of which the aboriginals are well treated, courteously gave me all the particulars with regard to their dealings with them. In rare cases of boys who had been with them for many years and were civilised, payment was made, wholly or partly, in money, but in most cases the remuneration consisted of two or three suits of clothes yearly, two or three pairs of boots, one or two blankets, one or two mosquito nets, an ample supply of meat, flour, tea, sugar, tobacco and pipes. If any boy should be taken into a settlement he always received a supply of money. The stations not only feed the aboriginals actually employed, but the supply is such that not only do those directly dependent on the working "boys," that is, their families, secure food, but also a large number of " hangers-on." The intensely communistic attitude of the aboriginals is an important factor in connection with their treatment on out-back stations. No sooner is anything given to one of them than he shares it with his friends; indeed, under normal conditions, there are certain individuals to whom, if they be near him, he is 


\section{WANDERINGS IN WILD AUSTRALIA сн.}

obliged to give a share of everything that he secures, and this feeling is very difficult to eradicate, with the result that one native will work hard and others, who do no work, will profit by his labour.

On arriving in Darwin I found that there was no accommodation provided for the Aboriginal Department, but Judge Mitchell kindly allowed me the use of a small room in his offices in which to store things and interview people -whites and natives-who were constantly coming in and out with requests and inquiries of all kinds. It was decidedly interesting work, and extracts from my diary and note-books will show what our life was like in Darwin in the early part of I 9 I 2 .

Fanuary I7th, I9I2.- Yesterday evening it began to rain in real earnest. Five and a half inches fell before midnight. My room in the hotel opens out on to an upper verandah twelve feet broad and shut in with rattan-cane trellis-work, forming a kind of open-air room in which I can write. However, this evening the rain simply streamed through the trellis in fine torrents, beating against the inner walls and windows and filling the rooms with warm moisture. The lightning was incessant and intensely brilliant, but before daybreak it cleared off and in the early morning, when I opened the trellis-work, Darwin was looking its best. In front was an open space with trees like a little park, covered by tracks with stray natives going to their work and Chinamen jogging along with their great baskets hanging from poles across their shoulders. Beyond were scattered houses belonging to Chinatown (Fig. 427), which, though they are made of sheets of corrugated iron, look very picturesque because they are jumbled together anyhow and painted all sorts of colours. Between the houses I caught glimpses of the blue waters of an arm of the harbour and, in the background, low hills rose covered with forest. The verandah is overgrown by a creeper with masses 
of pink flowers, amongst which big butterflies, four inches across their wings, jet-black with metallic-blue spots, and large bees, like the old-fashioned bumble-bee, enjoy themselves all day long. Later on in the year everything will become dried up and parched and probably more healthy, but, meanwhile, it is really beautiful and everyone seems quite pleased that the "wet" has really set in. Breakfast over I was down at the office by 9 a.m., where all day yesterday I had been discussing matters of procedure with my staff. News of the Chief Protector's arrival had gone round amongst whites and natives, and this morning I soon found that my work was to be of a somewhat varied nature, rather more so than I had expected and certainly not less interesting. "Big Gubment been come up " was the way in which the advent of a Government official, such as the Chief Protector, who was supposed to be endowed with special authority, was broadcasted amongst the natives. This morning I had been going through a good deal of official and very uninteresting correspondence when, looking up, I saw a blackfellow and his lubra, evidently not on the best of terms, but apparently intent on some important business. I beckoned them in and found that they had come to "Big Gubment" to consult him on matrimonial affairs. They were not getting on well together. The lady had taken a fancy to someone else, and, as her husband objected and used a waddy to emphasise his disapproval, she wanted to be rid of him. I could see that it was quite impossible for them to agree together, so I put it to the man that it was no good always fighting and that the best thing for him to do was to give her up, which, also, I could see that he was quite prepared to do but was anxious to have "Gubment" authority to back him up and save his face. In the end he decided, as he said, to "chuck 'em altogether," so he walked off in one direction and she in another, both of them 


\section{IO WANDERINGS IN WILD AUSTRALIA сн.}

with a high opinion of the profound wisdom of "Big Gubment."

In the afternoon I went with Inspector Beckett to examine the native camps in Darwin. There are two of these, one on the top of the cliffs, called the King Camp, and one immediately below it on the shore. The first is really the camp of the Larakia, which is the native name of the original tribe inhabiting the Darwin district, and owes its white man's name to the fact that the hereditary head-man of the tribe, known as King Solomon, and who, despite his tattered garments, was a fine, courteous old native, has his little humpy there. There is, of course, no such institution as that of kingship amongst Australian tribes. In many of them each local group has a man who is recognised as head-man, but his powers are very vague, save that he decides upon the holding and has charge of certain ceremonies, principally those of initiation. It is now too late to study the Larakia, of whose beliefs and customs very little of serious value has been recorded. A curious feature of their women, which distinguishes them from other women in the very mixed camp, is that the terminal joint of the left-hand index finger is removed. It is either bitten off by the mother at a very early age or at a later time cobweb is tied so tightly round that it drops off. It has nothing to do with initiation and the natives have now no idea of its significance (Fig. 428).

The second camp is mainly occupied by Worgait people whose country lies on the opposite side of the harbour. Nowadays the different tribes have become very mixed up and "civilised." The upper, that is the Larakia camp proper, is made up of a number of ramshackle humpies. Years ago there was a terrific cyclone that wrought great havoc in Darwin, foundering the pearling luggers or leaving them stranded high and dry amongst the mangrove swamps, obliterating half the little town, unroofing the stronger- 

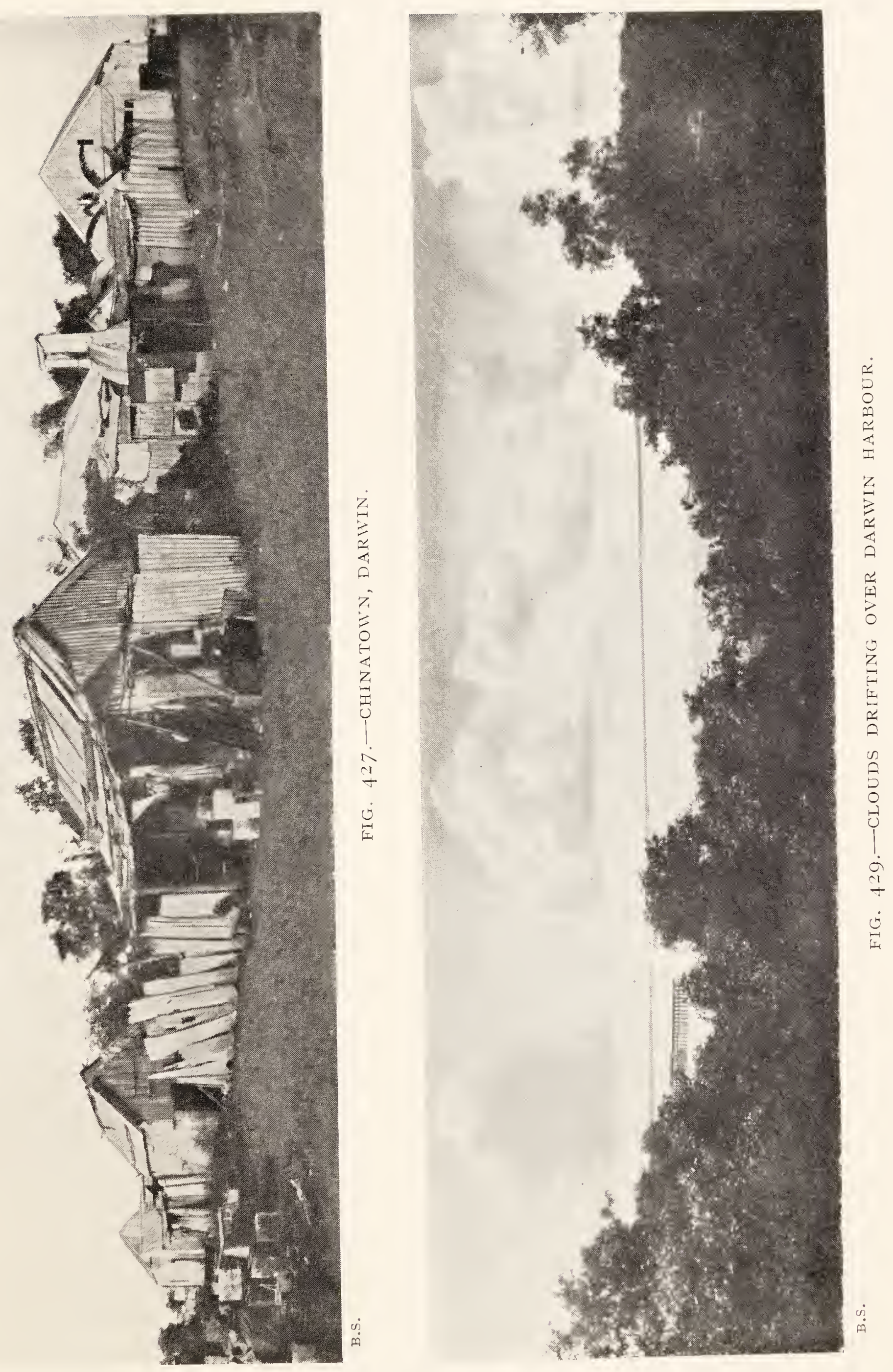


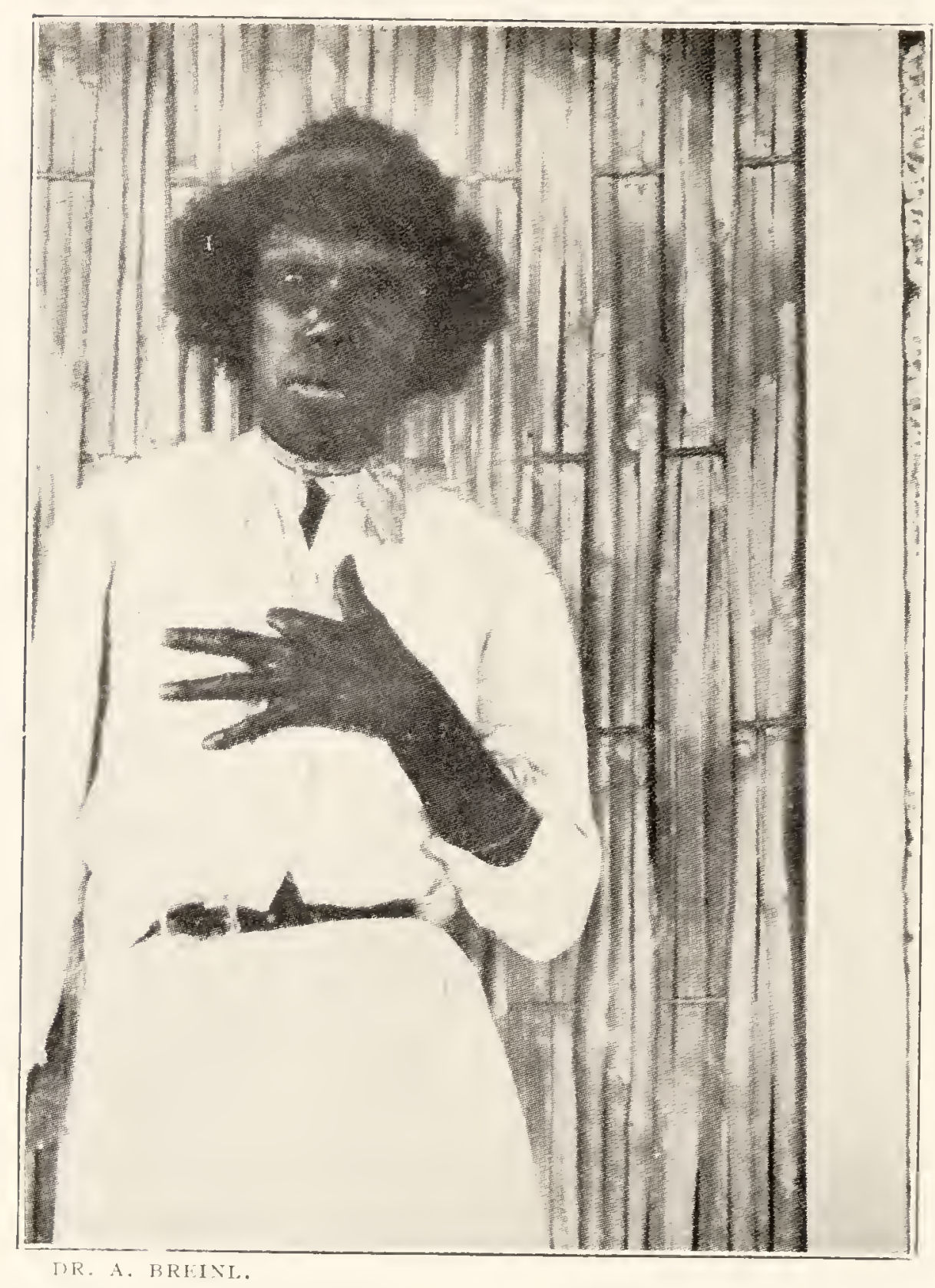

FIG, 42S.-.-LARAKIA WOMAN WITI JOINTS OF INDEX FINGER CUT OFE.

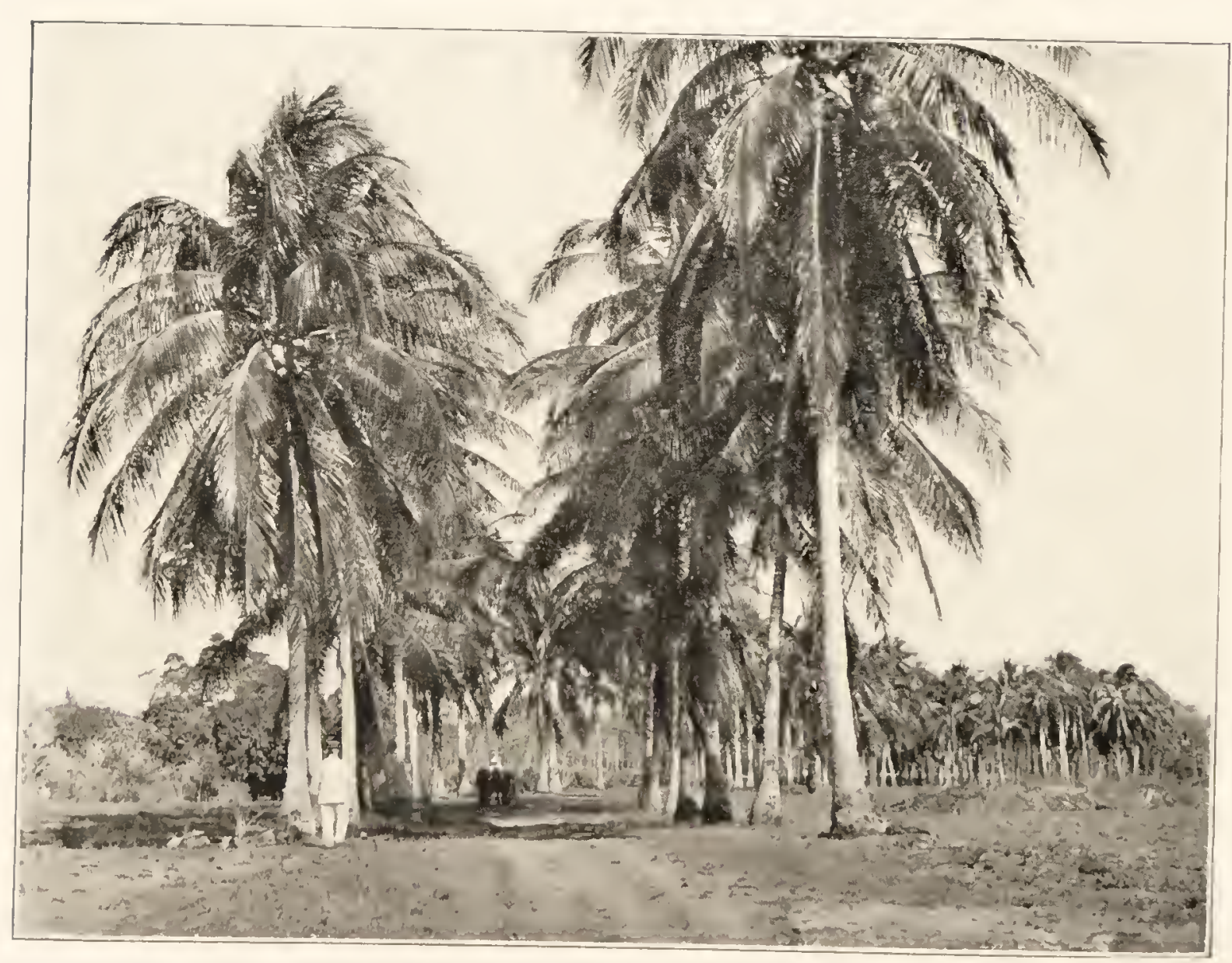

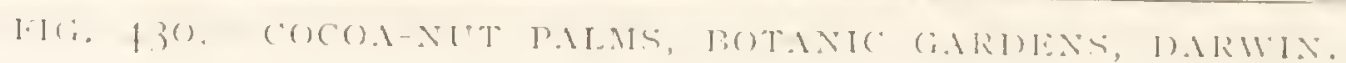


built stone houses and scattering great sheets of corrugated iron far and wide through the scrub. When things had quieted down, the natives collected the iron sheets and found them very useful in rebuilding their humpies. I went into a number of them. During the day they are boiling hot, but the natives do not seem to mind this and at night they close the door and light a fire that fills the hut with smoke, because, of course, there is no such thing as a chimney and the smoke can only get out through the chinks. The filth and dirt were simply indescribable, and the dogs, that were innumerable, are just as much part of the family as are the piccaninnies. Down on the beach the little huts, made partly of wood and partly of corrugated iron, nestled quite picturesquely amongst the fig trees that covered the cliff sides down to the level of the beach, on which dug-out canoes were drawn up, the Worgaits being largely a seafaring people, whereas the Larakias are landfolk. At one spot a little fresh-water spring, which was the reason for the location of the camp here, bubbled up just within a few yards of the salt water. The only way to get to this lower camp, known as the Lamaru camp, was by means of a very steep path down the cliff face, where, at times, we had to swing ourselves down with the aid of the branches of fig trees. We got drenched to the skin, but it was so hot that this did not matter. An inspection of the two camps made it quite clear that one of the first things that must be done was to remove them away from the town to some suitable place where they would be under the control and under easy supervision of a Protector.

Fanuary 20th. - After searching round the neighbourhood of Darwin, I have decided upon a site that seems to be well fitted for the new aboriginal compound. It is really a very picturesque spot, though this will not appeal in the least to the aboriginals, who, so far as I have been able to discover, have no appreciation of natural beauty. In 


\section{I 2 WANDERINGS IN WILD AUSTRALIA сн.}

their wild state they are attached to a particular country first of all because their ancestors have always lived there, and all their traditions are associated with it, and, secondly, because it provides them with food supplies. Genuine wild natives would be miserable away from their own country, but in the case of a heterogeneous crowd, such as is now gathered together in Darwin, there was no need to pay any heed to this aspect of the matter. They have all long since got beyond any traditional feeling and will only object to being removed from their old quarters because it will interfere with their freedom to do exactly what they like in regard to intercourse with Chinese, Malays and a certain class of Europeans.

In selecting the new camp three matters had to be taken into consideration.

First, its position. It must be capable of easy supervision and situated far enough away from the town to make it possible to isolate the aboriginals when necessary, as, for example, at night-time, and at the same time be near enough to allow of those in employment in Darwin to walk to and from their daily work. The site I selected was about a mile and a half out of Darwin. At that time there were no dwellings on it other than a few old Chinese hovels, and no prospect of any being erected either on or near to it. The Chinese gardeners were only permissive occupants who could easily be transferred elsewhere; in fact the buildings, save one or two, were deserted, tumble-down sheds and no one knew who lived in or had any legal claim to them.

Second, the site must, if possible, be such as to provide for an upper and a lower, like the upper, or King, and the lower, or Lamaru, camps in Darwin. From this point of view nothing could have been better adapted for its purpose. There was a stretch of level ground on the top of the low cliffs that sloped down abruptly to a foreshore, about two 
hundred yards in width, bounding the sandy beach of a quiet, half-moon-shaped bay that opened out northwards.

Third, it was very desirable to have land enough for a large garden. The foreshore and a broad valley running upwards and inland, forming in fact the western half of the proposed compound, had already been selected and used by Chinamen as a large fruit and vegetable garden, and they could be depended upon as being good judges of what land was suitable for this purpose. The ground had been cleared and, though now neglected and partly overgrown, needed very little labour to put it into good working order. There were fine mango trees in full bearing and, on the stony sides of the rising ground, pineapple plots were planted and only wanted looking after. With the aid of the officials of the Lands Department, the Chinese, who were then doing nothing with the land, and possibly had no right there, were given notice to quit and simply disappeared. I do not know exactly how it came about, but we walked in and they walked out, and so we took possession and started the Kalin beach compound.

fanuary 22nd.-All morning in the little office, first of all making arrangements to secure possession of some natives who, we heard, had been brought in illegally by a Malay man. Then a white man came in to see me. I had heard of him and what he was doing and had decided that it was necessary to cancel his licence to employ natives, so our conversation was neither long nor pleasant. In the afternoon I sent a constable to demand the return of his licence, but he declined to give it up, saying that he was going to give us as much trouble as he could.

fanuary 23 rd.-The white man whom I interviewed yesterday had evidently thought matters over and decided that it would be advisable not to interfere with us too much, so he handed in the licence and left Darwin. The little room in which I work is much too small for us, so this 


\section{I4 WANDERINGS IN WILD AUSTRALIA $\mathrm{CH}$.}

afternoon I looked round Darwin and found a little empty bungalow-cottage with three rooms that might be used as passable offices, with a small expenditure necessary to make the roof waterproof and the floors safe to walk on. There was nothing else available, so I wired down to Melbourne, asking for permission to rent it.

Fanuary 24th.-This morning we had the Malay up and found that he had brought four Port Essington lubras and two black boys with him. We took charge of the lubras and sent them down to the Larakia camp, where they are now being watched over by two or three older men to prevent them being spirited away. In the afternoon a great storm seemed to be coming up, but it divided into two and, unfortunately, left Darwin in the middle, with only a heavy shower. The rainfall is nearly thirty inches below the average, so people are getting anxious. My office opens on to a verandah that looks south across the harbour, over a line of trees growing at the base of the cliffs that border the beach all round. Every afternoon huge masses of cumuli gather and move slowly across, with long-drawn-out reflections in the almost glassy waters of the harbour, the colours of which are simply marvellous and ever changing-purples, blues, greens, silver-greys and mile-long shadows of great cloud masses, slowly drifting across (Fig. 429). It is very beautiful but very moist and muggy; however, we dress to suit the climate, though even then, when the dry bulb stands at $83^{\circ}$ and the wet at $8 \mathrm{I}^{\circ}$, there are only two degrees in which to get rid of the moisture that oozes out of every pore on your head and hands and makes office work rather sticky. My usual day's work is as follows:-About 6.30 a Chinese boy brings in a cup of tea-if it did not interfere with the policy of White Australia, I must confess that it would be very pleasant to have a Chinese boy as a body-guard. Then one sits quietly on the verandah for a while; then a shower- 
bath, which is refreshing but never really cold; then breakfast and a leisurely walk down to the office at 9 a.m. for routine work-natives and white men come in every day to see us on business of some kind or another; then lunch soon after midday and a rest and quiet read on the verandah till 3 p.m.; then the office again till 6 p.m., with perhaps a walk round the native camps to see how their removal and the new buildings are progressing; then dinner and, in the evening, a very pleasant talk and smoke with Judge Mitchell on the verandah of the Residency. Fortunately we usually have a cool breeze during the night, so that one can sleep comfortably under the shelter of a mosquito net.

Fanuary 26th.-To-day my friend Wilding came back from a trip across the harbour, where he had been inspecting mines. He had a very rough time, as the rains had made the country almost impassable. Later on in the evening he started off again on a small motor launch to Bynoe Harbour, about fifty miles away to the west of Darwin. He was much interested in the question of protection of the natives and most sympathetic towards the work of the Department. His experience on the mining fields made him realise keenly the evil influence, and often callous behaviour, of the Chinese miners out in the bush.

To-day we served a summons on a half-caste Malay woman, charging her with employing a native woman without a licence.

Fanuary 27th.-The case of the Malay woman came up in court this morning. We were anxious to secure a conviction, just as much from the point of view of our power of control over the native woman as in the case of the Malay. The former was one of several who were giving us trouble because they were always consorting with Malays and Asiatics, against whom their aboriginal husbands are practically helpless. The most important 
thing, however, from our point of view, was that she and her employer had given it out that we could do nothing to them and that they would do just what they liked despite our regulations. It was a case of killing two birds with one stone, or rather trying to do so. Fortunately for our prestige, the Malay woman, much to her surprise and disgust, was fined and, as Chief Protector, I took the lubraMary by name-from her and handed her over, for the time being, to some old men of the tribe, King Solomon amongst them, who were waiting outside the court and were quite pleased to be able to exercise a little of their tribal authority. They conducted her, much to their satisfaction, and to her mortification, to the camp. It was a sudden and ignominious downfall and rather an undignified proceeding, for one who had been boasting of her powers, to be thus solemnly and publicly conducted in broad daylight through the streets of Darwin to the native camp. All the natives, Malays and Chinese knew what had happened and "Big Gubment's" prestige was high for the time being. In a day or two she will go for a time to the Mission Station on Bathurst Island, both to give her the opportunity of thinking things over quietly and to let her lady friends realise that the same fate may, sooner or later, befall them if they do what she has done.

In the afternoon I went down to the camp and found everything all right. The four Essington women, who had been abducted, were sitting in a row, guarded by an old man or two. Mary the lubra was also there, looking very dejected. In view of her appearance in court, her hair had been " done up " in the most approved style, but it did not fit in well with her present primitive surroundings. Whilst I was there a Malay man made his appearance. He was trying to get into communication with the Essington lubras. The old men got ready to meet him, but I told them to wait and do nothing. He came on and, to his astonishment, met 
me as I came out from the shelter of a wurley and made him understand clearly that if he, or any of his countrymen, ventured into a native camp they would at once be sent to prison.

Fanuary 28th.-Dr. Burston, who is the second of the medical men attached to the Aboriginal Department, had arrived from the south, so we went down to the camp, where everything seemed quiet, but until we can move the natives into the new camp there will be no means of efficient supervision and it is very difficult to keep them from the Chinese; in fact so long as Chinese are anywhere near at hand, they will find some way of getting at the aboriginals. The Port Essington lubras were out for a walk under the charge of the old men. It is rather awkward to have so many eligible ladies thrown on your hands at one time. We can place two of them, who do not wish to return to their homes and are moderately young and fairly good-looking, in domestic service and provide them with suitable husbands, but the other two are more ancient and will have to be returned to their own country.

There are always a number of natives who come in from the Alligator River country to Darwin. They will not mix with the others and have always formed a little camp of their own, known as the Alligator camp, away in the scrub, about three miles outside the town. It is well situated on rising ground and looks out across the flats below, with glimpses of an arm of the harbour seen through the trees. At this season everything is beautifully fresh and green. We drove out along a rough track, running by the side of the railway line, to inspect a new building that we were putting up for them. It is in the form of a kind of common house with a number of rooms, one for each family. Then we came back by way of the Botanic Gardens, of which $\mathrm{Mr}$. Holtze is superintendent. Lack of funds prevents them from being maintained as they were in the early days, VOL. II. 


\section{I8 WANDERINGS IN WILD AUSTRALIA сн.}

when they were founded by Mr. Holtze's father, who, later on, became Director of the Adelaide Gardens, but they are still very beautiful with great clumps of giant bamboos, palms, tropical flowering plants, groves of cocoanut trees (Fig. 430) and pools flecked with water-lilies. They are kept in order with the help of native prisoners from the Fanny Bay Gaol close by. In the midst of them is a charming bungalow where $\mathrm{Mr}$. and Mrs. Holtze live, with its broad verandah overgrown with flowering creepers and beautiful with great clumps of maidenhair and other ferns, amongst which, in the evening, fireflies flit about, looking like dancing specks of electric light. We struck down to the bay, walked for a mile along a firm sandy beach overhung by palms and then back through the scrub to Darwin. The Botanic Gardens and an isolated stretch of country called the Jungle, a few miles outside the town, are really the only places where real tropical vegetation can be seen within easy reach of Darwin. Everywhere else the so-called forest land is covered with monotonous gum trees, and no interesting vegetation save countless numbers of cycad palms.

Fanuary 29th.-A steamer came in to-day from the south bringing mails and also a few officers for the Agricultural Department, so that a small colony of officials is being founded in Darwin. It is all right for the men, who will be engaged in very interesting work, but I feel very sorry for the women-folk when they come up, because it must be confessed that Darwin offers to them few of the ordinary amenities of city life to which they have been accustomed.

Fanuary 30 th. - I had a very interesting morning. After an hour in the office I drove out to Fanny Bay Gaol, which is about three miles outside Darwin, beyond the Botanic Gardens, on the cliffs that look out across the water between the mainland and Melville Island. The gaol is under the charge of Superintendent Strath, who, with Mrs. Strath, 
takes a genuine interest in the natives confided to his care, of whom there are almost always two or three at Fanny Bay. Mrs. Strath has the women with her during the day-time, engaged in domestic work, teaching them to wash and iron and sew. There is, of course, no such thing as prison dress and, so far as the few lubras in custody are concerned, it is more or less a family arrangement. The men are occupied all day long in outdoor work, chopping wood, making and keeping roads in repair and, more especially, on work in the Botanic Gardens that are close by. My chief object this morning was to see Mr. Strath, the Superintendent, about one of his charges, a native "boy" named Paddy Bull, who nearly four years ago had been convicted of murder. The facts, brought out clearly in evidence in the criminal court in Darwin, were that a white man who employed Paddy Bull was anxious to obtain possession of a lubra, but her blackfellow objected and, in order to get rid of him, the white man not only incited Paddy Bull to shoot him, but actually handed him a loaded rifle with which to do it. When it was over, the body was burned by Paddy and the white man, but charred remains were found. Paddy Bull was charged with the murder and the white man with inciting him and assisting in the disposal of the body. In those days it was practically impossible, in Darwin, to secure a conviction against a white man, so the jury, much to the indignation of the presiding Judge, brought in a verdict of guilty of murder against the aboriginal and of " not guilty" in favour of the white man. On the strong recommendation of the Judge, Paddy Bull's sentence was commuted to imprisonment in Fanny Bay Gaol. During his four years' imprisonment his conduct had been excellent, and the Superintendent and all the better class of whites in Darwin are anxious that he should be released, so I have drawn up a précis of the facts and am forwarding it to Melbourne with a recommendation that he be released. 
This afternoon, in company with Inspector Beckett, I went round Chinatown, the name given to the Chinese quarters in Darwin. It consists of stores and shops lining one of the two main streets of the town and a maze of little tenements, in all states of dilapidation and squalor, behind them. There are one or two really good stores, kept by reputable Chinese, and a single hotel run by a white man, but otherwise it is little else than a mass of hovels and a menace to the health of the town. All the same it is the most picturesque partof it and, on festival days, one wonders how it can produce such crowds of men, women and children, all looking as clean as if the hovels in which they lived were model dwelling-houses, and all of them dressed in beautiful silks of all shades and colours. As soon as the Health Department gets to work, I fear there will be no more Chinatown. Darwin will doubtless be healthier, but it will have lost its most picturesque feature. From the point of view of the efficient working of the Aboriginal Ordinance, it is a very difficult problem to deal with, and the only thing that we can do is to have it proclaimed a " prohibited area" so far as aboriginals are concerned.

February ist.-To-day, as the result of communications from the south giving permission to do so, I secured the small bungalow-cottage on the harbour front for use as offices (Fig. 43I). At present it is in a rather ramshackle state, but I hope it will soon be more habitable. The trouble is to get hold of a decent workman. A steady carpenter here is worth his weight in gold.

My friend Wilding came back from his trip to Bynoe Bay, about a hundred miles round the coast. He had had a fairly wet trip, but at this time of the year was lucky to get off with only about half a dozen storms. Just after he landed, the clouds banked up and the rain came down in a deluge. Chinatown, at all events, gets a good cleaning up at this time of the year. 
Another matrimonial affair. This time it was a visit from a boy and lubra who had decided to get the approval of "Big Gubment" for their union. I saw them hanging about the office door and, guessing what they had come for, beckoned them in and asked the boy "What name," which meant, "what is the matter," or, "what do you want." Our conversation was short but quite satisfactory. He came to the point at once and replied, "Big fella me been like it this one lubra." So I said to him, "You like it catch 'em this one lubra," which meant " you want to marry her." "Yes, me been like it all right." Then to her I put the question, "You like it this one boy." "Yes, me big fella like him." Then to the boy, to be on the safe side legally, "This one straight lubra longa you," which meant, does she belong to the right class for you to marry. "Yes, that one straight lubra all right." There was no need to ask whether anyone knew of any impediment to their union, such as a previously existing matrimonial connection on either side, any such difficulty, if there were one, would have made no difference and could easily be adjusted, according to custom, by a fight later on. They left the office perfectly contented and I returned to my papers.

February 2 d. - In the morning I had an interview with three natives who have come across from Bynoe Harbour to see us. There are a number of Chinese there who are using the natives badly and telling them that, as soon as we come, we are going to take them all out of their own country and put them on reserves. Mr. Wilding, who, as I said before, is much interested in our work and the welfare of the natives, had a talk with them and advised the "boys" to come over and see us, offering to bring them over with him. Accordingly he brought them in and, together, he and I had a talk to them and managed to dispel their fears. They went back with presents of food and tobacco, prepared to assure their countrymen that we 
were their friends and would protect them against the Chinese and were coming over to see them soon.

In the afternoon I was in consultation with a lawyer in regard to an appeal that had been lodged by the Malay woman against whom we secured a verdict, a few days ago, for employing a lubra without having a licence to do so. Everything depends upon the powers of the Chief Protector. The intention of the Ordinance is clear enough, but the wording is apparently a little ambiguous. It will take some time to get things even moderately straight and our experience, as we go along, may show it to be advisable to amend the Ordinance so as to make our powers quite clear, but meanwhile we are feeling our way. Technical legal objections are annoying, but it is interesting to try to find some way round them. Naturally we have to come up against some people. Just now we are trying to draw up plans with regard to keeping the aboriginals out of Chinatown. How to keep the Chinese away from the aboriginals is another and a much more difficult question to deal with.

February 5th.- In the morning a boy called me out of the office to look at a great crocodile that was swimming about in the bay. I had my glasses with me and so got a good look at the beast, which must have been eighteen or twenty feet long, and was probably the one that had dragged a horse down into the water last week near the native Lamaru camp on the beach.

February 6th.--The case of the Malay woman, who had appealed from the decision of the Lower to the Supreme Court, came on to-day. If we lost it, it practically meant that we had no power to issue licences and that anyone could employ natives just as they liked. The case lasted nearly all day, the only people in court being the Judge (Judge Mitchell), two lawyers, one on each side-the only two lawyers in Darwin-and myself. To my relief, the court decided that the Chief Protector had the right to 
issue licences. It would have given the greatest pleasure to a certain section of the whites and to all the coloured people if the case had gone against us, but fortunately it did not. By way of a minor set-off to our success, some Malay men to-day managed, at the last moment, to spirit away a lubra who, like Mary, had been giving us a good deal of trouble and whom we intended to send across to the Mission Station on Bathurst Island. It rained all day in torrents and everything was damp and sticky. Even matches in tin boxes got so damp that they would not strike and leather bags were coated with green mildew.

February 7th.-Another court case. We summoned and secured the fining of one of the Malay men who had been into a native camp without permission. He was one of those who had abducted the lubra, and is one of a few who have been giving us a good deal of trouble, and we are going to give them as much trouble as we can in return. I sent one of the Inspectors in to Chinatown to give final notice to the Chinese that, after to-morrow, no aboriginals will be allowed in and that anyone harbouring a native will be liable to a penalty under the law. They naturally are very upset and are sending a deputation to protest.

There are one or two good store-keepers there who might be trusted, but the greater number of the Asiatics in Chinatown are of a low class. They are engaged in opium smoking and supplying this and drink to the aboriginals, and it is impossible to discriminate.

A Japanese and a lubra came in. The former wanted to marry the latter, but it is against the regulations. I explained matters to him and he took it very philosophically, but evidently the lady was not keen on going back to her native husband. However, we will get her a "place" in some house in Darwin so that she will not have to go back into the wild bush.

February 8th.-To-day the men actually began painting 


\section{WANDERINGS IN WILD AUSTRALIA ch.}

the cottage that is to be the headquarters of the Northern Territory Department of Aboriginal Affairs. As yet I cannot unpack anything in my little office.

February 9th.-To-day is the first day of the coming in force of the notice declaring Chinatown a prohibited area. The Inspector and two constables were out patrolling, but only about six natives ventured in. Two of them were innocent of any deliberate defiance; one was a poor old lubra so stupefied with opium that she did not know what she was doing, so she was brought before a magistrate in order to be sent to the gaol hospital where she could be taken care of, and one was a boy who had deliberately gone in. He was seriously spoken to and kept in detention for twenty-four hours to warn him that we had power to deal with offenders in a way that he did not quite realise or relish.

February Ioth.-The three leading Chinese storekeepers in Chinatown came to see me and we talked over matters. They were so courteous that it was not pleasant to have to remain firm in regard to the prohibition, but it was not possible to discriminate. Of course they knew the habits of the great majority of their compatriots, and I think they realised that no other course was open to us. It was finally decided that we should send such natives as were employed by them back to their own country except one whom we took on to work in the Department. He was a big boy with enormous feet, so large that we could not get any boots to fit him in Darwin: a No. Io fitted easily inside the tracing of his foot. He was very proud of this, because a native's foot is usually small and he evidently gauged his importance by the size of his feet.

This morning the Government Resident, Mr. Francis, head of the Railway Department, Mr. Holtze, Government secretary, and myself drove out to a place about two miles away from the town to inspect a site that had 
been suggested as a suitable one for a Quarantine station. I do not quite know the use of our going, because not one of us had any expert knowledge qualifying us to express an opinion on so special a subject. However, I was glad to accept Judge Mitchell's invitation to join his party, because it meant a few hours' refreshing change in the open air, away from the hot little office. It was decidedly hot, especially as we had to clamber about in the scrub and down the steep face of a cliff. We came in contact with a most objectionable kind of green ant that makes its nest out of and amongst the leaves. They are very cleverly made. The ants combine together and a lot of them set to work to pull the edges of the leaves together. Then, holding on tightly, they spin a fine thread across from the edge of one leaf to the other. A number of leaves that are close together on a branch are first of all treated in this way, then others are cut off and brought to the nest, and the same process of sewing the leaves together is repeated until, finally, a good-sized, oval-pointed bag, as much as a foot or even eighteen inches in length and a foot in width, is made, large enough to house a community consisting of a thousand or more ants. The ants have a light pea-green head and thorax and a somewhat swollen yellow abdomen. The moment you touch it or shake the branch from which the nest hangs out, they stream out and drop down on you in hundreds and sting or bite you, probably both, mercilessly. I often intended to examine the inside of the nest, but to do this safely meant taking special measures and precautions that I never had the opportunity of doing. The ground originally proposed as a Quarantine station was much too near the town, small even as it now is, and after walking over it we came down to the beach, boarded a little launch and steamed very pleasantly over the harbour for about eight miles to a little island about a quarter of a mile wide that, years ago, had actually been used as a Quarantine 


\section{WANDERINGS IN WILD AUSTRALIA сн.}

station. It is quite a pleasant spot, with low hills from which you look across the blue waters of the harbour to Darwin. At night-time the line of lights fringing the cliffs far away on which the town is built would be quite picturesque. It is certainly isolated enough, but the water supply might be a difficulty and communication with the mainland precarious during the monsoonal period. We looked over the remains of the old station, wandered all over the island, steamed all round it and, after a very pleasant few hours, came back to Darwin.

The S.S.Mataram sailed for the south this evening, taking with it, to my regret, my friend Wilding.

February I I th.-A great storm came up. The thunder rolled along and the hotel seemed to shake. The rain came down in a deluge and my verandah was flooded. When it was over I went down to the Residency and had a talk with Judge Mitchell, who very kindly went through the Acts (South Australian, under which we were working) dealing with opium. Opium-smoking is one of the greatest troubles that we have to contend with in Darwin amongst the aboriginals, and I am anxious to have it made a punishable offence amongst them.

There is a great chorus of frogs this evening, which is probably a sign of more wet weather.

February I 2th.-In the court this morning we secured a conviction against a white man for trespass in a native camp. He was surprised. Then I had to lay an information against a man who had declined to return his licence to employ natives after it had been cancelled. Then a Filipino man, whose native wife was causing him trouble by going into Chinatown, came in for advice. Then an Inspector brought in a black boy who had been twice warned not to go into Chinatown but had deliberately disobeyed the notice, a Chinese man telling him that we could no nothing. To show him that we could, and for his own welfare and 
guidance in the future, and also for the benefit of the Chinese and his friends, we took charge of him for twentyfour hours, during which he would have time to think things over quietly. His lubra and mother came with him, but as they had done nothing wrong and had tried to dissuade him, I gave them some tobacco and sent them back to the camp with the news. This evening, so far as the Inspector and the patrolling Constable Macdonald, who is of great assistance to us, can tell, no natives have gone into Chinatown, but, until the native compound is built and under supervision at night-time, it will be impossible to control their movements.

February I 3 th. - The white man who refused to return his licence was brought up in court this morning and, to his annoyance, was fined and ordered to hand it in to the Chief Inspector, which he did.

February I 4th.-All day in the office. Joe Cooper, the well-known buffalo hunter, came in from Melville Island. He comes over to Darwin in his lugger every now and then with a load of buffalo hides, and I hope to get away for a time from the official routine and return with him to Melville Island, to do some work amongst the natives. The men are getting on slowly with our new quarters. It has taken ten days to put one coat of paint on. The Darwin climate is not conducive to hard work. In the evening a wire came through from Melbourne announcing the appointment of Dr. Gilruth as Administrator of the Territory.

February I 5th.- In order to convenience residents in Darwin who employ natives and may have to send them into Chinatown to the stores on business, we have issued a numbered series of brass discs to them which will act as permits to the boys carrying them. Each owner is responsible for his boy's disc, which must be in his possession from 6 p.m. to 6 a.m. and also always during the day when the boy is not actually transacting business 


\section{WANDERINGS IN WILD AUSTRALIA сн.}

in Chinatown for his employer. The great majority of residents are glad of the restriction, which will cause them the minimum of inconvenience, but, of course, there are a few irreconcilables who object to any restrictions.

February I6th.-I left Darwin with Inspector Beckett this morning by the 8 a.m. train for Pine Creek, which we reached at 5 p.m. after a very hot journey. My old friend Mr. Alfred Giles met me, and I went out with him to Bonrook Station, where he lives, some miles out of the township. The station consists of a bungalow-house in rather a pretty spot, amongst the scrub by the side of a water-hole surrounded with screw pines. The house itself is shut in with trees and creepers and brightened with crimson and buff-coloured Hibiscus and yellow Allamanders. The first thing that caught my eye was two tall gate-posts, each ornamented at the top with the skull of a blackfellow who, during life, had been in the service of Mr. Giles; a very original idea of ornamentation combined with the perpetuation of the memory of a faithful retainer but, I thought, rather a waste of good ethnological material. The evening passed very pleasantly, talking over old times, for there is no one who knows more about the Territory or who has had a longer or more varied experience of it than my host, who was always known to those of us who had been with him on our previous trip down the Roper, as "the General."

February I 7th.-Drove into Pine Creek with Mr. Giles. It is only a straggling township with one broad road (Fig. 432 ), or rather a series of irregular tracks amongst the grass, bounded on one side by the railway, which just ends nowhere in particular at a goods shed. On the other side of the road two or three stores and a few private houses were ranged with one quite comfortable country hotel. At the northern end of the township were the police quarters, and at the southern a small hospital, a Church of England, a 
Roman Catholic church and an excellent and commodious school-house, then in course of construction. Pine Creek has long since passed its zenith, and when the railway is carried through to the Katherine it will be merely a side station, and travellers will have little idea of the fact that it was once the centre of a busy mining district. There is a low range of hills away to the west, and over these are dotted endless heaps of mullock, with here and there forlorn derricks and the shanties of Chinamen who still manage to make a living out of mines long since deserted by white men. Away over the hills, unseen from the rail and road, there is even now a Chinese settlement of considerable size. On the hotel verandah the usual crowd of loafers was congregated, discussing horses and mining during the intervals of visits to the bar. On this occasion we gave them a fresh topic of conversation. Fortunately, Mrs. Weedon, the proprietress, keeps a small dining-room as well as the main one and we were very comfortable. In the afternoon, in company with Mounted Trooper Miller, I rode out to visit an encampment of natives who had come in from an outlying part. Soon after starting it came down in a regular deluge and, despite tarpaulin coats and sou'westers, we were drenched to the skin in a minute or two, but everyone is accustomed to this, so we went on. The natives were regular myals, only one or two of them knew a word of English. They were huddled together in a long row under the shelter of slabs of bark, slanted very ingeniously so as to keep the rain off. The sheets did not subtend more than two feet of ground, and all along in front of them the natives had scooped out a little trench to carry off the water. In this way they kept themselves almost dry. It was evident that they had simply come for opium, so we sent them off to camp far away in the bush instead of going on into the Chinese quarters, whither they were bound. I have little doubt, as it was impossible to supervise them at 


\section{WANDERINGS IN WILD AUSTRALIA сн.}

night, that they managed to get some, but next morning they were sent back to their own country. After drying ourselves at the Police Station, Giles and myself drove out to Bonrook.

February I 8th.-We drove in early to Pine Creek and then on over the hills and through the Chinese settlement, which spreads over a wide area that seems to be made up of overgrown mullock heaps with remains of pitheads, representing hundreds of mines. Endless little tracks lead in and out amongst them, forming a perfect labyrinth, and all over the place are groups of shanties. It was the Chinese New Year and all the houses were flying their quaint triangular flags, some blue, others red and blue with a white star, the flag of the revolutionary party in China. Everyone who belongs to that party-which includes every Chinaman here-has cut his pigtail off. Chinese lanterns, some of them five feet in diameter, were hanging under the verandah of every house. At night-time we could hear, over the hills, the incessant banging of thousands of crackers. As there were Government people about, not a sign of a native was to be seen. They were in hiding somewhere. We went over the whole place, watched by the Chinese, who were clothed most picturesquely. Just as in Darwin, it was difficult to understand how they look so clean and yet live amongst such dirty surroundings. The children were wearing most beautiful silk clothes-green, pink, blue, grey, black and yellow. Picturesque as they all looked, I would like to deport the whole lot of them, because with their opium and spirits they debauch and ruin the aboriginals, and are, apart from this, of little good to the country. On the other hand, one could only wish that the white labourers were even half as industrious as they are.

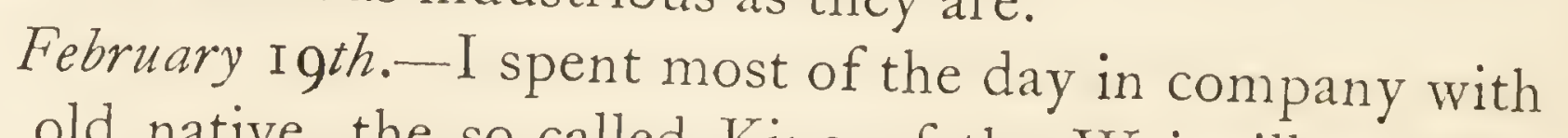
an old native, the so-called King of the Wai-willum tribe that once inhabited this part but is now nearly extinct. He 
is an old savage who has spent ten years of his life in gaol for murder and has served other sentences, but is still hale and hearty and does not seem to be troubled by the recollection of any past misdeeds. Quite possibly they were not even such, from his own tribal point of view, or were done quite justifiably, as he and his fellow-countrymen thought, in retaliation for wrongs done to him and his tribe by the white men. However, I have no doubt that he had fully expiated all such wrongs as he had done to the strangers who had usurped his lands and taken away everything that belonged to him and his people, and I was glad to come across him, because he knew a good deal. Late in the afternoon it came on to rain in torrents. Giles and myself tried to drive out to Bonrook, but the whole country had suddenly become covered with a sheet of shallow flood waters. We managed to get across two little creeks, where the water came up to the floor of our buckboard, but when we came to the edge of the one on the opposite bank of which the station lay, we found that it was running a banker. We had driven hard to try to reach it before the main flood came down, but by the time we reached its banks there was a stream at least fifteen feet deep roaring down between us and the station house that we could see, only a hundred yards away from us, comfortably perched, amongst its sheltering trees, on a knoll, high and dry above the flood. There was not the slightest hope of crossing nor was there any time to be lost if the smaller creeks between us and the township were to be negotiated, so without a minute's delay we simply turned round and headed back for Pine Creek. The whole of the flats were a sheet of running water. Had I been by myself there would have been nothing for it but climbing up a gum tree, with a suitable fork wherein to spend the night, but Giles knew every inch of the way, though all tracks through the scrub were under water and invisible. We got back safely into the township, of course 


\section{WANDERINGS IN WILD AUSTRALIA сн.}

once more drenched through to the skin, and spent a very comfortable evening in Mrs. Weedon's hostel.

February 20th.-We drove out to Bonrook early in the morning to bring my baggage into Pine Creek, as I had to catch the train next day to Darwin and could not risk another flood. The waters had gone down as quickly as they had risen and only scattered pools remained in hollows and along the creek beds. It did not take long and I was soon back and spent the rest of the day at the Police Station, busy over Departmental matters in consultation with Constable Miller and one of our Protectors who was to remain here on duty. Close by the station a creek had worn out a little gully for itself, and the former provided me with a dish in which to wash some "dirt" out of the creek bank, in which he said alluvial gold was to be found. By way of recreation and change from office work, I spent an hour doing this. I suppose that I ought to have taken out a "miner's right," but the constable dispensed with this formality and I set to work. It is a very simple matter. You scoop a handful or two of " dirt " into the dollying dish, then half fill it with water and swill it round and round, holding the dish so that the water slowly trickles out, carrying the dirt with it. You keep on washing and adding water at intervals. If there be any gold it sinks to the bottom and, when only a little "dirt" is left, you may see a few specks of gold, usually only tiny ones. I washed a good many tinfuls and, to my surprise and by sheer good luck, got very unmistakable "colours," not only a few mere specks, but one little piece an eighth of an inch in diameter -a veritable little nugget. It is a sign of good luck to get gold in your first wash, and certainly the work is very alluring while it lasts, and one feels inclined to go on and on, but I never had the chance of further experience in gold mining, and this remains my one and only nugget. I spent the evening with four of the leading townsmen whom 
I had asked to meet me and talk things over. Not unnaturally, they were rather sceptical about our work and intentions, but, after explaining matters to them and going in detail through the regulations, their attitude changed to one of friendliness, when they realised that our endeavour was to carry out our work, with which they sympathised, with as little inconvenience as possible to the white population. More especially they were quite in agreement with us in regard to the disastrous effects of contact between the Chinese and aboriginals and, before we parted, they formed themselves into an unofficial vigilance committee to help us in our work. The result of this visit to Pine Creek was decidedly good, so far as it went, but things have drifted to the bad for so many years past, during which there has been no attempt made to do anything with aboriginals, and the Chinese have acquired such an influence over them and are so astute that, with the small staff at our disposal, it will be very difficult to do what we want.

February $22 n d$.- Back in Darwin at work in the office and arranging for Dr. Holmes and Protector Kelly to go to Pine Creek and start work there.

We hope soon to move into our new quarters. When things are fixed up there I shall go across to Melville Island and get away from routine work for three or four weeks. It is still very hot and muggy. If you don't wear a pair of boots for two days they are covered with mildew, and a woman without special conveniences and domestic help, which is for the most part unobtainable here, must sometimes find housework very trying and rather depressing.

February 23rd.-Dr. Holmes and Protector Kelly left for Pine Creek. We shall have to keep a very sharp watch on Darwin, because, though the Chinese are now very quiet, they are equally wily. The natives are much impressed and, just now, not one of them ventures into VOL. II. 


\section{WANDERINGS IN WILD AUSTRALIA сн.}

Chinatown. The effect of taking two or three of the "boys," who had boasted of their being able to defy us, into custody was decidedly good. At first the lubras thought that we could not do anything with them, but, after much trouble, we have managed to catch another particularly objectionable lady who had defied the regulations and was hiding away with the connivance of some Malay men. She is a well-known character, and to her surprise and that of the other women, she is now on her way to the Mission Station on Bathurst Island, where she will be well but firmly looked after for some time.

We had an interesting native in to-day. At first Dr. Burston, who, as Dr. Holmes has gone to Pine Creek, is now in charge of the medical work here, thought that his heart must be on the wrong side, and certainly it seemed to be beating on the right side, but it turned out that the poor fellow, years ago, had been brutally ill-treated by a rough drover who had broken one or two of his ribs and in some way affected the position of the apex of the heart so that it was now abnormal. It was wonderful that he was alive, but natives can recover from injuries that would soon put an end to a white man.

February 25th.-Mr. Clarke, the Director of Agriculture, and myself spent all day going round the town with a plan, locating the various streets and park lands that look very well on a map but most of which, as yet, are covered with wild scrub. Amongst other things we found four small native camps, each with just a few Mia-mias, planted down in the bush, away from the other natives. In the afternoon we walked out and inspected the site on the Kalin beach, where the new camp is being formed, and walked all over the flat and the old Chinese garden with their mango trees, banana plantation and sweet potatoes and pumpkin patches. Though now in a state of neglect, they gave evidence of what could be done with them under 
cultivation, and I hope they will be in working order before long. It will be a great blessing if we can train the natives to work on them, because fruit and vegetables are now scarce in Darwin.

February 26th.-This morning there were very heavy clouds about, and by 9 a.m. the rain came down in a perfect flood for an hour or more, cooling the air for a little. When it cleared off, things were stickier and we perspired.

We are trying to get our new quarters into a habitable state. There is apparently only one person in Darwin, apart from incompetent natives, who can scrub floorsher present name is Mrs. Spain. She is a robust woman who has married several husbands of various nationalities, has a large family of mixed pedigree, dresses in an indescribable style altogether peculiar to herself, but redundant with colour, and is eminently capable and fearless of work in a climate that effectively subdues most women. It is not quite clear which of her husbands she has honoured by adopting his name as her present one. It is the common belief that she selects the one that appeals to her most at the moment when she bestows not only her hand and handcart, the most important item in her personal estate, upon her new spouse, but also the name that she has chosen for him. To watch Mrs. Spain trundling her handcart down to the wharf, to claim packages of newspapers and periodicals arriving from the south by an incoming boat, and then, leaving a damp trail behind her and spurning any proffered help, pushing her heavy load up a hill so steep that the very thought of walking up it makes an ordinary man perspire on a hot day, is an unforgettable lesson in what a woman of fixed determination can accomplish. It was equally invigorating to watch her when, on business bent, she walked the streets of Darwin on a windy day, in garments that antedated, but were the precursors of, short skirts, revealing, with no sense of false modesty as they fluttered 


\section{WANDERINGS IN WILD AUSTRALIA сн.}

in the breeze, limbs of great muscular power and generous proportions. Darwin could have done with half a dozen Mrs. Spains, but, at the same time, her back door opened into Chinatown and, much as we appreciated her personally, a licence to employ aboriginals was granted with considerable trepidation. However, we had confidence enough in her to take the risk. She never abused the trust and was a sturdy supporter of the Department. One of her chief features and attractions is a hat of which she is very proud. It is an old straw one that has evidently come down to her as a bequest from one of her earlier husbands. The brim, though retaining little of its original shape and colour, is still fortunately more or less stiff and intact, but the crown, after long years of strenuous and faithful service, has become detached, except for an inch or two at the back where it is firmly stitched on. To watch it rise and fall in the wind as she hurries along, because there is never time for her to fulfil all her appointments and walk in the leisured fashion adopted by most Darwinites, is a most engaging sight.

I was fortunately able to avail myself of, or rather she graciously granted me, her services when the workmen were good enough to retire from our premises. The horror with which she contemplated the state in which the floors were left, when I personally conducted her over the small establishment, justified, I hope, the remuneration that she suggested as a suitable return for the labour involved in making them, as she said, "fit for a blackfellow let alone a white man," to walk on. However, I was amply rewarded by hearing that, after recompensing her at the rate of pay recommended by herself, she allowed it to be known in public that, in her opinion, I was, at that time, "the only gentleman in Darwin." A year later, when I had left the Territory, wishing to send her something that she could show in public as evidence of my regard for her, I bethought 
me of a pair of stockings of a colour and pattern that could not fail to attract attention when she appeared in public. After ransacking the shops in Melbourne, I at last secured a multicoloured pair of striking design that seemed to fulfil all necessary requirements, including that of size, and was gratified to learn that, after receiving them, she never appeared without them on any important occasion, such as a wedding, christening, funeral, or Government House levee, and that she still looked upon me as a gentleman, because they were "clean ones" and had evidently not been worn before.

February 27th.-Busy all day moving into our new quarters and arranging things. Thanks to the strenuous efforts of Mrs. Spain, the floors are passably clean. They are made of rough-hewn, narrow planks with plenty of chinks that allow of ample ventilation, because the cottage is raised on piles three feet above the ground. Fortunately the underspace is enclosed all round by rabbit-proof netting to keep out stray dogs, cats and fowls, black piccaninnies and their parents also, to all of whom it would provide a convenient and agreeable shelter and sleepingplace during hot days and nights.

Joe Cooper came in again from Melville Island, in his little lugger the Buffalo, bringing this time a cargo of Cyprus pine. He will remain in Darwin until the next steamer from the south comes up, which I hope will not be for three or four days yet, because I want to go back with him and there is yet much work to be done in the office.

February 28 th. - In the morning I went down to the socalled harbour, a sheltered arm of the Bay, enclosed by mangrove-covered banks, to look at a little steam launch that will be useful to us in patrol work along the northern coast line. I hope that the Government may be willing to provide us with one, as, otherwise, patrol work in these parts, where no white men live and there is no possibility 


\section{WANDERINGS IN WILD AUSTRALIA сн.}

of police supervision, will be impossible, but I am afraid that the necessary expense involved will put the purchase out of question as, unfortunately for us, the Government is evidently in an economic mood just now. Of course I know nothing of launches, except whether they are comfortable to travel in, and we have asked Captain Edwards, who has had much experience in these matters, to give us an expert opinion on its condition and market value.

In the evening Dr. Burston and myself walked round to the Convent under control of the Society of the Sacred Heart, where the former had promised to see one or two children who were ill - there is an epidemic going the round of Darwin, which, as no one seems to know exactly what it is, is called influenza. The Convent with its little church is just on the outskirts of Darwin, amongst the gum trees, and when we got there evening service was being held. It really looked and sounded picturesque. The sisters are clothed in blue and white but, how they manage to wear such heavy garments, keep them spotless, look cool themselves and to be always cheerful and regardless of self, under all conditions of surroundings and climate, I cannot understand, but somehow they do and one can always rely upon them for assistance. The Mother Superior was a delightful, cultured, elderly Belgian lady who had formerly worked in New Guinea. Her greatest desire, so I heard later, was to end her days working amongst the Papuan natives, and I believe that, some years afterwards, this wish was gratified.

March 3rd.-Being Sunday, everything is quiet and I have spent the morning writing reports, free from interference in the office. Our departmental quarters consist now of a cottage-bungalow, containing two fair-sized rooms, two small ones for stores and a closed-in verandah behind, that serves as a dispensary for the medical officer and looks out on a yard with a great Punciana tree that in spring will be covered with masses of scarlet bloom, and 
always affords shade to the natives who are constantly coming in to see us.

On one side we face the esplanade and look right across the harbour, and on the other are the grounds of the little Church of England. On the north and west sides the windows are fixed in the middle of wooden slabs that are hinged along their upper edges in such a way that they can be slung outwards and propped open to allow of ventilation.

In the afternoon, Messrs. Clarke, Francis and myself walked to Fanny Bay Gaol, where I wished to consult Mr. Strath, the Superintendent, and interview a native prisoner who had been arrested for murder. He certainly speared a native, but I think that he was justified in doing so under tribal laws, so that we shall be able to put up a defence for him. I had a long talk both with him and the witnesses, who have been brought in with him from a long distance away and are kept in gaol till the case comes on. By sundry well-meaning people down south, who naturally know nothing whatever of the conditions that prevail in these remote parts, this detention of prisoners in a gaol pending a trial has been denounced, perhaps, also, not unnaturally, in terms of wrathful indignation. In reality this is the kindest method of treatment that could be followed, and is adopted only for the benefit and safety of the witnesses by those who alone know, and are in a position to judge of, what is best to be done for them. They must be brought in to give evidence, and in most cases they thoroughly appreciate the trip, provided always that they are under the protection of the police. A wild native from the back blocks would never, of his own accord, venture into or be left alone in strange country. He would be in mortal fear, indeed in imminent danger, of losing his life. In the Fanny Bay Gaol, under the protection of the police and the sympathetic treatment of the Superintendent and Mrs. Strath, they are perfectly happy, in comfortable quarters, 
with plenty to eat and smoke, feeling that they are quite safe. Outside, amongst strange natives, their life would be one of constant terror. Of course when we have a compound under proper supervision, we can house them there, but I much doubt if they will feel as safe, free and comfortable, with strange natives around them, as they now do, alone by themselves, in the gaol precincts. From Fanny Bay we walked the four miles back into Darwin and perspired considerably.

March 5th.-Raining hard all day. It looks as if the north-west monsoons, that generally come in January, had postponed their visit until now. They have been blowing so hard that there seems to be slight chance of Cooper's luggage getting away for a day or two. Outside Darwin the whole country has been flooded and the rivers are impassable. We have not seen the sun all day, which is a rare thing here. However, the rains cool the air and the wet bulb has been as low as $73^{\circ} \mathrm{F}$. We had the windows open and a refreshing breeze blowing all day long. To-day a little steamer went away to Borraloola and the Gulf, and on her we sent eight natives back to their own country. 

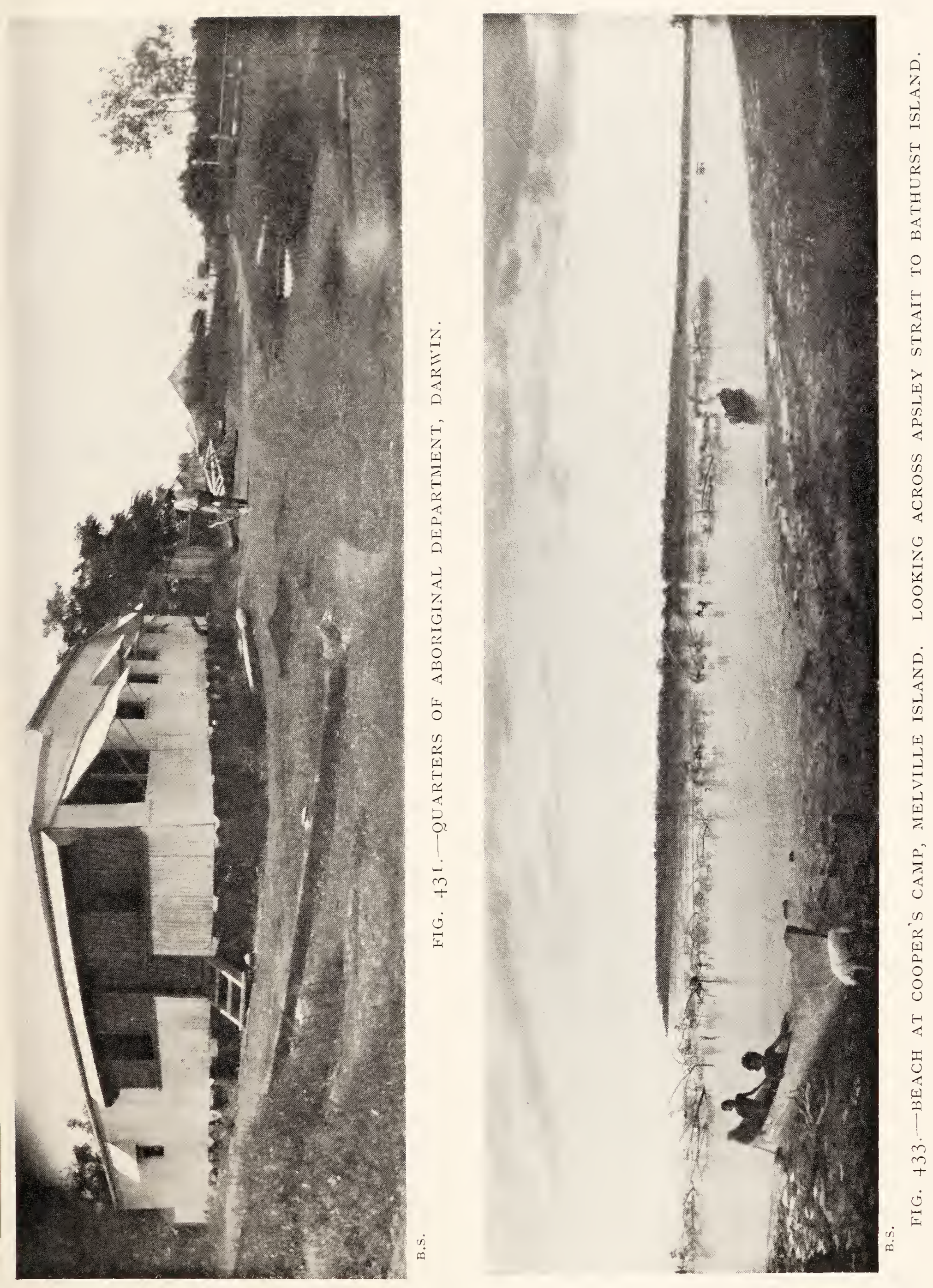


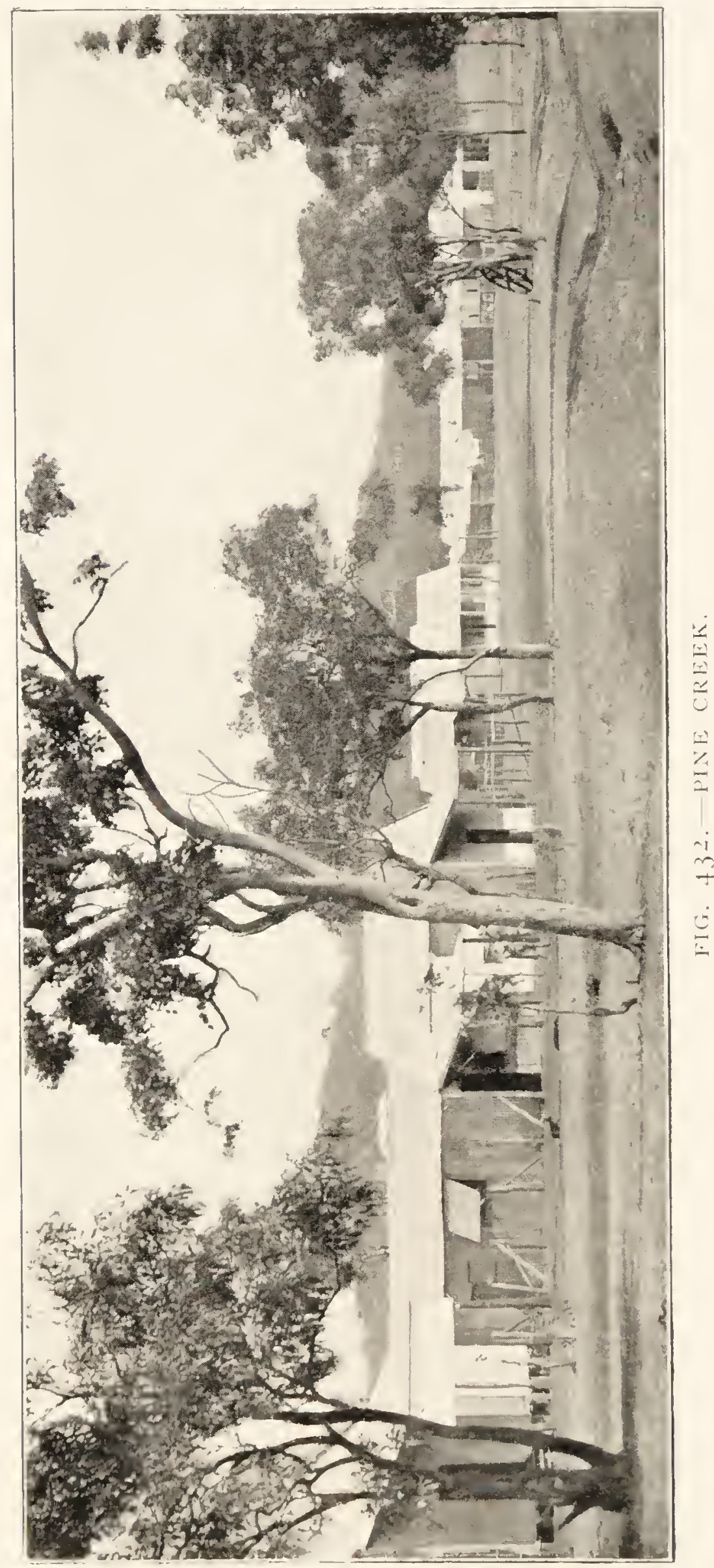




\section{CHAPTER XXVI}

MELVILLE AND BATHURST ISLANDS AND THE ISLANDERS

I HAD always wanted to see Melville Island and my first chance came during our little Commonwealth Expedition in I9II. Woolnough had gone over to Point Charles, geologising, Breinl was off down the line, on a medical inspection. Gilruth and myself had been waiting for a little steamer to come in by which we hoped to get across to the island, but word came in that it was stuck on a sand-bank-no one seemed to know exactly where. In Darwin, under ordinary circumstances, two or three weeks' waiting does not usually make much difference, but our time was counted by days because we had to be at the Roper mouth by a fixed date, to meet the Gayundah. We had given up hope of getting across and had packed our things on the train for Pine Creek when Mr. Stretton, who was then Protector of Aborigines and had been of great help to me, told us that he thought there was a motor launch that might be available, so we went with him at once to interview its owner in Chinatown and soon came to terms. This was late in the evening and there was no time to lose, as the train started for the south at 8 a.m. next morning and all our luggage, save hand-bags, was already on board it. We were up early and, with the courteous assistance of $\mathrm{Mr}$. Pickford, the station-master, were able to remove our belongings. It meant considerable inconvenience to the officials, involving unloading and reloading the van at the last moment, because our baggage was stowed away amongst stores and all kinds of packages 


\section{WANDERINGS IN WILD AUSTRALIA $\mathrm{cH}$.}

that filled it, arranged according to their destination, ours, as they were going to the termination of the line, being of course at the very bottom. The morning was spent in purchasing stores and repacking, and at noon we went down to the jetty and found that our personal luggage had gone by mistake to another jetty half a mile away, on the other side of the harbour, and that part of our stores had either not been sent down or had gone to the wrong place. As it was blazing hot, this did not make us feel in the best of humours, but Judge Mitchell came to our rescue and, with his ready help, everything was on the wharf by I.30 p.m., and soon afterwards was stowed away, along with ourselves and Cooper, whom we had been very glad to meet in Darwin and came over with us. Even then we had another delay. No sooner had the launch got clear of the jetty than the skipper discovered that there was something wrong with the engine, so for two hours we were stationary, bobbing up and down most annoyingly.

Our party consisted of Dr. Gilruth, Cooper, myself, the skipper, who was a half-caste Chinese, a Japanese man, who formed the crew, and Shepherd, whose services were kindly placed at our disposal by Judge Mitchell. The whole boat was only two and a half tons, about 25 feet long, and 8 feet in the beam, so we had not too much room to move about in.

At last we started, with wind and tide at first against us, so that we could not make more than two knots an hour. By nine o'clock we were out of sight of land and could just see the twinkling light of Point Charles lighthouse away to the south. Soon we lost this and there was nothing save the stars and the sea. It was a good thing that we had no need of the compass, because this, as the skipper said, "had gone wrong" and did not agree with the stars. It felt strange to be out in the open in such a cockle-shell boat, but the sea at this time of the year is more or less 


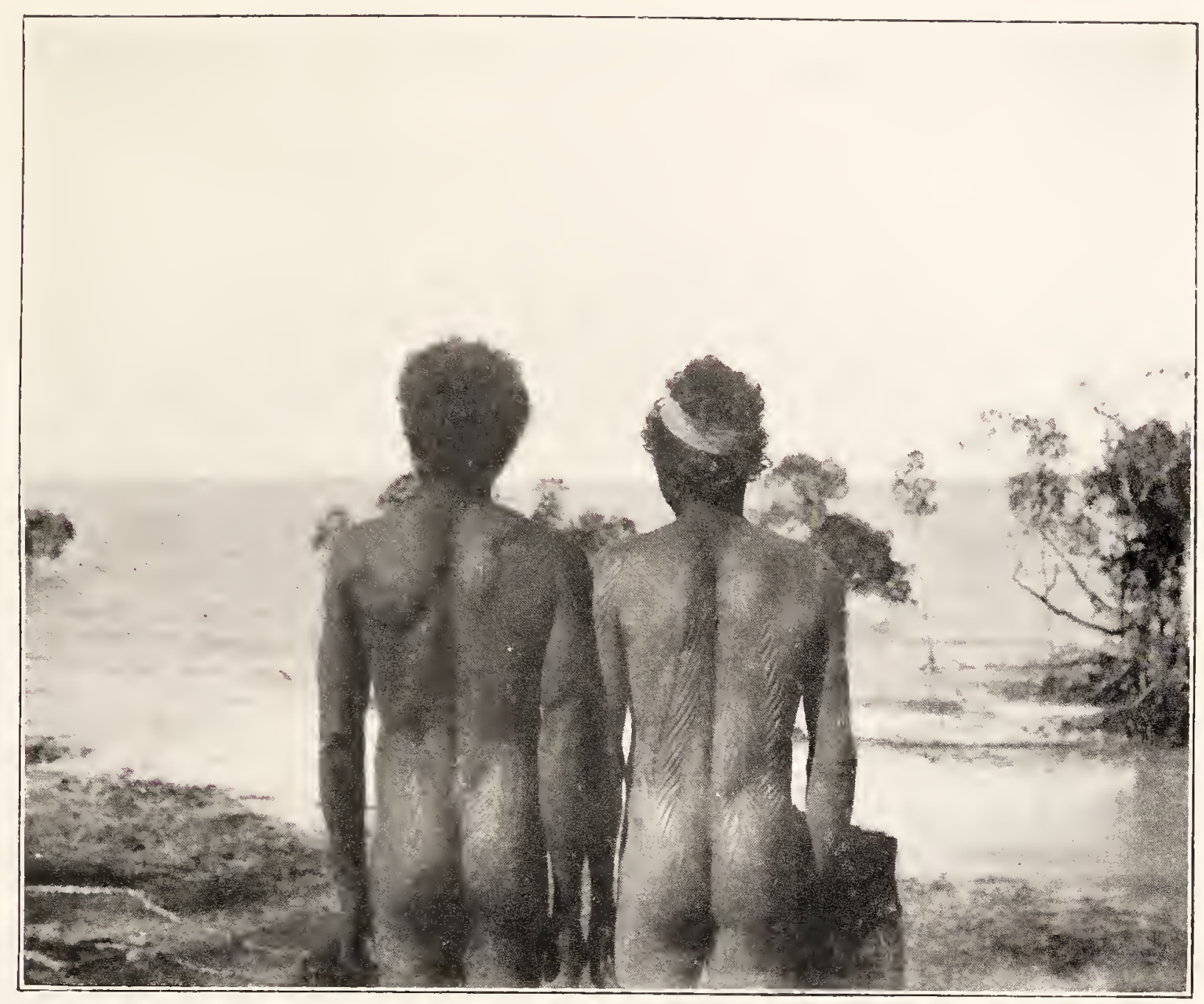

B.S.

FIG. 434.- TWO MELVILLE ISLAND MEN. BACK VIEW, SHOWING CICATRICES.

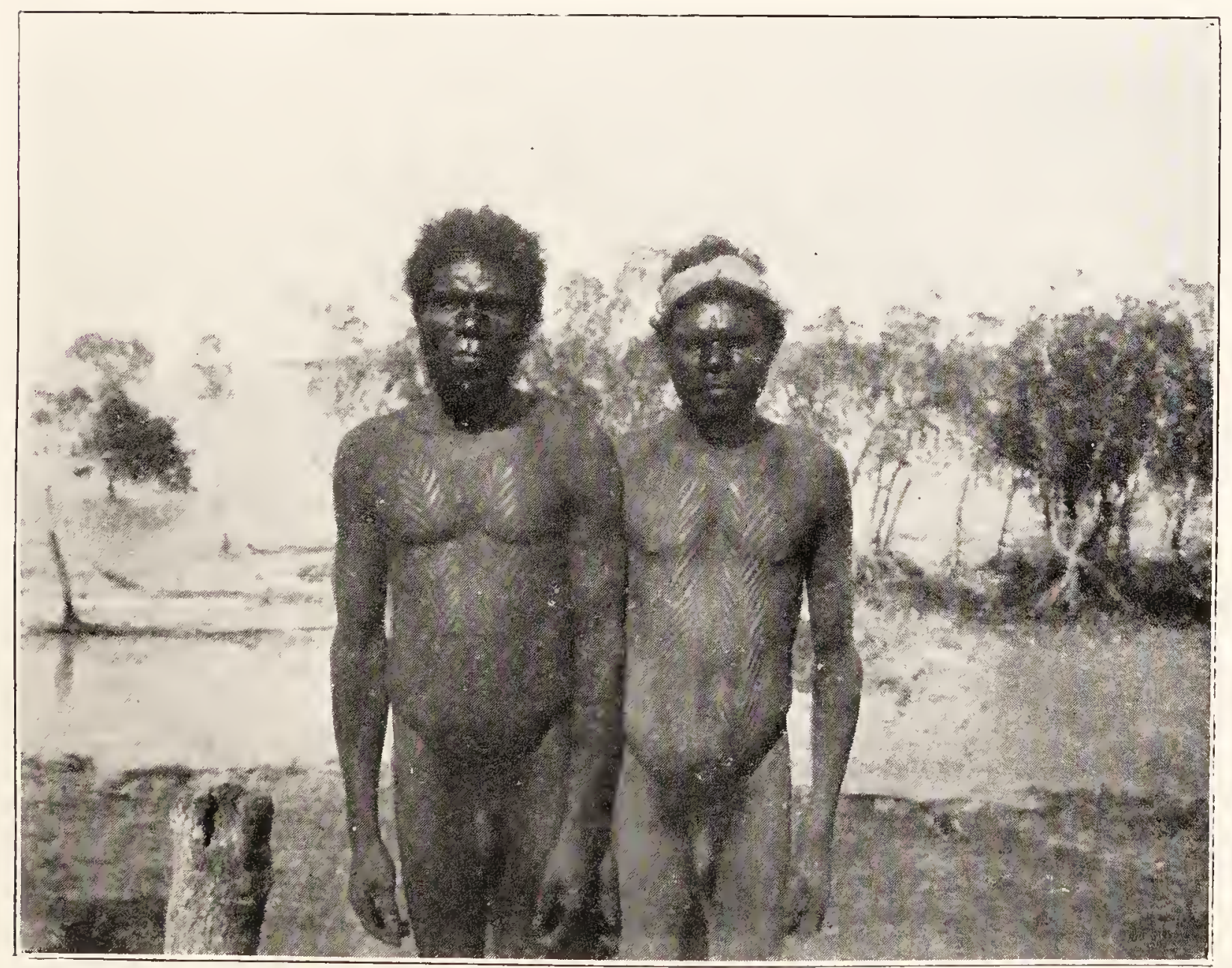

D. S.

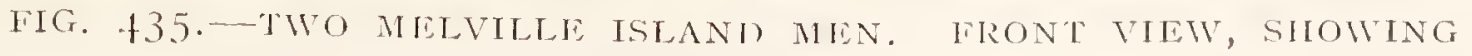
CICANRICES 


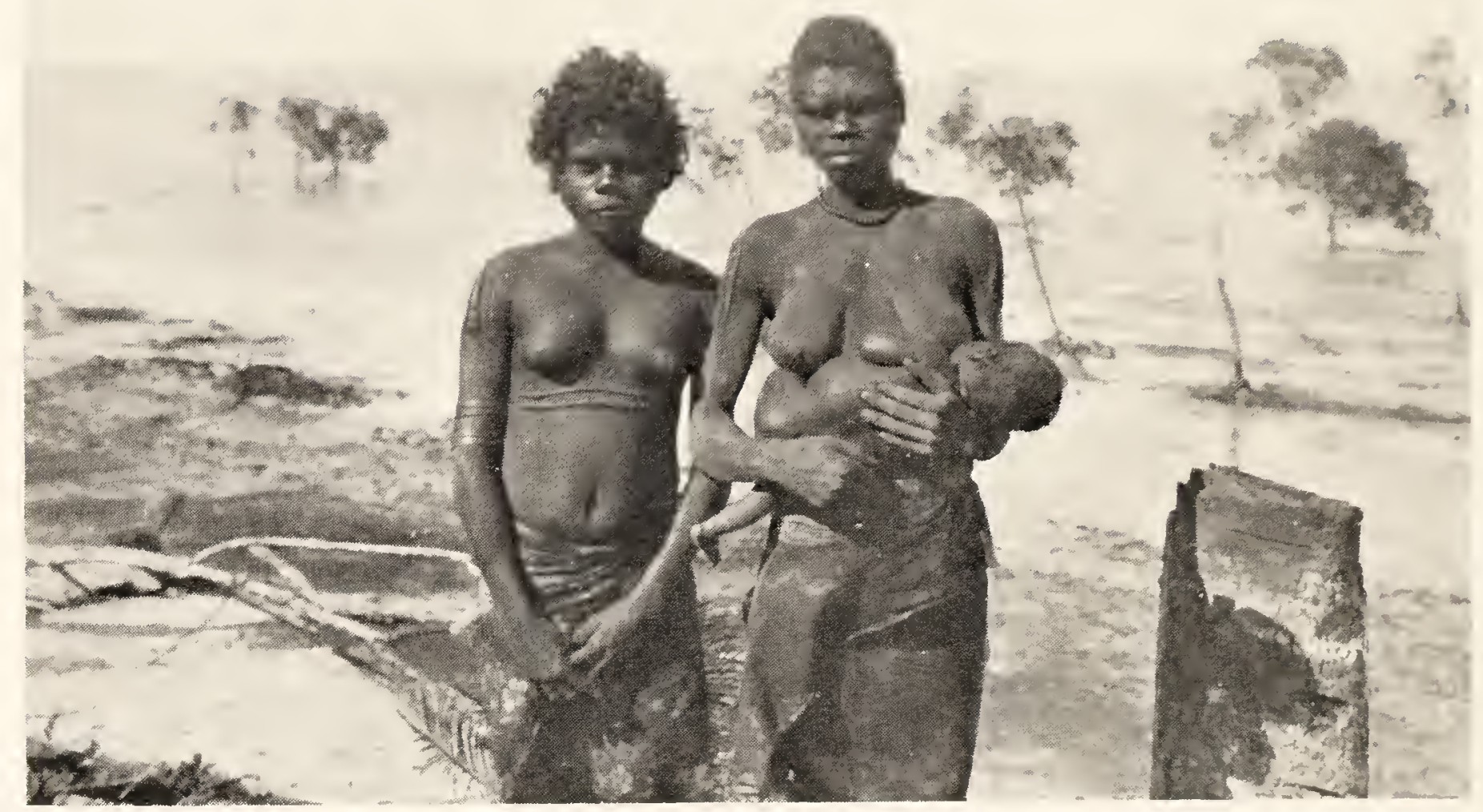

FIG. 436. TWO PORT ESSINGTON WOMEN AND BABY

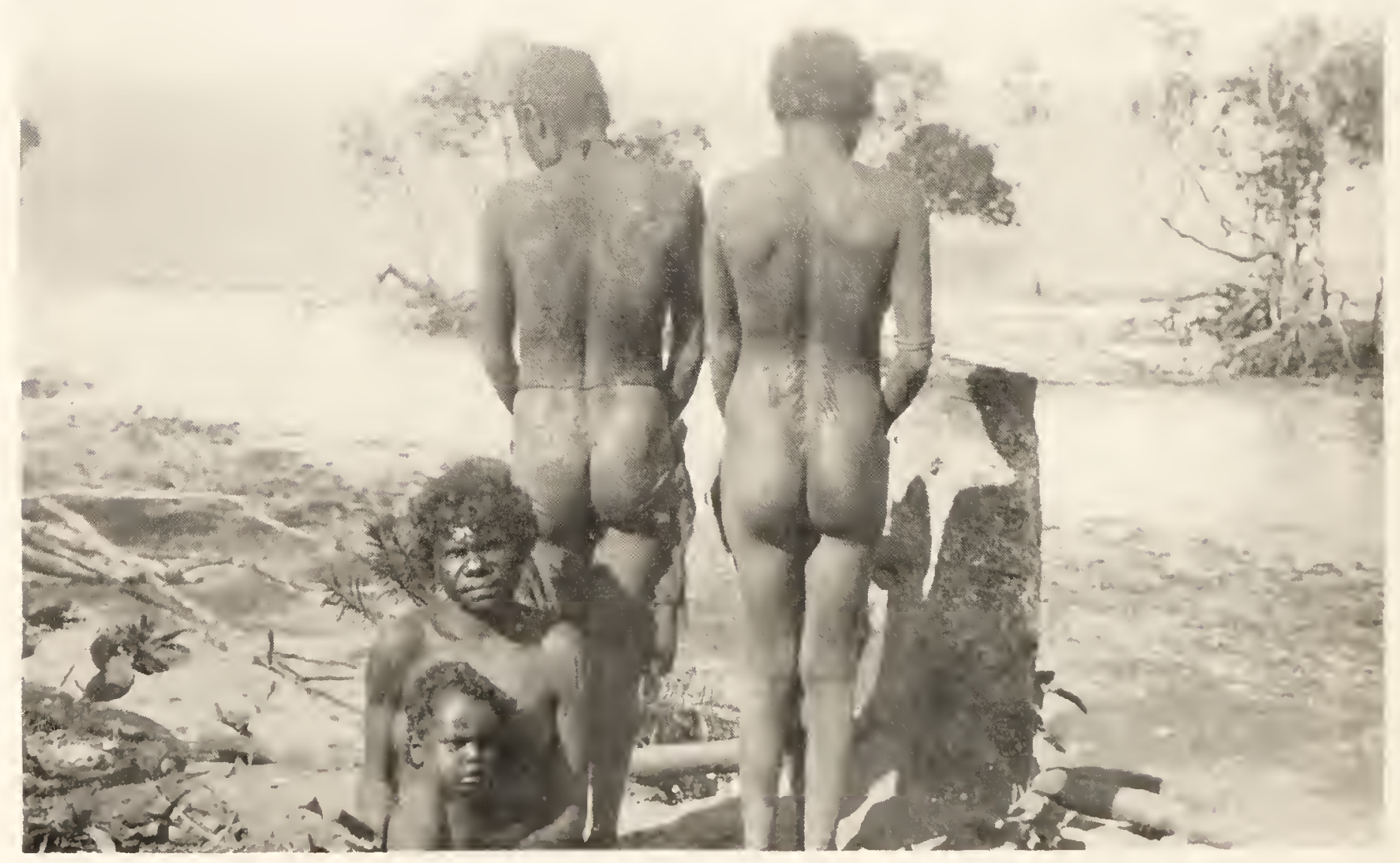

B.S.

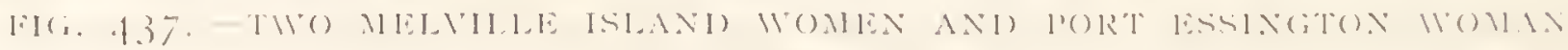

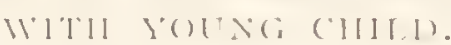


calm, and though we bobbed about a good deal we thoroughly enjoyed ourselves. Cooper took the tiller, Gilruth stretched himself out on a ledge on one side, and I on the other, and watched the Great Bear, right ahead of us. We went on peacefully all night, except every now and then when the engines broke down and the quiet woke us up.

At 3 a.m. we anchored under the shelter of Bathurst Island. There was nothing to be seen save a dim outline of land. There was a heavy swell on and we rolled about. As soon as it was light we lifted anchor, steamed round the south of the island into Apsley Strait, and at 8.30 were off Cooper's camp on Melville Island (Fig. 433). The shore was fringed with mangrove trees, save for a little beach on which about a hundred natives gathered to welcome us, or rather Cooper. As the tide was low we landed in a dug-out canoe. After landing our stores we had our midday meal in Cooper's camp and then wandered out into the bush for two miles to see a native grave. This consisted of a little mound, covered with slabs of paperbark and surrounded by six posts all rudely decorated with designs in red and yellow ochre, charcoal and pipe clay. It was right out in the wild bush, consisting of gum trees, "Plum trees," Currajongs, large Acacias, Screw Pines, Cycads and what are called Sago Palms. I collected a few plants, but hardly any were in flower or seed.

We had a whole bevy of natives with us, and of course we carried revolvers and a rifle or two. The natives are apparently quite friendly, but even Cooper never moves away from camp without being armed. He has his Port Essington boys with him and they look upon him as the great boss.

The natives of these two islands are quite different in personal appearance, and in many respects in their customs, from those on the mainland. In Cooper's camp there 


\section{WANDERINGS IN WILD AUSTRALIA сн.}

were both Islanders and Port Essington boys from the mainland, and they could be distinguished from one another at a glance. The former are, physically, the finest natives I have ever seen, that is, the men are, because there is a striking contrast in size between the men and women. The latter are seldom more than four feet six or cight, the former are often five feet ten or even six feet. The bodies of men and women are marked with very characteristic cicatrices, called Miunga, that are supposed to represent the barbs on their spears. They are arranged, as can be seen in the photographs, with remarkable regularity and form the only instance that I know of, in the whole of the Northern Territory, in which you can recognise the tribe of an individual by the body marks (Figs. 43444 I).

These keloid growths are the result of cuts made either by the individual himself or by someone else, quite voluntarily, with a stone flake or more usually a sharp-edged shell, and are added to from time to time. The Bathurst Islanders seem to have them chiefly on the upper arm, the Melville people in a double line on the front of the body, extending from the level of the collar-bone to below the navel, and on the back from the shoulder-blade down to the buttocks. They are always cut with great regularity.

One is often struck also by the curly nature of the men's hair (Fig. 439). Figs. 440, 44I represent a man decorated for a mourning ceremony. It is only on these islands that I have seen any decoration of the hair itself, apart sometimes from a certain amount of grease and red ochre that is frequently rubbed on amongst the Central tribes. Here, however, there is a regular design. The beards of these people are well developed, in strong contrast to many of the tribes on the adjacent mainland, such as the Kakadu and Geimbio, amongst whom it is only very sparsely developed. They have a curious custom also of pulling 


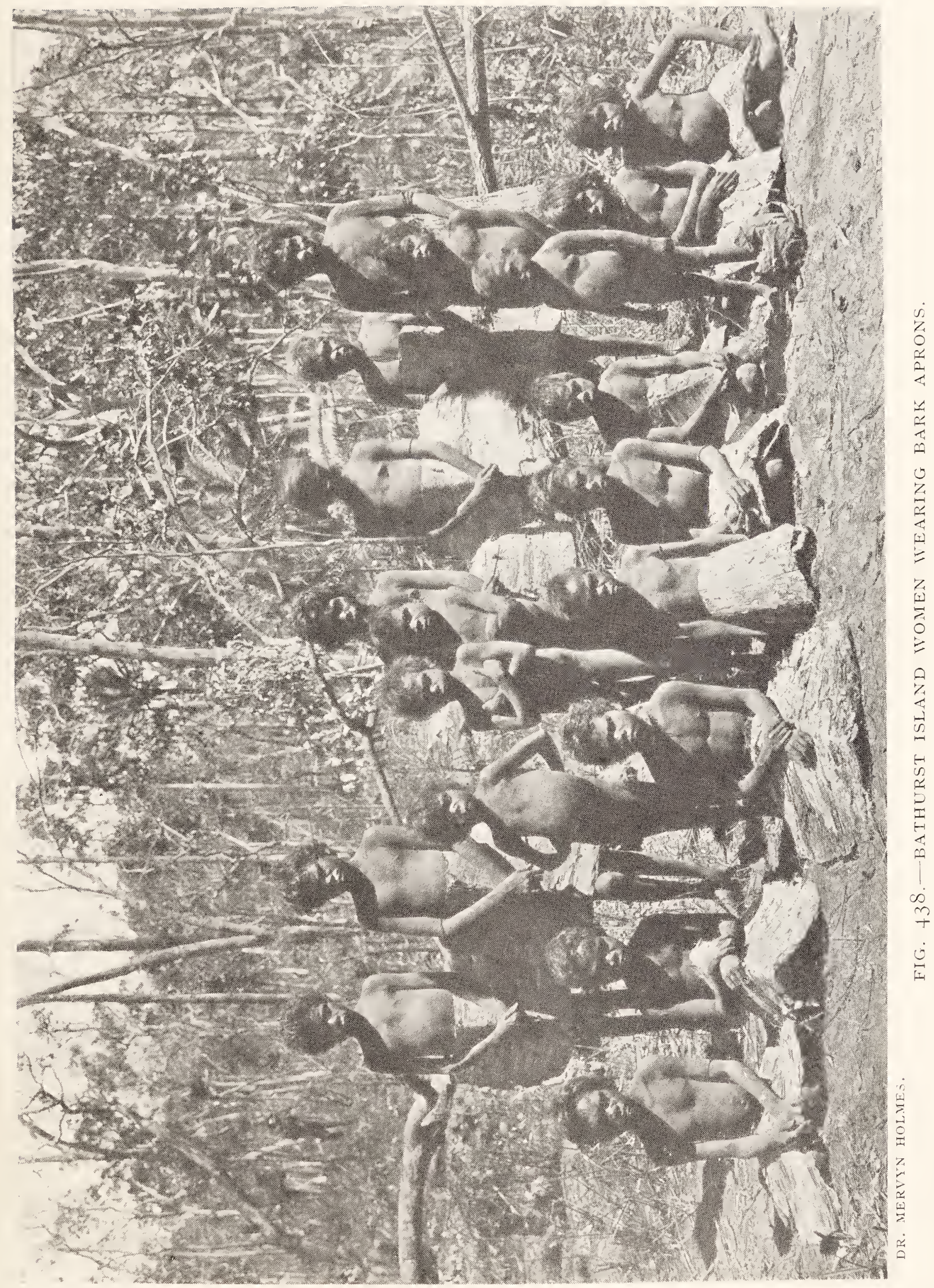




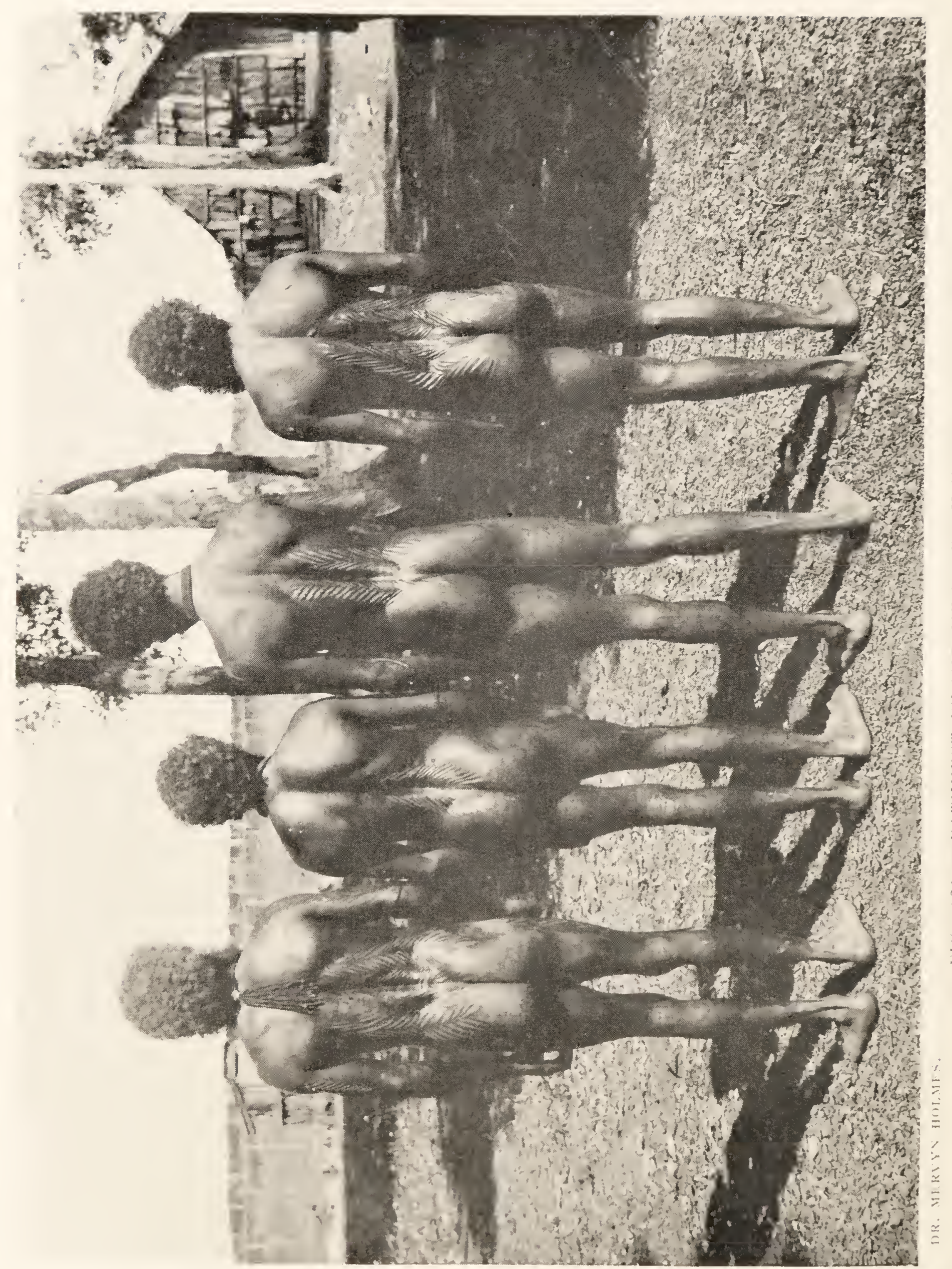


out their beards during certain ceremonies-their upper lips are always bare. The women have their hair short because they must cut it off periodically and use it for the manufacture of hair string.

They make excellent Mia-mias out of sheets of stringybark that are stripped during the wet season from the gum trees, in lengths of from six to ten feet by two or three feet in width. Sometimes they are dome-shaped (Fig. 443), at others they bend the sheet over a ridge-pole fixed in two upright forks. On the weather side the sheet touches the ground, the other half is propped up by another pole that, as in the one figured (Fig. 442), may be fastened to two handy saplings, so that the Mia-mia is open at the sides and front, though, if necessary, it can easily be closed in by additional sheets that are always kept handy. I was much struck with their very simple but effective contrivance of picking up and folding a sheet of bark in two and using it as an umbrella, slanting it on their heads in such a way as to keep off the torrents of rain that fall during the monsoon period. I found this a most useful contrivance as a protection for my cameras when, as often happened, we had to work in the rain. When available, paper-bark, the bark of Melaleuca leucodendron, is used, and in some respects is more efficient than stringybark, because it is very strong and tough and at the same time pliable.

Gilruth and myself rigged our mosquito nets close to Cooper's wooden log-house and, as night came on, we counted more than thirty fires all round us. It was wonderfully picturesque, especially just after dark, about 8.30 p.m., when some two hundred natives - men, women and children-came round and performed corrobborees in honour of Cooper's return. In these corrobborees, each of which lasted only a few minutes, they imitated special incidents such as a buffalo hunt, a crocodile seizing its 


\section{WANDERINGS IN WILD AUSTRALIA сн.}

prey, mound birds and geese, and the hauling up of the ropes on a ship going out to sea. In one they sang of Cooper's house, saying the Jokuppa (their rendering of his name) was tall but his house was taller still. The acting was realistic. The men gathered together and came on to the open space behind Cooper's house in a long line in single file. The main mass stood to one side, two or three performing at a time. In the buffalo dance, especially, the actions were very strenuous, sometimes the performer pawed the ground, then rushed wildly round with his head thrust back and his arms extended to their fullest, representing the horns of an infuriated bull (Figs. 444, 445). The audience stood round in a circle, each man savagely stamping the ground with his foot, while, in unison, they all struck their buttocks with their open palms, producing an extraordinary volume of sound that could be heard far away. Later on, when I was again on the Islands, I often heard this right across the mile-wide Apsley Strait at night-time when I was on Bathurst and the natives were corrobboreeing on Melville. When any man showed signs of flagging, another performer took his place, and so the dance went on until, at the end of each one, the audience closed in upon the performers, all bunched closely together, forming a dense mass of naked, howling savages, yelling wildly " $\mathrm{E}$ ! $\mathrm{E}$ ! $\mathrm{Ai}$ ! Ai!" with their arms waving in the air (Fig. 446). They have only one kind of musical instrument, commonly called a trumpet by the whites, but really a kind of conch, made out of a hollow bough. It sounds much like " biddel an boom," repeated incessantly with a very deep-sounding emphasis laid on the "boom." When all was over, the natives went to their camps and we laid down with the conchs still booming away in the distance.

Fune 29th.-We were up before 6 a.m.- - as a matter of fact the ground was so hard that we were constantly waking. 

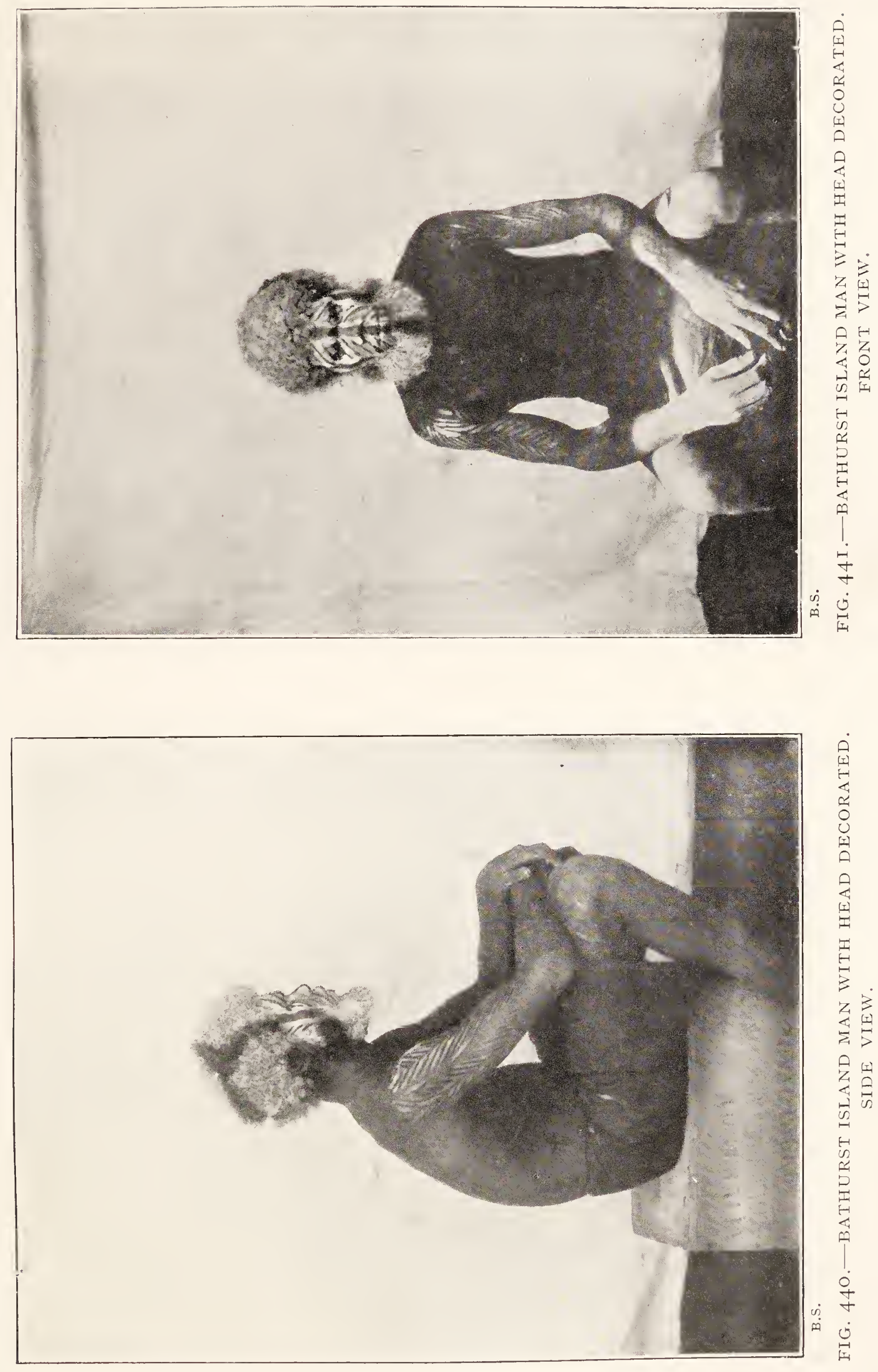


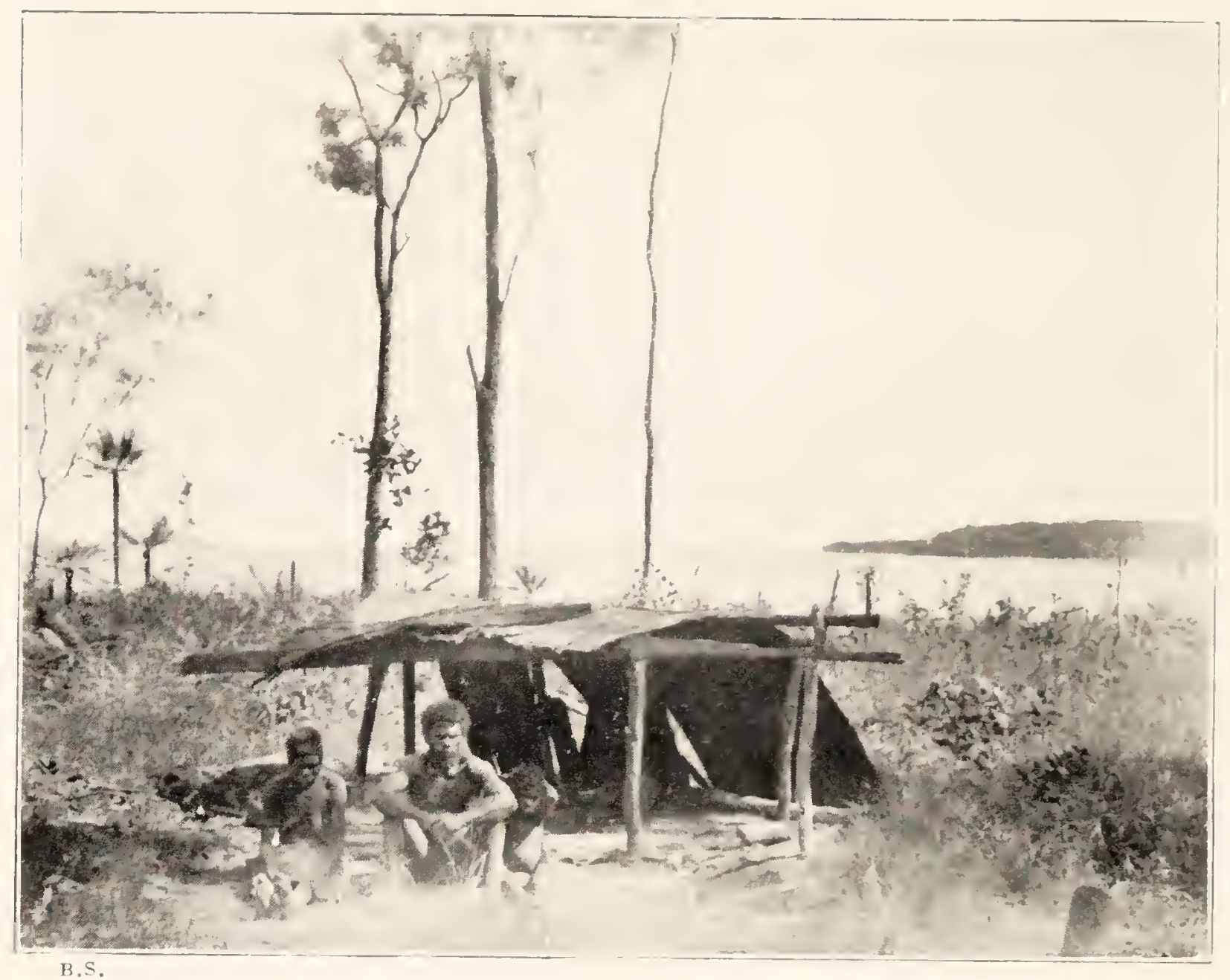

FIG. 442.-STRINGY-BARK MIA-MIA, WITH MAN, WOMAN AND CHILD, MELVILLE ISLAND.

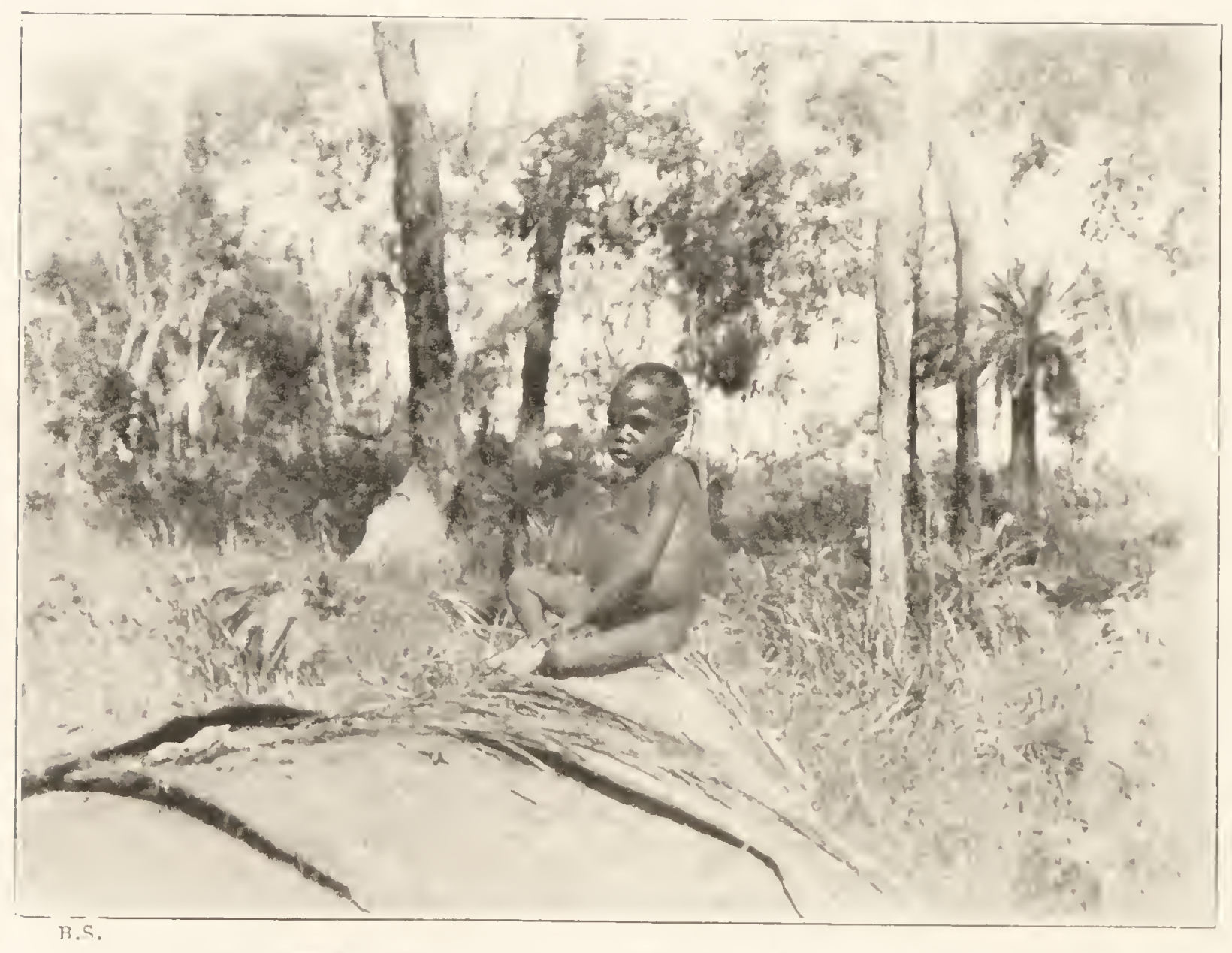

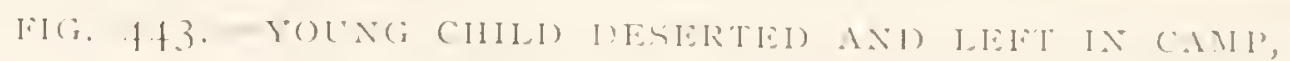
MIEISIILIE ISI.INII. 
There was a heavy dew, but it soon dried up. After breakfast, Gilruth went out with Cooper and some of his boys on a buffalo hunt. As we could only spare two days for our visit, I stayed in camp to try to get some information. Cooper allowed me the use of his best boy, who spoke both the Melville Island and Port Essington dialects, and also English fairly well. The boy had two or three others with him, and as soon as I told them things about the mainland natives, and showed them photographs of their ceremonies, they became interested and helped me as much as they could. With short intervals for mid-day meal and numerous smokes, I grafted hard with them until sunset, by which time we were all rather tired. However, I got enough material with regard to their organisation anc one or two other matters to serve as a start for further work later on. Cooper and Gilruth were camping out, so I was alone and shifted my camp close up to the house, and, as I lay down in the verandah, could see the mangrove trees standing out above the water and looked away across the Apsley Strait to the west, where the moon was setting. In the native camps the fires were burning and the conchs booming.

Fune 30th.-I was up early and did a good morning's work with the same natives until 2 p.m., when Gilruth and Cooper came in with the hide and remnants of a buffalo. Out in the scrub the natives had eaten every scrap of meat except the tongue and some steaks that Cooper saved for us. The tongue was passable, but Melville Island buffalo steak cannot be very highly recommended.

In the afternoon we were able to see a mourning ceremony that the Melville men were performing at the grave of a woman who had died a year or two ago. When a native dies his, or her, body-because the procedure is the same in both cases-is carried away into the scrub, always to 


\section{WANDERINGS IN WILD AUSTRALIA}

$\mathrm{CH}$.

some distance, half a mile or more away from the nearest camp. Here it is buried in the ground, a mound is mademuch like that on a newly-made grave in an English churchyard-and then covered with sheets of paper-bark and a space all round cleared of grass and shrubs (Fig. 447). For months, perhaps a year, it is left undisturbed, except that every now and then it is visited and the ground kept clear. Later on, the grave-poles are erected. Evidently there are slight variations in regard to this; sometimes only one pole is erected at a time, as on this occasion; sometimes, as I saw later, on both Melville and Bathurst Island, several may be put in position at once. We went on ahead to the grave, not knowing what was going to be done. The posts had all been newly decorated, and we stood to one side waiting for the natives to come. After a time we heard a loud shouting far away. Then there came a pause, and through the scrub we could see the smoke of a fire, with the men running round and round it. As I saw afterwards, they were actually running into it so as to singe the hairs on their legs (Fig. 449). Then all of a sudden, with a loud yell, they rushed up to the grave, hurling their great spears ahead of them (Fig. 457). The idea of this was to drive the spirit, called Mapuditti, into the grave. The posts, which had meanwhile been placed leaning against the trees on the fire ground, were brought up, holes were dug in the ground round the grave into which they were fixed. There is considerable variation in the details of procedure. Sometimes the poles are erected temporarily on the decoration ground and a dance takes place there (Fig. 458), after which they are taken to the grave and erected (Fig. 459), so that there is no delay in the beginning of the dance round them at the grave. When once, as on this occasion, the posts were in position the women and children ranged themselves on one side, some of them wearing the curious armlets made of stringy-bark, with 


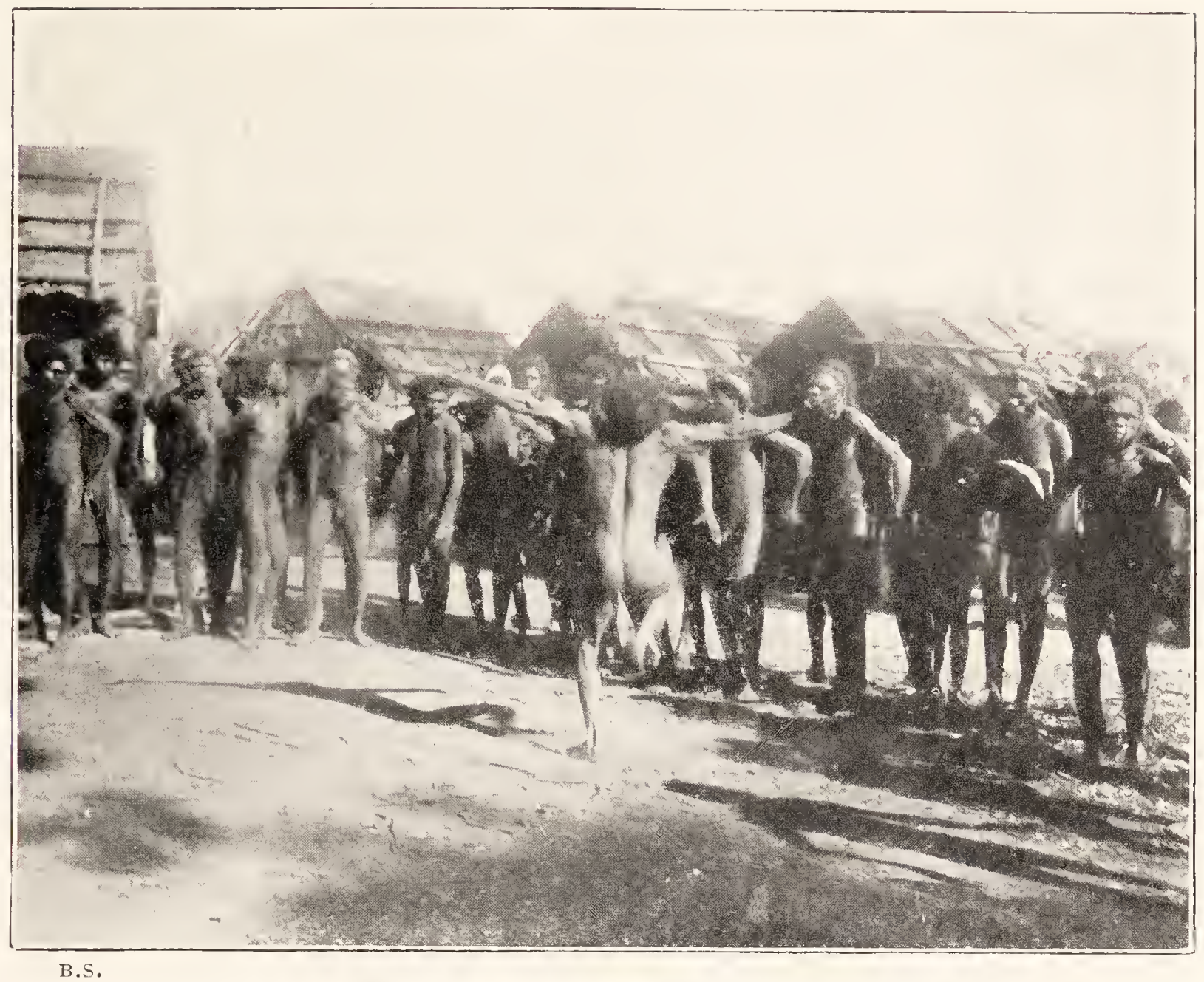

FIG. 445.-BUFFALO CORROBBOREE, MELVILLE ISLAND.

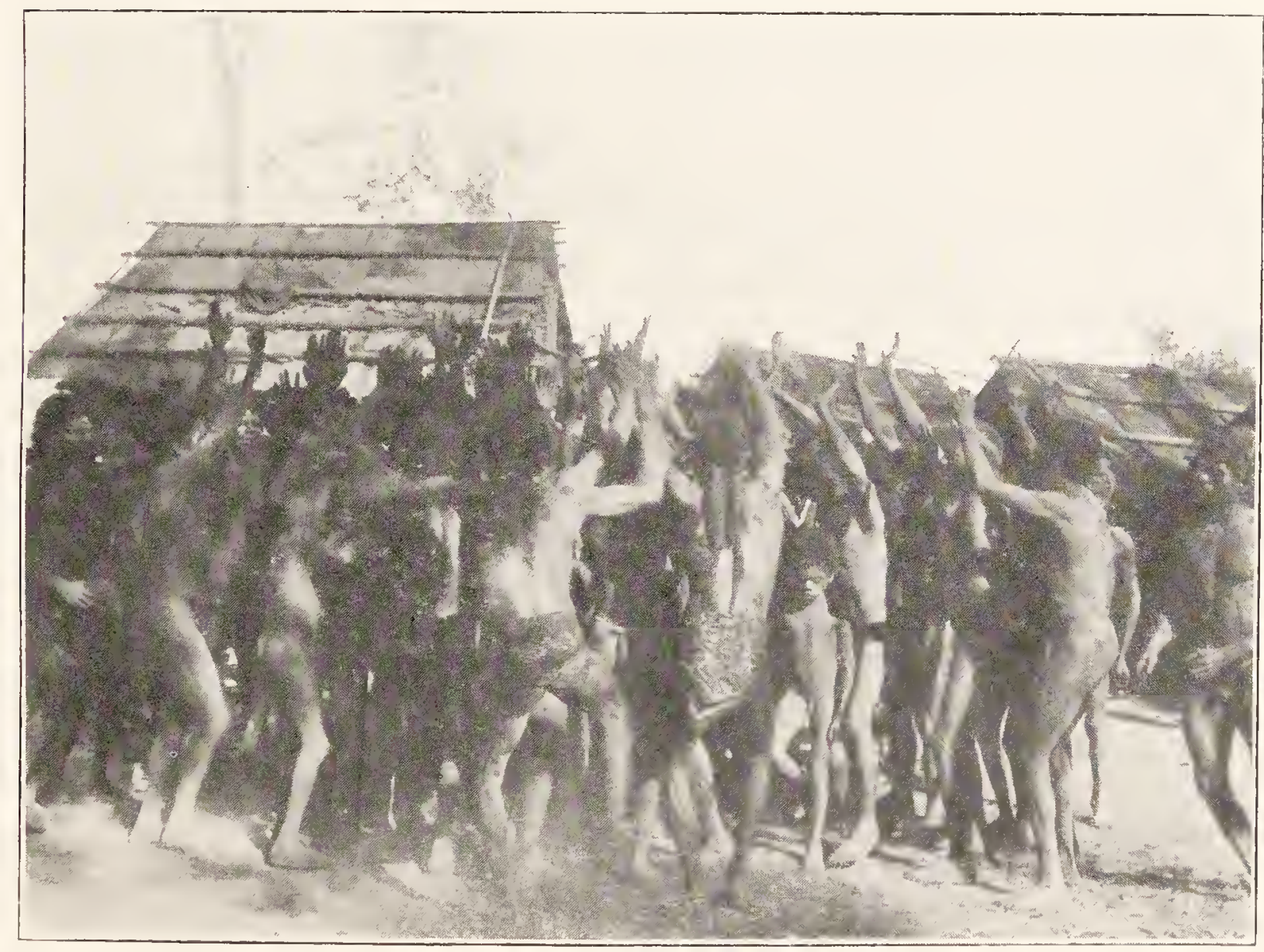

P.S.

FIG. 440.- END OF CORROBBOREE, MELVITLE ISLAND. 


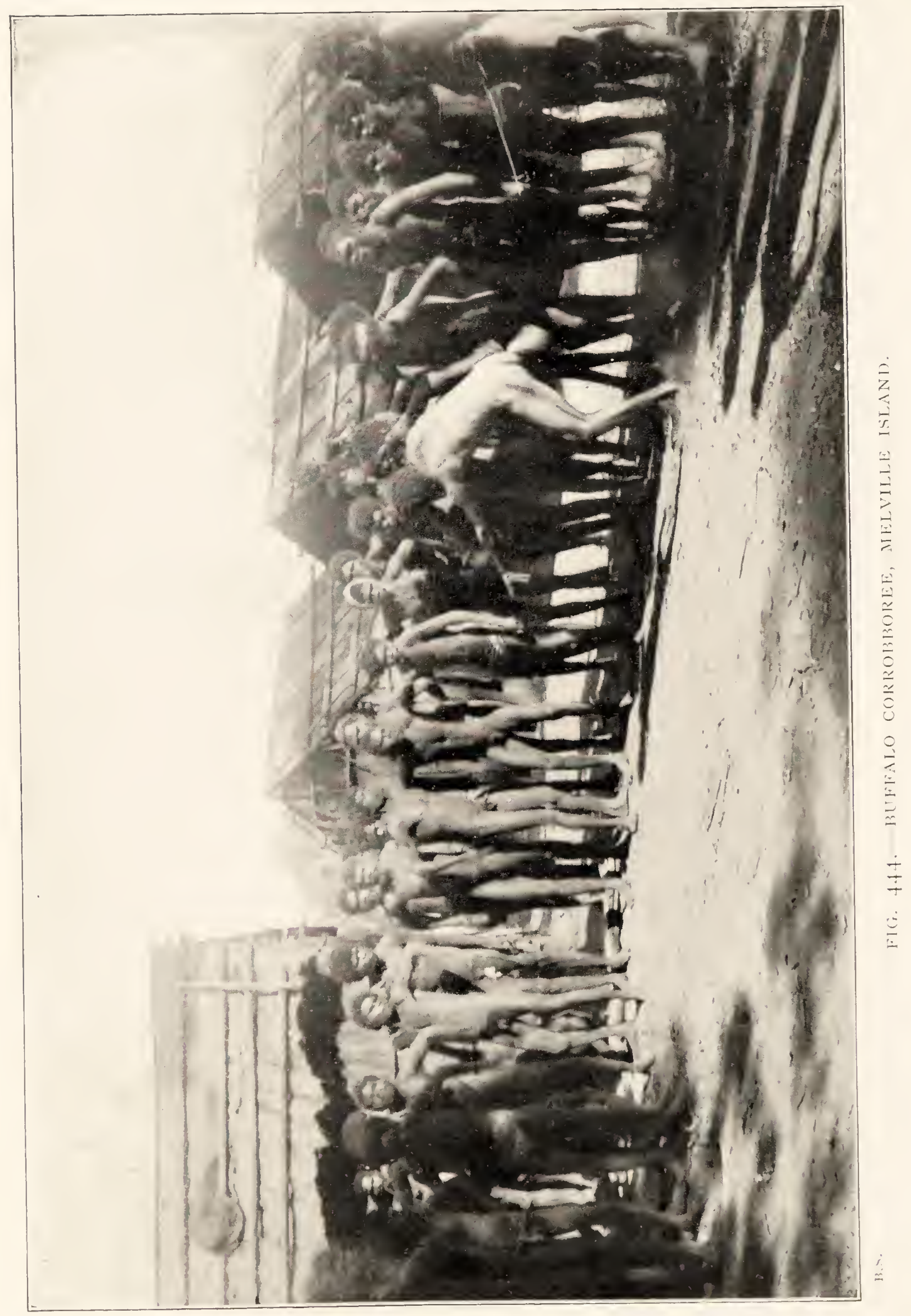


remarkable projecting decorations, others carrying ornaments like great circular discs, out of which in most cases the centres had been cut (Figs. 450, 45 I). Each of these was made of bands of pliable seed or cane over which human hair had been wound. The string was coloured red, yellow and black and often had masses of beeswax into which bright red Abrus berries were stuck, while tassels, ending in knots of wax decorated again with Abrus seeds, hung down (Fig. 450). The large ones measured as much as fifteen inches in diameter. In general shape they are much more like great flattened-out quoits than anything else. During the ceremony, and apparently the armlets are only used in connection with this, the women wear them on their arms (Figs. 455, 456), for which, in most cases, they are much too big and can only be kept in place by pressing the arms against the sides of the body and bending them at the elbow in a very characteristic fashion. Some of them were large enough to go round a woman's leg. 'The discs are held in the right hand, which is raised high when the women dance during the ceremony.

The men were decorated in various ways. Some had their bodies covered with red, others with yellow ochre, some with charcoal, others with lines of red and black or black and yellow. The women had the upper halves of their bodies painted red and the lower yellow; the leading one, a comparatively young lubra, in addition, had her face painted black. The performance began with the father dancing round and round the posts with his hands behind him and his head thrown well back. While he danced he sang :

$$
\begin{aligned}
& \text { "Pitti wa mi } \\
& \text { Ra du du re, } \\
& \text { Pitti wa mi } \\
& \text { Ra du du re," }
\end{aligned}
$$

ending always with long shouts of "Ia! Ia! E! E!" the last very long and prolonged. During the whole of VOL, II. 


\section{$65^{\circ}$ WANDERINGS IN WILD AUSTRALIA ch.}

the time the men, standing in a long line, were singing and stamping furiously, raising clouds of dust. The stamping is done in time to a very characteristic action that consists in every man striking his buttocks with the open palm of his hand. However excited they become they keep perfect time, and far away in the bush you can hear this strange sound. After a pause the father came on again, this time dancing right over the grave, in and out amongst the posts. A third time he came on, now representing a crocodile. $\mathrm{He}$ crouched down, low on the ground, walking on hands and toes with his body fully extended. Every now and then he lifted his head, peering about from side to side as if he were looking for his prey. This went on for some time, his acting being very good indeed, and then, jumping to his feet, he was joined by two other men, one coated from head to foot with yellow ochre, the other with black, and then the three, each with hands joined behind his back, and head thrown well back, rushed wildly round and round the grave. After a time they slowed down and the women joined in, led by a young girl, sister of the dead woman, who was painted all over in red, and solemnly and slowly danced round the posts. The women wear their bark aprons; some of them carry the armlets and discs, and a mother will often join in the dance carrying her baby on her shoulders (Fig. 460). The women then retired and the father, who was much exhausted, joined the audience. He was nearly worn out, but the two men, one in black, the other in yellow, took up the running, rushing madly round and round, pausing every now and then to face the posts and yell "Boo! whrr! whrr!" wildly at them. Then they stopped dancing and bent down, pointing at the grave in which the spirit was supposed to be watching them. Once more the women formed into a procession and, with their deliberate movement and peculiar high-knee action, danced, this time 


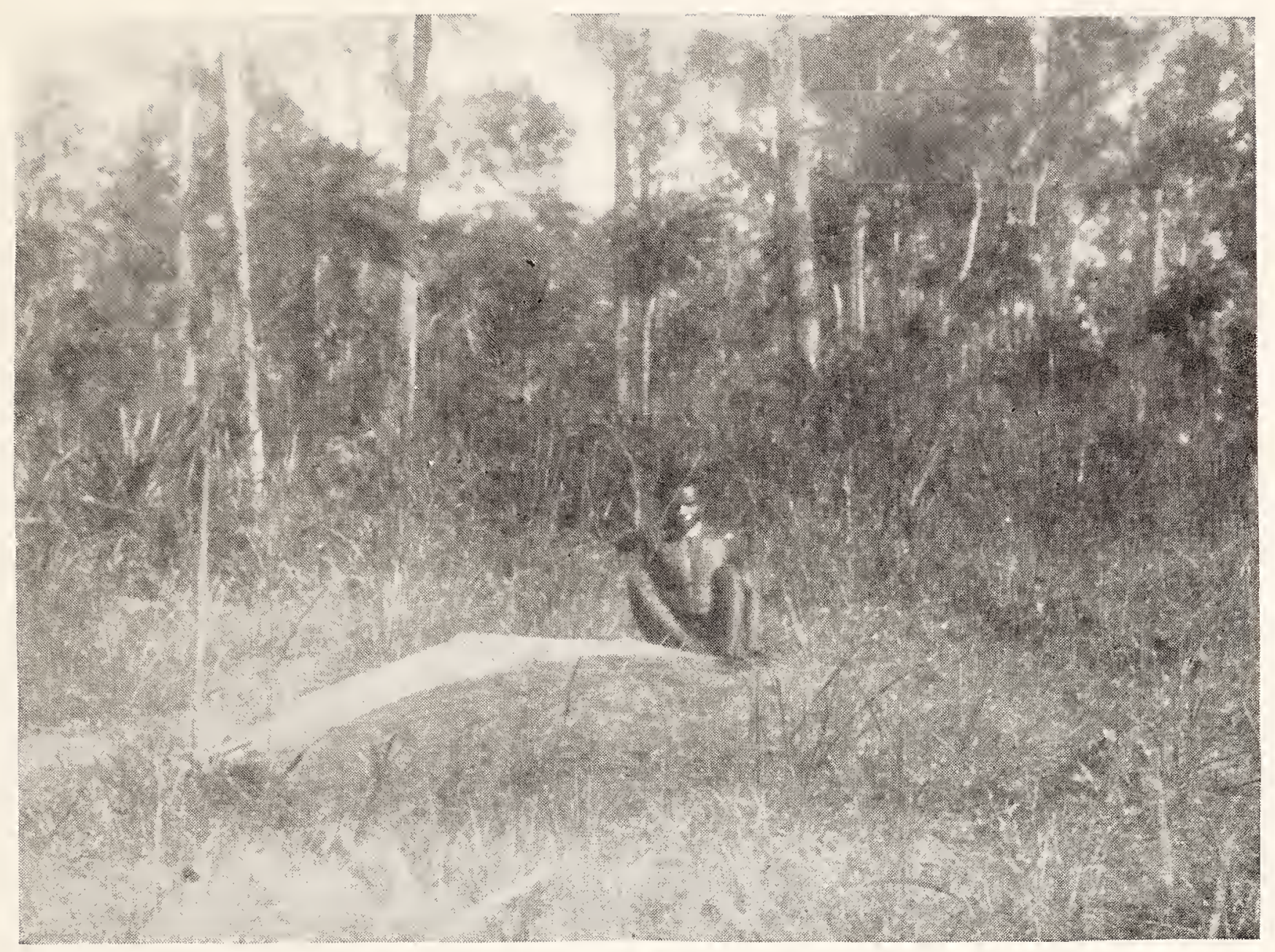

B.S.

FIG. 447.- NEWLY-MADE GRAVE, BEFORE ERECTION OF POSTS.

The mound is covered with a sheet of paper-bark.

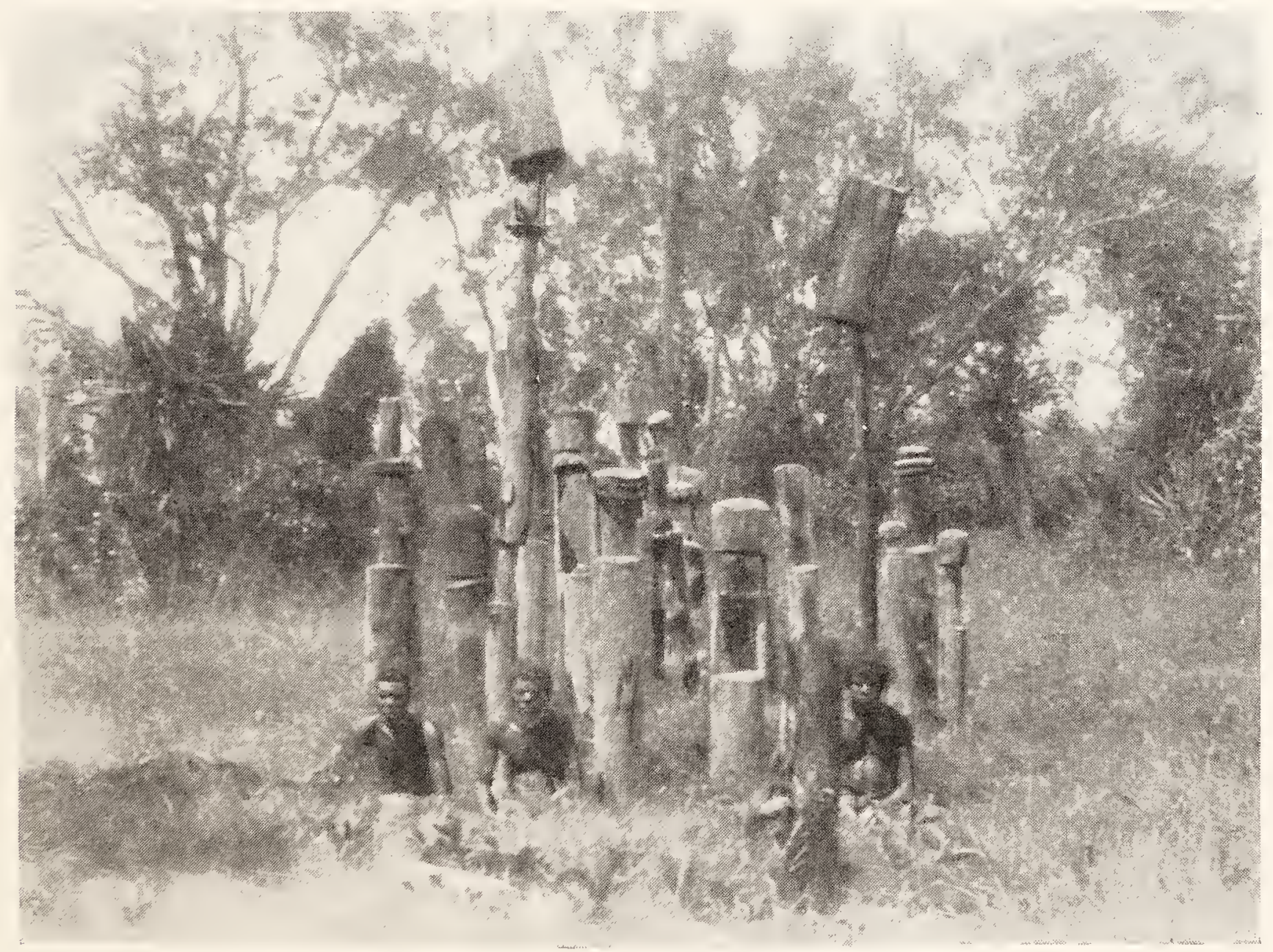

B.S.

FIG. H S.--TWO OLD GRAVES, MELVILLE ISLAND. 


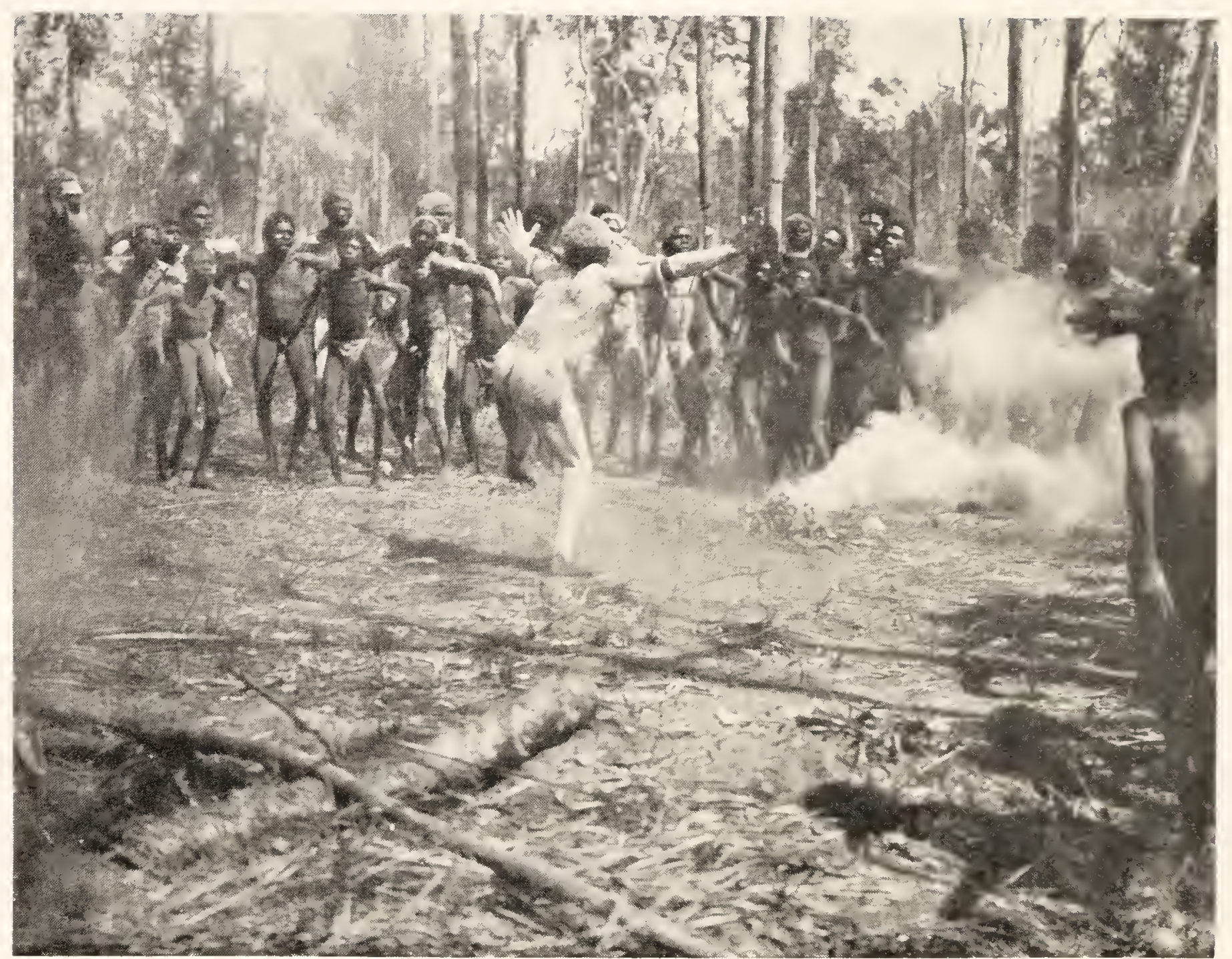

DR. MERYYN HOLMES.

FIG. 449.-DANCE ROUND THE FIRE DURING MOLRNING CEREMIONIES, BATHURST ISLAND. 
round and round the audience of men, who kept time to their movements, striking their buttocks, stamping and singing. Finally, all the men grouped themselves together, ran to the grave and circled round and round it. During one of the dances two men jumped so high into the air that their bent knees were on the level of the shoulders of the other men (Fig. 46I). After a rest, the father came on again and, after dancing round furiously, fell flat down on the ground beside the posts. Four other men came up, armed with short spears, and after peering from side to side in a stealthy way, crept up quietly to where the old man was supposed to be asleep and suddenly pretended to spear him through the chest. He writhed about from side to side while all the men and women danced round. This was supposed to represent the killing of a native by enemies who had crept on him unawares while he slept. Another very weird dance was supposed to represent a fight. All the men came to one side of the grave. Then they began prancing about in the most extraordinary fashion; men on the left would suddenly rush sideways across to the right and vice versa. This over they withdrew to one side and, after a pause, the father with the black and yellow men danced round and round, gesticulating wildly and yelling loudly, whilst time after time they hurled small spears into the grave. Once more the lubras joined in, and then the yellow man performed a prolonged dance with frenzied movements, stamping and yelling, and raising the dust, urged on by the stamping and yelling of the excited natives, who were keenly watching him until, thoroughly played out, he fell down on one side of the grave. Even then the dance was taken up by three others, two rushing round one way and one the other. It was now late in the afternoon, the sun was low and the shafts of light that pierced the scrub threw long shadows from the gum trees and cycads on the weird group of figures dancing wildly in 


\section{WANDERINGS IN WILD AUSTRALIA ch.}

the luminous dust. It was in vain that I tried to secure some records of the scene, but, under the shade of the scrub and gum trees and in the golden light of a tropical evening, my camera was useless.

The sun was setting, but on and on they danced. All that we could make out of the singing were refrains such as

"Ya ya, la we;

Wi, a, we a;

Ia, Ia, Ia," with a final prolonged " $\mathrm{E}$ !"

At length the performance came to an end. All the men took part in a final wild dance round the grave, the women moving slowly round on the outside until, suddenly, the men bent down, yelled at the mound with all their might and ceased dancing (Fig. 462). For a few minutes there was silence, the men gathered round the posts, leaned against them and over the mound, and then, in single file, passed away through the darkening forest.

Apart from the short, final scene, when they were clearly supposed to be mourning, there was not the slightest sign of sorrow. Everyone was very excited, but between the dances they laughed and talked as if they were taking part in an ordinary corrobboree, and evidently the whole ceremony is carried out with the idea of pleasing the spirit of the dead person and, at the same time, of intimating to it the fact that they expect it to remain quiet and not trouble them.

When the performance was over we came back to the camp, shooting a few birds on the way, the skinning of which kept me busy until late.

Fuly I st.-I spent the morning partly in gathering things from the natives. What they liked most, apart from tobacco, was red turkey-twill that they use as a diminutive skirt or loin-cloth. I managed also to get a couple of hours' work with my informants. 'Then we packed our things on the launch and crossed over to Bathurst Island 


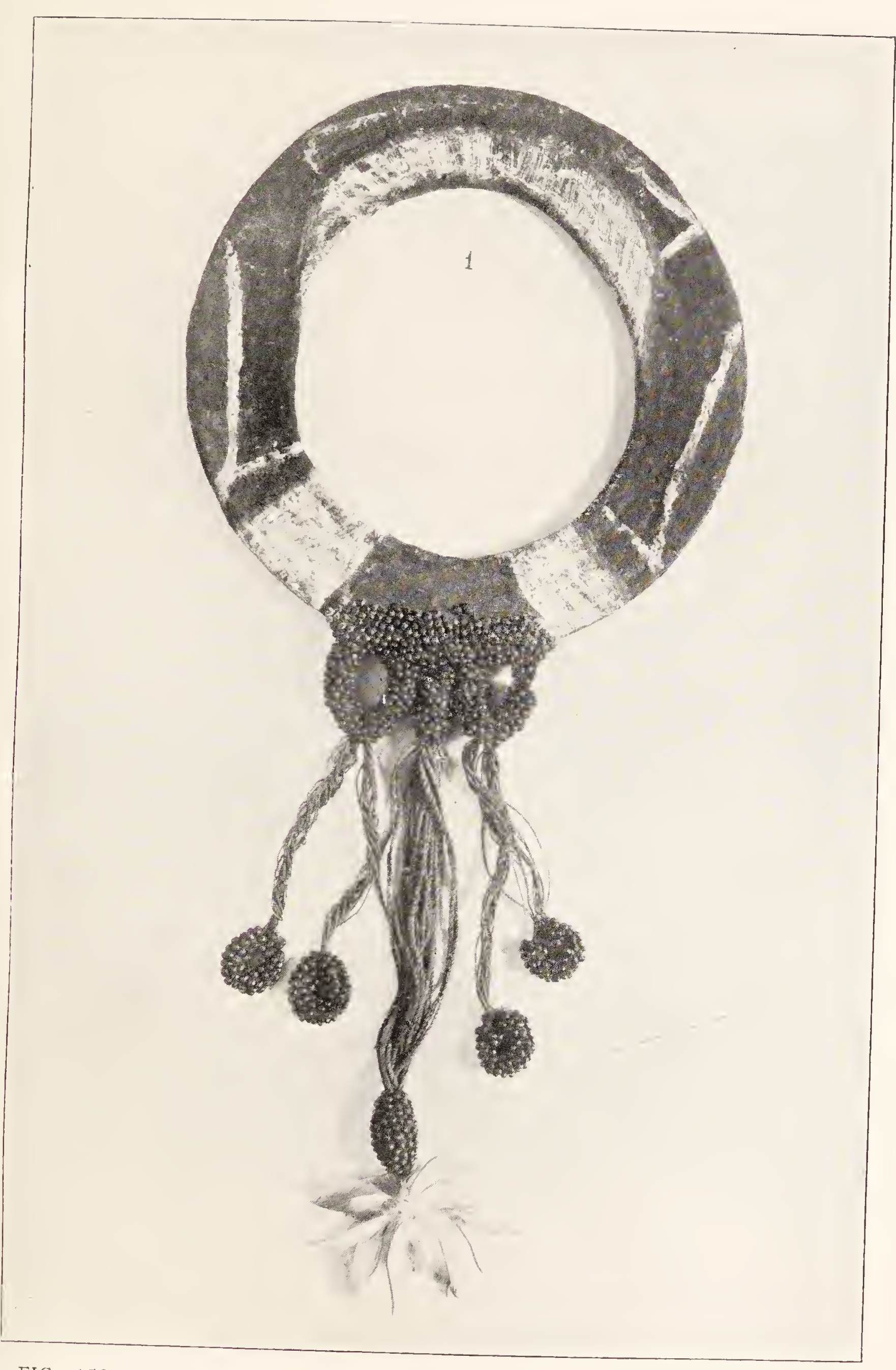

FIG. 450.-RING CARRIEI) BY WOMEN DURING MOURNING CEREMONIES ON MELVILLE ISLAND. 


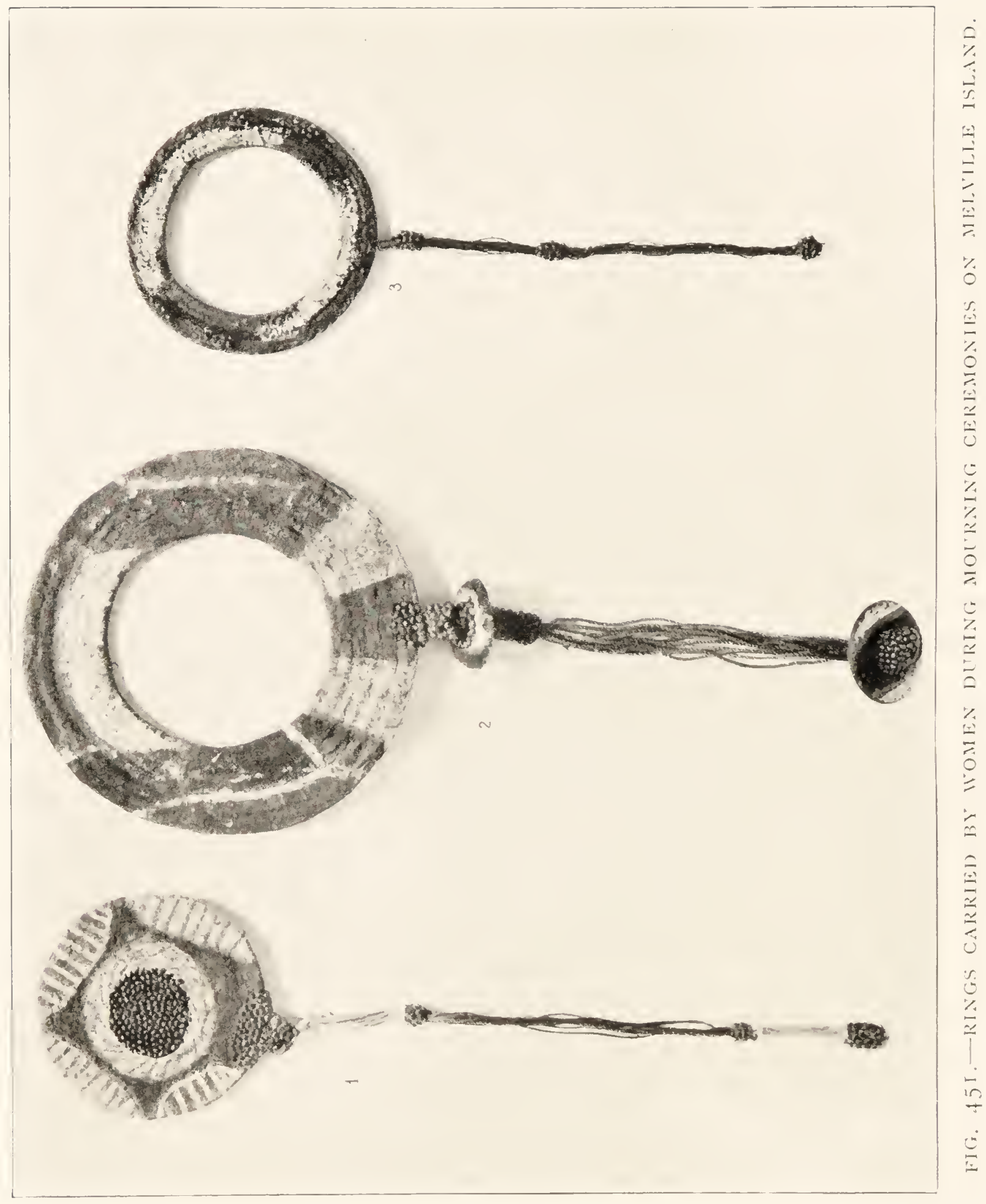


to see the Roman Catholic Mission station which is just being founded under the superintendence of Father Gsell. After two or three hours there we went up Apsley Strait for about ten miles, taking Father Gsell with us, then turned round, landed the Father at his lonely station and started south for Darwin. Just after sunset we lost sight of land and, as there was a good breeze, hoisted the sail and were in Darwin before sunrise.

During the course of the next year I had the opportunity of again visiting Melville Island whilst acting as Chief Protector, and had a most interesting time there, seeing a good deal more than was possible during our short visit in I9I. The following is taken from my notes and diary written then.

March 6th, I9I2.-Cooper came into the office this morning to say that as the weather was improving he intended starting for Melville Island this evening, so I got my things together. They comprised photographic material, including a cinematograph, collecting material for zoological and botanical purposes, and a certain amount of "trade" for use amongst the natives, with whom, through the aid of Cooper, I hope to establish friendly relations on behalf of the Department and to secure from them a number of their very interesting weapons and ceremonial objects that are quite different from any used by the mainland tribes.

My "trade" consisted of I 5 bags of flour, $25 \mathrm{lb}$. of the strongest twist tobacco available, a gross of pipes, 60 yards of turkey-twill, 60 gorgeous handkerchiefs, each a yard square and richly decorated with representations of striking scenes and animals, 24 tomahawks for special occasions, 48 knives, $20 \mathrm{lb}$. of assorted coloured glass beads, I 2 tins of black treacle, $28 \mathrm{lbs}$. of lollies for the piccaninnies, with the secondary aim of gaining the goodwill and personal ornaments of their mothers. These were 


\section{WANDERINGS IN WILD AUSTRALIA сн.}

all stowed away in the hold, forming the only ballast that we carried, and at 9.30 p.m. I went down to the little wharf off which the Buffalo was lying at anchor, tossing up and down as the waves rolled in. It was a two-masted, eightton boat with a jib, a fore and mainsail, a small cabin aft for the skipper, with a horizontal sliding door level with the deck, and a hold forward. By way of cook's galley, there was an ancient kettle that, in calm weather, could be boiled in an extremely primitive fireplace on deck, but was never used during our trip across. Soon after Io p.m. we were under weigh and started off. The wind had freshened and things looked threatening, so much so that we saw two small steamers that left shortly after we did put back to shelter. Cooper, however, decided to go on and therefore, having complete confidence in him, I did the same. We made slow progress, as the strong tide was against us, and before midnight a nasty squall came down. All night long we had alternate squalls with quiet intervals and great seas running; at least they looked great from the deck of our little boat. There was no such thing as sleep and I was not sorry when day broke. All next day we went on, unable to make much progress; in fact instead of heading straight north, as we ought to have done, we were gradually being carried away to the west. The boat was pitching and tossing heavily. Every now and then it rained in torrents and, just after dark, huge banks of black clouds piled themselves up on top of one another until it seemed as if the sky could hold no more. A heavy squall came on and, with it, a perfect deluge of rain, driven fiercely along before the strong wind. We could do nothing save run before it with only the mainsail up. It was decidedly uncomfortable, but, after a time, the storm died down, the clouds rolled away and we had an hour or two's comparative quiet, during which Cooper handed over the tiller to one of his three experienced black boys, who formed 


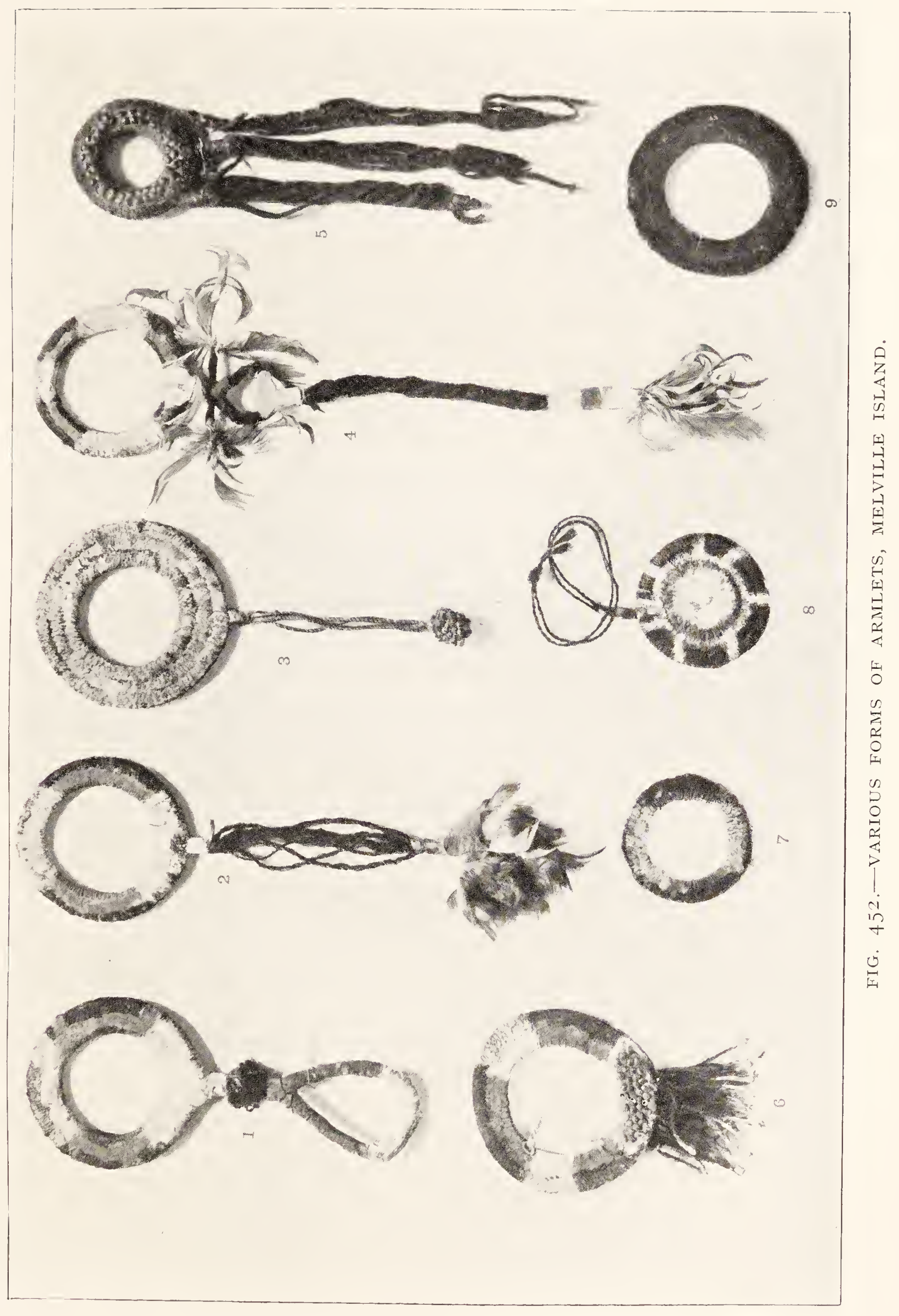




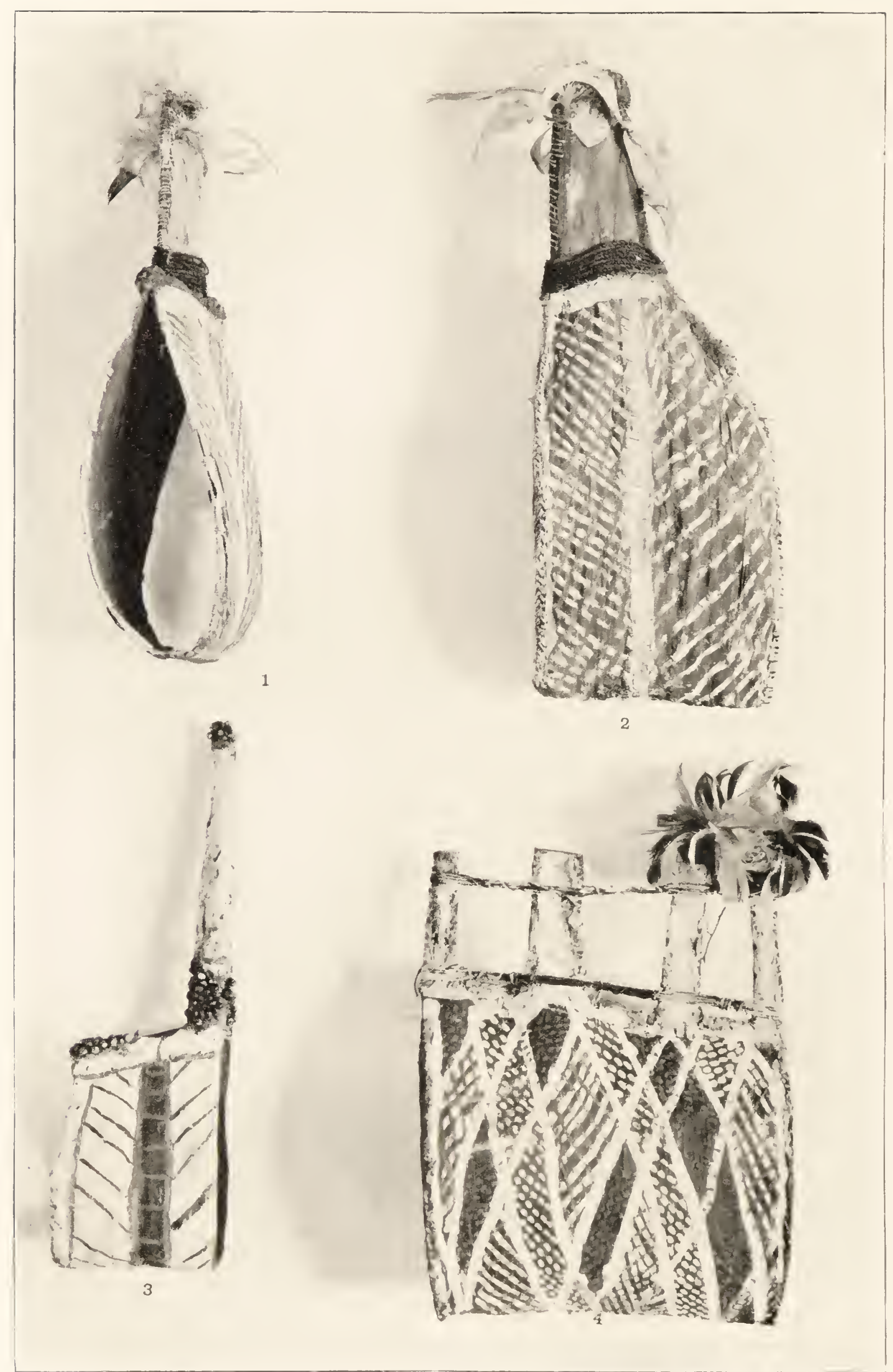

FIG. 453. BARK ARALETS WORA WY WOMEX DLRING MOLRNING CEREATONIES (N MELTLLE ANI) BATHLRST ISIANDS. 
the crew, and had a little rest. At I a.m. another fierce squall suddenly struck us. There was only just time to lower the jib and foresail before we were in the thick of it-blinding rain with a regular gale. It was not pleasant, and Cooper, sitting in the open at the tiller, bare of everything save a pair of dungarees, with his broad, bronzed back showing scars of wounds from native spears that, years ago on Melville Island, had nearly cost him his life, had an anxious time, though he did not show it. I could do nothing but watch and admire his skill and coolness, and it was clear that the native boys had as complete confidence in him as I had. By 2 a.m. it had quieted down. The weather was still thick and we hung around till daybreak, when, to our relief, it began to clear and, after a time, we caught sight of Bathurst Island, some ten miles away, and then knew where we were. Fortunately the squalls kept off until we were under the shelter of the land and then, after constant tacking, Cooper brought us into Apsley Strait, running between Bathurst and Melville Islands, and just at 7 a.m. we came slowly up and anchored off his little settlement on the latter, close to the entrance of the Strait. In favourable weather it takes about ten hours to cross from Darwin, instead of the two nights and a day that we had spent in the Buffalo. It was quite an interesting experience, if only for the opportunity of watching Cooper, and from the deck of a small lugger, only a foot or two above the water level, clouds and waves look far finer and more impressive during a monsoonal storm than they do from a steamer. All the same, I was glad to be safe on shore with the prospect of a meal, because we had only had a few biscuits on the boat. As we came in, the natives gathered on the shore and gave Cooper a very picturesque welcoming dance.

It was high tide when we anchored off a little sandy beach, running up to a bank about six or eight feet high, 


\section{WANDERINGS IN WILD AUSTRALIA сн.}

forming the sea edge of a flat on which his little settlement is built. Elsewhere the Strait, here about a mile broad, is fringed with mangrove trees. The house is a very primitive $\log$ hut, with a roof made of broad slabs of bark, and contains just one large room that serves for everythingdining, sleeping and housing of stores, which indeed occupy most of the space. It looked very much like a picturesque marine store. In the centre, a pole ran up to and supported the roof, with a small rough, board table round its base, on which, seated on boxes, we had our meals. There was no floor save the hard trodden earth. A door in each wall, back and front, opened on to a verandah and admitted light, because, for the sake of safety, there were no windows. Another door at one end served to communicate with the kitchen, that consisted of a little shed two or three yards away, its open end facing to the house, with a great fireplace, above which stretched a strong iron rod, let into the wall at either end, serving for the suspension of cauldrons and billy cans. All day long, men, women and children wandered in and out or squatted on the bed, floor and stores and on a pile of buffalo hides piled up in one corner, watching us with interest while we wrote or had our meals. Dogs, cats and fowls picking up odd scraps, all on good terms with one another, had the free run of the place. It was a most friendly and picturesque community. On the side facing seawards, and not more than twenty yards from the shore, one end of the verandah was enclosed, the end close to the door being left wide open. In this enclosure I took up my abode with my stores piled round me. There was a rough wooden bunk and plenty of fresh air. The ground all round had been cleared, and to one side of it was a group of wooden huts, in which the natives lived. Amongst them were a number of Port Essington men and women who had been brought over by Cooper to act as his body-guard and help in shooting buffaloes. The island 


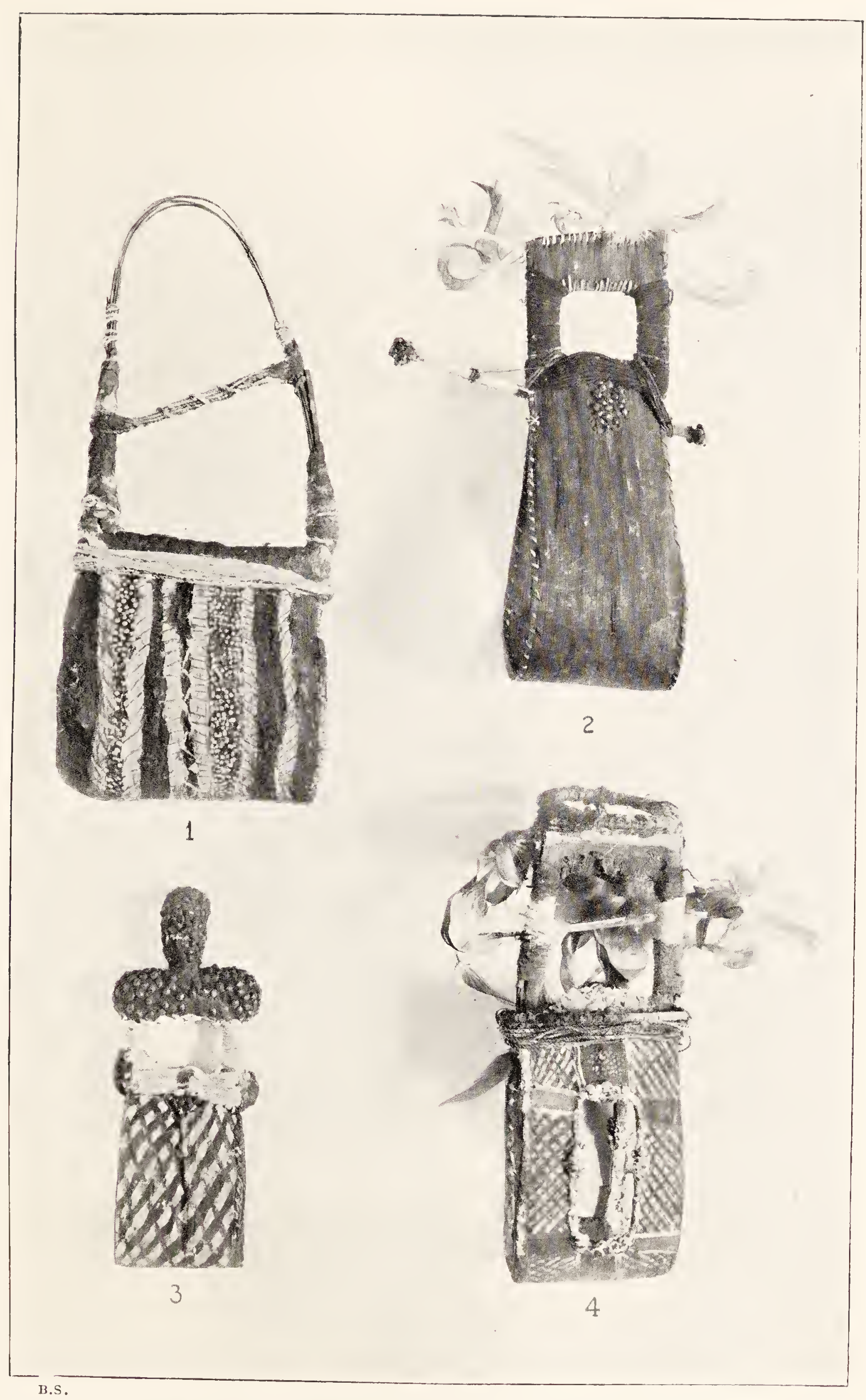

FIG. 454.-BARK ARMLETS WORN BY WOMEN DURING MOURNING CEREMONIES ON MELVILLE AND BATHURST ISLANDS. 


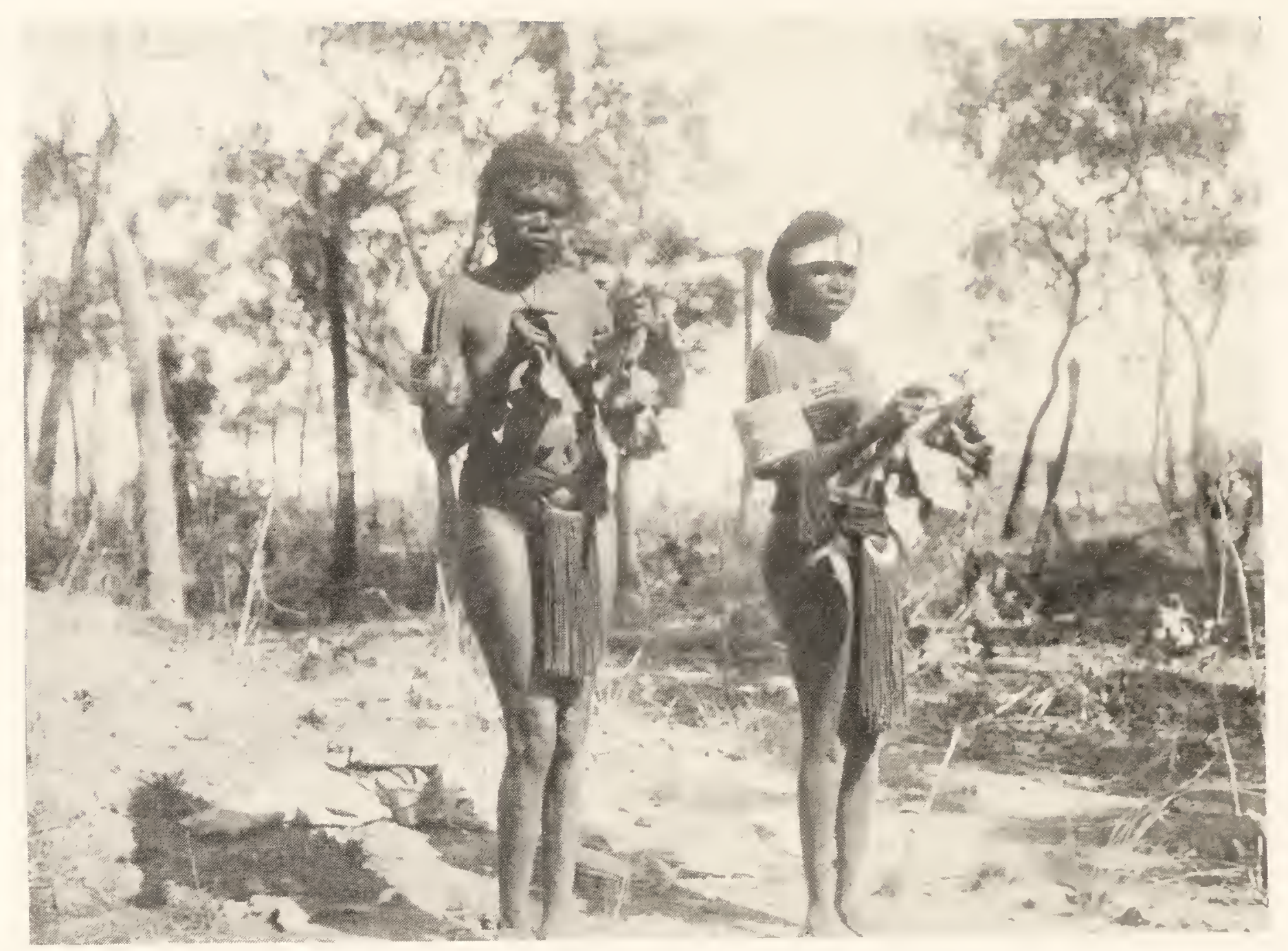

FIG. 455-WOMEN WEARING MOURNING ARMIETS, MELYILLE ISLAND. FRONT VIEW.

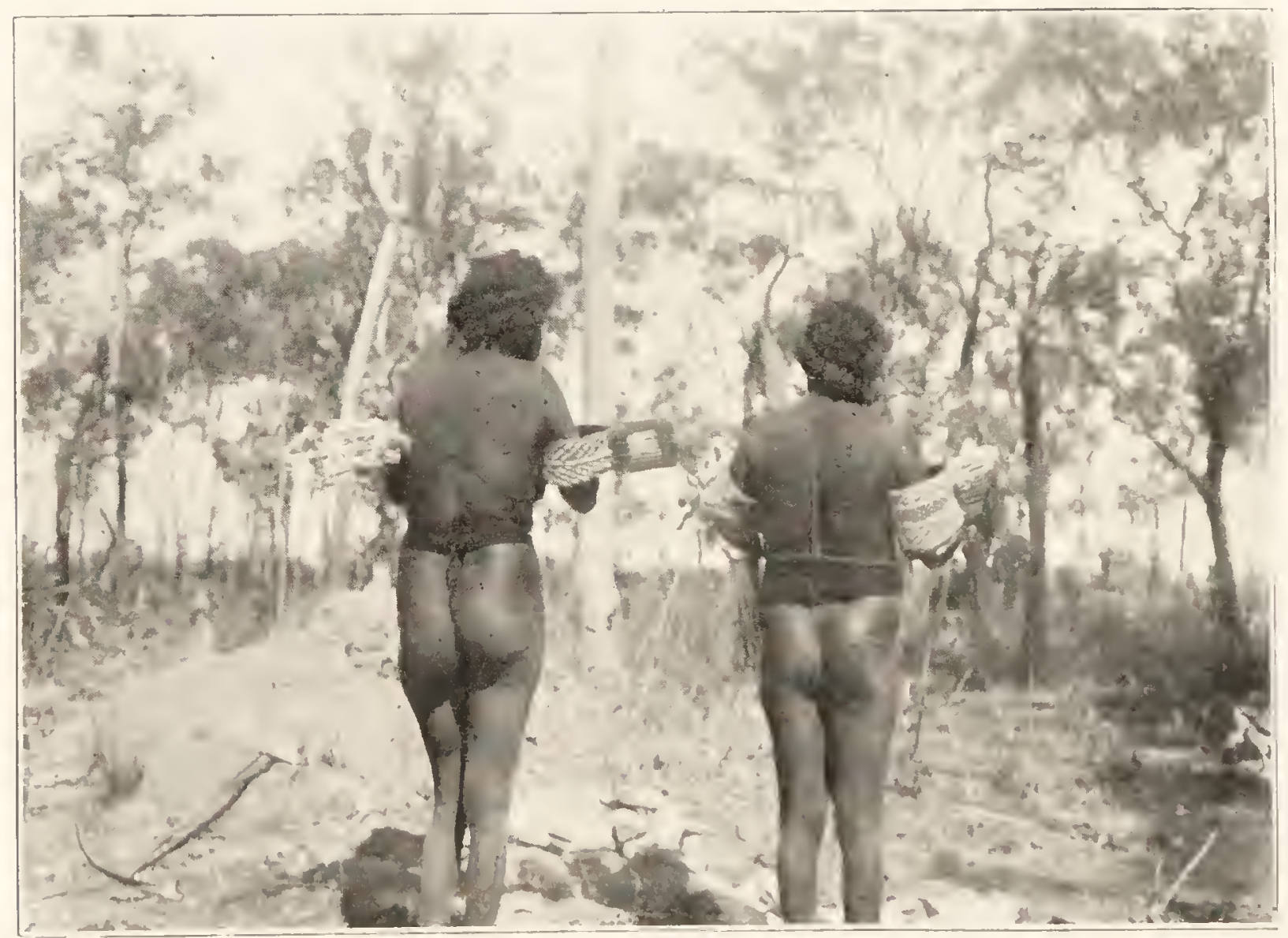

I:16. 450 I.ACK VIEW. 
was actually leased to a well-known Territorian, named Robinson, but Cooper was the active partner, who for years had lived alone there and by whom all the work and the actual buffalo shooting were done. He and Cahill on the east Alligator River, whom I came to know well later on, were renowned as the two great buffalo hunters of the Territory.

As far back as I 886 , Cooper, with his brother, had been working at Malay Bay on the north coast. In 1895 he decided to make an attempt to land on Melville Island. The natives there were well known for their determined hostility to the whites; in fact it was not a little due to the way in which they continually made things uncomfortable for the small military garrison, that found it necessary to entrench itself when it landed on the island, that the early settlement then formed at Fort Dundas was abandoned. Naturally the islanders concluded that their prowess had driven the white men away, and until Cooper with his brother ventured to land they were left alone in possession. On this first attempt Cooper took with him some Malay Bay natives, but it was no use. The Melville Islanders were implacable. They succeeded in spearing him and killing his brother, his own life being only saved by the faithfulness of a Port Essington lubra whom he afterwards married. He was, however, a man of resource, and when he was forced to leave, contrived to take away with him to the mainland four Melville Island natives, two men and two women. Here they remained with him, well treated and became attached to him. He himself and the Port Essington boys learned the Melville Island dialect and, of course, all of them a little English. When he thought the time was favourable he determined to make another attempt. This was in 1905. Reaching the island he sent one of the Melville Islanders on shore to treat with the natives, who were so impressed with what they heard about his treatment 


\section{WANDERINGS IN WILD AUSTRALIA сн.}

of their friends, that they allowed him to land, and there he has stayed ever since, though he takes good care to have his body-guard of Port Essington boys with him when he hunts. He has been practically king of the island, and his Port Essington wife, known to all of us as Alice, has great influence amongst the women, to whom she acts as a kind of mother-in-chief. It is only due to Cooper and his influence that white men have been able to land on the island during recent years, and that the Roman Catholic Mission was originally able to be founded on Bathurst Island, immediately across the Strait from and in view of his settlement. The first night after we arrived it rained in torrents, the wind howled round the house and through the forest, and I was glad to be safe under shelter and not quite so near the water as we were the night before. At nightfall, every evening, the natives went away: the house was closed up and I had the verandah to myself, always keeping a revolver close handy, listening to the breaking of the waves on the shore and the corrobboree songs that the natives in their camps not far away seemed never to grow weary of.

Here with the help of Cooper I settled down to work amongst them for six weeks, and was able to see and learn a good deal of their customs and beliefs.

March 9th, I9I2.-By good luck for me the natives were just beginning one of their initiation ceremonies that are always performed during the wet season. At first we were both quite in the dark as to exactly what they were doing and who were the chief actors, but, with the aid of Cooper, I gradually found this out. Meanwhile all that I could do was to watch and note things down as carefully as possible. The initiation of youths on Melville and Bathurst is intimately associated with what is known as a Yam ceremony. The close relationship that the native believes exists between themselves and one special kind of 


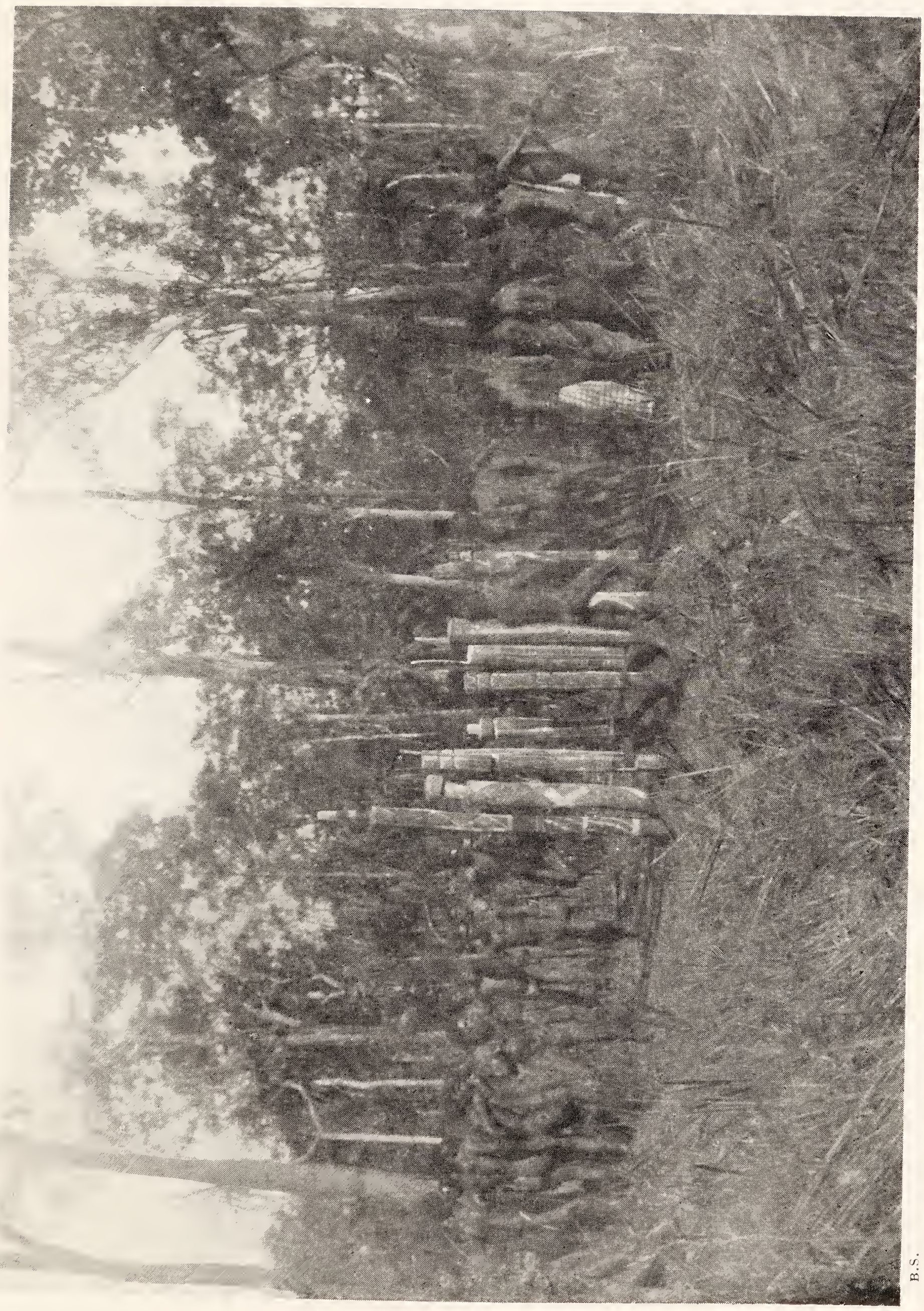

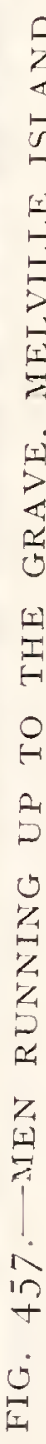




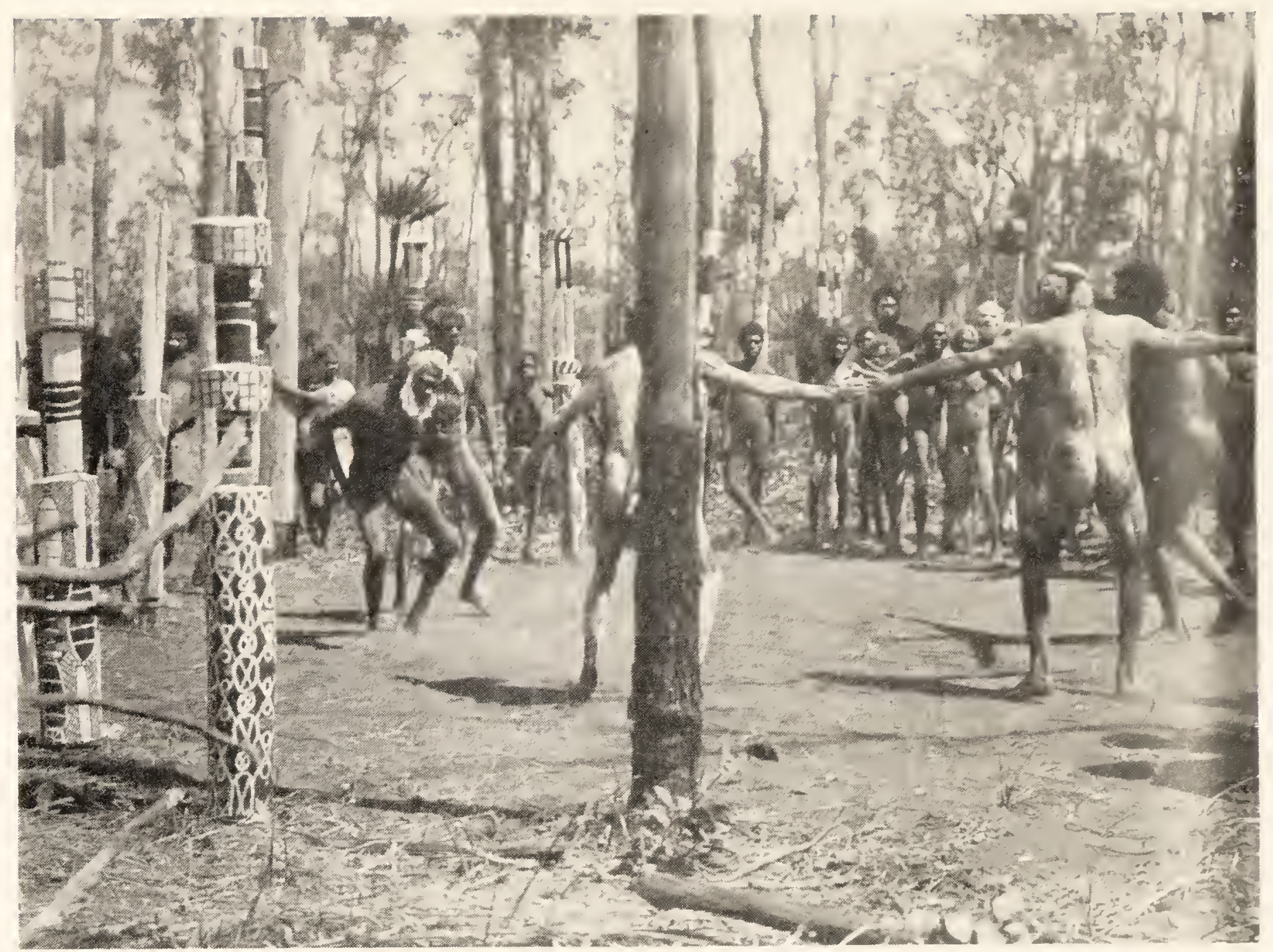

RR, MER'Y

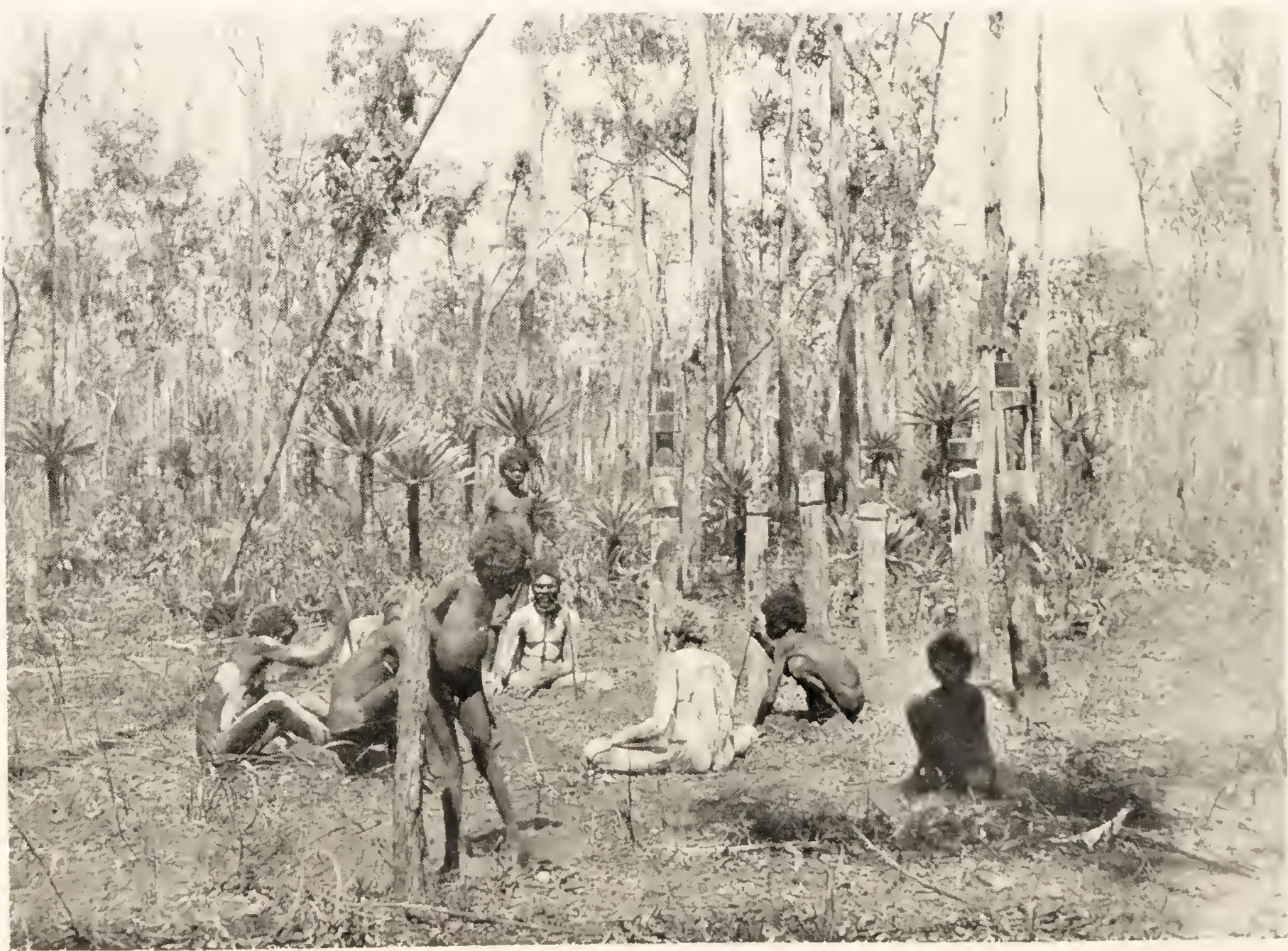


Yam, called Kolamma or Kulemma, can be gauged from the fact that, at one time during the ceremony, the men all unite in shouting out, "Yams, you are our fathers." Curiously, though this particular yam seems to be of special significance, it does not, though eaten, form such an important article of food as certain others. It is almost the size of a large potato and is covered with a number of little roots that look like coarse hairs and are called Itjimma, the same name being applied to the hair on the arms and legs. Whiskers are called Dunimma. The central figure was a youth who appeared to be not more than fourteen or fifteen years old. He was the initiate and was called Watjinyerti, which is a special status term applied to boys at this stage. There was also an older youth who had figured as Watjinyerti at the last initiation ceremony, a year earlier, and was now called Mikinyerti. In addition, there were two younger boys who will attain the status of Watjinyerti next wet season. They were called Marukumana. A very striking feature, quite different from anything amongst mainland tribes, was the definite part played in the performance by certain young girls. One of them, who could not have been more than ten or eleven years old, was called Mikinyertinga. She seemed to correspond amongst the girls to the Watjinyerti amongst the boys, and twice at least during the performance was specially decorated and much in evidence. In addition to her there were three other girls, called Mikijeruma, who, like the Marukumana boys, were passing through the ceremony for the first time. On this occasion the Mikinyerti was the brother of the Mikinyertinga girl's mother, that is, what we should call her maternal uncle, and, consequently, some years older than she was. The Mikinyerti man was one of the younger amongst the initiated men. The Mikinyertinga girl's father had decided that she should go through at this time, because her mother's brother was doing so. 
There were thus three grades of boys and girls who took a special part in the initiation ceremonies.

\author{
Grade I. $\left\{\begin{array}{l}\text { Marukumana, three boys. } \\ \text { Mikijeruma, three girls. }\end{array}\right.$ \\ Grade 2. Watjinyerti, one boy: \\ Grade 2. Mikinyertinga, one girl. \\ Grade 3. Mikinyerti, one young man.
}

There was no woman of the grade of the young Mikinyerti man taking part in the ceremony.

I was up early, but it was too soaking wet to make the bush inviting, so I set to work and got the cinematograph ready. At eight o'clock we heard a loud yelling, not far away, in the main camp and went over to find out what was happening. The little track through the scrub led through pools of water and thick bushes that were dripping wet, so that we were at once soaked through to the skin, in fact this was destined to be our normal state for days.

The men had already been out in the scrub, collecting yams, and the yelling indicated the fact that they had returned to decorate themselves. It took a long time and we waited patiently until it was complete. Their faces were covered with a mixture of whitish clay and bird's down, which was also fixed on the upper part of their bodies so that, in the distance, each of them looked as if he were wearing an ermine cape (Fig. 463). The really old men are allowed to decorate themselves in a most remarkable way that gives them, or at least it did the leader on this occasion, a grotesque, not to say fearsome appearance. For this purpose a tree called " milk-wood" (Alstonia sp.) is tapped. The sap oozes out in the form of a very sticky, white fluid, hence its name. The old man smoothes this on to his beard and whiskers, with the result that, when it sets, his face is framed in a remarkable-looking kind of ruff that stands out stiffly all round. The old leader had pulled out all the hairs on his upper and lower lips. He 


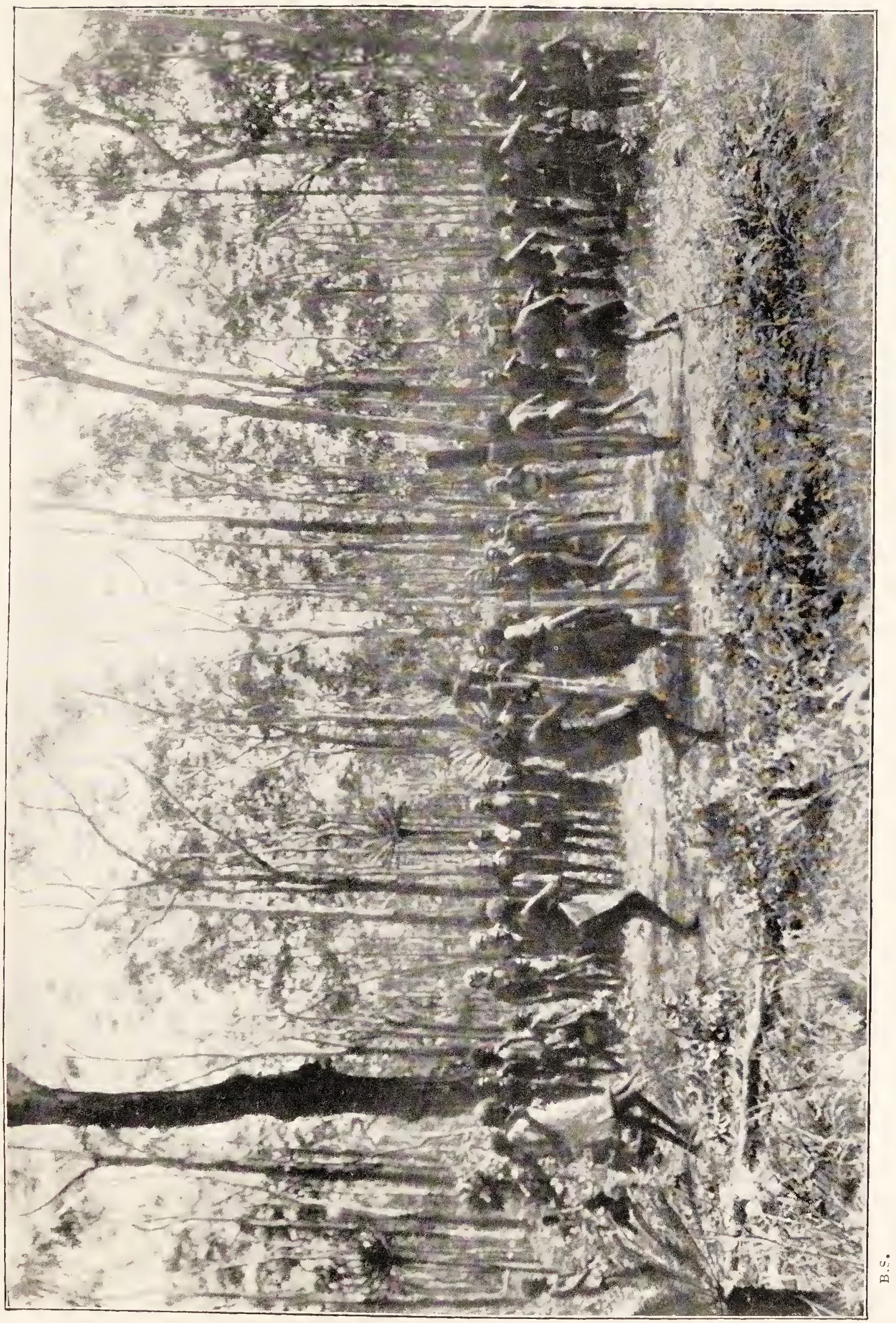

$-6$

(1)

$\pm$ 


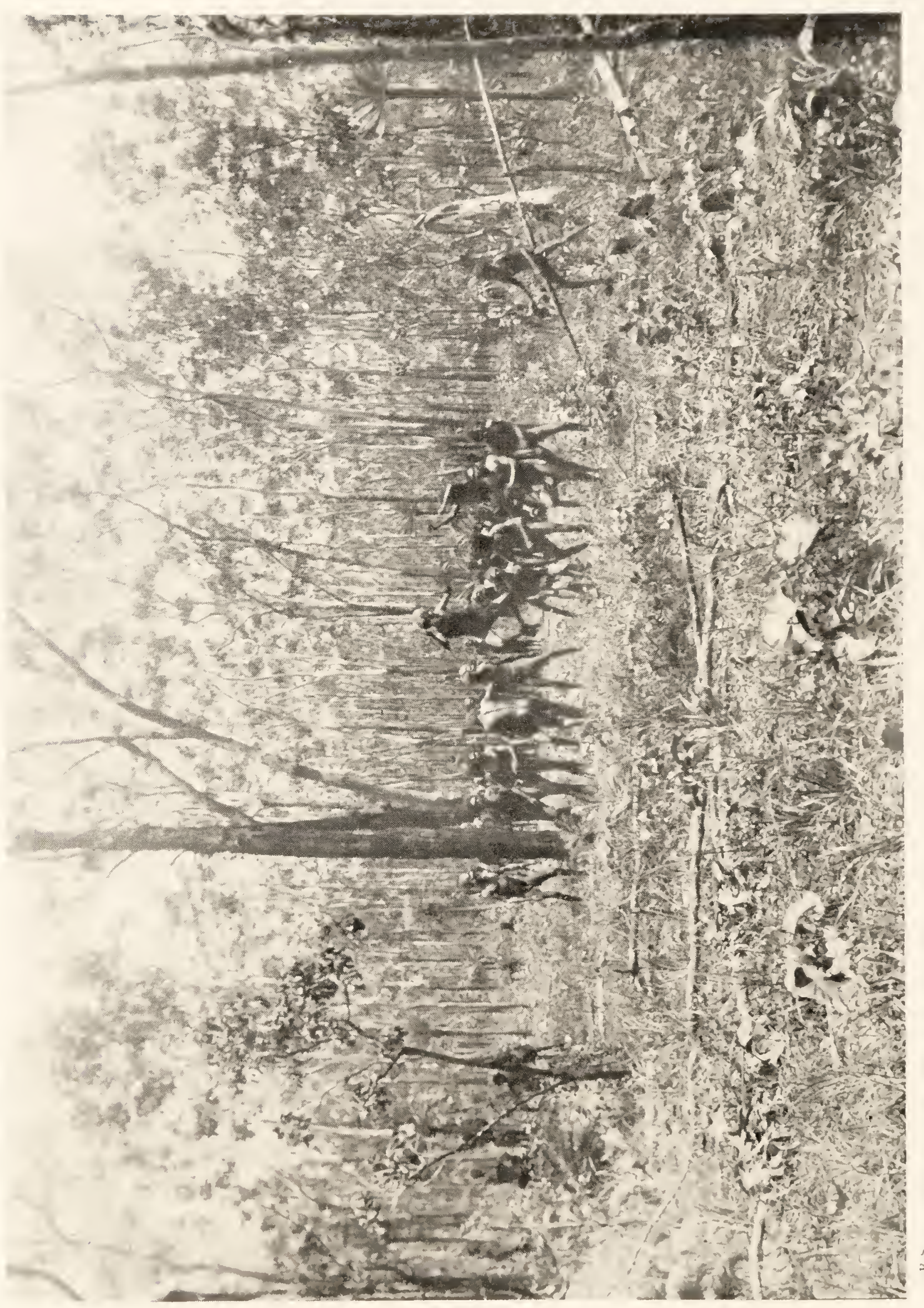


looked just like a cross between the well-known caricatures of Kruger and a patriarchal orang-utan, and was evidently immensely pleased with himself.

It was dull, gloomy and raining hard, and the painting and the singing went on till nearly three o'clock in the afternoon. When all was ready the men, amongst whom was the Mikinyerti, left the main camp and went to a site chosen for the ceremonial ground, all of them brandishing their yam-sticks, called Alluguni, which were really short clubs, used either for digging or throwing, and yelling "Ya, bai, e, e! Ya, bai, e!"

When the women, who were some little distance away in the scrub, and with whom also were the three Marukumana boys and the Watjinyerti, heard the yelling, some of them came up to watch what was being done, but the boys remained behind. Two of the women, one of whom was the mother of one of the Marukumana boys and the other the father's sister, that is, the equivalent of an aunt, of a Mikijeruma girl, had their hair curiously decorated. By means of beeswax it was made up into little balls, each the size of a large pea and all of them coated with yellow ochre, resulting in a striking coiffure. For a time the men stood bunched together, yelling loudly and waving their yamsticks over their heads. Then they suddenly separated, stooped down, plucked up by their roots the tussocks of grass that covered the ceremonial ground and threw them about in all directions, shouting out as they did so "Brr! Brr!" a cry that indicates both defiance and the fact that, in any contest the men who yell it are winning. Then they set to work vigorously with their yam-sticks, and in a very short time had the ground cleared of grass and shrubs and had also piled up earth in a ring, so as to enclose a circular patch of ground, measuring about thirty feet in diameter. While this was in progress the three young Mikijeruma girls ran on to the ground, joined the men for 


\section{WANDERINGS IN WILD AUSTRALIA сн.}

a little while and then ran back to the women. In a very short time there was quite an encampment of roughly-made bark wurleys round the ground, and no attempt of any kind was made to secure privacy. The only thing was that no women or children, except on the above occasion, were allowed to cross the ring, though, from the outside, they were allowed to look on and see everything. In fact everything was done in public and the whole scene, with the decorated men and women wandering about the little bark huts, each with its own fire from which the blue smoke curled up amongst the forest trees and Cycads, was most picturesque (Fig. 464). Unfortunately it rained hard, but this made not the slightest difference to anyone or to the procedure. When a particularly heavy shower fell, they either went into their Mia-mias or sheltered under sheets of stringy-bark, bent double. At this time of the year the bark is easily stripped from the tree and is used for many purposes, either for a house, a boat, a basket or an umbrella. The Mikinyerti youth was with the men, the Watjinyerti boy was kept away in the scrub under the charge of his future wife's brother, and the three Marukumana boys had been sent away into the bush by the old men with instructions as to what they were to do.

When the ground was cleared there was a short pause, and then an old man-it did not apparently matter whorose to his feet and walked round and round, knocking two sticks together (Fig. 465). While doing this everyone adopts the same very characteristic attitude. The performer lifts his left arm above his head so that the hand in which he holds a stick is behind the level of his head. He strikes it with another in his right hand, singing as he does so. This special stick is called Anadaunga. Men often walk round without a stick, and then they always hold the left arm in front of the head, touching the forehead with the forearm, so as to shield the eyes. 


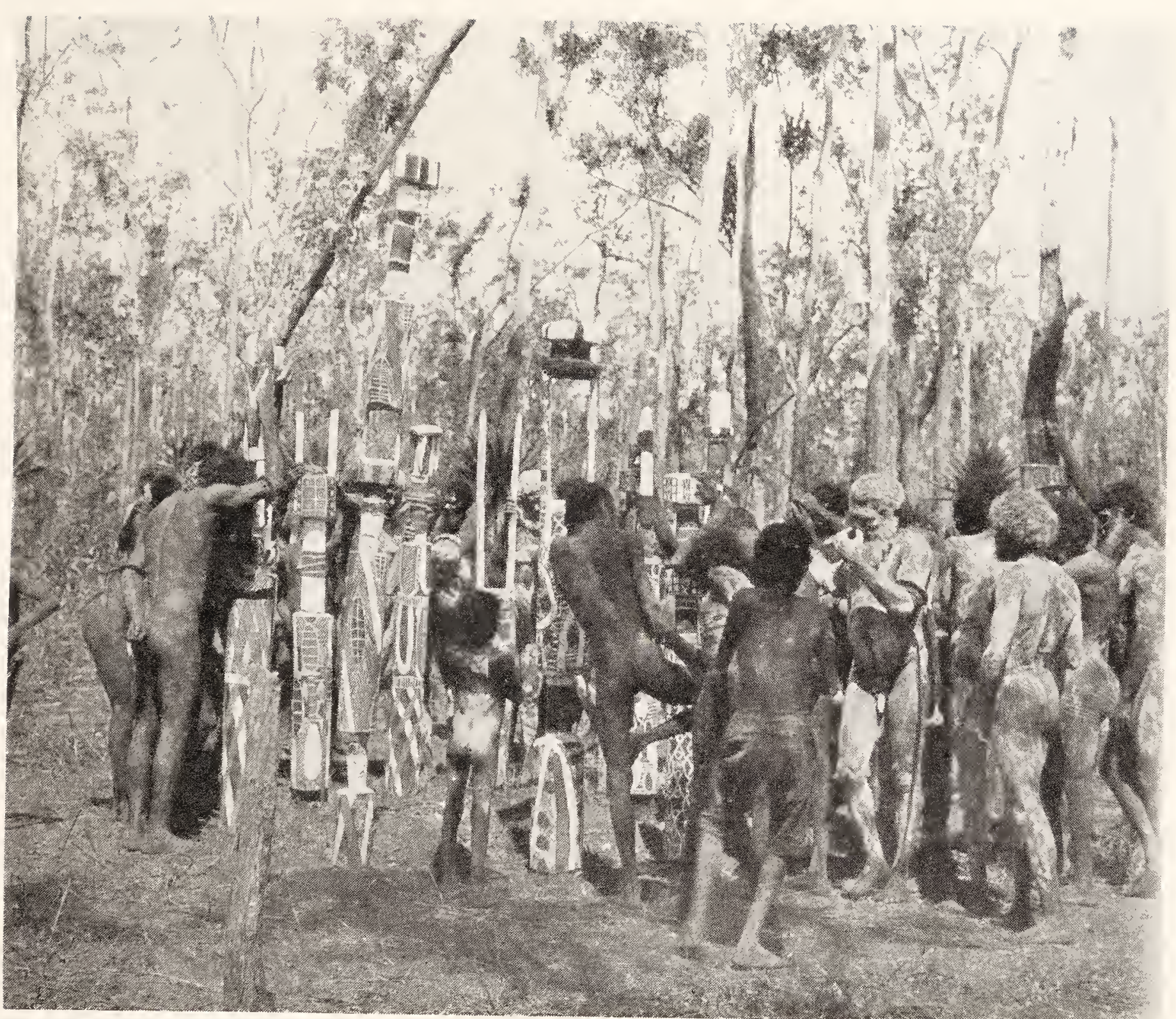

DR. MERYYN HOLMES.

FIG. 462.-CLOSING SCENE AT GRAVE DANCE, BATHURST ISLAND. 


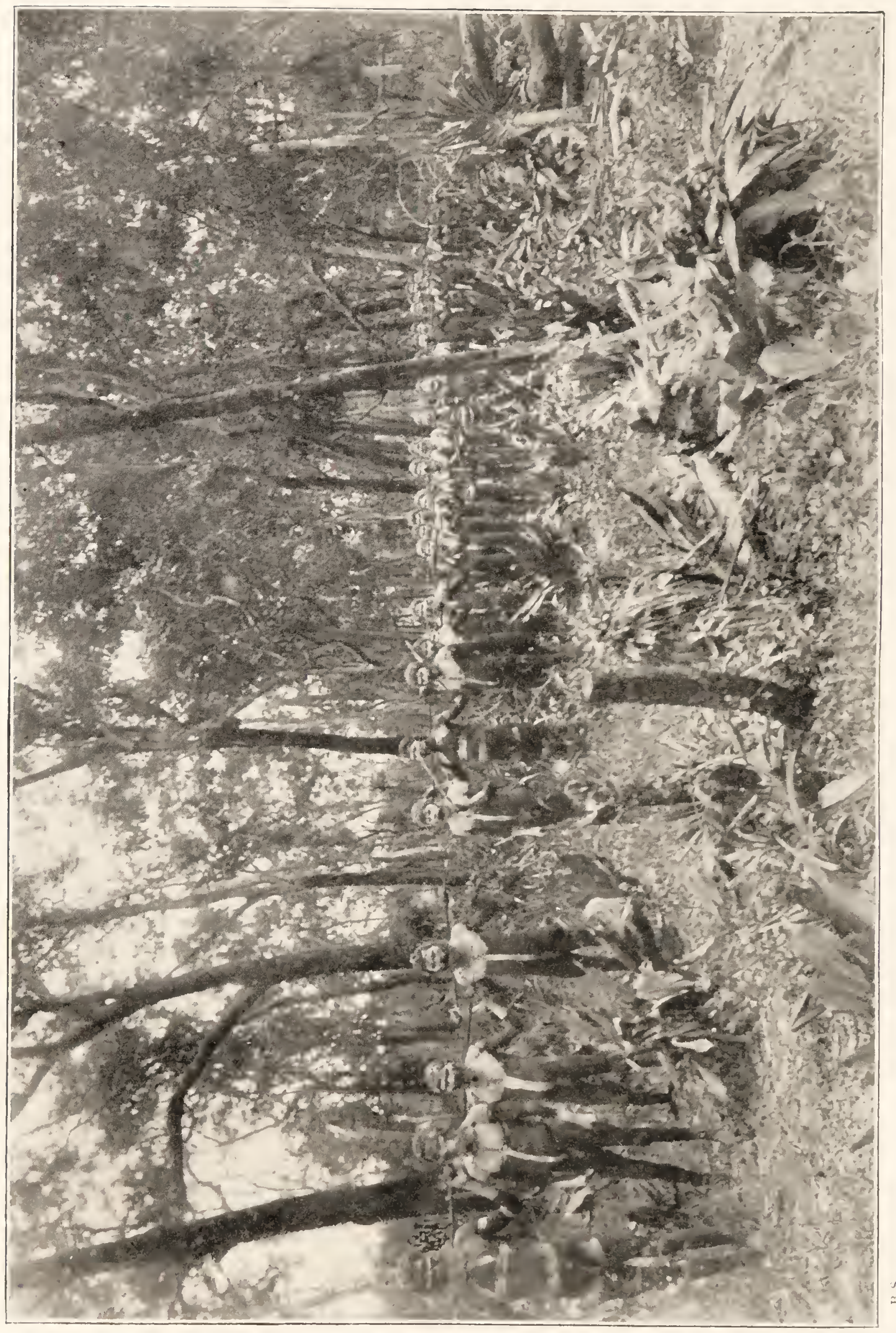


The first performer opened the ceremony by singing of the salt water, then another began and sang about Cooper and his house, saying that Jokuppa, the native rendering of Joe Cooper, was tall but not nearly as tall as his house. Finally all the men were singing of rain, sea, boats, trees, grass and, in fact, of everything that they could think of. Often a man would come to the end of one "song," and whilst evidently thinking of something else to sing, he always kept up a cry of "Ha-ha-ha-er-er-er," the former on a higher and the latter on a lower note.

After the singing had gone on for an hour and a half the Watjinyerti, whose face was all painted black, was brought on to the ground by his guardian and taken to his father. The latter led him up to a man who was the son of the elder brother of the boy's mother, that is, one of what we should call his cousins, called Yauaminni, who decorated him with cane armlets called Bamajinni. The old man then led him round and round the men, who by this time had grouped themselves together in the middle of the ground. The boy's father then linked the boy's right in his own left arm and the two marched round and round, the father telling the son that now that they had put armlets on him he was a Watjinyerti, saying repeatedly, "They can see you like this!" By this time all the women and children were gathered round the ground watching. The lubras sang, repeating what the men said, and every now and then one of the older women sang out telling the boy to follow his father and his Yauaminni. This went on till, late in the afternoon, all the men left the ceremonial ground, the women and children following a short distance behind them. It was rather a strenuous time, because one thing succeeded another in rapid succession, while, balancing a bent sheet of bark over my head, to try to keep the rain off my note-book and camera, I had both to watch what was happening, take occasional 


\section{WANDERINGS IN WILD AUSTRALIA сн.}

snapshots and at the same time note down as much as I could. All the time we were drenched through, but as the day was hot and steamy this did not matter. Cooper, who was not accustomed to such work, was trying, meanwhile, to keep up with my rapid series of questions as to who was who and what was said. I could have done absolutely nothing without him and he stuck to it gallantly, though he told me afterwards that it was the hardest afternoon's work that he had ever put in in his life, and was not anxious to have another of the same kind. He gave me to understand clearly that he would sooner face a hundred wild buffaloes than encounter another ethnologist. It was rather a relief to both of us when they all marched off in single file and there were no more notes to be taken or questions asked for a short space of time.

It was now pouring in torrents and, in parts, the ground was running with water through which we squelched along, pressing our way, drenched to the skin, through the dripping scrub and tall grass. Close to a water pool for which we were bound, a halt was made at a gum tree, around the base of which green boughs were piled. They were pulled aside, and under them we saw the three Marukumana boys crouching. Why they were hidden away there we could not find out. However, after much gesticulating and pretended surprise the party moved on, taking the boys with them, until we reached the pool, through which a stream was now running. The yams were in a little side pool with logs placed on them to prevent them floating away. They were inspected, and then several old men seized the $W$ atjinyerti and plunged into the water with him. As many as could get near enough gripped him by the legs and arms and, yelling, splashing and churning up the mud, which was peculiarly objectionable because it was near to a mangrove swamp, they dragged him backwards and forwards several times. It was like a 


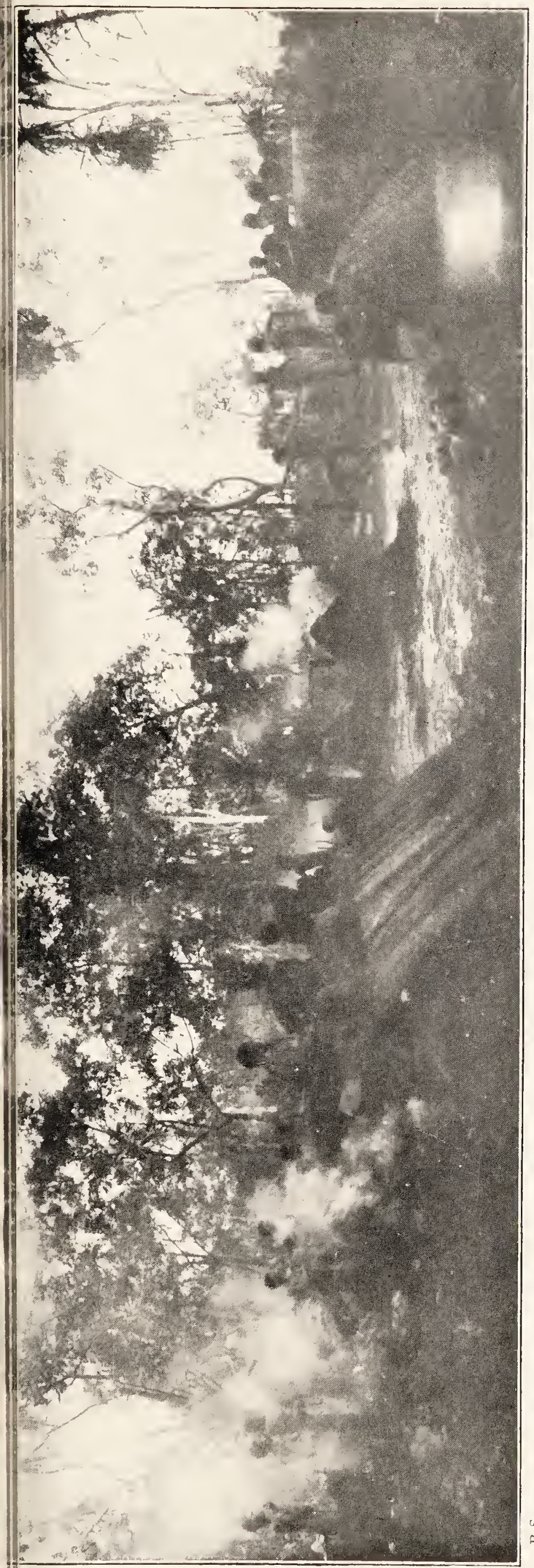

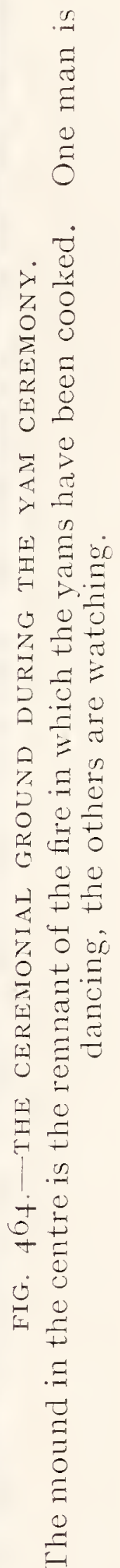

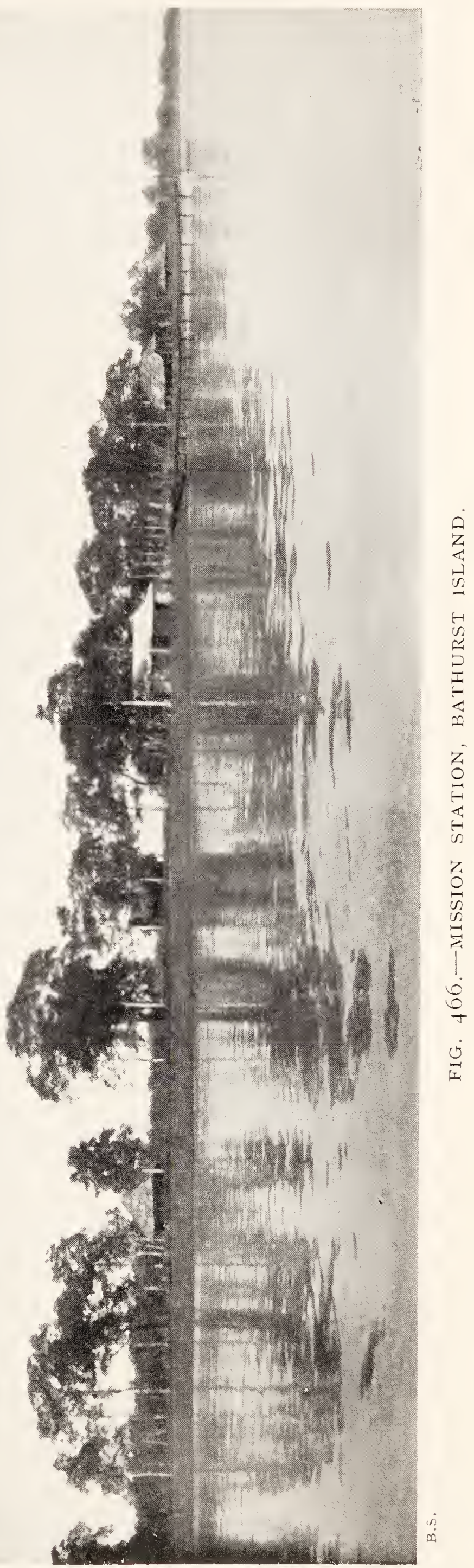




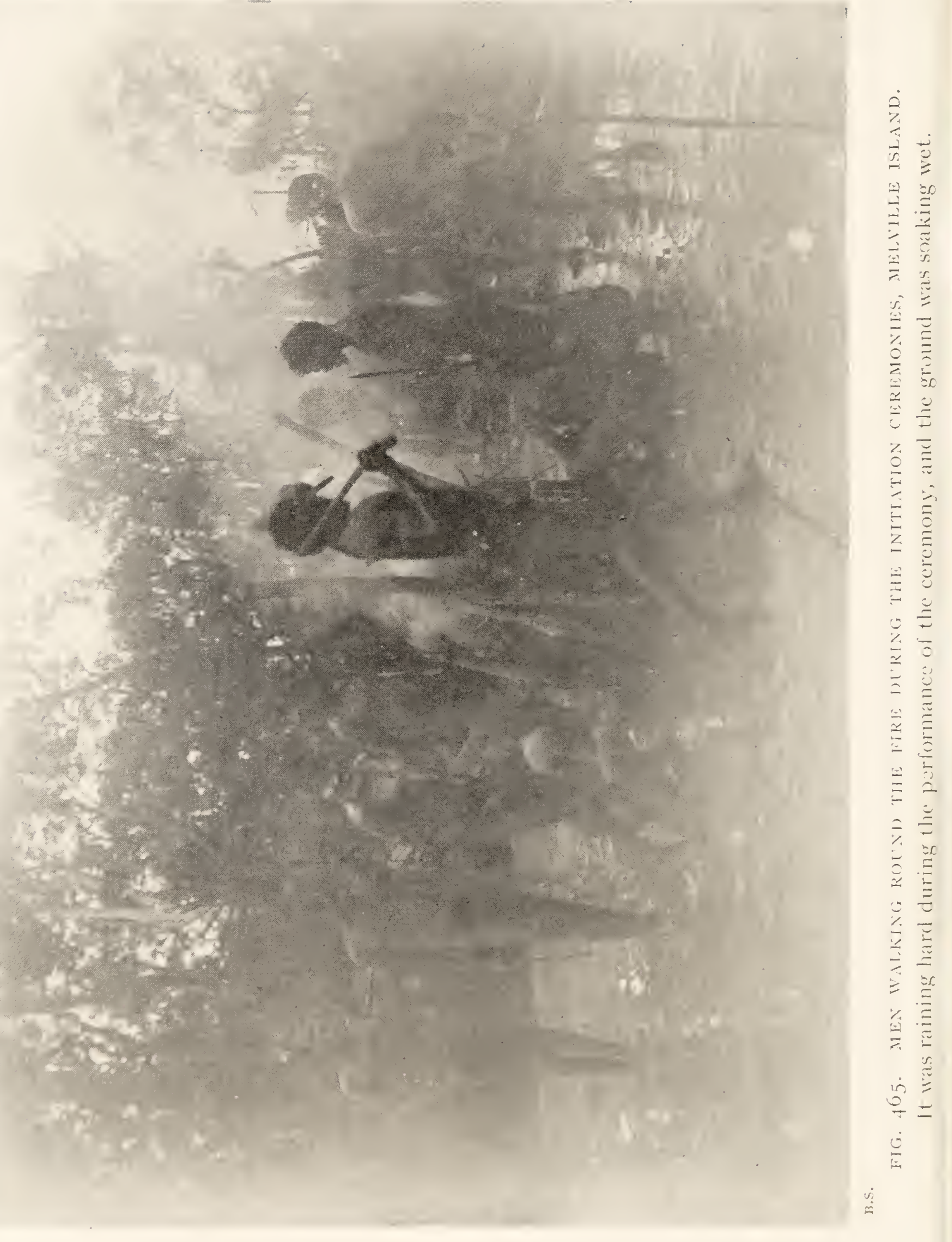


kind of violent baptism by total immersion. After this was over and while he was recovering his breath, four women, two of the boys' mothers and two sisters, jumped in and gave themselves a good ducking in the pool, which was now stinking like a mixture of rotten fish and decaying seaweed.

As soon as the Watjinyerti was released the men turned their attention to the Marukumana boys, who were made to lie down in the small side pool (Fig. 467). Each of them had a bark pitchi, containing a few yams, thrust over his head, and in this uncomfortable state he was held under the water, which was abominably muddy, for quite half a minute. As the yam had "whiskers," their close association with the heads of the boys was supposed to be efficacious in stimulating the growth of hair on their faces. The boys were then taken out and made to stand up, and, to assist further in the growth, each one had his skin rubbed with a hairy yam and then bitten freely by any older man who chose to do so. When it was all over they were very sore and uncomfortable, and, to add to their discomfort, they were taken away by a few of the older men to the mangrove swamp close by to have their chins rubbed with the evilsmelling mud. With the exception of this little group, we all went back at once to the camp, walking in single file. As it was hot and very humid, I rather envied the natives, who had no clothes to get wet through and no boots for the water to squelch in and out of. The women went to their Mia-mias or stood round watching the men, who, with the Mikinyerti and Watjinyerti, gathered on the ceremonial ground, dancing about and clanging their sticks, repeating time after time, "We have been to the water and washed." The only real washing that took place was in the dripping scrub, but, happily, this was quite effective and most welcome, because it was an evil-smelling crowd that left the dripping pool. 


\section{WANDERINGS IN WILD AUSTRALIA сн.}

By and by the Marukumana boys came up from the swamp and were put into a little Mia-mia just outside the ring. The Watjinyerti had another, all to himself, from which he could watch the men who began to perform dances and listen to the singing that went on all night long.

March Ioth.-From my bunk on the verandah I could hear everything, and a little before 6 a.m. there was a stirring in the camp, so I went over and found them starting to build a special fire in the middle of the ceremonial ground. It was dull and raining hard at intervals, so we were all soon wet through again. They took a number of stakes, from five to seven feet high, and fixed them upright in the ground so that they formed a circle about four feet in diameter (Fig. 469). Within this they piled up wood to the height of four feet, and then on the top of this placed a thick layer of pounded-up white-ant hill. We could not find out what this meant. Then for an hour they danced round and round it, "singing" it, but did not attempt to light the fire. The women and children watched them all the time. Soon after seven o'clock the men, taking the Watjinyerti and Mikinyerti with them, left the ground and, in single file, started off for the pool, the women this time remaining behind to take care of the Marukumana boys. Nothing special took place at the pool. The yams were taken out of the water and carried back by the Mikinyerti and Watjinyerti and then placed in two heaps, one on either side of the fire, covered with long grass stalks that were cut on the way back to camp. This is always done, but the natives do not know why. The fire was then lighted by the Mikinyerti, Watjinyerti, the Mikinyerti's father and the Mikinyertinga girl, who was summoned on to the ground for this purpose. It took them a long time, because everything was soaking wet and pools of water were lying about on the ceremonial ground. The men meanwhile danced round in the mud. The Watjinyerti had gone to 


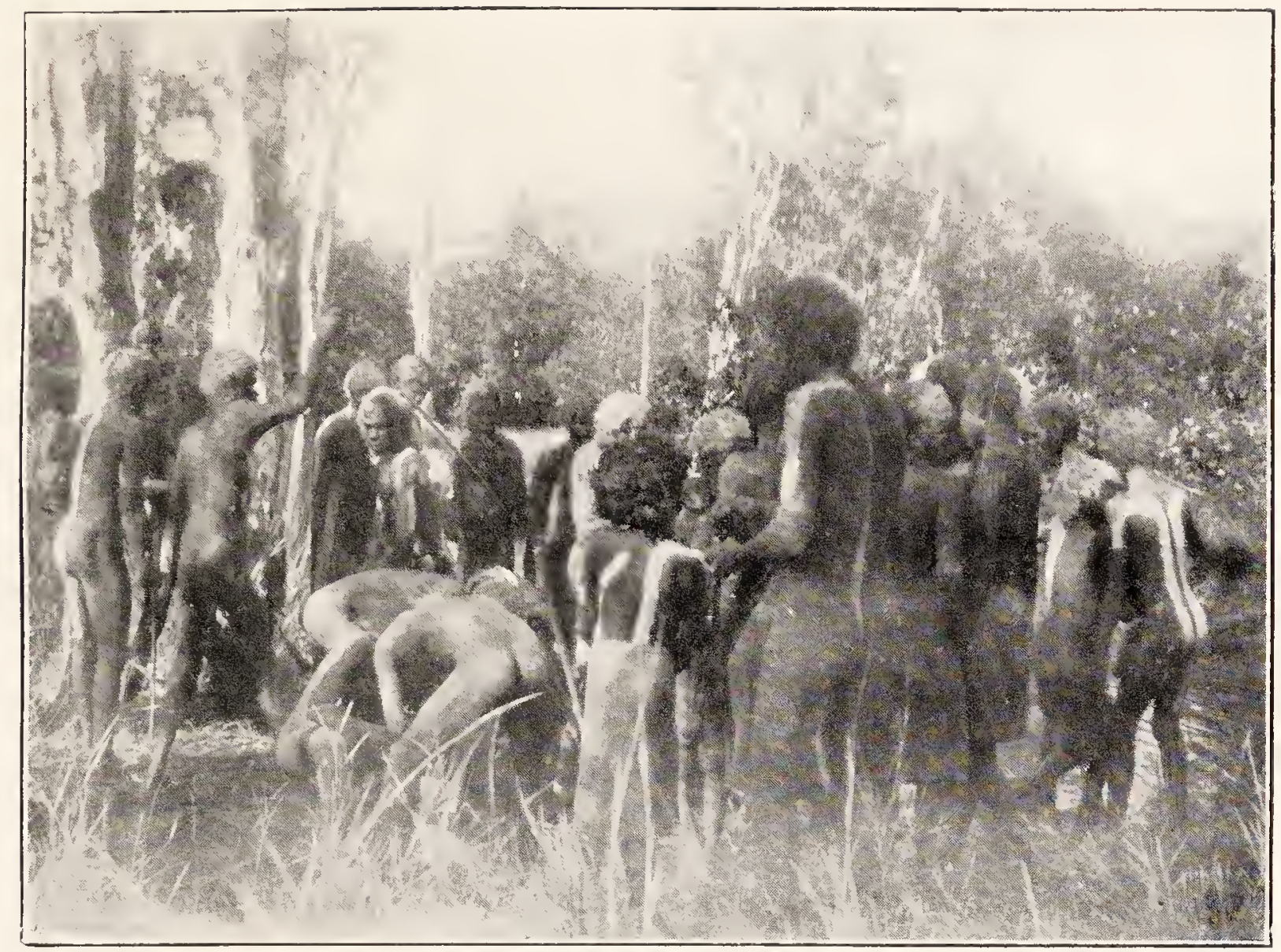

B.S

- FIG. 467.- THE THREE IIEN BENDING DOWN ARE HOLDING THE MARUKUMANA BOYS' HEADS IN BASKETS UNDER THE WATER.

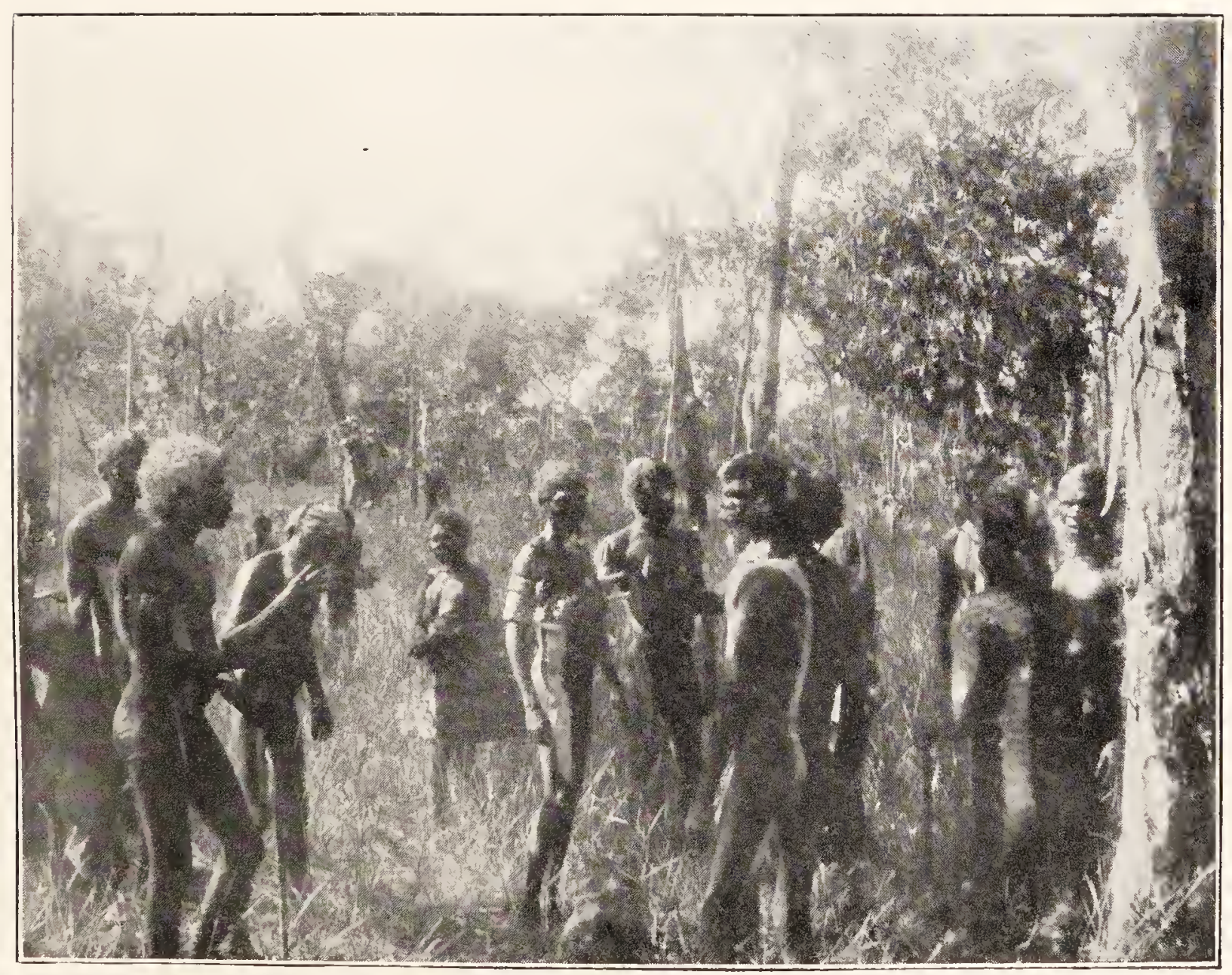

R.S.

FIG. 468. - MEN PULLING THEIR BEARDS OUT. THE OLD MAN ON THE LETT-IIANI) SIIE IS IN THE ACT OF PULLING, MELVILLE ISLAND. 


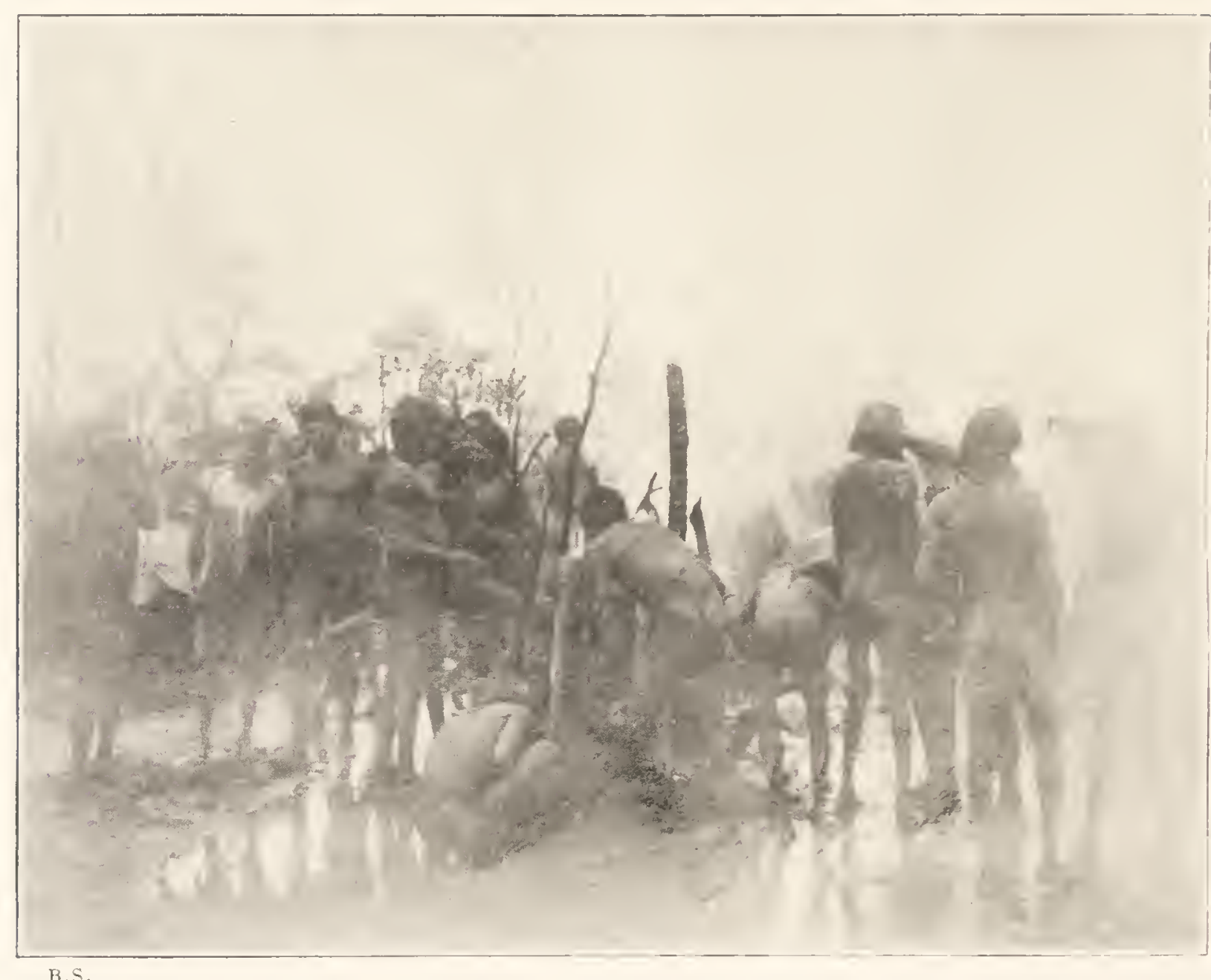

FIG. 469.-BUILDING A SPECIAL FIRE ON THE CEREMIONIAL GROTND TO ROAST THE YAMS, MELVILLE ISLAND.

It will be noticed that the ground is soaking wet.

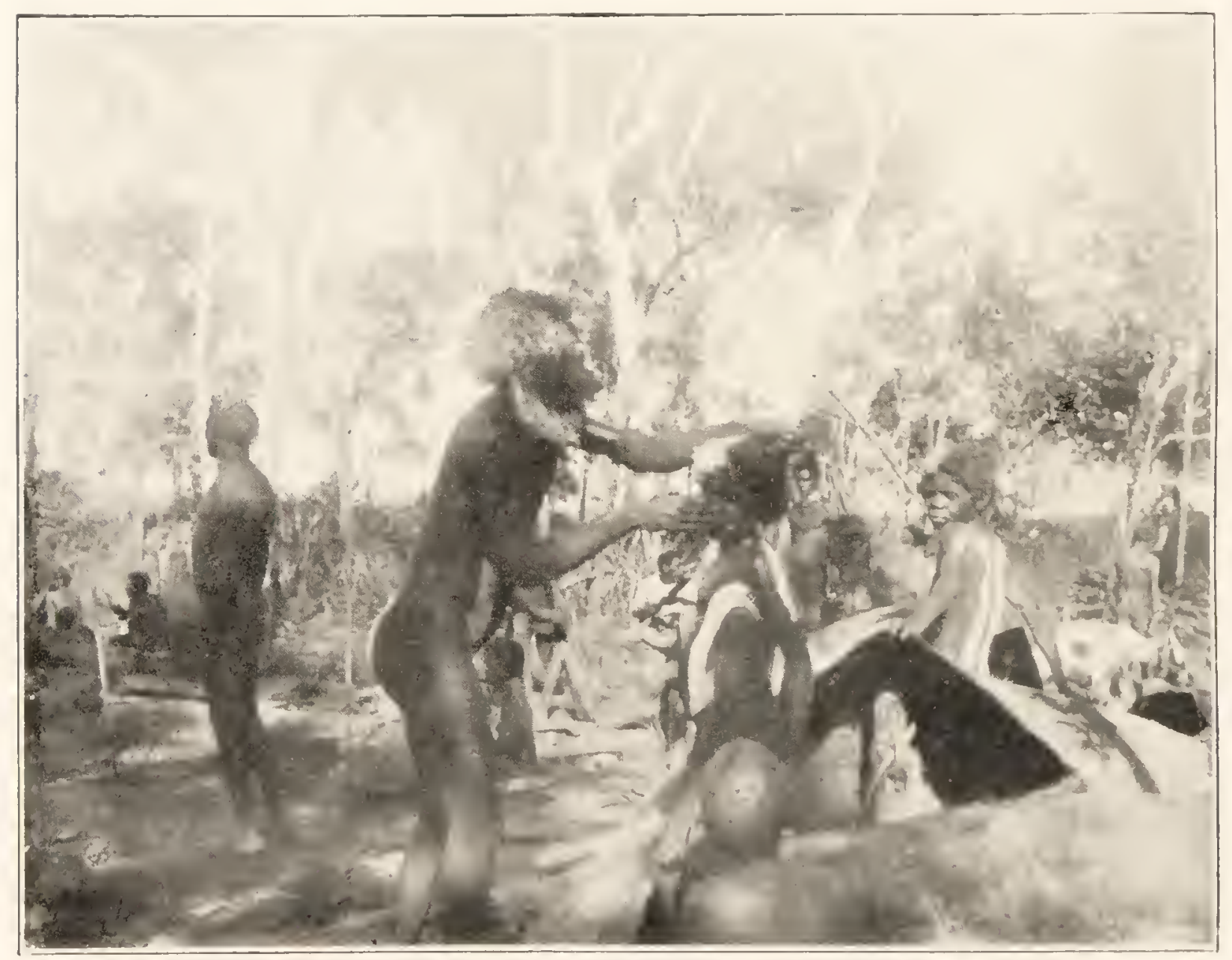

B.S.

HIG. 4TO.- FATHER PAINTING THE MIKINYERTINGA GIRL,

MELYILLE ISLAND. 
his Mia-mia. The singing went on. Once, the father took the Mikinyertinga girl by the left hand and led her round several times. The fire was burning, but for more than an hour nothing was done to it or to the yams. The Watjinyerti was surrounded by a few men who pulled out all his pubic hairs and also those on his upper lip and chin. While this went on the performers sang, "Too bad, pull out hairs," which was repeated by one woman who was the daughter of the brother of the Watjinyerti's mother, that is, a girl whom we should call his cousin. This repeating by the women of what the men said and sang was a striking feature and went on all through the ceremony. Meanwhile the main body of men kept marching round and round the fire, striking their buttocks and singing fiercely at intervals. At the end of about an hour the men went to the fire and drew out lighted sticks, which they threw away, first facing towards the north and then the south. Then once more they sang, the women outside the circle joining in. Taking small boughs the men surrounded the fire and beat it down from above, the idea of this being to cleanse it of all evil influence-if this were not done they believe that the evil would go inside them and sores would break out all over them. While doing this, they yelled "Brr! Brr! Brr! ee! ee!" The fire was then smoothed down and a rope, made out of some of the grass stalks, was twisted round it to prevent, so the men said, the yams from tumbling out. The rest of the grass was placed on the embers and the yams put on top. Sheets of paper-bark were spread over them and these, in turn, were covered with damp earth, dug up with yamsticks. No woman handled the yams or touched the fire. Every now and again the men knelt up and threw their bodies and arms back, while the onlookers yelled out a specially loud "Brr! Brr!" and struck their buttocks fiercely. Then there came a quiet pause, and, as it was 


\section{WANDERINGS IN WILD AUSTRALIA сн.}

eleven o'clock, we took advantage of the spell to have a little breakfast.

We were soon back again, and after a short time one man came out and performed a special shark dance, the audience singing and beating time. Then one old man, who took the lead and was always in front of the procession, walked slowly round and round the fire singing of yams and grass. Every now and then he went outside the ceremonial ground and, with both arms held up, told the women what to sing. It was just as if a wild hymn were being sung and the verses given out one by one. The three Marukumana boys and the Watjinyerti stayed in their Mia-mias, and the singing went on for another two hours until the yams were cooked. The men then sat round the fire, which was pulled to pieces and the yams raked out. The four young girls, that is, the Mikinyertinga and the three Mikijeruma, and two old women, the mother and father's sister of the Watjinyerti, were called up and given yams to skin. Any man was allowed to do this and also the Watjinyerti. The little Mikinyertinga girl, after skinning hers, handed them to her father. After being skinned the yams were cut up into slices with sharp shells, an operation that occupied a long time. It was done on the ceremonial ground and, all the time it was in progress, one or other of the men was walking round, striking sticks together while others chanted. 'Time after time the men sang, "Yams, you are our fathers." The natives said that after this all kinds of yams would grow plentifully. They also said that if a boy sees this ceremony and does not do what he is told to do by the old men when he is being initiated, he becomes very ill and dies. The Kolamma, perhaps because it is very "hot" and has to be specially treated before being eaten, is regarded as a superior kind of yam, endowed with properties that others do not possess.

The father of the Mikinyerting girl took some slices of 
yam in his hand and the daughter passed water over them from a palm-leaf basket, after which the man rubbed the daughter's hair with them, in order to make it grow. This over, the four girls left the ground. Then the men crunched up some of the slices in their hands and rubbed their own beards with them. The sister of the father of the Mikinyertinga and the mother of the Watjinyerti rubbed each other's heads and faces with yam slices, and then a general decoration of men and women began. The Watjinyerti was painted by one of his mother's elder brother's sons, that is, a cousin, and had his hair, a band across his nose and a band down each cheek coloured white. His armlets were red-ochred afresh. The Mikinyerti youth had his hair, a band across his nose and such beard and whiskers as he possessed painted yellow. The three Marukumana boys had their faces blackened. As soon as the slicing was over, a small Mia-mia, made of sheets of bark and gumtree boughs, was built close beside the remains of the fire, and into this the men put the Watjinyerti and the Marukumana boys, in order, so the natives said, that the women could not see them. This Mia-mia is called Malanni, the usual term for one being Irruwunni.

While the boys were thus hidden, the painting went on, one or two of the old yam men keeping up a continuous chant referring to the yams and grass. The father painted the Mikinyertinga girl's face all over with yellow (Fig. 470), and another girl had one side of her head painted white by her mother, the other yellow; above one eye she had a white line, and below, a yellow one, and vice versa on the other side. If, as was often the case, both white and yellow were used, the right side was always white, the left yellow. The old leader had one side of his hair white, the other yellow; the whole of his face was red, save for a yellow band across the forehead, just above the eyes, and a white band from ear to ear, across the bridge of the nose. 


\section{WANDERINGS IN WILD AUSTRALIA сн.}

His upper and lower lips were clean shaved, but a strong fringe of beard was made to project all round by means of the sticky sap of the milk-wood tree, and was further edged with white down. This design, together with a red-ochred body and long, sinuous lines of white and yellow from shoulder to knee, gave him a ferocious and remarkably weird aspect. Another of the older men had one side of his hair white, the other yellow, and a broad red median band right across from back to front and then down the middle of his face and on to the projecting beard, which was painted white on one side and red on the other. The rest of his face was a somewhat lighter red than the median band. Some of the men had their bodies all coloured with yellow, others with red and one or two with black. In most cases they had sinuous lines of white and yellow or yellow and red and sometimes all three, that usually began at the elbow, ran up to the shoulder and then, either close together down the back on one side to the knee, or else looping over one another. If the white was outermost on one side it was innermost on the other, this alternation of colour being most striking and characteristic, and a style of decoration that I have never met with amongst mainland tribes (Fig. 473). All the decorations, in fact, though decidedly ornate are almost startling and quite unlike any that are seen amongst other Australian tribes, but they are very roughly drawn in comparison with those used during sacred ceremonies of such tribes as the Arunta and Warramunga. Down is very little used and blood is never employed as a fixative.

While this was going on the singing was continuous, but what was sung was very simple. One old man suddenly shouted to the women, "I have painted my daughter's face yellow," which seemed to be quite unnecessary because everyone could see what he was doing. Another old man came out from the ceremonial ground, went near to where 


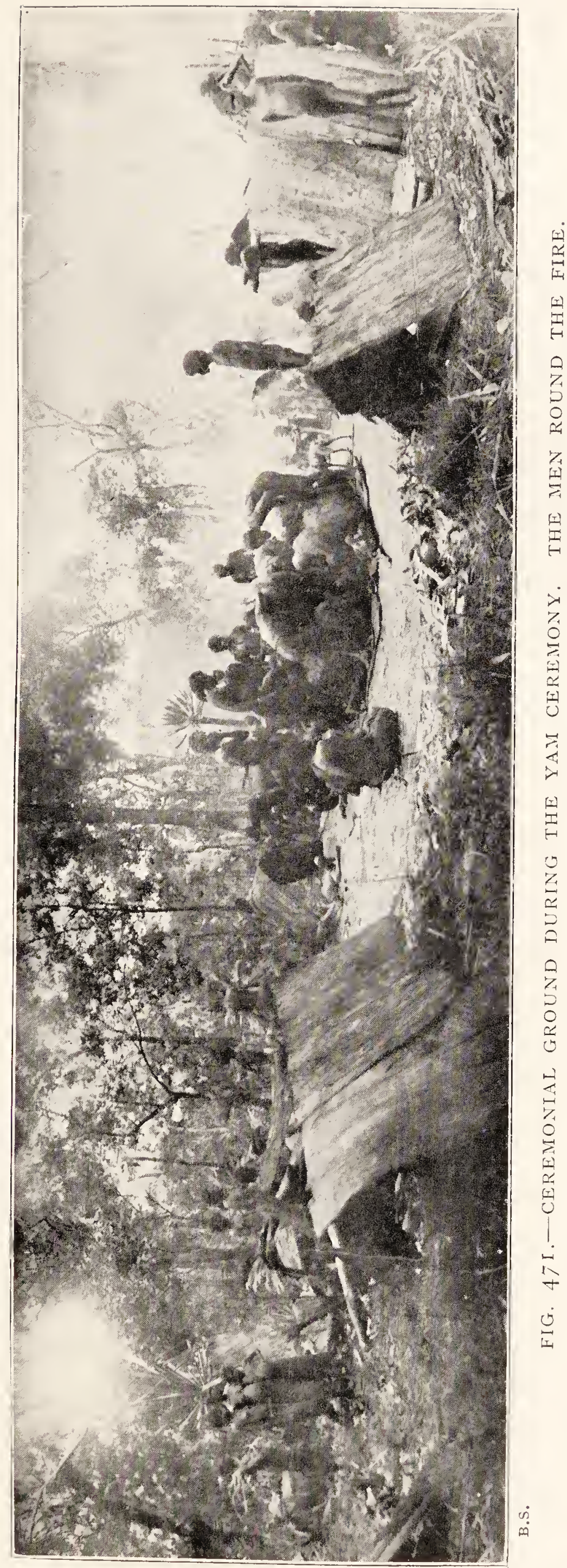




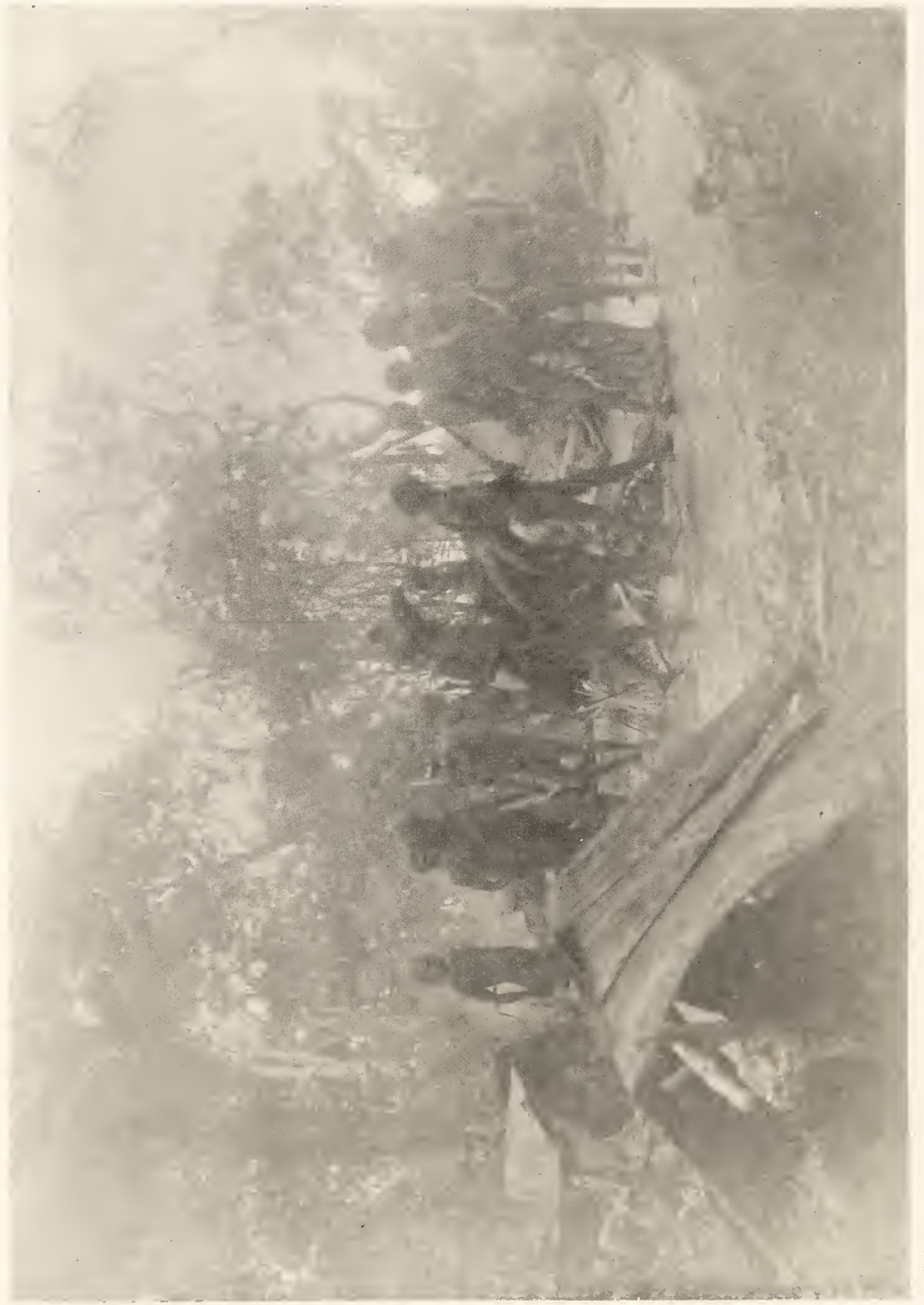


a number of women were grouped together, and sang out to them, "I have painted one side of my daughter white and the other side yellow." In one case the two wives and daughter of an old man were a little way off in a Miamia, painting themselves. The old man kept coming out from the ring and walking round so that they could both see and hear what he sang out, and time after time they replied, simply repeating what he said, which was merely a reference to the painting. The women in most cases only daubed red or yellow ochre over themselves, with little attempt at design. When the decorations were done there was a short pause, and then the men began to walk round and round the ground, singing and clanging sticks with their arms uplifted as usual. Then one old man "sang" the Mabanui, or shooting star, which is supposed to be an evil spirit. The object of this was to protect the boys in the Mia-mia from its evil influence.

They also "sang" the Bamajinni, that is, the armlets of the Watjinyerti, which is also supposed to help him against any shooting star. This over, several men walked round and round the Watjinyerti's Mia-mia, singing of an attack upon it by spears. At this stage the old leader was standing up issuing orders. $\mathrm{He}$ and another pranced wildly round and round the Mia-mia, while the men struck their buttocks with special vigour, yelling and stamping wildly. It was a crocodile dance, and the old man carried a ball of red-ochred down, throwing it up and down every now and then, to imitate fish jumping out of the water in front of the crocodile. This was followed by a shark dance, performed by a man with a blackened body and long, sinuous lines and white and yellow spots. These were the best performers, and they entered with zest into the performance, dancing and stamping round and round until they were exhausted. These dances entail a great amount of muscular exertion. Then followed a curious little 
performance, absolutely unlike anything in any mainland initiation ceremony. The father of the Mikinyertinga girl had decorated her with red and yellow ochre. He now called her up and spent some time in building up a kind of mop on her head by means of twisting into her own hair a number of little curled strands of human hair. The result was a great mop recalling to mind, on a small scale, that of many Papuans. Then he placed on her forehead a curious chaplet. It is made of a piece of bamboo bent round so as to fit the head closely from ear to ear, across the forehead, like a tiara (Plate IX, Fig. 6). On to it was fastened a series of flattened tufts of dog-tail hairsthe hairs being made to radiate from a little central disc of beeswax. Decorated with this mop and tiara, she was led by her father to the Mia-mia and put inside it with the four boys. It was a tight fit and they were all closely huddled together. Then there came another shark dance accompanied by a song consisting of a simple refrain, "The shark has a big mouth," "The salt water makes the shark's mouth big." Then came a devil-devil dance called Mabanui (shooting star). This was followed by a dance round the Mia-mia, the men working themselves up into a state of great excitement. They were supposed to be a hostile tribe coming up to kill the people in the Mia-mia. The men began to prance about, and after a minute or two the Mia-mia was opened up, so that the boys and girl could be seen. Then it was closed up again and a mock attack made upon it with spears, the occupants being supposed to be killed. After this there was a regular pandemonium, everyone dancing and yelling at the same time. This went on for some minutes and then, when they were thoroughly wound up and excited, they divided into two parties, the older men in one and the younger in the other. Just before this, however, the Mia-mia had been pulled down and the girl and boys had left the ceremonial 

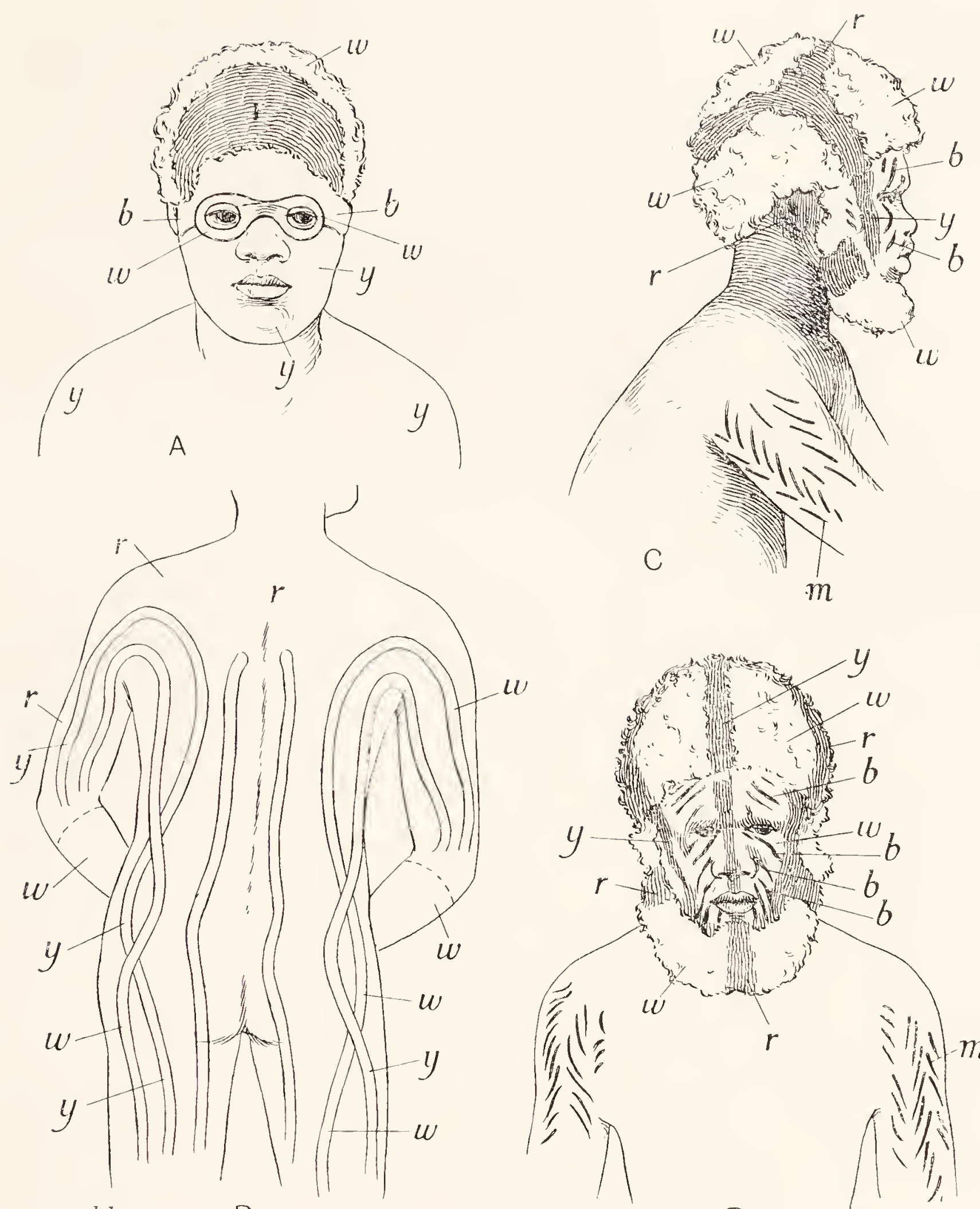

B.s. del.

B

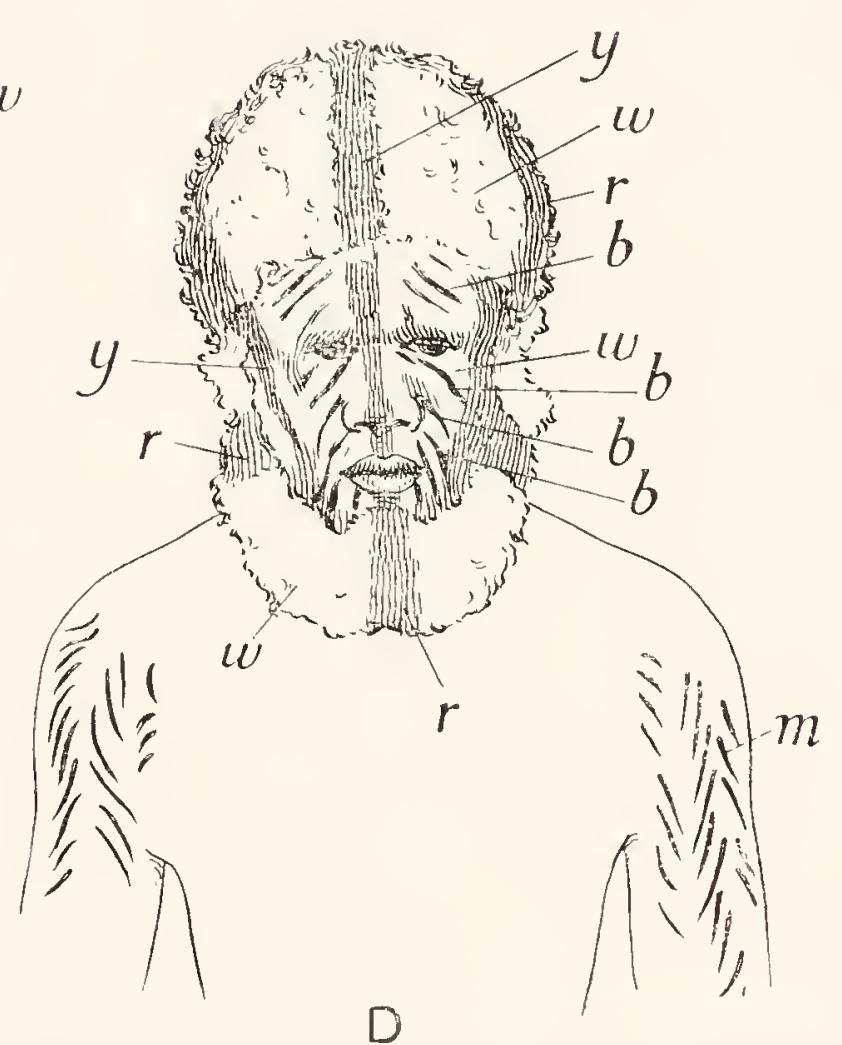

FIG. 473.-BODY DECORATIONS OF MELVILLE AND BATHURST ISLANDERS DURING THE PERFORMANCE OF CEREMONIES.

(A) Boy's head painted during the initiation ceremony. (B) Decoration on a man's back during the initiation ceremony, shorving the alternation of the lines of colour on the two sides. (C) and (D) Side and front view of a man's head, decorated for the performance of a mourning ceremony on Rathurst Island. The lettering refers to the colours used: (b) black; (v) red; ( $(u)$ white; ( $(1)$ yellow; ( $m$ ) keloid cicatrices, made on the arms, back, and chest. They are supposed to represent the minnga or spear barbs. 


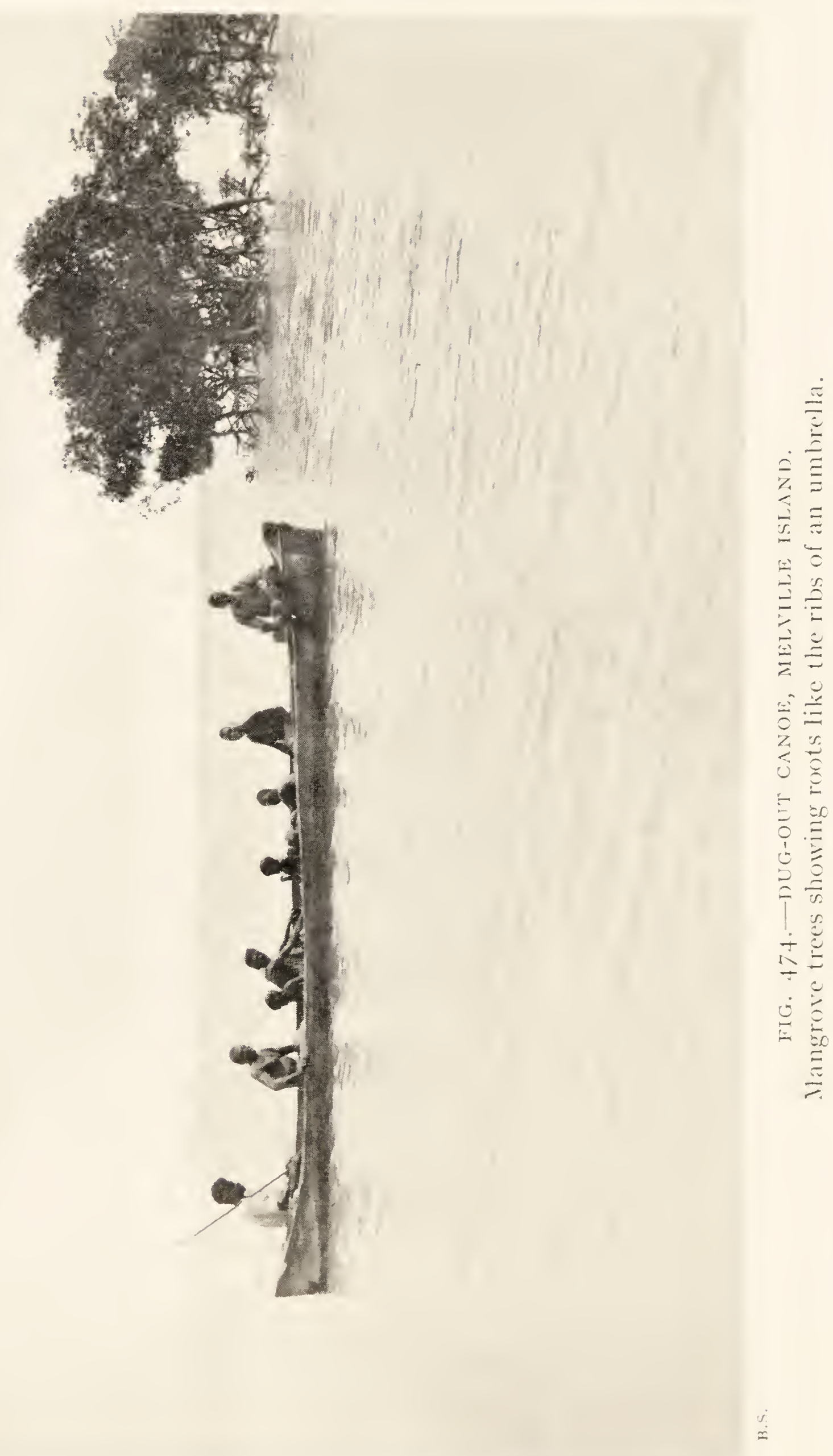


ground. The father took charge of the girl's chaplet, which later on I secured. The Watjinyerti and Mikinyerti joined the younger men. At first they had a long pole at which each party pulled, just as if it were a tug-of-war, but this was soon thrown away and then followed a regular scrimmage, on a big scale, the old men on one side, the younger on the other. They were all mingled togetherjust a mass of wildly excited savages, head, arms, legs, bodies, all mixed up together. It was just like a very willing, vigorous football scrum, and after a time, during which the yelling and confusion were indescribable, the older men managed to push the younger ones over, and they gradually undid themselves and the performance, called Arri madjunderri, came to an end. The men again gathered round the remains of the fire and the old leader, taking hold of the Watjinyerti's arms from behind, led him round the fire. After this the old men picked up some of the embers and threw them away in all directions. This was supposed to be emblematic of the throwing away of sickness.

Once more we all set off for the water-hole, the Watjinyerti and Mikinyerti carrying the sliced yams, accompanied by the Mikinyertinga and Mikijeruma girls and two old women, the other women and children following up some distance behind. When we reached the water-hole, the yams were placed in the water together with their whiskers or roots that had been carefully preserved and "sung." An extraordinary ceremony then took place. Most of the men began to pluck their beards and whiskers out (Fig. 468). They began at the ear on each side and went down to the middle of the chin, plucking the hair out in bunches. Some did it for themselves, others allowed other men to do it for them, and not a single man seemed to mind in the slightest degree during the operation, which must, to say the least, have been very uncomfortable. A strange thing was that no bleeding seemed to take place. When 


\section{WANDERINGS IN WILD AUSTRALIA cr.}

it was over, the hair was placed in the pitchis, along with the yams and their "whiskers," and left there for the night. We went to the pool a full-bearded party and returned almost beardless. This quaint ceremony brought the day's work to an end, everyone being somewhat tired out. Late in the afternoon we had a heavy storm, but this cleared away at sunset, leaving huge banks of peachcoloured clouds hanging on the horizon and reflected in the almost glassy sea. It was wonderfully picturesque as dusk came on, with a beautiful soft light on the water and nothing to be seen except the low shores of Bathurst Island in the distance, just like a deep purple line, and a solitary dug-out canoe with three natives strongly silhouetted against the water, paddling away to a little islet in search of turtle eggs.

March I th.-The sun was shining this morning and everything was fresh and bright. The little Mia-mias, with blue smoke curling up from them amongst the gums and Cycads and screw pines, and the ceremonial ground in the middle of them, just on the edge of a low cliff bounding the seashore, looked very much more picturesque than in the rain. The natives were all repainted, men, women and children, when I got to the camp about 7 a.m. One side of the head was yellow, the other white; their bodies were either yellow or red with stripes of yellow, red and white. We started off for the water-hole and were very soon dripping wet again. A halt was made at the same tree at which we had found the Watjinyerti on the first day. Early this morning, the leader had sent out the Mikinyertinga girl and one of the Marukumana boys, with two or three men, to conceal them under boughs at the foot of a tree. When the boughs were thrown aside, they came out and all the men and women formed themselves into a circle. First of all the boy danced round and round, and then her father decorated the girl's head with the 
same dog's tail chaplet that she had worn previously. Her hair was still in a mop. He also gave her a ball of redochred down, called Taquoia, about three inches in diameter (Plate IX, Fig. 7). This she carried in her mouth during a dance round in which she was accompanied by her father and three of his brothers. It was supposed to give her confidence. When this was over, the party moved on to the water-hole; the yams were taken out and carried back to camp, where all partook of them, everyone being supposed to begin eating at the same time. The hair was simply left behind with the yam whiskers in the pool and no further notice was taken of it. It was just eleven o'clock when we returned to camp and the eating began, which signalised the close of this part of the initiation ceremonies.

For some time after this, in fact for five months, the Watjinyerti had to remain away from the main camp. After a certain time he was given a very quaint kind of necklet called Marungwum (Plate IX, Figs. 4 and 5) and a waist belt called Olturuma (Figs. I and 2). His mother also during the same time had to wear an elaborate and cumbersome neck ornament (Fig. 3). The various articles worn by the Watjinyerti boy, the Mikinyertinga girl and the mother are shown in Plate IX. The ceremonies that we saw took place during the last week of March. I had to leave the island before the later ones were held, but was there again in November and heard what happened from my friend Alice, who also, though it was very difficult to persuade the natives to part with them, managed, through her influence with them, to secure for me all the articles used in connection with this initiation ceremony. She told me that the Watjinyerti remained away from the main camp until the end of April, when he came into his mother's camp, took off his old ornaments and washed himself, for the first time, in salt water brought for the purpose by his 


\section{WANDERINGS IN WILD AUSTRALIA сн.}

mother. New ornaments were put on him, including the belt called Olturuma (Figs. I and 2), that was made for him by his mother's brother. He kept them on till the performance of a final ceremony in September. On this occasion he sat down in the camp with his mother with all his ornaments on. His mother sang out to the older women to come up. They did so and took half of the ornaments off, and then the older men came up and took the others off. When this was over the $W$ atjinyerti danced a little. A Yauaminni man took the ornaments-armlets, necklets and waist girdles-and put them all on a special platform of branches, built like a big nest in an ironwood tree. While this was being done everyone stood round in a circle, in the middle of which were the mother and the $W$ atjinyerti. Then they all cut their heads and cried, and with this the ceremony came to an end, and the $W$ atjinyerti was free of the men's camp. At the next initiation he will act as Mikinyerti. Later on, by special permission of the old men, the ornaments were removed by Alice, but, under ordinary circumstances, no one is ever allowed to touch them and they remain in the tree until they rot away.

March I 3 th.- The weather seems to have cleared up for a time. It was bright sunshine and made me wish that we could have had a little of it during the days preceding when I was vainly trying, with the rain pouring down on my paper-bark umbrella, to get some records on the ceremonial ground in the scrub. Cooper, Alice and myself sat down under the verandah of the little house, and with their patient help I tried to find out a few things about the yam ceremony from a number of the old Melville Island men and women who had squatted round us. It took us till I 2.30 to find out very little. You ask them what seems to yourself a very simple, straightforward question and then they set to work and talk at length amongst themselves. It sounds sometimes almost as if 


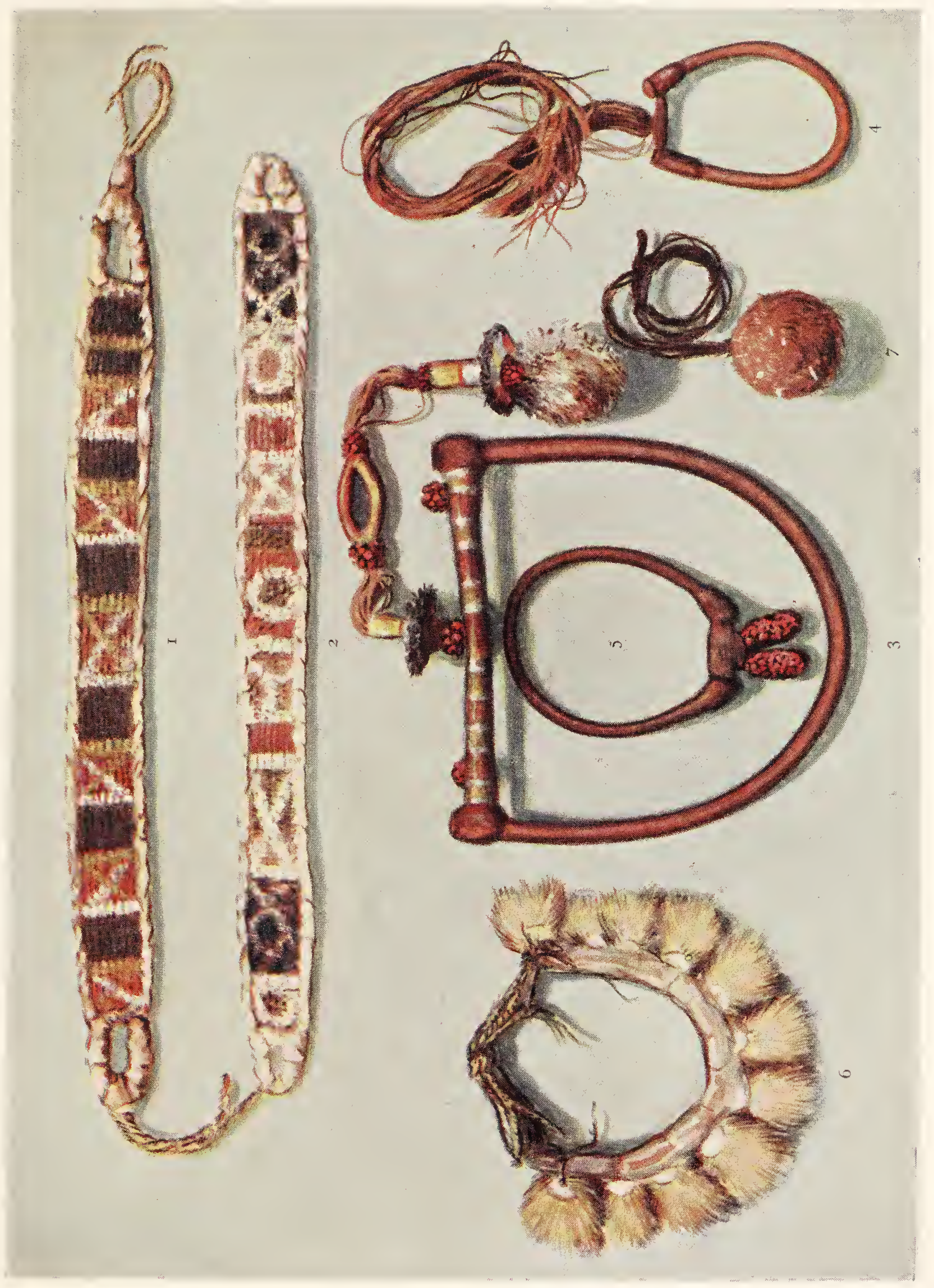

告 

they were going to fight one another, and then, after perhaps ten or fifteen minutes, you get a reply which, as likely as not, shows that they did not know what you meant and the whole thing has to be gone through again. Alice, being one of themselves, naturally understood their ways and Cooper was the soul of patience, but I fancy his thoughts often wandered away to the buffaloes that wanted shooting. However, we managed to find some things out, but three hours of mental work, of a kind to which they were unaccustomed, was quite enough for them, so we thanked them and sent them away to their camps with a present of flour, tea and sugar to talk things over, probably also to marvel at the stupidity of a white man who possessed what they would have given much to own, but could not understand things that to them were as simple as possible. After our midday meal I wandered round amongst the Mia-mias on the camping ground, with a good supply of tobacco in my pockets which was judiciously distributed amongst the older men and women, much to their satisfaction. Also it served for the purchase of a few native articles, but there was not much to be had. In the evening Cooper and myself wandered out into the bush and, coming home after dusk, found two little boys sitting on my bunk, waiting for us and whiling away the time by watching, with keen enjoyment, the wriggling about of a miserable rat that one of them had brought in, impaled on a short, sharp spear through the skin of its back to keep it safe. I gave it a whiff of chloroform and sent them away with some lollies. The Australian savage is quite callous in regard to inflicting pain upon anybody including, under certain circumstances, himself. Indeed he seems to enjoy watching its results. As a general rule they are fond of their own children, but Alice told me that the Melville Islanders will sometimes leave a sickly child behind them when they shift camp. There was one little mite that she 
was now looking after whom she had rescued from a forsaken camp in which he had been left alone to fend for himself, and this was only one of several such whom she had befriended and who owed their lives to her. Cooper told me also that he felt sure, though he had no positive proof of it, that old men were, every now and then, deliberately speared by young men who wished to take possession of their young wives. Under the cover of darkness, or away out in some lonely part of the scrub, it would be easy to do this with one of their great, heavy, javelin-like spears.

March I 4th.-This morning Cooper and myself started off in a dug-out canoe (Fig. 474) with one older and three younger boys. There were no seats, so one and all squatted in a row behind one another, on pieces of bark, beneath which the bilge-water collected. I was in the bow, then came one of the boys, paddling, then Cooper and the older native, and then two more paddlers. When we were all in, there was just about two inches between the gunwale and the water, but, luckily, the day was fine and calm and the boys paddled away gaily on a course that was remarkably good, seeing that none of the three paddlers apparently paid any attention to where they were going, and of course there was no rudder. We all sat plumb and low down in the middle of the boat, which was necessary, as it had no keel. All that they did was to keep approximately level with the shore, which, in view of sharks and crocodiles, I was relieved to find that we never went very far away from, except once or twice when we cut straight across from one point to another. We paddled southwards with the tide, which was running out of the Strait, rounded a low promontory called Cockle Point, then ran up a little creek and landed amongst the mangroves. By now the tide was falling. Each tree has a large number of roots that spread out like the ribs of an 
umbrella (Fig. 433), those of the adjacent trees all interlocked with one another, and from them the branches rise, crowned with thick, dark foliage. At high tide the roots are totally immersed and to attempt to walk amongst them is simply hopeless. At low tide all that you can do is to hang on to the branches and gingerly, with the aid of their support, try to walk on the slippery roots from one tree to another until you come near to dry land above water level. You only reach this after a final struggle through muddy ooze, down into which you sink for a foot or more, dragging your leg out each time with a squelch and an inch or two of mud coated all over it-horrid, smelly stuff. Reaching higher ground we washed ourselves in a little creek and followed this up. All along, remains of old camps were dotted about, with piles of empty shells, where the natives had been cooking and had built their little Mia-mias. One of these was right on the top of an old jungle fowl's mound-nest. The scrub was luxuriant with screw pines, Cycads, gum trees and giant tea-trees with vines hanging down in great tangled masses. After about two miles' walk we came across an old grave with some of the posts lying on the ground and the others ready to tumble down and rot away. For three hours we wandered about, finding two more graves. Then we came across one that was quite new. There was just a low mound in the middle of an open space in the thick scrub. No posts had been erected and it was covered with a large sheet of string-bark (Fig. 447). The natives had taken no notice of the old graves, but here they set to work at once and cleared away all the grass and herbage growing round it.

It was decidedly warm and moist, but we had some good exercise and a very pleasant paddle back to Cooper's camp. All the time the boys were singing out the names of different objects. One boy would say "mangrove," another " the leaves of a mangrove," another would 
say "dugong," another " the head of a dugong," and so on in endless succession. It sounded just as if they were vying with one another to see who could mention the most names, and all the time they were laughing gaily and evidently enjoying themselves.

The later part of the day was spent with the natives, whom, on our return, we found busy painting some posts to erect on a recent grave not far away from the camp. There were ten of them altogether, which was a large number to be painted and put up at one time. The poles were fixed upright in the ground, or leaning against trees, and there was no suggestion of anything special taking place. Men and boys of all ages were busy at work, each one apparently drawing any designs that occurred to him, and none of them, so far as I could find out, having any special meaning. The only restriction that I noticed was that no women were painting, though they were watching and wandering freely in and out amongst the posts. It was a strange sight. The evening was coming on and the sunset was an extraordinarily gorgeous one-not at all a pleasing mixture of colour-but the effect of the light on the trunks of the trees, the poles and the natives painting them was very fine.

March I 5th.-A heavy south-west squall came up during the night, and my sleeping apartment on the verandah let in a good deal of rain, so I pulled half of my big sail-cloth sheet over me, making a kind of low tent from which the water dripped off the bunk. After a time it stopped and the morning was beautifully bright and clear. At 8 a.m. we set off in the lugger, taking seven boys with us. There was a fair breeze blowing, so in three hours' sailing southeast out of the Apsley Strait we were off the mouth of a river called Dukkum-burra-milli. At the entrance there were two islands with a narrow passage between them that we had to pass through. There was no beach to be seen, 
the mangroves rising right out of the sea. The river was forty or fifty yards wide, bordered with mangroves, and behind these Cypress pines, native bamboos and gum trees. We sailed up for some five miles, after which the water became quite fresh - this, of course, was in the rain seasonand landed amongst the mangroves, where we saw a little creek entering in which it would be possible for us to wash ourselves. This over, we set out in search of two special old graves that the natives knew of and, after a walk of some miles, came upon them in a clearing, far away in the forest close to some swamp land. It was quite evident that they were old ones, because there were only traces of the original colour left on one or two of them. One of them had eleven and the other thirteen posts round it, and each enclosed a space of eight feet by four feet (Fig. 448). The natives with us did not show the slightest concern about them; evidently because they were old ones and all the necessary ceremonies with them had been performed. This was in striking contrast to their behaviour when an hour or two later on we once more came across a grave with no posts, when they immediately set to work to clear away all the grass around it.

With the full consent of the old men, who seemed nothing loath to part with them in return for a goodly supply of tobacco, knives and tomahawks, I secured them. Shortly afterwards they carried them down to the coast, whence Cooper brought them in to his camp in the lugger. There the natives cheerfully renewed the decorations on one set. They were all numbered, and when, months afterwards, they reached Melbourne, I set them up side by side in the Museum so as to represent as nearly as possible the two original graves, but it is impossible to realise their real impressiveness unless one sees them in their natural setting far out in the primeval forest.

The illustrations (Figs. 475, 476) will serve to show VOL. II. 


\section{WANDERINGS IN WILD AUSTRALIA сн.}

what these remarkable grave-posts are like. To begin with, a small tree is cut down, the bark stripped off and the trunk cut across, so as to provide a pole of suitable size. One end of it is cut so as to make a peg, about eighteen inches long, for insertion in the ground. It is then slowly and laboriously cut, nowadays with an iron tomahawk, but formerly with a sharp shell, until it has the form decided upon by the artificer.

Four main types may conveniently be distinguished (Fig. 477).

The first and simplest is merely a short, plain log which is not usually more than three feet high (I).

The second is the most common and the most variable in size (2). The largest ones usually, but not quite always, conform to this type and may reach a height of thirteen feet. These are two sub-types. In the first the pole terminates in a disc $(2 a)$. The simplest ones have simply a deep groove separating the head of the post from the basal part. In the great majority the groove is deepened and extended so as to produce a more or less narrow column of varying length to the top of which the disc is attached. Similar columns may be cut out along the length of the post so as to give rise to a succession of disc and cylindrical parts. In the second sub-type the post terminates in a little column, below which other discs, or discs and cylinders, are cut $(2 b)$.

The third is characterised by the fact that the column is pierced in such a way as to leave two broad rods or slabs supporting an upper portion. Four sub-types may, perhaps, be recognised. In the first there is only one perforation and the pole ends in a disc separated by a shorter or longer column from the basal part ( $3 a)$. This disc has sometimes a distinctly rounded top so as to suggest the idea of a hat. The perforation is oblong-shaped and usually close to the top of the post, but may be lower down, 


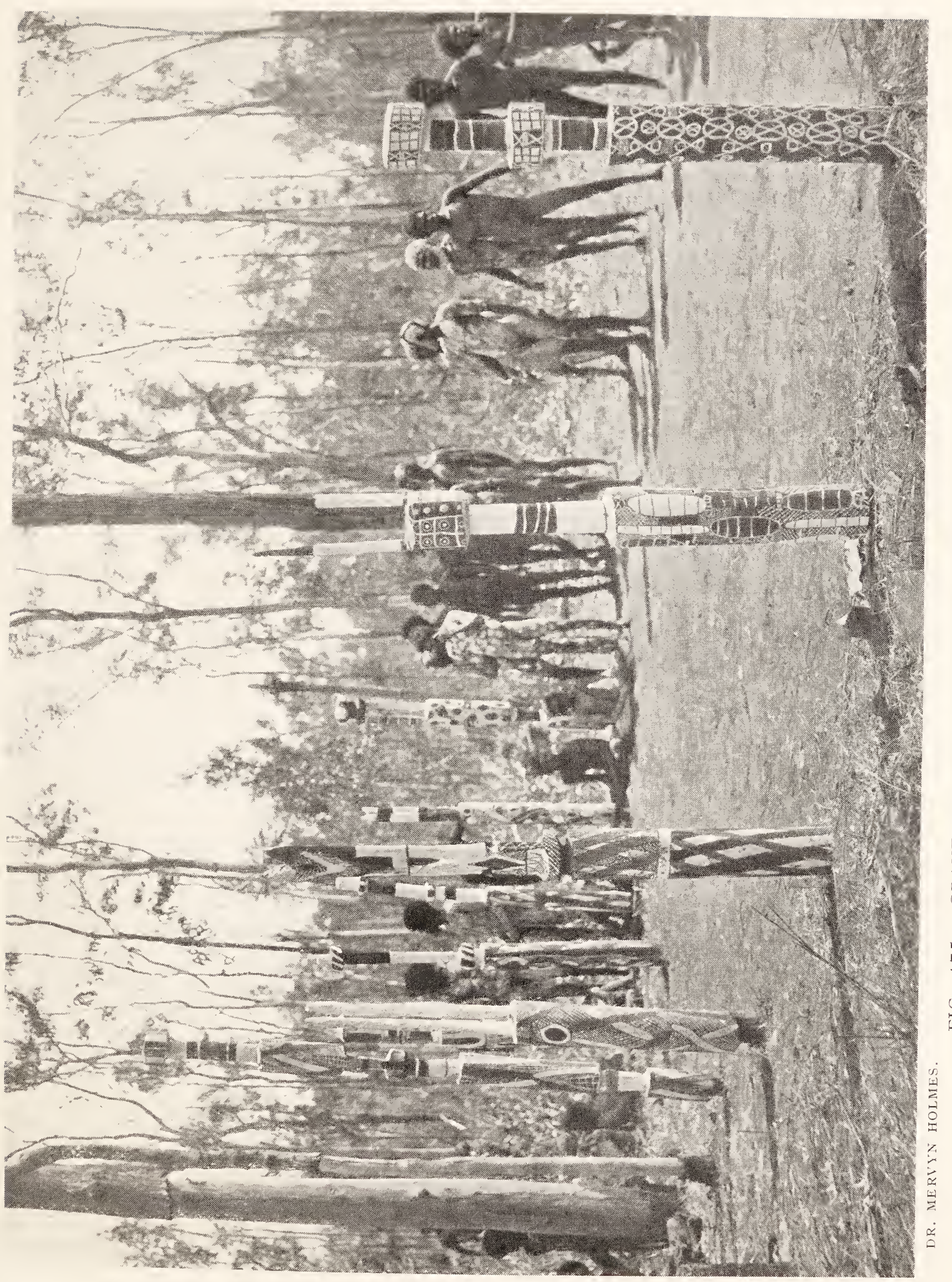




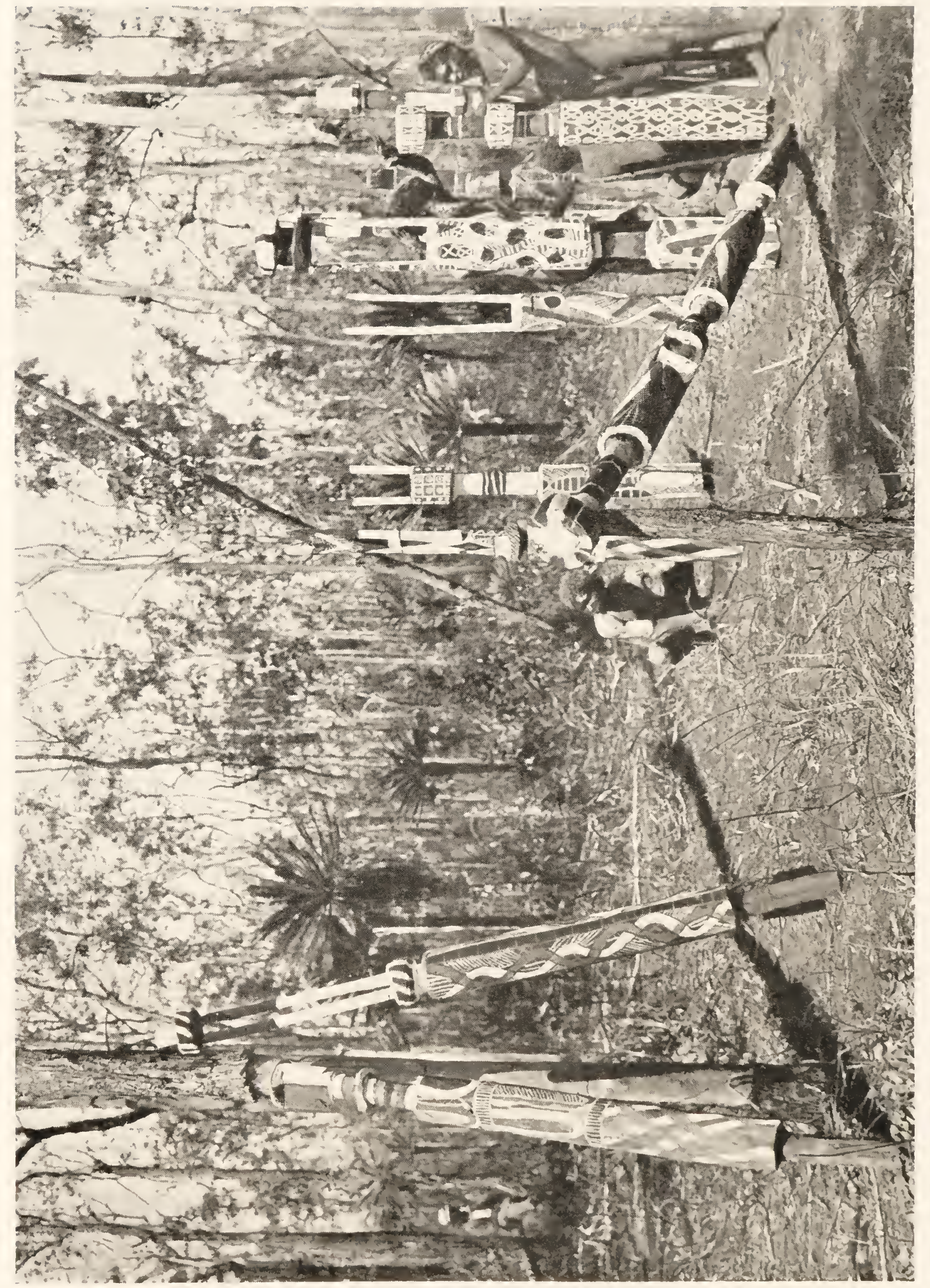


xxvi MELVILLE AND BATHURST ISLANDS 683
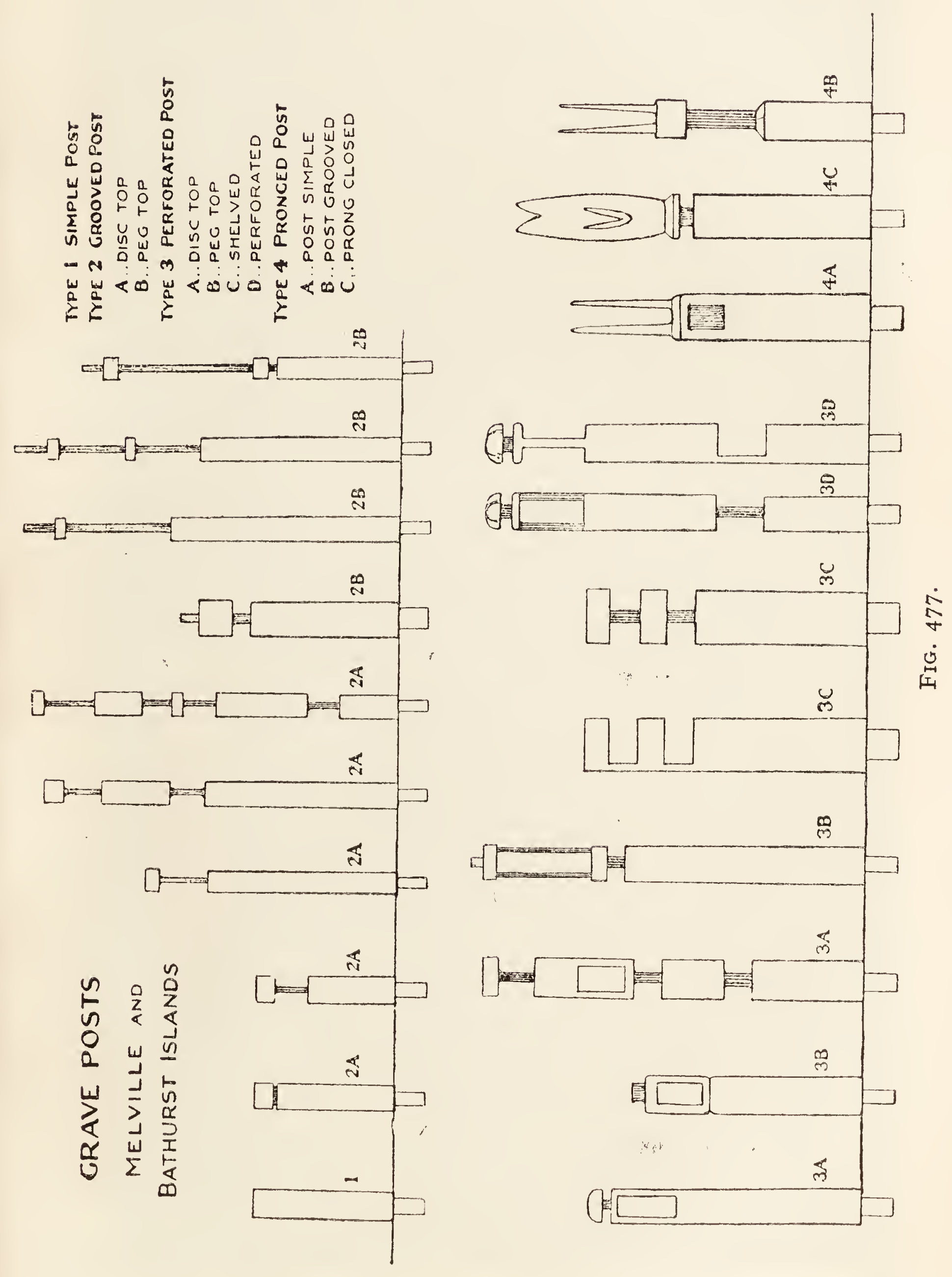


\section{WANDERINGS IN WILD AUSTRALIA сн.}

and other cuts may form columns with an intervening cylinder. In the second $(3 b)$ the post has a terminal short column and a single elongate perforation below this. The third $(3 c)$ is a rare form, but evidently derived from a post with two perforations, the supporting slab on one side having been cut away so as to leave two discs, each supported and attached on one side only. The fourth $(3 d)$ is also a rare and more complicated type. At the top is a disc separated by a short groove from the post below, the upper part of which is perforated, leaving two rod-shaped supports: lower down is the second perforation made at right angles to the first, but the rod support has been cut away on one side.

The fourth type is a distinct one and is characterised by having a pair of prongs projecting from its upper end. It varies in height from about five to eight feet. The prongs are sometimes as long as the main post. In the simpler form (4a) the latter is left entire. At the upper end on each side of one such post, over an oblong area measuring about nine inches by six, the surface wood had been removed to a depth of less than an inch, as if the maker had begun to cut a perforation and had stopped short, or perhaps contented himself with the suggestion of this. In some $(4 b)$ it is divided into an upper disc separated from the lower part by a narrow column. In one specimen ( $4 c$ ), seven feet in height, that is possibly a derivative of the typical form, there is a slab, three feet in height, terminating in two short prongs. A curious tongue-like process has been cut out in the middle of the slab. The slab arises from a disc that is marked off from the lower part of the post by a narrow groove, leaving a very short central column supporting the upper part of the post.

The natives themselves have no idea of the meaning of the prongs but, in side view, to anyone who knows that the natives are constantly on the watch for crocodiles, they 


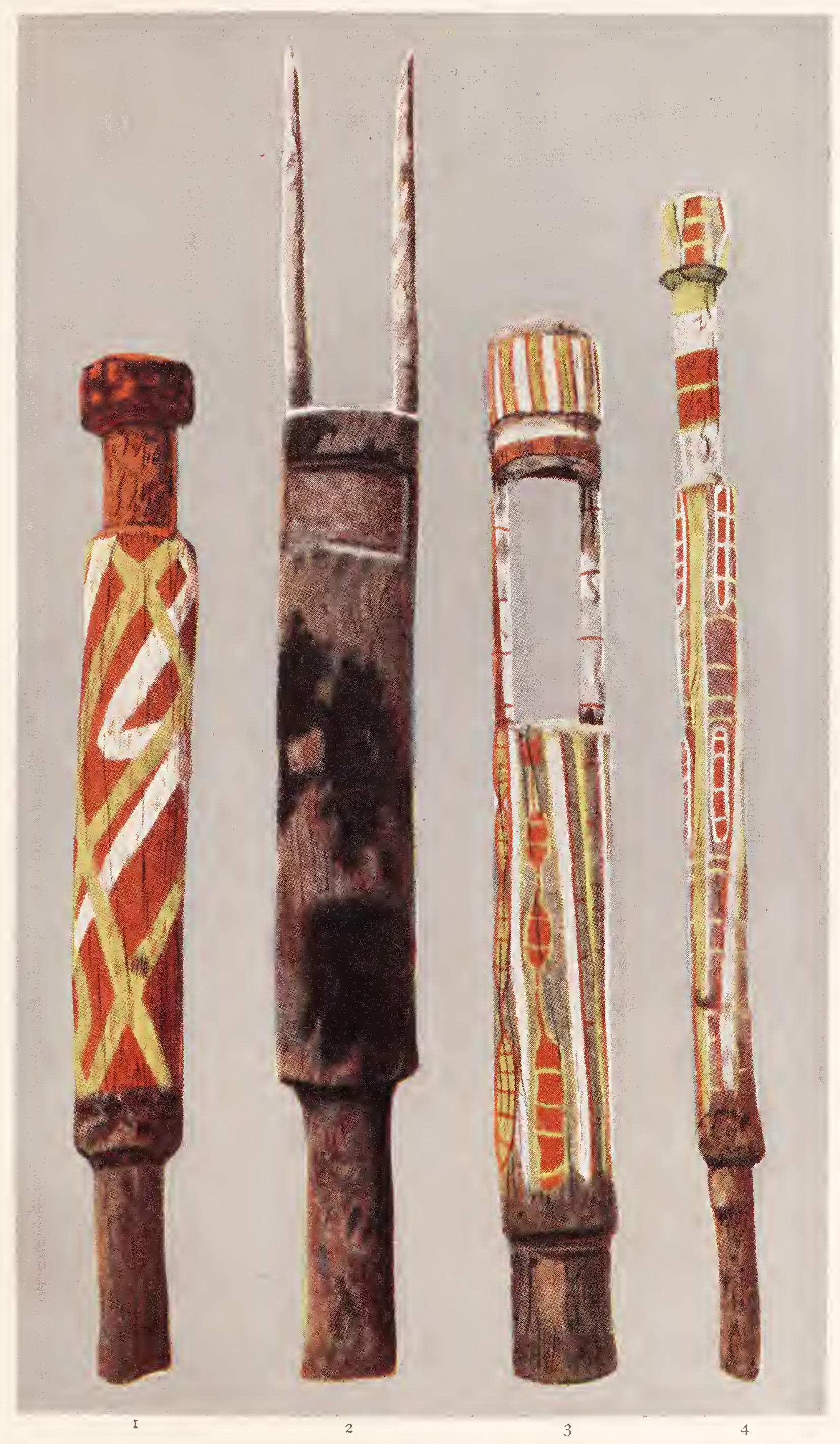

PLATE X.-GRAVE POSTS, MELVILLE ISLAND 

suggest two open jaws, but I could not detect any indication of teeth, either in design or carving.

A good idea of the colour scheme of decoration can be gained from Plate X. They are drawings of posts from one of the two old graves previously described. Three of them have been redecorated by the natives; one is just as we found it and shows what they are like when the grave has been standing neglected for some time after the final ceremony has taken place and a bush fire has swept over, obliterating almost all traces of the original design. Yellow, red and white are the prevailing colours, black is seldom and only slightly used.

In all cases in which I actually watched the design being painted, the post was, first of all, completely covered with a groundwork of red ochre. Then the design was added in red, yellow and white. It many cases it took the form of wavy, spiral or intertwining bands, running along the length of the post with ovals outlined in white or yellow and interspaces filled with criss-cross lines. Sometimes the broad bands were absent and the whole surface was covered with ovals and criss-crossed interspaces. The posts in Figs. 475, 476 will serve to give a good idea of the general nature of the designs. Those on the one to the extreme right are quite different from any others, with lines of larger ovals alternating with smaller circles, each enclosing a cross and arranged symmetrically both length and crosswise. The interspaces running from top to bottom of the post between the lines of ovals are filled up by a series of crosses, one arm of each of which runs slantingly from the lower side of one oval to the upper side of the oval next below it in the adjacent longitudinal row: the angles of the crosses are filled with small circles. In this case all the design was drawn in white on a red ground.

After a long tramp through the forest we got on board again at four o'clock and, as there was scarcely a breath of 
air, it was sunset when we reached the mouth of the river and saw the distant line of Bathurst Island standing out once more like a deep purple line against the gorgeous sunset and, later on, the after-glow. In the open there was a fair breeze, but it was against us and we had to tack and tack, making little progress, until, long after dark, we reached our moorings at Cooper's camp. The boys were as cheerful as possible, " singing" everything they could think of.

March I 7th.- Whilst out in the scrub searching for plants we came across a patch of so-called jungle, where the vegetation is very thick and the soil very moist. Here a number of women were busy digging up yams. It must be a very monotonous work, and certainly a very wet and dirty one. First of all, they find a yam plant, generally a creeper with leaves much like a convolvulus (Dioscoraa $s p$.), though there are half a dozen different kinds. Having traced the stalk down to its root, the woman squats on the ground and digs down with a pointed stick for perhaps two feet or even more, making a hole usually not more than six inches across, until, following the root, she finds the yam, which is sometimes shaped like a round potato or, the better ones, like a great, elongate, knobbed and swollen root of a very waxy consistency. They cook and eat them in hundreds as well as enormous numbers of cockles and spiral, trochus-like shell-fish about three inches long. Late in the afternoon the natives began another grave ceremony with the usual dancing. It was held where the posts were placed temporarily, prior to being carried to the grave. The men were mostly daubed over with bright red ochre, with a white circle round each eye, all of them of course stark naked. The women had their foreheads black, a broad yellow band across the bridge of the nose and cheeks; the face below this and the body extending often down to the waist was bright red. They are 
only too eager now to wear anything that they can get from a white man, but, fortunately, can usually only secure a little piece of red turkey-twill or a bright-coloured handkerchief, to use as a loin-cloth. This afternoon I came across a little mite of a girl proudly wearing as her only clothing and ornament a sardine tin-opener tied on to a thread of hair string round her neck.

On this particular occasion an interesting variant in the proceedings consisted in throwing the three Marukumana boys up into the air. It turned out that this was done because the man, in memory of whom the posts were being erected, was very tall, and therefore the throwing up of the youths would conduce to their growing tall.

The evening we spent questioning the natives. There were more than a dozen of them, men and women, inside the hut, squatting about, all of them naked and more or less painted, while half a dozen, for whom there was no room inside, watched us through the door, taking part in any discussion in which they felt interested. There were no chairs, so we all sat about anywhere-on boxes or the ground or anywhere handy. There was not very much room, as the whole house (one room) is chock-a-block with stores of all sorts-bags of flour and sugar, hundreds of tins of meat and fruits, great bags of salt for preserving the buffalo hides and no end of material-turkey-red, handkerchiefs, tomahawks, tobacco, etc.-for the natives, of whom Cooper keeps at least twenty men, apart from their wives and families, constantly in camp with him and looks after them well. From side to side the joists that run across where the ceiling would be, if one were present, carry saddles, bundles of native spears and rifles of various sizes and rustiness. Altogether the room held everything necessary for the upkeep of a self-contained establishment, excepting furniture, for which there is neither need nor room. 
March I 8th.-Soon after breakfast we heard the loud "Brr! Brr! Brr!" which meant that the men had gone to the ceremonial ground and that something was going to take place. It is as well to be on the spot as soon as possible when this sound is heard. If we had been a few minutes later we should have missed a very interesting little ceremony. The men had lighted a fire at the base of a blood-wood tree close to the grave-posts. Four boys, two of them Marukumana and two younger ones, were made to climb up the trunk. Green boughs were placed on the fire, from which a column of smoke, called Kujui, rose. The same name is applied to a waterspout, with which it is supposed to have some mysterious connection, though exactly what we could not find out. In turn, each of the boys had to climb down. The two younger ones were allowed to jump over the fire, but the Marukumana had to pass through it. As soon as this was over they began some of the ordinary dances. This gave me the chance of going on ahead to the grave, and I had just fixed up the cinematograph when I saw a very picturesque procession wending its way through the scrub. Everyone came, men, women and children. At first, the postbearers stood a little way off, while holes were dug to receive the posts. Then, one by one, they were placed in position while I ground away at the cinematograph. Then they began their dances round the post-buffalo, shark, crocodile, kangaroo, etc. Finally, they gathered round, leaning on the posts, howling and wailing though not a tear was shed. I do not think that anyone felt particularly sad, but it was a good imitation of profound grief and a very picturesque performance. The chief mourners amongst the men were smeared all over with red ochre and yellow bands, and one old lubra, a terrible-looking hag, the mother of the dead person, who persisted in getting in front of my camera, was likewise all in red. 
There was one man in camp who was always noticeable. He had only one leg but with the aid of a crutch made for him by Cooper he managed to get along surprisingly well. His right leg had been bitten off by a crocodile, but he had been dragged away by his comrades and the stump must in some way have suddenly contracted and prevented his bleeding to death. The cut end had simply been plastered over with clay (Fig. 479).

On the way back I saw the most comical-looking little piccaninny. The whole camp had cleared out to watch the performance, but by chance this little mite had been forgotten, and when we came back it was seated on the top of its Mia-mia, with a look of extreme annoyance and indignation on its little face (Fig. 443).

March I 9th.-We had intended to go up the Strait, but it rained hard, so we stayed at home. The weather, however, did not deter a party of six natives who set off in a dug-out canoe for a trip to Buchanan Island, about fifteen miles across the open water. They took no food or clothes with them, only a few spears, but were perfectly cheerful at the prospect of a feast on turtle eggs this evening (Fig. 478). At this season of the year they can always procure these in abundance.

March 20th.- We were up early and on board the lugger before 6 a.m. with our swags and provisions for two or three days, but when the boys tried to get the anchor up nothing they could do would shift it. The boat had drifted inshore during a gale in the night and the anchor had evidently got fouled amongst the mangrove tree roots. There was nothing for it but to wait for low tide at noon, so we came ashore and occupied the time with a spearthrowing contest amongst the natives. Their spears are quite unlike those of the mainland tribes. They are very heavy and might better be called javelins. For the contest we chose a good average specimen, ten feet six inches in 
length and four pounds in weight. The throwing took place on the beach, where the sand was hard and afforded a good foothold. The spear was thrown by the hand, because the Melville Islander has no spear-thrower. There were nine competitors, and they entered with zest into the competition, which was watched with keen interest by the other men in camp. Cooper saw that they started from the right mark, while I stood to one side with a keen-eyed native and noted where the spear fell. The distances thrown were as follows:

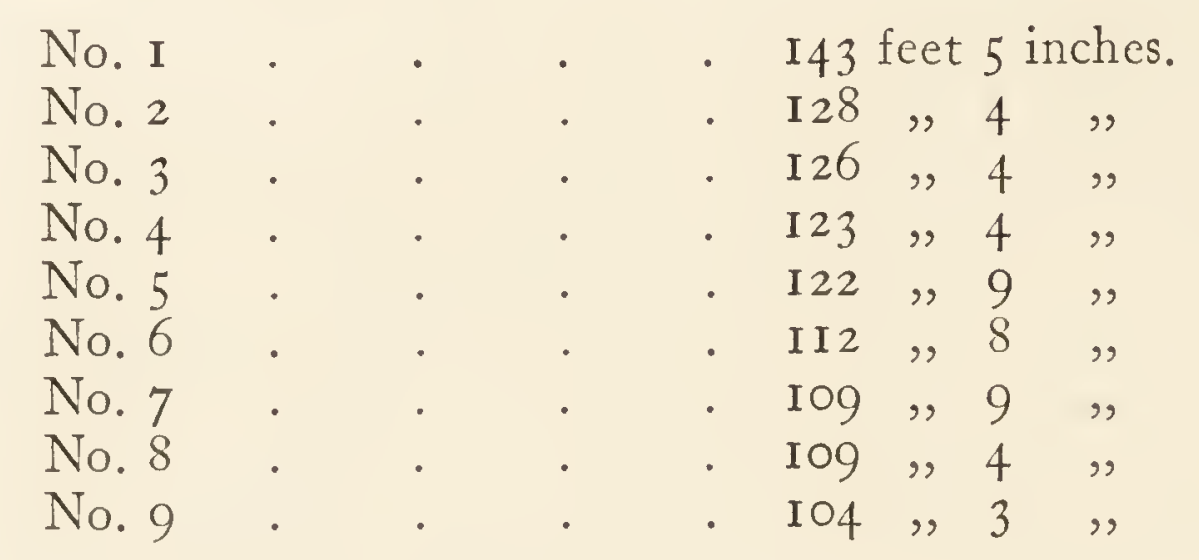

We gave them three tries each. I thought they would have thrown much further than this, but their spears are heavy ones and, under the normal conditions in the scrub, there is no chance of a long throw. By way of awards the first two men had a tomahawk each, the next two a knife and the last two tobacco. Unfortunately, and by pure accident, I got a wound in my right leg from one of the spears. I had to pay dearly and most annoyingly for it afterwards. As soon as the spear-throwing was over I went back to camp, and whilst writing up my notes, "Tom Thumb," as we call him, the little mite who had been rescued by Alice when his people had left him deserted in camp, came and sat down beside me, crooning away at a corrobboree song that sounded like "Milla na dai nai yam: bellam lair lai yam." He cannot be more than three or four, but has the look of a man of twenty, who has seen a great deal of the world. As soon as I bandaged 


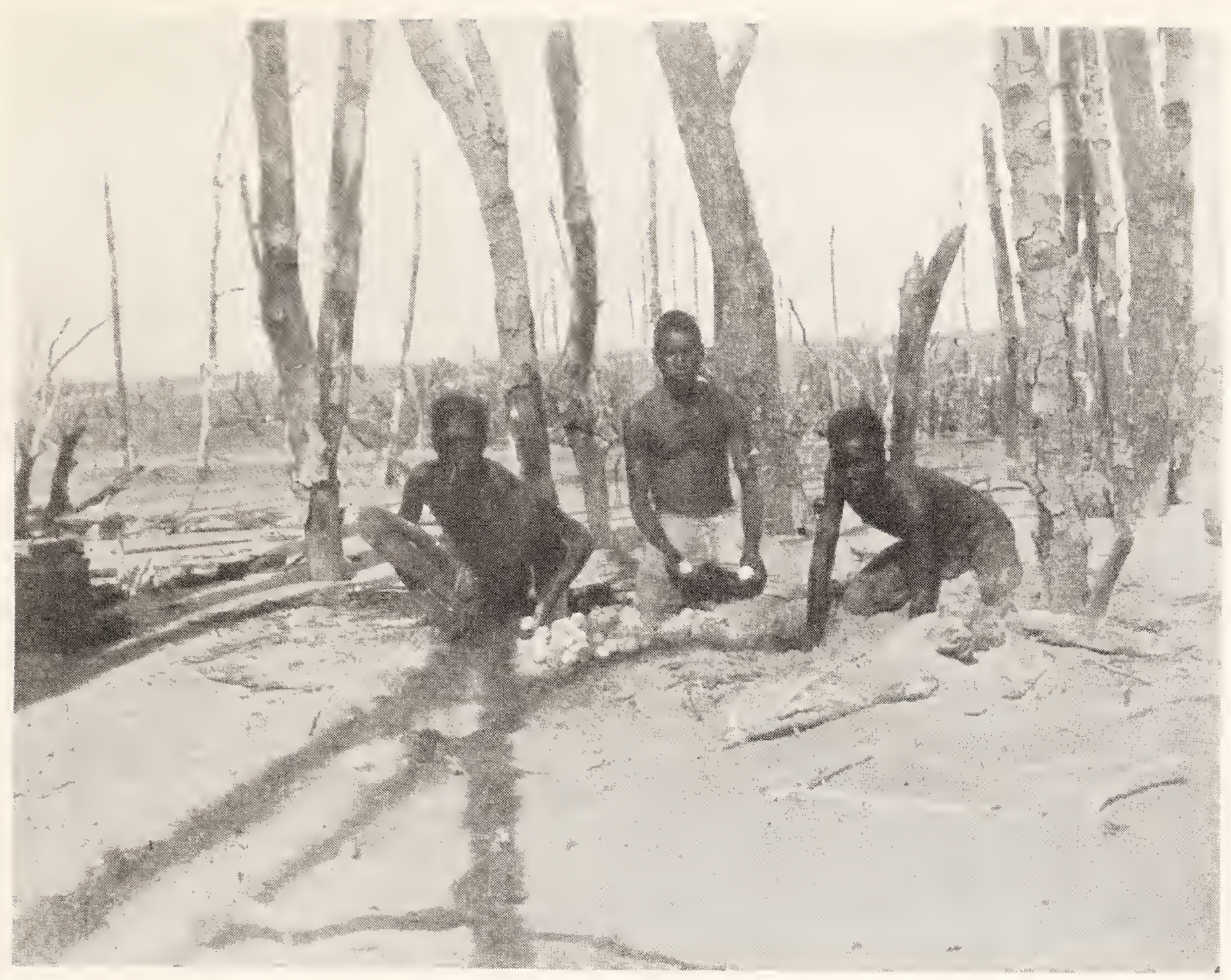

FIG. 4 7 S. GATHERING TURTLE EGGS, BATHURST ISLAN1).

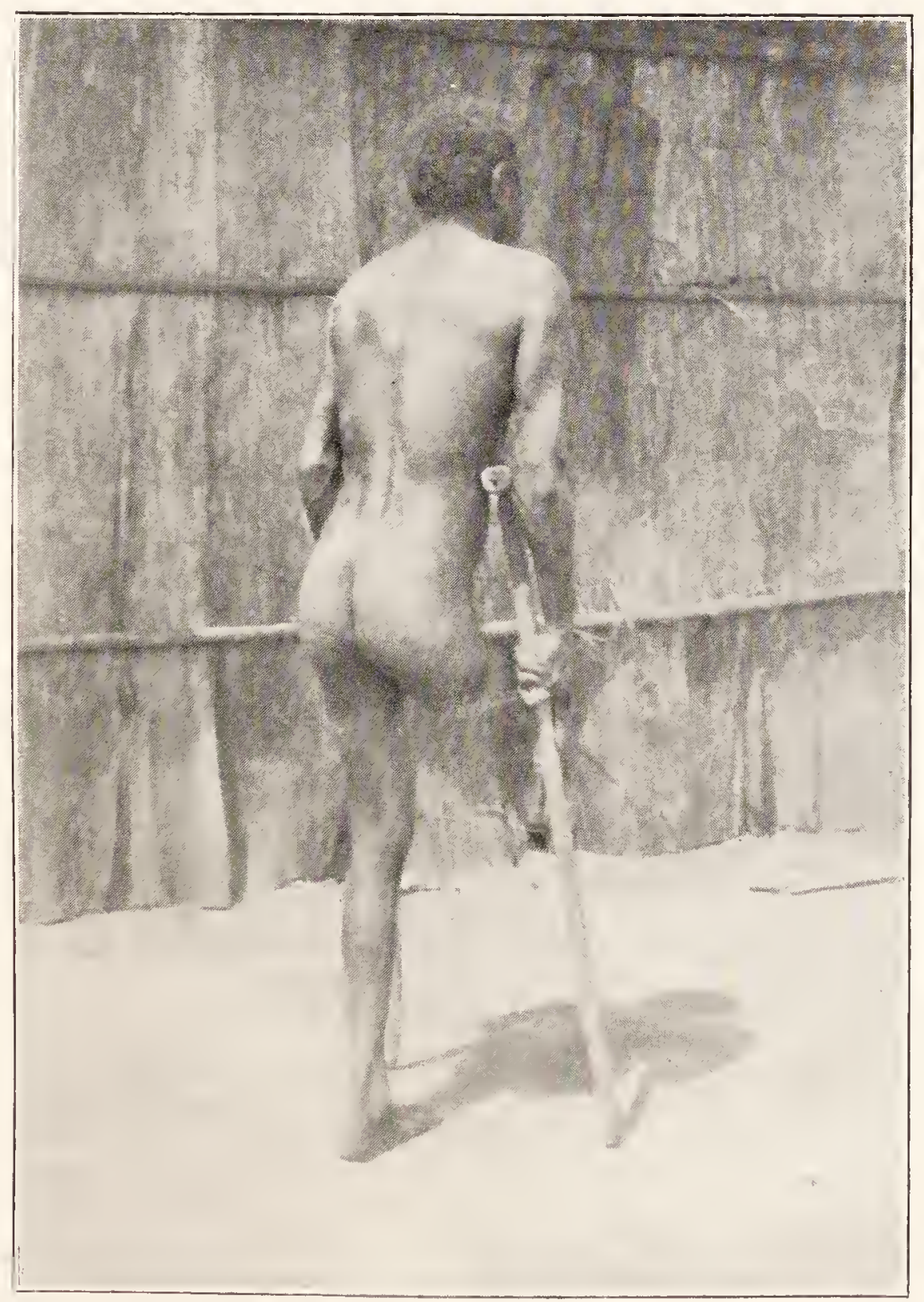

B.S.

JiG. 479.- MELVILLE ISLAND MAN WHOSE LEG WAS IBITTEN OFF HY A CROCODILE. 


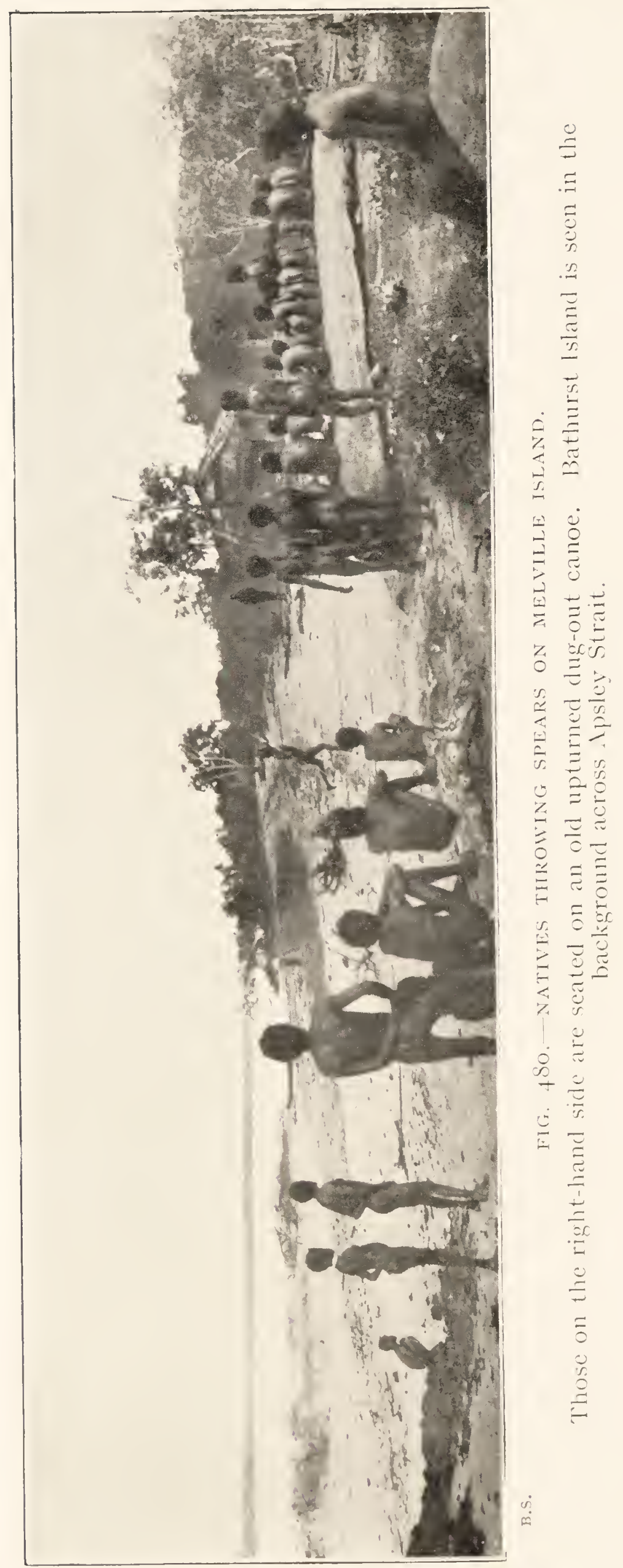


my leg he discovered a wound in one of his toes and was most anxious to have it treated in the same way. The toe was so small that the bandage had to go right round his foot and ankle to keep it on. He was very proud of it and went off to show it to all his friends in camp.

When the tide was low the anchor was released, and at 6 p.m. we went on board and, with the help of the tide, made slow progress up the Strait. It was a lovely, quiet evening. Cooper and myself sat in the stern, and in the bow the boys sat singing their corrobboree songs. We went on all night till I.30 a.m., when we anchored for a couple of hours at the entrance to a wide creek. Everything was as still as possible, save for a faint lapping of the water on the sides of the boat. At $3.30 \mathrm{a} . \mathrm{m}$. we started off again and were soon in the creek, up which we went, with the aid of the tide, that rises and falls about ten feet here.

March 2 Ist.-The creek for miles was often a hundred yards and never less than fifty yards wide and wound about in all directions. There was nothing to be seen but a thick belt of mangrove trees, rising directly out of the water, and behind them the tops of the gum trees, varied here and there with patches of Cypress pine. A few crocodiles slithered down the mud into the water but, except for these and white cockatoos, Nankeen herons and kingfishers, there was little to be seen, and after about eight miles we came to a little landing-stage. It was very small and consisted of a double row of planks fixed to the tops of a series of piles driven into the mud. It led into a kind of tunnel leading inland through the mangroves. When we came up, the tide was high and we landed from the dinghy, but two or three hours later the piles were high and dry, or rather they rose out of deep, evil-smelling mud, on which numbers of small, bright red-coloured crabs contrived to walk about. We went through the tunnel 


\section{WANDERINGS IN WILD AUSTRALIA cн.}

on the narrow, slippery and rickety planks and came to a track, leading back for a quarter of a mile to a saw-mill, where a solitary white man, with the aid of boys provided by Cooper, was sawing Cypress pine. This is about the only wood here that is not touched by white ants and it only grows in isolated patches. It was just as well that Cooper had come over with the stores, as the man had been without meat for ten days and was living on bread and tea. The jungle was very dense, but fortunately there were tracks through it that had been cut to get at the pines. The trunks were overgrown with epiphytic ferns and orchids, but it was not the flowering season for the latter. There was one special kind of fern that I had not seen before. It had a long series of cups, filled with decaying vegetable matter and made of two or three great sheathing leaves, one or two fronds arising from each cup. The cups were formed on a creeping rhizome that ran spirally round the trunk to a height of ten or twelve feet. The older and smaller cups at the base of the trunk had lost their fronds and were withering away. There were a few small, flatshelled snails, barred with yellow and black bands, crawling about, but I could find no other trace of animal life. The scrub everywhere was very disappointing in this respect. At 6.30 p.m., after the lugger had taken on board a load of Cypress pine logs and a few of Cooper's Port Essington natives who had been working at the saw-mill (Fig. 48I), we moved away from the landing and lay out in the stream. It was a lovely night, perfectly quiet and clear, and away in the north, above the mangrove trees, the Great Bear shone out. All night long there was a perfect silence except when some night bird stirred amongst the trees.

March 22nd.-Soon after 8 a.m. we were off on the tide down the river, and three hours later came out into Apsley Strait. It was one of those almost, but not quite, perfectly still days, when everything, trees and cloud masses, 
forms straight, long-drawn-out reflections in the water. For two hours we were almost becalmed and it was suffocatingly hot under the awning that we put up to shield us from the sun and the reflection from the water. Then suddenly the clouds came up from the north-west and we had a heavy rain squall that cooled things down. Then again the wind fell. We scarcely moved quicker than the tide carried us along, and it was 7 p.m. before we reached Cooper's camp.

March 25th.-I went across to Bathurst Island early in the morning and spent most of the day with Father Gsell. Since Dr. Gilruth and myself had been there, he and two other priests, Fathers Courbon and Croix, with the aid of some natives whom they were training, had already erected three or four large, stringy-bark huts with overlapping eaves and verandahs that looked quite picturesque. They had also cleared the land immediately round the station, so as to make a vegetable garden, and by cutting down the scrub, felling some trees and leaving other shady ones standing, had the beginnings of a delightful boulevard along the sea frontage (Fig. 482). I had a long and interesting talk with them about the customs and language of the natives, which they were studying carefully before beginning serious work amongst them. After returning I had the last of our usual evening talks with Cooper and Alice and a few of the boys, finding out things.

March 26th.-Packing all day. A young crocodile came swimming along close inshore. There was much excitement, but he was soon speared. He was only five feet long and just went into my largest collecting tin. By five o'clock we had everything on board the lugger, and two hours later were clear of the Strait, sailing along quietly, watching for the last time a gorgeous sunset behind Bathurst Island. It was a lovely moonlight night with a north-east breeze that brought us on splendidly until we were within sight of the entrance to the Darwin harbour when, at seven 
694 WANDERINGS IN WILD AUSTRALIA сн. xxvi o'clock, it suddenly fell away, and for three and a half hours we bobbed up and down in blistering heat on an oily sea. A great sea tortoise (Chelone midas) came up for a breath of air quite close to us. He was fully five feet in length and would have made no end of turtle soup, but he dived down as soon as he saw us. It was nearly midday before a breeze sprang up, only a slight one, but just enough to bring us into Darwin, and at I.30 p.m. we dropped anchor and reported ourselves to friends who had been rather anxious about us, wondering whether Cooper and his lugger had survived the gales that blew hard in Darwin, off and on, for two days after our departure, three weeks ago, just as they had done while we were crossing to the islands. 


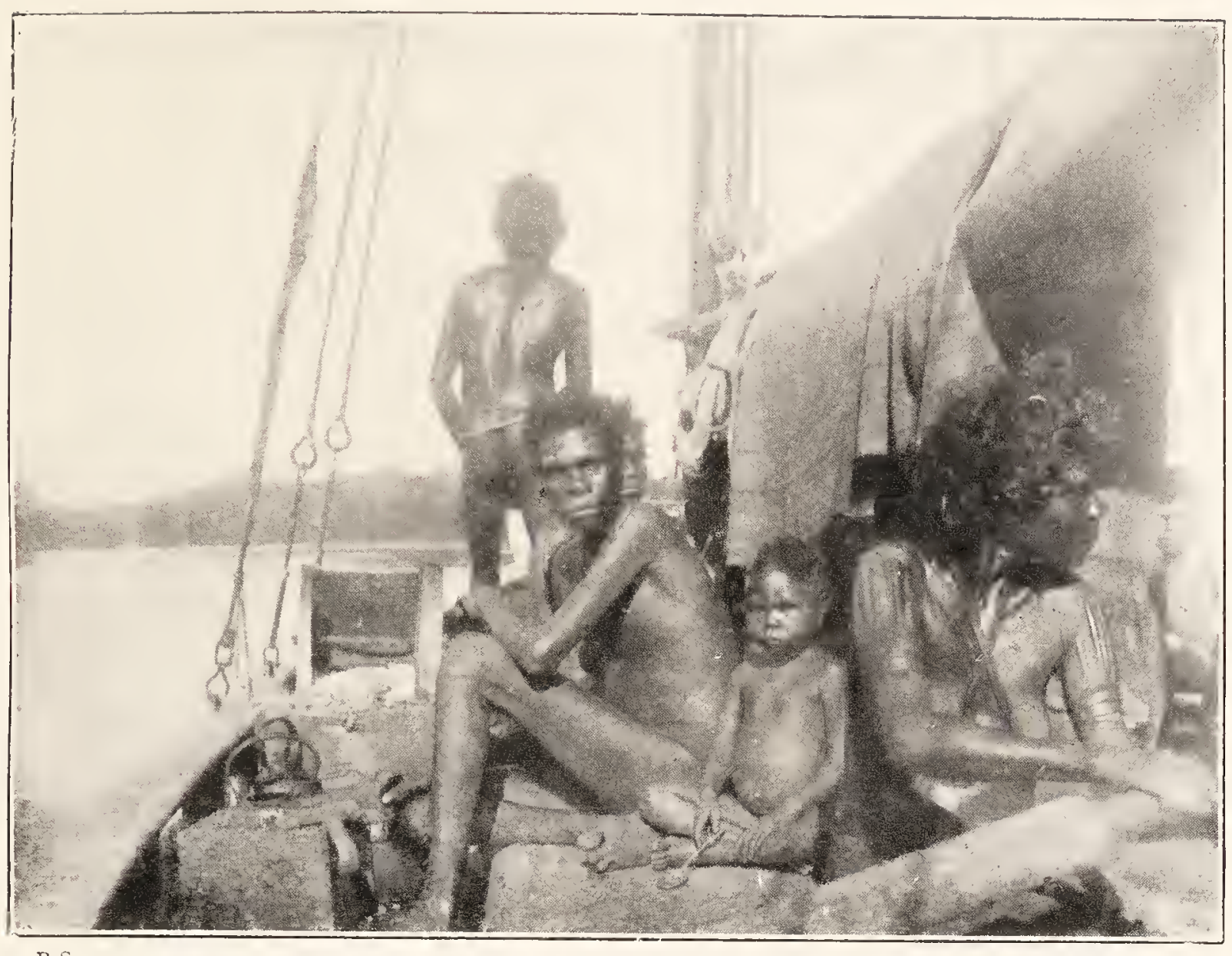

B.S.

FIG. +SI.-GROL'P OF PORT ESSINGTON NATIVES ON BOARD COOPER'S LUGGER, IN APSLEY STRAITS.

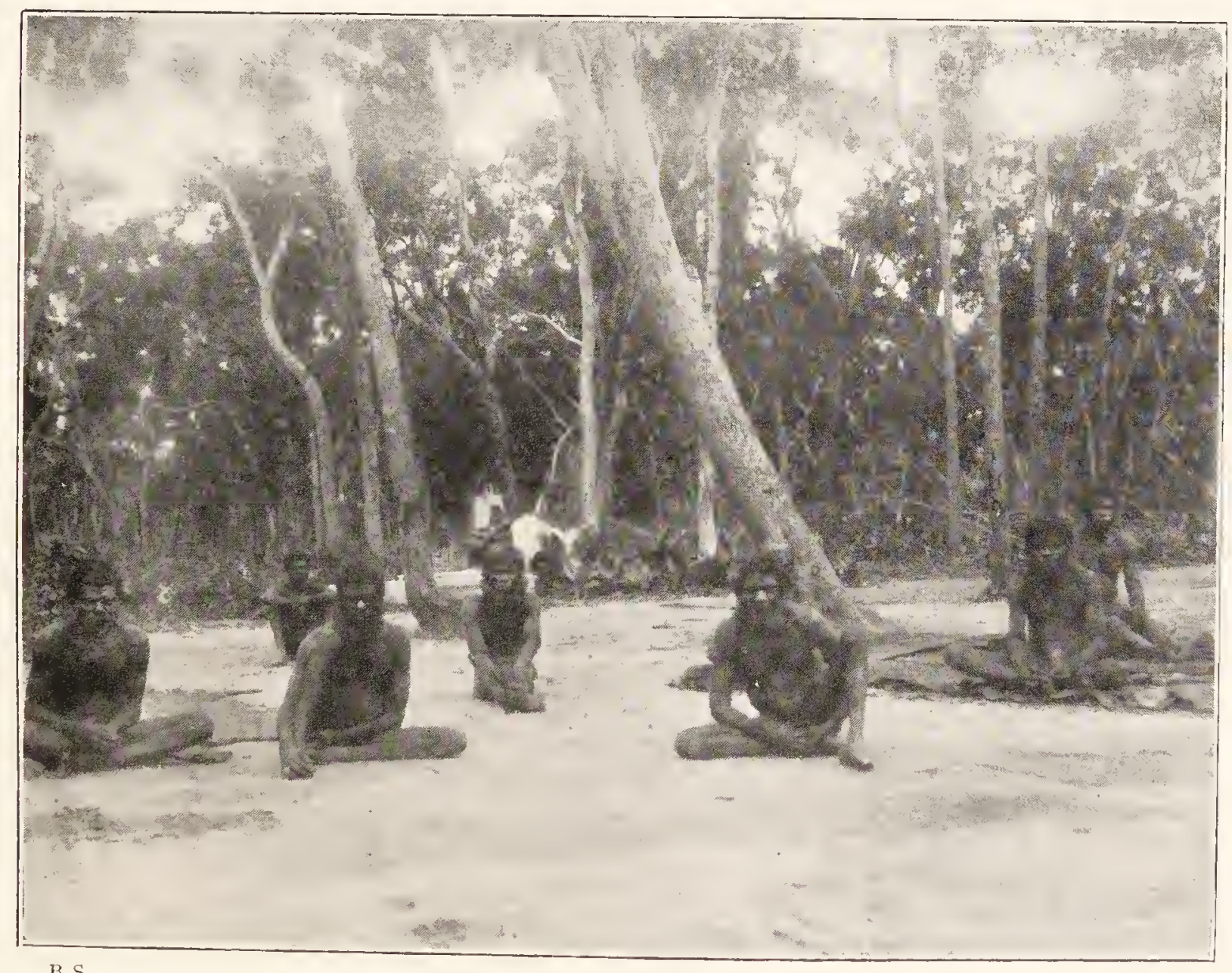

B.S

FIG. fS2. GROUP OF OLDER MEN IN CHARACTERISTIC ATTITUDES, HELVILLE ISLAND. 

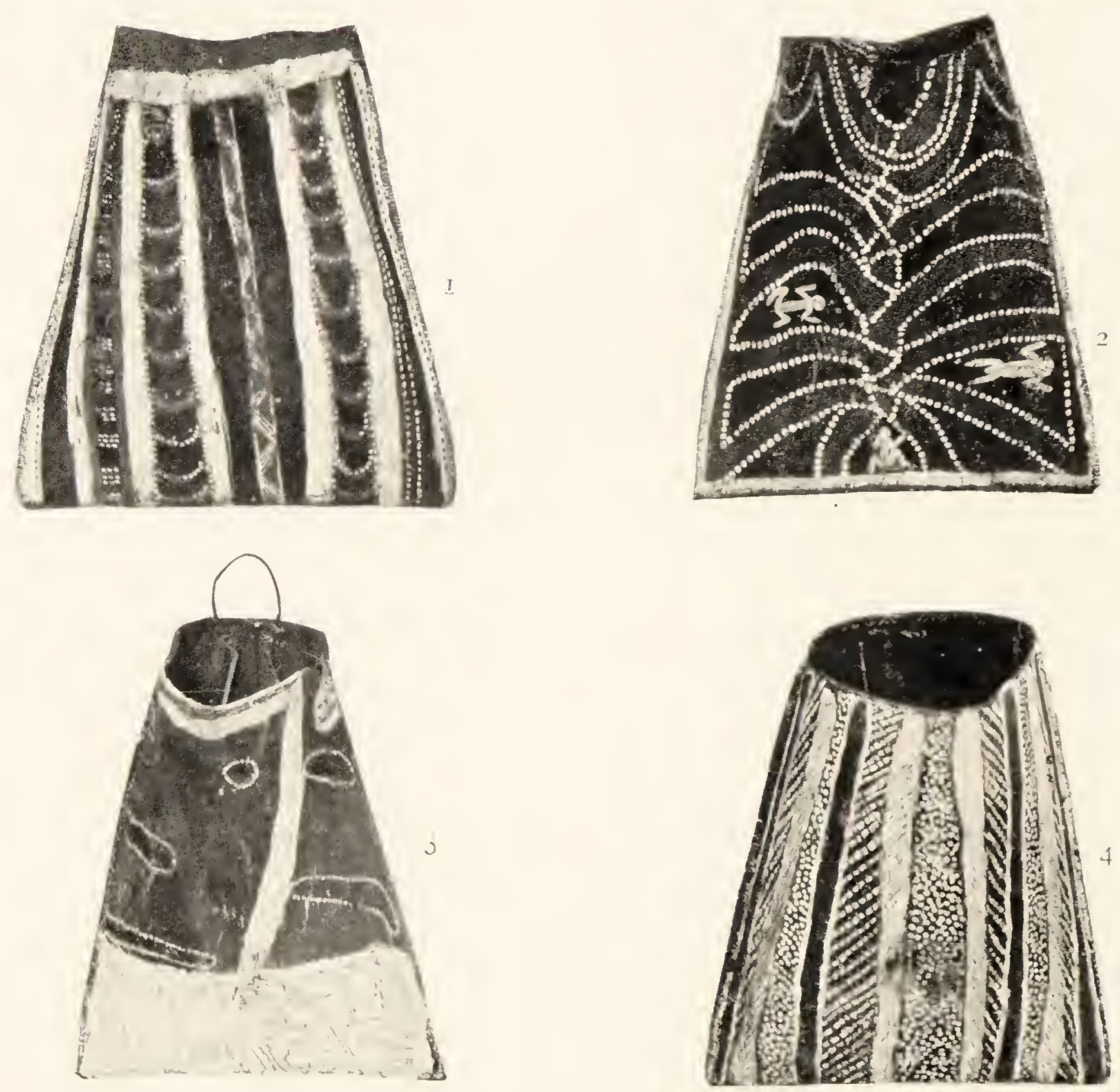

TIG, SS3-FASETS MADE FROMI STRIXGY-IARK, MELTILLE ISLAND. 


\section{CHAPTER XXVII}

\section{DECORATIVE ART OF THE MELVILLE ISLANDERS}

PAssing across from Darwin to Bathurst and Melville Islands you come into what feels to be like quite another world of aboriginal life as compared with that on the mainland, and yet, looking over the waters from Cape Don on the Coburg Peninsula, you can easily descry the shores of Melville Island. The natives mark themselves with skin cuts that give rise to great keloid scars, arranged with perfect regularity, and there is nothing like them on the mainland. Their initiation and burial ceremonies are wholly different, they have no spear-thrower, and their spears, clubs, baskets, and more especially their decoration schemes, are entirely unlike anything on the mainland.

Most interesting of all the things they make are perhaps the armlets, ring and discs that the women wear and carry during the mourning ceremonies around the grave-posts. The Arunta make the hideous chaplet of bones called Chimurillia and the Kakadu wear heavy armlets of plaited Banyan fibre string, but nowhere on the mainland is there anything in the least degree like the elaborate mourning paraphernalia of the Islanders. Those that are figured in Plate XI and Figs. 450-454 represent fairly well these quaint but decorative objects. The armlets are not made in pairs, indeed it is very rare to find two that are even as similar in detail as are the two lower ones on Plate XI.

Each one consists essentially of a sheet of bark, derived from the Stringy-bark gum tree, which is cut into various shapes, according to the design decided upon, and is then 


\section{WANDERINGS IN WILD AUSTRALIA cн.}

folded on itself in one of two ways, giving rise to two main types of armlets. One may be described as the single- and the other as the double-fold armlet.

Of the single-fold, Fig. 453, Nos. I and 2, is a good example. The original sheet of bark was shaped as shown in the sketch (Diagram I, p. 697). The total length is twenty-eight inches. The width at each end is four inches, and at a distance of five inches from each end gradually swells out, reaching a maximum of eight inches in the middle along the line c-d. A piece two inches square is cut out of each end and then the whole sheet bent over, so that the two ends come together, meeting along the lines $\mathrm{e}-\mathrm{f}$, enclosing thus an open space for the arm to pass through, eight inches in length and three in greatest width. Where the different edges come together they are sewn round with split cane which is continued all round the free margin. A light-coloured stick with knobs of beeswax, ornamented with red Abrus seeds, passes through the upper angle of the central space and is kept in place by human hair string, strands of which are bound round the open square. Split feathers of white cockatoo and brown owl are fastened between the square ends, the only other decoration consisting of a circle of beeswax on each side covered with Abrus seeds. This is one of the very few examples in which the surface of the bark has been left in its natural state, no colour design of any kind being drawn on it.

The double-fold type is sometimes simple, but may be complicated. Fig. 453, No. 3, represents a simple one. The original sheet had a central oblong, seven inches long and eight wide (Diagram 2), from each end of which a slip eight inches long and two broad projected. The first fold was along the line $\mathrm{a}-\mathrm{b}$, the second along $\mathrm{c}-\mathrm{d}$, so that when the armlet was formed there was a single projection on one side. The two projecting pieces are bound round with fur string, and while the bark was pliant were shaped so 

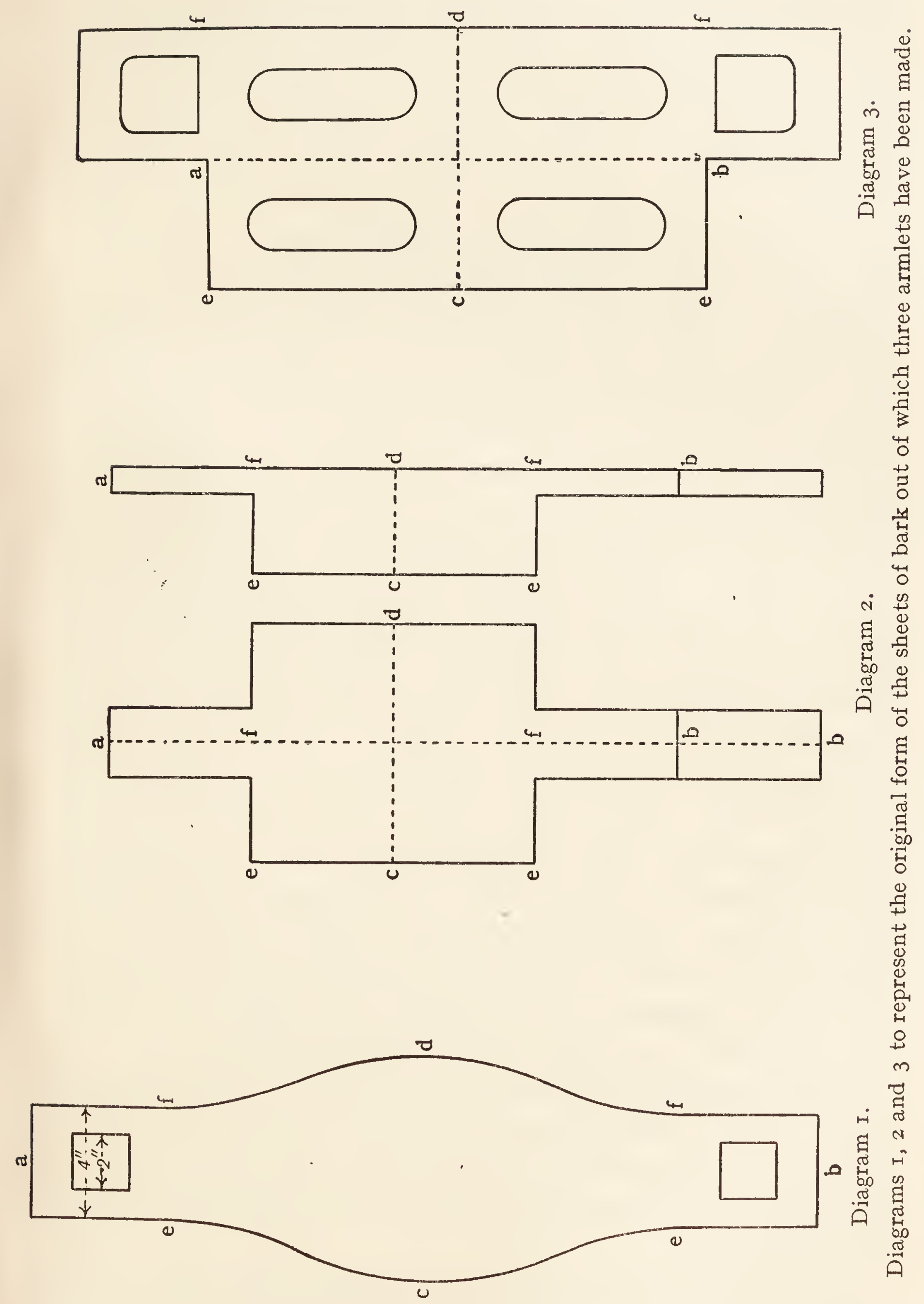

VOL. II. 


\section{WANDERINGS IN WILD AUSTRALIA ch.}

that they now form a kind of spout which has been smeared over with beeswax and white pipe clay. Abrus seeds are fixed in beeswax at the ends and base of the spout, and at the other end of the upper margin. The whole surface is ornamented with a central band of red squares, outlined with yellow and, outside this, white crossed with red lines.

A more complicated double-folded one is shown in Fig. 454, No. 4. The original sheet was as shown in Diagram 3. The total length was approximately twentyfour inches. In each projecting piece a square was cut and four oblongs in the central part, in such a position that, when the bark was folded over along the line $a-b$, the two upper and the two lower ones, respectively, coincided in position, and when again the sheet was folded along the line $\mathrm{c}-\mathrm{d}$ there were two window-like openings left, one on each side of the armlet. The free edges are sewn around with split cane. The projecting part is bound round, partly with split cane, partly with string, and a stick, fastened between the two original halves, runs across from side to side, its ends decorated with split cockatoo feathers. A flat ring is fixed on at the upper end of the projection and a round one at the other end. The whole surface is decorated with bands and lines of red, white, yellow and black. The general colour scheme is well shown on those figured in Plate XI, the two lower ones being amongst the most ornate of all these armlets, and it is possible that the string ornaments have been suggested by the rigging of a ship. The light brown feathers are those of the Nankeen night-heron.

There is a great variation in size of the armlets, the largest ones being so bulky that the women weaving them have to press their arms against their sides to keep them in place (Fig. 455). The smallest are just large enough to fit on to a child's arm.

In addition to the large bark armlets the women carry very remarkable flat discs, and others like these with the 
centre cut out, leaving a broad, flat margin, resembling in shape nothing so much as a quoit. They vary to a most extraordinary degree in size, from the large one, fifteen inches in diameter, drawn in Fig. 450, to the small child's armlet in Fig. $45^{2}$, the central opening in which measures only an inch and a half.

They are wonderfully picturesque and must take a long time in the making. The large disc represented in Fig. 450 , I saw being used during a grave ceremony on Melville Island in I9 I I. It is one of a special kind called Bamagun, and was carried by a woman who, while she danced, or rather ran round the grave, held it up in the air in her right hand. The disc itself is made of six circles of bent cane each wrapped round with split cane. The inner and outer margins of the disc are bound round with interlaced strips of split cane, as can be well seen in Fig. 45 I, No. 3. A certain amount of human hair, and sometimes Banyan string, is used to bind together the successive circles, and then the whole surface is coated with a layer of beeswax. In this one, the flat, quoit-like ring is three inches in width and encloses an open circle nine inches in diameter. The colour decoration is very distinctive. On the upper part of the circle, on the inner side, there is a white area edged with yellow, above and to the outside of this there is first a black and then a yellow area on the margin, the two being separated by a white line that has been a good deal rubbed out. Following down each side there is a red area, separated by a white line from a yellow space on the margin of the outer side. Then there follows a black band running across from the outer to the inner margin, then a broad white band edged with a narrow yellow line on the upper and a red on the lower side, and lastly, in the middle lower part, a broad yellow band. To the margin of this lower part there is attached a short median strand of Banyan string, and on either side of this a loop of the same, from each of which 
two strands hang down. The parts of the strands of string close to the disc are coated with beeswax, thickly studded with bright red Abrus seeds. Each of the five pendent strands ends in a rounded mass of wax, covered with seeds, the central one, in addition, being ornamented with a tuft of owls' feathers. The total length to the end of the central pendant is just thirty inches, and the woman held it in her hand so that the strands hung pendent.

The three specimens illustrated in Fig. $45^{\mathrm{I}}$ were also used in the same ceremony as the one just described. Fig. I is an illustration of a form called Pella-pella, and is made of a series of pieces of split cane, joined together and coated over with beeswax. The disc measures eight inches in diameter, the central circle, three inches in diameter, being occupied by Abrus seeds. Around these is a white ring crossed by yellow lines, and on the outer margin are four spaces, coloured in the same way; the remainder of the surface is covered with red ochre. At the lower end, by which it is held upright when in use, there is a mass of beeswax with Abrus seeds, and, hanging down from this strands of Banyan bark string form a pendant. The first five inches are whitened, then comes a lump of beeswax with Abrus seeds, then follows eleven inches of red-ochred string and more wax and seeds, with, finally, five inches of whitened string and a terminal lump of wax and seeds.

Fig. 2 shows another Bamagun. The flattened ring is ornamented like the large one (Fig. 450), but in this case there is only one pendant that passes through a disc at its upper and is attached to another at its lower end, where it terminates in a knob of wax covered with Abrus seeds.

Fig. 452, No. 5, is a child's armlet called Belliu-Belliu; it is covered all over with thick fur string and ornamented with Abrus seeds, and has three pendent strands of fur string, each ending in a knob of beeswax. Figs. 6, 7, 8 and 9 represent ordinary armlets in everyday use. 


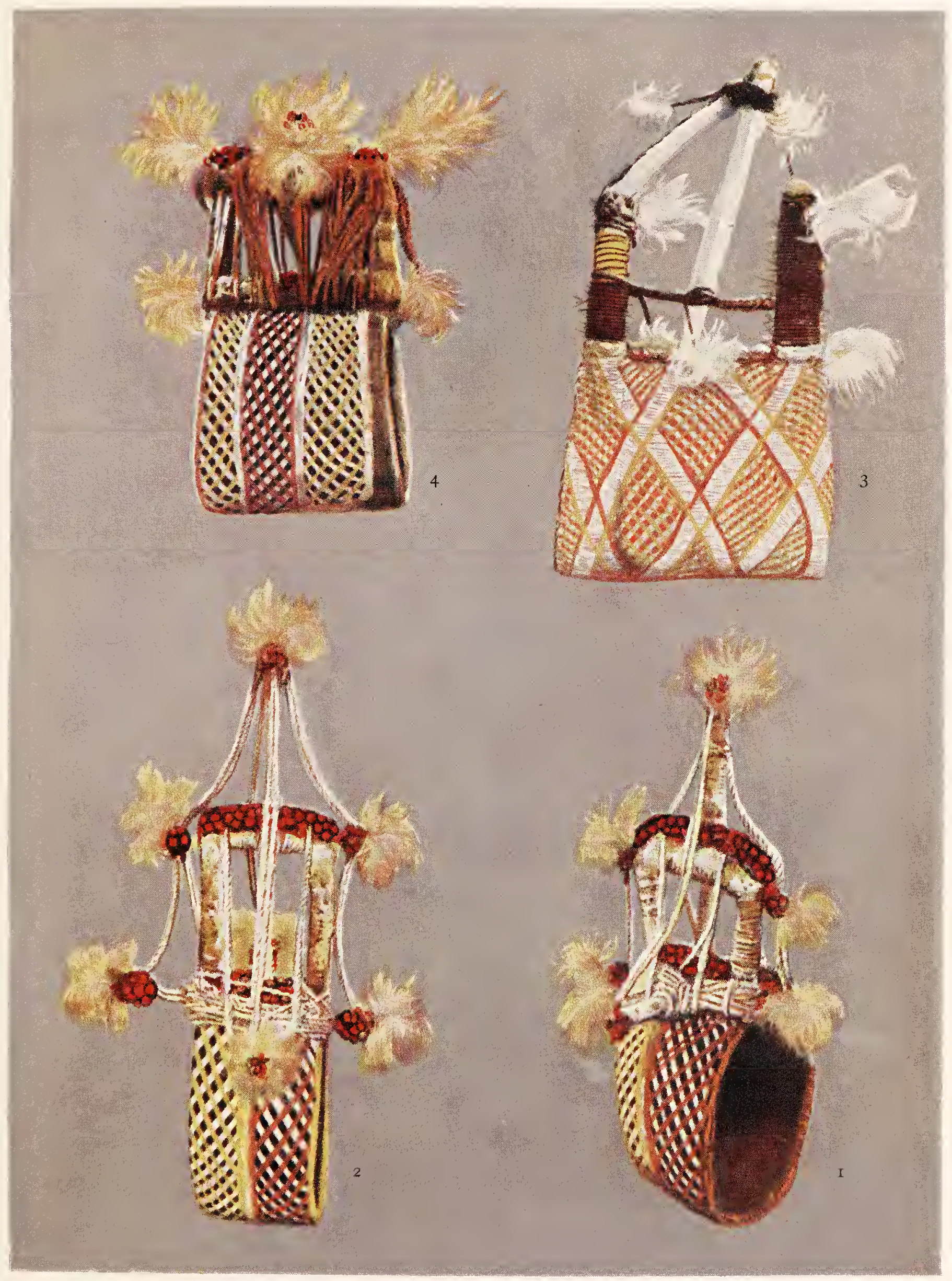

PLATE XI.-ARMLETS WORN BY WOMEN DURING MOURNING CEREMIONIES ON MELVILLE AND BATHURST ISLANDS 



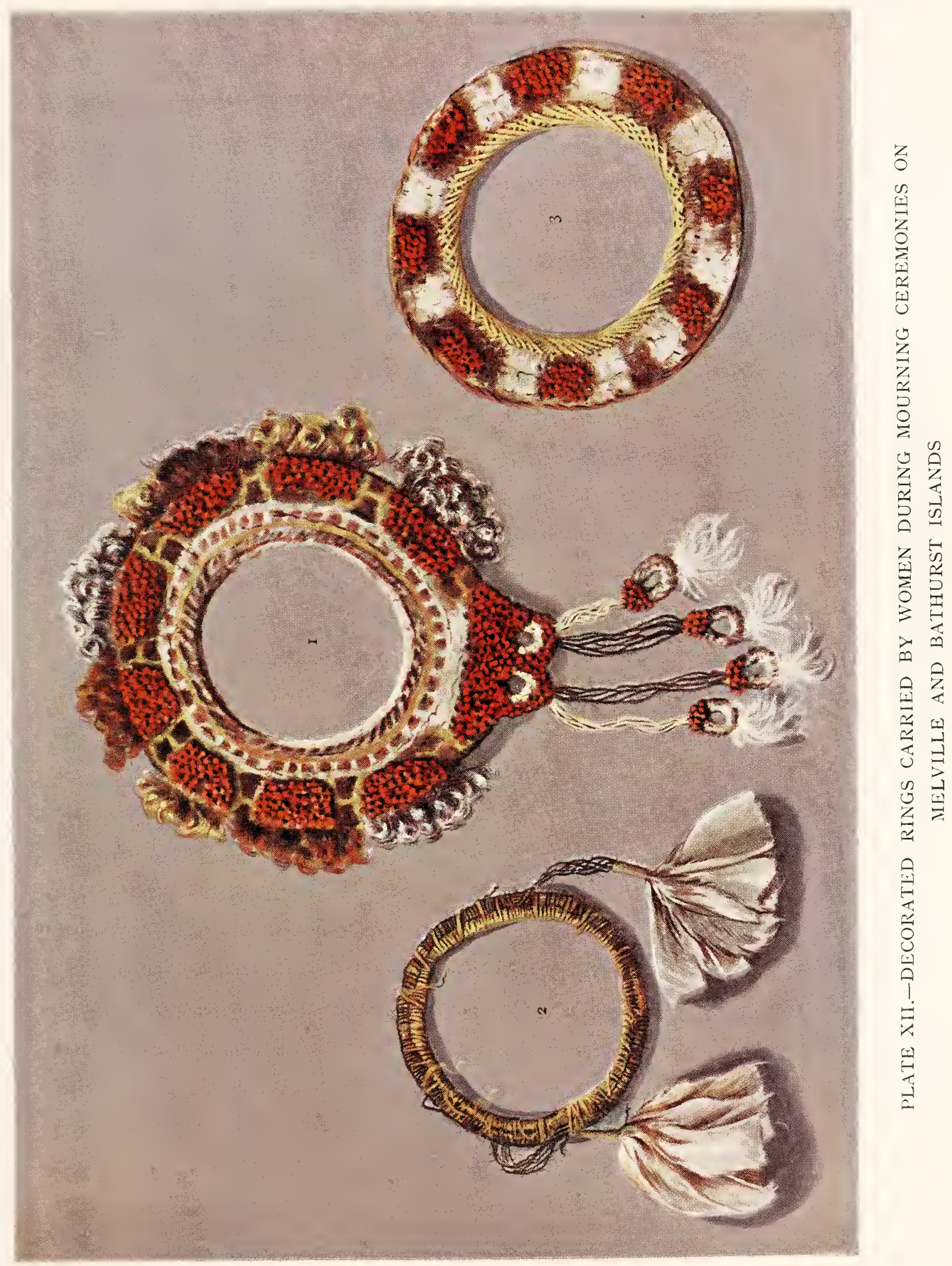



Various other forms are seen in the other illustrations, which represent not only armlets used on the ceremonial occasion of the grave dance, but also those in everyday use. In fact the ceremonial ones seem to be only a special form of the ordinary ones, such as are shown in Nos. 5,6 , 7,8 and 9 in Fig. 452, and the two series merge so gradually and completely into one another that it is evident they form, in reality, specialised developments of an original simple cane armlet that has been increased in size by the addition of one circle after another to form a flattened, but never a rounded, ring, with the addition of ornaments in the way of pendants and windings round and round of string, coatings of beeswax and groups of Abrus seed, until an extreme form is reached such as the large one shown on Plate XII, in which the outer margin is ornamented with eight groups of tufts of curly human hair, plucked by a man from his own beard and smeared over with white pipe clay and red or yellow ochre. So far as I could find out, amongst these Islanders no hair is ever cut from a dead man, as it always is, to use for magic purposes, by the Arunta and many other mainland tribes.

Bark baskets are known from other parts of Australia, but those made by these Islanders are remarkable for both their great size and bold designs (Plates XIII and XIV and Fig. 483 ). The native name for them is Wunga-dunga, the second half being the word for bark. The bark can only be stripped off during the wet season, when these baskets are always made. However large or small they may be, the process of making them is simple and unvaried. An oblong piece of bark of the desired size is cut from the tree, nowadays by means of an iron tomahawk, but originally by the sharp edge of a shell or stone axe. When the outlining cut has been made, it is easily prised off with a club handle or stout stick. First of all it is scraped over, to remove the outer rough surface and to thin it down, so that it can be bent on 


\section{WANDERINGS IN WILD AUSTRALIA сн.}

itself and the two sides sewn together by split cane. Beeswax Kapei (resin) is often used, but in any case the edges are brought so close together that the basket will easily hold water. The handle is always very small, and is made out of split cane, or Banyan bark string, attached to each end by a loop through the bark, and in many cases seems to be quite inadequate in size and strength for the weight of the material that the basket is capable of holding. Some of them are indeed so large that they look as if they had been made only for "show" purposes and, though scores of them were constantly seen in the camps, I never saw one of these abnormally large ones in actual use. When full, it is carried on the back by means of a stick passed through the handle. In many cases, as in Plate XIII, Fig. I, the two sides are strengthened near the opening by special strips of split cane sewn across from side to side in criss-cross fashion. In every case the margin of the back is sewn over with a double strip of split cane, also in criss-cross, the object being to prevent the bark from splitting down, as it might otherwise easily do in this part, where around the handle the pressure is greatest. Figs. I and 2 on Plate XIII represent specimens of, probably, maximum size-at least amongst a great number I have never seen any larger ones-and when full of yams are quite heavy enough for any blackfellow to carry. The largest (Fig. I) measures thirty inches in length or depth, and fourteen from side to side, across the opening. They vary in size from this down to a small one such as that in Fig. 483 , No. 4, which is only eight inches in height and five in width at the opening. Owing to the fact that the original sheet of bark is the same width along its whole length, the baskets all of necessity narrow down towards the widely open mouth end when the sides are sewn together.

There is a most extraordinary variety amongst them in regard to designs, and not only this, but those on the two sides 


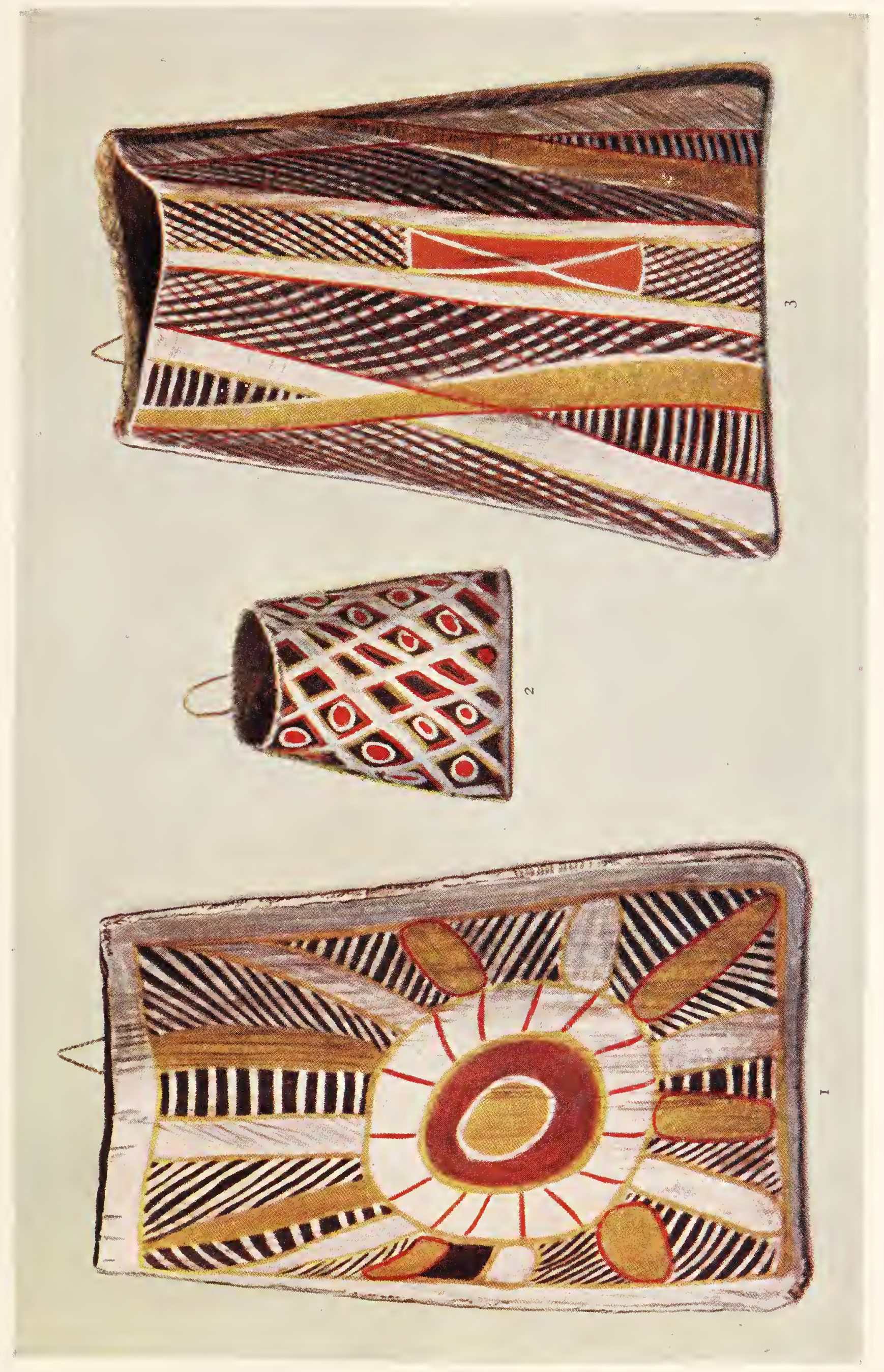





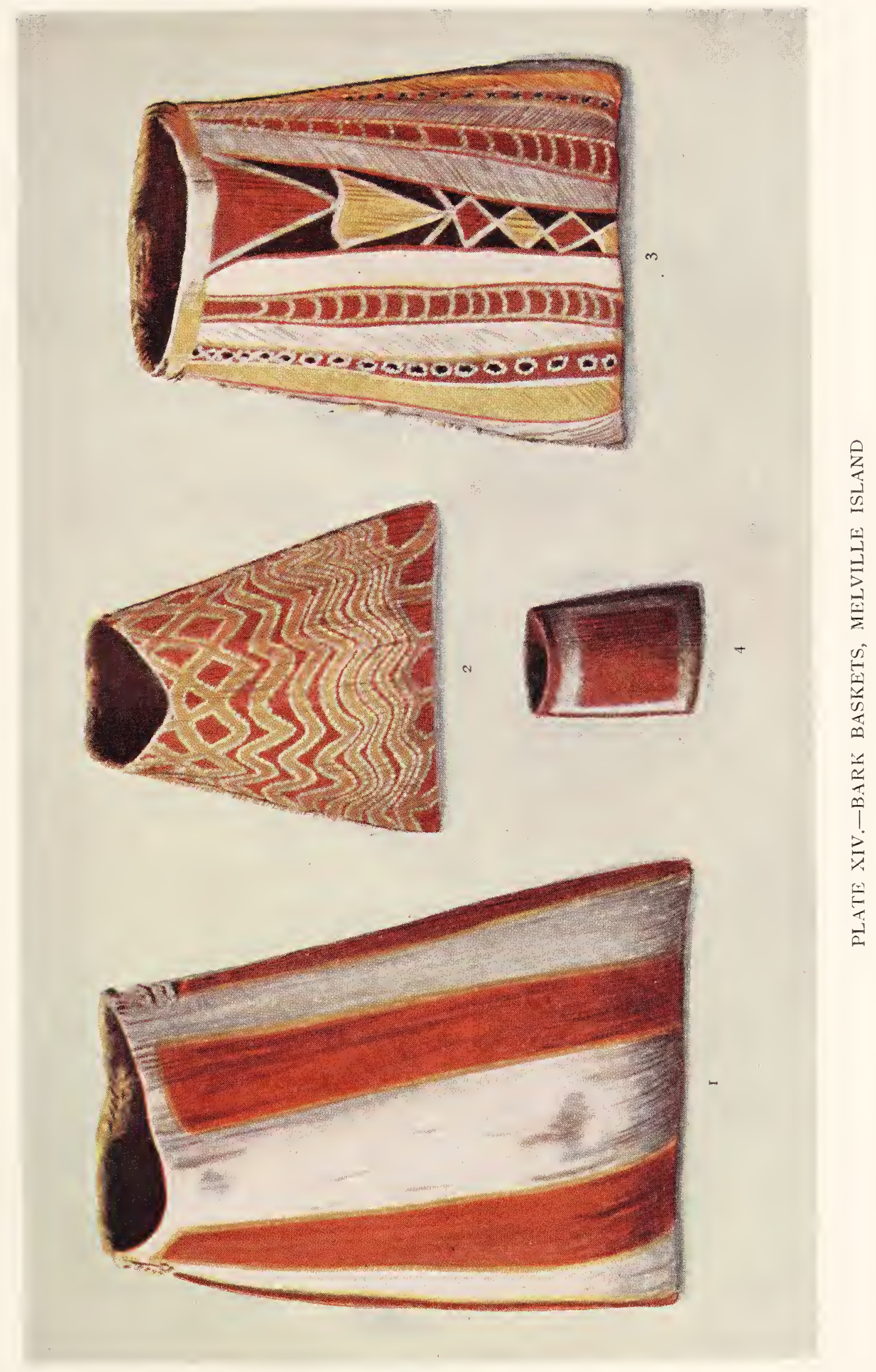



of the same basket are often different. In almost all cases it is purely conventional, zoomorphs or phytomorphs being very rarely met with. In some, as in Plate XIII, Fig. I, the design is simple and bold. The longitudinal white bands run into a circular one round the margin so that the intervening red ones edged with yellow do not reach this. Fig. 2 shows an entirely different design. The whole surface has originally been covered with red ochre. On this there are sinuous cross bands of yellow, the two upper ones interlacing, those below running parallel and close to one another with short bands passing downwards from the lowest transverse one to join similar bands drawn on the other side. The yellow bands are outlined with white dots that add much to the lightness and grace of the general effect, as compared with the heaviness of the broad, hardedged bands in most specimens. Fig. 3 is more ornate. The design is quite symmetrical and is repeated with very slight variations on the opposite side. A very effective feature, more so than appears in the drawing, is the series of black circles surrounded with white dots on a red ground. On both the white and yellow bands, a succession of fine lines, running in a slantwise direction, has been scratched out. The natives are very fond of this, the effect, if not the deliberate intention, being to make the band look much less solid and heavy. The effect that it produces can be seen on comparing Figs. I and 3 on both Plates XIII and XIV.

In Fig. I on Plate XIV a particularly bold design is seen. On this bag the two sides are different from one another. Fig. 2 is rather roughly painted but is different from all the others. There is a double series of slanting white bands, running lengthwise across the dark, uncoloured bark and crossing one another. The rectangular spaces enclosed by them are bordered with red, or red and yellow lines, and in most of those away from the middle line there are circular 
patches of red bordered with white. Fig. 3, one of the largest of the series, has different designs on the two sides and is also different from most other bags, though not so markedly, but still in the same way as that in which certain spears (Plate XV, Figs. 5 and 7) differ from the great majority of others. The narrow lines are finer and closer together, red ones are drawn across white ones, and the broad white and yellow bands are scratched across so that the dark bark beneath shows through, breaking up the heavy masses. The whole effect is that of a design finer and more delicately drawn than, for example, that on the two others on the same Plate.

Fig. 483 shows four baskets, on all of which dotted lines and masses of dots are employed in the design. Fig. 2 is remarkable as being one of the very few in which zoomorphs are introduced. They are in the form of three crude, conventionally drawn human figures that lie in interspaces of yellow, curved bands, painted on the bark, which has been red-ochred all over. The bands are outlined with white dots and look rather like ribs projecting from a central line of vertebræ. Fig. 3 is a remarkable, quite asymmetrical and, apparently, quite meaningless, crude design. The general surface is dull red. The lower part is coated with white pipe clay with lines roughly and irregularly scored across it. A white band runs partly round the margin, and, from its end another runs slanting down to a lower white patch. A few circles and very roughly curved bands are scattered irregularly over the surface. Fig. 4 shows what is rather rare, and that is longitudinal bands made up of white spots on a black ground.

The spears, or, at least, the majority of them, are no less characteristic of the Islands than are the baskets, and there are at least five different kinds. None of them have the little cavity at the tip of the handle end, made to fit on to the point of a spear-thrower, an implement that is not met with 


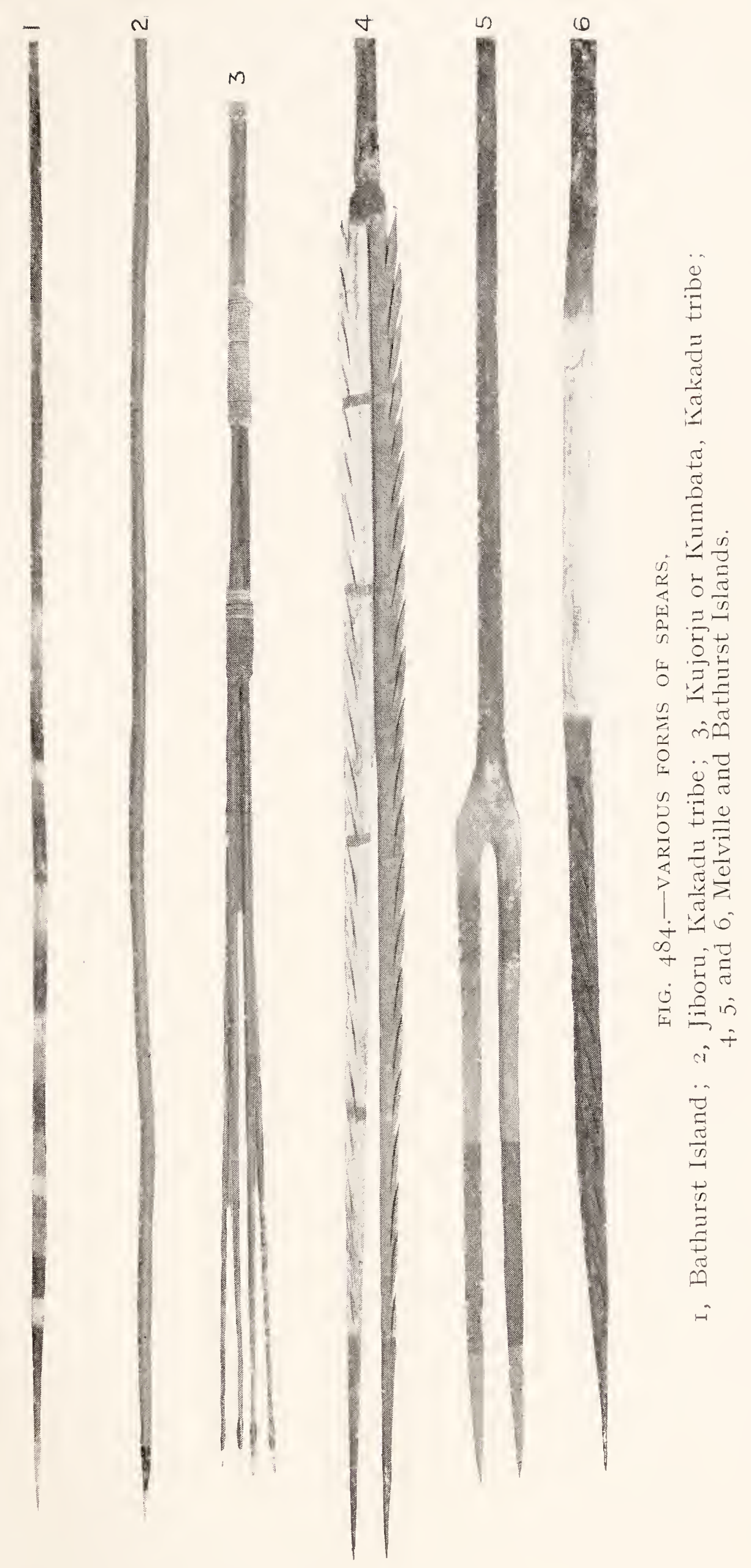




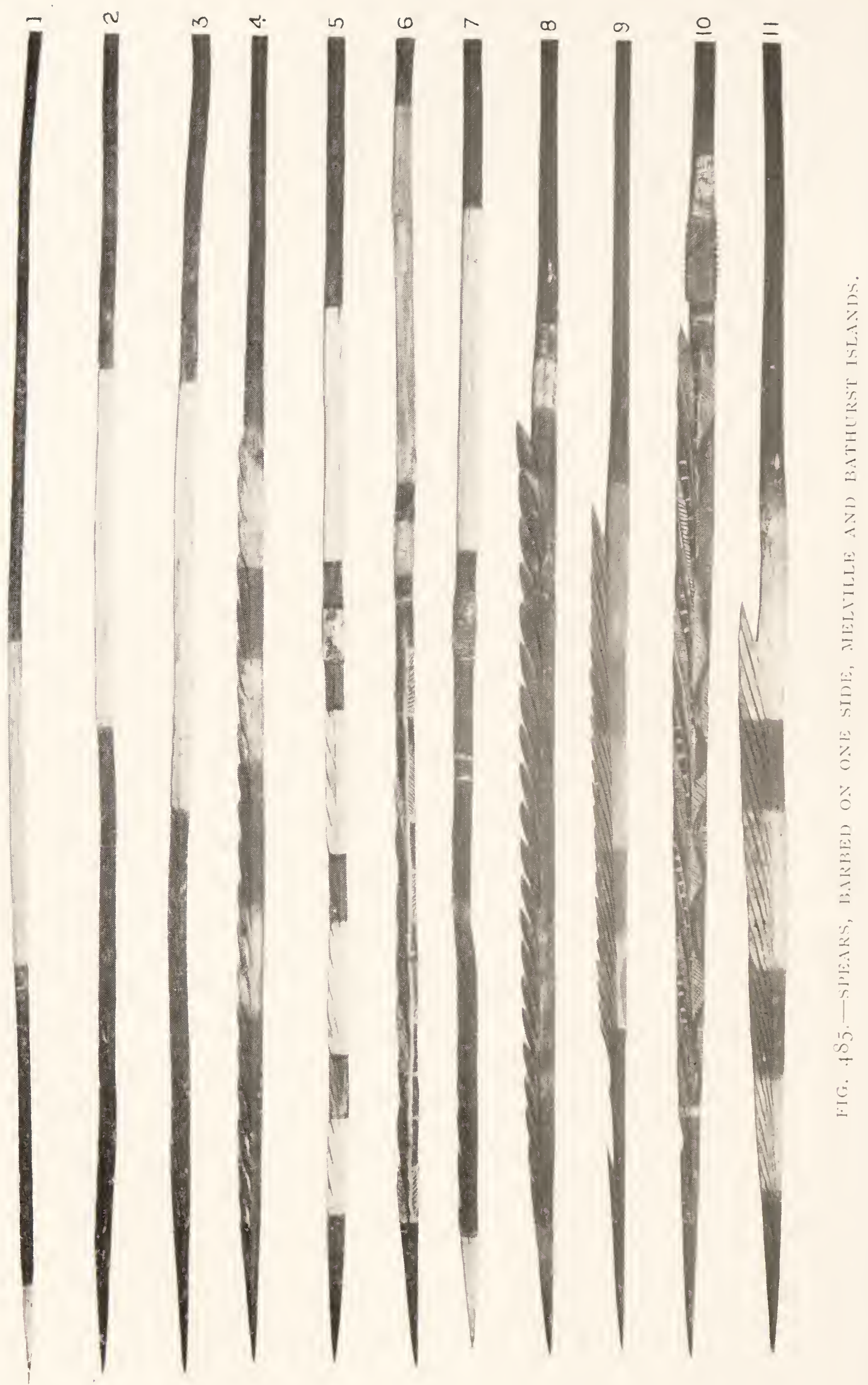


on the Islands, though very characteristic of the near mainland tribes on the Coburg Peninsula.

The first is a very simple one called Wallunka (Fig. 484 , No. I ; Fig. 485 , Nos. I, 2, 3). It has the simple form of a long, round, pointed, unbarbed stick of hard wood, from seven to ten feet long.

The second is single-pronged, with barbs on one side only, and is called Aunurgitch. There are very great variations in this type, ranging from very crudely-made ones (Fig. 485 , Nos. 4, 5, 6 and 7), on some of which the barbs are only few in number and very distinctly outlined, to others (Nos. 8, 9, IO, I I) in which they are numerous, very long and closely placed together, overlapping one another like the scales on a pine cone. No. 4 represents a crude form, Nos. 8, 9, Io and I I very carefully made ones. In No. Io we have a very characteristic form. It measures eleven feet five inches in length and has nineteen barbs, the point of the last one being fifty-two inches from the tip of the spear. Immediately beyond the barbs there is a flattened part ornamented with serrations; beyond this again there is a length of three inches wound round with vegetable-fibre string. This is very suggestive indeed of hafting; in fact, in the case of any ordinary spear from the mainland, the binding round with string, in this part, might safely be taken as proof of hafting. Fig. I I, which has a length of nine feet five inches, is a very good example of Aunurgitch. There are twenty-nine barbs, long, thin and close set, perfectly formed, and overlapping one another with a space between them only just wide enough to hold a knife blade, and yet the only cutting instrument that the native had was a sharp-edged shell of a species of Cyrena. They occupy a length of forty-two inches, back from the tip of the spear, which tapers to a very sharp point, just ten inches in front of the first barb. The handle end, as in all the Island spears, tapers to a point. 
The third very characteristic, and perhaps the commonest, type, is the double-barbed spear. Typical examples are shown in Fig. 486. They are called Tjunkuletti and are cut out of the solid, various woods being employed. Nos. I, 2 and 3 are in process of manufacture out of ironwood (Leschenhaultia sp.), a very hard, heavy wood, very useful to the native. It is from the root of this tree that he gets the resin which he uses, as the Arunta does the porcupinegrass resin, and the West Australian native the resin from the Grass tree (Xanthorrhea). The surface was so smooth that at first I thought they must have been cut by steel, but this was not so. The native, whom I watched at work, had no knife, but was using the sharp edge of a bivalve shell (Cyrena) which is very abundant on the coast. After he had shaped the spear in the solid (Nos. I, 2 and 3), he first of all incised lines, indicating one after the other the outlines of the barbs, until, with infinite patience and wonderful skill and precision, they were all cut out in perfect form and sequence on each side of the shaft. There are never as many barbs on the Tjunkuletti as on the Aunurgitch. Fig. 4 is a comparatively short one, measuring ten feet in length. It has fifteen barbs on each side. They are, relatively to those of many other spears, rather short, flat and broad, the greatest width across them being four inches. Immediately below the barbs there is a length of two and a half inches tied round with string that has been covered with beeswax and whitened, exactly as if a head had been hafted on to a shaft. Fig. 5 has only eleven barbs on each side, and just below them the blade is flattened out and has a square opening pierced through it. No. 6 represents one of the longest spears, measuring thirteen feet three inches, with a maximum width across the barbs of two and three-quarter inches. There are twenty-one barbs on each side. The blade from the point to the tip of the last barb measures five feet. No. 7 is an admirable example of what is, artistically, the most 


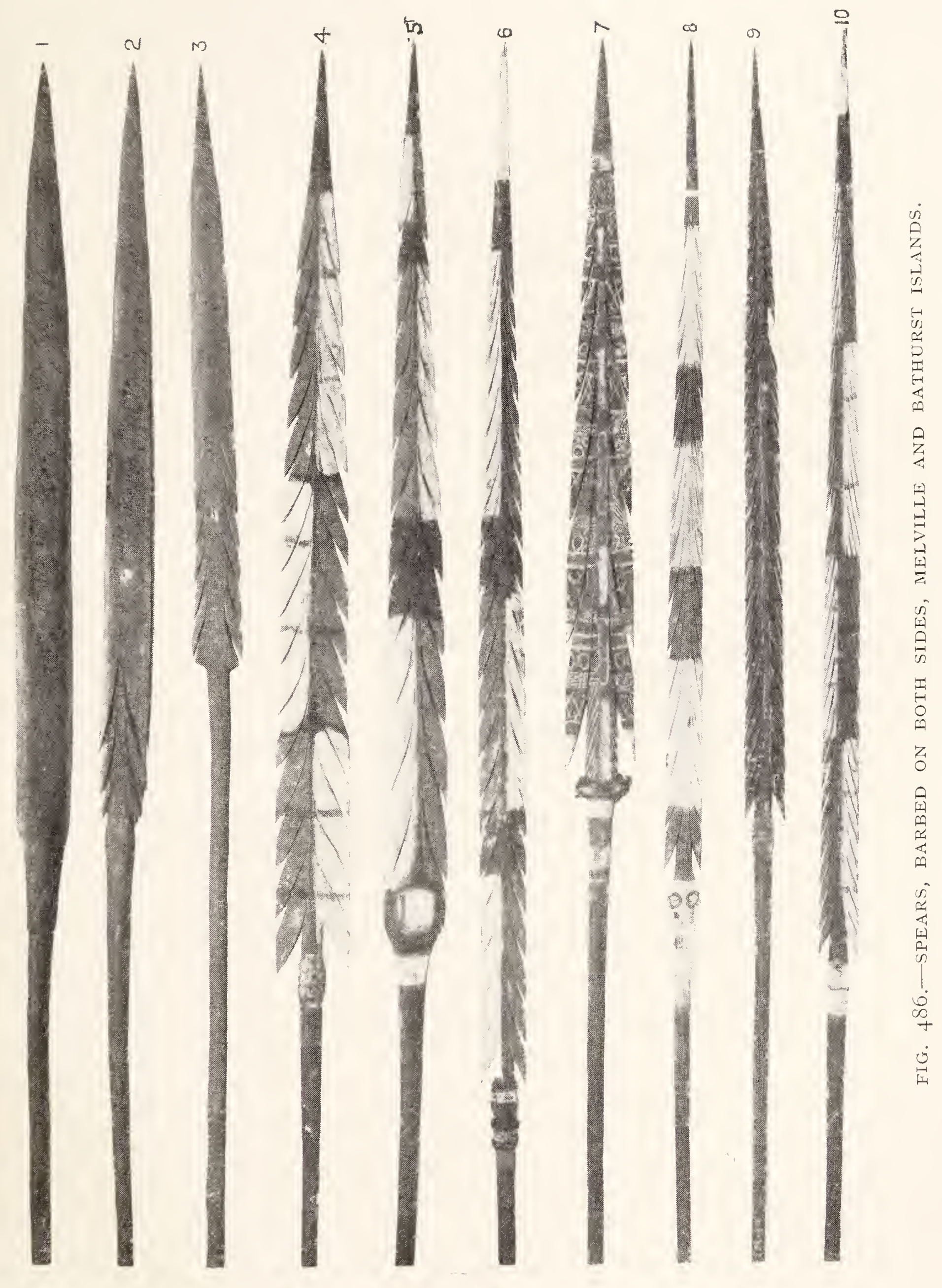


라.

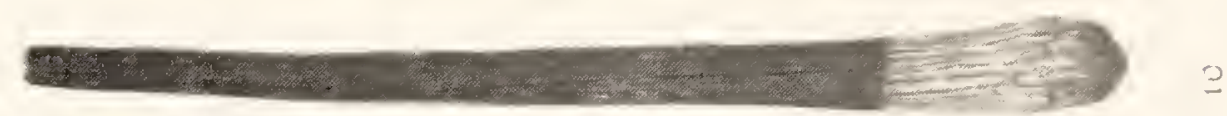

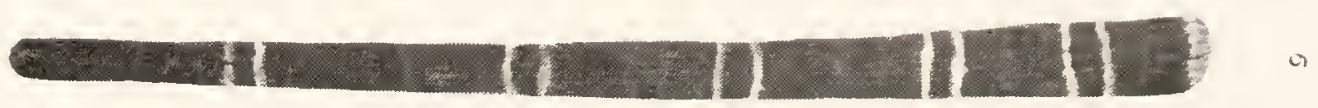

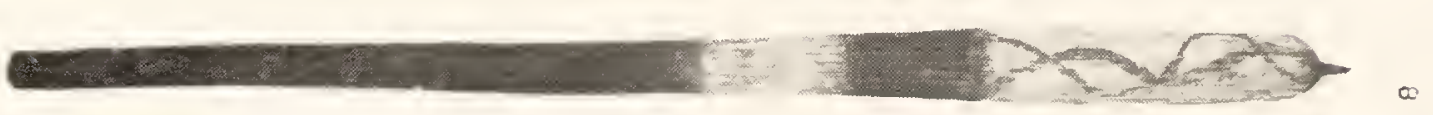

casmanom

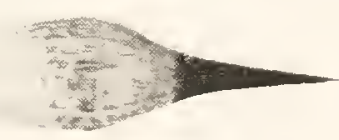

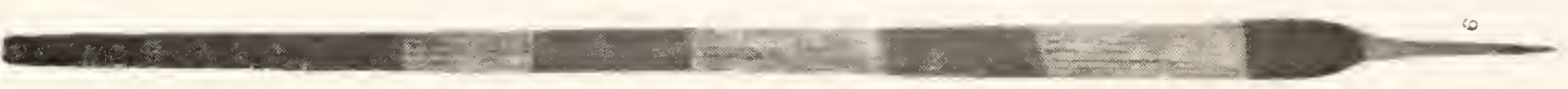
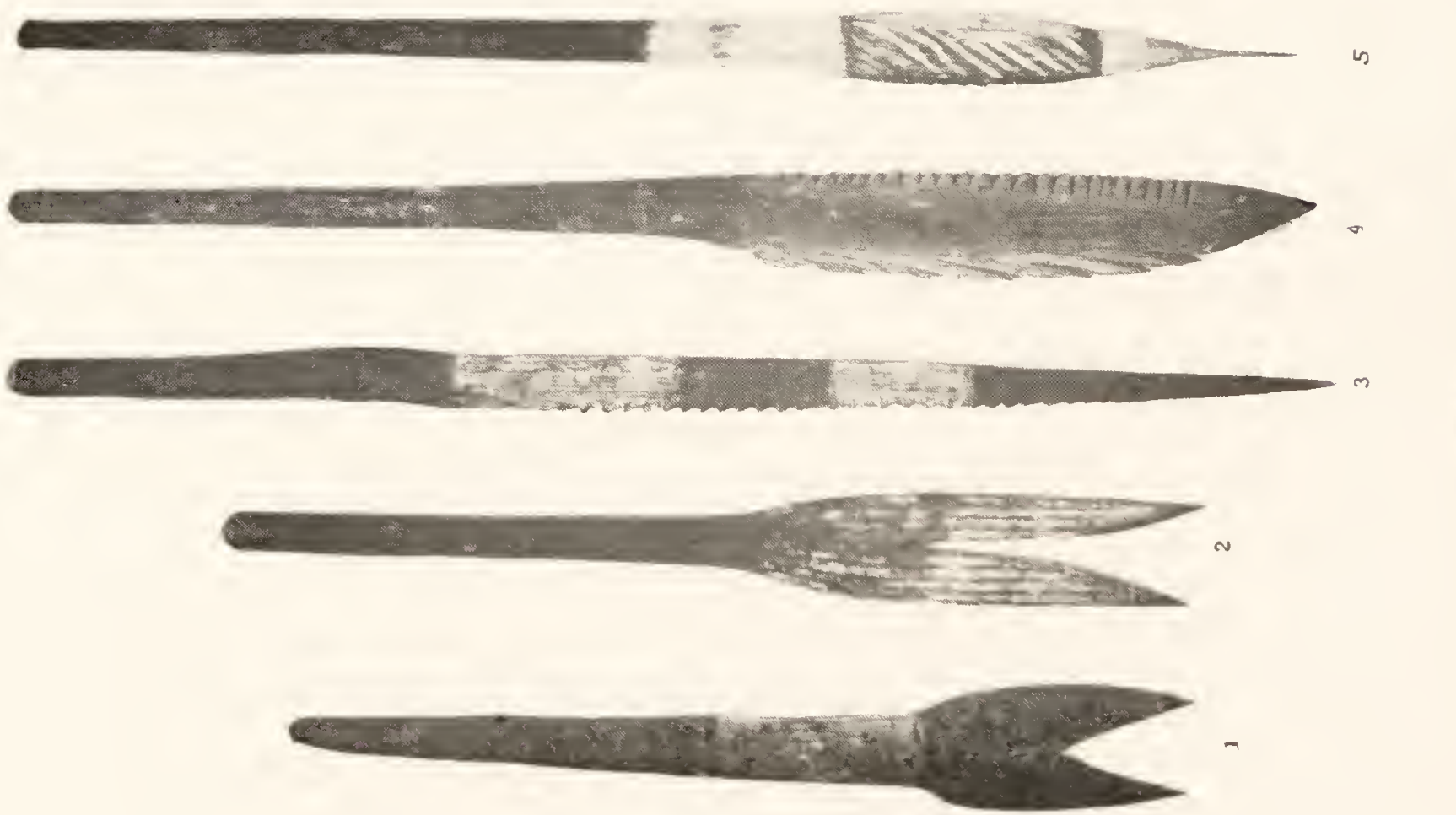
beautiful spear they make. The barbs are few in number, only five, but increase markedly in length, the last one measuring, from its tip to the point at which its upper edge joins the shaft, more than ten inches. Nos. 8, 9 and IO have the barbs numerous, close set and narrow across from side to side.

With only a small collection available, it might easily look as if these double-barbed spears could be divided into two series, one with a few broad barbs, the other with many close-set, narrow ones, but in a large collection this distinction does not hold good. Even in the few selected here for illustration on Fig. 486, it will be seen that, whilst Nos. 4 and 5 with their few heavy barbs, and Nos. 9 and Io with their numerous close-set, narrower ones, appear to be markedly distinct from one another, Nos. 6 and 8 are clearly intermediate forms between the two extremes.

From the drawing on Plate XV some idea may be gained of the really extraordinary and varied scheme of decoration on the spears. Much as they vary in detail, they may be divided, so far as design is concerned, into three main groups: first, those in which the surface is blackened, or the dark wood is allowed to show through and a design of lines and dots and circles is painted on this; second, those in which the surface is completely covered with a series of red, white and yellow bands; and third, those in which the colours alternate from side to side.

The first (Plate XV, Nos. 5 and 7 ) is a well-marked series, quite distinct from the other two. Along the middle of the shaft (No. 5) runs a series of narrow, elongate patches, coloured alternately white and yellow. Each barb, of which there are only five broad pairs, is a work of art in itself. In the first place they are cut with perfect symmetry, the space intervening between the successive barbs being so narrow as to make it a matter of wonder how it is incised with the shell (Cyrena) that they use for the purpose. To 


\section{WANDERINGS IN WILD AUSTRALIA $\mathrm{cH}$.}

take one barb as an example-the third from the end. The tip is yellow; then a red section crossed with white lines; then yellow spots on black; then white circles on black; then a white spot on black; then yellow lines on black; then white lines on black; then yellow spots on black; then red lines on black; then white spots on black; then white lines on black; then a red patch, and, lastly, yellow spots on black. In this spear the shaft expands just beyond the tips of the lowest barbs, to form a somewhat flattened, projecting band which is clearly reminiscent of the swollen hafting of many spears. It is ornamented with Abrus seeds fixed in beeswax. In No. 7 , a spear with thirty-four narrow, close-set pairs of barbs, the scheme of decoration is the same as on No. 5, and it is also met with on spears with a single row of barbs (Fig. 485 , No. Io). This type of decoration is quite distinct from any other either in the mainland or Island tribes, and it is much less frequently met with than either the second or third types, mainly, doubtless, because it takes an immense amount of time to execute and is the work of a few men who are very exceptionally gifted artificers and artists.

The second type (Plate XV, No. 6) is the simplest, but is not so common as the third. There are series of white, red and yellow circular bands of colour. On this specimen, what would have been the haft part, if one were present, is flattened out and has two holes pierced through it each ringed in red. The two holes are so suggestive of eyes that it is not difficult to imagine that rubbing away of the white pipe clay, such as occurred quite accidentally on the one in No.6, might suggest to the aboriginal artist the idea of depicting on the haft the broad features of a human face.

The third type (Fig. 486, Nos. 4, 5, 6 and I0) in the scheme is most frequently met with and seems to be peculiar to the Islanders, who employ it both on their body decoration and that of their clubs and spears. Its essential feature 


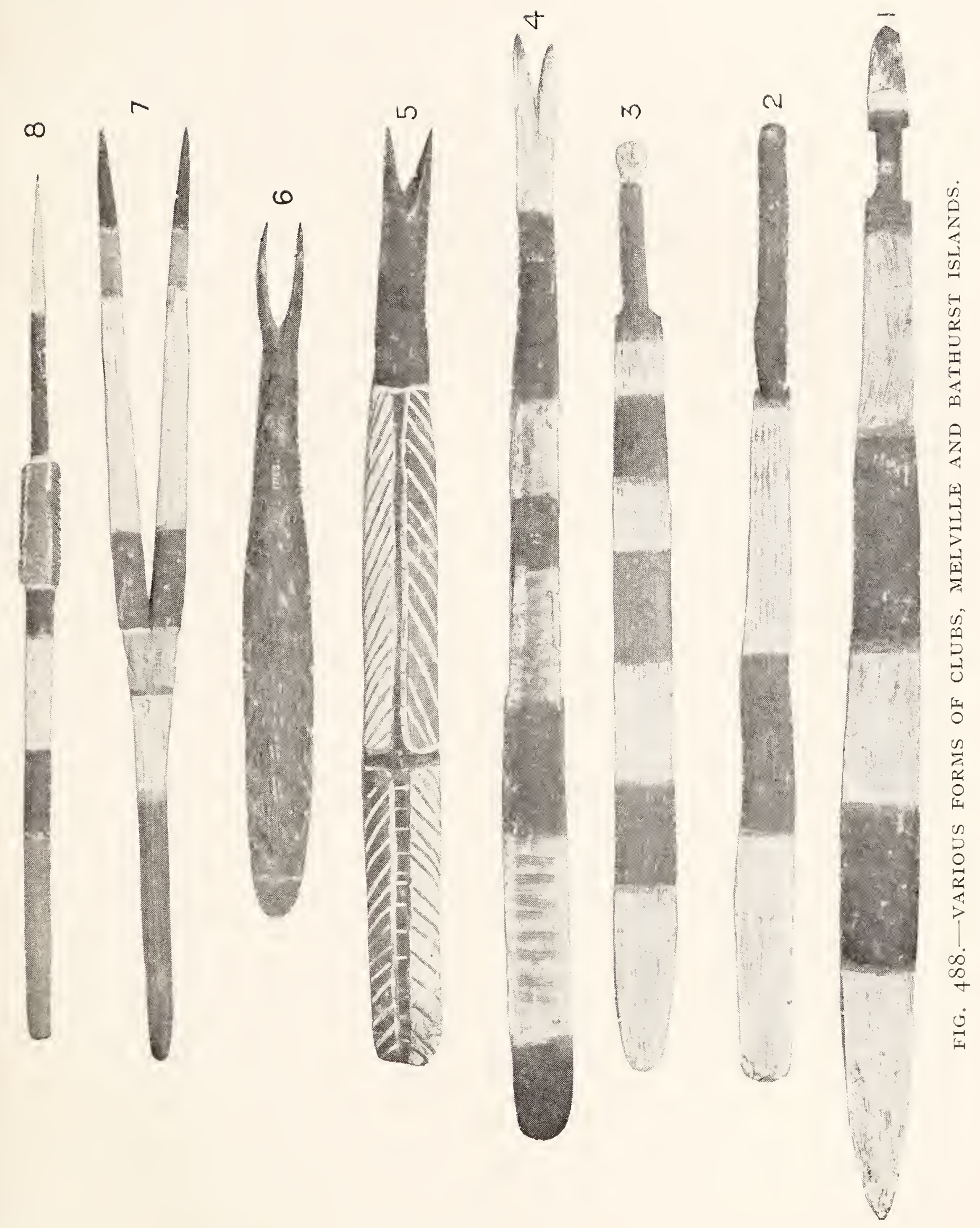




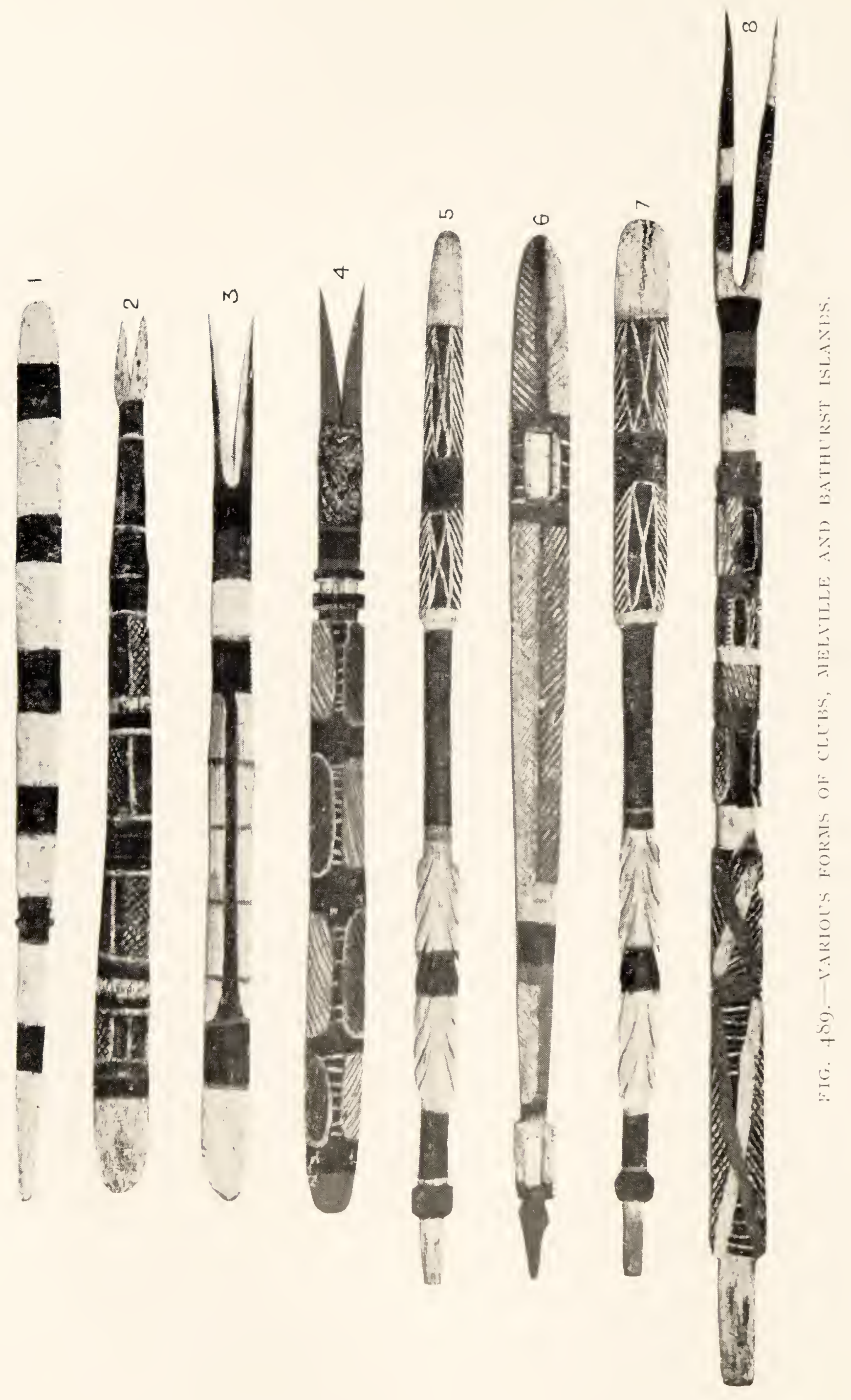


is the alternation of colour on the two sides. It is clearly shown in Nos. 2, 3, 4 and 8 (Plate XV). There is usually, but not always (No. 6), a central line of red running all the way between the barbs, alternate sections of which are coloured white on one side of the blade and yellow on the other. In some cases broad and in others narrow bands of red run transversely across the blade. In all cases they mark out the sections, but narrow ones run across irrespective of these (Nos. 2 and 8). As the barbs slant sharply backwards it follows that some of them are painted all three colours.

On the mainland right from Victoria in the south to the Coburg Peninsula in the far north the numbers of different kinds and types of clubs, throwing and fighting sticks are small. It is simply astonishing to cross the Dundas Strait, only sixteen miles broad, that separates Cape Don on the Peninsula from Melville Island, and meet in such a small, restricted area with a series of clubs and fighting sticks so varied, many of them indeed almost fantastic in form, as those shown in Figs. 487, 488, 489. The aboriginal in his dug-out canoe could easily cross the Strait, and yet the Iwaiji on the Peninsula have none of these clubs, nor have the Islanders any of the mainland types.

For long ages past a narrow stretch of water seems to have isolated the Islanders with their remarkable culture.

I have no doubt but that the Melville and Bathurst people have or had some other forms than those here described, but they will serve to give a good idea of what may probably be regarded as a fairly representative series. For the sake of convenience and simply from the point of view of form, they may be divided into two main groups, (I) single-pronged and (2) double-pronged, though amongst each of them there may be many distinct types.

(I) Single-pronged. These probably represent the simpler form. It is very difficult to classify them satisfactorily, but we may conveniently divide them first of all 


\section{IO WANDERINGS IN WILD AUSTRALIA $\mathrm{cH}$.}

into two sets, (A) those that are circular in cross section, (B) those that are flattened or elliptical.

(A) Those that are circular in cross section. These again may be divided into two groups, those with blunt and those with pointed ends. Nos. 9, IO and I I (in Fig. 487) represent three of the former; they are usually about twenty inches long, may be straight or slightly curved according to the natural shape of the wood, which is always dark and heavy, most often ironwood. The head end may be more or less swollen, and the surface always has very regular grooves running along its length. Those with pointed ends are very varied in form. Very characteristic ones are seen in Nos. 5, 6, 7 and 8. They are called Muragugna. There may be very little swelling at the head end or it may be swollen out into a distinct knob (7), and the point may be exceedingly short and abruptly marked or long and tapering. No. 6 measures thirty inches in length. Nos. 3, 4 and 5 represent a definite type on which serrations are clearly indicated. These are long drawn out along one surface in No. 3, where there is no head, only a long point. No. 4 shows a tendency for the head end, which is bluntly pointed, to become flattened and to have one surface that may be called the upper almost straight with a number of cross cuts, and the lower swollen out with serrations suggestive of spear barbs but pointing forwards. No. 5 has the same two series of serrations and is remarkable for its extremely attenuated point, which is as sharp as a large needle. It and No. 4 are twenty-seven inches long. All of these are very dangerous weapons and can be hurled at an enemy or bird with great force and precision.

A further development of the serrations is seen in Fig. 488 , No. 8, where the part carrying these is very distinctly marked off. The total length is thirty inches, and the pointed end beyond the head ten inches.

(B) Those that are flattened or elliptical in cross section. 
There are many forms of these, but those in Fig. 488 , Nos. I, 2 and 3, and Fig. 489, Nos, I, 5, 6, 7, will show what some of them are like. They vary in length from two and a half to four feet, and in width from two to three inches, and in thickness from half an inch to an inch. All of them have a handle that is usually distinctly marked off. The surface is regularly grooved or roughly smoothed down, and the decoration takes the form of a series of bands of red, yellow and white. The Melville Island name for them is Iruella. No. I in Fig. 489 is the simplest form, indicated only by two little knobs; Nos. I, 2 and 3 in Fig. 488 have a more definitely marked handle but are very simple in form and decoration. No.6 (Fig.489) is more ornate with slight serrations. Its length is fifty-four inches and it has two rectangular openings piercing the slab, one towards each end.

A very characteristic feature of this and other Island implements is seen in the middle and head end sections. The whole surface was first of all coated over with red ochre, this was then covered with white, which in its turn was scratched through to show the red beneath. Nos. 5 and 7 (Fig. 489) are very characteristic forms called Arrawunagiri. The natives told me they were used for catching fish in the mangrove swamp. The man sits on a mangrove above the water and "jabs" it down on the passing fish. One would have thought that a sharp-pronged instrument such as that represented in Fig. 8 would have been more efficient, but the natives were quite definite on the point. A remarkable feature of these two is the double series of barbs, which are not only useless but, one would think, liable to do serious damage if the hand slipped down.

(2) Double-pronged. Strange as it may appear, there are two very distinct types amongst these, in one of which, and that the more common, the prong actually forms the handle end, while in the other the reverse is the case. In 


\section{I2 WANDERINGS IN WILD AUSTRALIA $\mathrm{cH}$.}

every instance the native showed me how he held the weapon when using it. Those with the prong used as a handle end are shown in Fig. 488, Nos. 4, 5 and 6, Fig. 489, Nos. 2, 3 and 4. These are all said to be used for hand-to-hand fighting, and would form ugly weapons either for clubbing an enemy or bringing the prong down upon him or even prodding him with it at close quarters. Used in this way the prong end is the only suitable one for a handle. The specimen shown in Fig. 4 shows clearly the indication of the handle. It measures just four feet long, three inches in width and seven-eighths in thickness. The distance separating the points of the prongs is two inches and threeeighths. Their length is seven inches. Immediately beyond them vegetable-fibre string is wound round for a space of five inches in the way characteristic of handles, and beyond this there are projecting ridges as if to emphasise the lower end of the blade.

Those with the prong at the opposite end to the handle are illustrated in Fig. 487 , Nos. I and 2, and Fig. 488, No. 7 . They are all of comparatively small size. The prongs may be short and stout or long and thin, but there is no mistaking which is the handle end. No.2 (Fig. 487) is perhaps the commonest form, and though simple it is beautifully made of hard, heavy ironwood; the prongs are grooved and sharp, graceful in form and perfectly symmetrical. It measures twenty-one inches in total length, two and a quarter in greatest width, and the prongs to the end of the central incision eight inches. In No. 7 (Fig. 488) the prongs measure seventeen inches out of a total of thirty, and in No. I (Fig. 487) only two and a half out of nineteen. All these forms, despite their variation, are called $7 a p u-$ rarunga or Taburaninga.

There is one form that is quite different from the others, and it is really intermediate between a club and a spear. It is represented in Fig. 489 , No. 8. Its total length is 


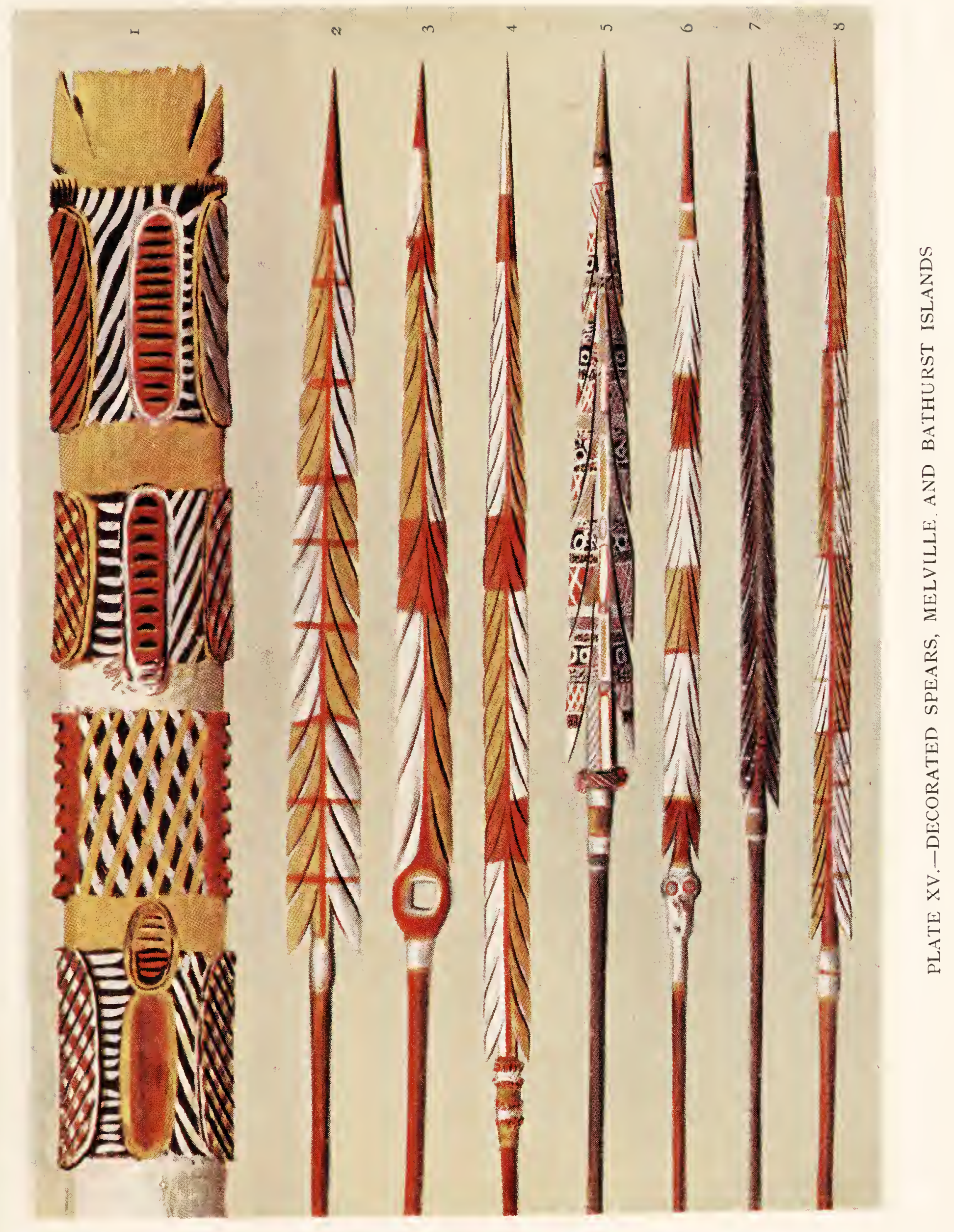



seventy-one inches; its general width three inches and its thickness one inch. There is a well-marked handle seven inches long, the prongs being fifteen inches. The decoration of this specimen, a part of which is shown in colours in Plate XV, Fig. I, illustrates admirably one form of the Melville Island schemes of design and colour. 


\section{CHAPTER XXVIII}

WORK IN DARWIN-(II)

ThE day after returning to Darwin, my leg, which had been injured during the spear competition on Melville Island, began to cause trouble, so much so that it made walking impossible for several weeks. Dr. Dawson, who was then acting Government Medical Officer, firmly, and to my very great personal ease and comfort, insisted on my removal to his quarters in a delightful bungalow at the foot of a rounded knoll, called Fort Hill, jutting out into the harbour (Fig. 490). Here I spent more than a month of enforced idleness, so far as moving about was concerned, though much of my time was occupied with routine work that could be transacted there as well as in the office. Friends like Dr. Burston, who was also looking after me, and Mr. Linton, the head of the Postal Department, were constantly in and out, and, not least, we had a most admirable Chinese boy, Ah Sue by name, whose cooking was excellent. He had a perfect mania for keeping things clean, himself and his white uniform-dress included, and our meals, served on the broad verandah on which, as walking was impossible, I lay day and night, were most pleasant interludes. When not cooking or sleeping or perhaps, during an afternoon siesta, enjoying on the quiet a few surreptitious whiffs from a little smuggled opium, he seemed to be continually sweeping, as he could not bear the sight of a speck of dirt. I had for two or three days been watching with interest two mason wasps building their nests in a shady and retired spot on the verandah, where they evidently thought, and I hoped, 


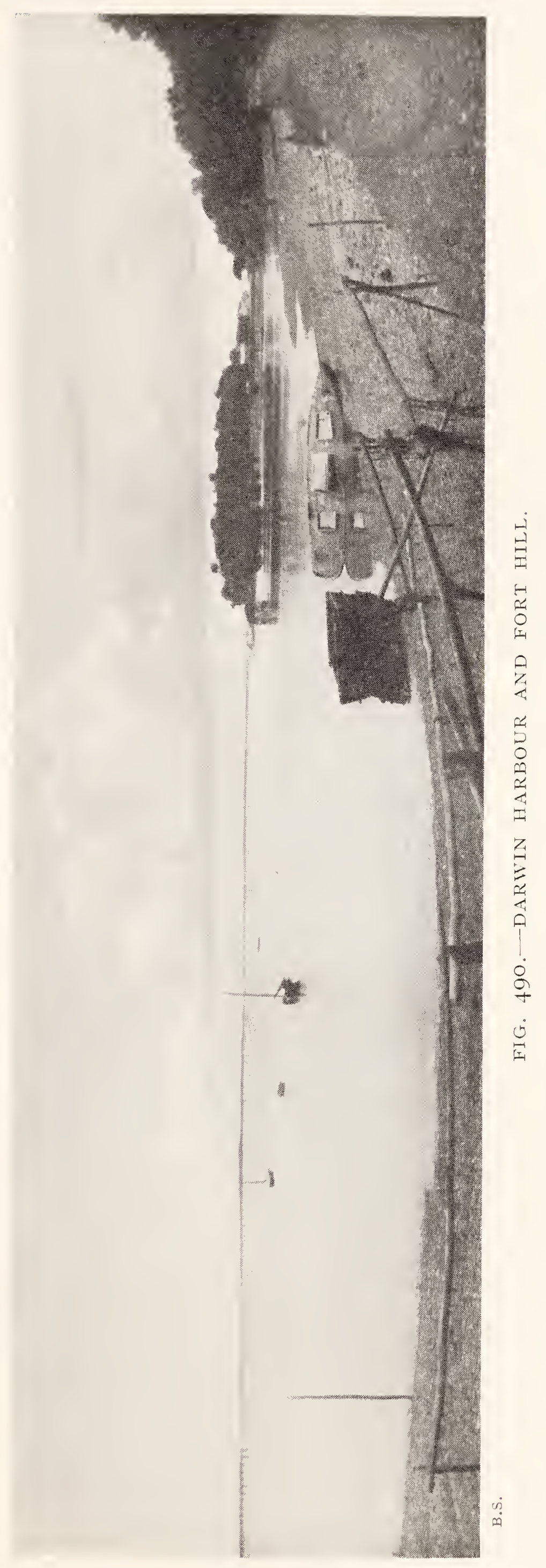




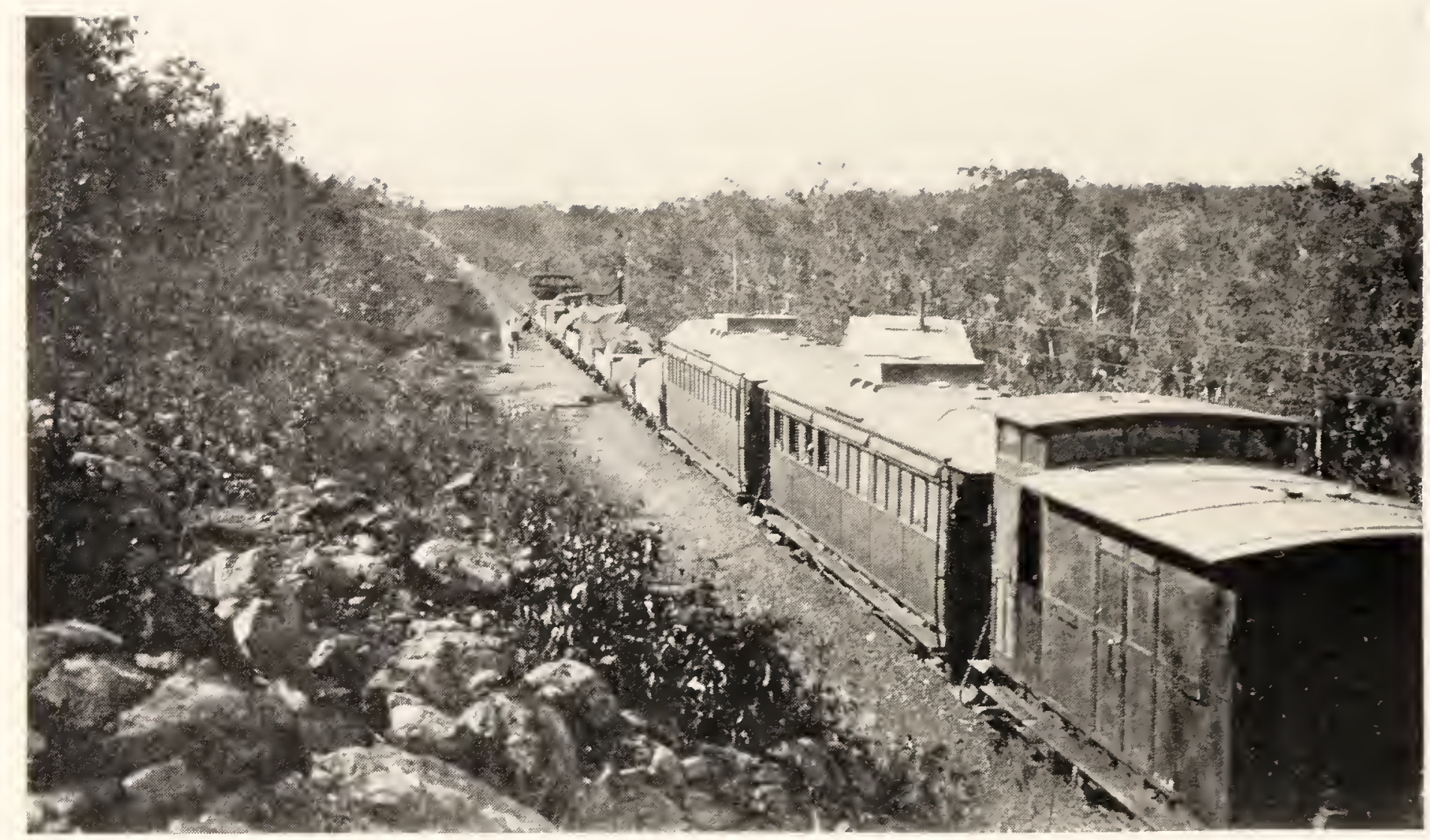

FIG. 49I.-WAYSIDE STATION ON DARWIN-PINE CREEK RAILWAI.

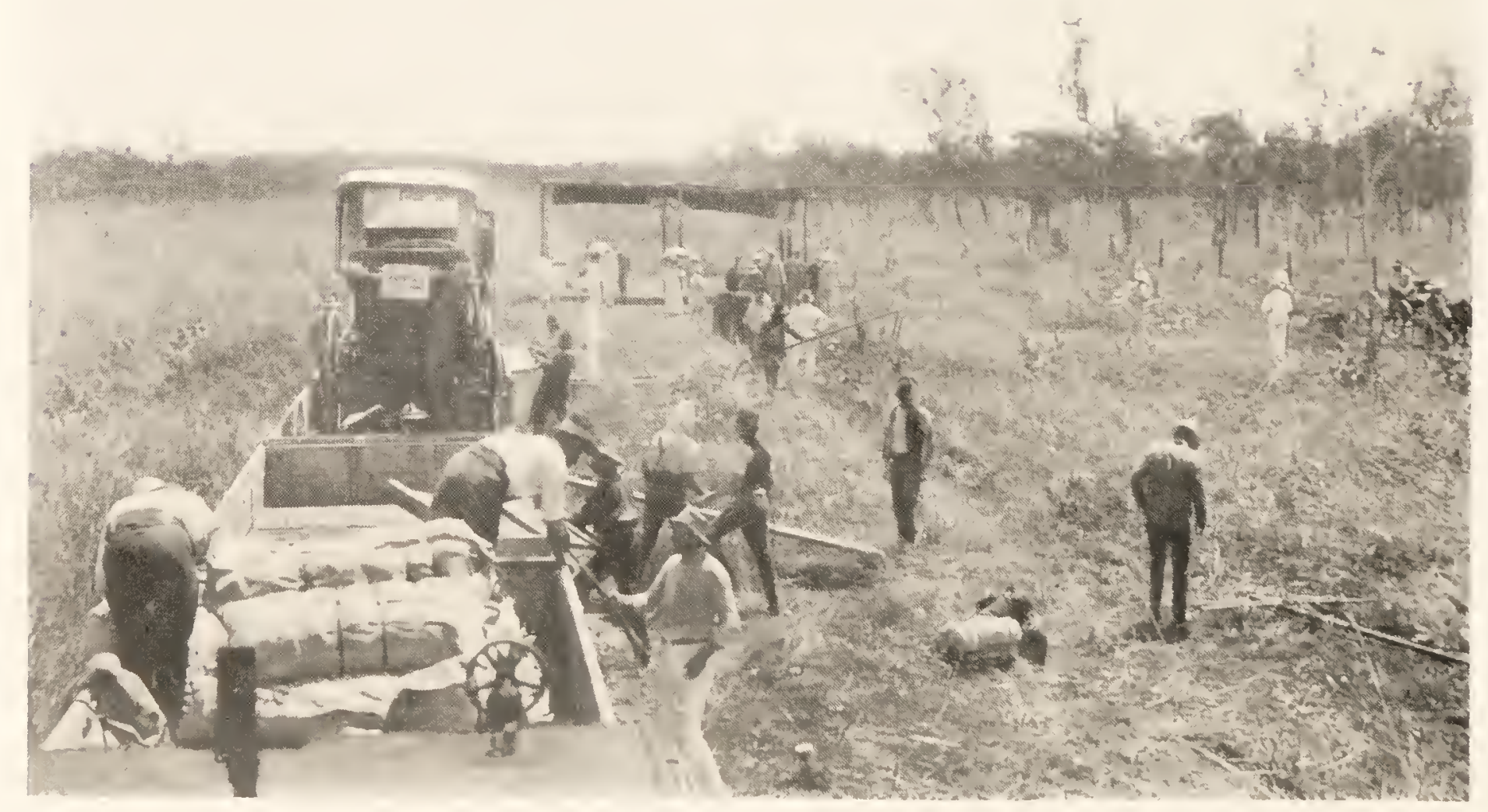

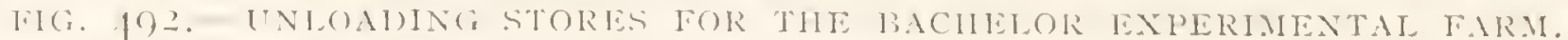


that they were safe from the watchful eye of Ah Sue, but it was no use. He spotted them and out they went. He had no liking for nature study. Ah Sue's chef-d'cuvre was a special kind of steak. I do not know exactly what his method was, but when, lying on my bunk in the afternoon, I heard a steady, pounding noise I knew that our evening meal would include the tenderest of steaks, cooked to perfection. Many a time later, when feeding, comfortably enough, in way back camps, on biltong and damper, the thought of Ah Sue's steaks came to me, and the memory of them recalled with pleasure the long days and nights spent on the verandah at Darwin.

The quarters of the Medical Officer lay at the base of Fort Hill, on its northern aspect, looking right up the harbour from the side of a small bay, bordered by cliffs that were clothed with trees down to the water's edge. Here the Japanese pearling boats used to come and anchor when they were in port, because they could water their boats from a spring that bubbled up close to the beach, and on the latter, just beneath my verandah, they emptied out, sorted and weighed their stores of pearl shell. It was sometimes decidedly smelly, but always picturesque, especially when, in the early morning, the boats, with long-drawn-out reflections of blue and brown, green and yellow sails, and the strong colour note of the divers' winch, always painted bright red, drifted slowly out to sea.

April I 2 th. - This morning there is a perceptible change in the air, clearly indicating the coming of the dry season. Before the sun was up it was actually fresh with a decided "nip" in it. The covers of my note-book, lying in the open on the table, instead of being damp and limp, as they always had been hitherto, were dry and actually showed signs of curling up. It was quite chilly, and the Darwinites would be shivering for an hour or two, if any of them were up in time to do so. Darwin is getting ready to welcome 


\section{I 6 WANDERINGS IN WILD AUSTRALIA сн.}

the new Administrator and at the same time a Parliamentary party.

April I 4th.-Another fresh early morning. I did not realise before how abruptly the wet season comes to an end. Perhaps it is not always so, but this year it is most marked. Most likely there will be no more rain till next December. The gorgeous sunsets, with their depths of rich colour, are impressive every evening, and the delicate peach-coloured light that floods the eastern sky every morning, before it gives place to the blazing sunlight, is beautiful, but they grow rather monotonous when you see them day after day for month after month with unfailing regularity. Sun-worshippers cannot really love the sun, they must worship and fear it because of its fierce strength. After months of brilliant light, when day almost suddenly gives place to night and night to day, one comes to understand more fully the beauty of twilights and grey days. The longing for "sacred, high, eternal noon" can only exist in hymnal imagination. You tire of gorgeous sunsets and afterglows, just as you tire of tropical fruits.

As I was enjoying the cool air before the sun rose, a little lugger sailed slowly, tacking about, into the harbour, and as it came nearer I saw that it was an old friend, the Buffalo, come across from Melville Island with the well-known figure of Cooper sitting at the helm. He soon found his way to my verandah, and I was delighted to see him again and hear all the recent news from the island.

Cooper was a big, quiet man of very few words. His work amongst the Melville Islanders had shown his remarkable capacity for dealing with natives. In view of this he had been appointed Sub-protector for Melville and Bathurst Islands. Every two or three weeks he came over to Darwin bringing cargoes of hides or Cypress pine. His figure was well known in the town. As soon as the boat was anchored he stepped ashore, always carrying a very 
small and ancient brown handbag, the contents of which were a mystery to everyone. He walked ahead, followed by three boys in single file. Arrived at the office of the Aboriginal Department the boys squatted outside, he entered, said "Good-morning " and sat down, always placing the bag on the ground beside his chair. It was a purely formal and official visit which he thought it his duty to pay. Very few words passed between us, perhaps only a formal greeting. After what he evidently regarded as officially the correct time to stay, he took the bag up and left as quietly as he had entered. This duty performed, the formal part of our intercourse was over and, when next we met, perhaps an hour later, we entered into ordinary relations.

April i 6th.- At noon the S.S. Mataram, with Dr. Gilruth, the first Administrator, Mrs. Gilruth and their family on board, steamed into the harbour, gaily decked out with flags. Darwin looked its best. The party was welcomed on board by the Heads of the various Government Departments and conducted by them to a train, with its engine wreathed in Union Jacks and Cycad fronds, that carried them from the jetty to the railway station, where the civic authorities took charge. Hence they were driven to the town hall, where a civic reception, with of course the usual speeches, was held, and so to the Residency, henceforth to be known as Government House. The latter is really a most charming and, in comparison with all others in Darwin, a palatial bungalow, with large rooms that run right across the house. Doors at each end of them open on to a spacious verandah, continuous all round the building and made beautiful with great clumps of fern and richly-coloured Croton plants. It stands on a cliff, surrounded with beautiful palms, Poncianas and Magnolias, through which, on its northern side, looking towards Cape Charles, the distant light of which can be seen twinkling at night-time, one catches glimpses of the waters of the harbour. 


\section{I8 WANDERINGS IN WILD AUSTRALIA сн.}

My leg was not yet serviceable enough to allow of my taking part in the receptions, but I managed to mount the hill from the doctor's quarters to the Residency and see Dr. and Mrs. Gilruth, their daughter and Miss Masson, who had come with them-all of them intimate University friends in Melbourne whom I was delighted to welcome and meet in Darwin.

April 2 Ist.-During the past four days the verandah has been my home and, to my regret, must remain so for a few days yet, as walking about does not agree with me. Dr. and Mrs. Gilruth and Miss Masson manage, though they are all as busy as possible, to find time to come in daily, the two latter finding their new surroundings and experiences full of interest. They have thoughtfully arranged for a large reception and garden party to which all Darwin is invited. As the local paper says, " the ceremony promises to be unique in the history of the Northern Territory." It probably will be.

It is very easy to arrange for one in Melbourne, but here, where there is no waiter or waitress available within a thousand miles, and natives, neither men nor women, can be efficiently washed, clothed, and trained, to fit them for such a profession, within the course of the only two days available, the problem of how to cater successfully for such a gathering is not by any means a simple one to solve. However, the Administrator's private secretary, Mr. H. E. Carey, is a host in himself on such an occasion. He may understand the phrase "better not," but once a line of action has been determined upon, neither he nor, be it also said, Mrs. Gilruth knows anything of "it can't be done."

The S.S. Eastern came in from the south at midday with the Parliamentary party, and I had a succession of visitors, amongst them a very old friend, Mr. H. Y. L. Brown, who, after fifty years of service, had retired from the post of Government Geologist of South Australia. His name is 
well known to everyone who has travelled in Central Australia, where he has spent long years of strenuous work. Until recent years, most of our knowledge of the geology of the Centre was due to him. The work that he did there was done under difficulties of travel and transport that the modern worker, with a car at his disposal, can scarcely appreciate.

Amongst the Parliamentary party were Mr. Wise, then member of the House of Representatives for Gippsland, and Mr. Gordon, a South Australian member, both old friends. After they had gone, Dr. Gilruth came down with the Hon. J. Thomas, the Minister for Home and Territories, in whose Department lay the control of the Northern Territory. I much appreciated his courtesy in coming to see me, because he was the Minister under whom I was working, and it was impossible for me to get up to Government House, where he, together with Captain Sir Edward Bartelott, A.D.C. to Lord Denman, the Governor-General of Australia, was the guest of the Administrator and Mrs. Gilruth.

April $22 n d$. - The great reception was held this afternoon and was an unqualified and signal success. All the Parliamentary visitors were there, together with every citizen of any note, including, of course, Mrs. Spain. It was, rightly, most thoroughly democratic and representative of all interests in the Territory, even to the extent of an old miner, by no means the least worthy member of the guests, who, as the day was warm and he had nothing else suitable to wear, was picturesquely and comfortably clad in an ancient flannel shirt devoid of sleeves and widely open in front, showing to full advantage his brawny arms and bronzed chest. Captain Bartelott was in his element, courteous and affable to everyone, listening with interest to wonderful tales of the Territory told him by an old resident who, as the result of a regrettable error in connection with cattle branding, had 
only that morning gained his freedom after some months' involuntary visit to Fanny Bay, under the charge of Superintendent Strath, but, fortunately, just in time to pay his respects to the new Administrator.

After this was over, everyone, or at least all the officials, settled down to hard work and Darwin resumed the even tenor of its way, but now buoyed up with the hope that at last something was really going to happen.

April 23rd.-Captain Bartelott came in to talk over matters in connection with a projected visit of Lord Denman to the Northern Territory, and we had a long and interesting talk both about this, the natives and the Territory generally. There were two men in the Territory whom, most of all, I had been anxious to meet. One of these was Joe Cooper, the second Paddy Cahill, both of them never known by any other name amongst Territorians, and both of them celebrated buffalo shooters and, what was much more attractive to me, both of them thoroughly well acquainted with and trusted by the aboriginals, amongst whom they lived and worked. Cooper I had already met. In the middle of this afternoon I heard a cheery voice inquiring of Ah Sue whether I was in, followed by a brisk walk down the verandah, and then Paddy Cahill announced himself. This was our first meeting, to be followed later on by many wonderfully interesting times spent together in the wilds amongst the natives. Cooper was a big, broadshouldered man, very slow and deliberate; Paddy Cahill was equally broad-shouldered but short and thick, brimful of cheerfulness, energy and go. We talked for long and made arrangements for me to visit as soon as possible his little station at Oenpelli where he was then living, away out on the East Alligator River. It was very important for us to have some kind of native Reserve there, but to be of any real service it must be under the charge of a man and woman both of whom understood, liked and were trusted by the 
aboriginals, and also were thoroughly accustomed to life out in the wilds where self-reliance and ability to cope with any emergency that might arise were essential requisites. There could not have been two people better fitted for the work than Paddy Cahill and Mrs. Cahill.

We discussed the matter carefully, and, when we parted I felt sure that, if the Government consented to the foundation of the Reserve, they would take charge of it. On the basis of this, as the beginning of serious work outside Darwin, I set to work writing reports and framing estimates which involved the laying down of a policy for future work amongst the natives.

April 26th.-The legislators went down the line to take part in the initiation of an experimental farm at a place to be called Bachelor. It was a large party with an imposing array of baggage and two or three tons of tucker, because they were going on afterwards to the head of the line and then up-country. There were also many trucks laden with all kinds of farm implements and machinery. In fact so valuable a train load of humanity and material had never before steamed out of Darwin into the wilds (Fig. 492). Fortunately for the legislators, it was a period when refreshing south-east winds were blowing, so they thought the Darwin climate a splendid one. Such official visits are always paid at a time of the year when it is possible to travel safely upcountry, and this also is the cool season. A visit during the humid, rain season, when there is not much difference between the wet and dry bulb, is a different matter altogether and affords a truer idea of the climate, so far as permanent settlement in the country is concerned, more especially, and above all, from the point of view of a white woman, who has to rear children and carry on domestic duties with only such help, usually sporadic in nature, as may be gained from native women, if indeed she be fortunate enough to secure even this. The members of the party, or 


\section{2}

$\mathrm{CH}$.

at least some of them, had interesting experiences when they got out into the bush beyond Pine Creek, and, whilst travelling over rough country, had now and then to put their shoulders to the wheel, which they manfully did to extricate their buckboard from the usual mud and mire of a creek at bad crossings (Fig. 493). The day after the party left Darwin a wire came down asking, amongst other things, for "Punch" to be sent up to overtake them at Pine Creek. This was the name of the Administrator's favourite riding horse, so there was a hurry and a scurry in the stables to catch the outgoing train. A horse-box was hitched on at the last moment, and to his astonishment, the Administrator, on his arrival at Pine Creek, received a horse that he did not then want, but a legislator had to go on without a copy of a well-known London periodical that for some reason he was anxious to have.

May Ist._- I had a long and interesting morning with the Minister, Mr. Josiah Thomas, who again courteously came to see me as I was still unable to walk. He was deeply interested in the aboriginal question, and I explained to him what we had been doing generally, and especially in Darwin, with regard to the Chinese and the new native compound at Kalin Beach, and plans with regard to the formation of the Oenpelli Reserve and the placing of Mr. and Mrs. Cahill in charge of it. He gave his cordial assent to this and other proposals for future work, but of course much will depend upon the Treasurer and how much money is available. He was most understanding and broad-minded and keenly interested in our work and in that of the other Departments and the future development of the Territory generally. I am glad to be able to express my appreciation not only of his sympathy but of his practical interest in our early work amongst the aboriginals.

At 8.30 p.m. most of the Parliamentary party left Darwin by sea to go round the north-west coast to the Daly River, 


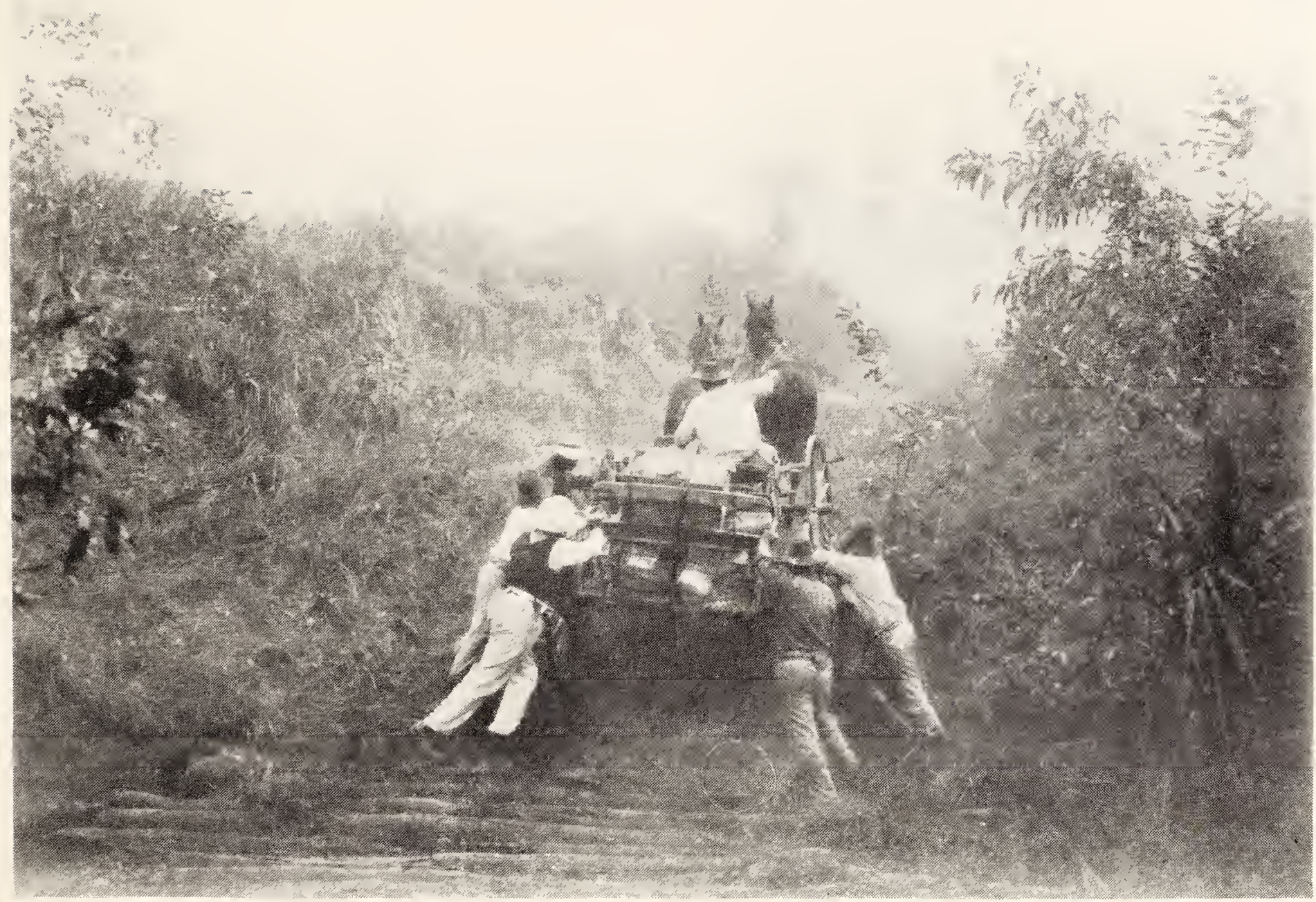

FIG. 493.-PARLIAMENTARIANS GETTING THEMSELVES OUT OF A HOLE. 

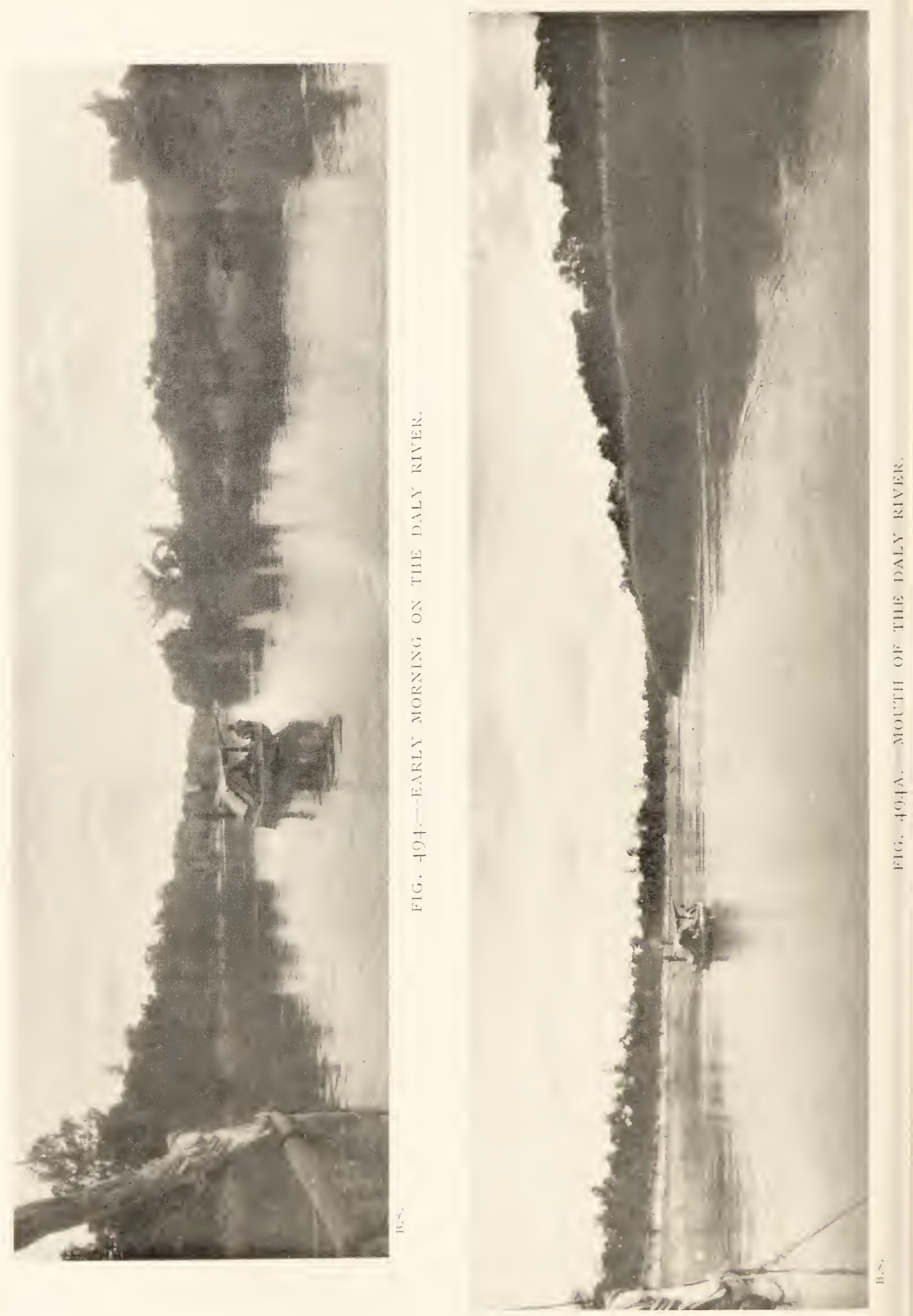
where they were to meet and pick up the few who had ventured overland from Pine Creek. It was rather a strange procession that could be watched that evening, heading its way in the moonlight along the channel and out of the harbour towards the Point Charles lighthouse. First of all there was a small tug-boat, carrying the Administrator, the Minister and two or three others, then a little launch carrying half a dozen others. At the last moment its engines refused to work, so, to avoid delay, it had to be towed, and behind this came a small lugger, also towed so that it could keep up with the main party. They have a hundred miles to go round a coast that no one seems to know very well, and dotted with plenty of sand-banks, on any of which they could easily spend a day or two waiting for a favourable tide to lift them off. Fortunately for them, and especially for those in the little launch, the weather is good and the sea calm. They all returned safely four days later.

At the Residency, Mrs. Gilruth was busy settling down and finding some amusement in a mixed staff of Chinese boys, whites and blacks. The latter included two lubras whom she was hoping to train. One of them was a very bright little girl called Kitty, with an abundant supply of long, wavy locks of hair. Shingling was not then fashionable, in fact it had not been invented, but Mrs. Gilruth, antedating fashion, decided that, on hygienic grounds, Kitty and her locks must part company. They did, but not exactly in the way arranged for by "the Missus."

The cry of "one man one job" had not as yet reached Darwin, which, amongst other contraveners of sound socialistic principles, possessed one individual who was a pronounced pluralist. He combined the two professions of barbering and dentistry. What was the exact relation between the two was not quite clear, except that he had one chair that did duty for both operations. His services had been engaged for a certain morning at the Residency, but 


\section{WANDERINGS IN WILD AUSTRALIA сн.}

when "the Missus" and barber appeared in the domestic quarter they were met by Kitty wreathed in smiles but without a trace of a lock. Charlie, her "boy," hearing of what was to be done, had secured both a pair of scissors and the locks, which were his by right. " Plenty make 'em string," was what Kitty said when she was asked why she had let Charlie operate. The shingle was certainly effective but equally clearly the work of an amateur, and all that remained for the professional man to do was to trim the very little that was left in such a way as to make the head presentable in public. Kitty was devoted to her "Missus," always standing behind her chair at table, waiting upon her with an eagerness that bordered on the dangerous when anything liable to overflow its bounds, such as a plate of soup, had to be dealt with, but always keenly interested in everything that was taking place, and never without a broad smile on her cheerful face, that often broke into a laugh, revealing to some of us, with envy, two perfect rows of beautiful white teeth. She was a very engaging little person, never took herself, or anyone else, seriously, except perhaps for a minute or two when, now and then, "the Missus" felt obliged to look cross.

May 5th.- The Parliamentary party returned safe and sound early this morning and I had visits from, and talks with, Mr. Thomas, Mr. Gordon, Mr. Wise and Colonel (now Sir Granville) Ryrie. The few who came overland have had a little taste of what travelling is like on a fairly good track during the good season. They know nothing of what it means on a bad track during the bad season, but all of them seem to have had an interesting time and will at least know a good deal more of the Territory and its difficulties than they did before.

May 9th.-This morning I started work once more in the office, which is, fortunately for me, only a little way off from the Residency. In a few days Mr. Clarke, the 
Director of Agriculture, intends to send a stock of material down to the Daly River settlement, and as this means an easy way of getting there by steamer, I am hoping to go with him and have the chance of seeing something of the natives there.

The S.S. Mataram came in from China and the East today on her way south to Sydney, so I have arranged to send down two large Jabirus, secured through the good offices of Judge Mitchell, to the Sydney Zoological Gardens. They have been living in the Residency grounds, but are rather too large and troublesome to have running about freely.

May I 3th.-At 9 p.m. we left Darwin in a little steamer, the $W$ aihoi, bound for the Daly River. Our party included the Administrator, Colonel Ryrie, who stayed behind when the legislators left, Mr. Clarke and the Government photographer who had come up with the Parliamentary party. There was also on board a party of eight, two men, two women and four children, all white, who were bound for a place on the coast where the Government was putting down a bore. There were no such things as bunks, so we just lay down in our rugs on deck and watched the stars. All night long we made poor progress as, once more, the Waihoi had to tow a small launch and a lugger heavily laden with stores. At 5 a.m. we were abreast of Peron Island, and then steamed to within five or six miles of the shore and anchored for a while to transfer the boring party to the motor launch. The Waihoi was moving up and down and of course the launch was still worse, but after some difficulty they were all transhipped safely, and we watched it bobbing up and down like a big cork on the water. I wondered what the women would feel like, landed in that solitary spot, far away from help of any kind, with nothing but a tent in the wild scrub to live in. When the launch returned we steamed on into Anson's Bay and anchored well within the mouth of the 


\section{WANDERINGS IN WILD AUSTRALIA сн.}

Daly River. By 8 a.m. we had transferred ourselves and our belongings to the lugger. The $W$ aihoi at once turned back to Darwin to bring another load and await our return to the coast. The little launch took the lugger in hand and snorted away up the river (Fig. 494), the pampas grass and rushes that margined the water bowing down before the long waves that the launch left behind in its wake. At Io p.m. it became too dark to make it safe to go further, so we anchored for the night. The stores, piled up on deck, left very little room to spare for us and we lay down, packed closely together, in our nets to protect us from the mosquitoes that are especially large and vicious along these northern rivers.

May I 6th.-At 4.30 a.m., as soon as the foreglow showed in the east, we lifted anchor and started off, only to come to a dead stop, within a few minutes, on a hidden sandbank. There was nothing to do but wait till the tide rose and floated us off, some two hours later. The launch enabled us to keep ahead of the tide so that we could steer, and we went on at a good pace. It was really delightful. The river banks were bordered with clusters of bamboos and cedars and gum trees, with here and there patches of dark mangrove. In some places the trees were literally white with cockatoos and there were scores of pelicans and ibises, black cockatoos, Nankeen herons, blue herons and great hawks, flying overhead. The sportsmen produced their guns and engaged in some shooting, which was irritating, because, if a bird were shot, it only fell into the water. However, the shooters in the party were fairly, not to say exceedingly, bad marksmen, so little damage was done, except to a few white cockatoos. Even the worst shot could hardly fail, now and again, to get a stray pellet or two into an unlucky member of a mob of big birds crowded closely together on a tree. Fortunately, in most cases, the snorting of the launch as we came along frightened the birds, and 
they rose into the air screeching their annoyance, and once on the move they were safe.

At 3 p.m. we came to a clearing on one side of a fine reach in the river that indicated the position of the future settlement, and the lugger was made fast to the bank because, as yet, there was no such thing as a jetty, and we were met by a small mob of natives who had gathered together, having heard afar off the sound of the launch. Unloading began at once, to the accompaniment of much noise on the part of the natives, who enjoyed everything, most of all they were pleased when a box of tinned meats broke and the contents emptied themselves out into the water, from which they were doubtless privately retrieved when we had left. We made a good camp under a big banyan tree, but the night was made restless by myriads of mosquitoes. Unfortunately, though the river was very tempting, bathing was out of the question. We had seen a very fine specimen of Crocodilus porosus basking on a mudbank not far away.

The launch went back to the river mouth to meet and tow up another lugger and we spent two days, partly unloading, partly wandering about and inspecting the future site. I spent most of my time in camp with a few of the natives of the Mulluk-mulluk tribe, and was glad in fact to be able to do so, as there was not much to be seen and unfortunately my leg had shown indications of becoming troublesome again. On the way back Dr. Gilruth treated it with a solution of a mercury compound, the only thing then available, which, from its colour, was henceforth known as "blue Peter." We pumped this in with a glass syringe that had not been specially designed for surgical work. It was perhaps rather a drastic measure, at least at the time it seemed and felt to be so, but it was effective, which was all that mattered, and from that day onward the leg gave me no further trouble. It was rumoured afterwards that the 


\section{WANDERINGS IN WILD AUSTRALIA сн.}

syringe and drug were intended for the treatment of stock on the Daly farm, but had by good fortune been accidentally overlooked and left behind on the $W$ aihoi.

Years ago there had been a Roman Catholic mission on the Daly River close by where we were camped, under the guidance of Father McKillop, but it was found impossible then to do any satisfactory work amongst the natives and had been abandoned. ${ }^{1}$ The natives, about a hundred all told, gave us a corrobboree, but there was nothing special about it except the noise and the great amount of dust they raised.

May I 8th.-We left the camp at noon in the launch and at 6 p.m. came to a halt some little way from the mouth of the river, as the tide was low. The sunset effects on the water and trees bordering it were wonderful, and when the tide rose we steamed slowly on, but it was I0.30 p.m. before we saw the lights of the $W$ aihoi away in the distance. All night we lay at anchor, far away from the reach of mosquitoes and sand-flies, and at $9.30 \mathrm{a} . \mathrm{m}$. next morning started off and steamed to the south, as we had to take on board a party of men who had been working a Government bore trying to find coal. The $W$ aihoi could not venture within five miles of the shore, so the dinghy went off for them, but it was carried a mile away from the landing-place and, even then, they could not get to the beach, so the passengers had to hump their swags along the shore and then wade out. They were so glad to see the steamer that they did not seem to mind this. We turned round and all day and night steamed north and at 7 a.m., after a perfectly smooth passage, we tied up to the Darwin jetty.

My stay with Dr. Dawson in his quarters where for several weeks he had looked after me now came to an end,

1 As the result of his studies Father McKillop published an interesting paper, "Anthrop. Notes on the Aboriginal Tribes of the Daly River," Trans. R.S. Soutb Australia, I893, Vol. XVII. 
as Mrs. Dawson, with her two children, was due from the south by the incoming steamer. I said good-bye to him and my old verandah with feelings of mingled gratitude and regret. Dr. and Mrs. Gilruth insisted on my going into the Residency. Nothing loath, I went, and thenceforth and until the close of the year, when my work in the Territory ended, the Residency was my home in Darwin. The Empire brought up Judge Bevan, an old Melbourne University man, who had been appointed Judge of the Supreme Court in Darwin, so that with the Administrator, Judge Bevan and myself, all from the University, and Miss Masson, daughter of our colleague, Professor (now Sir Orme) Masson, we were rather like an offshoot of Melbourne University, planted far away in the Northern Territory, and very pleasant it was for two of us, who were the guests of the Administrator and Mrs. Gilruth.

May 24th.-Empire Day. We had two small functions. First of all the Administrator, Mrs. Gilruth and her two daughters, the Judge, Miss Masson, Mr. Carey, the Private Secretary and myself visited the State school. After the National Anthem had been sung the Administrator presented to the school a framed portrait of the Royal Family. Then came the Judge, who, as no representative of the Press was present, was described in the next issue of the local paper as delivering a short but striking and appropriate address. This was followed by the singing of "Australia" and "We are Boys of the Bulldog Breed." The greater number of the children were girls, and the slant eyes of a goodly proportion of the boys showed clear traces of Asiatic affinity. Glancing at the Private Secretary I could see from a peculiar movement of his mouth and eyelid, which slightly interfered with his evident desire to join heartily in the singing, that the same thought had crossed his mind. However, with the prospect of a holiday ahead, sex and nationality were matters of small importance. We VOL. II. 
all carried it through manfully. To quote the same reporter, " the ceremony, slight as it was, served to link closer in these young and vibrant hearts the bonds of Empire."

After this we adjourned to the Aboriginal Office. We had fitted up a tent and decorated it with such flags as were obtainable in Darwin, friendly nations, such as Japan and China, being allowed to contribute their quota to the colour scheme. From a table, decorated with the Union Jack, Mrs. Gilruth distributed to each aboriginal the annual blanket provided by Government, a stick of tobacco and a box of matches. The ceremony was rendered somewhat informal, but perhaps none the less interesting, to Mrs. Gilruth by the irrepressible efforts of one ancient lubra who thought it was her duty to assist by volubly drawing attention to the name and qualifications of any important, or at least in her eyes important, recipient of the Government bounty. This over, Miss Gilruth distributed sweets to the piccaninnies, not one of whom was absent, and another successful function came to an end. On our way back to the Residency we met an old man walking along, trailing his blanket in the dust in the middle of the road. He was evidently doing it deliberately, and when we asked him why, he explained matters by saying, "That one all right now, plenty me been make him thick fellow blanket." The blanket certainly was, when received, on the thin side, but the idea of thickening it with dust was decidedly original.

May 27th.-After Empire Day we all settled down to work quietly. I was anxious to visit Pine Creek to see how things were getting on, and it was arranged that Mrs. Gilruth, accompanied by Miss Masson, should come at the same time, so that the former could see a little of the country and also during her visit preside at the annual distribution of blankets to the aboriginals.

May 28th. - The Private Secretary and myself were up 
with the foreglow and, after a kind of hurried passover breakfast, we left Darwin at 8 a.m. At 5 p.m. we reached Pine Creek and, before dinner, walked over the hills and through a part of the Chinese settlement. It certainly looked picturesque in the evening light, but the whole place is dotted over with hidden holes where prospectors had been delving for gold, and, to avoid stumbling into one of these, you have to be almost as careful to keep strictly to the narrow paths that wind about in all directions as if you were walking amongst boiling mud springs in New Zealand. Later on in the evening we went over to where the natives were sitting round their camp fires out in the scrub. The distribution of blankets passed off quite successfully and then, taking our camping-out material with us, our little party, under the guidance of Inspector Beckett, drove out to the spot selected for the camp. Fortunately Mrs. Gilruth was accompanied by her boy Shepherd from Government House. Here we spent two quiet days in the bush, wandering about during the day, sleeping on the ground at night, cooking our food at the camp fire. Then, packing up, we drove across country to meet the weekly, northward-bound train at a little siding where it stopped if the driver chanced to catch sight of anyone waving to him.

Fune 3rd.-The King's Birthday. Mrs. Gilruth gave a children's party to which all the children of the State school and the Convent, with their guardians, were invited. Exclusive of the latter, there were one hundred and twenty all told, and it was a very mixed assembly that gathered beneath the palm trees round the tennis court at the Residency. There were pure-bred whites, aboriginals, Chinese, Japanese and Malays, and half-caste and quarter-caste combinations of all five races. Very wisely, Mrs. Gilruth opened the party by eating, which rapidly broke down reserve and racial prejudice, and soon all were playing and mingling together, with the exception of the absolutely 
stolid, pure-bred Chinese, who, by the way, were accompanied by their fathers because, on such occasions, no Chinese woman appears. In their delightful festival attire of rich and many-coloured silks, that were the envy of many of us, they formed a strikingly picturesque feature in the gathering. It was a pronounced success and all Darwin appreciated the thoughtfulness that promoted it.

Fune 4th. A A few days ago there was a supposed case of bubonic plague in the Darwin hospital. The patient died and, to make everything as safe as possible, the body and everything belonging to him were burned and the hospital put into strict quarantine. To-day, a little gunboat came into harbour. Somehow the captain heard about the supposed plague case. He was so frightened that he would not tie up at the jetty, had his telegrams read out to him from the wharf, not venturing to touch them himself, and steamed away, leaving behind him supplies for his boat that had been ordered to await him. Later in the day, the S.S. Eastern came in, berthed as usual, and nothing more was heard of the plague.

Fune 5th. - This morning Miss Gilruth and myself walked out to inspect the buildings being put up on the Kalin Compound for the natives. The old head-man, King Solomon, was there hard at work, but he complained that the younger men were lazy and would not help him as much as they ought to do. It is very difficult to get the natives to help themselves. For a day or two they will often work hard, but they seem to be incapable of any sustained effort. Then, after working in the office till 4 p.m., I went out to Fanny Bay with Mr. Mallam, the lawyer who conducts our cases in court, to interview four native prisoners who have been brought in from out west. Three of them are charged with murder and one with inflicting grievous bodily harm. So far as I can tell, the three former have only been carrying out their tribal customs. We have enough evidence to 
make a good case. I remembered that some years ago Chief Justice Way of South Australia had given his opinion that, in dealing with wild natives, who know nothing of white man's law, the just thing to do in any case, for example, involving a charge of murder, was to take into account their tribal customs, and this aspect will be laid before the court.

It is strange what a great hold, especially in regard to magic, all old customs have, even upon natives who have been living for years with whites. For two weeks past we have had a lubra lying apparently ill in the little compound behind the office. Dr. Burston has been treating her but with no success. A day or two ago, one of her own tribal doctors chanced to come into Darwin, and his services were at once requisitioned by her native friends. She had much more faith in him than any white medicine man. I rather suspected that it was a case of auto-suggestion and, knowing the strong objection that most aboriginals have to going into hospitals, which they regard as full of evil magic, I told her yesterday that we were so anxious for her to get well that, if she were not better to-day, we should send her to the hospital, where she would be much better looked after than where she was. I asked her this morning if she were ready to go to the hospital, but, seeing that I was in earnest, she got up at once, saying, "No more, me all right, me work now, that one blackfellow doctor him all right, no good whitefellow doctor." She set to work at once, cheerfully and apparently quite recovered, and will remain so.

Fune I I th. - In court all day, as our cases came on. It was Judge Bevan's first appearance on the Bench, so the only two lawyers in Darwin made speeches, congratulatory to him and to each other. The Judge responded suitably and all started well, with everybody, including the prisoners, pleased with themselves and everyone else, and I hoped for the best. As there was no other entertainment on in Darwin 
at that time, the body of the court was full and it was decidedly warm.

A great difficulty in dealing with native prisoners and witnesses is that they have a liking for telling the truth in a way that disconcerts sometimes the defending and sometimes the prosecuting counsel; when once they understand, or think they do, what is wanted of them, they are anxious, without prejudice to either side, to lay the whole case, so far as they know the details, before the court. In these days when we had a case coming on we had sometimes to "coach" the native witnesses in court, in order to accustom them to surroundings and proceedings that might otherwise have completely mystified and stupefied them. I have often wondered what a Judge of the Supreme Court in Melbourne would have thought if, a day or two before a criminal case was coming on, he had wandered into his own court and found a layman occupying, for the time being, his Honour's place on the bench, a pseudo-criminal in the dock, and two or three strangers, personating jurymen, in the jury box, while a lawyer and constable put a witness through his or her facings in the witness box.

As Chief Protector I had to look after the interests of all native prisoners. The first case to-day was one of inflicting bodily harm. The evidence was quite clear, so it was no use doing anything except to place the facts before the court, but, for some reason, the prisoner at first pleaded not guilty. Very likely he forgot what we had told him to say and wanted the court to understand that the man he had attacked was not guilty of anything, and I was allowed to alter his plea, which he willingly did, when the matter was explained to him and he realised that pleading guilty was the same thing as saying that he had committed the assault. As I put it to him in pidgin English, while the Judge was thoughtfully occupied in reading notes that had not been written, it was thus:- "Suppose you been kill him then 
you yabber "me guilty.'" When, with the courtesy of the court, his first plea was withdrawn and the question was again put to him, his cheery response was, "Yes, me been kill him all right; me guilty all right."

Then the two murder cases came on. In the first, two black boys had speared a lubra, in the second one boy had speared another. The actual killing was not denied; we relied on the fact that the whole affair was a tribal matter and must be regarded from this point of view. The Judge was fully seized of this aspect, which he carefully explained to the jury. The foreman, fortunately for us, was a man who had considerable knowledge of natives, but even so, rather to my surprise, in each case the verdict was " Not guilty." I was standing close to the dock on the floor of the court when the last boy was acquitted and the constable told him he could go away, and was rather nonplussed when he turned to me, saying in a very audible voice of mingled reproach and disappointment, "What for me no go along Fanny Bay? me been spear 'em that one boy all right."

Fune I 4 th. - After clearing up a good deal of routine work in the office I have decided to try to get away to the East Alligator River both to see the Oenpelli country, where we are hoping to establish a native reserve, and to get, through Cahill, into touch with the natives in these parts, and also to do some work amongst them of which, except for my spell with Cooper on Melville Island, there has been little chance hitherto, the accident to my leg having been a great handicap during two months that might have otherwise been spent in the field. 


\section{CHAPTER XXIX}

THE EAST ALLIGATOR RIVER AND THE KAKADU PEOPLE-(I)

After searching round Darwin I managed at last to secure a little motor-launch, the owner of which assured me that he could provide a man who could run it efficiently and was acquainted with the coast, because it meant about I 30 miles along this and then some 60 miles up the river. I set to work to get stores and equipment together.

fune I 6 th. - After a final packing up and arranging things at the office I went down to a little wharf at the foot of Fort Hill, where the Don was lying, and at I I a.m. we started off. The boat was just i 8 feet long with a small hold forward, in which all my stores and "trade" were stowed away; in the middle was the engine, and behind this an open space with seats round it, below the water level, where the officers, crew and passengers sat. All told, there were four of us, the skipper, a Malay man, his assistant, a South-Sea Islander, myself and my black boy George. There was a fresh south-east wind blowing and we bobbed up and down, hugging the coast as far as East Cape. Between 5 and 6 p.m. the wind died down and we went on with a gentle roll until we got into shoal water, amongst the Vernon Islands, and thought it safer to anchor for a few hours until we could see where we were going. At 4.30 a.m. we started, but soon after leaving the shelter of the Islands got into a nasty, choppy sea which tossed our little launch about as if it were a cork. We passed Cape Hotham and steered across Chambers Bay, losing sight of land until, early in the afternoon, we turned in towards the coast 736 
for shelter. We followed up the coast, which was now trending north-eastwards, towards Point Stuart, though no one knew exactly where we were. There are no charts to be had of this coast and the skipper had not seen a map. Luckily I had brought a general map of the Northern Territory, which showed the coast roughly. The owner of the boat had assured me that the skipper knew the coast well and, forgetting that he was an old Darwinite, I had taken the statement literally. It turned out, when I began to question him, that the skipper's knowledge was limited to that gained during a trip that he once made "somewhere along the coast," in a lugger, and that he had neither been to, nor knew, where the Alligator Rivers were. I showed him my map, but he seemed to look at it rather vaguely. Wondering if he had any idea as to what it meant, I folded it up and, a little later on, produced it again, this time wrong side up. He was just as vague as before and I then found that, as he confessed, he was not accustomed to using maps and did not understand them, but, if he had once been to a place, he could go again. As he had never been to the Alligator this qualification did not seem to bear very closely upon our present trip, so I thought it better to take a hand in the matter. The map showed that we had to clear Cape Stuart, then run across Finke Bay to land projecting northwards, that had no name on my map; rounding this and going east, we must come to Peron and Barrow Islands and, going between these, and then on north-eastwards, we ought sooner or later to strike the mouth of the East Alligator. We could not well go too far because immediately to the east of the mouth of the river the land trended away due north. It looks quite simple on the map, but in this part all the shores are low lying and you can easily pass by the mouth of a big river without knowing anything about it, unless you are close inshore or a flood is coming down carrying débris out to sea, because your distance of vision is 


\section{$73^{8}$ WANDERINGS IN WILD AUSTRALIA ch.}

very limited when, as in our little launch, you are practically on sea level. When we came within a few miles of the shore of Chambers Bay, we saw that the most extraordinary cloud effects that we had been watching were really due to huge bush fires that the natives were evidently lighting, because we could watch them, one after another, starting at the eastern end and then joining one another, as the wind carried them westwards and piled up dense cloud masses, a mile or two high, in the sky. The summit was formed of huge masses of white cumuli; immediately below these everything was grey and blue and then, lower down, reaching to the ground, was a dense pall of orange-brown smoke. The clouds mounted up and up, changing their shape continuously as they rolled along. It was long after sunset when we rounded Cape Stuart and went on quietly along the coast, but far enough away, we thought, to avoid sandbanks. However, just about ten o'clock, we bumped and stuck fast. Luckily it was a sand-bank that we were on, not a rock. By dint of much pushing with poles we got off and anchored for the night, about half a mile offshore, as far as we could judge in the starlight. I lay down on the deck that was raised above the engine and, early in the morning, woke suddenly to find myself slipping down. The tide had gone out and left us high and dry, or, rather, tilted over at a very uncomfortable angle in the mud. Here we had to remain until the incoming tide restored us to our normal equilibrium and floated us off the mud bank. Meanwhile it was picturesque. It was a brilliant night, and looking seawards every bright star seemed to be reflected in a line of light in the wet, smooth mud on which crabs and other sea-shore animals were crawling about, making all the time an uncanny, crackling noise that seemed to fill the air. We had breakfast at sunrise and by 7.30 a.m. the tide was high enough to lift us out of the mud. The bank had a few mangroves on it and was now swarming 
with birds-pelicans, white cranes, gulls and terns. Every now and again they rose in flocks, flew round and settled down once more, taking no notice of us and scarcely moving out of our way as we passed close by them. Once round the Cape and well into Finke Bay, we began bobbing up and down and continued to do so, losing sight of land for several hours until we saw it lying right ahead of us, and then we turned to the north-east following the coast-line. In the afternoon we were evidently level with the northern end of the promontory that, on the map, juts out immediately to the west of the South Alligator River, so we went on turning eastwards until we could see the outlines of Field and Barrow Islands. At five o'clock we got into the Strait between them and suddenly ran crunching on to a reef. It was evidently no soft sand-bank that we were on and, for a few minutes, I thought a hole would be torn in the bottom of the launch, but, luckily, the tide was rising and flowing rapidly and, after half a dozen bumps, uncomfortably suggestive of what might happen if we had many more of them, it quietly lifted us up and carried us into deeper water. Navigation in these parts seems to be rather precarious, and perhaps we ought not to have attempted the Strait, which, by the way, is not as broad as it looks to be on the map or, at least, on the only map we had. Soon after we had cleared the Strait, the engine went wrong and stopped, so we bobbed up and down till dusk. There was no chance of reaching the mouth of the river until long after dark, so we put back and anchored for the night close in to Field Island.

June I 9 th. - We were off at 6.45 after a very quiet, restful night on an even keel, no mosquitoes and a very pleasantlooking island only half a mile away. We steered away to the north-east towards a headland that seemed to be the Point Farewell of our map, but everything is beautifully uncertain in these uncharted waters. It was clear that, 


\section{WANDERINGS IN WILD AUSTRALIA сн.}

unless the map was wrong, we must be getting near to the mouth of the East Alligator River, because as soon as we were abreast of the headland, we could just make out land in the far distance trending due north. A little further on we came across sticks and leaves that were being carried out to sea, so we turned to the south-east. The shores gradually narrowed in until the mangrove banks that bordered them were about five miles apart and we were ploughing through what looked like a sea of pea-soup. A strong tide setting in was meeting the down-flowing stream and stirring up the sand and mud. We must have got over the bar without knowing it. The skipper seemed to think it was the professional thing to do, so he produced a sounding line from somewhere and we, or rather his assistant, " heaved the lead" in what appeared to me to be rather an amateur kind of way and certainly served no purpose. It was the first time he had done anything, save eat, since we left Darwin, and I could not understand why he came, except that possibly it was to comply with some port regulation, requiring a sea-going boat to be staffed with a certain complement and he had been signed on as crew. Work was not then scarce in Darwin and he would have been more useful ashore or at any rate not less useful.

The river narrowed down from five miles to two or three hundred yards in width. As we followed it up, the country became rather interesting, with miles of flats, looking like English meadowlands, crossed by belts of trees and here and there picturesque ironstone ridges. The water was now, and remained to the end of our journey, pea-soup in colour. There were flocks of white cockatoos, cranes and ibises. Every now and then an ugly crocodile slithered down a bank and fell with a plop into the muddy water and a great black snake glided by, carried down by the stream. Once we passed a clump of bare trees, literally crowded with Nankeen night-herons - a beautiful bird with fawn-coloured 
wings and white breasts-but still there was no sign of habitation. The river was flowing across great flats, in a course so tortuous that sometimes after an hour's steady going we found ourselves separated by only a hundred yards from some special spot in the stream that we had passed an hour earlier, and at 7 p.m., as it was getting dark and we had no idea where the sand-banks were, we anchored for the night near to a very striking range of hills that must have been at least five hundred feet high, with cliffs rising sheer from a narrow tree-covered flat that separated them from the river. We had seen them in the distance at sunset, ablaze with colour.

Fune 20 th. - The night was a miserable one, with very little sleep for any of us, as there were myriads of mosquitoes. I had a net, but there was no hope of fixing it properly in the small space, so we were all glad to be astir as soon as the light came. The captain and crew were seriously perturbed and wanted to turn back. There are three Alligator Rivers and they were convinced that we had come up the wrong one. It would certainly have been awkward if we had, because our petrol supply was not enough to take us down to the sea up another river and back to Darwin, if we had gone astray. I felt sure that we must be somewhere near to Oenpelli and promised them that, if we saw no sign of it in the next two hours, we would turn back. Though we were now at least sixty miles from the mouth of the river it was still tidal and the muddy water was running down-stream, so we made slow progress. I stood in the bows on a box so as to get as good a view as I could over the river bank, hanging on to the rope that passed from the bowsprit to the top of the little mast, and, only half an hour later, to my relief, saw through the trees what looked like the top of a mast and, turning a sharp bend in the stream, Cahill's primitive little landing-stage came into view.

Cahill had been expecting me to come, though he did 


\section{WANDERINGS IN WILD AUSTRALIA сн.}

not know to within a week or two when this would be, so he told the natives to keep a look-out, and one of them was waiting on the bank. They had, of course, heard our snorting as the launch came up the river, and a messenger started off to give the news to Oenpelli, the station being eight miles away. The tide was low, so we could not get anywhere near to the bank and, as the mud was impassable, all that we could do was to wait patiently until both Cahill and the tide came to our relief, which they did together, the latter very suddenly with a rush and a clear-marked front, forming a definite bore that struck the launch and swung it round on to the bank.

Cahill had a retinue of at least twenty natives with him. They soon had all my stores out, and when the tide turned, the launch went off down the river on its way back to Darwin. The natives set off in single file along a track leading across a mile of swampy country, carrying the packages on their heads to where a dray was waiting for them. Cahill and myself drove in an ancient buckboard that must have been brought up in the early days and was now hanging together by means of wires and straps and sundry ingenious contrivances. Living far out in these wilds, Paddy Cahill is, and needs to be, a man of great resourcefulness. We drove across seven miles of rather rough country to his little station at Oenpelli, which is really the native name of the lagoon by the side of which it lies. It consists of a small house with a detached kitchen, built of stringy-bark, and sundry outhouses. The land all round is cleared and a large garden slopes down to the lagoon, nearly a mile long and a quarter of a mile broad. On the far side, luxuriant flats stretch back to a series of picturesque rocky ranges, running away for miles north and south. It is really a beautiful place, especially in the early morning when the Ranges, catching the soft pink light, rise out of the mists that lie along the flats and valleys, and again at evening, when 

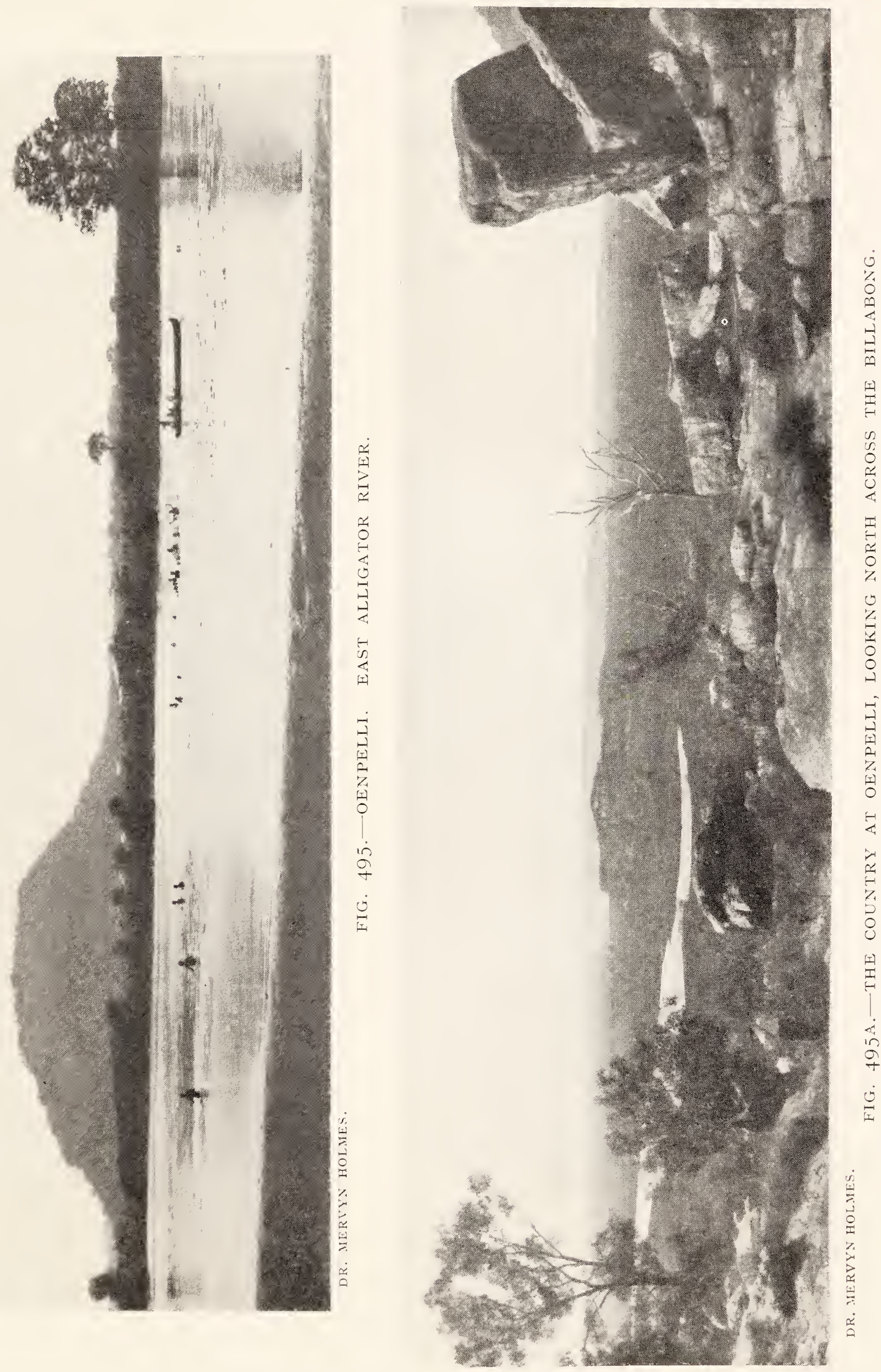

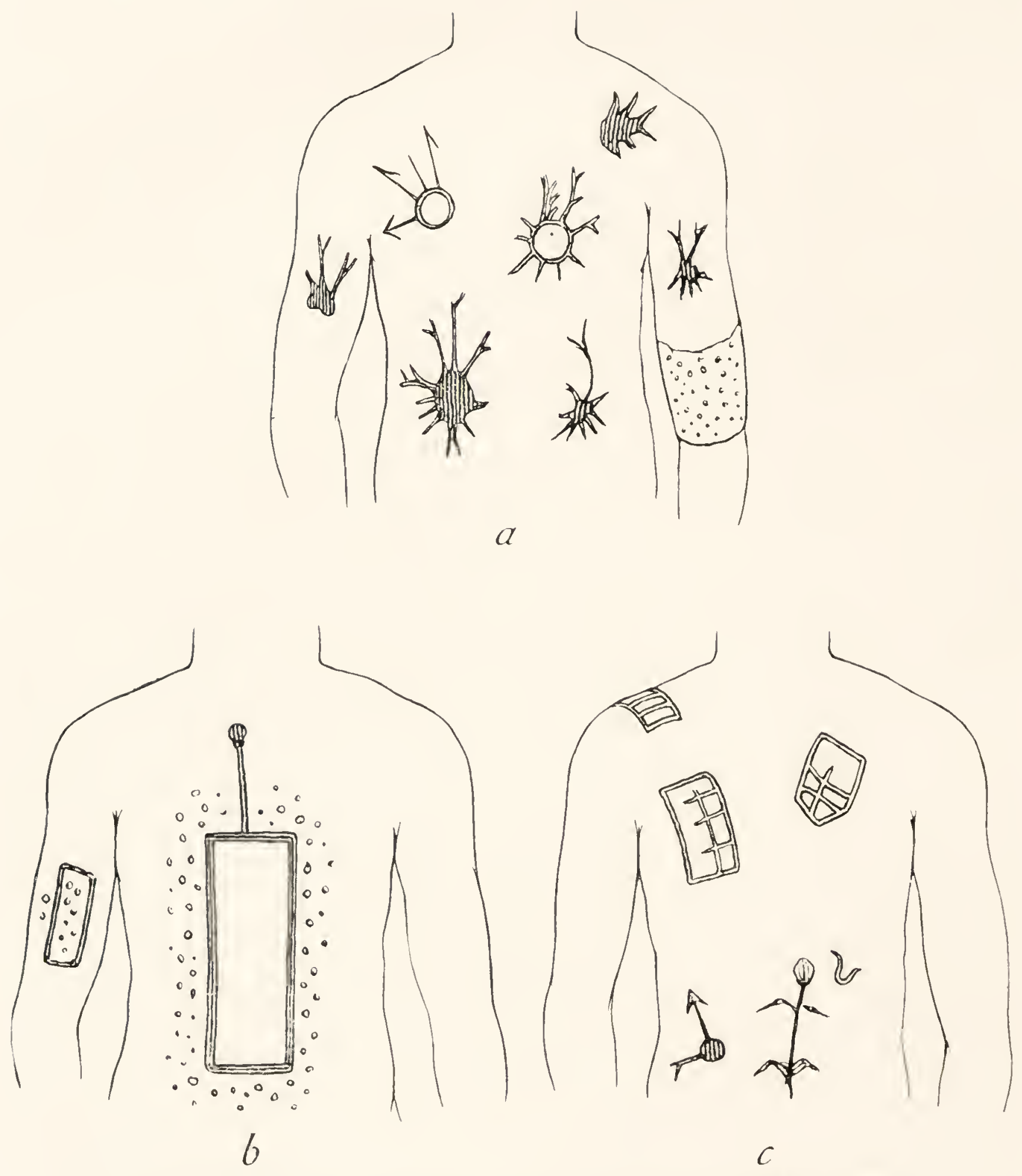

FIG. 496.- DESIGAS DRAWN ON THE BODIES OF RAKADL, TMORIT ANI GEIMIBO NATIVES DURING THE PERTORMANCE OF ORDINARY CORRORBOREIS. 
they are richly coloured with intense purples, blues, greens and reds. There are beautiful clumps of trees on the margin of the lagoon not far away from the house, and altogether it is much the most beautiful spot that I have seen in the Territory (Fig. 495).

Fune $22 n d$. - Yesterday and to-day I spent settling down and wandering round the place. It is a very small household, just Paddy Cahill and Mrs. Cahill with their niece Miss Mudford, who lives with them, both of the latter just as keen on bush life as is Cahill himself, and both of them never so much at home as when they are on horseback, exploring the country for miles round the homestead. The house has a broad verandah, front and back, each of them with great door-like shutters, reaching from eaves to ground, that can be propped open to let the air blow through, or closed to keep the rain out in the wet season. The front makes a delightful dining-room, the back has two hammocks where one can enjoy a quiet afternoon's siesta, gazing over the lagoon to the hills beyond, bathed in hot, shimmering haze.

This afternoon we drove down the long flats by the side of the lagoon. It was just like an English meadow, with luscious green grass, and reminded me also of the strong colours that you get on the luxuriant river flats in $\mathrm{New}$ Zealand. Birds are here in crowds-large Burdekin ducks, black and white geese, pigmy geese, great flocks of white and straw-necked Ibis, blue and white cranes, Stilts, with long toes, walking about on the lily leaves that fleck the lagoon waters, and, of course, flocks of Corellas-white cockatoos without the yellow crest. Mobs of very dignified pelicans were paddling about and round the water's edge were grey Native Companions and a few stately Jabirus, the only true stork found in Australia and perhaps the handsomest of all its birds. The two latter were very shy, but the others took little notice of us. 


\section{WANDERINGS IN WILD AUSTRALIA сн.}

Fune $23 \mathrm{rd}$.- We went over early in the morning to one of the native camps on the far side of the lagoon. When working amongst Australian aboriginals, habits both of late retiring and early rising-often very early —are essential to success as an ethnologist.

The local tribe is known as Kakadu but, since Cahill has been settled there, members of others, out east, have begun to come in and, at this time, there were two camps at Oenpelli, one belonging to the local people, with whom also were men of the Umoriu and Geimbio tribes, and the other, that we went to this morning, belonging to visitors from the Kulunglutchi tribe, inhabiting the King River country away to the east.

On the way we called at a camp where some of the local men had, overnight, been performing an ordinary corrobboree, that is, one that women and children may go to. They had decorated their bodies with designs quite irregularly arranged and done in simple pipe clay. They were quite different from any that I had seen before and were intended actually to suggest what they were supposed, very crudely, to represent. A few of them are shown in Fig. 496. A represents yams, the central part the yam itself, the lines running out the leaves and flowers. $B$, which at first I thought was a drawing of a white man's bottle, represents a "sugar bag," that is, the nest of a wild bee. The small circle at the top is the little hole leading into the trunk, the line going down is the passage and the oblong is the comb itself; the dots all around are the bees outside the tree.

The ceremonies that we went to see on the Kulunglutchi ground were of a different kind and belonged, though we did not know it then, to an important series called Muraian, of which we were to hear much more later on.

We had to traverse the swamp land at the head of the lagoon by way of a narrow trail where we could only walk in single file. After the parched-up, dreary and utterly 
monotonous country, in which most of the tribes that I had been accustomed to working amongst in Central Australia lived, the surroundings in which the Melville Islanders and the Kakadu performed their ceremonies came as a wonderfully welcome and pleasant change. As we followed our guides, we had before us a sinuous line of thirty or forty bronze-coloured, lithe-limbed natives, following a trail through the rich green of the swamp grass and herbage, bright, here and there, with yellow flowers and purple lilies on little water-pools; beyond were thick-foliaged trees with blue smoke of native camp fires curling up amongst them, and, in the background, the tall, red cliffs of the Ranges, cut through with clefts, lying in deep purple shadow.

The Kulunglutchi had built a large bough wurley that could hold at least twenty natives, with its opening facing away from the ceremonial ground, immediately on one side of which it was placed. There were only one or two old men on the ceremonial ground, but we could hear singing evidently not far away, and about fifty yards further on found the men gathered together on a special decorating ground that they had cleared in the thick scrub. The decorations were of the crudest description, cruder indeed than any connected with sacred ceremonies that I have ever seen. They consisted only in roughly smearing the whole upper part of the body with red or yellow ochre or pipe clay. Sometimes they drew lines and bands of colour, but never anything more, and yet these ceremonies were sacred totemic ones that no women might see. There was no set order, everything depended on two or three old men who acted as leaders. We found the decorating for several performances taking place at the same time, all close together, in both respects quite unlike what takes place in the Arunta or Warramunga. To-day we had a fire, wallaby and turtle ceremonies. When the decorating was over, each party, led by an old man, clanging sticks, came into the VOL. II. 


\section{WANDERINGS IN WILD AUSTRALIA ch.}

wurley, each man crouching down as he did so, like a goose going through an open gate, though the opening was high enough for him to walk upright. Here they all sat down, hidden from the audience of the Kulunglutchi and Kakadu men on the ceremonial ground. The performance opened with a fire ceremony. The performers were led out of and round the wurley, in single file, by an old man who stationed himself beside the ground, clanging his sticks and shouting "Kau, au, u, wai, ya!" while the men danced for a time. The dancing was certainly vigorous, the men often running round and round with exaggerated knee action and arms thrust forward. Then they knelt down swaying their bodies from side to side and moving their hands as if they were working fire-sticks. Then followed a wallaby ceremony. There was nothing special about this, just the usual energetic dancing, though this differed from that of the first in being more of the nature of an Irish jig. Lastly there came the turtle, which was a little more elaborate and interesting. There were the usual clanging of sticks, singing and dancing, the old leader always dancing in front of his men. Some of the performers had remained in the hut, out of which they crept on all fours through a hole that they made on the side facing the ceremonial ground, and came on to the latter rolling about. They were supposed to represent turtles feeding, and while they were doing this the others came and danced round them. Finally, everyone danced round violently with arms extended, yelling "Yer, Yer, ai, ai!" time after time. These ceremonies occupied all the morning.

Both Mr. and Mrs. Cahill were keenly interested in natural history, indeed Mrs. Cahill, to my surprise, had a small menagerie of her own at Oenpelli where she kept kangaroos and wallabies, reptiles and birds of different kinds. I was very anxious to secure some of the birds characteristic of the Alligator River country, more especially 


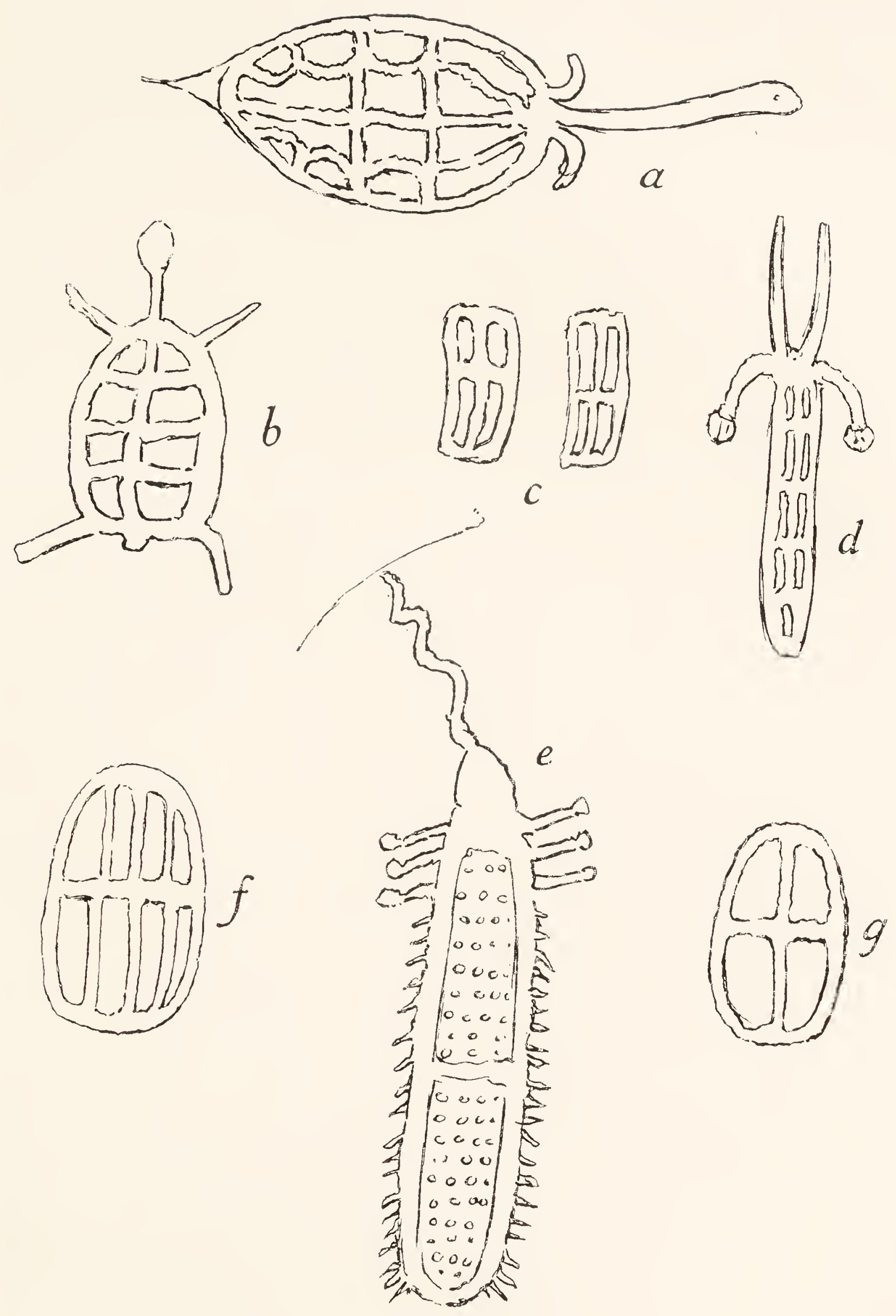

FIG. 497.- DESIGNS DRAWN ON THE BODIES OF MEN DURING THE PERFORMANCE OF A MURAIAN CEREMONY IN THE KAKADU TRIBE.

(a) and (b) Turtles. (c) Crocodile egg. (d) Jimidauapa, a fish. (e) Tjunara, a yan. (f) Turkey egg. (g) Kopereipi, Emu egg. 


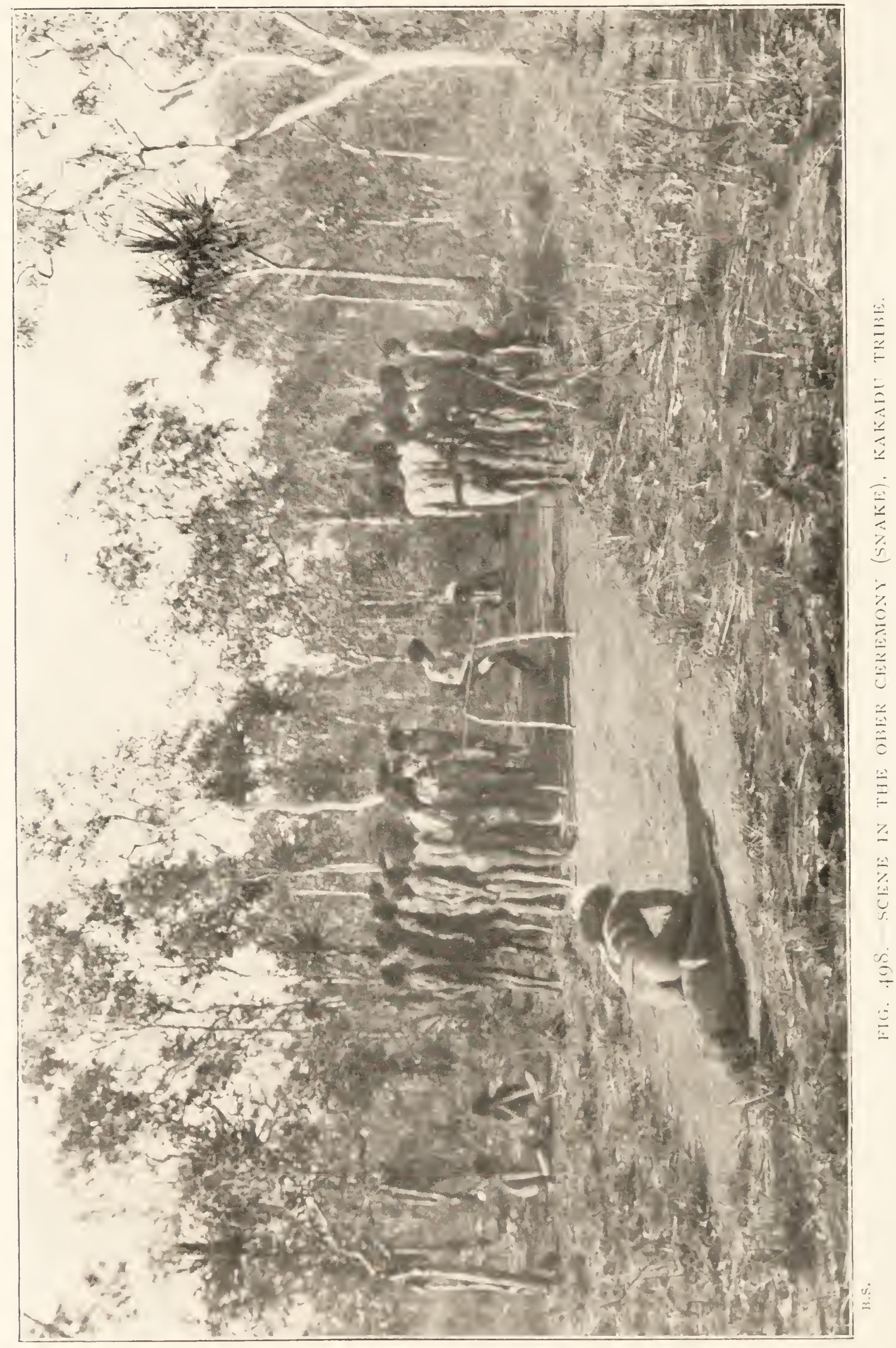


one or two of the Ibises, pigeons and parakeets and the Jabiru that we were in need of, or at least good specimens of, at the National Museum in Melbourne. Most of all I wanted to get hold of a black kangaroo of which Cahill told me. As a general rule, we spent all day amongst the natives either watching them perform ceremonies or getting information from them. It was, of course, only due to Cahill's knowledge of them and their language that I was able to do this, though after a time I began to understand a good deal of what they talked about.

There is one curious feature about all these natives in regard to their talking. In addition to their ordinary use of words in conversation they frequently adopt a form which makes what they say quite unintelligible to strangers even if the latter are able to follow an ordinary conversation. It consists in clipping words and running them into one another in such a way that one word will represent perhaps five or six separate words of a sentence spoken in the ordinary way. It forms a kind of " shorthand" spoken language. Most often when Cahill and myself were discussing matters with them they used, of course, the ordinary form of conversation with us, but, if they wanted to talk over the matter amongst themselves, they often dropped into their shorthand. It was not that they wished to hide anything from us, but that it saved time. The same system is adopted in other tribes such as the Arunta and Warramunga, and is probably universally in use amongst Australian natives.

Many long hours we spent with them. Often after a morning on the ceremonial ground we spent the afternoon under the shade of the banana trees in the garden on the edge of the lagoon-just a little group consisting of Cahill and myself with perhaps three or four of the men, our special informants, seated round us, with spells for a smoke at intervals. Then came the writing up of notes for the day. Every morning we sent one or two of them out into 


\section{WANDERINGS IN WILD AUSTRALIA сн.}

the scrub, often miles away, to try to get what we wanted, and it was only seldom that they returned empty-handed. To-day the boy brought us in two special kinds of pigeons. One was a lovely bird, ${ }^{1}$ larger than a blue-rock, with a pure white head, neck and breast. The lower row of feathers in the latter had yellow-brown tips, forming a kind of shield overlapping a broad band of black across the chest. The rest of the body had a beautiful grey colour, except for a white tip to each tail feather. The second ${ }^{2}$ had a general grey and brown colour with the under-throat white. The large wing feathers were a warm chestnut brown, wherefore it is known as the rufus-quilled rock pigeon. To prevent promiscuous shooting, the supply of cartridges is strictly limited. This boy was only given six, and he returned with two of each of the pigeons and a bower-bird with a lovely lilac crest.

Fune $24^{\text {th }}$.-Another morning with the Kulunglutchi. One is continually running up against little bits of ceremony. Last night, while we were skinning birds, we heard a loud wailing coming up from the Kakadu camp not far away. It was a kind of ceremonial wail, not one of grief, and was due to the fact that a boy about fifteen years old had just returned safely after an absence of nearly a year. To celebrate the event, the father rubbed him all over from the top of his head to the soles of his feet with well-greased red ochre, ornamented him with necklets and armlets and then set to work to howl. He was very noticeable when we met him this morning on our way to the Kulunglutchi camp. The boy had been sent out to visit distant camps as a preliminary to his future initiation.

The ceremonies were much the same as those that we watched yesterday. The kangaroo men had curious bands running slantwise down their chests and backs and along

1 Ptilopus alligator, so called because it was first found in this district.

2 Petrofassa rufipennis. 
their legs, supposed to represent the backbone of the animal. The turkey men came hopping out through the hole in the wurley, but before they did so, the men who had taken part in the kangaroo dance set to work to claw at the bushes on the outside in a ludicrous way. They were supposed to be imitating flying-foxes (large bats) hanging from the trees under which the turkeys were resting.

When the ceremonies were over we walked back by way of the Kakadu camp, and found them on the point of setting out to prepare a spot in the bush that had been chosen for the holding of a special ceremony next day, so we went with them. The preparation consisted of clearing it of all bushes and herbage and loose stones. This over they all sat down and "sang" it-that is, sang refrains, the object of which was to make the ground "slippery," so that they could dance properly.

Fune 25 th. - I was up early, at sunrise. It was absolutely still, with the Ranges delicately pink-tinted in the morning light and perfectly reflected in the lagoon, on the far shore of which two large Jabirus were slowly walking along. On these mornings, that are called chilly here, there is no early rush for the bath-room, which consists of a log hut with a tin pail that can be hoisted up full of water. By means of a special contrivance, the pulling of a cord releases the water that comes down in a shower through holes in the bottom of the tin. It is very refreshing, but the bath-room is usually free until later on in the day. The natives who work about the homestead come in shivering from their camps, but soon make a fire and sit around it until they feel warm enough to work. An hour or two later, you are glad of any shady spot, where, out of the sun, and with a south-east wind blowing, it is more or less cool. Most of the natives here are known by their native names and not, as on most stations, by adopted English ones. Three of the lubras working with Mrs. Cahill are called Minborka, 
Belgramma, Numereilmak; some of the men's names are Minborka, Minumaka, Mitcheralaka, Kopereiki, W'udeirti, the three latter of whom are our chief informants and constantly with us.

We walked across to the Kakadu ceremonial ground. I had my quarter-plate camera, my own boy carried the cinematograph case and another the legs with the iron stand, which are rather weighty. The ceremonial ground, called Goar, was about forty feet long by ten or twelve wide. In the middle of it there were two forked sticks fixed upright in the ground, each about three feet high. A third stick lay in the forks, like the ridge-pole of a tent. This was supposed to represent a wurley, or Mia-mia, called Fumungail, inhabited by two non-venomous snakes called Kuljoango and Jeluabi. The men all sat down to one side of the ground while three of them were decorated with bands of red ochre, dotted with white. Two represented the nonvenomous snakes, the third a special one called Ngabadaua, a quick-moving, vicious animal of which the natives are very much afraid. At each end of the ground there was a hollow log. Ngabadaua seated himself on one with his fire-stick beside him, the two others, back to back, sat on the other (Fig. 498). The men arranged themselves in two groups, one on either side of the ground, close to the non-venomous snakes, except two of them who served as an orchestra, one blowing a long conch, the other knocking sticks together. Then the dancing began. As a general rule only one man danced at a time. It consisted in the performer stamping as hard as he could with one foot, at the same time sliding the other foot backwards and forwards. It is a most difficult movement and requires considerable skill and practice, and there was a wonderful amount of difference in the degree of skill shown by the different performers. The other men were continuously moving their bodies up and down, striking their buttocks with the open 
palms of their hands and at the same time keeping up a continuous refrain that sounded like "Ia, ia, eio, eia, e, e, e! hok, yai, hok, yai!" ending up with a loud "E, E, E!" Each performer had the right of nominating his successor. This he did by touching the man's foot with his own, either after, during or immediately before he began. Sometimes he would touch more than one and sometimes, towards the end of his dance, he drew a line on the ground in front of three or four men who all came out and danced together. Whilst all this was going on the snake men were quivering and swaying their bodies about from side to side, quite irrespective of anything the others were doing. After the dancing was over there was a pause. All the men then came to Ngabadaua, who was quivering and swaying about vigorously, everyone shouting " Bora, Bora, Wa, Wa!" One old man then threw a stone over each of Ngabadaua's shoulders and, after this, the party ran away to the other two men, who then, amidst great excitement, crawled on their knees with a peculiar swinging motion to the Fumungail, rose up and leaned over it for a minute or two and then all of them went to one side. 'This was the signal for Ngabadaua to rise, which he did suddenly and then, walking deliberately up to the fumungail, brought his firestick down upon it and smashed it.

The natives say that the Fumungail was the home of the three snakes. The dancing men represent other kinds of snake men who have come up to look at Ngabadaua, who is regarded as the head of all the snake groups. The other snakes were frightened of him and were searching for and wanting to kill him. The stone throwing was supposed to represent an unsuccessful attempt to do this. They find the two non-venomous snakes in the bush and persuade them to show them Ngabadaua's home. The bending over the sticks represents their going into the latter, after which $N g a b a d a u a$ comes up, finds them there and kills them all. 


\section{WANDERINGS IN WILD AUSTRALIA $\mathrm{cH}$.}

Fune 29th. - There has been a cessation of ceremonies for the time being and the camps have been occupied only with the daily round of going out in search of food, which is not far to find in these parts, bringing it home and cooking it, and then, if they felt inclined for it, a corrobboree to while away the evening, so that we had the chance of a good deal of quiet work with the natives, and spent long hours with them struggling to master what at first was the very puzzling nature of the social organisation of the tribe.

Being so accustomed to tribes like the Arunta in which there is a very definite class organisation, it was very perplexing to find that apparently the Kakadu had no such system. Every individual belonged to a local group and had his or her totem name, but there was no such thing as any sections in the tribe corresponding to the Panunga, Purula, etc., of the Arunta. Whilst talking about old ancestors we met with a tradition relating to the far-past times during which a very celebrated ancestor lived, and this gave us a clue to the matter. The tradition, which scems to be common to the Kakadu and all the tribes now occupying the Coburg Peninsula and the country drained by the Alligator Rivers, is a very lengthy and detailed one, but it shows very clearly the ideas of the natives in regard to the origin of the members and different sections of the tribe and reveals a belief in reincarnation which is spread far and wide over Australia. I give an outline of what we found out during these days, because it shows how carefully the natives think these things out for themselves.

A man named Wuraka came away from the west, walking through the sea. His feet were on the bottom, but he was so tall that his head was well over the water. $\mathrm{He}$ landed at a place called Allukuladi, between two hills now known as Mts. Bidwell and Roe, both of which he made, and so on to Aruwurkwain. A woman named Imberombera came from the north, landed at what 
is now called Malay Bay and travelled south, till she met Wuraka at Aruwurkwain and asked him, "Where are you going ?" He replied, "I am going straight through the bush to the rising sun." At that time they both spoke the Iwaidja language and there were no blackfellows. Imberombera wanted Wuraka to come with her, but he was very tired, so he sat down where he was, and a great rock, called by the natives Wuraka and by the whites Tor Rock, arose to mark the spot. Imberombera went on alone. She was of huge size and carried many children in her body, and wore a bamboo ring on her head from which numbers of dilly-bags hung down, full of yams. At two places, called Marpur and Muruni, she left boy and girl spirit children, telling them to speak Iwaidja. She also planted many yams and said, "Mungatidda jam," these are good to eat. Then she went on to Mamul, on what is now Cooper's Creek, to the north of the East Alligator River, leaving children here and telling them to speak the Umoriu language. The only food supply she left them were Cyperus bulbs. After this she stopped at different places, opening her dilly-bags, throwing out yams broadcast and sent spirit children to ten different parts, telling them, as she did so, to speak different languages, in each case instructing them as follows :

(I) Gnaruk ngeinyimma tjikaru, gnoro Koranger.

(2) Watta ngeinyimma tjikaru, gnoro Kumboyu.

(3) Kakadu ngeinyimma tjikaru, gnoro Munganillida.

(4) Witji ngeinyimma tjikaru, gnoro Miortu.

(5) Puneitja ngeinyimma tjikaru, gnoro Jaijipali.

(6) Koarnbut ngeinyimma tjikaru, gnoro Kapalgo.

(7) Ngorbur ngeinyimma tjikaru, gnoro Illari.

(8) Umbugwalur ngeinyimma tjikaru, gnoro Owe.

(9) Djowei ngeinyimma tjikaru, gnoro Nauillanja.

(Io) Geimbio ngeinyimma tjikaru, gnoro Waimbi. 


\section{WANDERINGS IN WILD AUSTRALIA cH.}

The first word of each of these is the language the children were to speak; ngeinyimma means you or yours, tjikaru is talk or language, gnoro is go, and the last word is the name of the place to which she sent them. It is difficult to feel quite sure whether these are the names of the tribes or of local groups, but each place is now the central ground of the group or tribe named.

She came at last to Jayipali, in Kakadu country, searched around for a good camping-place and, at first, sat down in a water-pool, but the leeches came in numbers and fastened on her, so she decided to camp on dry land, saying that she would go into the bush. Accordingly, she did so and camped at Ibinjaira, where she became the great progenitor of the Kakadu people. While walking over the country she had made creeks, hills, animals and plants, in fact she was responsible originally for everything. She had already, as described above, sent out large numbers of spirit children to various places and, later on, all of them entered women who, in their turn, were sent to the same places later on.

I am using the term spirit children as the equivalent of the Kakadu word Iwaiyu and the Arunta Kuruna. Each is what we should call the soul or simply the spirit of the individual, but the native regards it as something perhaps a little more concrete and definite than what we figure to ourselves as a soul. The essential feature of the Iwaiyu or spirit-child belief of the Kakadu, and the Kuruna of the Arunta, is that it is, definitely, something concrete; every individual possesses one; it may, at times, leave the body either temporarily or, as at death, permanently; when it leaves the body at death it can, at will, enter a woman and so give rise to a new individual who is the reincarnation of the ancestor because it contains his unchanging Iwaiyu or Kuruna.

From Ibinjaira, Imberombera sent out five pairs of men and women. The tradition, so far as I could find out, 
says nothing about these, either as to their relationship to one another or their totems. Imberombera herself has no totem, but she is regarded as having instituted them all and given a totemic name to each of the spirit children that she deposited in certain places. She is essentially the equivalent of the great Numbakulla amongst the Arunta, except that she is a woman. Starting from Imberombera, the succession of events, so far as the production of offspring is concerned, may be represented briefly as follows :

(I) Imberombera carrying large numbers of spirit children.

(2) Spirit children deposited by her before she got into Kakadu country, to give rise to

(a) Iwaidja people.

(b) Umoriu people.

(3) Spirit children sent out by her during her wanderings before she came into Kakadu country, to give rise, later on, to ten different tribes or groups, as named in the table already given.

(4) Spirit children sent out by her from her camp at Ibinjaira to different parts of the Kakadu country.

(5) Five pairs of individuals, men and women, also carrying spirit children, sent out by her from Ibinjaira, her camping-place in Kakadu country, to various places in the latter.

(6) Five pairs of individuals, men and women, sent out again by each of the pairs in No. 5 to various places in Kakadu country, giving twenty-five pairs in all.

All the spirit children (included in Nos. 4 and 5) originally sent out by Imberombera to various places entered into the women of these twenty-five pairs and gave rise to the men and women who now form the different local groups into which the tribe is divided. 


\section{$75^{6}$ WANDERINGS IN WILD AUSTRALIA сн.}

It will be seen that Imberombera was responsible for everything, just as in the Arunta legend Numbakulla was; she gave every spirit individual his or her totemic name, furnished all food supplies, gave to the five pairs (No. 5) whom she sent out from Ibinjaira everything that they needed and full instructions as to where they were to go, telling them all about the Fereipunga, or totems, and ordered them to give these to the different spirit children. A peculiar feature of all the original lots of spirit children sent out is that they contained individuals of different totems, so that there is no special gathering together of men and women of the same name, such as emus and kangaroos, in any one locality in the way characteristic of the Arunta.

The only thing that I could find out, that governed marriage at the present day, was that a man of one group had to marry a woman from another group, but it did not matter what his totem was, nor was there any descent of the totem from either father or mother to son or daughter.

Not only are the names of each of the five pairs sent out, in the first instance by Imberombera from Ibinjaira, known and also those of the twenty-five, afterwards sent out by these, but, so extraordinary is the memory of the natives in matters such as these that they regard as of great importance, that, to our surprise, one of our informants, named Araiya, actually knew not only these sixty names and those of the places to which they were sent, but, also, those of the children born from the spirit individuals in the different localities. He also knew whom they respectively married and the totem group to which each belonged. What this means may be gathered from the fact that, in the case of the offspring of one only of the pairs sent out by Imberombera from Ibinjaira, it involved remembering one hundred and twenty-nine names and the totem of each. To take one instance only. Amongst five pairs sent out from Ibinjaira by Imberombera was Kroaran, a man, and Mun- 
jerimala, his lubra, who went to Unbaringadamba, where children were born to them, incarnations of spirits sent there by Imberombera. They then sent out five pairs of men and women to other places, giving them instructions, as received from Imberombera. Into the women of each of these pairs, spirit individuals, or Iwaiyus, entered, that had been sent there by Imberombera, and, when born in human form, they gave rise to the group of natives living in, and named after, that locality. The five pairs and their families were as follows :

(I) Pundamunga (m.) and Maramma (f.) went to Korenigin; they had forty children, twenty-three boys and seventeen girls.

(2) Miniorko (m.) and Japa (f.) went to Kunbarbi. They had twenty-seven children, thirteen boys and fourteen girls.

(3) Narapalo (m.) and Kolabiljailpinja (f.) went to Munmileri. They had sixteen children, eight boys and eight girls.

(4) Prienbi (m.) and Kurinuwalla went to Kulapari. They had twenty children, eleven boys and nine girls.

(5) Muraupu (m.) and Juluuperei (f.) went to Kupperi. They had twenty-four children, twelve boys and twelve girls.

These, it must be remembered, are only five out of twenty-five families, and, quite probably, the names of other children had slipped the memory of our informant, so that the families may have been still larger. The important point is that every native now born is the reincarnation of an ancestor who himself, or herself, was the incarnation of a spirit individual or Iwaiyu made by Imberombera.

Fune 3oth.-We had, amongst other things, been talking to the men about magic matters and they became so interested in telling us that they consented to show us exactly how one 


\section{$75^{8}$ WANDERINGS IN WILD AUSTRALIA сн.}

special form was carried out. Accordingly this morning we went with them to a secluded spot on the margin of the lagoon. There were five of them altogether, four men and one lubra. The special kind of magic they showed us is called Tjilaiyu, and is concerned with injuring a person by dealing in a very special way with his excrement or Korno. Whatever may have been the origin of the custom, it has one good effect, because it means that everyone is most anxious to cover over and hide from view all excrement, with the result that Kakadu camps and their surroundings are kept more cleanly than those of many other tribes. It is not, however, a very difficult matter for any evil-minded man who wishes to injure an enemy to secure some Korno. A medicine man, for example, will find out where it is buried and then, when no one is watching, he will go to the place and rake a little with a piece of bark with a stick, because it must not be touched. The bark and its contents are tied round with string and brought on to the ceremonial ground. Whether in this case it was genuine Korno I did not ask, but the performance was carried out quite as if they were in real earnest. First of all they made five little balls, called Jungana, one of Kapei-resin derived from the Ironwood tree-and four of beeswax. The first was about three inches in diameter, the others one inch. The beeswax is derived from four separate kinds of honeycomb. Each had a hole pressed into it with the thumb. The Korno was ground up finely on a flat stone and a little of it put in each of the spheres and the holes in them closed up. Then they scooped out a pit, about two feet in diameter, and a trench, about twelve feet long with the soil heaped up on each side of it, tapering away to a point (Fig. 500). The pit is called Narul, the trench Ye-eini. Along the course of the latter they placed long shreds of screw pine leaves, representing snakes. The five spheres were placed on one side of the Narul, with feathers $(6,7,8)$ stuck in the ground between 
them and the latter. These belonged to the Native Companion, white cockatoo, and Blue-mountain parakeet. A small, upright stick at the junction of the $Y_{e-e i n i}$ and Narul represented the Yalmuru or spirit of the victim (9). Then a fire was lighted in the Narul by means of rubbing one stick on another. The red-hot tinder had to be wafted about till it burst into a blaze. It must not be blown with the mouth. When the fire was lighted the lubra (A) fanned it with a Norkun, that is, a goose wing, in her left hand, and stones were placed on it. When it was hot enough the stones were removed and the real business began. The men sat in a row one behind the other, the woman to one side, all bending forward with their hands between their legs (Fig. 499). The front man took the stones out and, first of all, knocked the feathers one by one into the fire, all of them saying, "Keep quiet, keep quiet," the idea of which was that the birds, who are supposed to warn men of impending evil, would thereby be persuaded not to give notice to the victim that any danger, such as a snake or crocodile, threatened him. Then they began to sway about,

E.

D.

C.

B.

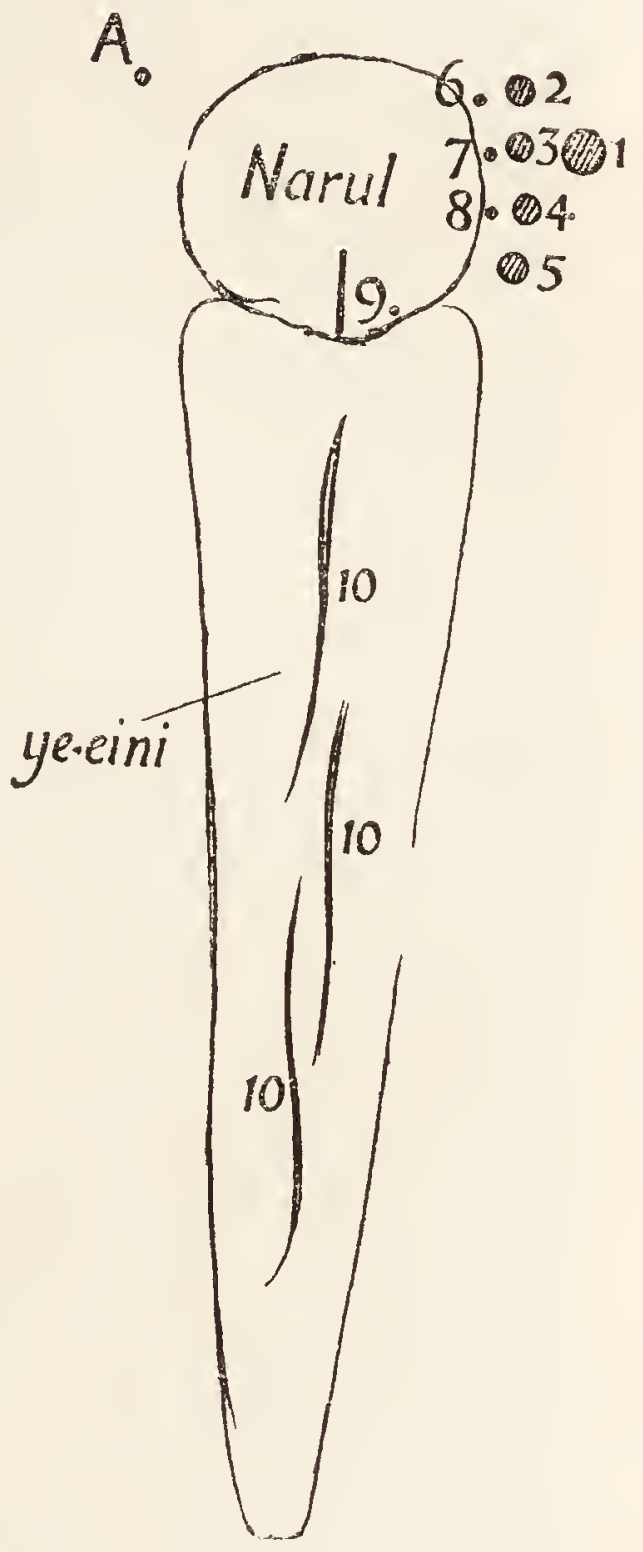

FIG. 500.-PLAN OF KORNO CEREMONY GROUND. looking as fierce as they could, while the front man put the spheres in the fire, the Kapei one below the others. The swaying about went on more vigorously than ever. Away in the distance they could hear the spirit cursing and swearing, saying "Mulyarinyu koiyu" and using other opprobrious 


\section{WANDERINGS IN WILD AUSTRALIA сн.}

expressions.1 The men mutter, "Nerk, nerk, nerk," and beckon it onwards towards the fire. It is under a spell and comes on cursing more and more loudly. When at last it is near, the men and women all crouch down silently, the front man ready for action. On it comes like a whirlwind, rushes along the trench, scraping along the sharp Pandanus leaves. Suddenly, when it reaches the opening into the Narul, the front man knocks the stick representing it into the fire on the top of the Korno. All of them shout "Ah! Ah! Ah! Ach! Ach! Brng! Brng!" at the top of their voices. Without a moment's pause, stones and earth are piled on the $Y$ almuru, one special large stone being placed on top, the men pressing down hard with all their might to keep it in (Fig. 5OI). The spirit beneath could be heard sizzling and swearing. It tried to lift the stone but could not. At length they heard it saying "Grr, Grr, u, u." Then it was quiet and all was over. The Pandanus leaves were rubbed on the top stone while the names of different snakes, Ngabadaua, Yidaburabba, Numberanergi, were hissed out. One or other of them is now sure to bite the victim before long. Finally, a log of wood, supposed to represent a crocodile, which it is hoped will seize him some day when he is bathing, was placed on the top and then, when the performers had smeared their bodies over with burnt cork-wood and grass, the ceremony was over and they went back to camp. Anyone coming across the remains of the trench and seeing the log and trench piled up above the small mound will know that evil magic has been performed. It is supposed that, by the capture of the Yalmuru, the man is left without his protector. If, for example, he be out in the bush, there will be no spirit to

1 This is one of various opprobrious epithets and expressions used by men when angry and excited. This particular one consists in cursing their mother : others are still more opprobrious and objectionable. Such expressions are met with in all the tribes. 


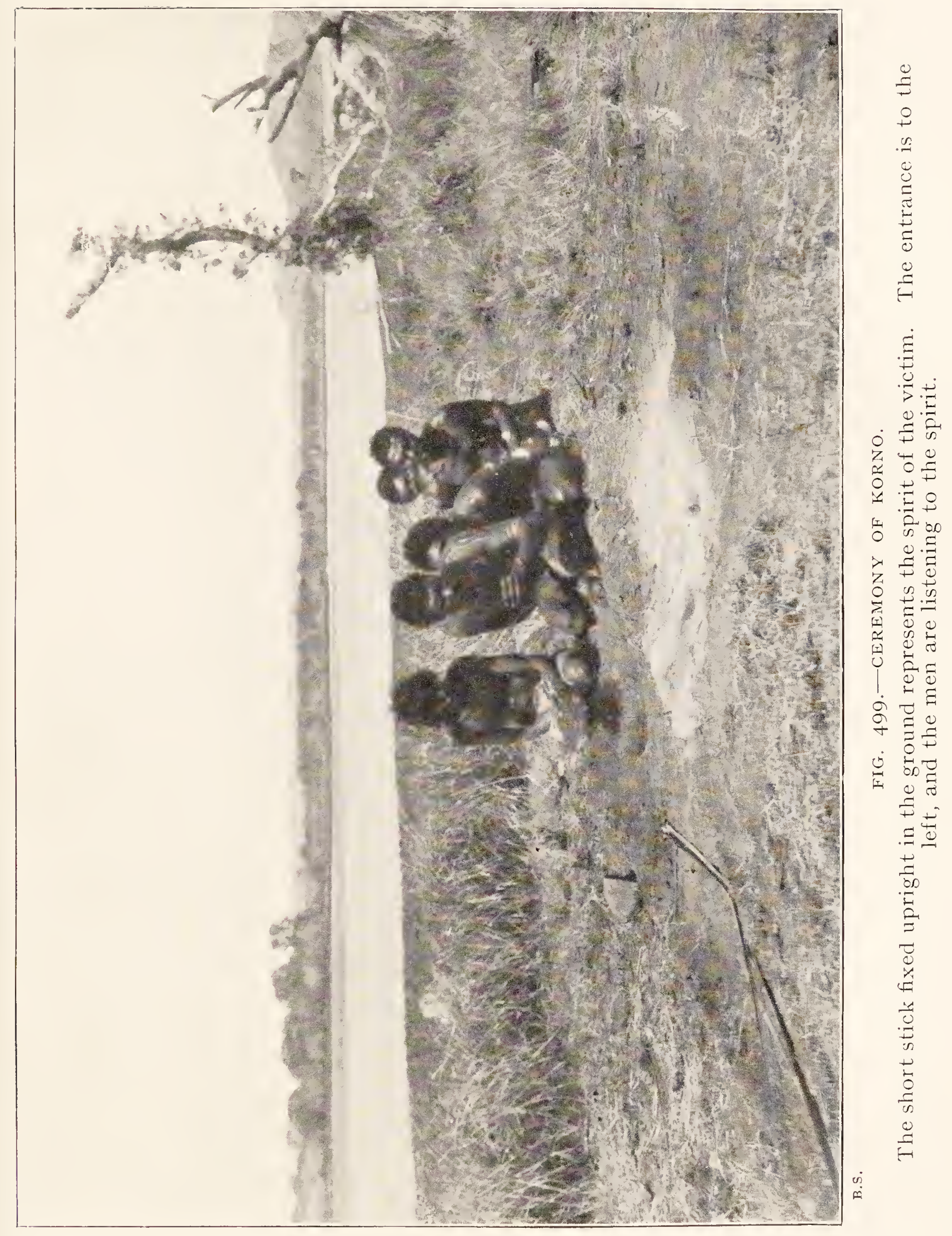




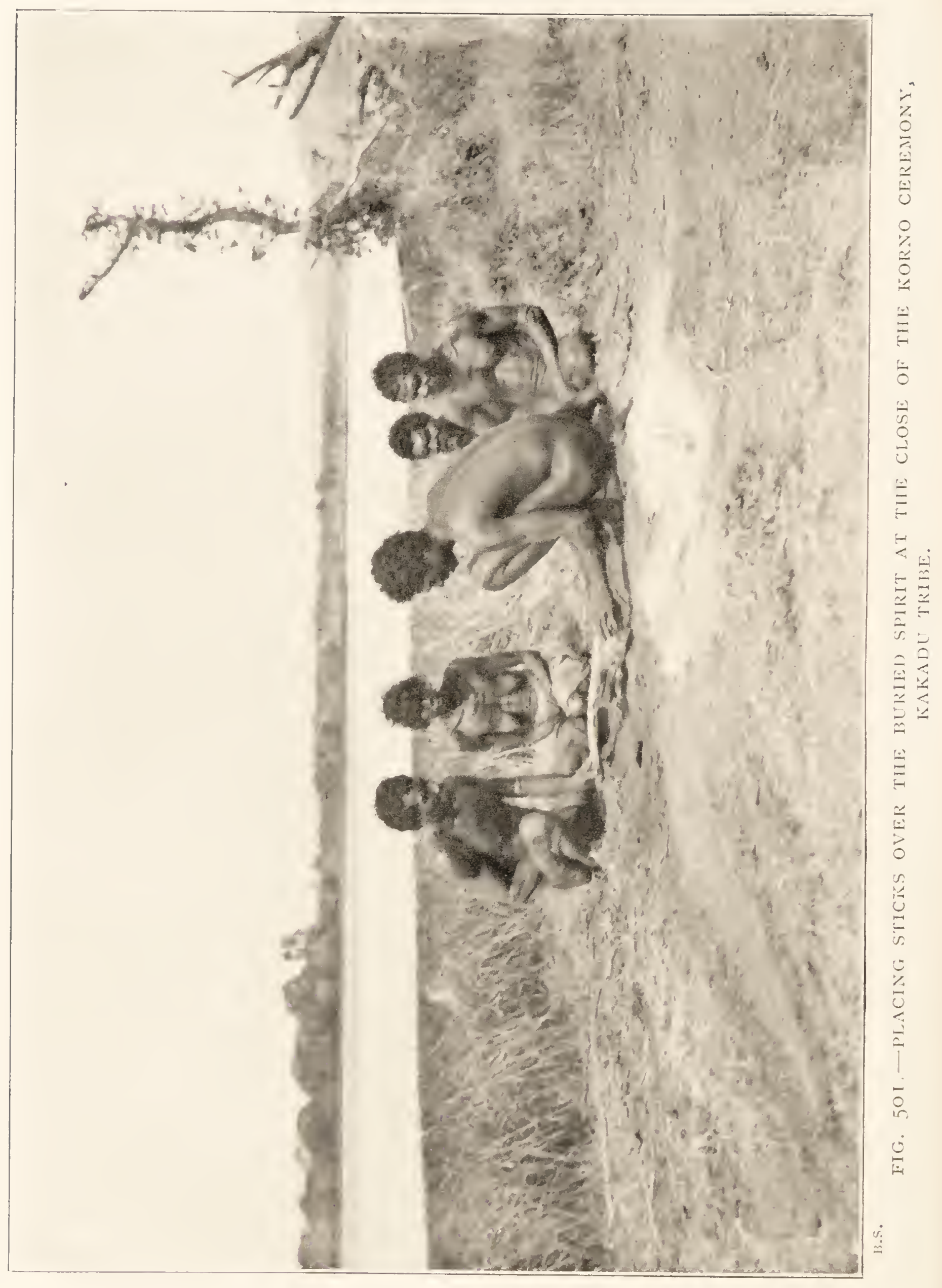


warn him of approaching danger or guide him to where he can secure his food.

The natives, of course, account for disease by evil magic. One form is associated with mud that becomes attached to the foot when.walking through a swamp. When the man comes on to dry ground he often scrapes it off with a little bit of bark. If someone else who wishes to injure him comes across the tracks he will take a little bit of the mud on the bark, wrap it up in fresh paper-bark, tie it round with hair string and take it to his camp, where, when it is quite dry, he will pound it up and make it into a little ball that he " sings," thereby projecting evil magic into it. Then he makes a hole at the foot of an ant-hill, pushes the little parcel in and closes it up. By and by the victim's hands and feet break out into sores that gradually spread over them. The toes and fingers drop off and the hands and feet decay. No medicine man can do anything against this kind of magic. It is a disease that, as a matter of fact, is every now and again met with amongst the Kakadu and other tribes and is commonly spoken of amongst the whites as leprosy.

Another kind of magic connected with Korno or excrement is supposed to help a boy who is weak and undergrown, at the expense of some strong man. His father, or his elder brother, secures a little of the man's Korno. The performers, who always include the boy, his father and a young mature woman who has not borne a child, go to some quiet spot in the scrub where they are well out of sight of the camp. A fire is lighted in a hole in the ground. This fire must be made on the spot by means of Ingornu, or drillingsticks. The Korno is finely pounded up, placed in a little sphere of Kapei resin and placed on the fire, which, while being made, must be fanned by a Norkun or goose wing, held by the woman in her left hand. The boy sits close beside his father, clasping him round the waist and looking over his shoulder at the fire. The woman sits to one side. VOL. II. 
The fire is covered over while the Korno burns away, and the father hits the boy with a little bundle of paper-bark called Yailla, saying as he does so, "Phu, Phu, jereini kumera wardua"; that is, Phu, Phu, very big man; then he rubs his son, saying, "Noornberi kumerawardna," my son very big; strikes him on the shoulder, saying, "Phu, Phu, umberabadua jereini," grow tall man; finally he hits him very hard, saying, "Pierda nugorto," strong arm; "Balera ngeinyimma jereini pierda," by and by you strong man. When all is over the burnt Korno is taken out and, together with the Norkun, is placed, as the natives say, Iwaji iiboulu, that is, inside a hollow tree and left there. The man whose Korno is used is supposed to part with his strength to the boy and die. They told us that they were very frightened of one special form of evil magic that consists of mischievous spirits, belonging to another tribe, placing in any Kakadu man whom they desire to injure a bone from a special kind of fish called Nuppadaitba that has been " sung." This is very serious and can only be cured by an exceptionally able medicine man. One of the latter was in camp, and he was good enough to show us just how he operated (Figs. 502, 503). The patient lay down flat on his back, the medicine man kneeling down beside him, and first of all blew hard on his chest. Then he massaged him and, finally, passing his hand through his own armpit so as to remove some of the perspiration that had gathered on the Wingorku, or hairs, rubbed this over the man's chest and then set to work to suck hard until, bit by bit, he removed all the bone, or would have done so, had any been present.

There is something special about this fish, which, to look at, is only like a good-sized perch. It lives in deep water-pools and may only be caught by really old men, and they must use nets or spears. The restrictions vary also in regard to different water-pools. At one called Munganilada, only Kakadu men may eat it. If anyone breaks this 


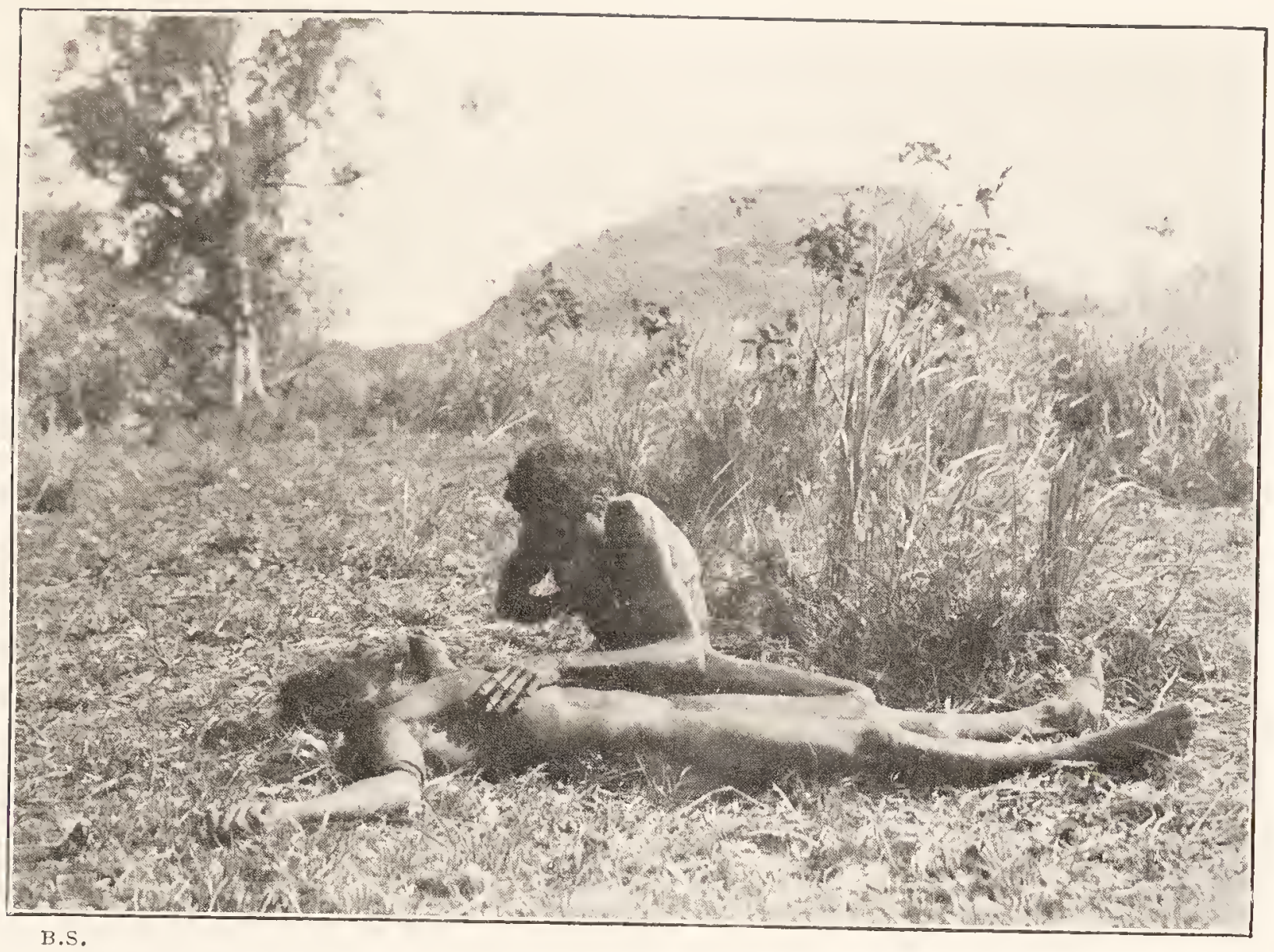

FIG. 5O2.-MIEDICINE MAN RUBBING HIS HAND UNDER HIS ARMPIT TO SECURE MIOISTURE TO RUB ON THE PATIENT, KAKADU TRIBE.

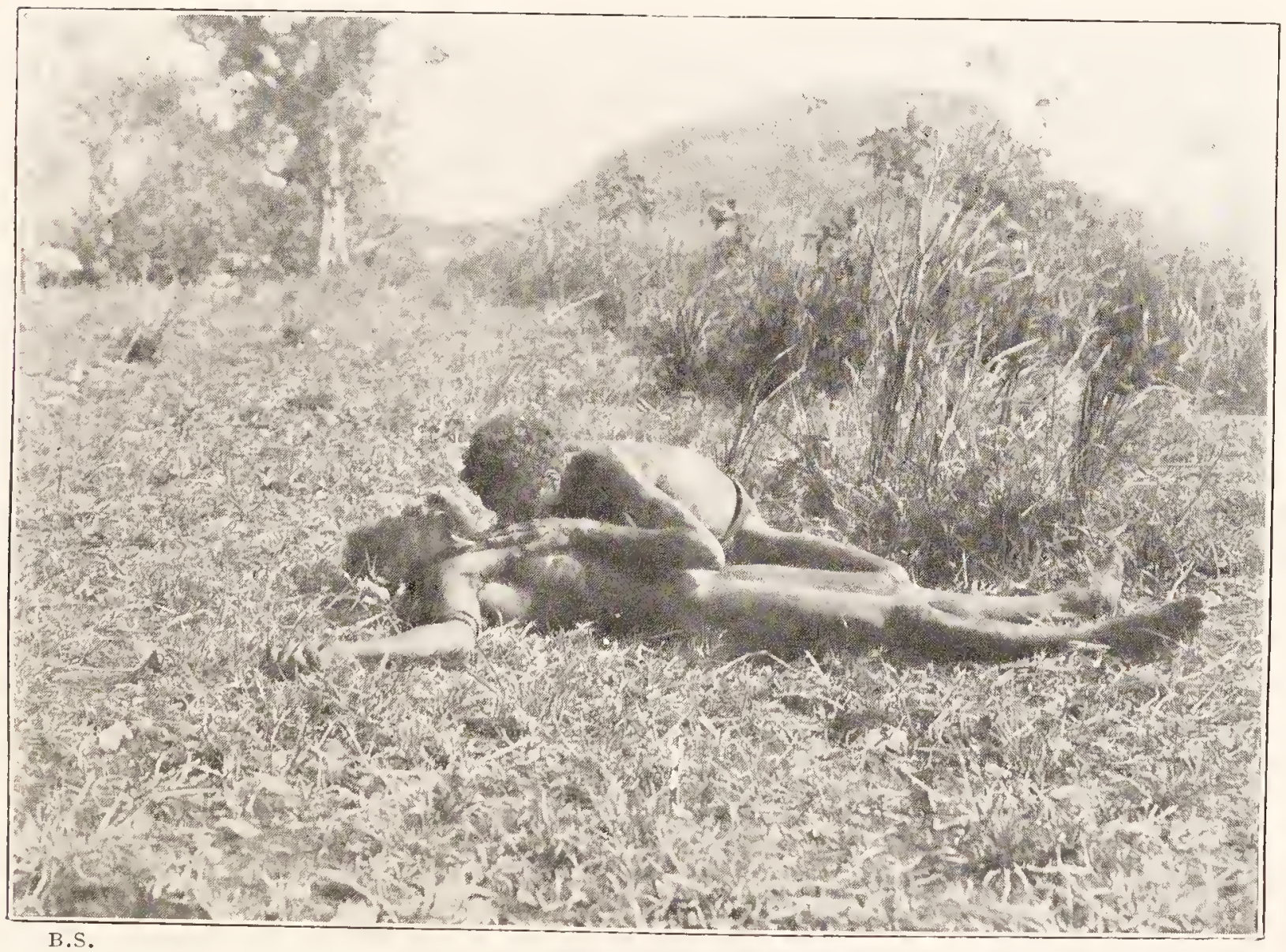

FIG. 503.-MEIICINE MAN SUCKING AND MASSAGING PATIENT TO WITHDRAW EVIL MAGIC, KAKADU TRIBE. 


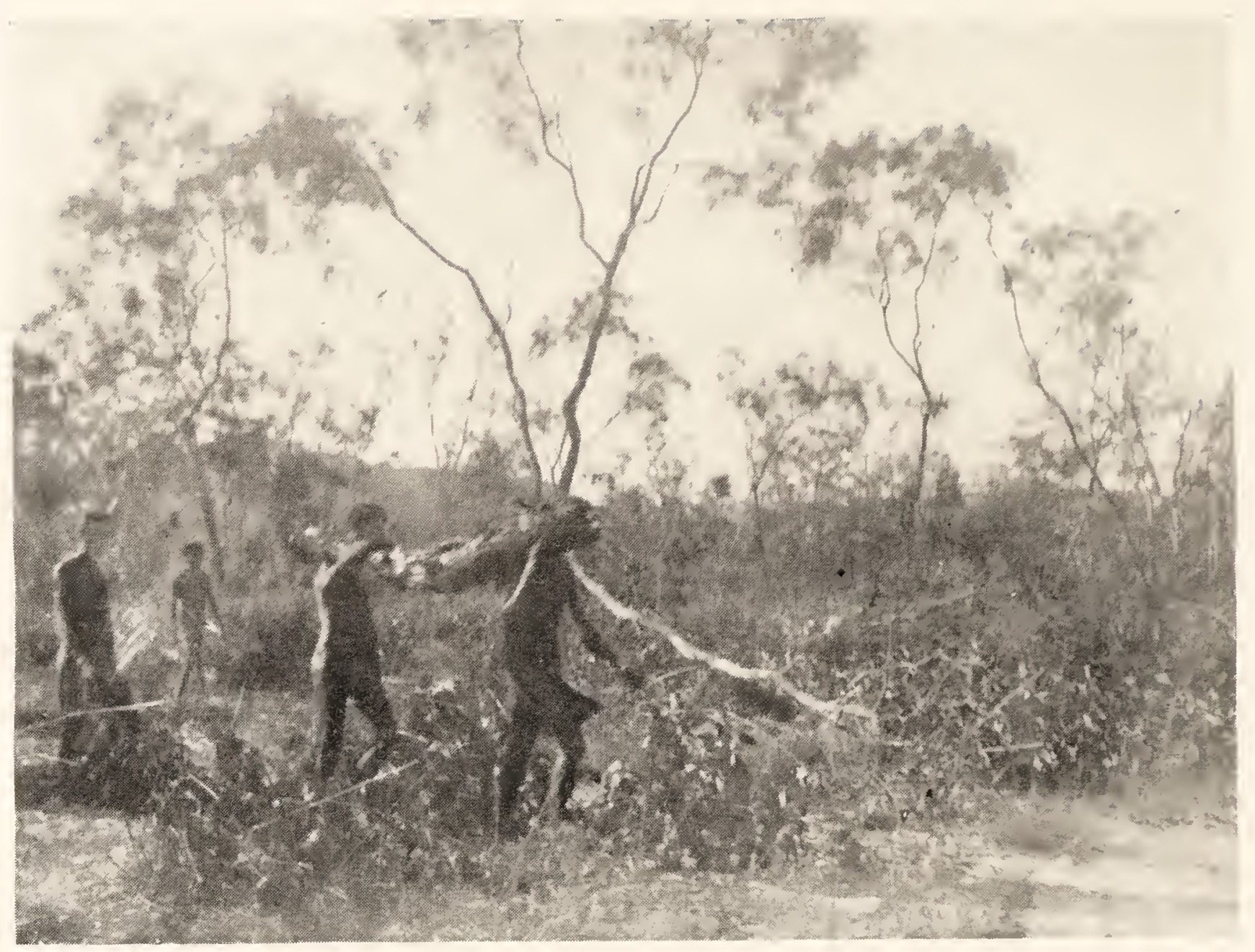

B.S.

FIG. 504.- CARRYING THE BODY, WRAPPED IN PAPER-BARK, TO THE GRAVE, KAKADU TRIBE.

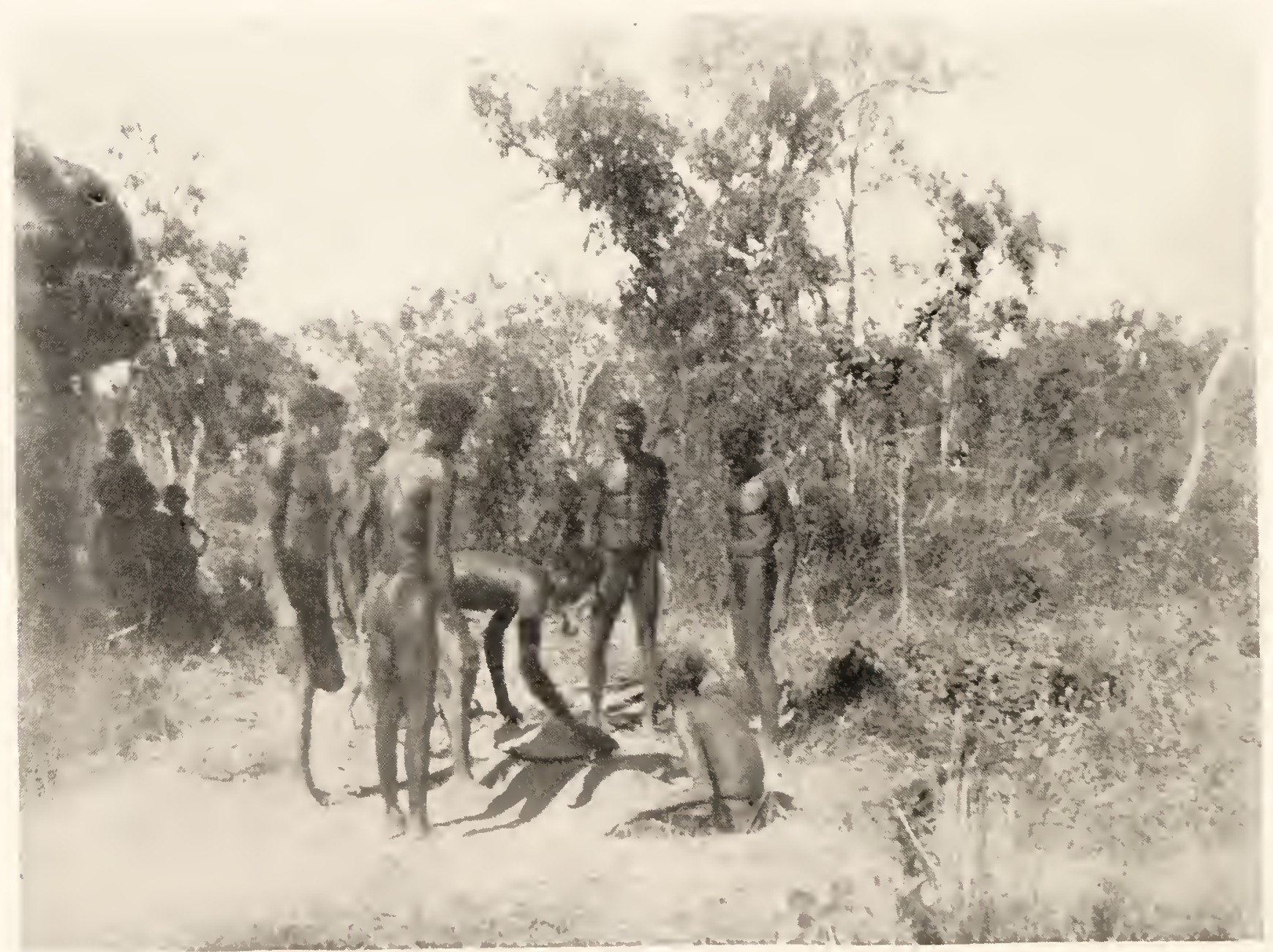

B.s.

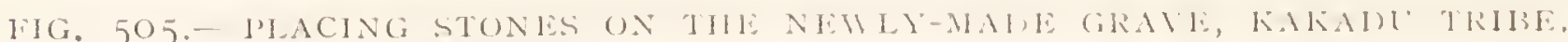


rule his eyes and ears swell up and sores break out all over his body. Only very old men may catch and eat it here; in fact a man's hair must be turning grey before he does so. Two fully initiated men were talking to us about it. One of them, Kopereik, was quite fifty years old, the other, Mitjeralak, was between thirty and thirty-five. The latter was not allowed to touch them; if he did so, he told us, and he believed it, that his arm would grow crooked. On the other hand, he might eat them if caught at another water-hole, called Nirriligauwa. Kopereik had given him permission to do so, but, even now, he only eats them if older men are with him. For a woman to be allowed to eat the fish it must be brought into camp on the point of the spear with which it was caught. If it tumbles off, only an old man may eat it, and, further still, it must be struck with a throwing-stick whilst still on the spear. The old men can also make it fit for the younger ones to eat by breaking its neck. Until a native becomes really old, his life is hedged in by numberless restrictions, such as this, which one would think must at times become rather burdensome, but so strong is the belief in evil magic that no one seems to be brave enough or at least to have confidence enough in himself to set them at defiance.

Fuly ist.-During the night there were sounds of wailing in the camp, about a mile away, and, knowing what this meant, we were down there early. An old woman named Muranga was dead. The camp was under a large Banyan tree and the body, wrapped in paper-bark, lay to one side, men, women and children sitting and standing around, looking very solemn and only speaking in whispers. The husband of the dead woman was seated with her head on his knees, while her two sons, one grown up called Wariut, the other, a young man named Mungortja, sat at her feet, where also, close by, was Minborku the wife of Wariut. In a very short time, Mitjeralak and Wudeirti, neither of 


\section{WANDERINGS IN WILD AUSTRALIA сн.}

them very closely related to the dead woman, lifted the body from the ground and carried it away on their shoulders, while all of us, men, women and children, followed in single file (Fig. 504). There is no obligation for any special men to carry the body, and, if it has to be carried a long distance away, any member of the local group may take his share in the work. After walking for about a mile we came to a large rock (Fig. 506) by the side of which the body was laid down. The spot had been selected for the grave by the husband and, as soon as we reached it, the women and children and most of the men went to one side and sat down, the women wailing. Three or four men began to dig, but, after some time, came down to bed rock, and so a new grave had to be dug a yard or two away. This time they were successful and a trench, about four and a half feet long, two feet wide and four feet deep, was dug with the aid of sticks and hands. Before, however, digging actually began, the women and children were summoned and came, led by one of the older women called Kumbainba. She carried in her hand a shell that the natives commonly use for holding water or ochre, but on this occasion it held a few small stones which she jingled about as the women and children followed her, in single file, round the spot chosen for the grave. As they walked round, they sang the following words which were supposed to be addressed to the spirit of the dead woman.

Tjukororu, lie down; koyada, do not; ngeinyimma, you; workai, come back; tjukororu, lie down; kala, a word meaning all right, just so; bialilla, children; unkoregora, see; iwaiyu, spirit; balera, later on; kutjeri, sick. That is, "You lie down quietly, do not come back, lie down all right; if the children see your spirit later on they will be sick."

When the grave was nearly dug, three women went into the scrub and gathered armfuls of grass stalks and leafy twigs and, returning, placed them beside the grave. When the trench was ready the husband, her two sons and Minborku, her daughter-in-law, sat by the side of the body, which 


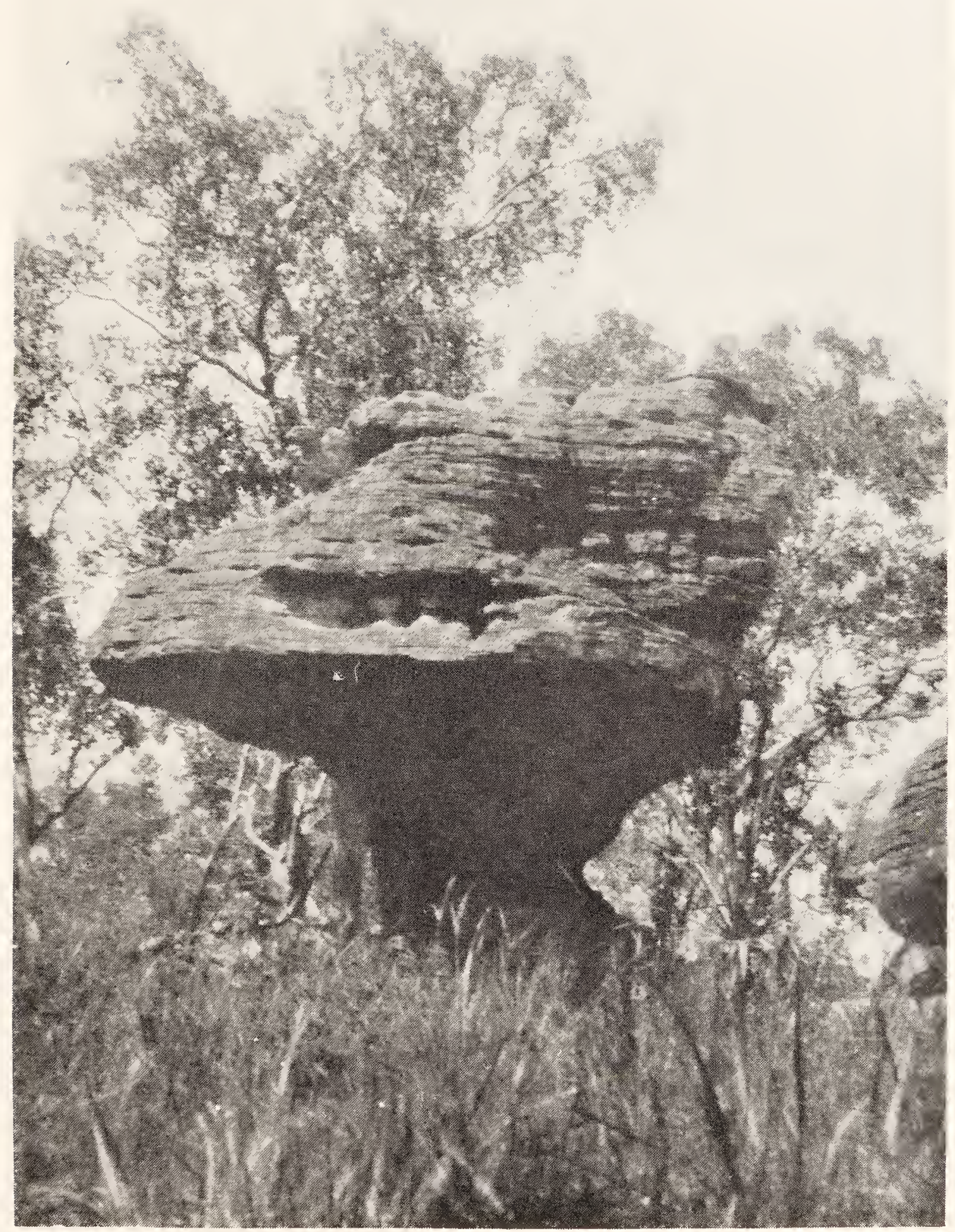

P. CAHILL.

FIG. 5O6.-BURIAL ROCK. OENPELLI, KAKADU TRIBE. 


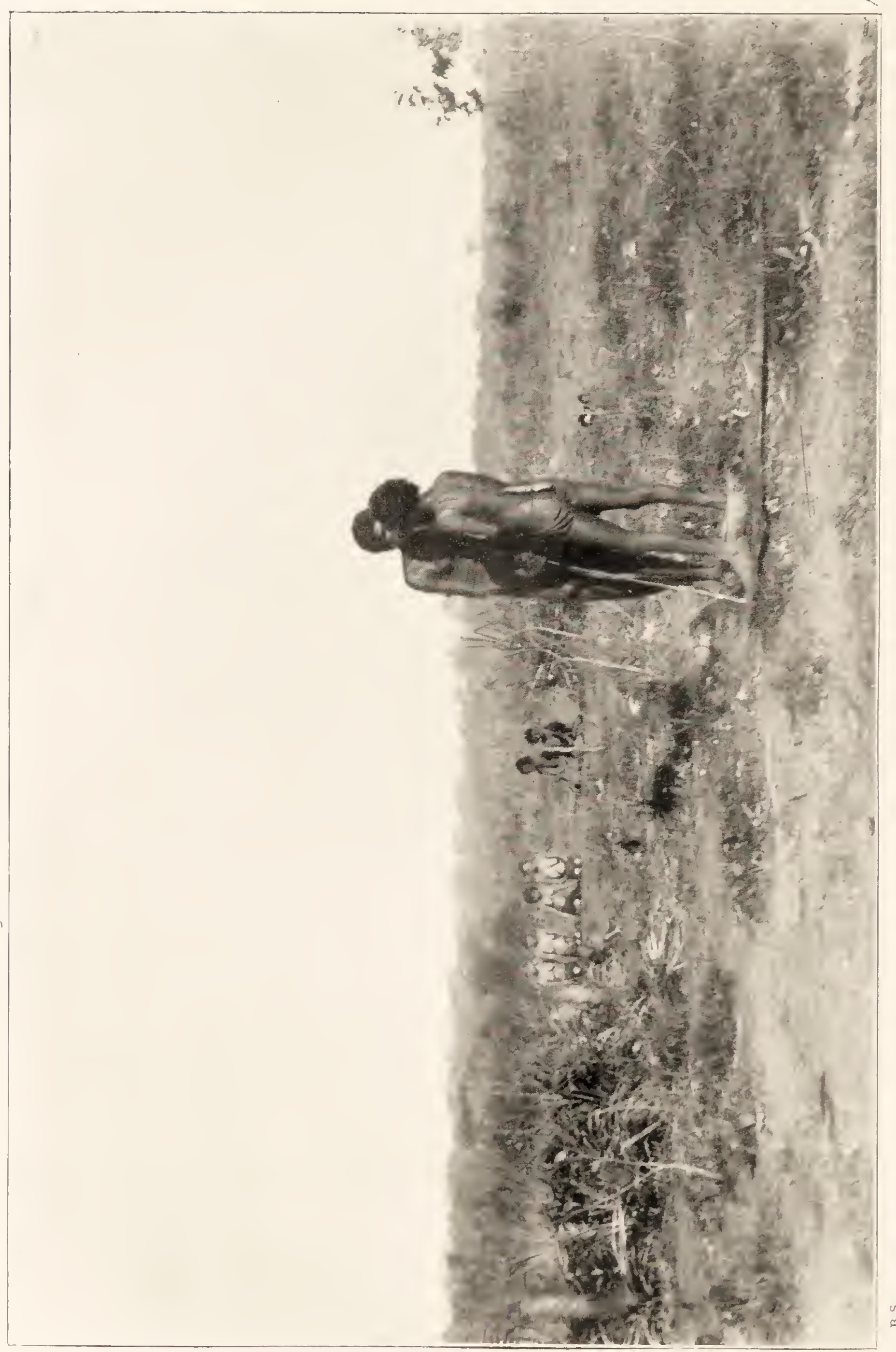

(

$\frac{1}{2}$

든

$=$

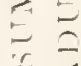

?

到

$=$

$=3$

:

$\because \frac{1}{1}$

6

$-7$

온

工

$\div$

4

\&

学

$=$

은

$\equiv$

$=$

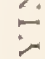

$\frac{1}{2}$

U

0

10

in

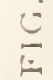


was still wrapped in bark, and cut their heads till the blood ran down their faces on to their bodies. Then one man went in to the grave, the grass stalks were handed to him and he trampled them down. The body was then placed on them, lying on its right side with legs bent up; a thick covering of grass was placed upon it and the soil piled on, so as to form a mound on which stones were firmly planted to prevent the dingoes from burrowing down into the loosened earth (Fig. 505). While this was going on and after it was over, everyone wailed and cut themselves freely, men and women alike. Some of the blood from the husband and his two sons was collected in a small piece of paper-bark in which the body had been wrapped, and, folding the rest of the bark round the belongings of the dead woman, such as dillybags, the mat on which she lay and her digging-stick, all of which had been brought to the grave, they carried the parcel back to camp and placed it in the Banyan tree, close to the spot on which she died, to await another ceremony that is to be held in a day or two. Meanwhile, no one must wash the blood off their bodies, so they will be uncomfortable.

Fuly 2 nd.--The natives began some important ceremonies to-day connected with initiation. Late yesterday evening we were sitting in our mosquito-proof tent, engaged in our usual evening occupation of skinning birds and various animals, when we heard a special singing, coming from the direction of the native camp. It was repeated again in the morning, when we found that the singing came from two youths who were standing close together facing one another, each of them leaning on a wand, coloured red and white (Fig. 507). The song they sang was:

\footnotetext{
"Kadimanga,

Da laian a,

Da laian a.

Kadimanga,

Da laian a,

Da laian a."
} 


\section{WANDERINGS IN WILD AUSTRALIA сн.}

It was repeated time after time, and always the women, sitting in camp, replied with the refrain, "Wait $B a !$ Wait $B a ! "$ repeated as often as they could without drawing breath. They sometimes do this fourteen or fifteen times. I often heard it thirteen, and naturally it dies away towards the close when their breath is exhausted. It is sung on a high note; the Wait is short, the $\mathrm{Ba}$ emphasised and prolonged. For days after the boys have come to the men's camp they stand up every now and then and chant their song and, time after time, from camps, some so far away that you can only just hear the sound, comes back the refrain "Wait $B a !$ Wait $B a ! "$ It is one of the most picturesque of their songs, especially when heard in the bush at nighttime. It is curious that the boys' song varies; one that we heard was:

$$
\begin{aligned}
& \text { "Le daming ge, } \\
& \text { Rai la la. } \\
& \text { Le daming ge, } \\
& \text { Rai la la," }
\end{aligned}
$$

but the women's is always the same. I managed, as we came near, to get a snap-shot of the boys standing together, with the women seated in their camp listening and replying to them. These two boys were passing through the second stage of initiation. They had been sent round to various camps, at each of which they had announced their approach by the song, which, together with the painted wands called uro-ammi, are a safe passport allowing them to go unhurt right across the country from group to group. As soon as the boys' song is heard in the distance everyone knows what it means, and an elder man goes out to the youths and says, "Mere willalu," come to the camp. They are the guests of each camp, and very often, by the time they get near their own home camp, are accompanied by a number of men, women and children, the former coming to take part in the ceremonies that will be performed on the return of the boys. 
Every Kakadu man has to pass through no fewer than five ceremonies before he attains to the status of what may be called full membership of the tribe. These ceremonies are known as (I) Jamba, (2) Ober, (3) Jungoan, (4) Kulori, and (5) Muraian. There is nothing so serious about them as either tooth knocking out or circumcision, neither of which rites is practised by these far northern tribes. For the most part each of them consists in showing the initiates a series of totemic ceremonies. The first, called Jamba, is, strictly speaking, the most important initiation ceremony and marks the turning point in the life of each youth, when he passes out of the ranks of the women and children, with whom he has hitherto associated, into those of the men, and is therefore allowed to see and gradually take part in the performance of the sacred ceremonies that are characteristic of the remaining four, although he is an elderly man before he is permitted to witness the Muraian. ${ }^{1}$ It is a very striking feature of these tribes that their initiation ceremonies are entirely devoid of any reference to anything equivalent to the bull-roarer that figures so prominently, in fact is the essential feature of the ceremony, in all Central, Eastern and South-eastern tribes. There does not seem to be any attempt to make the initiates suffer inconvenience of any kind; in fact a striking feature of the Jamba is numbers of little ceremonies the object of which is to remove food restrictions in regard to the eating of particular animals. As initiation proceeds through the various grades, the restrictions gradually disappear.

The two youths, who had now returned, had previously been through the Jamba, acquiring thus the status of Numulakiri, that is, a young man after initiation, and were being shown ceremonies connected with the second series called Ober. We found out now that the snake ceremony that we

1 A full account of these ceremonies is given in Native Tribes of the Northern Territory of Australia, I9I4. 
had seen before belonged to the same series. The sending out of young men who are just entering upon manhood to visit distant camps is often met with in Australia. It not only serves to let it be known widely who these men are, but it gives them the opportunity of broadening their outlook, by seeing foreign parts and meeting foreign peoples with languages, habits and customs often different from their own. It is, in fact, a kind of crude forerunner of the "grand tour" that, in years not very long ago, was the proper thing for young Englishmen of a certain status to undertake. Also, like the latter, the young savage was usually sent on his wanderings under the charge and tutelage of an experienced elder. An important difference between the two was that, making the grand tour was the privilege of every aboriginal, that it cost nothing and had to be made on foot.

There is no such regularity in regard to ceremonies in the Kakadu as there is in some of the Central tribes. Some are associated with the Jamba series, others with the Ober and so on, except the Muraian, which is a thing apart by itself. They all look very much like one another, but the natives will tell you that one is Jungoan, another Jamba and so on, though why it is so they do not know. Also, as we found out, you can have the different kind of ceremonies going on at the same time. In the Kakadu again, like the Arunta, there is no definite sequence, any totemic ceremony belonging to any totemic group can be performed at any time; in the Warramunga, on the other hand, there is a definite sequence and the ceremonies must be performed in this order. You must begin at the beginning and go steadily through to the end.

The men told us that they were going to perform an important Ober ceremony. First of all they prepared a special ground called Tjaina. It was out in the bush amongst the gum trees, a mile away from the main camp, 
and of course no women or children were allowed anywhere near, though there was no sounding of a bull-roarer to mystify and warn them off. All they knew was that the men were doing something that they must not pry into

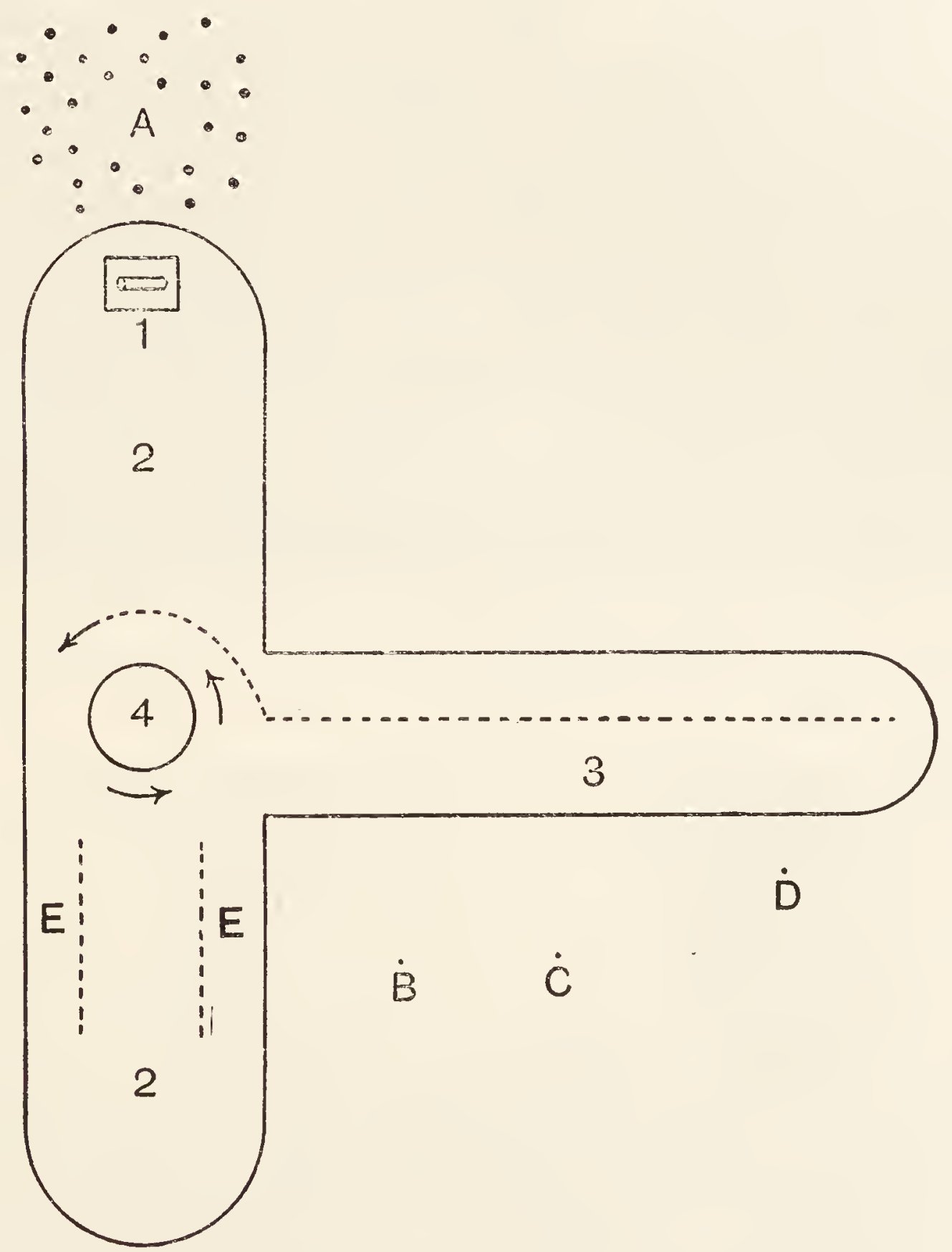

FIG. 508.-DIAGRAM ILLUSTRATING THE OBER CEREMONY.

I. Budjeir. 2. Tjaina ground. 3. Mungarni ground. 4. Wungaritja

A. Audience and performers during intervals in the ceremony.

B. Man with conch. C. Man with long stick. D. Man with clanging sticks. E. Two lines of performers.

and had to be content with being mystified. They had not even the satisfaction of knowing, as the Mara and Warramunga women do, that in their next reincarnation they would be men and the tables turned upon the present privileged performers. 
The Tjaina ground was forty fect long and ten feet broad. Half-way down it, a bush shade, called Wungaritja, was built, shaped like a great beehive, four feet high and five feet in diameter at its base. At right angles to the Tjaina, opposite the Wungaritja, another ground, called Mungarni, ran out for twenty-five feet, forming a kind of side stage. The general arrangement is shown in Fig. 508 .

At one end of the Tjaina, a piece of paper-bark was placed on the ground, and upon it a log of wood, that was supposed to represent the old kangaroo-man, or mankangaroo, watching the ceremony (I). He and the log were both called Budjeir. A few yards at the back of the Budjeir, out in the scrub, stood the performers and audience, all, at first, grouped together. Sixteen men were decorated, two of them represented Moain, or fish men, and the others Marabornji, or brush-tailed wallabies, who were painted with series of white boomerang-shaped lines down their backs and arms and wore tufts of white cockatoo feathers on their heads (Fig. 5 I I). The first part of the performance consisted of the decorated men being brought in, two by two, to the Wungaritja. They came in at a run, each pair led by two old men who stationed them close round the $W u n-$ garitja, with their backs to it and their bodies bent forward (Fig. 509). As they were placed in position they began swaying their bodies about from side to side. When all had been brought in, two old men went on to the Tjaina on the side furthest from the Budjeir. Followed by decorated men, and holding sticks in their hands, they performed a quaint dance, or movement, along the ground, to the far end of the Tjaina, during which they were supposed to be representing the movements of the native companion (Fimeribunna). Then they all walked back to the restingplace in the scrub (A), that served as a kind of green-room. The same old men again brought the performers in, one by one, and, beginning at the far end, placed them in a line, 


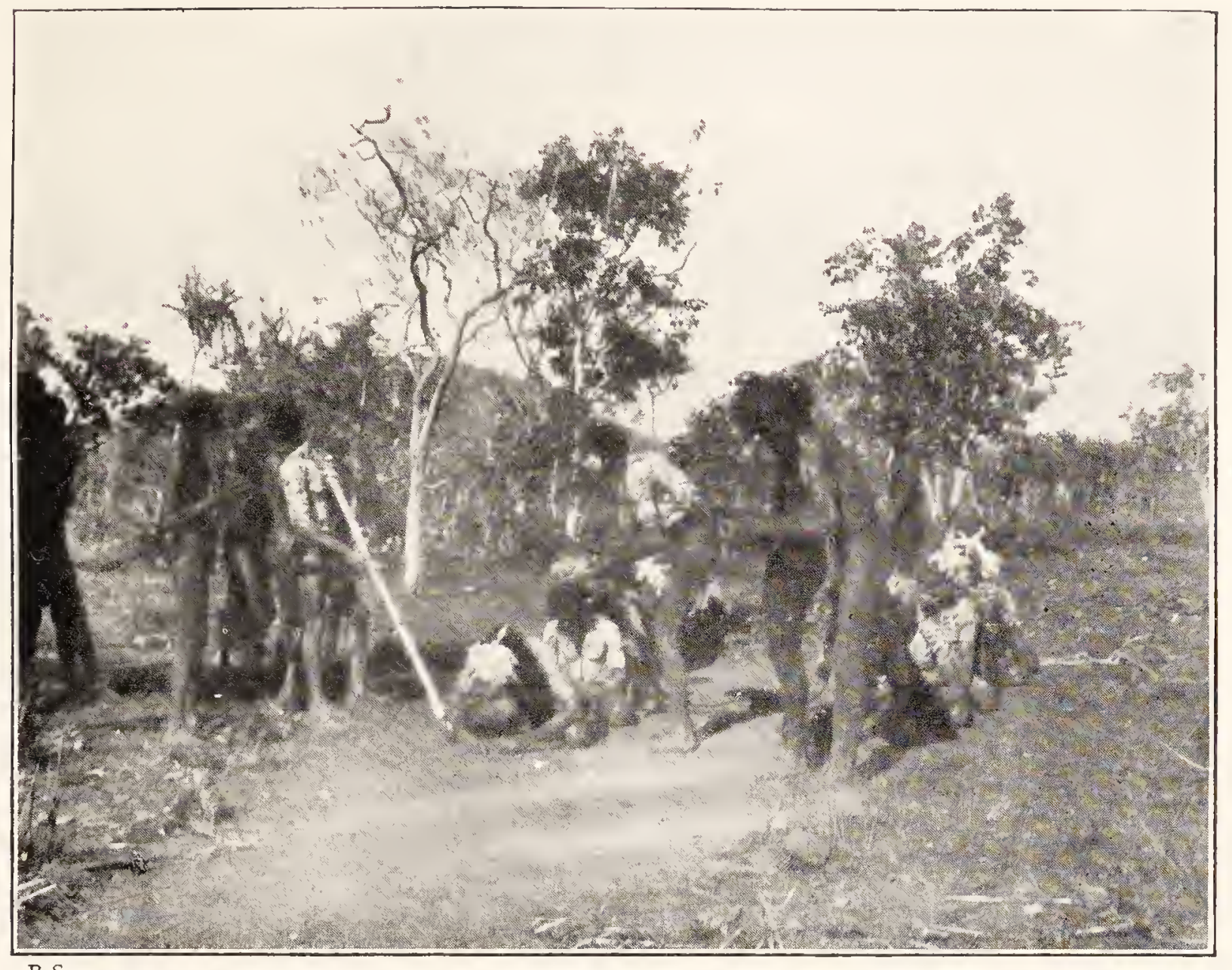

B.S.

FIG. 5O9.-SCENE IN KANGAROO PERFORMANCE. OBER CEREMONY, KAKADU TRIBE, THE MAN ON THE LEFT SIDE IS BLOWING THE CONCH.

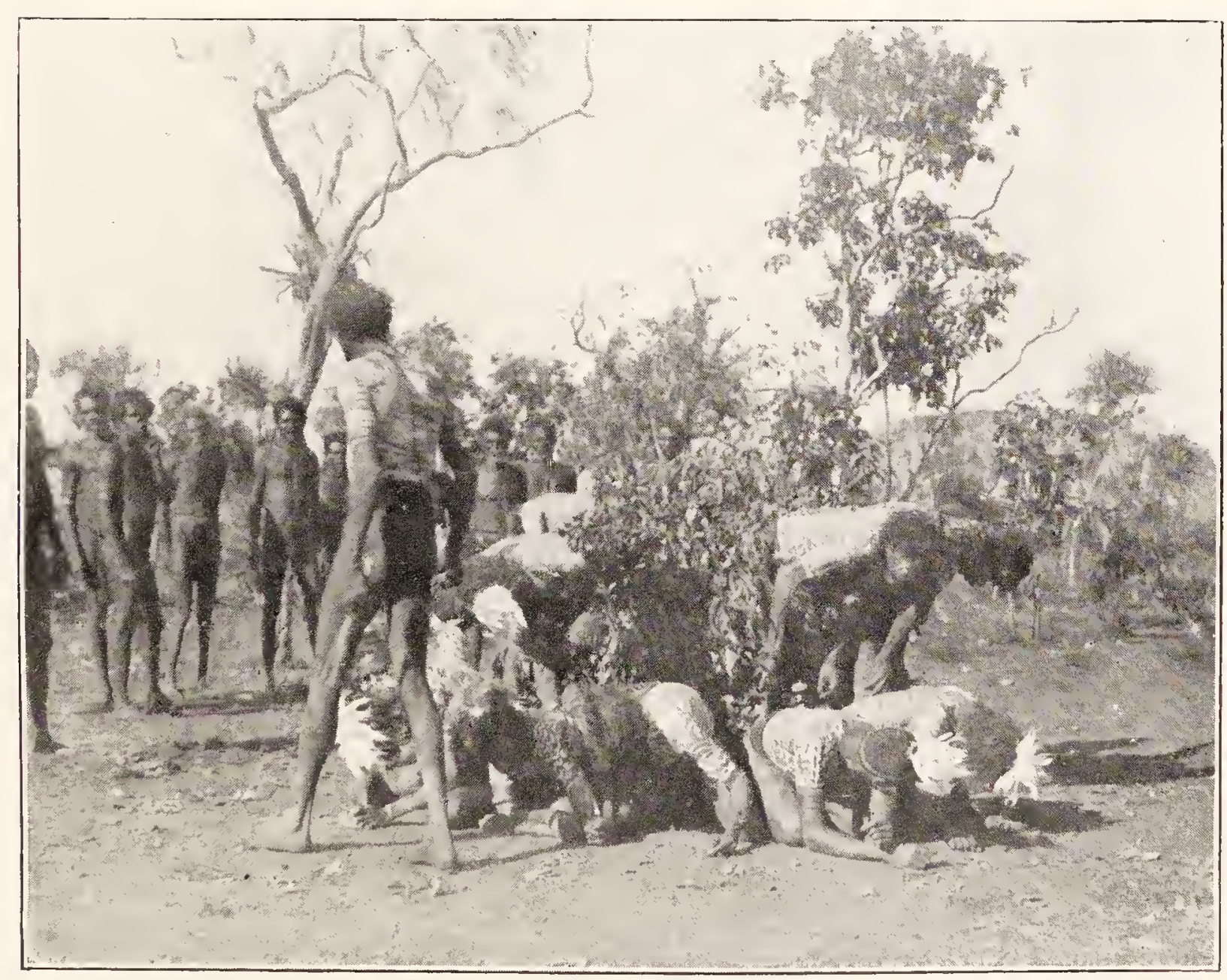

B.S.

FIG. 5IO. SCENE IN KANGAROO PERFORMANCE. OBER CEREMONY, KAKADU TRIBE. 


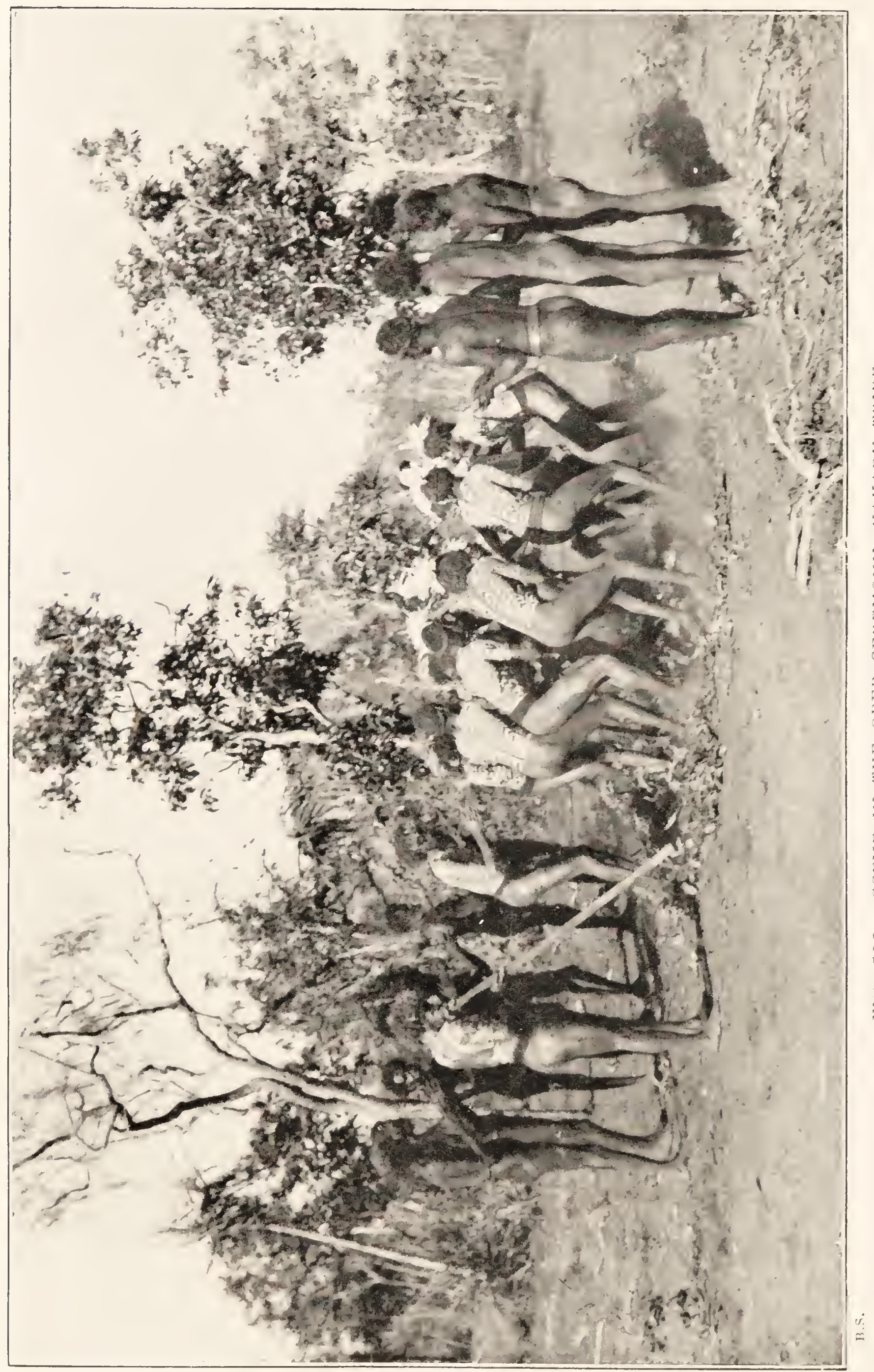


one behind the other, on the side stage, the Mungarni, the two Moain men in the lead. While this was going on, one man, B, was blowing hard at a bamboo conch, another, C, was constantly bringing down a long stick, that he held in both hands, with a crash on to the ground, and the third, $\mathrm{D}$, was clanging two sticks together. Each performer bent forward, placing his hands on the hips of the man next in front. In this position they swayed their bodies over from side to side. The swaying was done in such a way that there was a sinuous line of movement, accentuated by the white cockatoo plumes. This went on for some time and then, to the accompaniment of much clanging and trumpeting of the conch, they formed a procession, circled round the Wungaritja and dropped down on their knees, in two lines, on the Tjaina (E). The audience stood on either side of them (Fig. 5IO). The three men, B, C and D, came and sang over each one of them in turn as they quivered and swayed about from side to side. This occupied a considerable amount of time, and then they hopped away into the scrub, in single line, imitating kangaroos. Once more they were brought in, two by two, and placed close together, stooping down all round the Wungaritja, their backs pressed into it. Suddenly, with a yell, they all backed into it, smashed it down and threw the boughs into the air. Then they trampled them to bits and ended with a loud yell. All that they could tell us about it was that the ceremony was associated, in some way, with a group of ancestors who were led by a very big old kangaroo named Jeru Ober. The Wungaritja belonged to him and he used to rest in it during the day, just as an old kangaroo now rests in the shade of a tree or bush during the heat of the day. $\mathrm{He}$ told his men to kill white cockatoos and make head-dresses of their feathers. Then he made the Tjaina and also the Fiboulu, or conch, and showed them how to perform the ceremony. The men looked on and said, Mara (well done), 


\section{WANDERINGS IN WILD AUSTRALIA сн.}

kala (a word meaning amongst other things, certainly, all right), mabilabilla (dance). The kangaroo then said, "We are like blackfellows (Fereini) now, we will go underground or the men will see us." So they all went down, except the old Jeru Ober, who remained above for some time, but finally he went into the ground, close by his Tjaina, where there is now a big paper-bark tree that can still be seen at a place called Kupperi, between the East and South Alligator Rivers. Only men who have been through the Ober ceremony may go there; women and children must not go anywhere near.

Fuly 3rd.-For some reason or another the kangaroo ceremony was repeated to-day, but there was nothing new about it, though we had to spend hours watching it for fear lest there should be. We had just settled down to our evening's work of skinning when a boy came in post haste to say that " white fellow been come up." It turned out to be Protector Linacre, who had come across country from the railway line to bring two cases of tobacco that had been left behind in Darwin. The overland journey from Pine Creek had taken him just ten days. There were no tracks, so travelling was very rough and slow.

Fuly 4th.-Linacre started back to Pine Creek, so a goat was sacrificed to afford him meat for the first part of his journey.

In the afternoon the natives performed one of the closing scenes in connection with the death of the old woman who was buried three days ago. It was a very interesting one and consisted, in part at least, of the nature of a purification ceremony. Everyone, men and women alike, in the little camp in which she lived brought up all his or her belongings. The women had their mats, baskets, dilly-bags and diggingsticks; the men their spears, spear-throwers and tomahawks. The Kakadu have a convenient word, ardi, that means the total possessions of anyone. In the centre of 


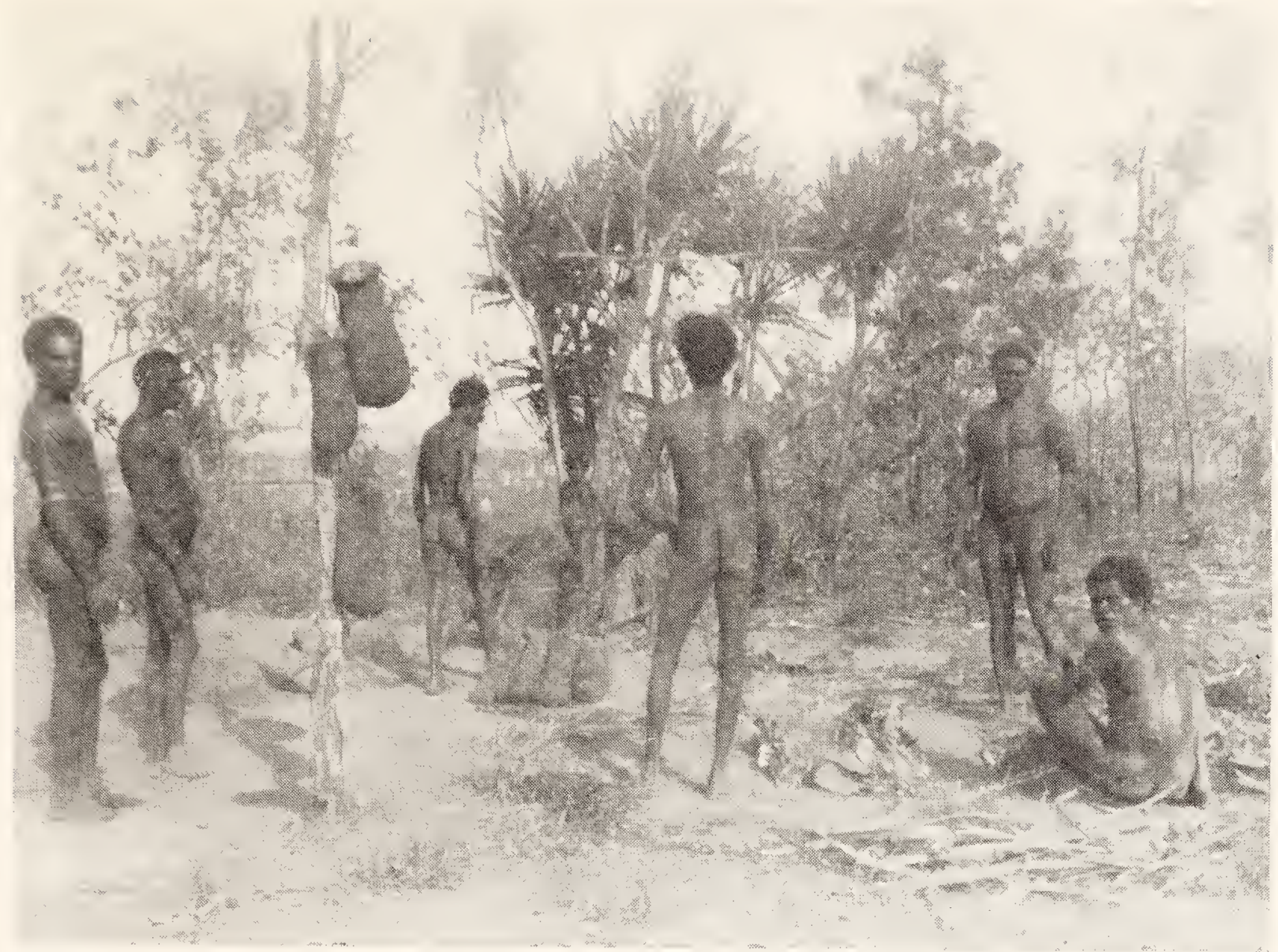

B.S.

FIG. 5I2.-CIRCLE OF GRASS STALKS WITH PAPER-BARK IN CENTRE, IN WHICH THE BODY OF THE DEAD WOMAN HAD BEEN WRAPPED. DILLY-BAGS, ETC. HANGING ON TREES ALL ROUND.

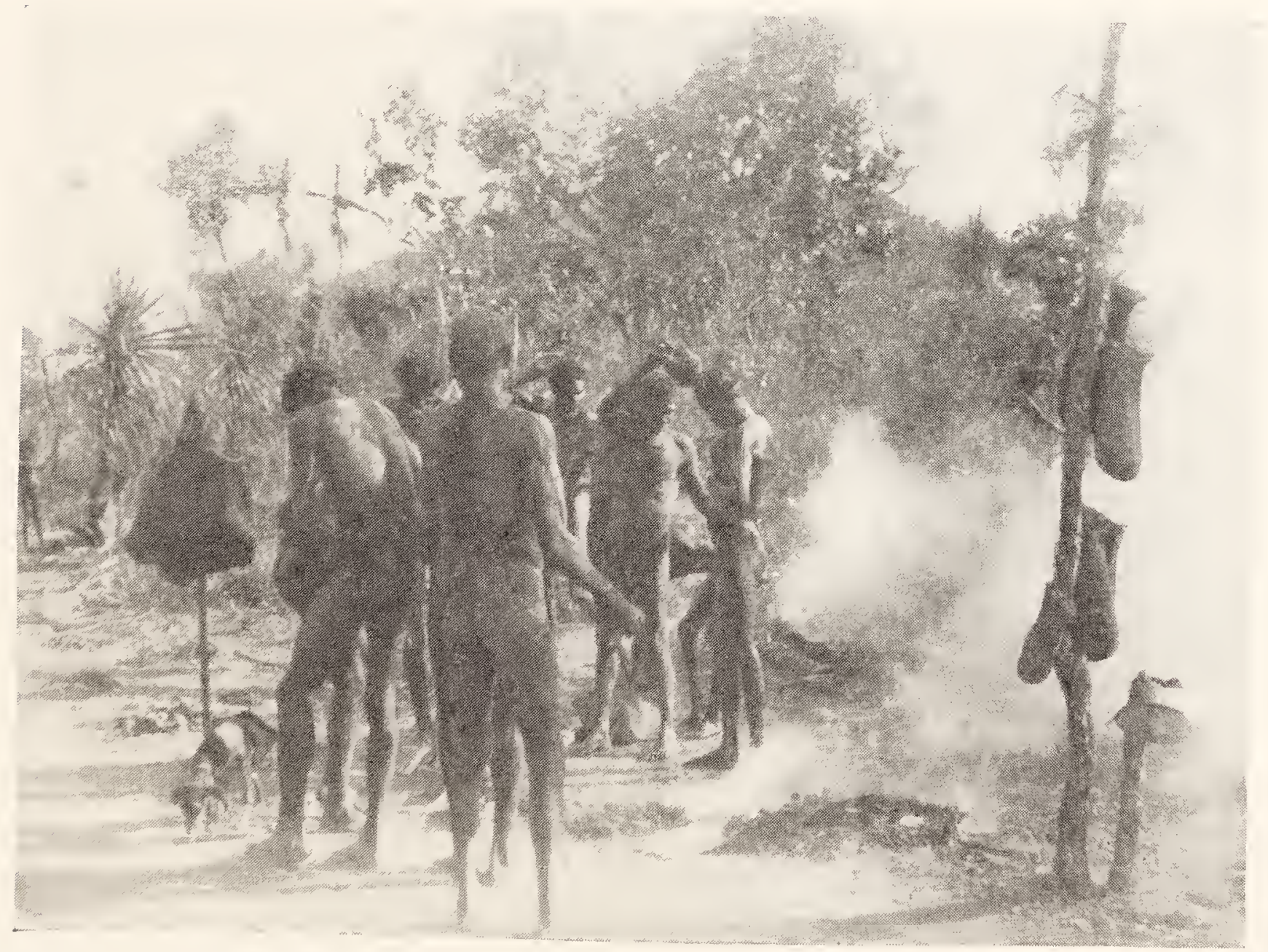

FIG. 5I3.-WATER-POURING CEREMONY. THE MEN ARE STANDING IN THE MIDDLE OF THE CIRCLE OF GRASS STALKS, WHICH IIAVE FIRST BEEN SET ON FIRE, KAKADU TRIBE. 


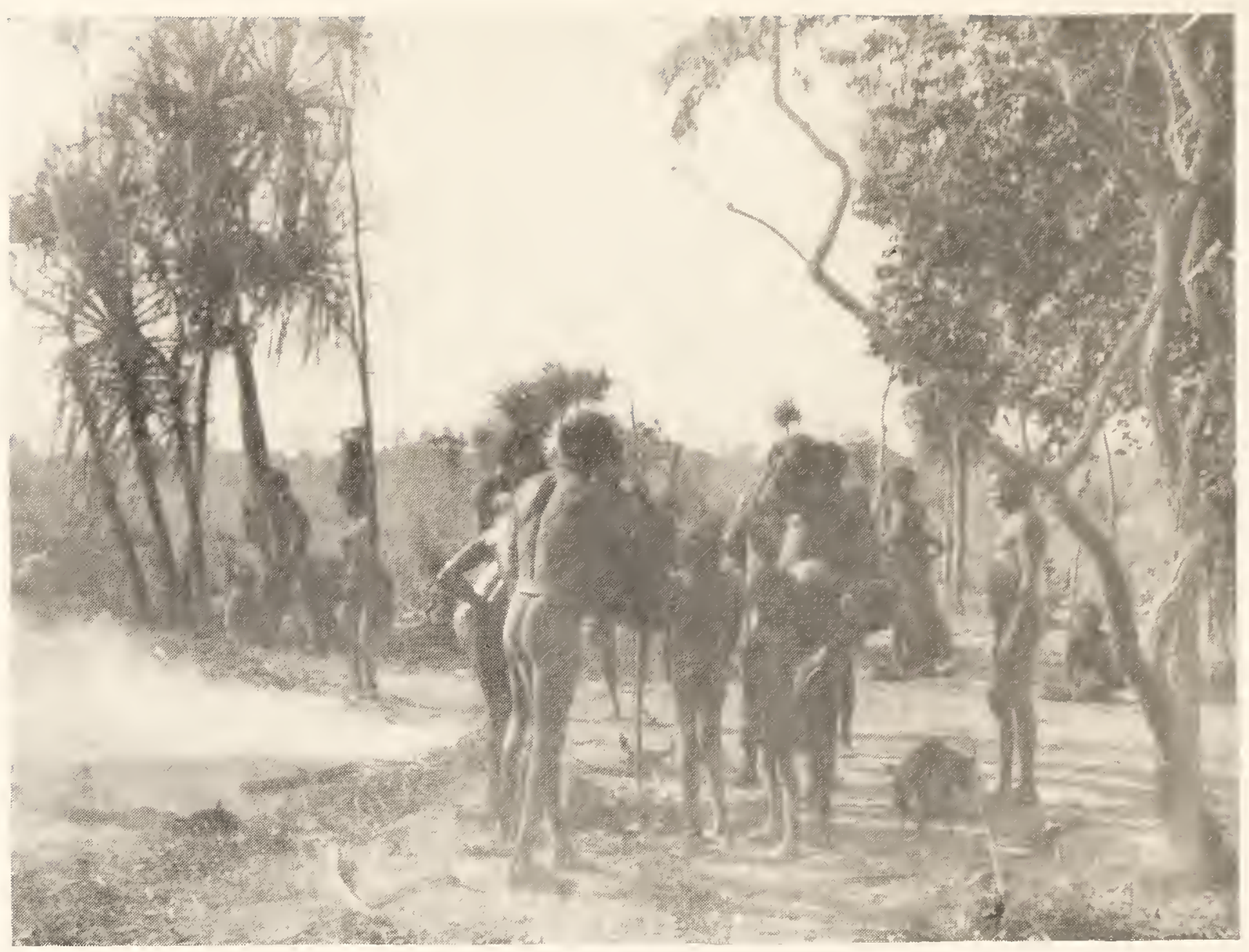

B.S.

FIG. 5I4-MEN PAINTING THEMSELVES AND CHILDREN WITH BLACK. THE SMOKE FROM THE GRASS STALKS IS SEEN ON TIE LEFT. THE DILLY-BAGS ARE HANGING ON THE TREES, KAKADU TRIBE.

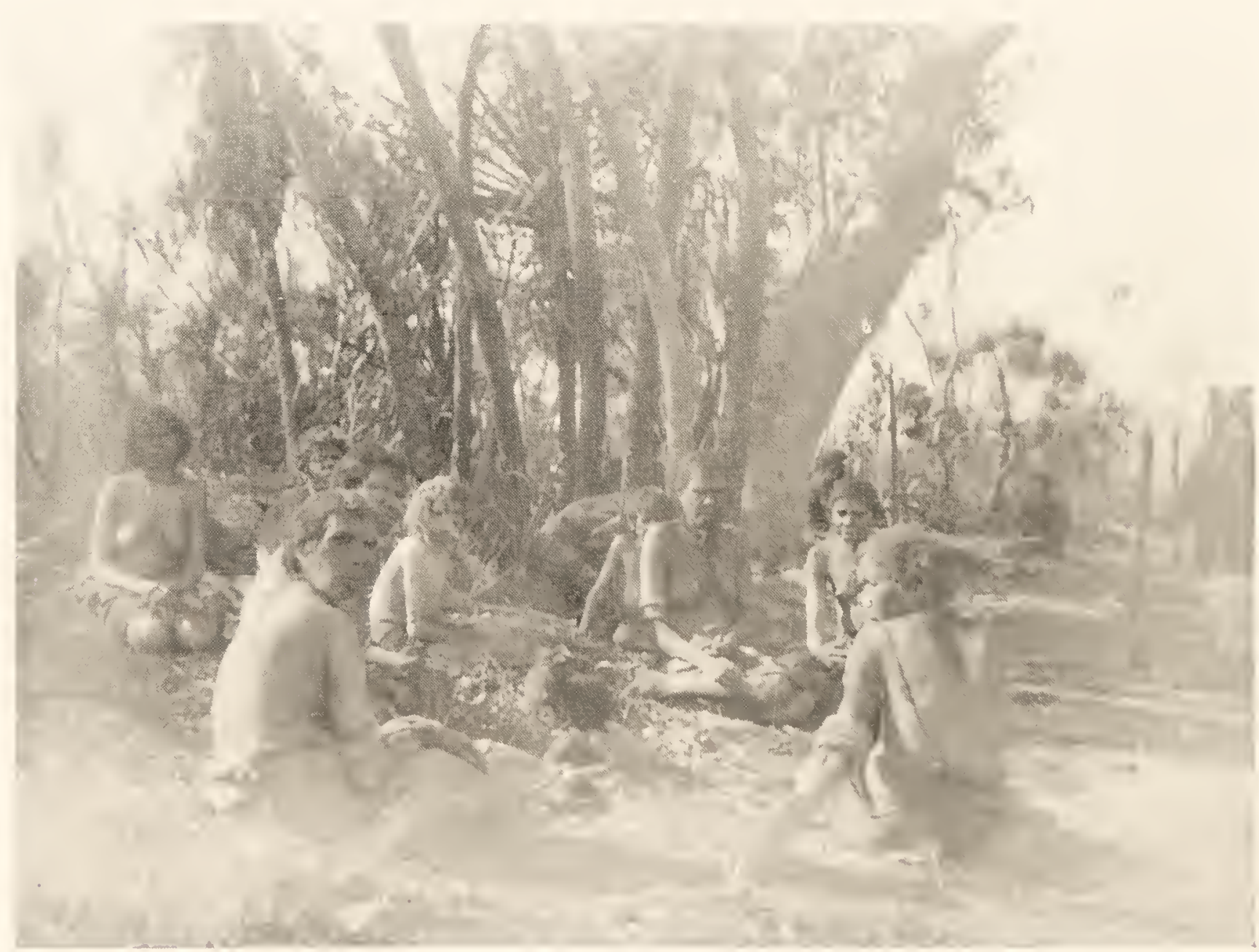

B.S.

LIG. 515. WOAEN WEARING ARMLETS CALLED KYTM.1\%, IOURING MUURNANG CERLAONL, KAKADU TRHII: 
the camping ground a circle of grass stalks was made, eight feet in diameter (Fig. 5 I2). Around this the dilly-bags and baskets of the women were hung on sticks and tree trunks close by. The men's weapons were placed on the ground. Within the circle were placed, first, the bundle of paper-bark or ranken in which the dead woman's body had been wrapped and carried to the grave; secondly, her belongings, mat, dilly-bag, digging-stick and baskets; thirdly, three palm-leaf baskets full of water, and fourthly, a basket full of charcoal made from a special pea bush. The ordinary name for charcoal is kumbeltji, this is called miornai.

First of all a special fire was lighted on one side of the ground and the dilly-bags of the eldest surviving sister were placed close to it, so that the smoke from the fire passed over and through them. The bags were thus purified and could be used again to hold food. If these were not smoked and anyone were to eat food carried in them, the result would at least be serious illness, indeed most likely death. After this the grass stalks were lighted and the men who were to paint themselves went inside the circle, and, with the smoke curling round them, lifted up the baskets containing water and poured this over their heads (Fig. 5 I3). The paperbark in which the body had been wrapped and all the women's belongings were burnt in the fire, and afterwards the ashes were very carefully covered over. In the case of a man, we were told that his weapons were broken up and burnt in the same way. After the water-pouring was finished the men took the charcoal and rubbed themselves and the children all over with it, until they were all as black as soot and shone with the water (Fig. 5 I4). The fire got so hot while they were doing this that they moved out of the circle. No women paint themselves at this part of the ceremony, but all the men do, or else the spirit of the dead person would be angry. The women brought in large 


\section{WANDERINGS IN WILD AUSTRALIA сн.}

numbers of little cakes called munduaii, made out of lily seeds. They were placed on a sheet of bark just outside the ring of fire and, when all was over, were eaten by the older men. The Umulakiri, or younger men, must not touch them. The ceremony occupied most of the afternoon.

Fuly 5th.-I spent some time skinning some pigmy geese. They are about half the size of an ordinary duck, with beautiful plumage, metallic blue and green, black and white, and are as good eating as they are beautiful. The natives go into the water after them, and will often remain perfectly quiet amongst the lily leaves and water plants, with just enough of their face above water to enable them to breathe, and will wait until some unwary bird comes near and then seize it by the legs. Their only idea of sport is to catch something-how it is secured does not matter, all they want is food. If they have a gun they will never fire unless they think they can get perhaps two or three birds at a shot, and both they and we, thanks to the lagoon close by, have plenty of game, teal and duck and, best of all, pigmy geese. The younger boys and girls spend the whole day either wading up to their necks in water or in their dug-out canoes, paddling about and swimming, gathering as many lily roots and stems and seeds as they can devour (Fig. 495). The roots, called parijiliji, they eat raw or cooked; the seeds, called wuridjonga, the women pound on stone, so as to make a kind of thick paste that they fashion into cakes called munduaii and bake in hot ashes. When the women and children have had enough bathing, they come out and light a fire on the bank wherever they happen to be, cook some of their lily food, eat till they can eat no more and then go to sleep.

Right through the Alligator Rivers district there are favourite camping grounds by the side of great billabongs. As long as they get lily seeds and roots in abundance, fish and wild fowl, there they stay, each family with its own 
Mia-mia or, in the hot months, with nothing more than a bough or two slanted against a tree or shrub to obtain a little shelter from the sun. All day long the women and children are in the water, gathering lily " tuck out," while the men spear fish and catch water-fowl, climb trees after flying-fox and honey-bag or hunt larger game such as kangaroos and emus. When they have thinned the lilies out and fish and fowl get hard to catch and honey-bags are scarce, then they move on to another camp, where the same round is gone through, day after day and month after month, all the year round. They cook in two ways. Under common conditions, when they make a more or less hasty meal, they simply use an ordinary fire, placing the food such as a flying-fox or lizard or fish on the red-hot embers. When they are camped in one place for any considerable length of time, they cook much more carefully, using what the Kakadu call peindi, or earth ovens. A hole is made in the ground perhaps two feet deep, in which a fire is made and stones heated on it. Then follow a layer of paper-bark, grass or green leaves, then the food, then a covering of paper-bark, etc., over which the earth is piled in.

We have secured so many specimens that my cartridges are finished and bird-skinning material nearly at an end, so Cahill is sending a trusty boy, Romula by name, to intercept the railway train from Pine Creek to Darwin, at a wayside station, with a note to a friend in the latter to send up supplies by the next weekly train, which Romula will wait for. It means that the latter will have a journey of 400 miles on horseback through the wild scrub, but this he quite enjoys. He is taking with him a little fellow named Butcha, not more than ten or twelve years old, a little imp but perfectly happy on horseback. We saw them off this morning, Romula leading one pack-horse and Butcha, who seemed to consist mainly of a great smile, a second one, very pleased with himself because of his temporary superiority 


\section{WANDERINGS IN WILD AUSTRALIA сн.}

to all the other children, who watched him off with much envy. The blackfellow is never so happy as when on horseback, but a day or two ago one of them came in after a rather tedious day's ride on a rough horse for sixty miles. The horse was glad enough to be set free and the boy was not sorry to dismount, being rather stiff and sore after sitting in the saddle for so long. When next day he turned up with only a red handkerchief on, we asked him what he had done with his trousers, and learnt that he had burnt them because they had "bitten" him and he was very angry with them. "No good like that," he said, "what for him all day long bite 'em."

Fuly 8th.-Once more, to my relief, there have been no ceremonies for three days, which has given us the chance of quiet talks with our chief informants, with whom we are getting on well now that they understand what we want. It takes also a good deal of time to sort out one's notes, because they are jotted down just as we see and hear things, and must be gone over daily, while they are fresh in memory, so that they can be transcribed legibly, and also so that one can get hints as to further work. We have been hearing a good deal about a great snake called Numereji who figures largely in their traditions. The first that we heard was this.

There were four men, Joemin, an elder brother, with his son Mukurlul, and Numuraupu, a younger brother, with his son Kardimenjil. Joemin had stolen a small snake and cut it in two. The front half grew a short, fresh tail, the hind half died. Joemin carried the front half under his arm. The old Numereji remained in the creek at Mungernauera, in fact he is there still. A medicine man can see him, but no one else, and the natives will not drink there because they think that, if they did so, Numereji would pull them in and eat them.

When Joemin cut the snake in two he drank some of the 
blood that flowed out, drained the rest into a shell and carried this and the snake with him. He came to a place called Mulipaji and left some of the snake's blood there, thus. making a wilalu kumali-that is, a kumali or sacred camp. The blackfellows call this Wilalu munangel, that is, the blood camp or country, and only medicine men go there, the others are too frightened. If they went near to it their fingers would break.

Joemin went to Mulipaji by himself and then came back to the others, bringing his snake with him. His younger brother Numuraupu said to him, "Brother, give me the snake to look at." Before entering the camp, Joemin had hidden the snake a little distance away. First of all he rubbed his younger brother's eyes, or else he would not have been able to look at the snake, and then went away and returned with it. When Numuraupu looked at it, the snake opened its mouth and rattled its teeth. Joemin said to Numuraupu, "Look hard." Numereji's eyes were large and bright. Joemin said, "Do not be frightened, look at it hard and your eyes will be all right." Numuraupu felt the snake and said, "It is very slippery." Joemin said, " Young brother, hold it firmly, lift it up high." Numuraupu did as he was told and lifted the snake with his arm underneath it, but he was very frightened and trembled all over. Joemin said, "Do not be frightened, hold it firmly." Numereji's mouth was open and his teeth rattled. The snake looked at the camp and was very angry, or, as the natives say, he was Tjiritjeriyu widjeru; the latter word means "very," the former is a word applied to any man or animal who is always what the natives call "growling," like an angry dog. Joemin said to his younger brother, "Hold it hard, if you do not your fingers will break." Joemin then gave the snake to Numuraupu, saying, "Young brother, this one is yours, I will get a new one." The snake lifted its body up with its head pointing forwards. It had a long VOI. II. 
snout and long jaws. When the two men came close to their camp they put the snake down on the ground and, after covering it over with leaves and grass, left it and went on into the camp. It was now midnight, and Numuraupu, instead of staying in camp, went to where Numereji was secreted, leaving Joemin asleep. He uncovered the snake, brought it back, and placed it by Joemin's side. Both Joemin and Numuraupu had a ranken kobonja, that is, a bush wurley, or shade, made of paper-bark (ranken). Numereji said, "Clck, Clck," and this woke up the natives who said, "Ameina, munanji?" What is it, what is the matter? Numuraupu kept very quiet, pretending to be asleep but really listening. One of the men came to Joemin and woke him, calling him Murabulba-that is, old man. Joemin said, "Go back, all right, lie down and sleep." Then Numuraupu lifted the snake up, took it back, covered it with leaves and said to it, "Lie down and go to sleep, I go to get food, to-night I come back to the camp and take you."

Two days later a child died and its body was put up in a tree on a stage of boughs. Joemin said to Numuraupu, "I am going to get a new Numereji." Before going he went to the tree, to cut the child's body open and get the kidney fat, he also cut off both heels for the same purpose. He wrapped the fat up in leaves and put it in a shell, after which he came back to the camp where Numuraupu was seated. Then they set out, Joemin carrying the fat and Numuraupu the snake. A long way off they came to a big ant-hill called Mupungalu. Joemin told Numuraupu to go a little distance away with his Numereji and hold it hard. Then he collected dry stringy-bark and, twirling one stick on another, made a fire at the foot of the ant-hill. Then he put a little of the child's fat on the fire and it sizzled. There were several Numerejis under the ant-hill and they smelt the burning fat. Joemin went a little way off and then came 
back and put some more fat on, and again it sizzled. This time a Numereji came out and Joemin caught it. Numuraupu, holding his snake hard, brought it up to where Joemin had the new one. The latter licked the old snake. Joemin's was a small one and he placed it on the ground by the place of the other which was much bigger. They measured the two on the ground, side by side. Joemin had a stone knife, Tjumaiin, and, holding this firmly in the left hand, he cut the hind end off Numuraupu's snake so as to make them both of the same length (Fig. 5I9). Neither of the snakes growled. Then they lifted up the two, rubbed and cleaned them. In this way Joemin got a new Numereji.

To-day the boys brought in a beautiful pied egret. There are plenty of white ones here, and the natives are as fond of their plumes for ornaments as white women are. This pied egret is much rarer and we have only seen a few. Instead of being white all over it has a black top to its head and a black plume, the neck is pure white and the remainder of its body has just the colour of a black pearl. A few of the white feathers of the neck end in thin, long spikes that lie over the black breast feathers. By the way of contrast to its delicate beauty they brought us a great ugly rat that they call Monmorlp. The largest was nearly two feet long, with a coarse, rough fur of a general greyish colour, with longer black hairs. The tail was as long as the body, short-haired and perfectly black for three-quarters of its length. The remaining quarter was covered with longer white hairs.

Fuly 9 th. - This morning we had a muster of natives in the Kakadu camp, half a mile away from the homestead. There were a few Geimbio people with them. The Kulunglutchi and some others who are visitors from distant eastern tribes on the King and Liverpool Rivers do not mix in camp with the former though they are all present at one another's ceremonies. Oenpelli is one of the main centres 


\section{WANDERINGS IN WILD AUSTRALIA сн.}

of the Kakadu, and the ceremonies that we had been watching were held in connection with the advance in grade of initiation of the two youths who returned from their wanderings, accompanied, or closely followed up, by the strangers.

There were, all told, eighty natives in camp. After photographing them, each man got a stick of tobacco, the women a coloured handkerchief and half a stick of tobacco, and the piccaninnies lollies and a little tobacco. Even children of four and five smoke. They take a shred of Pandanus leaf, fold it round a minute piece of tobacco, making in this way a kind of cigarette which is passed from mouth to mouth, each person taking a puff or two until it is done. We had a little difficulty in persuading them all to come. Two of the older men thought that we wished to take some of their wives away and give them to other men, so that they each sent two of them away into hiding. Fortunately, Cahill knew how many wives ought to be there, so, after mustering the families and discovering the deficiency, they were told that nothing in the way of tobacco was to be had unless everyone was there. A consultation with the others, who did not relish the prospect of losing their promised reward, soon resulted, after much loud shouting of instructions, in the emergence of the missing lubras from their hiding-places in the scrub. The full complement of wives in the case of one man was seven (Fig. 5 I7), but, for the most part, each had only one or two, and the small number of children was surprising. The seven-wifed man had only three.

In the afternoon we were busy with our assistants and heard some more traditions concerning the snake Numereji. It appeared first at a place called Kumbulmorma that lies on an open flat between Cooper's Creek and the mouth of the East Alligator River. Not far away, at Yiringira, a large number of natives were camped, and amongst them there was a baby crying. Numereji came along, holding his head high in the air, and said, "Waji bialilla," There is a child 


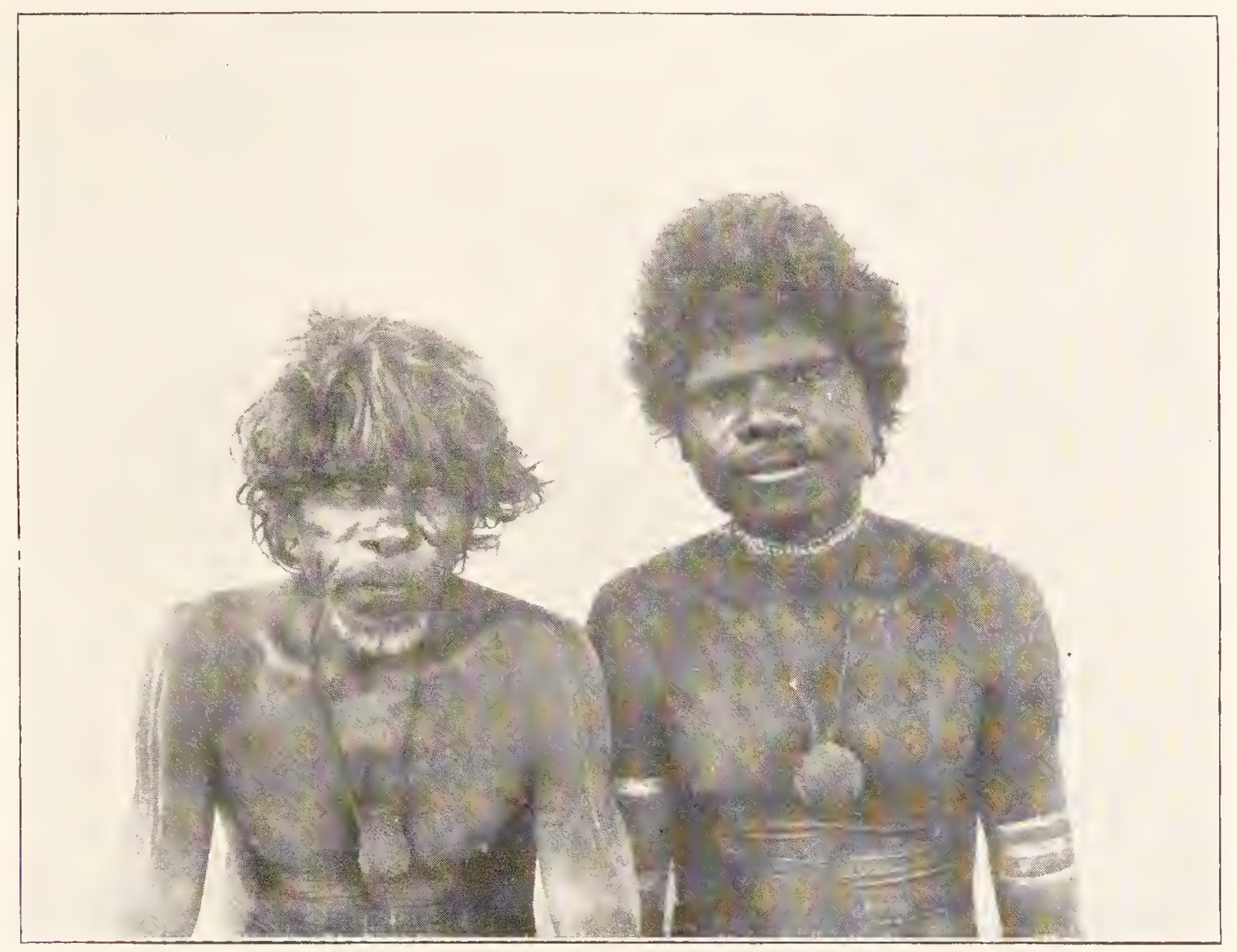

B.S.

FIG. 5I6.- TWO KAKADU MEN.

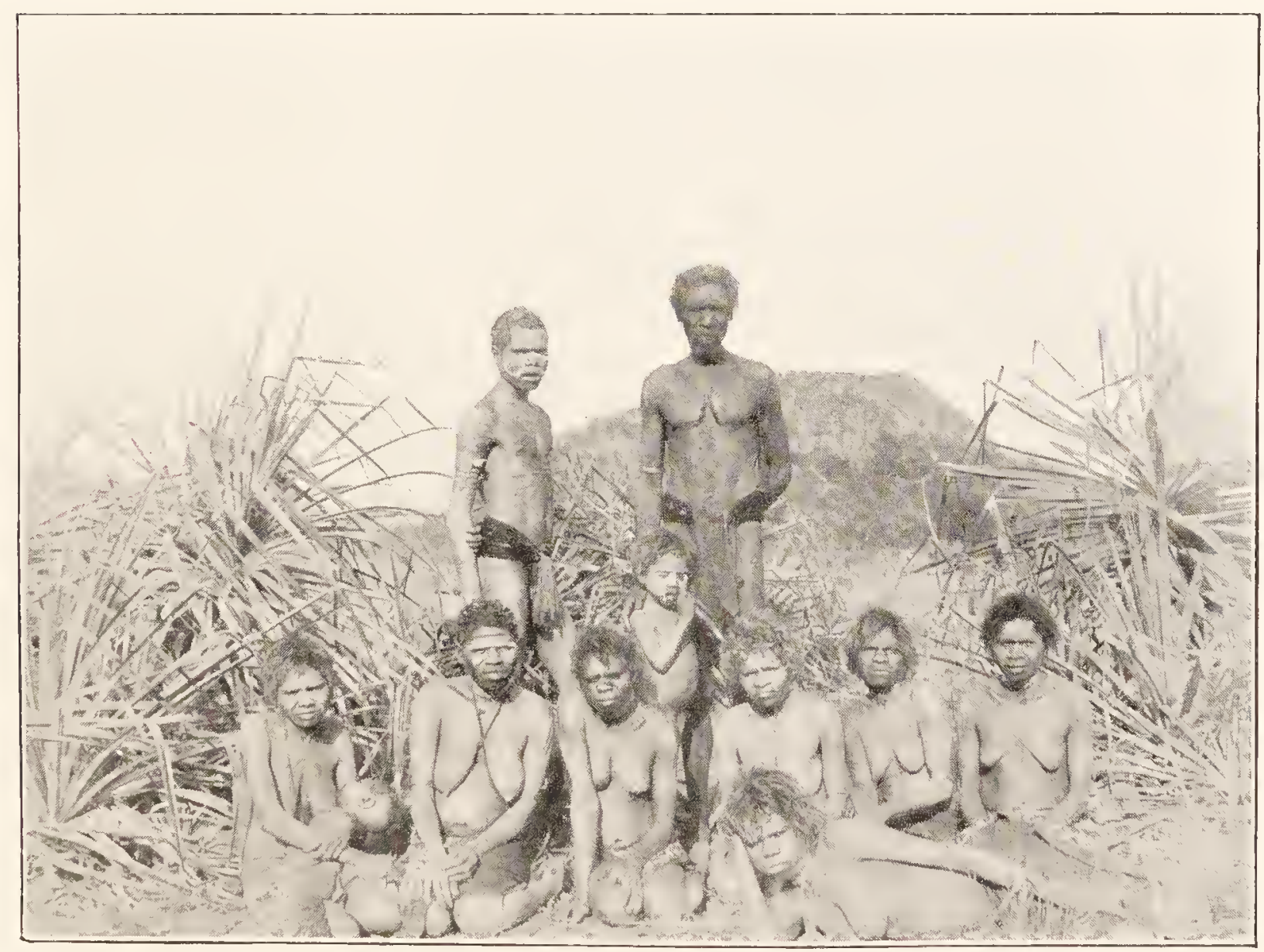

B.S.

FIG. 5I7.-GEIMBIO FAMILY, MAN WITH SEVEN WIVES. 


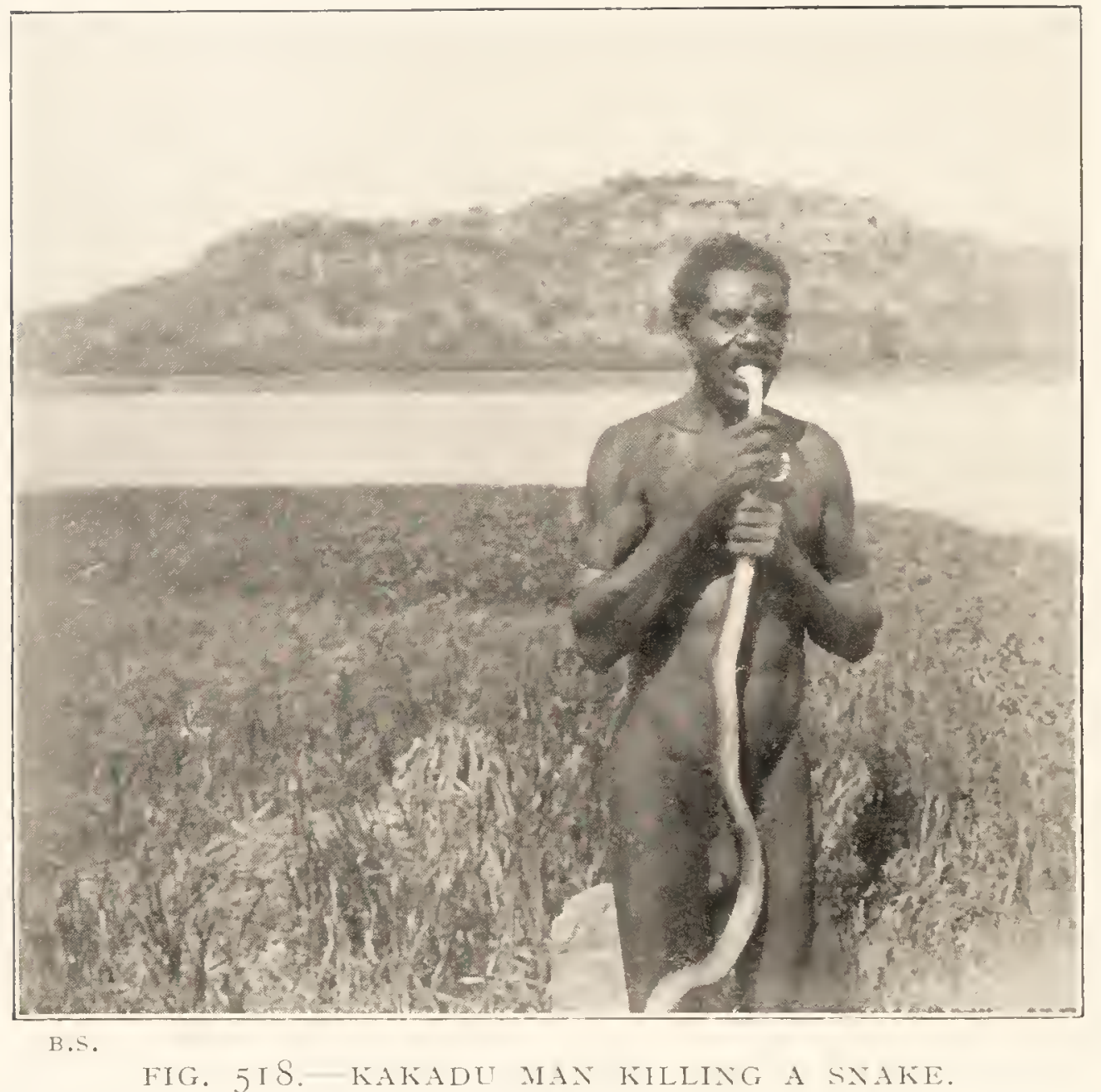


crying. "Yana waji bialilla?" Where is the child crying? It turned its head from side to side and went down in the ground, then it came out and circled round and round the camp. The child was crying and one man was blowing a conch. The snake then put its head up, close to the child, and sucked it in. The natives were very frightened and started to run away, but Numereji folded his tongue round each one in turn and licked them in until he had devoured them all, except one old lubra, named Kominiyamana, who had climbed up a tree and kept quiet for a long time. Most unfortunately the mosquitoes were so thick that she could not help smacking herself every now and then to kill them. Numereji listened and said "Hullo! there is someone there, on top." He lifted up his head and drew her in with his tongue. His stomach was now simply full of blackfellows.

He travelled along above ground to Maipolk on the East Alligator River, arched his head up and put it down on the other side, so that his body formed a great bow across the river, and then, leaning on his head, swung his tail across. As he travelled on he saw some natives, but though he now went along flat on the ground making as little noise as possible, he frightened a mob of white cockatoos and cranes that rose screaming from the trees. The natives knew that something must have disturbed them. They went to see, saying, "What is the matter, what has frightened them?" One of them went ahead and shouted out, "Kuwi, Kuwi," Come here, come here. He had caught sight of Numereji and said to the others, "Look, what is the name of the big fellow?" Numereji was now lying down, resting, gorged with blackfellows. They all cried out, "Ameina? Ameina?" What is it? What is it? Those in the front called to those behind to come up close and look at the Morpiu. ${ }^{1}$

1 Morpiu is the general term in Kakadu for animals, or animal food of any kind. 


\section{WANDERINGS IN WILD AUSTRALIA сн.}

Its belly was sunk deep in the mud. Numereji was so tired that he had gone to sleep. They all came close up, and the old man who had heard of him and of what he was like said, "This is Numereji." "Ah? Ah?" they said, Is it? Is it? The old man said to the snake, "What have you been doing, what have you been eating that your belly is so big?" but the snake made no reply. Then the old man accused him of eating the blackfellows, saying, "Urawulla jereini jau," It is the Urawulla men you have eaten. Then Numereji woke up, lifted himself up, put his head down and vomited forth the bones of all the men and women he had eaten. They remain there to this day in the form of heaps of stones. Numereji went on to Mungernauera, where he went into the ground and there he stayed.

Fuly 9th.-To-day the natives went on with their traditions concerning Numereji. This time it was about two brothers who came north to Kakadu country, walking above ground from a place close to what is now called Burundi on the railway line. They had very long beards and were much the same as blackfellows now are, only very much bigger. They had one old and one new Chipoiyu or fishing net. Travelling on, they came to a place called Ingertpu, a camp on the East Alligator River, just at the end of the tidal part. Here they threw their nets into the water and drew them out full of cat-fish. They decided to make a fire, cook, and eat the fish, which accordingly they did. When this was over they took their nets and went on to a place close to the stone that now marks the spot at which Imberombera died. They saw a snake in the grass and the younger said to the elder brother, "Ameina narenma?" What is the snake? or, What kind of snake is that? The elder replied, "It is Kintjilbara, we will eat him." They caught the snake, broke its.head, cut it off and threw it away. They made a fire in a hole in the ground with paper-bark and heated stones on it. Then they passed the 
snake's body through it so that they could easily rub the scales off. After this they took a stone knife and made two cuts, right along the body, one on either side of the backbone, and with the same flake they broke the latter at intervals along its length. Then they coiled the body round the stone, pushing the tail end into the cut at the front end. Paper-bark was placed above and the earth filled in. When cooked it was taken out and a cut made in the under surface, great care being taken to prevent any juice being spilt. This is called juri and is regarded as a great delicacy. The relator showed us exactly how the elder brother lifted up the snake by both ends with his arms extended, so that the body formed a loop, out of which he drained the juri into his mouth. The body was then cut in pieces and eaten. Finally, the bones were all broken up. When all was over the old man put all the fragments left into his mouth and spat them out in all directions, saying, now all men may eat Kintjilbara, bones included. They then resumed their travels and caught sight of some natives travelling to the north-east. The younger said to the elder, "I can see a blackfellow." The elder said, "Yes, that is Minmonan, we will go to him." They found him eating something and said, "Ameina jau ?" What are you eating? He said, "Kintjilbara jau," I am eating Kintjilbara. The elder man said, "I do the same, I have eaten one." Then he asked the old man where his camp was. He said, "Here," and asked them where theirs was. The elder replied, "We are going a long way." They left the old man and journeyed on and came to a big blood-wood tree on which swarms of bees were feeding on the gum-tree flowers. The younger brother heard the buzzing and said, "What is it; is it bees? Ha! Mormo." The elder brother was carrying a kerli or stone tomahawk, which he handed to the younger man, telling him to go and cut a forked bough. He himself gathered a leaf with a spider cocoon on it which 


\section{WANDERINGS IN WILD AUSTRALIA сн.}

he shredded out, and, having done this, climbed the tree with the aid of the forked bough which was placed slanting against the trunk. He put a little bit of the web on each bee that he could reach, singing out to them to go home and telling his younger brother to watch which way they went. They followed them up and put leaves in the holes in the trees into which they went, so that they would know, later on, where the honey-bags were. Some of the bees on which he put webs, he sent to different places to make honey-bags for the natives there. One he sent to Murarorabi, a place between the two Alligator Rivers where there are plenty of honey-bags now. Then he went to the first honey-bag, cut it out with his kerli and ate it. The two brothers then went back to the river where they had left their nets, took them out and carried them on with them. They came to a creek running into the East Alligator River and found a number of natives living in bark huts. They said, "We can hear the blackfellow's bamboo, we will go and look at them." They came close to the camp and a heavy rain fell. The younger man said, "I am cold, brother." When they came near they met an old man named Pundamunga, who was looking out for sugar bags. He was very frightened when he saw them and said, "Ameina? Ameina?" 1 Who are you? Who are you? They said to him, "Ameina kumeri?" Why are you frightened (or what are you frightened at). Come here, do not be frightened. Before this, each of the brothers had the skin of a Numereji snake and a separate head like a snake. They were men, but could change themselves into snakes when they wanted to and back again into men. As the natives say, they were

1 Ameina is a term that is heard very frequently. It implies that the speaker does not know or understand something that is heard or said and can be variously translated, according to the context, by, What? What do you mean? What is it? What is its name? What does it mean? What is it like? Why? It is another such term as Kala, which means All right; Just so; Yes; Enough. 
Fereini Numereji, that is, Numereji men. Before coming near the camp they had put their snake skins on, but now they took them off again and hid them. Pundamunga was still very frightened. They said to him, "We are blackfellows, do not be frightened, where is your camp?" Then they said, "Go and get a fire-stick, we are very cold." Pundamunga went and brought one. It went out and he brought another, which also went out. "Go again," they said. He did so a third and fourth time, but it always went out. After a fifth try the men told him to give it up and go to his camp and stay there. He did so and slept by his fire. The other men in camp were making a corrobboree and striking sticks together. The two brothers said, "We will put our Numereji skins on and eat the men." Then they went to where their skins were hidden, blew them up, took their blackfellows' skins off and went into the Numereji ones. They had heads and teeth just like a Numereji and were of immense size. After moving about for some time they went underground, until they came to the camp where the men were corrobboreeing. The natives, except Pundamunga, who was asleep, knew nothing about their presence, and the two snake men first of all came out and looked at the men in camp and then, going down again, suddenly arose under the camp, smashed it in bits and then devoured everything, men, women, children and weapons, in fact the whole camp and all that it contained. After that they went to sleep. The hole they made when they came out is still to be seen at Jipaiumba and also two depressions in the ground where they slept. When they awoke, they went on to Purluwa and vomited up the bones that are now represented there by stones. Once more they shed their skins and changed themselves into blackfellows, putting their Numereji skins into bags. Then they came to Kulpari and put one of their nets, which was a new one, into a waterpool there. During the night it changed into a Numereji 
which came out and went on to the plains bordering the river, and then back into the latter by way of a small creek.

The elder brother woke early next morning and went to the river to find if there were any fish in the net, but it was not there. He called out to his younger brother, "Chipoyu kaio," The net is not here. Then they put their snake skins into the one net remaining and followed up the tracks of the snake that they could see clearly going across the plain. The tracks led them across the plain and then back again to the mangroves, where they went into the creek. They decided to try to head the Numereji when he came round a great bend in the river, so they ran quickly across the plain, saw him coming up the stream and shouted out, "Here he is." They tried to pull him out but the snake said, "I will stop here, this is my home." The brothers said, "We will leave him," and went back to Tjironguda, close to Imori, two camping grounds on the East Alligator River. They travelled on to a place called Mijela willalu - the sand camp; then to Murakamiaiji, a billabong close to the range of hills that skirts the plain, and halted, saying, "We are hungry, we will fish." The young man made a fishing line out of shredded bark and they caught and cooked some fish.

Here they left Kakadu country and came into that of the Geimbio. The old man said to the younger, "Give me string." He only replied, "Um, um." The old man caught and ate fish again and talked to his younger brother in Kakadu, but he would not answer and only said, "Um, um," and nodded his head. When, later on, they tried to pull the line out they found that there was something very heavy on it. The two men pulled hard, swaying from side to side, but could not draw it out. The older man said, "Go and get a heavy stick and we will tie the string on and hold hard." It was all no use; the older man, who was close to the water, was pulled in, though his brother held on 
hard but could not keep him out. The water was very clear. and he could see right down to the bottom. He said, "Where is my brother?" At last he threw his net in and all that he had and dived down in search of him. He found him, and then the elder man said, "You stay in the Geimbio country and talk Geimbio, I will go down the river and speak Kakadu." The elder brother then went into his Numereji skin and slept. He has remained there ever since. Later on the salt water came up and mixed with the fresh, hurting his eyes, so that he went down underground, where he can still be seen by the medicine men.

The elder brother is now the Numereji of the southern division of the Kakadu. The net that changed into a snake is the Numereji of the northern division. It is supposed to live at a place called Mungaddabremner on the East Alligator River, and no native, except medicine men, go there because they are afraid that he would pull them into the water and eat them. The younger brother is now the Numereji of the Geimbio people.

Fuly Ioth.-To-day the natives brought in two live specimens of a water snake (Acrochordus javanicus), one seven and the other six feet long. The native name for them is Tradjinaro. They are repulsive, ugly-looking brutes, muddy bronze in colour, and live in holes on the banks of deep water-holes and spend, so the natives say, almost all their time under water, in which they can move quickly, but on land they are very sluggish. They are non-venomous and feed on fish. The natives catch a good number of them and actually carry them about alive in bags, killing them when they want some fresh meat. Each scale on the upper surface has a short spine, and on the ground they lie flat, always with ugly swellings and twists in their body, for which the skin seems to be much too big.

The natives have a very original way of killing snakes of which I had heard, but was rather sceptical about, until I 


\section{WANDERINGS IN WILD AUSTRALIA сн.}

saw the Kakadu men actually at work. They only, however, venture to treat non-venomous ones in this way. They hold the snake firmly behind the head and put it, upside down, into their mouth, gripping it hard with their teeth immediately behind the skull (Fig. 5 I8). Then they rapidly slide their hands a little way down the body and with a strong, sudden, downward jerk, dislocate the backbone. I saw them several times tackle snakes six and seven feet long in this way, but they assured me that it is quite easy to do it with the longer ones, even up to ten feet. The natives' jaws are much more powerful than those of most white men.

They are very frightened, however, of poisonous snakes and will not handle one until its head is either smashed completely or cut off. One day, wishing to secure a deaf adder, without spoiling it as a Museum specimen, I put a stick down on it, just behind its head, which is quite an easy thing to do, because it is short and stumpy and, under normal conditions, when not suddenly disturbed, is very lethargic. Then, in the usual way, I took hold of it behind its head and dropped it into a jar with some chloroform. The natives were frightened and astonished at anyone venturing to handle it alive, and moved some paces off until it was safely shut up out of harm's way.

To-day again they told us another Numereji story, this time concerned with the making of medicine men, between whom and Numereji there is a close association. They are supposed not only to be able to see him but to have eyes that can withstand his glance; other men cannot do this.

At the present time new medicine men are initiated by the old ones. In the early days Joemin was the first medicine man. He made others and showed them what had to be done. At first Joemin's eyes were like those of other men and he could not look at Numereji. One day he went to a water-pool and, looking over the edge saw his shadow, 
or Iwaiyu. ${ }^{1}$ He looked all about. Then he put his head under water and opened his eyes. He did this day after day. It is called Karareyu poro, which means washing eyes. Gradually they became very bright and piercing, Tjiralala poro, very good eyes, so that he could see things at any distance and look right through men, trees and rocks. He looked and looked all round but could not see Numereji. Then he travelled away to Kunyembulbul, where Numereji had eaten a lot of blackfellows and found him there resting quietly. "Ah," he said, "Numereji is lying down." Numereji was a huge size. Joemin said to him, "Where are the men you have eaten?" Numereji said nothing but just yawned. Joemin spoke to him again, saying, "You have eaten another camp of men." After this Numereji brought out an enormous mass of bones, that made a great hill that can now be seen at Kunyembulbul.

The old Numereji carried young ones twisted round it and feeding at its breasts. Joemin said, "I will have a little one; do not growl at me; you have eaten plenty of men." Numereji only shut his eyes. Joemin caught the little snake, while the old Numereji lay down and took no notice of him. Joemin had provided himself with a large shell and, after securing the snake, he cut it in two and allowed some of the blood, or munangel, to flow into the shell, which, with the snake in it, he carried on with him to Mulipaji. Joemin had a son, Murkulul. When he grew old he said to the latter, "Later on I die; later on you look out Numereji," which meant that his son was to take his place as a medicine man. Accompanied by Murkulul he went close to the Munangel wilalu, or blood camp at Mulipaji. Both Joemin and Murkulul had left all their armlets, necklets, wristlets and hair belts at the home camp. Joemin took his small Numereji with him, and, while Murkulul bathed and

1 The same term Iwaiyu is applied to a man's shadow, reflection or spirit part. 
washed himself clean, the former took the snake to the blood camp. Then he said to his son, "We two will go and see Numereji." Joemin brought out the shell that he had left full of blood at the camp and showed it to Murkulul, saying, "Look at the blood, look at it hard." Then he took a leaf, put some blood on it and rubbed it over Murkulul's head, arms and shoulders saying, "Strong back; strong arms; strong sinews; good eyes; kapena poro," which means eyes that see through. Then, taking some blood, he said, "Munagel jau," Eat blood; he made him open his mouth wide and gave him some, saying, "Eat the blood, right down; do not let your tongue taste it; Kulijidbo (a special little kind of yam) is kumali (forbidden); after this do not eat Kulijidbo, or your stomach will be very bad and swollen." Certain kinds of yams such as Kulijidbo, Mornun and Gunumaramila are kumali to a man who is being made into a doctor. They all belong to what are called "hot" yams that must be specially treated before being eaten, or else they cause irritation in the mouth. The idea that medicine men must not eat hot things seems to be widely prevalent. In the Arunta tribe a man has been known to lose his powers by drinking hot tea.

When all was over Joemin went and brought his Numereji back, saying to Murkulul, "Look, my son, it is all right." The boy was silent. Joemin said, "Look at the snake, look at Numereji." Numereji licked his mouth and rattled his teeth. Then Joemin handed it to the boy, saying, "Hold it hard; look hard or else your eyes will be bad afterwards." Then he put the snake under Murkulul's left arm, saying, "The snake is yours, hold it firmly." He then said, "You are Marunga (medicine man)." Murkulul replied, "Yes, I am Marunga." Joemin said, "We two will go back to the camp; you go in front, I will come behind." They went towards the camp, Murkulul carrying the Numereji and Joemin a special large Warbi or fighting 
club. When they came near Joemin said, "My son, you stay behind." Joemin left his club behind and went on alone. He told the lubras to go out and get paper-bark, which they brought in and built a new wurley or bough shade. Meanwhile Joemin made his camp between that of the men and the spot where Murkulul was hidden with the Numereji which he still held firmly. Later on, under cover of darkness, Murkulul came into the new wurley, bringing the snake with him. The natives said, "Nigeri Marunga, kumali," A new Marunga, he is kumali. Murkulul rubbed himself over with burnt grass and for four days remained in his wurley, food, collected by his mother, being taken to him by his father. No woman was allowed to go near the wurley, which was kumali, and no track passed near it. When the four days were over he came into the camp, but no one could see his Numereji save the other medicine men. 


\section{CHAPTER XXX}

THE EAST ALLIGATOR RIVER AND THE KAKADU

PEOPLE-(II)

Fuly I Ith.-This morning a native brought in a little bark-drawing. They are very fond of drawing both on rocks and the sheets of bark of which their Mia-mias are made. The drawings are quite unlike anything that the Arunta and Central tribes attempt. There is a complete absence amongst them of the conventional designs, with concentric circles and spirals, that are so characteristic of the Arunta, indeed these are completely wanting amongst the Kakadu and all the Coburg Peninsula tribes, as well as amongst the Melville Islanders. The animal and plant drawings amongst the Central tribes are extremely crude, and so conventionalised as rarely to be recognisable, but, on the other hand, their geometrical designs are wonderful, especially those associated with their totems and sacred ceremonies.

To-day I found a native who, apparently, had nothing better to do than sit quietly in the camp, evidently enjoying himself, drawing a fish on a piece of stringy-bark about two feet long and a foot broad. His painting materials were white pipe clay and two shades of red ochre, the lighter made by mixing white pipe clay with the pure ochre, and a primitive but quite effective paint-brush, made out of a short stick, six or eight inches long, frayed out with his teeth and then pressed out so as to form a little disc, shaped like a minute, old-fashioned, chimney-sweep's brush. It was most effective, and he held it just like a civilised artist 
sometimes holds his brush or pencil, with the handle between the thumb, then crossing the palm and out below the little finger, so that all four finger-tips rested on it, or sometimes it passed out of the hand above the little finger. Held in this way, he did line work, often very fine and regular, with very much the same freedom and precision as a Japanese or Chinese artist doing his more beautiful wash-work with his brush.

They are so realistic, always expressing admirably the characteristic features of the animal drawn, that anyone acquainted with the original can identify the drawings at once. A very remarkable feature, which I have seen nowhere else in Australia, is that in many of them, in fact in all that are used as food, so that the native knows something of their inward as well as of their outward parts, the main features of their internal anatomy are drawn. In this fish, for example, three cross lines at the front end, separating the head from the body part, indicated the shoulder girdle, the backbone ran along the central line; above it were two main blocks of pink, representing tjali, or flesh; there were an upper and under and tail fin, all three with fin rays. As two eyes were present, both of them had to be shown, though the animal was drawn in side view.

On further acquaintance with them and, after inspecting the paintings with which they had decorated the walls of their wurlies, I found that there was a notable range of ability amongst the artists. There was relatively, in proportion to the limited scope of their work, very much the same difference between them as between British artists, not so much, however, in regard to subject and conception as to execution, though indeed there was some hint of the former, one artist in particular specialising in mythological subjects. They were so interesting that, after collecting some from their studios, which meant taking down the slabs VOL. II. 


\section{WANDERINGS IN WILD AUSTRALIA cн.}

on which they were drawn, that formed, incidentally, the walls of their Mia-mias, I commissioned two or three of the best artists to paint me a series of canvases, or rather "barks," the price of which was governed by size, varying from one stick of tobacco (a penny halfpenny) for a two-feet by one-foot "bark," to three sticks (fourpence halfpenny) for "barks" measuring approximately three feet by six feet and upwards. The subject-matter I left entirely to the artist's choice. As a result I was able to secure some fifty examples that illustrate the present stage of development of this aspect of art amongst the Kakadu people. It was interesting to find that the natives themselves very clearly distinguished between the ability of different artists and that my own non-expert opinion in regard to their relative merits coincided with their own. The majority of those that I collected and that now hang in the National Museum at Melbourne are regarded as first-rate examples of firstrate artists. The highest price paid was actually fourpence halfpenny but, as the artists are now unfortunately dead, the market value of the "barks" is considerably higher than when they were originally purchased in the Kakadu studios at Oenpelli.

After a morning among the artists, we spent three hours' hard work trying once more to get information with regard to their marriage arrangements. It seems clear that they have no class organisation similar to that of the Arunta, and that the only one they have is based on the local groups that were originally founded by their great ancestor Imberombera. After long talking we came across the following tradition. In the far-past times the old head-men of the local groups talked the matter over amongst themselves and decided to institute an exchange of lubras between the different groups. Pundamunga, who had been sent to Korenigin, and Miniorko, who had been sent to Kunbarnbi, agreed upon this, so, one day, Miniorko set out from his 
camp at Kunbarnbi, taking with him Opeik, a man, and Maringjanga, a woman. He walked between them as they journeyed to Pundamunga's camp at Korenigin, where he found the old man seated on the ground with Mukalakki, a man, on one side of him and Kudbau, a lubra, on the other. In both cases the man and woman, that is Opeik and Maringjanga, Mukalakki and Kudbau were supposed, respectively, to be brother and sister. The two parties sat down immediately opposite to one another. The two women, Maringjanga and Kudbau, had each of them a Norkun, that is, two goose wings tied together, which is used to brush flies off, and is held in front of their faces, to prevent them from seeing, or being seen by, their brothers. Pundamunga said to Kudbau, "Go to Opeik, he is your ngnomukali (husband or proper blackfellow), go far away from your elder brother." Accordingly she went and sat behind him. In the same way, Maringjanga was told by Miniorko to go and sit behind Mukalakki, who was her proper ngnomukali. Maringjanga stayed in camp with Mukalakki at Korenigin, Kudbau returned with Opeik to Kunbarnbi.

When this ceremony was over, they started back, but before doing so, Pundamunga went over to where Miniorko was sitting and said to him, "Have you got plenty of lubras?" Miniorko said, "I have plenty of daughters here in my camp." Pundamunga said, "To-morrow we will all go." Accordingly next day he set off, taking with him one lubra, Madingeya, and four men, Monmuna, Kulungepa, Mupulbara and Mudanga. When they reached Kunbarnbi, they found Miniorko seated by himself with the Gerewin, that is, the men's, and the Umulakirri, the women's camp, a little way behind him, far enough away for him not to be heard unless he spoke loudly. The old man Pundamunga went and sat down beside Miniorko; the four men he had brought with him squatted on the 


\section{WANDERINGS IN WILD AUSTRALIA cH.}

ground in front of the two old men. Madingeya was by herself, a little to one side, with a Norkun in front of her face. Miniorko called a man named Muniali out of the men's camp and he came and sat down. Then Pundamunga told Madingeya to go and sit behind Muniali, because he was her proper husband, which she did. The mother of Muniali said to him, "Maba, jamo, jauo; ngeinyinna nungordua," which means literally, son, food, you eat; your lubra. In other words, this meant that the lubra would now provide him with food, that is, she was his wife. The elder brother, Opeik, who had already been provided with a wife, said to Muniali, "Younger brother, come and camp close by here." Pundamunga then called Monmuna up and he sat down. Miniorko called a lubra, named Mukulora, out of the woman's camp and told her to go and sit behind Monmuna, because he was her proper blackfellow. Then these two went some little distance away from Opeik and Muniali, who did not invite them to come close to their camp, because the woman was Opeik's sister.

The natives say that in this way, sooner or later, all the members of the different groups were provided with their proper husbands and wives. In each case the old leader of the local groups, who had received instructions emanating originally from Imberombera, determined upon the man or woman whom each individual was to marry, and, at the present day, a man of any one local group takes his wife from the same one from which the old ancestor of whom he is the reincarnation originally derived his. Araiya, the native who had previously told us the names of the people originally sent out by Imberombera, now gave us a list of the members of Pundamunga's group with their marriages. His memory on these matters was simply phenomenal.

Fuly I 4th.-Early this morning the view across the lagoon was very picturesque. There was a light mist hanging 
over it and the flats beyond, with the distant Ranges rising above them in the background. A flock of seven pelicans were flying above and quite close to the water surface, and on the far side there was a solitary native in a dug-out canoe, spearing fish. This old man, named Pundamunga, seems to do nothing else but fish and is remarkably clever at catching them. He has a spear about ten feet long with five prongs, each six inches long. In early days these were made of bone, now they prefer strong fencing wire. While I watched him he speared a large Barramunda, and later on he brought it in to us on his spear. This fish (Osteoglossum leichhardti) reaches a length of three or four feet and is very good eating. The same name, Barramunda, 1 is unfortunately given to a perfectly different fish in Queensland (Ceratodus forsteri) that is only found in the Burnet and Mary Rivers, and is known locally as the "Burnet salmon" because of the pink colour of its flesh, which, fortunately for the sake of the preservation of one of the most interesting representatives of ancient forms of animal life, left stranded in Australia, is very oily and quite inedible. It has nothing in common with either a true salmon or the Osteoglossum, but is very interesting because it is one of three kinds of "lung-fish " that are surviving relics of ancient Mesozoic fish, one found in South America, one in Africa and one in Australia. Ceratodus was known as a fossil in Europe long before a living representative was found in Queensland. They are really water-breathing fish on the way to become air-breathing animals, very much like a tadpole that has both gills and lungs before it loses the former.

The pelicans were soon busy. After flying round and

1 This is a native name, variously spelt Barramunda, Barramundi, Burramundi or Burramunda. It seems to have been the name for the fish, Osteoglossum, in some Queensland tribe and should be confined in its use to this which is perfectly distinct from the Ceratodus or "Burnet Salmon." The Australian form is usually called Neoceratodus. 


\section{WANDERINGS IN WILD AUSTRALIA сн.}

round they settled down in a circle on the water, swimming so as to drive the fish towards the centre, and then, with one accord, down went their heads into the water, each one soon reappearing with one or two fish, most often holding one of them wriggling in its beak, in quite the orthodox way of picture books, en route into the pouch. There were several Darters about. They are quite unlike any other birds in the water, with a long, stiff neck that always has a sharp kink in it, and their bodies must be very heavy, because, when they are floating, you can scarcely see a trace of them above the water. As soon as they get a fish, down swoops a hawk in pursuit and, as likely as not, they have to disgorge it, and the hawk goes back to its perch and waits until the next Darter gets something for it to eat. One old Darter swooped down, then rose from the water and perched himself on a post, a few feet out of the water. He had very sharp wings, a long neck and a wedge-shaped tail. As soon as he landed on the post, he balanced himself with his wings and tail spread out, looking just like a quaint, heraldic creature, and there he stood without attempting to move or put his wings down. Little Parra birds, with bodies about the size of a bantam hen, red and yellow helmets, long necks and legs, with all the toes long, the hinder one extraordinarily so, were walking about on the large, flat lily leaves. To-day when I was skinning a palmated goose, I found that the male bird, but not the female, had a very strange formation in its windpipe. Instead of going direct from the throat into the lungs it turned outwards on the left side and ran round in a kind of great loop between the skin and the breast muscles, back into the body.

We gave the natives a spell for two or three days from anything like hard work, which gave me also the chance of securing and skinning some specimens, of finishing up the entry of notes and reading these over, and also of 
going through my collections to see that all was well with them. The worst things to deal with are the ants, especially one very small one about an eighth of an inch long, but very destructive and very abundant; they appear from everywhere, the moment you put any specimen down. The only way we could keep them from destroying the skins was by means of storing them on a staging suspended from the joists of the verandah by means of stiff wires, each going through the cork of a bottle cut in half, turned upside down and partly filled with water. This baffled them completely, because, fortunately, they did not think of dropping down on to the staging from the ceiling, but simply ran up and down the wires aimlessly.

Fuly 20 th.-A native came up to us this morning carrying on his head a bag with six more Tradjinaros, the water snake. They were all alive, and the native just bundled them out of the bag on to the verandah floor, where they lay moving sluggishly and allowing us to handle them without making any objection. I skinned and handed back the bodies to the natives, who cooked and ate them at once and had a good feast, because one was very fat, and when it was opened I counted fifty-six eggs, each the size of the yolk of a hen's egg. With the snakes, the man brought me also the special spear called Kujorju (Fig. 484 , No. 3), with which they catch them. It is a very rare form and I had not seen one like it before. The total length was only five feet three inches. There were four prongs of hard wood and a short length of bamboo into which they are inserted. They are free for just three feet. From this point downwards, towards the handle, they are arranged round a central stick, immediately above which a pad of paper-bark is inserted between the prongs, which are then bound tightly round outside for four inches, first with banyan string and then with split cane. The result is that the prongs are divergent at their free ends and also 
have a certain amount of spring sideways. For some six inches the upper end of the bamboo is bound round with string to prevent it from splitting, as the pressure is considerable. Each prong ends in a sharp, pointed bone, an inch long, projecting from a rounded mass of hard resin.

There seems to be no restriction in regard to eating the Tradjinaro, but, while talking over this matter with the natives this afternoon, they told us some interesting things about restrictions in the case of other snakes. There is one snake, Kintjilbara, that not even a man who has been through the Kulori initiation ceremonies may touch, until special permission has been given to him. An old man goes out into the bush, kills one of the snakes and brings it back into the men's camp. He calls them up, saying, "Kulori men, come all of you, jump over the Kintjilbara." He puts it down on the ground and they all do this one after the other. This finished, the old man says, "All you Kulori men, eat Kintjilbara." An earth oven, or peindi, is then made and the snake cooked in it on the hot stones. When ready to be eaten, it has to be torn up by the teeth of an old man. Each Kulori man has a little piece of tjali (flesh), paloma (fat) and benogra (bones) given to him and is thereby made free of the animal.

There is another snake called Kuljoanjo to which also the same restrictions apply. It may only be eaten by really old men. One of the older men, Mukalakki, told us how narrowly he escaped with his life after eating some of the snake, though it was done quite innocently on his part. The severe illness that resulted from his disobeying the restriction took place, as nearly as we could tell, fifteen years after he had eaten the forbidden snake. He was out one day in the bush with another young man, named Murukambul, who caught a Kuljoanjo. The latter of the two men knew what it was but did not tell Mukalakki, who thought it was another kind of snake. Murukambul 
told him to eat it and replied, when Mukalakki urged him to have some, "No, I will go to the other camp." There was an old man there named Mudorna who also ate some, and then he, and Mukalakki, took some of the fat to a very old man who ate it and licked his lips as he did so, because the fat is very good indeed. He noticed, however, that Mukalakki had been eating some and said, "Why have you eaten Kumali (that is, a thing forbidden)? you are a little man; this is Kuljoanjo; you will be very ill.." Mukalakki was very frightened when he found out what he had done and said to the old man, "What is it? Shall I die?" The old man said, "Yes, by and by you will be very ill, you will die." Nothing happened then, but, years afterwards, Mukalakki had a terrible time, which he described very graphically to us. He was feeling very bad indeed and an old medicine man said to him, "What have you eaten to make you ill?" Mukalakki remembered what the old man told him long ago and he answered, "Kuljoanjo." Then the old doctor said, "To-day you die." He was very ill then, but, as the day wore on, he became much worse and at night it took three men to hold him down, one on his head and one on each leg. The spirit or Iwaiyu of Kuljoanjo had twisted itself round his body and every now and then came out through his forehead, rattled its teeth and hissed and looked straight into his eyes. It was terrifying. The natives, realising the gravity of the case, had sent away to Oenpelli for a special, celebrated medicine man, named Morpun, who happened, providentially, to be reincarnated at that time. He came post-haste, running and walking the whole way, about fourteen miles, without once stopping. All day and all night the men and women had sat on Mukalakki, trying to keep him quiet, but it was just as much as they could do. He was all tied up with the Irwaiyu and shuddered and shivered when the snake shook himself. The lubras and men did all they could to 
keep Kuljoanjo quiet, but he kept overpowering them and shaking Mukalakki to pieces. At length Morpun, the great medicine man, arrived. For a time he stood silently, some distance off, watching Mukalakki. First he ordered the women to go a long way off. Mukalakki sat up. Once more the snake came out of his forehead and looked into his eyes, but at that moment Morpun, who had come close up, made a sudden snatch at it and caught its head. No one but himself and Mukalakki could see it. He held it very firmly and carefully unwound it from Mukalakki's body. When he had done this successfully, he rolled the snake up in his hands and put it in his dilly-bag and, after staying in camp for one night, went back to his own country, taking the spirit of the Kuljoanjo with him. He put it in a water-hole, right away amongst the Ranges, saying to it, "Lie down in my camp; do not go back." As soon as ever the snake was removed Mukalakki felt immensely relieved. He perspired profusely, went to sleep and woke up all right in the morning. Since then Kuljoanjo has never troubled him again, but he had a great fright, and everyone knows that if it had not been for Morpun's removing the snake he must have died; and Morpun was the only man who could have done this.

Fuly 20th.-I have been going through the bark drawings with the natives who have been describing them to me. Some of the more interesting ones are represented in Figs. 5 I $9-535$.

The colour scheme is very simple, the darker lines and bands are red ochre, all the rest are drawn in white pipe clay. In the drawing of a gnome represented in Fig. 524 only white is used, but, to produce the furry effect, it has been scratched out in certain parts so that the bark shows through. In all cases the dark brown bark serves as a background and sometimes, but very rarely, as in Fig. 522, a little white has been rubbed over it. The appearance of white on the 


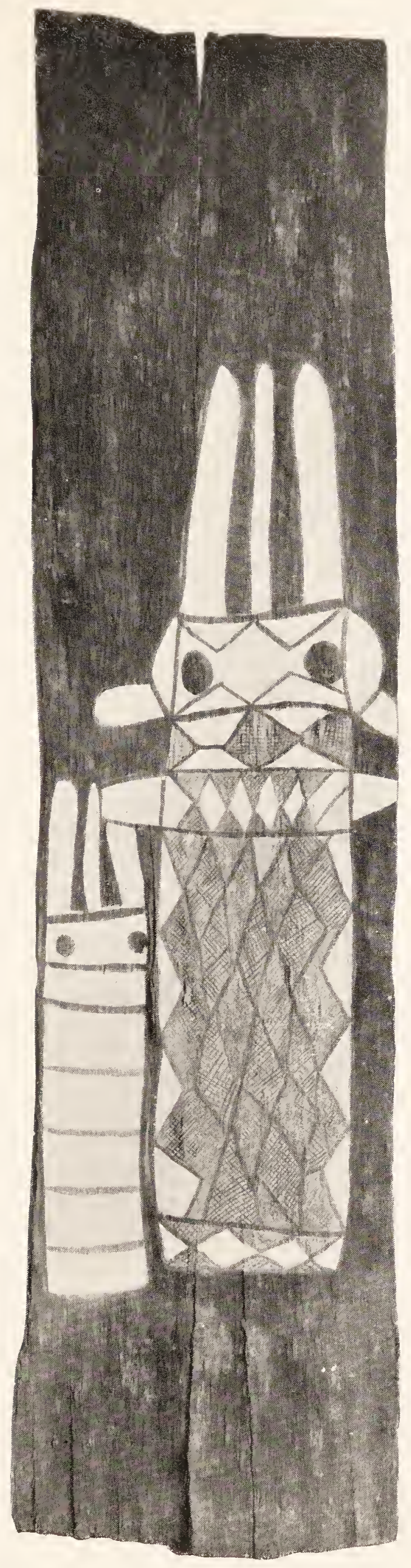

FIG. 5I9-- THE OLD AND THE YOUNG NUMEREJI SNAKES. A BARK DRAWING, KAKADU TRIBE.

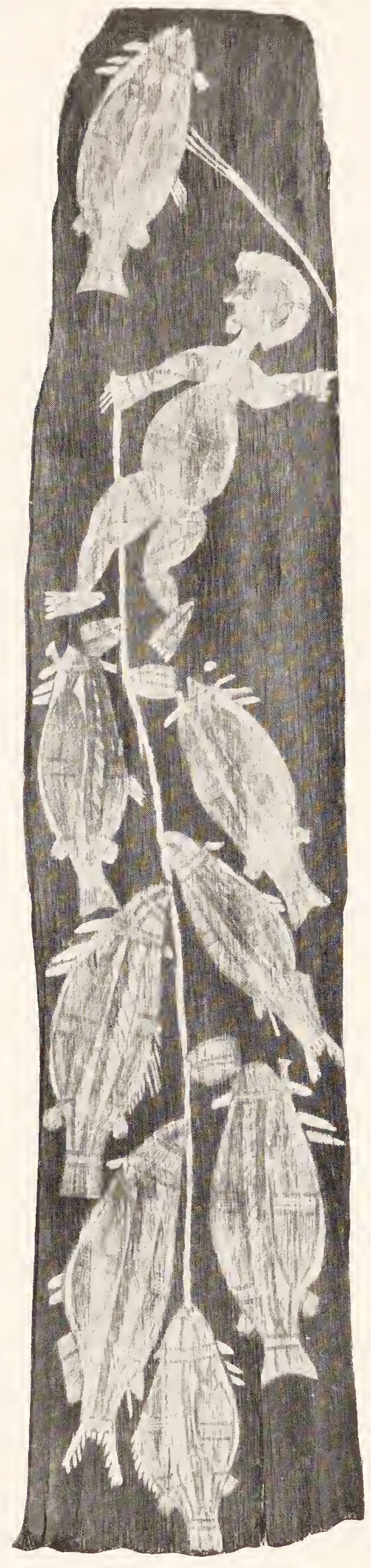

FIG. 520.-BUBBA PEIBI FROM A DRAWING ON BARK

He is dragging the fish that he has caught behind him by means of a stick which is passed through their gills, and is in the act of spearing one with the characteristic threepronged spear that the natives use for this purpose. 


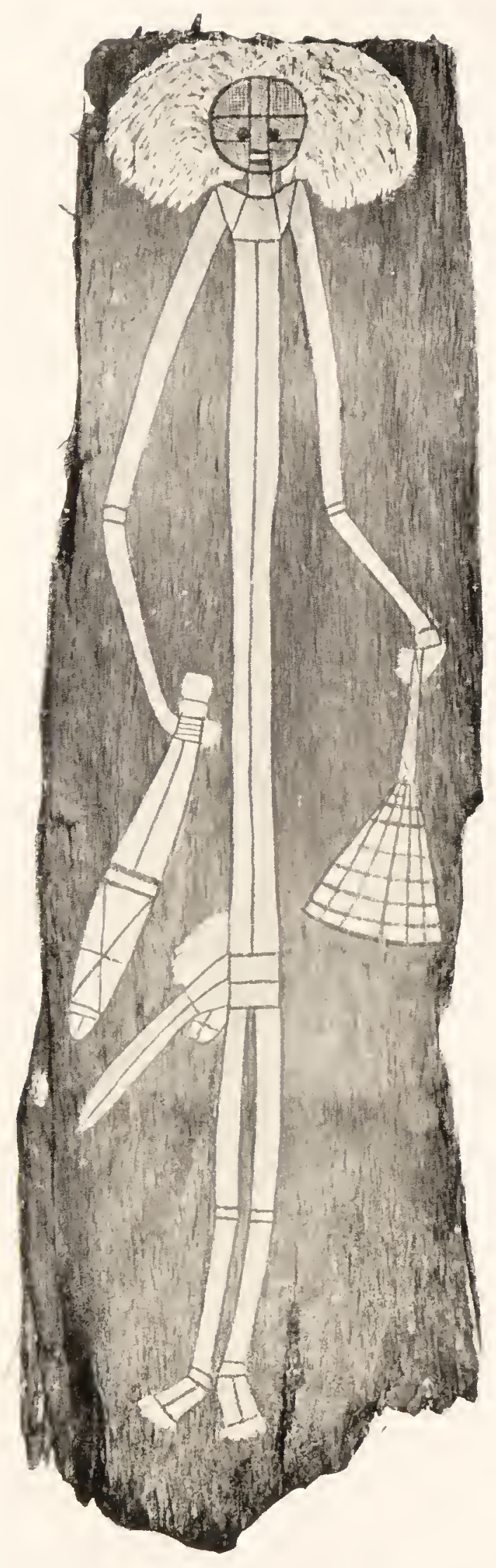

FIG. 52I, -A IBARK IDAWING OF A MORMO, CALLED INGIIAIN, KAKAIU TRIBE.

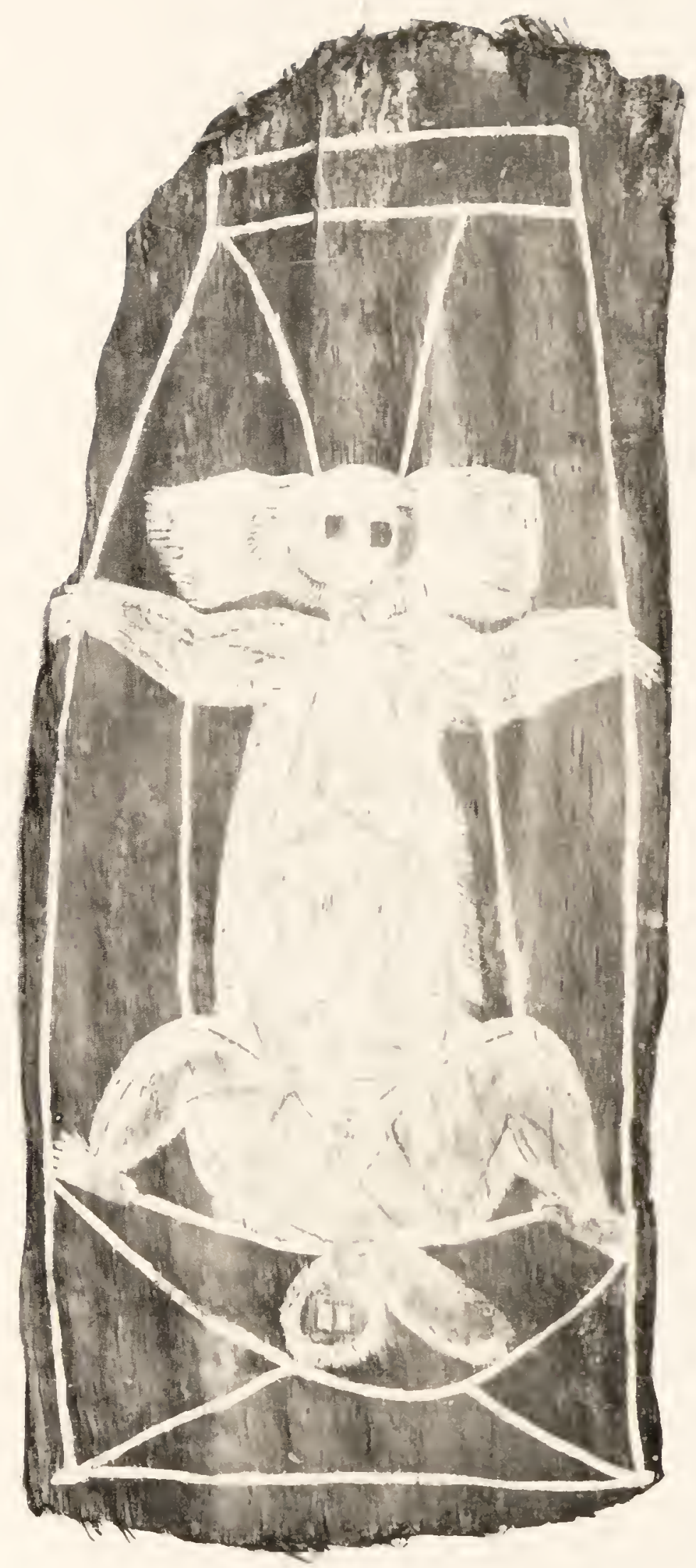

FIG, 524- BARK IIRAWING OF A MORMIO, GEIMHIO TRIBE. 
background is most often due to the fact that a little pipe clay has accidentally dropped from the brush on the bark and the artist has tried to rub it off.

Fig. 5 I 9 is a drawing of the head end of the old and the young Numereji snakes. Both of them have two jaws and a tongue; on the older one the scales are developed, but they have not yet grown on the young one, which is marked by cross bands.

Fig. 520 illustrates a little story dealing with a mythical person called "Bubba Peibi." $\mathrm{He}$ is supposed to be a very short, stout individual, only about two feet six inches in height. He has long spears and a large meilla or basket. $\mathrm{He}$ walks about at night-time only, catching fish. In shallow water he takes them out with his hands and puts them in his meilla. As he wanders about he can be heard talking to himself, saying, "Bi, Brr; Bi, Brr," with a long roll on the $r$. In deep water he uses his spears. If he sees a Kimberikara, or Barramunda fish, he spears it in the neck, which he then bites and puts it in his bag. This is supposed to drag behind him through the water. Sometimes, as in the illustration, he drags the fish behind him by means of a stick that passes through their gills. When he has caught enough he ties the mouth of his bag up and, carrying it on his head, goes back to his own place, saying, "Bi, Brr, Brr."

He lives inside a big Banyan tree by the side of a paperbark creek. The hole in the tree, through which he passes, is only a small one, but he can enlarge it by breathing through it, and when he has passed either in or out, he closes it up. At the top of the trunk there is a hole through which air comes in. He makes a fire inside and cooks the fish there. The ordinary blackfellow cannot see him, but the Margun, or medicine men, can and they also talk to him. Sometimes a medicine man happens to be close by when he comes back to the Banyan tree, after one of his 


\section{WANDERINGS IN WILD AUSTRALIA сн.}

fishing excursions. Bubba Peibi says, "Do not hit me." The medicine man says, "Do not be frightened; I watch; you go inside."

Sometimes, when Bubba Peibi is out fishing, and a medicine man hears him and is afraid that he will catch all the fish and leave none for the blackfellow, he plays a trick on him. He can go to the water-hole so quietly that Bubba Peibi does not hear him and does not know that he is there. In the water he hangs on to the bag that Bubba Peibi drags behind him, and the little man tugs and tugs but cannot move it. Then he goes back to find out what is the matter and, while he is feeling about to see if the bag has caught on something, the Margun takes hold of his hand. Bubba Peibi is very frightened but the Margun says, "Do not be frightened, but go to another water-hole and do not catch all the fish here." The ordinary blackfellows can hear him talking to himself, saying, "Bi, Brr, Brr," as he walks through the water, but only the Margun can see him.

There was one artist who was especially devoted to the drawing of mythological subjects and Figs. 52 I-526 are all from his brush.

In these mythological drawings, unlike those of animals, very little attempt is made to indicate internal anatomical details. This is because the native does not associate with them such mere animal traits. They are evidently drawn to give as forcibly and truly as possible an idea of the striking peculiarities that are associated with them in the native mind.

Fig. 52 I represents a special form of Mormo, which is the general name given to these mythical beings that are looked upon as mischievous sprites, or gnomes, and of which the natives are very afraid. This one is called Ingwalin. It is four feet six inches in height. There are supposed to be plenty of them living in the Delborji, or 


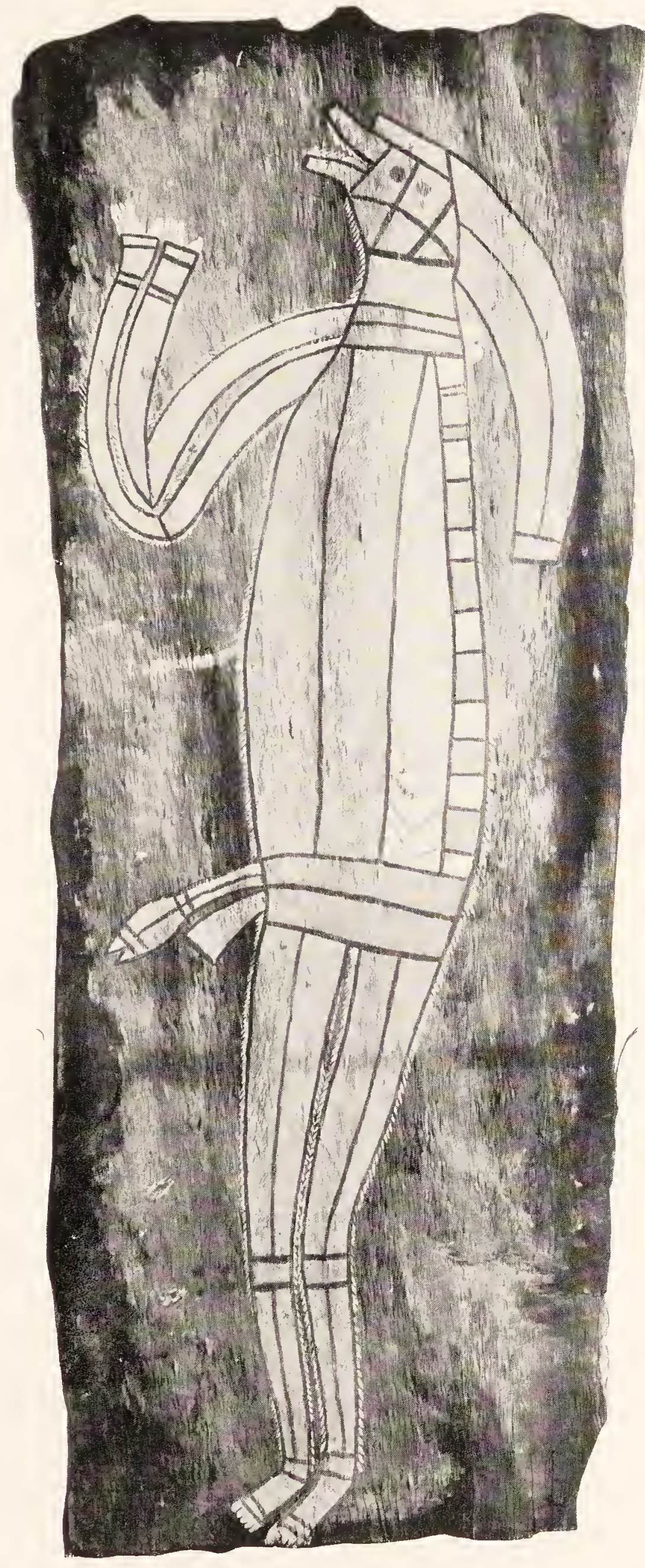

FIG. 522.-DEBIL-DEBIL CALLED NANGITAIN.

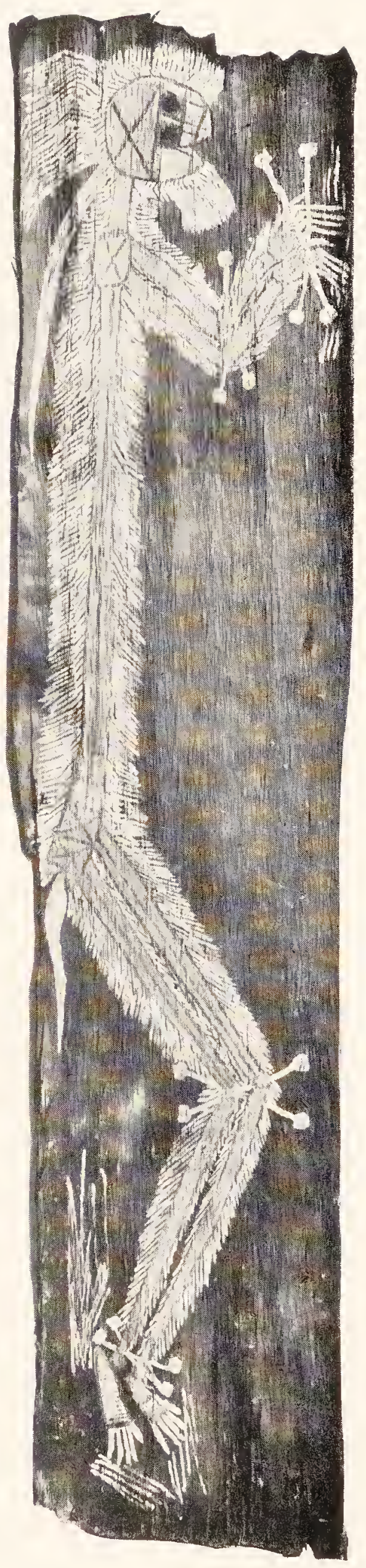

FIG. 523.-1)EIBIL-DEBIL

CALLED AUIENAU. 


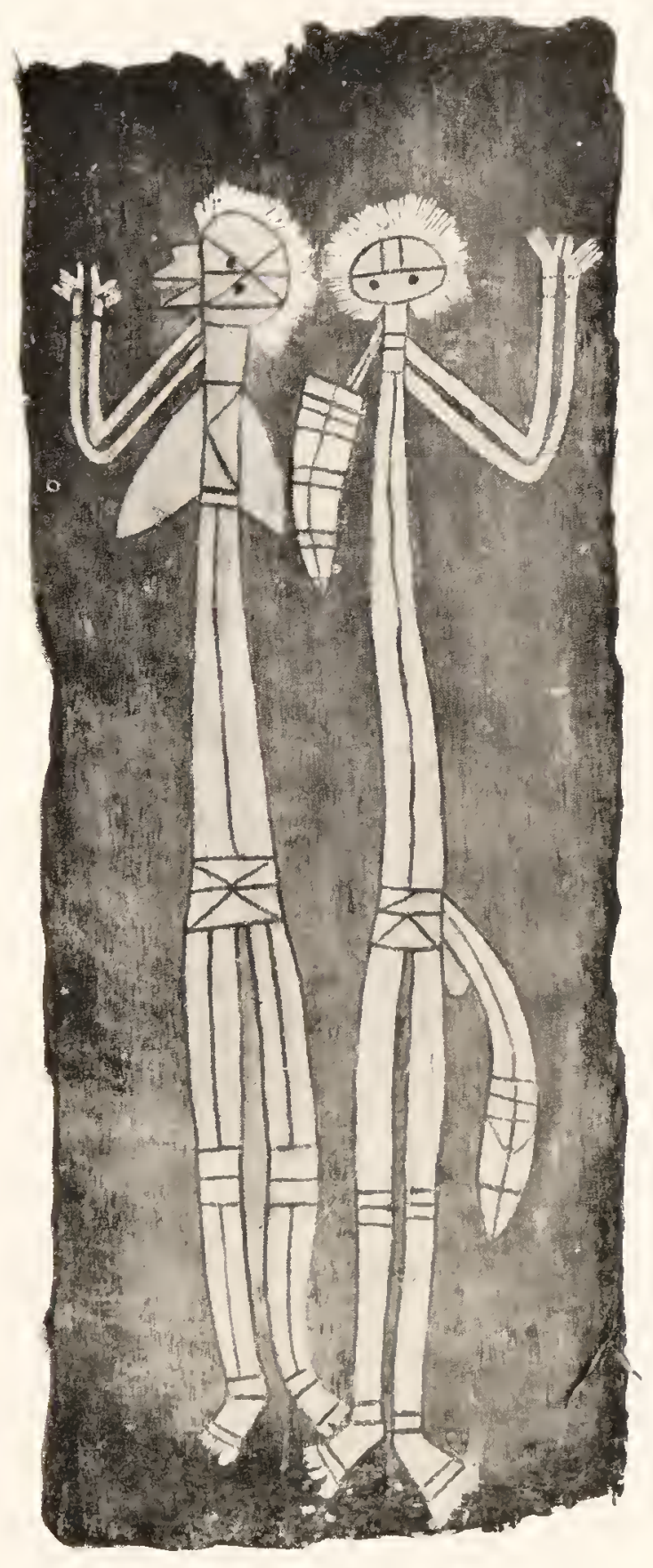

FIG. 525. I3ARK DRAWING OF A MORMO, CALIEL JEROBLIXI, KAKAIU TRIBE.
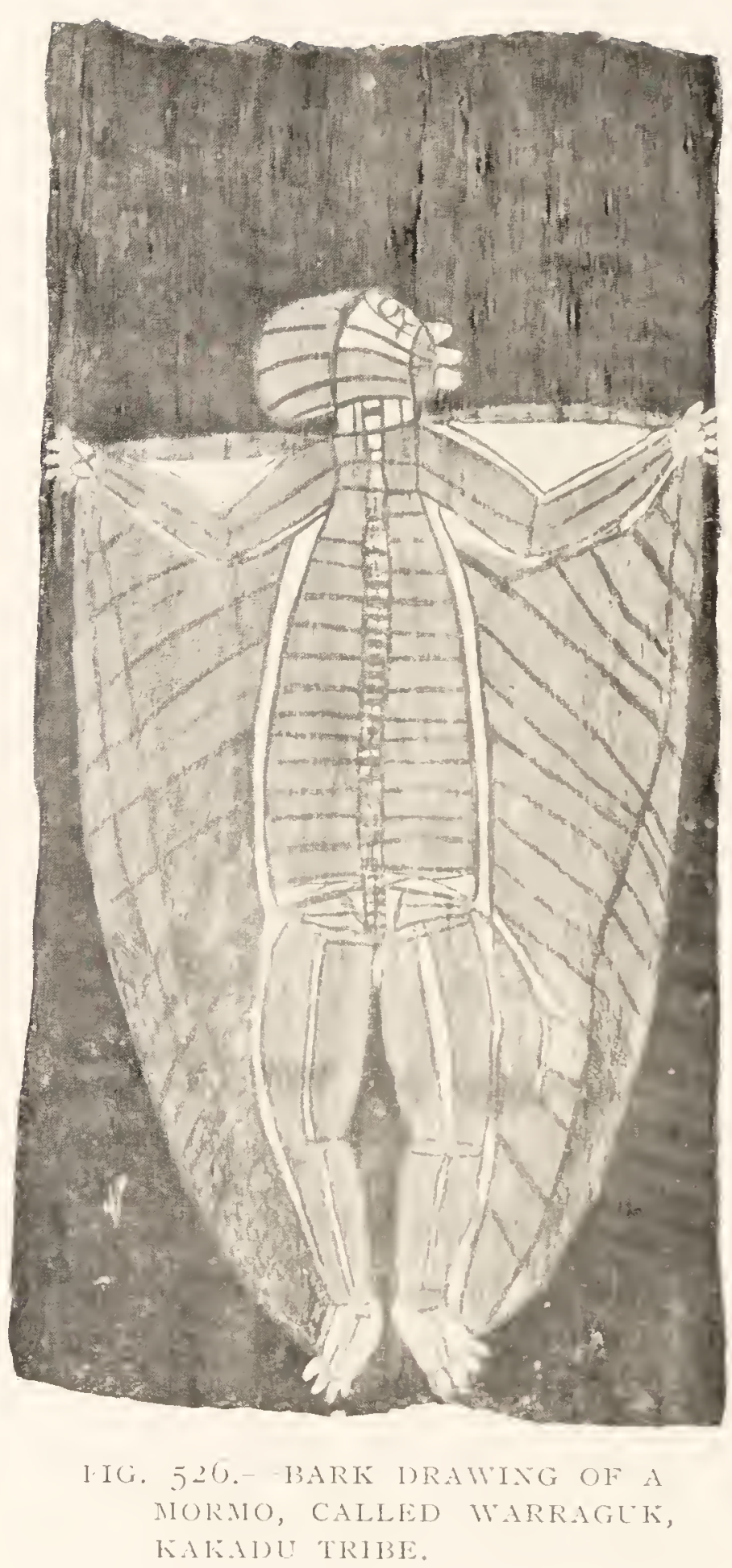
caves, amongst the Ranges. They are tall and thin and very emaciated, with long, bushy heads of hair, but their bodies are perfectly smooth and hairless. He carries in one hand a Kadumango club and in the other a bunch of feathers called Marra. These Ingwalins are supposed to visit the tree grave or wurkara in which a dead native is buried. They put their hands on him, talk to him and try to make him get up, but cannot do so. Then they make corrobborees and go away. Other spirits called Norminda come and see the body and they also make corrobborees.

The explanation of his carrying the club is that sometimes a mischievous spirit from another locality may come to visit the body, in which case the friendly Ingrwalin drives him away with it. These Ingwalins only move about at night-time, when they can be heard making a noise like "Brr, Brr." No one except medicine men can see them.

Fig. 522 represents a spirit or gnome of the Geimbio tribe called Nangintain. It is one of those mischievous individuals who, now and again, leaves his own country and comes to annoy the Kakadu people. He looks out for boys and young men and, if he finds one alone in the bush, tries to lure him away and take his Iwaiyu or spirit part of him. The only way in which the Irwaiyu can be recovered is by means of a medicine man who, carrying a Numereji under his arm, follows up the Nangintain. When he finds the latter, he shows him the Numereji, which so frightens the mischievous spirit that he at once hands over the Iwaiyu to the medicine man, who then hurries back to the camp, carrying it in his hands, of course unseen by ordinary men, and replaces it in the body of the boy.

The double projection from the back of the head represents two very long ears or kadi. When he shakes these he makes a strong, rushing wind. Both eyes are drawn and two sharply projecting jaws, with recurved teeth. Both 
eyes are shown. The neck is followed by three cross lines, indicating the moairu or shoulder region. From the front of this two arms project, and from the back, two outgrowths, faintly shown in white, that are supposed to represent especially long spines of vertebral bodies-much longer than in ordinary human beings. On the right-hand side of the body the backbone is shown, lying quite close to the surface; following it is a space crossed by $V$-shaped lines that are intended for ribs and, to the left of these, the two longitudinal bands indicate the skin. The two bands down the legs also represent skin; no muscles are shown, because the Nangintain is supposed to be very attenuated in body. There are five digits in each hand and foot, the thumbs being clearly marked. The whole of the body, save the jaws, ears, hands and feet, is covered with very fine hair.

This spirit is really a kind of bogey, the supposed existence of which is used by older people to frighten children and youths and prevent them from wandering away from the camp fires at night-time.

Fig. 523 is a drawing of a spirit called Aunenau, plenty of whom dwell in the rocky ranges in the country of the Geimbio tribe. It is shown in side view, extremely thin and attenuated and covered all over with a thick layer of long hair called ipimp. There is a great bunch of hair projecting from the back of the head and the beard is well developed. From the neck a long, stiff, curved spine hangs down, that can be erected and wagged about, so that the natives can hear it making a noise like a rattle. The body consists of bones as it has no flesh. The head is a rounded skull with two eyes; the neck, shoulder girdle, backbone, pelvic girdle, arm and leg bones are outlined in red. From the wrists, elbows, knees and ankles, lines project, ending in knobs. These represent bones that the spirit has taken from dead men and fastened on to itself. From 
the pelvis there is a downward projection supposed to represent the mulowa or lightning that the natives always see on the hill-tops at night-time when the Aunenau is prowling about. The straight lines above and below the hands and behind and under the feet indicate maggots. These spirits are supposed to wander about in search of dead men whose flesh they eat, and can only be frightened away by medicine men.

Fig. 524 represents a spirit of a different kind from the others. This particular one belongs to the Geimbio tribe and is supposed to fly about in the daylight and on moonlight nights, when it can be seen, but not on dark nights. It lives amongst the bamboo trees, hanging on to them by ropes, made out of banyan-bark string, called Mokinoborbu. Its general shape, except for the short tail, with its full body and short, but well-developed front and hind limbs, is rather suggestive of an opossum, which the natives see amongst the trees on moonlight nights. It is thickly covered with hair, called Ngoinbu, with very large hairy masses representing ears called Krabir. The whole body is white. This particular spirit is friendly to the natives and flies about watching them. If it sees a native ill, out in the bush, it goes in search of a medicine man, tells him to come and shows him the way.

Fig. 525 represents two spirits also belonging to the Geimbio tribe and called Ferobeni by the Kakadu. Some of them are women, some men. They are supposed to live in caves and holes in the ground or in Banyan trees, in the jungle, where they sleep at night-time, only coming out during the day, when they dance about under the tree graves but do not interfere with the bodies. The woman on the left-hand side is drawn with her head in profile, showing the long-drawn-out mouth and nose above it. Towards daylight they can often be heard singing out, " Yirkudda, quick; koapungi, daylight; nungortji, cold." 
They can be seen by the medicine men, wandering about in the bush, the man carrying a basket on his left shoulder in which he collects sugar bags. The hair on the head is well developed, but the bodies are smooth and attenuated. Both arms come off from one side of the body, which is done to fall in with the general arrangement so that they fit into the space available on the bark and allow of the figures being placed close together.

Fig. 526 represents a very special spirit which was first seen by a medicine man called Mituombo. It is called Warraguk and is supposed to walk about in the day-time, searching for Mormo or sugar bag. When at rest, it lives in the bamboos and paper-bark trees on to which it hangs like a bat. The head is seen in profile so as to show the nose and jaws, but both eyes are drawn. The hair is tied up to form a mop at the back of the head. On either side is a flap of skin, serving as a parachute with which it flies, running from hands to feet, with a special part above each arm, running across from the neck to the thumb. The backbone, ribs, pelvic girdle and leg bones are indicated. Its general form has probably been suggested by that of the flying-fox, or large bat, very common in these parts. It is not supposed to do any harm or render any service to the blackfellow.

Fig. 527 represents three snakes, the two left-hand ones being Narenma and the right-hand, Ngabadaua, a snake that figures largely in the traditions of the Kakadu. The forked tongue, of which the blackfellows are very frightened, is prominent, as also is the pointed tail, sharply marked off from the rest of the body. This is exaggerated, but demonstrates clearly what has evidently struck the native, and that is, the very distinct break in the under surface of every snake that is made by the vent and the shortness of the tail behind it as compared with that of a legless lizard. The blackfellow certainly has the capacity of seizing 


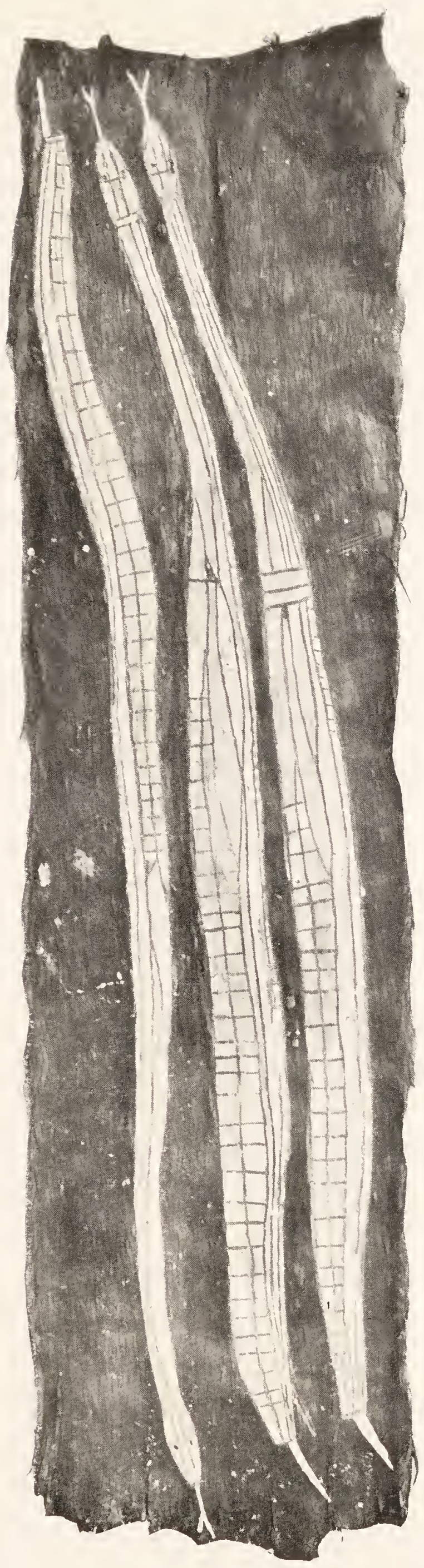

FIG. 527.-BARK DRAWING OF THREE SNAKES. THE TWO ON THE LEFT SIDE ARE NARENMA; THE RIGIT-HAND ONE IS NGABADAUA, KAKADU TRIBE.

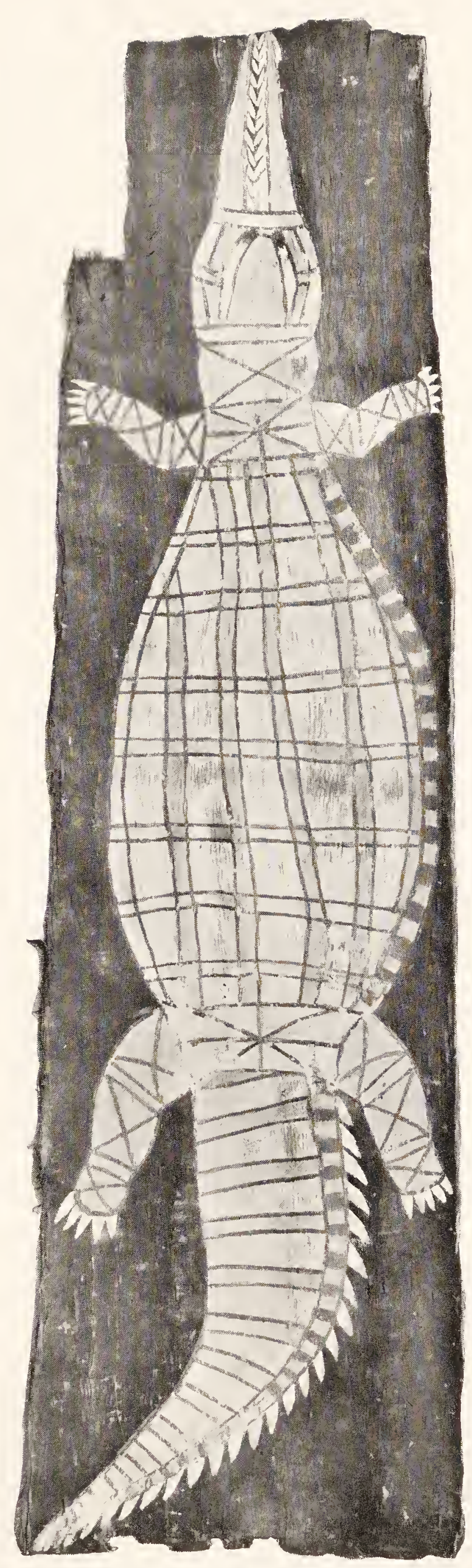

FIG. 528.-BARK DRAWING OF A CROCODILE, KAKADU TRIBE. 


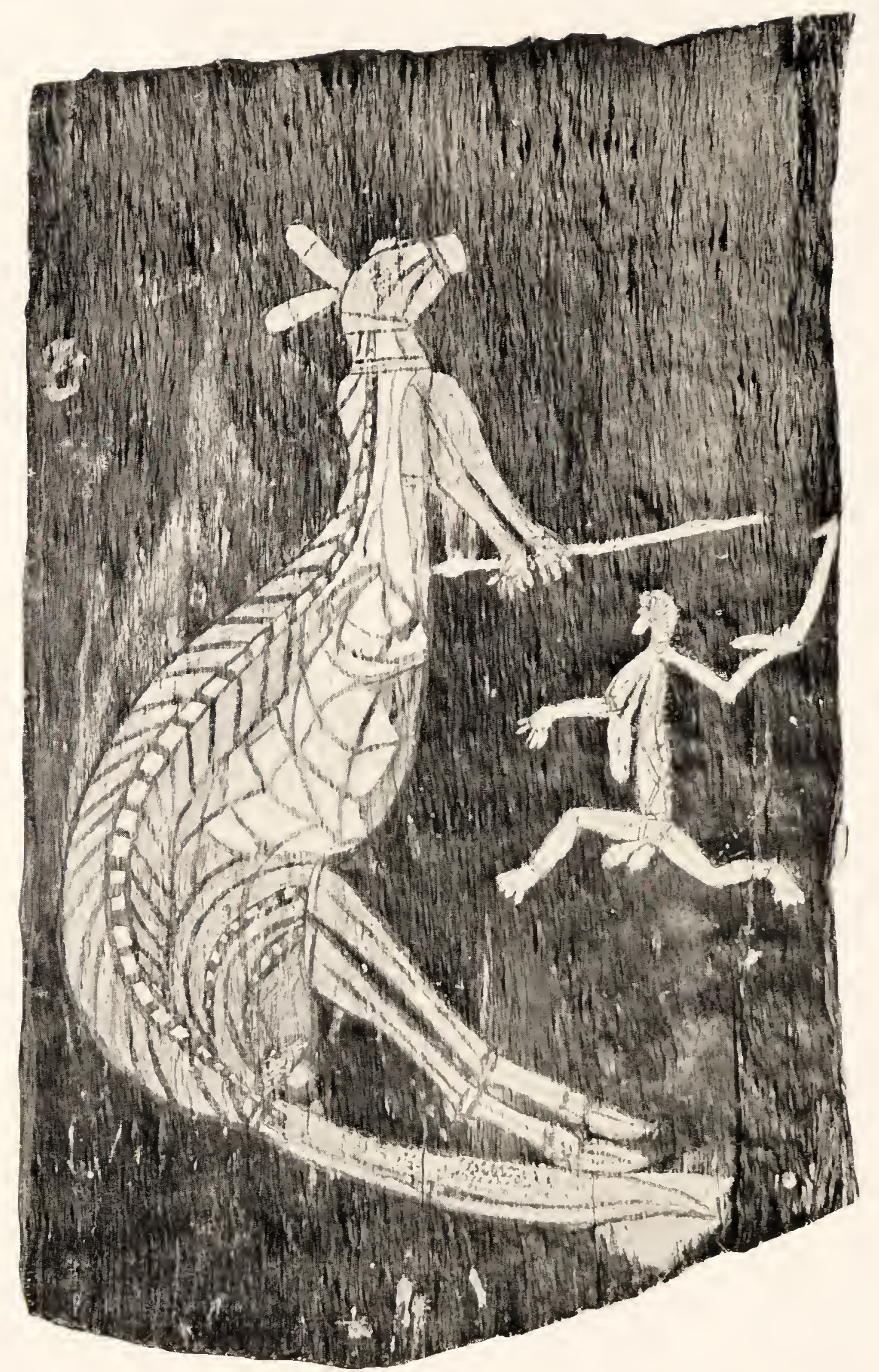

FIG. 529.- BARK DRAWING OF A NATINE SPEARING A LARGE BIACK KANGAROO, KAKADL TRIBE.

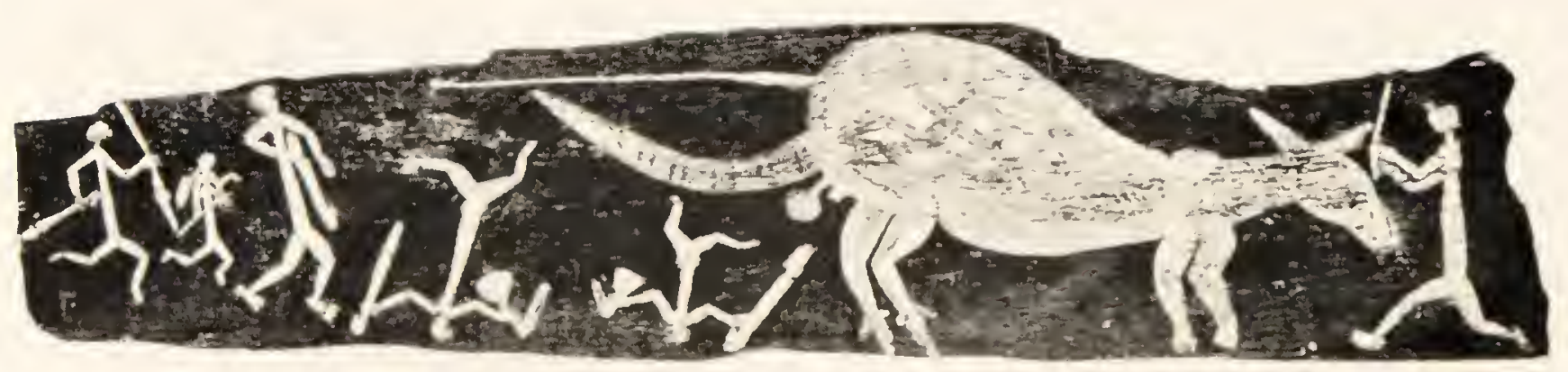

FIG. 530.- HARK IRAWING OF A KANGAROO HUNT, KAKADL TRIRE. 
intuitively on the salient features of all animals that he draws, however crude his drawings may be.

Fig. 528 is a drawing of an Eribinjori, or large crocodile (Crocodilus porosus), that is well known to, and respected by, the natives on account of its strength. Between the two jaws, that are represented sideways, the teeth are drawn. Then follows the head with the two small eyes. The stumpiness of the legs is well expressed, as also the strength of the hind ones that serve to propel the body when it is walking or running on land. At first sight it looks as if the whole animal were drawn in top view, but in reality the view is a very mixed one. On the right side of the drawing of the trunk, the backbone is drawn, the square patches representing the big scales on the ventral surface. The pelvic region is drawn in absolute ventral view with the vent in the middle of the radiating lines and the hind limbs arising on each side. The artist then went back to his original idea when he drew the trunk, and represents on the right side of the drawing the long row of dorsal spines, the backbone and the large ventral scales. It is a remarkable drawing and represents, however crudely, the striking features of the animal as they appeal to the savage mind.

Fig. 529 is a life-size drawing of a very rare form of black kangaroo (Macropus woodwardi) called Madjiborla, that lives amongst the Ranges and reaches a height of four feet. It is a very good example of native art, as illustrating the essential features of the distinctive structure and pose of a well-marked type of animal. No artist could have expressed better the relative proportions of the body and limbs, the small head, neck and fore limbs, the relatively narrow thorax, swelling out into the large trunk, the long tail which has been drawn up so as to make it fit into the canvas, and the strong hind limbs with their legs, feet and toes, in striking contrast to the small fore limbs. The VOL. II. 


\section{IO WANDERINGS IN WILD AUSTRALIA $\mathrm{cH}$.}

backbone is drawn, and above and below this are masses of flesh (Tjali). The lung is seen in the thorax; immediately below this is the liver, and the abdomen is filled up with the intestines. The backbone is regarded as the main, strong support of the body, and to emphasise the strength of the hind limbs the femur is drawn in the same way as the backbone. The most striking feature, however, to anyone who is acquainted with the kangaroo in its natural state is the really wonderful way in which the savage artist has depicted the pose that is always assumed by the animal when alarmed-the erect position of the body, the head thrown well up and slightly back, and the two little fore limbs held forwards helplessly.

There is one feature of interest that stands out clearly in this as in all other drawings in which men and animals are shown together, and that is the relative size of the two. Even when the animal, such as a fish, is small, the man, as in the drawing of Bubba Peibi, is markedly out of proportion, whilst in the case of large animals, such as kangaroos and emus, the disproportion is still more striking. The reason for this is a simple one, so far as animals are concerned. The native is only interested in drawing those that are of value to him as food. That is why he knows their shape so well and also, speaking generally, what he finds inside them when he cooks and cuts them open. In his animal drawings it is the animal that looms large to him, not the human; the latter is merely an accessory and is drawn just to show he is there, that is all, and therefore his size does not matter. The drawing of the blackfellow is, however, full of energy. The artist told me that the man had been out searching for Mormo, or honey-bag, and had filled his Numalka, or dilly-bag, with it and was carrying it round his neck. He was also carrying his stone spear-thrower, and on his way back to camp came across a big black kangaroo. In some way he managed 
to get in front of it, and while it stood up quietly for a moment or two, to look round, he ran up and speared it.

Fig. 530. This represents a kangaroo hunt and is really a composite drawing. The main scene shows the kangaroo, that has been chased and speared, receiving his coup de grâce at the hands of a blackfellow who runs in from the front and hits him on the head with a club. Three natives are running up behind, two men and a woman. One man has just thrown his spear, that has entered the animal's hind quarters and disabled him. The attitude of this man, leaning back with the spear-thrower in his right hand, is admirably drawn, as also are the figures of the man and woman, who are shown running up further away, and therefore drawn on a smaller scale, the man carrying his spear and spear-thrower, the woman with a dilly-bag hung round her neck and a yam-stick in her hand. This little group of three is a good example of native delineation of figures in movement and action. The artist, who was the same painter as that of Fig. 529, told me that the two upside-down figures, which at first sight I thought were natives who had been knocked over by the kangaroo, had really nothing to do with the main drawing. The bark was one day lying upside down and he put them in to fill up the space. If the drawing be turned upside down it will be seen that the men are really running along, each of them carrying a spear-thrower and a bunch of feathers.

Fig. $53 \mathrm{I}$ represents three different things. The uppermost is a pigmy goose, or Peevi, showing the backbone and the alimentary canal, with a triangular gizzard. The middle one is a fish called Bararil. It is characteristic of the drawings of all fishes that the backbone goes down the middle of the body, with a mass of Tjali, or muscle, above it. On the under side is the body cavity, with the alimentary canal, which is always represented as forming a compact mass. The lower one is a drawing, or rather a stencil, 
that is found over the whole of Australia. It has often been described as the "red-hand" and as having some mysterious, occult or sinister import, but it really has nothing of the kind and is made by placing the hand on a rock surface or piece of bark and then blowing either powdered pipe clay or red ochre over it from the mouth. It is only what the natives call "play-about," has no special significance whatever, and may be drawn anywhere and looked at by men, women and children.

Fig. 532 represents a Kimberikara or so-called Barramunda fish (Osteoglossum leichhardti). In contrast to the pigmy goose and Bararil, both of which are small animals and so can be drawn on one bark, this is a large one of its kind, and therefore needs a bark to itself. The head shows the upturned lower jaw, the strong opercular plates and both eyes. In the drawings of all fishes there are two projections, one above and one below, where the head merges into the body; these are conventional and have no meaning that the artist knew of, but are always drawn. The front fins are represented by two lines and the median ones by white lines, indicating the strong rays, or, in the case of the tail and ventral fins, by the fin as a whole. In this drawing the backbone is strongly marked, the dorsal arches and processes run the whole length, but the artist has rightly drawn the ventral ones as present in the tail region only. There is the usual great mass of Tjali above the backbone, and below this is the mass of intestines.

Fig. 533 represents two "Native Companions" or Jimeribunna (Grus australasianus), one being speared by a native. This is by the same artist as Fig. 529. The general proportions of the different parts of the body are well shown. It will be noticed that, in fishes, the main mass of flesh or Tjali is always drawn above the backbone; in birds it is, of course, on the breast. The pelvic girdle is represented by two cross bands, one for each leg. 


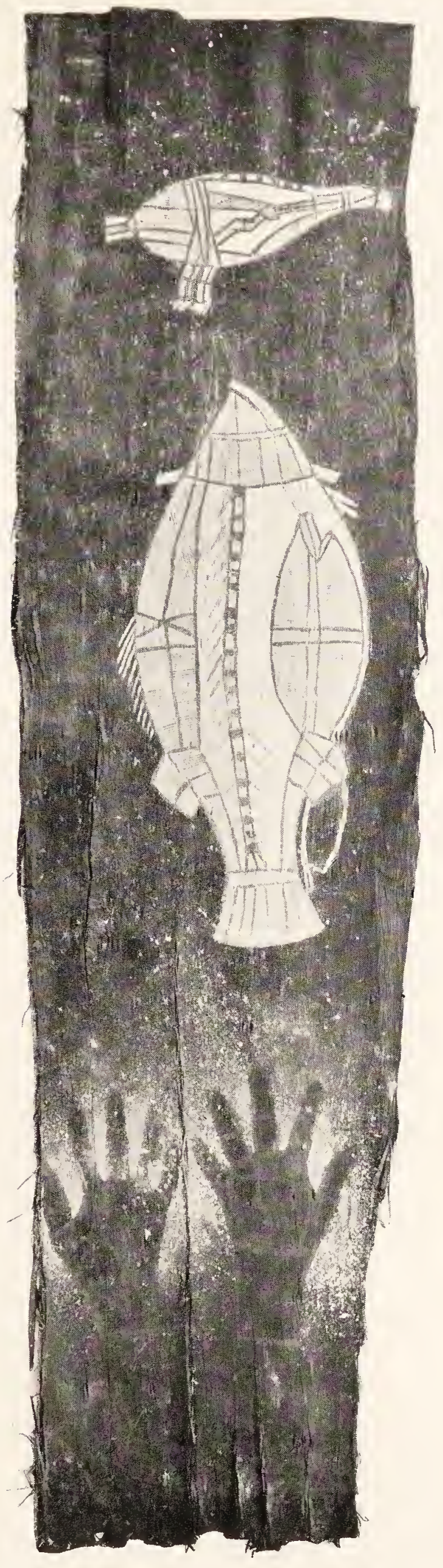

FIG. 53I.-BARK DRAWING. THE UPPER FIGURE IS A PIGMY GOOSE; THE MIDDLE IS A SMALL BARRAMUNDA FISII; THE LOWER ARE STENCILLED HANDS, KAKADU TRIBE.

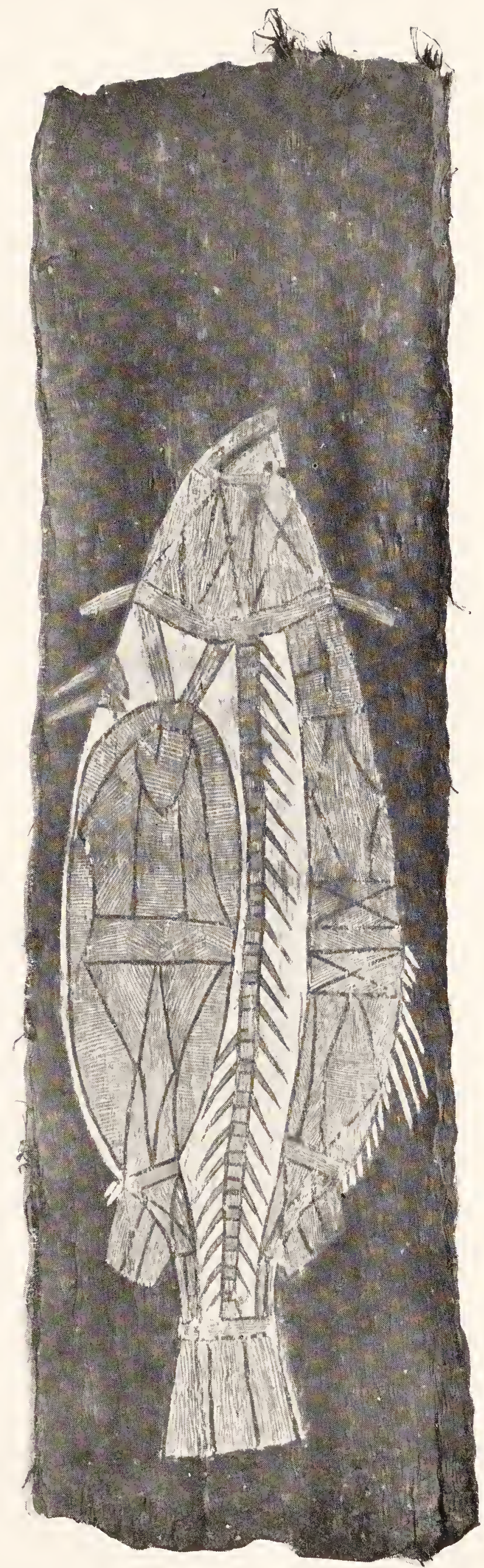

FIG. 532.-BARK DRAWING OF A BARRAMUNDA FISH (Usteoglossim leichhardti), KAKADU TRIBE. 


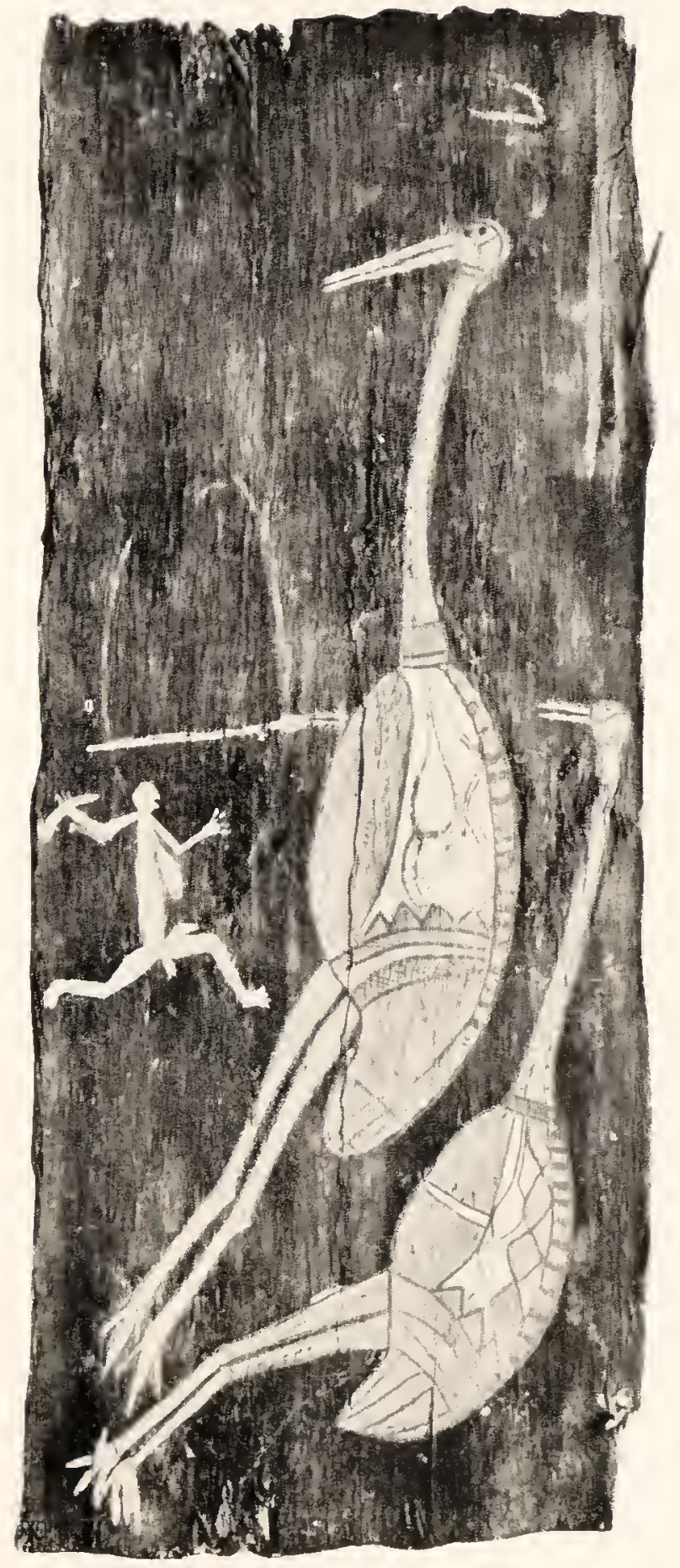

FIG. 533.- BARK DRAWING OF A NATIVE SPEARING A NATIVE COMPANION" (Gims amstrulasianUs) K.SADU TRIBE.

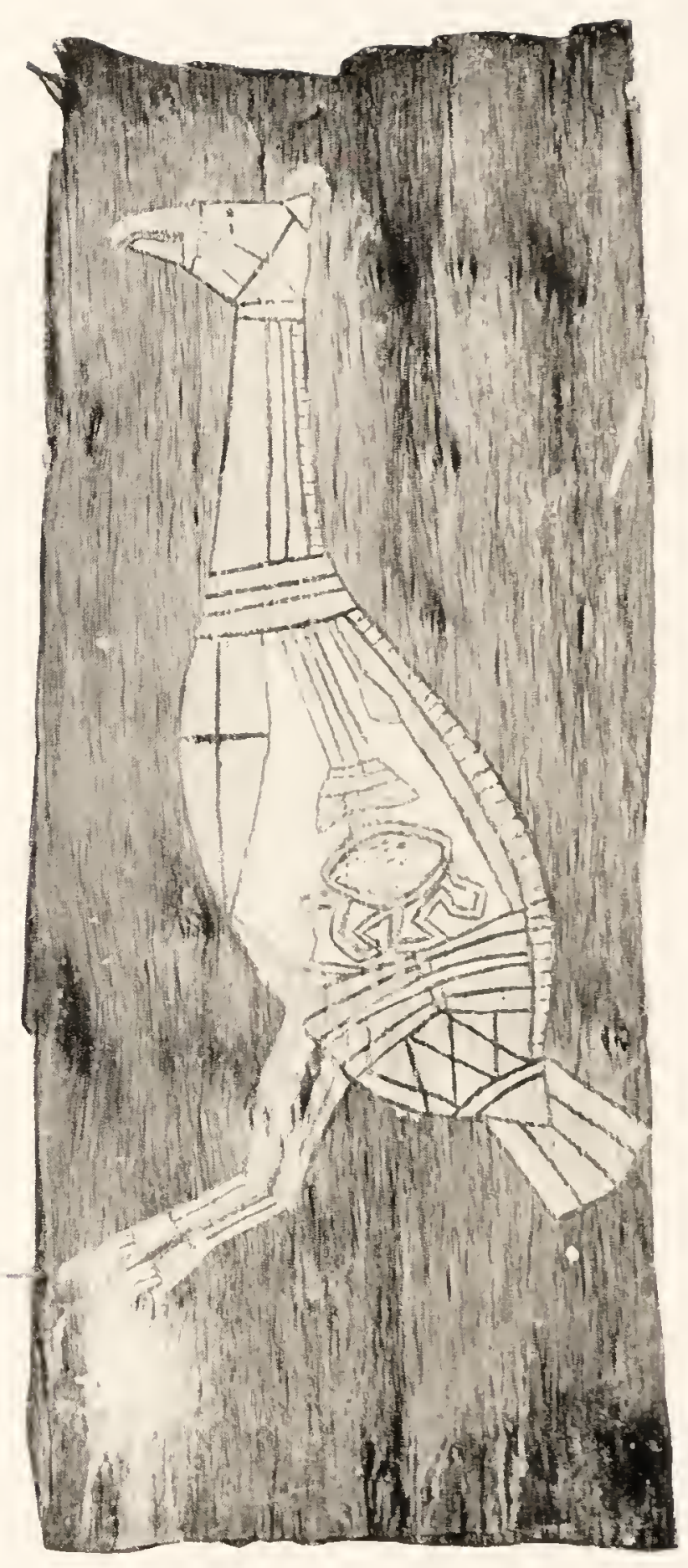

FIG. 53.- BARK DRAIIING OF A J.MLATED (GOOHE, K.SKADL TIIBE. 
Amongst the many drawings that I saw, no attempt was ever made to show the wings when the bird was seen in side view, though in a few front-view drawings they were well drawn. In mammals and fishes they are always shown. The blackfellow is carrying his Numalka or bag round his neck and has thrown a stone-headed spear from his Paliati or spear-thrower. As usual, the thought of the birds was uppermost in the artist's mind, so they occupy the main part of the picture.

Fig. 534 is a most excellent drawing of an old male palmated goose or Kurnembo. The hard, horny crest on the head, called Kundeiyu, is very characteristically drawn, as also is the beak. The œsophagus is drawn but not the tracheal tube, which is curious, because it is especially strongly developed in this bird, and running round amongst the breast muscles must have attracted the notice of the blackfellow. Both eyes are drawn. The shoulder girdle is represented by three bands. The backbone has a little Tjali shown below it, with the lung attached to it, at the upper end of the body cavity, across which runs the alimentary canal with the liver, followed by the strong gizzard, from which the zigzag intestine passes out. It is curious, again, that the heart never seems to be drawn. The pelvic girdle is represented by cross bands, two corresponding to each leg.

Fig. 535 is one of the best animal drawings. It represents an echidna or Erleringalura. The strong and compact body, showing the very characteristic curvature above, is covered with stiff bristles. The legs are short, stout and muscular, the head is pointed with its long tongue extended. Underneath the backbone is a band of flesh, then follow the intestines, and the whole of the under part and of the strong hind-quarters is a mass of Tjali and Paloma (fat). There is no mistaking its identity.

Fuly 2 Ist.-In the Kakadu, like most Australian tribes, 


\section{I4 WANDERINGS IN WILD AUSTRALIA $\mathrm{cH}$.}

every man and woman has his, or her, totem name, that is, the name of some object, most often an animal or plant, after which he or she is called and with which he or she is supposed to have some special close connection. In some tribes, like the Urabunna, far away in the Lake Eyre district, and the Mungarai, near at hand, on the Roper River, the child takes the mother's totem name; in others, such as the Djauan at Katherine Creek, it takes the father's. In the Kakadu, like the Arunta, the totemic name of either father or mother is no guide whatever to that of the child; it may be the same as one or other of its parents, but, as likely as not, it may be quite different from both of them. What was most puzzling was that every individual was the reincarnation of an ancestor, whose name he took, but his totem might not be the same, in fact it very rarely was. We worked at the names of family after family to try to get some clue, but for a long time it seemed hopeless to find anything.

Here are three, out of many families living in the camp at Oenpelli, all well known to us.

(I) A man named Ungara, whose totem is Kimberikara (the Barramunda fish); his wife Obaiya is Mormo, sugarbag. They have two children, Monmuna, a boy, who is Kunbaritja, a fish, and Murawillawill, who is Eribinjori, crocodile. The totem of Ungara's father is Kunbaritja and that of his mother is Mormo.

(2) A man named Mukalakki, whose totem is Mormo. That of one wife, named Mitjunga, is Kunaitja, mullet; that of another, named Numerialmak, is Kulekuli, cat-fish. His father, named Monmuna, was Kimberikara (Barramunda); his mother, named Kumbainba, was Eribinjori, crocodile; his brother was Murmo, opossum; the mother of Monmuna was Kintjilbara, a snake; his wife's mother was Kulekuli, cat-fish.

(3) A man named Oogutjali whose totem name is 


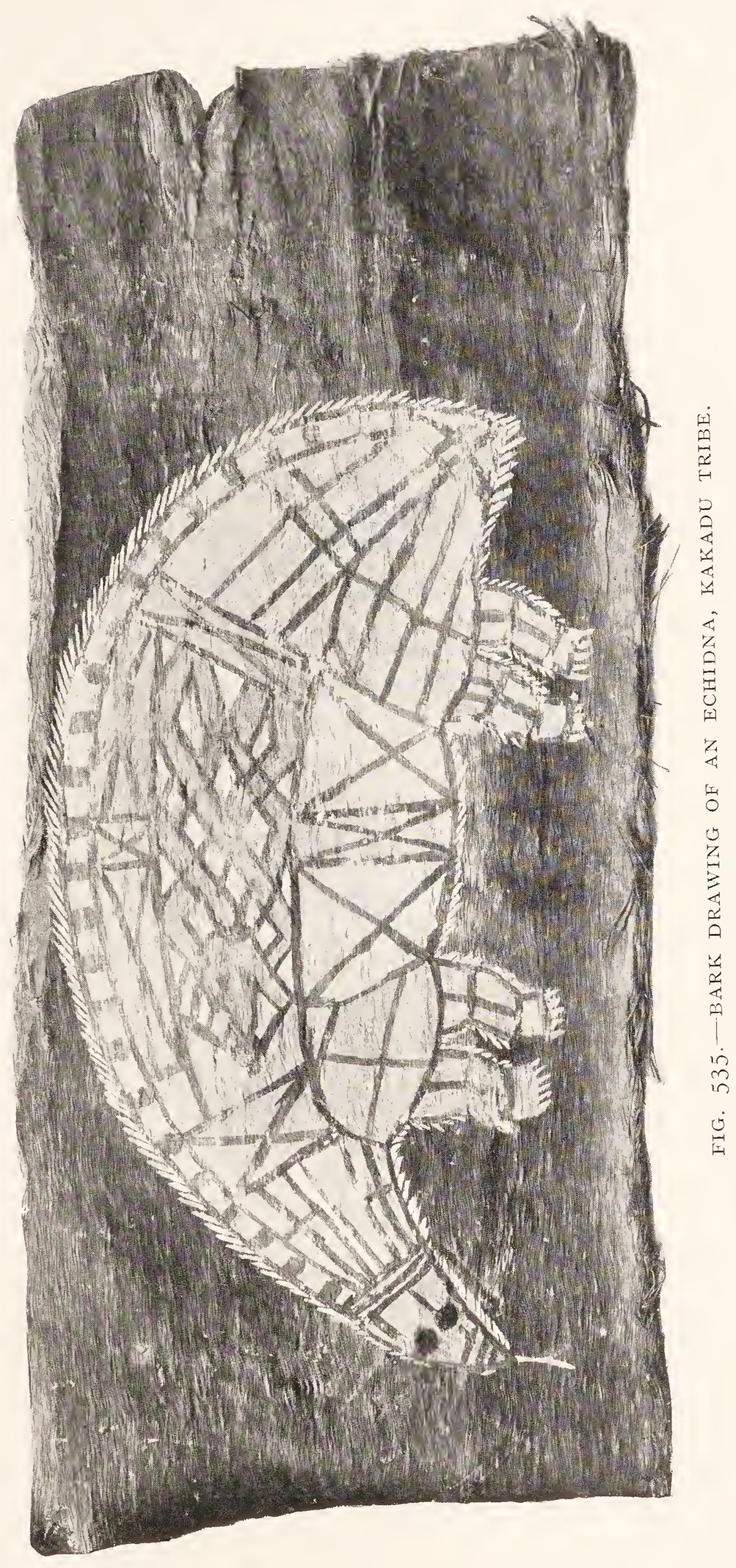



Kunbaritja, a fish; his wife, Belgramma, is Narenma, a snake; a son, called Tjurabego, is Eribinjori, crocodile; a daughter, Mikgurne, is Kulekuli, cat-fish; a daughter, Mirowargo, is Kalerungeno, flying-fox ; a daughter, Minagi, is also Kalerungeno, and another called Makuralu is Mormo, sugar-bag. These will show how complete and perplexing was the mixing up of the totems, so far as anything like counting descent is concerned. It was clear they had nothing to do with regulating marriage, nor was there any attempt made for each individual to retain the totem of the old ancestor of whom he is supposed to be the reincarnation. In the three families above there is actually only one, the woman Mitjunga, in which the living person has the same totem as the old ancestor.

To-day, while at work with Ungara and Mukalakki, we began talking about the Yalmuru, which they told us was the name given to the spirit part of each individual. In the legend of Imberombera, the great ancestress of the tribe, we learned that she had peopled the whole country with spirit individuals, to each of whom she had given his Fereipunga or totem, and that it was these same spirits who had given rise to the Kakadu people and had continuously undergone reincarnation ever since. The original spirit, the Yalmuru, was evidently the equivalent of the original Kuruna or spirit of the Arunta beliefs. They told us that when anyone died, the Yalmuru, after the final burial and mourning ceremonies were over, kept watch over the Benogra, or bones. After a time the Yalmuru divided into two, so that now there was the original Yalmuru, or rather one half of it, retaining the original name, and a second half called Iwaiyu. These two are distinct and have somewhat the same relationship to one another as a man and his shadow, which in the native mind are very intimately associated. For a long time they remain together, but, when the Yalmuru wishes to undergo reincarnation, the 


\section{I6 WANDERINGS IN WILD AUSTRALIA $\mathrm{cH}$.}

two leave the Benogra, or bones, which are often some distance away from a camp out in the bush. They go forth together, the Iwaiyu in the lead, the Yalmuru behind. Out in the bush they find the natives, who, of course, cannot see them, hunting for food. The Yalmuru takes the Iwaiyu and puts it in the form of a small frog, called Purnamunemo, which lives under the sheaths of the leaves of the screw pine, or Pandanus, into some food, such as a fish or sugarbag, that the man is searching for. If, for example, it be a fish, the Yalmuru goes into the water and drives them into the man's Chipoiyu, or fishing net; if it be Mormo, or sugar-bag, he guides him to the tree in which the bees have made their hive. In either case, as soon as the man has secured the fish or Mormo, out jumps the Iwaiyu, of course unseen by the man. It is caught by the Yalmuru, and together the two spirits return to their camping-place. The food in which the Iwaiyu was placed will be the child's totem. The latter is thus always selected by the Yalmuru and may change from one reincarnation to another. It is said that, sometimes, when an animal such as a fish or crocodile contains the Iwaiyu for a time, and the animal is speared, then the Bialilla or child, to which the Iwaiyu subsequently gives rise, bears the mark of the spear wound.

The natives return to their camp, quite unconscious of the fact that the Yalmuru and Iwaiyu have been out in the bush. At night-time the two latter come to the camp and watch the men and women. The Iwaiyu is again in the form of a little frog. When all are asleep, the two come up and enter the Mia-mia where a man and his wife are sleeping. The Iwaiyu goes up and smells the man; if he be not the "right" father he says, ngari koyada, which means, not this one. He tries another one, finds him right and says, ngari papa, this one is my father. Then he goes and smells the latter's lubra. The Iwaiyu gets into her hair, then feels her breasts and says, korngo ngari koiyu, 
these are my mother's breasts; ngari koiyu, this is my mother. Then he goes into the woman. The Yalmuru returns to the Benogra, or bones, at his own camp. Every now and then he comes to look at the woman, but does not speak. When it is evident that the woman is going to have a child, the Yalmuru comes up to the camp at nighttime and tells the father that the child is there, what his name is and also what its totem is, and that no other name must be given to it, because that is the child within his wife.

A man named Ungara told us exactly what happened in his own case. When his father's brother died, his Benogra, or bones, were left for some time in a tree not far away from the camp at which he died, but later on they were carried more than twenty miles away and placed in a large Banyan tree, overhanging a water-pool. Ungara, who had his wife Kumbainba and one child with him, was once camped near this place. He threw his net into the water and left it there for some little time. Then he gathered long grass stalks and went into the water to drive the fish into the net. He did not know that the Yalmuru had already done this and that the Irwaiyu was in one of the fish. The net was so heavy that he called out to Kumbainba to come and help him lift it out on to the bank. While they were doing this, the Iwaiyu jumped out and was caught by the Yalmuru, and then they both went back to the bones. Ungara and his wife took the fish out and carried them to their camp in dilly-bags. There were a good many other natives camped about. That night while they were sleeping the Yalmuru and Iwaiyu came into the camp and, after examining the man and the woman, the Iwaiyu went into Kumbainba. While telling us this, Ungara mimicked exactly the actions of the Iwaiyu going first to the father and then to the mother. He told us that, later on, the Yalmuru came one night and whispered into his, 
Ungara's, ear, Chipoiyu nanjil yapo araji, The fish went inside your net; jibul widgeru, it was full up; mukara bialilla ngeinyimma, your child was there; brau Monmuna Murkamora narama, give it the name Monmuna Murakamora; jereipunga Kunbaritja, its totem is Kunbaritja; balera koregora onje narama koyada, by and by do not look out another name; Monmuna Murakamora ngeinyimma ingordua bialilla araji, Monmuna Murakamora is the child inside your lubra.

When the child is young, the Yalmuru watches over it. If it strays away from camp and gets lost in the bush, the Yalmuru guides it back, and later, when the child has grown into a man, the $Y$ almuru still helps it, in fact a good deal depends on the Yalmuru, because if it be not vigilant, some other hostile one may work evil magic against the individual who represents its Iwaiyu. Finally, when the man grows really old, the Yalmuru comes some night and whispers in his ear words that mean Iwaiyu, you look after a child, my backbone and thighs are no good, my eyes are no good and sore, you look after the Fereipunga (totem). In other words, the Yalmuru is supposed to tell the Iwaiyu, that is the spirit within the man, that he, the former, is worn out and that the Iwaiyu must take on the part of providing for a new child being born and look after the totem. As the natives say, baranga Yalmuru wariji ge, the old Yalmuru is done for completely; Iwaiyu nigeri Yalmuru, the Iwaiyu is the new Yalmuru. It is really like a very crude forerunner of the theory of the continuity of the germ plasm. The old Yalmuru splits, as it were, into two; one half, the Iwaiyu, persists, the other finally disappears. In its turn the former becomes transformed into a Yalmuru, which again splits; one half remains and the other perishes, but there is an actual, spiritual continuity from generation to generation.

Fuly $22 n d$.-.-This afternoon we had the second part of 
the mourning ceremony called Morlil, the first part of which we had seen on July 4th. It was concerned chiefly with the women. As before, everyone was supposed to bring all his, or her, personal belongings, collectively called ardi, into the camp. The women's were placed at one spot, the men's at another, but nothing was done with them this time and, after the ceremony, everyone took away his own things. The description of the ceremony, given to us before it was enacted, was a model of briefness and accuracy. I took it down verbatim and it was as follows. Ngaia (I), nunborgi (sorry), wariji (dead or underneath), ngaia (I), warji (cry), murora (old woman), wunmali (mud), worejia (yellow ochre), gibu widjeru (all over), korto (arm), kundama (bracelets), ikitiokita (other, or each, side), geraiwin (young women), bialilla (children), kutjeri (red ochre). This meant that all were very sorry, that the old women would paint themselves all over with mud or yellow ochre and wear the special form of bracelets, called Kundama, on both arms and that the younger women and children would paint themselves with red ochre.

This was exactly what happened. The natives assembled under the shade of a clump of trees, this time a quarter of a mile away from the camp at which the woman had died. The women (Fig. 5 I5) were seated together at one spot, the older ones, coated with mud or yellow ochre. Each one wore two or more of the heavy armlets known as Kundama. They are made of a circlet of pliable cane, twisted round with a coarse string made from the fibres of the bark of the Banyan tree, the native name for which is Mukinoborbu. They are never decorated or coloured in any way, in which respect they differ markedly from the elaborate mourning bracelets of the natives on Melville and Bathurst Islands. At the same time the existence of special mourning armlets is not known, so far as I am aware, amongst any Australian tribes except those of the 
Islands and the Kakadu and allied tribes on the mainland, which seems to suggest a common origin.

The women had brought in supplies of lily-seed cakes that were eaten by the older men who were standing and sitting around. Nothing special was said or done, and everyone was very quiet. Narriyut, the son of the dead woman, said to another man named Bandiki, Ngeinyimma (you), niorki (white), kala (all right), ngeinyimma onje koiyu (you another mother), ngaia miorni (I black), koiyu widjeru (mother, proper or very). That is, Bandiki could paint himself with white at this ceremony but Narriyut and his younger brother, being own sons of the dead woman, continue to paint themselves black. Another man, named Romula, who had been absent from the camp when the first ceremony was performed, also painted himself black. The men who had painted themselves black at the first ceremony were supposed to paint themselves white at this one, except in the case of close-blood relatives, who will continue to use black. The idea at the root of this custom is really closely akin to that in accordance with which more highly civilised people use, at first, deep and, later on, thin black-edged paper to express varying stages and degrees of grief. In most Australian tribes white is the sign of deep mourning, but here it is black.

When anyone dies their name is not mentioned and they are referred to, if there be any necessity to do so, as "the old man" or "the old woman." If anyone, by chance, should mention a name they say monowei, koyada tjikaru narama-dead, do not say his name; ameina? mornda japul-why do you do that? it is bad talk. If a woman mentions it, any son or brother of the dead man may strike her.

There are special terms that you have to use when you speak of certain relatives of the dead person until the time of mourning is over. The son of the dead person is called 
Numulaiju; his brother, Noudbukara; the brother's husband, or husband in the case of a woman, Nunkudumuramuran; the wife of the dead man, Inkuduramuran.

If, for example, on the present occasion, anyone wished to call out to Narriyut, the son of the dead woman, to come and get food, instead of saying, as he would under ordinary circumstances, Narriyut preya jamo, he says Numulaiju preya jamo.

There is still a third ceremony to be gone through before the mourning is complete. It is called Kuderi, and is carried out after the end of the rain season succeeding the second Morlil ceremony. I was not fortunate enough to see this, but our informants described it to us. Everyone, once more, brings all his possessions to the camp where the Kuderi ceremony is held. Again the women's things are placed in one spot, the men's in another. The women bring in supplies of sugar-bag, lily cakes and yams, and these are placed on two or three mats. All present sit down, wail and work themselves up into a state of great excitement, the old women hammering themselves with their sticks. They also wear the Kundama armlets. Everyone is painted with red ochre. The men ask one another who stole his Korno? That is, who killed him by evil magic. The women and children go back to their camps, taking all their belongings with them. The older men eat the food. Their spears are brought up and arranged on the ground in groups so as to form roughly a circle, just like the grass stalks in the Morlil ceremony.

In some strange way this ceremony has become associated with a system of barter. Each man states what he wishes in return for his weapons. Next day, messengers start off carrying the spears to a distant camp. The Kakadu people, for example, send theirs to an Umoriu and vice versa. If there should happen to be any men from this distant camp visiting the Kakadu, they will carry the spears back with 


\section{WANDERINGS IN WILD AUSTRALIA $\mathrm{cH}$.}

them, but, otherwise, special messengers are sent. On arrival in the strange camp, where the meaning of their coming is understood, the spears are placed on the ground in bundles, each containing those of one individual, and the visitors are asked what they want in exchange for them. There seems to be a well-recognised tariff, and, if the barter takes place, goods that are being exchanged for the spears are placed opposite their respective bundles. When the business is over, the different articles received in exchange are gathered together, carried back by the visitors to the home camp and distributed amongst the owners of the spears that have been bartered. It is by means of this simple system that the natives in one part of the country, who are especially skilled in the making of one implement, such as spears, secure others that perhaps they do not make themselves owing to lack of suitable material.

For the first time to-day I came across a very rare type of spear-thrower. The one usually used, and very widely spread over the whole of the northern area, consists of a flattened slab of wood, three feet long and an inch and a half broad, with a notch cut at one end to afford a good grip. In this one the body of the thrower consists of a thin lath of hard, dark wood such as Acacia. It may sometimes be straight, but is usually curved like a boomerang. The one represented in Fig. 536, No. 3, may be taken as characteristic of this type. The total length is just four feet: the greatest width is two and five-eighths inches and the thickness only three-sixteenths. The handle is a truncated knob of Kapei, or ironwood-tree resin, measuring two and three-quarters of an inch in length and one and three-quarters in diameter. Its surface is always worked in such a way as to give the appearance of strands of string running round either end and lengthwise across a band in the middle of the knob. The Kakadu who make this thrower call it Palati. The wax handle-knob is called 
Kuleryu. At the other end is a small knob of wood, an inch in length and tapering rapidly from a diameter of five-eighths of an inch to a blunt point. This is fixed on to the flat side of the blade by means of Kapei resin, wound round with Banyan fibre string, and is called Inedi. The use of this form of thrower requires considerable dexterity but is most effective in the hands of a skilful native, because it is held so that the thin edge of the thrower cuts through the air, resulting in there being practically no friction, that is great in the case of the broad, leaf-shaped thrower of the Arunta. I only got a few of these and had to give as much as a stick and a half of tobacco, more than twopence, for each.

Whilst these are very rare, every man possessed one or more of the simpler kind, called Kunjolio (Fig. 536, No. I). It is merely a straight stick, from forty to forty-five inches in length and from a quarter to half an inch in diameter. At the handle end it is coated with Kapei resin, with a raised rim, about four or five inches from the end, that makes a very efficient handle. The knob on to which the end of the spear fits is simply a round, bluntly-pointed lump of resin. Small ones of this kind are often made for children to use with their toy spears.

Fuly 23 rd.-This morning we walked up to the top of the hill about half a mile away from the station. There was a very definite, narrow, well-worn track leading through the scrub, up which we had often, when night came on, watched the natives climb in single file, carrying their lighted fire-sticks. It was warm work in the hot sun, but from the top we had an extensive view (Fig. 495A) across the plains beneath with the Oenpelli lagoon and the Ranges in the distance. The most interesting things, and what we came up to see, were the rock-shelters of the natives, where they rest in the cool of the evening during fine weather, or are protected from the monsoonal rains during the wet 


\section{WANDERINGS IN WILD AUSTRALIA сн.}

season, when the flats below are transformed into swamps. The shelters were overhung with shelving rocks all round the top of the hill, so that they could change their camps to suit the changing weather. If the winds and rain blew in from the north, all they had to do was to pick up their few belongings and take their fire-sticks round to the shelters on the south side. The shelters were indeed such that they could accommodate themselves to any kind of weather.

The slanting roofs and sides were one mass of native drawings, precisely similar to those done on bark, but, here, the rocks had been blackened for long years by the smoke of countless camp fires and the drawings, most of them fishes, had been superimposed on one another, the brighter colours of the more recent ones standing out clearly on the dark background (Fig. 537). Here and there were groups of stencilled hands and feet. On other rock shelters on the hills along the Alligator River the drawings (Figs. 538, 539) were not superimposed and comprised fishes, turtles, crocodiles and snakes. Very rarely there was a drawing such as the one shown in Fig. 540 that represented a gnome-like creature. In this it may be noted that the curious tail-like structure has nothing to do with the main drawing, it is part of the irregular lines drawn on the rock to the left of the body.

In the afternoon, while we were at work with some of the natives, two others came up in a mysterious kind of way, peering carefully round to see that no lubras were about. They looked very solemn, and one of them was carrying something, wrapped up in paper-bark, that they evidently regarded as most important. As they came near, the man walking in front held his right hand before his face, with the forefinger crooked on the side of his nose. 'This is the sign always used by the natives to indicate anything that is Kumali or secret. We asked them to come up to the house and show it to us in a store-room where we kept our 


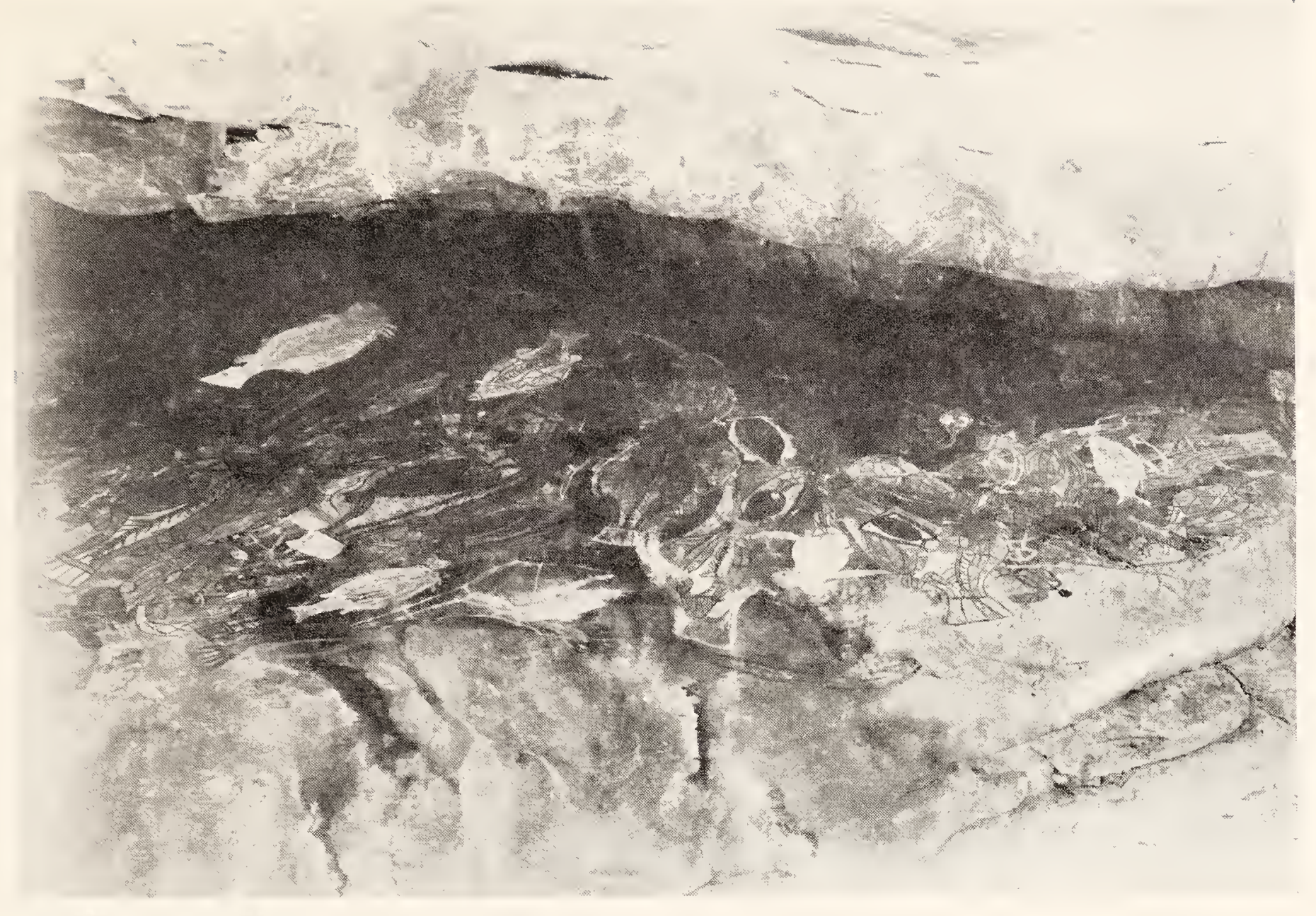

DR. MERVYN HOLMES.

FIG. 537.- ROCK DRAWINGS OF ANIMALS, MOSTLY FISHES, KAKADU TRIBE.

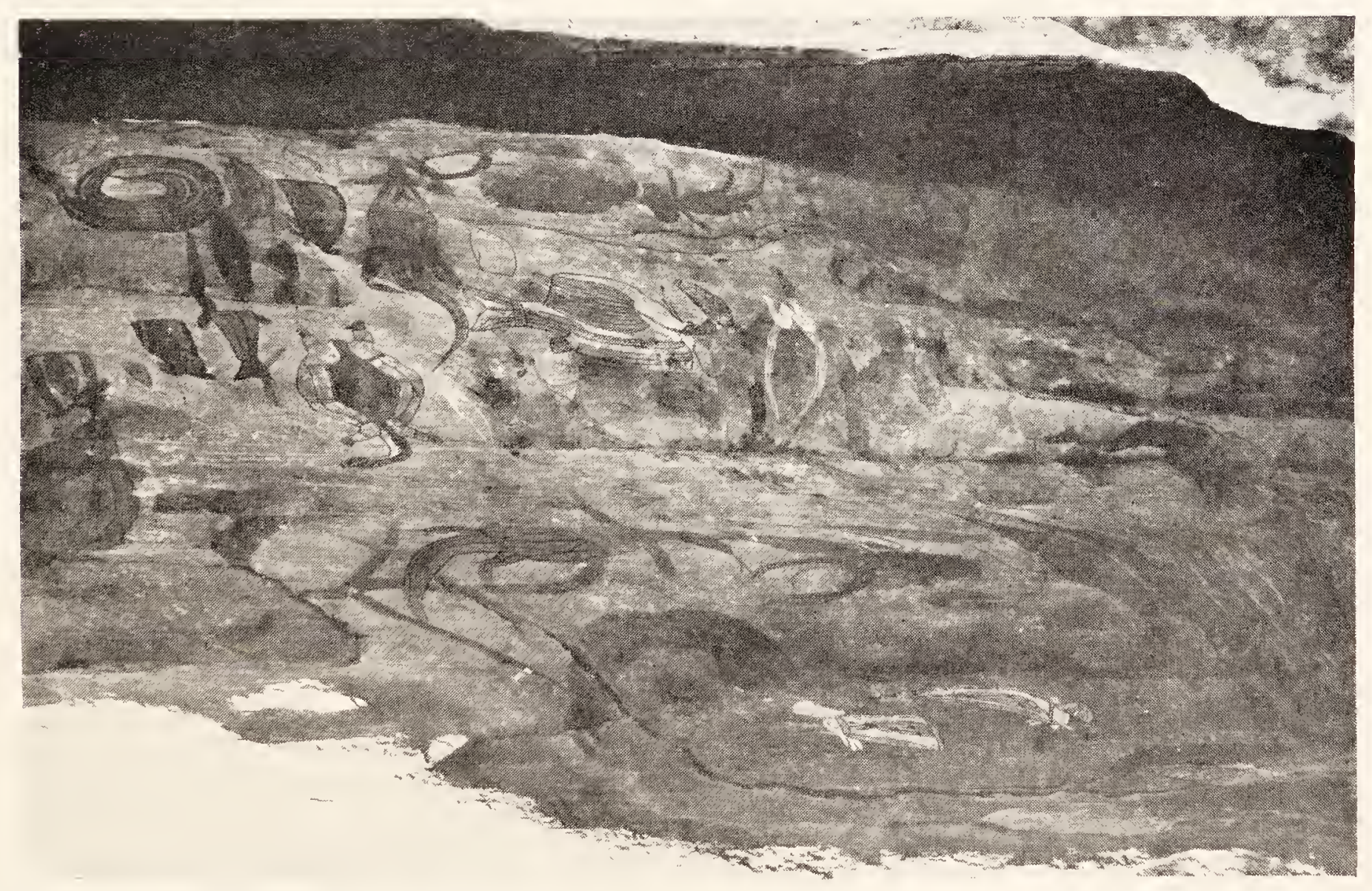

DR. MERVYN HOLMES.

FIG. 538.-ROCK DRAWINGS OF ANIMALS, FISIIES, TURTLES, LIZARDS AND SNAKES, KAKADU TRIBE. 


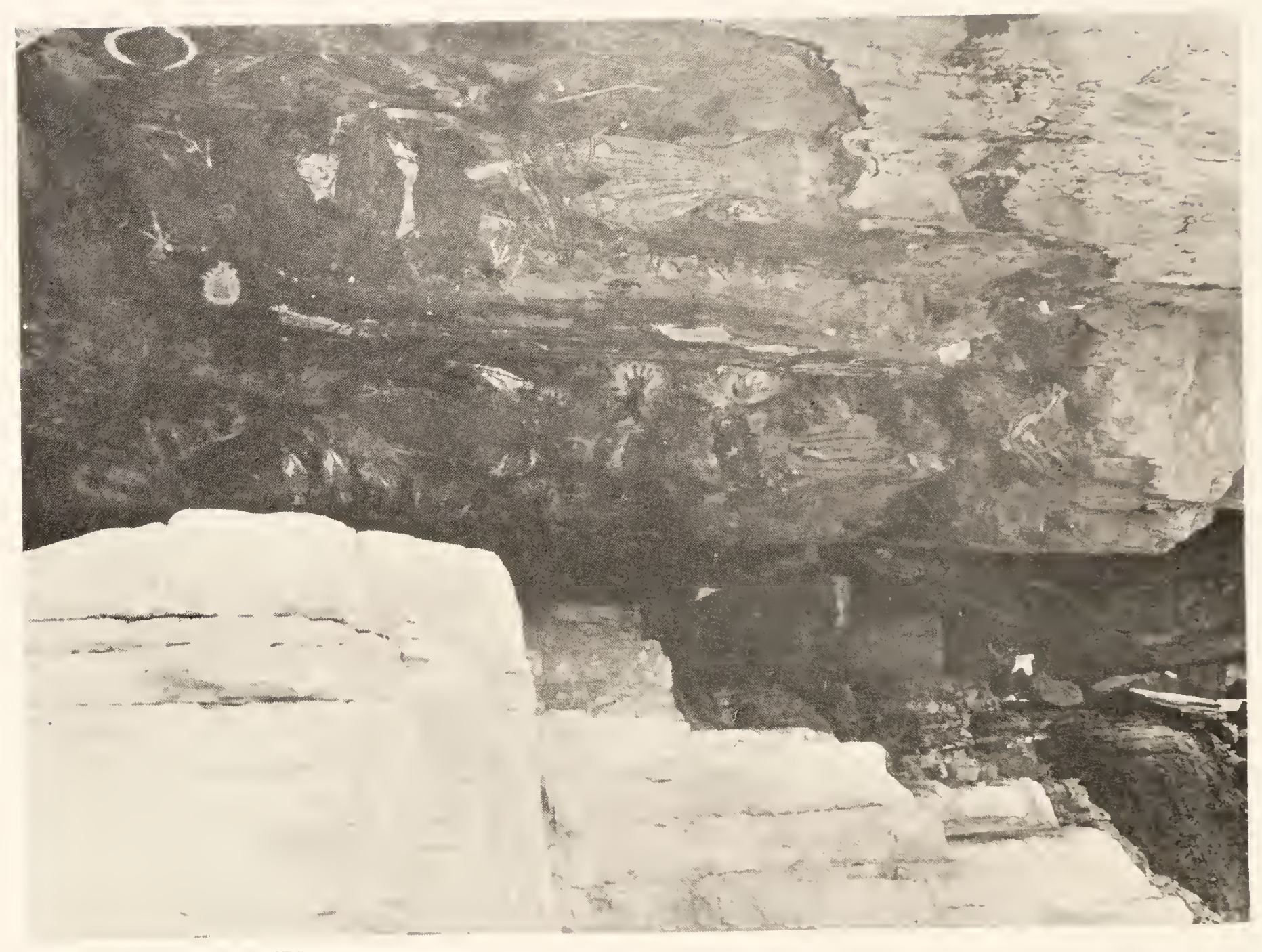

DR. MERVYN HOLMES.

FIG. 539.- ROCK DRAWINGS INCLUHING THE “ RED HAND, “ KAKAHL TRIBE. 
collection and where no one could see what we were doing. First of all we had to go on ahead and see that Mrs. Cahill and her niece went right away to the far side of the house. Then, with the three natives with whom we had been working, they came up in solemn procession to the house, where two of them mounted guard outside to see that no uninitiated person or woman came near. When all was safe, we went into the room and the parcel was opened out, very slowly and gravely, wrapper after wrapper being taken off, until at length we saw a forked stick (Fig. 545, No. 9). It measured four feet six inches in length. The fork was about one foot three inches long, the prongs arising from a flattened part, elliptical in section, about five inches in length by three in width, pierced by two elongated holes; behind this the main handle narrowed down and became gradually circular in section until it ended in a blunt point. The whole surface had been coloured red and then, except for the ends of the prongs and the handle, covered with white cross-hatched lines and spots. Each of the two holes had a tassel of white and black feathers threaded through it, and, judging by the structure of the other sticks that we saw later, were evidently the modifications of former eyes, the prongs representing jaws. It was supposed to represent a fish called Fimmidauappa.

The first object of this kind that we had seen was a curiously marked stone that we had come across by chance and could then find out nothing about except that in some way it was sacred. This was the first time that we heard anything definite about objects such as this stone and the stick that they had now brought in to show us. We should never have known about them had not the natives decided to tell us and let us into the secret. They are the most Kumali things that the Kakadu possess and are connected with a special ceremony called Muraian, which, as we now learned, is really the final initiation ceremony.

VOL. II. 


\section{WANDERINGS IN WILD AUSTRALIA cH.}

Fuly 26th.-Yesterday we sent out some lubras to get some paper-bark or Ranken. It is the bark of a giant tea tree (Melaleuca leucodendron) and is very useful for wrapping things up. The bark is formed of a thick series of layers, each separate one as thin as note-paper and beautifully soft but tough. These can be peeled off in strips several feet long, if necessary, and are used just as we use brown paper. Also, the natives wrap themselves up in them to keep warm during the cold nights. To-day we saw a quaint-looking procession coming up to the homestead, consisting of five lubras walking in single file, one behind the other, the oldest in the lead and the youngest at the tail end, each of them carrying on her head a great cylindrical bundle tied up with Banyan-fibre string and proportionate in size to that of its bearer. The general effect of them, seen in the distance, was so remarkably like that of the native drawings of human figures, that one realised at once how, in these simple outline sketches, they had caught the essential features. Each of the four elder lubras received a stick of tobacco and the youngest half a stick. Their fondness for tobacco is amazing. I could not find that these far northern natives had any home-made narcotic, equivalent to the Pituri of the south, but they eagerly fasten on to the slightest shred of white man's tobacco. One day I happened to throw away the end of a cigarette, close beside where Mrs. Cahill's three household assistants were seated, enjoying a talk. It was at once picked up and each of the three had a few very comfortable whiffs from it. When next one of them saw me, which was not often to be done, with a cigarette, she came up to me and said, quietly, so that no one else could hear, "Boss." Wondering what she wanted I said, "Ameina," that is, "What is it?" and she whispered, "Suppose you no want 'em that smoke-em-end, Boss, you give it longa me." The station natives have a word, Kuluru, that they are constantly using. It means a little bit of 


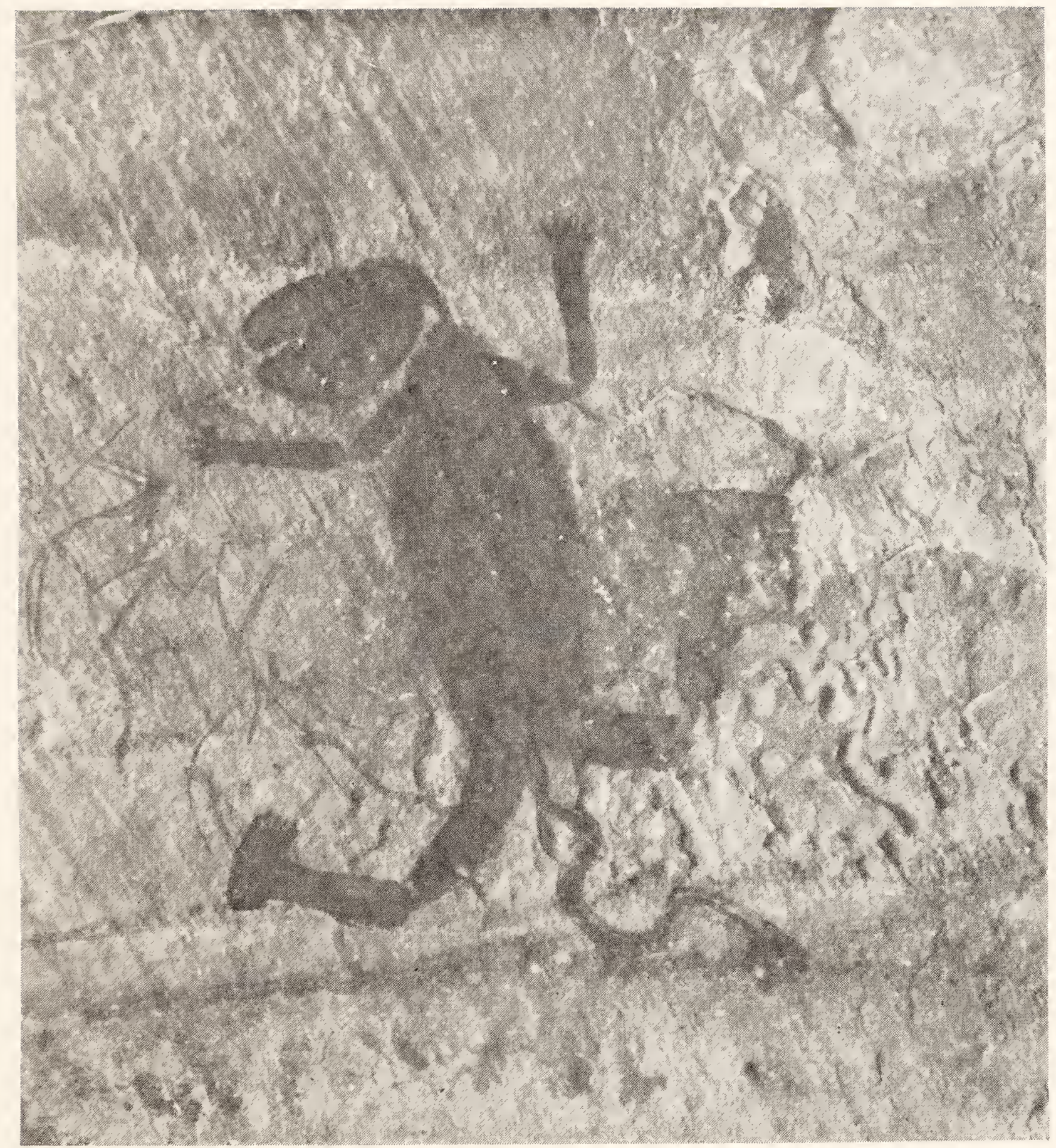

DR. MERVYN HOLMES.

FIG. 54O.-ROCK DRAWING OF A GNOME, GEIMBIO TRIBE.

The twisted tail-like line under the legs and the irregular dark lines have nothing to do with the drawing. 


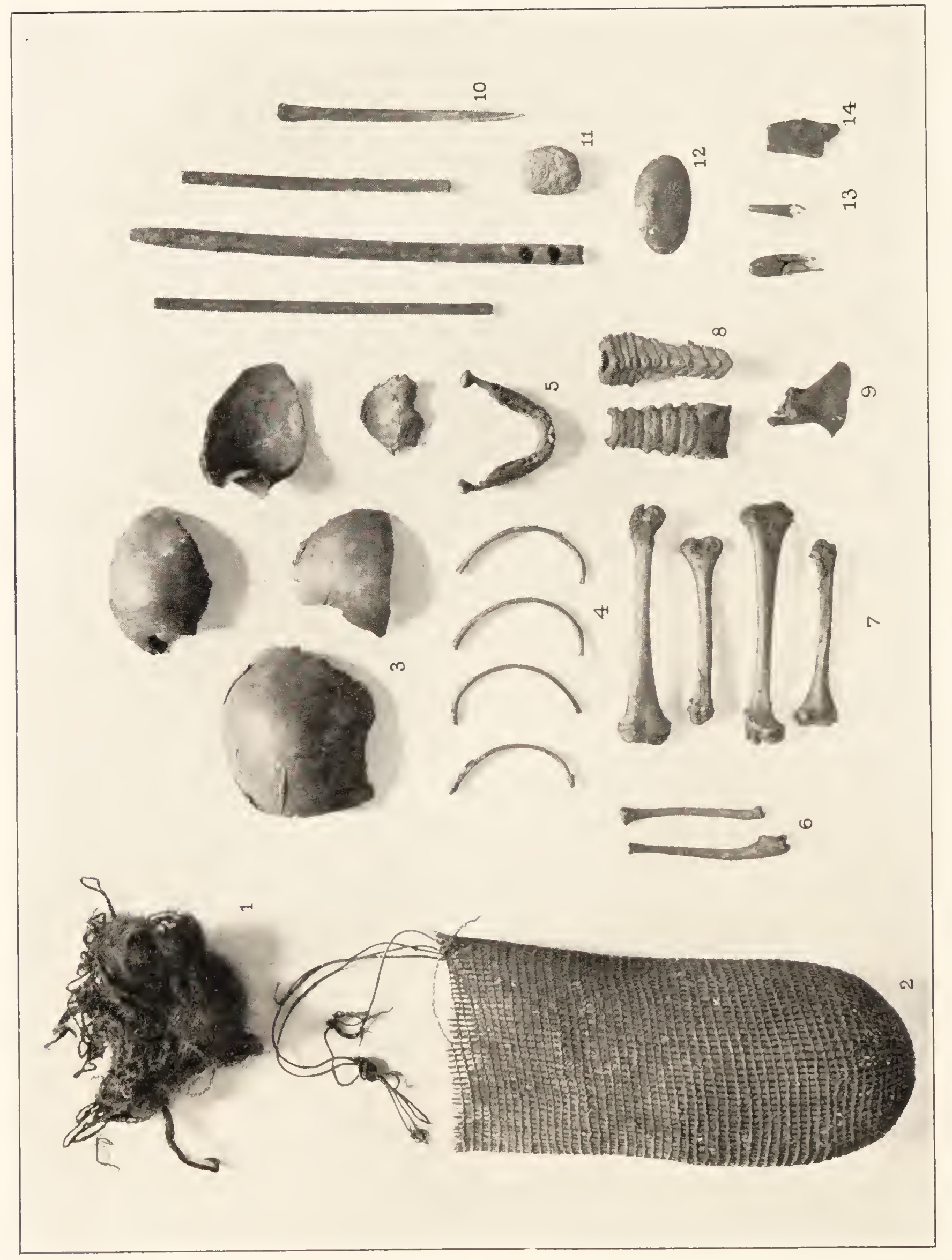

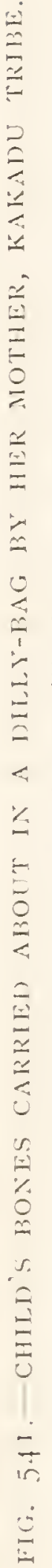


tobacco, for which they ask whenever there is any possible excuse for doing so. Any child of four or five years and upwards smokes whenever he or she gets the chance. I was out one morning looking at a mob of horses in the yard, when a little fellow named Butcha, not more than eight years old, who works with the stockmen, who of course are black boys, sidled up to me in a confidential kind of way and said interrogatively, "You give it me pipe, Boss?" All that he had been able to do, so far, was to enjoy periodical puffs from the pipes of his elders. When he had one of his own, his look of supreme pride was more than ample repayment for the price of the pipe. He was delightfully naive. Most times he wears nothing but a small, old straw hat that Mrs. Cahill once gave him and of which he is very proud. When he goes out riding, which he never loses the chance of doing, as a kind of groom-in-waiting to Mrs. Cahill and her niece, he always dons his hat and a tiny suit that once was white. This afternoon, when thus employed, he seized upon the opportunity of a quiet whisper to Miss Mudford, in his usual confidential tone, "You think it me good-looking fella, longa this hat?"

Fuly 27 th to 3 I st.-We gave the natives and ourselves a few days' spell, so far as anthropological work was concerned, except that we had a few hours every now and then with them getting information on different matters, learning something more especially about the Muraian. They were bringing in a number of sacred sticks and stones in preparation for a special ceremony that they were going to perform in which these are to be used. Apart from this, I spent all the time skinning birds and animals. Every evening, in our mosquito-proof tent, Mr. and Mrs. Cahill and myself were busy and the collection was growing apace. While we had been working with the natives we had sent out one boy to a special water-hole where Jabirus were to be had. There were two or three fine old ones who used to stalk about 


\section{WANDERINGS IN WILD AUSTRALIA сн.}

gravely every day on the banks of the lagoon opposite to the homestead, but we gave orders that they were not to be interfered with, in fact they were fortunately very wary. The Museum in Melbourne was, however, much in want of some of the birds that could be secured here, so I had to take the chance of getting them while I could. If I did not get them, probably the natives would and their beautiful skins would be lost. Late one evening the boy brought a Jabiru in. Its white feathers were rather stained, but it was quite fresh and in splendid plumage, so I set to work and washed it as carefully as I could, which took two hours. It was a beautiful male bird, standing four feet high, with a lovely, coppery-coloured crown to his head, long, metallic blue and green neck and bright red legs. I started work on him at Io a.m., but it was not till 3.30 p.m. that he was carefully wrapped up and stowed away to dry on the rack, out of reach of ants. The hardest birds to make skins of that I came across-speaking, of course, as the veriest amateur with only the smallest and, even that, sporadic experience, at long intervals of time-are the Jabiru with its long neck, the black cockatoo with its big head and beak, and the greasy, pigmy goose, whose feathers come out more easily than any of the many birds that I tried my prentice hand on, more easily even than those of some of the doves and pigeons. By way of contrast to the Jabiru, I had to set to work at once on a little so-called, crimson-backed warbler (Malurus dorsalis), with a body, when the skin came off, no bigger than a good-sized thumb-nail. It is a velvety black colour all over, except the long wing feathers that are dark brown, and the back and shoulders that are a rich, cardinal red.

Two more Jabirus came in, but our greatest prize which, after weeks of searching for it amongst the Ranges, the boys brought in, was a black kangaroo. Cahill had seen one or two of these in the distance when riding amongst the hills, 
and it was quite clear that they were not the ordinary Euro, so I was very anxious to secure a specimen. Whilst we were at lunch one day some natives came running up from their camp to tell us that they had seen two boys, a long way off on the hills, carrying a big black thing on a pole. When they came into camp we saw that it was undoubtedly what we were in search of. The boys were nearly as pleased with themselves as we were with them, and they were rewarded with a supply of tobacco, flour, tea and sugar sufficient to keep themselves and their families cheerful for some time. It really deserved the name of black kangaroo. It was, at least, darker than the darkest Tasmanian opossum and stood between four and five feet high. Its legs, arms and tail are dead black, but the body has a slightly warmer tint. The hair is not so thick as the ordinary kangaroo and its arms and legs are very strong and stout, the latter shorter and the former longer than usual. It uses them both when climbing amongst the stones and rocks on the Ranges and never seems to come down on to the plain country. The female, as we found out later, is much less dark in colour, more like the ordinary Euro, and we also got a small immature one, about a foot high, with black hands and feet, that I think must be a young male. It was quite fresh and, though a little the worse for wear, I was able to make at least a fairly good skin of it and preserved the skeleton. The natives say that it lives in rock shelters, and they either smoke it out or lie in wait for it at water-holes, but it is very shy and, as they say, can smell them a long way off.

One of the boys, who was out after birds, amused us, when he came in and asked for tucker, saying that he was very hungry. As a general rule we only give them tobacco, for the simple reason that they can catch game galore and their lubras provide them with plenty of Wuridjonga, that is, Lily plant "tuck-out," roots and stems and cakes made from the seeds. When asked how much he had eaten that 


\section{WANDERINGS IN WILD AUSTRALIA сн.}

day while out in the bush - it was then late afternoon-he told us "only little fella jam," and when we made closer inquiries, we found that his "little fella jam" (jam means food generally) consisted of one whole palmated goose, which is fully three-quarters of the size of our ordinary goose, two turtles, the leg of a kangaroo and a lizard, which latter he said, regretfully, was only "piccaninny fella" about, as he showed us with his hands, two feet long. The amount that a native will eat is astonishing. A day or two ago, after disposing of their usual generous midday meal, I saw five station boys polish off two big Echidnas, just as if they were little titbits to finish off with.

Jabirus and other birds kept me busy, with now and then interludes, when some of the old men brought in special Muraian things. One afternoon an old man came up to us mysteriously, with his finger crooked on his nose, and asked us to go down to the lagoon because he wanted to show us something. Of course we went with him, but found that what he wished us to see was on the other side of the water and that he proposed to take us across in his dug-out. As it was an exceedingly cranky craft, we suggested that it would be better for him to go and bring it to us. It was the upper end of the lagoon and the water was shallow, so he stood up, "poling" himself across and using his foot as a bailer in a very ingenious and effective way. Also every time he put his pole in, he deliberately jerked a splash of water ahead of him, but he came back safely with two friends and a sacred stone and stick, wrapped up as usual in fold after fold of paper-bark.

During this week the men have been continually bringing in their sacred sticks and stones, and I am hoping that they will let me have some of them. They bring just a few at a time to show us, taking always the most elaborate precautions lest any woman or child or even a young man was in sight. Before coming in they halted under the shelter 
of the bushes and reconnoitred the place, to make quite sure they were safe. When a man saw us, he always put his finger to his nose, the sign that he had something Kumali. Whilst showing them to us they only spoke in whispers, and so real was it to them that we, without thinking about it, instinctively did the same.

Every now and then we used to walk round the native camps, collecting things. You have a look through two or three wurlies, barter for a few things and think there is nothing else, but a day or two later you will probably find the store replenished. Their cane and string-plaited dillybags must take a long time to make, but they never seem to run short of them, though, unfortunately, they are already too fond of using white man's material in making and especially in decorating them. They actually prefer little tawdry tags of coloured calico or wool to their own beautifully made string and feather ornaments. Though they have not discovered the pigment for themselves, all Australian natives seem to have a wonderful liking for blue, especially, and unfortunately, Reckitt's blue. This, however, has not as yet (I 9 I 2) penetrated as far as Oenpelli and I hope it never will do. One afternoon, walking along by the side of the lagoon, as we usually did when the sun was getting low and it was comparatively cool, we met two women and their piccaninnies going back to camp laden with lily roots and seeds. One of them was carrying a small dilly-bag hung round her neck, so I offered half a stick of tobaccojust three farthings-for it. She agreed to the exchange most cheerfully. I was carrying two or three other things at the same time and did not notice, until looking over my afternoon's collection when we got home, that the dilly-bag contained anything special. It was only a small bag, roughly nine inches long and four wide, but it contained, as I found out afterwards, the greater number of the bones of one of her children, who had evidently died when it was very young 
(Fig. 54I). The lubra's blackfellow came to interview me next day and said that he was very angry, because she ought not to have parted with them. It was evidently not a matter of concern to him from the point of view of outraged parental feelings; his only trouble was that, according to tribal custom, she ought to have gone on carrying them for some time longer. This dereliction of duty on the wife's part was quite satisfactorily atoned for by the gift of a whole stick of tobacco for himself, so that, in the end, at the cost of twopence farthing, all three of us were perfectly satisfied. In addition to the bones, the bag contained all the personal belongings of the woman, except her larger dilly-bag, digging-stick and mat. They comprised (I) a small mass of her own hair that had been cut off preparatory to being made into string, (2) two pairs of small fire-sticks, (3) two kangaroo teeth embedded in wax, (4) two loose kangaroo incisor teeth, (5) a small lump of red ochre, (6) a small pounding stone, (7) a bone awl, (8) one valve of a freshwater mussel used for cutting and scraping.

August Ist.-This morning we saw the Muraian ceremonies performed. A special ground close by the edge of the lagoon had been cleared and surrounded with a brake of bushes, so that no one could see what was taking place. First of all the women and children were solemnly mustered in camp and marched off, under the charge of an ancient blackfellow, to a safe distance. This must have added to their curiosity and at the same time made them feel how vastly inferior they were to the men. The men then gathered on the ceremonial ground. The sticks and stones had been brought in, each one in the charge of some special individual, and placed on the ground to one side of the enclosed space. Only old men were present. If any young men are present who have not seen the Muraian before, the oldest man there says to him, Koregora, Muraian, kaiano jeri, balera, yadimma najei kubari kudanuji korto, that 
is, "Look (these are) Muraian, do not quarrel, (or) later on all your fingers will swell up."

We had no idea what the performance was going to be like and stood expectantly to one side, close to two men, one of whom was vigorously clanging two sticks together, the other clapping his hands. First of all a stick representing a fish called fimidauappa was brought in by the owner. He came from behind the bushes, creeping along with it in his hands, followed by the other men. On the ground he stood in the middle, all the other men circling round and round him, while he pointed the stick at each of them. At first they sang

\section{"Ka kai ka ka le}

Ka lulla le,"

and, after dancing for some time, they all extended their arms towards the stick, time after time, drawing them back rapidly and yelling "Brau! Brau!" which means, "Give! Give!" They were supposed to be demanding a plentiful supply of the fish Fimidauappa.

Finally the man fixed the stick upright in the ground and they all danced round and round it, pretending to rub their hands up and down it, after which they rubbed themselves. Then they retired behind the bushes. After a short time they came on again, this time bringing several sticks and, in addition, rushing round the other men who stood to one side (Figs. 546, 547, 548). One after another the sticks were fixed upright in the ground and stones placed beside them, until there were twenty or more there. At one stage, when only a few had been brought in, a special onethe Muraian itself-was produced. The owner carrying it tumbled down on the ground and was followed by the others, and they all wriggled and rolled about in the most grotesque way (Fig. 548). The Muraian was in the form of a slightly curved slab of wood with the representation of a head at one 
end (Fig. 543 , No. I), a very short tail and two little projections on each side, representing limbs. It was supposed to be a turtle, to which it certainly showed quite enough resemblance to be easily recognisable, and the rolling about of the men was in imitation of the movements of the animal itself.

When all the sticks and stones, many of them elaborately decorated, had been brought in, they were arranged in a circle and a final dance was held, the men rushing round and round them, stooping every now and then to thrust out, and draw back, their arms, with hands extended, while they yelled "Brau! Brau!" "Give! Give!" It was, as the natives told us afterwards, a request, in fact a demand, to the various animals and plants, represented by the sticks and stones, to provide them with these same animals and plants that form their food supply.

I was very interested in this ceremony, because it was clearly equivalent, fundamentally, to the Mbanbiuma or Intichiuma ceremonies that Gillen and myself had seen and described first of all in the Arunta. In the latter tribe the men of each totem group, kangaroo, emu, snake, lizard and so forth, perform by themselves, separately, a ceremony to increase the supply of their totem. The mere performance of this is supposed to bring about the desired result. In the Kakadu the men of different totems join together. The men of the Central tribes do not make anything by way of a personal appeal to any object that is supposed to represent the totem animal or plant, whereas amongst the Kakadu this aspect is most striking. By their insistent and fierce cry of "Brau! Brau!" "Give! Give!" they showed clearly that they were directly asking, even demanding, the animals and plants represented by the sticks and stones to provide them with food. Not only was this so, but the way in which the men danced round the ceremonial objects or rolled over on the ground, holding them tightly all the 
time in their hands, seemed to indicate clearly that, by doing so, they brought about some close connection between themselves and the totem animals and plants represented by the sacred sticks and stones. All that the men could tell us was that their old ancestors had always performed the ceremonies and that, after they had done so, the animals and plants had always multiplied.

We had waited until after the ceremony was over and we had seen it to question the natives in detail about Muraian matters, so this afternoon we started to work to find out what we could. For the next few days I was kept busy, not only with this, but in gathering together, labelling and packing up our collections, because the time had come to get back again to Darwin.

The old men told us that the first of the Muraian objects was found, very long ago, by an old ancestor called Kulbaran. He saw something strange in the form of a turtle moving about in the water, caught it and found that it was Muraian, or rather the turtle told him so. The turtle then described the ceremonies and taught Kulbaran how to perform them and how to make the sacred sticks and stones. He told Kulbaran that they were Kumali widjeru, very sacred; that the old men might eat Muraian animals, but the young ones must not.

Kulbaran, when first he saw the Muraian, said, Ngeinyimma ameina? which means literally "You, what?" in other words, "What are you?" or "Who are you?" Muraian replied, Ngainma Muraian, "I am Muraian"; Ngainma jerapo mubilabilla balera, "I dance corrobboree later on," and then he danced, lifting up his legs and arms, singing, "Yai! Yai!" The old man Kulbaran said, Onje mubilabilla yama, "Which way another dance?" or "Is there any other dance?" and Muraian showed him more. He said that all the dances were Kumali.

The history of every stick and stone was known. The 


\section{WANDERINGS IN WILD AUSTRALIA сн.}

first stone that we came across is a very good example. It was a small one, measuring four inches in length and two and a half in diameter, and was called Iwaija kopereipi, or Emu egg, and was sufficiently like an egg in shape to suggest the name (Fig. 544, No. 7). The general surface had been red-ochred, but a yellow band, not seen in the figure, ran round it, and two bands, each with a central row of white spots, ran half-way up each side. The remainder of the stone was covered with close-set, cross-hatched, white lines. Its history was as follows. Long ago, for the egg has now passed through the hands of nine old men, one after the other, an old ancestor, named Nauundel, was out in the bush, searching for sugar-bag, when he heard a strange, hissing sound. He looked round and saw an egg with a snake coiled round it. It was the hissing of the snake that Nauundel heard. The snake was one that is now called Kintjilbara. Nauundel got a stick and poked the snake, which by and by went away. He did not try to injure it. The egg stood up on end and Nauundel lifted it and tied it up in paper-bark. Then he cut some grass, laid it in his bag and put the egg on top of it, saying, "This is a Muraian stone all right; it is mine all right; I will put it in my bag." All night he heard the egg saying "Prr, Prr," as it moved about restlessly, indeed it moved about so much that it tossed all the grass out of the bag, and, as it would not keep still, and Nauundel was afraid of losing it, he placed the mouth of the bag near the fire and stupefied it with smoke.

Only Murabulba, that is, very old men, are allowed to see the egg. When its present possessor, a man named Narlinda, wishes to show it during the Muraian ceremonies, if any young men are present, he says to them, "Morpiu, yapu, ge," which means, "Food, go, all "-in other words, "All of you go out into the bush and collect food." The young men know that this means there is something they 


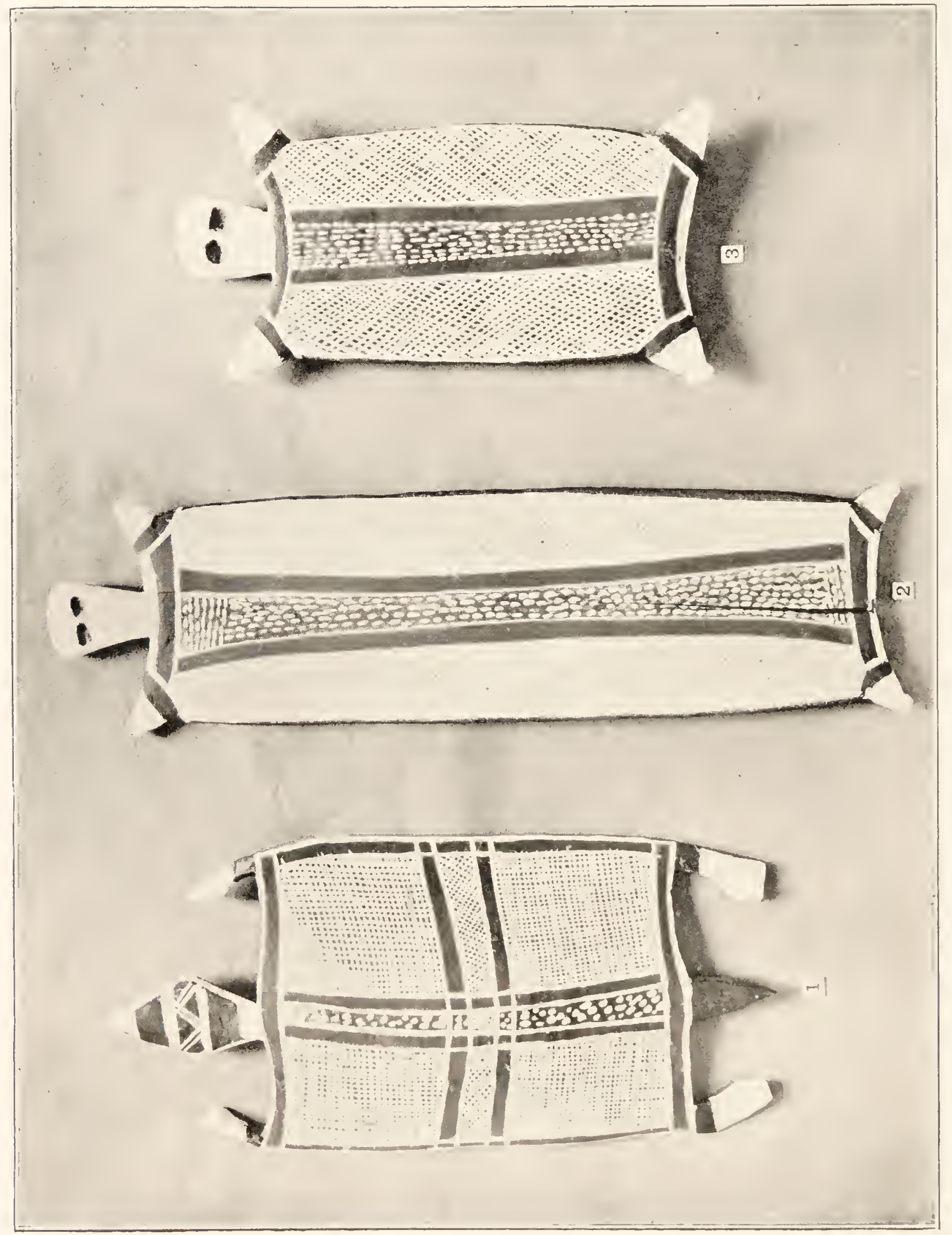


must not see and away they go. He says nothing to the other men but, as Narlinda told us, they know what he means and nudge one another. When the young men are far away, Narlinda sits down by himself, a little distance apart from the old men, unwraps the bark and calls them up. They come with their heads bowed down. Narlinda tells them to come near and not be frightened, because it will not "growl," that is, it will not be angry or harm them.

In addition to its function as an Intichiuma ceremony, the Muraian serves also as a finale to the initiation ceremonies, much as the Engwura does in the Arunta. When a man has passed through it, he receives the status of Lekerungen, just as, in the Arunta, a man is called Urliara after the Engwura. It also serves to enhance the importance of the old men and is very serviceable to them, because only real old men can eat freely of Muraian animals, which include the choicest foods. No young man, under any pretext, may touch any Muraian caught by an old man, but he must either hand any such animal that he gets over to the old men, or at least give them a good share of it. They have a curious belief that no men who have seen the Muraian must allow a dog to eat any remnant of his food; if he does so, then his arms and legs will become very sore.

The history of every stick and stone and the names of all individuals who have possessed them in succession is perfectly well known. They usually descend from father to son or may be given to a younger brother apparently irrespective of totems. In the case of an Eribinjori, or crocodile stick, one of the most important ones, that measures just five feet in length (Fig. 542, No. IO), tradition records the names of nineteen men who have owned it, one after the other. The original one was owned, long ago, by Kulbaran, who, when he became very old and unable to perform properly, gave it to his younger brother Midjail. Since then it has descended through seventeen men to its present owner, 
Miniamaka, who recently inherited it from a very old man, his father, Yiraman. This gives us, apart from the present holder, eighteen possessors, one after the other. So far as we could tell, the present owners of the Muraian objects varied in age from about thirty-five to sixty-five so that, if we take the average time of owning the Muraian stick or stone, in each individual case, as twenty years, which is probably below the mark, then this crocodile stick, or rather the earliest one known, must, according to tradition, have been made three hundred and sixty years ago. The sticks and stones are painted afresh for each ceremony. I watched one of them being redecorated. It was a serious matter and, whilst it was in progress, grave consultations were held by three old men in regard to details of the design. The sticks, apart from the designs on them, which become rubbed by handling, were all in a state of perfect preservation. They are hidden away in secret places in the Ranges, and if, as sometimes happen, they are seriously damaged by boring insects, which are very destructive in this climate, they are replaced by new ones that are exact replicas of the originals. Many of the Arunta Churinga are evidently very old and worn by constant rubbing and, so far as we know, under no circumstances are the old ones renewed. If they break under the pressure of periodic rubbing with grease and red ochre, the parts are carefully bound together with sinew; the Kakadu Muraian objects always look well preserved, at least they do when they are in actual use.

In the case of many of both the stones and sticks there were several that were representative of the same totemic animals and plants, and also distinct ones representing males, females and eggs of the one animal.

The natives brought in between seventy and eighty altogether. I was keenly anxious to secure these as a record of the beliefs of a tribe that must inevitably become profoundly modified in the course of only a very few short 


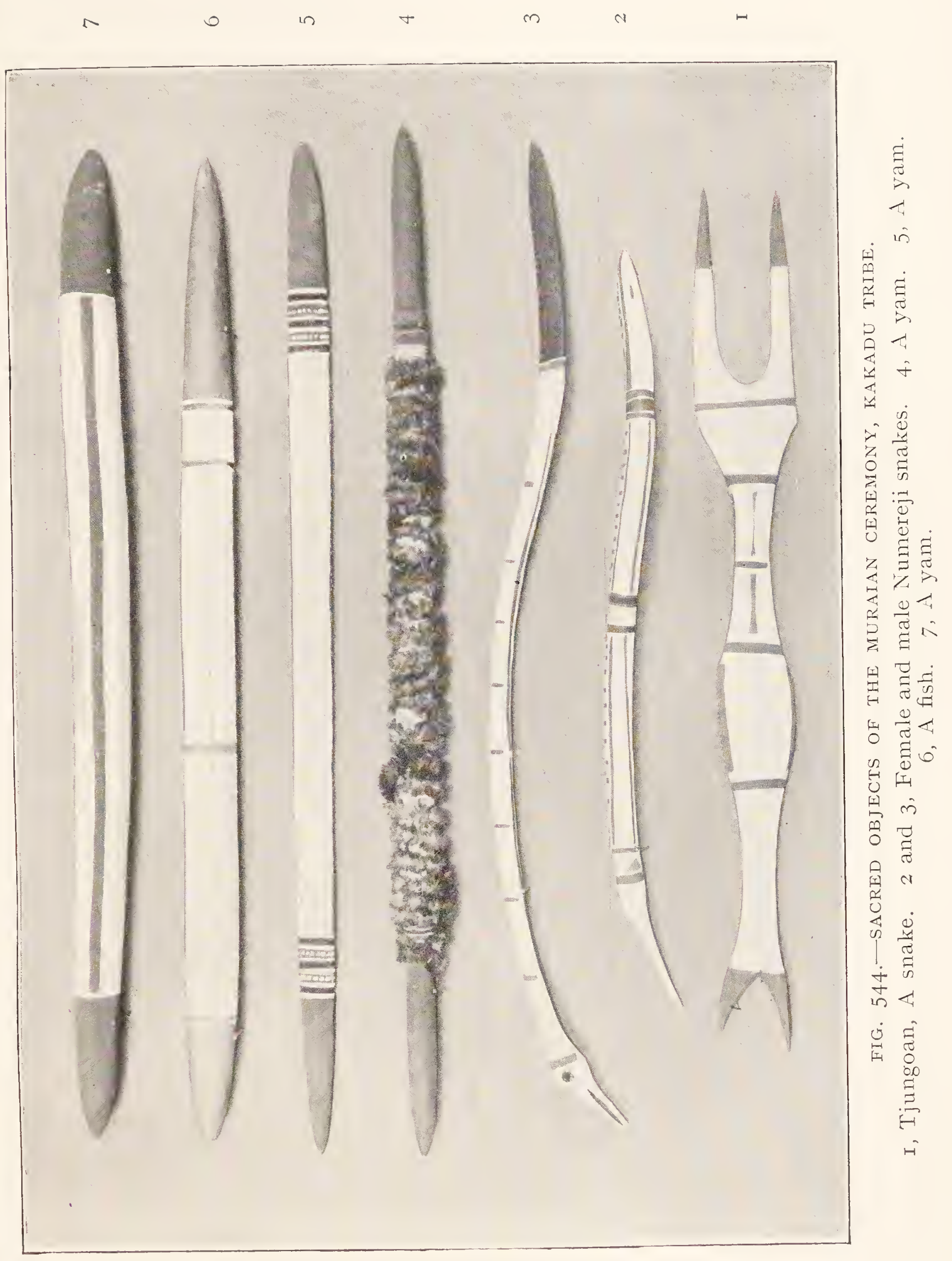




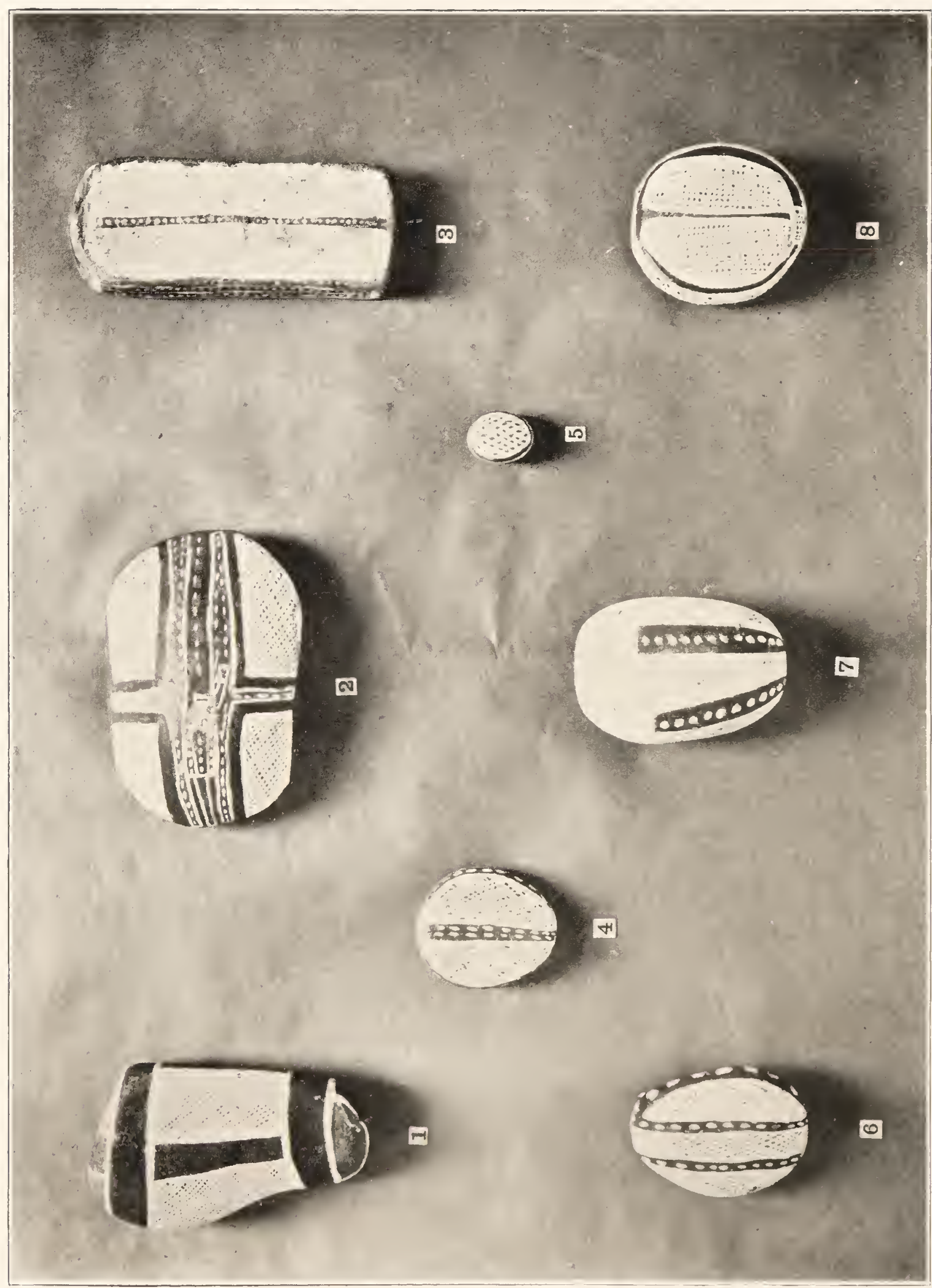

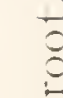

三

50

$=0$

$\bar{\xi}$

$\div$

$\frac{5}{\vdots}$

$\therefore=$

z

.

兴

产

乙

$=$

我

$z$

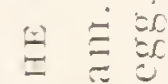

5

-

$\therefore$

ए

突

至

는

$\cong$

U.

i

in

¿을

空 
years, when all such ceremonies as the Muraian will be forgotten and neglected. The wooden ones would rapidly decay and the stone ones lose the designs that alone distinguished them from small sandstone boulders of no significance. Years ago, during the Engwura of the Arunta tribe, Gillen and myself had seen hundreds of Churinga used, but, though we could have had them, we refrained from doing so, because we realised what they meant to the natives; in fact we actually returned to them some that they gave us. Time went by, the Arunta rapidly degenerated, the old men died out, the younger ones ceased to care about such things, and it was then rather mortifying to find that many of these same Churinga had been secured and sent to German and other Museums. The old men were much impressed with the fact that we were evidently as keenly interested in their beliefs as they themselves were, so, when Cahill told them that I was anxious to have them, in order to show the white people who lived far away what great men the Kakadu were, and that they would always be safely kept and no one allowed to touch or see them without my consent-I could not tell them that white lubras and children would see them - they held solemn consultations, and finally, to my great delight, decided to give me the whole series. Even after I had left they brought in some more for Cahill to send, so that I had no compunctions about taking them.

A representative series is illustrated in Plate XVI and Figs. 542, 543, 544, 545; those on Plate XVI serving to give a good idea of the nature of the colour decorations. From the point of view of form, the most interesting thing about them is that, whilst the majority are quite as conventionalised as the sacred sticks and stones of the Central tribes, some of them indicate, at least roughly, the nature of the animals they are supposed to represent. The turtles in Fig. 543 are remarkably suggestive of the animal, especially No. I, with a total length of sixteen inches and a width of 
seven and a half inches. It is supposed to represent the Muraian itself. Nos. 2 and 3 have lost their tails, but in both the two eyes are seen, whereas the head in No. I is more conventionalised in design. On Plate XVI, Fig. I represents a fish called Bararil. It is quite flat, two feet in greatest length and about five inches in greatest width. One end is evidently suggestive of a head, with an eye, and the other suggests a tail. Fig. 2, twenty-seven inches in length, is decidedly conventionalised, but there is something in its shape that suggests a bird, such as the Native Companion, which it is supposed to represent, flying through the air, with its long black head and neck extended straight in front; its body relatively small and its legs stretched out behind. Fig. 3 is interesting, when compared with those in Fig. 543 . Like them, it is supposed to represent a turtle. It is twentytwo inches in length with a distinctly concave, shield-like body, tapering rapidly to a tail; at the other end is a long neck and head. It was very suggestive of a palmated goose because of the length of the neck, but its owner was definite upon the point that it was a turtle, and he was the only person really able to tell what it was meant for. All the remaining objects on this Plate represent yams, to which, with the possible exception of Fig. 5, they have not the slightest resemblance. The figures on this Plate indicate the general colour scheme of all the sticks. Fig. 545, No. I, which measures forty-four inches long and about threequarters of an inch in diameter, represents a snake, called Tjungoan, to which it has not the slightest resemblance. Figs. 2 and 3 represent, respectively, a female and a male Numereji snake. Both of them may be regarded as suggestive of snakes in general, the gliding movement being indicated by the graceful curvature of the body. The male measures forty-seven inches in length and has a very distinct head with mouth and teeth and an eye with black pupil and red iris. There are cross bands of yellow on the 


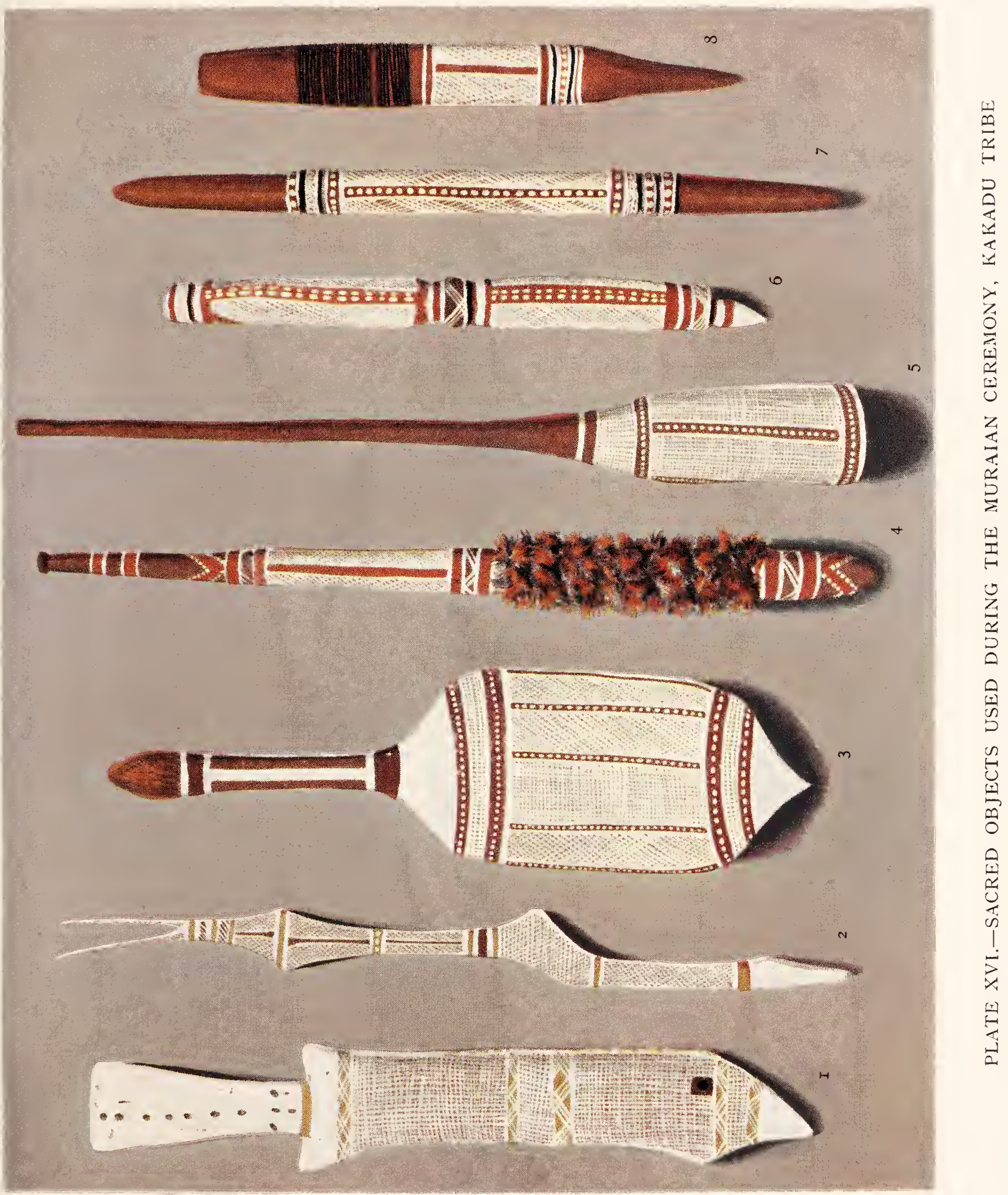



back, bands of light red along the under surface and the tail end in dark red. Fig. 4 represents a yam called Murlappa, and Fig. 5 another called Tjunara; Fig. 6 represents a fish, Bararil, and Fig. 7 a yam.

Fig. 542 represents an interesting series, all of which agree in two features, the presence of a very distinct fork at one end, the prongs of which clearly indicate two jaws and the clear indication of a head part. In most of them two eyes are shown, either in the form of holes pierced through the stick or of two white dots. In No. IO, which measures five feet in length, it is just possible that the double decoration immediately succeeding the fork represents the two sides of the head, each with one eye in the centre. One of these is drawn in black, the other pierced through the stick. Figs. 4 and 5 show the two sides of the same stick, which, unlike those of any other specimen, are differently decorated. It represents a spur-winged plover.

There were in all twenty-nine stones used during the ceremony, those shown in Fig. 545 being representative of all of them. They are all naturally shaped small boulders, or little flattened slabs of sandstone, and represent yams, to which they approximate in shape, or eggs of different animals. In most cases the stone has first of all been covered completely with red, but in some with yellow ochre, and then, just as in the case of the sticks, white cross lines and dots have been added. The more interesting ones are-Fig. 2, which represents a turtle's egg, Iwaija Kudjalinga, seven inches in length, the design in the centre suggesting an attempt to portray the animal with its head and front legs-it is flat on the under and convex on the upper surface; Fig. 3 is a curiously flat stone representing a yam, Gunumaramila; Fig. 4 is a lily root, Purijiliji; Fig. 5, the smallest of all the stones, is the egg of a wild turkey, Mundebendo; Fig. 6 is another kind of lily root, VOL. II. 


\section{WANDERINGS IN WILD AUSTRALIA $\mathrm{cH}$.}

Worki; Fig. 7 is the Iwaija Kopereipi, or emu egg, one of the earliest and most famous of the Muraian stones, and Fig. 8 is the Kulori yam that gives its name to one of the most important of the initiation ceremonies. These Muraian sticks and stones seem to be a peculiar feature of the Kakadu and allied tribes. They certainly extend as far eastwards as the Liverpool River. They are of interest as showing the way in which amongst these tribes ceremonial objects have possibly been developed. In the first instance, long ago, they may have been designed to represent, with fair accuracy, the salient features of some animal or plant. In a climate such as that of the far north of the Territory, no wooden objects last more than a comparatively short time, so that these Muraian objects must have been remade time after time. It is quite possible that, when they were thus remade, the artificer endeavoured to reproduce, not the actual form of the animal or plant, but that of the original sacred object, as he remembered it. It is well known how copies of original drawings, taken in succession, one after the other, become so modified in the course of a relatively small series that the last bears no resemblance to the original-it has become completely conventionalised. The Muraian objects may show us a series that has not yet become completely conventionalised, but is on the way to this, and that, in course of time, we might have had a series of sticks and stones that would have shown no more resemblance to the animals and plants whose names they bear than do the Churinga of the Arunta. There is, however, one important difference between the Muraian objects and the Churinga, so far as their significance is concerned. The latter are associated with individual human beings, the former, save in the one case of the original Muraian who was supposed to have been swimming about in the water, in the shape of a turtle, are always totemic animals or plants. They are very distinctly of this nature 


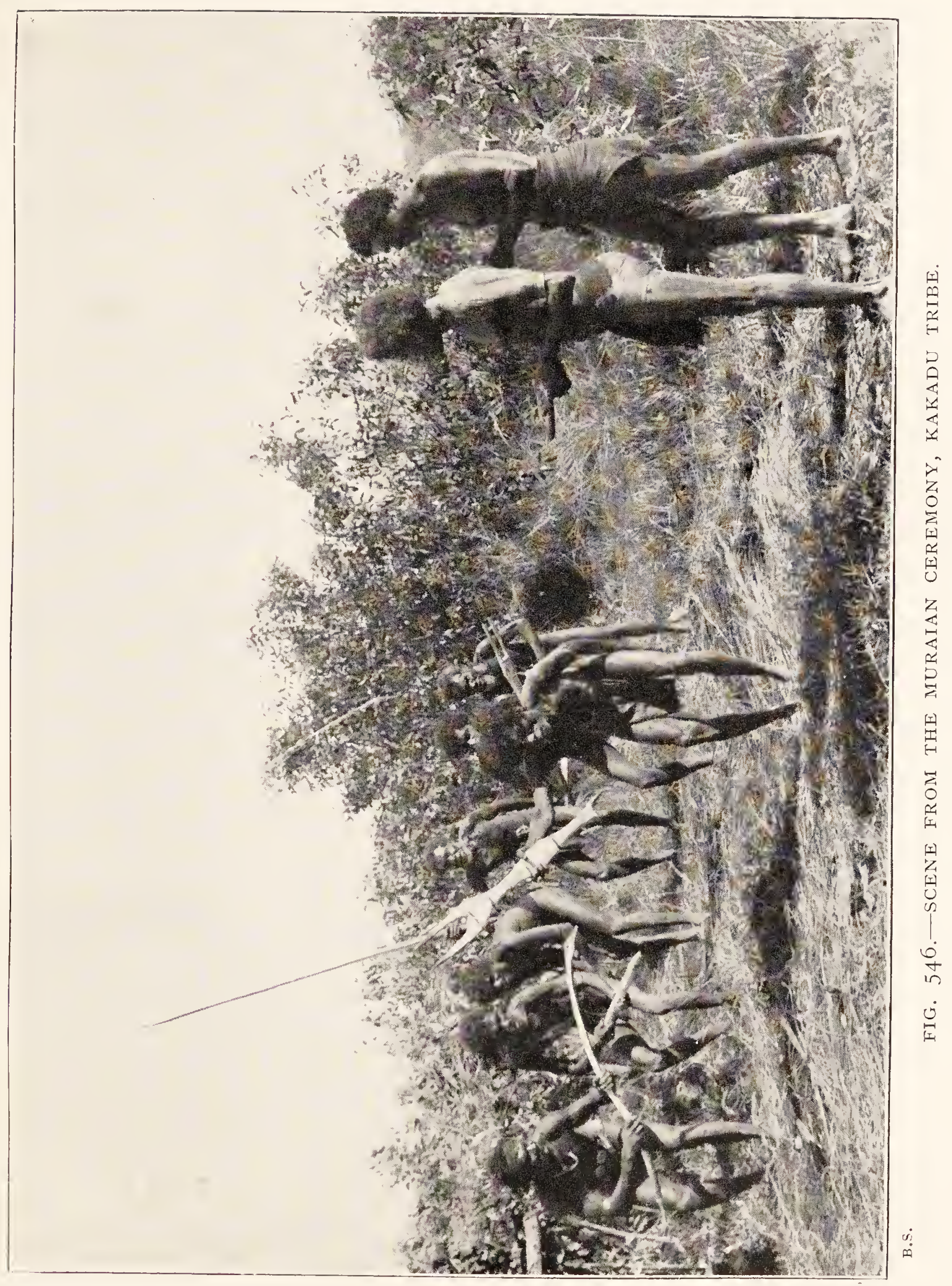




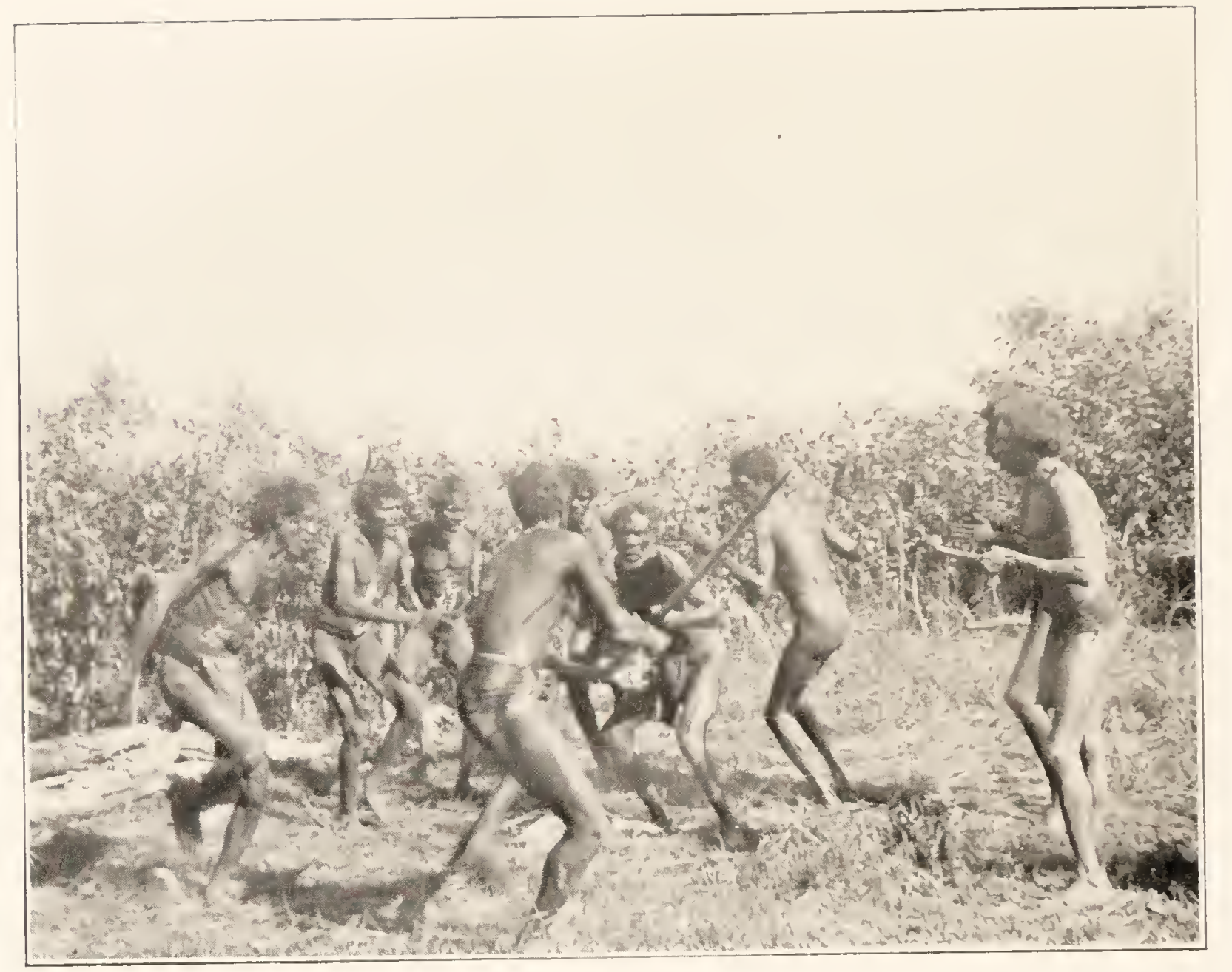

B.S.

FIG. 547. SCENE FROM THE MURAIAN CEREMONY, KAKADU TRIBE.

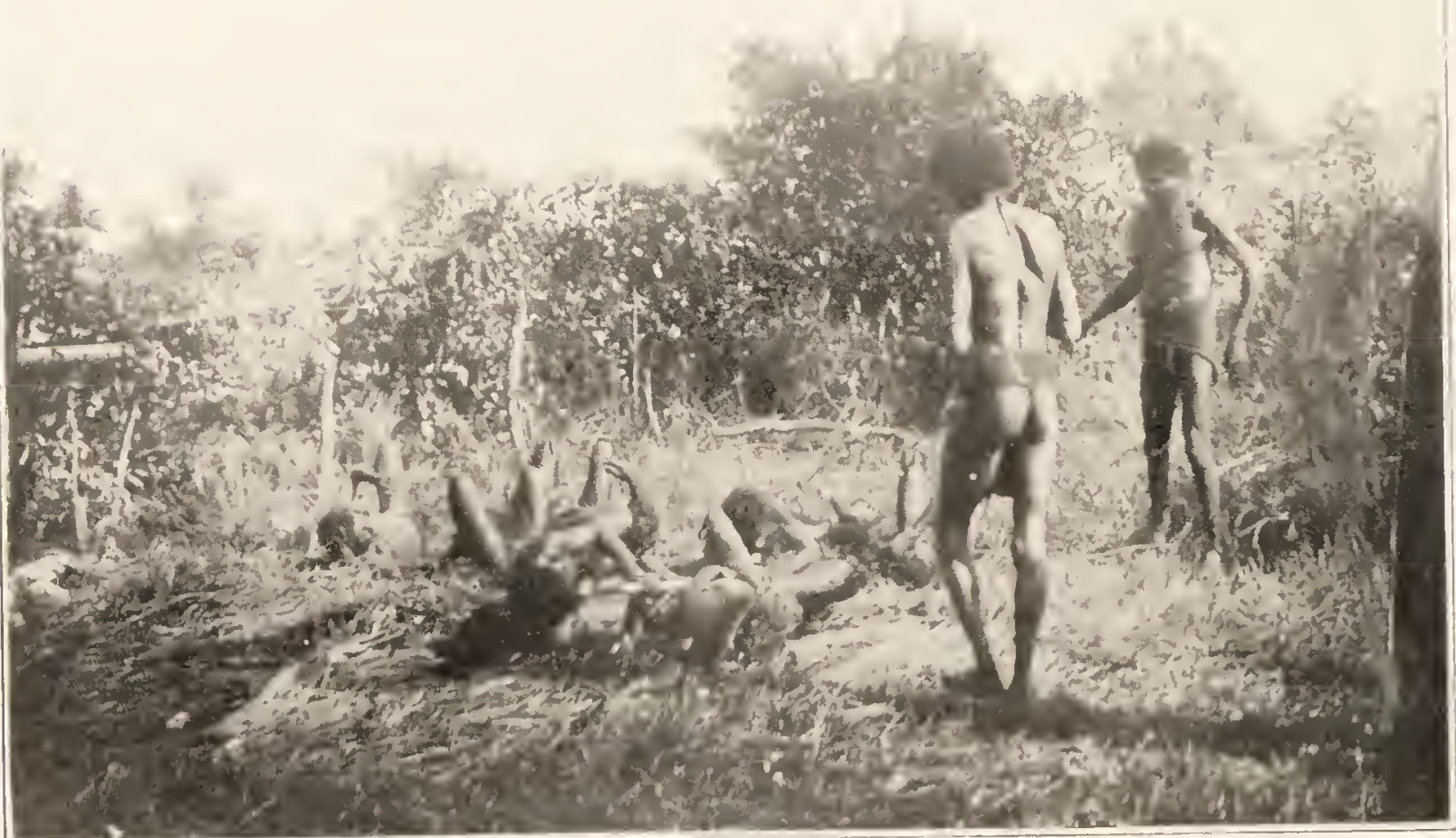

13.S.

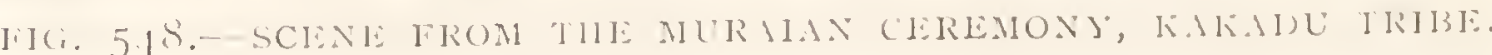


and thus differ markedly from the Churinga, with each one of which a human being's spirit part is intimately associated. The Muraian of the Kakadu represents the essence, as it were, of the totemic animal or plant in just the same way in which the Churinga of the Arunta represent the essence of the human totemite, and these two sets of sacred objects indicate development of savage thought along two different lines.

There is, further still, a very important point of difference between the Churinga and the Muraian objects in regard to their decoration. The former, with very rare exceptions, carry incised spirals or concentric circles, each of which has a very definite meaning. The Muraian objects are never incised and their ornamentation seems to have no such symbolic importance, or, at least, definite meaning, in reference to the totemic animal or plant with which it is associated as is so notably the case in regard to the Churinga designs.

August 4th.-Cahill has been busy trying to get the motor to work in his lugger, so that we can get round to Darwin with more certainty and speed than by sailing, but it is no use, so we have decided to sail down the East Alligator with the tide, then coast round to the South Alligator and up this, on the tide, to a place called Kapalgo. Thence we shall travel on horseback, across country, till we cut the line at Burrundie. This will take us less time than going all the way overland, so Cahill has been getting pack saddles ready for the horses, which the black boys will go on ahead with, so as to meet us at Kapalgo. They will take two or three days longer to get there than we shall, because they will have to head the creeks flowing into the Alligator Rivers, so as to avoid all the swamp lands that lie in a direct line between Oenpelli and Kapalgo.

We have also been very busy packing up the collections of native things that represent fairly well everything that 


\section{WANDERINGS IN WILD AUSTRALIA сн.}

the natives make and use. Apart from those already described, the chief ones are the clubs and baskets and bags of different kinds.

There are four types of clubs, each of which is represented in Fig. 549. Figs. I, 2 and 3 represent the commonest type. It is made of hard wood, is always circular in section and cut off square at each end. It varies in length from four feet six inches to five feet and tapers very slightly to the handle end; the other is ornamented with designs of lines and bands of red, white and black. Fig. 4 is less common. It is somewhat flattened with a broader end, bluntly pointed, and a narrower one marked with a very distinct concavity which the natives say they use for pinning down snakes. It measures fifty-eight inches in length, with a maximum width of three and a half inches. The Kakadu call it Periperiu. It was first found and described by Macgillivray in the Voyage of the Rattlesnake, amongst the Iwaidji at Port Essington, who called it Miru. The two remaining types are much rarer and are not, I think, found to the west of the Alligator River country. The one in Fig. 5 comes from the Iwaidji, Geimbio and Kulunglutchi country and is used, but not made, by the Kakadu, who call it Mabobo or Wakadi. It is shorter and rounder than the Periperiu. The one in Fig. 6 is the rarest and has much the shape of a bat. It is made by the Kulunglutchi, who call it Wakerti; the Kakadu name is Kadimango. Its blade is broader than that of the Periperiu and it has a very distinct handle end.

It is only very rarely that any stone implements are met with amongst the Kakadu and allied tribes. They and the Melville Islanders seem to use shells for cutting. They have no stone knives at the present day, and the three axes shown in Fig. 550 were the only ones I came across. They are extremely crude. No. I shows grinding, but this is almost entirely wanting on Nos. 2 and 3 , which are simply 


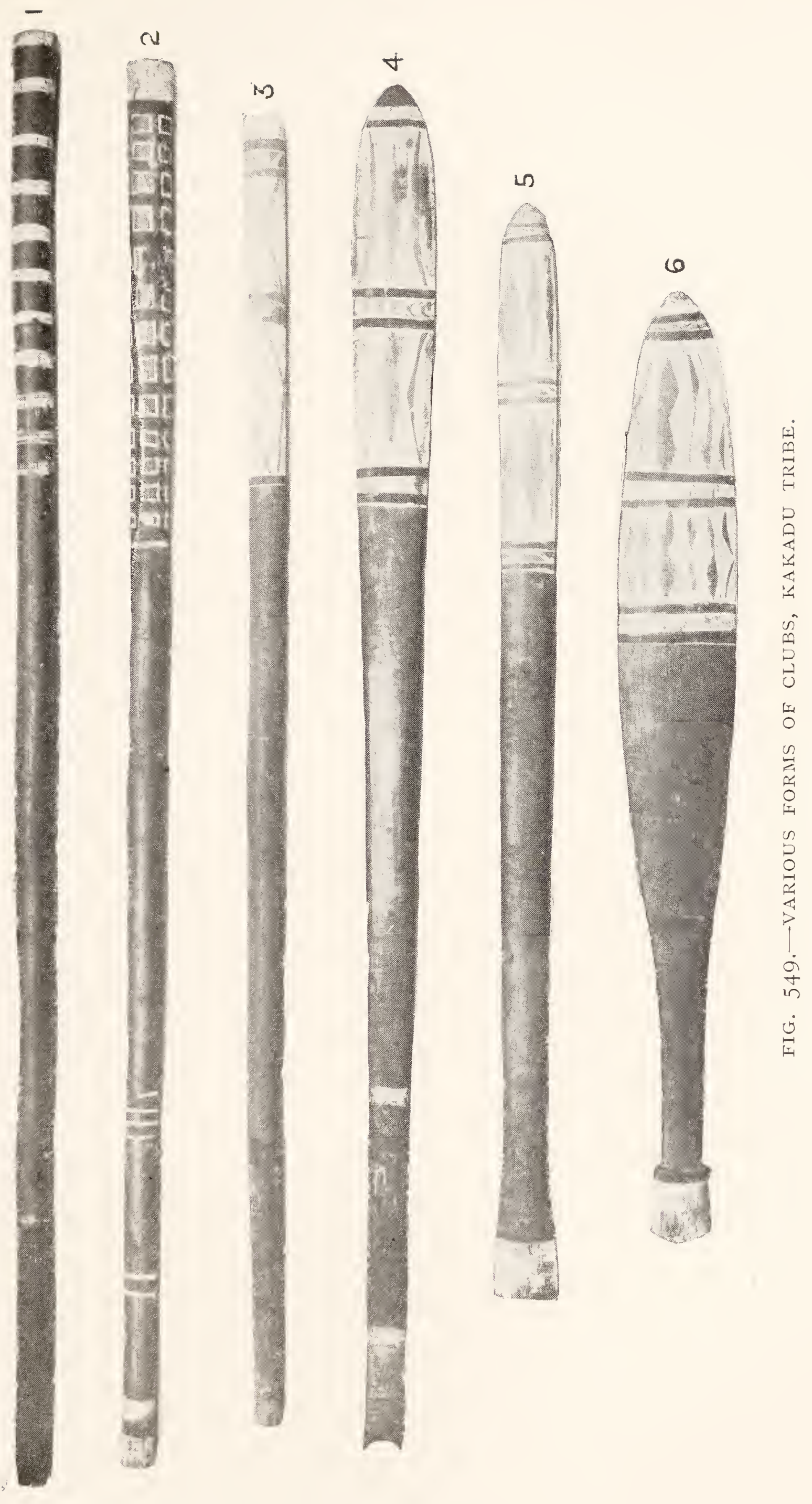




$$
176
$$


very roughly shaped stones that are of no use for cutting. No. 4 from Melville Island is equally crude.

The bags and baskets of the Kakadu are the most beautiful things they make, and their workmanship is just as good as that of a very highly skilled European craftsman. There are four main and very distinctive types, and it is interesting to find that the wooden troughs that are so characteristic of the Central tribes are never met with in the far north. They are not even traded here, nor are the baskets of the Kakadu traded south. It is equally strange that bark baskets like those of the Melville Islanders are never made. The four types are (I) those made out of paper-bark for temporary use, (2) those made out of palm leaves, (3) those woven out of grass, rushes or split cane, and (4) knitted bags.

There are two kinds of paper-bark bags. The first (Fig. 55 I, No. I) is roughly rectangular in shape. It measures eight inches in length by four in width and depth. The bark, which the natives call Ranken, is made of very thin sheets of soft, pliable material that easily shreds off, so that the surface is always ragged-looking. The handle is made of a thin piece of cane, each end passed through the folded bark, twisted back on itself and tied round. The second (Fig. 55 I, No. 5) is still rougher and is made of a thick sheet of paper bark, the two ends of which are pinched together and tied round with strips of bark. The one figured is sixteen inches long, seven in width and five and a half deep. For some reason it has one of the little knitted bags, called Ballduk, fastened on to it.

The baskets made out of palm leaves are very ingeniously constructed, but after a time, when the leaf dries, it easily splits, and so these baskets do not last long in use (Fig. $55 \mathrm{I})$. While the leaf is soft and pliant it is roughly cut so as to form a square plate with the stalk attached to one 
side. Each angle is then folded on itself so as to form a triangular flap. These double flaps are then folded back so as to form two sides of the basket with the stalk attached to one of them. The free end of the stalk is then bent over and passed between the median plate and the two outer flaps on the opposite side of the basket. It is then bent back on itself outside the latter, as shown in No. 3, and the folded flaps sewn together with thin split cane, the extent of the sewing, which includes the bent back part of the stalk, varying much in different baskets. These palm-leaf baskets vary very much in size. The one shown in No. 2 measures eleven inches in greatest and eight in least width; its depth is nine inches. Sometimes they are very small, almost like little toy things (No. 4). This one was used for holding a little red ochre. They are often decorated (No. 2) with designs in red ochre and pipe clay. No. 6 shows one painted with red and yellow ochre and ornamented with a flattened-out tassel, consisting of a central mass of beeswax, whitened with pipe clay, from which radiate the hairs forming the terminal tuft of a dog's tail.

The baskets made out of grass, rushes or split cane form a very distinctive series. So far as my experience goes, there is a wonderful uniformity in the manner of their actual manufacture, but, while this is so, they afford the natives more scope for the display of decorative work than any other of their ordinary implements. The different kinds are shown in the three Figs. 552, 553, 554. There are two main groups, those that have a distinct neck and those that have not.

The baskets with a neck vary in size, and there are three kinds to which the Kakadu give different names. The Kurokura have a very open network (Fig. 552, Nos. I and 4) and may reach a length of two feet or even more. The longitudinal strands may be made of thin, pliant 


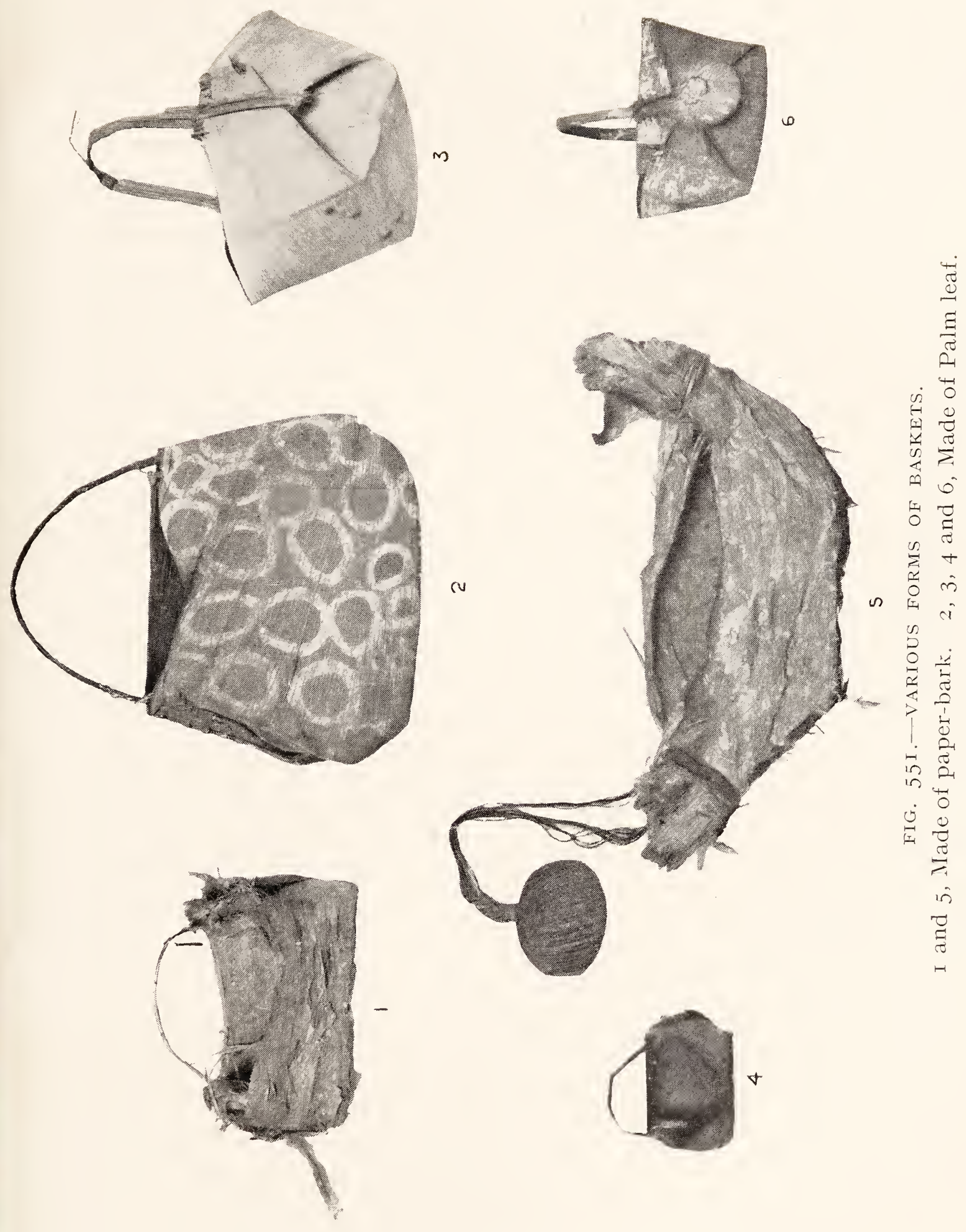




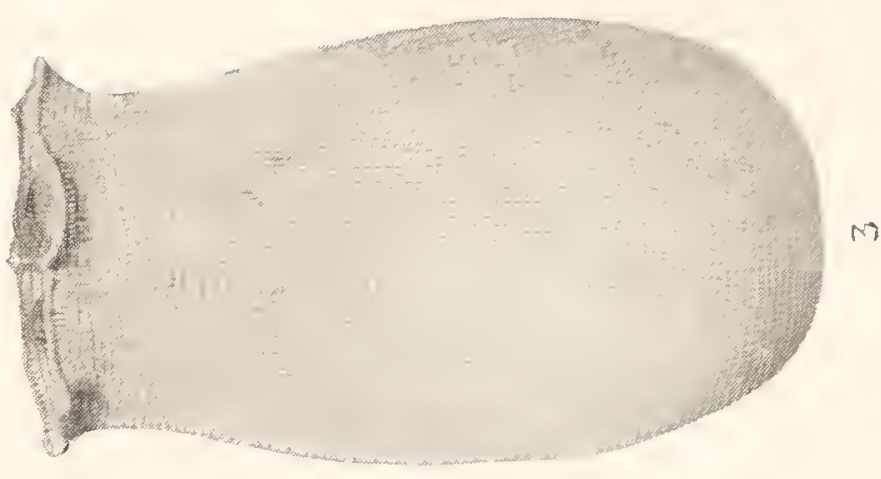

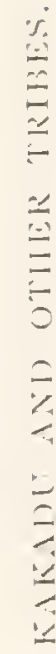
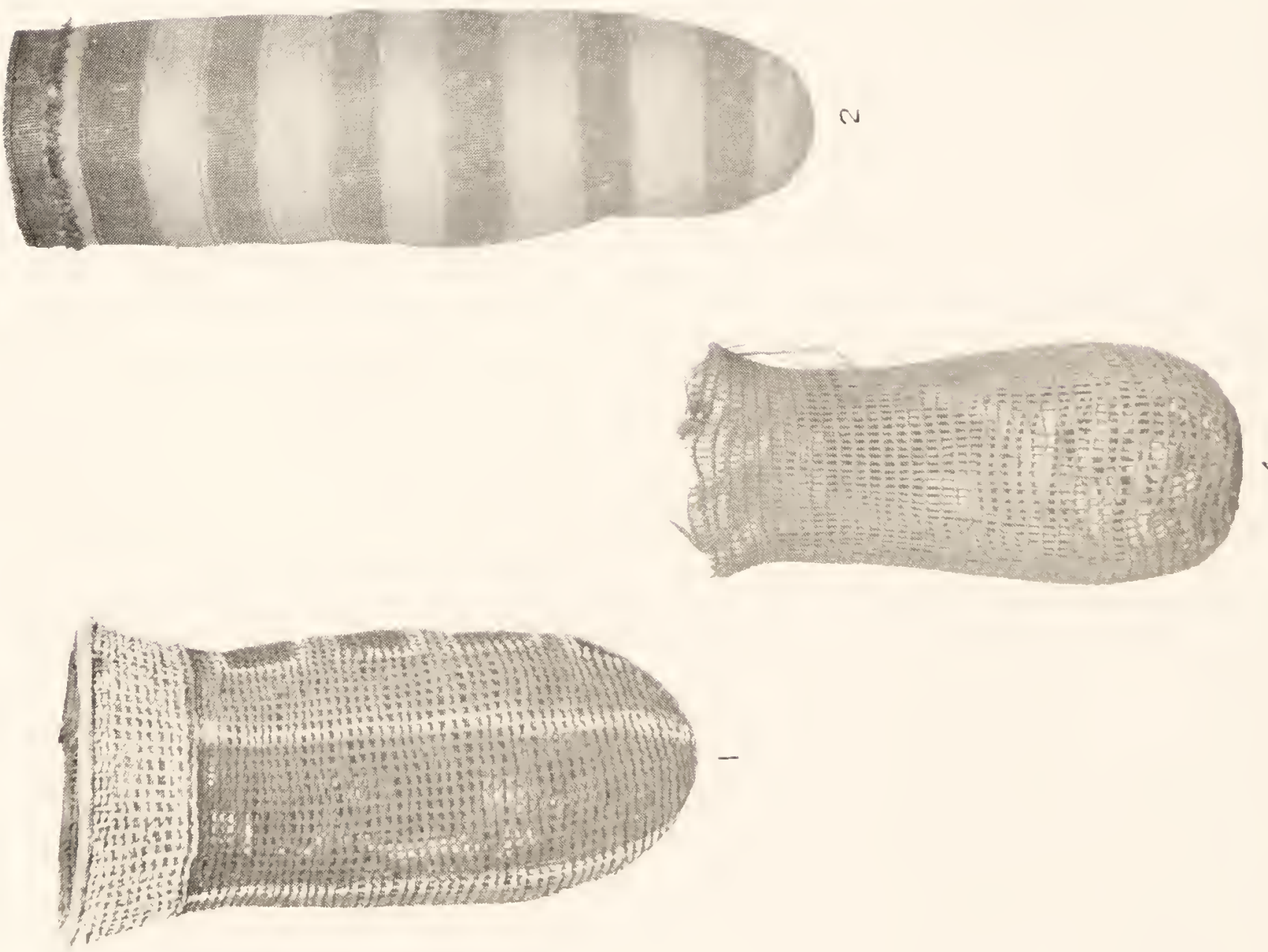
twigs, stiff grass or rushes; the transverse ones are always made of two strands of plaited bark-fibre string, knotted round the longitudinal strands. The Djilara has a relatively close meshwork (Fig. 553, No.4). The longitudinal strands are made of grass stalks, the transverse single strands of string. The Nuborgo (Fig. 552, No. 3, Fig. 553 , No. 5) at first sight is much like the Djilara, but the transverse bands are made of double strings.

The baskets without a neck are much more common than those with one and, though they are very numerous and differ much in size, they may be divided into two kinds. In the Maleba the meshwork is open. No. 3 in Fig. 553 may be taken as a typical example. It measures seventeen inches in length and five and a half in diameter. The longitudinal bars are made of two or more split rush or grass stalks, or shreds of Pandanus leaves; the transverse by two plaited single strands of string, just as in the Djilara. To carry the basket, a loop of four strands of vegetablefibre string is attached to one side, which may be spoken of as the back. No. 6 in Fig. 553 shows one with lines of the bright-coloured feathers of the Blue-mountain parakeet woven into the grass strands, so as to outline rectangular spaces, all of which have been painted with red ochre and most of them crossed with lines of white.

The Numalka (or Numalga) is perhaps the most interesting form, because the strands are so closely woven together that the basket can be used for carrying honey or even water. So far as shape, size and nature of the strands are concerned, it is similar to the Maleba. No. 2 in Fig. 552 is a good, simple example of this type. It measures twentyfive inches in length and seven in diameter. A little way below the mouth a circle of Blue-mountain parakeet feathers has been woven into the uppermost of the cross ridges. These are arranged in pairs and are utilised in the design to separate alternating bands of light and dark 
red ochre. No. 3 in Fig. 554 is included in the illustration because it shows how readily the blackfellow succumbs to the temptation to use some white man's material and at once spoils his own originally simple but beautiful native work. The maker of this, unfortunately, got hold of some dirty bits of red rag and has substituted these for the beautiful parakeet feathers that he used before his taste became vitiated by contact with the white man.

It is these closely woven baskets that afford most scope for the drawings of designs, the nature of which is well shown on the specimens shown in Figs. $55^{2}$ and 553 . The spacing of the design is largely governed by the presence of distinct, transversely running ridges. On some, the human figure is introduced (Fig. 554, No. 2). It is always conventionalised, but in all cases the drawing is remarkable, because it shows how clearly the artificer has recognised the equivalence, anatomically, of the fore and hind limbs and the fact that, just as in other mammals that walk on all-fours, the elbow normally points backwards and the knee forwards.

Amongst the Kakadu and all the northern coastal tribes, a very characteristic feature of the corrobborees is the use of a simple musical instrument always called a trumpet by the whites. This, of course, is a misnomer and the term conch is more appropriate. The Australian aboriginal has, indeed, only two forms of musical instrument. One consists of sticks, that he clangs together, and the other is the conch, which takes the form of a hollow stick or small $\log$, through which he blows. The white ant provides him with numberless hollow boughs of all sorts and sizes that he has only to cut into the desired length and then has his conch ready for use. Very often, also, he avails himself of the stem of a bamboo. The conch is blown through so as to produce, most often, a continuous repetition of the words that sound like "biddle-an-bum," with 


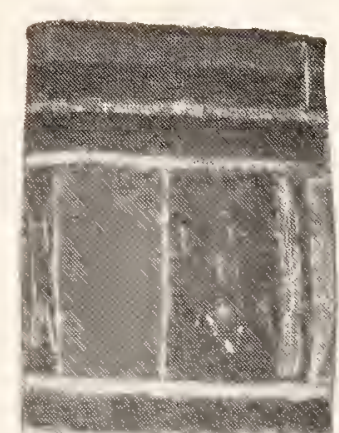

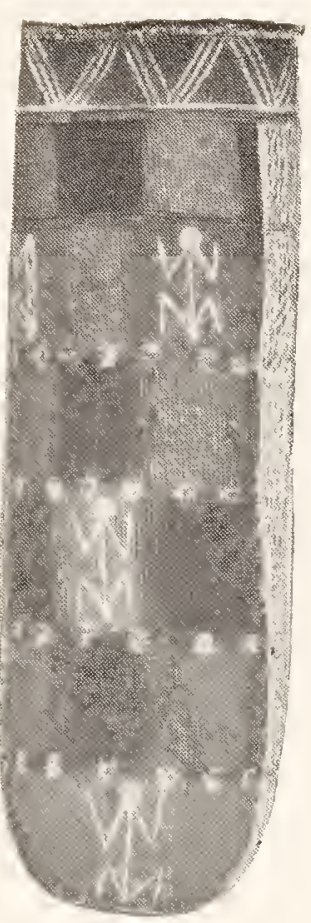

2

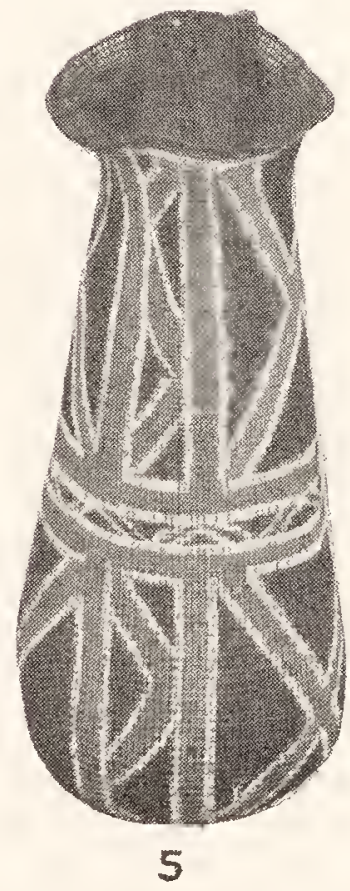

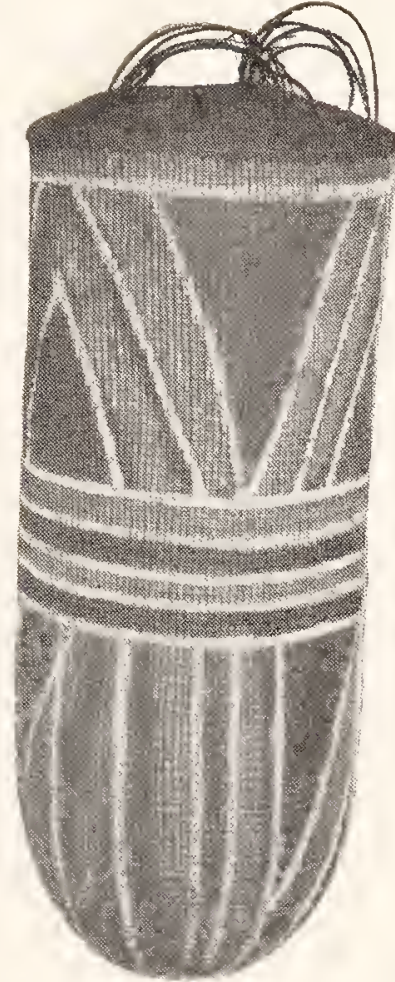

3

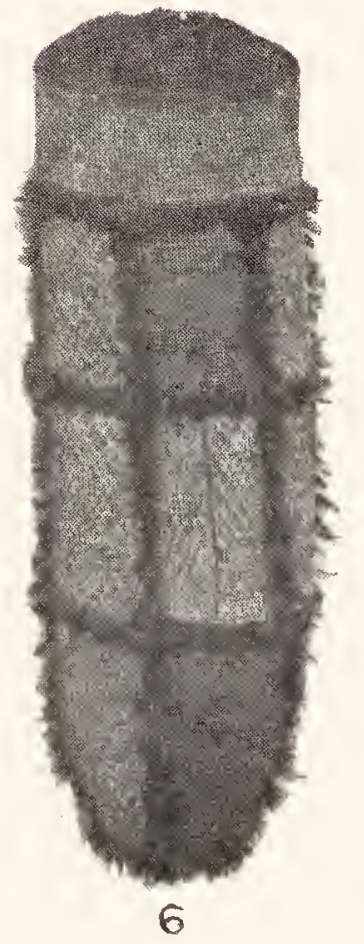

FIG. 553.-NETTED BASKETS, WOVEN OUT OF GRASS, ETC., KAKADU AND OTHER TRILES. 

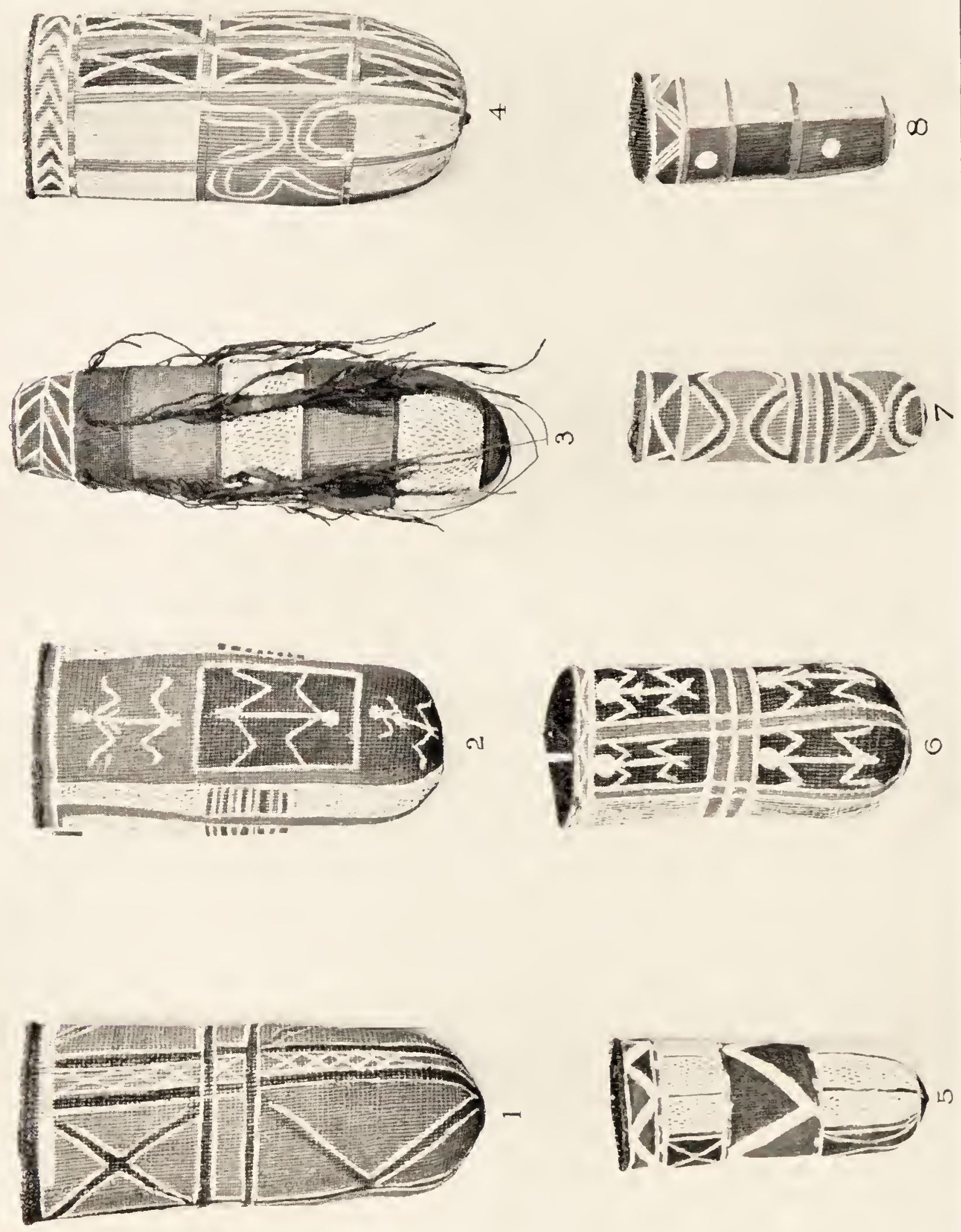
a long, strong emphasis on the "bum," the $u$ sound being long drawn-out. Sometimes, however, the conch is used to emphasise the call of various birds, and there is a very considerable range in regard to the ability of different musicians. In the Kakadu camp, for example, there is one man who is notably good and will imitate wonderfully well the call of various birds, such as the Native Companion. When in camp he is constantly called on to perform, and the natives listen to him by the hour. Most of the music is, however, extremely monotonous, and one can often hear the conchs booming away till late in the night, out in the scrub, where the natives are singing round their camp fires.

The five examples in Fig. 555 represent the various forms. Those shown in Nos. I, 2 and 3 are made out of gum-tree branches. No. 2 is very crude, and No. 3 a very good specimen, measuring five feet in length, with the thinner mouth-end coated with beeswax to make it smooth for the lips. Nos. 4 and 5 are made of bamboo and, like all of those which are often met with in the Gulf district, are ornamented with incised zigzag lines. The smooth surface of the bamboo is admirably adapted for such work.

We were constantly coming across odd and interesting things as we wandered through their camps, where we were allowed to look freely into their Mia-mias and even pry, with their amused consent and help, into the women's dilly-bags, always, of course, after a judicious gift of tobacco, which smoothed the way to confidence and friendship. A few of such things are shown in Fig. 556, on which Nos. I and 2 represent curious sticks which belong to men and are called Medjingeli. These are sent out to invite natives of other camps or tribes to take part in a fight. The upper one of these measures thirty-nine inches in.length, and is a solid stick with a bunch of stiff grass stalks attached 
to one end by means of shreds of Banyan bark. The whole thing is whitened with pipe clay and looks like a miniature broom. This form is sent out as a challenge to a general fight. The second is smaller and measures only twenty-one inches in length. It is made of reed or small bamboo, and is red-ochred, otherwise it is like the first and is used as a challenge to a single fight with a club called Periperiu (Fig. 549, No. 4).

The stick No. 3, though it looks much like the above, belongs to women. When it is quite evident that one of the spirit children has entered a woman, the father of the child makes some string out of opossum fur which he puts into the Mela, or bag that is carried round his neck. Unless this be done the child will be born blind. Then he takes a stick, about two feet in length, ties a tassel of human hair string on one end, smears it all over with sticky material that he obtains from an orchid growing on tree-trunks, ornaments it with bands of gypsum and hands it to the woman, saying, ngeinyimma, kala, bialilla, which means literally, you, all right or certainly, child, in other words you have a child. The stick is called Tjubulinjuboulu. It is enclosed in a dilly-bag specially made for it, and is carried about in this by the lubra, who must not part with it. She sleeps with it under her head and must not talk at night-time. If she were to lose it, the child would die inside her and the father would be very angry and punish her. After the child is born, she puts the bag safely away until it begins to walk. The father then takes it and hands it to a relative, usually his brother, telling him to carry it to some camp a long way off. If, for example, the child were born at Oenpelli, it would be taken to a place such as Port Essington, that is, into the country of another tribe.

The messenger approaches the camp, carrying the stick so that it can be seen by the men, who know immediately 
nn

$+$
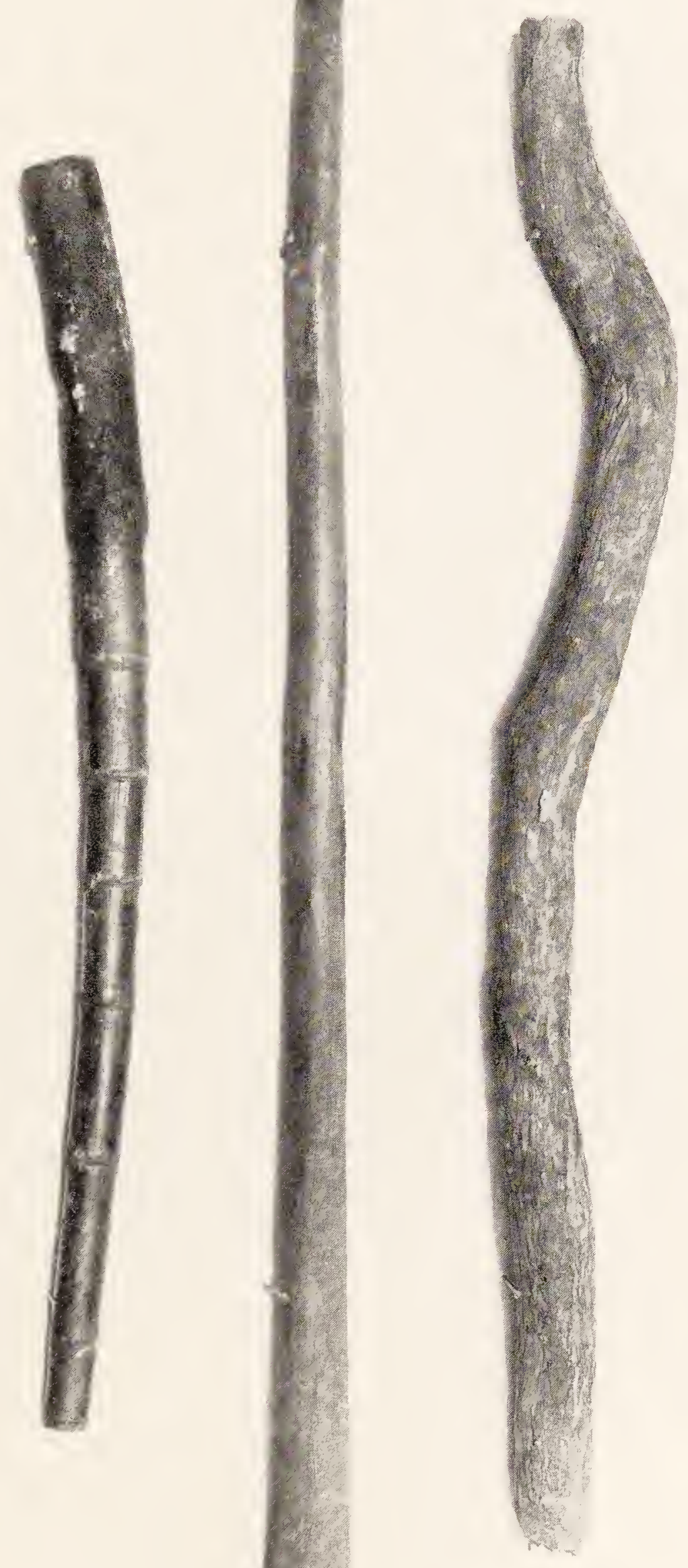

量

$\approx$

焉

学

?

选

ic

先

z

I.

in

in

㟔 


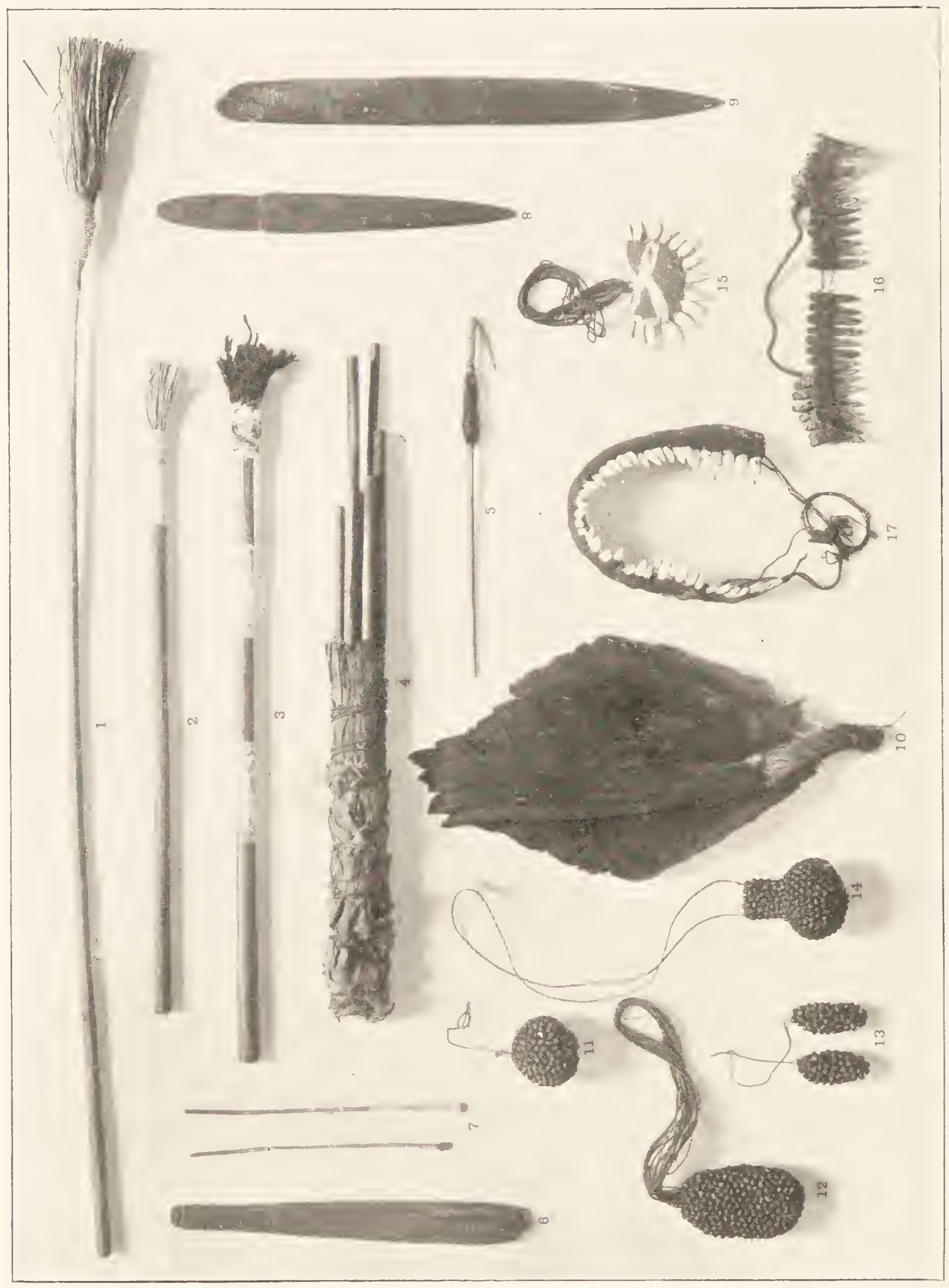

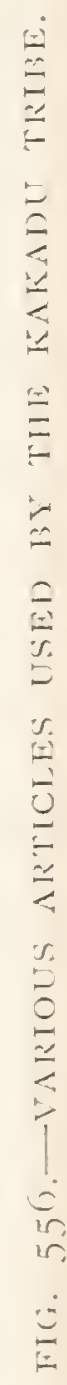


what it means, form into a square and come running up with their arms extended, shouting "Prr! Prr!" After a day or two the messenger returns, accompanied by some of the strangers. When they are a little distance away from the home camp, they halt for an hour or two and are then invited to come in. The mother brings the child up to them, having previously painted a white line across its forehead and lines of dots across its cheeks and nose. She herself is decorated in just the same way. The stick is given to the child, together with different kinds of dillybags, waist girdles, etc., brought by the visitors, to whom the relatives give spears and other things in exchange, so that this little custom serves as a method of barter. Then a corrobboree is held, and finally the father breaks the stick in pieces and throws them into a water-pool.

Fig. 557 represents a curious structure called Yai-illa, that is used for two entirely different purposes. It is about a foot long and two inches in diameter, and is made of a number of strands and folds of paper-bark, with an outer covering of the same that leaves one end free. This is the handle end, and during corrobborees the men, squatting down, strike the ground with the $r$ ai-illa, keeping time to the singing.

It has, also, quite a different use in connection with magic. We came across a man wearing one of these in his belt, in the small of his back. He had a pain in his back and it was supposed that this, or rather the evil magic causing it, would pass into the rai-illa and could then be thrown away with it.

In the Kakadu and other northern coastal tribes, bark waist-belts are sometimes worn. They are made from the bark of the Cypress pine and are called Kupelbi. Their nature can be seen from the illustrations of three in Fig. $55^{8}$ which were obtained from natives on the South Alligator River. The centre one was made of a strip of bark ninety 


\section{WANDERINGS IN WILD AUSTRALIA $\mathrm{cr}$.}

inches long and four inches wide, wrapped round so as to form three circles. The design extends over the whole surface except for a small distance at one end. There is a uniform ground colour of dull red ochre, on which white bands and cross lines are drawn, leaving lozenge- and crescent-shaped spaces between them. Sometimes, as in the case of the four cross bands, a bright red ochre is used.

A series of simple ornaments is shown in Fig. 559. Nos. I, 2, 3, 4 and 5 are ordinary armlets called Muraradi, made out of closely woven vegetable-fibre string, decorated in red and white; Nos. 6, 7, 8, 9 and Io are split-cane armlets called Winbegi; often a number of these, interlaced, are worn hanging round the neck and down the back (No. I3). The most attractive ornaments are pendants made from birds' feathers to represent flowers (Nos. I 5-20). They require very considerable skill and seem to indicate an appreciation of the beauty of natural objects such as the Australian aboriginal is not usually given credit for. Each consists of small feathers, such as the gaily-coloured ones of the Blue-mountain parakeet or the longer, light grey feathers of the Native Companion, all cut down to an even length and arranged in one or two rows to resemble the petals of a flower, the stamens being indicated by a little tuft of feathers in the centre. The stalks of the feathers are fixed into a little tapering mass of wax, from the end of which a string passes off to attach the pendant to the head-band in such a way that one hangs down over each ear. They are worn by both men and women.

August 7th.-Two days ago, the boys, with seventeen horses, went off en route to Kapalgo. Also we got two beautiful Jabirus which were too good to leave behind, so I started to work on them at midday and went on till midnight, then up again this morning at 6 a.m. and finished them off. After that Cahill and myself completed the packing up of the collections. There are four cases con- 


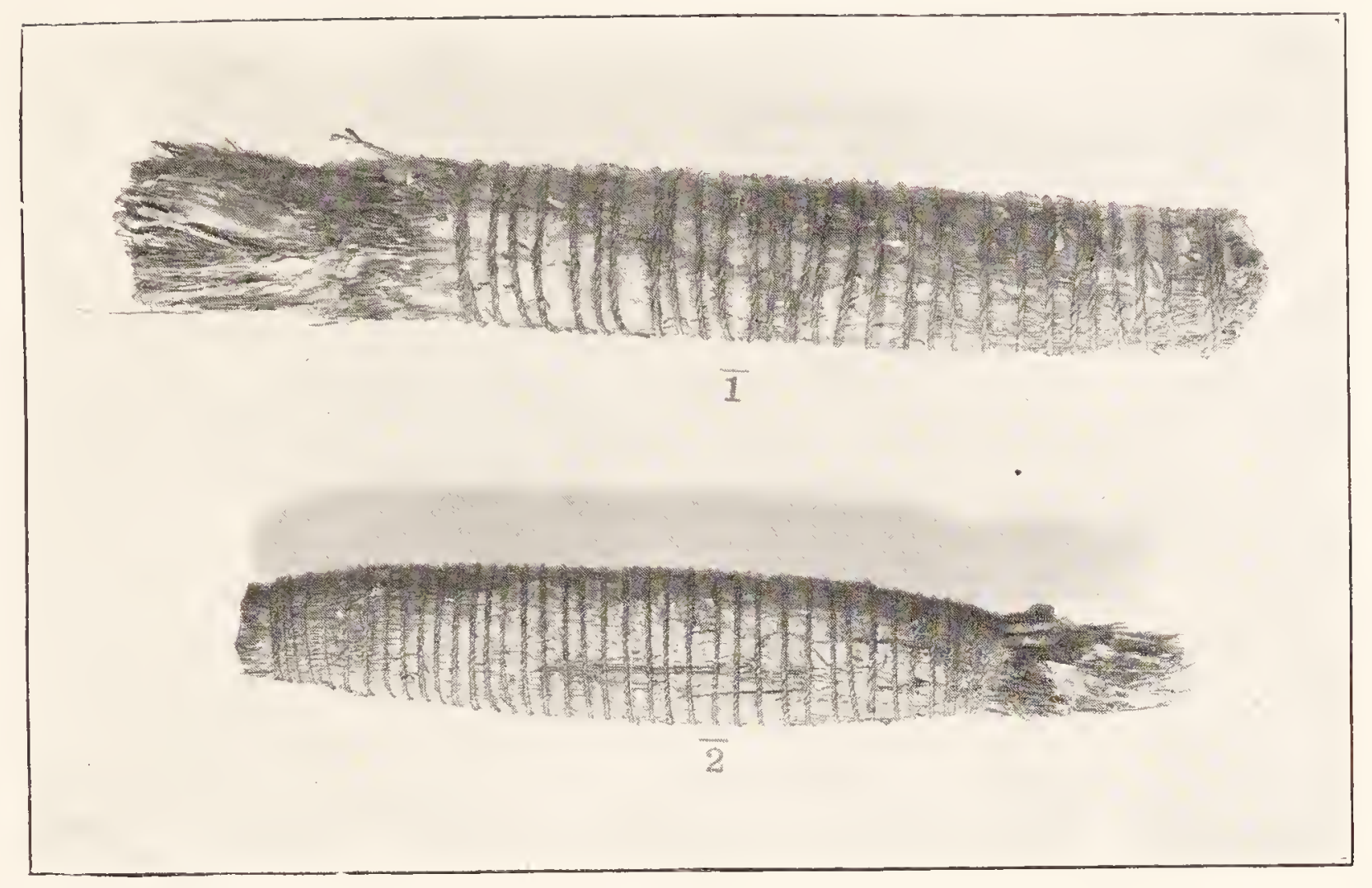

FIG. 557-CORROBBOREE WANDS OR YAI-ILLA, KAKADU TRIBE.
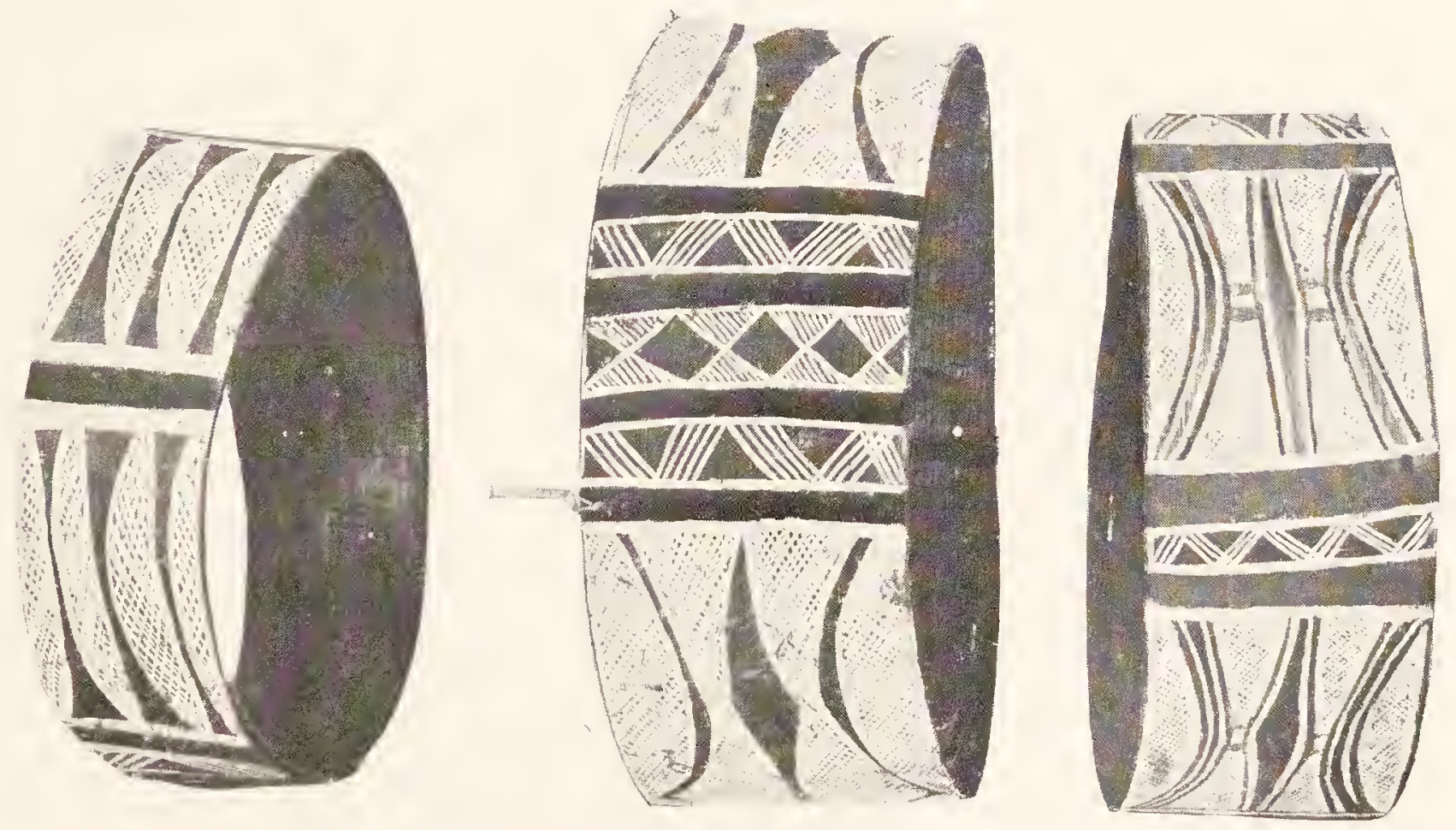

FIG, 558.--BARK BELTS, KAKADU TRIBE. 


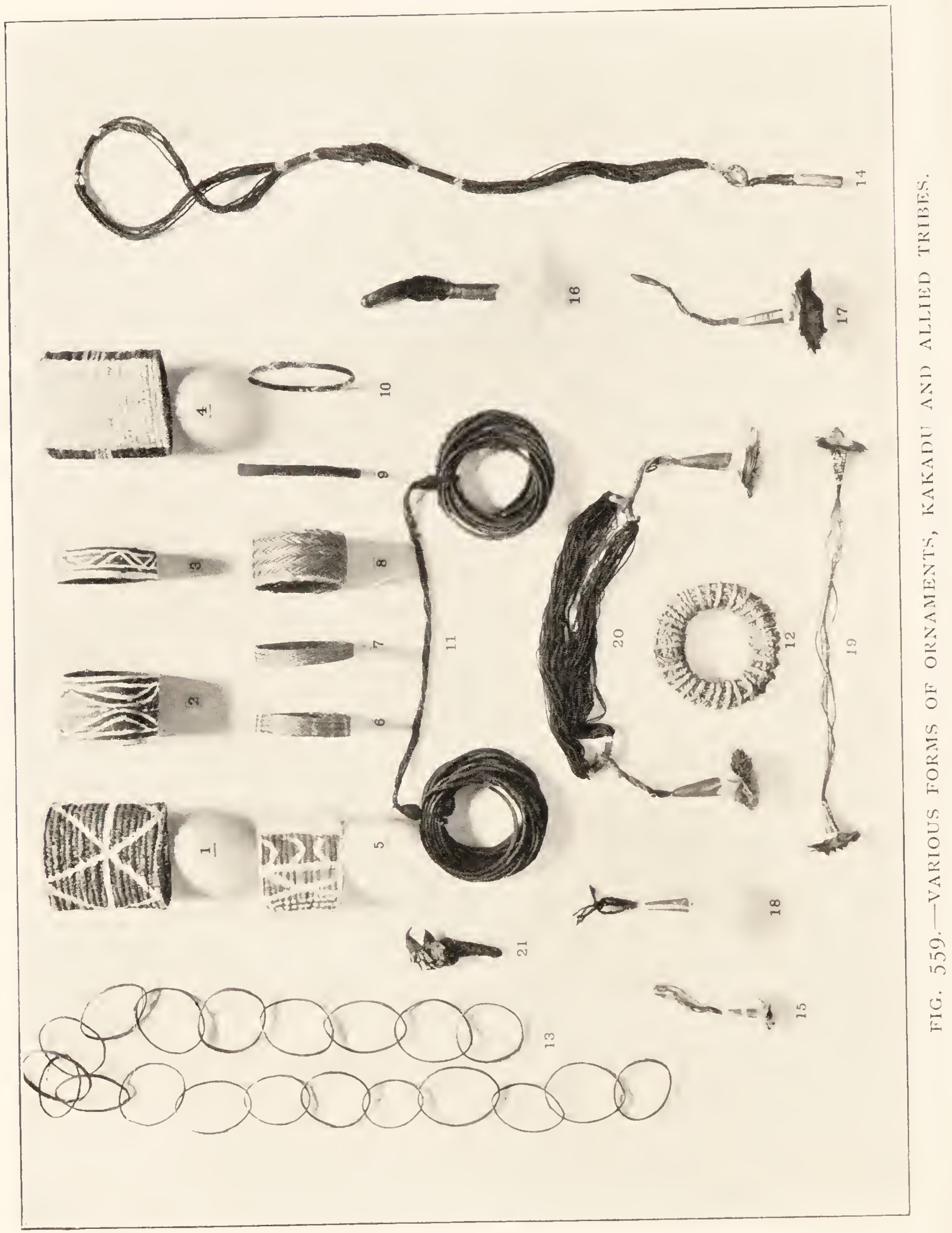


taining I 80 skins, Jabirus and kangaroos in one, smaller birds in the others. Four other cases are full of native things, and there are four great bundles, packed in paperbark, of spears, Muraian sticks and stones, clubs, spearthrowers and bark paintings. They look a formidable lot and will have to wait here until Cahill comes back overland and can return again with them later on to Darwin in his lugger.

August 8th.-This morning we gathered our few personal belongings and sent them, together with stores for the trip, down to the launch. In the afternoon we followed them and found about thirty of our Kakadu friends waiting to see us off. The boat was stuck in the mud and it needed a great deal of pulling and pushing and yelling, on the part of the natives, to get it into the stream, but at three o'clock we were afloat. The tide, which affects the river right up to Cahill's little landing, some eighty miles from the mouth, was still running out and we floated down with it, two natives, in turn, working at the sweeps to give us way enough to allow of steering. Every now and then we saw a dug-out canoe drawn up into a side creek, and plenty of crocodiles slithered down the mud banks into the stream and disappeared from view. It was picturesque when night came and there was only the faint light of a hurricane lamp in the hold and just ourselves with five boys on deck, watching the mud banks and dark lines of mangroves as we drifted slowly down-stream. The natives told us some things about the stars, but unfortunately I did not know the names of the constellations. The Southern Cross is a turtle. The dark " coal-sac," in the Milky Way, is the head of an emu whose body and legs are also in the Way. One constellation with eight stars arranged in three lines, at an angle to one, is an ancient native lying on his back with his legs crossed over one another. A specially bright star at the end of one is his head, and really, when the boy 


\section{WANDERINGS IN WILD AUSTRALIA сн.}

lay down on his back and showed us how the old man was lying, it was not at all a far-fetched idea. They wanted to know if there were as many white men in Melbourne as there were stars in the sky, and so, not wishing to disparage the Queen City of the South, I smiled at their ignorance and boldly asserted that there were "mobs more," at which they simply clucked in a way that the aboriginal does when he wishes to express surprise or astonishment or admiration. At I I p.m. we came to a stop on a mud bank where we remained till after 4 a.m., gradually tilting over till we were high and dry. The tide rose quickly and at 6 a.m. we were afloat, fortunately in a very broad part of the river, where the tide, though it came up quickly, was not confined between narrow banks, whereas, higher up in the stream, it met the down current and formed a bore. However, the current was too strong for us to make headway against it, as there was scarcely any wind, so we anchored and sent the boys on shore to collect some rocks, or logs, to act as ballast. It was very hot, lying at anchor, and there was nothing to be seen but stretches of mangrove and very watery mud, with an endless number of little fish (Periophthalmus) hopping about, with great, protuberant eyes on the top of their heads. Flocks of spoonbills and egrets were wading about on the shore, and hundreds of white cockatoos were screeching around and lighting on the gum trees behind the mangroves. At 5.30 p.m. we started down with the falling tide until it was too dark for us to go further ahead safely, so we anchored, about ten miles inside the river mouth, and had a quiet night, away from the mosquitoes.

August I I th.-We were off at 5.30 a.m. while it was decidedly cool and the water quite calm, but did not get out into the open till I I a.m., and all day sailed slowly along the coast, as there was scarcely any wind, until, late in the afternoon, we turned into the South Alligator River and anchored before sunset, sending two boys in the dinghy to 
get some firewood. We turned in for a few hours' rest, or rather lay down on the deck to wait for the tide.

August I 2th.- Just at midnight we started off in the starlight and had the five boys taking turns at the sweeps. It was decidedly chilly, and a blackfellow is never at his best under these conditions, so there was no singing and laughing and the boys, who were spelling, crouched down in the little hold, wrapped in their blankets. At 6.I 5 a.m. a heavy fog came down, so thick that we could not see the banks five yards away and, after going on for a short time, found ourselves running into mangroves, backed out, went on again, found ourselves once more scraping along the trees, got clear of them, and decided to anchor and wait for the rising of the fog, so that we could see where we were going. It was nine o'clock before it cleared off, and then the tide was running strongly against us, so we had to remain where we were till after midday. Two of the boys went ashore to make a fire and bake a big damper for themselves and their mates. Incidentally, they caught a large lizard and a fat diver and had a good meal while they were away. There was plenty of tucker for them on board, but this was a kind of extra. Then, when the tide turned, we started off with a slight breeze and, by dint of constant tacking, made our way slowly up-stream. The river was very broad and there were enormous bush fires all roundhuge columns of smoke going up for a mile or two into the sky (Fig. 559A). The river began to narrow until it was only about three-quarters of a mile across, and about five o'clock we saw two natives on a rising bank, who shouted out that they were all waiting for us at Kapalgo. The sun was just setting as we came into the last reach and there was an extraordinary light effect. Except that the sun, seen through the haze, was deep carmine and that a single broad band of red ran across the water, everything was a beautiful pearl-grey colour, with long-drawn-out reflections in the 


\section{WANDERINGS IN WILD AUSTRALIA сн.}

smooth-running river. As we came nearer, in the dark, the natives lighted a large fire to show us the landing-place, but the tide was now running strongly, so we anchored away from the bank and decided to camp on board, sending two boys with the dinghy and twenty sticks of tobacco for the natives. From the deck of our boat, on which we lay carefully enclosed in our nets, because the mosquitoes along the Alligator River are large, blood-thirsty "upenders," we could see the natives dancing round their camp fires in the forest. Right on the water's edge there was a fringe of mangroves, and behind them a vertical bank rose ten feet high, with great tortuous roots of gum trees standing out, where the rush of waters, sweeping round the river bend in flood-time, had carried the earth away and left them hanging in the air. As the bank is eaten further and further back, the roots, most of which grow towards the water, become more and more laid bare, until at length they lose their hold on the ground and the tree topples over into the river, forming hidden snags that make navigation difficult at any time and dangerous in the dark.

The natives, except for our two boys, had no pipes, and as theirs would not go round the whole camp with anything like satisfaction, the tobacco was divided into little plugs which they chewed. It was a wild scene, with the tree trunks standing out starkly against the darkness of the forest behind them, and the natives yelling loudly, as they danced furiously round and round their fires, some of them every now and then tumbling over from sheer exhaustion. It was late before there was quiet in the forest.

August I 3 th.-At 4.30 a.m. we moved nearer in to the bank and waited for nearly three hours until the tide was high and the fringe of mangroves nearly submerged, so that we could move our lugger close enough to the shore to land on the little cliff without having to wallow in the mangrove 
mud. First of all we gathered all the natives together, and I told them that Cahill was now "Big Gubment Boss" of their country, which pleased them mightily, and then distributed tobacco. After this we packed up and our caravan of seventeen horses, Cahill, myself and four boys started off across country. The cinematograph and cameras were packed on a quiet horse that was always led lest it should bang the side packs against a gum tree. It was quite a relief to be on horseback after the confinement of the lugger. In the scrub, the Hakeas were a mass of bright orange blooms, and along the watercourses there were beautiful patches of paper-barks in full flower. We went on till sunset and then camped.

August I 4th.-Up before sunrise and off at 7.30. The country was very dry and dreary with open forest land and often patches of huge white-ant hills as tall again. as a man on horseback (Fig. 560). We only travelled for four hours to a water-hole, beyond which we had a traverse of thirtyfive miles to the next water, which would have meant getting in after dark, so we camped. We wandered about in the scrub, watching the boys, who were out hunting for honeybags and cutting them out of trees. The natives distinguish and have separate names for four kinds of combs. Mormo in the main trunk, some distance up; Podanerji, right at the foot; Tjungara, high up on the trunk, and Tjaina, high up on the boughs, with a short wax funnel projecting from the bough, by which the bees enter.

August I 5th.- Yesterday we camped beside a water-pool on the Mary River and to-day reached the McKinley Creek. Having an hour or two to spare before dark, we amused ourselves by scraping some "dirt" out of a gravel bed at the bottom of the steep bank of the creek in search of gold. The gravel was more or less cemented together and was evidently an old river bed, through which the present stream was cutting down. In the gravel I found some chipped VOL. II. 
stones that looked like native work, so I showed them amongst other stones to our boys, who at once picked them out as being made by the blackfellows. They must be of considerable age, as there is a deposit of twelve to twenty feet of sand and loam above the gravel.

August I 6th.- To-day we came across tracks in the scrub and also remains of old diggings, showing that we must be near the railway line, and a few hours later struck the latter at Brock's Creek. To-morrow we catch the bi-weekly train from Pine Creek to Darwin.

August I 7 th to September 2nd.-Back in Darwin and very busy with routine office work. The Administrator was planning a motor trip down the telegraph line as far as Newcastle Waters, thence across to the Gulf of Carpentaria and back again by the Roper River, and I was very glad to avail myself of his invitation to go with him, as I wanted to see something more of the natives on the Roper than I had been able to do on our hurried visit in I 9 I I. Accordingly, I arranged with Cahill, who was returning to Oenpelli, to come back to Darwin again with the collections and then meet me at the Roper Bar, where I proposed to join him on our way back on the motor trip. When we left Darwin on September 2nd we had no idea that this would take us just about twice as long as we calculated upon. 


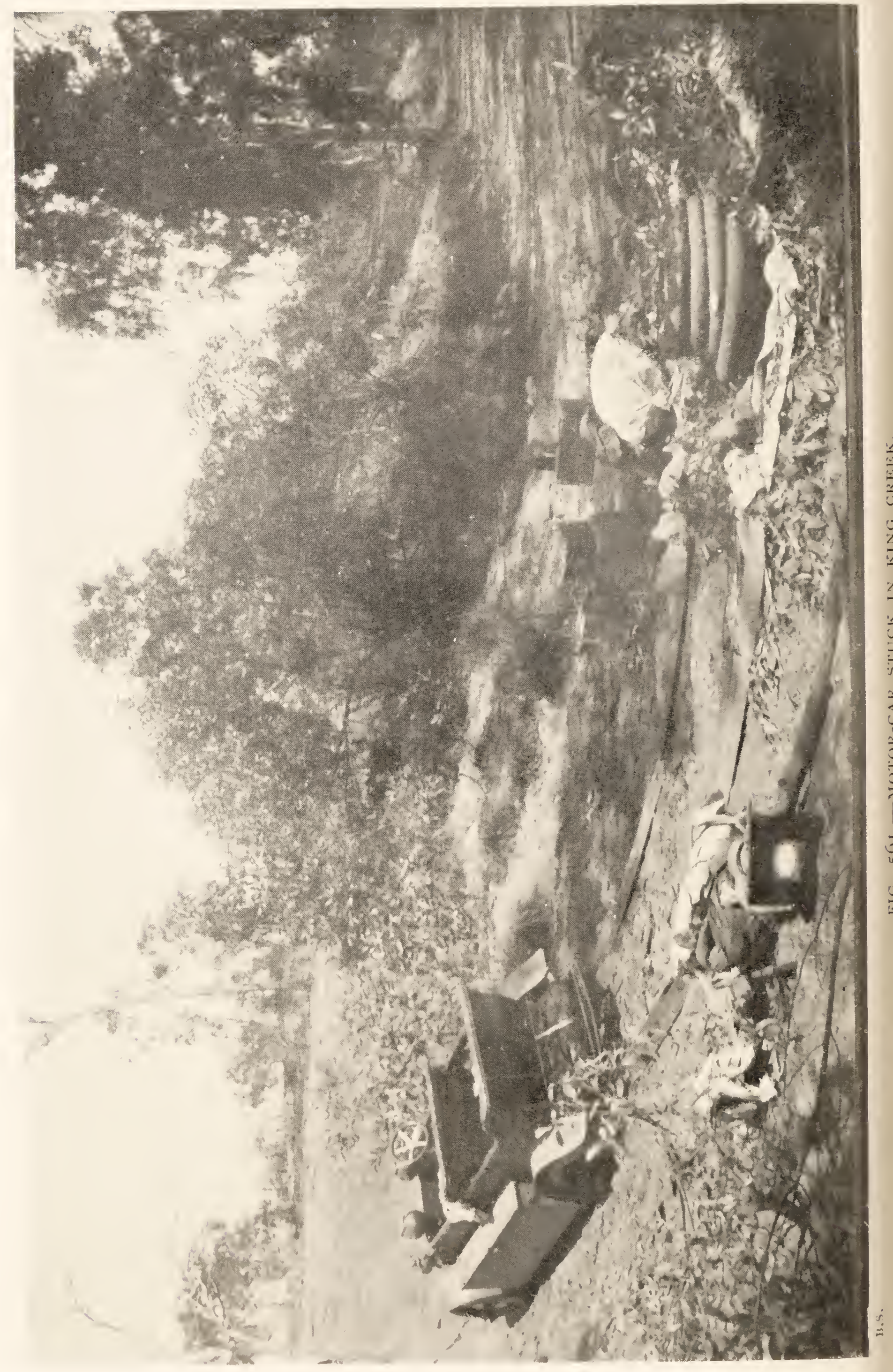




\section{CHAPTER XXXI}

BY MOTOR TO THE GULF OF CARPENTARIA

DURING the first year of his office as Administrator of the Territory, Dr. Gilruth decided to try the experiment of taking a motor-car across country from the telegraph line to the Gulf of Carpentaria. One or two cars had come right across the continent, following the track by the telegraph line, but up to this time (I9I2) there had been no attempt to take one across country either to the east or the west of the line. The route mapped out was to follow the latter south to Newcastle Waters and then strike right overland to Eva Downs Station and Anthony Lagoon, from which a track led down to Borraloola at the mouth of the Macarthur River. Thence we were to run north to the River Roper, zigzagging across country, so as to touch the outlying cattle stations at the Macarthur River, Bauhenia Downs, O.'T. Lagoon, Tanumbirini, Nutwood Downs, Hodgson Downs, McMinns' Bar on the Roper and so back to the Katherine by way of Mataranka or Bitter Springs (Map 4).

The great difficulty was the supply of petrol, but stores of this were sent on ahead to await the car, if and when it, and the petrol also, should reach Anthony Lagoon, Borraloola and McMinns' Bar, on the return journey. The trip took a good deal longer than we thought it would. The car was a I 5-horse-power Napier. It was spick and span when we left Pine Creek, but somewhat ancient-looking and travel-stained when it returned. Apart from its dilapidated tires, a broken spring and external appearance, it was 
practically in just as good going order when it ran back in to the Katherine as it was on the day when it started out. It was marvellous how it managed to stand the continuous strain of eight weeks' traverse of country where there were, at best, only the roughest of tracks and often none at all; ploughing through miles of soft sand, often sinking down to its axles, when it had to be jacked up on to logs and bushes to give its wheels a hold for a fresh start; running down a steep bank and landing with a thud on the sandy bed of a dry creek, up the other bank of which it had to be dragged with block and tackle; jolting across stony plains or boulder-strewn river courses; bumping fearfully over "Bay of Biscay" country, with cracks big enough to hold a wheel easily; crashing through scrub and saplings; and last, but not least dangerous, every now and then running a tilt at a hard ant-hill, hidden in the tall grass, that might by good fortune be knocked over, or by bad luck get jammed under the body of the car, bending the front axle on its way. That it came through safely was a wonder and a matter of great astonishment not unmingled, perhaps, with a slight feeling of disappointment to not a few pessimists in Darwin, who, knowing the country well, foretold all manner of dire mishaps and hopeless breakdowns. It certainly was not a joy-ride, but it was a pioneer trip and showed what it was possible for a sound car to accomplish that had not even been specially built for such a test.

September 3rd.-We left Pine Creek at the head of the railway line at $10.35 \mathrm{a} . \mathrm{m}$. Our party consisted of the Administrator, Dr. Gilruth, myself, the half-caste boy Shepherd, to assist generally and look after the camp, and, most important, Cowper, our chauffeur, short and not thin but brimful of energy and resource and always cheerful, except for odd moments when he thought a gudgeon pin was going wrong. For some reason the dread of this seemed always to be present with him, ready to be called up 
at a moment's notice when any unusual sound was heard in the engine, just like the fear of evil magic is always present to an otherwise cheerful and light-hearted blackfellow.

The whole of the space under the seats was transformed into petrol tanks; cases of petrol and water supply were carried on the foot-boards. Dr. Gilruth was in front, Shepherd and myself behind together with all personal luggage. Save for the "blow out" of a tire all went well until I.30 p.m., when we halted for lunch at the hut of the mounted trooper at Horseshoe Creek, where there were a few Chinese miners, patiently dollying away in the bed of a creek for tin. At 2.30 p.m. we were off, and after an uneventful run along the very uninteresting track through open forest country, came at $5 \cdot 30$ p.m. to the northern edge of the deep ravine in which runs the Katherine River. On the opposite bank, at intervals of about a quarter of a mile from one another, we could see the hotel, police quarters and telegraph station. Gilruth and myself walked on, leaving the car to follow. The track crosses the bed of the river just below the hotel where the stream runs low between two long water-holes. The water came just up to the body of the car, but Cowper rushed it through successfully and up the long, steep track on the opposite side, and we soon settled down on the spacious verandah of the telegraph station and wired back to Darwin that our first day's journey was over without mishap. It had even been foretold that we should never reach the Katherine. The country did not allow of rapid running, but in seven and a half hours, including lunch and two minor breakdowns, we had easily traversed country in crossing which with horses we had spent four full days only a few months earlier.

September 4th.-At the telegraph station we found $\mathrm{Mr}$. Perry in charge, Mr. Woodruffe with him as assistant, and, to my surprise, my old friend Captain Gore was acting in the capacity of cook. The last time that I had seen him 
was when he came into Borraloola on the little ketch Venture, more than ten years ago, with his arm speared through by natives on his way down the Gulf. It was now perfectly right again. Cowper spent a day overhauling the car and was quite pleased to be able to show us that his suspicions with regard to his gudgeon pin were founded on fact. Fortunately, however, the damage was decided to be not serious enough to prevent our going on, though he rather feared that " anything might happen to it at any time." Luckily it did not.

September 6 th. - We left the Katherine at 8 a.m. with our side luggage increased by the addition of three "green" hides that were to be cut into strips and used for covering and protecting the tires. In two hours we were at the Maude Creek mines, once very busy, now deserted, and at I p.m. came to the King Creek that we had been assured, even by the few optimists in Darwin, would be the "very devil of a one" to get over, and, with great satisfaction by the pessimists, that no car yet built had the slightest ghost of a chance of crossing it, only their language was more emphatic. We did not realise that we had reached this fateful spot until suddenly, without warning, we found ourselves there, ran down a steep bank that, seen from below, looked like a little precipice and almost jumped into the sandy bed, where we came to a sudden stop. We were rather relieved that no one in Darwin knew where we were. It was a case of unloading everything and then, first of all, jacking the wheels up. We had brought narrow lining boards and lengths of canvas, with the idea that they might help in crossing sand, but they were useless, the boards simply smashed up and the wheels whizzed round on the canvas. By dint of jacking the car up, so that we could set small logs and bushes under it, making a kind of rough corduroy road, it was gradually worked across the sand until, late in the afternoon, we got the front wheels on 
to the foot of the steep southern bank, but up this it absolutely refused to go (Fig. 56I). By good fortune there was a gum tree a little way over the top of the bank, in the direct line of the track. We had a block and tackle with us, so, by means of a long rope, this was hitched on to the tree at one end and the car at the other, and we began pulling at the endless chain. It was very hot. Perspiring hard and covered with grease and dirt, our hands chafed with the chain, we pulled away, getting it up inch by inch, until at Io p.m., after nine hours' hard work, we gave it best for the night and, tired out, lay down to sleep in our rugs on the ground, just as we were. The pessimists in Darwin would have gone to bed quite happy if they could have seen us.

September 7 th. - Things seemed to work better in the daylight and fresh air of the early morning, and after breakfast, and a quart pot of tea, we set to work again on the chain, and by 7.30 a.m. the car was on the level ground above the creek, and we were safely over, with nothing smashed. By 9 a.m. we had carried all the loading up, repacked and started off and, within an hour, struck the Roper Creek. Though there was no definite Range we were now on high land forming a line of watershed from which some of the creeks were flowing westwards to join the Daly and Victoria Rivers flowing into the Indian Ocean; others, like the Roper, which we struck near to its beginning, were flowing eastwards to the Gulf of Carpentaria. The same high lands sweeping south-eastwards on the one side and southwestwards on the other serve to demarcate the coastal regions from the great inland plains. Shortly after midday we left the telegraph line, turning slightly eastwards. Trying to avoid a very sandy patch, we struck off into the scrub and came to a dead stop in sand that was still worse. There is nothing much more uncomfortable, in the way of travelling, than to be pushing hard behind a car on a boiling hot day, with the sun streaming down and the wheels whizzing 
round, pelting you hard with a shower of penetrating fine sand. The sight would again have afforded a melancholy pleasure to the Darwin pessimists, and there were moments such as this, and not a few other similar ones, when we ourselves felt somewhat chastened in spirit and began to wonder why we had chosen this particular method of travel. It was 4 p.m. before we were clear of the sand, and shortly afterwards, to our relief, found a pool of clear water and lunched in peace and comfort, after the luxury of a good wash, the first for a day and a half, as our King Creek camp was a dry one and we carried water for drinking only, not for washing, for which we depended on water-holes. At 6.30 p.m. we were glad to camp beside a shallow pool of muddy water, called Easter's billabong, Easter being the name of one of the men on the construction party of the overland telegraph line.

September 8 th.-Over-night one of the green hides had been cut up to make long thongs for the purpose of binding round the tires. They were left to soak and soften in the water of the billabong so that they could be wound closely round the tires. To our annoyance we found that, under cover of darkness, dingoes had come in to drink and had taken them away to eat. Wie were off early, crossed the Stirling Creek, and went on till 9.30 a.m., when the off hind wheel blew out and we stopped for an hour for repairs. We were now on the upper waters of the Roper River, the streams feeding which rise on these uplands. One of them, the Birdum, flows almost due north from close to the Daly Waters and then junctions with the main Roper, flowing eastwards (Map. 4).

These northern streams are, however, only distinctly traceable during the rain season: their courses are very broad and shallow and, for the most part, only indicated, in the dry season, by a chain of water-holes, very few of which retain water for any length of time. Soon after midday we 
reached Bitter Springs, the native name of which is Mataranka (Map 4.4). It is quite different from any other spot within hundreds of miles and very picturesque. There are a number of springs bubbling up in pools of beautiful, clear, blue-green water, sometimes hot, sometimes cold, calling to mind, on a very small scale, the cold and hot springs of New Zealand. They lie side by side just as these do. Their banks are overhung with dense masses of moss, on which you have to venture with care lest you plunge through them into the hidden waters underneath. They overflow into water-holes bordered with Paper-barks and Screw pines. Here we spent five refreshing hours, luxuriating in a bath in a pool of green water six feet deep, at the bottom of which we could see the hot spring bubbling up. I would like to have spent a day or two in surroundings so interesting and so much more picturesque than anything we had yet come across, but we had to push on and started off at 5 p.m., only to come to a stop half an hour later when the flapping of the cow-hide covers of the wheels showed that they were being split and torn off and must be repaired. We left the main valley of the Roper, which was running eastwards, and turned south, with the telegraph line a few miles to the west of us, until, just after dark, we saw ahead the belt of trees bordering the long reach of the Elsey Creek, and camped on its banks close to where was once the homestead well known to all readers of $W e$ of the Never Never. As we ran in, our head-lights flashed on a grave showing its bronze slab and little rail enclosure, but there was no sign of human habitation-nothing save silence and desolation and, in the dim light, we could see no trace of Mrs. Gunn's old homestead (Map 4.I I).

September 9th.-Wandering about in the early morning we made out traces of walls and the outlines of rooms, while a few straggling bushes showed that once there had been a garden here with English flowers and fruit trees. The 
buildings had all been taken down some years earlier and the station removed to McMinns' Bar on the Roper River. We were away at 9 a.m. and, turning westwards, struck the telegraph line in less than half an hour, at Warlocks' Ponds, where there was not a drop of water, so far as we could see, though probably there were little pools somewhere, because for the first time since leaving the Katherine, we met a small party of natives here, or rather they caught sight of us and disappeared in to the scrub before we could get near to them. Just at midday we bumped into a low, very hard ant-hill hidden in the grass, and broke the "cow-catcher," fixed on the front of the car to protect the axle. All day till four o'clock we went on through dreary scrub with Mulga and small gum trees and here and there patches of Lance-wood, where the ground was harder and the going better. Suddenly, as we were running through some tussocks of grass, the car gave a sudden kind of jump and then stuck fast. In some strange way the fore-part had been lifted over an old stump hidden in a tussock. The front axle had gone over without being smashed, though it was slightly bent and twisted at an angle, as if the car were trying to turn sharply round. The stump was jammed under the body of the car. By sheer good luck no really serious damage was done, but it took an hour and a half's hard work, jacking it up, until it was clear of the stump, and then, to our great relief, we found that it would still run. Soon after 6 a.m. we camped not far from the telegraph line.

September Ioth.-All day, except when one tire blew out, we went on from 6.30 a.m. until 4 p.m., when we reached the Telegraph Station at Daly Waters where we were welcomed by Mr. Holtze, the officer in charge. The station is a large building, with quarters for half a dozen officers, and much too large, like the one at the Katherine, for the present diminished staff. It was, of course, built when the overland line was the only means of telegraphic communication with 
Europe. We spent a very pleasant day at Daly Waters while Cowper was overhauling the car, which it much needed after the vicissitudes it had experienced since we left the Katherine.

September I $3^{\text {th. }}$-Left Daly Waters at 9.30 a.m. and soon got into heavy sand, and at I I a.m. damaged the cowcatcher once more on a small ant-hill. It is impossible to avoid these, unless you crawl along in a continuous zigzag, because there are so many of them. Fortunately, the great majority, about two or three feet high, go down easily; the dangerous ones are the old worn-down ones that are usually hard and dome-shaped and hidden by grass. At I I.4O we came to what is locally known as a "jump-up," that is, a sudden rise, usually short and very steep, leading on to the high ground that in these parts forms really the line of watershed separating the belt of coastal country, from the great Central area. This "jump-up" faced towards the north. It was very steep and very rocky, and we were glad to be safely over it, though the climb only occupied ten minutes, and at II.5O we halted for half an hour's rest and boiled a billy of tea. At 3.20 a tire blew out, and at 3.50 another ant-hill caught the cow-catcher, or vice versa, and it was decided to dispense with it. At the top of the "jump-up" the elevation was approximately Iooo feet, but now we began to descend, but so gradually that it was scarcely noticeable. At 6 p.m. we came out on to the Sturt Plain, coated with thick black soil and seared with great cracks in the dry season, but so swampy with deep, sticky mud in the wet season as to be quite impassable. It is covered with tussocks of coarse grass and here and there a few low, wiry shrubs, but no trees. We bumped slowly across for half an hour and then camped. The sky looked threatening, but fortunately for us only a slight shower fell.

September I 4 th.-We started away at 7.30 and by 8.30 were safely over. Just as we entered the scrub and lightly- 
timbered country, on the southern side of the plain we saw, close by the track, one of those lonely graves that every now and then are met with far out in the Central wilds. The grave of this wanderer had been cared for and a slab above it was inscribed simply, "To the Memory of Lindsay Gordon. Died of Exposure on Sturt Plain, I90r." Many, in fact most of them, like the one here figured, have no record on them; no one knew who it was who had lain down to die far away from everywhere beside a little dried-up pool (Fig. 562). A passing drover had found his bones and buried them, fixing around the grave some rough-hewn stumps that would remain until a bush fire came or white ants ate them through.

At 8.50 we came out of the scrub on to the margin of Newcastle Waters, which form the northern end of Lake Woods. The latter occupies the lowest part and lies to the northern end of the great Central area that extends southwards to the Macdonnell Ranges, and eastwards to the Ranges of the Gulf country and the highlands that form the eastern boundary of the great inland drainage area of Queensland. The westward limits of the basin are only vaguely known, but they extend towards the Victoria River. Lake Woods really consists of a great chain of shallow depressions, filled with sheets of water that become continuous in the wet season. Fortunately it lies within the area affected by the annual monsoonal rainfalls, and though these vary to a considerable extent in this southern part, they are always sufficient to maintain a certain supply and the water is always fresh (Fig. 563A). It always has a very characteristic milk-white colour, due to the presence of innumerable minute particles of clay derived from a shale formation underlying the sandstone rocks of the Ashburton Range in which the main crceks that carry water into Lake Woods arise.

The place at which we halted for an hour was interesting to me because it was just here that, eleven years earlier, 


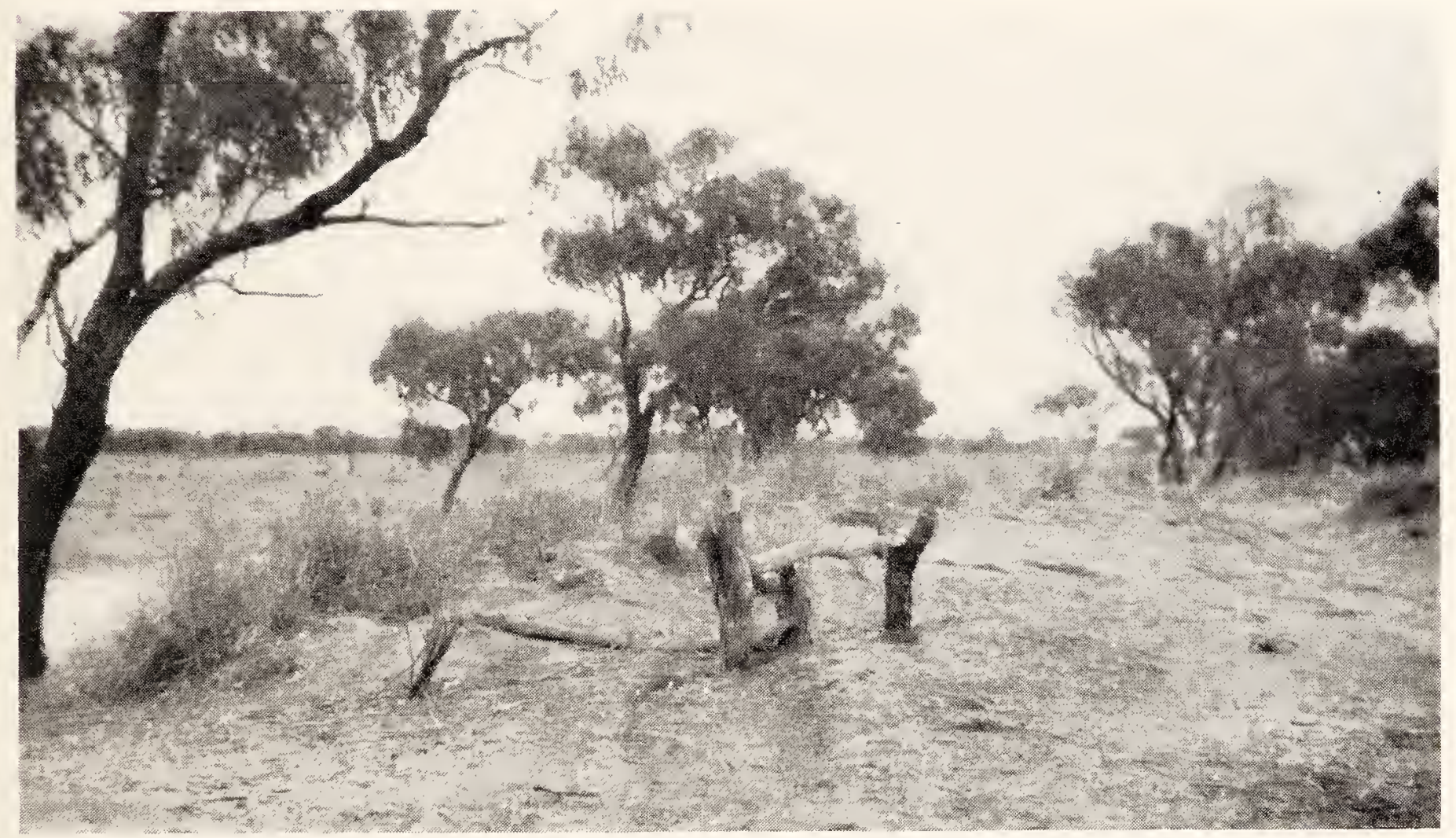

DR. KEITH WARD

FIG. 562.-A LONELY GRAVE IN THE AUSTRALIAN WILDS. 

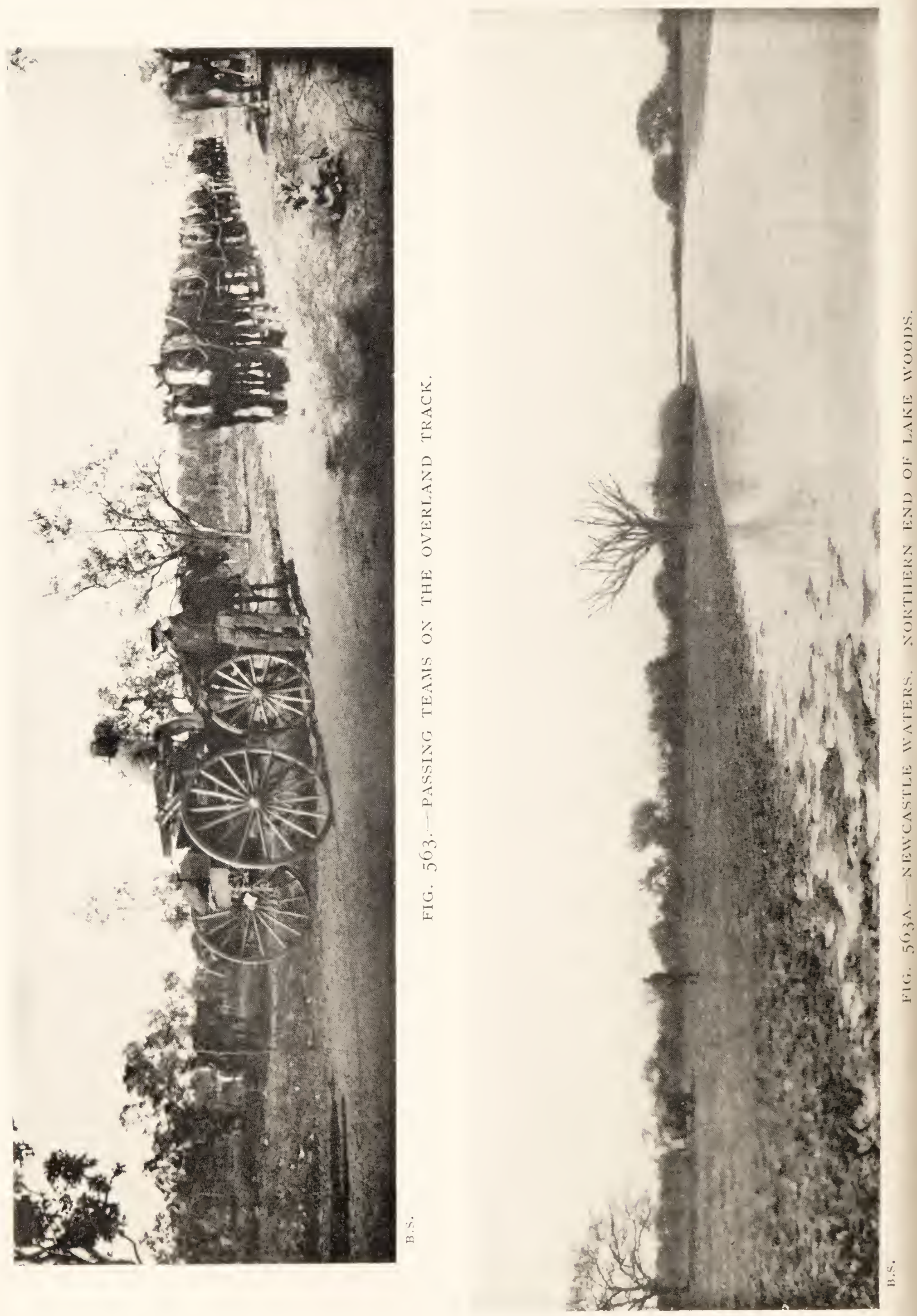
Gillen and myself, coming up from the south, had turned off eastward to Bates Lagoon on our way to the Gulf, so that this morning I completed my traverse of the continent from Adelaide in the south to Darwin in the north (Map 4.I3). In less than an hour, as we had a stretch of smooth country to traverse, we were at Newcastle Waters Head Station, where we were welcomed by Mr. Godley the manager and Mounted Trooper Noblett (Map 4.I2). During the night there was a heavy rain storm, and we were glad to be under shelter and not camped out in the open on the black soil of the Sturt Plain.

September I 6th.-Newcastle Station was our furthest south along the telegraph line. From here Dr. Gilruth had planned to strike across country, eastwards to Anthony Lagoon, where we could cut the track running northwards to the Macarthur River at Borraloola. We left the station at 7.30 a.m., M.C. Noblett accompanying us for some distance. He left us at 8.40. At first the country was good, with scrubs of Lance-wood and hard flats, across which we made most refreshing headway. There were no tracks and we were simply going across country, pretty well due east, making for a water-hole about fifty miles away, called Tandidja, which was supposed to be holding out yet. There was, of course, no such thing as a map of the country. Up here, when away from the telegraph line, one depends on rough plans drawn by, and information gained from, travellers, especially those who know the country from having travelled it with stock. All such knowledge is made common property, and at the outlying police stations you constantly see notices posted such as, "No water at Tandidja "; "Water very little at Tandidja" ; "Tandidja good water"; "No water between Anthony Lagoon and Powell Creek"; "Tandidja track closed"; "Only enough water Tandidja hundred head, rapidly drying," and so on. Water-holes are the most important topic of 


\section{WANDERINGS IN WILD AUSTRALIA сн.}

conversation amongst travelling stockmen. If you listen to the conversation between them when they meet in the bush, each leaning forward, in characteristic fashion, on the horse's neck, you will hear little but an exchange of questions and information about water-holes. "Is there any water at the King Creek crossing ?" "No, it's quite dry, but if you go up the left bank there's water about half a mile up." "So-long," and off each goes on his own way (Fig. 563). We were dependent on two water-holes, first of all Tandidja, and then Pundara, to carry us through to Eva Downs Station and so on to Anthony Lagoon. Shepherd, our half-caste boy, was very good in many ways, but of course was quite unacquainted with this country. There were no conspicuous landmarks to go by, at least not to a white man's eye, just simply wide, open country with belts of scrub and gum trees, all very much like one another; so, to be on the safe side, it was decided to secure a black boy, who knew the country, to act as guide. At I0.30 a.m. we pulled up and sent Shepherd back with a note to M.C. Noblett, asking him to send out to us a reliable boy, who knew the country, and to keep Shepherd at Newcastle Waters until anyone travelling north came through, so that he could get back along the line to the railhead at Pine Creek and so to Darwin. Meanwhile we settled down in camp for the rest of the day. We were some twenty miles out of Newcastle Waters and it was very hot, so that Shepherd would go slowly-probably have a good rest a few miles after leaving us until the worst heat of the day was over. He had a billy-can of water and plenty of tucker and was perfectly cheerful, but I was glad he was doing the walk back and not myself. When we were no longer on the move, the flies were a nuisance-right on till after sunsetbut the moonlight night was cool and refreshing, and we lay reading and smoking by our camp fire and listening to the mopokes calling in the scrub. 
September I 7th.-At 6.30 a.m. we heard the sound of horses approaching, and soon M.C. Noblett came in, accompanied by the owner of Betaloo Downs Station, where Gillen and myself had camped in I90I, by the side of a water-hole called Bates Lagoon after the former (Map 4. I 3). He was well known in these parts and right away down to the Gulf under the name of Bates, which for some unknown reason had either been adopted by or bestowed upon him, his real name, as we learnt afterwards, being either Bathern or Bethune; he himself did not seem to be quite sure which and was quite indifferent as to which of the three was used. M.C. Noblett had brought with him a boy named Jack who knew the country well, and at 7.30 we started off under his guidance, our two friends going back to Newcastle Waters. For four hours we went along over the plains slowly, where the country was sandy, but every now and again at a good pace across hard flats, the whereabouts of which Jack knew accurately. He and I sat at the back of the car, and it was interesting to watch him. It was remarkable that though he had never seen, or been, in a car before, nothing seemed to astonish him. He never spoke a word but leaned forward behind Cowper, who was driving. If he wanted him to steer to the right hand, he simply tapped him on the right shoulder and pointed out the direction with his right hand; if to the left, he tapped his left shoulder and pointed with his left hand. I could see nothing to guide him. To me one tree, or clump of trees, was very much like another and there was no sign of a creek or water-hole, but, after four hours' traverse, he pointed straight ahead to a few gum trees, half a mile away, and, for the first time, sat back in his seat. When we came up to them we found ourselves on the edge of a small waterhole, lying well below the level of the surrounding country. It would have been quite easy for anyone, who did not know the country intimately, to have passed within a few hundred 


\section{WANDERINGS IN WILD AUSTRALIA}

yards of it without catching sight of the water. The country was not stocked, so there were no cattle tracks running in that might have served to guide an ordinary traveller to it. We spelled an hour for lunch and were off again at $\mathbf{2}$.30. It was decidedly hot and we soon got into difficult country, known locally as "Bay of Biscay" or "debil-debil" country. The ground was hard and bumpy, with great cracks and mile after mile of tall, stiff, hard grass stalks, often three or four feet high, through which we crackled and bumped our way laboriously, wondering when the car would come to a stop in an extra wide crack or break an axle. It meant using a lot of petrol, and an inspection of the remaining supply was anything but reassuring. To lighten the load as much as possible, Gilruth, myself and Jack started to walk at 2.30 and went on till 5.30 , easily keeping pace with the car through the grass stalks and over the bumps and cracks. It was hot, dreary, monotonous work. Then came a little stretch of better country and at 6 p.m. we decided to camp on a low ironstone ridge.

September I 8 th.--During the night there were a good deal of thunder and a slight shower and it was nine o'clock, late for us, when we started. Till I0.30 we were slowly traversing rough ironstone ridges alternating with soft sand and " debil-debil" country. From the last ridge we saw a level plain covered with a broken line of Coolibah trees running across it, bordering the Monmoona Creek, where in good seasons water stands for long. Once more we started to walk. The creek, quite dry, was crossed just before noon and then on we went, hoping that we might reach the Pundara water-hole, for which we were making, under the guidance of Jack, before the petrol gave out completely, but at I. I 5, when we were still a good mile and a half away from a few scattered Coolibah gums that showed where the creek ran across the plain, the car came to a dead stop (Map 4.I8). There was not a drop of petrol left and we 
were stranded in the midst of an undulating plain, covered with grass so tall that, only a short distance away from it, the car was hidden from view. We rigged up a towel on the end of the only remaining slab of wood that we had fortunately kept, so as to show us where the car was and guide us back to it, and set off to find out if there was any water in the Pundara Creek, making of course for the gum trees. The hole we first came to was very small, nearly dried up, and what water there was, was rather like thin mud. However, we followed the creek down and found a larger pool. The water was a light khaki colour because of the fine sediment that was stirred up every day by the flocks of birds that came in to drink. It was margined by what was evidently a rapidly widening border of clayey mud, that had already dried into curled, glistening flakes all round the banks, where it was furthest from the water, and clogged our boots with masses of mud when we tried to get near to the pool in the centre. Its smell was decidedly strong. However, we were relieved to find any water that was drinkable.

It was fortunate for us that, in sending Jack, M.C. Noblett had provided us with a most excellent and reliable boy, as we had now to depend on him to secure help. The nearest habitation, and also water supply, was a little outlying station called Eva Downs, anything from forty-five to fifty miles away from Pundara, where the solitary white man in charge might, or might not, be camped. The nearest supply of petrol, that had been sent up to await our coming, was at Anthony Lagoon about the same distance further on. At 3.30 p.m. Jack started off quite cheerfully. He carried a supply of tea, sugar and flour and a small billy-can of water which was to carry him through to Eva Downs. We settled ourselves down by the car to await events, feeling sure that Jack, who knew his way over the country perfectly, would find someone, even if he had to go right through to Anthony Lagoon. If, which VOL. II. 


\section{WANDERINGS IN WILD AUSTRALIA сн.}

we did not contemplate, he were unsuccessful, and did not return, then it meant at least an extremely uncomfortable time for us crossing a waterless fifty miles of miserable and very rough, trackless country on foot, carrying, which we did not look forward to with pleasure, a supply of food and water sufficient to see us through.

We walked down to the water-hole, watched Jack, with his billy-can and bag of tucker, disappear from view in the tall grass, and then made another careful inspection of the water-hole, trying to form some idea of how long it was likely to last. Towards sunset flocks of galahs and white cockatoos came in and settled on the gum trees, rising every now and then to fly round, screaming, and then alight on the margin of the pool, to take their fill of water before settling down for the night. It was a picturesque sight, but they gave the muddy water an unpleasant smell and flavour and made us devoutly wishful that Jack would find the manager of Eva Downs at home when he reached the station. However, there was nothing to do but wait, so we gathered sticks enough from under the gum trees to light a fire, because there was no wood anywhere else on the plain, and walked back to where we could see the flag above the grass that concealed the car until we were close to it. For the sake of safety we trampled down the grass, which was dry and brittle, for a space round the car, lest it might catch fire, and then lighted a small one in a kerosene tin just big enough to boil a billy. The night was cool and fortunately we were far enough away from the water-hole for the mosquitoes not to trouble us.

September I 9th.-A disagreeable, strong south-east wind blew all day, but it kept the flies away to a great extent, so we were thankful for it and managed, with the aid of the car as a support on one side, to rig up a canvas sheet that we carried with us to cover things in case of rain, as a shelter from the sun, which was shining hotly. Examination of 
the car showed that the near hind spring had been broken with the incessant bumping of the last day's journey over the "Bay of Biscay" country. Fortunately we carried a spare one, so Cowper replaced the damaged one. During the morning we carried down to the water-hole three empty petrol tins which had been brought on for use in case of emergency, waded into the pool, filled them with the least foul water that we could find in the deepest part, which was now not more than two feet deep, and planted them, covered with sand and boughs, as a reserve store in the bank, under a gum tree on the north side of the water-hole, so as to keep them as cool as possible. It was evident that the water was drying up rapidly, and the lower it got, the worse the birds made it.

September 20th. - The day was hot with plenty of flies and there was nothing to do except read under the shelter of the fly and wander down to the water-hole to see if our store was safe and had not been disturbed by dingoes or perhaps a wandering blackfellow, which was not impossible though not likely. Our supply of bread, bought from Newcastle Waters, was done, so we made a few "Johnny cakes "- not a notable success, though edible - and, when darkness came on, flashed the car head-light every half-hour to indicate our whereabouts, in case, by very good chance, help might be coming. It was a cold, clear, moonlight night.

September 2 Ist.-Early in the morning, standing on the car seats, we saw something moving in the grass, far away on a slight rise on the horizon. After an hour it was near enough for us to make out a black boy on horseback. Just at eight he crossed the creek and came up to our camp, bringing a note from $\mathrm{Mr}$. Holt, who was then in charge of Eva Downs, to say that he would follow as soon as possible and had sent the boy on ahead with some tucker, as he thought we might be running short. He told us also that 


\section{WANDERINGS IN WILD AUSTRALIA сн.}

Jack, who left us on Wednesday at 3.30 p.m., had walked the forty-five miles to Eva Downs, reaching there on Thursday evening about 6.30 p.m. He had walked all night long and spelled a little in the heat of the day. There was no one there when he arrived, so he stayed the night, hoping $\mathrm{Mr}$. Holt would turn up early in the morning, but, as he did not do so, he commandeered a horse and started off for Anthony Lagoon. Fortunately for us Mr. Holt, who was returning from the latter, met him eight miles out and immediately sent his own boy Billy to us, leaving Jack to ride on to Anthony Lagoon to deliver his note to the constable in charge and secure the petrol. Billy started from Eva Downs at 2.30 p.m. on Friday, travelled all night and reached us at 8 a.m. on Saturday. At 8 p.m. in the evening Mr. Holt came in with a dray and ten horses. Needless to say, though we knew we could rely upon it, if once our message reached him, we were grateful to $\mathrm{Mr}$. Holt for his prompt action and kindness and keenly appreciated the trustworthiness and assistance of the black boys Jack and Billy.

September 22nd.-It was no use waiting at Pundara till the petrol came, so, early in the morning, the car was hitched on to the dray with ropes and we left our camp (Fig. 564). The car did not look its best, dragged and bumping along, but we were glad to be on the move, even at the rate of about three miles an hour. At midday we halted and sent the horses back for a drink at Pundara, starting off again at 4.30 . After another halt at 6.30 p.m. we were off again. The night was cold but it was brilliant moonlight and we walked most of the way, quite enjoying the fresh air, until 4.30 a.m., when we gave the horses a spell and had a sleep for five hours, or rather tried to have one, because the ironstone ridge on which we camped was hard.

September 23 rd.-We left camp at 9.30 a.m., and an hour later met M.C. Holland, who brought us a case of petrol. The car was unhitched and, leaving Mr. Holt to follow 


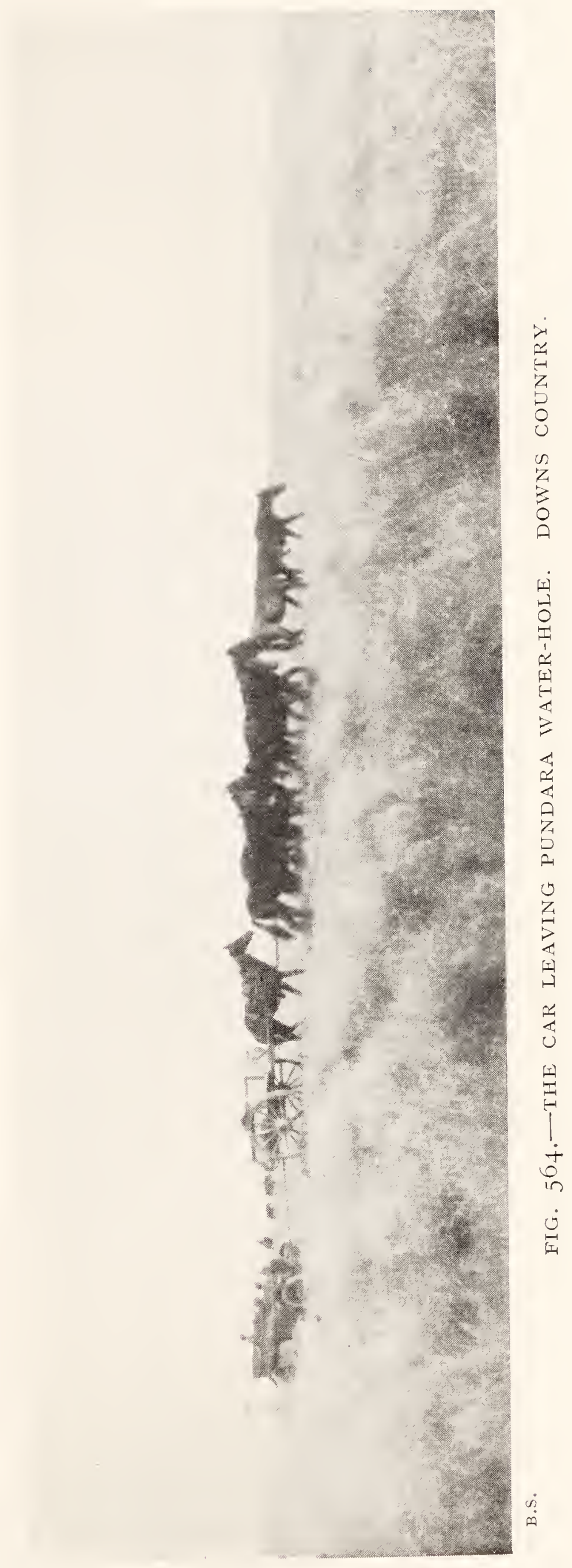




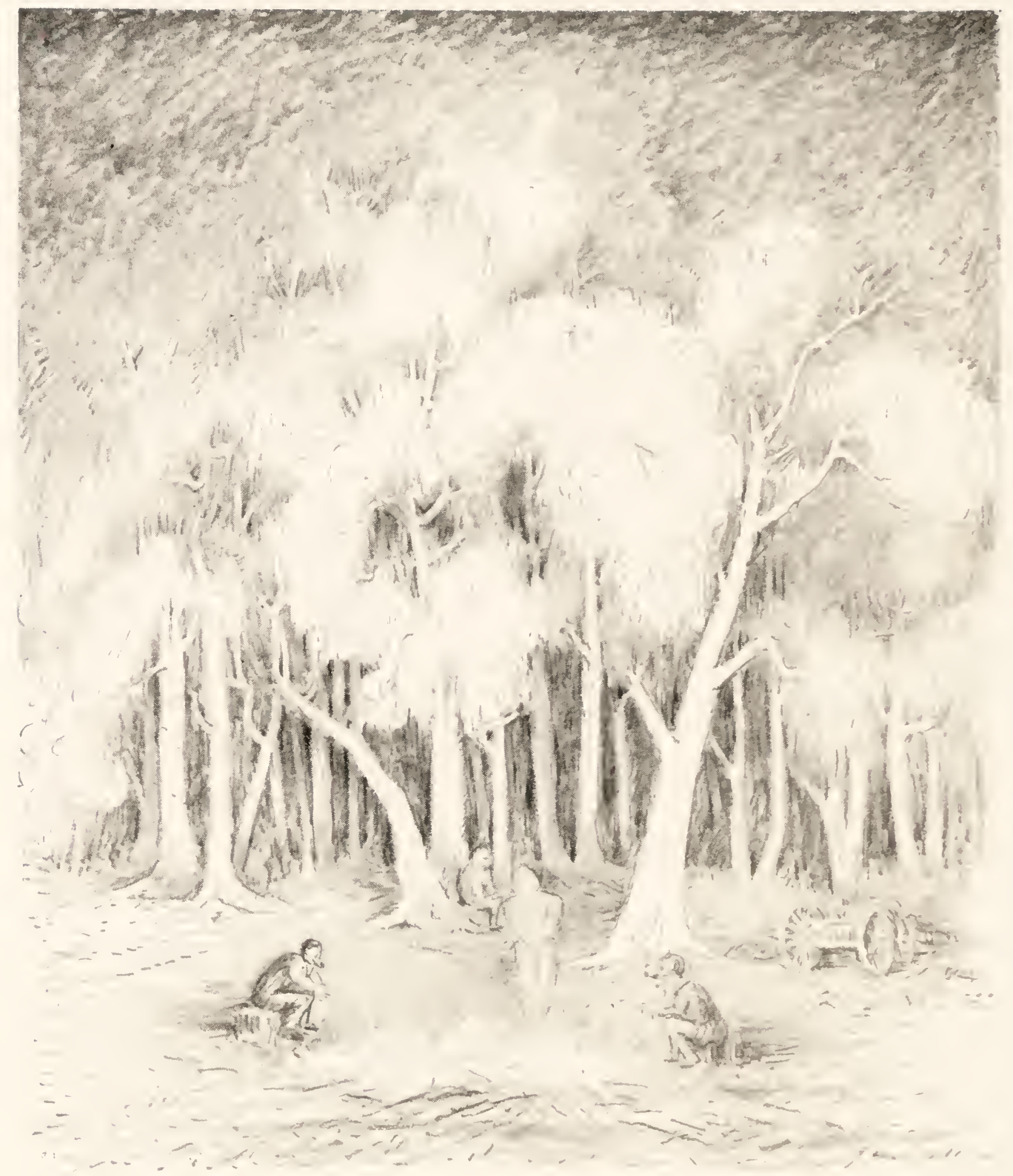

B.S. dei.

FIG. 565 - XIGHT CAMP AMUNGST THE WHIE GLMS. 
after with the dray, we motored slowly on over very rough country, damaging the near hind spring, for fourteen miles to a water-hole called the Broads, where we waited for Mr. Holt, and, when he came, lunched luxuriously on fresh steak, grilled on the coals, and tomatoes from Eva Downs. From here on to the station there was a fair track and the running for the most part was smooth, so, leaving the black boys to bring the dray in, we took Mr. Holt on with us. He had lived away in the back blocks for long years. 'This was the first time he had been in a car, so he sat back and enjoyed himself thoroughly, finding it much more pleasant than jolting along over "Bay of Biscay" country in a dray.

September 24th.-Cowper spent the morning overhauling the car. The hind spring was repaired by putting a new leaf on the top of the broken one. Of course springs and tires were all bound round with green hide thong which had to be renewed time after time. At Eva Downs (Map 4. I9) we fortunately met with a well-known Territorian, Mr. Grainger, who was then over-landing cattle southwards, and committed the boy Jack to his care, as he would, later on, be travelling through to Newcastle Waters. Jack was not the loser by his efforts on our behalf, but he seemed to regard them all as part of the day's work. It was 5.30 p.m. when the car was put together again, and we started. For the time being there was no more "debildebil" country. We were on a track; the evening was delightfully cool and, in the moonlight, we ran through to Anthony Lagoon and reached the station just before midnight (Map 4.20).

September 28 th. - Anthony Lagoon is a large water-hole, about half a mile long and perhaps two hundred feet broad, but it is only in the rain season that the basin is full. It was not more than a quarter full when we were there. The police quarters are placed on a flat on the east side; on the west, north and south, the scrub comes down to the margin 
of the lagoon. A track leads away for half a mile from the east bank through the scrub to a little store. Why it is placed in such an absolutely out-of-the-way spot and who goes to it is a problem. The officer in charge of the station, M.C. Holland, a second officer, M.C. Harrison, and Biondi, the store-keeper, comprised the total population of Anthony Lagoon, though it is on the track running from Cammoweal to Borraloola and there are occasional passers-by, including a monthly mail man. There are beautiful Jasper and Onyx stones to be picked up on the flats, but beyond these there is nothing of interest. After three quiet days here we started off, taking M.C. Holland on with us. Since leaving Newcastle Waters the country has been gradually, though almost imperceptibly, rising. As we were in no great hurry we stopped for an hour to boil a billy of tea and, after about sixty miles' easy run, during which we passed Walhalla Station and here and there small mobs of cattle gathered round one or two water-holes that were rapidly drying up, came to the edge of the table-land. Approaching, as we did, from the inland side, you could see nothing but more or less flat, gently rising country through which valleys begin to run down eastwards. Approaching from the coast you see what looks like a long range of hills rising somewhat abruptly from the lowlands. Following one of the valleys amongst the hills, as it rises towards the interior, you suddenly come, at its upper end, to a short, sharp ascent that sometimes forms a definite little escarpment. These " jump-ups," as they are called, are very characteristic of the coastal ranges and, here and there, form definite lines of little cliffs that margin the valleys. If the coastal edge of the inland plain were much loftier than it is, and the valleys had been correspondingly eroded to a greater depth than they have been, the same physiographical features would have been produced, with great gorges and precipices similar to those that are characteristic of the celebrated 
Blue Mountains that border the coastal margin of the inland plains in New South Wales. From the top of the "jumpup " we looked far away over the coastal country into which the coastal ranges dipped down. In the evening light, the face of the hills looking eastwards was all rich purple and brown with the valleys between them in deep purple shade. We camped amongst the foothills by the side of Top Creek water-hole.

September 29th. -We only came on for a few miles to-day and camped at the Top Spring, where we found a few Binbinga natives and also three white men with a mob of horses. Like ourselves they were out of meat. We bathed in a beautiful pool amongst rocks with clumps of ferns, Screw pines and Paper-barks. Close by, on the trunk of a large white cedar, the following record was cut: "Arthur Catts came from Macarthur River, June I 885." Twentyseven years ago, when he found his way up here, there were no tracks and he must have had rather a rough time.

September 30 th. - It was 2.30 p.m. before we left Top Spring and came down on to the gum-tree flats. At six o'clock we came to a stop, as the petrol ran out, so there was nothing for it but to camp and wait until a further supply, which was to be sent up to us from Borraloola, arrived. On the way, Holland had shot a large Varanus lizard, five feet long, out of which he made a most excellent stew. The legs and back are very good and, save by an anatomist, would easily be mistaken for a rabbit when dismembered and cooked. A travelling drover who came along the track in to our camp a few hours later, and had been without meat for a day or two, enjoyed it very much until he heard what he had been eating.

October I st.-A quiet day round the camp. In the afternoon we went along the flats for three miles and then turned into the Ranges, in search of a water-hole called by the natives Dungaminni. We went up a narrow valley with 
Karbeen gum trees and Angophoras and found a very picturesque rock-pool, shut in with precipitous cliffs that rose straight out of the water and must have been nearly 200 feet high. Down the crevices hung great festoons of luxuriant, dark green ferns, dripping with moisture and falling in cascade-like masses till they touched the water. Palmlilies overhung the end of the pool leading out into the valley. The contrast between the semi-tropical luxuriance of the pool and its surroundings and the dry country, only a few yards away, was very striking. Dr. Gilruth and Holland went in search of meat and secured a young heifer, which we had been told to do if our supply ran short, so our larder was replenished and once more we fed on fresh steak grilled on the coals. It was dark when we walked back to camp, and for miles the forest land round the foot-hills and on the flats was ablaze with bush fires but, fortunately, they did not burn our camp out.

October 2nd.-M.C. Giles came in from Borraloola with enough petrol to carry us through, so we started off and camped that night within a few miles of the Macarthur Station (Map 4. I 7). Early in the morning, trying to cross the river bed, which was of course quite dry, the car stuck fast amongst the boulders. Dr. Gilruth and myself walked on to the station and Mr. Amos, the owner and manager, kindly sent two strong horses to drag it back on to the north bank, because it was evidently safer to continue on the main track to Borraloola, which ran on that side, rather than risk a double crossing of the river bed by bringing it into the station. After a few very pleasant hours with Mr. Amos, whom I had last seen when Gillen and myself spent Christmas Day of I90I with him and Sergeant Stott at Borraloola, we crossed the river just below the station and met the car. Things were very different now from what they were ten years ago. The native camp with the dead blackfellow's bones in the middle of it was gone, and the old station 
buildings were fast falling into disrepair, showing little sign of the many thousands of pounds that it had cost, in the early days, to import and transport material from the mouth of the river to establish and build what was then a very picturesque and comfortable bungalow homestead. We followed the track along the Macarthur Valley that Gillen and myself had traversed on horse in I9O I and reached Borraloola on October 4th (Map 4. 7).

October 5 th to 8 th. -We spent four days at Borraloola, where the Administrator was busy making inspections with Sergeant Dempsey, the officer in charge of the Police Station. My old friend Mr. McLeod was still in charge of the store, with the trade of which overland carriage from Queensland to the out-back stations had sadly interfered. The old court house was as bare as when Gillen and I lived in it, ten years ago, and more dilapidated, and the Chinese garden was in ruins. The little township was absolutely dead. At the hotel was a certain Captain Barclay. I had known him long years ago when his name was not quite the same. The official title had also been self-bestowed. He had been wandering about the Centre for years and, amongst other things, had persuaded himself that he was a great explorer and the discoverer of the Barkly table-lands. It had not occurred to him that these were called after a Governor of Victoria whose name was spelt differently from his own. During his wanderings he must have learned to use a theodolite and was now employed, I think, on a survey of the mouth of the Macarthur River and the surrounding country, with the idea of running a line from Borraloola to the mouth of the river and so help in opening up the back country. Fortunately the results of an earlier rough survey of the country by Kilgour were available to work upon, but, even so, I have not heard of any important outcome of his work. Some months after returning from the Territory, I was interested to read in a southern paper a 
notice to the effect that H.M.S. surveying ship the Anne, Captain Barclay in command, had sailed from Darwin to continue surveying work in the Gulf of Carpentaria. It would probably have surprised the Admiralty to find that H.M.S. the Anne was a ketch of some twenty tons with a crew consisting of a captain, chief mate, a boy or two and perhaps a cook. However, Captain Barclay was a man of considerable resource and had complete confidence in himself, but, at the same time, I should think it possible that his surveys might need careful checking.

We left Borraloola on the afternoon of October 8 th, and, after a hold-up in some sandy country, where we had to improvise a corduroy road with the help of bushes, camped in the dark at what is called the Top Crossing on Blarney Creek. The Administrator was anxious to see as much as possible of the outlying country and cattle stations between the Macarthur River and the Roper, so we pursued a very interesting but somewhat zigzag course across the country, which has remained practically unmapped since, in I 845 , Leichhardt traversed it on his journey from Queensland northwards along the western side of the Gulf of Carpentaria and then on to the Coburg Peninsula and Port Essington. The stations that we planned to visit were Bauhenia Downs, Tanumbirini, Nutwood Downs, Hodgson Downs and McMinns' Bar on the Roper River; then on to Mataranka, following up the Roper Valley, and so to Providence Knoll and the telegraph line and back to Katherine Creek and the railway head at Pine Creek.

October 9th.-Left camp at 6 a.m. and had a good run to Buffalo Creek, where was camped the drover who had, years ago, been concerned in the case in which the aboriginal Neighbour had been convicted of murder and he had been acquitted. We spelled for half an hour, but of course no reference was made to the matter during our talk, though I was interested to meet him. One wonders if memories 
of old times and things that are past are sometimes recalled to a man like this during quiet evenings in the solitary bush when the light from a lonely camp fire makes the white, ghost-like trunks and gnarled branches of the gum trees stand out starkly against the darkness of scrub and sky. At ten o'clock we were off again, got into heavy-going sand which meant pushing behind, and then on to Shady Creek at 2 p.m., where we found M.C. Giles, who had carried on ahead from Borraloola seven cases of petrol. Here again the car had to be jacked up and a bush track made for some distance. At 6.I 5 we camped at Day's Lagoon.

October I oth.- - Started at 5.30 a.m. There was a difficult creek to cross an hour later and a worse one at 6.45 , out of which, after much pushing behind, we emerged at $7 \cdot 30$ and, just one hour later, came to Bauhenia Downs (Map 4. 22). The station consisted of a small log hut with outhouses, where we were welcomed by the manager, $\mathrm{Mr}$. Scrutton, an old identity of the Gulf country. It was built on the bank of a long, narrow lagoon, called Jajujin by the natives, overhung with lovely Paper-barks and really very picturesque (Fig. 566).

October I th.-Left Bauhenia Downs at 5.30 a.m. Amongst its many drawbacks in the wild bush, there is one great advantage of a motor-car, which is that you have not to wait for the horses to be brought in if, as often happens, they have strayed far away during the night. At 5 p.m. we camped at O.T. Lagoon. The name is due to the fact that when the Overland Telegraph Line, commonly known as the O.T., was being erected, this lagoon was an important camping ground for teams carrying up stores and materials from the coast to the line parties (Map 4. I 5). The country was all burnt out and nothing like so pleasant to travel over as when Gillen and I had been there in I90I. Also there was a little hut with a box, in which chance travellers could leave any letters and papers that they might have brought 
from Borraloola on the one side, or the telegraph line on the other, for the isolated dwellers at Tanumbirini station for which we were now making. Here we camped for the night, some hours being spent in lacing fresh cow-hide thongs round the tires.

October I 2th.-We had rather a tedious day's journey with "Bay of Biscay" country, stony creeks and still rougher stony ridges to cross, on which both petrol cases and two water tins bumped off and our tires blew out. At 3.30 we came to a deep creek and had to make a long detour until, at last, we came to a place where the deep banks were slightly less precipitous, and with a rush down that carried us some way across the sandy bed and a second gallant one up the opposite bank, we landed safely, and thankfully, on the top and paused to take breath and cool the engines. Then came a run of two and a half hours, over smooth, hard country, and at 4.30 we were at Tanumbirini, which is as isolated a little homestead, far away from everywhere in the never-never country, as can well be imagined (Map 4. 34). There were only two white adults living on the station, Mr. and Mrs. Mara, and, when we came, we found Mrs. Mara absolutely alone there except for her little baby, only a few months old. The work of her husband, the manager, forced him to be often away for days together on the run. The little homestead was delightful and we could not but feel the deepest admiration for the woman who thus shared her husband's life and work in the attempt to open up the great, lone lands of the north. Elsey Creek, so well known to all readers of $W$ e of the Never Never, was a centre of civilisation compared to Mrs. Mara's little home in the intense isolation of Tanumbirini. For weeks at a time she was perforce living alone, surrounded by wild blacks, no one to do house work save one or two station lubras whom she herself had trained, and no help in time of need nearer than Borraloola, at least a week's ride away on horseback. Now and then a 
stray traveller left letters and papers in the little box at the O.T. Lagoon, but, save for this, no news came in to Tanumbirini from the outside world.

October I 3th.-We would willingly have stayed longer at Tanumbirini, but had to press on and, early in the morning, motored off, leaving the lonely white woman to carry on her work. Perhaps it may some day occur to our legislators to erect in Canberra a monument to commemorate the work of the women pioneers of the Australian bush.

It was a rough day on the motor. There were plenty of " debil-debil " country and two "jump-ups," and it grew dusk and then dark, but still there was no sign of Nutwood Downs station for which we were making. It was not until I 0.45 , and pitch dark, that we caught sight of some flaming lights. The station natives had, of course, heard the droning noise of the car from afar. They had been told that what, when they had seen it, they afterwards described as " a little-fellow dray with insides that made him go self" was coming. But at last, when it did come, they could not imagine whatever weird, wild, awful thing with two terrible, enormous, blinding eyes, it was that was bearing down upon them from the outer darkness. The flaming lights we saw were great torches of Paper-bark with which, much to the terror of Cowper, they ran careering round us as the car came to a stop. It was a wild welcome, but there was too much petrol on board for us to appreciate it, and with the aid of Mr. Farrar and one or two station men the natives were persuaded to remove their torches to a safe distance.

October I 4th.-A quiet morning at Mundallan, which is the native name for Nutwood Downs, with Mr. and Mrs. Farrar, who are really wonderful. They are two of the oldest settlers in the Gulf country, and though, both of them, beyond threescore and ten, are brimful of energy and brightness. It was quite refreshing to be with them. The car, of course, was the centre of attraction. It was a little time 


\section{WANDERINGS IN WILD AUSTRALIA cн.}

before the natives became accustomed to it. Cowper started it in the morning, to see if it were all right, and when he tootled the horn to add to the effect, there was a wild stampede of the natives standing round and a mad rush for the scrub. Some of them went like cats up the gum trees, but when two of them fell down, fortunately on their heads, so that no damage was done, either by the fall or the car, consternation gave place to peals of laughter, and, in a short time, the children were clamouring for the real "joy-rides" that Cowper gave them to their intense delight.

October I 5th.-Yesterday afternoon we left Nutwood Downs and camped for the night at Crawford Creek. At 7 a.m. this morning we started. The country gradually rose until at 8.30 we came to a "jump-down," which was rather a severe and sudden one. The ground was very rough and, twenty minutes later, a tire was punctured. At nine o'clock we ran down into a nasty creek which there was no avoiding and had to be crossed somehow. Its banks were steep and the bed full of soft sand in which we stuck fast. By dint of jacking the wheels up on to small logs and boughs and pushing behind, when the engine started, we at last got it to a spot where there was a small gum tree on the top of the bank to which the block and tackle could be fixed. Then came a continuous pulling on the endless chain until, hot and grimy with perspiration and sand, we dragged it to the top of the opposite bank at I.3O, and rested from our labours for an hour while we boiled a billy of tea and had a smoke. For three hours after that we had no further serious trouble, but the last part of our journey to Hodgson Downs, called Minyeri by the natives, was through scrub where, fortunately, the bushes that came in our way were easily knocked down by the car. The owner, Mr. Angus Mackay, was at home and made us feel more than welcome. The homestead was built close to a water-hole, beside which was a large garden under the management of Ah Toy, who 
with the aid of his staff of black boys and lubras produced a plentiful supply of vegetables. That evening Ah Toy must have excelled himself. You need to have been in the bush for some time, feeding on damper and jerked beef, to appreciate to the full the delight of fresh vegetables. We had no fewer than seven kinds-spring onions and Spanish onions, ordinary potatoes and sweet potatoes, tomatoes, cabbage and lettuce - all of them prize specimens fit for any horticultural show, or at least it seemed so to us-and then, by way of dessert, a plentiful supply of water-melon. We must have been full of vitamins of all kinds. What with these and delicious, fresh and beautifully cooked steak, rice, served up as only a Chinaman can, and jam, we fared sumptuously and forgot all such minor discomforts as hauling on an endless chain for three hours at a stretch.

October I 6th.-We spent a quiet morning at the station. I had a long and interesting talk with Mr. Angus Mackay, who has had much experience of the Territory, on aboriginal matters. When we were leaving at two o'clock, Ah Toy brought a great wheelbarrow loaded to its fullest capacity with water-melons, cabbages and shallots. We were piled up with luggage, petrol cases and water tins, but gratefully stowed away as much as we could and started off. By reason of a stiff, rocky " jump-up " and a creek, in which we stuck and had, as usual, to push behind, we only did thirtyfive miles, and camped on stony ground, very uncomfortably, in the dark.

October I 7th. - Left camp at 5.30 a.m. It had originally been our intention to go across country north-west from Hodgson Downs to the Roper Bar, but we were long behind our scheduled time, so this part of the programme had to be abandoned, and, instead, we made straight north for McMinns' Bar (Map 4. 32). Mr. Mackay very kindly arranged for a boy to go across country to the Roper Bar with a note to Cahill, who was waiting for me there, telling 
him that I was obliged to give up the Roper River part of our trip and asking him to retrace his steps and meet me at the Katherine, where I would wait for him. The track between these two places was reputed to be a good one. There certainly was a track, but what is a good track for a heavy dray is not necessarily a good one for a motor-car. Three hours out from camp it bifurcated. We had no clue as to which track to take and, presumably, chose the wrong one, at all events we soon got into difficulties on "debildebil " country and bumped along slowly, wondering how long the springs could possibly stand it. They were bound round with green hide thongs, because both hind ones had already been broken. At noon, to our great relief, we came to a patch of Pandanus trees and saw a delightful waterpool, full of purple lilies. In five minutes we were in the water and, after lunch, started off refreshed. There were no tracks and we got into very rough country with grass as tall as the car and holes that had to be carefully looked out for. Ahead of us we could see a range that we knew was near the Red Lily Lagoon on the Roper River (Fig. 567A), so made for this and struck the lagoon shortly before three o'clock. It was a lovely sight with acres of great lotus leaves and endless big red flowers standing erect on stalks four and five feet high above the water. From McMinns' Bar we were on a fair track, and in less than an hour were at the station, which is situated above the Roper where the river is hemmed in by steep banks, and, as the name implies, a bar runs across it. These bars are very characteristic features in the beds of all the rivers, such as the Roper and Macarthur, flowing into the Gulf. Very often, as on the Roper, they hold back the stream and form (Fig. 567) the lower end of a beautiful permanent water-pool that may often be a hundred yards broad and a quarter of a mile or more long. The stream below the station was actually flowing as, indeed, it was at many parts of the Roper, but not every- 
where. In places, such as the Red Lagoon, it spreads out and there is no actual flow of water during the dry season. Of course in the "wet" the whole country is flooded and impassable; in the "dry," a yard or two away from the water's edge, everything is parched. It is strange to see great sheets of water in the midst of land covered with grass so dry that it often powders up when rubbed in the hand.

October I 9th. - A quiet day at the station. Mr. Stevens, the manager, came in and I was very glad of the chance of a talk with him.

We were in difficulties as to petrol. A case sent here contained one empty tin and one only three-quarters full, so that our supply was running short. Mr. Stevens kindly arranged to send some horses after us so that, if the supply of petrol failed entirely, it would be possible to get on to the Katherine. We left McMinns' Bar in the afternoon and went on up the Roper Valley, where the river, in parts, ran between cliffs in a regular gorge and where, every now and then, we crossed curious, fan-shaped patches of limestone.

October 20th. -We were off at 5.30 and had a delightful run, still up the Roper Valley, to Bitter Springs or Mataranka. The valley was bordered with low, wooded hills, and along by the river were great gum trees, enormous Paper-barks and tall palms. As we motored up in the early morning when everything was fresh and cool, it was just like passing along a magnificent avenue that would have made a great entrance to some city of the future. It is sincerely to be hoped that no settlers will be allowed to interfere with the great trees that border the Roper and other rivers in the Gulf country. It is difficult to understand why it is said to have been decided to abandon Mataranka as the site of the future headquarters of the Territory Administration, in favour of such a hopelessly forsaken spot as Newcastle Waters, where there is no beauty, and never VOL. II. 
can be, and where, for the greater part of the year, anywhere away from the margins of the muddy water-holes, the surroundings are sterile, utterly depressing and monotonous beyond description. One can only pity the poor officials and, more still, their women-folk who are condemned to live in such a place. From Mataranka we went on and camped at Providence Knoll, where we were on our old tracks close to the telegraph line.

October 2 Ist.-At King Creek our petrol gave out completely, but, fortunately, the horses came up, so Dr. Gilruth and M.C. Holland rode on to the telegraph station at Katherine Creek. Next day petrol came to the car and we were all in the station by the evening, though, between it and King Creek, we had five punctures and began to wonder whether, after all, the end of our journey would not be done on foot. 

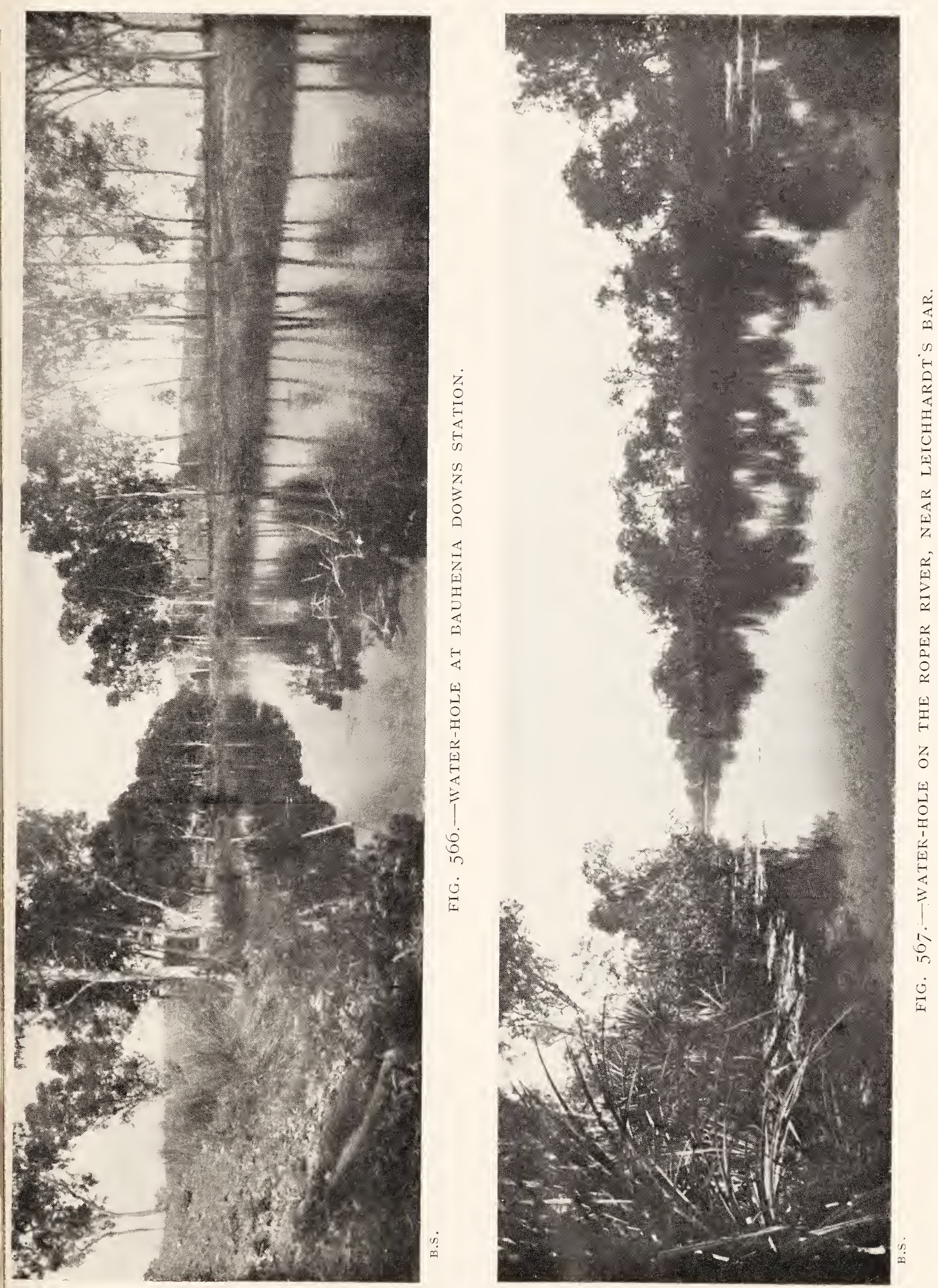

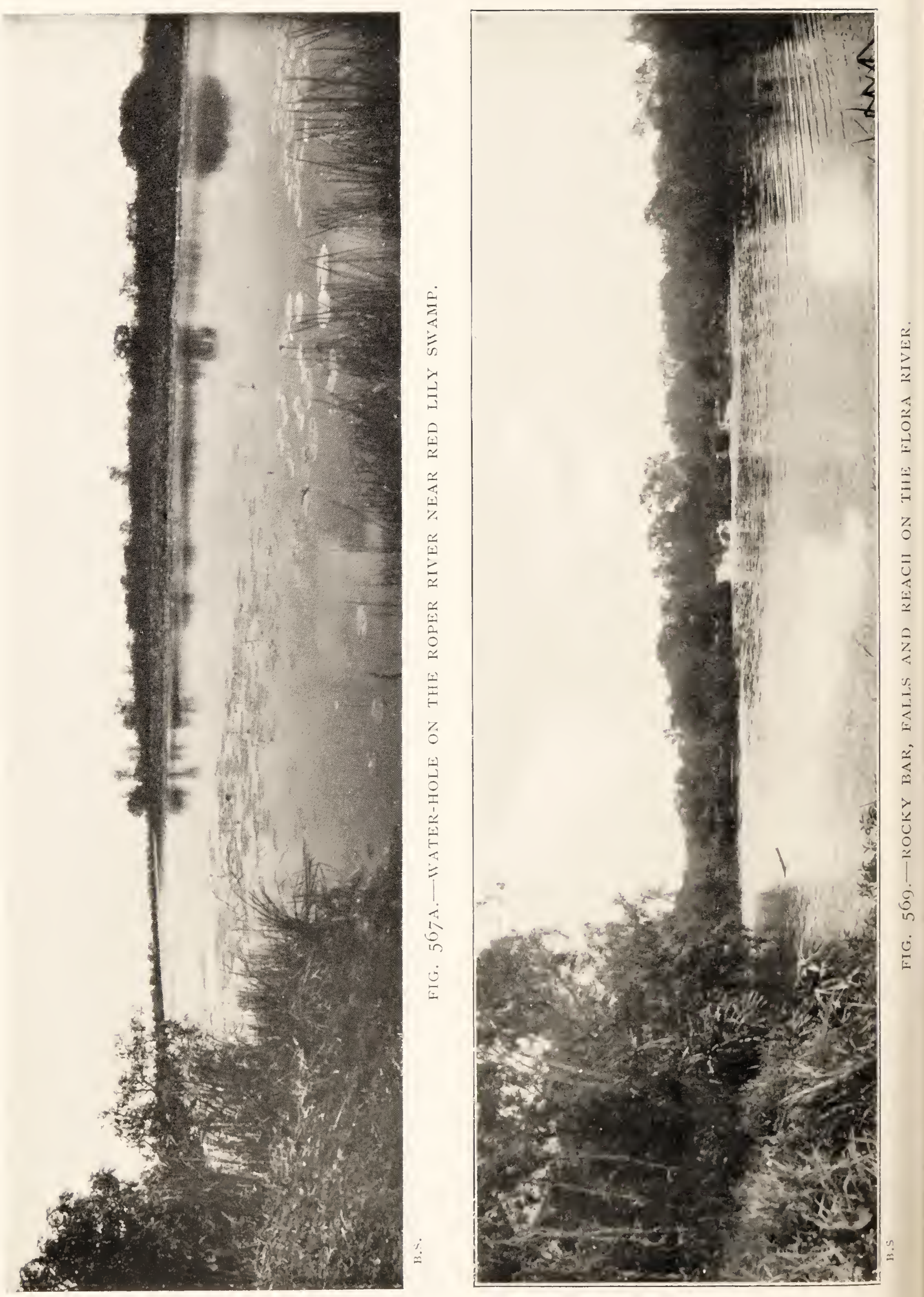


\section{CHAPTER XXXII}

THE FLORA RIVER, AND BATHURST ISLAND

After our motor trip was over and Dr. Gilruth had gone to Darwin I stayed behind at the Katherine, waiting for Cahill, who came in from the Roper on October 26th. I had sent down to Melbourne for a phonograph and, fortunately, it had come in time for Cahill to bring it with him, so we managed to secure some good records of native corrobborees and ceremonial songs. The station was built on the southern margin of the gorge, through which the river flows, and which also will necessitate the building of the only bridge of any serious size, on the overland railway line between Darwin and Oodnadatta, a distance of 1200 miles. A steep path leads down to a large permanent water-hole in the river. There are no crocodiles in it, so bathing is safe.

November 4 th.-There was a good deal of departmental correspondence, which I had arranged to have sent to me at the Katherine Station, to be attended to, and also the few quiet days spent there gave me the chance of doing some work amongst the natives. We packed up and, to-day, Cahill and myself started off for the Flora River, where we hoped to come in contact with one or two tribes, more especially the Waduman and Mudburra, who live on the Victoria River country. Leaving the station we went out into the bush, along the south bank of the river. Our cavalcade consisted of a buckboard drawn by two horses on which the cinematograph, phonograph and photographic material and our swags were carried, six pack-horses, carrying supplies, 


\section{WANDERINGS IN WILD AUSTRALIA сн.}

and five or six spare ones. We are now near the end of the hot, dry season; there has been no green feed for the stock for months, so the horses are in poor condition and we have to travel slowly. This afternoon we had four difficult creeks to cross, which involved some cutting down banks and filling up holes with stones.

November 5th.- Started at 6.30 a.m., which meant breakfast at $5 \mathrm{a} . \mathrm{m}$. with loading and packing afterwards. Our course was running roughly parallel to the main river, so we were continuously crossing nasty creeks, and at $\mathrm{I} .30$ came to a larger one, called King Creek. It looked almost impossible, so we gave the horses a spell, had some lunch and reconnoitred, but could find no better way down. The rough track went, at a formidable angle, down into the creek, which had hollowed out for itself a narrow gully, fully twenty feet deep, and about twenty yards across. It had, of course, formed an outlet for the flood waters streaming from the surrounding flats into the creek during the last rain season, so that the wheel marks had been transformed into runnels, into which the horses could easily slip and break their legs. The creek bed was full of stones on the near, and soft sand on the far side, where, luckily, the ascent was not quite so abrupt. It took us nearly two hours to cut down the bumps and fill the ruts with stones and earth. Then we unloaded the buckboard, dragged it close to the edge of the precipice, ran a small sapling through the spokes of the hind wheels and tied a rope on to the axle. The horses were put in, the three boys and myself dug our heels in and clung on to the rope as if we were engaging in a tug of war. Cahill hung on to the reins and the brake, and then, down the whole thing went and landed on the stones without turning head over heels. The sapling was taken out, we pushed behind with all our might to help it through the sand, and then with a sudden rush, and much language, Cahill took the horses up the other 
bank and reached the top in safety. The hind axle was a little bent and the wheels did not run quite true, but nothing was smashed.

Once across the King, we turned north into the scrub until we came to its junction with the Katherine, where we camped. The river was flowing between steep banks, and we had a bathe where the water was shallow and running over stones; there were deep pools, but these are to be avoided because of crocodiles, for which reason also the horses had to be carefully shepherded. At sunset great banks of clouds came up, so we spread a tarpaulin over the buckboard and its contents. We used the overlap of the tarpaulin as a tent fly, the boys sheltering under the buckboard.

November 6th.-A few drops fell during the night, but by early morning the clouds had cleared off. The only excitement of the day was crossing Scott's Creek-a wide channel with steep banks and deep sand. It was just as much as the horses could manage, because they were very poor, but, somehow, Cahill got them over. After this there was bumpy, " debil-debil " country and we camped beside a muddy water-hole called Sardine Creek. It secured its name in very much the same way that native names are given to places. It was very simple. Tradition says that an ancestral drover, who must have been of rather a refined type, wandering over the country, as the native ancestors did, had eaten a tin of sardines here-hence the name. In the evening a teamster named Krugercame in. He is camped about a mile away, with a wagon and team carting stores to Willeroo station, and has to wait until a storm comes, because there is no water on the track south for forty miles.

November 7 th.-For hours we plugged along through sand and thin scrub and then got in to better country, where there had evidently been passing storms, because, in patches extending sometimes over many acres, the ground was 


\section{WANDERINGS IN WILD AUSTRALIA сн.}

covered with a growth of fresh green grass and young seedlings. After long weeks of nothing but yellow, dried-up tussocks of grass, the change to green was most refreshing to the eye, and we enjoyed it all the more because it meant good feed for the horses. The rate of growth of the grass immediately after a rainfall is astounding. We were camped out two or three nights in places where there had been a heavy storm. Lying amongst the grass, with my head on the ground, there was, each morning, a curious effect which, at first, I could not understand. There was a layer of green - that of the grass-on top and, below and between this and the ground, a layer of very light, yellowish tinge. Then I realised what it meant and how marvellously rapid was the growth. The light layer simply represented the growth during the darkness of the night, when no green chlorophyll was formed. Not only the rate but the regularity of growth was wonderful. The drawing (Fig. 568) is a reduction of an actual tracing of two blades growing from one root, close to my head, that I gathered just at daybreak. The whole of the smaller one and the lighter lower portion of the larger one had grown during the night, because the evening before the whole of the blades above ground were everywhere green and there was no sign of colourless ones.

Birds also were much in evidence, flocks of honey-eaters and parakeets were busy amongst the gum-tree flowers, and every now and then the air was heavy with the scent of honey.

It was very hot and we were glad when, just before noon, we came to the banks of the Flora River and heard the sound, not only of running, but of falling water. The river flows in a deep cutting amongst most beautiful trees with dense foliage and deep shade-Screw pines, Bauhenias, She-oaks, Paper-barks and Gums. The water is deep and clear and all shades of green. There are great pools - a quarter of a mile long-and between them are rock bars, over which the 


$$
8
$$


water tumbles in cascades. We selected a little flat for our camping ground, close by one of these rock bars. In front was a deep pool, then two ledges of rock, one behind the other, about twelve feet apart, each from six to eight feet in height, and, all around, the high banks were covered with trees overhanging the water. It would be picturesque anywhere, but doubly so in this part of the world where, for very long, weary scores, often hundreds, of miles, there is little beauty in the landscape. We shall be able, day and night, to hear the water tumbling over the rocky bars. At one place there was a shallow pool where, keeping a careful look-out for crocodiles, the horses could be watered with safety (Fig. 570).

November 8th.-As we intended spending some time here, we made a comfortable camp and also one that would protect us if rain fell. We had brought a big tent with us, I 2 feet by Io feet, with canvas roof and cheese-cloth sides, that folded inward on the ground. The end that has normally two flaps was made with a special adaptation to fly country. Instead of two flaps it was a complete piece, like the closed end, except that its lower part was drawn out in the form of a funnel. You were supposed to put the open end of this over your head, pass it down your body and walk, or rather crawl, into the tent at the other end. In theory it was excellent, but in practice it was a great nuisance, so we just looped it up and risked the flies. Over the tent the boys built a great bough shelter enclosing also a kind of room behind capable of holding the buckboard. In this we spent the evenings, skinning birds. On the side away from the weather and facing towards the river, we rigged up the tarpaulin to form an awning. We had brought stretchers with us to keep us above the wet ground if a deluge suddenly came down, as it is liable to do in these parts. Cahill had his in the main tent, I had mine under the awning. The floor of all three rooms was thickly 


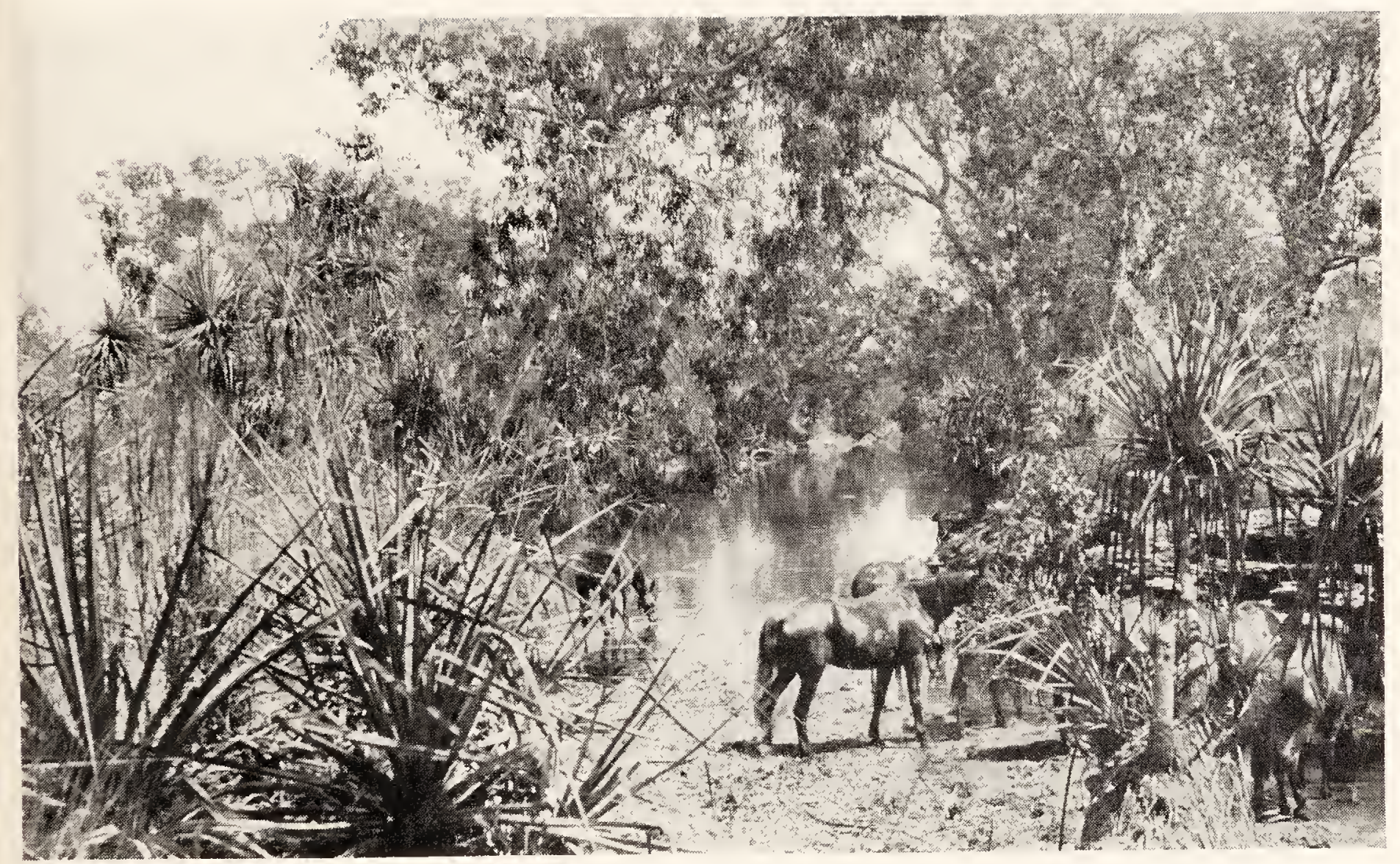

DR. WOOLNOUGH.

FIG. 570.-A IVATERING POOL. 


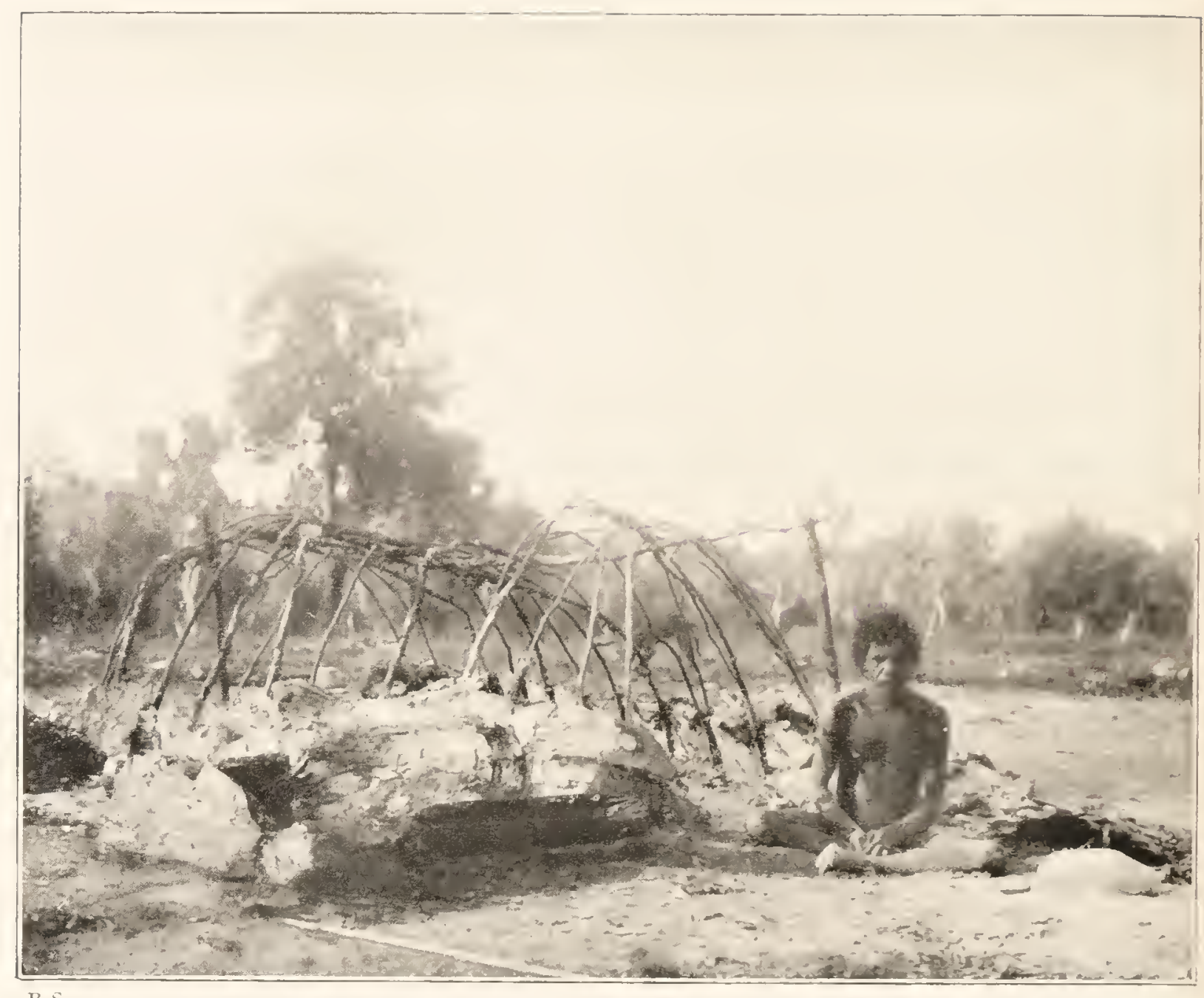

FIG. 572.--SKELETON OF MOSQLITO MIA-NIA, ROPER RIVER.

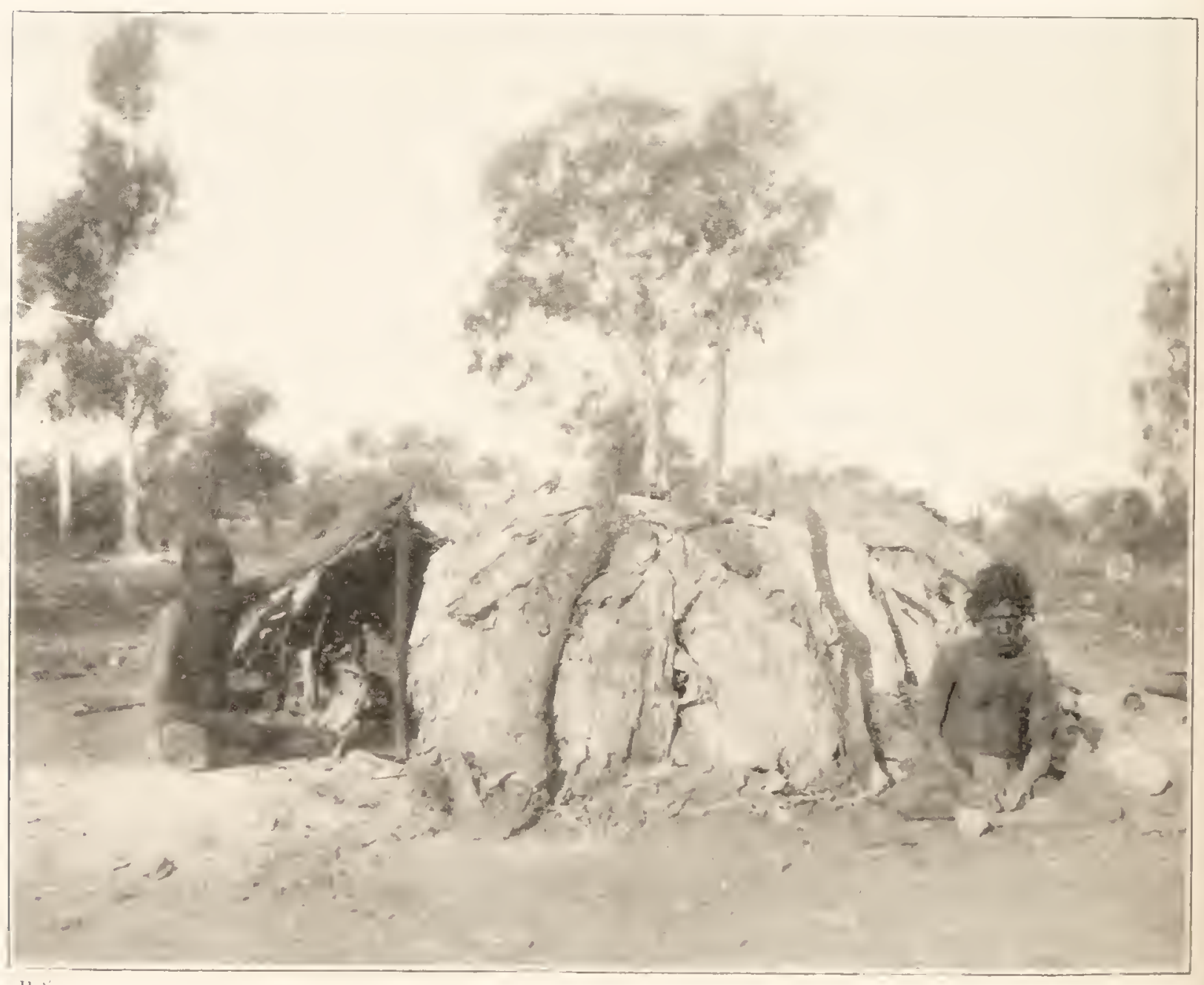

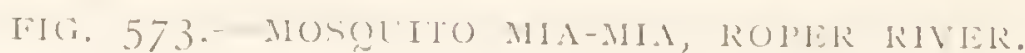


carpeted with small, leafy, gum-tree twigs that gave out a delicious scent when trampled on.

November 9th.-With everything fixed up comfortably we set to work, first of all, to explore the immediate neighbourhood. The Pandanus and other scrub were very thick immediately around the water's edge and it would be quite easy to slip in, but, wandering along, we found a native track that led down to the rock bar running across the stream. Later on, we saw the natives constantly using this to get from one side to the other. The bar was really a double one. There was an upper one (BI), six feet high and six feet broad, then a ledge (A2), fifteen feet broad, and then another bar (B2) from six to eight feet high. This double bar separated an upper pool ( $\mathrm{A}$ I) from a lower one $\left(\mathrm{A}_{3}\right)$, the water level in the upper being approximately fourteen feet above that of the lower one (Fig. 57I). Across the length of the ledge there was a succession of pools (A2) from five to ten feet long and three to six feet deep, into which the water poured through depressions scooped out in the upper bar and from which, again, it fell in three or four smaller, and one long cascade, which is clearly seen in the illustration (Fig. 569), into the lower pool that was fully I 50 yards broad and a quarter of a mile long, gradually shelving up towards the further end, from which it flowed away quietly to join the Katherine. There were crocodiles in both the upper and lower pools and we searched carefully along the ledge and banks leading to it, lest a stray one should be lurking about. The boys kept a sharp look-out for them whilst we enjoyed a bathe daily in the small pools.

In the evening, at six o'clock, huge banks of clouds came up and soon the lightning and thunder were incessant. Then a heavy wind came down on us and the rain fell in torrents. Protected by the bough shelter, we watched it from under our tent and enjoyed both the sight and the relative coolness, though it was rather damp. 
At this season of the year the mosquitoes are a great pest, especially near to the water-holes where the natives camp. They make special tent-like Mia-mias, some of which are of great size. The one figured was on the Roper River. It was fifteen feet long, between four and five feet broad and four feet high. The framework was rather like that of a boat turned upside down. Sheets of paper-bark were laid on which were both rain- and smoke- and mosquito-proof. There was a small opening at one end. At night-time the natives crawled in until it could hold no more. Smoke fires were lighted, and here they sweltered and choked until the morning light drove most of the mosquitoes away (Figs. 572 and 573).

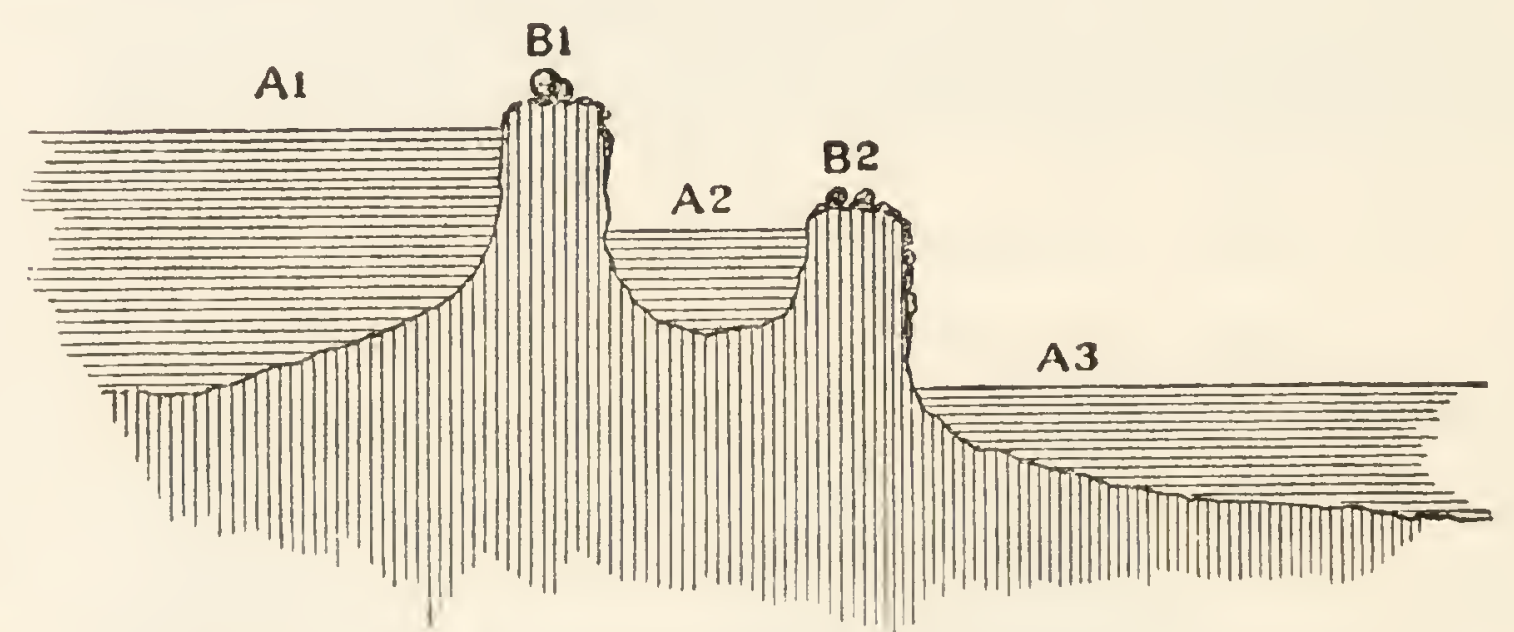

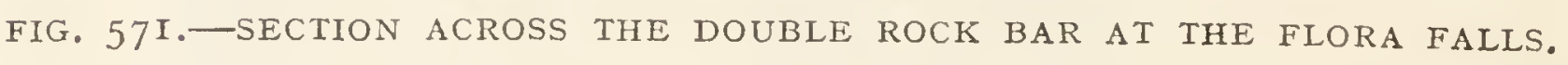

November Ioth.- It rained on and off all night long, but this morning it is clear and bright and everything is looking wonderfully fresh.

The rain has brought out a number of insects, chiefly ants, which are a perfect pest. We had only been there a few hours before lines of them appeared, marching to our camp from nests, the nearest of which are twenty yards away. The only way to deal with them was to place grass and firewood across their tracks and keep this burning. This afternoon they appeared suddenly in enormous numbers, so we traced them back on to the flat and found six holes in the ground, in and out of which they were streaming in 
crowds. At first there was only the common little black ant to be seen. After a time a few hundred small black ones with wings came out and ran about, but not very quickly, and following them came a third set-great big ones, fifty or sixty times the bulk of the ordinary small ones. They had wings, and, after running about on the ground for ten minutes, they rose and flew away in a long stream, leaving the ordinary workers and the small winged ones behind on the ground. After they had flown away the excitement, which, judging by the way in which they were all rushing about, must have been great, subsided and both the small wingless and the winged ones went down the holes until not one was to be seen on the ground.

November I 2 th.-As it was impossible, owing to shortness of time, for us to get as far as Willeroo station, where my friend Mr. Pierce lived, I had written asking for his kindly assistance. He has much influence with the natives in these parts and, thanks to his help, a good number of Mudburra and Waduman natives came in to our camp. Cahill, who had years ago been manager of Wave Hill station in this part of the country, was well known to them, so we had no difficulty in entering at once into very friendly relations with them, and spent a week getting as much information as we could. As our time was limited, I devoted myself chiefly to matters concerned with their organisation and totemic systems so as to try to link this up with what I had previously learnt of the tribes at Katherine Creek and down the Roper to the Gulf of Carpentaria. The tribes that I was able to study now formed the last link in a chain extending from the Daly River on the west, right across to the Gulf of Carpentaria on the east. It was rather a strenuous week, but we managed to secure a good deal of information, working from early morn till evening, when, by way of a change, we spent three or four hours skinning birds that we sent our boys out to shoot while we were working in the camp. It was 


\section{WANDERINGS IN WILD AUSTRALIA сн.}

fortunate for me that Paddy Cahill was not only known far and wide amongst the natives, but that, like my old friend and comrade, Gillen, he was deeply interested in them and knew their ways. He was brimful of energy and enthusiasm and never suffered from the tired feeling that comes over so many people in the Territory.

Every day we used to wander over to where, half a mile away from us, the natives were camped. There was plenty of native food about and we supplemented this with a small, but only very small, amount of flour, because we could not carry much. However, we had plenty of tobacco, which they prized most of all. Every morning a few of the men went out in search of flying-foxes-that is, the big bat. They lived in huge colonies, hanging on to gum trees during the day-time, when they slept. There must have been myriads of them. Every evening just before sunset they set forth to spend the night amongst the flowering gums in some special feeding ground and, as regularly, returned just before sunrise. One evening, as I watched them from our camp, they passed along the river valley just above the level of the trees in a continuous stream. I timed them carefully. They were flying from south to north and I was facing west. The vanguard appeared at twelve minutes to seven and there was no break in the stream, which gradually thickened until, at seven, they hid the sun from view and for ten minutes the dense mass flew on; then it began to thin, but it was just fifteen minutes later before the rearguard had passed the point at which I had seen the first ones appear in the sky. It was a wonderful sight and the same flight took place every evening with absolute regularity. In point of numbers and closeness of flying they reminded me of a flight of mutton birds across the Bass Strait.

I spent some time trying to get cinematograph pictures of camp life. It would be quite easy to do this with a small hand machine of which, after a while, they would 


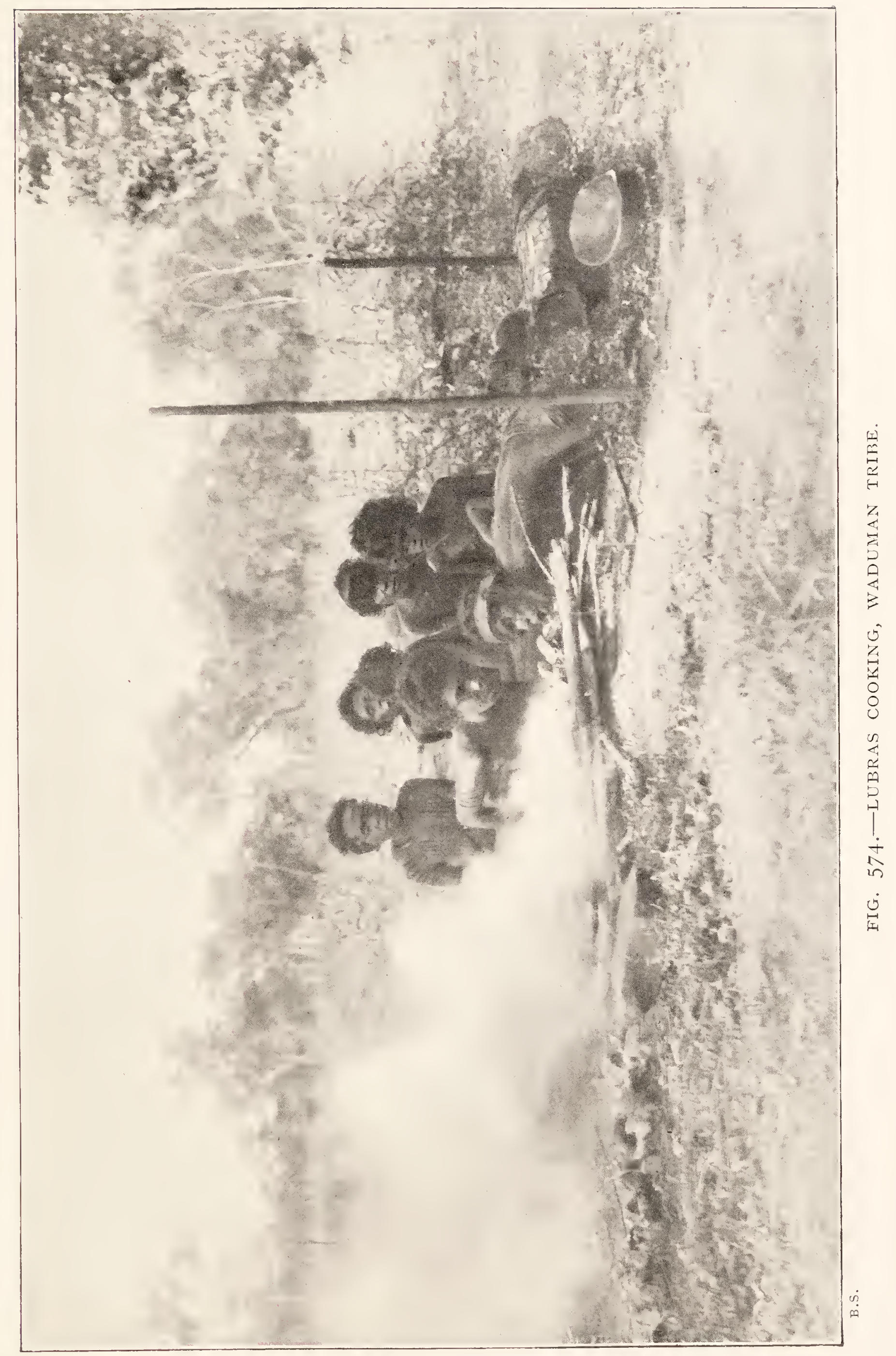



take little notice, but a large one attracts too much attention and makes their actions rather unnatural. However, I managed to secure some good and characteristic cooking scenes (Fig. 574). The men brought in their flying-foxes and threw them to the women to cook, though sometimes they did this themselves. If the men cooked, they always did it at a fire by themselves. Twice I saw a man doing this and the women, who had been cooking, went away when the man came to the fire. The method was very simple: they were placed on the red-hot embers of a camp fire so as to singe the hair off, the bodies being taken off every now and then and rubbed. Perhaps half a dozen women sat round one fire with a few children. As a general rule one or, at the most, two women acted as cooks, turning the bodies over to cook both sides. Before they were done, the cook always took the body and, using both hands and teeth, tore it up into joints and pieces that were then either handed round and eaten or replaced on the fire for further cooking. It was not an appetising sight and, though I was invited to do so, I could not bring myself to taste the meat, which the natives relish as much as anything they get, except perhaps sugar-bag and emu eggs. They have, however, like all other aboriginals, a much better way of cooking of which also I was able to get a record. When doing this the woman sits on the ground and, with a digging-stick in one hand and using the other as a scoop, makes a hole, usually about a foot and a half in diameter, or even less, according to what she is going to bake. She then makes a fire in it and heats rounded stones on it, if any are available, as they were here; if not, she simply waits till there is a good mass of red-hot embers. In either case the fire is covered with leaves, the damper or perhaps flying-fox put on these, then more leaves are added and then the earth piled on top. The cooking takes anything from an hour upwards, according 
to the judgment of the cook. I watched one woman making little dampers in this way out of a big lot of wild orange (Capparis) seed that she pounded up on stone so as to make a kind of gritty dough, which she then shaped with her hands into little cakes, just like a white woman would, put them carefully side by side on the green grass and leaves, covered them up and cooked them. The whole operation of making the earth oven, pounding the seeds, making the little cakes and closing them in the oven occupied more than two hours. The same woman, another time, was preparing a special kind of yam which has first of all to be cut in slices and cooked in an earth oven, after which it is well soaked in water and then is eaten, either raw or after roasting in hot embers.

For our own consumption we have sent two of the boys out to see if they can get a bullock, as we are out of fresh meat, and flying-foxes, the one kind of game easily obtainable in sufficient quantity for food, do not appeal to us. There are a number of wild cattle about and we are hoping to get a "clean-skin," that is, a young one that has been missed in the mustering and has not been branded. If it has been branded, we shall apologise to the owner, $\mathrm{Mr}$. Pierce, and be told that he is very glad that we took it.

Every day we hear the storm bird singing out. It is a large cuckoo with a note something like a glorified "cawcaw." There are two of them round our camp, and we see them every day being chased by the crows, in whose nests they lay their eggs.

We are having rain and thunderstorms almost every day and night, and are wondering whether the wet season is going to set in early. By good chance, after one specially warm, muggy day, on which there had been a tropical downpour in the afternoon, I went out in to the scrub after dark, with a hurricane lamp, to see if any insects were about and would be attracted to the light. They came to 
the light in our camp where we were skinning birds in hundreds, but they were almost entirely flying ants with only a few beetles. As soon as I got amongst the gum trees, I found myself in the midst of a scene of the most extraordinary, indeed feverish, activity. In places the ground was dotted over with numbers of what looked like gaping, horny jaws, which were really the open ends of chrysalises, out of which great gum-tree moths either had pushed or were in the act of pushing their bodies. Those that had just come out were filling their wings with air preparatory to flying away. Every now and then a little lump rose on the ground, opened out and the end of the chrysalis appeared and at once split open. Even more strange was the activity on the trunks of the gum trees. On some there were as many as a dozen pupa cases of a Cicada. The pupæ came out of the ground close round the bases of the gum-tree trunks and immediately set to work to climb. After going up, sometimes for only a foot or two, at others for five or six, they came to a stop, clinging on tightly with their feet. Then the middle line of the thorax slit open along the back and, through the pliable skin of the case, a soft hump was forced out which was the thorax of the insect, with the soft, folded-up wings attached to it. The forcing out went on without a pause until, first of all, the thorax and abdomen came out completely, and then, holding on by its legs, the head was drawn out and the adult insect remained quiet for just a very little time, making you feel as if it were trying to get its breath after its hard struggle for freedom. Then, still clinging on to the empty case, it looked as if it were taking in deep breaths of air, the body expanding and contracting, evidently to force air into the little tracheal tubes in the wings, which gradually unfolded and straightened themselves out. The skin of the body seemed to harden rapidly and, usually within twenty minutes of the pupa fixing itself on to the 


\section{WANDERINGS IN WILD AUSTRALIA ch.}

trunk, the adult Cicada had forced its way out and was ready to fly up into the gum tree and be safe from the attacks of its bird enemies. It made you feel as if you were in a world of life and activity that could only be carried on under cover of darkness and was something quite apart from the life of daylight. When morning came there was not a trace left of all this activity, except the gaping ends of the chrysalises on the ground and the stiff, empty cases of the Cicadas clinging to the gum trees.

It seemed as if the rain were setting in and, as I had still a good deal of work to do in Darwin, and was anxious to get over to the Mission Station on Bathurst Island before returning south, we decided that it would not be safe to stay longer on the southern side of the Katherine, which might at any moment come down in flood and isolate us. Early in the morning at $5 \mathrm{a}$.m. on November I gth, after a week's hard, but very interesting, work amongst the natives, we left our pleasant camp on the Flora with much regret, crossed the Katherine, which was now flowing strongly, at I I a.m. and then struck across country for Pine Creek, which we reached three days later.

November 29th.-Left Darwin at 9 p.m. in a little motor launch, the Bolwarra, for Bathurst Island. Our party consisted of the Administrator, Dr. Gilruth, and Mr. Clarke, the Director of Agriculture, and we took across with us the Rev. Mother of the Sacred Heart Convent and Sister Adrian, the latter of whom was going to work at the Mission Station that was being formed on the Island.

November 3oth.-Early in the morning we were off Bathurst and met Cooper's lugger, the Buffalo, in which he was taking Father Courbon across to Darwin from the Mission Station. As we were anxious to have Cooper with us, we towed him in his lugger back into Apsley Strait and landed at the Mission Station for an hour, to take off the stores that Cahill and myself had brought. Then we 
started off to visit Fort Dundas, thirty-five miles up the Strait.

This was the scene of the earliest settlement in Northern Australia. We landed on Garden Point, where we found the remains of an old brick kiln, where the bricks used in building the fort and houses at Fort Dundas in 1824 had been fired. There were thousands of them heaped up and lying about, but all were soft and crumbling. Here we camped for the night.

December Ist.-We moved off early in the morning and entered Port Cockburn, from the shore of which a track led up to Fort Dundas. Everything had fallen into ruinthe whole settlement must have been demolished by the natives after its abandonment by the military. It had evidently been built with the idea that it would be necessary to defend it against attacks, partly on the side facing Port Cockburn and partly from the land side. There was a great, broad, horseshoe-shaped ditch enclosing a series of zigzag fortifications built of brick. The open end of the fortifications faced towards Apsley Strait. Within these were traces of the foundations of houses and, in the centre, was a well. In the timbering of the latter, logs of Ironwood (Leschenhaultia sp.) were used, and these were as sound as the day, now eighty-eight years ago, on which they were put in place. They were indeed the only things that remained intact. The fort had evidently been built with the idea that its occupiers would have to defend themselves against a formidable foe, and when, only a short time later, in 1827 , it was abandoned, the Melville Islanders, armed with only wooden clubs and spears, must have imagined that the white men regarded them as such and have exulted in their might accordingly.

In view of the fact that, after his first repulse, Cooper landed on the island for the second time in 1895 and, by entirely peaceful means, while living alone in his little log VOL. II. 
hut, "subdued" the natives who had been left unmolested, since they had watched the last marine march out of Fort Dundas and had entered into peaceful possession of the fortifications, the meaning of which must have sorely puzzled them, Captain Bremer's report to the Admiralty, written on board H.M.S. Tamar, dated November Ioth, I 824 , Port Cockburn, Melville Island, now makes interesting reading.

On September 20th, I 824, the ship Countess of Harcourt, carrying an expedition despatched from Sydney to take possession of the coasts of Northern Australia and found a settlement, arrived at Port Essington on the Coburg Peninsula. The country was examined, His Majesty's colours hoisted on Point Record under a salute and a feu de joie from a guard on shore answered by a Royal Salute from H.M.S. ship, The Tamar. Captain Bremer goes on to say, "I am directed to take special care that formal possession was taken of the coast included between the western side of Bathurst Island and the eastern side of Coburg Peninsula. I was also to make a settlement in Apsley Strait my first object."

Though not strictly authorised to do so, Captain Bremer determined " to venture on the measure of taking possession of the whole coast from I $35^{\circ} \mathrm{E}$. Lat. to $\mathrm{I} 29^{\circ} \mathrm{E}$., the last of these meridians being to the westward of Bathurst Island. I have therefore to express my earnest hope that, having in this instance to perform His Majesty's Service, your Lordship will be pleased to honour me by your approval of my conduct."

Port Essington, from lack of water, was not then deemed suitable for a settlement. It was, however, described as "one of the most noble and beautiful harbours that can be imagined, perfectly secure, with a modest depth of water, a capacity of containing rooo sail of vessels and a place worthy of the notice of His Majesty's Government, if 
their view should ever lead them to increase the establishment on this part of the coast."

The expedition set sail and arrived in Apsley Strait on the 26th September, where possession was taken of Melville and Bathurst Islands. Excellent water was found in a cove named King Cove after the discoverer of the Island. Point Barlow, named after the first Commandant, was fixed upon as the site for Fort Dundas and the whole anchorage named Port Cockburn, "in honour of that distinguished officer Admiral Sir George Cockburn." The report goes on to say, "The position of the establishment having then been decided on, I began immediately to erect a fort (which, considering the known treachery of the Malays and the numbers in which they come on the coast, as well as the probable hostility of the natives, I determined should be secure as far as I could from circumstances render it) and to commence a commissariat store-house, huts for the soldiers and prisoners and a pier extending nearly to low-water mark in order that provisions and heavy stores might be landed without injury.

"The labours of everyone in the Expedition were given so cheerfully that on 2 ist October, having completed one Bastion and the sea face of the Fort, I had the satisfaction of hoisting His Majesty's colours on Fort Dundas (so named in honour of the noble Lord at the Head of the Admiralty) under a Royal Salute from two nine-pounder carronades which were ready."

The guns were taken from the quarter-deck of the Tamar, which had evidently come up from the south. The pier was made of " exceedingly heavy logs of timber and stones: it is a solid piece of work which will last for years, twenty-one yards long and six wide. The troops and convicts have built themselves good and comfortable quarters close to the Fort. Regular barracks, however, in the square are to be immediately commenced for the former. 


\section{WANDERINGS IN WILD AUSTRALIA cн.}

The house for the Commandant and two of the officers of the garrison is inhabited and the other house for the remaining officers is in a forward state."

No natives were seen until four weeks after landing, after which there was a little trouble from them, in the way of stealing axes, "of the use of which they seemed to have a correct idea," but nothing serious. Captain Bremer noted and gives an interesting description of the remarkable graves. He says, "It is perfectly unusual to find this respect for the dead, and consequent acknowledgment of a future state and a Superior Power, in the natives of Australia. I trust your Lordship will pardon my having detained you so long by this relation; but as this country has hitherto been untrodden by European foot, I presumed that a short account of it might be interesting.

"The soil of the country so far as I can form a judgment, is most excellent and probably capable of producing many if not all the fruits and valuable shrubs of the Eastern Islands. The plants brought from Sydney flourish luxuriantly, particularly the Nagat (?), the Banana and the Sugar lime. Pumpkins, radishes are soon above the ground, and the maize came up on the fourth day from its being sown. In pursuing the stream of water I have mentioned to your Lordship in the first part of my letter, several large pools were discovered in the neighbourhood, of which I can have no doubt most valuable rice plantations may be made. Amongst the trees, some of which are of majestic height and well calculated for many purposes of human industry, are the Eucalypts, a sort of Lignum vitx, ${ }^{1}$ the Cabbage palm and the Sago palm, with several others with the names of which I am unacquainted." He goes on further to describe the plants and animals met with, and says that " the climate of these Islands is decidedly as good a one as can be found between the tropics. The thermometer rarely

1 This is probably the Ironwood (Lescbenbaultia). 
reaching $88^{\circ}$ in the hottest part of the day, and in the morning at dawn sometimes falling to $76^{\circ}$." "By the chart," he says, "which I have forwarded to the Lords Commissioners of the Admiralty, your Lordship will perceive that this is a port of the finest description. . . The capabilities and situation both in a military and commercial point of view will, I confidently believe, answer the wishes and intention of His Majesty's Government in establishing a colony in this quarter." Having fulfilled his mission he left the settlement in the charge of Captain Manners Barlow of the 3 rd Regiment, fifty-five officers and men, four convicts and three free mechanics, leaving behind him also the Colonial brig Nelson with ten men.

This glowing report was written in 1824 . Of what happened during the next year or two at Fort Dundas there seems to be no record. As a commercial port it was simply a fiasco, no trading boat went in or out of Port Cockburn. As a military outpost it was useless, except, perhaps, to show that the northern coasts of Australia, which no other nation then seemed at all anxious to become responsible for, were held as a British possession. With no encouragement from Sydney, with which communication was precarious, and apparently no attempt to make it anything more than the military settlement that its name suggested, Fort Dundas practically vanished out of ken until, only three years later, it was abandoned, and it was left to one solitary white man, Joe Cooper, unaided, to accomplish, at a later time, so far as the natives were concerned, what a whole well-equipped garrison had failed to do.

December 2nd.-The Bolwarra left Bathurst Island in the morning, taking the Administrator and Mr. Clarke back to Darwin. Cahill and myself stayed behind to work amongst the natives. There were a large number of them camped out in the bush not far away from the Mission 
Station. Through the courtesy of Father Gsell, we occupied, much to our convenience, a spacious empty building, recently erected, that was designed to become, later on, a school for native children, under the control of the Sisters of the Sacred Heart Community. The station was picturesquely built with a little chapel, houses for the Missioners and a large, lofty and open bush house, that served as a common meeting-place for all the natives. It was built on the bank close to the water's edge so that the natives could draw their canoes up under its shelter. Father Gsell had planned, designed and superintended the building of the station, with the aid of the natives whom he was thus training to work industrially and for their own benefit. He himself was able to do all the practical work with his own hands, and, whilst doing all this hard manual labour, he and his two fellow-missioners, who were labouring with him, were also hard at work studying the beliefs, customs and language of the natives, preparatory to entering seriously upon the difficult task of attempting what is commonly spoken of as the conversion of the natives. They realised fully that the only method of attacking seriously, with any chance of success, the problem of uplifting the aboriginal was to begin work from the industrial side, so far as the adults were concerned, and to contentrate their energies especially on the children. To attempt to alter, or even influence radically, the fundamental beliefs of the adults is practically impossible. I could not help wishing that other communities who are as sincerely interested, as was his, in the aboriginal problem, had the opportunity of sending into these wild parts men of the practical capacity and wisdom, and also of the culture, of Father Gsell and his fellow-missioners, both men and women.

Whilst on Bathurst Island we had the opportunity of watching once more the burial ceremonies of the natives. At the time of our visit there were two district groups 
called, respectively, Malauulla and Tjikalauulla, taking part in them. During the performance of any ceremony they came together, but immediately it was over they separated, went to their own camps and had no intercourse with one another. On returning to their own camping grounds, the women immediately went to one fire, the men to another. Following up this clue, we found that on Melville and Bathurst Islands there were a number of local groups each of which was supposed to be the owner of a certain definite part of the country and had a definite name.

There was first of all the main separation of the natives into Melville Islanders and Bathurst Islanders. They speak the same language, perform the same ceremonies, use the same objects and make implements all quite distinct from those of the mainland, and yet, though separated only by the narrow Apsley Strait, are, in certain respects, apart from one another in feelings. The men of Melville Island periodically raid the Bathurst territory-even carry off their women-and vice versa. = Each island, again, is divided up into local areas, much like, for example, the counties of England, the boundaries of which are well known and in each of which there is a main camping ground, like a primitive county capital, but in this case the buildings are only log and bark huts. The Tjikalauulla and Malauulla are two of these groups on Bathurst Island, and, after long inquiry, we were able to find out the names of others. There seemed to be more on Melville than on Bathurst Island, but, for some reason, it was hard to find out the exact number. Probably this is to be explained by the extraordinary reticence of a native, that is, of one who is more or less in his natural state and uncontaminated by contact with white men, to speak of anything that concerns groups of people other than his own. Officially, he is not supposed to know about such things: he resents anyone prying into his own private matters, or those that he regards 


\section{I2 WANDERINGS IN WILD AUSTRALIA сн.}

as such, partly perhaps because, in many cases, he thinks that strangers with too much knowledge might be thereby helped in working him some harm. The result is that it is often difficult to gain what seems to you to be very simple and harmless knowledge from some special man, while another will part with it to you freely. When once the native is semi-civilised, this difficulty of gaining information largely disappears, but then there arises another onehow far is the information reliable, or how far is it due to a desire to provide the white man with knowledge that the native shrewdly sees he wants to have? I think the list for Melville Island, which I got later, with the help of Cooper, is fairly complete, but, though we were now on Bathurst Island, it was impossible to get the names of more than four local groups. The names of fifteen, eleven on Melville and four on Bathurst, are given on the map, and the numbers in the following list correspond to those on the latter map. There is first the name of the locality and second that of the group inhabiting and owning it, this name being always formed by adding the suffix -ulla to that of the locality.

So far as I could find out, no one married within his own local group; he had to obtain his wife from another, and she also had to belong to a totem different from his own.

The grave dances were precisely similar to those that we had seen on Melville Island. The women stood to one side and, every now and then, danced across and back again, but never round the grave, with their usual highknee action, holding their bark aprons on to their sides with their elbows. They always kept away from the men, and several of them carried piccaninnies on their shoulders. As on Melville Island, one or two of the other men had decorated their heads elaborately; they were so much alike as to suggest the existence of a set design used for this 
occasion. The colours comprised the only four pigments known to the natives, yellow, red, white and black. The

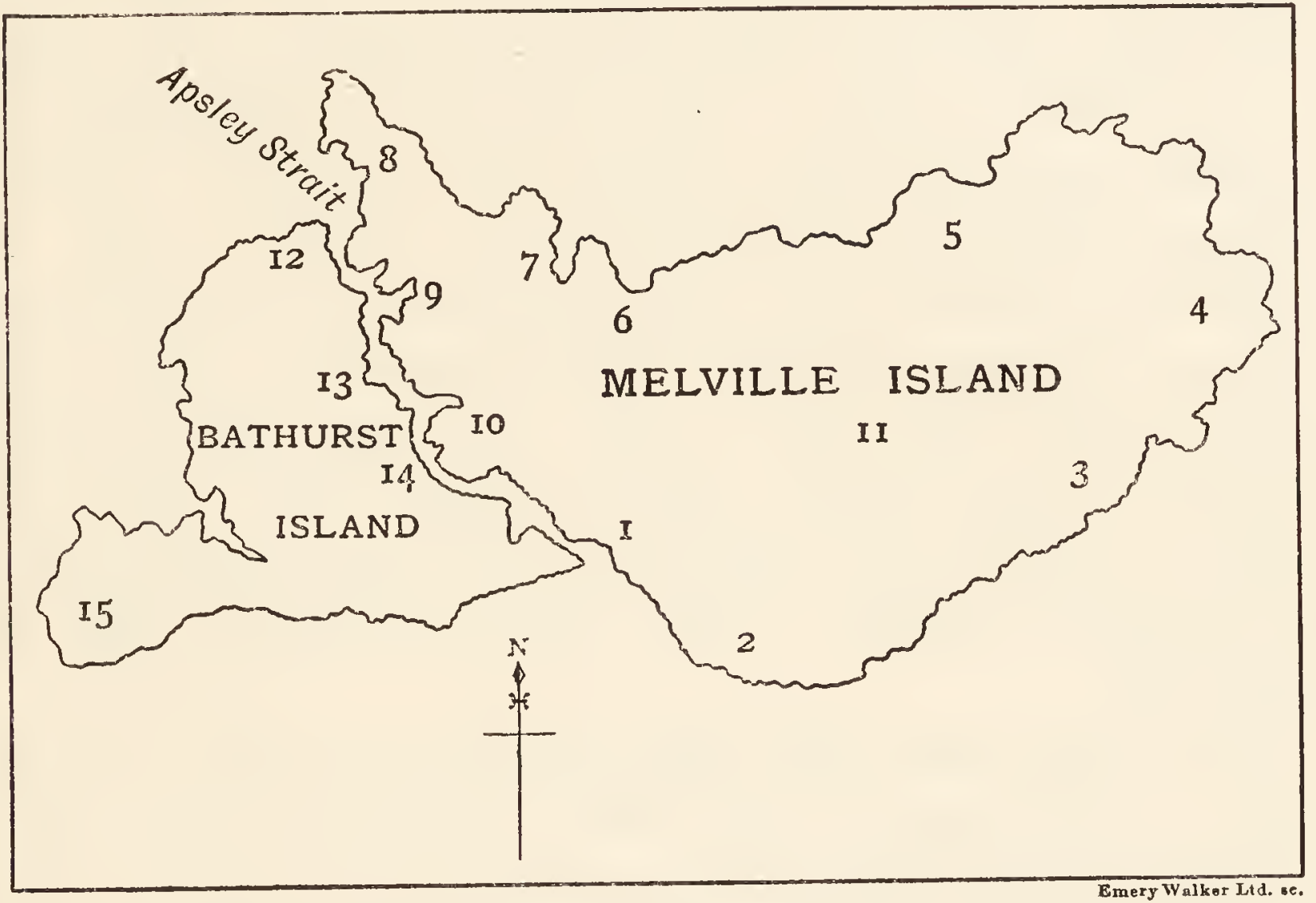

MAP SHOWING DISTRIBUTION OF LOCAL GROUPS ON MELVILLE AND BATHURST ISLANDS.

The numbers correspond to those in the list of localities and local groups given in the text.

(a) Melville Island Groups.

(I) Mundiimbu (Mundiimbulla).

(2) Ulobu (Ulobulla).

(3) Arangijera (Arangijerulla).

(4) Yeimbi (Yeimbulla).

(5) Cherupu (Cherupulla).

(6) Kambuambu (Kambuambulla).

(7) Barranpunalli (Barranpunalliulla).

(8) Munupu (Munupuulla).

(9) Purumunapu (Purumunapulla).

(Io) Mindalu (Mindaluulla).

(I I) Balinungamba (Balinungambulla).

(b) Bathurst Island.

(I2) Marungallambu (Marungallambulla).

(I3) Malau u (Malauulla).

(I4) Urongu (Uronguulla).

(I 5) Tchikalaua (Tchikalauulla).

effect was certainly very striking because the hair was included in the scheme, a feature that I never noticed amongst the mainland tribes. The more elaborately 


\section{I 4 WANDERINGS IN WILD AUSTRALIA ch. XxxII}

decorated of the two is drawn in Fig. 440. They were very pleased with themselves, and when, after the ceremony was over, I made a rough sketch of this man's head to use as a colour key, the other was most anxious that I should do the same for him. They both took themselves very seriously and evidently thought that they had made a strong impression on us, which, as a matter of fact, was quite true, because they looked about as wild and fearsome as human beings could do. I had brought the phonograph over, so we were able to get, not only cinematograph records of the dances, which included the usual ones, buffalo, crocodile and sailing boat, but also very interesting phonograph records of the songs associated with the ceremony.

When the motor boat returned from Darwin to take us back, we were glad to find that it brought Judge Bevan and Dr. Holmes, who came over for the trip, and to catch also a glimpse of the islands, though the latter had been there before. That evening, together with the members of the Mission Station, we formed a much larger party of white men and women than had ever been gathered together on the shores of Apsley Strait, since the day on which the Nelson, in 1827 , had carried away from Fort Dundas the last of the garrison and left the natives in undisputed possession of their islands. As night came on we could see, on Melville Island, the solitary light shining through the open door of Cooper's hut, and every now and then, as it rose and fell, heard the distant singing of the natives, carried to us across the still waters that were flowing silently out to sea. Two days later we were back in Darwin and my wanderings in Australia's Great Lone Land were over. 
MAP 4.

NORTH AUSTRALIA.

lixplanation of reference numbers.

1. Darwin.

Brock's Creek.

Burrundie.

Mataranka (Bitter Springs)

Flora River and Falls.

Leichhardt's Bar on the Roper River.

Borraloola.

Oenpelli.

Cooper's settlement at Medina Inlet, Melville Island

. Roman Catholic Mission Station, Bathurst Island (Wongok.)

I. Old Elsey Station.

2. Newcastle Waters Station.

3. Bates Lagoon and Betaloo Downs Station.

14. Munda waterhole.

5. O.T. Lagoon.

6. Pinda waterhole.

7. Macarthur River Station.

Pundara waterhole.

Eva Downs Station.

Anthony Lagoon and Police Station. Walhalla Station.

Bauhenia Downs Station.

Nutwood Downs Station.

Hodgson Downs Station.

Kakadu tribe.

Geimbio tribe.

Waduman tribe.

Mudburra tribe.

Mulluk-Mulluk tribe.

Iwaidji tribe.

Mi.Minn's Bar Station.

Red Lily Lagoon, Roper River.

Tanumbirini Station.

Thapauerlu.

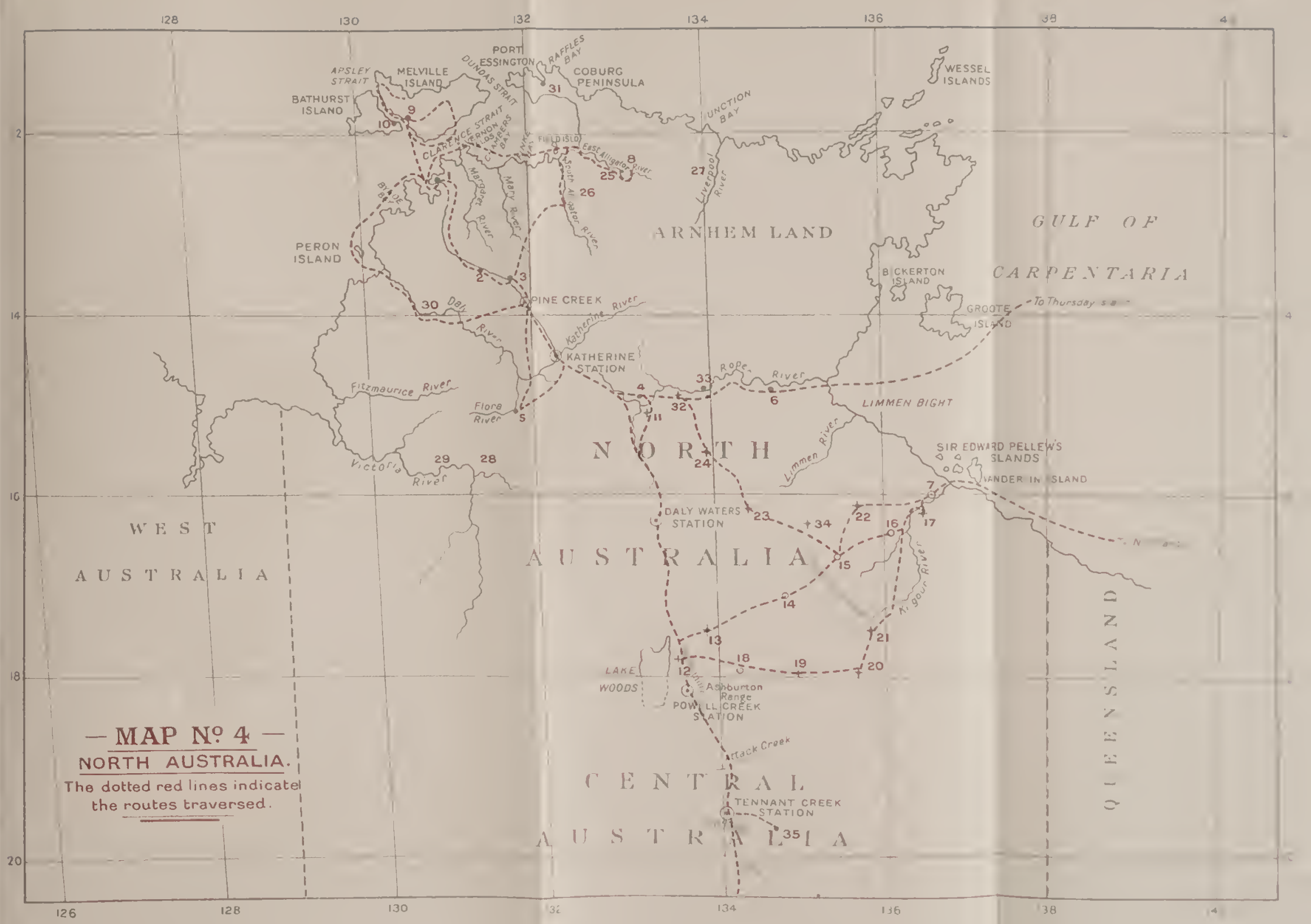





\section{INDEX}

ABILITY of artists, natives' discrimination of, 794

Abmoara, taking charge of young men, 322, 34I

Aboriginal, a nomad, 205

Aboriginal, colour of, 186

Aboriginal, his character, 197

Aboriginal ordinance, 604

Acacia aneura, 32

Acacia cyperophila, 32

Acacia Farnesiana, 29

Acacia homalophylla, Giddea tree, 9

Acacia salicina, Ioo

Acacia salicina, ironwood, 369

Acacia, stinking, 4

Acacia ulicina, 38

Achilpa Inkata, 286, 288

Achilpa totem, 285

Achilpa tradition, 288

Acrochordus javanicus, 787

Actions of native, judgment of, 202

Adaptation to climate, Ioo

Adze, 50I

Estivation of snails, I 43

Agriculture, absence of, 206

Ah Sue, 7 I 4

Ah Toy, 887

Akuntilia, hair locks, 4I3

Alatunja, head-man, 3I 3

Alberga River, 26, I 35, 354

Alchera, I06, 272, 275, 277

Alchera ancestors, 289

Alchera camp, mother's, 4II

Alchera myths, 275

Alchera, use of term by Arunta, 279

Alexandra Station, 522

Alice Springs Station, I05, 370

Alkiva aldorla, western sky, 28I

Alla, the nose, on Mt. Gillen, Io6

Allan, Jim, I32

Alligator River, 740

Alligator River natives, $6 \mathrm{I} 7$

Alligators, 552

Allotment of women, 435

Alpita, tail-tips of rabbit bandicoot, 380

Alternation of colour in design, 709

Altherta, corrobboree, Arunta, 230

Altjira. See Alchera.
Ambilia-ekura ceremony, 335, 338

Ambilia-ekura, bag of Churinga, 288

Amadeus, Lake, I6I

Ameina, meaning of word, 784

Amera, spear-thrower, Arunta, 220

Amos, Mr., Macarthur Station, 880

Amos, Mr., at Macarthur River Station, 555

Amunga-quinia-quinia, a lizard, I47

Anatomy, internal, drawing, 808

Ancestors, Alchera, associated with localities, 289

Ancestors, Arunta, 275

Ancestors, beliefs in regard to, Binbinga tribe, 566

Ancestors, spirits of, 333, 472

Animal, spirit of dead in form of, 482

Animals characteristic of Higher Steppes, 90

Animals, drawings of, 793, 808, 8I3

Animals, survival of, 36

Antechinomys, 68, 93

Anthony Lagoon, 877

Ant-hill used for ceremony, 666

Ant-hills, 542

Ant and Coccidæ, 73

Ant, honey, I 72 , I 74

Ant, meridian, 390

Ant mounds, ro3

Ant nest, material of, 74

Ants at Flora River, 899

Ants, green, nests of, 625

Anua, wife or husband, 224

Appetite of native, 829

Apsley Strait, 643, 904

Apus, 27, I 35, I40

Ardi, 772

Aritna Churinga, sacred name, 284

Arm bones of dead man, $55^{6}$

Armlets, cane, 663

Armlets, mourning, Kalsadu tribe, 8 I9

Armlets, mourning, Melville Island, 648

Artists, native, ability of, 793, 794

Arumburinga, a spirit, double of the Kuruna, 280

Arungquilta, evil magic, 57, 251, 256, $362,428,486$ 
Arunta natives, 37I

Ashburton Range, 530, 868

Atnilinga, pointing-stick, 407

Atninga, avenging party, 375

Atnongara stones, of medicine man, 267,268

Atnuta, limp, I8I, 213

Attack by natives, Gulf of Carpentaria, 588

Attack by natives on Barrow Creek, $40 \mathrm{I}$

Attack Creek, 5 I 7

Atua Kurdaitcha, Kurdaitcha men, $26 \mathrm{I}$

Australia, size of, 347

Avenging party, 375, 38I

Avoidance of elder brother and sister, 795; of mother-in-law, Arunta, 228

Axe, stone, making of, 497; of Kakadu, 844

Ayers Rock, 57, I65; map 2, 57

Babblers, 540

Bag, special one carried by pregnant woman, 850

Bags and baskets, Kakadu, 845

Bags, Arunta, 223

Ban of silence, 436, 444

Bandicoot, 94

Bandicoot, pig-footed, I 50

Bandicoot woman, 470

Banka Banka Station, 5 I9

Bar, rock, on Roper River, 888

Barclay, Captain, 88 I

Barcoo rot, I 7

Bark baskets, Melville Island, 70 I

Bark canoe, 569

Bark drawings, Kakadu tribe, 792, 802

"Barking " spider, 98

Barlow, Captain Manners, 909

Barramunda fish, 797; drawing of, 812

Barrow Creek, 399; attack on, 40I, 4 I 3

Bartelott, Captain Sir Edward, 7 I9

Barter, I 59, 82 I

Baskets, Melville Island, 7or

Bat, great white, 95

Bat totem, 469

Bates Lagoon, 869

Bathurst Island, 640, 713

Bathurst Island Mission Station, 634

Bathurst Island natives, 9 I I

Bats, 900

"Bay of Biscay" country, 532, 539, 872

Bradshaw, Mrs., 370

Bauhenia Downs Station, 883

Bauhenias, 524
Bean tree, 217, 394

Beard, Arunta, I96; decorating Melville Island, 660; plucking out, Melville Island, 673

Bee nests, different names for, 857

Bees, tracking to nest, 783

Betaloo Downs, 533

Belt, waist, of man, Arunta, 223; Kakadu, 85I

Belt worn by initiate, Melville Island, 676

Besley, Mr. and "Barking " spider, 98

Bevan, Judge, 729, 733, 9I 4

"Billy," 352

Binbinga tribe, 555

Birds at Barrow Creek, 409

Birdum River, 864

Bishop of Carpentaria, 4I 5

Biting snake's head, 787

Bitter Springs, 865,889

Black kangaroo, 809, 829

"Blacks," I 95

Blatherskite, Mt., Map 2, 27, I I5, I 20, I 25

Blood camp, 777, 789

Blood, drinking, 377; at burial, 765; letting at ceremonies, 324 ; smeared on Kauwa-auwa, 287; used during corrobboree, 232

Blood of snake, eating, rubbing on body, 789,790

Blood's Creek, 32

Blue colour not used by natives, 83 I

Boats, 569

Boils, tradition of, 57

Bone, breaking and burial of, 493; choking with, 395; used for piercing arm, I 3

Bones, burial of, Gnanji tribe, 545

Bones of child, 83I; of dead man in Binbinga camp, 555; of dead man, Warramunga tribe, 489, 49I; watched over by Yalmuru, 81 5

Bonrook Station, 628, 63 I

Boomerang, Arunta, 220

Boomerang leg, I94

Bore, Hamilton Creek, 30

Borraloola, 559

Boundary stones, 30

Bow, formed by snake, $78 \mathrm{I}$

Bower bird, 55I

"Boys," native, 35I ; treatment of, 607

Bradshaw, Mrs., $3 S_{7}$

Breinl, Dr. A., 598

Bremer, Captain, report on Bathurst Island, 906, 909

Brinkley Bluff, I $0_{4}$

Bronze-wing pigeon, 96

Brown, H. Y.L., 55, I08, 7 I 8 
Buffalo Creek, 882

"Buffalo," Melville Island, 647, 654

"Bull-dog " ant and medicine man, 267

Bull-roarers, 232, 250,274

"Bung-eye," 355

Burial ceremonies, Binbinga tribe, 556, 558; Kakadu, 764, 772; Warramunga, 476-494

Burial, Tree, of child, 4 I 5

Burston, Dr., 617, 634

Burt Plain and Well, 388

Burt Plain, F Map 2, IO4, I27

Bush fires, 855,858

Butcha, a Kakadu boy, 827

Byrne, P. M., xvii, 40, 5O, I3I, I44, I 54

Cahill, P., xviii, 720, 742, 747, 857 , $891,900,909$

Callitris, pine tree, 75

Camels, abstinence from water, I5; introduced by Sir Thomas Elder, I 5 ; loading, I7; mail, I 5; motion of, 18 ; riding, 20

Camp and implements, 2 I 7 ; Alchera, 285 ; arrangement of, 207 ; Cooper's Melville Island, 643,656

Camps, men's and women's, 207 , 795

Camps, native, 610, 900

Camptocnemia, I94

Canoe, dug-out, $67^{8}$

Cannibalism, 203

Cape Charles, 7 I 7

Carey, H. E., 71 8, 729

Carpentaria, Bishop of, 4I 5

Casuarina, 37

Casuarina Descaineana, 53

Cassias, 96

Cat-birds, $54^{\circ}$

Cat's cradle, $58 \mathrm{I}$

Caterpillar, social, 29

Catholic toad, 398

Centipede, bite of, $58 \mathrm{I}$

Central Mount Stuart, 394

Ceratodus in Central Australia, 28

Ceratodus, lung-fish, I2

Ceremonial ground, Warramunga, 425

Ceremonial objects, development of, 842

Ceremonies, at Engwura, 320 ; " clearing," 455 ; of cutting off lock of hair, 435; Muraian, performance of, 833; Ober, Kakadu tribe, 77 I preparation for, 323 ; purification, Kakadu tribe, 772; releasing from ban of silence, 444; rain, 359; snake, Kakadu tribe,
750; snake totem, Urabunna tribe, I3; sun totem, 372; to increase cockatoos, 433; totemic, Kaitisha tribe, 405; of Tjingilli tribe, 528; Umbaia tribe, 538; Warramunga, 458 ; wild cat totem, 459; witchetty grub, 372; yam, Melville Island, 638

Chæropus, I 50

Chetocercus cristicauda, I5O

Challenge sticks, 849

Chambers Pillar, 54; Map 2, 43

Chance, Mounted Trooper, 348, 397. 562

Character of natives, I97, 200, 202, 677,734

Charcoal used during ceremony, 773

Charlotte Waters, 39, 357

Chee Quee, 6oI

Cheiroleptes, water-holding frog, 47 , I 40

Chelodina longicollis, 544

Chelone midas, 694

Chewings, Mt., Map 2, 36

Chignon of emu feathers, I9I, 223

Chilara, forehead band, I9I

Child-birth beliefs, 289,8 I6, 8 I 7

Child, presentation of, $85 \mathrm{I}$

Children, aboriginal, I 89

Children acquiring totem, 289

Children, native, treatment of, 187

Chinatown, 608, 620, 628, 636

Chinese, 630

Chinese and natives, 62I, 623, 624

Chipoyu, a net, 786

Churinga, 58, 249, 274; designs on, 295, 298, 306; examining, 333; few in Warramunga, 458; making of, 297 ; and Muraian objects, 843; men's and women's, 288; sacred, 64; shown to initiate, 273; yam, 470

Churinga cult, 273

Cicadas, hatching out, 903

Cicatrices, I93

Cinematograph, 359

Circles, concentric, on Churinga, 300

Clarke, Mr., Director of Agriculture, 634,909

Classificatory system, 563

Clay, covering body with, 453

Clay pans, 4 I

Claytonia, 33

Climate, 22, 716,721

Climatic conditions and plants, 39

Clothing, of natives, 2 I9, 223, 384

Clouds arising from whiskers, 406

Clover fern, 34

Clubs, Kakadu, 844; Melville Island, 709 
Coastal country, 878

Coccidæ and ant, 73

Cockatoo ceremony, 433

Cockburn, Admiral Sir George, 907

Cockburn, Port, 907

Coffin for bones, Binbinga tribe, 557

Coglin Creek, 4I

Cold- and warm-blooded animals, $x_{4} 8$

Cold, ceremony of, 5 I 3

Colour of a boriginal, I 86

Colour of frogs, I $34, I_{42}$

Colour of lizards, $\mathrm{r}_{4} 6, \mathrm{I}_{4} 8$

Colour of newly-born child, i 86

Colour of water, Lake Woods, 868

Colours used by natives, 802

"Combo," 603

Comet tail and spears, magic, 409

Communistic attitude of natives, 607

Compound, native, 6ri

Conch, 77r, 848

Conlon Lagoon, 4I

Connor's Well, $39 \mathrm{I}$

Constellations, 853

Convicts, native, 6 19

Cooking, native methods, I8I, 2II, $775,783,90 \mathrm{I}$

Cooper, Joe, 627, 637, 642, 646, 653, $655,657,676,716,904,905,909$, $9 \mathrm{I}_{4}$

Corrobborees, 32r; Arunta, 230; handing on to guests, 237,314 ; Illionpa, 254; Melville Island, 645

Coucal, a cuckoo, 55 I

Counting, native, $2 \mathrm{I}_{5}$

Country, coastal, 878

Cowle, E. C., Mounted Trooper, 69, I03, I 57, I 62

Cowper, chauffeur, 860

$\mathrm{Crab}$, fresh-water, 28

"Crab-holes," $35^{8}$

Cretaceous sea, 28

Crocodile, 549

Crocodile, biting man's leg off, 689

Crocodile, drawing of, 809

Crocodile, skinning, 574

Crocodilus johnstoni, 549

Crocodilus porosus, 459

Crows, colour of eyes, 397

Crown Point, 47, Map 2, 52

Crown Point Station, 3ro

Crustaceans, 27

Cunningham Gap, 47

Cutting by means of shell, 705

Cutting ceremony, Arunta, 243

Cycad Gorge, 88

Cyrena shell used for cutting, 705

Dalhousie Mound Springs, 30

Daly River, 725

Daly Waters, 866
Damper, 353

Dance at corrobborees, 234

Dances at grave, Melville Island, 689

Darwin, 599, 608

Dasyuroides byrnei, a new genus, $\mathrm{I} 53$

Davenport Creek, Map 2, I

Davenport Ranges, 4I7

David, Sir Edgeworth, 31, 50, 109, I 27

Dawson, Dr., $7 \mathrm{r}_{4}$

Dead man's hair, 376

Death amongst Kakadu, 763

Death from evil magic, 256

Death of native, 480

"Debbil-debbil," Arunta, 259

Decoration of bags and baskets, Kakadu tribe, 848; of girl during initiation, 672; nature of, Melville Island, 669, 670; of Muraian objects, 843

Decorative art, Melville Island, 695$7 \times 3$

Degeneration, rapid, of natives, 386

Dempsey, Sergeant, Booraloola, 880

Depot sand-hills, 52, 363

Descent, indirect male in Arunta, 226

Desert gum tree, I $_{5} 8$

Desert lands, $\mathrm{r}_{5} 6$

Desert oaks, $37,53, \mathrm{I} 65,363,366$

Design, alternation in colour, Melville Island, 709; of armlets and rings, Melville Island, 695, 70r; on baskets, Melville Island, 702 ; on body, Kakadu tribe, 744; on Churinga, 274, 295, 296; of corrobborees, 233; drawing on graveposts, 680; on spears, 707 ; of totem on rock, 286.

Designs, totemic, 295, 459

Desiccation of interior, $\mathrm{I}_{52}$

Devil's marbles, 418

Dialects, 526

Diprotodon, I62

Dispersal of eggs during sand-storms, 27

Distribution of plants, sporadic, 76

Dog man and two women, 432

Dog totem, tradition of, 292

Downs Country, 52 I

Drawing of totem on rock, 286

Drawing, rock, of witchetty grub totem, 292

Drawings, ground, 467

Drawings, native, Ayers Rock, 169

Drawings on bark, Kakadu tribe, 792

Drawings, rock, 64

Drawings, scale in, animal, 8r I

Dream, word for, Alchera, 277

Drosera, sun-dew, 395 
Duboisia Hopwoodi, Pituri plant, I $5^{8}$ Dug-out boat, 569,678

Dundas, Fort, 905, 907,909

Dungaminni water-hole, 880

Eagle-hawk ceremony, 373

Earthworm, English at Alice Springs, 84,85

Easter Billabong, 864

Eating, restrictions on, 763, 800

Eating snake's blood, 790

Echidna, I 50

Edward, Mt., 33, Map 2, 33

Egret, pied, 779

Ekeirinja, Arunta term for Tabu, 64, 344

Elder, Sir Thomas, introduction of camels, 14

Ellery Gorge, Ior, I29, Map 2, 22 and 30

Elsey Creek, 865

Emanation of Spirits, 459

Embers of fire, throwing away, 673

Emily Gap, 291, Map 2, No. I 7

Emily Gap and reincarnation, 283

Emily Plains, 369

Emu feathers, used for Kurdaitcha shoes, 260

Emu in " Milky Way," 853

Emu, methods of capturing, 2 ro

Emu pad chignon, rgr

Emu, stupefied by Pituri, r 59

Encephalartos Macdonellensis, 88

Engoordina, 50, Map 2, No. 5 r.

Engwura ceremony, 308, 344 ; arranging for, 3 r 3

Engwura ground, plan of, 3 I 5

Eruncha, making medicine man, 268

Eruncha, mischievous spirits, 332

Erunchilcha, design on medicine man, 268

Erlkintera, large white bat, 95

Erythrina vespertilio, bean tree, $2 \mathrm{I} 7$

Essington, Port, 906

Etiquette amongst natives, 528

Etiquette, during ceremony, 433

Eucalyptus microtheca, 47

Eucalyptus platypoda, 525, 895

Eucalyptus rostrata, 47

Eucalyptus terminalis, 77

Euro, 9 I

Eva Downs, 873

Exccecaria sp., 532

Eyes in native drawings, 805, 8r3

Eyes of medicine men, 777,788

Eyes of snake, 777

Eyre, discoveries of, 4

Eyre, Lake, I3 I

Eyre, Lake, Basin, area of, 4
Eyre, Lake, supposed part of Lake Torrens, 4

Eyrean Basin, 8

Fan, made of goose-wing, 759

Fan, used to shield face, 796

Fanny Bay Goal, Darwin, 6r 8, 640

Farrar, Mr. and Mrs., 885

Father, Oknia, in Arunta, 224

Father-in-law, duties towards, 225, 227,383

Fergusson Range, II3, Map 2, O.

Ferns, 63, 692

Field Island, 739

Field, J., 420

Fig trees, 78

Fight in camp, 429

Fight, sham, during initiation ceremony, Melville Island, 673

Fighting club, women's, 2 I9

Finger, index, removing joints, 6 ro

Finke River, I0, 21, 29, 47, 83, II6, II7; drainage area, 4

Finke River Gorge, 83, 87, I29, Map 2, Nos. 10, 2 I and 29

Finke sandstone, 49

Fire, at Engwura, 342, 343; at grave, 555

Fire ceremonies, Arunta, 334; Warramunga, 446; Melville Island, 688

Fire, embers of, throwing away, 673; made by hawks, 470; making, methods of, 209; on ceremonial ground, Melville Island, 666; punishing boy, 429; special, during mourning ceremony, 773

Fire-stick, 761

Fish, Ceratodus, in Queensland, 797

Fish, crowded in pool in James Range, 8o; no burrowing form, 8o; on hill-sides, 7I; Palm Creek, 96; restrictions on eating, 762; six species in Red Bank Gorge, 79

Fish, Osteoglossum leichhardti, 797

Fishing, methods of, 544

Flaked stone implements, 500

Flakes, chipped, 368

Flesh, human, eating by Arunta, 203

Flies, 29, $35^{\circ}$

Flinder's charts, 593

Floods, 529

Flora River, 894

Flying-fox man, tradition of, 432

Flying foxes, flocks of, 900

Fog on Alligator River, 855

Food, eating forbidden, 800

Food, human flesh, 203

Food, native, 425

Food, nature of, 206

Food restrictions, Arunta, 248 
Food, woman providing man with, as sign of marriage, 796

Forbidden food, eating, 800

Forehead band, I 9 I

Forest land, 54I

Fort Dundas, 657, 905

Fossils, possible origin of mixture of, in numbers, 26

Foster Range, 398

Fountain, Jack, mail-man, 3 I

Francis, Mt., Map, 2, 35

Frazer, Sir James, I 85

Frog, burrowing, 44

Frog ceremony, 327

Frog, spirit in form of, Kakadu, 8I 6

Frog, water-holding, 45

Frogs, colours of, in wet season, I34, I 42

Galleries, sand, of ants, 72

Gap, Emily, 290; Heavitree, origin of, 291, 292; Jessie, 290

Gaps and gorges, Map 2

Gaps in the Macdonnell Ranges, I I 4, I 2 I, I 23, I 25, 369

Garden Point, Melville Island, 905

Geese, pigmy, 774

Geimbio tribe, 779

George Gill Range, 63

George Gill Range, M, Map 2

Gesture language, 436, 444

Gibber field, 23, I 5

Giddea, smell of, I 39

Giddea tree, 9

Gidgee. See Giddea.

Gidya. See Giddea.

Giles, Alfred, 598, 628

Giles, H., I 62

Giles, Mounted Trooper, 880

Gill, George, Ranges, M, Map 2

Gillen, F. J., xvi, xvii, I84, I85, 3 I I, 883

Gillen, Mrs., xvii, I 85, 228

Gillen, Mt., I 05, I 24

Gilruth, Dr. J. A., xviii, 597, 627, 645, $717,727,860,904$

Gilruth, Mrs., xviii, 7I 8, 723, 730, 73 I

Girls, during initiation ceremony, Melville Island, $659,665,668,672$, 675

Glacial beds, 49, 55

Glacial Period in Central Australia, 3 I

Glen Helen, 63, 77

Glen Helen Station, Map 2, No. 44

Gnanji native, 539,542

Gnoilya, dog men, 292

Gnoilya, dog totem, 29 I

Gnoilya-mbainda, Camp of Dogs, IO5

Gnomes, Kakadu tribe, 805
Goar, ceremonial ground, 750

"God," use of term by missionaries, 277

Godley, H. A., Newcastle Waters, 689

Gold, dollying, 632

Goodenia Horniana, 77

Goose, palmated, drawing of, 8 13

Gordon, Lindsay, grave of, 868

Gore, Captain, 86I

Gosse Range, 86, Map 2, No. 58

Government of native camp, 3 I 7

Goyder River, 47

Grainger, Mr., 877

Grand tour, 768

Grass and rush bags, 846

Grass, porcupine, I 63

Grass, rate of growth, 894

Grass seed totem, 406

Grass, Spinifex paradoxus, 36

Grass tree, new species, 76

Grave ceremony, Kakadu, 764; Melville Island, 688

Grave in the bush, 868

Grave, Melville Island, 643, 648, 679, 908

Grave-posts, different forms of, Melville Island, 682

Grave, tree, of child, Kaitisha tribe, 4 I 5

Grave, tree, Warramunga tribe, 482 , 487,489

Grave, visiting, Warramunga tribe, 486

Gregory, Professor, 237

Grinding munyeru, 34

Grinding stone axe, 497

Grinding stones, 34

Ground drawings, 467

Group relationship, 225

Groups, local, 3I 2

Growth, ceremony to increase, $76 \mathrm{I}$

Growth of animals ceremony to ensure, 373

Growth of grass, rate of, 894

Growth, throwing boys in the air to produce, 687

Gudgeon pin, 860

Gum, red, 47

Gum tree, not an Australian name, I 52

Gum tree, spreading roots of, 56

Gum, "Whitewash," 77

Gums, swamp, 29

Gunn, Mrs. ÆEneas, 865

Gutta-percha tree, 532

Gsell, Father, 653, 910

Hair, as emblem of betrothal, 435

Hair-cutting, 435

Hair, dead man's, used for magic, 376 , 4I 3 
Hair, Kaitisha and Unmatchera, 404

Hair locks, Akuntilia, 4I3

Hair, Melville Island, 644

Hair, nature and growth of, amongst Arunta, I91, I92

Hair, plucking, out of men, 673

Hairs, pulling out, of initiate, 667

Hair, treatment of, I9I

Hair, Warramunga pulling out, 423

Hair, woman's, used for string girdle, I 92

Hamilton Creek, 30

Hanson Creek, 395

Hatching out of cicadas, 903

Hawks and fire, $47^{\circ}$

Headache, curing by magic, 427

Head, biting, Melville Island, 665

Head-man of Local Group, 3 I 3

Head-men, control of, 3 I 7

Head-rings, woman's, man wearing, 427

Heat, killing a lizard, I 48

Heavitree Gap, I05, 29I, Map 2, No. I6

Hedge wood, 533

Height of Arunta natives, I95

Helen, Glen, Station, 44, Map 2

Helioporus pictus, I4I

Henbury, 56

Hermannsburg, 85, 276, Map 2, No. 45

Heuglin, Mt., 37, Map 2

Higher Steppes, animals characteristic of, 90

History of Muraian objects, 835

Hodgson Downs Station, 886

Holland, Mounted Trooper, 876

Holmes, Dr. Mervyn, 602, 633, 9 I 4

Holmes, Thomas, 5 I 9

Holt, Mr., Eva Downs, 875

Holtze, Mr., Daly Waters, 866

Holtze, Mr., Director of the Botanic Gardens, Darwin, 618

Honey ant, IO3, I 72, I 74

Honey-bag, finding, 547

Honey-bags, different names for, 857

Hopeless, Mt., 4

Horn Expedition, 4, 6

Horn Valley, 77,83 , I 02, I Io, I I 3

Horse-shoe Bend, 5I, I I8, Map 2, No. $5 \mathrm{I}$

Hotels, Darwin, 600

Housekeeping difficulties, 228

Howchim, Professor, 31, 50

Howitt, Dr. A. W., and medicine man, 247; finding of King, I I

Hugh River, 6, 7, I2, I3, 23, 51, I I2, I $8,364, \operatorname{Map} 2$

Human beings, making of, 28I

Human flesh, eating, 203

WIID AUST. VOL. II.
Hunting, 209, 549

"Husht," signal to camels, 4 I6

Hyla rubella, 44, I42

Ice in water-bags, I 83

Idracowra, 55

Ilcha, hand, 3 I 3

Ilchinkinja, sacred messenger, 3 I 3

Ilkinia, totem design, 286, 34I

Illapurinja, the first woman created, Arunta, 288

Illionpa corrobboree and Mauia, 255

Illness from eating forbidden snake, 800

Ilpilla Creek, 49, Map 2

Ilpintiva, rock drawing of totem, 286

Imanda, on Hugh River, 328

Imberombera, tradition of, 752, 757

Inapatua, Arunta, incomplete human beings, 28I

Increase of animals, ceremony to provide for, 60,433

Increase of totem, 294

Indada, corrobboree, Arunta, 230

Indiarubber tree, 532

Injilla, pointing-stick, 25I

Inkata achilpa maraknirra, 286

Inkata achilpa oknirra, 288

Inkata, head-man of local totem group, 286, 29I

Inkata kupitcha, little leader, 288

Initiate and Churinga, 273

Initiate and women, 516

Initiate shut in Mia-mia, 669

Initiated youths, covered during ceremony, 452

Initiates, showing ceremonies to, 465

Initiation ceremonies, Arunta, 250; Melville Island, 658; Kakadu, 765; different forms of, 273

Inkulta, flaked sticks, 240

Insect life, 903

Insects, absence of, on flowering shrubs, 97

Intwailiuka, tradition of wanderings of, 29I

Irna, pointing-stick, 25 I

Ironwood, Acacia salicina, Iоo, 369

Ironwood used for wells, 905

Irriakura bulb, 2 I I, $35^{8}$

Irrimunta, stroking ceremony, 462

Irvitcha puncha, tradition of, 394

Irundeva, father-in-law, 227

Iruntarinia and medicine men, Arunta, 266

Iwaiyu, 754, 789

Jabirus, 828

Jack, a black boy, reliability of, 871 , 876

H H 
James Range, 6o, Map 2, K.

Javelin throwing, Melville Island, 690

Jay River, Map 2, Nos. 8, I 4, 24

Jerboa rats, 67,68 ; plague of, 9I ; exterminated by rabbit, I 53

Jessie Gap, 290, Map 2, No. I 8

Jiboulu, Conch, 77I

Jimeribunna, native companion, drawing of, 8 I 2

" Jump down," 886

" Jump up," 867

Jumping method of progression, 68

Kakadu people, $736-858$

Kakadu tribe, 736

Kakita, earth mound, 482,489

Kala, meaning of word, 784

Kalal, ceremonial ground, 557

Kalin compound, 613, 634

Kangaroo, black, 829

Kangaroo ceremony, Kakadu tribe, $77 \mathrm{I}$

Kangaroo hunt, drawing of, 8 I I

Kangaroo man, tradition of, 57

Kangaroos, numbers influenced by drought, 92

Kaolin grinding with teeth, 467

Kapei resin, $75^{8}$

Kapok tree, 552

"Karbeen" gum tree, 525

Karrabobba, 54I

Katherine Creek, 86I

Kauaua Pole, 339

Kanwa-auwa, pole used by Numbakulla, 286, 287

Keartland, G. A., collecting birds, 8I

Kell, F. J., 524.

Keloid growth, 644

Kempe, E. C., at Peake Station, 8

"Khaki" gum tree, 525

Kidney fat, 778

" Killed," use of word, 2 I 4

King Creek, 862

King Creek crossing, 892

King, found by Howitt, I I

Kingilli moiety, 458

Knanikilla, local totem place, 283 , 287

Knanja, totem, Arunta, 59, 278, 282

Knife, stone, 502

Kochia bush, I I

Kolamma, a yam, 659

Korno, evil magic, $758,76 \mathrm{I}$

Krichauff Range, 87, B., Map 2

Kujorju, spear, 799

Kulemma, a yam, 659

Kuljoanjo, snake, 8oo, 80 I

Kulunglutchi tribe, 745

Kuluru, small piece of tobacco, 826

Kumali, forbidden, 790, 79I
Kumali, secret, sign for, 824

Kupitcha of medicine man, 476

Kurdaitcha, 259, 264

Kurdaitcha, after death, 445

Kurdaitcha man, making of, 26 I

Kurdaitcha shoes, 26I

Kurtitina, native well, I64, Map 2, No. 56

Kuruna and Churinga, 280, 297

Kuruna, made by Numbakulla, 286

Kuruna, spirit, Arunta, 278, 280, 376

Kuruna, spirit, entering a woman, 289

Kuru-urkna, hair girdle, 376

Kwatcha alia, salt water, $28 \mathrm{r}$

Lake Woods, 530, 868

Lamaru Camp, Darwin, 6 I I

Lance-wood, 533

Language, gesture, 436, 444

Larakia Camp, Darwin, 6 Io

Larapinta, " flowing spring or water," 3,47

Larapinta Land, Map 2; Io9; land, area of, 3; view from the air, III

Laughing Boy totem, 460

Laura Creek, I I 9

Laycock, the cook, 22, 8I

Leaves, size of sapling, 525

Leichhardt, 530

Leichhardt, Pine, 555

Levi Range, 63, Map 2, N.

Licence to employ natives, 6 I 3

Life in Warramunga camp, 427

Lily, Darling, I 38

Lily, eating, 545

Lily pools, 545

Limestone formations, Macdonnell Ranges, I 25, I 26, I27, I 28

Limnadopsis squirei, I37

Limnodynastes ornatus, 44, I42

Liparus spenceri, 88

Livistona Maria, palm, 89

Lizard and medicine man, Arunta, 269

Lizards, coloration in wet season, I 46; eating, 879; killed by heat of ground, $\mathrm{I}_{4} 8$

Local groups, Arunta, 3I2; Melville Island, 91 2; Kakadu, 755

Lonely, Mt., 394

Lonka-lonka, shell used for magic, 258

Love's Creek Station, Map 2, 59

Lower Steppe lands, 366

Lubras, as collectors, I 50

Lucas and Frost, Description of lizards, $146 n$.

Lukwurra, women's camp, 207

Lungarinia, the second woman created, Arunta, 288 
Lung-fish, I2, 797; remains of, in Central Australia, 28

Luritcha natives, 169

Lurkun, bough coffin, 557

Mabanui, shooting star, 67I

Macarthur River, 554

Macarthur Station, 880

Macdonnell Ranges, Map 2, D.; general features of, I08, II3, II 7 , I 22; sections across, 122, 124 , block diagrams $\mathrm{I}$ and 2

Macgillivray, "Voyage of Rattlesnake," 844

Mackay, Mr. Angus, 886

Macroderma gigas, white bat, 95

Macropus robustus, 91

Macropus rufus, $9 \mathrm{I}$

Macropus woodwardi, black kangaroo, 809

Macropteranthes Kekwickii, lance or hedgewood tree, 533

Macumba River, 27

Macumba Station, I38, 355

Magic, Arunta, 246, 25I; associated with yai-illa wand, Kakadu tribe, 85I; dead man's hair, 4I3; from knife entering man, 485 ; influence on natives, 733; Kakadu, 761; man wearing head-rings, 427; medicine men, 476 ; of distant place, 257; not a means of gain, Arunta tribe, 248

Magic, evil, Arunta, 25I ; ceremony amongst Kakadu, 759; death from, 256; entering a man, 479; Mauia, 255 ; thought of, 204

Maiden, J. H., on ant nests, 74

Malays and natives, 568, 61 3, 6I5, 622

Mallee gum, 75

Mangroves, 678

Mapuditti, spirit of dead man, Melville Island, 648

Mara, Mr. and Mrs., Tanumbirini Station, 884

Mara tribe, social organisation, 563, 564,565

Mava, very, Arunta, 286

Maraknirva, very great, 288

Mavilla, design on medicine man, 269

Marriage regulations, Arunta, 226; Kakadu tribe, 794; Mara tribe, 564

Marukumana boys, 664

Marunga, medicine man, Kakadu tribe, 790

Marungwum, a necklet worn by the initiate, 675

Marsilia quadrifolia, Nardoo, 2 I 2

Marsupial mole, I44
Mason wasps, 579

Masonic signs, 436, $5 \mathrm{I} 7$

Masson, Miss E., 718, 729

Mataranka, 865,889

Mania, evil magic from Kaitisha, 254

McFeat, A., 387

McKillop, Father, 728

McMinns Bar, 866

Mbainda, a camp, 293

Mbanbiuma cerenony, 294

Measurements of natives, I95, 423

Medicine men, Arunta tribe, 265, 266, 270; Binbinga tribe, 566; Kakadu tribe, 790; Unmatchera, 4I2; Worgaia, 462; and Bubba Peibi, 803; and Kupitcha, 476; and lizard, Arunta, 269; and Numereji snake, 777, 788; and curing, 257, 801; loss of power, 267; practising, Arunta, 269; recovering a spirit, 805; seeing snake, 776,787 ; three schools of, Arunta, 265

Medicine men at work, Warramunga tribe, 478

Medjingeli, challenge sticks, 849

Melaleuca leucodendron, paper-bark tree, I02, 645

Melophorus cowlei, I03, I 75

Melophorus inflatus, honey ant, Io3, I 72

Melville Island, 273, 64 I-713, 905, 9 I I

Melville Island, local groups, 913

Memory of natives, 756

Men's Churinga, stone, 288

Mentality of natives, 202, 2I 5, 565

Mereenie Bluff, Map 2, 38

Mereenie Valley, 77 I Io, I27,

Meridian ant, 390, 542

Messengers, sanctity of, 313, 546

Mia, mother in Arunta, 224

Mia-mia, 208; Melville Island, 645; on ceremonial ground, 672

Migration of Central tribes, lines of, 237

“ Milk-wood," 660

Milky Way and Emu, 853

Miller, Mounted Trooper, 629, 632

Miniimburu, name of Wollunqua. mound and ceremony, 466

Miniurka ceremony, 5 I 5

Mirages, 39, 357

Mission Station, Bathurst Island, 693

Missionaries Plain, 75, Map 2, C.

Mitchell, Judge, 598, 600, 626, 642

Miunga, cicatrices on natives, 644

Modification of plants, 33

Moieties, division of Arunta into, 225. 315; Moities of tribe, Warramunga, 447, 458; Mara, 564 
Mole cricket, 72

Mole, marsupial, I 44

Molonga corrobboree, 238

Monmorlp, a rat, 779

Moon man, 47 I

Moral standard of natives, 200, 202

Mormo, honey-bag, 783, 857

Mormo, mythical beings, 804

Morpiu, general term for animals, $78 \mathrm{r}$

Mosquito Mia-mias, 898

Mother, Mia, in Arunta, 224

Mother-in-law, Arunta, 229; avoidance of, 228; eating tooth, Warramunga, 43 I

Mother's Alchera camp, 4 I I

Motor-car and natives, 356, 885; stranded at Pundara, 873 ; stuck in King Creek, 862

Motor trip to Gulf of Carpentaria, 859

Mound representing sand-hill, 463

Mound Springs, Dalhousie, 30; Old Peake Station, Lake Eyre, 8; remains of, Kurtitina, 164 ; Unterpata, I6o

Mourning armlets and rings, Melville Island, 695

Mourning ceremonies, Kakadu tribe, 819, 82I; Melville Island, 647 , 650; of Warramunga women, 484

Mourning scars, 194

Mourning, women in white, 378

Mouse, 67, 9I

Mudburra tribe, 899

Mulga, red, 32, I 4 I

Mulga scrub, 390

Munda water-hole, 540

Munga-munga women, 470

Mungai, totem places, Warramungai, 471

Munyeru seeds, grinding, 34, 2 I 2

Mura woman, Arunta, 228

Murabulba, old man, Kakadu tribe, 836

Muraian objects, 825 ; history of, 835,838 ; significance of, 842

Muraian objects and Churinga, 843

Mus musculus, 67, 9 I

Musical instruments, Kakadu tribe, 848

Mussel, fresh-water, 29; growth of, 53 I

Myles, Captain, 592

Mythological drawings, 804, 808

Myths of Alchera, 275

Nama, grass, $25^{8}$

Namatwinna, used for charming, 258

Name of dead person not mentioned, Kakadu tribe, 820; sacred, or secret, 284, 40I, 474; special usage, 46I; of Wollunqua not used, $46 \mathrm{I}$

Names, totemic, Kakadu tribe, 8I4; native, Kakadu tribe, 749 ; popular ones misleading, I5I; special, applied to relatives of dead person, 820

Napier motor-car, 859

Nardoo, Io, 34, 38, 2 I 2

Nardoo leaves and frogs' heads, I4I

"Nation," Arunta, 404

"Native Companion," drawing of, 8 I 2

Native wells, I6o, 164

Natives, Arunta, I 84 ; attack Barrow Creek, 40I; callous to pain, 677; camp, 900; character, 734; colour of, I 86; communistic attitude of, 607; employment of, 6I3; and motor-car, 885; odour of, 3 I 8 ; and phonograph, 356 ; showing astonishment, 356 ; treatment of, 383 ; trials of, 578,590

Necklet, bean seed, 2 I9

Net changing into Numereji snake, 785

Newcastle Waters, 530, 868

Ngabadaua, a snake, 750

Noblett, Mounted Trooper, 869

Nola lugens, social caterpillar, 29

Nomad life of aboriginals, 205

Norkun, goose wing, use of, as fan, 759

Notaden bennetti, 398

Notodrilus eremius, 84

Notoryctes typhlops, "marsupial mole," I 44

Numbakulla and Alchilpa tradition, 285; giving instructions, 287; making Churinga and Kurunas, 286; superhuman beings, Arunta, $28 \mathrm{I}$

Numereji snake, tradition of, 776 , $779,780,787,788,79 \mathrm{I}$

Nurtunja, in Kaitisha tribe, 405

Nurtunja, sacred pole, 6o, 329

Nutwood Downs Station, 885

Oak, desert, 53

Ober ceremony, Kakadu, 770

Odour of natives, 45 I

Oenpelli Lagoon, 823

Oenpelli Reserve, 722, 742

Oknia, father in Arunta, 224

Oknirra, great, Arunta, 286

Oknirrabata, wise old men, I9I

Okunjepunna oknirra, much infatuated, 258

Olga, Mt., I68, I 72, I 75 
Olturuma, belt worn by initiate, 676

Oodnadatta, I $4,133,348$

Ooraminna, 367

Ooraminna Range, H, Map 2

Opium Act, 626

Opium smuggling, 6oI

Opossum, not an Australian name, I 5 I

Opossums, catching, 547 .

Ordovician formations in the Macdonnell Ranges, I 25, I 27

Orange seed, making cakes of, 902

Orange tree, native, 78

Organisation of Arunta, 224, 564

Organisation of Mara tribe, 564

Organisation of natives, Bathurst Island, 9 I I

Organising ability of natives, 3 I 9

Ormiston Creek, Map 2, No. 3

Ornaments of initiate, Melville Island 675,676

O. T. Lagoon, 883

Outrigger canoe, 569

Oven, earth, 90I

Owen Springs, 46, Map 2

Paddy Bull, a native convict, 6r9

Pain, native callous to, 677

Painta Spring, I05

Paint-brush, native, 468, 792

Paintings, native, price of, 794

Paintings, rock, 824

Paisley Bluff, IO2

Palm Creek, 87, 89, I I8, Map 2, No. 48

Palm-leaf baskets, 845

Palm, Livistona Maria, 89

Palm tree, no animals on, 99

Palmated goose, 798

Palmer River, 74, I I9

Palmer River Gorge, Map 2, No. 28

Paper-bark, 645.773

Paper-bark baskets, 845

Paper-bark tree, I02, I60, 554

Paper-yabber, 546

Parakeet, Princess Alexandra, 8I

Parakilia, 34

Parliamentary party, 7I9, 721, 723

Parra mound, 3I8, 335

Peake Station, 8

Peindi, earth oven, 775

Pelicans, 536

Pellew Islands, 593

Peragale lagotis, 94

Periophthalmus, 854

Permo-Carboniferous age of glacial deposits, 55

Perta, a stone, 293

Perta knanja, Arunta, totem rock, 283
Pertalchera, Arunta, sacred storehouse, 280

Pertalchera, robbing by white men, 285

Petrophasa rufipennis, $74^{8}$

Phascologale macdonnellensis, pouched mouse, 95

Phascologale minor, I 54

Phillip Creek, 5I6

Phlogius, large spider, 98

Phonograph and natives, 356

Photography, 359, 370, 42I

Physical features, Arunta, I87, I95; Binbinga, 566; Kaitisha, 404; Unmatchera, 404; Warramunga, 423

Physignathus, I 47

Piccaninnies, naming of, 368, 384 , 827

Pick, 508

Pickford, Mr., Darwin, 64I

Pied egret, 779

Pierce, Mr., Willeroo Station, 899

Pigeon people, Urabunna tribe, I3

Pigeon, Torres Strait, 580

Pigeons, drinking, 96

Pig-footed bandicoot, I 50

Pigmy geese, 774; drawing of, 8 I I

Pinda, 549

Pine Creek, 628, 630, 633, 860

Pine Point, 86, Map 2, No. 39

Pitchis, 33, 217; carrying baby in, I 87

Pittongu, bat totem, 469

Pituri, I 58

Plants on Higher Steppes, 99 ; modifications of, 33; protection of, against evaporation, 38; survival of, 36

Platypus, I 52

"Play-about" drawings, I 7o

Plover, imitating call of, 36I

Pluralist in Darwin, 723

Pointing-sticks and bones, 25I, 252

"Poison-bone," 252

Pole, at fire ceremony, Warramunga, $45^{\circ}$

Pole, Kanana, 329

Police Paddock, Alice Springs, Io6, I 24

Police Station, Alice Springs, I24

Polytelis alexandre, 8I

Pomatostomus rubeculus, 540

Porcupine grass, I63

Porcupine-grass ant, 73

Port Cockburn, Melville Island, 905

Port Essington, 906

Port Essington natives, 656

Portulaca, 33

Posts, grave, Melville Islands, 648; different forms of, 682 
Pouched mouse, Phascologale, 95

Pouched mouse, sand-hill, I62

Powell Creek, 524, 53I

Pre-Cambrian hills, I 23

Prentice Lagoon, 522

Preparation for ceremonies, 458

Presentation of child, Kakadu tribe, $85 \mathrm{I}$

Price of native objects, 37I ; of native paintings, 794

Princess Alexandra parakeet, 8I

Prognathism, 404, 424

Prohibited areas, 620

Projecting evil magic, 242, 409

Pronged clubs, 7II

Propitiation ceremony, 466

Protection of plants, 38

Ptilopus alligator, 748

Pundara water-hole, 872

Punishing boy, 428 ; woman, 428

Punishment among natives, 20I

Purification ceremony, Kakadu tribe, 773

Quabara, ceremonies, $32 \mathrm{I}$

Quail, booming sound, 98

Quarrelling in camp, 429

Quarrels, ceremony to end, 455

Quart pot, 352

Quatcha, water country, I95

Questioning natives, 676

Rabbit, bandicoot, 94

Rabbit exterminating Jerboa rats, I 53

Rabbit, invading the Centre, I 53

Racecourse, Alice Springs, Io6

Railtchawa, medicine man, Arunta, 265

Rain ceremony, 359, 405

Rainfall, Eyrean Basin, I 2

Rain men, Urabunna, 9

Ranken, paper-bark, 773

Rats, 9I

Rhagodia, salt bush, 35

Redbank Creek, 78, Map 2, No. 2

" Red hand," I 70, 8I2

Red mulga, 32

Reedy Creek, 63, 69

Refuge, house of, Arunta, 284

Reincarnation, $59,202,280,283,372$, $395,754,8 \mathrm{I} 6$

Reliability of black “ boy," 873, 875

Remains of different animals in Gap, 79

Renners Springs, 523

Repetition of names, Melville Island 663

Resin, I63

Restrictions, food, Arunta, 248
Restrictions on eating snake, 800

Reticence of natives, 9 I I

Ridges of Macdonnell Ranges, II3, I I 4 , I 28

Rift Valley, Torrens, 6

"Right side " of tribe, I69

Rings, mourning, Melville Island, 649

River bed, change in, by floods, 48

River gum trees, 26

River systems of Larapinta Land, I 6

Rock Bar, Flora Falls, 897

Rock drawings, 64, 169, 824

Rock pigeon, 96

Rock shelters, 823

Rola knanja, Arunta, totem tree, 283

Roly-poly, 24

Roper River, 863

Ross, Mrs. A., xvii, 5I, 3 Io

Ross River, II 5, I2I, Map 2, No. 20 Roth, Dr., 238

Rubbing with stones, 474

Rudall Creek, i I8

Running Waters, 62, Map 2, No. 50

Ryan, Mrs., 600

Ryan's Well, 393

Sacred beliefs, Arunta, 272

Sacred Heart, Society of, 638, 904 , 9 IO

Scale in animal drawings, 8 10

Scalp, corrugated, 436

Scars, keloid, I93

Scars, meaning of, I 94

Scars on head, 424

Scent of natives, 3 I 8

Schulze, on Arunta beliefs, 276

Scott, W., 399, 409, 420

Scrutton, Mr., Bauhenia Downs, 883

Seasons in Central Australia, I5

Secret name, 474

Section across East Macdonnells, I22, I24; Western Macdonnells, I27

Section names, Arunta, 225

Sections uniting after quarrel, 245

Seeds made into loaves, 545

"Self-existing," Numbakulla, 28 I

Sex, alternation of, 489

Sacred objects, Kakadu, 835

Saltatory movement, 68

Salsola kali, 24

Salt bush, 35

Sand dunes, 363

Sand-hill and Snake, 463

Sand-hills, I 58, I63

Sandhills, Depot, 52, 84

Sardine Creek, 893

Shadoof, 47

Shadow of man, 8I 5

Shaking body at ceremony, 462 
Shell, Cyrena, used for cutting, 705

Shell, growth of mussel, 53I

Shepherd, "Billy," 600, 642, 870

Shields, 22 I

Shield striking, 379

Shoes, Kurdaitcha, 260

Signs, Masonic, 436

Silence, ban of, $436,444,528$

Silicification, 55

Simpson's Gap, I 20, Map 2, No. 9

" Singing," 464, 663

" Singing," pointing-sticlss, 25I ; the ceremonial ground, 749; armlets, Melville Island, 67I

Skin of snake men, 785

Skull, smashing of, 489

Smelling evil magic, 477

Sminthopsis, new species, I 64

Smuggling opium, 602

Snails, æstivation of, I 43 ; land, 88

Snake ceremony, Kakadu tribe, 750 ; eating, natives, $778,78 \mathrm{I}, 785$; and medicine men, 788; men and skin of snake, 785 ; method of killing, 787 ; net changing into, $785 ; \mathrm{Nu}$ mereji and medicine men, 777; poisonous and natives, 788 ; restrictions on eating, 800 ; tradition of, in Binbinga tribe, 567; traditions of, Kakadu tribe, 776; and teeth, 4 Io; Wollunqua, drawing of, 463; Wollunqua, 457

Soakage, 395, 397

Social organisation, 563

Solomon, "King," 610, 732

Sonder, Mt., 79, I 27

Sorcerers, Arunta, 265

Southern Cross and turtle, 853

Spain, Mrs., 635

Spathopterus (Polytelis) alexandre, 8I

Spear, stone-headed, 5 Io

Spear-thrower, absent on Melville Island, 690

Spear-throwers, 220, $57 \mathrm{I}$

Spear-throwing, Melville Island, 690

Spears, Arunta, 220

Spears, comet tail, 409

Spears, Melville Island, 704

Spencer Gorge, Map 2. No. 6

Spider, " barking," 98

Spines and thorns on plants, I I

Spines on plants, 33,38

Spinifex, 36

Spirits, ancestral, 333, 472; children, 754; children inhabiting Mungai, 47I; emanation of, 459; in whirlwind, 427; entering woman, Arunta, 283; of dead man, 482; and medicine men, 808; in tree, 407; mischievous, 332; splitting of, in Kakadu, 8I5; Yalmuru, Kakadu tribe, 8 I 5

Splitting of Churinga, 287

Splitting of Kuruna, 280

Splitting of rain ancestors, 405

Splitting of spirit, Kakadu tribe, 8I 8

Sporadic distribution of plants, 76

Springs, Mound, Dalhousie, 30

Strath, Superintendent, 6 18,640

Steppe Lands, Higher, 55, 62, Map 2, B-O.

Steppe Lands, Lower, 4I, 60, 366, Map 2, A.

Stevens, Mr., McMinns Station, 889

Stevenson River, 27

Stevenson Valley and flies, I39

Stick, pointing, native using, 408

Stone Age savages, I 83, 506

Stone axe, malking of, 497

Stone, ceremonial, Anjulukuli, 538

Stone implements, 495,5 II ; rare in Kakadu tribe, 844

Stone knives, malking, 503, 523; used by Numbakullas, Arunta, 28 I

Stone, sacred, kangaroo tail, 58

Stones, Atnongara of medicine man, 267,268

Stones, grinding, 34

Stones, Muraian, $84 \mathrm{I}$

Stones representing bones of natives, 782,785

Storm bird, 902

Storm Creek, I33

Stott, Sergeant Robert, 383, 56o, 606

Strehlow, Rev. C., 85, 277

Stretton, Mr., Protector of Aborigines, $64 \mathrm{I}$

Striated stones, 50

Stridulating organ, on spider, 98

String-bark, used as umbrella, 662

String games, $58 \mathrm{I}$

String, native, $57 \mathrm{I}$

Stroking the Wollunqua mound, 464

Struggle between men at initiation, 673

Struthidea, 540

Styphelia, 78

Sugar ant, I72

Sun a woman, 47 I

Sun ceremony, 372

Sundew plant, 397

Survival of ancient forms of life, 20

Survival of animals, 36

Survival of plants, 37

Swarming of ants, 899

Stuart Creek, 7

Stuart, McDouall, 48, 395, 5 I 7

Stuart, Mount, Central, 394.

Stuart township, I05

Stuart Valley, I23, I24

Sturt Plain, 867 
Tabu or ekeivinja, 344

Tail, of kangaroo, 58

Talkara, stone Churinga, 287

Tamar, H.M.S., 906

Tandidja water-hole, 869

Tanumbirini Station, 884

Tanunda, Churinga platform, 3 I 6

Tappin ceremony, 5 I 2

Tasmania, separation of, 507

Tate, Professor, Io9

Tchintu, magic object, 254

Tea-tree (see also Ti-tree), I6o

Teeth and snakes, 4 Io

Teeth, knocking out, Arunta, I95; Warramunga, 43 I

Teeth, of natives, 35

Telegraph, Overland Line, 40

Telegraph Station, Alice Springs, I o6 ; Barrow Creek, 40I; Tennant Creek, 420; Powell Creek, 524

Tempe Downs Station, Map 2, 47

Tempe Vale, 62, 70

Temperatures, in Macdonnell Ranges, 22, 75; high, 519; Gulf country, 576, 579; Darwin, 6I 4

Temple Bar Creek, I I9, I 20, I 26

Temple Bar Gap, II5, I26, Map 2, Nos. 1 5, 25, 26

Tendon, from kangaroo, I 80

Tennant Creek, 4 I 9

Teppa, a line of hills, 290

Terms of relationship, 227

Thaballa, laughing boy totem, 460

Thalaualla, black snake totem, 459

Thapauerlu, home of the Wollunqua, 460,469

Thapauerlu, plan of, 472

Thelphusa transversa, a fresh-water crab, 28, Fig. 27

Thomas, Hon, J., 719, 722

Thorns and spines on plants, 37-39

Three-cornered Jack, I I

Throwing boys in the air, 248,687

Tidal river and natives, 586

Tidjaniva, wooden Churinga, 288

Tietkins, I 76

Tiliqua occipitalis, killed by heat, $\mathrm{I}_{4} 8$

Tillite, 49

Time, counting, by Natives, 308, 32 I

Ti-tree, I02; spelling of, I6o

Tjaina, ceremonial ground, Kakadu tribe, 769

Tjantjiwanperta, camp at, 9

Tjingilli tribe, 527

Tjitjingalla corrobboree, $23 \mathrm{I}$

Tjubulinjuboulu, stick carried by pregnant woman, 850

Tjurunga. See Churinga.

Tjuokitcha. 540

Tmara Alchera, Alchera Camp, 285
Toad, Notaden, 398

Todd River, I06, I I 9, I 2 I, I 25, Map 2, No. 32

Tooth, knocking out, Arunta, 273; Kaitish tribe, 4I0; Tjingilli, 545; Warramunga, 431

Tooth, mother-in-law eating, 43 I

Top Spring, 879

Topography of totem groups, 289

Torches, Wanmanmirri, 449, 453

Torrens Lake, original map of, 4, 5

Torrens Rift Valley, 6

Torres Strait pigeon, 580

Tortoise, 544, 694

Totem, Achilpa, wild cat, 320

Totem, acquiring of, 289

Totem, bat, 469

Totem ceremony, cockatoo, 433

Totem, ceremony to increase, 294

Totem, grass seed, 406

Totem names, Kakadu tribe, 8I 4

Totem places, decided by Numbakulla, 286

Totem, Thaballa, laughing boy, 460

Totem, Unjailga a grub, 29 I

Totem, wild cat, 459

Totem, witchetty grub, 292

Totemic design drawn on backs of men, 34 I

Totemic designs, 296

Totemic topography, 270

Totems, Knanja, origin of Arunta, 282

Totems of five families, Arunta, 284

Townsend, Mt., 42, Map 2

Tracking bees to nest, 784

Tracking powers of natives, 66, 2 I3, 391, 393

Tracks, recognition of, 2 I 4

Trading, I 59

Tradition, Achilpa, 286, 288

Tradition of Bubba Peibi, 803

Tradition of kangaroo man, 57

Tradition of Wollunqua, 469

Tradition, rain man, Kaitisha, 405

Tradition, Undiara, 59

Tradjinaro, water snake, 799

Tree grave of child, 4 I 5

Trial of natives, $577,589,734$

Triodia, porcupine grass, I6 3

Tungulla, a Kaitisha man, 400

Tunna or Twinna, to strike, 258

Turtle, Muraian, 842

Twanyirrika, a spirit, 250, 273, 297

Twine, native, $57 \mathrm{I}$

Twinna or Tunna, to strike, 258

Twins, 202

Tylor, Sir Edward, I 84

Types of plants, dominant, 36 
Ullinka, pointing-stick of spirits, 254

Ulpailiurkna, native name, 4I2

Uluuru moiety, $45^{8}$

Umbaia tribe, 537

Underga, Emily Gap, 290

Undiara, Map 2, 54

Undiara, cave at 57,59

Undoolya, I9

Undoolya Gap, Map 2, I9, II 3

Undoolya, Mt., 369

Ungakura, magic object, 253

Ungunja, men's camp, I90, 207

Ungwulan, spirit of dead man, 482

Unio, fresh-water mussel, 29

Unjailga, a grub totem, 29I

Unmatchera, tribe, 404

Unterpata, a native well, I60, I83, Map 2, No. 55

Urabunna tribe and natives, 8, I2

Urliara, status name, 3 I9

Vegetables, 424, 887

Venture, 587

Vigilant, pilot boat, 592

Visiting ceremonies, Arunta, 239, 245,325

Vitality of snails, $\mathrm{I} 43$

Vocabulary, illustrations of, 2 I 5

Waduman tribe, 899

Wai-inyuri tribe, 253

Wailing for dead, 378

Waist-belts, $85 \mathrm{I}$

Wait-Ba song, 766

Wai-willum tribe, 630

Walker River, Map 2, No. 47

Walking of women, 197

Wallabies, rock, 92

Wallet and contents, Arunta, 223

Waninga, 330

Wanmanmirri torches, 447,453

Warblers, superb, 96

Ward, Dr, L. Keith, 3I, 50, 55, Io8, I o9, I 2I, I3 8

Warlock Ponds, 866

Warm food and medicine man, 267

Warramunga and Churinga, 458

Warramunga tribe, 423

Water, colour of, 53I, 540, 54I, 868

Water, coming out of whiskers, 406

Water-holding frog, 47

Water-hole, putting snake in, 802

Water-holes, 56; Tandidja, 869; Pundara, 873

Waterhouse Range, II2, Map 2 G.

Water immersion of initiate and boys, Melville Island, 665

Water, increased flow of, 70
Water-snake, 787

Water-supply, native, I66; of Stations, 522

Waters, Inspector, 605

Watershed, lines of, 66, I I6, 387, 863

Watjinyerti, Term for initiate, Melville Island, 659, 663

Watt, Dr., I09, I 84

Watt, Mt., Map 2, No. $4 \mathrm{I}$

Weapons, men's, 220

Welcoming deputation, 370

Welcoming strangers, 325

Well, native, I6o, I64, 392

Wells, Government, 4 I 9

Wellesley Islands, 594

"Wet," the, 609, 63I

Whakutnimma, 326

Whirlwind, spirit in, 426, 5 I 3

Whiskers, Euros coming out of, 406; giving rise to clouds, 406; water coming out of, 406

White, Dr., Bishop of Carpentaria, 4I 5

White ant-hills, 857

White ants, habits of, 543

White man and aboriginal, relations of, 188, I 98

White, mourning colour, Arunta, 379; semi-mourning colour, Kakadu tribe, 820

"Whitewash" gum, 77, 366

Widows, 483

Wife, promise of, 434

Wigley Gorge, 32

Wigley Gorge, ro6, Map 2, No. 32

Wilding, Mr., 600, 6I 5, 62I

Wild-cat totem, 288

William Mt., Map 2, No. 34

Winbegi, cane armlet, 852

Wind ceremony, 426

Wind-pipe of palmated goose, 798

Wind, south-east, 22

Wingara times, 457

Winnalls, Ridge, 40, Map 2

Winnecke, Charles, 6

Winnecke, Mt., 394

Wintari Pole, $45^{\circ}, 454$

Wire Creek, bones of animals, 26

Witchetty grub ceremony, 372

Witchetty grub totems, 292

Withy for stone axe, 495

Witnesses, native, treatment of, 639

Wives, man with seven, 780

Wives, original allotment of, $\mathrm{Ka}$ kadu tribe, 796

Wizards, Arunta, 265

Wollunqua ceremonies, 457,475 ; propitiating, 466; tradition of, 469

Wombaia. See Umbaia 
Women and ban of silence, 444; at burial ceremony, Binbinga tribe, 558; carrying child's bones, 83I; and Churinga, 288, 273, 275, 296, 306; and climate, 633; cutting themselves, 430; digging yams, 686; driven on by men, 452; at fire ceremony, 449; the first two formed, Arunta, 288; hair, I92; charming of, 258; and initiates, 5I6; at initiation ceremony, 663, 665,668 ; during mourning ceremonies, 483; native, as collectors, I50; personal appearance, 424; scars on, I93; stone knife, 505; taking part in grave dance, 65I; throwing fire, 334; treatment of, 20o, property of, 494

Woods, Lake, 530, 868
Woods, Lake, Basin, 388

Woolnough, Dr. W. E., 598

Worgaia tribe, 462

\section{Xanthorrhoea Thorntoni, 76}

Xerophila nigrocincta, 409

Yabber, paper, 546

Yalmuru spirit, Kakadu tribe, 760, 8I 5; watching over child, 8 I 8

Yam ceremony, Melville Island, 658

Yam or digging-sticks of women, 218 , 494

Yam women, 470

Yams, cooking during initiation ceremony, 667

Yarumpa, honey ant, I75

Yellow Cliff, 49, Map 2, No. 53

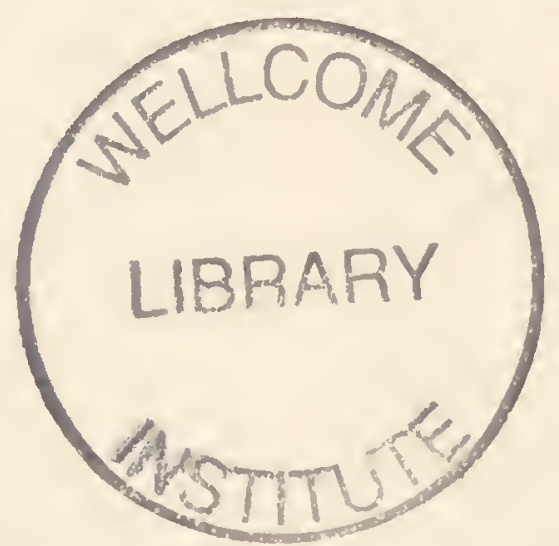

Printed in Great Britaln by Richard Clay \& Sons, Limited, BUNGAY, SUFFOLK. 


\section{THE A R U N T \\ A STUDY OF A STONE AGE PEOPLE}

With plates in colour, map, and other

illustrations

2 vols. $\quad 8$ vo. $\quad 36$ s. net

Prof. G. Elliot Smith in The Sunday Times.- "The publication of "The Native Tribes of Central Australia,' in I 899, instantly attracted such widespread attention that the book soon came to be regarded as the classical treatise on Australian ethnology. . . . Since then other books were issued by them in I904 and I914; and now we are indebted to Sir Baldwin Spencer for perhaps the most valuable of the series. For, with thirty years' experience, he has been able to appreciate what are the really vital elements of Australian culture and to collect and set forth new evidence relating to them with all the fullness their importance deserves."

The Saturday Review.- "The two volumes of over six hundred pages are a monument of honest and careful work of which the English anthropological world may justifiably be proud."

The Spectator.- " The book is a record which can never be repeated; it provides a mass of minute details about ritual, beliefs, and customs which is invaluable to all students of early society and of the primitive mind."

\section{BY SIR BALDWIN SPENCER}

\section{NATIVE TR I B E O F THE NORTHERN TERRITORY OF A USTRALIA}

With illustrations. $\quad 8$ vo. $\quad 25$ s. net

Nature.- "With the experience gained in his previous investigations, the author has produced an excellent volume, which is in every way equal to its forerunners in anthropological interest, in scientific value, and in clear description of another group of the totally uncivilised tribes of Australia. . . . The work is an exceedingly valuable contribution to anthropological literature, indispensable for the student of primitive beliefs and ceremonial."

The Morning Post.- "A volume which is a model of what an anthropological work should be, and will doubtless take its place beside its author's earlier studies among the classics of the science."

Man.-_" The book is full of interest and contains much information of a high anthropological value."

MAGMILLAN \& GO., LTD., LONDON 


\section{WORKS ON ANTHROPOLOGY}

Ancient Hunters, and their Modern Representatives. By Prof. W. J. Sollas, Sc.D., F.R.S. Third Edition. Illustrated. 8vo. 25s. net.

Natural Man. A Record from Borneo. By Charles Hose, Hon.Sc.D. With a Preface by Prof. G. Elliot Smith, F.R.S. Illustrated. Super royal 8vo. 3os. net.

Origins of Education Among Primitive Peoples. A Comparative Study in Racial Development. By W. D. Hambly, B.Sc. With a Preface by Dr. Chardes Hose. Illustrated. 8vo. 25s. net.

The Kiwai Papuans of British New Guinea. A Nature-born Instance of Rosseau's Ideal Community. By Gunnar Landtman, Ph.D. With an Introduction by Dr. A. C. HadDon, F.R.S. Illustrated. 8vo. 3os. net.

Savage Life in Central Australia. By G. Horne, V.D., M.D., and G. Aiston. Illustrated. 8vo. i8s. net.

Ritual and Belief in Morocco. By Edward WesterMARCK, Ph.D. Illustrated. 2 vols. 8vo. 5os. net.

People of the Veil : Being an Account of the Habits, Organisation and History of the Wandering Tuareg Tribes which inhabit the Mountains of Air or Asben in the Central Sahara. By Francis Rennell Rodd. Illustrated. Super royal 8vo. 3os. net.

Big Game and Pygmies. Experiences of a Naturalist in Central African Forests in Quest of the Okapi. By Cuthbert Christy, M.B. With an Introductory Chapter by Sir Harry H. Johnston, G.C.M.G. Illustrated. 8vo. 2 Is. net.

The Ila-Speaking Peoples of Northern Rhodesia. By the Rev. Edwin W. Smith and Captain A. M. Dale. 2 vols. Illustrated. 8 vo. 5os. net.

The Life of a South African Tribe. By Henri A. Junod, D.Litt. Second edition, revised and enlarged. 2 vols. Illustrated. 8vo. 50s. net.

The Lhota Nagas. By J. P. Mills, I.C.S. With an Introduction and Supplementary Notes by J. H. Hutron, C.I.E. Illustrated. 8vo. 25s. net.

The Ao Nagas. By J. P. Milus, I.C.S. With a Foreword by Henry Balfour, F.R.S., and Supplementary Notes and Bibliography by Dr. J. H. Hutton, C.I.E. Illustrated. 8vo. 3os. net.

MACMILLAN \& GO., LTD., LONDON 



if 